FRIEDRICH KRINZINGER - PETER RUGGENDORFER (Hrsg.)

\title{
DAS THEATER VON EPHESOS
}

Archäologischer Befund, Funde und Chronologie

Textband

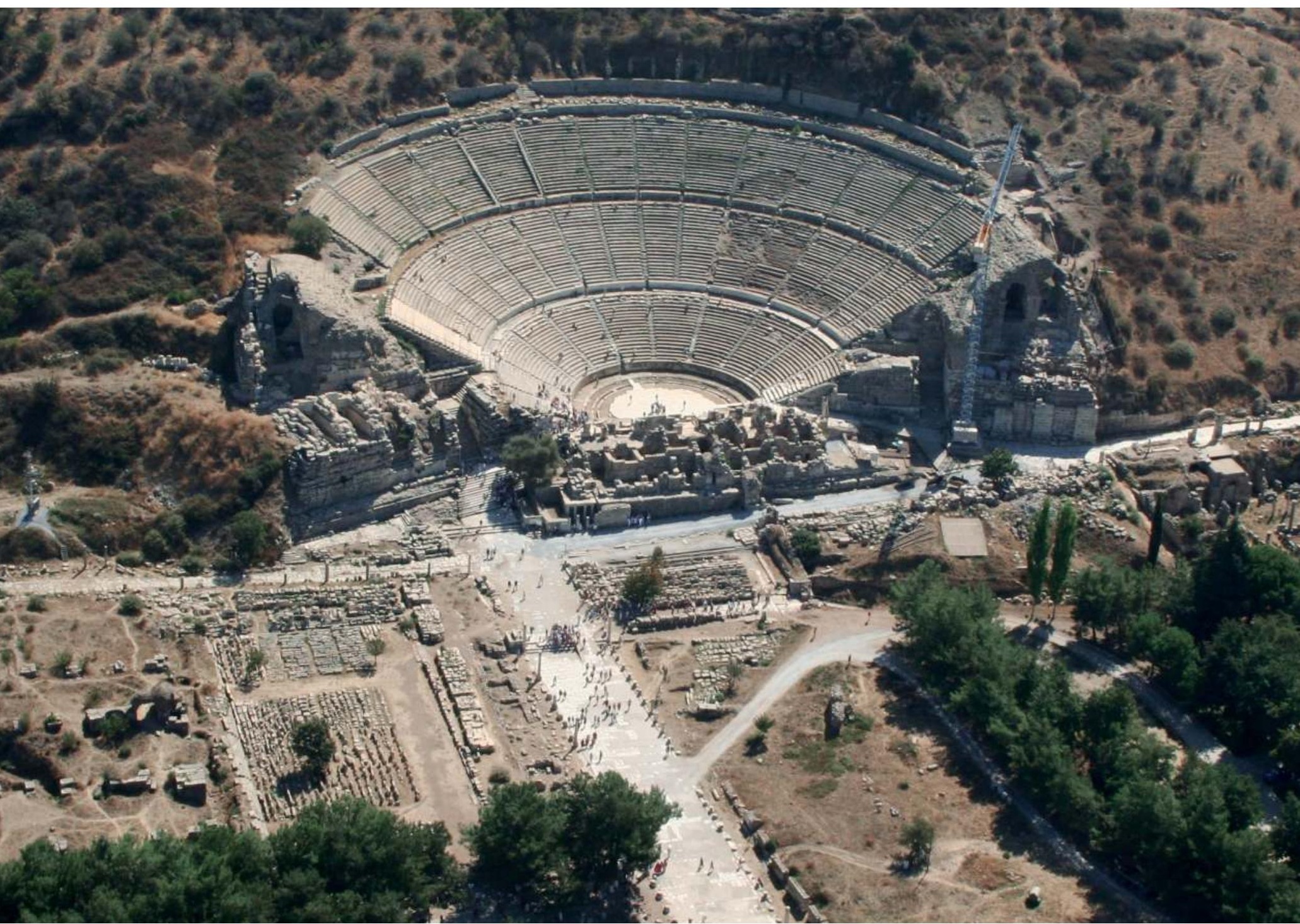


FRIEDRICH KRINZINGER - PETER RUGGENDORFER (HRSG.)

DAS THEATER VON EPHESOS

ARCHÄOLOGISCHER BEFUND, FUNDE UND CHRONOLOGIE

TEXTBAND 


\title{
FORSCHUNGEN IN EPHESOS
}

\author{
Herausgegeben vom \\ ÖSTERREICHISCHEN ARCHÄOLOGISCHEN INSTITUT
}

BAND II/1 


\title{
DAS THEATER VON EPHESOS
}

\section{ARCHÄOLOGISCHER BEFUND, FUNDE UND CHRONOLOGIE}

\section{TEXTBAND}

\author{
HERAUSGEGEBEN VON \\ FRIEDRICH KRINZINGER - PETER RUGGENDORFER
}

\author{
MIT BEITRÄGEN VON
}

DUYGU AKAR-TANRIVER, MARIA AURENHAMMER, VIKTOR BÖHM, GERHARD FORSTENPOINTNER, ALFRED GALIK, TINA HOBEL, MARTIN HOFBAUER, BIRGIT ÖHLINGER, ARZU ÖZTÜRK (†), ANDREA M. PÜLZ, ELISABETH RATHMAYR, CHRISTOPH SAMITZ, PATRICK SÄNGER, URSULA SCHACHINGER, GUDRUN STYHLER-AYDIN, HANS TAEUBER, MARCEL TSCHANNERL, ALICE WALDNER, GERALD E. WEISSENGRUBER 


\section{Veröffentlicht mit Unterstützung des Austrian Science Fund (FWF): PUB 341-G25}

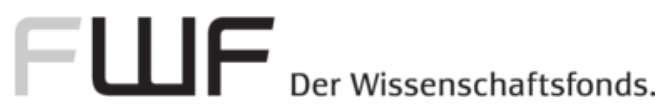

Open Access: Wo nicht anders festgehalten, ist diese Publikation lizenziert unter der Creative-Commons-Lizenz Namensnennung 4.0.

Open access: Except where otherwise noted, this work is licensed under a Creative Commons Attribution 4.0 Unported License.

To view a copy of this license, visit

http://creativecommons.org/licenses/by/4.0/

Umschlagabbildungen: Vorderseite, Vedat Süer/2007, Rückseite, Martin Hofbauer/ÖAI

Lektorat: Gudrun Wlach

Redaktion: Ireen Kowallek

Koordination: Peter Ruggendorfer

Bibliografische Information der Deutschen Nationalbibliothek

Die Deutsche Nationalbibliothek verzeichnet diese Publikation in der Deutschen Nationalbibliografie,

detaillierte bibliografische Daten sind im Internet über http://dnb.d-nb.de abrufbar.

Diese Publikation wurde einem anonymen, internationalen

Peer-Review-Verfahren unterzogen.

This publication has undergone the process of anonymous, international peer review.

Die verwendeten Papiersorten sind aus chlorfrei gebleichtem Zellstoff hergestellt, frei von säurebildenden Bestandteilen und alterungsbeständig.

Bestimmte Rechte vorbehalten.

ISBN 978-3-7001-7590-2

Copyright (C) 2017 by

Österreichische Akademie der Wissenschaften, Wien

Satz und Layout: Hapra GmbH, Puchenau

Druck und Bindung: Prime Rate kft., Budapest

http://epub.oeaw.ac.at/7590-2

http://verlag.oeaw.ac.at 


\section{INHALTSVERZEICHNIS}

VORWORT DER GRABUNGSLEITUNG EPHESOS …….................................................... XI

VORWORT DER HERAUSGEBER UND DES VORSITZENDEN

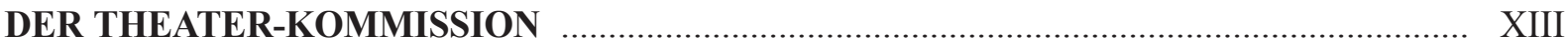

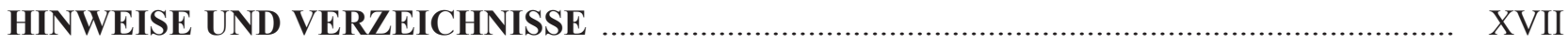

1. Abgekürzt zitierte Literatur ………................................................................ XVII

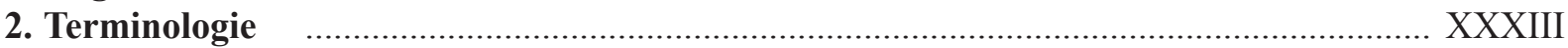

3. Glossar ausgewählter architektonischer Begriffe ................................................ XXXIV

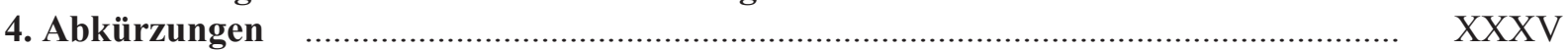

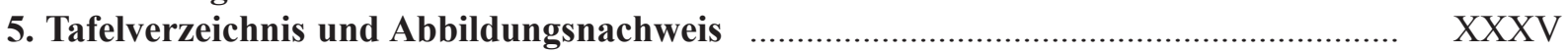

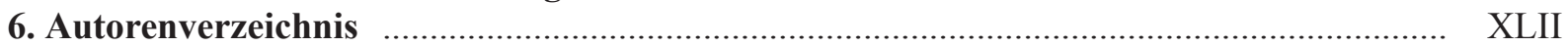

1. TOPOGRAFIE UND FORSCHUNGSGESCHICHTE

(Martin HofbaUER - Arzu ÖZtÜRK - Gudrun StYhLER-Aydin) …….............................................. 1

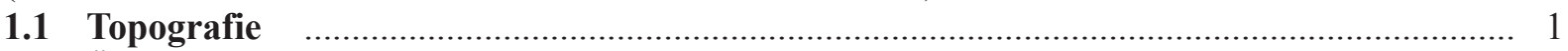

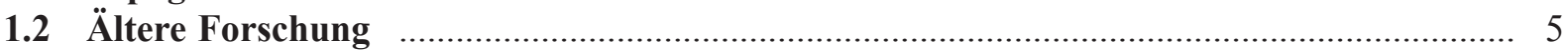

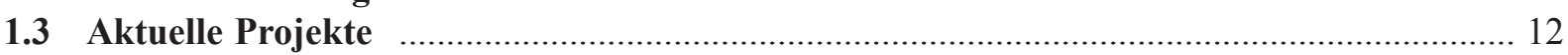

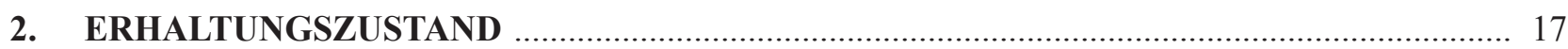

2.1 Skene (Martin HofBAUER - Arzu ÖZtÜRK) ……….......................................................... 17

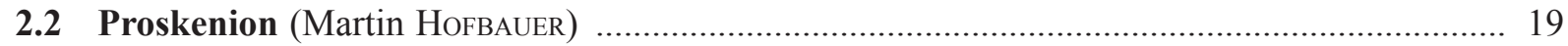

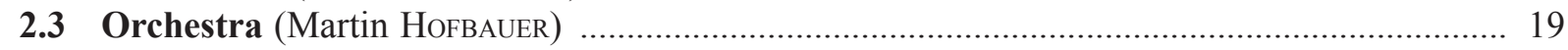

2.4 Auditorium (Gudrun STYHLER-AYdin) ……................................................................. 20

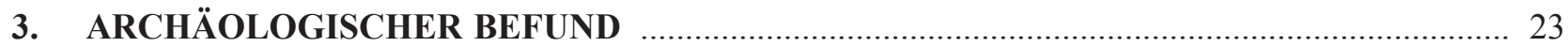

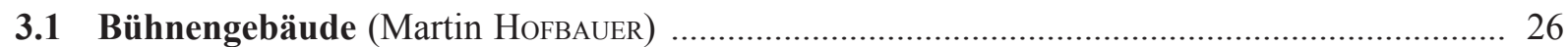

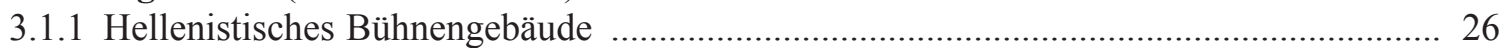

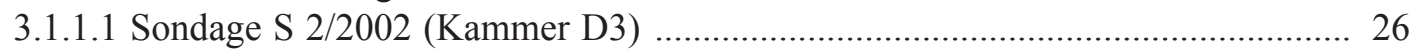

3.1.1.2 Sondage S 2/2005 (Kammer D8) ……………............................................. 27

3.1.2 Kaiserzeitliches Bühnengebäude ……………….................................................... 29

3.1.2.1 Sondage S 2/2004 (Kammer E1) ………….................................................... 29

3.1.2.2 Sondage S 1/2004 (Kammer E3) ……………................................................ 30

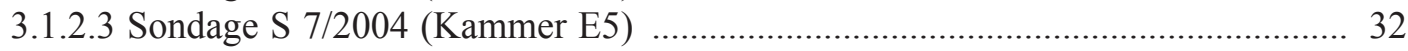

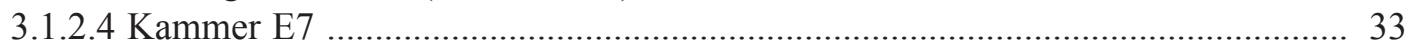

3.1.2.5 Sondage S 3/2005 (Kammer E8) ................................................................ 33

3.1.3 Raum RN1, nördlich des Bühnengebäudes ……......................................................... 34

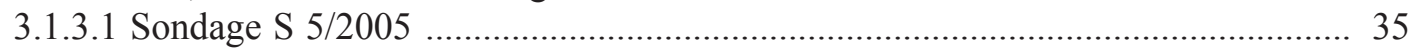

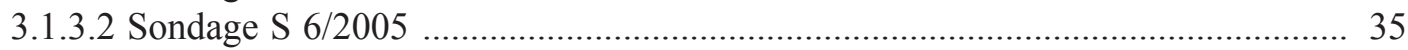

3.1.4 Oberflächenuntersuchungen im Bereich des Bühnengebäudes ................................... 36

3.1.4.1 Nordseite der Theaterterrasse …………..................................................... 36

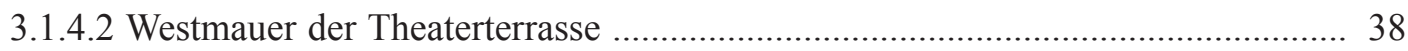

3.1.4.3 Bereich südlich des Bühnengebäudes ............................................................ 38

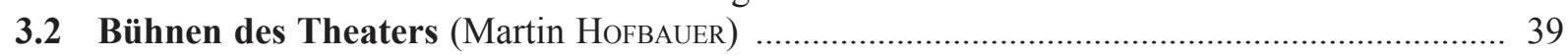

3.2.1 Hellenistische Bühne ................................................................... 39

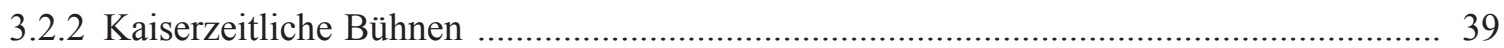

3.2.2.1 Sondagen S 1/2001-Süd, S 3/2003 und S 6/2004 ...................................... 40

3.2.2.2 Sondagen S 1/2001-Nord und S 1/2002 …….............................................. 41

3.2.2.3 Sondage S 5/2004 und der nördliche Bereich des Logeion ............................. 44

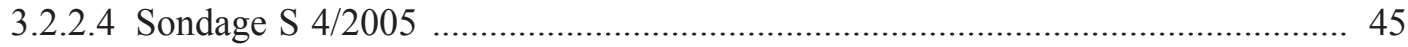

3.2.2.5 Sondagen S 1/2003 und S 2/2003 …………….......................................... 46 


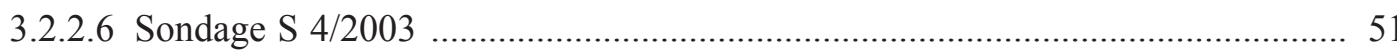

3.2.3 Zusammenfassung Bühnen des Theaters ............................................................. 53

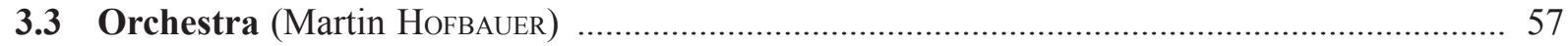

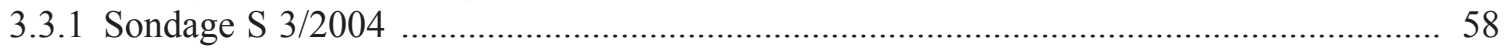

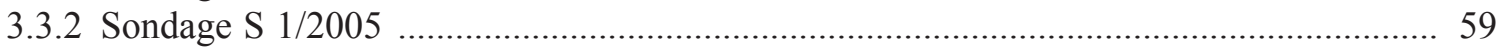

3.3.3 Interpretation des Befunds ...................................................................................... 62

3.3.3.1 Orchestra in hellenistischer Zeit ..................................................................... 62

3.3.3.2 Orchestra in der Kaiserzeit .............................................................................. 64

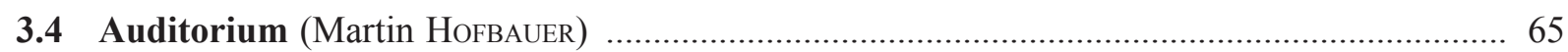

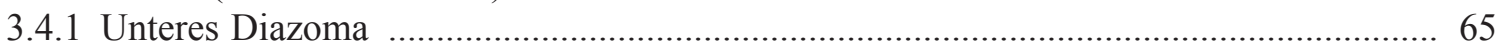

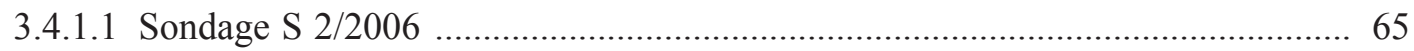

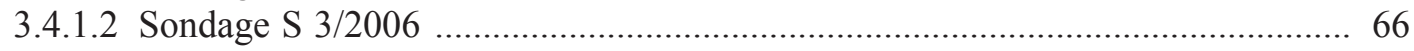

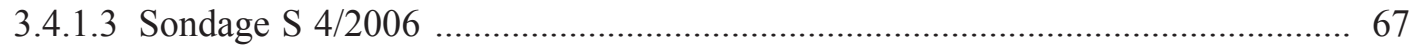

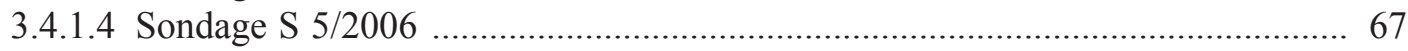

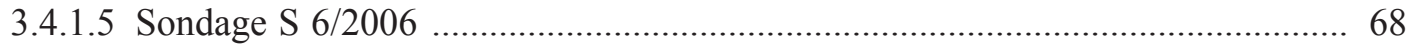

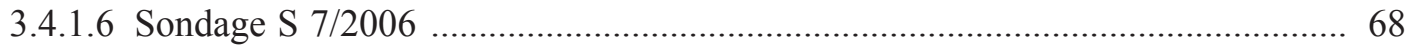

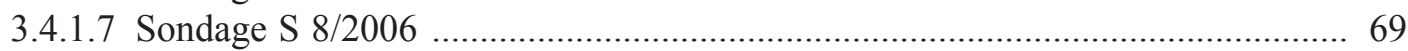

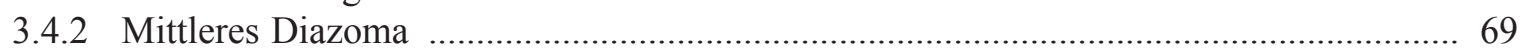

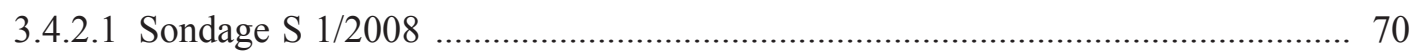

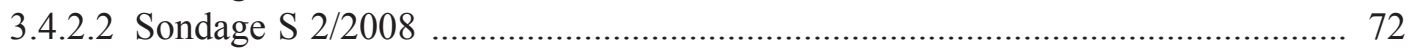

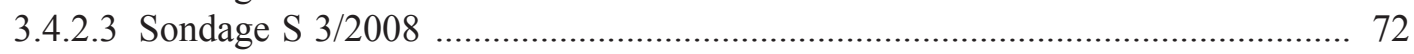

3.4.2.4 Sondage S $4 / 2008$.................................................................................. 73

3.4.2.5 Sondage S 5/2008 …………................................................................ 74

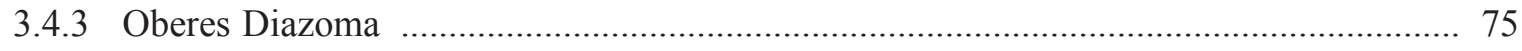

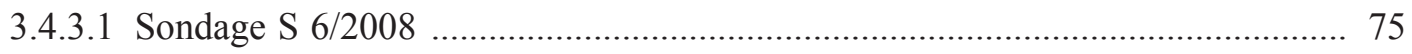

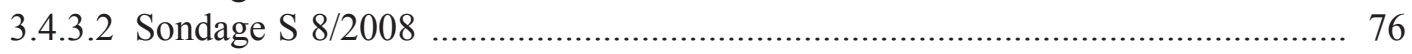

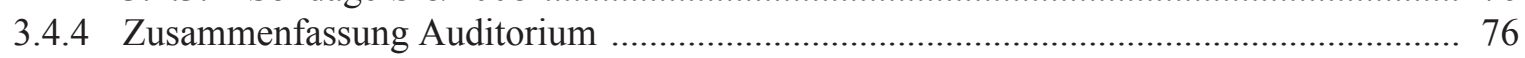

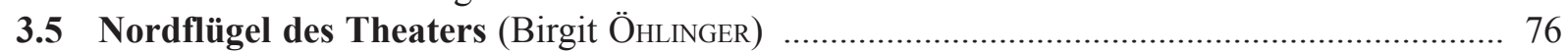

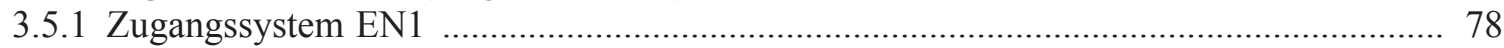

3.5.1.1 vomitorium EN1 ………..................................................................... 78

3.5.1.1.1 EN1, nördlicher Bereich ………………....................................... 78

3.5.1.1.2 EN1, südlicher Bereich …………………….................................. 81

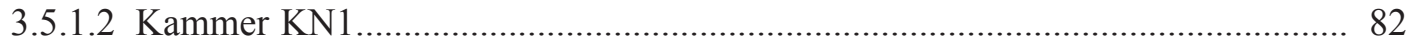

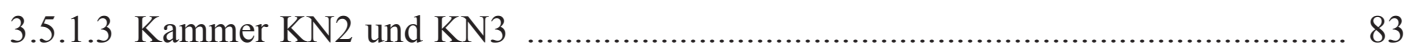

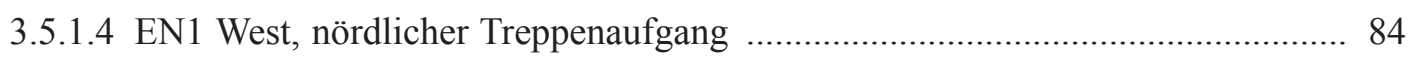

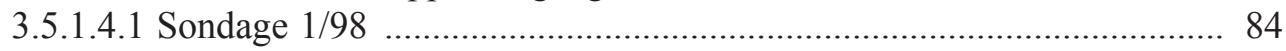

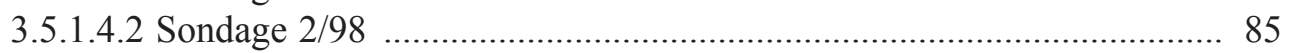

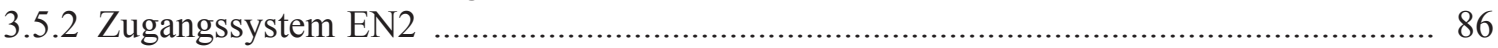

3.5.2.1 vomitorium $\mathrm{EN2}$............................................................................... 86

3.5.2.1.1 Sondagen 4/98 und Norderweiterung ………................................... 86

3.5.2.1.2 Sondage 5/98 ............................................................................ 87

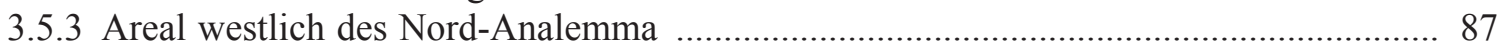

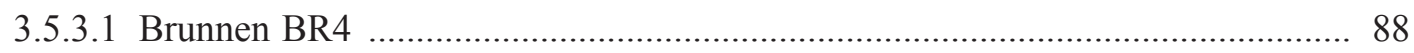

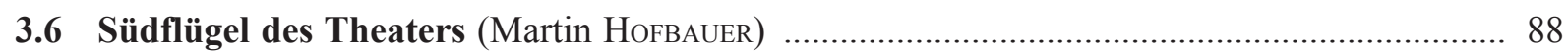

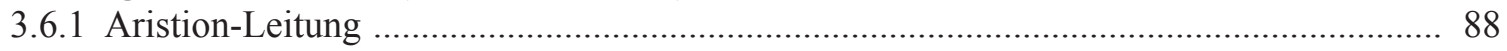

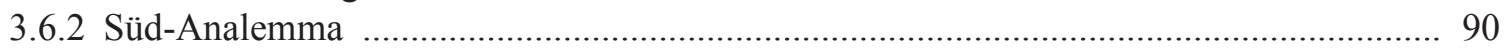

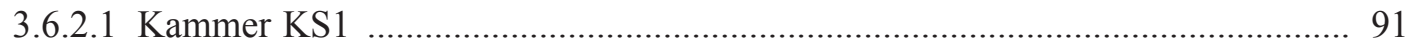

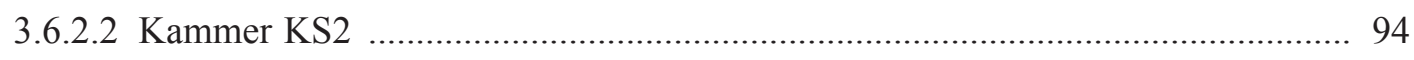

3.6.2.3 Kammer KS3 ……………................................................................... 95

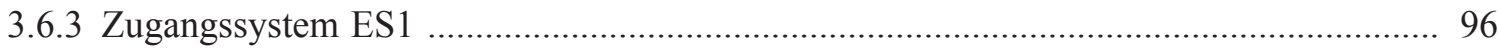

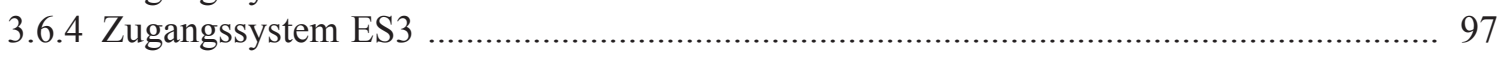




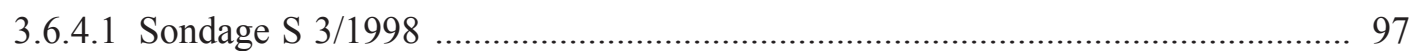

3.7 Areal südlich des Theaters, Stiegengasse (Martin HofBAUER) ............................................. 98

3.7.1 Die Treppe und ihre Zugangspodeste vor den Eingängen ES1 bis ES3 ......................... 99

3.7.1.1 Zugangspodest ES3 ……............................................................................ 99

3.7.1.2 Oberer Treppenabschnitt zwischen den Eingängen ES2 und ES3 .................. 100

3.7.1.3 Zugangspodest ES2 …………................................................................... 101

3.7.1.4 Unterer Treppenabschnitt zwischen den Zugängen ES1 und ES2 ….............. 101

3.7.1.5 Zugangspodest ES1 .............................................................................. 102

3.7.2 Aufgabe der Stiegengasse ..................................................................................... 103

3.7.2.1 Oberer Treppenabschnitt und Zugangspodest ES3 …..................................... 104

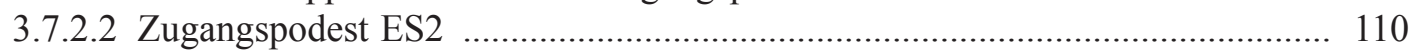

3.7.2.3 Unterer Treppenabschnitt und Zugangspodest ES1 ...................................... 112

3.7.3 Zusammenfassung Areal südlich des Theaters, Stiegengasse ..................................... 118

3.8 Grabung östlich der summa cavea (Marcel TSCHANNERL) …………………....................... 119

3.8.1 Aufgabenstellung und Methode …………........................................................... 119

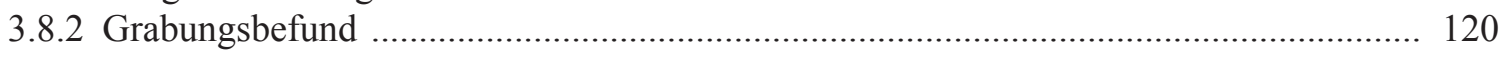

3.8.2.1 Mauerzüge ................................................................................................ 120

3.8.2.2 Weitere bauliche Strukturen .................................................................. 121

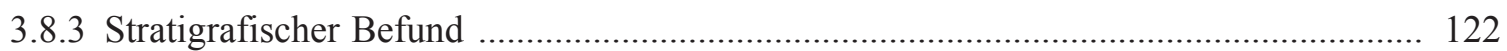

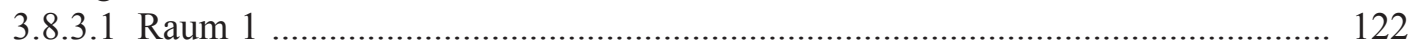

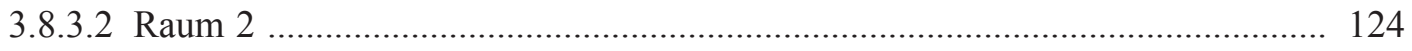

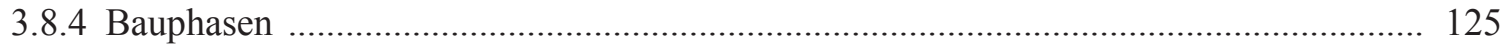

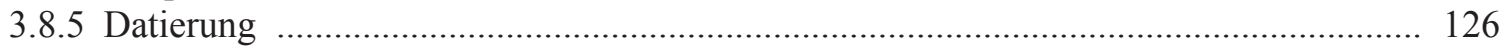

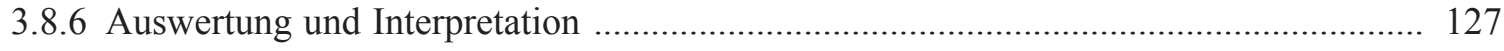

3.9 Zusammenfassung archäologischer Befund (Martin HOFBAUER) ....................................... 129

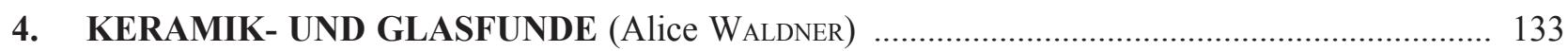

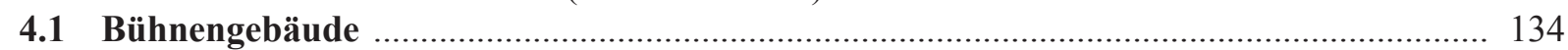

4.1.1 Funde aus den Sondagen im hellenistischen Bühnengebäude ...................................... 134

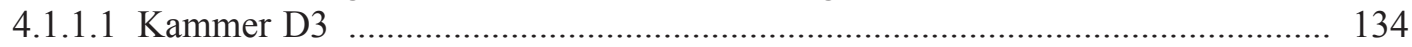

4.1.1.2 Kammer D8 …………...................................................................... 137

4.1.1.3 Auswertung und Interpretation ................................................................. 139

4.1.2 Funde aus den Sondagen im kaiserzeitlichen Bühnengebäude ................................. 139

4.1.2.1 Kammer E1 ....................................................................................... 140

4.1.2.2 Kammer E3, Verfüllung der Pithoi 1 und 2 ................................................ 140

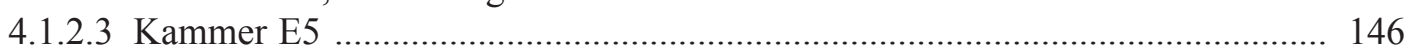

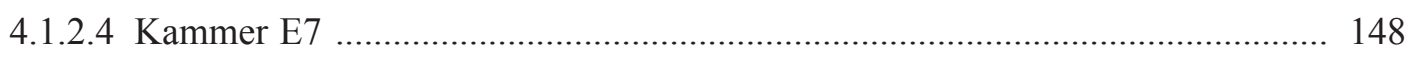

4.1.2.5 Kammer E8 ........................................................................................ 149

4.1.3 Funde aus Raum RN1, nördlich des Bühnengebäudes ............................................. 150

4.2 Funde aus den Sondagen im Bereich der kaiserzeitlichen Bühnen ............................... 150

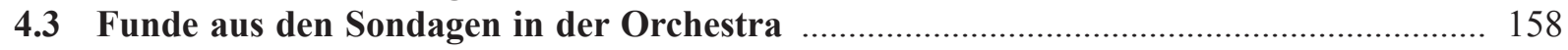

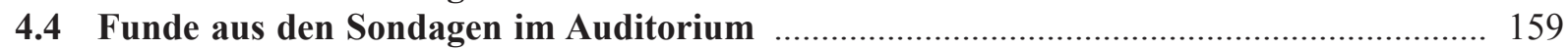

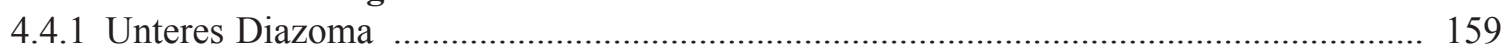

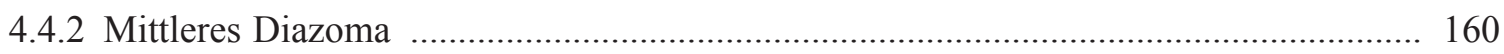

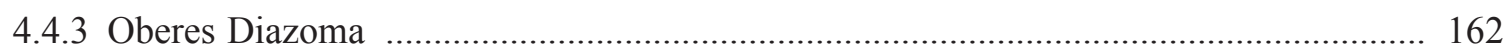

4.5 Funde aus den Sondagen im Nordflügel des Theaters ……......................................... 163

4.5.1 Funde aus dem Zugangssystem EN1 ………....................................................... 163

4.5.1.1 EN1, nördlicher Bereich ....................................................................... 163

4.5.1.2 EN1, südlicher Bereich ....................................................................... 164

4.5.1.3 Kammer KN1....................................................................................... 164

4.5.1.4 EN1 West, Nördlicher Treppenaufgang …………………........................... 166 
4.5.2 Funde aus dem Zugangssystem EN2 …………................................................. 167

4.5.3 Funde aus dem Areal westlich des Nord-Analemma ................................................. 168

4.6 Funde aus den Sondagen im Südflügel des Theaters …….......................................... 169

4.6.1 Funde aus der Aristion-Leitung ……………......................................................... 169

4.6.2 Funde aus dem Süd-Analemma ........................................................................ 170

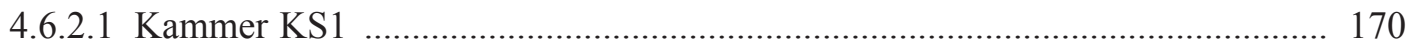

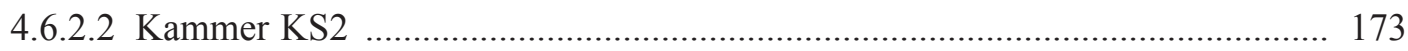

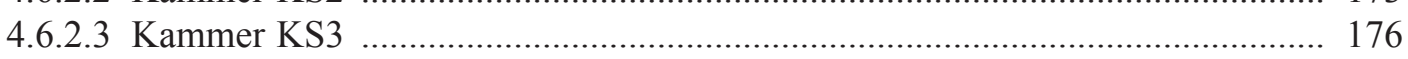

4.6.3 Funde aus der Sondage im Zugangssystem ES1 .................................................... 177

4.6.4 Funde aus der Sondage im Zugangssystem ES3 ………............................................ 177

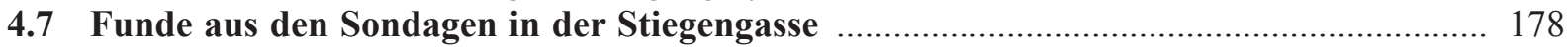

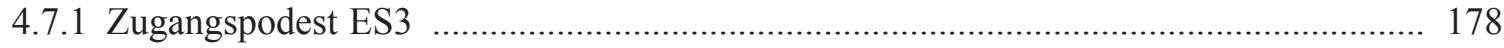

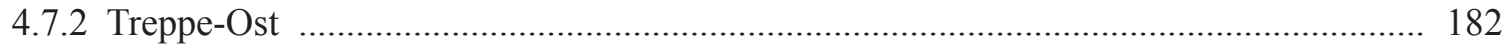

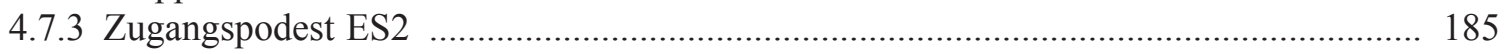

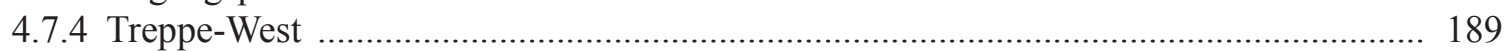

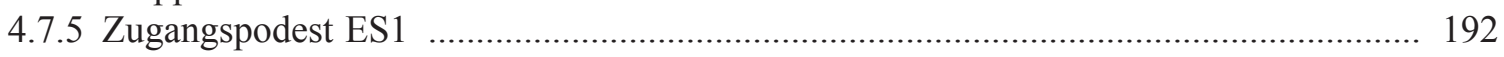

4.8 Funde aus den Grabungen oberhalb der summa cavea ………......................................... 194

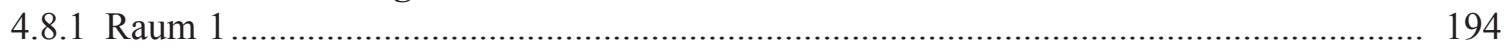

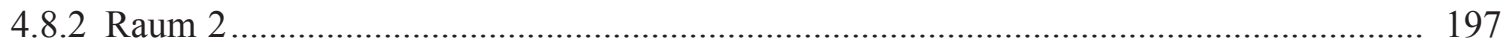

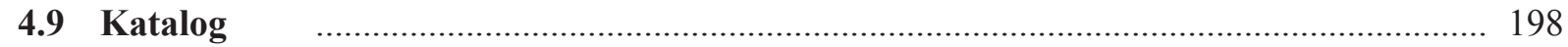

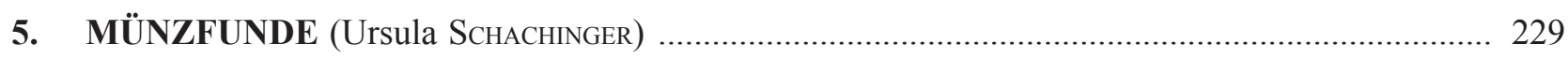

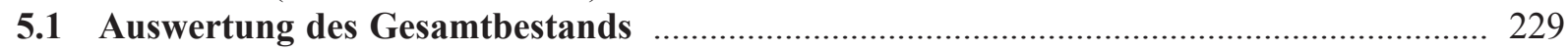

5.1.1 Stückzahlen und Fundgeschichte _............................................................................ 229

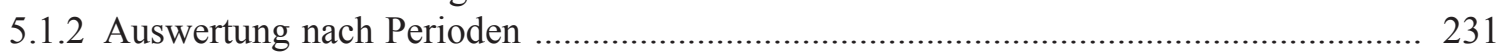

5.1.2.1 Griechische Münzen ...................................................................................... 231

5.1.2.2 Autonome Städteprägungen ................................................................ 234

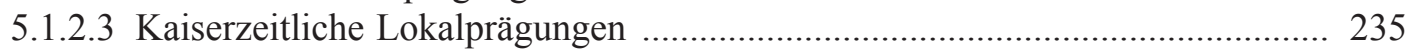

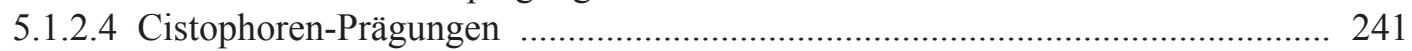

5.1.2.5 Römische Reichsprägungen ………….................................................... 245

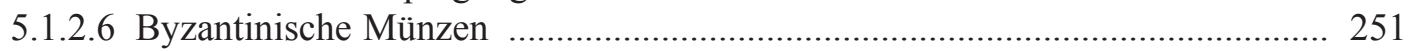

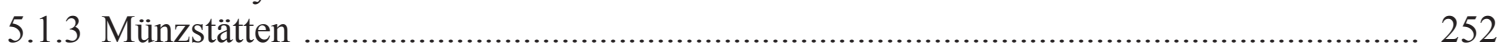

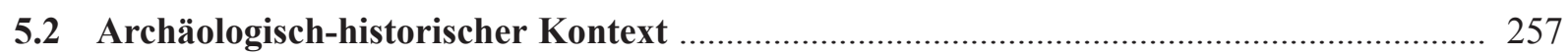

5.2.1 Münzfunde aus dem Bühnengebäude .................................................................... 257

5.2.2 Münzfunde aus dem Bereich des Logeion ................................................................ 260

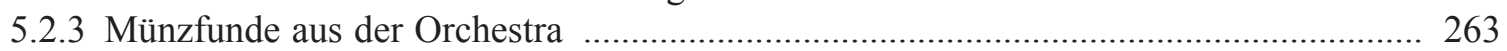

5.2.4 Münzfunde aus dem Auditorium ............................................................................... 263

5.2.5 Münzfunde aus dem Nordflügel .............................................................................. 263

5.2.6 Münzfunde aus dem Südflügel ................................................................................ 266

5.2.7 Münzfunde an der Stiegengasse, im Süden des Theaters ......................................... 274

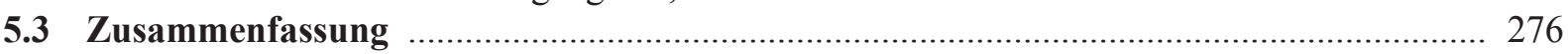

5.4 Katalog der Münzfunde in chronologisch-geografischer Ordnung ............................... 277

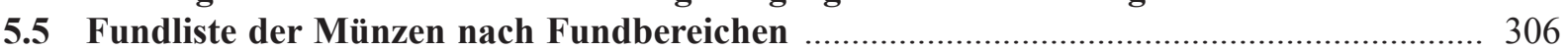

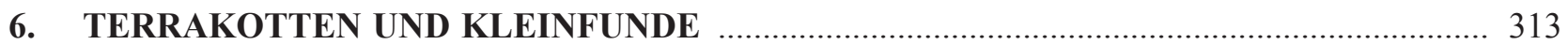

6.1 Terrakotten (Elisabeth RATHMAYR) …………................................................................ 313

6.2 Kleinfunde (Duygu AKAR-TANRIVER - Andrea M. PÜLz) ……………………..................... 322

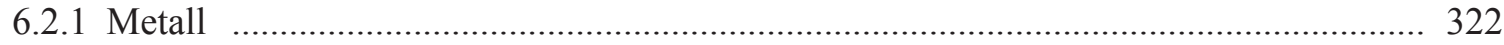

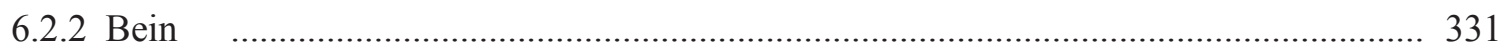

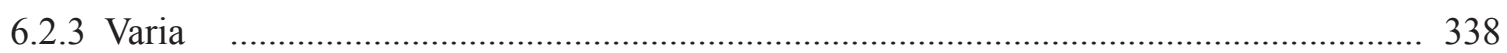


7. SKULPTUREN UND INVENTAR: FUNDE AUS DEN JAHREN 1993 BIS 2012

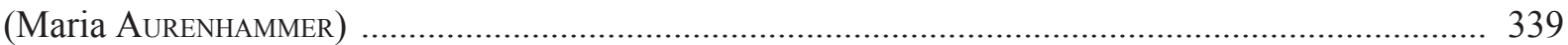

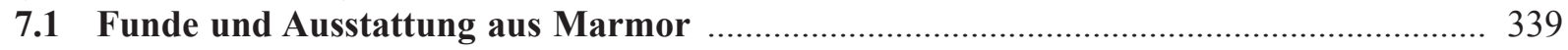

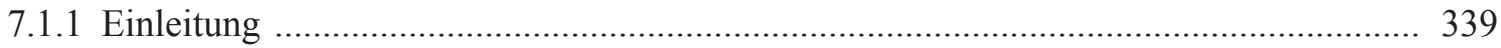

7.1.2 Erhaltungszustand und Fundorte der Skulpturen sowie des Inventars ......................... 339

7.1.3 Material und Bearbeitung ………........................................................................ 341

7.1.4 Formate der Skulpturen ........................................................................................ 341

7.1.5 Zur Datierung der Skulpturen ................................................................................. 341

7.1.6 Zur Ausstattung des Theaters anhand der Funde aus den Jahren von 1993 bis 2009 ... 342

7.1.6.1 Gladiatorenpfeiler ..................................................................................... 343

7.1.7 Ikonografie, Funktion und präsumtive Aufstellungsorte der nicht zur Ausstattung des Theaters gehörenden Denkmäler ……………….................................................. 345

7.1.8 Katalog der Funde aus Marmor _............................................................................. 347

7.2 Skulpturen aus Bronze: Funde aus den Jahren von 1993 bis 2009

(Maria Aurenhammer - Duygu Akar-TanRiver) …….......................................................... 368

7.2.1 Katalog der Skulpturen aus Bronze ...................................................................... 369

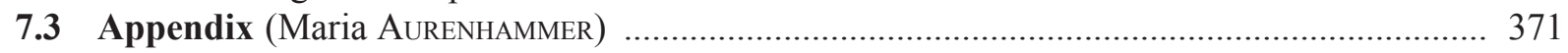

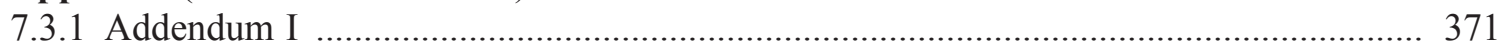

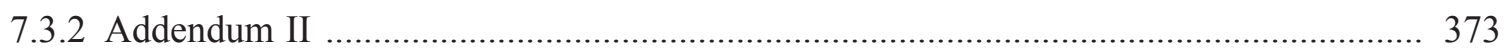

8. NEUE INSCHRIFTEN AUS DEM THEATER VON EPHESOS

(Patrick SÄNGER - Hans TAEUBER) ……………………............................................................ 375

8.1 Inschriften, die mit dem Bau oder dem Betrieb des Theaters in Zusammenhang stehen ... 375

8.2 Ehreninschriften, die im Theater aufgestellt waren ................................................ 376

8.3 Inschriften, die sekundär im Theater verbaut waren ………..................................... 382

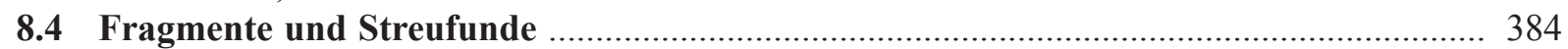

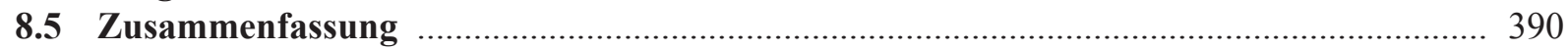

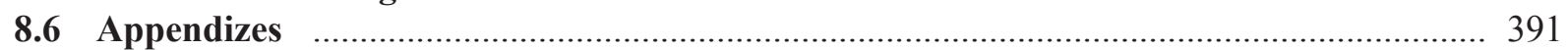

8.6.1 Appendix 1: Altbestand der Bauinschriften aus dem Theater

(Hans TAEUBER - Viktor BöHM - Tina HobeL) ………................................................ 391

8.6.2 Appendix 2: Gesamtverzeichnis der im Bereich des Theaters gefundenen Inschriften (Hans TAEUBER - Christoph SAmitz) …………………............................................... 401

9. DER ARCHÄOZOOLOGISCHE BEFUND AUS DER VERFÜLLUNG DER ARISTION-LEITUNG

(Alfred GaliK - Gerhard ForstenPointner - Gerald E. Weissengruber) …………….................... 417

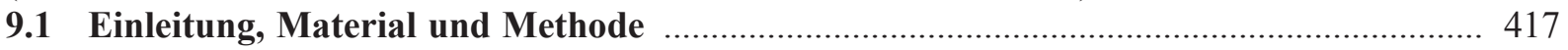

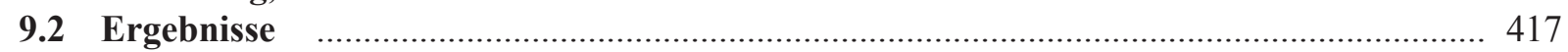

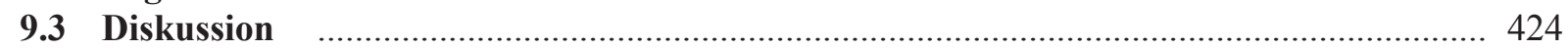

10. DIE BAULICHE ENTWICKLUNG DES THEATERS

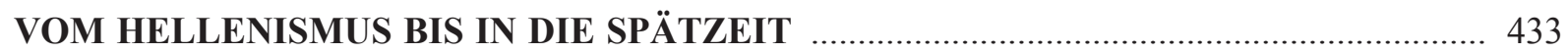

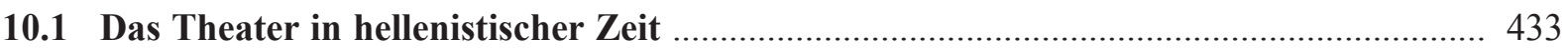

10.1.1 Hellenistisches Bühnengebäude (Martin HofBAUER) ................................................. 433

10.1.2 Hellenistische Orchestra (Martin HofBaUer) ............................................................. 438

10.1.3 Hellenistisches Koilon (Gudrun STYHLER-AYdin) …….................................... 439

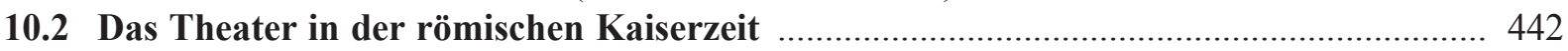

10.2.1 Kaiserzeitliche Theaterfassaden (Arzu ÖZTÜRK) ……………................................. 442

10.2.2 Kaiserzeitliches Bühnengebäude (Martin Hofbauer) …………………….............. 447

10.2.3 Kaiserzeitliche Orchestra (Martin HofBaUeR) ...................................................... 448

10.2.4 Kaiserzeitliche Cavea (Gudrun STYHLER-Aydin) ...................................................... 448 
10.2.4.1 Frühkaiserzeitliche Bauaktivitäten ............................................................ 448

10.2.4.2 Erweiterungen des Auditorium unter Domitian bis Traian ........................ 449

10.2.4.3 Umbauten und Reparaturen in antoninischer Zeit .................................... 467

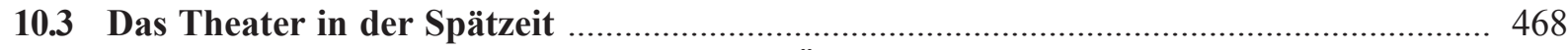

10.3.1 Theaterfassade in der Spätzeit (Arzu ÖZTüRK) ....................................................... 468

10.3.2 Bühnengebäude in der Spätzeit (Martin Hofbauer) ………….................................. 468

10.3.3 Änderungen an Orchestra und Bühnenfront (Martin HofBAUER) ................................ 469

10.3.4 Veränderungen im Auditorium (Gudrun STYHLER-Aydin) ........................................ 469

11. THE ARCHITECTURAL DEVELOPMENT OF THE THEATRE FROM THE

HELLENISTIC PERIOD TO LATE ANTIQUITY (Übersetzung: Catherine LeISSER) .............. 475

12. ZUSAMMENFASSUNG UND CHRONOLOGISCHER ÜBERBLICK

(Martin HofBAUER - Arzu ÖZTÜRK - Gudrun STYHLER-Aydin) ……………………................... 513

Summary (Übersetzung: Catherine LeISSER) ………….......................................................... 523

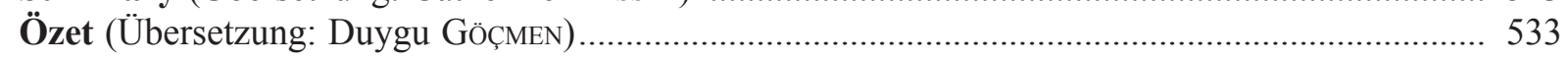




\section{VORWORT DER GRABUNGSLEITUNG EPHESOS}

Als im September 2012 das Große Theater von Ephesos mit einem Konzert der Berliner Philharmoniker im Rahmen des Izmir-Festivals wieder eröffnet wurde, waren sich wohl nur wenige im Publikum bewusst, dass diesem künstlerischen Genuss fast 150 Jahre Ausgrabungs- und Restaurierungstätigkeit vorangegangen waren.

Bereits im späten 15. Jahrhundert war das Theater erstmals von Cyriacus von Ancona erwähnt worden, die eigentlichen Grabungen unter der Leitung des Engländers John Turtle Wood setzten hier aber erst im Jahr 1866 ein. In zwei Jahren und unter der Beteiligung von bis zu 70 Mitarbeitern wurden vor allem Orchestra und Bühnengebäude freigelegt und der Zuschauerraum anhand langer Suchschnitte definiert, sodass ein erster, auf Grabungsdaten basierender Rekonstruktionsversuch des Grundrisses erstellt werden konnte. Als knapp 20 Jahre später österreichische Archäologen die Arbeiten erneut aufnahmen, mussten sie jedoch feststellen, dass das von Wood ausgegrabene Steinmaterial zum Teil abtransportiert und in den umliegenden Dörfern als Baumaterial verwendet worden war. In insgesamt fünf Kampagnen und kleineren Nachuntersuchungen 1901 und 1904 gelang trotzdem eine für die damalige Zeit detaillierte Untersuchung des Gebäudes, deren Ergebnisse in dem 1912 erschienenen Band II der »Forschungen in Ephesos« publiziert wurden.

Stand zu Beginn der Aktivitäten somit die Erforschung des antiken Gebäudes im Zentrum, traten spätestens in den 60er Jahren des 20. Jahrhunderts, als sich die Ruinenstätte in einen archäologischen Park verwandelte und zu einer Touristenattraktion entwickelte, Überlegungen für eine Nutzung als Veranstaltungsort in den Vordergrund. In den darauffolgenden Jahrzehnten wurde mehr oder weniger ununterbrochen an dem Gebäude gearbeitet, um den antiken Bestand zu sichern und für die Anforderungen moderner Bespielbarkeit zu adaptieren.

Als Versammlungsplatz für das Volk von Ephesos, Aufführungsort szenischer Darbietungen sowie Austragungsstätte von Gladiatorenkämpfen, aber auch als Station der zahlreichen durch die Stadt geführten Prozessionen war das Große Theater der zentrale Ort öffentlichen Lebens und städtischer Repräsentation, betont durch die hier zur Schau gestellten Inschriften und Skulpturen. Das Gebäude war allerdings seit seiner Gründung im späten Hellenismus eine Baustelle und wurde wohl nie vollständig fertiggestellt. Noch in der Spätantike neuerlich mit Skulpturenschmuck ausgestattet, veränderte sich in der unmittelbar folgenden Siedlungsphase die Funktion des Theaters grundlegend, als zumindest das Bühnengebäude in die byzantinische Befestigungsanlage integriert wurde. Der tatsächliche Verfall setzte mit dem Steinraub im Zuschauergebäude ein, wo Sitzstufen für die Errichtung der Fortifikation des Ayasoluk-Berges entfernt wurden. Diese Eingriffe erklären auch den relativ schlechten Erhaltungszustand des Gebäudes und die Notwendigkeit, nach den Ausgrabungen Konservierungsarbeiten zur Sicherung des antiken Bestands vorzunehmen.

Dank großzügiger öffentlicher und privater Geldgeber ist es in den letzten Jahren gelungen, das monumentale Gebäude soweit zu sichern, dass es nicht nur für den täglichen Besucherandrang, sondern auch für Großveranstaltungen erneut zugänglich gemacht werden konnte. Unter Einhaltung strikter Auflagen, die beispielsweise eine Kapazitätsobergrenze von 2500 Personen und das Verbot von Verstärkeranlagen vorsehen, können nun antiker Tradition folgend kulturelle Veranstaltungen im Großen Theater von Ephesos abgehalten werden. Mein expliziter Dank gilt in diesem Zusammenhang dem Bundesministerium für Wissenschaft, Forschung und Wirtschaft, das die Arbeiten durch eine Sonderdotation ermöglicht hat, sowie der Ephesus Foundation für ihre generöse Unterstützung bei der Errichtung wegen massiver Erdbebenschäden unbedingt notwendig gewordener Stützkonstruktionen.

Parallel zu den Konservierungsarbeiten wurde von dem Institut für Kulturgeschichte der Antike an der Österreichischen Akademie der Wissenschaften die wissenschaftliche Bearbeitung des Monuments zügig 
vorangetrieben. Mein herzlicher Dank gilt allen beteiligten Kolleginnen und Kollegen, die sich dieses komplexen Themas angenommen und es letztendlich auch erfolgreich abgeschlossen haben. Bereits Otto Benndorf verfolgte das Publikationskonzept einer kontextuellen Vorlage von Architektur und Fundmaterial. Auch 100 Jahre später ist uns dies noch nicht vollständig gelungen, es darf aber erhofft werden, dass auch die noch ausstehenden Vorlagen des Bühnengebäudes und des Zuschauerraums alsbald in gedruckter Form vorliegen werden.

Wien, März 2016 


\section{VORWORT DER HERAUSGEBER UND DES VORSITZENDEN DER THEATER-KOMMISSION}

In der wechselvollen Geschichte und Gestaltung des Theaters von Ephesos spiegelt sich zum einen die Größe und Bedeutung der römischen Metropolis Asiae wider, zum anderen ist dieses Bauwerk in den letzten Jahrzehnten auch ein beredter Zeuge für die sich wandelnden Realitäten einer großen archäologischen Forschungsstätte, für welche neben den rein wissenschaftlichen Fragestellungen der Altertumswissenschaften auch andere kulturelle Interessen zu berücksichtigen sind.

Es ist eine Tatsache, dass seit Jahrzehnten alle größeren Restaurierungsmaßnahmen im Theater von Ephesos von der Zielsetzung geleitet waren, die Ruine als Veranstaltungsort nutzen zu können. Mit dem Beginn des aufblühenden Tourismus ist dieser Wunsch seitens der türkischen Autoritäten deutlich gewachsen und der damit verbundene Druck auf die Verpflichtungen der Archäologie und Denkmalpflege in einer modernen Freizeit-Gesellschaft gestiegen. Mit ministeriellen Sondergenehmigungen wurden immer wieder international vielbeachtete Großveranstaltungen ermöglicht, die viel Publikum angezogen haben. Gerade die ganz großen Erfolge zeigten aber auch die realen Grenzen und akzeptablen Rahmenbedingungen für die Sicherheit der Zuschauer und des Monuments deutlich auf. Weder die vollständige Schließung des Theaters und die damit verbundenen Einschränkungen für die Besucher (wie von 1993 bis 1997 verfügt), noch die uneingeschränkte Freigabe des Monuments für eine moderne Nutzung stellten realisierbare Positionen dar. Unter Abwägung aller positiven und negativen Aspekte wurde eine rational ausgewogene Annäherung zwischen der archäologischen und bauhistorischen Forschung sowie dem Denkmalschutz einerseits und den Wünschen nach Nutzung des Theaters anderseits als gemeinsames Ziel formuliert.

Ohne Beeinträchtigung der autonomen Wirkungsmöglichkeiten können sich Archäologie und Denkmalpflege diesen nachvollziehbaren Wünschen nicht entziehen, zumal die moderne Nutzung von antiken Theatern eine im gesamten Mittelmeerraum diskutierte Problematik in sich birgt. Es gibt eine Reihe von international anerkannten, grundsätzlichen Positionen zu diesen Fragen und auch beispielhaften Lösungen, die als Orientierung für den notwendigen Interessensausgleich dienen konnten. Wir können heute in dieser Frage auf eine vorbildliche Zusammenarbeit zwischen dem Konzessionsträger der Grabung Ephesos, dem Österreichischen Archäologischen Institut, sowie der Österreichischen Akademie der Wissenschaften auf nationaler Seite und der Generaldirektion für Kulturgüter und Museen des Ministeriums für Kultur und Tourismus der Republik Türkei sowie den zuständigen regionalen Autoritäten auf Seiten des Gastlandes zurückblicken. Alle widmeten sich seit fast zwanzig Jahren dem großangelegten Projekt zur Erforschung und Konservierung des Theaters von Ephesos.

Mit dem Wunsch, die antike Spielstätte für eine zeitgenössische Nutzung als Veranstaltungsort zu bereiten, kam es seit den späten 1960er Jahren zu mehreren großangelegten Aktivitäten, die zu teilweise sehr einschneidenden Adaptierungen des Bühnengebäudes und des Zuschauerraums führten. Leider waren diese Maßnahmen nicht immer von einer entsprechenden wissenschaftlichen Aufsicht begleitet. In den folgenden Jahrzehnten ist hier eine ganz entscheidende Sensibilisierung eingetreten. So wurde mit Beginn der 1990er Jahre seitens des Österreichischen Archäologischen Instituts ein neuer Anlauf genommen und ein Projekt initiiert, das zunächst in Zusammenarbeit mit dem Museum Selçuk durchgeführt und ab 1993 durch die österreichische Grabungsleitung fortgesetzt wurde. Unter der Leitung von Stefan Karwiese konnten grundlegende Sicherungsarbeiten an den Analemmata verdienstvoll abgeschlossen werden. Begleitend wurden erste gezielte Grabungen angelegt, die bereits wesentliche Aufschlüsse zur Baugeschichte des Theaters lieferten. Leider kam die angestrebte Finanzierung eines EUROCARE-Projekts nicht zustande, wodurch die Arbeiten vorerst wieder unterbrochen wurden. Das Teilprojekt zur Neubearbeitung der römischen Bühnenwand des Theaters konnte in kleinerem Rahmen fortgesetzt werden. 
Im Jänner 1999 wurde schließlich an der Österreichischen Akademie der Wissenschaften eine international besetzte Kommission eingerichtet, die alle Arbeiten zur Erforschung, Konsolidierung und Restaurierung des Theaters von Ephesos in der Planung kritisch bewerten und in der Ausführung kontrollierend begleiten sollte. Unter Berücksichtigung international anerkannter Bestimmungen des Denkmalschutzes und aufgrund von vielfältigen Erfahrungen an anderen Ruinenstätten konnte in mehreren Sitzungen eine detaillierte Empfehlung erarbeitet werden, die im Juli 1999 als Vorschlag für die weitere Vorgangsweise an die Generaldirektion für Kulturgüter und Museen übermittelt wurde.

Als prinzipielle Voraussetzung für eine Nutzung galt der Theater-Kommission das Gleichgewicht folgender Faktoren, die für die Realisierbarkeit eines solchen Projekts von herausragender Wichtigkeit sind:

a) Die Sicherung der Ruine als antikes Monument mit möglichst schonenden und minimalen Eingriffen in die Bausubstanz und die vorgefundene historische Gestalt.

b) Die Sicherheit der Besucher, wobei die Wegeführung für die große Masse von Tagesbesuchern und für die Veranstaltungsbesucher unterschiedlich zu beurteilen ist.

c) Alle Notwendigkeiten für die Künstler und Akteure im Hinblick auf den Schutz der Ruine sowie die räumlichen und logistischen Optionen des Betriebs.

d) Die notwendigen technischen Voraussetzungen für die Durchführbarkeit von regulären Veranstaltungen, für die auch alle hygienischen und praktischen Bedürfnisse zu berücksichtigen sind.

Nach der Approbation dieser Empfehlungen durch ein Schreiben der Generaldirektion vom November 1999 an den Vorsitzenden der Kommission kam es allerdings nicht zu der ins Auge gefassten Finanzierung des Gesamtprojekts durch das türkische Ministerium für Kultur und Tourismus; so mussten sich konkrete Maßnahmen aus Kostengründen auf die Fortführung der wissenschaftlichen Arbeiten im Rahmen der Grabungskonzession beschränken, die als solide Grundlage für alle zukünftigen Entscheidungen dienen konnten.

Folgende inhaltliche Ziele standen im Zentrum:

a) Archäologische Untersuchungen am Bühnengebäude (Leitung: Martin Hofbauer), in der Orchestra und am südlichen Analemma zur Klärung der Chronologie des Theaters und seiner baulichen Veränderungen.

b) Bauforschung zur Gesamtanlage des Theaters, die in einer im Jahr 2004 neu formulierten Zusammenarbeit mit der TU Wien an das Institut für Architekturgeschichte und Bauforschung (Leitung: Marina Doering-Williams) abgetreten wurde und die Gudrun Styhler unter konsequentem Einsatz von 3DLaserscanning vor Ort realisieren konnte und deren Analyse derzeit zum Druck vorbereitet wird.

c) Abschluss der Neubearbeitung der verstreuten Reste der scaenae frons (Leitung: Arzu Öztürk $\dagger$ ) mit dem Ziel einer exakten Dokumentation und einer theoretischen Rekonstruktion der Bühnenwand ausgehend von den Arbeiten von George Niemann.

Im Jahr 2005 bestanden konkrete Möglichkeiten die geplanten Konsolidierungsarbeiten am Theater gemeinsam mit der Gemeinde Selçuk umzusetzen, welche dann jedoch wegen noch ungelöster statischer Probleme am Süd-Analemma und der beeinträchtigten Sicherheitslage nicht in Angriff genommen werden konnten.

Schließlich wurde der Grabung vom Ministerium für Kultur und Tourismus TÜRSAB als Partner an die Seite gestellt. Mit dem im Frühjahr 2007 vor dem Süd-Analemma errichteten Turmkran waren nun die Voraussetzungen zum Abtransport der gewaltigen Massen an Schutt und Abraum im Süden des Theaters gegeben, welche für die erfolgreiche Umsetzung der großen Untersuchungen erforderlich waren.

Mit dem Ausscheiden von Friedrich Krinzinger aus der Grabungsleitung Ephesos mit Ende 2007 und dem ein Jahr später erfolgten Wechsel in der Leitung des Instituts für Kulturgeschichte der Antike an der Österreichischen Akademie der Wissenschaften wurde die Zusammenarbeit insgesamt neu geregelt. In der Sitzung der Theater-Kommission im Juni 2008 wurde beschlossen, die wissenschaftlichen Untersuchungen auch weiterhin von allen Fragen der eventuellen Restaurierung zu trennen. Zur Wahrung der Kontinuität für das wissenschaftliche Arbeitsprogramm wurde Peter Ruggendorfer als Koordinator seitens der Österreichischen Akademie der Wissenschaften bestimmt. 
Ab 2008 folgten die archäologischen und bauhistorischen Untersuchungen dann den Zielsetzungen eines auf drei Kampagnen ausgelegten Schwerpunktprogramms, das neben den Grabungen im Osten des Theaters die umfangreichen Freilegungen in den Kammern des Süd-Analemma und an der Stiegengasse umfasste, welche schließlich 2010 erfolgreich abgeschlossen wurden.

Das im Rahmen eines Workshops im Jahr 2009 entwickelte Publikationskonzept sieht vor, dass die Österreichische Akademie der Wissenschaften für die Vorlage des archäologischen Befunds, die TU Wien hingegen für die Drucklegung der Ergebnisse der bauhistorischen Untersuchungen im Zuschauerraum (STYHLER-Aydin, in Vorbereitung) verantwortlich zeichnet. Die weiteren Faszikel zur Theaterforschung werden vom Österreichischen Archäologischen Institut getragenen. Insbesondere ist hier das weit gediehene Publikationsprojekt zum Bühnengebäude und zur scaenae frons zu nennen. Dafür hatte Arzu Öztürk (†) lange Jahre hindurch wertvolle Dokumentationen und Feldarbeiten geleistet, die von einem archäologischen Beitrag von M. Hofbauer begleitet werden sollten. Nach dem unerwarteten Ableben der Kollegin im Frühjahr 2016 wird dieses Projekt neu zu organisieren sein. Die Bearbeitung des Eroten-Frieses von der Bühnenwand wird in Kooperation mit dem Kunsthistorischen Museum Wien durchgeführt.

Für den ersten Punkt des Publikationsvorhabens, die archäologische Untersuchung des Theaters, ist es nun zu einem verantwortbaren Abschluss gekommen. Die Ergebnisse dieser einschließlich der Altgrabungen nunmehr rund zwei Jahrzehnte währenden Forschungen sind Gegenstand der vorliegenden Publikation.

Wie im folgenden Kapitel zur Forschungsgeschichte ausführlich dargestellt ist, hat man schon in den ersten fantasievollen Rekonstruktionsversuchen des Stadtbilds von Ephesos dem Theater besondere Bedeutung zugemessen. In den ersten Grabungen von J. T. Wood und später unter österreichischer Leitung von R. Heberdey kam das Bauwerk allerdings in einem sehr schlechten Erhaltungszustand zutage. Vom Bühnengebäude und auch von den Sitzstufen des Zuschauerraums waren zum größten Teil nur mehr die Fundamente erhalten, überdeckt von einer hoch anstehenden, verstürzten Masse an Schutt und Erdreich. Auch wenn keine gesicherten Belege für die Existenz eines hellenistischen Theaters bekannt sind, die dem Stadtentwurf unter Lysimachos zuzuweisen sind, können an dem monumentalen Gebäude nunmehr acht Bau- bzw. Nutzungsphasen von der fortgeschrittenen hellenistischen (ab dem 2. Viertel des 2. Jhs. v. Chr.) bis in die byzantinische Zeit unterschieden werden. Dabei waren besonders die Umgestaltungen von der spätflavischen bis in trajanische Zeit mit tiefgreifenden und nachhaltigen Veränderungen des architektonischen Erscheinungsbilds verbunden, die etwa die Erweiterung des Koilon zu den mächtigen Analemmata und die Ausführung der scaenae frons als dreigeschossige Tabernakelfassade beinhaltete. In der Spätantike war das Theater schließlich in die byzantinische Befestigung einbezogen und dabei weiteren einschneidenden Umbauten unterworfen. So ging die Errichtung eines Stadttors unmittelbar westlich des Theaters mit zusätzlichen Mauerverstärkungen und dem Einbau eines Turms im Bühnengebäude einher. Seiner ursprünglichen Funktion als Veranstaltungsort beraubt, diente das Gebäude schließlich der intensiven Gewinnung von Steinmaterial, wie seine im Stadtgebiet verstreuten Bauglieder nahelegen.

Mit diesem Band werden neben der Auswertung der archäologischen Kontexte mit der Vorlage der unterschiedlichen Fundgattungen, wie Keramik- und Glasfunde, Terrakotten, Kleinfunde, Münzen und archäozoologische Funde, auch neue epigrafische Zeugnisse und die im Theater zwischen 1993 und 2009 geborgenen Skulpturen in breiter, systematischer Bearbeitung vorgelegt. Somit kann der Kenntnisstand zur baulichen Entwicklung und Chronologie des Theaters von Ephesos in geschlossener Form vermittelt und überprüft werden.

Die bauhistorischen Analysen, die seitens der TU Wien von Gudrun Styhler zur Publikation vorbereitet werden, sind weit gediehen und werden als nächster Faszikel folgen. Auch wenn das Theater von Ephesos durch die aktuellen archäologischen Grabungen, bauhistorischen Dokumentationen und weitreichenden Konservierungs- und Sicherungsmaßnahmen in den letzten Jahren zu einer Großbaustelle geworden ist: Die Zielvorstellung, der kulturhistorischen Bedeutung des Theaters einerseits durch die präzise Erforschung gerecht zu werden, andererseits den Besuch dieser mächtigen antiken Ruine und ihre verantwortungsvolle Nutzung für kulturelle Veranstaltungen zu erreichen, rechtfertigt den gemeinsamen Aufwand aller beteiligten Institutionen und fachlichen Disziplinen in jeder Weise.

Unser besonderer Dank gilt den verantwortlichen türkischen Institutionen, allen voran dem Ministerium für Kultur und Tourismus der Republik Türkei und der Generaldirektion für Kulturgüter und Museen sowie dem zuständigen Kurul in Izmir, TÜRSAB, dem Museum Selçuk und der Gemeinde Selçuk. Herzlich ge- 
dankt sei an dieser Stelle auch den Mitgliedern der Theater-Kommission an der Österreichischen Akademie der Wissenschaften. Das Österreichische Archäologische Institut, das die enorme Aufgabe der Restaurierung und Konsolidierung des Gebäudes trägt, stellte während der Feldkampagnen die Infrastruktur am Ort der Forschungen und im Grabungshaus bereit. Dafür und für die gute Zusammenarbeit sowie für mannigfache Hilfestellung bei der Materialaufarbeitung darf dem Institut und seiner Direktorin, Frau Sabine Ladstätter, gedankt werden. Gedankt sei auch Herrn Stefan Karwiese, der die Kampagnen während der 1990er Jahre seitens des Österreichischen Archäologischen Instituts geleitet und seine Grabungsunterlagen für die Publikation zur Verfügung gestellt hat.

Ohne das zum Teil hohe kollegiale Engagement der Autorinnen und Autoren, die im Inhaltsverzeichnis genannt sind und für ihre Beiträge verantwortlich zeichnen, wäre die Realisierung dieses Bandes nicht zustande gekommen. Ihnen gebührt unser Dank. Ebenso danken möchten wir allen an den Feldkampagnen, bei der Aufarbeitung und bei der Publikationsvorbereitung mitwirkenden studentischen Mitarbeitern sowie den Geodäten Christian Kurtze, Stefan Klotz und Christian Schirmer für ihre tatkräftige Unterstützung bei den Vermessungsarbeiten.

Die Redaktion dieser Forschungsergebnisse, denen einige Jahre intensiver Feldarbeit zugrunde liegen, war nicht einfach. Auch deshalb wurde die Nummerierung der Anmerkungen in den Kapiteln der verschiedenen Autoren beibehalten und auf eine durchgehende Nummerierung verzichtet. Die Redaktion lag in den verdienstvollen Händen von Frau Gudrun Wlach und von Frau Ireen Kowalleck, die darüber hinaus noch so manche andere essentielle Hilfestellung für den Band geleistet hat.

Der Faszikel ist dem Andenken an Frau Prof. Dr. Arzu Öztürk gewidmet, die ihr großes wissenschaftliches Interesse neben vielen anderen Aufgaben auf die Bauforschung zu den Theatern von Perge und Ephesos ausgerichtet hatte.

Friedrich Krinzinger, Peter Ruggendorfer, Herausgeber HeRwig Friesinger, Vorsitzender der Theater-Kommission 


\section{HINWEISE UND VERZEICHNISSE}

\section{Abgekürzt zitierte Literatur}

Die Zitierweise folgt den Richtlinien des Österreichischen Archäologischen Instituts <http://www.oeai.at/ index.php/hinweise-fuer-autorinnen.html >. Die Abkürzungen der antiken Autoren und Werktitel entsprechen den Vorgaben in DNP 3 (1997) S. XXXXVI-XLIV. Zusätzlich werden folgende Abkürzungen verwendet:

AdLER 1872

AibABIN 1999

Alanyali 2005

ALDINI 1996

ALDINI 2000

AleXANDridis 2004

Alram 2007

AlzINGER 1972

Alzinger 1987

Anabolu 1991

Angelov u. a. 1996

ASAMER -

WoHLMAYER 2003

ATAÇ 1997

AtAÇ 1999a

ATAÇ 1999b

Atalay 1972

Atalay 1989

Augé - LinAnt

DE BELleFonds 1986

Auinger 2009

AuInger 2010

Auinger - Aurenhammer 2010

Aurenhammer 1990

Aurenhammer 2003

AYBEK 2009

AYDAȘ 2006

BACHMANN 2009

BAIER 2009

BAIER 2010

BAIER 2013
F. AdLER, Erläuterungen zum Stadtplane von Ephesos, in: CurTius 1872, 34-44.

A. Aibabin, Ethnische Geschichte der frühbyzantinischen Krim (Simferopol 1999).

H. S. Alanyali, Patara tiyatrosu 2004 çalişmalari, Anadolu 29, 2005, 1-12.

T. Aldini, Elementi per una più corretta classificazione delle anfore forlimpopolensi, in: Atti e memorie. Deputazione di storia patria per le province di Romagna 47. Nuova Serie (Forlimpopoli 1996) 11-22.

T. Aldini, Archeologia Betinorense Forlimpopoli, Documenti e studi 11 (Forlimpopoli 2000) 23-66.

A. AleXANDridis, Die Frauen des römischen Kaiserhauses (Mainz 2004).

M. Alram - F. Schmidt-Dick (Hrsg.), Numismata Carnuntina. Forschungen und Material (Wien 2007).

RE Suppl. XII (1972) 1588-1704 s. v. Nachträge: Ephesos B (W. AlzINGER).

W. Alzinger, Ephesos, in: Frontinus-Gesellschaft 1987, 180-184.

M. Anabolu, Efes Müzesi'nde bulunan masa ayakları, TürkAD 29, 1991, 71-84.

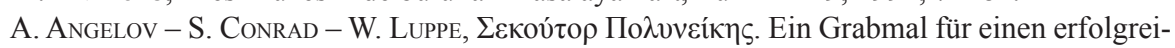
chen Gladiator aus Marcianopolis, Nikephoros 9, 1996, 135-144.

B. AsAmer - W. Wohlmayer (Hrsg.), Akten des 9. Österreichischen Archäologentages Salzburg 2001 (Salzburg 2003).

İ. AtAÇ, Das antike Theater von Ephesos, Forum Archaeologiae, 4/VIII/1997<http://farch. net> (23.05.2010).

İ. AtAÇ, Das antike Theater von Ephesos: Grundlagen des Projektes Raumforschung und Restaurierung, in: FriesINGER - KRINZINGER 1999, 429-435.

İ. AtAÇ, Neue Beobachtungen am Theater von Ephesos, in: SchERrER u. a. 1999, 1-6.

E. AtAlay, Efes'de Büyük Tiyatro'nun restorasyonu için yapılan kazılar ve bu kazılardan elde edilen buluntular, Efes Müzesi Yıllı̆̆1 1, 1972, 49-55.

E. Atalay, Weibliche Gewandstatuen des 2. Jahrhunderts n. Chr. aus ephesischen Werkstätten, DenkschrWien 206 (Wien 1989).

LIMC III (1986) 705-708 s. v. Elagabalos (C. AugÉ - P. LinAnt DE Bellefonds).

J. AuINGER, Zum Umgang mit Statuen hoher Würdenträger in spätantiker und nachantiker Zeit entlang der Kuretenstraße in Ephesos, in: LADSTÄTtER 2009, 29-52.

J. Auinger, Der Togatus aus SR 18, in: Krinzinger 2010, 666-669.

J. Auinger - M. Aurenhammer, Ephesische Skulptur am Ende der Antike, in: Daim - DrauschKe 2010, 663-694.

M. Aurenhammer, Die Skulpturen von Ephesos. Idealplastik I, FiE 10, 1 (Wien 1990).

M. Aurenhammer, Skulpturen aus Stein und Bronze, in: LANG-Auinger 2003a, 153-208.

S. AyBeK, Metropolis İonia I. Heykel (Istanbul 2009).

M. AYdAș, Gladiatorial Inscriptions from Stratonikeia in Caria, EpigrAnat 39, 2006, 105-110.

M. BachmanN (Hrsg.), Bautechnik im antiken und vorantiken Kleinasien, Byzas 9, Veröffentlichungen des Deutschen Archäologischen Instituts Istanbul (Berlin 2009).

C. BAIER, in: ÖAI-BERICHT 2009, $15<$ www.oeai.at, Jahresberichte> (03.05.2013).

C. BAIER, in: ÖAI-BERICHT 2010, 34-36<www.oeai.at, Jahresberichte> (03.05.2013).

C. BAIER, Attolitur monte Pione. Neue Untersuchungen im Stadtviertel oberhalb des Theaters von Ephesos, ÖJh 82, 2013, 23-68. 
BAILEy 1988

BÁLINT 2000

BAMMER 1961

BAMMER 1978/1980

BARKÓCZI 1986

BARTOSIEWITZ 1998

BECK - Bol 1983

Benecke 1998

Bergemann 1990

Bernabò-Brea 1998

BERns u. a. 2002

Besques 1972

BezecZKy 2004

BEZECZKy 2005

BiEBER 1920

BIEBER 1961

BMC IONIA

BMC Phrygia

BODNAR - Foss 2003

BOULASIKIS 2003

BoRGHINI 1989

BRANDT u. a. 2005

BRINKE 1991

BRINKE 1999

BRONEER 1930

Buttenhuis u. a. 1998

\section{BURMEISTER 2005}

BURMEISTER 2006

BÜRCHNER 1905

BÜYÜKKOLANCI 1999

M. BÜYÜKKOLANCI 2002

P. BÜYÜKKOLANCI 2002

BuRRELL 2004

ÇAKMAKÇI 2009
D. M. BAiLey, A Catalogue of the Lamps in the British Museum, III. Roman Provincial Lamps (London 1988).

Cs. BÁlint, Byzantinisches zur Herkunftsfrage des vielteiligen Gürtels, in: Cs. BÁlint (Hrsg.), Kontakte zwischen Iran, Byzanz und der Steppe im 6.-7. Jahrhundert (Budapest 2000) 99162.

A. BAMmER, Zur Topographie und städtebaulichen Entwicklung von Ephesos, ÖJh 46, 19611963, 136-157.

A. BAMmER, Elemente flavisch-trajanischer Architekturfassaden aus Ephesos, ÖJh 52, 1978/1980, 67-90.

L. Barkóczi, Geschliffene Gläser aus der ersten Hälfte des dritten Jahrhunderts in Pannonien, AErt 113, 1986, 166-189.

L. Bartosiewicz, Interim Report on the Bronze Age Animal Bones from Arslantepe, in: Buitenhuis u. a. 1998, 221-232.

H. BeCK - P. C. Bol (Hrsg.), Spätantike und frühes Christentum. Ausstellung Frankfurt Liebieghaus Museum Alter Plastik (München 1983).

N. Benecke, Animal Remains from the Neolithic and Bronze Age Settlements at Kirklareli (Turkish Thracia), in: Buitenhuis u. a. 1998, 172-179.

J. Bergemann, Römische Reiterstatuen. Beiträge zur Erschließung hellenistischer und kaiserzeitlicher Skulptur und Architektur 11 (Mainz 1990).

L. Bernabò-Brea, Le maschere ellenistiche della tragedia greca, Cahiers du Centre J. Bérard 19 (Neapel 1998).

C. Berns - H. von Hesberg - L. Vandeput - M. Waelkens (Hrsg.), Patris und Imperium, BABesch Suppl. 8 (Leuven 2002).

S. Besques, Catalogue raisonné des figurines et reliefs en terre-cuite Grecs, Étrusques et Romaine III. Époques hellénistique et romaine Gréce et Asie Mineure (Paris 1972).

T. BEzECZKY, Early Roman Food Import in Ephesus (Amphorae from the Tetragonos Agora), in: EIRING - LuND 2004, 85-97.

T. BEZECZKy, Late Roman Amphorae from the Tetragonos-Agora in Ephesus in: KrINZINGER 2005, 203-230.

M. Bieber, Die Denkmäler zum Theaterwesen im Altertum (Berlin 1920).

M. BIEBER, The History of the Greek and Roman Theater (Princeton 1961).

B. V. Head, A Catalogue of Greek Coins in the British Museum 14, Catalogue of Greek Coins of Ionia (London 1892).

B. V. Head, A Catalogue of Greek Coins in the British Museum 25, Catalogue of Greek Coins of Phrygia (London 1906).

E. W. Bodnar - C. Foss, Cyriac of Ancona Later Travels (Philadelphia 2003).

D. Boulasikis, Das sogenannte Freudenhaus zu Ephesos. Neues zur Hausentwicklung des Komplexes, ÖJh 72, 2003, 29-40.

G. Borghini (Hrsg.), Marmi antichi (Rom 1989).

B. Brandt - V. Gassner - S. Ladstätter (Hrsg.), Synergia. Festschrift für Friedrich Krinzinger (Wien 2005).

M. BRINKE, Kopienkritische und typologische Untersuchungen zur statuarischen Überlieferung des Aphrodite-Typus Louvre-Neapel, Antiquitates 1 (Hamburg 1991).

M. BRINKE, Die Aphrodite Louvre-Neapel, AntP1 25 (München 1996) 7-64.

O. BRONEER, Terracotta Lamps, Corinth 4, 2 (Cambridge 1930).

H. Buitenhuis - L. Bartosiewicz - A. M. Choyke, Archaeozoology of the Near East III. Proceedings of the Third International Symposium on the Southwestern Asia and Adjacent Areas (Groningen 1998).

E. Burmeister, Anmerkungen zur Bautypologie antiker Theater, in: Brandt u. a. 2005, Bd. 2, $157-161$.

E. BURMEISTER, Antike griechische und römische Theater (Darmstadt 2006).

RE V 2 (1905) 2773-2822 s. v. Ephesos (L. BÜRCHNER).

M. BüyÜKKolanci, Ein Vierfigurenrelief des Meterkultes vom Panayır Dağ in Ephesos, in: SCHERRER u. a. 1999, 19-21.

M. BÜYÜKKKolancI, Neue Venatoren- und Gladiatorenreliefs im Ephesos Museum, in: GlaDIATOREN IN EPHESOS, 83-88.

P. BÜYÜKKKOLANCI, Kleinfunde mit Gladiatorendarstellungen im Ephesos Museum, in: GLADIATOREN IN EPHESOS, 93-95.

B. Burrell, Neokoroi. Greek Cities and Roman Emperors (Leiden 2004).

Z. ÇAKмакÇı, A Typological Approach to Glass Goblet Production from Late Antiquity to the Middle Ages in the Light of Recent Finds, in: E. LAfLI (Hrsg.), Late Antique/Early Byzantine 
Calwer Bibellexikon

Calza Bini 1953

Cansever 2010

Caputo 1950

CAPUTO 1959

\section{Caputo 1987}

Carstens 2008

CARTER 2004

CAspo - Slater 1994

Cavalier 2010

Christof 2010

Ciancio Rossetto -

PisAnI SARTORIO 1994

CID

Curtius 1872

CZurda-Ruth 2007

ÇAN - LisE 2006

D'ANDRIA - ROMEO 2011

Daim - Drauschke 2010

DALCHER 2001

DANGUILlier 2001

DAVIDSON 1952

De Bernardi Ferrero 1970

De Bernardi Ferrero 1974

DE LABORDE 1838

De Rossi 1888

Delivorrias 1984

Deschler-Erb 1998

DEVIJVER 1976-1993

DöRING-WiLLIAMS - LIEBICH 2003

DÖRPFELD - REISCH 1896

DONDERER 1996

DRÄGER 1993
Glass in the Eastern Mediterranean. Conference Papers and Abstracts Presented at the International Colloquium Late Antique Glass in Anatolia ( $4^{\text {th }}$ to $8^{\text {th }}$ cent. A.D.), October 25-28, 2009 in Izmir, Turkey (Izmir 2009) 49-66.

Calwer Verlagsverein (Hrsg.), Calwer Bibellexikon. Biblisches Handwörterbuch illustriert (Stuttgart 1893).

A. Calza Bini, Il teatro di Marcello: forma e strutture, Bollettino del Centro di Studi per la storia dell' architettura 7 (Rom 1953).

M. CANSEVer (Hrsg.), Ephesos Museum Selçuk (Istanbul 2010).

G. CAPUTO, Architettura del teatro di Leptis Magna, Dioniso 13, 1950, 164-178.

G. CAPUTO, Il teatro di Sabratha e l'architettura teatrale africana, Monografie di archeologia libica 6 (Rom 1959).

G. CAPuto, Il teatro Augusteo di Leptis Magna. Scavo e restauro (1937-1951), Monografie di archeologia libica 3 (Rom 1987).

A. M. Carstens, Huwasi Rocks, Baityloi, and Open Air Sanctuaries in Karia, Kilikia, and Cyprus, Olba 16, 2008, 73-93.

M. CARTER, Archiereis and Asiarchs. A Gladiatorial Perspective, GrRomByzSt 44, 2004, 41-68.

E. CASPO - W. J. Slater, The Context of Ancient Drama (Michigan 1994).

L. Cavalier, Rez. zu Gros 2009, <http://histara.sorbonne.fr/cr.php?cr=990\&lang=de >

(30.10.2014).

E. Christof, Skulpturen, in: KrinZINGer 2010, 656-667.

P. Ciancio Rossetto - G. Pisani Sartorio (Hrsg.), Teatri antichi greci e romani. Alle origini del linguaggio rappresentato: censimento analitico, 3 Bd. (Rom 1994).

Corpus des Inscriptions de Delphes (Paris 1978-).

E. Curtius (Hrsg.), Beiträge zur Geschichte und Topographie Kleinasiens (Ephesos, Pergamon, Smyrna, Sardes), AbhBerlin (Berlin 1872).

B. Czurda-Ruth, Hanghaus 1 in Ephesos. Die Gläser, FiE 8, 7 (Wien 2007).

Ö. ÇAN - Y. LisE, The (Re)discovery of Striped Hyaena in Turkey, Poster at the $1^{\text {st }}$ European Congress of Conservation Biology, 22-26 August 2006, Eger, Hungary (Eger 2006).

F. D'ANDRIA - I. Romeo (Hrsg.), Roman Sculpture in Asia Minor, Proceedings of the International Conference 2007 in Cavallino (Lecce) = JRA Suppl. 80 (Portsmouth 2011).

F. Daim - J. DrauschKe (Hrsg.), Byzanz - Das Römerreich im Mittelalter, Teil 2, 2 Schauplätze (Mainz 2010).

K. DAlCher, Schwarze Steine aus dem Himmel oder weshalb Hannibal Rom nicht erobern konnte, in: S. BuZZI - D. KäCH - E. Kistler (Hrsg.), Zona Archeologica. Festschrift H.-P. Isler, Antiquitas 3, 42 (Bonn 2001) 83-89.

C. Danguillier, Typologische Untersuchungen zur Dichter- und Denkerikonographie in römischen Darstellungen von der mittleren Kaiserzeit bis in die Spätantike, BARIntSer 977 (Oxford 2001).

G. R. Davidson, The Minor Objects, Corinth 12 (Princeton 1952).

D. De Bernardi Ferrero, Teatri classici in Asia Minore 3, Città dalla Troade alla Pamfilia (Rom 1970).

D. De Bernardi Ferrero, Teatri classici in Asia Minore 4, Deduzioni e proposte (Rom 1974).

A. L. J. De Laborde, Voyage de l'Asie mineure par Mrs. Alexandre de Laborde, Becker Hall et Léon de Laborde (Paris 1838).

G. B. De Rossi, Inscriptiones Christianae urbis Romae septimo saeculo antiquiores (Insc. Christ.) II (Rom 1888).

LIMC II (1984) 2-151 s. v. Aphrodite (A. Delivorrias).

S. Deschler-Erb, Römische Beinartefakte aus Augusta Raurica. Rohmaterial, Technologie, Typologie und Chronologie, Forschungen in Augst 27 (Augst 1998).

H. DeviJver, Prosopographia militiarum equestrium quae fuerunt ab Augusto ad Gallienum I-V (Leuven 1976-1993).

M. Döring-Williams - H. A. Liebich, Das große Theater von Ephesos. Möglichkeiten und Grenzen der Laserscan-Technologien in der Bauforschung, in: K. Heine - K. Wulf-RheidT - U. Weferling (Hrsg.), Von Handaufmaß bis High Tec. Messen, Modellieren, Darstellen. Aufnahmeverfahren in der historischen Bauforschung (Mainz 2003) 126-137.

W. Dörpfeld - E. Reisch, Das griechische Theater. Beiträge zur Geschichte des DionysosTheaters in Athen und anderer griechischer Theater (Athen 1896).

M. DonDERER, Die Architekten der späteren römischen Republik und der Kaiserzeit. Epigraphische Zeugnisse (Erlangen 1996).

M. DrÄGER, Die Städte der Provinz Asia in der Flavierzeit. Studien zur kleinasiatischen Stadtund Regionalgeschichte (Frankfurt 1993). 
ECK 2002

EIRING - LUND 2004

ELKINS 2004

ENGELMANN 2004

ENSSLIN 1931

FABRICIUS 1931

FAKHARANI 1975

FALKENER 1862

Feissel 1998

Feuser 2008

FIECHTER 1914

FIEChTER 1930

FIECHTER 1931

Filges 1999

FinKIELSZTEJN 2001

FISCHER 1994

FitTSCHEN 2009

FITTSCHEN - ZANKER 1983

FitTsChen u. a. 2010

FLeISCHER 1974

FLEISCHER 1972/1975

FLICKINGER 1918

FORCHHEIMER 1923

FORSTENPOINTNER U. a. 1993

FORSTENPOINTNER 1998

FORSTENPOINTNER u. a. 2002

FORSTENPOINTNER u. a. 2008

ForstenPOINTNER u. a. 2010

Foss 1997

FLuss 1937

FRERE 1972

FreYer-SCHAUENBURG 1980

FrICKENHAUS 1917
DNP 12, 1 (2002) 604 s. v. Tineius 5 (W. ECK).

J. EIRING - J. Lund (Hrsg.), Transport Amphorae and Trade in the Eastern Mediterranean, Acts of the International Colloquium at the Danish Institute at Athens (Athen 2004).

N. T. Elkins, Locating the Imperial Box in the Flavian Amphitheatre. The Numismatic Evidence, NumChron 164, 2004, 147-157.

H. Engelmann, Tiberius Claudius Flavianus Eudemus und das Theater von Patara, in: Korkut 2004, 293-296.

RE XV (1931) 1166 s. v. Messalinus 3 (W. EnssLin).

RE XV (1931) 1166 s. v. Messalinus 6 (E. FABRICIUs).

F. El FaKharani, Das Theater von Amman in Jordanien, AA 90, 1975, 377-403.

E. FALKENER, Ephesus and the Temple of Diana (London 1862).

D. Feissel, Gouverneurs et édifices dans les épigrammes de Smyrne au Bas-Empire, REG 111, 1998, 125-144.

St. Feuser, Zu einem Löwenkopftischbein aus Alexandria Troas, in: E. Winter (Hrsg.), Vom Euphrat bis zum Bosporus. Festschrift E. Schwertheim, AMS 65, 1 (Münster 2008) 229-235.

E. R. FIECHTER, Die baugeschichtliche Entwicklung des antiken Theaters (München 1914).

E. R. FIEChTER, Das Theater von Oropos (Stuttgart 1930).

E. R. FIEChTER, Das Theater von Oinadai und Neupleuron (Stuttgart 1931).

A. Filges, Marmorstatuetten aus Kleinasien. Zu Ikonographie, Funktion und Produktion antoninischer, severischer und späterer Idealplastik, IstMitt 49, 1999, 377-430.

G. Finkielsztejn, Chronologie détaillée et révisée des éponymes amphoriques rhodiens, de 270 à 108 av. J.-C. environ, BARIntSer 990 (Oxford 2001).

J. Fischer, Griechisch-Römische Terrakotten aus Ägypten. Die Sammlungen Sieglin und Schreiber, Tübinger Studien zur Archäologie und Kunstgeschichte 14 (Berlin 1994).

K. FitTschen, Rez. zu Oberleitner 2009, GGA 261, 2009, 157-179.

K. FitTSChen - P. ZanKer, Katalog der römischen Porträts in den Capitolinischen Museen und in den anderen kommunalen Sammlungen der Stadt Rom III. Kaiserinnen- und Prinzessinnenbildnisse. Frauenporträts (Mainz 1983).

K. FitTsChen - P. ZANKer - P. CAin, Katalog der römischen Porträts in den Capitolinischen Museen und den anderen kommunalen Sammlungen der Stadt Rom II. Die männlichen Privatporträts (Berlin 2010)

R. Fleischer, in: A. Bammer - R. Fleischer - D. Knibbe, Führer durch das Archäologische Museum in Selçuk-Ephesos (Wien 1974).

R. FleISCHER, Skulpturenfunde, ÖJh 50, 1972-1975, Grabungen in Ephesos 1960-1969 bzw. 1970, 421-467.

R. C. Flickinger, The Greek Theater and its Drama (Chicago 1918).

P. ForchHeImer, Wasserleitungen, in: E. ReISCh (Hrsg.), Forschungen in Ephesos, FiE 3 (Wien 1923) 224-255.

G. ForstenPointner - P. Scherrer - O. SchUlZ - H. SatTMAnN, Archäologisch-paläoanatomische Untersuchungen an einer hellenistischen Brunnenanlage in Ephesos, Wiener Tierärztliche Monatsschrift 80, 1993, 216-224.

G. ForSTENPOINTNER, Untersuchungen zur osteologischen Manifestation des Tieropfers im ägäischen Raum anhand der Tierknochenfunde aus dem Artemision von Ephesos (Habilitationsschrift Vet. Med. Universität Wien 1998).

G. Forstenpointner - G. Weissengruber - A. GaLiK, Banquets at Ephesos; Archaeozoological Evidence of Well Stratified Greek and Roman Kitchen Waste, in: H. Buitenhuis - A. Choyke - M. Mashrour - M. Al-ShiYab, Archaeozoology of the Near East V, ARC Publicaties 62 (Groningen 2002) 282-304.

G. Forstenpointner - A. Galik - G. Weissengruber - St. Zohmann, Archäozoologie aus dem Vediusgymnasium in Ephesos, in: STESKAL - LA TORRE 2008, 211-233.

G. Forstenpointner - A. GaliK - G. Weissengruber, Tierreste, in: KrinZinger 2010, 357-369. 684.

P. W. Foss, Watchful Lares. Roman Household Organization and the Rituals of Cooking and Eating, in: R. Laurence - A. Wallace-Hadrill (Hrsg.) Domestic Space in the Roman World. Pompeii and Beyond, JRA Suppl. 22 (Portsmouth 1997) 196-218.

RE VI A (1937) 1380-1381 s. v. Tineius 8 (M. Fluss).

S. S. Frere, Verulamium Excavations 1 (Oxford 1972).

B. Freyer-Schauenburg, Büsten mit reliefverzierten Indextäfelchen, in: Eikones. Studien zum griechischen und römischen Bildnis, Festschrift H. Jucker, AntK Beih. 12 (Basel 1980) $118-125$.

A. Frickenhaus, Die altgriechische Bühne (Strassburg 1917). 
FRIESINGER - KRINZINGER 1999

FRONING 2002

FrontinUS-GesELlsChAFT 1987

Frontinus-TAGUngen 2006

FuCHS 1987

FuCHS 1999

FUHRMANN 1940

FuHRMANN 1941

FÜNFSCHILLING 2011

FURGER 2011

FURTWÄNGLER 1966

Gagetti 2006

GALIK u. a. 2010a

GALIK u. a. 2010b

GASPARRI 1996

GASSNER 1997

Georgousopoulos - Gogos 2002

Gerasa

Gelzer 1926

GiULIANI 1986

GiULIANI 2004

GLADIATOREN IN EpHesos

GoEtTe 1990

Gogos 2009

Gogos 2011

Golvin 1988

Graefe 1979

GraF 1999

GREEN 1995

Gregarek 1999

GROH 2006

Gros 2009

GSELL 1952

GiULIANI 1987

GÜlbay 2008

GÜNAY TULUK 2001

GÜNDEM 2010
H. Friesinger - F. Krinzinger (Hrsg.), 100 Jahre Österreichische Forschungen in Ephesos, Akten des Symposions Wien 1995, DenkschrWien 260 (= AForsch 1) (Wien 1999).

H. Froning. Bauformen - Vom Holzgerüst zum Theater von Epidauros, in: S. Moraw - E. NöLlE (Hrsg.), Die Geburt des Theaters in der griechischen Antike (Mainz 2002) 31-59.

Frontinus-Gesellschaft e. V. (Hrsg.), Die Wasserversorgung antiker Städte, Geschichte der Wasserversorgung 2 (Mainz 1987).

Frontinus-Tagungen 2004/2006 in Wien und Berlin, Schriftenreihe der Frontinus-Gesellschaft Heft 27 (Bonn 2006).

M. Fuchs, Untersuchungen zur Ausstattung römischer Theater in Italien und den Westprovinzen des Imperium Romanum (Mainz 1987).

M. Fuchs, In hoc etiam genere Graeciae nihil cedamus. Studien zur Romanisierung der späthellenistischen Kunst im 1. Jh. v. Chr. (Mainz 1999).

H. Fuhrmann, Leptis Magna (Tripolis), AA 55, 1940, 551-553.

H. Fuhrmann, Leptis Magna, AA 56, 1941, 716-733.

S. FÜNFSCHILLING, Glasrecycling bei den Römern: https://www.nike-kulturerbe.ch/fileadmin/ user_upload/Bulletin/2011/06/PDF/Glas.pdf (06.07.2012)

A. R. Furger, Ruinenschicksale: Naturgewalt und Menschenwerk (Basel 2011).

A. Furtwängler, Die Bronzen und die übrigen kleineren Funde von Olympia, Olympia 4 (Berlin 1966).

E. Gagetti, Preziose sculture di età ellenistica e romana. Il Filarete 240 (Mailand 2006).

F. Galik - G. Forstenpointner - G. Weissengruber - St. Zohmann, Archäozoologischer Befund, in: A. Pülz (Hrsg.), Das sog. Lukasgrab in Ephesos, FiE 4, 1 (Wien 2010) 211-233.

F. Galik, - G. Forstenpointner - G. Weissengruber - St. Zohmann, Die Tierreste aus dem Schachtbrunnen und der Nische des Präfurniums, in: Ş. PfeIfFer-TAŞ, Funde und Befunde aus dem Schachtbrunnen im Hamam III in Ayasuluk/Ephesos, AForsch 16 (Wien 2010) 77-119.

C. GASPARRI, Prosopa e personae. Maschere teatrali in marmonella decorazione architettonica di età adrianea, in: M. G. PICOzZI - F. CARINCI (Hrsg.), Studi in memoria di Lucia Guerrini. Studi Miscellanei 30 (Rom 1996) 235-259.

V. GASSNER, Das Südtor der Tetragonos-Agora, Keramik und Kleinfunde, FiE 13, 1, 1 (Wien 1997). K. GeOrgousopoulos - S. Gogos, Epidauros. To archaio theatro, hoi parastaseis (Athen 2002). C. B.Welles, The Inscriptions, in: C. H. Kraeling (Hrsg.), Gerasa. City of the Decapolis (New Haven 1938).

RE XIII 1 (1926) s. v. Licinius (Lucullus) 375-414 (M. GeLZER).

L. GiUliani, Bildnis und Botschaft. Hermeneutische Untersuchungen zur Bildniskunst der römischen Republik (Frankfurt 1986).

A. GiULIANı, Namensignaturen hellenistischer Lampenwerkstätten, ÖJh 73, 2004, 137-157.

Österreichisches Archäologisches Institut - Grabung Ephesos (Hrsg.), Gladiatoren in Ephesos. Tod am Nachmittag, Eine Ausstellung im Ephesos Museum Selçuk seit 20. April 2002 (Wien 2002).

H.-R. GoEtTE, Studien zu römischen Togadarstellungen (Mainz 1990).

S. Gogos, Das Theater von Oiniadai (Wien 2009).

S. Gogos, Das Theater von Epidauros (Wien 2011).

J.-C. Golvin, L'Amphithéâtre Romain I-II (Paris 1988).

R. Graefe, Vela erunt. Die Zeltdächer der römischen Theater und ähnlicher Anlagen (Mainz 1979).

F. Graf, Ephesische und andere Kureten, in: Friesinger - KrinZINGER 1999, 255-262.

J. P. GREEN, Theatre Productions 1987-1995, Lustrum 37, 1995, 7-202. 309-318.

H. GREGAREK, Römische Idealplastik aus Buntmarmor, KölnerJb 32, 1999, 33-284.

St. Groh - V. Lindinger - K. Löcker - W. Neubauer - S. Seren, Neue Forschungen zur Stadtplanung in Ephesos, ÖJh 75, 2006, 47-116.

P. Gros, Les sanctuaires in summa cavea. L'enseignement des recherches récentes sur le théâtre de Pompée à Rome, in J.-Ch. Moretri (Hrsg.), Fronts de scène et lieux de culte dans le théâtre antique, Travaux de la Maison de l'Orient et de la Méditerranée 52 (Lyon 2009) 53-64. S. Gsell, Cherchel. Antique Iol-Caesarea (Algier 1952).

L. Giuliani, Die seligen Krüppel, AA 1987, 701-721.

O. Gülbay - H. Kireç, Efes Kurşun Tesseraeları, Ephesian Lead Tesserae (Izmir 2008).

G. GÜNAY TuluK, Hellenistische Reliefbecher im Museum von Ephesos, in: KrinZINGER 2001, 51-69.

C. Y. GünDEM, Animal Based Economy in Troia and the Troas During the Maritime Culture (c. 3000-2200 B.C.) and a General Summary for Western Anatolia (Diss. Universität Tübingen 2010). 
GÜNTHER 1985

GuNDEL 1964

GUNTHER 1913

HABERMEHL 1975

HALFMANN 1979

\section{HaLfMANN 2001}

Hallett 2005

HANSLIK 1958

HANSLIK 1975

HANSLMAYr 2016

HAYES 1985

HAYES 1972

HEBERDEY 1898

HEBERDEY 1900

Heberdey u. a. 1912

HeIMERL 2001

HeInZ - RUgGendDoRfER 2002

HenKel 1913

HERDEJÜRGEN 1972

HERRMANN 1959

HÖRMANN 1923/1924

HOFBAUER 2002

Hofbauer 2005

HOFBAUER 2007

Hofbauer 2008

HofF 1994

Horn - BoEHringer 1966

Howego 1985

HuEBer 1997a

Hueber 1997b

HÜLSEN 1912

HÜLSEN 1933

HrYCHUK KontoKosta 2008

ICARD-GIANOLIO 1994 ICARD-GIANOLIO 1997 IGLSYR

IMHOOF-BLUMER 1901/1902

İNAN - ROSENBAuM 1966

IRO U. a. 2009

ISINGS 1957

ISLER 1994

ISLER 2007
W. GÜNTHER, Gladiatorendenkmäler aus Milet, IstMitt 35, 1985, 123-138.

KLP I (1964) 608 s. v. Arruntius 8 (H. G. GuNDEL).

R. W. D. Gunther, Pausilypon. The Imperial Villa Near Naples (Oxford 1913).

K.-H. HABERMEHL, Die Altersbestimmung bei Haus- und Labortieren (Berlin 1975)

H. Halfmann, Die Senatoren aus dem östlichen Teil des Imperium Romanum bis zum Ende des 2. Jahrhunderts n. Chr., Hypomnemata 58 (Göttingen 1979).

H. Halfmann, Städtebau und Bauherren im römischen Kleinasien. Ein Vergleich zwischen Pergamon und Ephesos, IstMitt Beih. 43 (Tübingen 2001).

C. Hallett, The Roman Nude. Heroic Portrait Statuary 200 BC-AD 300 (Oxford 2005).

RE AIII 2 (1958) 1972 s. v. Vibius 36 (R. HANSLIK).

KLP V (1975) 854 s. v. Tineius 4 (R. HansLik).

R. Hanslmayr, Die Skulpturen von Ephesos. Die Hermen. FiE 10, 2 (Wien 2016).

J. W. HAYES, Sigillate orientali, in: Atlante delle forme ceramiche II, EAA Suppl. (Rom 1985) $1-95$.

J. W. HaYes, Late Roman Pottery (London 1972).

R. HeberdeY, Vorläufige Berichte über die Ausgrabungen in Ephesus II, ÖJh 1, 1898, Beibl. 72-82.

R. Heberdey, Vorläufiger Bericht über die Ausgrabungen in Ephesus, ÖJh 3, 1900, Beibl. 83-96.

R. Heberdey - G. Niemann - W. Wilberg, Das Theater von Ephesos, FiE 2 (Wien 1912).

A. HeimerL, Die römischen Lampen aus Pergamon. Vom Beginn der Kaiserzeit bis zum Ende des 4. Jhs. n. Chr., PF 13 (Berlin 2001).

R. HeInZ - P. RUGGENDORFER, Forschungen am Mausoleum von Belevi, ÖJh 71, 2002, 149176 .

F. HenKEL, Die römischen Fingerringe der Rheinlande und der benachbarten Gebiete (Berlin 1913).

H. HerdeJÜRgen, Archaistische Skulpturen aus frührömischer Zeit, JdI 87, 1972, 299-313.

H.-V. Herrmann, Omphalos (Münster 1959).

H. HörmanN, Die römische Bühnenfront zu Ephesos. Ein neuerer Konstruktionsversuch und seine Würdigung in der zeitgenössischen Fassadenarchitektur, JdI 38/39, 1923/1924, 275345 .

M. Hofbauer, Zum Theater von Ephesos. Eine kurze Darstellung der Grabungsgeschichte zwischen 1866 und 2001, ÖJh 71, 2002, 177-187.

M. Hofbauer, Theater, Archäologie, in: JahresBericht 2004, 334-335.

M. HofBAUER, Archäologische Untersuchungen am Theater von Ephesos in den Jahren 20012006 (ungedr. Diss. Universität Wien 2007).

M. HofBAUER, Theater, Archäologie, in: JAHRESBERICHT 2007, 410.

R. von den Hoff, Philosophenporträts des Früh- und Hochhellenismus (München 1994).

R. Horn - E. Boehringer, Die Ausgrabungsarbeiten zu Pergamon im Jahre 1965, AA 1966, 415-483.

C. J. Howego, Greek Imperial Countermarks. Studies in the Provincial Coinage of the Roman Empire (London 1985).

F. Hueber, Zur städtebaulichen Entwicklung des hellenistisch-römischen Ephesos, IstMitt 47, 1997, 251-269.

F. Hueber, Ephesos. Gebaute Geschichte (Mainz 1997).

Сн. Hülsen, I lavori archeologici di Giovannantonio Dosio, Ausonia 7, 1912, 1-100.

Сн. Hülsen, Das Skizzenbuch des Giovannantonio Dosio (Berlin 1933).

A. C. Hrychú Kontokosta, Gladiatorial Reliefs and Elite Funerary Monuments, in: C. Ratté - R. R. R. Sмiтн (Hrsg.), Aphrodisias Papers 4. New Research on the City and its Monuments = JRA Suppl. 70 (Portsmouth 2008).

LIMC VII (1994) 569-585 s. v. Psyche (N. ICARD-Gianolio).

LIMC VIII (1997) 73-85 s. v. Tritones (N. ICARD-Gianolio).

Inscriptions grecques et latines de la Syrie (Paris 1929-).

F. ImHoof-Blumer, Kleinasiatische Münzen (Wien 1901/1902).

J. İNAN - E. Rosenbaum, Roman and Early Byzantine Portrait Sculpture (London 1966).

D. Iro - H. SchWAiger - A. WALDNER, Die Grabungen des Jahres 2005 in der Süd- und Nordhalle der Kuretenstraße. Ausgewählte Befunde und Funde, in: LADSTÄTter 2009, 53-87.

C. IsINGS, Roman Glass from Dated Finds (Groningen 1957).

H. P. Isler, Die antike Theaterarchitektur, in: Ciancio Rossetto - Pisani Sartorio 1994, 86125.

H. P. IsLER, Das Theater. Grabungen 1997 und 1998, Eretria 18 (Gollion 2007). 
IvE

JAHRESBERICHT 2003

JAHRESBERICHT 2004

JAHRESBERICHT 2005

JAHRESBERICHT 2006

JAHRESBERICHT 2007

JACQUEMIN 1986

JILEK 1997

JILEK 2003

JILEK 2005

JUNKELMANN 2002

KAHIL 1984

KARANASTASSIS 1987

KARWIESE 1985

KARWIESE 1992

KARWIESE 1994

KARWIESE 1995a

KARWIESE $1995 b$

KARWIESE 1996

Karwiese Archiv ÖAI

KARWIESE

SCHLUSSBERICHT

KARWIESE 1997a

KARWIESE $1997 b$

KARWIESE 1998a

KARWIESE 1998b

KARWIESE 1998c

KARWIESE 1999

KARWIESE 2003

KARWIESE 2007

KASPAREK 1986

KASPAREK u. a. 2004

KAYAN 1972

KeARSLey 1988

KEAY 1984

KeIL 1915

KeIL 1923
Inschriften griechischer Städte aus Kleinasien 1-67 (Bonn 1972-2006); Ephesos: IvE 1aVIII 2 (1979-1984).

JAHRESBERICHT 2003 des Österreichischen Archäologischen Instituts, Ephesos Theater, ÖJh 73, 2004, 355-357.

JAHRESBERICHT 2004 des Österreichischen Archäologischen Instituts, Ephesos Theater, ÖJh 74, 2005, 336-337.

JAHRESBERICHT 2005 des Österreichischen Archäologischen Instituts, Ephesos Theater, ÖJh 75, 2006, 330-331.

JAHRESBERICHT 2006 des Österreichischen Archäologischen Instituts, Ephesos Theater, ÖJh $76,2007,404-406$.

JAHRESBERICHT 2007 des Österreichischen Archäologischen Instituts, Ephesos Theater, ÖJh 77, 2008, 409-411.

LIMC III (1986) 249-259 s. v. Chimaira (A. JACQUEMIN).

S. Jilek, Die Kleinfunde aus Metall, Bein, Stein und Ton, in: V. Gassner, Das Südtor der Tetragonos-Agora. Keramik und Kleinfunde, FiE 13, 1, 1 (Wien 1997) 219-229.

S. JILEK, Die Metall- und Beinfunde, in: LANG-AuINGER 2003a, 253-312.

S. JILEK, Kleinfunde aus Metall und Bein, in: THÜR 2005, 389-404.

M. Junkelmann, Bewaffnung und Kampftechnik der Gladiatoren, in: Gladiatoren in Ephesos, 25-42.

LIMC II (1984) 618-753 s. v. Artemis (L. KAHIL).

P. Karanastassis, Untersuchungen zur kaiserzeitlichen Plastik in Griechenland II. Kopien, Varianten und Umbildungen nach Athena-Typen des 5. Jhs., AM 102, 1987, 323-428.

St. Karwiese, Das Beben unter Gallien und seine anhaltenden Folgen, in: Lebendige Altertumswissenschaft. Festschrift H. Vetters (Wien 1985).

St. Karwiese, Metrologische Fragen der kaiserzeitlichen autonomen Münzprägung von Ephesos, Litterae Numismaticae Vindobonenses 4, 1992, 127-188.

St. KarwieSE, ÖJh 63, 1994, Beibl., Grabungen 1993, 28-31.

St. Karwiese, ÖJh 64, 1995, Beibl., Grabungen 1994, 30-33.

St. KarwiEse, Groß ist die Artemis von Ephesos. Die Geschichte einer der großen Städte der Antike (Wien 1995).

St. KARWIESE, ÖJh 65, 1996, Beibl., Grabungen 1995, 29-31.

St. Karwiese, Das Theaterprojekt von Ephesos. Dokumentation der Arbeiten des Österreichischen Archäologischen Institutes in den Jahren 1993 bis 1998 (Dokumentationsarchiv ÖAI).

St. KARWIESE, Das Theater von Ephesos. Schlussbericht über die Arbeiten 1996-1998 (Dokumentationsarchiv ÖAI).

St. KarwieSE, ÖJh 66, 1997, Beibl., Grabungen 1996, 44-48.

S. KARWIESE, Research and Conservation of the Theatre of Ephesus, in: EU 140 EUROCARE, Concluding Report of the Austrian Chairmanship 1994-97 (Wien 1997).

St. Karwiese, ÖJh 67, 1998, Beibl., Grabungen 1997, 24-29; 41-42.

St. KARWIESE, Theateph. 1998 Çalişma Günlüğü, (Dokumentationsarchiv ÖAI).

St. KARWIESE, Efes büyük Tiyatrosu. 1998 Yili Sezon Raporu (Dokumentationsarchiv ÖAI).

St. Karwiese, ÖJh 68, 1999, Beibl., Grabungen 1998, 25-27.

St. KarwiEse, Liste der Fundmünzen aus den Grabungen im Hanghaus 1 von Ephesos 1960 bis 1998, in: LANG-AUINGER 2003a, 340-355.

St. Karwiese, Die Fundmünzen von Basilika, Sockelbau und Staatsmarkt, in: MitsopoulosLeON - LANG-Auinger 2007, 187-204.

M. KaspareK, On a Historical Occurrence of the Lion, Panthera leo, in Turkey, Zoology in the Middle East 1, 1986, 9-10.

M. Kasparek - B. Aygün Gözcelioğlu - E. ÇOlaK - N. Yiğit, On the Status and Distribution of the Striped Hyaena, Hyaena hyaena, in Turkey, Zoology in the Middle East, 33, 2004, 93-108.

D. KAYAN, 1972 yılı Efes Büyük Tiyatro kazısında bulunan trajik masklar, Efes Müzesi Yıllığı $1,1972,56-64$.

R. A. Kearsley, A Leading Family of Cibyra and Some Asiarchs of the First Century, AnSt 38, 1988, 43-51.

S. J. KeAY, Late Roman Amphorae in the Western Mediterranean. A Typology and Economic Study: The Catalan Evidence, BARIntSer 196 (Oxford 1984).

J. KeIL, Denkmäler des Meter-Kultes, ÖJh 18, 1915, 66-78.

J. KeIL, 7.C. Inschriften auf Statuenbasen, in: E. ReISCH (Hrsg.), Forschungen in Ephesos, FiE 3 (Wien 1923) 107-168. 
KeIL 1926

KeIL 1930

KeIL 1932

KeLLER 2005

KERSCHNER U. a. 2008

KERSCHNER (in Vorbereitung)

KIILERICH 1993

$\mathrm{KLP}$

KLEBINDER-GAuss 2007

KLoSE 1987

KNIBBE 1981

KNIBBE 1999

KNIBBE - İPLIKÇIOǦLu 1981/1982

KNOLL u. a. 2011

\section{Косн 1994}

KoLB 1999

KoLLER 2000

Koller 2005

KorkUT 2004

Kos 1986

KoUDELKa 1885

Kowalleck - Rathmayr 2010

KRAFT 1972

KRAFT u. a. 2000

KRAFT u. a. 2005

Krauss 1973

KRIERER 1995

KREILER 1975

KRINZINGER 2001

KRINZINGER 2005

KRINZINGER 2010

KRON 1992

KumerLoeve 1975
J. KeIL, XII. Vorläufiger Bericht über die Grabungen in Ephesos, ÖJh 23, 1926, Beibl. 247-300. J. KeIL, XV. Vorläufiger Bericht über die Ausgrabungen in Ephesos, ÖJh 26, 1930, Beibl. 5-66.

J. KeIL, XVI. Vorläufiger Bericht über die Ausgrabungen in Ephesos, ÖJh 27, 1932, Beibl. $1-72$.

D. KelLeR, Social and economic aspects of glass recycling, in: J. Bruhn - B. Croxford D. Grigoropoulos (Hrsg.), TRAC 2004, Proceedings of the Fourteenth Annual Theoretical Roman Archaeology Conference, which took place at the University of Durham, 26-27 March 2004 (Oxford 2005) 65-78.

M. Kerschner - I. KowallecK - M. Steskal, Archäologische Forschungen zur Siedlungsgeschichte von Ephesos in geometrischer, archaischer und klassischer Zeit, ErghÖJh 9 (Wien 2008).

M. Kerschner (Hrsg.), Neue Forschungen zu Ephesos von geometrischer bis frühhellenistischer Zeit. Die Grabungen auf dem Panayırdağ 2008 und 2009 (in Vorbereitung).

B. KIILERICH, Late Fourth Century Classicism in the Plastic Arts (Odense 1993).

Der Kleine Pauly, Lexikon der Antike (München 1979).

G. KleBinder-Gauss, Bronzefunde aus dem Artemision von Ephesos, FiE 12, 3 (Wien 2007). D. O. A. Klose, Die Münzprägung von Smyrna in der römischen Kaiserzeit, Antike Münzen und geschnittene Steine 10 (Berlin 1987).

D. KnIBBe, Der Staatsmarkt, die Inschriften des Prytaneions, die Kureteninschriften und sonstige religiöse Texte, FiE 9, 1, 1 (Wien 1981).

D. KNIBBE, ÖJh 68, 1999, Jahresbericht 1998, 34.

D. KnibBe - B. İpLIKÇıơ̆LU, Neue Inschriften aus Ephesos VIII, ÖJh 53, 1981/1982, 86-150.

K. Knoll - Chr. Vorster - M. WoelK (Hrsg.), Skulpturensammlung. Staatliche Kunstsammlungen Dresden. Katalog der antiken Bildwerke II. Idealskulptur der römischen Kaiserzeit 1. 2 (München 2011).

L. Косн, Weibliche Sitzstatuen der Klassik und des Hellenismus und ihre kaiserzeitliche Rezeption. Die bekleideten Figuren, Charybdis 4 (Münster 1994).

F. Kolb, Die Sitzordnung von Volksversammlung und Theaterpublikum im kaiserzeitlichen Ephesos, in: Friesinger - KRINZINGER 1999, 101-105.

K. Koller, »Ja, nicht stumm ist das Bild «, in: L. Dollhofer - C. KNERINGer - H. NOEDL - K. SChaller - E. Trinkl (Hrsg.), Altmodische Archäologie. Festschrift F. Brein <http://www. farch.net> (14.03.2000)

K. KolLER, Marmorausstattungen, in: THÜR 2005, 144-151.

T. Korkut (Hrsg.), Anadolu'da Doğdu. Festschrift F. Işık (Istanbul 2004).

P. Kos, The Monetary Circulation in the Southeastern Alpine Region ca. 300 B. C.-A. D. 1000, Situla 24 (Ljubljana 1986).

F. KoudelKa, Das Verhältnis der Ossa longa zur Skeletthöhe bei den Säugetieren, Verhandlungen des naturforschenden Vereines in Brünn 24 (Brünn 1885) 127-153.

I. Kowalleck - E. Rathmayr, Funde aus Metall und Bein, in: KrinZinger 2010, 605-648.

K. KRAFT, Das System der kaiserzeitlichen Münzprägung in Kleinasien, Materialien und Entwürfe, IstForsch 29 (Berlin 1972).

K. Kraft - I. Kayan - H. Prückner - G. Rapp, A Geologic Analysis of Ancient Landscapes and the Harbors of Ephesos and the Artemision in Anatolia, ÖJh 69, 2000, 175-223.

K. Kraft - H. PrüCKner - I. Kayan, The Sea under the City of Ancient Ephesos, in: Brandt u. a. 2005 , Bd. $1,147-156$.

F. Krauss, Das Theater von Milet. Das hellenistische Theater. Der römische Zuschauerbau, Milet IV, 1 (Berlin 1973).

K. KRIERER, Sieg und Niederlage. Untersuchung physischer und mimischer Phänomene in Kampfdarstellungen der römischen Plastik, Wiener Forschungen zur Archäologie 1 (Wien 1995). B. M. KreILER, Die Statthalter Kleinasiens unter den Flaviern (Diss. Universität München 1975).

F. KRINZINGER (Hrsg.), Studien zur hellenistischen Keramik in Ephesos, ErghÖJh 2 (Wien 2001). F. KRINZINGER (Hrsg.), Spätantike und mittelalterliche Keramik aus Ephesos, AForsch 14 (Wien 2005).

F. KRINZINGER (Hrsg.), Hanghaus 2 in Ephesos. Wohneinheiten 1 und 2. Baubefund, Ausstattung, Funde, FiE 8, 8 (Wien 2010).

U. Kron, Heilige Steine, in: H. Froning - T. Hölscher - H. Mielsch (Hrsg.), Kotinos. Festschrift E. Simon (Mainz 1992) 56-70.

H. Kumerloeve, Die Säugetiere (Mammalia) der Türkei: Die Säugetiere (Mammalia) Syriens und des Libanon, Veröffentlichungen der Zoologischen Staatssammlung München 18 (München 1975). 
KUSSINGER 1988

LADSTÄTTER 2002

LADSTÄTTER 2003

LADSTÄTTER u. a. 2003

LADSTÄTTER 2005

LADSTÄTTER 2007

\section{LADSTÄTTER 2008}

LADSTÄTTER 2009

LADSTÄTTER 2010a

LADSTÄTTER 2010b

LADSTÄTTER 2010c

LADSTÄTTER 2010d

LADSTÄTTER 2014

LADSTÄTTER - LANG-AUINGER 2001

LADSTÄTtER - SAUER 2005

LADSTÄTTER - STESKAL 2009

LAHUSEN 1999

LAHUSEN - FORMIGLI 2001

LANDWEHR 1998

LANDWEHR 2006

\section{LANG 2006/2007}

LANG-AUINGER 1996

LANG-AUINGER 2003a

LANG-AuINGER 2003b

LANG-AUINGER 2007

LANG-AUINGER 2010

LeyenAar-Plaisier 1979

LAUMONIER 1977

LAUTER 1986

LAWALL 2004

LAWALL 2007

LAWALL 2011

LAZZARINI 2002

LAZZARINI 2006
S. Kussinger, Tierknochenfunde vom Lidar Höyük in Südostanatolien (Grabungen 19791986) (Diss. Universität München 1988).

S. LAdSTÄtTER, Die Chronologie des Hanghauses 2, in: F. Krinzinger (Hrsg.), Das Hanghaus 2 von Ephesos. Studien zur Baugeschichte und Chronologie, AF 7 (Wien 2002) 37-39.

S. LAdStÄtter, Ein hellenistischer Fundkomplex in SR 12, in: LANG-AuInger 2003a, 70-80.

S. Ladstätter - C. Rogl - A. Giuliani - T. Bezeczky - B. Czurda-Ruth - C. Lang-Auinger, Ein hellenistischer Brunnen in SR 9C, in: LANG-AUINGER 2003a, 22-69.

S. LADSTÄTtER, Keramik, in: THÜR 2005, 230-358.

S. LAdstÄtTER, Mode oder politisches Manifest? Überlegungen zur Übernahme römischen Formenguts in die frühkaiserzeitliche Keramik von Ephesos, in: M. MeYer (Hrsg.), Neue Zeiten - Neue Sitten. Zu Rezeption und Integration römischen und italischen Kulturguts in Kleinasien. Kolloquium Wien 31. März bis 2. April 2005 (Wien 2007) 203-219.

S. LAdstätter, Römische, spätantike und byzantinische Keramik, in: STESKAL - LA TORRE 2008, 97-189.

S. Ladstätter (Hrsg.), Neue Forschungen zur Kuretenstraße von Ephesos. Akten des Symposiums für Hilke Thür vom 13. Dezember 2006 an der Österreichischen Akademie der Wissenschaften, AForsch 15 (= DenkschrWien 382) (Wien 2009).

S. Ladstätter, Kap. A.X. Keramik, in: Krinzinger 2010, 172-279.

S. Ladstätter, Kap. B.X. Keramik, in: Krinzinger 2010, 530-587.

S. Ladstätter, Keramik, in: M. Steskal, Das Prytaneion in Ephesos, FiE 9, 4 (Wien 2010) 85-172.

S. Ladstätter, Ephesos in byzantinischer Zeit. Das letzte Kapitel der Geschichte einer antiken Großstadt, in: DAIM - DrauschKe 2010, 493-519.

S. Ladstätter, Keramik/Kap. XV.2.5 u. XV.2.6, in: WALdner - LAdstätTer 2014, 461-473.

S. LAdstÄtTER - C. LANG-Auinger, Zur Datierung und kunsthistorischen Einordnung einer Apollon-Kitharodos-Statuette, in: KRINZINGER 2001, 71-81.

S. LAdStÄtTER - R. SAUER, Late Roman C-Ware und lokale spätantike Feinware aus Ephesos, in: KRINZINGER 2005, 143-202.

S. LAdstätTER - M. SteskAL, Die Grabungen 1999 im Bereich der Alytarchenstoa (mit einem Betrag von M. Steskal), in: LADSTÄTTER 2009, 89-100.

G. LAHUSEN, Zu römischen Statuen und Bildnissen aus Gold und Silber, ZPE 128, 1999, 251266.

G. LAHUSEN - E. FORMigl, Römische Bildnisse aus Bronze (München 2001).

CH. LANDWEHR, Konzeptfiguren. Ein neuer Zugang zur römischen Idealplastik, JdI 113, 1998, 139-194.

CH. LANDwehr, Die römischen Skulpturen von Caesarea Mauretaniae III. Idealplastik (Mainz 2006).

J. LANG, Exempla römischen Wohnluxus'. Zu einigen löwenköpfigen Tischfüßen in der Antikengalerie Gustav III. in Stockholm, OpRom 31-32, 2006-2007, 167-188.

C. Lang-Auinger, Hanghaus 1 in Ephesos. Der Baubefund, FiE 8, 3 (Wien 1996).

C. Lang-Auinger (Hrsg.), Hanghaus I in Ephesos, Funde und Ausstattung, FiE 8, 4 (Wien 2003).

C. LANG-Auinger, Terrakotten, in: LANG-Auinger 2003a, 209-252.

C. LAng-Auinger, Terrakotten, in: Mitsopoulos-Leon - LANG-Auinger 2007, 124-169.

C. LANG-AuInger, Terrakotten, in: Krinzinger 2010, 343-356. 677-683.

G. LeyenaAr-Plaisier, Collections of the National Museum of Antiquities of Leiden C. N. M. A. L. III (Leiden 1979).

A. Laumonier, Exploration archéologique de Délos 31. La céramique hellénistique à reliefs, 1 - Ateliers ioniens (Paris 1977).

H. Lauter, Die Architektur des Hellenismus (Darmstadt 1986).

M. Lawall, Archaeological Context and Aegean Amphora Chronologies: A Case Study of Hellenistic Ephesos, in: EIRING - LuND 2004, 171-188.

M. Lawall, Hellenistic Stamped Amphora Handles, in: Mitsopoulos-Leon - Lang-Auinger 2007, 28-57.

M. Lawall, Early Hellenistic Amphoras from Two Closed Contexts: Kerenya Shipwreck and Ephesos well LB, $7^{\text {th }}$ Scientific Meeting on Hellenistic Pottery, Aigion, Greece, April 3-9 2005 (Athen 2011) 673-682.

L. LAZZARINI, La determinazione della proveninenza delle pietre decorative usate a Roma, in: M. De NucCiO - L. Ungaro (Hrsg.), I marmi colorati della Roma imperiale. Ausstellung Rom (Venedig 2002) 223-265.

L. LAZZARINI, Poikiloi Lithoi. Versiculores maculae: I marmi colorati della Grecia antica. Marmora 2, Suppl. 1 (Pisa 2006). 
LAZZARINI u. a. 2006

LIEBICH - StyHLER 2009

LIKO 2001

\section{LINFERT 1992}

LouKOPOULOU 2005

LRBC

Maderna-Lauter 1993

Malcus 1967

Matolcsi 1970

MARQuARDT 1995

MAYER 1995

MAYer 2003

MCGarvey 1881

MEKACHER 2006

MERIÇ 2002

MERIÇ 2004

Merkelbach 1998

MerT 2002

Metcalf 1980

Metaxas 2005

MIB

MIBE

Miltner 1937

MiLTNER 1959

Mionnet Suppl.VI

MIR 36

MIR 47

Mitsopoulos-LeOn 1991

Mitsopoulos-Leon 2007

Mitsopoulos-LeON -

LANG-AUINGER 2007

Mollard-Besques 1963

MoretTi 1992

Moretti 1993a
L. LAZZARINI - I. M. VILLA - D. VisOnÀ, Caratterizzazione e identificazione di alabastri usati in antico, in: Archaemetria del costruito. Atti del convegno nazionale di archaeometria, Ravello 2003 (Bari 2006) 273-281.

H. A. Liebich - G. Styhler, Theater Ephesos - Aspekte der Adaption im Zuschauerraum der römischen Zeit, in: BACHMANN 2009, 469-481.

H. LIKO, Hellenistische Keramik aus der Grabung beim sogenannten Lukasgrab, in: KRINZINGER 2001, 83-97.

A. Linfert, Rez. zu Aurenhammer 1990, Gnomon 64, 1992, 422-426.

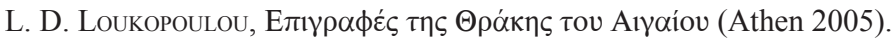

P. V. Hill - J. P. C. Kent - R. A. G. Carson, Late Roman Bronze Coinage (London 1965).

C. Maderna-Lauter, Rez. zu Aurenhammer 1990, BJb 193, 1993, 569-572.

B. Malcus, Die Prokonsuln von Asien von Diokletian bis Theodosius II, OpAth 7, 1967, 91-160.

J. Matolcsi, Historische Erforschung der Körpergröße des Rindes auf Grund von ungarischem Knochenmaterial, Zeitschrift für Tierzüchtung und Züchtungsbiologie, 1970, 87-137. N. Marquardt, Pan in der hellenistischen und kaiserzeitlichen Plastik, Antiquitas 3, 33 (Bonn 1995).

C. MAYER, Untersuchungen zum Schriftbild ephesischer Steininschriften. Von den Mithridatischen Kriegen bis zum Ende des ersten Jahrhunderts n. Chr. (ungedr. Diss. Universität Wien 1995).

C. Mayer, Ephesos. Die Schrift der >Großen Spenderliste $<$ aus der Zeit des Tiberius (IvE V 1687), Tyche 18, 2003, 77-90.

J. W. McGarvey, Lands of the Bible. A Geographical and Topographical Description of Palestine, with Letters of Travel in Egypt, Syria, Asia Minor, and Greece (Philadelphia 1881).

N. Mekacher, Die vestalischen Jungfrauen in der römischen Kaiserzeit, Palilia 15 (Wiesbaden 2006).

R. MERIÇ, Späthellenistisch-römische Keramik und Kleinfunde aus einem Schachtbrunnen am Staatsmarkt in Ephesos, FiE 9, 3 (Wien 2002).

R. Meriç, Metropolis. City of the Mother Goddess (Istanbul 2004).

R. Merkelbach, Steinepigramme aus dem griechischen Osten 1. Die Westküste Kleinasiens von Knidos bis Ilion (Stuttgart 1998).

I. H. Mert, Der Theater-Tempelkomplex von Stratonikeia, in: Berns u. a. 2002, 187-203.

W. E. Metcalf, The Cistophori of Hadrian, Numismatic Studies 15 (New York 1980).

S. MetaXAs, Frühbyzantinische Ampullen und Amphoriskoi aus Ephesos, in: KrINZINGER 2005, 67-123.

W. HAhn, Moneta Imperii Byzantini, 3. Teil, Von Heraclius bis Leo III./Alleinregierung (610720), Veröffentlichungen der Numismatischen Kommission X, DenkschrWien 148 (Wien 1981).

W. Hahn - M. A. Metlich, Money of the Incipient Byzantine Empire, Anastasius I-Justinian I (491-565), Veröffentlichungen des Instituts für Numismatik Wien 6 (Wien 2000).

F. Miltner, Die Einzelfunde (Lampen), in: C. Praschniker (Hrsg.), Das Cömeterium der Sieben Schläfer, FiE 4, 2 (Wien 1937) 93-200.

F. Miltner, XXII. Vorläufiger Bericht über die Ausgrabungen in Ephesos, ÖJh 44, 1959, Beibl. 243-314.

T. E. Mionnet, Description de médailles antiques, grecques et romaines, Suppl. 6 (Paris 1833, Neudruck 1972).

R. GöBL, Die Münzprägung der Kaiser Valerianus I./Gallienus/Saloninus (253/268), Regalianus (260) und Macrianus/Quietus (260/262), Moneta Imperii Romani 36/43/44, Veröffentlichungen der Numismatischen Kommission 35, DenkschrWien 286 (Wien 2000).

R. GöBL, Die Münzprägung des Kaisers Aurelianus (270/275), Moneta Imperii Romani 47, Veröffentlichungen der Numismatischen Kommission 29, DenkschrWien 233 (Wien 1995).

V. Mitsopoulos-Leon, Die Basilika am Staatsmarkt in Ephesos. Kleinfunde 1. Teil: Keramik hellenistischer und römischer Zeit, FiE 9, 2, 2 (Wien 1991).

V. Mitsopoulos-Leon, Lampen, in: Mitsopoulos-Leon - Lang-Auinger 2007, 64-113.

V. Mitsopoulos-Leon - C. Lang-Auinger (Hrsg.), Die Basilika am Staatsmarkt in Ephesos. 2. Teil: Funde klassischer bis römischer Zeit, FiE 9, 2, 3 (Wien 2007).

S. Mollard-Besques, Catalogue raisonné des figurines et reliefs en terrecuite Grecs et Romains II, Myrina, Musée du Louvre et collections des Universités de France (Paris 1963).

J.-Ch. Moretti, L'architecture des théâtres en Asie Mineure (1980-1989), Topoi 2, 1992, 9-32.

J.-Ch. Moretri, Des masques et des théâtres en Grèce et en Asie Mineure, REA 95, 1993, 207-217. 
MoretTi 1993b

MoretTI 1997

MvE

NAUMANn 1983

Neutsch 1956

NIEWÖHNER 2008

NORMANBY

OBERLEITNER u. a. 1978

OBerleitner 2009

ÖAI-BERICHT 2008

ÖAI-BERICHT 2009

ÖAI-BERICHT 2010

ÖAI-BERICHT 2011

ÖZKURT 1998

ÖZTÜRK 2005a

ÖZTÜRK 2005b

ÖZTÜRK 2006a

ÖZTÜRK 2006b

ÖZTÜRK 2009

ÖZTÜRK 2010

ÖZTÜRK (in Vorbereitung)

ÖZIș - ATALAY 1999

ÖZREN 1996

OUtSCHAR 1996

OXÉ - COMfort 2000

Panella 2002

PaUl 1965

Peacock - Williams 1986

PEKÁRY 1985

Pensabene 2011
J.-Ch. Moretti, Études sur la nomenclature grecque de l'architecture thèatrale: pétasos et la denomination greques des velums, Anatolie Antique 2, 1993, 133-158.

J.-Ch. MoretTi, Formes et destinations du proskènion dans les théâtres hellénistiques de Grèce, in: B. LE GuEN (Hrsg.), De la scène aux gradins: Théâtre et représentations dramatiques apres Alexandre le Grand, Pallas 47 (Toulouse 1997) 13-39.

St. Karwiese, Die Münzprägung von Ephesos 5. Katalog und Aufbau der römerzeitlichen Stadtprägung mit allen erfassbaren Stempelnachweisen, I. Katalog (Wien 2012).

F. NAumann, Die Ikonographie der Kybele in der phrygischen und der griechischen Kunst, IstMitt Beih. 28 (Tübingen 1983).

B. Neutsch, Archäologische Grabungen und Funde im Bereich der unteritalischen Soprintendenzen von Tarent, Reggio di Calabria und Salerno 1949-1955, AA 1956, 193-450.

$\mathrm{Ph}$. NiewÖHNER, Sind die Mauern die Stadt? Vorbericht über die siedlungsgeschichtlichen Ergebnisse neuer Grabungen im spätantiken und byzantinischen Milet. Mit geoarchäologischen Anmerkungen zur Friedhofskirche von H. Brückner und M. Müllenhoff, AA 2008/1, 181-201. R. Bland - A. Burnett, The Normanby Hoard and other Roman Coin Hoards, Coin Hoards from Roman Britain 8 (London 1988).

W. Oberleitner - K. Gschwantler - A. Bernhard-Walcher - A. Bammer, Funde aus Ephesos und Samothrake. Kunsthistorisches Museum Wien, Katalog der Antikensammlung 2 (Wien 1978).

W. Oberleitner, Das Partherdenkmal von Ephesos. Schriften des Kunsthistorischen Museums 11 B (Wien 2009).

Wissenschaftlicher Jahresbericht des Österreichischen Archäologischen Instituts 2008 $<$ http://www.oeai.at/tl_files/img/Dateien/Jahresbericht_2008-neu.pdf $>$ (18.11.2011).

Wissenschaftlicher Jahresbericht des Österreichischen Archäologischen Instituts 2009 $<\mathrm{http}$ ://www.oeai.at/tl files/img/Dateien/Jahresbericht 2009-neu.pdf $>$ (18.11.2011).

Wissenschaftlicher Jahresbericht des Österreichischen Archäologischen Instituts 2010 $<$ http://www.oeai.at/tl_files/img/Dateien/JB_ebook_vers 3.pdf $>$ (18.11.2011).

Wissenschaftlicher Jahresbericht des Österreichischen Archäologischen Instituts 2011 $<$ http://www.oeai.at/tl_files/img/Dateien/kopie vom Jb_2011_ebook_kleiner.pdf> (09.04.2014).

Ş. ÖZKURT - M. Sözen - N. YIĞIT - E. ÇolaK, Notes on Distributional Records and Some Characteristics of Five Carnivore Species (Mammalia: Carnivora) in Turkey, Turkish Journal of Zoology 22, 1998, 285-288.

A. ÖzTÜrk, Zwei Deckenabschlüsse aus der scaenae frons des Theaters in Ephesos, in: BRANDT u. a. 2005, Bd. 1, 209-214.

A. ÖztÜRK, Zur scaenae frons des Theaters in Ephesos, Architectura 35, 2005, 4-14.

A. ÖzTÜRK, Re-Use Problems Related to the Great Theater in Ephesos, in: Z. AhunbaY - Ü. İzmirLigil (Hrsg.), Arkeolojik Yapılar ve Sitlerin Korunması, 2006, 86-89.

A. ÖZTÜRK, Restaurationsprojekt des Bühnengebäudes des Theaters von Ephesos, ÖJh 75, 2006, 205-218.

A. ÖZTüRK, Die Architektur der scaenae frons des Theaters in Perge, Denkmäler Antiker Architektur 20 (Berlin 2009).

A. ÖzTüRK, Die flavische scaenae frons des Theaters in Ephesos, in: N. RÖRING - S. F. RAMALLO (Hrsg.), La scaenae frons en la arquitectura theatral Romana, 2010, 331-342.

A. ÖZTÜRK, Das Theater von Ephesos. Forschungen zur scaenae frons, FiE (in Vorbereitung). Ü. ÖzIș - A. Atalay, Fernwasserleitungen von Ephesos, in: Friesinger - KrinZINGER 1999, $405-411$.

A. C. ÖZren, Die Skulpturenausstattung kaiserzeitlicher Theater in der Provinz Asia, am Beispiel der Theater in Aphrodisias, Ephesos und Hierapolis, Thetis 3, 1996, 99-127.

U. OUtSCHAR, Analyse und Dokumentation exemplarisch ausgewählter keramischer Komplexe, in: LANG-AUINGER 1996 (Wien 1996) 27-85.

A. OxÉ - H. COMfort, Corpus Vasorum Arretinorum. A Catalogue of the Signatures, Shapes and Chronology of Italian Sigillata (Bonn 2000).

C. Panella, Le anfore di età imperiale nel Mediterraneo occidentale. Céramiques héllenistiques et romaines 3, Publications du Centre Camille-Julien 28 (Paris 2002) 177-275.

E. PAuL, Wörlitzer Antiken. Eine Skulpturensammlung des Klassizismus (Wörlitz 1965).

D. P. S. Peacock - D. F. Williams, Amphorae and the Roman Economy (London 1986).

T. PEKÁRY, Das römische Kaiserbildnis in Staat, Kult und Gesellschaft dargestellt anhand der Schriftquellen. Das römische Herrscherbild 3, 5 (Berlin 1985).

P. Pensabene, Su alcuni aspetti produttive delle $>$ scuole $<$ di scultura di Docimio, Afrodisia e Nicomedia, in: D'ANDRIA - ROMEO 2011, 37-61. 
XXVIII

Pensabene - Lazzarini 1998

PerlzWeig 1961

Petrakos 1997

PETZL 1974

PfeIfFer 1931

Pfisterer 2008

Pflaum 1970

Pflaum 1960

Pfuhl - MöBIus 1979

PhILIPP 1981

Philipps 2008

Pickard-CAmbridge 1946

PIESKER 2009

Pietsch 2002

PIETSCH - TRINKL 1995

PINKWART 1965a

PINKWART 1965b

PlattNer 2003

PLRE

POCOCKE 1745

Powell 1904

PRICE 1991

Pülz 2009

PÜlz 2010

PÜlZ - LAdstätter 2007

QUATEMBER 2003

QuATEMBER 2006

QUATEMBER 2010

QuATEMBER 2011

RADT 1988

RADT - DE LUCA 1999

RAKOB 1994

RAKOB 1997

RAUSA 1997

RATHMAYR 2005a

RATHMAYR 2005b

RATHMAYR 2010

RATHMAYR 2011

RATHMAYR 2014
Hinweise und Verzeichnisse

P. Pensabene - L. Lazzarini, Il problema del bigio antico e del bigio morato: contributo allo studio delle cave di Teos e di Chios, in: P. Pensabene (Hrsg.), Marmi antichi II. Cave e tecnica di lavorazione, provenienze e distribuzione, Studi Miscellanei 3 (Rom 1998) 141-172.

J. Perlzweig, Lamps of the Roman Period, Agora 7 (Princeton 1961).

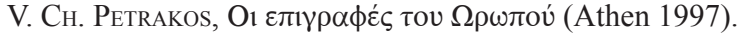

G. Petzl, Gladiatoren-Denkmäler aus den Skizzenbüchern von Josef Keil, ZPE 14, 1974, 285-293.

H. F. Pfeiffer, The Ancient Roman Theater at Dugga, MemAmAc 9, 1931, 145-156.

M. Pfisterer, Münzen, in: Steskal - La torre 2008, 208-211.

H.-G. Pflaum, Les officiers equestres de la legion VII Gemina, in: Legio VII Gemina (Leon 1970) 353-380.

H.-G. Pflaum, Les carrières procuratoriennes équestres sous le Haut-Empire romain I (Paris 1960).

E. Pfuhl - H. MöBIus, Die ostgriechischen Grabreliefs II (Mainz 1979).

H. Philipp, Bronzeschmuck aus Olympia, OF 13 (Berlin 1981).

L. K. Philipps, Figural Table Supports. Aspects of the Archaeology of Dining in the Roman World, in: C. Ratté - R. R. R. Smith (Hrsg.), Aphrodisias Papers 4 = JRA Suppl. 70 (Portsmouth 2008) 253-283.

A. W. Pickard-CAmbridge, The Theatre of Dionysus in Athens (Oxford 1946).

K. Piesker, Das antike Theater von Patara, Türkei. Befunde und Erkenntnisse zu den Außenfassaden des Bühnengebäudes, Architectura 39, 2009, 42-58.

W. Pietsch, Der Gladiatorenfriedhof von Ephesos. Der archäologische Befund, in: GladiatoREN IN EPHESOS, 15-17.

W. Pietsch - E. Trinkl, Der Grabungsbericht der Kampagnen 1992/93, in: D. KnibBe - H. THÜR (Hrsg.), Via Sacra Ephesiaca II, BerMatÖAI 6 (Wien 1995) 19-48.

D. PInKwart, Das Relief des Archelaos von Priene und die >Musen des Philiskos` (Kallmünz 1965).

D. Pinkwart, Das Relief des Archelaos von Priene, AntPl 4 (Berlin 1965) 55-65.

G. A. Plattner, Ephesische Kapitelle des 1. und 2. Jhs. n. Chr. Form und Funktion kaiserzeitlicher Architekturdekoration in Kleinasien (ungedr. Diss. Universität Wien 2003).

The Prosopography of the Later Roman Empire (Cambridge 1971-1992).

R. Pococke, Description of the East (London 1745).

B. Powell, Oiniadae I-IV, AJA 8, 1904, 137-237.

J. Price, Decorated Mould-Blown Glass Tablewares in the First Cenutry AD, in: M. NewBy K. Painer (Hrsg.), Roman Glass: Two Centuries of Art and Invention (London 1991) 56-75.

A. M. PüLz, Goldfunde aus dem Artemision von Ephesos, FiE 12, 5 (Wien 2009).

A. Pülz, Das Stadtbild von Ephesos in byzantinischer Zeit, in: DAIM - DrauschKe 2010, 541-571.

A. PÜlz - S. Ladstätter, Ephesos in the Late Roman and Early Byzantine Period: Changes in its Urban Character from the $3^{\text {rd }}$ to $7^{\text {th }}$ Century AD, in: A. Poulter (Hrsg.), The Transition to Late Antiquity, Acts of a Symposium at the British Academy 2003 (Oxford 2007) 391-433.

U. Quatember, Marmorinventar, in: LANG-Auinger 2003a, 121-152.

U. Quatember, Tischstützen aus dem Hanghaus 2 in Ephesos, RömHistMitt 48, 2006, 87102 .

U. Quatember, Marmorinventar, in: KrinZInger 2010, 649-655.

U. Quatember, Das Nymphaeum Traiani in Ephesos, FiE 11, 2 (Wien 2011).

W. Radt, Pergamon. Geschichte und Bauten, Funde und Erforschung einer antiken Metropole (Köln 1988).

W. RAdT - G. DE LuCA, Sondagen im Fundament des grossen Altars, PF 12 (Berlin 1999).

F. Rakob, Die Fabrica-Produktion, in: M. Khanoussi - T. Kraus - F. RaKob - M. Vegas, Simitthus II. Der Tempelberg und das römische Lager (Mainz 1994) 107-137.

F. Raков, Chemtou, AW 28/1, 1997, 1-20.

LIMC VIII (1997) 125-141 s. v. Tyche/Fortuna (F. RAUSA).

E. RATHMAYR, Skulpturen, in: THÜR 2005, 207-229.

E. RathmaYr, Skulpturen aus buntem Stein aus dem Hanghaus 2 in Ephesos, in: Brandt u. a. 2005, Bd. 1, 279-285.

E. Rathmayr, Glocken, in: Kowalleck - Rathmayr 2010, 618.

E. RathmaYr, Die Skulpturenausstattung des C. Laecanius Bassus Nymphaeum in Ephesos, in: D'ANDRIA - RoMEo 2011, 131-149.

E. Rathmayr, Skulpturenfunde, in: H. Thür - E. Rathmayr (Hrsg.), Hanghaus 2 in Ephesos, Die Wohneinheit 6, Baubefund, Ausstattung, Funde, FiE 8 (Wien 2014) 376-431. 
RATHMAYR (in Druckvorbereitung)

RATHMAYR (in Vorbereitung)

Rembart (in Vorbereitung)

ReYNOLDS 1982

RIC I

RIC II

RIC II ${ }^{2}$

RIC IV/3

RIC V/1

RIC VI

RIC VII

RIC VIII

RIC IX

RIC X

RICHTER 1966

RIEMANN 1877

RIHA 1986

RIHA 1990

RILEY 1979

RiтTI 1977

RitTI - YILMAZ 1998

ROBERT 1940

ROBERT 1948

ROBERT 1971

Rogers 1991

Rogl 2001

RoGL 2003

RogL 2008

RPC

RPC IV

ROSSNER 1974

RotroFF 1982

ROTROFF 2001

ROTROFF 2006

ROUECHÉ 2002a
E. Rathmayr, Terrakotten, in: S. Ladstätter (Hrsg.), Das Hanghaus 2 von Ephesos, Die Wohneinheiten 3 und 5 (in Druckvorbereitung).

E. Rathmayr, Skulpturenausstattung, in: M. Aurenhammer (Hrsg.), Das Nymphäum des Laecanius Bassus, FiE (in Vorbereitung).

L. Rembart, Keramik, in: M. Aurenhammer (Hrsg.), Das Nymphäum des Laecanius Bassus, FiE (in Vorbereitung).

J. ReYNolds, Aphrodisias and Rome (London 1982).

C. H. V. SutherLand, The Roman Imperial Coinage I, Revised Edition, from 31 BC to AD 69 ${ }^{2}$ (London 1984).

H. Mattingly - E. A. Sydenham, The Roman Imperial Coinage II, Vespasian to Hadrian (London 1926).

I. A. Carradice - T. V. Buttrey, The Roman Imperial Coinage 2,1, From AD 69-96, Vespasian to Domitian, Fully revised edition ${ }^{2}$ (London 2007).

H. Mattingly - E. A. Sydenham - C. H. V. Sutherland, The Roman Imperial Coinage IV/3, Gordian III. to Uranius Antoninus (London 1949).

P. H. WeBB, The Roman Imperial Coinage V/1, Valerian to Florian (London 1927).

C. H. V. Sutherland, The Roman Imperial Coinage VI, from Diocletian's Reform (AD 294) to the Death of Maximinus (AD 313) (London 1967).

P. M. Bruun, The Roman Imperial Coinage VII, Constantine and Licinius, 313-337 (London 1966).

J. P. C. Kent, The Roman Imperial Coinage VIII, The Family of Constantine I. 337-364 (London 1981).

J. W. E. Pearce, The Roman Imperial Coinage IX, Valentinian I.-Theodosius I. (London 1933).

J. P. C. Kent, The Roman Imperial Coinage X, The Divided Empire and the Fall of the Western Parts (London 1994).

G. M. A. Richter, The Furniture of the Greeks, Etruscans and Romans (London 1966).

O. Riemann, Inscriptions grecques provenant du recueil de Cyriaque d'Ancône, BCH 1, 19877, 286-294.

E. RIHA, Römisches Toilettgerät und medizinische Instrumente aus Augst und Kaiseraugst, Forschungen in Augst 6 (Augst 1986).

E. Riнa, Der römische Schmuck aus Augst und Kaiseraugst, Forschungen in Augst 10 (Augst 1990).

J. A. Riley, The Coarse Pottery from Berenice, in: J. A. Lloyd (Hrsg.), Excavations at Sidi Khrebish Benghazi (Berenice) II, Supplement to Libya Antiqua 5 (Tripoli 1979) 91-467.

T. RitTI, Immagini onomastiche sui monumenti sepolcrali di età imperiale, MemLinc 21, 1977, 257-396.

T. RitTi - S. YiLmaz, Gladiatori e venationes a Hierapolis di Frigia, MemLincei 10, 1998, 444-542.

L. Robert, Les gladiateurs dans l'Orient grec (Paris 1940).

L. RoBert, Monuments des gladiateurs dans l'orient grec, Hellenica 5, 1948, 77-99.

L. RoBert, Les gladiateurs dans l'orient grec (Amsterdam 1971).

G. Rogers, The Sacred Identity of Ephesos. Foundation Myths of a Roman City (London 1991).

C. RogL, Töpfersignaturen auf hellenistischen Reliefbechern: Eine Liste, ÖJh 70, 2001, 133155 .

C. RogL, Hellenistische Keramik aus den Grabungen auf der Tetragonos-Agora. Ein mittelhellenistischer Fundkomplex, in: AsAMER - WOHLMAYER 2003, 175-182.

C. RogL, Die hellenistischen Reliefbecher aus Lousoi. Material aus den Grabungen Phournoi 1983-1994, ErghÖJh 10 (Wien 2008).

A. Burnett - M. Amandry - P. P. Ripolès, Roman Provincial Coinage 1, From the Death of Caesar to the Death of Vitellius (44 BC-AD 69) (London 1992).

C. J. Howego - V. Heuchert, Roman Provincial Coinage Online 4, The Antonines $<$ http://rpc. ashmus.ox.ac.uk> (03.05.2013).

M. Rossner, Asiarchen und Archiereis Asias, StudClas 16, 1974, 101-142.

S. I. Rotroff, Silver, Glass and Clay - Evidence for the Dating of Hellenistic Luxury Tableware, Hesperia 51, 1982, 329-337.

S. J. Rotroff, Rez. zu RadT - De Luca 1999, AJA 105, 2001, 129-130.

S. I. Rotroff, Hellenistic Pottery. The Plain Wares, Agora 33 (Princeton 2006).

Ch. Roueché, The Image of Victory: New Evidence from Ephesus, in: Mélanges G. Dagron, TravMem 14, 2002, 527-546. 
ROUECHÉ 2002b

RÜPKE 2008

RUGGENDORFER (in Druck)

RUgGi D’ARAgONA 2002

RUMSCHEID 1992

RUMSCHEID 1994

RUMSCHEID 2001

RUMSCHEID 2004

RUMSCHEID 2006

SACK u. a. 2010

SÄNGER 2011

SALAmine

SCATOZZA HöRICHT 1991

SCHACHINGER 2006

SCHÄFER 1968

SCHÄTZSCHOCK 2005

SсHÄTZSCHOCK 2010a

SсHÄTZSCHOCK 2010b

SCHEIBLER 1976

SCHERRER 1995

SCHERRER 1997

SCHERRER 2001

SCHERRER 2008

SCHERRER U. a. 1999

SCHERRER - TrinKL 2006

SCHINDEL 2009

SCHMAUdER 2000

SCHNEIDER 1999

SCHRÖDER 2004

Schulte 1994

SChULze-DörRLAMm 2009

SEAR 1990

SEAR 2006

SIEBERT 1990

SIMON 1997

SiMON - BAUCHHENSS 1992

SмIтн 1999
C. Roueché, Images of Performance: New Evidence from Ephesus, in: P. EAsterling - E. Hall (Hrsg.), Greek and Roman Actors: Aspects of an Ancient Profession (Cambridge 2002) 254-281.

J. RÜPKE (Hrsg.), Festrituale in der römischen Kaiserzeit (Tübingen 2008).

P. RugGendorfer, Das Mausoleum von Belevi. Archäologische Untersuchungen zu Chronologie, Ausstattung und Stiftung, FiE 6, 2 (in Druck).

M. G. Ruggi d’Aragona, in: M. De Nuccio - L. Ungaro (Hrsg.), I marmi colorati della Roma imperiale. Ausstellungskatalog Rom (Venedig 2002).

F. RUMSCHEID, Überlegungen zum archaistischen Kopftypus Brüssel-Konservatorenpalast, AA 1992, 83-98.

F. RuMscheID, Untersuchungen zur kleinasiatischen Bauornamentik des Hellenismus (Mainz 1994).

J. RumscheID - F. RumscheID, Gladiatoren in Mylasa, AA 2001, 115-136.

F. RuMsCHEID, Regionale Moden bei Gladiatoren und athletische Eurythmie eines Kochtopfes: Vier neu gefundene Grabreliefs aus Mylasa, in: KoRKut 2004, 631-647.

F. RuMSCHEID, Die figürlichen Terrakotten von Priene (Wiesbaden 2006).

D. Sack - T. Schulz - U. Wulf-Rheidt - K. Tragbar, Bericht über die 45. Tagung für Ausgrabungswissenschaft und Bauforschung vom 30. April bis 4. Mai 2008 in Regensburg (Stuttgart 2010).

P. SÄNGER, Neue Inschriften aus der nördlichen Außenmauer des ephesischen Theaters, Tyche 26, 2011, 235-246.

J. Pouilloux, Testimonia Salaminia 2 (Salamine de Chypre XIII; Paris 1987).

L. A. Scatozza Höricht, Syrian Elements Among the Glass from Pompeii and Herculaneum, in: M. Newby - K. Painer (Hrsg.), Roman Glass: Two Centuries of Art and Invention (London 1991) 76-85.

U. SCHACHINGER, Der antike Münzumlauf in der Steiermark, Die Fundmünzen der römischen Zeit in Österreich Abt. 6, Forschungen zur geschichtlichen Landeskunde der Steiermark 49, Veröffentlichungen der Numismatischen Kommission 43, DenkschrWien 341 (Wien 2006).

J. SCHÄFER, Hellenistische Keramik aus Pergamon, PF 2 (Berlin 1968).

M. SснÄTZSCHOCK, Glas, in: THÜR 2005, 363-388.

M. SсHätzschock, Glas, in: KrinZINGER 2010, 286-321.

M. SCHÄtZSChOCK, Glas, in: KrinZINGER 2010, 592-604.

I. Scheibler, Kerameikos 11. Griechische Lampen (Berlin 1976).

P. Scherrer (Hrsg.), Ephesos. Der neue Führer (Wien 1995).

P. SCHERRER, Das Ehrengrab des Kaiserpriesters am Embolos - Eine Personensuche, in: THÜR 1997, 113-139.

P. SchERRER, The Historical Topography of Ephesos, in: D. PARRISH, Urbanism in Ancient Asia Minor, JRA Suppl. 45 (Portsmouth 2001) 57-95.

P. SCHERRER, Die Stadt als Festplatz: Das Beispiel der ephesischen Bauprogramme rund um die Kaiserneokorien Domitians und Hadrians, in: RÜPKE 2008, 35-65.

P. Scherrer - H. Taeuber - H. Thür (Hrsg.), Steine und Wege. Festschrift D. Knibbe, SoSchrÖAI 32 (Wien 1999).

P. SCherrer - E. TrinkL, Die Tetragonos Agora in Ephesos, FiE 13, 2 (Wien 2006).

N. Schindel, Die Fundmünzen von der Kuretenstraße 2005 und 2006. Numismatische und historische Auswertung, in: LADSTÄTter 2009, 171-245.

M. SchMAUdER, Vielteilige Gürtelgarnituren des 6.-7. Jahrhunderts: Herkunft, Aufkommen und Trägerkreis, in: F. DAIM (Hrsg.), Die Awaren am Rand der byzantinischen Welt (Innsbruck 2000) 15-44.

C. SchneIDER, Die Musengruppe von Milet, MilForsch 1 (Mainz 1999).

S. F. SchröDER, Katalog der antiken Skulpturen des Museo del Prado in Madrid (Mainz 2004). C. Schulte, Die Grammateis von Ephesos. Schreiberamt und Sozialstruktur in einer Provinzhauptstadt des römischen Kaiserreiches (Stuttgart 1994).

M. SCHULZE-DörRLAMm, Byzantinische Gürtelschnallen und Gürtelbeschläge im Römisch-Germanischen Zentralmuseum, Kataloge vor- und frühgeschichtlicher Altertümer 30, 1-2 (Mainz 2009).

F. SEAR, Vitruvius and Roman Theater Design, AJA 94, 1990, 249-258.

F. SEAR, Roman Theatres. An Architectural Study (Oxford 2006).

LIMC V (1990) 285-387 s. v. Hermes (G. SIEBERT).

LIMC VIII (1997) 1108-1133 s. v. Silenoi (E. SIMON).

LIMC VI (1992) 500-554 s. v. Mercurius (E. Simon - G. BAuchHENss).

R. R. R. Smith, Late Antique Portraits in a Public Context: Honorific Statuary at Aphrodisias in Caria, A.D. 300-600, JRS 89, 1999, 155-189. 
SмITH 2006

SNG AuL

SNG CoP

SNG LEYP

SNG Mü 20

SNG MÜ 24

SNG TÜв

Sokolicek 2010

SOYKAL 1993

SOYKAL 1998

STARK 2007

Starkovich u. a. 2009

Steskal - La Torre 2008

STROCKA 1981

STROCKA 2005

StURGEON 2004a

Sturgeon 2004b

STYHLER 2010

STYHLER-AYdin 2010

STYHLER-Aydin (in Vorbereitung)

TAEUBER 2008

TAeUber 2010

TeICHERT 1975

THIRION 1963

THÜR 1989

THÜR 1997

THÜR 2002

THÜR 2005

THÜR - RATHMAYR 2014

TRAPICHLER 2010

TRINKL 2003

TRINKL 2006

TURNOVSKY 2003
R. R. R. Sмith, Roman Portrait Statuary from Aphrodisias. Aphrodisias II (Mainz 2006). Sylloge Nummorum Graecorum, Deutschland, Sammlung H. von Aulock, 18 Bde. (Berlin 1957-1981).

Sylloge Nummorum Graecorum, The Royal Collection of Coins and Medals, Danish National Museum, Parts 1-39 (Copenhagen 1942-1965).

W. SzaIvert - C. Daburon, Sylloge Nummorum Graecorum Österreich, Sammlung Leypold, Teil I: Pontus-Lydien (Wien 2000).

SNG München, Staatliche Münzsammlung München, 20. Heft, Ionien 1, bearbeitet von D. O. A. KLOSE (München 1995).

SNG München, Staatliche Münzsammlung München, 24. Heft, Phrygien, bearbeitet von W. LESCHHORN (München 1989).

SNG Tübingen, Münzsammlung der Universität Tübingen, 4. Heft, Mysien-Ionien, bearbeitet von D. MANNSPERGER (München 1989).

A. Sокоцicek, Chronologie und Nutzung des Magnesischen Tores von Ephesos, ÖJh 79, 2010 , 359-381.

F. SOYKAL, Eine spätklassische Terrakottastatuette der Kybele aus Ephesos, BerMatÖAI 5, 1993, 53-56.

F. SOYKaL, Denkmäler des Kybele-Meterkultes in Ephesos (ungedr. Diss. Universität Wien 1998).

I. StARK, Kybele als keltische Göttin: Zur Aufnahme der Kybele von Pessinus als Magna Mater unter die römischen Staatsgötter 205/204 v. Chr., Klio 89, 2007, 67-117.

B. Starkovich - M. Stiner - C. Mary, Hallan Çemi Tepesi: High-Ranked Game Exploitation Alongside Intensive Seed Processing at the Epipaleolithic-Neolithic Transition in Southeastern Turkey, Anthropozoologica 441, 2009, 41-61.

M. StesKal - M. La Torre, Das Vediusgymnasium in Ephesos, FiE 14, 1 (Wien 2008).

V. M. SтRоскA, Das Marktor von Milet, BWPr 128 (Berlin 1981).

V. M. Strocka, Griechische Löwenkopf-Wasserspeier in Ephesos, in: BrandT u. a. 2005, Bd. $1,337-348$.

M. C. Sturgeon, Sculpture. The Assemblage from the Theater, Corinth 9, 3 (Ann Arbor, Michigan 2004).

M. C. Sturgeon, Dedications of Roman Theatres, in: A. P. Chapin (Hrsg.), Xópıs. Essays in Honor of Sara A. Immerwahr, Hesperia Suppl. 33 (Princeton 2004).

G. STYHLER, Zur Verkleidungstechnik im Zuschauerraum des Theaters von Ephesos, in: SACK u. a. 2010, 181-189.

G. STYHLER-Aydin, Bauforschung am Theater von Ephesos. Ergebnisse der Untersuchungen im Zuschauerraum in den Jahren 2003-2008, AnzWien 145, 2010, 61-105.

G. STyhler-Aydin, Das Theater von Ephesos. Baubefund und architekturhistorische Analyse, FiE (in Vorbereitung).

H. TAEUBER, Epigraphik, in: JAHRESBERICHT 2007, 422.

H. TAEUBER, Graffiti, in: KRINZINGER 2010, 72-78.

M. TEICHERT, Osteometrische Untersuchungen zur Berechnungen der Widerristhöhe bei Schafen, in: A. T. Clason, Archaeozoological Studies (Amsterdam 1975) 51-69.

M. Thirion, Cistophores contremarqués sous Vespasien, SM 49, 1963, 1-8.

H. THÜr, Das Hadrianstor in Ephesos, FiE 11, 1 (Wien 1989).

H. THÜR (Hrsg.), »... Und verschönerte die Stadt ...«. Ein ephesischer Priester des Kaiserkultes in seinem Umfeld, SoSchrÖAI 27 (Wien 1997).

H. THÜR, Kontinuität und Diskontinuität im ephesischen Wohnbau der frühen Kaiserzeit, in: BERNS u. a. 2002, 257-274.

H. THÜR, Das Hanghaus 2 in Ephesos. Die Wohneinheit 4. Baubefund. Ausstattung. Funde, FiE 8, 6 (Wien 2005).

H. ThÜR - E. Rathmayr (Hrsg.), Hanghaus 2 in Ephesos, Die Wohneinheit 6, Baubefund, Ausstattung, Funde, FiE 8 (Wien 2014).

M. TRAPICHLER, Die hellenistische Keramik vom Maussolleion in Belevi. Zeugnis eines Totenkults?, in: M. MeYer - V. Gassner (Hrsg.), Standortbestimmung, Akten des 12. Österreichischen Archäologentages Wien 2008 (Wien 2010) 65-77.

E. TrinKL, Artefakte für die Textilbearbeitung, in: LANG-AuIngER 2003a, 313-327.

E. TRINKL - P. SCHERrer, Die Tetragonos Agora in Ephesos. Grabungsergebnisse von archaischer bis in byzantinische Zeit - Ein Überblick. Befunde und Funde klassischer Zeit, FiE 13, 2 (Wien 2006).

P. Turnovsky, Glaslampen aus der Marienkirche in Ephesos, in: Asamer - WohlmaYr 2003, 237-241. 
XXXII

TuRNOVSKY 2005a

TURNOVSKY 2005b

UERPMANN 2006

UZUNASLAN 2010

VARRIALE 2007

Vermaseren - De Boer 1986

VERMASEREN 1987

VETTERS 1966

VETTERs 1970

VIKELA 2001

Voegtli 1993

V. AuLock II

VOLLKOMMER 1997

VON DEN DRIESCH 1976

VON GERKAN 1921

VON GERKAN - MÜLLER-WIENER 1961

vON HESBERG 1980

VON MiLLER (in Druck)

von PRITTwitZ von Graffon 2007

VON ROHDEN 1895

VONDROVEC 2007

WALDBAUM 1983

WALDHAUER 1936

WALDNER u. a. 2008

WALDNER 2009

WALDNER 2014

WALDNER 2016

WALDNER - LADSTÄTter 2014a

WALDNER - LADSTÄTTER 2014b

Wegner 1976

WeLCh 1998

WeLCH 2009

WIPLINGER 2006a

WIPLINGER 2006b

WIPLINGER 2006c
Hinweise und Verzeichnisse

P. Turnovsky, Late Antique and Byzantine Pottery of the Church of St. Mary in Ephesos. An Introduction, RCRF Acta 39, 2005, 217-224.

P. TuRnovsky, The Morphological Repertory of Late Roman/Early Byzantine Coarse Wares in Ephesos, in: LRCW I: Late Roman Coarse Wares, Cooking Wares and Amphorae in the Mediterranean. Archaeology and Archaeometry, BARIntSer 1340 (Oxford 2005) 635-645.

M. Uerpmann, Von Adler bis Zahnbrassen. Der Beitrag der Archäozoologie zur Erforschung Troias, in: M. O. KoRfMAnN, Troia: Archäologie eines Siedlungshügels und seiner Landschaft (Mainz 2006) 283-296.

A. UzUnASLAn, Gladiatörler. Arenanın Tutsak Savaşçıları (Ankara 2010).

I. Varriale, La villa imperiale di Pausilypon, in: R. Ciardiello (Hrsg.), La villa romana, Collana Archeologia 8 (Neapel 2007) 147-165.

LiMC III (1986) 22-44 s. v. Attis (M. J. Vermaseren - M. B. De Boer).

M. J. Vermaseren, Corpus Cultus Cybelae Attidisque I. Asia Minor, EPRO 50 (Leiden 1987).

H. VetTers, Wachsen, Blühen und Vergehen: Ephesus, Merian 12/1966, 32-37.

H. VetTers, Ephesos. Vorläufiger Grabungsbericht 1969, AnzWien 107, 1970, 105-123.

E. ViKELA, Bemerkungen zu Ikonographie und Bildtypologie der Meter-Kybelereliefs, AM $116,2001,67-123$.

H. Voegtli, Die Fundmünzen aus der Stadtgrabung von Pergamon, PF 8 (Berlin 1993).

H. v. Aulock, Münzen und Städte Phrygiens, IstMitt Beih. 27 (Tübingen 1987).

LIMC VIII (1997) 237-269 s. v. Victoria (R. VOLLKOMMER).

A. von DeN Driesch, Das Vermessen von Tierknochen aus vor- und frühgeschichtlichen Siedlungen (München 1996).

A. vON GERKAN, Das Theater von Priene. Als Einzelanlage und in seiner Bedeutung für das hellenistische Bühnenwesen (München 1921).

A. von GerKan - W. Müller-Wiener, Das Theater von Epidauros (Stuttgart 1961).

H. von Hesberg, Konsolengeisa des Hellenismus und der frühen Kaiserzeit, RM Ergh. 24 (Mainz 1980).

A. von Miller, Die archaischen Siedlungsbefunde von Ephesos: Keramik, Kontexte und Chronologie (in Druck).

H.-H. von Prittwitz von Graffon, Die hellenistische Plastik von 160 bis 120 v. Chr., in: P. C. BoL (Hrsg.), Die Geschichte der Bildhauerkunst III. Hellenistische Kunst (Mainz 2007).

RE II 1 (1895) 1264-1265 s. v. Arruntius 15 (P. von RoHDEN).

K. Vondrovec, Gesamtdarstellung und Auswertung der antiken Fundmünzen im Museum Carnuntinum, in: Alram 2007, 146-156.

J. S. Waldbaum, Metalwork from Sardis. The Finds through 1974, Archaeological Exploration of Sardis, Monograph 8 (Cambridge 1983).

O. Waldhauer, Die antiken Skulpturen der Ermitage III. Archäologische Mitteilungen aus russischen Sammlungen 5 (Berlin 1936).

A. Waldner - U. Quatember - M. Aurenhammer - M. Pfisterer, Die Grabung 2005 beim Nymphaeum Traiani in Ephesos, ÖJh 77, 2008, 265-334.

A. WaldNER, Keramische Evidenzen zur Baugeschichte des unteren Embolos von Ephesos (ungedr. Diss. Universität Wien 2009).

A. Waldner, Keramik/Kap. XV.1-2.4, in: WALDNER - LadSTÄtter 2014a, 435-460.

A. Waldner, XII Keramik, in E. Rathmayr (Hrsg.), Das Hanghaus 2 in Ephesos. Die Wohneinheit 7. Baubefund, Ausstattung, Funde, FiE 8/10 (Wien 2016) 311-424.

A. WALDNER - S. LADSTÄTter, Keramik, in: ThÜR - RATHMAYR 2014a, 435-588.

A. WALDNER - S. LADSTÄTter, Ephesus - local vs import: The Early Byzantine fine ware, in: H. Meyza (Hrsg.), Late Hellenistic to mediaeval fine wares of the Aegean coast of Anatolia (Warschau 2014) 49-58.

M. Wegner, Bildnisbüsten im 3. Jh. n. Chr., in: H. Keller - J. Kleine (Hrsg.), Festschrift G. Kleiner (Tübingen 1976) 105-132.

K. WelCH, Greek Stadia and Roman Spectacles: Asia, Athens and the Tomb of Herodes Atticus, JRA 11, 1998, 117-145.

K. WelCH, The Roman Amphitheatre (Cambridge 2009).

G. WipLINGER, Stand der Erforschung der Wasserversorgung in Ephesos / Türkei, in: FronTINUS-TAGUNGEN 2006, 15-48.

G. WiPLINGER, Wasser für Ephesos. Stand der Erforschung der Wasserversorgung, in: WiPLINGER 2006c, 23-37.

G. WiPlinger (Hrsg.), Cura Aquarum in Ephesus. Proceedings of the Twelfth International Congress on the History of Water Management and Hydraulic Engineering in the Mediterra- 
WIPLINGER - WLACH 1996 WitULSKI 2011

Wood 1877

WoYTeK 2010

WREDE 1972

WREDE 1985

WREDE 1987

YAVUZ u. a. 2011

ZANKER 1995

ZÜLKADIROĞLU - İÇTEN 2002

ZeLLe 1997

ZIEBART 1902

ZIEGLER 1992 nean Region, Ephesus/Selcuk, Turkey, October 2-10, 2004, 1, 2006, BABesch Suppl. 12 (= SoSchrÖAI 42) (Leuven 2006).

G. WiPLINGER - G. Wlach, Ephesos. 100 Jahre österreichische Forschungen (Wien 1996).

T. WitUlsKI, Kaiserkult in Kleinasien. Die Entwicklung der kultisch-religiösen Kaiserverehrung in der römischen Provinz Asia von Augustus bis Antoninus Pius ${ }^{2}$ (Göttingen 2011).

J. T. Wood, Discoveries at Ephesus (London 1877).

B. WoyteK, Die Cistophore der Kaiser Nerva und Traian (mit einem systematischen Anhang zu typologisch verwandtem Provinzialsilber), SchwNumRu 89, 2010, 69-144.

H. WREDE, Die spätantike Hermengalerie von Welschbillig, Römisch-Germanische Forschungen 32 (Berlin 1972).

H. WredE, Die antike Herme, Trierer Beiträge zur Altertumskunde 1 (Mainz 1985).

H. Wrede, Die spätantike Herme, JbAC 30, 1987, 118-148.

A. B. Yavuz - M. Bruno - D. Attanasio, An Updated, Multi-Method Database of Ephesos Marbles, Including White Greco Scritto and Bigio Varieties, Archaeometry 53, 2, 2011, 215-240.

P. ZANKER, Die Maske des Sokrates (München 1995).

A. ZÜLKADíRoĞLU - C. İçten, Gladiatorenreliefs in der Ausstellung, in: Gladiatoren IN EpheSOS, 75-82.

M. ZelLe, Die Terra Sigillata aus der Westtor-Nekropole in Assos, AMS 27 (Münster 1997).

E. ZiebART, Cyriacus von Ancona als Begründer der Inschriftenforschung, Neue Jahrbücher für das klassische Altertum, Geschichte und deutsche Literatur 5, 1902, 214-226.

R. ZIEGLER, Methodische Überlegungen zur Rekonstruktion von Nominalsystemen der städtischen Aes-Prägung im Osten des römischen Reiches, Litterae Numismaticae Vindobonenses 4, 1992, 189-213.

\section{Terminologie}

Die Bauteile des Theaters werden mit den in der wissenschaftlichen Literatur etablierten und üblichen Fachtermini bezeichnet ${ }^{1}$. Im Kontext der vorliegenden Forschung zusätzlich aufgetretene, seltene architektonische Begriffe wurden von H. Taeuber und T. Hobel in einem knappen gesonderten Glossar am Ende dieses Abschnitts zusammengestellt.

Für den Zuschauerraum wird die Anwendung der Termini mit dem Ziel einer klaren Beschreibung und chronologischen Unterscheidung des Befunds zwischen den beiden Hauptbauphasen differenziert. Das heißt, dass die Elemente des hellenistischen Theaters mit den für den griechischen Theatertypus gültigen Begriffen angesprochen werden, während für die Bennung der im Zuge des kaiserzeitlichen Um- und Ausbaus hinzugefügten Bauteile Termini des römischen Theatertypus verwendet werden. So bezeichnet beispielsweise Koilon den hellenistischen und Cavea den römischen Zuschauerraum, wohingegen Auditorium als allgemeiner Begriff für den Zuschauerraum fungiert.

Obwohl für das römische Theater grundsätzlich die Verwendung von griechischen Termini bei der Bezeichnung von Bauteilen nicht üblich ist, kommen im Zusammenhang mit der römischen Bühne basierend auf der Erstpublikation ${ }^{2}$ und bedingt durch die trotz der kaiserzeitlichen Umbauten erhalten gebliebenen hellenistischen Bühnenelemente auch weiterhin griechische Begriffe zur Anwendung?3. Dabei werden die Begriffe Skene, Bühnengebäude und Bühnenhaus synonym verwendet werden.

Die systematische Erfassung der einzelnen Bauteile erfolgt mittels spezifisch für das ephesische Theater gewählten Kurzbezeichnungen (z. B. EN1, EN2, EO1, ES1 etc. für die Zugänge), welche überblicksartig in den Tafeln 2 und 3 sowie im Plan 18 verzeichnet sind und die in Bezug auf das Bühnenhaus, die römische Bühne und die Orchestra auf die Erstpublikation ${ }^{4}$ zurückgehen. Folgende Ergänzungen wurden vorgenommen: Für die Räume des hellenistischen Obergeschosses wurde die Buchstabenbezeichnung des Untergeschosses übernommen, aber jeweils ein »'« nachgestellt. Die übrigen Räume des Obergeschosses werden als Raum 1, Raum 2, Raum 3 angesprochen.

Der Buchstabe H steht in der Erstpublikation für den gesamten kaiserzeitlichen Bühnenbereich ${ }^{5}$. Das wurde jetzt dahingehend modifiziert, dass $\mathrm{H}$ die eigentliche Bühnenfront bezeichnet, der Buchstabe $\mathrm{H}$ ergänzt um ein Numeral benennt die Pfeilerstellung an der Rückseite der Bühnenfront (H3-H11). Die Säulen, die die Bühnen tragen, nehmen die Bezeichnung der Pfeiler auf, werden aber zusätzlich durch ein W (West) oder O (Ost) in ihrer Reihe verortet. Die Nummerierung erfolgt immer von Nord nach Süd.

\footnotetext{
${ }^{1}$ Vgl. z. B. Ciancio Rossetto - Pisani Sartorio 1994, Bd. 1, 134-137.

${ }^{2}$ Heberdey u. a. 1912.

${ }^{3} \mathrm{Vgl}$. auch ÖZTÜRK 2006b, $205 \mathrm{f}$.

${ }^{4}$ HeBerdey u. a. 1912.

${ }^{5}$ Heberdey u. a. 1912.
} 
Der Profilring in der Orchestra trägt nun den Buchstaben J (Profilring J), die Orchestrawand erhielt die Kennzeichnung X (Orchestrawand X). Eine Signatur für den hellenistischen Orchestrakanal wurde nicht vergeben (Plan 18).

Die Bezeichnung der Sektoren im Auditorium richtet sich nach dem jeweiligen Rang, wobei die Zählung wieder im Norden beginnt. Bei der Nummerierung wurden auch nicht mehr existierende Sitzbereiche berücksichtigt. Demnach ergibt sich aktuell folgender Bestand: in der ima cavea I1-I11, in der media cavea M4-M20 sowie in der summa cavea S6-S19.

Die Bezeichnung der Radialtreppen T1-T23 bleibt für alle drei Ränge gleich. Da nur jede zweite Treppe von der Orchestra bis zum oberen Diazoma verläuft, befinden sich im unteren Rang nur Treppen mit ungerader Nummerierung.

Für die baulichen Einrichtungen im Theater wurden im Text und in den Plänen folgende Kurzbezeichnungen verwendet:

$\mathrm{KN}=$ Kammer Nord

$\mathrm{KS}=$ Kammer Süd

$\mathrm{SK}=$ Substruktionskammer

$\mathrm{RN}=$ Räume nördlich des Bühnengebäudes

RS = Räume südlich des Bühnengebäudes

$\mathrm{PT}=$ Portikustreppe

$\mathrm{BR}=$ Brunnen

MA1 = Rückwand der porticus in summa cavea

Die in Klammern gesetzten Buchstaben geben die in der Erstpublikation verwendeten Bezeichnungen für den Zuschauerraum $\mathrm{an}^{6}$. Kursiv und in Klammern gesetzte Angaben unterhalb einer Bezeichnung sind ein Hinweis zur Lage, falls diese in der Grundrissdarstellung nicht eindeutig zu erkennen ist.

Die Treppe südlich des Theaters wird als Stiegengasse bezeichnet. Ihre beiden Abschnitte werden als Treppe-West und TreppeOst angesprochen. Die Bezeichnungen ES1 bis ES3 umfassen sowohl die Eingänge zum Theater als auch die davor befindlichen Zugangspodeste. Die Nummerierung der Treppe wurde von West nach Ost vorgenommen; die Zählung der Stufensteine, einschließlich der Fehlstellungen, erfolgte von Nord nach Süd.

Die antiken Straßennamen sind weitgehend unbekannt. Daher werden für die in unmittelbarerer Nähe zum Theater verlaufenden Straßen moderne Bezeichnungen verwendet: Marmorstraße, Akademiegasse, Badgasse. Die einzige Ausnahme bildet die Kuretenstraße, deren antike Bezeichnung durch Schriftquellen bekannt ist und wohl Embolos lautete. Aufgrund der allgemeinen Bekanntheit der modernen Straßenbezeichnungen werden diese anstelle eines mit neutraler Nummerierung versehenen Straßensystems verwendet.

M. HOFBAUER

A. ÖZTÜRK

G. STYHLER-AYDIN

\section{Glossar ausgewählter architektonischer Begriffe}

Die hinter den Termini angefügten Nummern beziehen sich auf die im Kap 8.6.1 (Appendix 1 Altbestand der Bauinschriften aus dem Theater) verwendete Nummerierung der Inschriften.

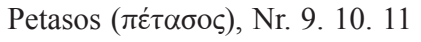

Podoma ( $(\pi \delta \delta \omega \mu \alpha)$, Nr. 9

Psalis ( $\left.\psi \alpha \lambda i \varsigma_{\varsigma}\right)$, Nr. 1.5

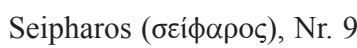

Ein Schutzdach (über dem Logeion?)

Belege: CIG 3422 = IGR IV 1632; CIG 4283 = IGR III 664 = TAM II 408; CIG 3428 = IGR IV 1645; IvE 2039; IvE 2040; IvE 2041; SEG XI 464; SEG XI 851; SEG XXXV 705; SEG XLIII 1328.

Orchestrawand? (nach CSAPO - SLATER 1994, 51).

Belege: IGR III 714; IvE 2039; Gerasa 51.

Überwölbter Gang unter den Sitzreihen des Theaters.

Belege: MAMA VIII 435 = CIG 2755 + 2808 + ADD. II 1109; IvE 2033; SEG II 582; I.DéLos 2229; I.DÉlos 2055; I.DÉlos 2056; TAM III 438. 750; TAM III 590.

Sonnensegel

Belege: IvE 2039; IGLSYr 6, 2979.
H. TAEUBER

T. HoBeL

\footnotetext{
${ }^{6}$ Heberdey u. a. 1912.
} 


\section{Abkürzungen}

Folgende Abkürzungen werden verwendet:

$\begin{array}{llll}\text { [A]: } & \text { archäologischer Befund } & \text { GK: } & \text { Gebrauchskeramik } \\ \text { [B]: } & \text { bauhistorische Analyse } & \text { GWSÜ: } & \text { Graue Ware mit schwarzem Überzug } \\ \text { [E]: } & \text { epigrafischer Befund } & \text { H.: } & \text { Hälfte } \\ \text { ARS: } & \text { African Red Slip Ware } & \text { ITS: } & \text { italische Sigillata } \\ \text { Bdm: } & \text { Bodendurchmesser } & \text { KDm: } & \text { Körperdurchmesser } \\ \text { Bh: } & \text { Buchstabenhöhe } & \text { KW: } & \text { Küchenware } \\ \text { Dm: } & \text { Durchmesser } & \text { LRC: } & \text { Late Roman C } \\ \text { DWK: } & \text { Dünnwandige Keramik } & \text { NS: } & \text { Nebenseite(n) } \\ \text { erh. L: } & \text { erhaltene Länge } & \text { OK: } & \text { Oberkante } \\ \text { erh. B: } & \text { erhaltene Breite } & \text { OS: } & \text { Oberseite } \\ \text { erh. H: } & \text { erhaltene Höhe } & \text { Rdm: } & \text { Randdurchmesser } \\ \text { Erh.: } & \text { erhalten/Erhaltungszustand } & \text { ROW: } & \text { Red-on-White } \\ \text { ERSW: } & \text { Ephesian Red Slip Ware } & \text { RS: } & \text { Rückseite } \\ \text { ESA: } & \text { Eastern Sigillata A } & \text { RSW: } & \text { Red Slip Ware } \\ \text { ESB: } & \text { Eastern Sigillata B } & \text { T: } & \text { absolute Höhe (bezogen auf den Meeresspiegel) } \\ \text { ESC: } & \text { Eastern Sigillata C } & \text { TRL: } & \text { Tonrohrleitung } \\ \text { ETH: } & \text { Ephesos Theater } & \text { UK: } & \text { Unterkante } \\ \text { Frgt: } & \text { Fragment } & \text { US: } & \text { Unterseite } \\ \text { GHD: } & \text { Grabungshaus-Depot } & \text { VS: } & \text { Vorderseite }\end{array}$

\section{Tafelverzeichnis und Abbildungsnachweis}

\section{Tafeln}

Abb. 1:

Abb. 2:

Abb. 3:

Abb. 4-6:

Abb. 7:

Abb. 8:

Abb. 9:

Abb. 10:

Abb. 11:

Abb. 12:

Abb. 13:

Abb. 14:

Abb. 15:

Abb. 16:

Abb. 17:

Abb. 18:

Abb. 19:

Abb. 20:

Abb. 21:

Abb. 22:

Abb. 23:

Abb. 24:

Abb. 25:

Abb. 26:

Abb. 27-29:

Abb. 30. 31:

Abb. 32:

Abb. 33:

Abb. 34-44:

Abb. 45:
M. Hofbauer; Grundlage: Digitaler Stadtplan Ephesos, ÖAI

Zeichnung G. Styhler-Aydın, TU-Wien

Zeichnung M. Hofbauer, ÖAI

Fotoarchiv, ÖAI Wien

ÖAI Wien, Bildarchiv, Inventar-Nr. K II 260 Neg 419, 21

Postkarte ohne Datierung, Privatbesitz

The Gertrude Bell Archive, Newcastle University, A_012-Dez-1899

Archivaufnahme des Archäologischen Museums in İzmir, Ordner datiert mit 1954

ÖAI Wien, Bildarchiv, Inventar-Nr. K II 258 FoN 1959

De Bernardi Ferrero 1970, 59 Abb. 61

De Bernardi Ferrero 1970, 49 Abb. 38

Fotoarchiv, ÖAI Wien, ohne Inventar-Nr.

Fotoarchiv, ÖAI Wien, ohne Inventar-Nr.

Foto A. Öztürk

Heberdey u. a. 1912, Abb. 5

HeBerdeY u. a. 1912, Abb. 30

M. Hofbauer, ÖAI

HeBerdey u. a. 1912, Abb. 57

HeBerdeY u. a. 1912, Abb. 6

G. Styhler-Aydın, TU Wien

G. Styhler-Aydın, TU Wien

H. A. Liebich, G. Styhler-Aydın, TU Wien

G. Styhler-Aydın, TU Wien

ÖAI Wien, Bildarchiv, Inventar-Nr. ETH98_10-36

M. Hofbauer, ÖAI

Aufnahme und Umzeichnung: M. Hofbauer, ÖAI

M. Hofbauer, ÖAI

Aufnahme und Umzeichnung: M. Hofbauer, ÖAI

M. Hofbauer, ÖAI

Aufnahme und Umzeichnung: M. Hofbauer, ÖAI 
Abb. 46:

Abb. 47:

Abb. 48-54:

Abb. 55:

Abb. 56-62:

Abb. 63:

Abb. 64-104:

Abb. 105-106:

Abb. 107:

Abb. 108:

Abb. 109-112:

Abb. 113:

Abb. 114-122:

Abb. 123-126:

Abb. 127-142:

Abb. 143:

Abb. 144:

Abb. 145:

Abb. 146-152:

Abb. 153-154:

Abb. 155:

Abb. 156:

Abb. 157:

Abb. 158:

Abb. 159:

Abb. 160:

Abb. 161:

Abb. 162:

Abb. 163:

Abb. 164-168:

Abb. 169:

Abb. 170:

Abb. 171:

Abb. 172-173:

Abb. 174:

Abb. 175-180:

Abb. 181-182:

Abb. 183-184:

Abb. 185-188:

Abb. 189-193:

Abb. 194:

Abb. 195-196:

Abb. 197:

Abb. 198-208:

Abb. 209:

Abb. 210:

Abb. 211-213:

Abb. 214-223:

Abb. 224:

Abb. 225-230:

Abb. 231-232:

Abb. 233-236:

Abb. 237:

Abb. 238:

Abb. 239:

Abb. 240:

Abb. 241-248:

Abb. 249-250:

Abb. 251-261:

Abb. 262:

Abb. 263-269:
Aufnahme: E. Budak, G. A. Arapoğlu; Umzeichnung: E. Profant, ÖAI

Aufnahme und Umzeichnung: M. Hofbauer, ÖAI

M. Hofbauer, ÖAI

Aufnahme und Umzeichnung: M. Hofbauer, ÖAI

M. Hofbauer, ÖAI

S. Swientek, ÖAI

M. Hofbauer, ÖAI

A. Sulzgruber, ÖAI

M. Hofbauer, ÖAI

Aufnahme und Umzeichnung: M. Hofbauer, ÖAI

M. Hofbauer, ÖAI

Archiv, ÖAI

M. Hofbauer, ÖAI

A. Sulzgruber, ÖAI

M. Hofbauer, ÖAI

Aufnahme: E. Budak, M. Skoric; Umzeichnung: M. Hofbauer, ÖAI

Aufnahme: S. Yıldırım; Umzeichnung: E. Profant, ÖAI

Aufnahme: E. Budak; Umzeichnung: E. Profant, ÖAI

M. Hofbauer, ÖAI

M. Hofbauer, ÖAI

HEBERDEY u. a. 1912, Abb. 38

Heberdey u. a. 1912, Abb. 39

HEBerdey u. a. 1912, Abb. 40

Aufnahme: I. Çokuğraş; Umzeichnung: M. Hofbauer, ÖAI

HeBerdey u. a. 1912, Abb. 46

Heberdey u. a. 1912, Abb. 47

Heberdey u. a. 1912, Abb. 49

Archiv, ÖAI

M. Hofbauer, ÖAI

A. Sulzgruber, ÖAI

M. Hofbauer, ÖAI

A. Sulzgruber, ÖAI

M. Hofbauer, ÖAI

Aufnahme: S. Swientek; Umzeichnung: M. Hofbauer, ÖAI

Heberdey u. a. 1912, Abb. 21

M. Hofbauer, ÖAI

Aufnahme und Umzeichnung: M. Hofbauer, ÖAI

M. Hofbauer, ÖAI

Aufnahme: M. Hofbauer; Umzeichnung: E. Profant, ÖAI

M. Hofbauer, ÖAI

Aufnahme: J. Reuckl; Umzeichnung: E. Profant, ÖAI

M. Hofbauer, ÖAI

Aufnahme: S. Swientek; Umzeichnung: E. Profant, ÖAI

M. Hofbauer, ÖAI

M. Hofbauer, ÖAW

Aufnahme: M. Grebien, B. Öhlinger; Umzeichnung: E. Profant, ÖAW

Aufnahme: B. Öhlinger; Umzeichnung: E. Profant, ÖAW

M. Hofbauer, ÖAW

M. Grebien, ÖAW

M. Hofbauer, ÖAW

Aufnahme: K. Preindl, N. Reitinger; Umzeichnung: E. Profant, ÖAW

M. Hofbauer, ÖAW

Aufnahme: R. Yazici; Umzeichnung: E. Profant, ÖAW

B. Öhlinger, ÖAW

M. Hofbauer, ÖAW

B. Öhlinger, ÖAW

M. Hofbauer, ÖAW

E. Tekin

Grabungsdokumentation St. Karwiese, ÖAI

M. Hofbauer, ÖAW

Grabungsdokumentation St. Karwiese, ÖAI 
Abb. 270:

Abb. 271:

Abb. 272:

Abb. 273:

Abb. 274:

Abb. 275:

Abb. 276:

Abb. 277:

Abb. 278-280:

Abb. 281:

Abb. 282-289:

Abb. 290-292:

Abb. 293:

Abb. 294:

Abb. 295-298:

Abb. 299-300:

Abb. 301-304:

Abb. 305-308:

Abb. 309-313:

Abb. 314-316:

Abb. 317-325:

Abb. 326:

Abb. 327:

Abb. 328:

Abb. 329:

Abb. 330-339:

Abb. 340:

Abb. 341:

Abb. 342-360:

Abb. 361:

Abb. 362-363:

Abb. 364-365:

Abb. 366:

Abb. 367-373:

Abb. 374-375:

Abb. 376-378:

Abb. 379-382:

Abb. 383-385:

Abb. 386-392:

Abb. 393:

Abb. 394:

Abb. 395-401:

Abb. 402-483:

Abb. 484:

Abb. 485-506:

Abb. 507:

Abb. 508:

Abb. 509:

Abb. 510-517:

Abb. 518:

Abb. 519-539:

Abb. 540:

Abb. 541-558:

Abb. 559:

Abb. 560-583:

Abb. 584-586:

Abb. 587-594:

Abb. 595:

Abb. 596:

Abb. 597:

Abb. 598:
M. Hofbauer, ÖAW

Grabungsdokumentation St. Karwiese, ÖAI

M. Hofbauer, ÖAW

Grabungsdokumentation St. Karwiese, ÖAI

G. Styhler-Aydin, TU-Wien

Grabungsdokumentation St. Karwiese; Umzeichnung: M. Hofbauer, ÖAI

Grabungsdokumentation St. Karwiese, ÖAI

M. Hofbauer, ÖAW

Grabungsdokumentation St. Karwiese, ÖAI

Grabungsdokumentation St. Karwiese; Umzeichnung: E. Profant, ÖAI

Grabungsdokumentation St. Karwiese, ÖAI

M. Hofbauer, ÖAW

Grabungsdokumentation St. Karwiese; Umzeichnung: M. Hofbauer, ÖAI

M. Hofbauer, ÖAW

Grabungsdokumentation St. Karwiese, ÖAI

M. Hofbauer, ÖAW

Grabungsdokumentation St. Karwiese, ÖAI

M. Hofbauer, ÖAW

M. Hofbauer, ÖAI

J. Reuckl, ÖAI

M. Hofbauer, ÖAI

Aufnahme: M. Hofbauer, J. Reuckl; Umzeichnung: M. Hofbauer, E. Profant, ÖAI

Aufnahme: J. Reuckl; Umzeichnung: E. Profant, ÖAI

Aufnahme: S. Swientek; Umzeichnung: M. Hofbauer, ÖAI

M. Hofbauer, ÖAW

M. Hofbauer, ÖAW

Aufnahme: E. Budak, U. Hermann, M. Hofbauer; Umzeichnung: M. Hofbauer, E. Profant, ÖAW

Aufnahme und Umzeichnung: M. Hofbauer, ÖAW

M. Hofbauer, ÖAW

Aufnahme: U. Reiterer; Umzeichnung: E. Profant, ÖAW

Aufnahme: U. Reiterer; Umzeichnung: M. Hofbauer, ÖAW

M. Hofbauer, ÖAW

Aufnahme: J. Reuckl; Umzeichnung: M. Hofbauer, ÖAW

M. Hofbauer, ÖAW

Aufnahme: J. Reuckl; Umzeichnung: M. Hofbauer, ÖAW

M. Hofbauer, ÖAW

Grabungsdokumentation St. Karwiese, ÖAI

M. Hofbauer, ÖAW

Grabungsdokumentation St. Karwiese, ÖAI

Grabungsdokumentation St. Karwiese; Umzeichnung: E. Profant, ÖAI

M. Hofbauer, ÖAW

Grabungsdokumentation St. Karwiese, ÖAI

M. Hofbauer, ÖAW

Fotos, Entzerrung, Montage und Umzeichnung: M. Hofbauer, ÖAW

M. Hofbauer, ÖAW

M. Grebien, ÖAW

M. Hofbauer, ÖAW

Aufnahme: R. Yazici; Umzeichnung: E. Profant, ÖAW

M. Hofbauer, ÖAW

Aufnahme: M. Grebien; Umzeichnung: E. Profant, ÖAW

M. Hofbauer, ÖAW

Fotos, Entzerrung, Montage und Umzeichnung: M. Hofbauer, ÖAW

M. Hofbauer, ÖAW

Zeichnung, Fotos, Entzerrung, Montage und Umzeichnung: M. Hofbauer, ÖAW

M. Hofbauer, ÖAW

N. Gail, ÖAW

M. Hofbauer, ÖAW

digitale Bearbeitung M. Tschannerl, ÖAW

ÖAW IMG_1630 u. ÖAW IMG_1632, 24.08.2009, digitale Bearbeitung M. Tschannerl

ÖAW IMG_1622 u. ÖAW IMG_1623, 24.08.2009, digitale Bearbeitung M. Tschannerl

ÖAW IMG_1634, 24.08.2009 u. ÖAW IMG_1649, 03.08.2009, digitale Bearbeitung M. Tschannerl 
Abb. 599:

Abb. 600:

Abb. 601:

Abb. 602:

Abb. 603:

Abb. 604:

Abb. 605:

Abb. 606:

Abb. 607:

Abb. 608:

Abb. 609:

Abb. 610:

Abb. 611:

Taf. 302-344:

Taf. 345-354:

Taf. 355:

Taf. 356:

Taf. 357:

Taf. 358:
ÖAW IMG_1622 u. ÖAW IMG_1608, 24.08.2009, digitale Bearbeitung M. Tschannerl

ÖAW IMG_1620, 24.08.2009, digitale Bearbeitung M. Tschannerl

ÖAW IMG_1573, 11.08.2009

ÖAW IMG $1574,11.08 .2009$

ÖAW IMG ${ }^{-}$1584, 17.08.2009

ÖAW IMG 1613, 24.08.2009

ÖAW IMG $1586,17.08 .2009$

ÖAW IMG_1596, 18.08.2009

ÖAW IMG 1572, 11.08.2009

Zeichnung erstellt v. M. Grebien, digitale Umzeichnung M. Tschannerl, ÖAW

ÖAW IMG_1598, 20.08.2009, digitale Bearbeitung M. Tschannerl

Zeichnung erstellt v. M. Grebien, digitale Umzeichnung M. Tschannerl

ÖAW IMG_1642, 24.08.2009

J. Struber, A. Waldner, ÖAW; Digitalisierung: J. Struber (K 1-K 378)

Fotos: N. Gail, ÖAI Wien mit Ausnahme von Abb. 655, K 37 (M. Gessl); Abb. 655, K 106 (A. Waldner); Abb. 662, K 280 (J. Struber); Abb. 664, K 338 (J. Struber)

M 1, IMG 6861 und IMG 6861, M. Pfisterer, KHM; M 2, Ephesos 2007/Münzen/Etütlük/Museum/053 und 054, N. Gail, ÖAI Wien; M 3, Ephesos 2008/Münzen/Depot-GH/477 und 478, N. Gail, ÖAI Wien; M 4, Ephesos $2007 /$ Münzen/Envanterlik/Museum/021 und 022, N. Gail, ÖAI Wien; M 10, Ephesos 2009/Münzen/Envanterlik/099 und 100, N. Gail, ÖAI Wien; M 13 IMG_0806 und IMG_0901, M. Pfisterer, KHM; M 19, Ephesos 2009/Münzen/ Envanterlik/095 und 096, N. Gail, ÖAI Wien; M 24: Ephesos 2010/Münzen/Theater/043 und 044, N. Gail, ÖAI Wien; M 25, Ephesos 2010/Münzen/Theater/045 und 046, N. Gail, ÖAI Wien; M 26, Ephesos 2010/Münzen/ Theater/057 und 058, N. Gail, ÖAI Wien; M 27, Ephesos 2010/Münzen/Theater/041 und 042, N. Gail, ÖAI Wien; M 28, Ephesos 2010/Münzen/Theater/039 und 040, N. Gail, ÖAI Wien; M 29, Ephesos 2010/Münzen/Theater/047 und 048, N. Gail, ÖAI Wien; M 30, Ephesos 2010/Münzen/Theater/049 und 050, N. Gail, ÖAI Wien; M 31, Ephesos 2010/Münzen/Theater/051 und 052, N. Gail, ÖAI Wien; M 32, Ephesos 2010/Münzen/Theater/015 und 016, N. Gail, ÖAI Wien; M 33; Ephesos 2010/Münzen/Theater/017 und 018, N. Gail, ÖAI Wien

M 34, Ephesos 2009/Münzen/Etütlük/1155 und 1156, N. Gail, ÖAI Wien; M 35, Ephesos 2009/Münzen/Etütlük/1161 und 1162, N. Gail, ÖAI Wien; M 36, IMG_2999 und IMG_3000, M. Pfisterer, KHM; M 37, Ephesos 2007/Münzen/Etütlük/Museum/079 und 080, N. Gail, ÖAI Wien; M 38, Ephesos 2007/Münzen/Envanterlik/Museum/109 und 110, N. Gail, ÖAI Wien; M 39, Ephesos 2010/Münzen/Theater/167 und 168, N. Gail, ÖAI Wien; M 41, Ephesos 2010/Münzen/Theater/037 und 038, N. Gail, ÖAI Wien; M 42, Ephesos 2009/Münzen/Envanterlik/097 und 098, N. Gail, ÖAI Wien; M 43, IMG_0812 und 0909, M. Pfisterer, KHM; M 44, PA051270 und PA051271, M. Pfisterer, KHM; M 45, Ephesos 2007/Münzen/Etütlük/Museum/051 und 052, N. Gail, ÖAI Wien; M 46, Ephesos 2010/Münzen/Theater/023 und 024, N. Gail, ÖAI Wien; M 50, IMG_2994 und IMG_2995, M. Pfisterer, KHM; M 52, Ephesos 2007/Münzen/Etütlük/Museum/085 und 086, N. Gail, ÖAI Wien; M 54, Ephesos 2007/Münzen/Envanterlik/Museum/107 und 108, N. Gail, ÖAI Wien; M 56, Ephesos 2007/Münzen/Envanterlik/ Museum/031 und 032, N. Gail, ÖAI Wien; M 57, Ephesos 2007/Münzen/Envanterlik/Museum/073 und 074, N. Gail, ÖAI Wien; M 58, Ephesos 2007/Münzen/Envanterlik/Museum/033 und 034, N. Gail, ÖAI Wien; M 59, Ephesos 2010/Münzen/Theater/159 und 160, N. Gail, ÖAI Wien

M 60, Ephesos 2008/Münzen/Etütlük/277 und 278, N. Gail, ÖAI Wien; M 61, IMG_0815 und IMG_912, M. Pfisterer, KHM; M 62, Ephesos 2009/Münzen/Envanterlik/087 und 088, N. Gail, ÖĀI Wien; M 63, Ephesos 2007/Münzen/Envanterlik/Museum/075 und 076, N. Gail, ÖAI Wien; M 64, Ephesos 2007/Münzen/Envanterlik/ Museum/105 und 106, N. Gail, ÖAI Wien; M 65, Ephesos 2010/Münzen/Theater/019 und 020, N. Gail, ÖAI Wien; M 66, Ephesos 2009/Münzen/Envanterlik/089 und 090, N. Gail, ÖAI Wien; M 67, Ephesos 2010/Münzen/ Theater/011 und 012, N. Gail, ÖAI Wien: M 68, Ephesos 2007/Münzen/Envanterlik/Museum/111 und 112, N. Gail, ÖAI Wien; M 69, Ephesos 2007/Münzen/Envanterlik/Museum/119 und 120, N. Gail, ÖAI Wien; M 70, Ephesos 2009/Münzen/Envanterlik/091 und 092, N. Gail, ÖAI Wien; M 71, Ephesos 2007/Münzen/Envanterlik/ Museum/017 und 018, N. Gail, ÖAI Wien; M 72, Ephesos 2007/Münzen/Envanterlik/Museum/121 und 122, N. Gail, ÖAI Wien; M 73, Ephesos 2007/Münzen/Envanterlik/Museum/027 und 028, N. Gail, ÖAI Wien; M 74, Ephesos 2007/Münzen/Etütlük/Museum/107 und 108, N. Gail, ÖAI Wien; M 79, Ephesos 2007/Münzen/Envanterlik/Museum/035 und 036, N. Gail, ÖAI Wien; M 80, Ephesos 2010/Münzen/Theater/061 und 062, N. Gail, ÖAI Wien; M 81, Ephesos 2008/Münzen/Depot-GH/475 und 476, N. Gail, ÖAI Wien

M 83, Ephesos 2007/Münzen/Envanterlik/Museum/103 und 104, N. Gail, ÖAI Wien; M 84, Ephesos 2008/Münzen/Etütlük/265 und 266, N. Gail, ÖAI Wien; M 85, Ephesos 2007/Münzen/Envanterlik/Museum/013 und 014, N. Gail, ÖAI Wien; M 87, Ephesos 2009/Münzen/Envanterlik/093 und 094, N. Gail, ÖAI Wien; M 88, Ephesos 2007/Münzen/Envanterlik/Museum/117 und 118, N. Gail, ÖAI Wien; M 90, Ephesos 2007/Münzen/Envanterlik/ Museum/019 und 020, N. Gail, ÖAI Wien; M 91, Ephesos 2010/Münzen/Theater/001 und 002, N. Gail, ÖAI Wien; M 92, Ephesos 2007/Münzen/Envanterlik/Museum/003 und 004, N. Gail, ÖAI Wien; M 93, Ephesos 2010/ Münzen/Theater/145 und 146, N. Gail, ÖAI Wien; M 107, Ephesos 2008/Münzen/Envanterlik/067 und 068, N. Gail, ÖAI Wien; M 111, Ephesos 2010/Münzen/Theater/013 und 014, N. Gail, ÖAI Wien; M 113, Ephesos 
Taf. 359:

Taf. 360:

Taf. 361-381: Abb. 612-732: Taf. 411-421: Abb. 733-744: Abb. 745: Abb. 746: Abb. 747-749: Abb. 750: Abb. 751: Abb. 752: Abb. 753: Abb. 754-759: Abb. 760: Abb. 761: Abb. 762: Abb. 763: Abb. 764: Abb. 765:

Abb. 766: Abb. 767: Abb. 768: Abb. 769:
2007/Münzen/Envanterlik/Museum/115 und 116, N. Gail, ÖAI Wien; M 118, Ephesos 2007/Münzen/Envanterlik/Museum/091 und 092, N. Gail, ÖAI Wien; M 119, Ephesos 2009/Münzen/Envanterlik/079 und 080, N. Gail, ÖAI Wien; M 125, IMG 3003 und IMG 3004, M. Pfisterer, KHM; M 126, Ephesos 2009/Münzen/Envanterlik/085 und 086, N. Gail, ÖAI Wien; M 127, Ephesos 2009/Münzen/Envanterlik/083 und 084, N. Gail, ÖAI Wien; M 128, IMG_0814 und IMG_0911, M. Pfisterer, KHM; M 136, Ehesos 2007/Münzen/Envanterlik/Museum/077 und 078, N. Gail, ÖAI Wien

M 137, IMG_2996 und IMG_2997, M. Pfisterer, KHM; M 140, Ephesos 2007/Münzen/Etütlük/Museum/093 und 094, N. Gail, ÖAI Wien; M 145, IMG 3011 und IMG 3012, M. Pfisterer, KHM; M 173, Ephesos 2007/Münzen/ Envanterlik/Museum/113 und 114, N. Gail, ÖAI Wien; M 176, Ephesos 2007/Münzen/Etütlük/Museum/129 und 130, N. Gail, ÖAI Wien; M 184, Ephesos 2010/Münzen/Theater/009 und 010, N. Gail, ÖAI Wien; M 185, Ephesos 2010/Münzen/Theater/119 und 120, N. Gail, ÖAI Wien; M 186, Ephesos 2007/Münzen/Envanterlik/Museum/057 und 058, N. Gail, ÖAI Wien; M 187, Ephesos 2007/Münzen/Envanterlik/Museum/085 und 086, N. Gail, ÖAI Wien; M 189, 2008/Münzen/Etütlük/273 und 274, N. Gail, ÖAI Wien; M 190, Ephesos 2007/Münzen/Envanterlik/Museum/123 und 124, N. Gail, ÖAI Wien; M 191, Ephesos 2007/Münzen/Envanterlik/Museum/083 und 084, N. Gail, ÖAI Wien; M 192, Ephesos 2007/Münzen/Envanterlik/Museum/053 und 054, N. Gail, ÖAI Wien; M 193, Ephesos 2009/Münzen/Envanterlik/081 und 082, N. Gail, ÖAI Wien; M 195, Ephesos 2007/Münzen/ Envanterlik/Museum/049 und 050, N. Gail, ÖAI Wien; M 196, Ephesos 2007/Münzen/Envanterlik/Museum/061 und 062, N. Gail, ÖAI Wien; M 200, Ephesos 2007/Münzen/Envanterlik/Museum/089 und 090, N. Gail, ÖAI Wien; M 201, Ephesos 2010/Münzen/Theater/067 und 068, N. Gail, ÖAI Wien; M 202, Ephesos 2007/Münzen/ Envanterlik/Museum/099 und 100, N. Gail, ÖAI Wien; M 203, Ephesos 2007/Münzen/Envanterlik/Museum/051 und 052, N. Gail, ÖAI Wien; M 210, Ephesos 2007/Münzen/Envanterlik/Museum/055 und 056, N. Gail, ÖAI) Wien; M 216, Ephesos 2007/Münzen/Envanterlik/Museum/097 und 098, N. Gail, ÖAI Wien; M 217, Ephesos 2007/Münzen/Etütlük/Museum/011 und 012, N. Gail, ÖAI Wien; M 221, Ephesos 2007/Münzen/Envanterlik/ Museum/087 und 088, N. Gail, ÖAI Wien; M 222, Ephesos 2007/Münzen/Envanterlik/Museum/043 und 044, N. Gail, ÖAI Wien; M 224, Ephesos 2007/Münzen/Envanterlik/Museum/011 und 012, N. Gail, ÖAI Wien; M 225, Ephesos 2007/Münzen/Envanterlik/Museum/047 und 048, N. Gail, ÖAI Wien; M 226, Ephesos 2007/Münzen/ Envanterlik/Museum/065 und 066, N. Gail, ÖAI Wien; M 230, Ephesos 2007/Münzen/Envanterlik/Museum/067 und 068, N. Gail, ÖAI Wien; M 235, Ephesos 2007/Münzen/Etütlük/Museum/019 und 020, N. Gail, ÖAI Wien; M 237, PA051277 und PA051278, M. Pfisterer, KHM; M 238, PA051273 und PA051274, M. Pfisterer, KHM; M 240: PA051283 und PA051284, M. Pfisterer, KHM; M 241, Ephesos 2010/Münzen/Theater/081 und 082, N. Gail, ÖAI Wien; M 242, Ephesos 2010/Münzen/Theater/149 und 150, N. Gail, ÖAI Wien

M 243, Ephesos 2010/Münzen/Theater/151 und 152, N. Gail, ÖAI Wien; M 244, Ephesos 2010/Münzen/Theater/065 und 066, N. Gail, ÖAI Wien; M 245, Ephesos 2010/Münzen/Theater/153 und 154, N. Gail, ÖAI Wien; M 246, Ephesos 2010/Münzen/Theater/147 und 148, N. Gail, ÖAI Wien; M 261, Ephesos 2010/Münzen/Theater/027 und 028, N. Gail, ÖAI Wien; M 263, Ephesos 2010/Münzen/Theater/085 und 086, N. Gail, ÖAI Wien; M 264, Ephesos 2010/Münzen/Theater/123 und 124, N. Gail, ÖAI Wien; M 265, Ephesos 2010/Münzen/Theater/105 und 106, N. Gail, ÖAI Wien; M 282, Ephesos 2008/Münzen/Envanterlik/069 und 070, N. Gail, ÖAI Wien; M 283, Ephesos 2008/Münzen/Envanterlik/071 und 072, N. Gail, ÖAI Wien

Fotos: N. Gail, ÖAI Wien; Zeichnungen: Y. Kara, ÖAI

N. Gail, ÖAI Wien

H. Taeuber, P. Sänger

A. Galik

M. Hofbauer, ÖAW

Fotos: N. Gail, M. Hofbauer; Vermessung: M. Hofbauer, Ch. Kurtze; Montage: M. Hofbauer, ÖAI

M. Hofbauer, ÖAI

A. Sulzgruber, ÖAI

Heberdey u. a. 1912, Abb. 8

HEBERDEY u. a. 1912, Abb. 31

HEBERDEY u. a. 1912, Abb. 56

M. Hofbauer, ÖAI

HeBERDEY u. a. 1912, 44, Abb. 86

I. Mayer, TU Wien, in Kooperation mit dem KHM

G. Styhler-Aydın, TU Wien

H. A. Liebich, TU Wien

C. Erlach, TU Wien

G. Styhler-Aydın, TU Wien (zu den MitarbeiterInnen während der Bauaufnahme sowie der digitalen Umzeichnung s. den Nachweis zu Plan 1)

I. Mayer, TU Wien

H. A. Liebich, TU Wien

G. Styhler-Aydın, TU Wien

G. Styhler-Aydın, TU Wien 
Abb. 770-780: A. Öztürk

Abb. 781:

Abb. 782:

Abb. 783:

Abb. 784:

Abb. 785:

Abb. 786-787:

A. Grünsteidl, TU Wien

G. Styhler-Aydın, TU Wien

Heberdey u. a. 1912, 7 Abb. 5

Heberdey u. a. 1912, 32 Abb. 57

M. Maringer, TU Wien

Abb. 788:

Abb. 789:

Abb. 790a:

Abb. 790b-794:

G. Styhler-Aydın, TU Wien

Abb. 795:

Abb. 796:

Abb. 797:

Abb. 798 rechts:

G. Styhler-Aydın, TU Wien (Analyse und grafische Bearbeitung); zu den MitarbeiterInnen während der Bauaufnahme sowie der digitalen Umzeichnung s. den Nachweis zu Plan 1

G. Styhler-Aydın, TU Wien

Heberdey u. a. 1912, 45 Abb. 93

Abb. 798 links:

G. Styhler-Aydın, TU Wien

V. Felber, TU Wien

S. Akyüz, TU Wien

G. Styhler-Aydın, TU Wien

Heberdey u. a. 1912, 114

Abb. 799: $\quad$ S. Akyüz, TU Wien

Abb. 800: $\quad$ I. Mayer, TU Wien

Abb. 801: $\quad$ G. Styhler-Aydın, TU Wien

Abb. 802: $\quad$ I. Mayer, TU Wien

Abb. 803:

Abb. 804-805:

Abb. 806:

Heberdey u. a. 1912, 160 Nr. 35

Abb. 807-809:

Abb. 810:

Abb. 811:

I. Mayer, TU Wien

A. Grünsteidl, TU Wien

G. Styhler-Aydın, TU Wien

A. Grünsteidl, TU Wien

Heberdey u. a. 1912, 128 Abb. 194

Abb. 812-816:

G. Styhler-Aydın, TU Wien

Abb. 817:

Abb. 818-819:

Heberdey u. a. 1912, 41 Abb. 77

Abb. 820:

G. Styhler-Aydın, TU Wien

Abb. 821:

Heberdey u. a. 1912, 161 Nr. 37

Abb. 822:

Heberdey u. a. 1912, 175

Abb. 823-825:

Abb. 826:

Abb. 827:

Abb. 828:

Abb. 829:

Abb. 830:

H. A. Liebich, TU Wien

G. Styhler-Aydın, TU Wien

H. A. Liebich, TU Wien

G. Styhler-Aydın, TU Wien

HeBERDEY u. a. 1912, 48 Abb. 96

Abb. 831-833:

Abb. 834:

M. Maringer, TU Wien

G. Styhler-Aydın, TU Wien

Abb. 835:

Abb. 836-838:

A. Grünsteidl, TU Wien

M. Maringer, TU Wien

G. Styhler-Aydın, TU Wien

Abb. 839:

Abb. 840:

A. Öztürk

M. Hofbauer, ÖAI

Abb. 841-845:

I. Mayer, TU Wien

Abb. 846:

G. Styhler-Aydın, TU Wien

Abb. 847:

A. Grünsteidl, TU Wien

I. Mayer, TU Wien 


\section{Textabbildungen}

Textabb. 1-3: Textabb. 4 Textabb. 5: Textabb. 6 Textabb. 7 Textabb. 8: Textabb. 9 Textabb. 10: Textabb. 11: Textabb. 12: Textabb. 13: Textabb. 14: Textabb. 15: Textabb. 16. 17: Textabb. 18: Textabb. 19:

Textabb. 20:

Textabb. 21:

\section{Pläne}

Plan 1:

Plan 2:

Plan 3:

Plan 4:

Plan 5:

Plan 6 oben:

Plan 6 unten:

Plan 7:

Plan 8:

Plan 9:

Plan 10:

Plan 11:

Plan 12:

Plan 13:

Plan 14:

Plan 15:

Plan 16:

Plan 17:

Plan 18:
M. Hofbauer, ÖAI

Pococke 1740 (1745), Taf. 49 zu S. 75

DE LABORDE 1838, 90 Taf. 43

FALKENER 1862

FALKENER 1862

FALKENER 1862

WoOD 1877, gegenüber S. 68

Heberdey u. a. 1912, 12 Abb. 15

HEBERDEY u. a. 1912, 50 Abb. 98

HEBERDEY u. a. 1912, 48 Abb. 96

Postkarte, vermutlich Anfang der 1980er Jahre, Privatbesitz

N. Gail, ÖAI Wien

A. Öztürk

G. Styhler-Aydın, TU Wien (grafische Bearbeitung); C. Walcher (Bauaufnahme); C. Erlach (digitale Umzeichnung) G. Styhler-Aydın, TU Wien

G. Styhler-Aydın, TU Wien (Analyse und grafische Bearbeitung); zu den MitarbeiterInnen während der Bauaufnahme sowie der digitalen Umzeichnung s. den Nachweis zu Plan 1

G. Styhler-Aydın, TU Wien (Grafik, Fotos); P. Mayrhofer (Bauaufnahme, Fotos); E. Budak (Bauaufnahme); J. Florianschütz (digitale Umzeichnung)

G. Styhler-Aydın, TU Wien

G. Styhler-Aydın, TU Wien (grafische Bearbeitung); S. Akyüz, G. A. Arapoğlu, O. Arisan, A. Aschauer, N. Bachofner, M. Berlinger, E. Budak, V. Capresi, M. Demirli, C. Erlach, V. Felber, A. Grünsteidl, U. Herrmann, M. Hofbauer, R. Kellner, E. Köse, H. A. Liebich, M. Maringer, I. Mayer, R. Ochsenfarth, A. Öztürk, G. StyhlerAydın, S. Swientek, B. Thuswaldner, G. Varinlioğlu, C. Walcher, A. Willmer, R. Yazıcı (Bauaufnahme); S. Akyüz, G. Alğok, E. S. Bellibaş, E. Demir, O. Dolman, J. Florianschütz, M. Hofbauer, B. Kepenek, M. Maringer, R. Ochsenfarth, S. Seidel, C. Şerbest, G. Styhler-Aydın, N. E. Tekin (digitale Umzeichnung)

Martin Hofbauer, ÖAI

G. Styhler-Aydın, TU Wien (grafische Bearbeitung); S. Akyüz, O. Arisan, M. Berlinger, C. Erlach, V. Felber, H.A. Liebich, M. Maringer, I. Mayer, G. Styhler-Aydın (Bauaufnahme); H. Schwaiger (Photogrammetrie); E. S. Bellibaş, E. Demir, U. Herrmann, B. Kepenek, M. Maringer, T. Schuöcker, G. Styhler-Aydın, N. E. Tekin (digitale Umzeichnung)

G. Styhler-Aydın, TU Wien (Analyse und grafische Bearbeitung); A. Grünsteidl, I. Mayer, C. Walcher (Bauaufnahme); C. Erlach, G. Styhler-Aydın (digitale Umzeichnung)

G. Styhler-Aydın, TU Wien (Analyse und grafische Bearbeitung); A. Grünsteidl, H. A. Liebich, I. Mayer (Bauaufnahme); J. Florianschütz (digitale Umzeichnung)

G. Styhler-Aydın, TU Wien (grafische Bearbeitung); I. Mayer, TU Wien (3D-Scan); G. A. Arapoğlu, E. Budak, M. Demirli, G. Styhler-Aydın, H. A. Liebich, E. Köse, A. Öztürk, G. Varinlioğlu (Bauaufnahme); E. S. Bellibaş, E. Demir, B. Kepenek, C. Şerbest, G. Styhler-Aydın, N. E. Tekin (digitale Umzeichnung)

N. E. Tekin, ÖAI und G. Styhler-Aydın, TU Wien (grafische Bearbeitung); G. A. Arapoğlu, O. Arisan, E. Budak, E. Demir, M. Demirli, E. Köse, A. Öztürk, G. Varinlioğlu, C. Walcher (Bauaufnahme); E. Demir, C. Erlach (digitale Umzeichnung)

G. Styhler-Aydın, TU Wien (Analyse und Grafik); S. Akyüz, M. Berlinger, C. Erlach, V. Felber, H. A. Liebich, M. Maringer, G. Styhler-Aydın (Bauaufnahme); M. Maringer, T. Schuöcker, G. Styhler-Aydın (digitale Umzeichnung) G. Styhler-Aydın, TU Wien (Analyse und grafische Bearbeitung); O. Arisan, M. Berlinger, C. Erlach, I. Mayer, G. Styhler-Aydın (Bauaufnahme); E. S. Bellibaș, M. Maringer, G. Styhler-Aydın (digitale Umzeichnung) Aufnahme: M. Hofbauer, Sebastian Swientek; Umzeichnung: M. Hofbauer, ÖAI

M. Hofbauer, ÖAI

Aufnahme: M. Hofbauer, U. Reiterer, J. Reuckl; Umzeichnung: M. Hofbauer ÖAW

Aufnahme: M. Gessl, M. Hofbauer, R. Yazici; Umzeichnung: E. Profant, ÖAW

Aufnahme: E. Budak, U. Hermann, M. Hofbauer; Umzeichnung: M. Hofbauer, E. Profant, ÖAW

Aufnahme: E. Budak, U. Hermann, M. Hofbauer; Umzeichnung: E. Profant, ÖAW

Fotos, Entzerrung, Montage und Umzeichnung: M. Hofbauer, ÖAW

Fotos, Entzerrung, Montage und Umzeichnung: M. Hofbauer, ÖAW

M. Hofbauer, ÖAW

Aufnahme: M. Hofbauer, H. Liebich; Umzeichnung: M. Hofbauer, ÖAI 


\section{Autorenverzeichnis}

Duygu Akar-Tanriver

Dokuz Eylül Üniversitesi

Edebiyat Fakültesi

Arkeoloji Bölümü

Tinaztepe Kampüsü

35160 Buca-Izmi

duygu.akar@deu.edu.tr

Maria Aurenhammer

Österreichisches Archäologisches Institut Österreichische Akademie der Wissenschaften

A-1190 Wien, Franz Klein-Gasse 1

Maria.Aurenhammer@oeaw.ac.at

Viktor Böhm

c/o Institut für Alte Geschichte und Altertumskunde,

Papyrologie und Epigraphik

Universität Wien

A-1010 Wien, Universitätsring 1

viktor.boehm@univie.ac.at

Gerhard Forstenpointner

Department für Pathobiologie

Veterinärmedizinische Universität Wien

A-1210 Wien, Veterinärplatz 1

Gerhard.Forstenpointner@vetmeduni.ac.at

Alfred Galik

Österreichisches Archäologisches Institut

Österreichische Akademie der Wissenschaften

A-1090 Wien, Franz Klein-Gasse 1

Alfred.Galik@oeaw.ac.at

Martin Hofbauer

3002 Purkersdorf, Waldgasse 13/1

martin-hofbauer@gmx.at

Tina Hobel

c/o Institut für Alte Geschichte und Altertumskunde,

Papyrologie und Epigraphik

Universität Wien

A-1010 Wien, Universitätsring 1

tina.hobel@univie.ac.at

\section{Birgit Öhlinger}

Institut für Archäologien

Fachbereich Klassische Archäologie

und Provinzialrömische Archäologie

Universität Innsbruck

A-6020 Innsbruck, Langer Weg 11

Birgit.Oehlinger@uibk.ac.at

Arzu Öztürk (†)

Mimar Sinan Güzel Sanatlar Üniversitesi

Fen Edebiyat Fakultesi

Arkeoloji Bölümü

Bomonti-Sişli - Istanbul,

Cumhuriyet Mah. Silahşör Cad. Nr. 71
Andrea M. Pülz

Österreichisches Archäologisches Institut

Österreichische Akademie der Wissenschaften

A-1190 Wien, Franz Klein-Gasse 1

Andrea.Puelz@oeaw.ac.at

Elisabeth Rathmayr

Institut für Kulturgeschichte der Antike

Österreichische Akademie der Wissenschaften

A-1020 Wien, Hollandstraße 11-13

Elisabeth.Rathmayr@oeaw.ac.at

Christoph Samitz

Institut für Kulturgeschichte der Antike

Österreichische Akademie der Wissenschaften

A-1020 Wien, Hollandstraße 11-13

Christoph.Samitz@oeaw.ac.at

Patrick Sänger

Institut für Alte Geschichte und Altertumskunde,

Papyrologie und Epigraphik

Universität Wien

A-1010 Wien, Universitätsring 1

patrick.saenger@univie.ac.at

Ursula Schachinger

c/o Institut für Kulturgeschichte der Antike

Österreichische Akademie der Wissenschaften

A-1010 Wien, Bäckerstraße 13

ursula.schachinger@uni-graz.at

Gudrun Styhler-Aydın

Institut für Kunstgeschichte, Bauforschung und Denkmalpflege Technische Universität Wien

A-1040 Wien, Karlsplatz 13/251-1

gudrun.styhler@tuwien.ac.at

Hans Taeuber

Institut für Alte Geschichte und Altertumskunde,

Papyrologie und Epigraphik

Universität Wien

A-1010 Wien, Universitätsring 1

hans.taeuber@univie.ac.at

Marcel Tschannerl

A-1190 Wien, Billrothstraße 23/15-16

m.tschannerl@gmx.at

Alice Waldner

Österreichisches Archäologisches Institut

Österreichische Akademie der Wissenschaften

A-1090 Wien, Franz Klein-Gasse 1

Alice.Waldner@oeaw.ac.at

Gerald E. Weissengruber

Department für Pathobiologie

Veterinärmedizinische Universität Wien

A-1210 Wien, Veterinärplatz 1

Gerald.Weissengruber@vetmeduni.ac.at 


\section{Topografie und Forschungsgeschichte}

\subsection{TOPOGRAFIE}

Begibt man sich auf eine der höher gelegenen Sitzreihen des großen Theaters von Ephesos (Taf. 1 Abb. 1; Plan 1), von wo aus man den Trubel der Besuchermassen tief unter sich gerade noch wahrnimmt, und lässt den Blick nach Westen schweifen, hinweg über das spätantike, heute sumpfige Hafenbecken und die den Hafen umgebende riesige Schwemmlandebene, ein Ergebnis des Kaystros (heute Küçük Menderes) im Zusammenspiel mit tektonischen Bewegungen ${ }^{1}$, kann man in der Ferne noch das Meer als schmalen Streifen erkennen (Textabb. 1). Etwa sechs Kilometer liegen heute zwischen dem antiken Großbau und der Küste. Das war nicht immer so. In archaischer Zeit verlief die Küstenlinie nahe am Fuß des Bülbüldağ (Preon) und des Panayırdağ (Pion)². Noch in hellenistischer Zeit, als das Theater errichtet wurde, lag es unweit des Hafens in unmittelbarer Nähe der bald nach der Stadtgründung durch Lysimachos errichteten Tetragonos Agora ${ }^{3}$. Bereits in der Kaiserzeit war die Verlandung so weit fortgeschritten, dass eine Reihe großer Bauten, wie das Hafengymnasium oder das Olympieion, errichtet werden konnten. Heute ist die tiefe Meeresbucht durch die Anschwemmungen des Kaystros verschwunden. Nur eine sumpfige Senke erinnert daran, dass die Stadt einst mit dem Schiff zu erreichen war.

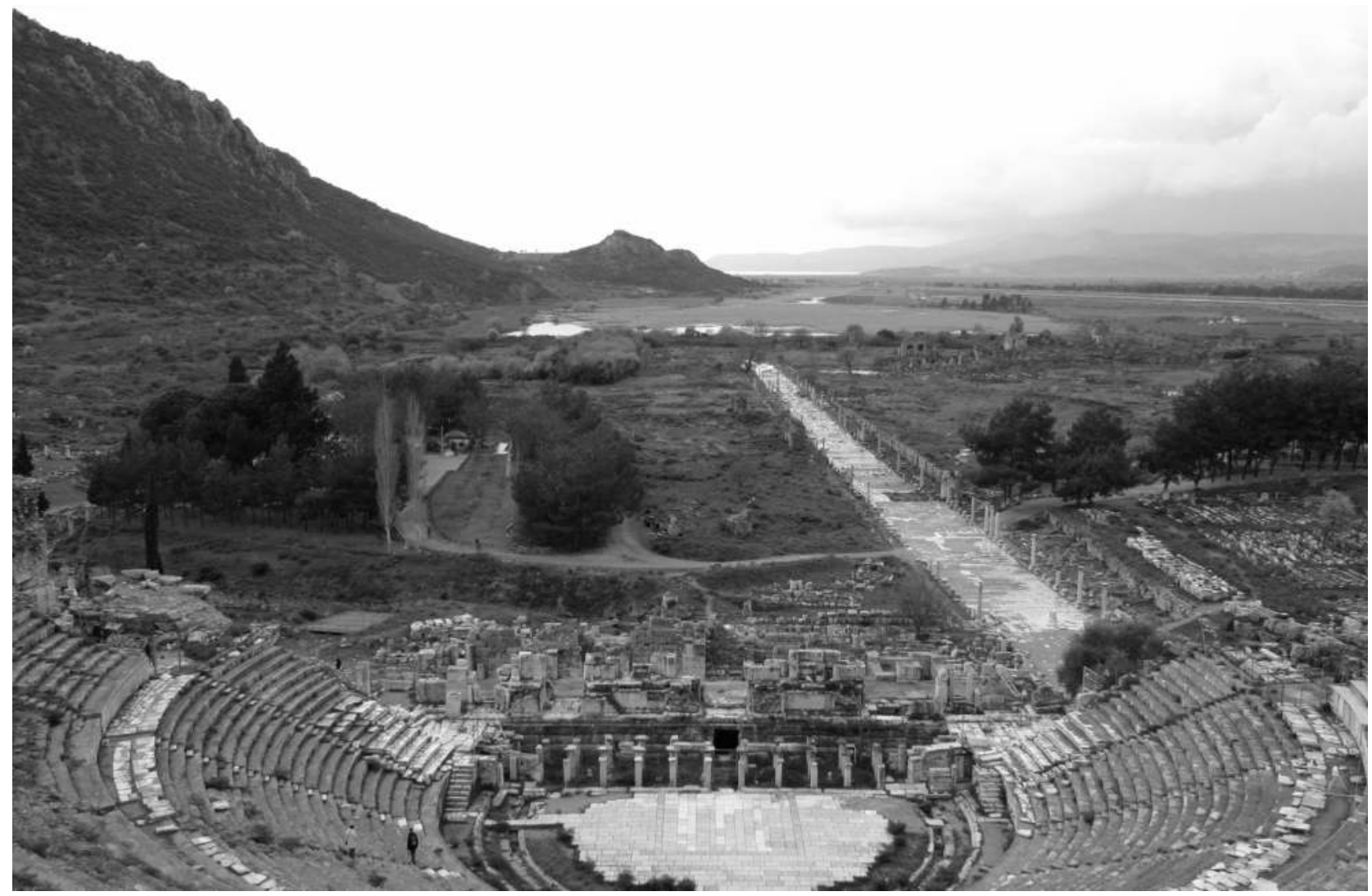

Textabb. 1: Blick vom Theater über die Schwemmlandebene zur Küste

\footnotetext{
${ }^{1}$ Kraft u. a. 2000, 175-233; Kraft u. a. 2005, 147-156.

${ }^{2}$ KersChNER U. a. 2008, Taf. 49. 50.

${ }^{3}$ Scherrer 2001, 57-93. In Scherrer - TrinkL 2006, 15 wird der aus dem frühen 3. Jh. v. Chr. stammende Brunnen LB unter der Tetragonos Agora in Zusammenhang mit der Gründung von Arsinoeia durch Lysimachos gebracht. Bis 270/260 v. Chr. erfolgten Aufplanierungen, über denen der erste große Magazinbau H-WSS errichtet wurde. Zu Fragen der Chronologie s. LawaLl 2011.
} 
Für die Anlage des Theaters wurde eine Mulde am Westabhang des Panayırdağ genutzt (Textabb. 2. 3). Nur die beiden aus dem Hang heraustretenden Flügel mussten aus Stein, Erde und opus caementitium aufgebaut werden. Trotz des ruinösen Zustands sind die Abschlussmauern im Westen noch heute ein eindrucksvoller Anblick. Große Teile der Orchestra wurden über dem anstehenden Fels errichtet, der für diesen Zweck zugerichtet wurde. Für den Bau der Skene war jedoch eine Terrassierung notwendig. Mit gut 4,0 m Höhe an der Nordwestecke bildete die aus großen Polsterquadern bestehende Terrassenmauer einen mächtigen Sockel für das sich darüber erhebende Bühnengebäude. Unmittelbar westlich der Terrasse führt die Straße vorbei. Das mit einer etwa 7,5 km langen Mauer großzügig eingegrenzte Stadtgebiet ist von rechtwinkelig sich schneidenden Straßen durchzogen ${ }^{4}$. Auf die Hangsituation wird die Tatsache zurückzuführen sein, dass das Theater in seiner Ausrichtung ein wenig von diesem Straßenraster abweicht. Nach den jüngsten Erkenntnissen besaß das ephesische Theater bereits in hellenistischer Zeit drei Ränge, wovon aber nur der unterste Rang bis an die beiden Parodoi vorgezogen $w^{5}{ }^{5}$. Damit dürfte sich das hellenistische Theater deutlich besser in das Straßensystem eingefügt haben als der kaiserzeitliche Bau, der an drei Seiten das Raster der Insula sprengte (Plan 17) ${ }^{6}$. Es ist nicht auszuschließen, dass der Platz bereits bei der Stadtgründung für das Theater vorgesehen war. Archäologische Funde belegen aber, dass der Bau des Theaters erst deutlich verzögert stattgefunden hatte, sofern nicht mit einer einfacheren Anlage vor dem 2. Jh. v. Chr. zu rechnen ist ${ }^{7}$.

Mit seiner Nordwestecke lag das Theater an einem alten Prozessionsweg, der den Panayırdağ entlang zum Artemision führte. In einer umfangreichen Inschrift aus dem Theater erfahren wir von einer großzügigen Spende des C. Vibius Salutaris im Jahr 104 n. Chr., wonach eine Reihe von Gold- und Silberstatuetten zu verschiedenen Anlässen in einer Prozession vom Artemision in das Theater gebracht werden sollten ${ }^{8}$. Dazu gehörten das Neujahrsopfer, die monatlichen Volksversammlungen und verschiedene Feste wie das Fest der Sebasteia, der Soteria oder der penteterischen großen Ephesien?. Da das Theater auch heute noch am Weg aller EphesosBesucher liegt, nimmt es nicht Wunder, dass die Besichtigung dieses imposanten Bauwerks zu einem festen Bestandteil der Besichtigungstour gehört. Vielen Besuchern ist das Theater aus der Apostelgeschichte bekannt, in der berichtet wird, dass sich die Silberschmiede, aufgebracht durch die Predigten des Paulus, im Theater versammelten und zwei Stunden lang 》Groß ist die Artemis der Ephesier « riefen ${ }^{10}$. Dadurch wurde das Theater, neben seiner einstigen antiken Funktion als Versammlungs- und Aufführungsort sowie als Arena, heute zur 〉Gedenkstätte und zum Ort des Gebets der auf den Spuren des Apostels Paulus Reisenden.

\footnotetext{
${ }^{4}$ Zum Straßensystem von Ephesos s. Bammer 1961, 136-157; Hueber 1997a, 251-269; Hueber 1997b, 39-43 Abb. 47. 48; SCHERRER 2001, 57-93; GROH 2006, 47-116 mit Abb. 20. Übereinstimmung herrscht im Bezug auf die folgenden Nord-Süd-Straßen: Marmorstraße (Groн 2006: Straße 50), Akademiegasse (Groн 2006: Straße 48) und Badgasse (GroH 2006: Straße 46). Divergenzen gibt es bei den von Ost nach West verlaufenden Straßenzügen. Es dürfte aber davon auszugehen sein, dass bei der Anlage des Theaters das Straßensystem nicht ignoriert wurde, wie im Falle der Nord-Süd-Straßen zu erkennen ist. Zum Magnesischen Tor, welches Teil der hellenistischen Stadtbefestigung war, vgl. Sокоцісек 2010.

${ }^{5}$ Kap. 10.1.2.

${ }^{6}$ Scherrer 2001, 93 Abb. 3; Groh 2006, Abb. 20. Der großzügige Ausbau des Theaters seit der 2. Hälfte des 1. Jhs. n. Chr. war nicht mehr in das hellenistische Rastersystem zu integrieren. An den drei Seiten, wo die bestehenden Straßen vom Theater überlagert wurden, kam es zu Sonderlösungen, wie in diesem Band für die Süd- und Ostseite des Theaters aufgezeigt werden soll, s. Kap. 3.7.

${ }^{7}$ KARWIESE 1995a, 64. Archäologisch ist bislang kein eindeutiger Nachweis für die Existenz des Theaters im 3. Jh. v. Chr. erbracht worden, doch ist nicht auszuschließen, dass mit den Arbeiten am Koilon oder der Errichtung der Orchestra bereits vor dem 2. Viertel des 2. Jhs. v. Chr. begonnen wurde. Möglicherweise können neue Grabungen im Orchestra-Bereich darüber Aufschluss geben, s. HofBauer 2007, 45; zur Bauforschung s. STYHLER-Aydin (in Vorbereitung). Die Ausgrabungen auf der Tetragonos Agora zwischen 1978 und 2001 vermitteln einen guten Eindruck von der Anlage und Entwicklung einer Neustadt. Der Platz wurde unmittelbar nach der Gründung Arsinoeias, wie die Stadt zunächst von Lysimachos benannt war, errichtet. Dabei entsprach die Ausstattung zunächst dem Notwendigsten, und war von einer monumentalen Anlage, wie sie einer Residenzstadt entsprach, weit entfernt: Ein Areal mit Lehmboden und vorerst einfachen Gebäuden aus Holz und Lehmziegeln. Erst nach und nach wurden diese Bauten in der Zeit vom 3. bis in das 1. Jh. v. Chr. durch steinerne Hallen ersetzt (SCHERRER - TrinkL 2006, 15-19). Das an der Nordwestecke der Theaterterrasse errichtete kleine hellenistische Brunnenhaus wurde neuerdings aufgrund stilistischer Vergleiche der Löwenkopfwasserspeier mit denen des Mausoleums von Belevi in die zeitliche Nähe der Stadtgründung gerückt (vgl. Strocka 2005, 346) und belegt damit Aktivitäten im Stadtbereich nördlich der Tetragonos Agora.

${ }^{8}$ IvE 27. Vgl. dazu auch Graf 1999, 255-262; SOKOLICEK 2010.

${ }^{9}$ IvE 2027, 51-56.

${ }^{10}$ Apg 19, 23-40.
} 


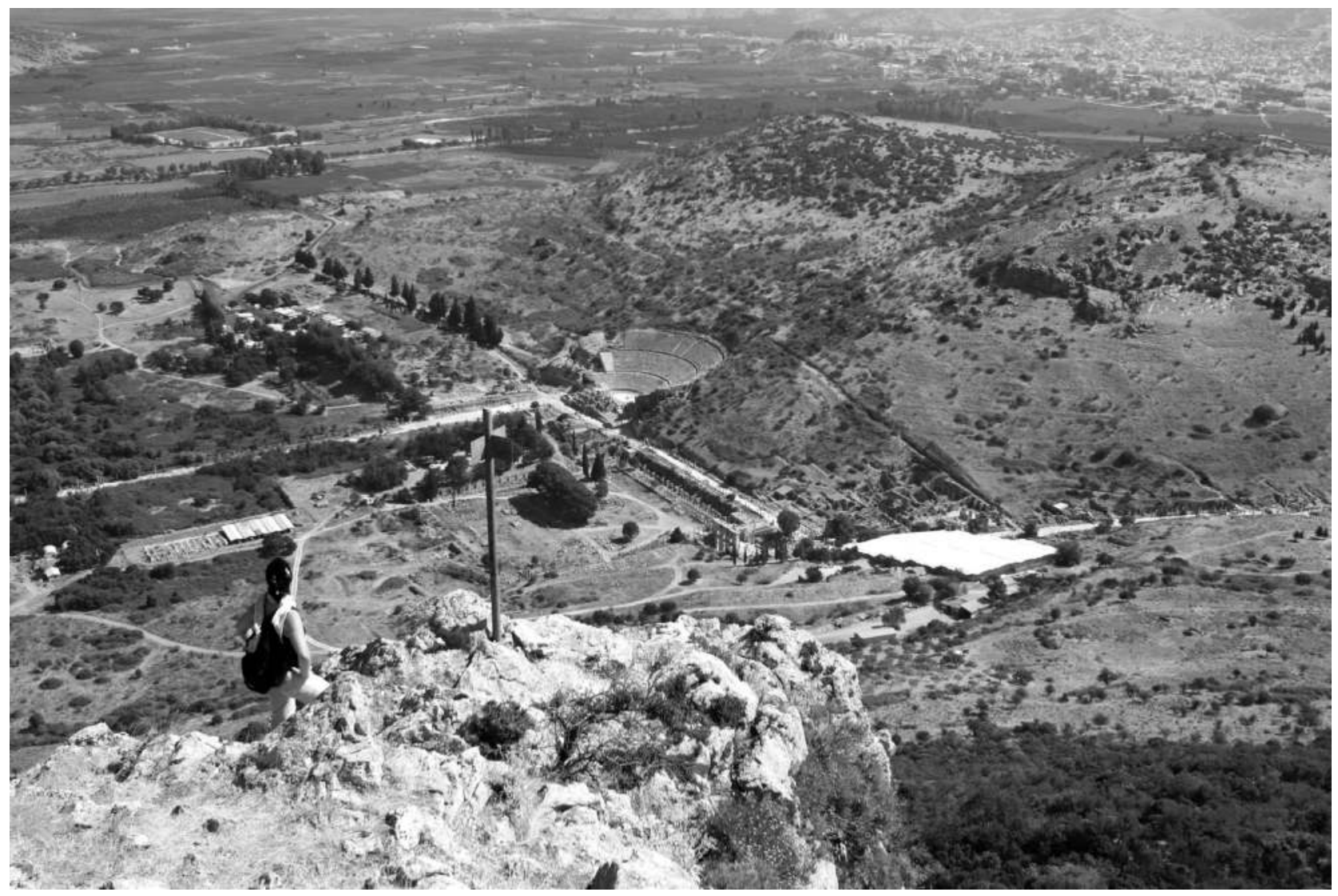

Textabb. 2: Theater, Ansicht von Südwesten

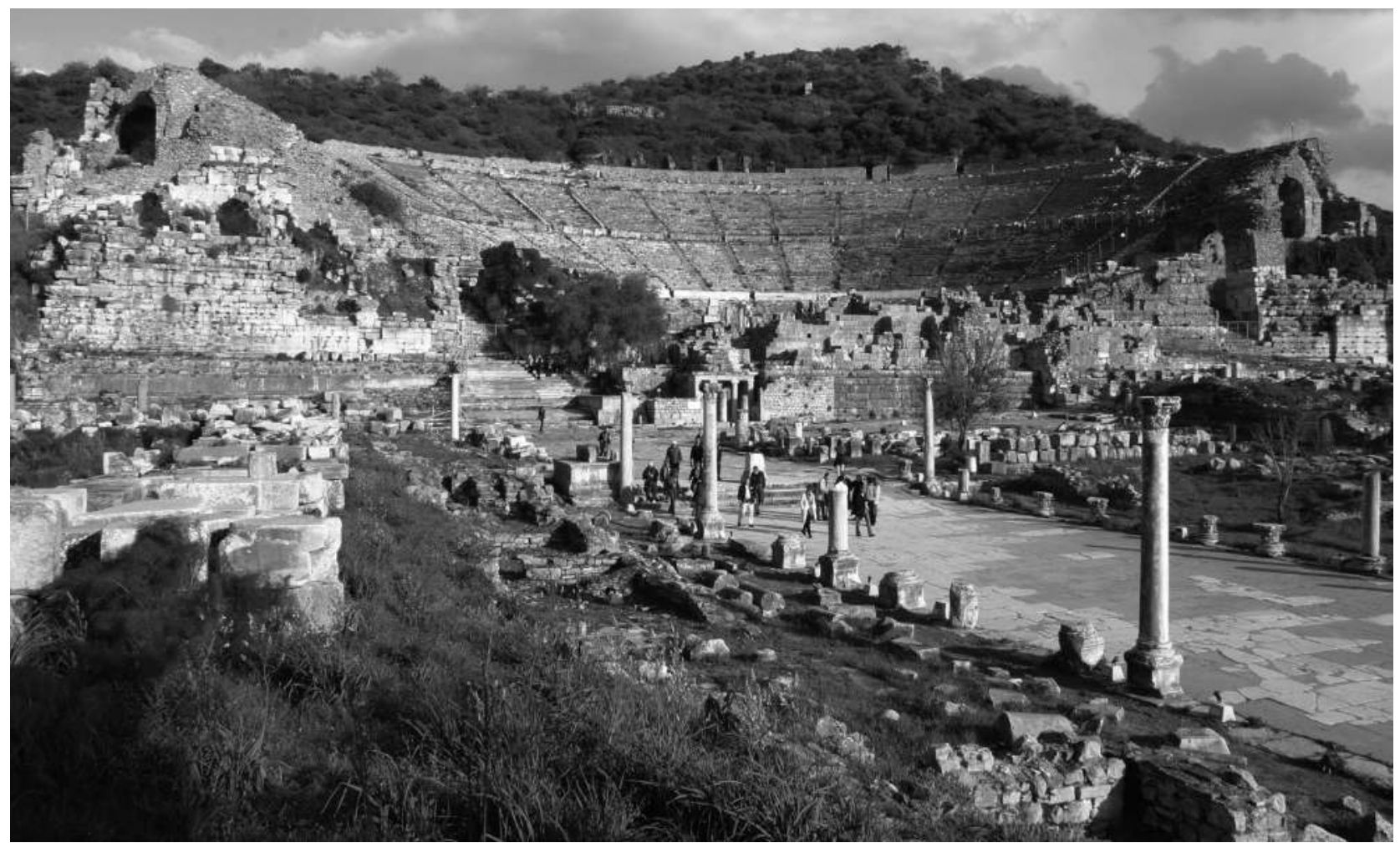

Textabb. 3: Theater, Ansicht von Nordwesten 


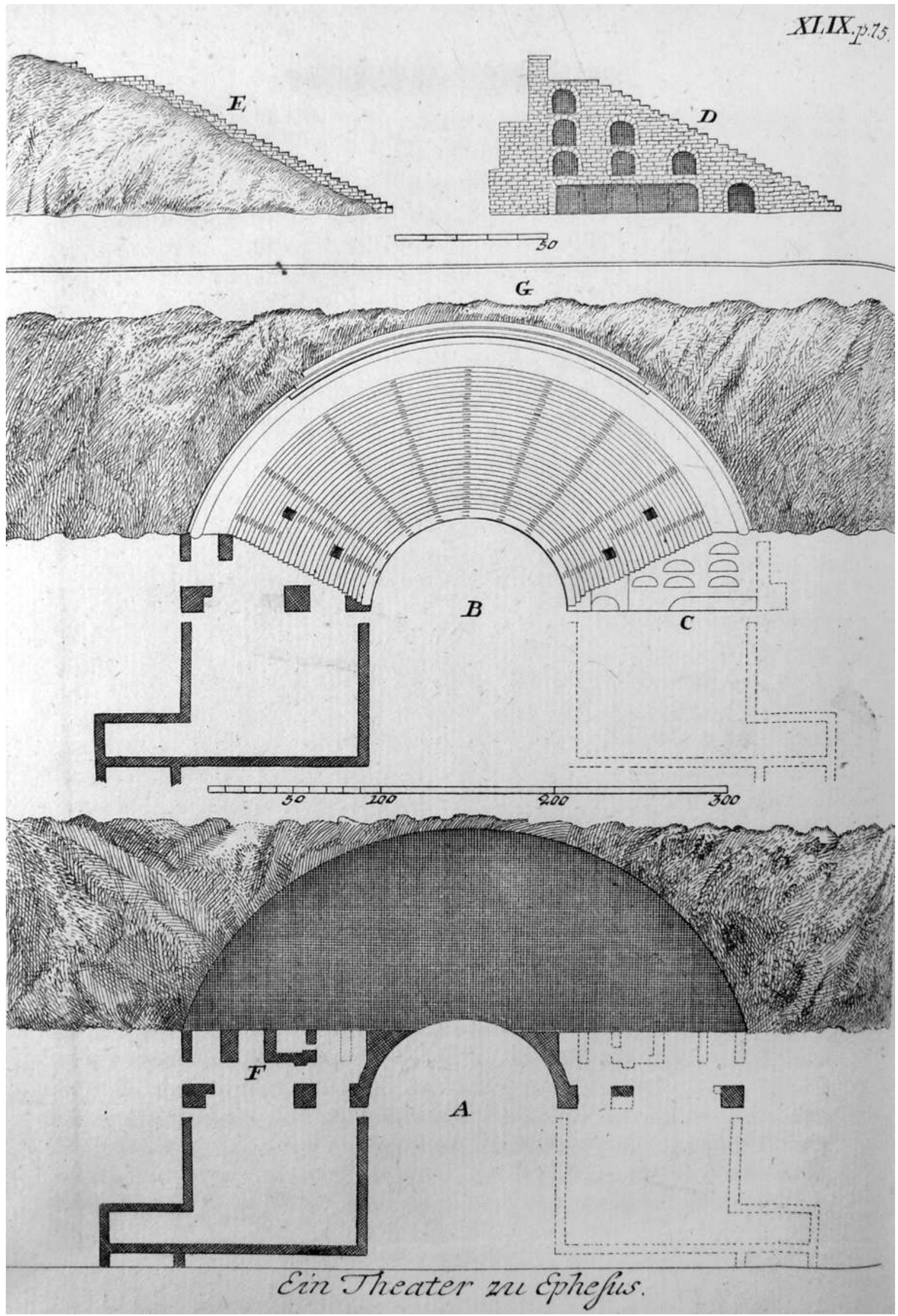

Textabb. 4: Darstellungen des Theaters. Von R. Pococke bei seinem Besuch 1740 angefertigt 


\section{2 ÄLTERE FORSCHUNG}

Wie aus verschiedenen historischen Berichten hervorgeht, hatte die raumgreifende, gebäudetypische Gestalt der Theaterruine bereits Reisende in vergangenen Jahrhunderten stark beeindruckt. Die früheste bekannte Erwähnung der zunächst als amphitheatrum magnum bezeichneten Anlage stammt aus der Frührenaissance. Der Kaufmann, Humanist und Reisende Cyriacus von Ancona ${ }^{11}$ besuchte das Theater in den Jahren 1446 und 1447 und dokumentierte die ersten Inschriften ${ }^{12}$. Vor allem ab dem 18. Jh. kam es vermehrt zum Besuch der Ruinen von Ephesos durch europäische Reisende ${ }^{13}$. Zu den meist kurzen Berichten gesellten sich Überblickspläne und Perspektiven der Ruinenlandschaft von Ephesos mit dem Theater, die in verschiedenen Beschreibungen, Reisehandbüchern und Nachschlagewerken abgebildet wurden ${ }^{14}$. Da die erhaltenen Strukturen des Bühnengebäudes unter hohen Versturzmassen lagen und kaum erkennbar waren, bildeten die Verfasser das Bauwerk in idealisierter Darstellung ab. Ferner besuchte R. Pococke 1740 während seiner mehrjährigen Orientreise (1737-1742) Ephesos und erstellte - im weitesten Sinne - analytische Grundrissund Schnittskizzen des Theaters ${ }^{15}$. Darin ist bereits eine erste Einordnung der Dimensionen des Gebäudes sichtbar (Textabb. 4).

Auch A. L. J. de Laborde ${ }^{16}$ zeigte in seinem 1838 erschienenen Buch das Theater (Textabb. 5). Die Darstellung ist jedoch stark idealisiert. So ist es recht unwahrscheinlich, dass de Laborde das Theater zwar zerstört vorgefunden hatte, aber ohne jegliche Versturzmasse im Westen, die den später als Marmorstraße bezeichneten Straßenzug meterhoch bedeckte. Zur Südfassade werden hingegen Details angegeben, die vermutlich zu beobachten waren. So ist der Zugang ES2 an der Außenseite gut erkennbar, während die

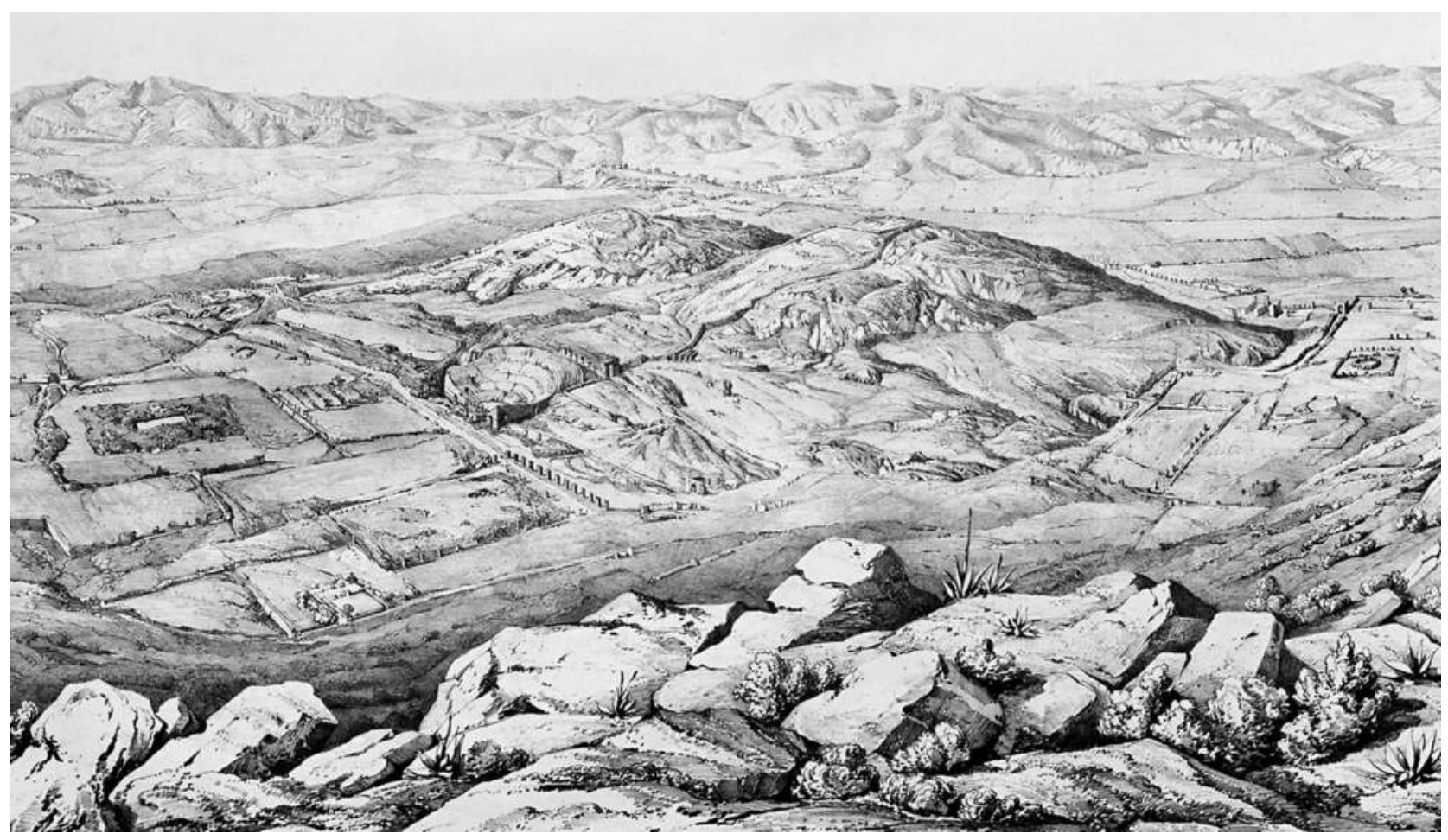

Textabb. 5: Stadtansicht nach dE LABORDE 1838, Detail

${ }^{11}$ BÜRCHNER 1905, 58; HeBERDEY u. a. 1912, 1.

${ }^{12}$ Eine ausführliche Beschreibung der Ruinen von Ephesos durch Cyriacus von Ancona liegt nicht vor. Es ist nur eine insgesamt 20 Inschriften umfassende Dokumentation erhalten (ZieBART 1922, 222), wobei aus diesem Konvolut lediglich IvE 2044 und (nach Riemann 1877, 289-294 auch) IvE 709 aus dem Theater stammen. Vgl. De Rossi 1888, 373; Heberdey u. a. 1912, 164 f.; Bodnar - Foss 2003, 217. 283.

${ }^{13}$ L. Bürchner benannte für das 17. bis 19. Jh. über vierzig Reisende, deren Aufenthalt in Ephesos überliefert war (BÜRCHNER 1905, $58 \mathrm{f}$.).

${ }^{14}$ Beispielhaft seien die Reiseberichte von McGarvey 1881, 576 sowie das CAlwer BibelleXIKon 1893, 187 genannt.

${ }^{15}$ POCOCKe 1745, 74 f. Taf. 49.

${ }^{16}$ DE LABORDE 1838, 90 Taf. 43. 


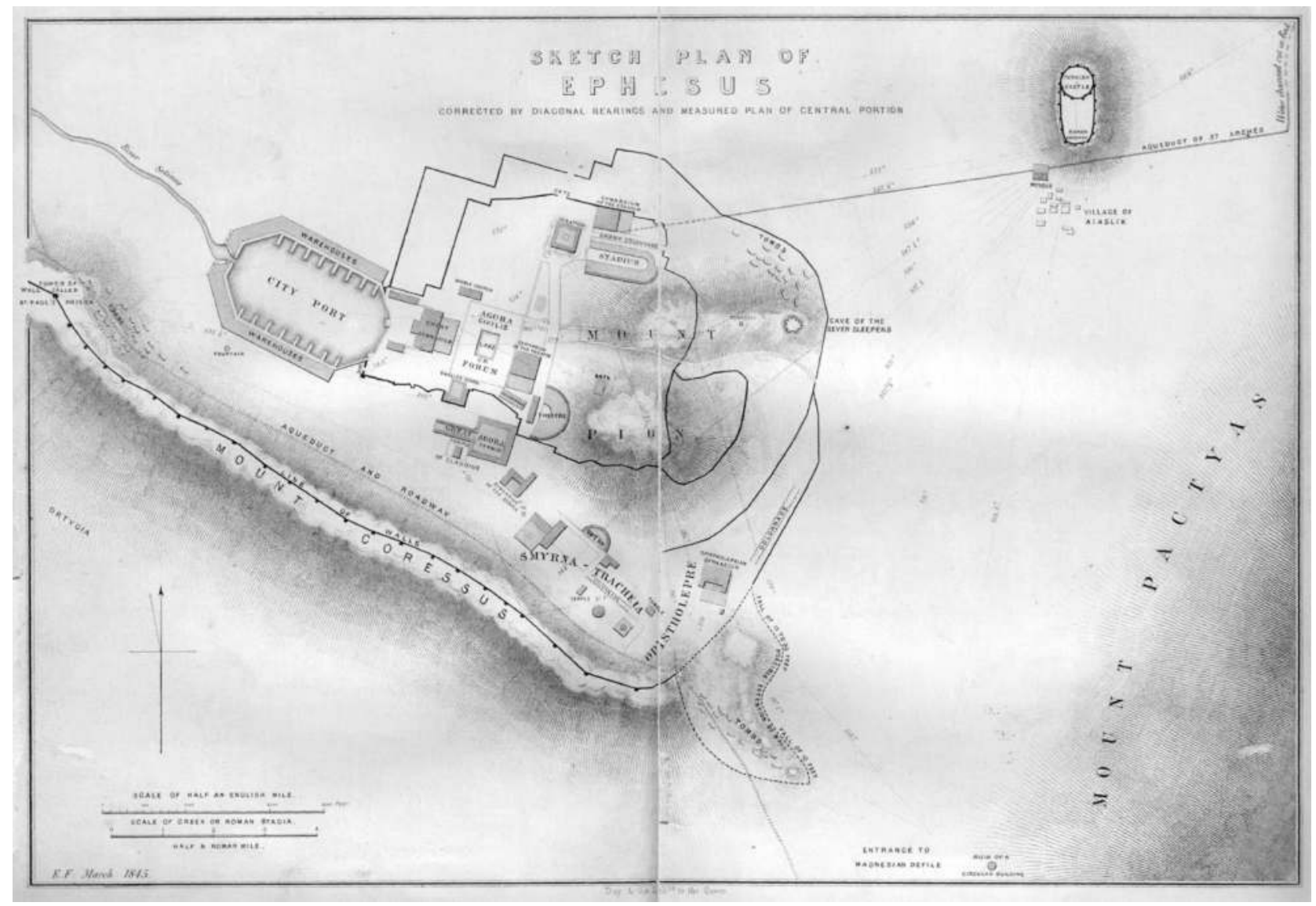

Textabb. 6: Stadtplan nach E. Falkener (1845)

Theatermauer nach Osten hin noch weitgehend vom Schutt bedeckt wird. Eine Darstellung also, die soweit doch der Realität entsprach und uns heute ein Bild davon gibt, wie sich der Zustand des Theaters vor allen archäologischen Tätigkeiten, die etwa drei Dezennien nach de Laborde einsetzten, geboten hat. In de Labordes Darstellung ist außerdem nordöstlich des Theaters ein Stadttor zu erkennen. Dabei wird es sich um das in den 1960er Jahren freigelegte Tor in der Badgasse handeln. Von diesem führte er eine Mauer bis an das Theater heran. Wie weit das damals tatsächlich zu erkennen war, muss offenbleiben. Hier wurde in der Zeichnung scheinbar der Befund mit der Interpretation in Verbindung gebracht. Das dürfte jener Mauerzug nahelegen, der vom Theater nach Süden (im Bild nach rechts) abbiegt. Hier hat es niemals einen Teil der Stadtmauer gegeben. Tatsächlich aber ist heute im Hang südlich des Theaters ein kurzes Stück einer Quadermauer zu erkennen, die als Terrassierung innerhalb einer Wohninsula anzusehen ist.

Den anschaulichsten Eindruck der Stadt gab E. Falkener in seinem 1845 entstandenen Plan von Ephesos ${ }^{17}$ (Textabb. 6). Dieser zeigte neben Bauten wie dem Stadion, dem Bouleuterion, der Domitiansterrasse, der Agora, dem Theatergymnasium, den Verulanushallen, dem Hafengymnasium und dem Hafenbecken auch das Theater. Die Gebäude wurden auf ihre wesentliche Form reduziert, ohne Detailangaben. Das Auditorium wurde als halbkreisförmiger Bogen dargestellt, dem das Bühnengebäude als kleines Rechteck im Westen vorgesetzt war.

Die 1859 angefertigte Stadtansicht ${ }^{18}$ (Textabb. 7. 8), die auf diesen topografischen Studien beruhte, war detailreicher gestaltet, wenngleich sie teilweise als frei rekonstruiert bezeichnet werden muss. Hier zeigte E. Falkener bereits eine Kolonnade am oberen Rand des Zuschauerraums. Dem Bühnenhaus war eine dreigeschossige Fassade vorgesetzt, deren unteres Geschoss einer mächtigen Sockelzone entsprochen hat. Neben

\footnotetext{
${ }^{17}$ FALKener 1862, Vorsatzbild, gez. 1854.
}

${ }^{18}$ FALKENER 1862, Vorsatzbilder, gez. 1859. 


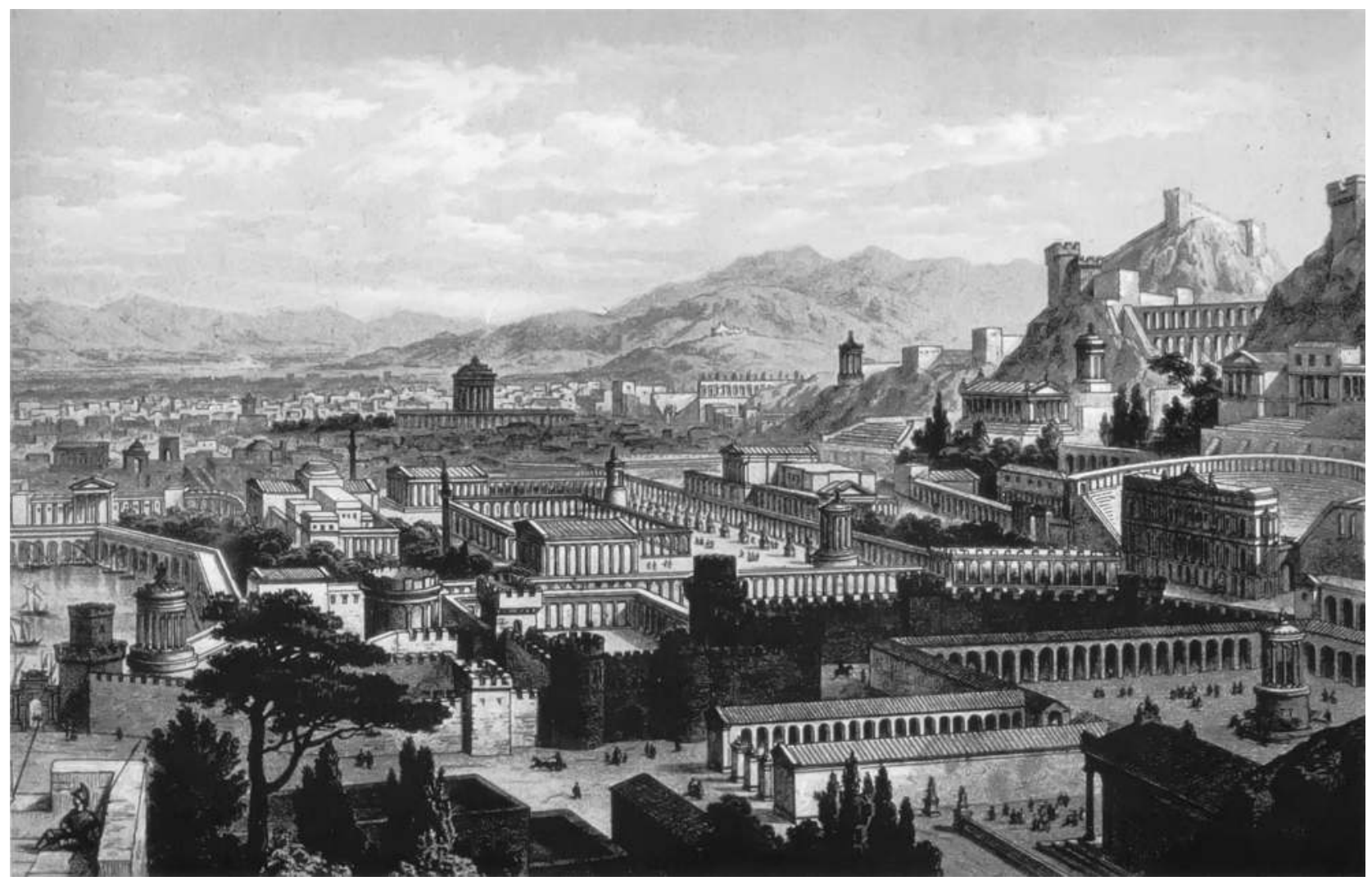

Textabb. 7: Stadtansicht nach E. Falkener (1859)

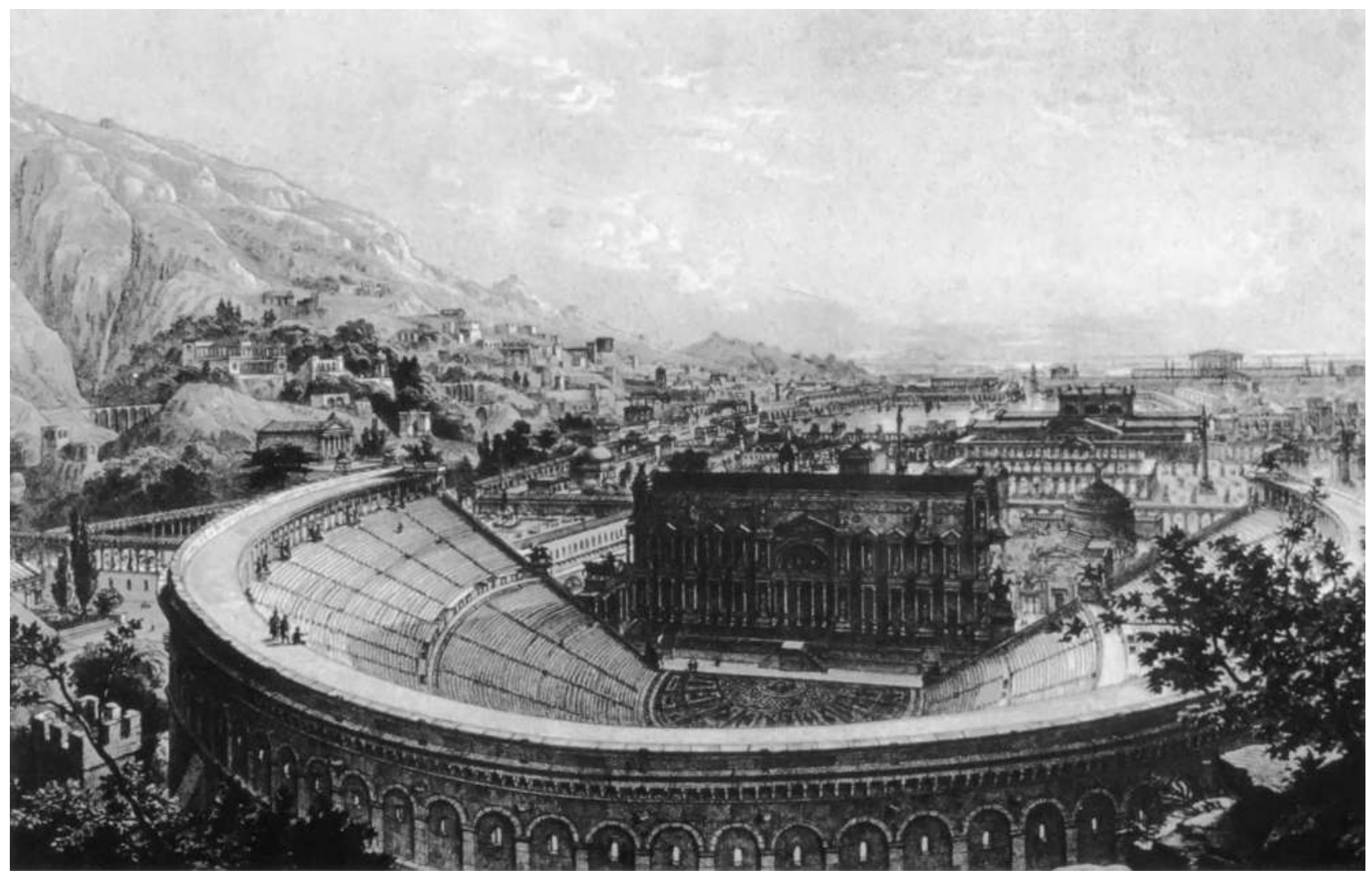

Textabb. 8: Stadtansicht mit Theater im Vordergrund nach E. Falkener (1859) 


\section{PLAN OF GREAT THEATRE,} E PHESUS.

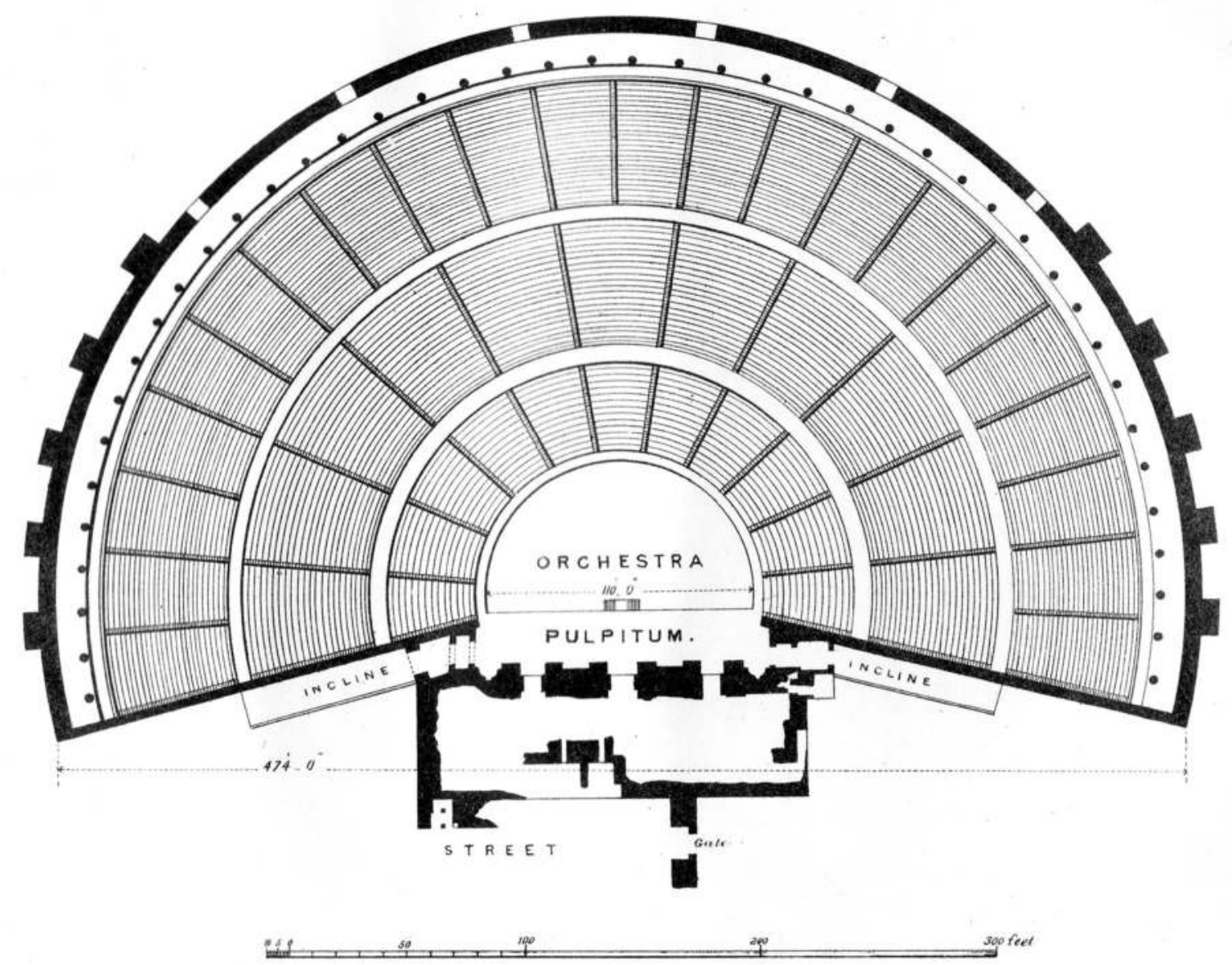

Textabb. 9: Rekonstruktion des Grundrisses des Theaters nach Wood 1877

der zur Orchestra gerichteten scaenae frons stellte E. Falkener auch die Westfassade monumental dar. Obwohl die beiden Fassaden fantasievoll rekonstruiert wurden, hatte Falkener das Bühnengebäude in Augenschein genommen ${ }^{19}$. Details, wie etwa die zweiläufige Treppe, die sich in der Symmetrieachse der Fassade befand und aus der Orchestra auf die römische Bühne führte, wurden in seiner Rekonstruktion der scaenae frons berücksichtigt. Diese Treppe war um 1900 noch erhalten ${ }^{20}$, wurde im Zuge der österreichischen Grabungen aber beseitigt.

Mit den Arbeiten des englischen Architekten und Ingenieurs J. T. Wood begannen 1866 bis 1868 die ersten schriftlich dokumentierten Ausgrabungen am Theater ${ }^{21}$. Eigenen Beschreibungen zufolge konzentrierte sich Wood überwiegend auf Inschriften- und Skulpturenfunde. Seinen aufsehenerregendsten Fund stellte die Entdeckung der Inschrift zur Stiftung des C. Vibius Salutaris dar, die in sechs Kolumnen am orchestraseitigen Beginn des südlichen Analemma angebracht war $^{22}$. Von einer planmäßigen Freilegung der Ruine konnte bei diesen Arbeiten aber nicht die Rede sein. Wood bemühte sich zumindest, die Front des Proskenion zu fassen. Bühnengebäude und Orchestra blieben indessen weiterhin unter dem Schutt verborgen. Der aus Woods Arbeiten resultierende Plan beinhaltete aber erstmals Details und gab das Bühnengebäude mit

\footnotetext{
${ }^{19}$ FALKener 1862, 102-104.

${ }^{20}$ HeBerdey u. a. 1912, 4 Abb. 3.

${ }^{21}$ WoOD 1877, 68-96.

${ }^{22}$ IvE 2027. Vgl. Heberdey u. a. 1912, 127-147. 188-198. Der Hauptteil der Inschrift befindet sich heute im British Museum in London.
} 


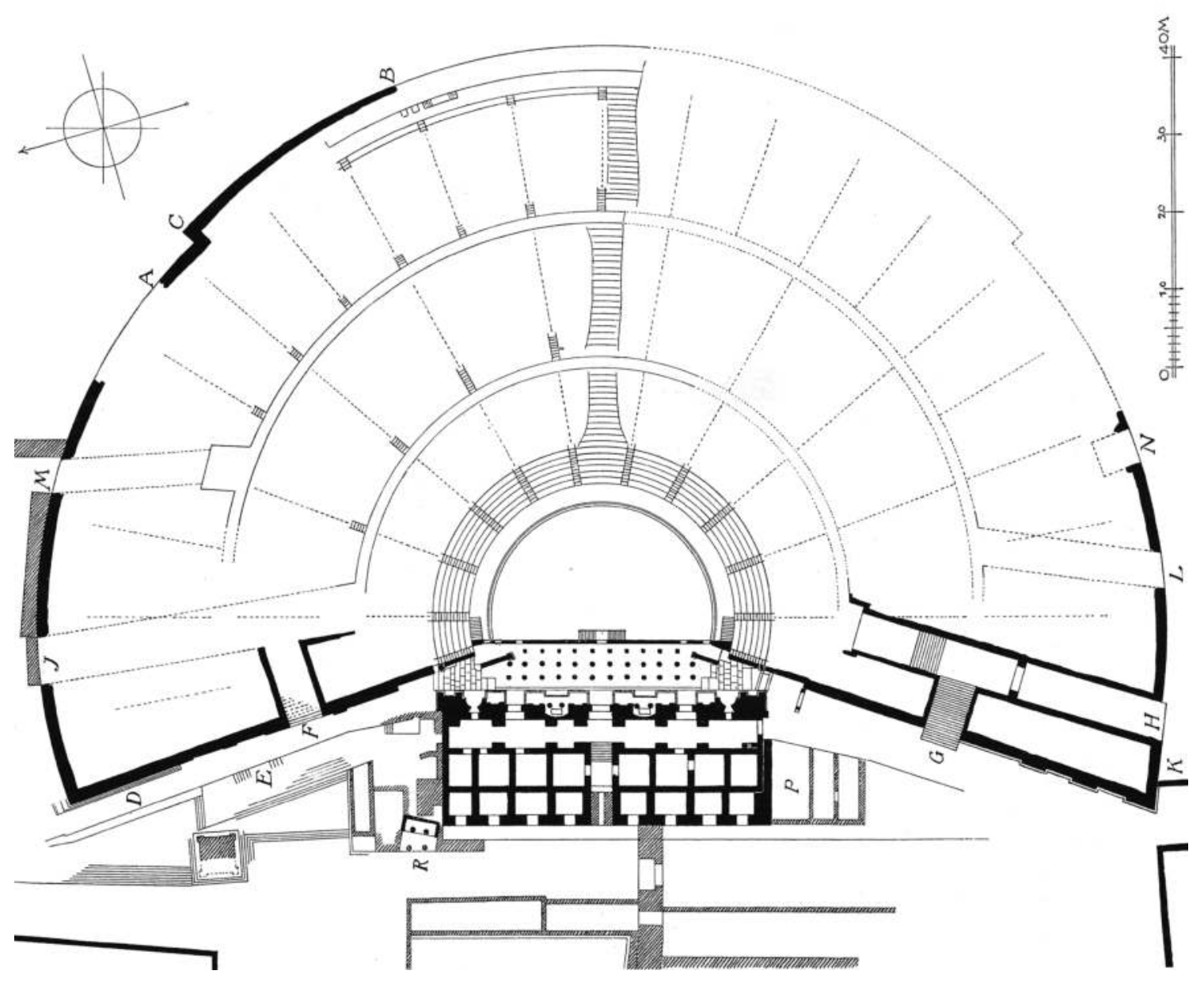

Textabb. 10: Grundriss des Theaters nach der Ausgrabung 1897-1900 (HeberdeY u. a. 1912)

einigen seiner markanten Elemente wieder. Die Rampen zwischen Skene und Cavea sowie die Form der scaenae frons wurden erfasst. Andererseits enthielt der Plan Ungenauigkeiten, vor allem bei den Maßen des Bühnengebäudes im Ganzen, aber auch in Details, wie im Falle der scaenae frons. Die nicht ergrabenen Bereiche im Inneren der Skene und die westlichen Kammern wurden weitgehend ausgespart. Auf das Auditorium ging Wood nur sehr partiell ein, nahm aber dennoch Messungen vor und fertigte eine zwar maßstäbliche, aber überwiegend hypothetische Grundriss-Rekonstruktion des Theaters an (Textabb. 9) ${ }^{23}$. Dabei blieben verschiedene bauliche Merkmale unberücksichtigt, obwohl sie sichtbar waren und auch in anderen seiner Skizzen Beachtung fanden ${ }^{24}$. Nachfolgende Forscher übten besonders an der Arbeitsweise Woods, aber auch an dem zum Verständnis des Bauwerks veröffentlichten Grundriss, starke Kritik ${ }^{25}$.

Die von C. Humann im Jahr 1894 erstellte Planskizze von Ephesos ${ }^{26}$ beschränkte sich dagegen auf die Darstellung sichtbarer Mauerfluchten, während die nicht ergrabenen Bereiche durch die Darstellung von Geländekanten wiedergegeben wurden. Auch das Theater war in diesem Plan nur sehr schematisch dargestellt.

\footnotetext{
${ }^{23}$ Der Umfang der von J. T. Wood tatsächlich im Auditorium durchgeführten Untersuchungen kann nicht mehr nachvollzogen werden. Er selbst sagte dazu lediglich: »I cleared out the Theatre sufficiently to enable me to make a plan of it. As far as I explored the auditorium, some of the steps were found remaining, but the marble from the seats had been removed.« (Wood 1877, 77).

${ }^{24}$ Das betrifft besonders die Zugänge zu den Rängen, deren Angabe im Grundriss ganz fehlt. Vgl. Wood 1877, Lithografie gegenüber S. 68 mit Lithografie gegenüber S. 74 sowie mit Abb. S. 69.

${ }^{25}$ AdLer 1872, 39; Heberdey u. a. 1912, 2.

${ }^{26}$ Planskizze von Ephesos von C. Humann, 1894 (ÖAI Archiv Inv. 167); Scherrer - TrinKL 2006, Abb. 6.
} 
Bauforschungen und archäologische Untersuchungen am Theater im Sinne wissenschaftlicher Nachvollziehbarkeit fanden erstmals von 1897 bis 1904 durch R. Heberdey, W. Wilberg und G. Niemann unter Leitung des Österreichischen Archäologischen Instituts statt (Taf. 4 Abb. 4-6) ${ }^{27}$. In ihrer umfassenden Monografie »Das Theater in Ephesos«, die 1912 als zweiter Band der »Forschungen in Ephesos« erschien, erarbeiteten sie nicht nur das grundlegende Datierungsgerüst zum Gebäude, sondern schufen auch die Basis für die weiteren wissenschaftlichen Auseinandersetzungen mit dem Monument. Die Publikation fand darüber hinaus vielfach Beachtung im wissenschaftlichen Diskurs der Zeit sowie in den theoretischen Theaterabhandlungen der folgenden Jahrzehnte ${ }^{28}$. Die Forschungen des ÖAI markierten außerdem den Beginn der systematischen Ausgrabung des Monuments, die in mehreren Etappen erfolgte und bis heute andauert. Im Zentrum der ersten Arbeiten stand die Freilegung und Untersuchung des Skene-Orchestra-Komplexes inklusive der fünf unteren Sitzreihen des Stufenkörpers. Als Ergebnis konnte eine Einteilung in Bauphasen von hellenistischer bis in frühbyzantinische Zeit vorgenommen werden. Wenngleich von A. von Gerkan teilweise heftig widersprochen ${ }^{29}$, blieb die Rekonstruktion des hellenistischen Bühnenhauses und seines Proskenion lange Zeit verbindlich. In der Publikation des ÖAI wurde das Bühnengebäude von W. Wilberg, die römische scaenae frons von G. Niemann behandelt. Niemann hatte zwei Rekonstruktionsversuche für die Bühnenfassade erarbeitet. Diese beiden Rekonstruktionen differierten insbesondere im zweiten Geschoss. Wie Niemann selbst zugab, waren die Rekonstruktionsversuche nicht sehr überzeugend. Die Ursache für diesen Umstand schrieb er der allgemeinen Situation des Ruinenfelds sowie dem besonderen Charakter der ganzen Kunstepoche zu. Tatsächlich war es wohl in einer gewissen Befangenheit den selbst ergrabenen Funden gegenüber begründet ${ }^{30}$. Später hatte $\mathrm{H}$. Hörmann ${ }^{31}$ einen weiteren Rekonstruktionsversuch für die ephesische scaenae frons entwickelt. Seine 1923 publizierte Arbeit beruhte auf seinen Untersuchungen zur antiken Fassadenarchitektur. Allerdings hatte er, obwohl in Ephesos tätig, den Baubefund des ephesischen Theaters nie vor Ort bearbeitet. Hörmann legte seinem Vorschlag den zweiten Rekonstruktionsversuch Niemanns zugrunde und modifizierte ihn in einigen wenigen Details.

Um die Dimensionen des Theaters zu erfassen und dessen Grundrissorganisation nachzuvollziehen, wurde während der Grabungen der Schutt vor den hoch aufragenden Fassaden im Westen und in den seitlichen Zugangskorridoren im Norden und Süden, soweit zum Verständnis nötig, abgetragen. Im Auditorium legte man Suchschnitte an, die - vom heutigen Wissensstand aus betrachtet - zwangsläufig zu einem exemplarischen Grundriss führten (Textabb. 10) ${ }^{32}$.

So wurde für die Bestimmung der drei Diazomata-Niveaus sowie der Anzahl der Sitzstufen pro Rang in Ost-West-Achse des Gebäudes eine ca. 4,0 m breite Sondage ausgehoben, beginnend am Rand der Orchestra bis zur porticus in summa cavea. Weiters deckte man zum Verständnis des Einteilungssystems im Auditorium im mittleren und oberen Rang lediglich die Fußpunkte der Radialtreppen in der Nordhälfte des Gebäudes auf. So konnte u. a. nicht erfasst werden, dass durch weitere Radialtreppen, die erst auf der DiazomaWand des mittleren Diazoma begannen, bereits der mittlere Rang in 22 Sektoren geteilt war. Dies blieb folglich im Grundriss von 1912 unberücksichtigt. Mit Abschluss der österreichischen Forschungen lag jedoch erstmals Planmaterial zum Theater vor, in dem die Gesamtgestalt des Gebäudes im Wesentlichen messtechnisch und zeichnerisch erfasst war (Textabb. 11. 12).

Neben der Darstellung in den detaillierten Bauaufnahmezeichnungen und Rekonstruktionen des ÖAI wurde die Theaterruine seit dem Ende des 19. Jhs. auch in Heliogravüren und Fotografien dokumentiert (Taf. 5 Abb. 7-8) ${ }^{33}$. Andere frühe Aufnahmen sind z. B. von G. Bell bekannt, die das Theater auf ihren Reisen u. a. zur Zeit der Forschungstätigkeit des ÖAI besuchte (Taf. 6 Abb. 9).

\footnotetext{
${ }^{27}$ HeberdeY u. a. 1912, 2-4: Die Grabungskampagnen fanden von 1897-1900 statt. Nachträgliche Untersuchungen an Einzelbauteilen wurden über die Zeit der Grabungskampagnen hinaus bis 1904 vorgenommen.

${ }^{28}$ z. B. Fiechter 1914, 55. 90-92 Abb. 27; Frickenhaus 1917, 38 Abb. 7 Taf. 1; Bieber 1920, 38-49 Taf. 19. 20; De Bernardi FERRERo 1970, 49-66 Taf. 7-10.

${ }^{29}$ VON GERKAN 1921, 90-93.

${ }^{30}$ Vgl. Hörmann 1923/1924, 283.

${ }^{31}$ HöRMANn 1923/1924, 275-345.

${ }^{32}$ Heberdey u. a. 1912, 12 Abb. 15.

${ }^{33}$ Vgl. z. B. Heberdey u. a. 1912, 1-6 mit Abb.
} 


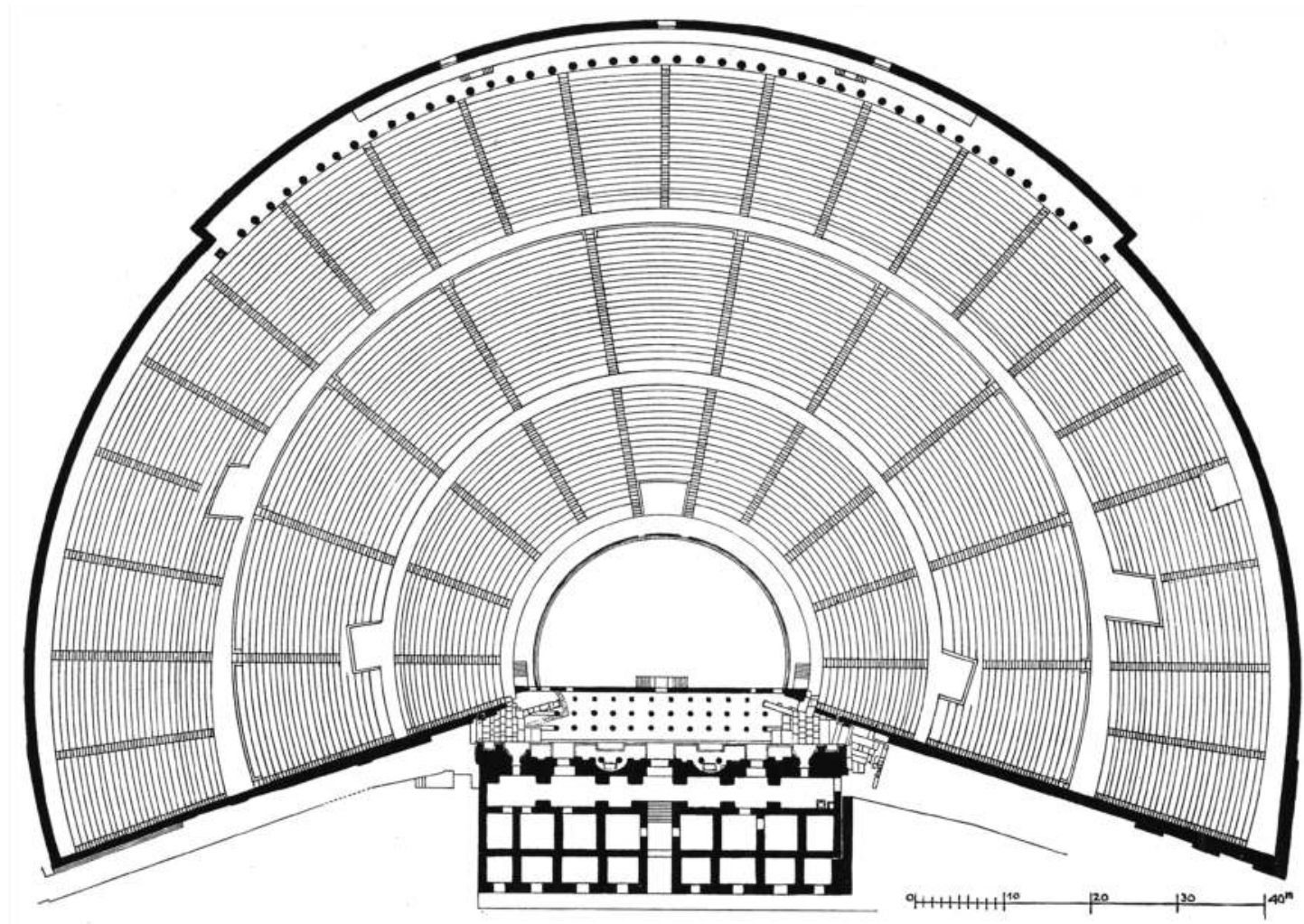

Textabb. 11: Rekonstruktion des Grundrisses des kaiserzeitlichen Theaters (HeBERDEY u. a. 1912)

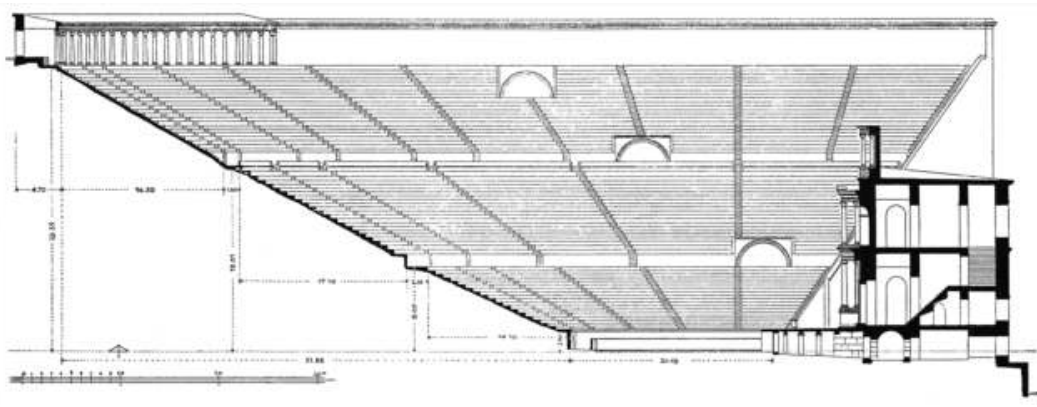

Textabb. 12: Schnitt durch das rekonstruierte kaiserzeitliche Theater (HEBERDEY u. a. 1912)

Im ÖAI-Archiv befindet sich ein unpubliziertes Manuskript, das aus Basel stammt, 1987 aber dem ÖAI übergeben worden war. Es handelt sich um den Entwurf und die Handreinschrift eines Aufsatzes von K. Stehlin mit dem Titel »Rekonstruktion der römischen Fassade des Szenenhauses zu Ephesos«. Dieses undatierte Manuskript bezieht sich anscheinend auf den Aufsatz von H. Hörmann ${ }^{34}$.

Nach heutigem Wissensstand wurden erst ein halbes Jahrhundert nach den ersten Ausgrabungen des ÖAI wieder Arbeiten am Theater aufgenommen. Um die Mitte der 1950er Jahre begannen zunächst unter Leitung des Archäologischen Museums in Izmir Freilegungen im Bereich des südlichen Aufgangs auf das untere Diazoma (Taf. 6 Abb. 10). Auch wurden erste Konsolidierungen am Monument geplant und durchgeführt ${ }^{35}$. Ab 1959 fanden seitens des Museums in Selçuk unter Leitung von M. Baran weitere Arbeiten statt ${ }^{36}$. Wie Archivaufnahmen zeigen, war das Auditorium des Theaters jedoch noch bis Anfang der 1960er Jahre groß-

\footnotetext{
${ }^{34}$ Dieses Manuskript wird in der Endpublikation zum Bühnengebäude ausführlich behandelt, s. ÖzTÜRK (in Vorbereitung).

${ }^{35}$ Hinweise darauf geben Fotos und Berichte im Archiv des Archäologischen Museums in Izmir. Dem Ministerium für Kultur und Tourismus in Ankara sei für die Genehmigung der diesbezüglichen Recherche gedankt. Herzlicher Dank gebührt auch dem ehemaligen stellvertretenden Direktor des Museums, dem Archäologen H. Köktürk, für die Unterstützung während der Archivarbeit.

${ }^{36}$ SCHERRER 1995, 44; Wiplinger - Wlach 1996.
} 
teils mit Erde bedeckt (Taf. 7 Abb. 11). Von der lokalen Bevölkerung wurde die Ruine bereits ab dieser Zeit als Festplatz für das jährliche Selçuker Maifestival genutz $\mathrm{t}^{37}$. Mit großflächigen Freilegungsarbeiten begann das Museum erst um die Mitte der 1960er Jahre unter Leitung von S. Türkoğlu. Ab Ende 1966 wurden auch Vorbereitungen zur Restaurierung getroffen und großteils bis Anfang der 1970er Jahre umgesetzt. In Teilbereichen dauerten die Restaurierungen sowie die Arbeiten zur Rekonstruktion der Sitzstufen bis 1979 an $^{38}$. Diese Etappe der Freilegung des Theaters von Mitte der 1950er bis zum Ende der 1970er Jahre sowie damit einhergehende Konsolidierungen, Restaurierungen und Rekonstruktionen waren nur wenig dokumentiert und können derzeit kaum noch im Einzelnen nachvollzogen werden. Einen kleinen Einblick in den Arbeitsprozess während der Ausgrabung überlieferte die italienische Archäologin D. De Bernardi Ferrero, die das Theater zum Zeitpunkt der Tätigkeiten besuchte und fotografisch festhielt (Taf. 7 Abb. 12; 8 Abb. 13) ) $^{39}$.

Etwa in diese Zeit fiel auch die kurze Grabungstätigkeit W. Alzingers im Bereich des Logeion ${ }^{40}$. Ziel seiner Untersuchung sollten Hinweise auf das hellenistische Proskenion sein, »insbesondere dessen vorderste Begrenzung $«{ }^{41}$. Das sollte nicht gelingen, doch brachten Alzingers Ergebnisse gute Argumente und Anhaltspunkte für die jüngsten Untersuchungen.

Anfang der 1990er Jahre wurden erneut Forschungen im Auditorium aufgenommen. Vor dem Hintergrund einer mit dem Österreichischen Bundesministerium für Wissenschaft und Forschung geplanten Zusammenarbeit übernahm F. Hueber für das Museum in Selçuk die Arbeiten ${ }^{42}$. Die Untersuchungen konzentrierten sich auf das untere Diazoma und führten zu einer Teilrekonstruktion des Marmorbelags an den Eintrittspunkten der vomitoria ${ }^{43}$.

\subsection{AKTUELLE PROJEKTE}

Seit der Restaurierung und Teilrekonstruktion des Stufenkörpers in den 1970er Jahren entwickelte sich das Theater im Rahmen der Ephesos-Besichtigungen zu einem beliebten Besucherziel und wurde seit 1987 auch verstärkt für musikalische Großveranstaltungen genutzt (Textabb. 13) ${ }^{44}$. Bis Anfang der 1990er Jahre hatte sich jedoch der Zustand der Ruine aufgrund von Witterung, Bewuchs und moderner Nutzung derart verschlechtert, dass eine sichere Besichtigung des Bauwerks in verschiedenen Bereichen nicht mehr gegeben war und das Gebäude durch die türkische Generaldirektion für Monumente und Museen für Besucher gesperrt werden musste. Vor diesem Hintergrund trat die türkische Antikenverwaltung 1992 an die österreichische Grabungsleitung mit dem Wunsch nach einer Sanierung des Monuments heran ${ }^{45}$.

Die Arbeiten des ÖAI erfolgten zunächst 1993 bis 1998 unter der Leitung von St. Karwiese als Grabungsleiter in Zusammenarbeit mit dem Architekten I. Ataç. Nach einer Aufnahme der Schäden wurden in einem ersten Projektabschnitt bis 1996 dringende Maßnahmen zur Konsolidierung des Theaters durchgeführt ${ }^{46}$. Die Arbeiten konzentrierten sich vorrangig auf die westlichen Gebäudeflügel inklusive der Fassaden und Substruktionen sowie die äußeren Umfassungswände des Auditorium (Taf. 8 Abb. 14). In diesem Zusammenhang führte man auch weitere Freilegungsarbeiten in den Zugangskorridoren zum unteren und mittleren Diazoma (Taf. 133 Abb. 268. 269) sowie entlang der äußeren Umfassungswände durch (Taf. 9 Abb. 15). Gleichzeitig wurde unter Leitung von St. Klotz erstmals eine Gesamtdokumentation des seit Mitte der 1950er Jahre in Etappen freigelegten und restaurierten Auditorium auf Basis einer digitalen Vermessung begonnen. Nach Abschluss der dringendsten Konsolidierungsmaßnahmen konnten die beiden unteren Ränge 1995 wieder für

\footnotetext{
37 Vetters 1966, 34 f.; Karwiese Archiv ÖAI.

${ }^{38}$ Atalay 1972, 46 f.; Scherrer 1995, 44.

${ }^{39}$ Vgl. z. B. De Bernardi Fererro 1970, 58 Abb. 55. 56.

${ }^{40}$ Das Ergebnis ist unpubliziert, liegt aber in Form von Tagebuchnotizen und einigen Zeichnungen im Archiv des ÖAI vor.

${ }^{41}$ Grabungstagebuch vom 05.06.1969.

${ }^{42}$ Karwiese Archiv ÖAI.

${ }^{43}$ Kap. 2.4 u. 10.2.4.2.

${ }^{44}$ Protokoll zur Sitzung der Theater-Kommission am 29.01.1999 an der ÖAW, 2 (Archiv ÖAI Wien).

${ }^{45}$ Karwiese 1994, 31.

${ }^{46}$ KarWIESE ARChIV ÖAI.
} 


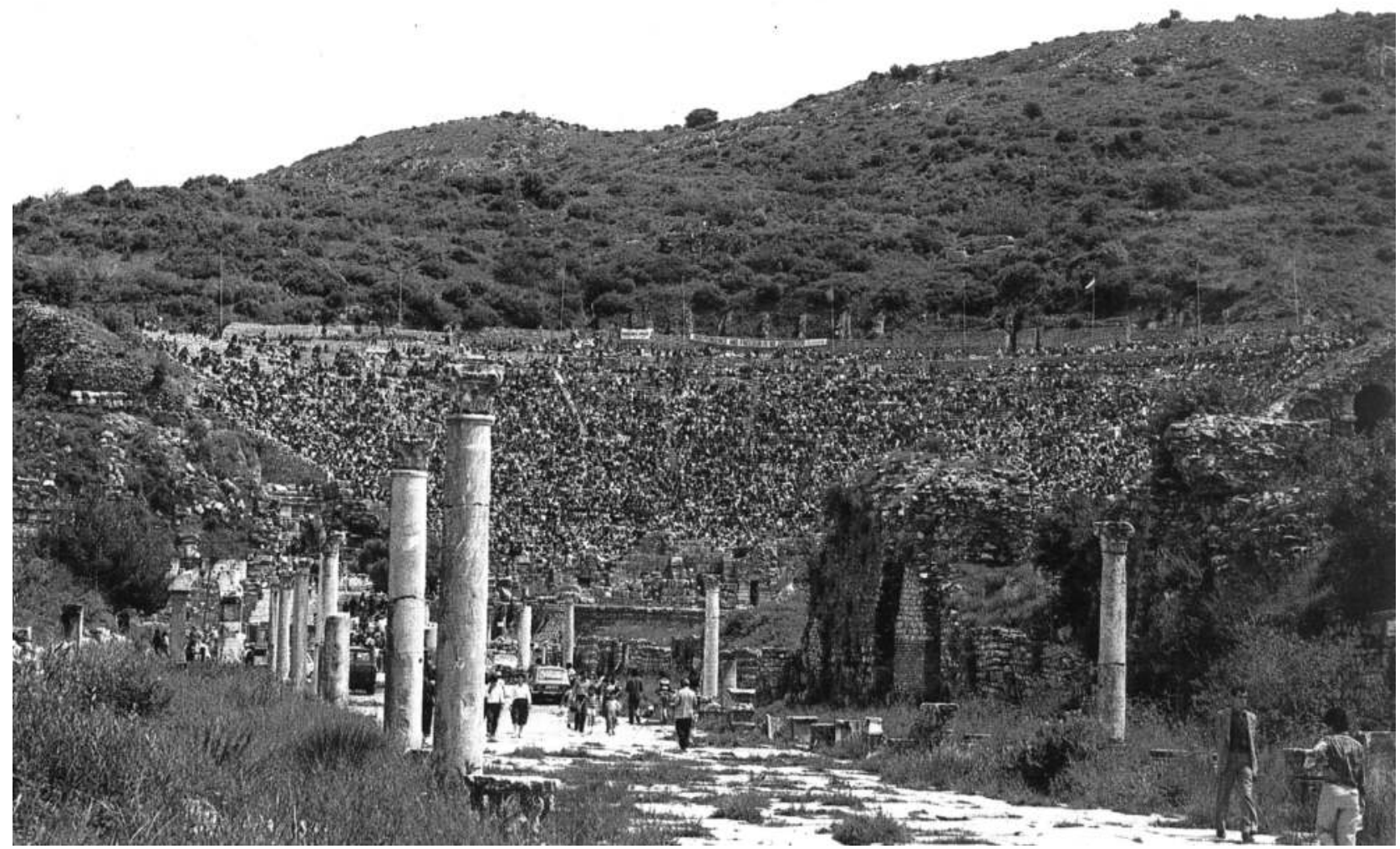

Textabb. 13: Eine Großveranstaltung im Theater. Postkarte (vermutlich Anfang der 1980er Jahre)

Besucher geöffnet werden. Der obere Rang sowie das Bühnengebäude blieben weiterhin aus Sicherheitsgründen gesperrt ${ }^{47}$.

Von 1996 bis 1998 widmeten sich die Arbeiten verstärkt der Bauforschung und archäologischen Freilegung bisher wenig untersuchter Bereiche des Auditorium. Dazu zählten besonders die noch immer stark verschütteten Zugangskorridore zu den Rängen. Unterstützung erhielt die österreichisch-türkische Projektkooperation im Rahmen der europäischen Forschungsinitiative EUREKA/EUROCARE ${ }^{48}$.

Im Rahmen der Arbeiten von St. Karwiese und I. Ataç wurden 1997 und 1998 erste baugeschichtliche Untersuchungen am Bühnengebäude von A. Öztürk durchgeführt. Diese wurden nach einjähriger Unterbrechung im Jahr 2000 als ein ÖAI-Projekt wieder aufgenommen und im Jahr 2005 abgeschlossen ${ }^{49}$. Nach einer Ordnung der Architekturteile wurden insgesamt 668 Bauglieder der Bühnenfassade gesammelt, nummeriert und gemäß ihrer Abfolge im baulichen Zusammenhang in der Palästra des Theatergymnasiums ausgelegt (Taf. 9 Abb. 16). Der gesamte bauliche in situ-Bestand des Bühnengebäudes sowie sämtliche dislozierten Bauteile wurden einer eingehenden bauhistorischen Dokumentation unterzogen ${ }^{50}$. Die Inschriften, die in unmittelbarem Zusammenhang mit dem Bühnengebäude stehen, wurden erneut von F. Dönmez Öztürk (Mimar Sinan Universität der schönen Künste, Istanbul) aufgenommen.

\footnotetext{
${ }^{47}$ KARWIESE 1996, 29.

${ }^{48}$ KARWIESE 1997b, 61; Zu THEATEPH Project EU 1384 s. a. <http://eurocare.factlink.net/fsDownload/1384_TEATETH.pdf? forumid=274\&v=1\&id=142034> (08.05.2017).

${ }^{49}$ Dabei konnten auch Schäden am Bühnengebäude und die Möglichkeit für eine Anastylose der scaenae frons geprüft werden; vgl. ÖZTÜRK 2006a, 205-218; ÖZTüRK 2006b, 206-209.

${ }^{50}$ An der jährlich achtwöchigen Dokumentationsarbeit in Ephesos haben jeweils fünf bis sechs Mitarbeiter teilgenommen. Zu den Mitarbeitern s. die Berichte, die jährlich in den Jahresheften des Österreichischen Archäologischen Instituts (ÖJh) erschienen sind.
} 
Die vorläufigen Ergebnisse der baugeschichtlichen Arbeiten über das Bühnengebäude und die scaenae frons wurden bereits in mehreren Aufsätzen vorgelegt, eine Abschlusspublikation von A. Öztürk mit Beiträgen von M. Hofbauer ist in Vorbereitung ${ }^{51}$.

Im Zuge des 1998 erfolgten Wechsels in der Grabungsleitung in Ephesos von St. Karwiese zu F. Krinzinger, der seit 1999 auch die Gesamtprojektleitung am Theater übernommen hatte, kam es zu einer Verlagerung des Schwerpunkts. Die archäologischen Arbeiten an den bis 1998 sanierten Analemmata wurden beendet, während die Bauforschung am Koilon und am Bühnengebäude fortgesetzt wurde. Die Durchführung der Grabungstätigkeit oblag seit dem Jahr 2001 M. Hofbauer. Bis 2006 konnten das hellenistische und kaiserzeitliche Bühnengebäude, der Bereich der kaiserzeitlichen Bühne und die Orchestra einer eingehenden archäologischen Untersuchung unterzogen werden (Plan 2) ${ }^{52}$.

Vor dem Hintergrund der von türkischer Seite geplanten Wiedernutzung des Gebäudes in seiner ursprünglichen Funktion als Veranstaltungsort wurde 1999 an der Österreichischen Akademie der Wissenschaften eine international besetzte Theater-Kommission eingerichtet. Ziel der Kommission war es, Grundlagen und Prinzipien festzulegen, die langfristig eine Balance zwischen der notwendigen denkmalpflegerischen Erhaltung und somit dem Schutz des Monuments einerseits sowie einer modernen Nutzung des Theaters als Veranstaltungsort andererseits gewährleisten sollten. Gemäß den internationalen Deklarationen >Charta di Siracusa<, >Charta di Verona oder >Charta di Segesta< sind eine vollständige bauhistorische Untersuchung sowie die formtreue Bauaufnahme und Dokumentation des Bestands eine unabdingbare Voraussetzung dafür.

Im Rahmen der Kooperationen mit dem Institut für Kulturgeschichte der Antike an der Österreichischen Akademie der Wissenschaften und dem Österreichischen Archäologischen Institut ${ }^{53}$ führte das Fachgebiet Baugeschichte/Bauforschung der Technischen Universität Wien unter Leitung von M. Döring-Williams seit 2003 die von St. Karwiese und I. Ataç begonnene bauhistorische Untersuchung des Auditorium fort. Die Durchführung und Leitung der Arbeiten im Feld oblag, nach V. Capresi und H. A. Liebich, seit 2007 G. Styhler-Aydın ${ }^{54}$. Auf Basis eines 3D-Laserscans und Messungen mit der Totalstation erfolgte bis 2010 die detaillierte Dokumentation und Analyse der gesamten freiliegenden Gebäudesubstanz des Zuschauerraums inklusive moderner Veränderungen und Ergänzungen ${ }^{55}$.

Um für die Wiedernutzung des Theaters die Zugangsmöglichkeiten zu schaffen, wurde, begleitet durch mehrere Sitzungen der Theater-Kommission, ab 2005 ein Konzept zur Gestaltung der Zugänge für Tagesund Veranstaltungsbesucher erarbeitet ${ }^{56}$. Dafür sollten das vomitorium ES1 und die große Stiegengasse im Süden des Theaters freigelegt werden. Diese verband nicht nur die drei südlichen Tore des Theaters (ES1ES3) untereinander, sondern stellte die Anbindung zum Straßensystem der Stadt her (Taf. 1 Abb. 1; Plan 17). Erste vorbereitende Arbeiten erfolgten bereits 2006; zwischen 2007 und 2009 wurde die Freilegung der gesamten Treppe bewerkstelligt (Pläne 12-16). Die archäologischen Arbeiten im vomitorium ES1 mussten aus statischen Gründen eingestellt werden. 2010 und 2011 fanden kurze Nachuntersuchungen statt. Die bislang völlig ungeklärte Situation im Osten des Theaters wurde 2009 von M. Tschannerl untersucht.

Ebenfalls 2009 begann unter der Leitung des Österreichischen Archäologischen Instituts (ÖAI) die Planung und Durchführung umfangreicher, dringend notwendiger Restaurierungsarbeiten am Monument ${ }^{57}$.

\footnotetext{
${ }^{51}$ ÖzTüRK 2005a, 209-214; ÖzTÜRK 2005b, 4-14; ÖzTÜRK 2006a, 205-218; ÖzTÜRK 2006b, 206-209; ÖzTÜRK 2010, 331-342; ÖZTÜRK (in Vorbereitung).

${ }_{52}$ Aus diesen Untersuchungen ging die ungedruckte Dissertation HofBaUER 2007 hervor.

${ }^{53}$ Seit 2007 war das Projekt am Institut für Kulturgeschichte der Antike (IKAnt) der Österreichischen Akademie der Wissenschaften (ÖAW) angesiedelt und wurde von P. Ruggendorfer koordiniert.

${ }^{54} \mathrm{Zu}$ Arbeitsschwerpunkten, Mitarbeitern und Mitarbeiterinnen der Kampagnen seit 2003 s. a. JAHRESBERICHT 2003,356 f.; JAhresbericht 2004, 336 f.; JahresBericht 2005, 330 f.; JAhresbericht 2006, 404-406; ÖAI-Bericht 2008,15 f.; ÖAI-Bericht 2009, 12; ÖAI-BERICHT 2010, 25-28.

${ }^{55}$ Zur Aufnahmemethodik s. Döring-Williams - Liebich 2003. Teilergebnisse dieser Forschungen wurden seit 2004 auf internationalen Konferenzen vorgestellt oder liegen als Aufsätze vor, s. Liebich - STYHLER 2009; STYHLER 2010; STYHLER-AYdiN 2010.

${ }^{56}$ Basis war eine Studie zur Nutzung des Theaters als Veranstaltungsort, 2005 vorgelegt an der ÖAW, Projektleitung M. DöringWilliams (TU Wien), Bearbeitung: H. A. Liebich, G. Styhler-Aydın.

${ }^{57}$ Projektleitung: E. Tekin. Vgl. ÖAI-Bericht 2009, 20 f.; ÖAI-Bericht 2010, 45-48; ÖAI-Bericht 2011, 34 f.
} 


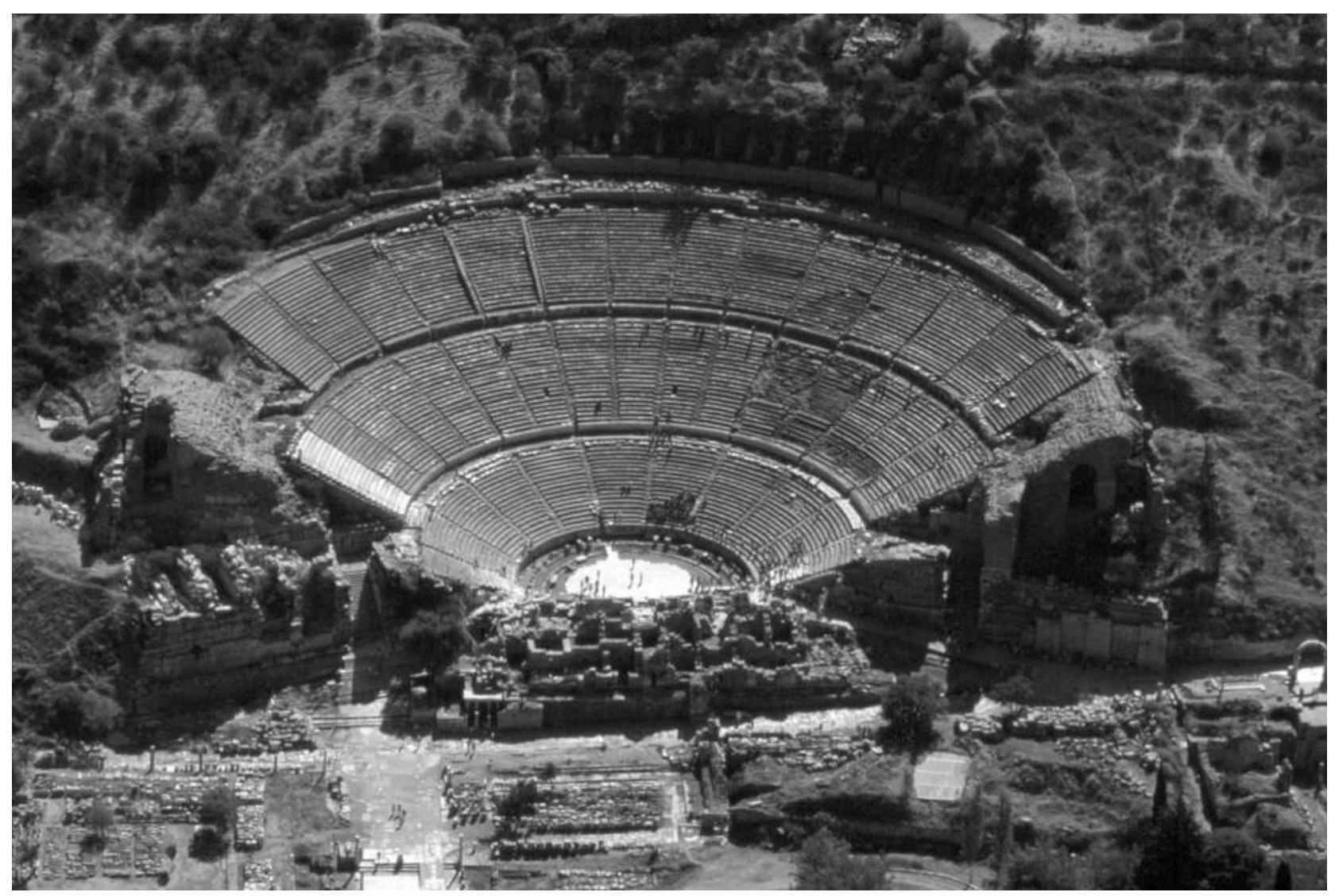

Textabb. 14: Luftaufnahme des Theaters von Westen

Heute zeigt sich das Theater, anders als für die ersten Forscher, nicht allein als Zeugnis seiner historischen Nutzungs- und Verfallsgeschichte. Vielmehr bestimmen besonders die Restaurierungs- und Sicherungsmaßnahmen der Zeit nach der Freilegung sein aktuelles, teilweise neuzeitliches Erscheinungsbild (Textabb. 14).

M. HofBAUER

A. ÖZTÜRK

G. STyHLER-AydiN 


\section{Erhaltungszustand}

\subsection{SKENE}

Der größte und heute weithin sichtbare Teil des Theaters ist das in den Hang des Panayırdağ gebaute Koilon (Textabb. 2. 3; Plan 1). Um die Skene errichten zu können, musste das von der Orchestra nach Nordwesten hin stark abfallende Gelände durch das Anlegen einer aufgeschütteten Terrasse angeglichen werden. An der Nordwestecke ist die aus großen Polsterquadern errichtete Terrassenmauer noch etwa 4,50 m über dem heutigen Niveau der Marmorstraße sichtbar (Taf. 17 Abb. 27). Ihre etwa gleich hohen Quaderreihen weisen Niveausprünge auf und haben meist vertikale, zum Teil schräge Stoßfugen. Nördlich der an das Bühnengebäude anschließenden byzantinischen Stadtmauer ist die Terrassenmauer deutlich besser erhalten als im Süden.

Den Kern der heute sichtbaren Anlage bildet die hellenistische Skene (Tab. 127; Taf. 430 Abb. 758. 759). Das Untergeschoss ist bis auf die Nordwestecke beinahe vollständig erhalten, wird an einigen Stellen aber durch kaiserzeitliches Mauerwerk verdeckt. Es ist aus gut gefügten, isodom geschichteten Porosblöcken ausgeführt und gehört mit 41,65 m Länge und 10,77 m Breite zu den größten Bühnengebäuden Kleinasiens. Im Inneren bestand die Skene aus einem von Nord nach Süd verlaufenden Korridor A (Taf. 10 Abb. 17), in dem heute nur das kaiserzeitliche Mauerwerk zu sehen ist. An allen Türen aber lässt sich das hellenistische Mauerwerk gut erkennen. Zu betreten war die Skene durch Türen im Norden und Süden des Korridors. Drei Türen, von denen zwei nachgewiesen sind, führen nach Osten in das Proskenion und zur Orchestra. Nach Westen schließt eine Reihe von zweimal vier Kammern (D1-4; D5-8), die durch einen 2,60 m breiten Durchgang $\mathrm{C}$ getrennt sind, an den Korridor A an (Taf. 3 Abb. 3). Jeweils drei Kammern vom mittleren Durchgang $C$ nach Norden und Süden haben ihre Zugänge vom Korridor aus. Die beiden äußersten Kammern D1 und D8 sind von Westen über die Theaterterrasse aus zugänglich. Sie haben im Untergeschoss keinerlei Verbindung zum Korridor A. In den Kammern ist das hellenistische Mauerwerk ohne spätere Verkleidung sichtbar. Deutlich ist auch die Konstruktion der Zwischendecke zum Obergeschoss zu erkennen. Balkenlöcher und Bretternuten (Taf. 17 Abb. 28) geben eine gute Vorstellung vom Aussehen der hölzernen Einbauten. In den äußeren Kammern D1 und D8 sind jeweils in der Südhälfte Fundamente erhalten, die mit Türen im Oberstock korrespondieren. Diese Kammern sind somit als Treppenhäuser anzusprechen.

Deutlich schlechter ist der Erhaltungszustand des hellenistischen Obergeschosses (Taf. 18 Abb. 29). Vor allem im Nordteil ist davon vielfach nichts mehr erhalten. Hier wurden die Mauern bis auf das Niveau der Zwischendecke aus Kunststein wieder aufgebaut. Besser ist die Situation in der südlichen Hälfte. Hier wird stellenweise die Höhe der Dachbalken erreicht. So klar sich der Grundriss des Untergeschosses nachvollziehen lässt, so sehr täuschen spätere Abänderungen und Umbauten das Auge im Obergeschoss, was zu fehlerhaften Rekonstruktionen (Taf. 11 Abb. 18) und daraus resultierenden Erklärungsmodellen geführt hat ${ }^{1}$. Das Schema, langer Korridor im Osten und Kammerreihen nach Westen, wiederholt sich, wenngleich die Kammern hier ursprünglich anders organisiert waren als im Untergeschoss ${ }^{2}$. Die Westwand des Korridors A' wird nicht von kaiserzeitlichen Mauern verdeckt, war also sichtbar. An einigen Stellen wurden in späterer Zeit Pfeiler errichtet (Taf. 13 Abb. 21; 18 Abb. 29). Dafür wurde die Mauer an diesen Stellen teilweise zerlegt und mit den Pfeilern im Verband wieder errichtet. Die Ostseite war in Form einer siebentorigen Thyromata-Fassade gestaltet. Die weißgrauen Marmorquader der zweiten Phase sind im Mauerwerk der römischen scaenae frons erhalten geblieben. Das nördliche und südliche Marmorwandstück trägt eine Liste

\footnotetext{
${ }^{1}$ W. Wilberg nahm alle vorhandenen Mauern im Obergeschoss, unabhängig von der Mauertechnik, bereits für die hellenistischen Phasen an und rekonstruierte den Grundriss in Analogie zum Untergeschoss, s. Heberdey u. a. 1912, 10 f. Die Situation der Eingänge in diese Kammern muss als unbefriedigend bezeichnet werden. Leider wurde sie ein Jahrhundert lang nie überprüft. $\mathrm{DE}$ BernARdi FerRero 1970, 49-66 scheint sich mit Wilbergs unkonventionellem Lösungsvorschlag recht unwohl gefühlt zu haben, sucht aber eher nach Erklärungen für dieses Modell als es in Frage zu stellen.

${ }^{2}$ Kap. 10.1.1 Obergeschoss
} 
mit den Namen der Agonotheten ${ }^{3}$. Die Liste reicht bis in die Jahre 18/17 v. Chr. und belegt damit eine Nutzung des hellenistischen Baus zumindest bis in die augusteische Zeit hinein. Bauaktivitäten in der frühen Kaiserzeit sind durch eine Stifterinschrift an der Archivolte des Eingangs ES3 ${ }^{4}$ belegt.

Für das Bühnengebäude erfolgte eine tiefgreifende Umgestaltung in flavischer Zeit (Tab. 127; Taf. 12 Abb. 20; 13 Abb. 21; 430 Abb. 758. 759; Plan 18). Sie prägt das Erscheinungsbild auch heute noch maßgeblich, auch wenn der Erhaltungszustand des kaiserzeitlichen Baus in Anbetracht seiner einstigen Größe und der architektonischen Gestaltung der Schaufassade als deutlich schlechter bezeichnet werden muss als der des hellenistischen Vorgängers. Wie zuvor betont, wurde die hellenistische Skene nicht beseitigt. Sie dürfte zum Zeitpunkt des Umbaus intakt gewesen sein. Die stärkere Zerstörung der hellenistischen Mauern an der Nordwestecke geht an dieser Stelle auch am kaiserzeitlichen Bau mit einer gleichermaßen umfangreicheren Verwüstung als an anderen Gebäudeteilen einher. Die Schäden an beiden Bausubstanzen gehören derselben Zeit an.

Die auffälligste Veränderung am hellenistischen Untergeschoss ist die Einwölbung des Korridors A. Dieser erhält entlang seiner beiden Längswände jeweils eine vorgeblendete Mauer (Taf. 12 Abb. 20) aus wiederverwendeten Polsterquadern als Auflager eines flachen Gewölbes aus Bruchsteinen. Da man die Höhe des Geschosses weitgehend beibehalten hatte, ging der Einbau des Gewölbes zu Lasten der Türen in die Kammern D2 bis D7. Sie sind deutlich niedriger als die Zugänge hellenistischer Zeit. Aufgegeben wurden auch zwei der Türen nach Osten. Nur die mittlere Öffnung blieb erhalten. An den Kammern gab es keine Änderungen. Allerdings wurde das Gebäude nach Westen bis zur Terrassenmauer durch eine zusätzliche Reihe von Räumen erweitert. Von ihnen sind heute die Mauern aus stark verwitterten, aber sehr sorgfältig bearbeiteten und verklammerten grauen Marmorquadern zu sehen. Das Grundrissschema entspricht dem der hellenistischen Kammern. Jeweils vier Kammern (E1-E4; E5-E8) befinden sich zu beiden Seiten des nach Westen verlängerten Durchgangs C (Taf. 3 Abb. 3). Der schmale Durchgang (Taf. 51 Abb. 98), den der Betrachter von außen erblickt, täuscht. Er hatte ursprünglich die gleiche Weite wie sein hellenistischer Vorgänger. Die Spolien, die zu seiner Verschmälerung geführt haben, entstammen späterer Zeit und hängen mit dem schweren Gussmauerwerk darüber zusammen. Die kaiserzeitlichen Kammern haben wie die hellenistischen keine Verbindung untereinander.

An die Stelle der Thyromata trat eine reich geschmückte scaenae frons ${ }^{5}$. Sie ist über einem massiven Unterbau errichtet, dem ein ca. 2,65 m hohes Bühnenpodium vorgesetzt war, und erhob sich etwa auf dem Niveau des hellenistischen Obergeschosses. Die ephesische scaenae frons besaß eine dreigeschossige Tabernakelfassade (Textabb. 15). Bei der Freilegung wurde das erste Geschoss bis in eine Höhe von ca. $4 \mathrm{~m}$ in seiner ursprünglichen Lage vorgefunden. Die gesamte Fassade misst ca. $43 \mathrm{~m}$ in Nord-Süd-Richtung und ist etwa 3,70 m tief. Die Rückwand wird von fünf Türen durchgebrochen, die in das Bühnengebäude führten. Zwischen der Mitteltür und den großen seitlichen Türen sind jeweils zwei Sockel zu einem Doppelsokkel vereint. Über diesen ist je eine große Nische mit Ädikula zu erkennen. Die Wandebene wird durch Pilaster gegliedert, vor denen die Frontsäulen standen. Die Säulenstellung erhebt sich über einer alternierend vor- und rückspringenden Sockelzone mit je zwei Säulen. Den nördlichen und südlichen Abschluss der scaenae frons bildeten jeweils zwei Pfeiler. Da das untere Geschoss der scaenae frons nirgendwo den oberen Abschluss erreicht, können die oberen Ordnungen nur rekonstruiert werden ${ }^{6}$, was in Folge von J. T. Woods Aktivitäten allen späteren Forschern große Mühen bereitet hat ${ }^{7}$. Im Inneren wurden die Räume verkleinert und entsprachen nun den Kammern im Untergeschoss. Damit ging auch eine Abänderung der Zugänge einher. Zwischen den Kammern D'4 und D'5 sind die unteren Stufen einer nach oben führenden Treppe erhalten (Taf. 34 Abb. 61). Eine erst späte Vermauerung der Tür zu Kammer D'8 lässt vermuten, dass auch die aus hellenistischer Zeit stammenden Treppenhäuser in den beiden äußersten Kammern im Bühnengebäude der Kaiserzeit weiterhin in Verwendung waren.

Der Norden des Bühnengebäudes ist durch starke Überformungen geprägt. Bei all diesen Resten handelt es sich nicht unbedingt um spätere Ergänzungen. Eine Schwelle nahe dem Nordeingang in den Korridor A

\footnotetext{
${ }^{3}$ IvE 9.

${ }^{4}$ IvE 2033.

${ }^{5}$ Kap. 10.2.1 mit Textabb. 15.

${ }^{6}$ Zur scaenae frons der römischen Kaiserzeit, s. Kap. 10.2.1; ÖZTÜRK (in Vorbereitung).

${ }^{7}$ ADLER 1872, 38 bezeichnet J. T. Woods Hinterlassenschaft als »ein unbeschreibliches Chaos von Bruchstücken«.
} 
belegt möglicherweise eine Verbauung des Areals bereits seit flavischer Zeit. Ähnlich dürfte die Situation auch im Süden gewesen sein. Die niedrigen, aber deutlich erkennbaren Mauern gehören zu einer teilweise mit Mosaiken ausgestatteten Raumabfolge, die wohl am Ende des 1. oder zu Beginn des 2. Jhs. n. Chr. entstanden sind. Deutlich jünger sind die den nördlichen Zugang begleitenden Brunnenbecken, die in byzantinischer Zeit sehr beliebt waren und an vielen Stellen um das Theater festzustellen sind. Der Stadtmauerbau, der das Theater in den Verteidigungsring integrierte ${ }^{8}$, blieb nicht ohne Folgen für das Bühnengebäude. Die Außenmauern mussten verstärkt werden und viele Eingänge wurden verschlossen. Mit bis zu 2,5 m starken, aus riesigen Spolien errichteten Mauern schien das Theater im 6. oder 7. Jh. n. Chr. einen festungsartigen Charakter erhalten zu haben (Taf. 40 Abb. 72; 46 Abb. 85; 47 Abb. 86; 51 Abb. 96).

M. HOFBAUER

A. ÖZTÜRK

\subsection{PROSKENION}

Unmittelbar vor dem Sockel der scaenae frons geben zwei Säulenreihen und eine Pfeilerstellung mit Stylobat die Ausmaße der römischen Bühne an (Taf. 430 Abb. 758; Plan 10. 18). Diese hatte ein steingedecktes Logeion, wie einige Platten am Nord- und Südende der Bühne bezeugen. Die Bühnenfront stand an der Wende vom 19. zum 20. Jh. noch teilweise aufrecht und wurde erst im Zuge der Arbeiten am Theater vollständig abgetragen. Über den schrägen Seitenteilen der Bühnenfront (Mauern P und Q; Taf. 12 Abb. 20; 13 Abb. 21) ist der Rest eines schmalen Metopen-Triglyphen-Frieses mit Konsolengesims zu sehen (Taf. 78 Abb. 152; 436 Abb. 770. 771). Die Teile gehörten der römischen Bühnenfront an. Vom hellenistischen Proskenion ist nichts mehr erhalten. An seiner Stelle wurde die scaenae frons errichtet.

M. HOFBAUER

\subsection{ORCHESTRA}

Die Orchestra zeigt heute den Zustand mehrerer Bauphasen (Taf. 13 Abb. 21; 77 Abb. 151; Plan 18). Der teilweise renovierte Boden und der äußere Umgang gehören einer frühantoninischen Umgestaltungsphase an (Tab. 127). Zu dieser gehört ein kleiner Rest eines Abwasserkanals im Norden. Dieser verlief einst um die Orchestra und befand sich über einem älteren Kanal aus hellenistischer Zeit. Letzterer wurde nach den Ausgrabungsarbeiten um 1900 offen gelassen und prägt das heutige Erscheinungsbild nachhaltig. Der hellenistische Kanal war nicht gedeckt. In den Achsen der Koilontreppen wurden aber Steinplatten als Brücken darüber gelegt, die eine Verbindung zwischen dem Zuschauerbereich und der Orchestra herstellten (Taf. 432 Abb. 762. 763). Der flavisch-trajanische Bau nutzte weiterhin den alten Kanal. Dazu wurde er innen mit einer rötlichen Putzschicht versehen und erhielt durchgängig Deckplatten, wovon heute nur mehr die Kantenabarbeitungen der Kanalwangen zeugen.

In hellenistischer Zeit reichten die Sitzreihen näher an den Orchestrakanal heran, wurden aber im Zuge des kaiserzeitlichen Umbaus abgetragen. Die Oberkante des älteren Kanals gibt somit das Bodenniveau der hellenistischen Orchestra an. Von diesem ist an den sichtbaren Stellen nichts mehr erhalten. Die Zone um den Ringkanal wurde bei Grabungsarbeiten um 1900 aufgegraben und anschließend wieder verfüllt. Dabei wurde auch ein ringförmiges, heute nicht mehr sichtbares Steinfundament innerhalb des Ringkanals freigelegt (Taf. 4 Abb. 6; 13 Abb. 21). In der Achse der Treppen des 1. Rangs sind Brückensteine teils noch in situ erhalten, teils ist ihre einstige Lage durch Ausarbeitungen an den beiden Wandungen des Kanals zu

\footnotetext{
${ }^{8}$ Foss 1979, 106 f. Abb. 35 gibt an der Südseite des Theaters die Fortifikationslinie von der Südwestecke des Theaters bis etwa auf Höhe der Verlängerung der Akademiegasse an, was sich mit den im vorliegenden Band vorgestellten Ergebnissen deckt. Einzig das bei Foss eingezeichnete Tor an der Theater-Südwestecke kann nicht verifiziert werden. Hier dürfte wohl eher das Tor im Westen des Bühnengebäudes gemeint sein, dass in der Foss'schen Abbildung tatsächlich fehlt, s. Pülz 2010, 68. Zur vergleichbaren Situation in Milet, s. NIEWÖHNER 2008, 181-201.
} 
erkennen. Die westlichen Enden des hellenistischen Kanals sind von der römischen Bühne geringfügig überbaut. Reparaturen und Reste von Verputz im Kanal bezeugen, dass der Kanal nach dem Umbau des 1. Jhs. n. Chr. weiterverwendet wurde. Abarbeitungen an den Oberkanten der Kanalwandungen deuten auf eine Eindeckung des Kanals in der Kaiserzeit.

Von der hochkaiserzeitlichen Orchestra sind Reste des Marmorplattenbelags bzw. dessen Mörtelbettung heute noch erhalten und gut sichtbar. Im Zuge der Restaurierungsarbeiten der 1960er und 1970er Jahre wurde dieser Plattenboden ergänzt (Taf. 77 Abb. 151). Zu den kaiserzeitlichen Phasen gehört ein umlaufendes Profil im Abstand von 1,55 m (>Profilring`) zum hellenistischen Ringkanal (Plan 18). Die darüber zu ergänzenden Marmorschranken trennen einen Umgang an der Stelle der einstigen unteren Sitzreihen von der Orchestra ab. Gegenwärtig führt vom Umgang nur eine der Radialtreppen (T11) zu den Sitzreihen hinauf. Ob das ursprünglich so der Fall war, lässt sich derzeit nicht sagen. Große Teile der Wand des Koilon sind restauriert. Auffallend ist jedoch, dass die Struktur der Wandgestaltung der etwa 1,80 m hohen Mauer die Treppenbereiche deutlich zeigt (Taf. 444 Abb. 789). Der Boden des Umgangs war, wie heute noch zu sehen ist, durch radial verlaufende Marmorplatten in einzelne Sektoren unterteilt und mit opus sectile ausgestattet. Geringe Reste davon sind erhalten.

M. HofBAuER

\subsection{AUDITORIUM}

Der räumliche Eindruck des Theaters nach Abschluss der kaiserzeitlichen Erweiterungs- und Modernisierungsphasen um die Mitte des 2. Jhs. n. Chr. mit dem monumentalen, vollständig in weißem Marmor verkleideten und reich ausgestatteten Auditorium ist für einen heutigen Besucher kaum noch nachvollziehbar (Tab. 127). Es existiert lediglich noch ein Bruchteil der einstigen repräsentativen Marmorverkleidung der Sitzbereiche, der Ausstattung mit Sitzbänken sowie der Ausschmückung mit Inschriften und Statuen. Hingegen wird die aktuelle Wahrnehmung des Monuments stark durch die Unterkonstruktion des Stufenkörpers bestimmt. Gegenwärtig sind vom Auditorium zweiundvierzig der ehemals fünfundfünfzig keilförmigen Sektoren mit ihren Sitzstufen und den dazugehörigen Radialtreppen erhalten (Taf. 2 Abb. 2; Plan 1). Ausgehend von diesem aktuellen Bestand können zwei Drittel des sichtbaren Sitzstufenunterbaus als bauzeitlich eingeordnet werden. Zu einem Drittel wurde die Stufenform in den Restaurierungsphasen des 20. Jhs. wieder aufgebaut, weicht jedoch in Maß und Form vom bauzeitlichen Bestand oft ab. Die aus der Errichtungszeit erhaltenen Sektoren befinden sich hauptsächlich im Bereich des terrassierten Berghangs. Anders verhält es sich mit den auf Substruktionen lagernden Abschnitten des Zuschauerraums. Hier sind die Ränge vielfach eingestürzt oder haben sich lediglich als geneigte opus caementitium-Oberfläche ohne die charakteristische Stufenform der ansteigenden Sitzreihen erhalten. Die für die Herstellung des Sitzstufenunterbaus verwendeten bauzeitlichen und modernen Materialien können an den Ansichtsflächen der Sitzreihen sehr gut unterschieden werden (Taf. 15 Abb. 24). Besonders auffallend sind dabei die Sicherungen und Teilrekonstruktionen des 20. Jhs. Im Rahmen dieser Arbeiten erfolgten auch Konsolidierungen an den Diazomata. Während die Maßnahmen am oberen und mittleren Umgang sich vorrangig auf die Diazoma-Wände konzentrierten, wurden auf dem unteren Diazoma zusätzlich zur Sicherung der Wand auch Zonen des Laufbelags rekonstruiert. Jeweils am nördlichen und südlichen Eintrittspodest der vomitoria (EN1. ES1) auf das Diazoma bzw. im direkt anschließenden Bereich des Umgangs sind Fragmente der vorgefundenen Bodenplatten aus Marmor neu verlegt worden. Auch die in diesem Bereich erfolgte Eindeckung der Sitzreihen mit dislozierten Sitzplatten der ehemaligen Marmorverkleidung steht mit der Rekonstruktion des Laufbelags in Zusammenhang9.

\footnotetext{
${ }^{9}$ Eine Dokumentation der baulichen Sicherungen an den Diazoma-Wänden liegt nach heutigem Kenntnisstand nicht vor. Die Arbeiten standen unter der Verantwortung des Museums und sind vermutlich in die Phase der umfassenden Konsolidierung und Rekonstruktion des Monuments während der 1960er/1970er Jahre einzuordnen. Die Teilrekonstruktionen am unteren Diazoma erfolgten hingegen erst um 1992 vor der Wiederaufnahme der Forschungen durch das ÖAI unter der Leitung von F. Hueber, s. auch Kap. 1.2 u. 3.6.1.
} 
Die rangbezogen an der Theateraußenwand angeordneten Publikumszugänge sind trotz nachträglicher Veränderungen sowohl im Norden als auch im Süden nachvollziehbar ${ }^{10}$. Einschließlich der Gewölbe besthen jedoch nur noch die vomitoria zum mittleren Diazoma. Auch sie zeigen besonders an den Tonnengewölben aus Werkstein starke Beschädigungen. Zum unteren Diazoma führten - annähernd parallel zu den Analemmata verlaufende - tonnenüberwölbte Korridore von 40-42 m Länge (EN1. ES1), die über westseitig anschließende Treppenaufgänge (EN1 West; ES1 West) auch von der Marmorstraße aus betreten werden konnten (Plan 7. 8. 17). Teilbereiche dieser Korridore sind bis heute durch massiven Versturz unzugänglich. Dennoch ist erkennbar, dass sich die hoch aufragenden Seitenwände mit den in Orthostaten-Binder-Technik angeordneten Marmorquadern und dem Kämpfergesims partiell erhalten haben. Das abschließende Werksteingewölbe sowie die zum Aufbau der Rangneigung oberhalb angeordneten Substruktionskammern sind jedoch eingestürzt. Einzig auf der Südseite zeigen einige Bogenquader des Tonnengewölbes, die in fünf Reihen oberhalb des Kämpfergesimses noch in situ liegen, die ursprüngliche Gewölbekonstruktion (Taf. 14 Abb. 22).

Die beiden westseitig an die Korridore anschließenden Treppenaufgänge (EN1 West; ES1 West) wurden in einer modernen Restaurierungsphase, vermutlich in Zusammenhang mit der Konsolidierung der Ränge, erneut begehbar gemacht. Hierfür richtete man den ursprünglichen Treppenunterbau unter Verwendung von Bruchstein, Spolienfragmenten und Mörtelverguss derart wieder her, dass die an den Seitenwänden erhaltenen Kontaktflächen der ehemaligen Marmorstufen sichtbar blieben und so die bauzeitliche Tritthöhe der einzelnen Stufen bis heute anzeigen (Taf. 14 Abb. 23). Im Bereich der nördlichen und südlichen Theateraußenwand wurden sämtliche Publikumszugänge nachträglich verschlossen (Plan 4. 5). Die erhaltenen Verschlussmauern haben überwiegend den Charakter statischer Sicherungsmaßnahmen ${ }^{11}$. Ferner spielten die Umnutzung von Gebäudeteilen ${ }^{12}$ sowie fortifikatorische Überlegungen durch die Einbindung des Theaters in den Verlauf der byzantinischen Stadtmauer eine Rolle (Taf. 1 Abb. 1; 146 Abb. 294).

Auch eine der vier die Stadt Ephesos versorgenden Fernwasserleitungen, die Aristion-Leitung ${ }^{13}$, durchquert das Auditorium und hat sich im baulichen Bestand fast vollständig erhalten (Taf. 152 Abb. 309. 310; 154 Abb. 314. 315; 155 Abb. 316; 159 Abb. 326; 160 Abb. 327. 328). Ihr Verlauf im Gebäude korrespondiert räumlich und konstruktiv mit der Anlage der zwei vomitoria EN2 im Norden und ES1 im Süden ${ }^{14}$.

Im Westen wird das Auditorium von ca. $60 \mathrm{~m}$ langen Analemmata begrenzt, die gegenwärtig noch bis zu 10,0 m Höhe mit ihrer Fassadenarchitektur erhalten sind (Plan 7. 8). Oberhalb dieser Bereiche ist durch den Ausbruch der Fassadenquader oftmals der Wandkern sichtbar. Bei vollständigem Einbruch der Fassade zeigt sich das dahinter liegende Kammersystem. An beiden Analemmata haben in der 2. Hälfte des 20. Jhs. mehrfach Konsolidierungs- und Restaurierungsarbeiten stattgefunden. So wurde unter anderem die südliche Gebäudeecke restauriert und am oberen Abschluss zusätzlich eine Betonkrone zur Sicherung der erhaltenen Wandstruktur angebracht. Während der Konsolidierungen konzentrierten sich die Arbeiten von 1993 bis 1998 vor allem auf die Sicherung der vielfach ausgebrochenen und instabil liegenden Wandquader des Mauerkerns ${ }^{15}$. Eine weitere Aufgabe stellte der Schutz der stark durch Witterung und Bewuchs erodierten opus caementitium-Oberflächen in den Bereichen der Substruktionskammern dar. Der Erhaltungszustand der Umfassungswände im Norden und Süden ist mit dem der Analemmata vergleichbar. Auch hier ist die Fassade in den unteren Bereichen bis in eine Höhe von ca. $6 \mathrm{~m}$ intakt. In den oberhalb folgenden Schichten liegen vor allem die Quader des Wandkerns in statisch unsicherer Position und wurden ebenfalls bei den Restaurierungsarbeiten der 1990er Jahre durch Unterfütterungen aus Bruchstein, auch als Mauerplomben bezeichnet, stabilisiert (Taf. 16 Abb. 25). Seitdem das Theater vor nun über 140 Jahren in das

\footnotetext{
${ }^{10}$ Einzig für den Zugang des oberen Rangs können im Norden aufgrund des Erhaltungszustands des Theaters keine Aussagen getroffen werden. R. Heberdey und W. Wilberg gingen von einer dem Eingang ES3 im Süden vergleichbaren Erschließungsmöglichkeit aus, s. Heberdey u. a. 1912, 41. Aufgrund der anderen topografischen Situation im Norden, fehlender baulicher Evidenzen sowie der neuen Kenntnisse über den Verlauf des Stadtrasters bleibt dies gegenwärtig jedoch fraglich, vgl. GroH 2006.

${ }^{11}$ Eine moderne Veränderung erfolgte am nördlichen Zugang zum mittleren Diazoma. Sowohl J. T. Wood als auch die ersten Ausgräber des ÖAI fanden ihn noch verschlossen vor, s. Wood 1877, 69; HeBERDEY u. a. 1912, 52. 164 f. Heute ist der obere Teil der Mauer, inkl. einer damals in situ befindlichen Dankschrift über die Wiederherstellung des Theaters (IvE 2043), abgetragen.

${ }^{12}$ Beispielhaft sei genannt der Umbau des nördlichen unteren vomitorium EN1 in einen Wasserspeicher, s. Kap. 10.3.4.

${ }^{13}$ Kap. 3.6.1.

${ }^{14}$ Kap. 10.2.4.2.

${ }^{15}$ KARWIESE 1994-1998.
} 
Interesse der Forschung rückte, sind zahlreiche Bauteile der verstürzten Architektur und Skulpturenausstattung während der etappenweisen Freilegungen und verschiedenen Restaurierungsphasen beräumt und zum Teil für die wissenschaftliche Bearbeitung außerhalb des Gebäudes - vor allem auf dem `Theaterplatzı sowie auf der Palästra des Theatergymnasiums, aber auch nördlich des Theaters - ausgelegt worden (Taf. 9 Abb. 16; 16 Abb. 26). Andere Fragmente lagern witterungsgeschützt in Depots auf dem Grabungsgelände. Besondere Einzelobjekte befinden sich in den Museen in Selçuk und Wien sowie im British Museum in London ${ }^{16}$.

G. STYHLER-AYDIN

${ }^{16}$ Dazu zählen z. B. die Inschrift des C. Vibius Salutaris im British Museum London sowie der Erotenjagdfries im Ephesos-Museum in Wien. 


\section{Archäologischer Befund}

\section{EINLEITUNG}

Zwischen 1896 und den 1970er Jahren des 20. Jhs. wurde das ephesische Theater im Innenbereich vollständig freigelegt, umfangreichen Restaurierungsarbeiten unterzogen und schließlich als Veranstaltungsort verwendet. Als am Beginn der 1990er Jahre von Seiten der türkischen Regierung zur Sicherung der aufragenden Baumassen erneut eine Sanierung des Gebäudes gewünscht war, wurde diese zunächst vom Efes-Museum Selçuk organisiert. Mit der Übernahme der Arbeiten durch das ÖAI kam es ab 1993 zu einer Reihe von archäologischen Untersuchungen innerhalb und außerhalb des Theaters, die - mit einer Unterbrechung in den Jahren 1999 und 2000 - bis 2011 andauerten.

Die archäologischen Maßnahmen fanden begleitend zu den für die Sanierung notwendigen baugeschichtlichen und bautechnischen Untersuchungen statt. Erste Tiefsondierungen konnten, nachdem viele Tonnen an oberflächigem Hangschutt entfernt worden waren, in den Jahren 1997 und 1998 unter St. Karwiese im Bereich der aus dem Berghang heraustretenden Flügel vorgenommen werden. Daraus ließ sich bereits eine recht komplexe Geschichte eines fortwährenden Ausbaus des Zuschauerraums ablesen. 1998 erfolgten auch erste Sondierungen an der südlichen Außenseite des Theaters als Vorbereitung für eine projektierte Freilegung der Zugänge ES1 bis ES3, deren Durchführung zwischen 2007 und 2009 realisiert wurde. Die vom Verfasser getätigten Grabungen konzentrierten sich ab 2001 auf das Bühnengebäude, den Bereich der römischen Bühne (das sog. Logeion) und die Orchestra ${ }^{1}$. Das Bühnenareal wurde zu einem großen Teil freigelegt, wobei die Arbeiten aufgrund der beschränkt zur Verfügung stehenden freien Grabungsfläche, der sicherzustellenden $\mathrm{Zu}$ gänglichkeit für die Besucher und für die weiterhin stattfindenden Veranstaltungen nur in mehreren Etappen zwischen 2001 und 2005 erfolgen konnten. Dabei wurden auch ältere Grabungsbereiche unter Berücksichtigung aktueller Erkenntnisse einer erneuten Untersuchung zugänglich gemacht. Dies betraf den mittleren Durchgangsbereich, größere Teile in der Nordhälfte des Logeion mit dem von W. Alzinger 1969 sondierten Areal und Abschnitte am südlichen Ende des Bühnenbereichs. Die Zielsetzung war, Aufschluss über den tiefgreifenden Umbau der hellenistischen Anlage zum Theater der römischen Kaiserzeit zu bekommen sowie eventuelle spätere Bau- und Reparaturmaßnahmen feststellen zu können. Die Grabungen im Bühnengebäude erfolgten sowohl in den Räumen des hellenistischen Kernbaus als auch in der kaiserzeitlichen Erweiterung im Westen des hellenistischen Baus. Hier stand vor allem die Frage nach der Entstehungszeit des hellenistischen Theaters im Vordergrund, die bislang auf Vermutungen basieren musste.

Die beiden in der Orchestra durchgeführten Schnitte (S 3/2004 und S 1/2005) sollten neue Aufschlüsse über die kaiserzeitlichen Umgestaltungen des Theaters erbringen. Vor allem die zeitliche Stellung dieser Maßnahmen stand in besonderem Interesse, wenngleich auch hier, infolge der umfangreichen Altgrabungen und des relativ dicht unter der Oberfläche zu erwartenden Felsuntergrunds, eine gewisse Zurückhaltung bezüglich des Aussagewerts der Befunde in Rechnung zu stellen war.

\footnotetext{
${ }^{1}$ Mitarbeiter und Dauer der Feldkampagnen von 2001-2011: - Kampagne 2001: 30.07.-14.08.2001; - Kampagne 2002: 15.07.-09.08.2002; - Kampagne 2003: 02.07.-02.08.2003, Mitarbeiterin: M. Skoric †; - Kampagne 2004: 27.08.-30.09.2004, Mitarbeiter: S. Swientek; - Kampagne 2005: 22.08.-23.09.2005, Mitarbeiter: S. Swientek; - Kampagne 2006: 23.03.-10.04.2006 und 24.07.-22.09.2006, MitarbeiterInnen: M. Gessl; J. Reuk1; S. Swientek; M. Weißsteiner; - Kampagne 2007: 30.04.27.10.2007, Mitarbeiterinnen: N. Fuchshuber; J. Köck; S. Mayer; P. Mayerhofer; J. Reukl; M. Weißsteiner; - Kampagne 2008: 10.07.-18.10.2008, MitarbeiterInnen: F. Dinius; M. Gessl; M. Grebien; B. Öhlinger; K. Preindl; U. Reiterer; N. Reitinger; Kampagne 2009: 01.06.-11.07.2009, Mitarbeiterin: B. Öhlinger; - Kampagne 2010: 13.09.-24.09.2010; - Kampagne 2011: 12.09.-23.09.2011. Allen Mitarbeitern und Mitarbeiterinnen sei an dieser Stelle herzlichst gedankt. Die Aufarbeitung der Grabungsjahre 1993-1998 wurde von B. Öhlinger übernommen. Für die freundliche Bereitstellung der Dokumentation sowie zahlreiche Hinweise und Gespräche darf St. Karwiese aufs herzlichste gedankt werden. Zu den Arbeiten vgl. auch Kap. 1.3.
} 
Von 2006 bis 2008 verlagerte sich die archäologische Tätigkeit im Theaterinneren auf den Zuschauerraum. Da die Sitzränge in den 1970er Jahren bis auf den anstehenden Fels bzw. den darüber errichteten Unterbau für die Sitzreihen freigelegt worden waren, und somit der Bauforschung bereits offen vorlagen, kamen für eine archäologische Sondierung nur mehr die Diazomata selbst in Betracht. Wie im Fall der Orchestra musste auch bei den Grabungen auf den Diazomata damit gerechnet werden, dass sich in der äußerst dünnen Planierung zwischen dem Felsuntergrund und dem antiken Plattenbelag - bzw. der rezenten Schotterung - möglicherweise nur geringe Hinweise für Datierungsfragen finden lassen würden. Die Untersuchungen fanden darum in enger Zusammenarbeit mit der Bauforschung statt, für die, neben den Beobachtungen an den freiliegenden Rängen der ima, media und summa cavea und den Flügelbauten sowie den unter St. Karwiese getätigten Grabungen, zusätzliche Erkenntnisse über die komplexe Baugeschichte des Zuschauerraums erwartet werden konnten.

Der größte zusammenhängende Grabungsbereich lag im Süden des Theaters. Hier wurde ein Teil des Schutts über dem Süd-Analemma (Zugangssystem ES1) entfernt und eine vom unteren Zugang ES1 bis zum oberen Zugang ES3 reichende monumentale Treppe freigelegt, welche die Theaterzugänge verbunden und über einen Anschluss an die Akademiegasse verfügt hat. Die von R. Heberdey hypothetisch erschlossene Verbindung zwischen ES1 und der Marmorstraße ist grabungstechnisch bislang nicht nachgewiesen. Die große Grabungsfläche ließ darüber hinaus vor allem auf weitere Erkenntnisse zur Geschichte des Theaters und der Stadt hoffen. Das durchschnittlich $33^{\circ}$ steile Gelände wurde aus grabungstechnischen und sicherheitsrelevanten Gründen in mehrere Grabungsabschnitte (A1-K2) unterteilt und abschnittsweise flächig abgegraben. Es mussten immer wieder Stufen für einen sicheren Abtransport des Aushubmaterials angelegt werden, was die Schichtgrabung deutlich aufwendiger gestaltete. Darum sollte ein mittleres Profil zwischen den Reihen 1 und 2 nicht nur der Dokumentation, sondern auch einer stetigen Überprüfung des Schichtbefunds dienen, der im Wesentlichen aus Zerstörungsschutt auf Zerstörungsschutt bestand.

Östlich des Theaters, unmittelbar hinter der Rückwand der Portikus, oberhalb der summa cavea wurde 2009 von M. Tschannerl eine Sondierung durchgeführt. Damit sollte die Situation und Bedeutung der hinter dem Theater befindlichen radialen Mauerzüge untersucht werden.

Die Lage der einzelnen Sondagen ist in einer Übersicht dargestellt (Plan 2). Zu den einzelnen Bereichen des Theaters und seinen Bezeichnungen s. den Abschnitt zur Terminologie im Kapitel »Hinweise und Verzeichnisse« (Taf. 2 Abb. 2; 3 Abb. 3; Plan 18).

\begin{tabular}{|c|c|c|c|}
\hline Bezeichnung & Lage & Kapitel & Abbildungen \\
\hline Sondage $1 / 1969$ & röm. Bühne (Nord) & 3.2 .2 .3 & Plan 2; Taf. 59 Abb. 113; 63 Abb. 121 \\
\hline \multirow[t]{2}{*}{$\begin{array}{l}\text { KK + >Doppelstiegen- } \\
\text { haus } \text { ( }(1997)\end{array}$} & \multirow[t]{2}{*}{ Zugangssystem EN1 } & $\begin{array}{l}3.5 .1 .1 .1 \\
\text { (= Nord })\end{array}$ & $\begin{array}{l}\text { Plan 2; Taf. } 127 \text { Abb. 254; } 128 \text { Abb. 256. 257; } 129 \\
\text { Abb. 260; } 131 \text { Abb. 264; } 132\end{array}$ \\
\hline & & 3.5.1.1.2 (= Süd) & Plan 2; Taf. 129 Abb. 258. 259 \\
\hline KN1 (1997) & Nord-Analemma, Kammer KN1 & 3.5 .1 .2 & $\begin{array}{l}\text { Plan 2; Taf. } 127 \text { Abb. 254; 134; } 135 \text { Abb. 272; } 136 \\
\text { Abb. } 275\end{array}$ \\
\hline KN2 (1997) & Nord-Analemma, Kammer KN2 & 3.5 .1 .3 & $\begin{array}{l}\text { Plan 2; Taf. } 127 \text { Abb. 254; } 128 \text { Abb. 256; } 137 \text { Abb. } \\
277\end{array}$ \\
\hline Sondage $1 / 1998$ & unteres Diazoma/EN1 & 3.5.1.4.1 & Plan 2; Taf. 137 Abb. 278; 138; 139 Abb. 281 \\
\hline Sondage 2/1998 & EN1 Treppenabsatz & 3.5.1.4.2 & Plan 2; Taf. 139 Abb. 282; 140 Abb. 283. 284; 141 \\
\hline Sondage 3/1998 & Zugangssystem ES3 & 3.6.4.1 & Plan 2; Taf. 188 Abb. 386; 189-191; 192 Abb. 393 \\
\hline Sondage $4 / 1998$ & Zugangssystem EN2 innen & 3.5.2.1.1 & Plan 2; Taf. 142-145 \\
\hline Sondage 5/1998 & Zugangssystem EN2 außen & 3.5 .2 .1 .2 & Plan 2; Taf. 146. 147 \\
\hline vomitorium ES1 (1998) & Zugangsystem EN1 & 3.6 .3 & Plan 2; Taf. 185 Abb. 379. 380; 186 \\
\hline Sondage $1 / 2001$ & röm. Bühne (Mitte) & $3.2 .2 .1,3.2 .2 .2$ & $\begin{array}{l}\text { Plan 2. 10; Taf. 52; 56; 58; } 60 \text { Abb. 114; 62; } 63 \\
\text { Abb. } 120\end{array}$ \\
\hline Sondage $1 / 2002$ & röm. Bühne (Mitte) & 3.2 .2 .2 & Plan 2. 10; Taf. 56. 57. 60. 61 \\
\hline Sondage $2 / 2002$ & Bühnengebäude, Kammer D3 & 3.1.1.1 & Plan 2. 10; Taf. 18 Abb. 30; 19; 20 Abb. 32 \\
\hline Sondage $1 / 2003$ & röm. Bühne (Süd) & 3.2 .2 .5 & $\begin{array}{l}\text { Plan 2. 10; Taf. 70; } 71 \text { Abb. 138. 140; } 72 \text { Abb. } \\
\text { 141; } 73\end{array}$ \\
\hline
\end{tabular}




\begin{tabular}{|c|c|c|c|}
\hline Bezeichnung & Lage & Kapitel & Abbildungen \\
\hline Sondage $2 / 2003$ & röm. Bühne (Süd) & 3.2 .2 .5 & $\begin{array}{l}\text { Plan 2. 10; Taf. } 70 \text { Abb. 137; } 71 \text { Abb. 138; } 72 \\
\text { Abb. 142; 74; 75; } 76 \text { Abb. 146. } 147\end{array}$ \\
\hline Sondage $3 / 2003$ & röm. Bühne (Mitte) & 3.2.2.1 & Plan 2. 10; Taf. 53; 54 Abb. 103. 104 \\
\hline Sondage $4 / 2003$ & röm. Bühne (Süd) & 3.2 .2 .6 & $\begin{array}{l}\text { Plan 2. 10; Taf. } 70 \text { Abb. 137; } 71 \text { Abb. 138; } 76 \\
\text { Abb. 148; } 77 \text { Abb. 149. } 150\end{array}$ \\
\hline Sondage $1 / 2004$ & Bühnengebäude, Kammer E3 & 3.1.2.2 & Plan 2. 10; Taf. 24-27 \\
\hline Sondage $2 / 2004$ & Bühnengebäude, Kammer E1 & 3.1.2.1 & Plan 2. 10; Taf. 22. 23 \\
\hline Sondage $3 / 2004$ & Orchestra (Ost) & 3.3 .1 & Plan 2. 10; Taf. 82 Abb. 163; 83-87 \\
\hline Sondage $4 / 2004$ & $=$ Sondage $1 / 2005$ & & \\
\hline Sondage $5 / 2004$ & röm. Bühne (Nord) & 3.2 .2 .3 & Plan 2. 10; Taf. 64-67 \\
\hline Sondage $6 / 2004$ & röm. Bühne (Mitte) & 3.2.2.1 & Plan 2. 10; Taf. 52 Abb. 99; 54 Abb. 105; 55 \\
\hline Sondage $7 / 2004$ & Bühnengebäude, Kammer E5 & 3.1 .2 .3 & Plan 2. 10; Taf. 28-30; 31 Abb. 52 \\
\hline Sondage $1 / 2005$ & Orchestra (Nord) & 3.3 .2 & $\begin{array}{l}\text { Plan 2. 10; Taf. } 88 \text { Abb. 175. 176; 89-91; } 92 \text { Abb. } \\
182\end{array}$ \\
\hline Sondage $2 / 2005$ & Bühnengebäude, Kammer D8 & 3.1 .1 .2 & Plan 2; Taf. 20 Abb. 33; 21 \\
\hline Sondage $3 / 2005$ & Bühnengebäude, Kammer E8 & 3.1 .2 .5 & Plan 2; Taf. 35 \\
\hline Sondage $4 / 2005$ & röm. Bühne (Süd) & 3.2.2.4 & Plan 2; Taf. 68.69 \\
\hline Sondage $5 / 2005$ & Raum RN1 & 3.1.3.1 & Plan 2; Taf. 36. 37 \\
\hline Sondage $6 / 2005$ & Raum RN1 & 3.1 .3 .2 & Plan 2; Taf. 38 Abb. 68 \\
\hline Kammer E7 & Bühnengebäude, Kammer E7 & 3.1.2.4 & Taf. 32 \\
\hline Sondage $1 / 2006$ & $=$ Aristion-Leitung & 3.6 .1 & Plan 2; Taf. 152 Abb. 309. 310; 153-167 \\
\hline Sondage $2 / 2006$ & unteres Diazoma & 3.4 .1 .1 & Plan 2; Taf. 92 Abb. 183; 93; 94 Abb. 186. \\
\hline Sondage $3 / 2006$ & unteres Diazoma & 3.4.1.2 & Plan 2; Taf. 94 Abb. 187; 95; 96 Abb. 190 \\
\hline Sondage $4 / 2006$ & unteres Diazoma & 3.4.1.3 & Plan 2; Taf. 96 Abb. 191; 97 \\
\hline Sondage $5 / 2006$ & unteres Diazoma & 3.4.1.4 & Plan 2; Taf. 98; 99 Abb. 196 \\
\hline Sondage $6 / 2006$ & unteres Diazoma & 3.4.1.5 & Plan 2; Taf. 99 Abb. 197; 100-102 \\
\hline Sondage $7 / 2006$ & unteres Diazoma & 3.4 .1 .6 & Plan 2; Taf. 103; 104 Abb. 206 \\
\hline Sondage $8 / 2006$ & unteres Diazoma & 3.4 .1 .7 & Plan 2; Taf. 104 Abb. 207; 105 Abb. 208 \\
\hline Sondage $1 / 2008$ & mittleres Diazoma & 3.4.2.1 & Plan 2; Taf. 105 Abb. 209; 106-112; 113 Abb. 225 \\
\hline Sondage $2 / 2008$ & mittleres Diazoma & 3.4.2.2 & Plan 2; Taf. 113 Abb. 226; 114 Abb. 227 \\
\hline Sondage $3 / 2008$ & mittleres Diazoma & 3.4.2.3 & Plan 2; Taf. 114 Abb. 228; 115 \\
\hline Sondage $4 / 2008$ & mittleres Diazoma & 3.4.2.4 & Plan 2: Taf. 116; 117; 118 Abb. 235 \\
\hline Sondage $5 / 2008$ & mittleres Diazoma & 3.4 .2 .5 & Plan 2; Taf. 119. 120 \\
\hline Sondage $6 / 2008$ & oberes Diazoma & 3.4.3.1 & Plan 2; Taf. 121; 122; 123 Abb. 245 \\
\hline Sondage $7 / 2008$ & $\begin{array}{l}\text { Stiegengasse-Süd,Zugangspodest } \\
\text { ES2, Teil der Grabungsfläche F2 }\end{array}$ & 3.7 .2 .2 & Plan 2 \\
\hline Sondage $8 / 2008$ & oberes Diazoma & 3.4.3.2 & Plan 2; Taf. 123 Abb. 246; 124 \\
\hline KS1 $(2007 / 2008)$ & Süd-Analemma, Kammer KS1 & 3.6.2.1 & Plan 2. 12; Taf. 173 Abb. 354. 355; 174-177 \\
\hline KS2 (2007) & Süd-Analemma, Kammer KS2 & 3.6.2.2 & Plan 2. 12; Taf. 172; 178-180 \\
\hline KS3 (2007) & Süd-Analemma, Kammer KS3 & 3.6 .2 .3 & $\begin{array}{l}\text { Plan 2. 12; Taf. 172; } 178 \text { Abb. 364; 181-184; } 185 \\
\text { Abb. } 378\end{array}$ \\
\hline $\begin{array}{l}\text { Stiegengasse-Süd } \\
(2007-2009)\end{array}$ & $\begin{array}{l}\text { südlich des Theaters im Bereich } \\
\text { der Zugänge ES1-Süd bis ES3 }\end{array}$ & 3.7 .1 & $\begin{array}{l}\text { Plan 2. 12-17; Taf. } 192 \text { Abb. 394; 193-289; 291- } \\
296\end{array}$ \\
\hline ETH09-Ost & im Osten, oberhalb des Theaters & 3.8 & Plan 2; Taf. 297-301 \\
\hline
\end{tabular}

Tab. Grabungsflächen 


\subsection{BÜHNENGEBÄUDE}

\subsubsection{Hellenistisches Bühnengebäude}

\subsubsection{Sondage S 2/2002 (KAMmer D3)}

\begin{tabular}{|c|c|c|c|c|c|}
\hline Schicht & OK in $\mathbf{m}$ & UK in $\mathbf{m}$ & Beschreibung/Interpretation & Keramik & Münzen \\
\hline SE B1 & 10,77 & 10,69 & rezenter Betonboden & - & - \\
\hline SE B2 & 10,69 & 10,61 & Schotterung unter Betonboden, rez. & - & - \\
\hline SE B3 & 10,61 & 10,56 & $\begin{array}{l}\text { grober Schutt mit zahlreichen kleinen } \\
\text { Steinen }\end{array}$ & $\begin{array}{l}\text { 2. H. 1.-Anfang 2. Jh. } \\
\text { n. Chr., einige Frgte. } 4 . \\
\text { Jh. n. Chr. }\end{array}$ & - \\
\hline SE B4 & 10,56 & 10,50 & Asche (Feuerstelle) & $\begin{array}{l}\text { 2. H. 1. Jh. v. Chr.- } \\
\text { Anfang 1. Jh. n. Chr., } \\
1 \text { Frgt. 4.-7. Jh. n. Chr. }\end{array}$ & - \\
\hline SE B5 & 10,56 & $\begin{array}{l}10,44- \\
10,38\end{array}$ & $\begin{array}{l}\text { hellbrauner Schutt mit Steinen und } \\
\text { Mörtelbrocken }\end{array}$ & 1. H. 1. Jh. n. Chr. & $\begin{array}{l}\text { M } 96 \text { (1. Jh. v. Chr.- } \\
\text { 1. Jh. n. Chr.) }\end{array}$ \\
\hline SE B6 & $\begin{array}{l}10,44- \\
10,38\end{array}$ & $\begin{array}{l}10,33- \\
10,23\end{array}$ & $\begin{array}{l}\text { hellbrauner, sandiger Schutt mit Steinen } \\
\text { und Kalksteinabschlag }\end{array}$ & $\begin{array}{l}\text { vorhell.-frühhell., } 1 \\
\text { Frgt. 1. Jh. v. Chr. }\end{array}$ & M 5 (klass.-frühhell.) \\
\hline SE B7 & 10,33 & 8,83 & rotbrauner Schutt mit Steinen & 1. H. 2. Jh. v. Chr. & - \\
\hline SE B8 & $\begin{array}{l}10,23- \\
10,00\end{array}$ & $9,58-9,40$ & $\begin{array}{l}\text { hellbrauner tlw. rötlicher Schutt mit Steinen } \\
\text { und Brekzieabschlag }\end{array}$ & 1. H. 2. Jh. v. Chr. & - \\
\hline SE B9 & 10,45 & 9,58 & $\begin{array}{l}\text { mittel- bis mittelbrauner Schutt mit } \\
\text { wenigen kleinen Steinen }\end{array}$ & arch.-klass. & - \\
\hline SE B10 & $9,40-9,58$ & $8,91-8,74$ & $\begin{array}{l}\text { mittel- bis dunkelbrauner Schutt mit } \\
\text { wenigen kleinen Steinen }\end{array}$ & $\begin{array}{l}\text { 1. H.-Mitte 2. Jh. } \\
\text { v. Chr. }\end{array}$ & - \\
\hline SE B11 & 8,83 & 8,04 & mittelbrauner Schutt mit kleinen Steinen & $\begin{array}{l}\text { 1. H.-Mitte 2. Jh. } \\
\text { v. Chr. }\end{array}$ & - \\
\hline SE B12 & 8,04 & 7,42 & brauner Schutt & arch.-frühhell. & - \\
\hline Fels & 7,42 & - & gewachsener Fels & - & - \\
\hline
\end{tabular}

Tab. 1

Das vorrangige Ziel der Grabungstätigkeit in der hellenistischen Skene war die Datierung der ursprünglichen Anlage. Da das natürliche Gelände westlich der Orchestra nach Nordwesten hin stark abgefallen ist, musste der Platz für den Bau der Skene terrassiert und aufgeschüttet werden. Im Nordwesten der Theaterterrasse reichte diese Aufschüttung bis zu 4,50 m über das Straßenniveau empor, weshalb die Untersuchungen im nördlichen Teil des Gebäudes begonnen wurden. Die Kammern D1 und D2 schieden aufgrund moderner Einbauten für den Veranstaltungsbetrieb aus. So fiel die Wahl auf Kammer D3, die immer noch ein hoch anstehendes Füllmaterial sowie eine weitgehende Unversehrtheit unterhalb des rezenten Betonbodens erwarten ließ. Der Beton wurde auf einer Breite von 2,0 $\mathrm{m}$ in der nördlichen Raumhälfte abgetragen und das darunter befindliche Schotterbett entfernt. Zunächst wurden die östlichen 2,50 m bis in eine Tiefe von etwa 1,50 m unter Bodenniveau ( $T^{\mathrm{a}} 9,07 \mathrm{~m}$ ) gegraben, ab hier auf etwa $1 \mathrm{~m}$ entlang der Nordfundamente verschmälert und bis auf ein Niveau von T 7,74 m vertieft. Damit wurde die Unterkante der Fundamente in der Nordostecke erreicht. In weiterer Folge wurde die Grabung bis an die Westmauer ausgedehnt. Die Fundamente des hellenistischen Baus (Taf. 20 Abb. 32) ruhen auf dem gewachsenen Boden, der teils aus Fels, teils aus einer dichten, lehmigen, gelb-weiß gesprenkelten Verwitterungsschicht besteht. Kleinere Unebenheiten wurden mit einer Mischung aus Lehm und kleinen Steinen ausgeglichen. Der Aufbau zeigt gleichmäßig durchlaufende Horizontalfugen. Die Höhe der Steinlagen variiert zwischen 0,32 und 0,46 m. Die oberste Fundamentschar weist eine durchschnittliche Höhe von $0,23 \mathrm{~m}$ auf. Lager- und Stoßflächen wurden mit dem Spitzeisen vorbereitet, die Frontflächen sind grob bearbeitet. Obwohl das Füllmaterial im Fundamentbereich zwischen 
den wandnahen Zonen im Norden und den weiter entfernten geringfügig differiert (Taf. 18 Abb. 30), ließ sich keine Baugrube nachweisen. Vielmehr zeichnet sich ein Schichtaufbau ab, der relativ klar mehrere Niveaus unterscheidet, die mehr oder weniger horizontal verlaufen (Taf. 19 Abb. 31). In Fundamentnähe ist dichter Steinabschlag auf Höhe der einzelnen Niveaus zu erkennen. Daraus kann man Arbeitsniveaus ableiten, die den Bau der Fundamente begleiteten. Die Einbringung der Verfüllung ging mit dem Aufbau der Fundamente Hand in Hand. Nachdem die Fundamente - und wahrscheinlich auch die Terrassenmauer selbst - eine gewisse Höhe erreicht hatten, wurde der verbleibende Raum mit Schutt gefüllt und einigermaßen eben abgezogen. Daraufhin konnte wieder an den Fundamenten gearbeitet werden, bis diese erneut eine gewisse Höhe erreicht hatten, wie die Steinabschlagschichten belegen. Dadurch erreichte man einerseits geringe Arbeitshöhen für das Versetzten der Blöcke, andererseits konnte sich auf diese Weise das Füllmaterial besser verdichten.

Die unterste Füllschicht SE B12 war direkt über dem anstehenden Fels aufgebracht. Im darüber befindlichen Stratum SE B11 zeichnet sich deutlich eine Schüttrichtung von Ost nach West ab (Taf. 19 Abb. 31). Im Wesentlichen enthielt SE B11 nur kleinere Steine, jedoch entlang des Fundaments der Ostmauer ein deutliches Niveau aus Kalksteinabschlag an der Oberfläche. Die darüber liegende Zone unterscheidet sich zwischen Nord und Süd (Taf. 18 Abb. 30): mittel- bis dunkelbrauner Schutt von großer Homogenität in der Südhälfte (SE B10), helleres Material mit zahlreichen kleineren bis mittelgroßen Steinen am Nordfundament (SE B7). Wieder wird die Oberfläche, diesmal am Westfundament, durch eine dichte Lage aus Kalksteinabschlag gebildet. Bei der Schicht SE B8 handelt es sich um ein Gemisch aus rotbraunem, sandigem Schutt, der stark mit Steinen verschiedener Größe durchsetzt ist. Im Gegensatz zu SE B7 ist, zumindest in Konsistenz und Farbe, kein auffälliger Unterschied zwischen dem Bereich am Nordfundament und dem Material aus der Kammermitte auszumachen. Dieser liegt höchstens darin, dass der fundamentnahe Schutt kaum Brekzieabschlag enthält, während er ansonsten dicht damit durchsetzt ist. Die Keramik der Schichten SE B12 bis SE B7 ist relativ homogen. Die für die Datierung entscheidenden Exemplare sind zwei Fragmente von Reliefbechern, deren lokale Produktion ab dem 2. Viertel des 2. Jhs. v. Chr. belegt ist. Interessant in diesem Zusammenhang ist ferner das Fehlen charakteristischer Waren, wie z. B. das der weißgrundigen Keramik und der ESA, die erst im Verlauf des späten 2. Jhs. v. Chr. nachzuweisen sind².

Schicht SE B6 und SE B5 enthalten bereits Material aus dem 1. Jh. n. Chr. Im Zuge des Umbaus in flavischer Zeit scheinen auch die Fußböden erneuert worden zu sein. Erhalten ist davon nichts. Eine kleine Feuerstelle (SE B4) nahe der Nordostecke und die oberste Schicht SE B3 unmittelbar unter dem rezenten Boden enthielten spätes Material aus dem 4. Jh. n. Chr.

\subsubsection{Sondage S 2/2005 (KAMmer D8)}

\begin{tabular}{|c|c|c|c|c|c|}
\hline Schicht & OK in $\mathbf{m}$ & UK in $\mathbf{m}$ & Beschreibung/Interpretation & Keramik & Münzen \\
\hline SE B13 & 10,46 & 10,38 & $\begin{array}{l}\text { grober, sandiger Schutt an der Oberfläche; } \\
\text { enthält kleinere Steine, Putz und Mörtelreste }\end{array}$ & - & M 12 (frühhell.) \\
\hline SE B14 & 10,38 & $\begin{array}{l}10,16- \\
9,84\end{array}$ & $\begin{array}{l}\text { hell- bis mittelbrauner, sandiger Schutt mit } \\
\text { Steinabschlag }\end{array}$ & $\begin{array}{l}\text { 2. Jh.-Mitte 1. Jh. } \\
\text { v. Chr. }\end{array}$ & - \\
\hline SE B15 & $\begin{array}{l}10,16- \\
9,84\end{array}$ & $9,50-9,34$ & hell- bis mittelbrauner, sandiger Schutt & $\begin{array}{l}\text { 1. H.-Mitte 2. Jh. v. } \\
\text { Chr. }\end{array}$ & M 8. 21 (hell.) \\
\hline SE B16 & $9,50-9,34$ & $9,31-9,13$ & $\begin{array}{l}\text { hell- bis mittelbrauner, sandiger Schutt mit } \\
\text { Steinabschlag }\end{array}$ & $\begin{array}{l}\text { arch.-klass., } 1 \text { WS } \\
\text { 2. Jh. v. Chr. }\end{array}$ & - \\
\hline SE B17 & $9,31-9,13$ & $8,90-8,71$ & $\begin{array}{l}\text { rotbrauner, sandiger Schutt mit } \\
\text { Steinabschlag }\end{array}$ & arch.-klass.-frühhell. & - \\
\hline SE B18 & $8,90-8,71$ & 7,89 & rotbrauner Schutt mit viel Steinabschlag & 3.-2. Jh. v. Chr. & - \\
\hline SE B19 & 10,50 & 10,46 & $\begin{array}{l}\text { rötliche Erde zwischen der Steinverfüllung } \\
\text { des Treppenfundaments }\end{array}$ & $\begin{array}{l}\text { wenig Funde } \\
\text { (evt. 3./2. Jh. v. Chr.) }\end{array}$ & M 9 (frühhell.) \\
\hline
\end{tabular}

Tab. 2

\footnotetext{
${ }^{2}$ Kap. 4.
} 
Kammer D8 ist der südlichste Raum. Hier wurden bei Reinigungsarbeiten im Jahr 2004 eine Reihe von Skulpturfragmenten aus Marmor und Bronze gefunden ${ }^{3}$. Die Reinigung erfolgte bis auf Höhe der Fundamentoberkante. Auf diesem Niveau befand sich ein 1,33 m breiter, befestigter Streifen entlang der Südmauer (Taf. 21 Abb. 34. 35). Es sollte untersucht werden, ob es sich dabei um Reste eines Steinplattenbodens oder - was wahrscheinlicher erschien - um eine Fundamentierung handelt. So wurde eine Sondage von der Nordostecke der Kammer in 1,50 m Breite bis zur Steinkante angelegt. Gleichzeitig bot sich dadurch die Möglichkeit, den Befund von D3 an einer anderen Stelle zu überprüfen und zusätzliches Material für die Datierung der Theaterterrasse zu gewinnen. Der tiefste Punkt der Sondage liegt ein wenig tiefer als die Fundamentunterkante. Das Fundmaterial entspricht dem von Kammer D3. Und wie in D3 zeichnen sich wiederum deutlich diverse Arbeitsniveaus im Profil ab (Taf. 20 Abb. 33).

Bei dem 1,33 m breiten Einbau an der Südwand handelt es sich um eine Fundamentierung. Deren Nordseite ist aus großen Steinblöcken ohne Mörtelbindung geschichtet und bildet eine Schale. Sie reicht gerade so tief wie die Fundamente des Bühnenhauses, ohne mit diesen verbunden zu sein. Der Raum zwischen der nördlichen Fundamentschale und dem Südfundament der Skene ist mit größeren Steinbrocken (meist das vom Hang selbst stammende Brekziegestein) und einem Erde-Lehm-Gemisch verfüllt. Dieser Aufbau zeichnet sich deutlich an der gereinigten Oberfläche ab, mit Ausnahme eines schmalen Streifens im Westen (Taf. 21 Abb. 35). Hier wird die Oberfläche aus geglätteten Quadern mit groben Risslinien gebildet. Eine Baugrube konnte nicht ausgemacht werden. So weit es möglich war, wurde in Verlängerung des Schnitts S 2/2005 nach Süden auch ein wenig von dem Erde-Lehm-Gemisch aus der Verfüllung zwischen Fundamentschale und Bühnenhaus-Südmauer ausgehoben. Da keine Steinbrocken entfernt wurden, konnte auf diese Weise naturgemäß nur eine sehr geringe Ausbeute gemacht werden, was sich im Fundmaterial widerspiegelt. Es lässt keinerlei Aussage über die Datierung des Fundaments zu. Darüber hinaus wurden aber auch zwei Münzen aus der Verfüllung geborgen. Münze M 8 gehört frühhellenistischer Zeit an. Die schlecht erhaltene Münze M 77 dürfte dagegen bereits der Kaiserzeit angehören, ist aber als Datierungskriterium nicht unbedingt aussagekräftig. Die Oberfläche des Fundaments geht mit dem Fußbodenniveau einher. Demzufolge könnte ein so kleiner Gegenstand wie diese Münze auch viel später in die lehmige Oberfläche der Fundamentfüllung eingedrückt worden sein. Das Fehlen einer entsprechenden Baugrube, der mit den anderen hellenistischen Fundamenten vergleichbare Aufbau, vor allem aber eine Tür im Obergeschoss der Ostwand von D8, und zwar unmittelbar an der Südmauer, exakt über dem Fundamenstreifen, spricht für die Gleichzeitigkeit dieser Fundamentierung mit dem ältesten Bühnengebäude. Hier ist über dem Fundament eine Treppenanlage - vielleicht aus Holz - zu ergänzen, die beide Geschosse miteinander verbunden hat. Eine Parallele ist in der nördlichsten Kammer D1 zu finden, wo durch den Einbau eines Abwassertanks in den 1970er Jahren auch ein kleines Stück einer solchen Fundamentoberkante freigelegt worden war. Auch in D1 ist das Fundament an die Südwand der Kammer gesetzt, und nicht entlang der Nordwand, wie man aus Gründen der Symmetrie erwarten würde.

Die Grabungsbefunde aus den beiden Kammern D3 und D8 sind für die Frage nach der chronologischen Einordnung der bekannten hellenistischen Strukturen des ephesischen Theaters von entscheidender Bedeutung und werfen ein neues Licht auf eine seit 1912 kontrovers geführte Forschungsdiskussion: Während die ersten Ausgräber R. Heberdey und W. Wilberg von der Annahme ausgingen, dass das Theater bereits im Zuge der Neugründung der Stadt unter Lysimachos errichtet worden war ${ }^{4}$, hielten St. Karwiese und I. Ataç eine Errichtung des Theaters erst um 133 v. Chr. im Zuge der Errichtung der Provinz Asia für wahrscheinlich $^{5}$. Daneben gab es eine Reihe weiterer Datierungsvorschläge, die sich alle im Zeitraum zwischen der Mitte des 3. Jhs. v. Chr. und der Zeit um 200 v. Chr. bewegten ${ }^{6}$. Wie jedoch aus den Ergebnissen der kontextuellen Auswertung der Befunde und Funde aus den Grabungen in den Kammern D3 und D8 her-

\footnotetext{
${ }^{3}$ Kap. 7.

${ }^{4}$ Heberdey u. a. 1912, 18. 52.

${ }^{5}$ Ataç 1999b, 3; Karwiese 2000, 158.

${ }^{6}$ Um 250 v. Chr: Bieber 1961, 117. - Um 200 v. Chr.: De Bernardi Ferrero 1970, 50. 64. Diese Datierung findet sich auch bei SEAR 2006, 335 »ima and perhaps media cavea c. 200 BC; summa cavea $1^{\text {st }}$ century AD; scene building with thyromata $125-100$ BC«. Hofbauer 2007, 17 schlug aufgrund des damaligen Bearbeitungsstands eine Datierung an die Wende vom 3. zum 2. Jh. v. Chr. vor.
} 
vorgeht, kann der zeitliche Ansatz für die Errichtung - zumindest das hellenistische Bühnenhaus betreffend $-\mathrm{ab}$ dem 2. Viertel des 2. Jhs. v. Chr. präzisiert werden?.

\subsubsection{Kaiserzeitliches Bühnengebäude}

Während in den Kammern des hellenistischen Baus eventuell vorhanden gewesene Spuren einer spätantiken/ frühbyzantinischen Nutzung spätestens mit der Renovierung dieser Kammern für den Spielbetrieb und dem Einbau der Betonböden beseitigt worden waren, blieben die Kammern der kaiserzeitlichen Erweiterung weitgehend unberührt. So haben sich gerade in letzteren einige Hinweise für ihre vielfältige Nutzung erhalten, für die wir sonst kaum Zeugnisse aus den Theaterbauten besitzen.

\subsubsection{Sondage S 2/2004 (KAMmer E1)}

\begin{tabular}{|c|c|c|c|c|c|}
\hline Schicht & OK in $\mathrm{m}$ & UK in $\mathrm{m}$ & Beschreibung/Interpretation & Keramik & Münzen \\
\hline SE B22 & $\begin{array}{l}10,83- \\
10,71\end{array}$ & $\begin{array}{l}10,81- \\
10,68\end{array}$ & Oberflächenreinigung & - & - \\
\hline SE B23 & $\begin{array}{l}10,81- \\
10,68\end{array}$ & 10,22 & $\begin{array}{l}\text { heller, sehr sandiger Schutt } \\
\text { mit vielen kleinen Steinen }\end{array}$ & $\begin{array}{l}\text { 1. H. } \\
\text { 1. Jh. n. Chr. }\end{array}$ & - \\
\hline SE B24 & 10,53 & 10,23 & $\begin{array}{l}\text { heller, sandiger Schutt über } \\
\text { Bruchsteinmauer; fester als SE B21 }\end{array}$ & neuzeitlich & - \\
\hline SE B25 & 10,53 & 10,20 & $\begin{array}{l}\text { heller, sehr fester Schutt mit Steinen und } \\
\text { Mörtelbrocken über Terrassenmauer südlich } \\
\text { der Bruchsteinmauer }\end{array}$ & hellenistisch & - \\
\hline SE B26 & 10,22 & $9,74-9,72$ & $\begin{array}{l}\text { heller, sandiger Schutt mit Steinen und } \\
\text { (Dach)Ziegelfragmenten }\end{array}$ & $\begin{array}{l}\text { 2. Viertel } \\
\text { 1. Jh. n. Chr. }\end{array}$ & - \\
\hline SE B27 & $9,74-9,72$ & $9,74-9,66$ & Steinabschlag & $\begin{array}{l}\text { 1. H.-M. } \\
\text { 1. Jh. n. Chr. }\end{array}$ & - \\
\hline SE B28 & $9,74-9,66$ & 8,78 & $\begin{array}{l}\text { rötlicher Schutt mit kleinen Steinen und } \\
\text { Marmor-/Steinabschlag }\end{array}$ & $\begin{array}{l}\text { 3. Viertel } \\
\text { 1. Jh. v. Chr. }\end{array}$ & - \\
\hline SE B40 & 8,78 & 8,42 & brauner, sandiger Schutt & $\begin{array}{l}\text { 1. H. } \\
\text { 1. Jh. n. Chr. }\end{array}$ & - \\
\hline
\end{tabular}

Tab. 3

Wie in den hellenistischen Kammern sollte auch im nördlichen Raum E1 des römisch-kaiserzeitlichen Anbaus das Keramikmaterial des Aushubs zur Überprüfung der Datierung dienen. Darüber hinaus waren die Fundamente, und zwar vor allem ihr Verhältnis zur Terrassenmauer, von besonderem Interesse. Obwohl diese Kammer ebenso wie die östlich anschließende aus hellenistischer Zeit zu den am schlechtesten erhaltenen Räumen des Untergeschosses gehört, wurde sie aufgrund der tief reichenden Schuttverfüllung im Fundamentbereich ausgewählt. An der Nordseite, wo die frühe kaiserzeitliche Mauer nicht mehr vorhanden ist, gibt es geringfügige Störungen durch Baumaßnahmen späterer Zeit. Diese betreffen allerdings nur den Oberflächenbereich und reichen nicht in die Tiefe.

Die Sondage 2/2004 (Taf. 22. 23) wurde entlang der südlichen Wand von E1 mit einer Breite von 2,0 m angelegt und später auf die gesamte Fläche der Kammern erweitert. Im Gegensatz zu D3 und D8 wurde wegen des brüchigen Mauerwerks an der Nordseite darauf verzichtet, bis zur Unterkante der Fundamente bzw. bis zum gewachsenen Boden zu graben. Mit einer Sondagentiefe von fast $3 \mathrm{~m}$ dürfte dennoch sichergestellt sein, dass die noch tiefer reichenden Fundamente auf den festen Boden unter der Terrassierung

\footnotetext{
${ }^{7}$ Zur Datierung des keramischen Fundmaterials s. Kap. 4.1.1.3.
} 


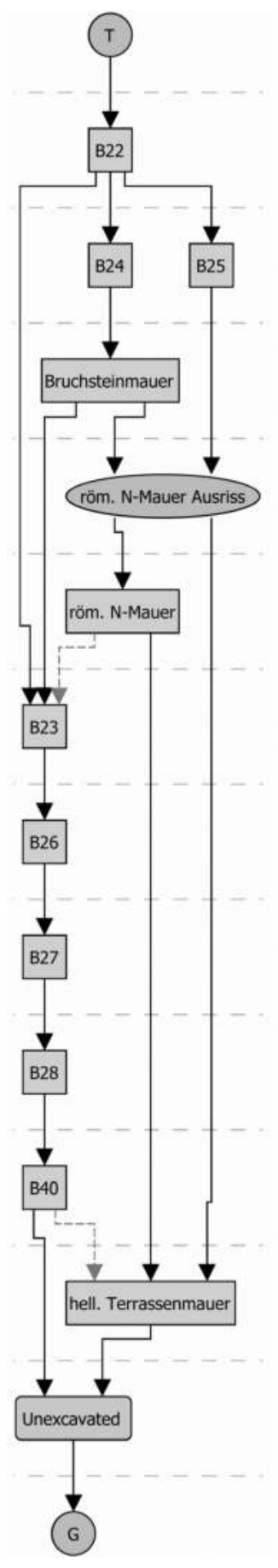

Grafik 1:
Harris-Matrix S 2/2004

gesetzt worden sind. Die Verfüllung zwischen den Fundamenten der römischen Kammer und dem Fundament der hellenistischen Westmauer ist in ihrer Art der Aufschüttung vergleichbar mit den Füllungen der weiter oben beschriebenen hellenistischen Kammern D3 und D8. Wieder gibt es keine erkennbare Baugrube. Die untersten ergrabenen Schichten sind SE B40 und B28. Darüber befand sich SE B27, ein massives Band aus kleineren Steinen und Steinabschlag. Es gewährt einen Einblick in die Arbeitsweise bei der Errichtung der Fundamente. SE B26 und SE B23 bildeten den obersten Bereich der Auffüllung. Das gesamte Fundmaterial aus den Schichten SE B40 bis B23 weist auf die Bauzeit der Kammerreihe E um oder nach der Mitte des 1. Jhs. n. Chr. Der Befund lässt Schlüsse auf die Arbeitsweise beim Bau der Fundamente zu. Um diese sicher auf einen tragfähigen Grund setzen zu können, wurde der gesamte Bereich zwischen dem Westfundament der hellenistischen Skene und der Terrassenmauer ausgehoben. Beim Bauvorgang ist man ähnlich wie bei der Errichtung der hellenistischen Fundamente vorgegangen, indem man die schichtweise aufgebrachte Verfüllung gleichzeitig auch als Arbeitsniveau für das Versetzen der Fundamentblöcke verwendet hat, wie das Niveau SE 27 nahe legt.

Kammer E1 ist, wie gesagt, der am schlechtesten erhaltene Raum des Bühnengebäudes. An der Nordwestecke ist kaum etwas vom aufgehenden Mauerwerk (Taf. 22 Abb. 36) erhalten. Im Gegenteil, die Zerstörungen reichen bis in die obere Fundamentschicht. An der Nordwestecke des hellenistischen Bühnenhauses ist innerhalb der Kammern E1 der Rest einer Bruchsteinmauer zum Vorschein gekommen (Taf. 22 Abb. 37). Sie umschließt die großen Quader des kaiserzeitlichen Baus L-förmig und läuft dann weiter nach Westen. Die Bruchsteinmauer muss nach der Zerstörung der Nordwestecke errichtet worden sein. Das wenige aus der über der Bruchsteinmauer liegenden Schicht SE B24 stammende Fundmaterial gibt leider keine datierenden Anhaltspunkte für deren Zerstörung. Ein kleiner Rest einer stark verfestigten Schicht (SE B25) wurde direkt an der Nordwestecke der Kammer E1 ausgehoben. Die Schicht befand sich über der obersten erhaltenen Steinlage der Terrassenmauer, unmittelbar südlich der nach Westen verlaufenden Bruchsteinmauer. Das wenige Fundmaterial entstammt hellenistischer Zeit, die vielen Mörtelbröckchen weisen aber auf eine spätere Umlagerung.

\subsubsection{Sondage S 1/2004 (KaMmer E3)}

Nach der Reinigung der Kammer E3 kam im Jahr 2003 ein Ziegelplattenboden (SE B29b) zum Vorschein (Taf. 24 Abb. 40; 26 Abb. 44; 27 Abb. 46). Das dazugehörige Mörtelbett SE B29a war noch über die gesamte Fläche des Raums erhalten und ließ darum einen unversehrten archäologischen Befund erwarten. Zum Ziegelplattenboden gehört der

Rest eines 1,54 × 0,89 m großen Podests in der Nordwestecke der Kammer E3. Es ist direkt auf den Fußboden gesetzt und ebenfalls aus Ziegeln errichtet. Im südlichen Drittel der Kammer gab es große Fehlstellen im Bodenbelag, jedoch ein unversehrtes Mörtelbett. An dieser Stelle wurde 2004 eine Sondage entlang der Südmauer angelegt. Sie erstreckte sich mit $1,50 \mathrm{~m}$ Breite über die gesamte Raumlänge. Bereits nach dem Entfernen des Mörtelbetts zeichneten sich die Randzonen zweier Pithoi am Nordprofil ab (Taf. 24 Abb. 41). Nach einer geringen Abtiefung rund um die Pithoi wurde deren Verfüllung geborgen (SE B33 = Pithos 1, SE B34 = Pithos 2). Diese enthielten vorwiegend großformatige Gefäßfragmente. Die Pithoi (Taf. 25 Abb. 


\begin{tabular}{|c|c|c|c|c|c|}
\hline Schicht & OK in $\mathrm{m}$ & UK in $\mathrm{m}$ & Beschreibung/Interpretation & Keramik & Münzen \\
\hline SE B35 & - & $\begin{array}{l}11,17- \\
11,11\end{array}$ & Oberflächenreinigung & - & - \\
\hline SE B29a & 11,17 & - & Ziegelplattenboden & - & - \\
\hline SE B29b & $\begin{array}{l}11,14- \\
11,11 \\
\end{array}$ & 11,08 & Mörtelbett für Ziegelplattenboden & $\begin{array}{l}\text { 1.-3. Jh. } \\
\text { n. Chr. }\end{array}$ & - \\
\hline SE B30 & 11,08 & 10,84 & heller, sandiger Schutt unter dem Mörtelbett & spätes 2. Jh. n. Chr. & $\begin{array}{l}\text { M } 50 \text { (Marcus } \\
\text { Aurelius) } \\
\end{array}$ \\
\hline SE B31 & 10,84 & $\begin{array}{l}10,50- \\
10,08\end{array}$ & $\begin{array}{l}\text { heller, sehr lockerer Schutt mit großen } \\
\text { Steinen und Ziegelstücken }\end{array}$ & - & - \\
\hline SE B32 & 10,50 & 10,08 & $\begin{array}{l}\text { hellbrauner, fester Schutt mit Steinen und } \\
\text { Steinabschlag }\end{array}$ & - & - \\
\hline SE B33 & 11,08 & - & Pithos 1 (Verfüllung) & $\begin{array}{l}\text { 3. Viertel } \\
\text { 1. Jh. n. Chr. }\end{array}$ & - \\
\hline SE B34 & 11,09 & - & Pithos 2 (Verfüllung) & $\begin{array}{l}\text { 3. Viertel } \\
\text { 1. Jh. n. Chr. }\end{array}$ & - \\
\hline
\end{tabular}

Tab. 4

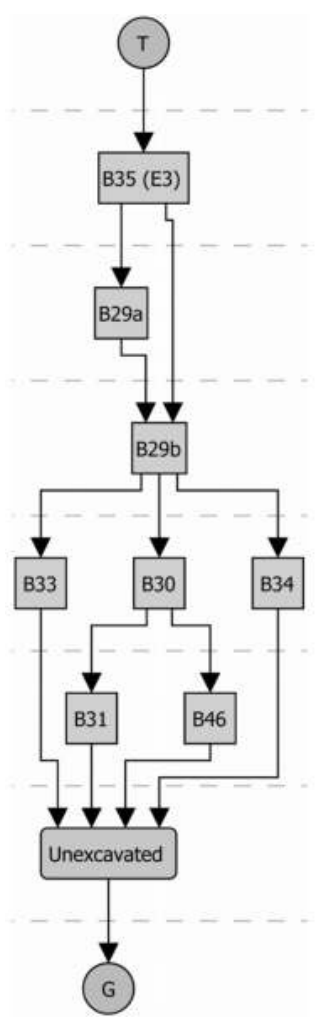

Grafik 2:

Harris-Matrix S 1/2004
42. 43) selbst bestehen aus rotgebranntem Ton mit einer durchschnittlichen Wandstärke von 5,0 cm. Sie messen 1,40 m in der Höhe und haben knapp oberhalb der Mitte einen Durchmesser von etwa 1,10 m (Taf. 26 Abb. 45). Das die Gefäße umgebende Füllmaterial SE B31 und SE B46 ist sehr inhomogen, locker und stellenweise mit großen Steinblöcken vermischt. Jenes gleicht in keiner Weise den Anplanierungen der anderen Kammern. Die Nutzungszeit der Pithoi muss in die Zeit unmittelbar nach der Errichtung der Fundamente bzw. der Fertigstellung des Bühnenhauses fallen. Das Füllmaterial selbst entstammt neronischer Zeit und wurde in den Pithoi entsorgt ${ }^{8}$, was auch deren Nutzungsende bedeutete.

Der Fußboden ist deutlich jünger als die Pithoi. Unmittelbar unter dem intakten Mörtelbett SE B29b, direkt auf Schicht SE B30 gelegen, gibt eine Münze des Marcus Aurelius (M 50 Taf. 356) zusammen mit dem keramischen Fundspektrum der Schicht einen zeitlichen Anhaltspunkt für den Einbau des Ziegelplattenbodens in das späte 2. oder frühe 3. Jh. n. Chr.

\footnotetext{
${ }^{8}$ Kap. 4.1.2.2.1.
} 


\subsubsection{SONDAGE S 7/2004 (KAMMER E5)}

\begin{tabular}{|c|c|c|c|c|c|}
\hline Schicht & OK in $\mathbf{m}$ & UK in $\mathbf{m}$ & Beschreibung/Interpretation & Keramik & Münzen \\
\hline SE B21 & - & 10,90 & Oberflächenreinigung & - & - \\
\hline SE B41 & 10,90 & 10,83 & Verfüllung des nördlichen >Beckens〈 & 5. Jh. n. Chr. & $\begin{array}{l}\text { M } 148 \text { (Constantius } \\
\text { II.); dazu noch M } 146 . \\
149 \text { aus dem mittleren } \\
\text { >Becken ( beide } \\
\text { Constantius II.) }\end{array}$ \\
\hline SE B42 & 10,90 & 10,74 & lockerer Schutt & 4. Jh. n. Chr. & $\begin{array}{l}\text { M } 125 \text { (Diocletianus); } \\
\text { M } 133 \text { (Constantius I.) }\end{array}$ \\
\hline SE B43 & 10,74 & 10,62 & graubrauner, verfestigter Schutt & $\begin{array}{l}\text { ab 2. Viertel } \\
\text { 1. Jh. n. Chr. }\end{array}$ & - \\
\hline SE B44 & 10,62 & 10,54 & gelber Lehm; teilweise verbrannt & 2. Jh. n. Chr. & - \\
\hline SE B45 & 10,54 & 10,47 & brauner, sandiger Schutt & $\begin{array}{l}\text { 2. H. 1. Jh.- } \\
\text { 1. H. 2. Jh. n. Chr. }\end{array}$ & - \\
\hline SE B46 & 10,47 & 10,26 & graubrauner Schutt & 1. Jh. n. Chr & - \\
\hline
\end{tabular}

Tab. 5

In Kammer E5 wurde entlang der Nordwand eine 1,20 m breite Sondage angelegt (Taf. 28 Abb. 47; 29 Abb. 48). Auch in dieser Kammer sind nach einer Reinigung der Oberfläche Einbauten einer späten Nutzung zum Vorschein gekommen. Es handelt sich dabei um eine dreiteilige Beckenanlage entlang der Ostwand. Die Becken sind zwischen 0,80 und 1,30 m lang, durchschnittlich 1,13 m breit und aus Halbformat-Ziegeln errichtet. Das nördlichste der drei Becken wurde freigelegt und dabei ein Ziegelplattenboden vorgefunden (Taf. 29 Abb. 49; 30 Abb. 50), der auch für die anderen beiden Becken vorausgesetzt werden kann. Das Material aus dem Becken (SE B41) datiert in das 5. Jh. n. Chr. Dazu gehört die Münze M 148 (Constantius II.). Der Schutt der beiden südlich anschließenden Becken wurde nicht ausgehoben. Bei Reinigungsarbeiten kamen aus dem mittleren Becken aber zwei weitere Münzen des Constantius II. zutage (M 146. M 149). Die Beckenwandung war ein bis zwei Ziegelscharen hoch erhalten und sowohl innen als auch außen mit einer glatten, stuckähnlichen Putzschicht versehen (Taf. 30 Abb. 51). Obwohl auch an den Wänden der Kammer wenigstens zwei verschiedene Wandputze festzustellen waren (Taf. 31 Abb. 52), ergab sich aus ihnen kein Hinweis auf die Höhe der Beckenwandung. Zu schlecht war der Erhaltungszustand der Wandverputze. Die Funktion dieser Anlage bleibt somit ungewiss. Eine Verwendung zur Aufbewahrung von Flüssigkeiten scheidet aufgrund des dafür ungeeigneten Verputzes aus. Möglicherweise dienten sie der Lagerung nichtflüssiger Dinge. Westlich der Beckenanlage bedeckt eine lockere Schuttschicht (SE B42), die durch Münzfunde (M 125 Taf. 358 = Diokletianus und M 133 = Constantius I.) in das 4. Jh. n. Chr. verwiesen wird, ein festes Niveau SE B43. Seine Oberfläche T 10,74 m geht mit der Unterkante der Verputzschicht der Beckenwandung einher. Wie sich nach dem Abtragen der Schicht B43 herausstellte, waren die Becken über diesem Stratum errichtet worden und gehören damit einer Zeit ab dem 4. Jh. n. Chr. an. Unterhalb der Schicht B43 befindet sich ein teilweise verbranntes Niveau SE B44 aus gelbem, stellenweise verbranntem Lehm (OK 10,62 m). Dabei handelt es sich um den Rest eines Bodenniveaus der Kammer aus dem 2. Jh. n. Chr. SE B45 und SE B46 unter dem Lehmboden gehören zur Aufplanierung nach der Mitte des 1. Jhs. n. Chr. Ein kleiner Rest eines Ziegelplattenbodens in der Nordwestecke des Raums markiert vermutlich das jüngste Bodenniveau. Der Bodenunterbau befindet sich, soweit aus den erhaltenen Resten ersichtlich ist, über SE B43. Mit einem Oberflächenniveau von T $10,89 \mathrm{~m}$ ist der Ziegelplattenboden zwar geringfügig tiefer als die Reste der abgetragenen Beckenwandung, dieser überragte aber die Verputzunterkante um $0,15 \mathrm{~m}$ und lag auch höher als der Ziegelboden des nördlichen Beckens $\left(\mathrm{T}^{\mathrm{a}}\right.$ 10,83 m). Der Eingang zu E5 ist wie bei den anderen Kammern der Reihe E zugemauert. Dabei variiert die Art der Vermauerung der Eingänge an den Kammern E5 bis E8 südlich der byzantinischen Stadtmauer, die zwischen den Eingängen der Kammern E5 und E6 an das Bühnengebäude anschließt, gegenüber der an den Eingängen E1 bis E4 nördlich der Stadtmauer, was auf eine unterschiedliche zeitliche Stellung schließen lässt. Die späte 
Stufe vor dem Eingang zu E5 wurde nach der Entfernung der obersten Quaderlage der Terrassenmauer errichtet und setzt die Stadtmauer bereits voraus (Taf. 31 Abb. 53); ein Indiz dafür, dass die Eingänge innerhalb der Stadtmauer länger in Verwendung standen als die Eingänge extra muros.

\subsubsection{KAMMER E7}

\begin{tabular}{|l|l|l|l|l|l|}
\hline Schicht & OK in $\mathbf{m}$ & UK in $\mathbf{m}$ & Beschreibung/Interpretation & Keramik & Münzen \\
\hline SE B35 & & & Oberflächenreinigung & - & - \\
\hline $\begin{array}{l}\text { SE B36 }= \\
\text { SE B37 }\end{array}$ & 11,94 & 10,75 & lockerer Ziegelschutt & ab 3. Jh. n. Chr. & M 36 (Augustus) \\
\hline SE B38 & 10,75 & 10,62 & Ascheschicht & 4. Viertel 3. Jh. n. Chr. & - \\
\hline SE B39 & 10,62 & 10,42 & Steinabschlag & 2. Jh. n. Chr. & - \\
\hline
\end{tabular}

Tab. 6

Die Kammer E7 enthält wie die Kammer E8 als Besonderheit eine der Westwand vorgelagerte Mauer (Taf. $32 \mathrm{Abb}$. 54). Sie ist 1,20 m breit und bis zu einer Höhe von 1,47 m über der Fundamentoberkante der Kammer erhalten. Wohl gleichzeitig mit der Errichtung der Mauer wurde auch die Tür in der Westwand verschlossen. Das Material beider - eine Mischung aus Bruchsteinen und Ziegeln in fester grauer Mörtelbindung - ähnelt dem Mauerwerk der byzantinischen Stadtmauer im Bereich der Kammer E5/E6 derart, dass von einer zumindest annähernden Gleichzeitigkeit auszugehen ist. Die Ostseite der Mauer ist nicht auf Sicht gearbeitet, sondern verbreitert sich unregelmäßig nach unten (Taf. $32 \mathrm{Abb}$. 55). Sie wurde über einem sandigen Aschenband SE B38 aus dem 3. Jh. n. Chr., das sich mit 0,11 m Stärke über eine 0,18 m hohe Schicht SE B39 aus Steinabschlag zieht, errichtet. Beide Niveaus liegen bereits höher als die hellenistische bzw. kaiserzeitliche Fundamentoberkante. Es kann davon ausgegangen werden, dass die Kammer aufgegeben wurde, sofern sie nicht über eine Leiter von oben her zugänglich war. Vermutlich stammt daher auch die Schuttauffüllung (SE B35-37) über dem Aschenniveau SE B38, die 2004 bis zur Oberkante der Verstärkungsmauer vorhanden war. Es handelt sich dabei um umgelagertes Material aus dem 3. Jh. n. Chr. Bei der Reinigung über der Verstärkungsmauer und der Schuttauffüllung wurde eine Reihe von Skulpturfragmenten gefunden?

Die Verstärkungsmauer und der Türverschluss sind wohl im Zusammenhang mit dem Bau der Stadtmauer zu sehen ${ }^{10}$. Darauf verweist auch die ähnliche Mauertechnik und Mörtelstruktur.

\subsubsection{SONDAge S 3/2005 (KAMmer E8)}

\begin{tabular}{|l|l|l|l|l|l|}
\hline Schicht & OK in $\mathbf{~}$ & UK in $\mathbf{~ m}$ & Beschreibung/Interpretation & Keramik & Münzen \\
\hline SE B48 & 10,54 & 10,27 & graubrauner Schutt mit kleinen Steinen & kaiserzeitlich & - \\
\hline SE B49 & 10,27 & 10,03 & brauner, sandiger Schutt & 2.-1. Jh. v. Chr. & - \\
\hline SE B50 & 10,03 & 9,83 & Dachziegelschutt & 2.-1. Jh. v. Chr. & - \\
\hline SE B51 & 9,83 & 9,61 & brauner, mörteliger Schutt & $\begin{array}{l}\text { 2. Jh. v. Chr.- } \\
\text { frühe Kaiserzeit }\end{array}$ & - \\
\hline SE B52 & 9,61 & 9,54 & dunkle, sandige Erde & kaum aussagekräftig & - \\
\hline SE B53 & 9,54 & 9,41 & $\begin{array}{l}\text { rotbrauner Schutt mit großen } \\
\text { Keramikfragmenten }\end{array}$ & 2.-1. Jh. v. Chr. & - \\
\hline SE B54 & 9,41 & 9,18 & rotbraune Erde mit Steinen & 1. H. 1. Jh. n. Chr. & - \\
\hline
\end{tabular}

Tab. 7

\footnotetext{
${ }^{9}$ Kap. 7.

${ }^{10}$ Kap. 3.7.2.
} 
Auch Kammer E8 besitzt eine Verstärkungsmauer an der Westseite (Taf. 33 Abb. 56). Die Situation ist ähnlich wie in E7. Allerdings ist die Ostseite der Mauer in E8 lotrecht und auf Sicht gearbeitet. Weiters hat es in E8 keine Auffüllung hinter der Verstärkungsmauer gegeben. Durch die besondere Situation der beiden äußeren Kammern der hellenistischen Skene, die ihre Zugänge immer schon von Westen hatten, ist hier eine Verbindung zwischen E8 und D8 gegeben. Letztere war zwar nicht ebenerdig von dem Korridor A des Bühnengebäudes zugänglich, war aber vom darüberliegenden Geschoss zu betreten ${ }^{11}$. So jedenfalls wird die Konstruktion des römischen Pfeilers vor der Tür von D'8 (Taf. 33 Abb. 57. 58) zu verstehen sein. Er ist nicht wie die anderen massiv gemauert (Taf. 34 Abb. 59. 60), sondern besteht aus einer aufrecht stehenden Säule und einer pfeilerartigen Stütze, die zumindest einen schmalen Durchschlupf ermöglicht hätte. Letztendlich wurde aber auch diese Tür durch eine Mauer verschlossen. Die Verstärkungsmauer sitzt nicht auf dem ursprünglichen Niveau des Kammerbodens, welches durch die Oberkante der Fundamente der Kammermauern gegeben ist. Sie ist ohne zusätzliche Fundamentierung über einer etwa 0,23 m starken Schicht aus Steinabschlag errichtet.

In dem verbleibenden kleinen Raum wurde eine 1,50 m breite Sondage an der Nordwand angelegt. Ziel war es, neben E1 an einer weiteren Stelle einen Blick auf die Fundamente der Westwand zu werfen. Diese bestehen aus wiederverwendetem Material, große Quader in Mörtelbindung (Taf. 35 Abb. 62). Wie in E1 handelt es sich um einen hydraulischen Mörtel. Die Verfüllung zwischen den Fundamenten (SE B54-48) ist inhomogen: stellenweise fest, an anderer Stelle wieder sehr locker, durchmischt mit teils größeren Steinbrocken. Bei einer 0,20 m starken Zone (SE B50) handelt es sich um eine reine Dachziegelschicht (Taf. 35 Abb. 63). Obwohl das Fundmaterial differiert, geht es über das 1. Jh. n. Chr. nicht hinaus.

\subsubsection{Raum RN1, nördlich des Bühnengebäudes}

Von dem im Norden direkt an die hellenistische Skene anschließenden Raum RN1 ist nur mehr der südliche Raumteil erhalten (Taf. 37 Abb. 66). Ob dieser einst die gesamte Länge der kleinen Terrasse zwischen dem Bühnengebäude und den Wasserbecken im Norden einnahm, kann nicht entschieden werden. Die senkrechte Kante am Nordende der Westmauer und die Trittspuren an einer Schwelle belegen eine Tür, durch die wahrscheinlich ein weiterer Raum im Westen betreten werden konnte. Doch ist durch spätere Umbauten nichts mehr davon erhalten. Beide Längsmauern bestehen aus Bruchsteinen und zahlreichen Marmorspolien und setzen an der hellenistischen Mauer und an dem römischen Pfeiler an. Dieser ist der Nordwand des hellenistischen Baus vorgelagert (Taf. 37 Abb. 66; 39 Abb. 71). Die Ostmauer wurde zu einem großen Teil über einer Marmorschwelle errichtet, welche die Mauer nach Norden um 0,82 m überragte. Aufgrund der absolut sauberen Verarbeitung des Anschlusses an den obersten Fundamentblock des T-förmigen Pfeilers kann angenommen werden, dass bereits mit dem kaiserzeitlichen Umbau des 1. Jhs. n. Chr. ein Raum bzw. eine Gruppe von Räumen an die Skene anschloss. Auch die spätere Mauer, die über einem Teil der älteren Schwelle errichtet ist, weist an ihrem Nordende eine vertikal durchgehende Kante auf, die an dieser Stelle eine Tür vermuten lässt.

Zwischen dem römischen Pfeiler und der Westwand von RN1 wurde der hellenistischen Nordwand in einer späteren Umgestaltungsphase eine neue Mauer vorgeblendet (Taf. 37 Abb. 66). Sie ist aus einheitlich großen Bruchsteinen ohne Marmorspolien errichtet und verdeckte zwei Tonrohrleitungen, die in den beiden Südecken des Raums RN1 von oben nach unten führen. Die Leitungen biegen auf dem Fußbodenniveau von RN1 um und führen unter dem Fußboden nach Norden. An den beiden Stellen, wo die Wasserleitungen unter dieser späten Mauer hindurchführen, ist im Fundamentbereich jeweils eine $0,36 \mathrm{~m}$ breite Lücke ausgespart, welche das Bodenniveau leicht nach oben überragt. In die westliche Innenecke des T-förmigen Pfeilers, die zugleich die Südostecke von RN1 nach Errichtung der jüngeren Südmauer ist, wurde ein Ziegelpfeiler gesetzt (Taf. 37 Abb. 66; 39 Abb. 71). Der Boden war zur Gänze mit weißen Marmorplatten ausgestattet, von denen sich Reste noch in situ befinden (Taf. 38 Abb. 69). Durch Abdrücke im Mörtelbett SE B55 ist der Marmorboden gut rekonstruierbar. An den Wänden verlief eine etwa $0,08 \mathrm{~m}$ hohe und $0,11 \mathrm{~m}$ breite Sockelleiste. Sie ist in der Südostecke, am Fuß des Ziegelpfeilers, noch gut erhalten und besteht wie der Boden aus weißem Marmor. An der Ost- und Westwand sind spärliche Reste von Verputz erkennbar.

\footnotetext{
${ }^{11}$ Kap. 3.1.1.2.
} 
Im Raum RN1 wurden zwei kleine Bereiche unter dem Fußbodenniveau näher untersucht, jedoch mit mäBigen Ergebnissen. Da die Räume an der Nord- und Südseite des Bühnengebäudes nicht vorrangiges Thema der Arbeit sein sollten, wurden die Grabungen in RN1 eingestellt. Für das kaiserzeitliche Theater hingegen könnten diese Bereiche sehr wohl von Interesse sein, sodass eine genauere Untersuchung wünschenswert bleibt.

\subsubsection{SONDAGE $S$ 5/2005}

\begin{tabular}{|l|l|l|l|l|l|}
\hline Schicht & OK in m & UK in m & Beschreibung/Interpretation & Keramik & Münzen \\
\hline SE B55 & 10,82 & & Mörtelbett für Marmorplattenboden & - & $\begin{array}{l}\text { M 240 } \\
\text { (Iustinianus I.) }\end{array}$ \\
\hline SE B56 & 10,90 & 10,82 & braune Erde über Mörtelbett & kaiserzeitl. & $\begin{array}{l}\text { M 238 (Iustinus I.); } \\
\text { M 250 (byz.) }\end{array}$ \\
\hline SE B57 & 10,68 & 10,58 & Schutt unter dem Mörtelbett & Anfang 1. Jh. n. Chr. & M 237 (Iustinus I.) \\
\hline SE B58 & 10,91 & 10,60 & Verfüllung östl. Rohrdurchlass & 6. Jh. n. Chr. & - \\
\hline SE B59 & 10,90 & 10,62 & braune Erde vor dem westl. Rohrdurchlass & - & - \\
\hline SE B60 & 11,00 & 10,61 & Verfüllung westl. Rohrdurchlass & - & $\begin{array}{l}\text { M 55 } \\
\text { (Septimius Severus) }\end{array}$ \\
\hline
\end{tabular}

Tab. 8

S 5/2005 wurde mit 1,0 m Breite zwar über den gesamten Raum entlang der Südwand ausgesteckt (Taf. 36 Abb. 64; 37 Abb. 66), aber nur an den beiden Stellen um die Wasserleitungen näher untersucht, wo das Mörtelbett des Bodens Störungen aufwies, was in erster Linie der Klärung des Verlaufs der Wasserleitungen diente (Taf. 36 Abb. 65; 37 Abb. 66. 67). Bei der Reinigung des Mörtelbetts wurden die Münzen M 238 (Taf. 359, Iustinus I.) und M 250 (byz.) aus der dünnen, humosen Bedeckung SE B56 geborgen. Unmittelbar auf dem Mörtel aufliegend kam M 240 (Taf. 359, Iustinianus I.) zutage. SE B58 ist die Verfüllung des östlichen Rohrdurchlasses. Das Fundmaterial reicht bis in die 1. Hälfte des 7. Jhs. n. Chr. Die Funde der Schichten SE B59 (Erde vor dem westlichen Rohrdurchlass) und SE B60 (Verfüllung des westlichen Rohrdurchlasses) enthalten kaum aussagekräftiges Material. Aus SE B60 stammt aber M 55 des Septimius Severus.

\subsubsection{SONDAGE S 6/2005}

\begin{tabular}{|l|l|l|l|l|l|}
\hline Schicht & OK in $\mathbf{m}$ & UK in $\mathbf{~ m}$ & Beschreibung/Interpretation & Keramik & Münzen \\
\hline SE B61 & 10,76 & 10,34 & graubrauner Schutt & - & $\begin{array}{l}\text { M 239 (Anastasius } \\
\text { od. Iustinus I.) }\end{array}$ \\
\hline SE B62 & 10,34 & 10,24 & braune Erde & 6. Jh. n. Chr. & - \\
\hline SE B63 & 10,24 & - & hellbraune, feste Erde & fundleer & - \\
\hline
\end{tabular}

Tab. 9

Mit S 6/2005 (Taf. 38 Abb. 68) sollte die Frage nach dem weiteren Verlauf des Fundaments nördlich der weiter oben erwähnten Schwelle unter der Ostmauer geklärt werden. Das Mörtelbett des Fußbodens war im Sondagenbereich nicht mehr vorhanden. Außer der Freilegung einer weitgehend zerstörten Tonrohrleitung blieb die Arbeit ergebnislos, was - wie das Fehlen des Mörtelniveaus bereits angedeutet hatte - an einer Störung durch antike Bau- oder aber moderne Renovierungsarbeiten liegt. An Stelle der zu erwartenden Fundamente kam lediglich lockerer Schutt zutage. Das Fundmaterial der Schicht SE B61, zu dem auch die Münze M 239 (Anastasius od. Iustinus I.) gehört, und die ins 5./6. Jh. n. Chr. datierende Schicht SE B62 passen dennoch gut zu den übrigen Funden aus RN1 und belegen eine Nutzung des Raums zumindest bis in das 6. Jh. $\mathrm{n}$. Chr. 


\subsubsection{Oberflächenuntersuchungen im Bereich des Bühnengebäudes}

Bedeutend mehr Erkenntnisse brachte eine Reihe von Detailuntersuchungen am hellenistischen und römischen Bühnengebäude. Nähere Betrachtung erfuhren der Nordabschluss von Kammer E1, die gesamte bisher wenig zufriedenstellend geklärte Situation in dem Mauerngewirr unmittelbar nördlich davon, die Fuge zwischen Terrassenmauer und Westfundament der römischen Erweiterung sowie die Südseite des Bühnengebäudes. In keinem dieser Bereiche wurden Ausgrabungsarbeiten durchgeführt, mit Ausnahme einer winzigen Stelle in der Ecke zwischen der Westmauer von RN1 und den Nordmauern von D1 und E1. Alle übrigen Bereiche lagen bereits offen und mussten lediglich einer gründlichen Reinigung unterzogen werden.

\subsubsection{NordSEITE DER THEATERTERRASSE}

Die älteren Grundrisspläne zeigen den Anschluss einer etwa 1,08 m starken kaiserzeitlichen Nordmauer an die Nordwestecke des hellenistischen Baus. Dabei wird die hellenistische Mauer nicht nach Norden überragt. Im Süden hingegen läuft die entsprechende römische Mauer mit einer Breite von 2,19 m auf die Südwestecke der hellenistischen Skene zu, wobei die hellenistische Südmauer um 1,27 m nach Süden überragt wird (Taf. 13 Abb. 20). Ab der Südwestecke des hellenistischen Baus setzte eine nochmals spätere Mauer an den nach Süden vorragenden Teil der römischen an und verstärkt damit die $0,76 \mathrm{~m}$ starke hellenistische Mauer. Die Zweiphasigkeit der an den hellenistischen Bau ansetzenden Mauern wurde anscheinend bereits von R. Heberdey und W. Wilberg festgestellt ${ }^{12}$. Dem sollte im Jahr 2005 nachgegangen werden. Nach einer Reinigung des gesamten Areals im Norden des Bühnengebäudes (Taf. 40 Abb. 72) konnte entlang der römischen Quadermauer eine 1,27 m breite weitere Mauer aus Kalksteinquadern festgestellt werden, die im Westen knapp östlich der Nordwestecke des römischen Baus beginnt (Taf. 41 Abb. 73. 74). Das entspricht etwa der Ostseite der tiefer liegenden Rückwand des hellenistischen Brunnenhauses. Mit nur mehr einer erhaltenen Quaderlage im Westen beginnend, steigt die Höhe dieser Mauer nach Osten hin um zunächst eine zweite, schließlich um eine dritte Quaderlage an. Die großen, quer über dieser Mauer befindlichen Quader gehören nicht mehr dazu. Bei dem Quaderwerk handelt es sich um dasselbe Material wie bei den Kammern der kaiserzeitlichen Westerweiterung des Bühnenhauses. Wie dieses ist es in Längs- und Querrichtungen verklammert. An jener Stelle, wo die hellenistische Nordwestecke erreicht wird, ist aufgrund des sauberen Fugenschlusses, mehr aber noch aufgrund der Anordnung der Klammerlöcher, eindeutig die Zusammengehörigkeit der >beiden` Quadermauern festzustellen (Taf. 42 Abb. 75). Ein Klammerloch am westlichsten Block der Mauer verlangt nach einem weiteren Anschluss, sodass hier ein schmaler Block zu ergänzen ist, der bis an die Außenflucht der kaiserzeitlichen Westmauer reicht. Er würde die Ostwand des hellenistischen Brunnenhauses $^{13}$ geringfügig überlagern, ohne sie aber zu belasten. Somit ist eine der Südseite vergleichbare Situation festzustellen. Eine 2,35 m breite Mauer bildet den Abschluss nach Norden, wobei die hellenistische Nordwand um 1,27 m überragt wird (Taf. 43 Abb. 77). Überragt wird dadurch auch die nördliche Terrassenmauer (Taf. 43 Abb. 78), von der wir allerdings nicht wissen, wie sie hinter dem hellenistischen Brunnen weiter verläuft ${ }^{14}$. Dass dafür allfällige Fundamente errichtet worden waren, darf vorausgesetzt werden. Durch die späteren Bauvorgänge sind diese heute aber an keiner Stelle mehr sichtbar.

${ }^{12}$ Das ergibt sich aus der Darstellung Heberdey u. a. 1912, Abb. 57. Hier endet die kaiserzeitliche Südwand ohne rechten Abschluss auf Höhe der hellenistischen Mauerecke. Alle anderen Abbildungen (Abb. 6. 15.95. 98 und die Taf. zwischen S. 16 u. 17) nehmen darauf keine Rücksicht. In Abb. 15 werden wohl die nachdomitianischen Phasen durch eine schräge Schraffur der Mauern angegeben, im Fall der Südmauer des kaiserzeitlichen Bühnengebäudes aber wird keine Differenzierung vorgenommen.

${ }^{13}$ Das Brunnenhaus an der Nordwestecke der Theaterterrasse stammt aus hellenistischer Zeit. Es wurde um die Wende zum 20. Jh. teilweise zerstört aufgefunden und wieder aufgebaut, wobei Fehlendes modern ergänzt wurde. Diese nicht ausreichend dokumentierte Rekonstruktion erfordert eine eingehende bauhistorische Untersuchung, weshalb das Gebäude nicht in die aktuelle Studie integriert wurde. Die Datierung des Brunnenhauses orientiert sich an stilistischen Kriterien und variiert erheblich: W. Wilberg sprach sich für das 2. Jh. v. Chr. aus (HeBerdeY u. a. 1923, 266-273). W. Alzinger dagegen datierte das Brunnenhaus aufgrund der Kapitelle erst in das 1. Jh. v. Chr. (Alzinger 1974, 70 f.), wohingegen sich V. M. Strocka, der die LöwenkopfWasserspeier des Brunnenhauses mit denen anderer Bauten in Ephesos und Belevi verglich, wiederum für eine Errichtungszeit des Brunnenhauses schon um 280 v. Chr. aussprach (StrocKa 2005, 337-348).

${ }^{14}$ Die gesamte, teilweise sehr späte Verbauung östlich des kleinen hellenistischen Brunnenhauses erlaubt es uns nicht mehr, die hier

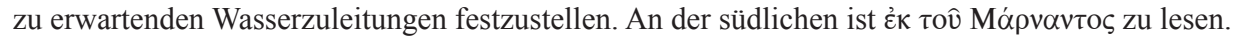


Da im Norden, anders als im Süden, wo an der Südwestecke der hellenistischen Skene die späte Mauer an die römische ansetzt, ein kleiner Bereich zwischen der Nordwestecke der hellenistischen Skene und der Westmauer von RN1 noch unter Schutt lag, wurde dieser entfernt. Es gelang, die Oberkante des Fundaments unter der kaiserzeitlichen Quadermauer zu erreichen (Taf. 42 Abb. 76). Dieses endet hier, wie auch die Mauer selbst, $0,70 \mathrm{~m}$ östlich der hellenistischen Gebäudeecke. Die Quadermauer zeigt einen gestuften Rücksprung. Diese Gestaltung ist vergleichbar mit der des T-förmigen Pfeilers, der 3,35 m weiter im Osten der Mauer des hellenistischen Baus vorgeblendet ist und an den die Ostmauer von RN1 ansetzt. Nochmals wiederholt sich diese Situation östlich des Nordeingangs zum Korridor A der Skene, wo der Abschluss der scaenae frons geringfügig um die Nordostecke biegt. Es zeigte sich, dass das hellenistische Gebäude von dem römischen Umbau zwischen Bühnenfassade und Westerweiterung an beiden Schmalseiten umfasst wird. Dies geschah, wie im Fall der Nordseite ersichtlich ist, nicht mit einer durchgehenden geschlossenen Mauer, sondern durch eine mittels Pfeiler (Taf. 44 Abb. 79; 45 Abb. 81) aufgelockerte Wand, wodurch das hellenistische Mauerwerk sichtbar blieb.

Die Nordostecke konnte in der Kampagne 2006 einer gründlichen Reinigung unterzogen werden (Taf. 44 Abb. 80; Plan 9). Dabei wurde nicht nur die Ecke des hellenistischen Bühnenhauses zumindest als Negativ durch die daran anschließende römische Verbauung festgestellt, sondern auch die Konstruktion des kaiserzeitlichen Umbaus verdeutlicht, wobei nicht zu bestreiten ist, dass ganz wesentliche Konstruktionsmerkmale bereits ohne diese Reinigung erkennbar waren. Der Baukörper des Sockels der scaenae frons reicht um 1,60 m über das Nordende des hellenistischen Baus hinaus, wobei er diesen auf einer Länge von 2,88 m nach Westen umfasst. Diese Mauer trägt die schräg gearbeiteten Auf- oder - besser gesagt - Widerlager für das Gewölbe der mit dem Umbau neu angelegten, gedeckten Parodos. Das Gewölbe ist bis auf den Abschluss im Westen zur Gänze erhalten. Die Stirnfläche des westlichsten Gewölbesteins mit einer deutlich erkennbaren Anathyrose zeigt eindeutig, dass das Gewölbe ursprünglich noch weiter nach Westen reichte, nämlich so weit wie das um die Nordostecke des hellenistischen Bühnenhauses biegende kaiserzeitliche Mauerwerk (Taf. 46 Abb. 8385). Damit ist auch die Breite der Nordrampe gegeben, die bereits in der flavischen Phase nicht nur zwischen Analemma und Skene zu fassen war, sondern auch in einer Breite von 2,88 m gegen die Wand des Bühnengebäudes verlief. Das macht aber nur dann Sinn, wenn dieser Teil der Rampe auf einen Eingang zuführte, der folglich der Umbauzeit selbst angehörte und nicht erst der Mitte des 2. Jhs. n. Chr. ${ }^{15}$, wie W. Wilberg meinte. Damit ist auch die Problematik um die Datierung des dritten Geschosses entschärft. Da Wilberg, wie gesagt, die Zugänge erst in die Mitte des 2. Jhs. n. Chr. datierte, musste zwangsläufig das dritte Geschoss, für dessen Errichtung er die Stützpfeiler voraussetzte, später datieren, da diese die Türen unbrauchbar machten (Taf. 44 Abb. 80; 45 Abb. 82) ${ }^{16}$. Wie das jüngst erfolgte Studium der Architektur des dritten Geschosses durch A. Öztürk zeigte, scheint dieses Geschoss zwar sekundär, aber noch in flavischer Zeit errichtet worden zu sein. Wie einige späte Zwischenwände im hellenistischen Teil des Obergeschosses der Skene bezeugen, die mit den Stützpfeilern im Verband stehen, sind Letztere als nicht gleichzeitig mit der Errichtung des dritten Geschosses zu sehen. Die Pfeiler dürften erst im Zusammenhang mit einem späteren Erdbebenschaden - vermutlich aus gallienischer Zeit - stehen. Somit waren die seitlichen Zugänge doch über einen langen Zeitraum zugänglich.

In chronologischer Reihung folgen dem kaiserzeitlichen Bau Ost- und Westmauer von RN1 (Taf. 39 Abb. 70. 71), dann die Verblendung der hellenistischen Nordwand in RN1 (Taf. 37 Abb. 66) und schließlich eine 2,15 m starke, von West nach Ost verlaufende Mauer aus riesigen Spolien. Sie schließt an die kaiserzeitliche Quadermauer an und reicht vom hellenistischen Brunnenhaus bis an die Westmauer von RN1 (Taf. 40 Abb. 72; 47 Abb. 86). Das Spolienmauerwerk wird durch einen harten Mörtel zusammengehalten. Vergleichbare Reste blieben auch auf dem Rampenaufgang nördlich der scaenae frons erhalten (Taf. 46 Abb. 84. 85). Aus diesem Grund wurde das Gewölbe der darunterliegenden Parodos um je eine dichte Säulenstellung an beiden Längswänden verstärkt. Die Mauertechnik - großformatige Spolien und sehr fester Mörtel - findet sich auch bei der Vermauerung der Türen jener Kammern wieder, die innerhalb des durch die byzantinische Stadtmauer befestigten Areals liegen. Die Verschlüsse der extra muros gelegenen Türen sind im Aufbau grundlegend anders. Man kann darin einen gewissen zeitlichen Abstand zwischen diesen mächtigen Mauerresten im Norden des Bühnengebäudes und der byzantinischen Stadtmauer sehen.

\footnotetext{
${ }^{15}$ IvE 2039. Vgl. HeberdeY u. a. 1912, 47 f. Den wichtigsten Hinweis sieht W. Wilberg in den in der Inschrift erwähnten $\lambda \varepsilon \varepsilon_{i} \pi$ ov $\sigma \alpha 1$ $\theta \dot{\rho} \rho \alpha 1$; s. dazu auch Kap. 8.6.1, Nr. 9 u. Kap. 8.6.2.

${ }^{16}$ Heberdey u. a. 1912, 49.
} 


\subsubsection{Westmauer Der TheaterterRasse}

Westlich der Kammern E2 bis E4 wurde im Jahr 2004 die Fuge zwischen der Terrassenmauer und dem Westfundament der römischen Westerweiterung bis in etwa $0,70 \mathrm{~m}$ Tiefe gereinigt (Taf. $47 \mathrm{Abb}$. 87). Die ca. $0,30 \mathrm{~m}$ breite Fuge ist im oberen Teil dieses Abschnitts durch eine leichte Neigung der Terrassenmauer nach Westen entstanden. Der Grundrissplan zeigt deutlich, dass die Mauer an dieser Stelle nach Westen hängt (Plan 1). Die Westseite des kaiserzeitlichen Bühnengebäudes ruht nur auf dem Fundament, das an die Terrassenmauer im Osten anschließt. Das Fundament wird von der Mauer nirgendwo überragt. Kleinere Hohlräume, die sich zahlreich durch die sehr uneinheitliche Blockgröße der kaiserzeitlichen Fundamente im Anschlussbereich zur Terrassenmauer ergaben, wurden mit kleineren Steinen und Mörtel verschlossen (Taf. 48 Abb. 88). Der Aufbau der Fundamente entspricht dem der weiter oben besprochenen Fundamentierungen in den Sondagen S 1/2004 und S 3/2005.

\subsubsection{BEREICH SÜDLICH DES BÜHNENGEBäUDES}

Ähnlich wie an der Nordseite des Bühnengebäudes wurden auch im Süden Räume (RS1-2) im Anschluss an das Theater errichtet (Plan 1). Diese wurden freigelegt, bisher aber kaum eingehend analysiert. Fest steht, dass der an das Bühnengebäude anschließende $10 \times 5 \mathrm{~m}$ große, saalartige Raum RS1 mit einem Mosaikfußboden ausgestattet ist. Nach Süden ist der Abschluss von RS1 erhalten. Dieser öffnet sich in der Osthälfte zu einem kleinen Hof (?) RS2 hin. Die Interkolumnien der ursprünglichen Kolonnade wurden später mit einem Ziegelmauerwerk verschlossen. Der Hof selbst besitzt einen Steinplattenboden, von dem Reste erhalten sind. Wenigstens noch ein weiterer rechteckiger Raum schließt nach Süden an. Die genaue Erforschung steht noch aus.

Aufgrund der Ergebnisse der Untersuchungen an den Nordmauern des Bühnengebäudes lag es nahe, auch die Verhältnisse im Süden noch einmal zu überprüfen (Plan 9). Im Frühjahr und Sommer 2006 ergab sich die Möglichkeit, die Südseite des Bühnengebäudes zu untersuchen. Die Situation wurde bereits weiter oben kurz angesprochen. Nach der oberflächlichen Reinigung aller Mauern am südlichen Abschluss des Bühnengebäudes trat folgender Befund zutage: Die 2,19 m breite kaiserzeitliche Quadermauer ragt im Osten über die hellenistische Südwestecke hinaus (Taf. 48 Abb. 89; 49 Abb. 90. 91). Ein abgestufter Abschluss - analog zur Situation im Norden - konnte aufgrund des Erhaltungszustands der äußeren südlichen Hälfte der kaiserzeitlichen Mauer nicht mehr festgestellt werden. Die beschädigten Stellen werden von einer späten Mauer verdeckt (Taf. 51 Abb. 96), welche der hellenistischen Wand im Süden vorgesetzt wurde. Sie zeigt mit ihren großen, in Mörtelbindung verlegten Quadern einen gänzlich anderen Charakter als das mit Klammern versehene Mauerwerk der früheren Kaiserzeit. Durch die späte Mauer wird der Eingang zur kaiserzeitlichen Süd-Parodos geringfügig verstellt. Wenn die kaiserzeitliche Mauer auch im äußeren Bereich beschädigt ist, so gibt eine Verputzschicht an der nördlichen (inneren) Hälfte doch den Abschluss nach Osten an. Dieser liegt 1,28 m östlich der hellenistischen Südwestecke. Der Verputz setzt sich an der Südseite der hellenistischen Mauer fort und bildet mit dem Abschluss der kaiserzeitlichen Mauer eine Innenecke (Taf. 49 Abb. 92; Plan 9). 3,01 m weiter östlich konnten an der Oberseite der späten Mauer teilweise stark verwitterte Quader festgestellt werden, die denen der kaiserzeitlichen Mauer entsprechen (Taf. 49 Abb. 93; 50 Abb. 94). Die Südseite ist beschädigt und durch die späte Mauer verblendet. Ausbruchstellen am östlichen Quader lassen auf ausgerissene Klammerlöcher schließen, die zeigen, dass nach Süden noch ein weiterer Block zu ergänzen ist. Die in Ost-West-Richtung auf etwa 2,20 m Länge erhaltenen Quader entsprechen dem T-förmigen Pfeiler im Norden (Taf. 44 Abb. 79). Dass die kaiserzeitliche Südmauer und der Pfeiler zusammengehören, wird durch die vorhin genannte Putzschicht bestätigt, die zwischen hellenistischer Südwand und Westseite des Pfeilers eine zweite Innenecke bildete (Taf. 50 Abb. 95).

Die Verputzreste gehören zu dem Raum RS1 mit dem Mosaikfußboden und belegen, dass das Raumensemble im Süden des Bühnengebäudes älter ist als die spätere Quadermauer. Im Jahr 2007 wurde das Mosaik untersucht. Dabei konnte ein zweiter Mosaikboden unter dem bereits bekannten entdeckt werden. Stilistisch gehört der ältere Boden nahe an die Umbauzeit oder spätestens in die Zeit Trajans ${ }^{17}$. Ähnlich wie an

${ }^{17} 2008$ erfolgte die Aufnahme der Mosaiken durch W. Jobst. Ihm sei für die hier angeführten Informationen und umfangreichen Diskussionen vor Ort herzlichst gedankt. 
der Nordseite gab es allen Anschein nach auch an der Südseite eine Gruppe von Räumen, die mehr oder weniger gleichzeitig mit dem großen Umbau des Theaters in flavisch-trajanischer Zeit errichtet wurden. Damit sind sie vermutlich auch in Zusammenhang mit dem Betrieb des Theaters zu verstehen. Der jüngere Boden ist deutlich später und zeigt die Bedeutung dieser Räume über eine lange Zeitspanne. Da die Mosaikfußböden bereits höher liegen als der Fußboden der gedeckten Süd-Parodos, deren Raumhöhe ohnedies schon recht niedrig ausfiel, hätte sich dieser Eingang nur >gesenkten Hauptes $<$ betreten lassen. Daraus könnte man die Aufgabe dieses Zugangs bereits mit der Errichtung der Raumabfolge im Süden des Bühnengebäudes in Verbindung bringen. Doch ob dem so ist, muss gegenwärtig unbeantwortet bleiben. Eine detaillierte archäologische Untersuchung steht nach wie vor aus. Somit wissen wir zu wenig über die genauen baulichen Verhältnisse. Es ist nicht auszuschließen, dass der Verschluss der Parodos mit der späten Quadermauer vor der hellenistischen Südwand zeitlich einherging. Diese Mauer könnte der Zeit des Stadtmauerbaus angehören, wo eine Verstärkung der nur $0,76 \mathrm{~m}$ breiten hellenistischen Wand angeraten schien (Taf. 49 Abb. 91; 51 Abb. 96). Mit dem späteren Mauerwerk im Norden ist diese Mauer nicht zu vergleichen (Taf. 47 Abb. 86), eher mit der Orthostatenverkleidung am Tor der Stadtmauer (Taf. 51 Abb. 97).

\subsection{BÜHNEN DES THEATERS}

\subsubsection{Hellenistische Bühne}

Eindeutige archäologische Befunde, die mit dem hellenistischen Proskenion in Verbindung gebracht werden können, liegen bislang nicht vor. Das wurde bereits von R. Heberdey um die vorige Jahrhundertwende ${ }^{18}$ und W. Alzinger im Jahr $1969^{19}$ festgestellt. Ein positiver Nachweis konnte auch nicht durch die jüngsten Grabungen erbracht werden. Der Grund für das Fehlen jedweder Hinweise ist im Bau der kaiserzeitlichen scaenae frons zu sehen, die praktisch die gesamte Grundfläche des alten Proskenion einnimmt. Nachdem bereits die vermeintlichen architektonischen Reste, die von W. Wilberg dem Proskenion hellenistischer Zeit zugewiesen worden waren ${ }^{20}$, von A. von Gerkan in den 1920er Jahren richtigerweise als kaiserzeitlich erkannt wurden ${ }^{21}$, bleibt nur die Möglichkeit einer theoretischen Rekonstruktion, die sich an Proportionen und an Vergleichen mit anderen Theatern Kleinasiens orientiert, was jedoch nicht Thema dieses Bandes ist. An dieser Stelle muss auf den Folgeband verwiesen werden ${ }^{22}$.

\subsubsection{Kaiserzeitliche Bühnen}

Im Bereich der römischen Bühne, dem Logeion, wurde in den Jahren 2001 bis 2005 eine ganze Reihe von Schnitten angelegt (Plan 18), die von Norden bis Süden einen großen Teil des Areals umfassen. Obzwar die Fläche mit $32 \mathrm{~m}$ Länge und einer Breite von gut 5,30 m durchaus nicht als klein bezeichnet werden kann, sind die Verhältnisse sehr beengt. Eine Vielzahl unterschiedlicher Fundamente verschiedenster Bauphasen zerschneidet die Fläche in kleine Einheiten, die mehr oder weniger exakt dem Geviert der sichtbaren Stützenstellungen entsprechen. Kanaleinbauten und die seit 100 Jahren andauernde Grabungstätigkeit - nicht immer in ausreichender Weise dokumentiert - haben eine kleinteilige stratigrafische Landschaft hinterlassen, die stellenweise schwer, manchmal auch kaum zu interpretieren ist. Um jedenfalls die bauliche Struktur in größeren Zusammenhängen besser fassen zu können, wurden mehrfach Altgrabungen erneut geöffnet. Gelegentlich konnte erst im Zuge der Arbeiten das genauere Ausmaß älterer archäologischer Tätigkeit festgestellt werden.

\footnotetext{
${ }^{18}$ HeBERDEY u. a. 1912, 26.

${ }^{19}$ Das Ergebnis ist unpubliziert, liegt aber in Form von Tagebuchaufzeichnungen am ÖAI vor. Vgl. dazu auch VetTERs 1970, 4.

${ }^{20}$ HeBerdey u. a. 1912, $21 \mathrm{f}$.

${ }^{21}$ VON GERKAN 1921, 90-93. Hier präsentiert A. von Gerkan auch einen Rekonstruktionsvorschlag und spricht sich für ein Proskenion aus Stein aus, welches seiner Meinung nach bereits der Errichtungszeit des Proskenion angehörte.

${ }^{22}$ STYHLER-Aydin (in Vorbereitung).
} 


\subsubsection{SONDAGEN S 1/2001-SÜD, S 3/2003 UND S 6/2004}

\begin{tabular}{|c|c|c|c|c|c|}
\hline Schicht & $\mathrm{OK}$ in $\mathrm{m}$ & UK in $\mathbf{m}$ & Beschreibung/Interpretation & Datierung & Münzen \\
\hline SE L2 & 11,11 & 10,80 & Schotter/Sandplanierung, rezent & - & - \\
\hline $\begin{array}{l}\text { SE L3 }= \\
\text { SE L6 }\end{array}$ & 10,80 & 10,71 & rotgraues Laufniveau, rezent & - & - \\
\hline $\begin{array}{l}\text { SE L4 = } \\
\text { SE L77 = } \\
\text { SE L 79 }\end{array}$ & 10,80 & 9,82 & $\begin{array}{l}\text { Verfüllung der Altsondage } \\
\text { (Ost-West-Kanal) } 1899\end{array}$ & - & $\begin{array}{l}\text { M 11. 130. 134. } 144 . \\
\text { 212. 231. (hell.-Leo I.) }\end{array}$ \\
\hline SE L42 & 10,61 & 9,84 & Kanalverfüllung (Ost-West-Kanal) & 2. H. 5. Jh. n. Chr. & $\begin{array}{l}\text { M 131. 132. 159. } 163 . \\
204 \text { (Constantius I.-- } \\
\text { Theodosius I.) }\end{array}$ \\
\hline SE L43 & 11,09 & 10,87 & sandiger Schutt, rezent gestört? & 1. Jh. n. Chr. & - \\
\hline SE L44 & 11,11 & 10,87 & sandiger Schutt, rezent & - & - \\
\hline SE L45 & 10,83 & 10,73 & braune Erde, rezent & - & M 265 (osman.) \\
\hline SE L76 & 11,06 & 10,74 & Schutt unter Betonboden, rezent & - & - \\
\hline SE L78 & 10,51 & $?$ & $\begin{array}{l}\text { Verfüllung der Altsondage } \\
\text { (Nord-Süd-Kanal) } 1899\end{array}$ & - & - \\
\hline
\end{tabular}

Tab. 10

S 1/2001 bildete den Beginn der Ausgrabungen im Skene-Orchestra-Bereich ${ }^{23}$. Die Sondage wurde zwischen der westlichen und östlichen Säulenreihe der römischen Bühne in den Interkolumnien H6/H7 und H7/ H8 angelegt (Taf. 52 Abb. 99). Der Durchgangsbereich H7/H8 zwischen Bühnengebäude und Orchestra war bereits 1899 geöffnet worden, doch gibt es keine ausreichende Dokumentation des Befunds. Der Nordteil der Sondage (H6/H7) war ungestört. Der Schnitt wurde bis 2004 mehrfach erweitert. Der gesamte Bereich im mittleren Durchgang H7/H8 wird durch den anstehenden Fels geprägt (Taf. 52 Abb. 100), dessen eben abgearbeitete Oberfläche mit einer Höhe von $\mathrm{T}^{\mathrm{a}} 10,71 \mathrm{~m}$ nur geringfügig unter dem hellenistischen Orchestraniveau ( $T^{\mathrm{a}} 11.06 \mathrm{~m}$ ) liegt. Nach Westen und Norden fällt der Fels abrupt ab. Im Osten sinkt das Niveau zunächst allmählich, fällt dann aber gleichfalls steil ab. Ähnliches dürfte für die Südrichtung gelten, was aufgrund der Überbauung aber nur vermutet werden kann. Etwa in der Mitte des Durchgangs ist eine 0,86 m tiefe, sich nach unten verjüngende Rinne in den Fels geschlagen. Sie verläuft von Ost nach West in einer nicht ganz exakten Normalen auf den Sockel der scaenae frons zu und ist etwa 0,10 m aus der Achse des Durchgangs nach Norden verschoben. Zwei kleinere Rinnen schneiden die große im rechten Winkel: eine südlich, die andere nördlich. Die Situation erinnert an einen Steinbruch, auch wenn die Rinne mit einer Breite von 0,45 $\mathrm{m}$ am oberen Rand und 0,24 $\mathrm{m}$ am Boden etwas größer ist als etwa die im selben Jahr freigelegten Schrotkanäle beim Mausoleum von Belevi ${ }^{24}$. Dass das anstehende Material gebrochen und als Baumaterial verwendet worden war, zeigen zahlreiche Blöcke aus dem Koilon und den Fundamenten der Skene. Die Rinne wurde erst nachträglich in einen vom Scheitelpunkt der Orchestra im Osten bis zur Terrassenmauer im Westen verlaufenden Kanal integriert. Sowohl östlich als auch westlich setzen dessen Bruchsteinmauern an die Felsrinne an. Sie sind in Mörteltechnik ausgeführt. Da das ganze Areal im Durchgangsbereich bereits einmal ergraben worden war, handelte es sich bei dem gesamten Aushubmaterial (SE L4) um eine Wiederverfüllung der alten Sondage. Der Kanal enthielt zahlreiche Tonrohre und Tonrohrfragmente, die kreuz und quer hineingeworfen worden waren. Über SE L4 hatte sich seit den Altgrabungen etwa auf dem Niveau der Felsoberkante ein rötliches Laufniveau SE L3 gebildet. Funde von Batterien, die sich in die Oberfläche eingetreten hatten, belegen eine Nutzung bis in jüngere Zeit. Infolge der modernen Nutzung des Theaters für Veranstaltungen wurde der Durchgang zusätzlich mit einer Sand/Schotterplanie-

\footnotetext{
${ }^{23}$ Vgl. dazu auch Hofbauer 2002, 182-202.
}

${ }^{24}$ Vgl. Heinz - Ruggendorfer 2002, 150. 
rung SE L1 auf ein einheitliches Niveau mit dem Durchgang im Sockel der scaenae frons und der Schwelle an der Bühnenfront gebracht und mit einem zweireihigen Betonplattenboden ausgestattet.

Im Jahr 2003 konnte durch Anlegen von S 3/2003 im Durchgang H7/H8 die Sondage von 2001 nach Osten bis zum Fundament unter dem römischen Proskenion erweitert werden (Taf. 53 Abb. 101). Auch diese Stelle war 1899 bereits einmal geöffnet worden, wobei sich aus der Dokumentation keine genaueren Auskünfte ergeben, ob das über den gesamten Bereich bis auf die Kanalsohle hinab erfolgt ist. Im oberen Bereich des Kanals gleicht der Grabungsbefund dem von S 1/2001: Tonrohre und Rohrfragmente waren in großer Zahl in den offenen Kanal geworfen worden. Immer wieder fanden sich Objekte der vorletzten Jahrhundertwende in der Wiederverfüllung (SE L4). Westlich des Pfeilerfundaments wurde eine Marmorplatte, etwa auf halber Höhe des Kanals, vorgefunden. Sie lag schräg zwischen den Kanalwangen eingeklemmt. Vermutlich ist sie im Zuge der Wiederverfüllung nach den Altgrabungen an diese Stelle gekommen, und bildet die untere Grenze des alten Aushubs. Unterhalb der Marmorplatte wurde somit ein ungestörter Bereich (SE 42) angeschnitten. Bei den Funden handelt es ich zumeist um viele vollständig erhaltene Öllämpchen, die zusammen mit Keramik der 2. Hälfte des 5. Jhs. n. Chr. zutage kamen. Aus derselben Schicht stammen fünf Münzen (M 131. M 132. M 159. M 163. M 204) aus der Zeit des Constantius I. bis Theodosius I. Auch aus der darüber befindlichen Sondagenverfüllung SE L4 wurde eine Reihe von Münzen (M 11. M 130. M 134. M 144. M 212. M 231, hellenistisch bis Leo I.) geborgen. Der Kanal ist im gesamten Abschnitt S 3/2003 aufgemauert (Taf. 53 Abb. 102). Das gilt auch für die Kanalsohle, die im mittleren Sondagenbereich freigelegt wurde. Der anstehende Fels muss deutlich tiefer liegen und wurde nirgendwo erreicht.

Besonders hervorzuheben ist die Situation im Kreuzungsbereich des Ost-West-Kanals mit dem >Doppelfundament $<$ (= Fundament der eigentlichen Bühnenfront und Pfeilerfundament). Während die südliche Kanalwange >durchläuft und den schmalen Zwischenraum zwischen dem Fundament der Bühnenfront und dem Pfeilerfundament verschließt (Taf. 54 Abb. 103), lässt die nördliche Wange diesen Zwischenraum offen. Die Ecken sind sorgfältig gemauert (Taf. 54 Abb. 104).

Eine zweite Erweiterung erfolgte im Sommer 2004, nachdem der rezente Betonboden im Durchgang des Sockels der scaenae frons entfernt worden war (Taf. $54 \mathrm{Abb}$. 105). Wieder muss betont werden, dass die Stelle bereits 1899 ergraben worden war. Die bereits aus S 1/2001 bekannten gemauerten Kanalwangen, die im Westen die Felsrinne fortsetzen, gehen im Sockelbereich der scaenae frons in sehr mächtige Mauern über. $\mathrm{Zu}$ beiden Seiten des an dieser Stelle $0,70 \mathrm{~m}$ breiten Kanals reichen die Kanalwandungen bis unter den Sockel der scaenae frons. Wie aus anderen Abschnitten des Ost-West-Kanals bekannt ist, sind die Wangen aus Bruchsteinen mit grauem Mörtel errichtet worden. Oberhalb der Kanalwandungen gibt es eine dicke Schicht hydraulischen Mörtels. Dieser ist zwar mit den Kanalwandungen verbunden, nicht aber mit dem Sockel der scaenae frons. Dessen Fundamentierung ist an der Südseite der Sondage gut zu erkennen (Taf. 55 Abb. 106). Unter der östlichen Sockelfront ist ein 0,60 m breiter gemauerter Streifen aus Bruchsteinen und Spolien zu erkennen. Westlich dahinter schließt eine Schuttplanierung bis zur Unterkante des Sockels an. Der Mörtel des Fassadenfundaments ist grau. Im Kanal konnte kein Boden mehr festgestellt werden. Die Unterkanten der Mauern ruhen auf einem festen, mittelbraunen, mit kleinen Steinen durchsetzten Erde-Lehm-Gemisch über dem gelb-weißen Verwitterungslehm. An der Südseite, nahe dem Sockel der scaenae frons, mündet ein aus dem Süden heranführender Kanal ein (Taf. 55 Abb. 107) ${ }^{25}$.

\subsubsection{SONDAGEN S 1/2001-NORD UND S 1/2002}

Im Nordteil von S 1/2001 und in S 1/2002 wurde im Jahr 2002 durchgehend bis auf das Niveau einer Wanne (SE L18) gegraben, deren Boden und Wände aus estrichartigem und mit Ziegelstückchen angereichertem Material bestehen. Ein schmaler Streifen dieser Wanne konnte in der östlichen Hälfte des Schnitts durchschlagen werden (Taf. 56 Abb. 108; 57 Abb. 109). Hier wurde unter dem Unterbau des Wannenbodens (SE L19), einer festen Bürste aus stehendem Ziegelbruch und einer Schicht aus braunem Lehm bestehend (SE L20), der gelb-weiß gesprenkelte Verwitterungslehm SE L21 erreicht (Taf. 57 Abb. 110). Die Wanne ist an dem anstehenden Fels im Süden hochgezogen, ebenfalls am Sockel der scaenae frons (Taf. 58 Abb. 111. 112), wie bereits

\footnotetext{
${ }^{25}$ Kap. 3.2.2.7.
} 


\begin{tabular}{|c|c|c|c|c|c|}
\hline Schicht & OK in $\mathbf{m}$ & UK in $\mathbf{m}$ & Beschreibung/Interpretation & Keramik & Münzen \\
\hline SE L1 & 11,17 & 11,12 & Oberflächenabhub, rez. gestört & $\begin{array}{l}\text { 4.-frühes } \\
\text { 5. Jh. n. Chr. }\end{array}$ & $\begin{array}{l}\text { M } 82 \\
\text { (Gordianus III.) }\end{array}$ \\
\hline SE L5 & 11,12 & 10,78 & hellbrauner, sandiger Schutt & $\begin{array}{l}\text { späthell.- } \\
\text { frühkaiserzeitl. }\end{array}$ & - \\
\hline SE L5a & 10,92 & 10,82 & $\begin{array}{l}\text { hellbrauner, sandiger Schutt; zwischen } \\
\text { Gussfundament und Plinthe; von SE } \\
\text { L5 in Material und Konsistenz nicht zu } \\
\text { unterscheiden; nicht ergraben }\end{array}$ & - & - \\
\hline SE L7 & 10,78 & 10,43 & $\begin{array}{l}\text { lockere, sandige Erde mit großen Steinen } \\
\text { (Ausriss über Streifenfundament) }\end{array}$ & 5. Jh. n. Chr. & - \\
\hline SE L7a & 10,78 & 10,44 & sandiger Schutt in Verlängerung von SE L7 & $\begin{array}{l}\text { späthell.- } \\
\text { frühkaiserzeitl. }\end{array}$ & - \\
\hline $\begin{array}{l}\text { SE L8a }= \\
\text { SE L14 }\end{array}$ & 10,78 & 10,45 & $\begin{array}{l}\text { hellbrauner, verfestigter Schutt mit kleinen } \\
\text { Steinen und Ziegelstücken }\end{array}$ & $\begin{array}{l}\text { späthell.- } \\
\text { frühkaiserzeitl. }\end{array}$ & - \\
\hline SE L8 & 10,78 & 10,44 & sandiger Schutt & $\begin{array}{l}\text { späthell.- } \\
\text { frühkaiserzeitl. }\end{array}$ & - \\
\hline SE L9 & 10,45 & 10,15 & $\begin{array}{l}\text { heller, sandiger Schutt mit Marmorabschlag } \\
\text { (wahrscheinlich identisch mit SE L11 = SE L16) }\end{array}$ & $\begin{array}{l}\text { späthell.- } \\
\text { frühkaiserzeitl. }\end{array}$ & - \\
\hline SE L10 & 10,15 & 10,05 & braune Erde & späthell.- & - \\
\hline $\begin{array}{l}\text { SE L11 }= \\
\text { SE L16 }\end{array}$ & 10,61 & 10,27 & $\begin{array}{l}\text { heller, sandiger Schutt; lockere und verfestigte } \\
\text { Bereiche wechseln (wahrscheinlich identisch } \\
\text { mit SE L9) }\end{array}$ & $\begin{array}{l}\text { 1. Jh. v. Chr.- } \\
\text { 1. Jh. n. Chr. }\end{array}$ & - \\
\hline SE L12 & 10,05 & 9,88 & Schutt mit Steinen & $\begin{array}{l}\text { 1. Jh. v. Chr.- } \\
\text { 1. Jh. n. Chr. }\end{array}$ & - \\
\hline SE L13 & 9,88 & 9,80 & Schutt mit Steinen und Mörtelbrocken & frühkaiserzeitl. & - \\
\hline SE L15 & 10,99 & 9,59 & $\begin{array}{l}\text { Verfüllung der Altsondage } 1899 \\
\text { (Doppelfundament) }\end{array}$ & - & - \\
\hline SE L17 & 9,93 & 9,81 & hellbrauner, sandiger Schutt; verfestigt & 2. Jh. v. Chr. & - \\
\hline SE L18 & 9,81 & 9,77 & Estrich & - & - \\
\hline SE L19 & 9,77 & 9,71 & Ziegelbürste & - & - \\
\hline SE L20 & 9,71 & $9,70-9,53$ & brauner Lehm & $\begin{array}{l}\text { spätklassisch- } \\
\text { hellenistisch }\end{array}$ & - \\
\hline SE L21 & 9,53 & - & Verwitterungslehm (gewachsener Boden) & - & - \\
\hline
\end{tabular}

Tab. 11

W. Alzinger festgestellt hatte ${ }^{26}$. In der Nordwestecke konnte die zur scaenae frons schräg verlaufende Stufe, die auch im Südprofil von S 1/1969 erkennbar ist (Taf. 59 Abb. 113), in Ansicht freigelegt werden. Die Wanne wurde im Osten hingegen nicht vollständig ergraben. Der Wannenboden läuft hier unter den Fundamenten der Bühnenfront durch. Das >Doppelfundament ` (= Fundament der eigentlichen Bühnenfront und Pfeilerfundament) ruht direkt auf dem Wannenboden, wie in den Profilen unter den Maueransichten erkennbar ist (Taf. 56 Abb. 108; 59 Abb. 113), ist aber in der Fläche zwischen den Fundamenten nicht mehr erhalten. Wahrscheinlich wurde der Wannenboden im Zuge der Grabungen um die Jahrhundertwende beseitigt. Dass damals an dieser Stelle gegraben wurde, konnte durch den Fund zahlreicher Konserven aus jener Zeit festgestellt werden (SE L15). Westlich des Pfeilerfundaments spricht hingegen nichts für einen gestörten Befund.

\footnotetext{
${ }^{26}$ Grabungstagebuch vom 11.06.1969.
} 
Wie bereits festgestellt, sitzen die Fundamente unter der Bühnenfront und der Pfeilerreihe direkt auf dem Boden der großen Estrichwanne auf. Das Fundament der Bühnenfront läuft jeweils über das Süd- bzw. Nordprofil hinaus. Das Pfeilerfundament setzt im Süden an den steil abfallenden Fels an und reicht über das Nordprofil hinaus (Taf. 60 Abb. 114. 115; 61 Abb. 116). In dem etwa 0,50 m breiten Raum zwischen den beiden Fundamentmauern ist der Fels am Südprofil bis auf ein Niveau von $\mathrm{T}^{\mathrm{a}}$ 9,941 m abgearbeitet. Nach Norden hin wurde er bis unter den tiefer liegenden Estrich bei $\mathrm{T}^{a} 9,763 \mathrm{~m}$ abgeschrägt. Im oberen Teil sind beide Fundamente im Abstand der Pfeilerjoche miteinander verbunden (Taf. 61 Abb. 117). Unter den Standplatten der Pfeiler, die exakt über diesen Bindern angebracht wurden, sind, wie unter den Plinthen der Säulen, gelegentliche Schutteinschlüsse zu erkennen.

Etwa in der Mitte zwischen dem Pfeilerfundament und der scaenae frons kam ein weiteres 0,70 bis $0,74 \mathrm{~m}$ breites, streifenförmiges Fundament zutage (Taf. 60 Abb. 114; 62 Abb. 118), das wie seine östlichen Nachbarn auf den Boden der Wanne gesetzt worden war. Es besitzt kaum mehr als drei Steinlagen und wurde im Bereich des Schnitts bis auf ein Niveau von $\mathrm{T}^{\mathrm{a}} 10,43 \mathrm{~m}$, also rund 0,76 m unter dem Bodenniveau, ausgerissen. Der Ausrissgraben (SE L7; SE L7a) war mit lockerem Schutt und zahlreichen großen Steinen verfüllt worden (Taf. 62 Abb. 119). Zu keinem der Fundamente konnte eine Baugrube festgestellt werden. Die Estrichwanne ist mit den Bauarbeiten am Theater, wahrscheinlich mit dem Bau des Bühnengebäudes flavischer Zeit, zu verbinden. Vermutlich war die Wanne noch vor der Erbauung der Bühne zugeschüttet worden, möglicherweise um eine ebene Arbeitsfläche, z. B. für Baustellengerät, zu schaffen. Erst nach der Fertigstellung der Skene, als man daran ging, die Bühne zu errichten, wurden die dafür erforderlichen Fundamentgräben gezogen. Im Bereich der Säulen des Logeion H6 und H7 wird die östliche Seite des Streifenfundaments von größeren Steinblöcken überlagert (Taf. 62 Abb. 118; 63 Abb. 120). Zwischen ihnen und der Fundamentoberkante war eine Ausgleichsschicht aus Mörtel und kleineren, aber geschichteten Steinen angebracht (Taf. 56 Abb. 108; 63 Abb. 120). In den Bereichen, wo die Steinblöcke das Streifenfundament überragen, reicht auch diese Untermauerung etwas tiefer hinab. Im Südprofil von S 1/2001 ist zwischen den Säulen H8-W und H8-O ein dritter, auf gleiche Art versetzter Steinblock erhalten geblieben, der hier auf dem anstehenden Fels ruht. Alle drei Blöcke liegen in keiner exakten Flucht; ihre Oberkanten differieren um bis zu neun Zentimeter. Da ihre Position mit den späteren Säulenstellungen korrespondiert, dürften sie mit dem kaiserzeitlichen Logeion in Verbindung stehen.

Die heute sichtbaren Säulen der kaiserzeitlichen Bühne sind über punktförmigen Gussfundamenten platziert, die sich zu beiden Seiten des Streifenfundaments befinden (Taf. 56 Abb. 108; 58 Abb. 112; 62 Abb. 118) ${ }^{27}$. Mit Ausnahme der Säule H7-W konnten zwischen den Fundamenten und den Plinthen der Säulen und der Pfeiler ausgleichende Schuttlagen von bis zu zehn Zentimeter Höhe festgestellt werden. Somit lässt sich folgende relative Abfolge feststellen. Die Wanne setzt am Fundament der scaenae frons an. Folglich ist sie jünger als diese oder annähernd gleichzeitig. Auf die Wanne folgt das >Doppelfundament höchstwahrscheinlich auch das Streifenfundament. Die Wanne wird dem Baustellenbetrieb des flavischen Umbaus zuzurechnen sein, als man zwar an der Fassade arbeitete, die Bühne aber noch nicht errichtet war ${ }^{28}$. Die Fundamentierungen gehören bereits der Bühne an. Für diese wurde die Wanne nicht beseitigt. Während die Innenseiten des >Doppelfundaments< exakt aufgemauert wurden, weisen die Westseite des Pfeilerfundaments (die Ostseite des Fundaments unter dem Proskenion wurde nicht freigelegt) sowie beide Seiten des Streifenfundaments Unregelmäßigkeiten auf (Taf. 61 Abb. 116). Die Fundamentmauern werden nach unten hin schmäler und weisen an vielen Stellen herausgequollenen Mörtel auf, sodass der Anschein entsteht, dass die Fundamente nicht freistehend aufgemauert wurden, was naheliegend wäre. Vielmehr dürfte in die bereits, warum auch immer, verfüllte Wanne ein Graben von entsprechender Breite ausgehoben worden sein, dessen Seiten quasi als Schalung dienten, an welche die Fundamente seitlich angesetzt wurden. Dadurch war ein sauberer Abstrich nicht möglich. Der überschüssige Mörtel wurde in die Hohlräume gedrückt, die zwischen Fundament und Graben bestanden. Im Fall des >Doppelfundaments ist anzunehmen, dass der Graben in voller Breite beider Fundamentmauern ausgehoben wurde, sodass man beim Mauern zwischen beiden stehen konnte, was den einander zugewandten Seiten natürlich einen anderen Charakter gibt als den beiden abgewandten.

\footnotetext{
${ }^{27}$ Hofbauer 2002, 185.
}

${ }^{28}$ Hofbauer 2002, 186. 


\subsubsection{SONDAGE S 5/2004 UND DER NÖRDLICHE BEREICH DES LOGEION}

\begin{tabular}{|l|l|l|l|l|l|}
\hline Schicht & OK in m & UK in m & Beschreibung/Interpretation & Keramik & Münzen \\
\hline $\begin{array}{l}\text { SE L65 } \\
\text { bis } \\
\text { SE L67 }\end{array}$ & 11,04 & 10,12 & $\begin{array}{l}\text { Verfüllung zwischen Doppelfundament, } \\
\text { Altgrabung 1969 }\end{array}$ & - & $\begin{array}{l}\text { M 97 } \\
\text { (Vespasianus od. Titus) }\end{array}$ \\
\hline $\begin{array}{l}\text { SE L68 } \\
\text { bis } \\
\text { SE L75 }\end{array}$ & 11,13 & 9,53 & Verfüllung der Sondage, Altgrabung 1969 & - & $\begin{array}{l}\text { M 145 } \\
\text { (Constantius II.) }\end{array}$ \\
\hline
\end{tabular}

Tab. 12

Mit S 5/2004 sollte der Norden des Logeion zwischen H3 und H5 noch einmal eingehender untersucht werden (Taf. 64 Abb. 122. 123). Es galt weitere Hinweise für oder gegen ein durchlaufendes Streifenfundament zu finden, aber auch die Situation am Nordende des >Doppelfundaments〈, dort wo es an den hellenistischen Ringkanal anschließen musste, zu untersuchen. Daneben wurde der bereits 1899 ergrabene und seither offenstehende Bereich am Nordende des Logeion, zwischen H3 und der Nordmauer des Logeion, gereinigt und am Sockel der scaenae frons weiter abgetieft. S 5/2004 deckt sich weitgehend mit einem bereits von W. Alzinger ergrabenen Bereich ${ }^{29}$. Der Schnitt von 1969 umfasste die gesamte Breite im Interkolumnium H5/H6 und zumindest den mittleren Bereich zwischen den Säulen bei H4/H5. Im selben Interkolumnium fanden bereits 1899 Untersuchungen um das `Doppelfundamentく statt. Für das Areal gab es jedoch keine ausreichende Dokumentation. Mit S 5/2006 wurde der Streifen zwischen den Säulenreihen erneut geöffnet. Die Beschreibung konzentriert sich daher auf den architektonischen Befund. Das Pfeilerfundament reicht bis in eine Tiefe von $\mathrm{T}^{\mathrm{a}}$ 9,883 m. Gleiches wird für das Fundament unter der Bühnenfront gelten, doch wurde hier aufgrund der Enge zwischen den beiden Fundamentmauern nicht bis zur Unterkante gegraben. Die beiden Fundamente enden im Norden an der Wandung des hellenistischen Kanals. Der Aufbau der >Doppelfundamentierung $<$ ist aus anderen Grabungsbereichen gut bekannt ${ }^{30}$. In der Achse der Pfeiler binden Steinplatten in beide Fundamentmauern ein. Diese Binderbereiche beginnen knapp unterhalb der Fundamentoberkanten, reichten also nicht bis ganz hinunter. Ähnlich wie bei den Säulen konnten auch unter den Plinthen der Pfeiler Schutteinschlüsse festgestellt werden. Knapp 0,45 m unter der Oberkante des Pfeilerfundaments, mittig im Interkolumnium, endet auf $\mathrm{T}^{\mathrm{a}}$ 10,07 $\mathrm{m}$ eine kleine Quermauer zwischen den Fundamenten. Zu beiden Seiten ist der Zwischenraum mit brauner Erde verfüllt. Aufgrund der sehr beengten Situation erfolgte kein weiterer Aushub. In geringem Abstand westlich des Pfeilerfundaments wurde knapp unter der Oberfläche eine längliche Ansammlung größerer Steine freigelegt (Taf. 65 Abb. 124). Sie ist ähnlich wie die Fundamente orientiert und ragte aus dem Südprofil etwa 1,22 m nach Norden. Die Reihe dieser Steine machte zunächst den Eindruck, bewusst, wenn auch sehr nachlässig, aufgeschichtet worden zu sein. Dennoch kann man sich bei näherer Betrachtung nicht des Eindrucks eines zufällig entstandenen Steinhaufens erwehren. W. Alzinger erwähnte mit keinem Wort eine Mauer im südlich angrenzenden Interkolumnium H5/H6. Die Steine sind eher mit den Grabungen von R. Heberdey in Zusammenhang zu bringen. Kleine Ansammlungen dicht beieinander liegender größerer Steine und Spolien waren in den Wiederverfüllungen der alten Schnitte mehrfach zu beobachten ${ }^{31}$.

Zwischen H4 und H5 konnte das Streifenfundament noch einmal im Nordteil des Logeion nachgewiesen werden, wo es bis auf $0,28 \mathrm{~m}$ an das Nordprofil reichte und in weiterer Folge gänzlich ausriss (Taf. 65 Abb. 125; Plan 10). Es ist hier direkt in die Aufplanierung gesetzt und reicht bei weitem nicht so tief wie das Pfeilerfundament. Von der Estrichwanne wurde nichts gefunden. Im südlich anschließenden Interkolumnium wurde 2005 nur zwischen der westlichen und östlichen Säulenreihe gegraben. Die Situation ist

\footnotetext{
${ }^{29}$ Grabungstagebuch vom 06.06.1969. Neben den Schnitten S 1/1969 und S 3/1969 wurde weiter nördlich, westlich des hellenistischen Kanals, Schnitt S 2/1969 angelegt. Grabungstagebuch vom 05.06.1969: »Versuch einer Nachschau im Bereich des Orchestrakanalknies im Norden (S 2), um eine etwaige Ecke der frühhellenistischen Proskenionfront festzustellen. Dieser Versuch verläuft ergebnislos, da der Raum zu beschränkt ist«.

${ }^{30}$ Kap. 3.2.2.2.

${ }^{31}$ Kap. 3.2.2.6
} 
vergleichbar mit dem Befund von S 1/1969 (Taf. 66 Abb. 126). Das Streifenfundament zwischen H4 und H5 ist ausgerissen, aber im Nord- und Südprofil noch erhalten. Darunter erstreckte sich der Wannenboden ursprünglich über die gesamte Fläche, wurde aber im mittleren Bereich bei den Grabungen 1969 durchschlagen $^{32}$. In S 5/2004 sind keine Brekzieblöcke unter dem Estrich vorhanden.

Das ganze Areal im Norden zwischen der nördlichen Abschlussmauer des Logeion, der scaenae frons, der einstigen Analemmawand Q und H3 war im Zuge der Ausgrabungen unter R. Heberdey freigelegt worden und blieb seither offen zugänglich. Obwohl heute schwer vorstellbar, stellte dieser Bereich die NordParodos des hellenistischen Theaters dar. Der aus der Orchestra kommende Ringkanal windet sich um den südlichen Bereich des Analemma und knickt dann abrupt nach Norden ab (Taf. 66 Abb. 127. 128; Plan 10). Der Kanal verlief unter dem Fußboden der Parodos und war in diesem Abschnitt bis zum Brückenstein T (Taf. 66 Abb. 127) gedeckt. Um die Jahrhundertwende war die Abdeckung noch erhalten, wurde aber bis etwa auf Höhe der Säule H1-W entfernt. Die Kanalabdeckung ist deutlich tiefer als die Fundamentoberkante des Analemma. Hier muss über den Deckplatten noch der eigentliche Fußboden ergänzt werden, von dem nichts mehr vorhanden ist. An der westlichen Kanalwange fehlt heute ein Quader (Taf. 67 Abb. 129). Der entfernte Porosquader wurde im rechten Winkel wieder angesetzt und bildet heute einen Teil der rezenten Rinne. Diese Maßnahme ist im Zusammenhang mit einer im Sockel der scaenae frons angelegten Sondage zu sehen. Diese reichte bis auf das Fundament herab und blieb offen. Die östliche Wand des Sockels blieb zwar bestehen, im Fundamentbereich wurde aber eine Öffnung angelegt. Das Ganze scheint der Ableitung des Regenwassers aus dem freigelegten Orchestrakanal zu dienen.

Der Boden dieser Verbindungsrinne, auf gleichem Niveau wie der Kanalboden, besteht aus sehr sauber ohne Mörtel versetzten Brekzieblöcken (Taf. 67 Abb. 130). Sie sind unmittelbar an die Bodenplatten des hellenistischen Kanals im Westen angesetzt. Die schmale Fuge dazwischen ist mit feinem Steinabschlag gefüllt. Das Fundament, das diese Blöcke bilden - wahrscheinlich handelt es sich dabei um jene, die auch im Grabungstagebuch als »in der Tiefe « ${ }^{33}$ liegend beschrieben wurden -, sind mit allen anderen hellenistischen Fundamenten des Bühnengebäudes und den Parodos-Mauern vergleichbar. Nach Westen hin endet diese Steinlage rund 0,30 m vor den Fundamenten der römischen Bühnenfassade. Nach Süden kann sie nicht weiter verfolgt werden, weil alles in diesem Bereich durch Restaurierungsmaßnahmen überformt ist. Im Norden behindert das gleichfalls stark restaurierte Fundament von Säule H1-W die Suche nach dem weiteren Verlauf. Deshalb wurde zwischen dem Fundament der scaenae frons, dem Fundament unter H1-W und der Westkante der Brekzieblöcke weiter abgetieft. Bei dem Material an der Oberfläche handelte es sich um Aushub aus humosen Einschwemmungen, die sich über dem weiß-gelb gesprenkelten Lehm angesammelt hatten. Auch hier wurde um 0,45 m abgetieft. Eine Fortsetzung des Brekziefundaments konnte aber in dem schmalen Graben nicht festgestellt werden.

\subsubsection{SONDAGE S 4/2005}

Südlich des Durchgangs H7/H8 wurde bis H10 zwischen östlicher und westlicher Säulenreihe gegraben (Taf. 68 Abb. 131. 132). Knapp unter der Oberfläche konnte über die gesamte Länge das Streifenfundament freigelegt werden. Gegenüber den anderen Abschnitten in S 1/2001 und den weiter unten angeführten Resten im Norden und Süden des Logeion fällt es durch seine teilweise etwas unregelmäßige Kante auf. Die Steinplatten in den Säulenachsen wiederholen sich bei H9 (Taf. 68 Abb. 131. 132; 69 Abb. 134) und H10 (Taf. 68 Abb. 131. 132). H7 ist bereits aus S 1/2001 bekannt. Die Platten wirken infolge der >Einrahmung< durch kleineres Bruchsteinmaterial wie sekundär in das Fundament, das unterhalb der Steinrahmung weiterläuft (Taf. 69 Abb. 134), gesetzt. Das bestätigt den Eindruck aus S 1/2001, wo das Niveau der Platten über dem Streifenfundament durch eine geringe Aufmauerung ausgeglichen wurde. Unter den Plinthen der Säulen konnten wiederum punktförmige Gussfundamente nachgewiesen werden (Taf. 69 Abb. 133). Die zu beiden Seiten des Streifenfundaments anstehende Planierung enthält im Westen (SE L87 zwischen H9-W und H10-W) Keramikfragmente des 1. Jhs. v. Chr., während an der Ostseite das datierende Material bis in die flavisch-trajani-

\footnotetext{
32 Grabungstagebuch vom 10.06.1969.
}

${ }^{33}$ Grabungstagebuch vom 24.09.1900. 


\begin{tabular}{|c|c|c|c|c|c|}
\hline Schicht & OK in $\mathbf{m}$ & UK in $\mathbf{m}$ & Beschreibung/Interpretation & Keramik & Münzen \\
\hline $\begin{array}{l}\text { SE L80 = } \\
\text { SE L82 }\end{array}$ & 11,19 & $\begin{array}{l}11,11- \\
10,93\end{array}$ & lockerer, hellbrauner Schutt & $\begin{array}{l}\text { Mitte des } 2 . \text { Jhs. } \\
\text { n. Chr., vereinzelt } \\
\text { bis in die späte } \\
\text { Kaiserzeit-5. Jh. n. } \\
\text { Chr. }\end{array}$ & - \\
\hline SE L81a & 10,98 & 10,93 & brauner Schutt zw. H8-O u. H9-O & flav.-trajan. & - \\
\hline SE L81b & 11,11 & 10,90 & braune, schuttige Erde zw. H8-W u. H9-W & - & - \\
\hline SE L83 & 10,93 & 10,86 & hellbraune, schuttige Erde zw. H8-O u. H9-O & $\begin{array}{l}\text { 1. Jh. v.-1. H. 2. Jh. } \\
\text { n. Chr. }\end{array}$ & - \\
\hline SE L84 & 10,86 & 10,66 & $\begin{array}{l}\text { braune, schuttige Erde mit etwa faustgroßen } \\
\text { Steinen zwischen H8-O und H9-O }\end{array}$ & $\begin{array}{l}\text { 1. Jh. v.-frühes } 1 . \text { Jh. } \\
\text { n. Chr. }\end{array}$ & - \\
\hline SE L85 & 11,93 & 10,68 & brauner Schutt zwischen H9-O und H10-O & $\begin{array}{l}\text { 1. Jh. v. Chr.-1. H. } 1 . \\
\text { Jh. n. Chr. }\end{array}$ & - \\
\hline SE L86 & 11,09 & 10,97 & $\begin{array}{l}\text { hellbrauner, sandiger Schutt zwischen } \\
\text { H9-W und H10-W }\end{array}$ & - & - \\
\hline SE L87 & 10,97 & 10,58 & $\begin{array}{l}\text { brauner, fester Schutt zwischen H9-W und } \\
\text { H10-W }\end{array}$ & 1. Jh. v. Chr. & - \\
\hline
\end{tabular}

Tab. 13

sche Zeit (SE L81a, SE L83 zwischen H8-O und H9-O) reicht. Das Streifenfundament ist im oberen Bereich ausgerissen und wird an diesen Stellen von SE L80 bedeckt. Das aus SE L80 stammende Fundmaterial ist heterogen. Wenige Funde reichen bis in das 5. Jh. n. Chr. Der Großteil der Keramik gehört noch in die Zeit nach der Mitte des 2. Jhs. n. Chr., was zumindest auf bauliche Aktivitäten im Bühnenbereich verweisen könnte, die laut einer im Theater gefundenen Inschrift ${ }^{34}$ um die Mitte des 2. Jhs. n. Chr. anzusetzen sind ${ }^{35}$.

\subsubsection{SONDAGEN S 1/2003 UND S 2/2003}

S 1/2003 wurde in H13/H14 zwischen den westlichen Säulen und dem römischen Proskenion angelegt (Taf. 70 Abb. 136. 137; 71 Abb. 138; Plan 10). Im Südosten wird die Sondage durch die Stirnseite der Mauer Q begrenzt. Der Abschnitt über dem `Doppelfundament` und entlang der Mauer Q im südlich angrenzenden Interkolumnium wurde bereits 1899 untersucht. Aus der Wiederverfüllung des alten Schnitts (SE L25) konnten mehrere Architekturteile, darunter ein Fragment eines Kapitells der Logeion-Säulen, ein Volutenfragment eines Konsolengesimses sowie eine Theatermaske aus Marmor (Taf. 71 Abb. 139) geborgen werden. Im gesamten Sondagenbereich wurde zwischen den Fundamenten der gewachsene Boden erreicht, der wie an vielen anderen Stellen aus dem typisch gelb-weiß gesprenkelten Verwitterungslehm SE L21 besteht. Oberflächlich hatte sich eine etwa 2 bis $4 \mathrm{~cm}$ dünne, sehr harte Schicht gebildet, in der kleine Steinchen, Holzkohlenstückchen und vereinzelt winzige Keramikfragmente enthalten sind. Im Osten des Südprofils ragte die bis zum Fundament vollständig freigelegte Parodos-Mauer Q (Taf. 71 Abb. 138. 140) etwas in die Sondage hinein. Das Fundament ist in die Lehmoberfläche eingetieft, wobei der Fundamentgraben das Fundament sowohl seitlich als auch an der Stirnseite deutlich überragte (Taf. 71 Abb. 138. 140). Die Grabenverfüllung SE L68 = L71 war zwar fundleer, entspricht in S 2/2003 aber den Schichten SE L62 und SE L69, die dem 3./2. Jh. v. Chr. angehören und passt damit gut zu den Ergebnissen der Auswertung des

${ }^{34}$ IvE 2039; s. auch Kap. 8.6.1, Nr. 9 u. Kap. 8.6.2.

${ }^{35}$ Kap. 3.2.3. 


\begin{tabular}{|c|c|c|c|c|c|}
\hline Schicht & OK in $\mathbf{m}$ & $\mathbf{U K}$ in $\mathbf{m}$ & Beschreibung & Keramik & Münzen \\
\hline SE L1 & $\begin{array}{l}11,20- \\
11,13\end{array}$ & $\begin{array}{l}11,16- \\
11,07\end{array}$ & Oberflächenreinigung, rezent umgelagert & - & - \\
\hline SE L21 & $\begin{array}{l}10,56 \\
(\max .)- \\
10,08 \\
(\min .)\end{array}$ & - & $\begin{array}{l}\text { gelb-weiß gesprenkelter Lehm (gewachsener } \\
\text { Boden; entspricht SE L31) }\end{array}$ & - & - \\
\hline SE L21a & 10,57 & 10,56 & $\begin{array}{l}\text { Lehmoberfläche (Übergang von Natur- zu } \\
\text { Kulturschicht) }\end{array}$ & - & - \\
\hline SE L23 & 11,07 & 10,93 & lockerer Schutt mit Steinen, rezent gestört & - & - \\
\hline SE L24 & 10,93 & $\begin{array}{l}10,82- \\
10,71\end{array}$ & hellbrauner Schutt mit Steinen, rezent gestört & $\begin{array}{l}\text { 1. Jh. v. Chr.-1. } \\
\text { Viertel 1. Jh. n. Chr. }\end{array}$ & - \\
\hline $\begin{array}{l}\text { SE L25 }= \\
\text { SE L27 = } \\
\text { SE L29 }= \\
\text { SE L30 }\end{array}$ & 10,86 & 10,08 & $\begin{array}{l}\text { braune Erde mit zahlreichen } \\
\text { Tonrohrfragmenten und Spolien (Verfüllung } \\
\text { der Altsondage von 1899) }\end{array}$ & - & - \\
\hline SE L26 & 10,82 & $\begin{array}{l}10,81- \\
10,75\end{array}$ & $\begin{array}{l}\text { dünnes, mörteliges Stratum östlich von } \\
\text { H12-O, fundleer }\end{array}$ & - & - \\
\hline SE L31 & 10,08 & - & $\begin{array}{l}\text { grau-weiß gesprenkelter Lehm (= } \\
\text { gewachsener Boden, entspricht SE L21) }\end{array}$ & - & - \\
\hline SE L32 & $\begin{array}{l}11,11- \\
10,75\end{array}$ & 10,65 & $\begin{array}{l}\text { hellbraune, sandige Erde mit großen Steinen } \\
\text { und Marmorabschlag (Verfüllung einer } \\
\text { großflächigen Störung) }\end{array}$ & $\begin{array}{l}\text { aug.-Mitte 1. Jh. n. } \\
\text { Chr }\end{array}$ & - \\
\hline SE L33 & 11,15 & 10,84 & $\begin{array}{l}\text { braune Erde mit kleinen Steinen und } \\
\text { Marmorabschlag (im W-Profil sichtbar, in S } \\
\text { 1/2003 nicht ergraben) }\end{array}$ & - & - \\
\hline SE L34 & 10,96 & 10,87 & $\begin{array}{l}\text { hellbraune, teils rötliche Erde mit } \\
\text { Marmorabschlag (im S-Profil sichtbar, in S } \\
\text { 1/2003 nicht ergraben) }\end{array}$ & - & - \\
\hline SE L35a & 10,50 & 10,35 & hellbraune, teils rötliche Erde & 1. Jh. v. Chr. & - \\
\hline SE L37 & $\begin{array}{l}10,87- \\
10,65\end{array}$ & $\begin{array}{l}10,55- \\
10,47\end{array}$ & $\begin{array}{l}\text { gelbbraune Erde mit kleinen und wenigen } \\
\text { größeren Steinen (im N-Profil sichtbar, nicht } \\
\text { ergraben) }\end{array}$ & - & - \\
\hline SE L38 & 10,55 & 10,16 & $\begin{array}{l}\text { braune Erde mit großen Steinen } \\
\text { (Grubenverfüllung) }\end{array}$ & - & M 89 (gallienisch) \\
\hline SE L39 & 11,16 & 10,90 & braune, sandige Erde & $\begin{array}{l}\text { aug; } 1 \text { spätantikes } \\
\text { Frgt. (S } 4 / 2003)\end{array}$ & - \\
\hline SE L40 & 10,65 & 10,43 & braune Erde (Verfüllung über Mauerausriss) & (2. H.) 1. Jh. v. Chr. & - \\
\hline SE L65 & 10,84 & 10,82 & $\begin{array}{l}\text { dünnes, mörteliges Band südlich von H12-W } \\
\text { (im W-Profil sichtbar, nicht ergraben) }\end{array}$ & - & - \\
\hline SE L66 & 10,82 & 10,78 & $\begin{array}{l}\text { dünnes Band aus Lehm und Mörtelgrieß unter } \\
\text { L065 (im W-Profil sichtbar, nicht ergraben) }\end{array}$ & - & - \\
\hline SE L67 & $\begin{array}{l}10,84 \\
10,78\end{array}$ & $\begin{array}{l}10,80 \\
10,55\end{array}$ & $\begin{array}{l}\text { hellbrauner Schutt (im W-Profil sichtbar, in S } \\
1 / 2003 \text { nicht ergraben) }\end{array}$ & - & - \\
\hline
\end{tabular}




\begin{tabular}{|l|l|l|l|l|l|}
\hline Schicht & OK in $\mathbf{m}$ & UK in $\mathbf{m}$ & Beschreibung & Keramik & Münzen \\
\hline $\begin{array}{l}\text { SE L68 } \\
\text { = SE L71 }\end{array}$ & 10,50 & 10,20 & $\begin{array}{l}\text { braune, etwas lehmige Erde am Nordende } \\
\text { des Analemmafundaments (Verfüllung des } \\
\text { hellenistischen Fundamentgrabens; entspricht } \\
\text { SE L62 = SE L69 und daher einer Datierung } \\
\text { ins 3./2. Jh. v. Chr. wie in S 2/2003); fundleer }\end{array}$ & - & - \\
\hline
\end{tabular}

Tab. 14

\begin{tabular}{|c|c|c|c|c|c|}
\hline Schicht & OK in $\mathbf{m}$ & UK in $\mathbf{m}$ & Beschreibung & Keramik & Münzen \\
\hline SE L1 & $\begin{array}{l}11,22- \\
11,13\end{array}$ & $\begin{array}{l}11,16- \\
11,09\end{array}$ & Oberflächenreinigung, rezent umgelagert & - & $\begin{array}{l}\text { M } 1 \\
\text { (Alexander III.) }\end{array}$ \\
\hline SE L28 & 11,09 & 10,74 & $\begin{array}{l}\text { braune Erde mit großen Steinen und Spolien } \\
\text { (Verfüllung der Altsondage von 1899) }\end{array}$ & - & M 264 (osmanisch) \\
\hline SE L33 & 11,16 & $\begin{array}{l}10,91- \\
10,81\end{array}$ & $\begin{array}{l}\text { braune Erde mit kleinen Steinen und } \\
\text { Marmorabschlag }\end{array}$ & - & - \\
\hline SE L34 & 10,91 & 10,75 & $\begin{array}{l}\text { hellbraune, teils rötliche Erde mit } \\
\text { Marmorabschlag }\end{array}$ & - & - \\
\hline SE L35 & 10,75 & 10,33 & $\begin{array}{l}\text { hellbraune, teils rötliche Erde mit } \\
\text { Marmorabschlag und Spolien }\end{array}$ & - & - \\
\hline SE L36 & 10,81 & 10,46 & braune Erde mit Steinen und Spolien & - & - \\
\hline SE L41 & 10,46 & 10,38 & dunkle Erde mit Steinen & - & - \\
\hline SE L52 & 10,78 & 10,35 & braune Erde mit gelbem Lehm durchmischt & - & - \\
\hline SE L53 & 11,19 & 11,15 & braune Erde über Steinpackung SE L60 & aug.? & - \\
\hline SE L60 & 11,15 & 10,98 & Steinpackung & - & - \\
\hline SE L61 & 10,98 & 10,74 & braune Erde unter Steinpackung SE L60 & 1. Jh. v. Chr. & - \\
\hline $\begin{array}{l}\text { SE L62 = } \\
\text { SE L69 }\end{array}$ & 10,47 & 10,17 & $\begin{array}{l}\text { braune, lehmige Erde an der Westseite des } \\
\text { Analemmafundaments (Verfüllung des } \\
\text { hellenistischen Fundamentgrabens; entspricht } \\
\text { SE L68=SE L71 in S 1/2003) }\end{array}$ & 3./2. Jh. v. Chr. & - \\
\hline SE L70 & 10,74 & 10,47 & braune Erde mit gelbem Lehm durchmischt & - & - \\
\hline Fels & 10,34 & - & Fels & - & \\
\hline
\end{tabular}

Tab. 15 


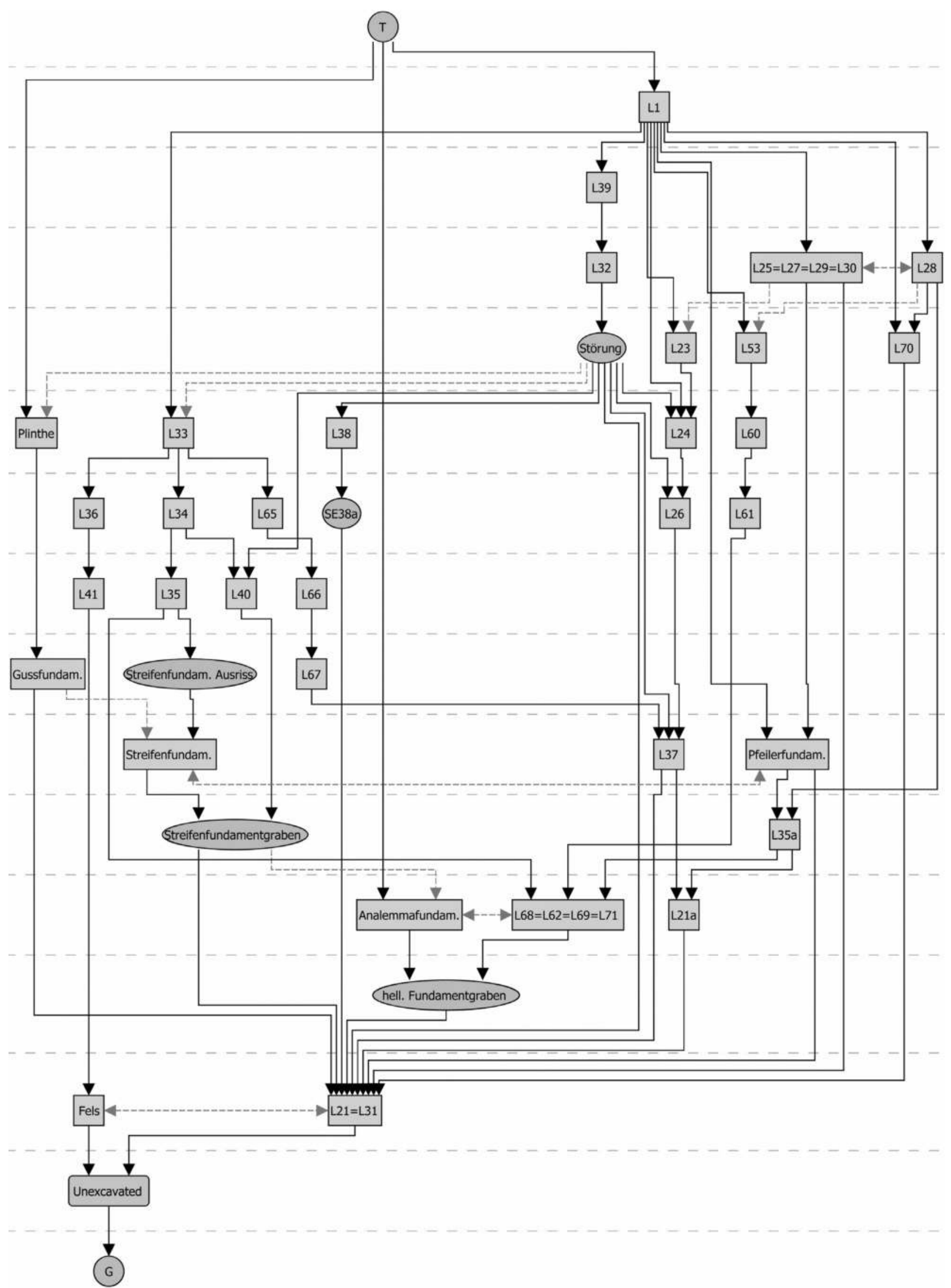

Grafik 3: Harris-Matrix S 1/2003 und S 2/2003 
Fundmaterials aus den Kammern D3 und D8. Auch in Baumaterial und -technik gleicht das Fundament den bereits aus Kammer D3 bekannten Fundamentierungen der Skene. Die Flucht der über dem Fundament errichteten Mauer Q weicht merklich von der des Fundaments ab. In Bezug auf die Mittelachse des Theaters nimmt die Flucht des aufgehenden Mauerwerks der Mauer Q einen Winkel von $71^{\circ}$ ein und ist somit mit dem Winkel des Aufgehenden der Mauer P im Norden identisch. Das Fundament unter der Mauer Q dagegen steht in einem Winkel von ca. $78^{\circ}$ auf die Mittelachse des Theaters. Dieser Winkel lässt sich für das Fundament unter der Mauer P nicht nachweisen. Die Abweichung zur Ausrichtung der Mauer ist hier deutlich geringer. Beide Mauern stammen im unteren Teil noch aus hellenistischer Zeit, wurden weiter oben aber mit Spolien ergänzt. Westlich der Mauer Q verlief vermutlich einst die hellenistische Süd-Parodos ${ }^{36}$. Davon ist weder in S 1/2003 noch in S 2/2003 etwas erhalten, doch gibt die Fundamentoberkante analog zur Situation im Norden einen Anhaltspunkt für die Höhe des hellenistischen Laufniveaus. Am Nordende der Mauer Q bildet Stein 2 (Taf. 72 Abb. 141; 73 Abb. 143; = FiE II Stein R) die Entsprechung zu den Brückensteinen über dem hellenistischen Orchestrakanal. Sein Oberseitenniveau von $\mathrm{T}^{\mathrm{a}} 11,053 \mathrm{~m}$ ist identisch mit dem Niveau der östlich des römischen Proskenionsockels anschließenden Kanalwandung (11,060 m). Die Platte R liegt auf Block 1, der den Kanal nach Westen abschließt und mit einem Oberflächen-Niveau von 10,73 m den höchsten Punkt des Kanals bildet. Die Nordseite von Block 2 dürfte ursprünglich an die innere Kanalwange angeschlossen haben. Die Fehlstelle in Block 1 liegt exakt im freien Bereich des direkt anschließenden >Doppelfundaments« unter der Front des Proskenion und der Pfeilerreihe. Man möchte an eine spätere Abflussöffnung denken. Der Raum zwischen Pfeilerfundament und Frontfundament kann jedoch nicht als sekundärer Abflusskanal gedient haben. Wie in S 3/2003 festgestellt wurde ${ }^{37}$, ist eine Verbindung zum Ost-West-Kanal im mittleren Durchgang nicht gegeben. Block 1 liegt auf dem gelb-weißen Lehm auf. Für die Fundamente der Mauer Q wurde, wie bereits erwähnt, ein Graben im gewachsenen Lehmboden angelegt.

Zwischen westlicher und östlicher Säulenreihe sind die Reste einer aus Bruchsteinen im Mörtelverband errichteten Fundamentierung erhalten. In S 1/2003 sind davon jedoch nur mehr Reste im Nord- und Südprofil vorhanden. Dazwischen ist das Fundament ausgerissen. Die Oberkante des am Nordprofil von S 1/2003 erhaltenen Rests liegt bei $\mathrm{T}^{\mathrm{a}} 10,71 \mathrm{~m}$. Im Planum war deutlich eine in Nord-Süd-Richtung verlaufende Kante zu erkennen (Taf. 71 Abb. 138), die der Flucht an der Ostseite der Mauer entspricht. Der Mauerausriss ist bis hinunter auf Ta $10,426 \mathrm{~m}$ mit braunem Schutt verfüllt (SE L40). Das Fundament ist nochmals in S 2/2003 nachzuweisen. Die unterste Steinlage ragt gerade noch aus dem Nordprofil heraus (Taf. 75 Abb. 145). Das Oberkantenniveau von 10,75 m ist geringfügig höher als der Rest im Nordprofil von S 1/2003. Unmittelbar an diesen Ausriss schließen - allerdings tiefer liegend - zwei Marmorspolien an, die in keiner erkennbaren Ausrichtung zu anderen Elementen des Theaters liegen (Taf. 76 Abb. 146. 147). Sie sind möglicherweise der Grund für die Zerstörung des Fundaments. Über den Marmorplatten sind zwei Marmorquader übereinander geschichtet, deren Orientierung der Nord-Süd-Flucht des Logeion durchaus entspricht. Die Spolien sind ohne Mörtel versetzt. Ihr funktioneller Zusammenhang mit dem Logeion ist unklar. Südlich der Marmorspolien verläuft wieder ein Mauerrest aus Bruchsteinen in Mörtelbindung (Taf. 76 Abb. 147). Es dürfte sich dabei um einen Teil des Streifenfundaments handeln. Wenn das zutrifft, muss es unmittelbar südlich der Säulen H13 einen Knick nach Südwesten gegeben haben. Möglicherweise eine Reaktion auf den durch die schräg verlaufende Mauer Q enger werdenden Raum. Der Mauerrest halbiert - soweit das aus den unregelmäßigen Resten hervorgeht - tatsächlich den Winkel zwischen Mauer Q und der scaenae frons. Westlich der Spolien, bis zum Sockel der scaenae frons wurde der gelb-weiß gesprenkelte Lehm SE L21 bis knapp vor das Südprofil auf den Fels abgetieft vorgefunden. Das Felsniveau wurde von einer durchschnittlich $13 \mathrm{~cm}$ hohen Schicht aus dunkler, recht homogener Erde mit wenig Keramik bedeckt (SE L41). Der darüber aufgebrachte Schutt SE L36 enthielt Steine und Spolien. Daraus entstammt auch SK $1^{38}$. Östlich der beiden oberen Marmorquader wurde die Marmorbasis von SE L35 bedeckt. SE L34 bedeckte SE L35 und das ausgerissene Streifenfundament. Östlich des Streifenfundaments verläuft bis zu den Fundamenten von Mauer Q ein von SE L35 kaum zu unterscheidendes Material auf tieferem Niveau weiter (SE L35a).

\footnotetext{
${ }^{36}$ Zur Bedeutung dieses komplexen Baubefunds für das hellenistische Auditorium s. STYHLER-AYDIN (in Vorbereitung).

${ }^{37}$ Kap. 3.2.2.1.

${ }^{38}$ Kap. 7.2.1.
} 
Die teilweise rezent gestörte Oberfläche SE L33 reicht vom Sockel der scaenae frons bis auf die Höhe von Säule H13-O und bedeckte sowohl SE L36 als auch SE L34. Weiter nach Osten hin wurde, wie bereits weiter oben festgestellt, 1899 bis knapp unter die Fundamentoberkante der Mauer Q gegraben und anschließend wieder zugeschüttet (SE L28). Die bereits erwähnte SE L35a wurde unter der Altgrabung gerade noch erfasst. Deutlich sichtbar ist das Stratum unterhalb des Quaders von H13-O. Die Verfüllung des Fundamentgrabens (SE L62 = L69) blieb somit durch die Altgrabung unberührt, was eine Datierung der Fundamente in das 3./2. Jh. v. Chr. erlaubt (vgl. SE L68 = L71 in S 1/2003, s. o.). In der Südostecke des Logeion, südlich des Pfeilers H14-O, wurde auf einem Niveau von $\mathrm{T}^{\mathrm{a}}$ 10,80 m ein kleiner Rest einer Stein-Mörtel-Packung (SE L60) gefunden. Sowohl das Material darüber (SE L53) als auch die darunter befindliche Schicht SE L61 waren nur mehr in geringem Ausmaß vorhanden. Die wenigen Funde erlauben keine Aussage zur Datierung der Steinpackung. Ebenso wenig lässt sich ein Anhaltspunkt zur ursprünglich bedeckten Fläche ausmachen. Möglicherweise handelte es sich um einen flächenmäßig begrenzten Einbau im Süden. Jedenfalls ist kein weiteres befestigtes Bodenniveau in einem anderen Bereich der kaiserzeitlichen Bühne bekannt.

Die recht komplexe Situation in S 1/2003 resultiert aus einer Reihe von Störungen, welche von der westlichen Säulenflucht bis zum >Doppelfundamentく reichen. Davon ist SE L25 und SE L27 bis SE L30 der Grabung 1899 zuzurechnen. Die Westgrenze von SE L25 verlief ungefähr zwischen der Südwestecke der Aufstandsplatte von H12 und der Nordwestecke des Fundaments unter Mauer Q. Der übrige Bereich, gekennzeichnet durch die Schichten SE L32 und SE L39, dürfte nicht zu der 1899er Grabung gehören. Diese Störung befindet sich an der Stelle, wo sich einst ein Kanal befunden hatte, dessen Reste noch im nördlich angrenzenden Schnitt S 4/2003 vorgefunden wurden. Obschon SE L32 sich über einer Reihe relativchronologisch späterer Strukturen bzw. Eingriffen erstreckt ${ }^{39}$, reicht das Fundmaterial nicht über die 1. Hälfte des 1. Jhs. n. Chr. hinaus. SE L32 reicht auf die Verfüllung des Streifenfundamentgrabens (SE L40) und weiter östlich auf SE L37 herab. Von letzterer war SE L32 nur mit Mühe zu unterscheiden. Bei beiden Straten handelte es sich um hellbraune, sandige Erde mit großen Steinen und Marmorabschlag. Auch Festigkeit und Konsistenz ähneln sich sehr. SE L37 liegt bereits über dem gewachsenen Boden SE L21 bzw. L 21a sowie über einigen Gruben. Dazu gehört eine große Grube nahe dem Pfeilerfundament (SE L38) und einige kleinere Gruben, deren Verfüllung kein Fundmaterial enthielt. Im Bereich des verlängerten Streifenfundaments ließ sich ein seichter Graben (SE L40) feststellen. Das wenige daraus geborgene Material datiert in die hellenistische Zeit. Vom Ende des Fundaments unter Mauer Q bis zur Säule H13-O zieht sich - gleichfalls unter SE L37 liegend - ein Rest der Schicht SE L35a. Sie verläuft unmittelbar über dem gewachsenen Boden SE L21/L21a sowie über der hellenistischen Fundamentgrabenfüllung SE L68 = L71. SE 35a wird von SE L37 bedeckt.

Im Nord- und Südprofil wurden Schichten sichtbar, die außerhalb der Störungen lagen. Dazu gehört ein dünnes Mörtelniveau SE L65 ( $\mathrm{T}^{\mathrm{a}}$ 10,84 m) über SE L66 und dem hellbraunen Schutt SE L67, der eventuell eine Fortsetzung von SE L37 westlich des Streifenfundaments darstellt. Mit einer Oberkante von T ${ }^{\mathrm{a}} 10,82$ $\mathrm{m}$, also mit fast gleichem Niveau wie SE L65, gibt es auch im Nordprofil ein mörteliges Niveau zwischen H12-O und dem Pfeilerfundament. Es befindet sich über SE L37 und wird von SE L24 und L23 bedeckt.

\subsubsection{SONDAGE $S$ 4/2003}

Nördlich an S 1/2003 anschließend wurde der Bereich vom Sockel der scaenae frons bis zur östlichen Säulenreihe freigelegt (Taf. 76 Abb. 148). Auch hier wurde bis auf den gewachsenen Boden gegraben. Die geringfügig in S 1/2003 hineinragende Mauer konnte in S 4/2003 weiter nach Norden verfolgt werden, ist allerdings auch hier nur mehr in Resten erhalten. Die auffälligste Struktur ist ein aus Bruchsteinen aufgemauerter Kanal (Taf. 76 Abb. 148; 77 Abb. 149. 150), der S-förmig von knapp nördlich des Nordprofils von S 1/2003, durch die westliche Säulenreihe hindurch, nach Norden verläuft, wo er sich, wie in S 6/2004 bestätigt werden konnte, entlang des Sockels der kaiserzeitlichen scaenae frons bis zum Ost-West-Kanal im Mitteldurchgang H7/H8 zieht, in den er schließlich mündet. Der Kanal besitzt einen aus Bruchsteinen gemauerten Boden und ist ab H12-W und H12-O nach Süden bzw. Südosten hin zur Gänze ausgerissen. Er liegt über der Nord-Süd verlaufenden Mauer, die wohl als der südliche Teil des Streifenfundaments anzusprechen

\footnotetext{
${ }^{39}$ Kap. 3.2.2.6 u. 3.2.2.7.
} 


\begin{tabular}{|c|c|c|c|c|c|}
\hline Schicht & OK in $\mathbf{m}$ & UK in $\mathbf{m}$ & Beschreibung & Keramik & Münzen \\
\hline SE L1 & 11,21 & $\begin{array}{l}11,14- \\
11,12\end{array}$ & Oberflächenreinigung, rezent umgelagert & - & M 269. 271 \\
\hline SE L21 & 10,38 & - & $\begin{array}{l}\text { gelb-weiß gesprenkelter Lehm } \\
\text { (gewachsener Boden) }\end{array}$ & - & - \\
\hline SE L32 & 11,12 & 10,70 & $\begin{array}{l}\text { hellbraune, sandige Erde mit großen Steinen } \\
\text { und Marmorabschlag (Verfüllung einer } \\
\text { großflächigen Störung) }\end{array}$ & $\begin{array}{l}\text { aug.-- } \\
\text { Mitte 1. Jh. n. Chr. }\end{array}$ & - \\
\hline SE L39 & 11,14 & 10,87 & braune, sandige Erde & $\begin{array}{l}\text { aug.; } \\
1 \text { spätantikes Frgt. }\end{array}$ & - \\
\hline SE L46 & 11,12 & 10,97 & Erde mit großen Steinen & 1. Jh. n. Chr. & - \\
\hline SE L47 & 10,97 & 10,88 & sandige Erde mit vielen kleinen Steinchen & flav.-hadr. & - \\
\hline $\begin{array}{l}\text { SE L48 = } \\
\text { SE L49= } \\
\text { SE L54b= } \\
\text { SE L56 = } \\
\text { SE L57 }\end{array}$ & $\begin{array}{l}10,94- \\
10,88\end{array}$ & 10,65 & rötliche Erde (Kanalverfüllung) & flav.-hadr. & - \\
\hline SE L50 & 10,88 & 10,73 & braune, sandige Erde & 1. Jh. n. Chr. & - \\
\hline SE L51 & 10,75 & 10,73 & mittelbraune Erde & 1. Jh. v. Chr.? & - \\
\hline SE L54a & 11,14 & 10,94 & rötliche Erde & $\begin{array}{l}\text { aug.-- } \\
\text { 2. H. 4. Jh. n. Chr. }\end{array}$ & - \\
\hline SE L55a & 11,14 & 11,06 & braune, sandige Erde mit Marmorabschlag & 2.-4. Jh. n. Chr. & M 102 \\
\hline SE L55b & 11,06 & 10,86 & $\begin{array}{l}\text { mittelbraune Erde mit etwas } \\
\text { Marmorabschlag }\end{array}$ & flav.-trajan. & - \\
\hline SE L58 & 10,73 & 10,55 & $\begin{array}{l}\text { mittelbraune Erde mit Marmorabschlag und } \\
\text { Holzkohle }\end{array}$ & $\begin{array}{l}\text { 2. H. 1. Jh.-- } \\
\text { 3. Jh. n. Chr. }\end{array}$ & - \\
\hline SE L59 & 10,55 & 10,38 & Grubenverfüllung & 1. Jh. v. Chr.? & - \\
\hline SE L63 & 11,06 & 10,66 & Steinverfüllung, fundleer & - & - \\
\hline SE L64 & 10,86 & 10,53 & braune Erde & flav.-trajan. & - \\
\hline
\end{tabular}

Tab. 16

ist. In seinem besonderen Verlauf nimmt der Kanal Rücksicht auf die Säulenstellungen, zu denen ursprünglich die Punktfundamente gehörten, die praktisch im gesamten Südbereich des Logeion nachgewiesen wurden. Andererseits wurden die Kanalwangen an manchen Stellen durch die Plinthen der Säulen zerstört.

Wie sich zeigte, war der Kanal ausschließlich mit älterem Fundmaterial aus flavisch-hadrianischer Zeit verfüllt (SE L 48 = L 56; SE L 49 = L 57 und SE L54b) und gibt daher weder Aufschluss über die Aufgabe des Kanals noch über den Zeitpunkt der Verfüllung.

Da der Kanal jedoch auch zwischen den Punktfundamenten der zweiten Stützreihe, die im Zuge des Umbaus der Bühne in antoninischer Zeit eingebaut wurden, verläuft und auf diese Bezug nimmt, ist davon auszugehen, dass der Kanal entweder zeitgleich, d. h. mit dem Einbau dieser Stützreihe, oder aber erst danach eingezogen wurde.

Das Eingreifen der Plinthen einiger Säulen, die über den Punktfundamenten ruhen, in die Kanalwandung lässt sich nur durch eine spätere Umgestaltung oder Reparatur des Bühnenbereichs erklären. 


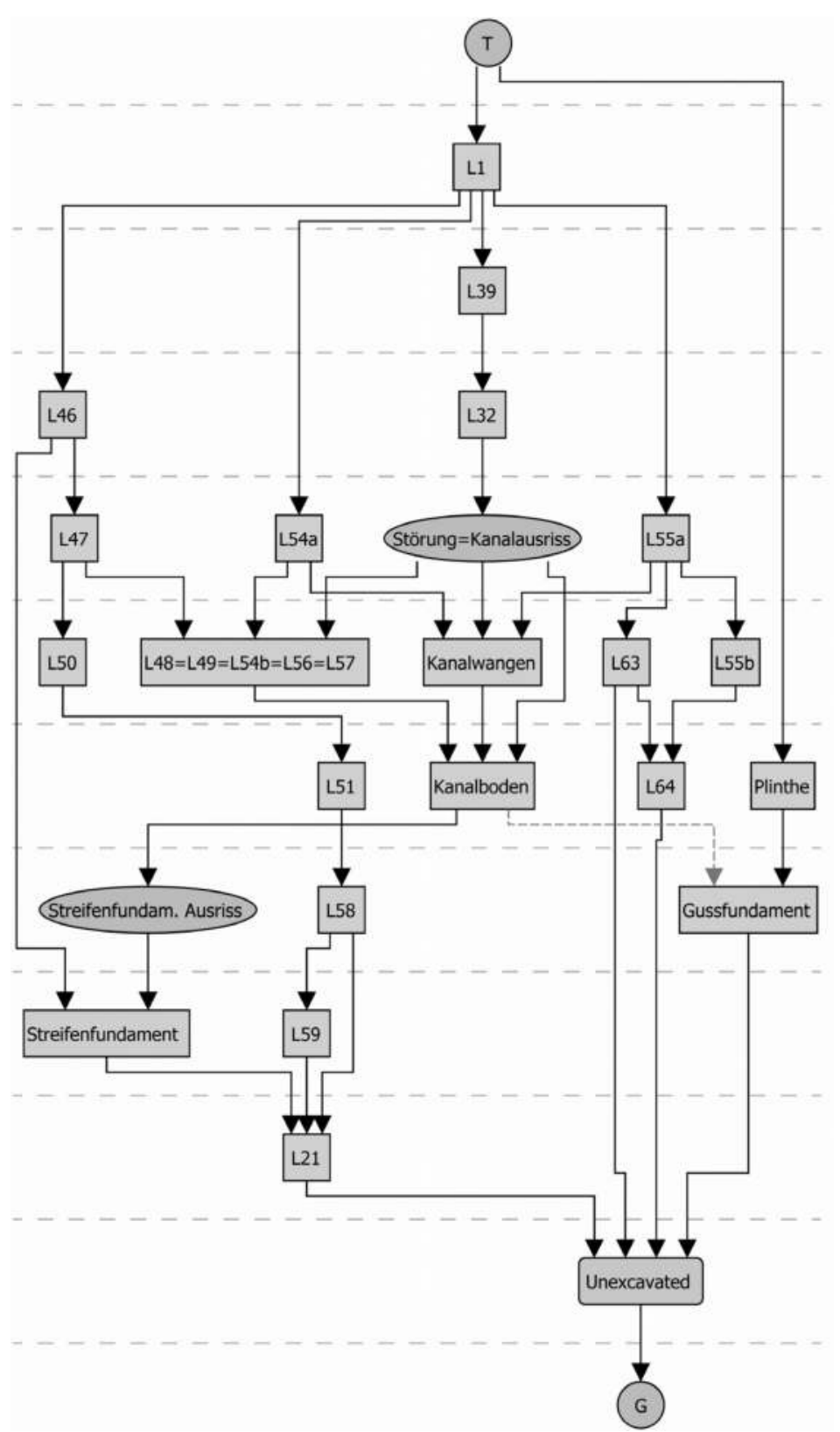

Grafik 4: Harris-Matrix S 4/2003

\subsubsection{Zusammenfassung Bühnen des Theaters}

Im Folgenden werden die Grabungsergebnisse im Bereich des Logeion zusammengefasst und unter Einbeziehung der bereits in der Erstpublikation vorgelegten Ergebnisse eine Rekonstruktion der römischen Bühnen versucht. Zu den ältesten Teilen im Bereich der kaiserzeitlichen Bühne gehören die Mauern P und Q. Wie bereits W. Wilberg darlegte ${ }^{40}$, handelt es sich bei diesen um Reste der hellenistischen Analemmata, die in den kaiserzeitlichen Bau integriert wurden (Taf. 73 Abb. 143; 74 Abb. 144; 75 Abb. 145). Die Mauern enthalten zwar eine Reihe sekundär verwendeter Marmorquader, sind aber - vor allem im unteren Teil original erhalten. Dazu gehören die erste Quaderreihe, das Fußprofil, die Abschlussquader und die Funda-

\footnotetext{
${ }^{40}$ Heberdey u. a. $1912,15$.
} 
mente. Aus diesem Grund weist die späthellenistische Inschrift ${ }^{41}$ des Abschlussquaders von Mauer Q nach Westen. Also dorthin, wo ehemals der Zugang lag. Das Fundmaterial aus dem Fundamentgraben von Mauer Q lässt sich zwar nur recht allgemein in das 3./2. Jh. v. Chr. einordnen, zeigt aber erneut, dass man das Theater nicht zu früh ansetzen darf. Der aus der hellenistischen Orchestra heranführende Kanal biegt um den südlichen Abschluss der Mauer P und verläuft ab hier unter dem Boden der Nord-Parodos. Von den Parodoi ist nichts mehr erhalten. Ihr Fußbodenniveau lässt sich aber aus der Fundamentoberkante der Mauern P und Q ableiten. Negativ verlief in allen Grabungen die Suche nach Hinweisen auf das hellenistische Proskenion. Seine Lage wird sich weitgehend mit dem Bereich der aus flavischer Zeit stammenden scaenae frons decken ${ }^{42}$. Deren Errichtung stellt die zweite nachweisbare Phase im Logeion dar. Der heute vor dem Sockel der scaenae frons existierende `Stützenwald (Taf. 77 Abb. 151; 78 Abb. 152) entspricht aber nicht der flavischen Bühnenanlage. Lediglich die Reste der Bühnenfront gehören zu den sichtbaren Elementen dieser Phase. Trotz zahlreicher baulicher Aktivitäten und späterer archäologischer Grabungen, die vielerorts eine Umlagerung des Bodens bedingten, lassen sich weitere Hinweise für eine Rekonstruktion der Bühne aus flavischer Zeit finden. Beim ältesten Einbau im Bereich unter dem römischen Logeion handelt es sich um eine Estrichwanne im Bereich zwischen $\mathrm{H} 4$ und $\mathrm{H}^{43}$. Sie ist nicht nur am Fels in der Mitte des Logeion hochgezogen, sondern auch am Fundament der scaenae frons, und kann also nicht älter als diese sein. Spätestens mit der Errichtung der Bühne selbst musste diese aufgegeben worden sein. Die Wanne ist damit am ehesten mit den flavischen Bauaktivitäten am Theater in Zusammenhang zu bringen. Wie sich aus dem Grabungsbefund ergibt, hatte die Wanne einst einen großen Bereich der nördlichen Hälfte des Logeion eingenommen. Weder im Norden noch im Osten wurde die Begrenzung der Wanne erfasst. Doch zeigte sich, dass der Wannenboden unterhalb des Fundaments der Bühnenfront noch weiter nach Osten reichte (Taf. 56 Abb. 108; 59 Abb. 113). Die Wanne ist in den Boden hinein getieft. Den Unterbau bildet eine Bürste aus Ziegelstücken. Boden und Wände sind verputzt. Unterhalb der Wanne wurden im Interkolumnium H5/H6 von W. Alzinger größere Brekzieblöcke gefunden (Taf. 63 Abb. 121). In der Hoffnung, einen Hinweis auf das hellenistische Proskenion gefunden zu haben, legte Alzinger auch das nördlich angrenzende Interkolumnium H4/H5 frei, konnte aber keine weiteren Steinquader unterhalb des Wannenbodens finden. Aus den wenigen Brekzieblöcken ist keine klare Struktur zu erkennen.

Oberhalb der Wanne konnte als älteste Bausubstanz eine rund 0,72 $\mathrm{m}$ breite streifenförmige Fundamentierung zwischen den beiden Säulenreihen festgestellt werden (Taf. 60 Abb. 114). Das aus Bruchsteinen in Mörtelbindung ausgeführte Fundament ist an mehreren Stellen (H4/H5 und H5/H6) ausgerissen. Sein Verlauf kann aber von H3/H4 im Norden (Taf. 65 Abb. 125) bis zum Fels bei H7 über eine Länge von 8,30 m nachvollzogen werden (Plan 18). In der südlichen Hälfte des Logeion setzt sich das Streifenfundament auch außerhalb der Wanne fort und ist zwischen H8 und H10 (Taf. 68 Abb. 131. 132), H13/H14 (Taf. 70 Abb. 137; 76 Abb. 147) sowie mit großer Wahrscheinlichkeit in einigen Resten bei H11/H12 nachweisbar. Auch das Pfeilerfundament und die Fundamentierung unter der Bühnenfront sind zwischen H5 und H7 auf den Wannenboden gesetzt und es besteht kein Zweifel, dass alle drei derselben Bauphase angehören. Wie sich am Streifenfundament und an der Westseite des Pfeilerfundaments zeigte, dürfte das Mauerwerk auch im Bereich der Wanne gegen die Auffüllung gebaut worden sein. Die Wanne wurde also zuerst mit Schutt aufgefüllt, erst später wurden Gräben in Breite der Fundamente ausgehoben. Man kann daraus schließen, dass für die Errichtung der Fassadenarchitektur selbst, also das Heben und Versetzen der teils großen Marmorteile, ein ebener und hindernisfreier Arbeitsplatz geschaffen wurde. Nach Fertigstellung der Fassade erfolgte schließlich als letzter Schritt die Errichtung der Bühne, wozu in das eingeebnete Gelände die Gräben für die Fundamente geschaffen wurden, die entweder auf dem Fels, seiner verwitterten Oberfläche oder - wie in der nördlichen Hälfte des Logeion nachgewiesen - auf dem Boden der Wanne enden.

Das $>$ Doppelfundament $<$ (= Pfeilerfundament und Fundament unter der Bühnenfront) wurden an einigen Stellen (H3/H4, H5-H7 und H12/13) freigelegt. An den Standorten der Pfeiler binden im oberen Bereich größere Steinplatten in beide Fundamente ein (Taf. $61 \mathrm{Abb}$. 117). Alle drei streifenförmigen Fundamente (Streifenfundament, Pfeilerfundament und Fundament unter der Bühnenfront) sind zueinander parallel,

\footnotetext{
${ }^{41}$ IvE 2058; s. auch Kap. 8.6.2.

${ }^{42}$ STyHLer-Aydin (in Vorbereitung).

${ }^{43}$ Kap. 3.2.2.2 u. 3.2.2.3.
} 
zeichnen sich aber durch eine geringfügig schräge Lage im Verhältnis zum Fassadensockel aus; die Fundamente liegen im Norden näher am Sockel als im Süden. Die Differenz zwischen H3 und H12 beträgt 0,16 m. Man wird für die flavische Phase von einer Konstruktion ausgehen können, die zwischen der Fassade und der Pfeilerreihe mit nur einer Stützenstellung das Auslangen fand. Dadurch ergibt sich für die Platten des Bodens des Logeion von der Marmorkante über dem Sockel bis zur Mittelachse des Streifenfundaments (wo die Säulenstellung angenommen wird, und dadurch auch der darüber verlaufenden Architrav seine Längsachse hat) ein Maß von durchschnittlich 2,41 m (H3 = 2,33 m; H12 = 2,49 m). Von dort bis zur Achse des Pfeilerfundaments ergibt sich durch den parallelen Verlauf ein einheitliches Maß von 2,54 m. Berücksichtigt man die gegenüber den anderen Fundamenten etwas größere Breite des Streifenfundaments, hat man einen gewissen Spielraum für die Platzierung der Säulenstellung und kommt dem gleichen Maß für beide Spannweiten einigermaßen nahe. Zusammen mit der Jochweite der Stützen in Nord-Süd-Richtung von rund 2,24 m ergibt sich ein fast quadratisches Stützenschema von 2,24 $\times 2,47 \mathrm{~m}$ für die erste Phase der kaiserzeitlichen Bühne (Taf. $78 \mathrm{Abb}$. 153). Spannweiten bis 2,50 m finden sich an zahlreichen Theatern wieder ${ }^{44}$, größere Längenerstreckungen scheinen grundsätzlich vermieden worden zu sein.

Von der Bühnenfront sind einige Teile erhalten. Das gilt vor allem für den Stylobat der Bühnenfront. Dieser ist über eine Länge von 25,64 $\mathrm{m}$ vollständig erhalten. Die $0,30 \mathrm{~m}$ hohen und 0,78 $\mathrm{m}$ breiten Platten bilden den Sockel. Er verläuft über einer 0,18 m hohen Plattenreihe, die gleichzeitig das Schwellenniveau der drei Türen in der Proskenionfront darstellt. An der Oberseite des Stylobats sind die Standflächen für die Stützen gut erkennbar. Daraus ergibt sich eine Gesamtlänge der Front von rund 25,40 m. Sie liegt im Norden um 1,65 m und im Süden um 1,53 m weiter im Osten als die Enden der alten Analemma-Mauern P und Q, an deren Ostseite die neuen, eingewölbten Parodoi entlang führen. Daraus ergab sich die Notwendigkeit, die römische Proskenionfront an den Enden durch kurze Stirnwände mit P und Q zu verbinden (Taf. 12 Abb. 20; Plan 18). Erhalten ist ferner eine große Anzahl von schmalen Pfeilern, die um 1900 noch im Abstand von $1,12 \mathrm{~m}$ über dem Stylobat standen. Die wenigen ganz erhaltenen Stücke haben eine Höhe von 1,495 m. Die Standfläche der Pfeiler misst 0,23 $\times 0,50-0,54 \mathrm{~m}$, nach oben ist eine leichte Verjüngung festzustellen. Drei Seiten sind fein mit dem Zahneisen hergerichtet, die Vorderseite wurde jedoch äußerst grob abgearbeitet (Taf. 80 Abb. 158). Dasselbe gilt für die östliche Seite der Sockelschicht. W. Wilberg ergänzt die fehlende Seite der Pfeiler mit dorischen Halbsäulen (Taf. 79 Abb. 155. 156) ${ }^{45}$. Über diesen war ursprünglich ein Gebälk angebracht, von dem einige Teile über den Mauern P und Q zu sehen sind (Taf. 81 Abb. 159; 436 Abb. 770. 771). Architrav und Triglyphenfries sind aus einem Stück gearbeitet und 0,30 m hoch. Die Metopen sind mit sechsblättrigen Rosetten gefüllt. Fünf Triglyphen gehen auf ein normales Joch, sechs über die Mitteltür (Taf. 81 Abb. 161). Auf die Frieszone ist ein 0,21 m hohes Gesims mit flachen Konsolen gelegt. Die Konsolen sind jeweils über den Triglyphen angeordnet, die Kassetten mit fünfblättrigen Rosetten versehen (Taf. 81 Abb. 160). Im Abstand von je drei Konsolen sind kleine Löwenköpfe an der Sima ausgearbeitet. Die Höhe eines kleinen Pfeilerkapitells von 0,15 m, das er einer der zurückspringenden Enden der Bühnenfront zuweist, verwendet Wilberg auch als Maß für die nicht mehr vorgefundenen Halbsäulenkapitelle und errechnet eine Gesamthöhe der Front von 2,44 m über dem Schwellenniveau (Taf. 81 Abb. 161). Das entspricht einer absoluten Höhe von $\mathrm{T}^{\mathrm{a}}$ 13,670 m über den nicht abgetretenen Stellen der mittleren Schwelle (11,230 m). Die Höhendifferenz zur Marmoroberkante $\left(\mathrm{T}^{\mathrm{a}} 13,901\right)$ an der scaenae frons, an die der Boden des Logeion anschloss, beträgt $0,23 \mathrm{~m}$. Für die 6,47 m tiefe Bühne bedeutet das ein Gefälle von 3,55 cm je Meter. Der im Norden und Süden des Logeion noch in situ befindliche jüngere Marmorboden liegt dagegen etwa $0,10 \mathrm{~m}$ tiefer als diese Kante, was einer Höhendifferenz von nur $0,13 \mathrm{~m}$ entspricht.

$\mathrm{Ob}$ die Interkolumnien zwischen den Halbsäulenpfeilern der flavischen Bühne geschlossen waren, ist ungewiss. Es sind keine technischen Vorrichtungen zum Verschluss der Interkolumnien, wie sie z. B. durch Pinakes bei hellenistischen Proskenien bekannt sind, vorhanden. Bei genauem Hinsehen lässt sich an fast allen Pfeilerlängsseiten im Abstand von $0,23 \mathrm{~m}$ von den rückwärtigen Kanten ein vertikaler Streifen von 0,04 bis $0,05 \mathrm{~m}$ Breite in der Oberflächenstruktur der Zahneisenbearbeitung feststellen (Taf. 80 Abb. 158). Das scheint auf Arbeitsschritte bei der Zurichtung der Oberflächen an den Halbsäulenpfeilern hinzuweisen.

\footnotetext{
${ }^{44}$ Beispiele dafür sind etwa die Theater von Milet und Alabanda.
}

${ }^{45}$ Heberdey u. a. 1912, 22. 
Der architektonische Aufbau und die Dimensionen der Bühnenfront zeigen, dass es sich hierbei nicht um ein Proskenion der hellenistischen Zeit handeln kann. Die nur 0,90 m messende lichte Weite der Interkolumnien zählt zu den geringsten im gesamten bekannten antiken Theaterbau. Der insgesamt 0,48 $\mathrm{m}$ hohe Sockel und die Höhe von nur 1,495 m zwischen Sockelzone und Architrav (Taf. 81 Abb. 161) erlauben keine Verwendung im ursprünglichen Sinne, als das Proskenion eine der Skene vorgelagerte Säulenhalle war, die daneben auch der Anbringung von Pinakes diente. Die ephesische Bühnenfront ist eine reine Schmuckfassade, die den hellenistischen Typ des Proskenion mit einer dorischen Halbsäulenstellung zitiert. Durch den Sockel, der die Pfeiler mit den Halbsäulen um 0,48 m höher als den ursprünglichen Boden der Orchestra hebt, war es möglich, die Säulen sehr zierlich wirken zu lassen. Die filigranen Proportionen der Architektur werden durch den kleinen Metopen-Triglyphen-Fries unterstrichen. Fünf Triglyphen auf ein Säulenjoch stellen eine Ausnahme im Theaterbau dar ${ }^{46}$.

Im Zusammenhang mit dem Streifenfundament ist auf eine Reihe von großen Blöcken bzw. Platten zurückzukommen, die sich an sieben Stellen von H4 bis H10 über dem Streifenfundament erhalten haben (Taf. 63 Abb. 120; 66 Abb. 126; 68 Abb. 131. 132; 69 Abb. 134. 135). Auffallend ist vor allem die Tatsache, dass sie exakt in der Achse der einzelnen Stützenstellungen liegen. Das Niveau der Oberkanten variiert um wenige Zentimeter und fast allen gemeinsam ist die Lage über dem Streifenfundament. Sechs der sieben Blöcke sind im Verhältnis zu dessen Mittelachse eindeutig nach Osten verschoben, wobei sie in vier Fällen (H4-H7) das Fundament sogar überragen, wozu dem Streifenfundament an der Ostseite eigens eine kleine Fundamentierung angesetzt wurde. In Folge ihrer mit den Säulen korrespondierenden Platzierung wird man an Standplatten für Stützen denken. Doch wie der Ausriss des Streifenfundaments im oberen Bereich von S 1/2001 sowie die ausgleichende Aufmauerung zwischen dem verbleibenden Streifenfundament und dem Block etwa bei H6 zeigen (Taf. 56 Abb. 108; 63 Abb. 120), sollte man beide zwar demselben Zweck, aber nicht unbedingt derselben Zeit zuschreiben. Auch an anderen Stellen ist ersichtlich, dass das Ganze nicht aus einem Guss stammen kann. Als eindeutig jünger erweisen sich die punktförmigen Gussfundamente unter den heute sichtbaren Säulen des Logeion. Die Jochweite in Nord-Süd-Richtung wurde beibehalten, der ursprünglich halbierte Abstand zwischen Fassade und Pfeiler dagegen durch eine zweite Säulenreihe jetzt gedrittelt. Die Konstruktion dieser Bühne beruht auf kleinen Rechtecken von durchschnittlich 1,65 × 2,24 m Größe (Taf. 78 Abb. 153). Wann diese Umbauten erfolgt sein könnten, lässt sich trotz Auswertung des Fundmaterials nicht eindeutig feststellen. Abgesehen von einigen Fundstücken aus spätantiker Zeit, die den Oberflächenschichten angehören, reicht das Fundmaterial über dem Streifenfundament nicht über das 2. Jh. n. Chr. hinaus. Damit lässt sich zumindest ausschließen, dass das Streifenfundament vor dem Einbau der Steinplatten noch einer Phase angehörte, die einen Umbau bzw. eine Neuerrichtung von Proskenion und Logeion in frühantoninischer Zeit erwähnt ${ }^{47}$. Die Betonung von Proskenion und Logeion spricht $\mathrm{m}$. E. nicht bloß für eine Renovierung, sondern für einen tiefer gehenden Eingriff in die Bausubstanz. W. Wilberg bemerkte beim Abtragen der Pfeiler des Proskenion, dass die Verdübelung zwischen Pfeilern und Sockel nicht mehr intakt war, und dass folglich ein zweimaliger Aufbau der Bühnenfront stattgefunden haben muss. Allein die zeitliche Schlussfolgerung sollte sich als falsch herausstellen. Wilberg wies die erste Aufstellung einer zweiten hellenistischen Phase $\mathrm{zu}^{48}$. Dem hatte bereits A. von Gerkan heftig widersprochen ${ }^{49}$. Wie sich herausstellte, gehörte das oben besprochene Proskenion der flavischen Bauphase an. Es zitiert eine hellenistische Bühnenfront, ist als solche aber aufgrund seiner Konstruktion und seiner Abmessungen nicht mehr verwendbar. Später wurden sogar die Halbsäulen abgeschlagen und die Interkolumnien mit Ziegelmauerwerk verschlossen (Taf. 79 Abb. 157) ${ }^{50}$. Die Sichtseite erhielt eine Marmortäfelung, die zwischen Stylobat und Marmorboden der Orchestra noch erhalten ist.

${ }^{46}$ FiECHTER 1914, 30: »Die formale Entwicklung geht, kurz gesagt, von der trockenen sachlichen architektonischen Gestaltung allmählich über zu einer rein dekorativen flüchtigen Durchbildung der Proskenionswand; Athen ist das Anfangsglied, Ephesos steht am Schluß«.

${ }^{47}$ IvE 2039; s. auch Kap. 8.6.1, Nr. 9 u. Kap. 8.6.2. Mittels einer anscheinend großzügigen finanziellen Unterstützung des P. Vedius Antoninus konnten neben anderen Dingen, z. B. Türen oder andere Einrichtungsgegenständen, vor allem die Erneuerung oder Renovierung von Proskenion und Logeion vorgenommen werden. Zur Datierung s. auch Kap. 3.3.2.1.

${ }^{48}$ Für die erste hellenistische Phase nimmt W. Wilberg eine Konstruktion aus Poros für das Proskenion an, schließt aber eine hölzerne Lösung nicht aus (HeberdeY u. a. 1912, 17). Erst mit der Errichtung der späteren Thyromata-Wand aus Marmor hätte das Theater auch ein dazu passendes, marmornes Proskenion erhalten (HEBERDEY u. a. 1912, 21).

${ }^{49}$ VON GERKAN 1921, 92.

${ }^{50}$ Heberdey u. a. 1912, 46. 
Für die Beseitigung der Halbsäulen an den Proskenionpfeilern scheint ein genereller Abbau der gesamten Bühnenfront - die ja auch den Fußboden des Logeion trug - ein doch recht hoher Aufwand zu sein, der, vor allem in Hinblick auf die nachfolgende, massive Vermauerung der Interkolumnien, als übertrieben bezeichnet werden kann. Hiermit dürfte ein größeres Vorhaben verbunden gewesen sein, welches den Aufwand erklären könnte, wie etwa die Aufstockung der scaenae frons um ein weiteres Geschoss. Da das dritte Geschoss, das nach der älteren Forschungsmeinung erst später errichtet wurde ${ }^{51}$, nach den jüngsten stilistischen Untersuchungen bereits flavischer Zeit zugerechnet wird ${ }^{52}$, scheidet das als mögliche Ursache für die Demontage der Bühne aus. Aus der bereits oben erwähnten Inschrift lässt sich aber auf einen umfangreichen Umbau der Bühne schließen, mit dem auch der Einbau der Punktfundamente zusammenhängen könnte ${ }^{53}$. Demnach wäre es zum Abbruch der flavischen Bühne gekommen, um sie von Grund auf neu und mit einer zusätzlichen Stützenreihe zu errichten. Die Punktfundamente sind aber leider nicht zu datieren und es ist nicht auszuschließen, dass sie erst in späterer Zeit errichtet wurden. Die Mehrheit der Plinthen unter den Säulen und Pfeilern liegt nicht direkt auf den Fundamenten auf. In diesen Fällen befindet sich eine ausgleichende Schuttschicht dazwischen ${ }^{54}$. Während sich die Punktfundamente in den Achsen der Joche befinden, sind manche der darüber positionierten Säulen deutlich in Nord-Süd-Richtung verschoben. Manche Pfeiler an der Rückseite der Bühnefront sind nach Osten gerückt. Diese Veränderungen lassen an sekundäre Maßnahmen an den Säulen und Pfeilern denken, die möglicherweise in Folge von Erdbebenschäden des 3. und 4. Jhs. n. Chr. erforderlich waren.

\subsection{ORCHESTRA}

\section{Vorbemerkung zum heutigen Zustand der Orchestra}

$\mathrm{Zu}$ Beginn unserer archäologischen Untersuchungen zeigte die Orchestra ein sehr uneinheitliches Bild, in dem sich die verschiedenen Bau- und Nutzungsphasen bis in die jüngste Geschichte des Theaters widerspiegelten. Da waren zunächst die mächtig verstürzten Bauglieder von der scaenae frons, die von J. T. Wood freigelegt worden waren und auch von G. Niemann nicht bewegt werden konnten. Der von R. Heberdey untersuchte Kanal in der Mittelachse wurde nach den Ausgrabungen wieder verfüllt und liegt heute unter dem rezenten Plattenboden aus Kunststein, der zur leichteren Bespielbarkeit des Theaters vor einigen Jahrzehnten verlegt wurde und unsere Untersuchungen begrenzte. Der aus hellenistischer Zeit stammende Ringkanal hingegen blieb nach den Grabungen offen und prägt auch heute noch das Bild der Orchestra in entscheidender Weise (Taf. 77 Abb. 151; 78 Abb. 152). Mit seiner fein gestalteten Oberfläche und den eingearbeiteten Lagerflächen für Brückensteine in Verlängerung der Treppenachsen im Koilon ist damit ein gesichertes Niveau des hellenistischen Orchestrabereichs gegeben. Die innerhalb des Ringkanals umlaufende Steinsetzung (Fundament U) wurde ebenfalls bereits von R. Heberdey untersucht (Taf. 82 Abb. 162). Da ihre Oberkante tiefer als der Ringkanal liegt, wurde sie nach den Ausgrabungen wieder zugeschüttet. Sie ist für den Besucher heute nicht sichtbar. Deutlich zu erkennen ist ein profilierter Sockel (Profilring J), welcher außerhalb des hellenistischen Ringkanals um die Orchestra verläuft. Er vermittelt zwischen dem auch in der flavischen Umgangsphase gleich gebliebenen Niveau der Orchestra und dem höherliegenden OrchestraUmgang mit der mannshohen Brüstung des Koilon.

An der westlichen Begrenzung der Orchestra bietet sich dem heutigen Besucher ein Blick auf einen hinter der Bühnenfront gelegenen `Stützenwald`, der ursprünglich nicht sichtbar war (Taf. 78 Abb. 152).

\footnotetext{
${ }^{51}$ Heberdey u. a. 1912, 48-50. 52.

${ }_{52}^{52}$ Kap. 10.2.1.

${ }^{53}$ IvE 2039.

${ }^{54}$ Von den 26 Säulen und zehn Pfeilern der kaiserzeitlichen Bühne konnten insgesamt 20 Säulen und sechs Pfeiler freigelegt werden. Hierbei ließ sich bei allen Pfeilern und bei 14 Säulen Schuttniveaus zwischen der Oberkante des Fundaments und den Standplatten der Stützen feststellen. Dieses Merkmal ist über die gesamte Länge der Bühne festzustellen. Es gibt keine Bereiche mit einem verstärkten Aufkommen der Schuttniveaus. An 13 Säulen ist eine einfache Basis mit anlaufender Profilierung angearbeitet. In den übrigen Fällen sind die Säulen auf Plinthen versetzt. Diese unterschiedliche Gestaltung könnte mit dem Einbau der zweiten Säulenreihe zusammenhängen. Es lassen sich jedoch keine Regelmäßigkeiten feststellen. Beide Typen kommen sowohl in der westlichen als auch in der östlichen Reihe vor.
} 
Neben der Bestandssicherung und der möglichen Rekonstruktion der verschiedenen Bodenniveaus war die Klärung der Funktion der Kanäle eine interessante Frage. Hält man sich die gesamte Ausdehnung des Theaters vor Augen, das bei jedem Starkregen wie ein großer Trichter wirkt, ist die gesicherte Ableitung des Regenwassers ohne Zweifel der hauptsächliche Grund für die Kanäle. Für die zu erwartende Frischwasserversorgung konnten keine befriedigenden Hinweise gefunden werden. Problematisch ist auch die Vorstellung, dass in späterer Zeit Wasser in die Orchestra geleitet wurde, um diese für > Wasserspiele $<$ zu fluten, wie dies teilweise in der Fachliteratur evoziert wurde ${ }^{55}$. Dafür fehlen im Westen vor dem Bühnenhaus Hinweise auf notwendige Elemente für eine Beckenbegrenzung und Isolierung.

2004 und 2005 konnten in Bereichen, die von keinem rezenten Boden bedeckt waren, zwei Schnitte (S 3/2004. S 1/2005) angelegt werden. Zumindest in S 1/2005 konnte ein kleiner Teil des nicht mehr von Marmorpflaster bedeckten Unterbaus der späteren Orchestra geschnitten und so Aufschlüsse über die Konstruktion ermittelt werden.

\subsubsection{Sondage S 3/2004}

\begin{tabular}{|l|l|l|l|l|l|}
\hline Schicht & OK in $\mathbf{~}$ & UK in $\mathbf{m}$ & Beschreibung/Interpretation & Keramik & Münzen \\
\hline SE O0 & 11,38 & 10,03 & $\begin{array}{l}\text { Verfüllung der Altsondage um den Ost- } \\
\text { West-Kanal westlich des hellenistischen } \\
\text { Ringkanals, um 1900 }\end{array}$ & - & - \\
\hline SE O1 & 10,76 & 10,73 & $\begin{array}{l}\text { dunkle Erde unter der Steinpackung } \\
\text { (Orchestra-Unterbau) zwischen hell. } \\
\text { Ringkanal und Profilring J }\end{array}$ & - & - \\
\hline SE O1a & $\begin{array}{l}11,07- \\
11,04\end{array}$ & 10,61 & $\begin{array}{l}\text { Grubenverfüllung in der Ecke zwischen } \\
\text { N-Profil und } \\
\text { Profil J, fundleer }\end{array}$ & - & - \\
\hline SE O2 & 11,05 & 10,76 & $\begin{array}{l}\text { Steinpackung zwischen hell. Ringkanal und } \\
\text { Profil J (Unterbau der Orchestra), fundleer }\end{array}$ & - & - \\
\hline SE O3 & $\begin{array}{l}11,53- \\
11,49\end{array}$ & 11,45 & Mörtelbett für opus sectile, fundleer & - & - \\
\hline SE O22 & $10,73-$ & - & Verwitterungslehm (gewachsener Boden) & - & - \\
\hline Fels & 11,45 & - & Fels (Serizit-Phyllit) & - \\
\hline
\end{tabular}

Tab. 17

In der Ost-West-Achse der Orchestra wurde im Jahr 2004 eine 7,30 m lange und 2,00 m breite Sondage angelegt (Taf. 82 Abb. 163; 83 Abb. 164. 165). Diese erstreckt sich von der Orchestra bis an die Wand des Koilon. Der Bereich innerhalb des Ringkanals wurde durch R. Heberdey ergraben und dokumentiert (Taf. $82 \mathrm{Abb} .162)^{56}$. Die nun wieder aufgenommenen Arbeiten sollten das Verhältnis zwischen Ost-West-Kanal und späterem Ringkanal klären ${ }^{57}$. Außerhalb des Ringkanals wurde der Profilring J und der Umgang entlang der Wand des Koilon untersucht.

Im mittleren Sondagenbereich lag der hellenistische Ringkanal bereits seit den Ausgrabungen R. Heberdeys offen, während der innerhalb dieses Kreissegments verlaufende Ost-West orientierte Kanal in seiner

${ }^{55}$ De Bernardi Ferrero 1970, 63. Dagegen spricht Isler 1994, 496 zutreffenderweise lediglich vom »Umbau der Orchestra für eine Arena«.

${ }^{56}$ Heberdey u. a. 1912, 46.

${ }^{57}$ Auch sollte jenes bei HeBerdeY u. a. 1912, 24 mit Abb. 47.48 erwähnte Konsolengesims geborgen werden, welches im Rahmen der Altgrabungen als Deckplatte des Ost-West-Kanals aufgefunden und als Bauteil der Bühnenfront erkannt wurde (Taf. $81 \mathrm{Abb}$. 160; 82 Abb. 162). Dieses wurde nicht mehr aufgefunden, da es 1899 zusammen mit weiteren Platten bereits abgenommen und nicht mehr über dem Kanal versetzt wurde; s. Kap. 3.3.2.2. 
östlichen Hälfte erneut freigelegt wurde. Der Ost-West-Kanal beginnt hier in unmittelbarer Nähe des hellenistischen Ringkanals, durchschneidet die Steinsetzung U, und führt unter dem Orchestraboden nach Westen durch das Logeion und die Skene bis an die Terrassenmauer westlich des Bühnengebäudes. Dort biegt er nach unten und wurde mittels mehrerer Rohrstränge zum nahegelegenen Straßenkanal geleitet. Im mittleren Durchgangsbereich des Logeion wurde der Kanal aus dem anstehenden Fels geschlagen. An allen anderen Stellen ist er aus Bruchsteinen aufgemauert, sein Boden wird durch kleine Bruchsteine in fester Mörtelbindung gebildet (Taf. 85 Abb. 168).

Der massiv gemauerte Ostabschluss verfügt zusammen mit der Innenwandung des hellenistischen Ringkanals über eine Breite von 0,76 m (Taf. 84 Abb. 166), wobei zwischen den beiden Kanälen zu keinem Zeitpunkt eine Verbindung bestand. Die Wandungen des Ost-West-Kanals reichen bis knapp unter das Oberkantenniveau des hellenistischen Ringkanals. Unter Berücksichtigung der Deckplatten in Form großformatiger Spolien wird deutlich, dass der Ost-West-Kanal mit der Niveauerhöhung der jüngeren Orchestra in Zusammenhang steht (Taf. 84 Abb. 167; 87 Abb. 172).

Diesem jüngeren Orchestraniveau gehörte gleichfalls ein umlaufender Kanal an. In S 3/2004 ist davon nichts mehr erhalten. Ein kleiner Rest in S 1/2005 aber belegt seine Position über dem älteren Ringkanal (Taf. 89 Abb. 177) ${ }^{58}$, wobei aufgrund dieser Anordnung klar wird, dass es auch zwischen diesem jüngeren Kanalverlauf und dem Ost-West-Kanal keine Verbindung gegeben haben kann (Taf. 88 Abb. 174).

Das als Deckplatte verwendete Konsolengesims wurde nicht mehr vorgefunden. Es wurde 1899 zusammen mit weiteren Deckplatten abgenommen, aber anscheinend als einziges Stück nicht wieder über dem Kanal verlegt. Bei der Neuverlegung hatten die Ausgräber keine Rücksicht auf die ursprüngliche Position der Platten genommen. Manche Spolien wurden dabei um $180^{\circ}$ gedreht, wie aus der zeichnerischen Aufnahme des ursprünglichen Zustands hervorgeht. Die Lücke, die durch das nicht mehr versetzte Konsolengesims entstanden war, hatte man durch das Nachrücken der östlichen Platten geschlossen. W. Wilberg hatte in dem Konsolengesims einen Teil des Proskenion erkannt. Während dieses von ihm noch der hellenistischen Phase zugeordnet worden war, bestimmte bereits A. von Gerkan seine Zeitstellung als kaiserzeitlich, nach den aktuellen Untersuchungen ist es der Bühnenfront flavischer Zeit zuzuweisen ${ }^{59}$. Das ist insofern von Bedeutung, da das Bauglied frühestens nach der Umgestaltung des Proskenions in antoninischer Zeit entbehrlich wurde. Sowohl dieses Faktum als auch die Oberkante der Kanaldeckung, die ohne Niveauerhöhung des Orchestrabodens nicht möglich wäre, sprechen für eine Nutzung des Kanals ab antoninischer Zeit.

Zwischen dem hellenistischen Ringkanal und dem Profilring J war bereits an der Oberfläche der Unterbau des römischen Bodens erkennbar (Taf. 85 Abb. 169). Es handelt sich dabei um hydraulischen Mörtel mit etwa faustgroßen Steinen (SE O2). Entlang des Nordprofils wurde ein schmaler Streifen dieses Unterbaus entfernt. Er liegt über einer dünnen Erdschicht (SE O1), die ihrerseits über dem Verwitterungslehm (SE O22) verläuft (Taf. 87 Abb. 173). Die spärlichen Funde aus SE O1 geben keinen datierenden Anhaltspunkt. Die Steinpackung SE O2 enthielt überhaupt keine Funde. Trotz einiger Unregelmäßigkeiten im Verlauf des Profilrings J ließ sich bei einer 2010 abgeschlossenen Gesamtaufnahme der Orchestra feststellen, dass die Unterkante des Profilrings mit dem Oberflächenniveau der hellenistischen Kanalwandungen weitgehend einhergeht. Östlich des Profilrings J erstreckte sich die Stein-Mörtel-Packung SE O3 bis zur Wand des Koilon (Taf. 86 Abb. 170. 171). Sie bildete den Unterbau für einen opus sectile-Boden, von dem an einigen Stellen noch wenige Reste erhalten sind. Ein schmaler Streifen des Unterbaus wurde beseitigt. Unter einer dünnen sandigen Ausgleichsschicht (SE04, fundleer) wurde der eben abgearbeitete Fels SE O23 erreicht (Taf. 87 Abb. 172).

\subsubsection{Sondage S 1/2005}

Die Sondage erstreckt sich vom Profilring J 4,90 m nach Süden und vom Sockel der kaiserzeitlichen Bühnenfront 4,80 m nach Osten (Taf. 88 Abb. 175. 176; 89 Abb. 177. 178; 90 Abb. 179). Man kann die Fläche grob in drei Abschnitte unterteilen: den Bereich südlich des Fundaments U, den Zwischenraum zwischen U und dem hellenistischen Orchestrakanal sowie den Abschnitt zwischen Orchestrakanal und dem Profilring J.

\footnotetext{
${ }^{58}$ Kap. 3.3.2.

${ }^{59}$ Kap. 10.2.1.
} 


\begin{tabular}{|c|c|c|c|c|c|}
\hline Schicht & OK in $\mathrm{m}$ & UK in $\mathbf{m}$ & Beschreibung/Interpretation & Keramik & Münzen \\
\hline- & - & - & Oberflächenreinigung & - & - \\
\hline SE O4 & 11,25 & 11,17 & $\begin{array}{l}\text { Oberfläche: braune Erde über dem } \\
\text { Orchestraniveau, rezent gestört }\end{array}$ & - & - \\
\hline SE O5a & 11,32 & 11,26 & $\begin{array}{l}\text { graue Stein-Mörtel-Packung (Orchestra- } \\
\text { Unterbau), innerhalb Orchestrakanal }\end{array}$ & - & - \\
\hline SE O5 & $\begin{array}{l}11,26- \\
11,17\end{array}$ & $\begin{array}{l}10,94- \\
10,85\end{array}$ & $\begin{array}{l}\text { rosafarbene Stein-Mörtel-Packung } \\
\text { (Orchestra-Unterbau), innerhalb } \\
\text { Orchestrakanal }\end{array}$ & $\begin{array}{l}\text { kein aussagekräftiges } \\
\text { Material }\end{array}$ & - \\
\hline SE O6 & 10,94 & $\begin{array}{l}10,88- \\
10,85\end{array}$ & $\begin{array}{l}\text { braune Erde unter der Stein-Mörtel-Packung, } \\
\text { innerhalb Orchestrakanal }\end{array}$ & $\begin{array}{l}\text { kein aussagekräftiges } \\
\text { Material }\end{array}$ & - \\
\hline $\begin{array}{l}\text { SE O7 = } \\
\text { SE O18 = } \\
\text { SE O19 }\end{array}$ & 11,27 & 10,78 & $\begin{array}{l}\text { braune Erde } \\
\text { (Wiederverfüllung, um 1900, rez. gestört) }\end{array}$ & - & - \\
\hline $\begin{array}{l}\mathrm{SE} \mathrm{O} 8= \\
\mathrm{SE} \mathrm{O} 20\end{array}$ & 10,78 & $\begin{array}{l}10,57- \\
10,46\end{array}$ & $\begin{array}{l}\text { braune Erde zwischen Orchestrakanal und } \\
\text { Fundament U (Wiederverfüllung um 1900) }\end{array}$ & - & - \\
\hline SE O9 & 10,58 & 10,53 & $\begin{array}{l}\text { brauner, sandiger Lehm zwischen } \\
\text { Orchestrakanal und Fundament U, sehr } \\
\text { kleiner Fundkomplex }\end{array}$ & - & - \\
\hline SE O10 & 11,05 & 10,95 & $\begin{array}{l}\text { graue Stein-Mörtel-Packung (Orchestra- } \\
\text { Unterbau), außerhalb Orchestrakanal }\end{array}$ & $\begin{array}{l}\text { kein aussagekräftiges } \\
\text { Material }\end{array}$ & - \\
\hline SE O11 & 10,95 & 10,78 & $\begin{array}{l}\text { rosafarbene Stein-Mörtel-Packung } \\
\text { (Orchestra-Unterbau), außerhalb } \\
\text { Orchestrakanal }\end{array}$ & $\begin{array}{l}\text { kein aussagekräftiges } \\
\text { Material }\end{array}$ & - \\
\hline SE 012 & 10,78 & $\begin{array}{l}10,73- \\
10,66\end{array}$ & $\begin{array}{l}\text { braune Erde unter der Stein-Mörtel-Packung, } \\
\text { außerhalb Orchestrakanal }\end{array}$ & $\begin{array}{l}\text { kein aussagekräftiges } \\
\text { Material }\end{array}$ & $\begin{array}{l}\text { M } 257 \\
\text { (spätant.-byz.) }\end{array}$ \\
\hline SE O13 & 11,05 & $\begin{array}{l}10,79- \\
10,71\end{array}$ & $\begin{array}{l}\text { lehmige, braune Erde über Stein-Mörtel- } \\
\text { Packung des Orchestra-Unterbaus, außerhalb } \\
\text { Orchestrakanal, rezent gestört }\end{array}$ & - & - \\
\hline SE O14 & $\begin{array}{l}10,85- \\
10,46\end{array}$ & 10,44 & $\begin{array}{l}\text { Stein-Erde-Gemisch zw. Orchestrakanal und } \\
\text { Fundament U, sehr kleiner Fundkomplex }\end{array}$ & - & - \\
\hline SE O15 & 10,44 & 10,31 & $\begin{array}{l}\text { feste, dunkle Erde mit kleinen Steinen, sehr } \\
\text { kleiner Fundkomplex }\end{array}$ & - & - \\
\hline SE O16 & 10,84 & 10,78 & braune, kompakte Erde & augusteisch & - \\
\hline SE 017 & 10,78 & 10,32 & dunkle Erde mit Ziegel und Steinen & $\begin{array}{l}\text { Ende } 2 . / 1 \text {. Jh. } \\
\text { v. Chr. }\end{array}$ & - \\
\hline SE O21 & 10,83 & 10,69 & braune Erde südlich Fundament U & $\begin{array}{l}\text { kein aussagekräftiges } \\
\text { Material }\end{array}$ & - \\
\hline
\end{tabular}

Tab. 18

Nur entlang der West- und Nordseite war der jüngste Unterbau der Orchestra zusammen mit dem Rest des kaiserzeitlichen Kanals weitgehend erhalten. Nach Südosten war eine großflächige Störung bereits an der Oberfläche zu erkennen, die mit den Ausgrabungsarbeiten um 1900 zusammenhängt. Die Wiederverfüllung (SE O4. 7-9. 14. 18. 20) wurde ausgehoben. Dabei kam auch der um 1900 bereits einmal zur Gänze freigelegte Fundamentring U zum Vorschein. Die Blöcke sind von fast einheitlicher Größe, ihre Oberseiten sind gegenüber den grob bearbeiteten Seitenflächen abgeglichen, sind aber nicht geglättet. Sie sitzen direkt auf dem gewachsenen Boden SE O19 (weiß-gelb gesprenkelter Lehm), in den sie stellenweise leicht eingetieft sind. Das ringförmige Fundament U (Taf. 89 Abb. 178; 90 Abb. 179. 180) lässt sich sowohl im Norden als 
auch im Süden bis ca. 2,0 m vor die römische Bühne verfolgen, wobei im Süden einer der Blöcke etwas weiter gegen Westen reicht. $\mathrm{Ob}$ es an den beiden Enden ausgerissen ist, lässt sich aufgrund des durch die Altgrabungen gestörten Befunds nicht mehr feststellen. Die massiven Eingriffe der kaiserzeitlichen Bauaktivitäten hätten das Fundament U im Bühnenbereich jedoch mit Sicherheit beseitigt. Die Blöcke stehen heute in keinem stratigrafischen Zusammenhang mehr. Die Oberkante liegt durchschnittlich um 0,20 m tiefer als die Oberkante des hellenistischen Kanals. Alle vier freigelegten Steinblöcke haben kleine, leicht rechteckige Einarbeitungen von 6 bis $9 \mathrm{~cm}$ Seitenlänge und einer Tiefe von 12 bis $15 \mathrm{~cm}$ in der Mitte der Oberseite. Die Abstände sind mit 0,54 bis 0,60 m annähernd gleichmäßig. Zusätzlich sind bei den drei westlichen Blöcken quer verlaufende Rillen eingearbeitet (Taf. 90 Abb. 180).

Auffallend ist, dass R. Heberdey und W. Wilberg die Einarbeitungen in ihrer zeichnerischen Aufnahme nicht wiedergeben ${ }^{60}$, obwohl die Zeichnung vereinzelt vorhandene Dübellöcher durchaus dokumentiert (Taf. 82 Abb. 162). Da zum Fundament U keine lückenlose Dokumentation vorliegt, lässt es sich leider nicht feststellen, ob es im Süden eine vergleichbare Situation mit einer Reihe von regelmäßigen Einarbeitungen gegeben hat. Mit Sicherheit lässt sich das Vorhandensein entsprechender Einarbeitungen im gesamten nordöstlichen und östlichen Abschnitt des Fundaments ausschließen ${ }^{61}$. Als Dübellöcher haben die Einarbeitungen vermutlich nicht gedient. Nicht nur, dass sich die vier im Schnitt S 1/2005 vorgefunden Einarbeitungen von den in der alten Aufnahme vereinzelt notierten Dübellöchern unterscheiden, fehlt auch in allen Fällen ein Gusskanal. Die Einarbeitungen, vielleicht auch die Rinnen, sind wohl eher mit einer Holzkonstruktion in Verbindung zu bringen, von der sich gegenwärtig kein Bild machen lässt. Weiters fällt die Gestaltung der Außenseite des Fundaments U auf. Mit Ausnahme der in S 1/2005 freigelegten Schar, die auch außen einen gleichmäßigen Kreisbogen erkennen lässt, ragen die Blöcke im östlich anschließenden Teil bis an das südliche Ende an der Außenseite der Steinsetzung unterschiedlich weit vor (Taf. 4 Abb. 6; 82 Abb. 162). W. Wilberg ${ }^{62}$ hat dem Fundament die wiederverwendeten, leicht gekrümmten Standplatten zugewiesen, die unter einigen der kaiserzeitlichen Pfeiler des Logeion angetroffen wurden, und deutete das Ganze (zeitgleich mit dem hellenistischen Ringkanal) als Einfassung der älteren Orchestra ${ }^{63}$. Die Platten, die vermutlich erst bei der sekundären Aufstellung der Pfeiler des Logeion dorthin gelangten ${ }^{64}$, könnten aber genauso gut zur Abdeckung des hellenistischen Kanals bei der Neuadaptierung des Kanals in der flavischen Bauphase oder zu einem Teil des Umgangs gehört haben.

Nördlich des Fundaments U wurde der Boden SE O19 für den Bau des hellenistischen Orchestrakanals weiter abgetieft. Die verbleibende Grube ist mit einem festen Gemisch (SE O15) aus dunkler, lehmiger Erde und Steinen verfüllt. Der kleine Fundkomplex enthielt kaum Keramik. Beinahe alle Schichten enthielten überaus wenige Keramikfragmente. In der Regel handelt es sich dabei um Wandscherben, die keine zeitliche Einordnung erlauben. Bodenplatten und Wandungen bestehen aus dem gelblichen Poros, der auch an der hellenistischen Skene Verwendung fand. An ihren Außen- und Innenkanten zeigen die Wandblöcke des hellenistischen Kanals sehr grobe, schräg oder stufenförmig angebrachte Abarbeitungen. Dabei handelt es sich um die Anschlussstellen einer nicht mehr erhaltenen Pflasterung und Kanalabdeckung, die beide zur flavisch-trajanischen Phase des Theaters gehören. Wie der Platz in hellenistischer Zeit ausgesehen hat, lässt sich nur vermuten. Vom älteren Boden der hellenistischen Orchestra wurden keine Reste mehr gefunden. Die Oberseite der Kanalwandung gibt zumindest das Niveau der Orchestra an. Für die hellenistische Anlage kann man einen Lehmboden voraussetzen.

Der Unterbau der jüngeren Orchestra besteht innerhalb des Orchestrakanals aus einer gut 0,30 $\mathrm{m}$ hohen Platte aus einer Stein-Mörtel-Packung (SE O5c) und einer Steinpackung mit hydraulischem Mörtel (SE O5b) über einer dichten Steinbürste SE 06 (Taf. 90 Abb. 179; 91 Abb. 181; 92 Abb. 182). Die eigentliche Bettung für die darauf verlegten Marmorplatten wurde gesondert in einer dünnen Schicht (SE O5a) aufgebracht. Auch dafür wurde der Mörtel mit Ziegelsplitt angereichert. Aus den Schichten SE O15 und SE O16 unter-

\footnotetext{
${ }^{60}$ Bei der auf Taf. 82 Abb. 162 wiedergegebenen Zeichnung handelt es sich um die originale, bislang unpublizierte Aufnahmeskizze der Altausgräber.

${ }^{61}$ Herberdey u. a. 1912, Abb. 20.

${ }^{62}$ Herberdey u. a. 1912, 14 mit Abb. 16.

${ }^{63}$ In Hofbauer 2007, 45 wurde das Fundament U auch als möglicherweise zu einer Vorgängerphase des ephesischen Theaters gehörig diskutiert und eine dazugehörige schlichte Skene aus Holz vorgeschlagen. Aufgrund des fehlenden stratigrafischen Bezugs ist dieses Erklärungsmodell jedoch rein hypothetisch.

${ }^{64}$ Kap. 3.2.2.2.
} 
halb der Bürste konnten die einzigen halbwegs aussagekräftigen Keramikfunde gemacht werden. Sie reichen vom 2./1. Jh. v. Chr. bis ins 2. Jh. n. Chr. Das deckt sich durchaus mit einem in frühantoninischer Zeit postulierten Umbau der kaiserzeitlichen Bühne, mit dem auch die Erhöhung der Orchestra einherging. Das Oberflächenniveau des Unterbaus überragt die Kanalwandung aus hellenistischer Zeit. Ein dazu passender kleiner Rest eines höher gelegenen Kanals, unmittelbar über dem hellenistischen, ist ganz im Westen des Schnitts erhalten. Wie dort zu erkennen ist, setzt sich der Unterbau der Orchestra auch außerhalb des Kanals bis zum Profilring J fort. Ein 1,50 m breiter Streifen wurde bei den Grabungen entfernt. Der Aufbau ist bis auf die Bürste vergleichbar; eine graue Stein-Mörtel-Packung (SE O10) und darüber ein Niveau aus hydraulischem Mörtel (SE O11, Stein-Mörtel-Packung), das hier etwas gröber wirkt als SE O5b. Der durchschlagene Bereich enthielt überhaupt keine Keramik. Der einzige Fund ist die Münze M 257. Sie stammt aus der Schicht SE O12 unter der Stein-Mörtel-Packung, ist aber in einem so schlechten Erhaltungszustand, dass sie zur Datierung nicht herangezogen werden kann. Damit bleiben nicht mehr als die wenigen Scherben aus den Schichten SE 015 und SE 016 zur zeitlichen Einordnung der späteren Orchestra.

\subsubsection{Interpretation des Befunds}

\subsubsection{OrChestra IN HELLENISTISCHER ZeIT}

Das am besten erhaltene bauliche Element in der Orchestra ist der aus Poros gefertigte Ringkanal. Der Kanal beginnt im Süden vor der Mauer Q, die ein Rest des hellenistischen Süd-Analemma ist. Von da an verläuft er mit kontinuierlichem Gefälle um die Orchestra herum bis an das Ende des hellenistischen NordAnalemma (Parodosmauer P) ${ }^{65}$. Ab hier führt der Kanal gedeckt unter der nördlichen Parodos nach draußen. Der Kreis, den die Innenkante des Ringkanals beschreibt, hat einen Durchmesser von 24,65 m. Zum Vollkreis ergänzt, wird er einigermaßen exakt vom Skenengebäude tangiert (Taf. 430 Abb. 759). Die Orchestrawand $\mathrm{X}$ ist durch die Beseitigung der untersten Sitzreihen im Zuge der kaiserzeitlichen Umgestaltung entstanden. Im ursprünglichen Zustand müssen die Sitzreihen bis nahe an den Ringkanal herangeführt haben. Das zum Ringkanal im Abstand von knapp $1 \mathrm{~m}$ konzentrisch verlaufende Fundament $\mathrm{U}$ steht heute in keinem stratigrafischen Zusammenhang mehr zu anderen baulichen Elementen, wurde aber bereits von W. Wilberg in hellenistische Zeit gesetzt ${ }^{66}$. Gemeinsam mit R. Heberdey erwog Wilberg für die Steinsetzung, den Ringkanal und die anderen hellenistischen Baubefunde eine Entstehung im Zusammenhang mit der Stadtgründung im frühen 3. Jh. v. Chr. Auf Basis der jüngsten Forschungen ist aber die Errichtung der Skene, und damit einhergehend die Gestaltung der Orchestra, nun ab dem 2. Viertel des 2. Jhs. v. Chr. anzusetzen.

Die Funktion der Steinsetzung U als Fundamentierung für eine die Orchestra vollständig umlaufende Abschrankung erscheint wenig wahrscheinlich. Ausgehend von der chronologischen Zuordnung bieten sich für die Fundamentierung folgende zwei Interpretationsmöglichkeiten:

Variante 1 - Fundament U zeitgleich mit dem Ringkanal ab dem 2. Viertel des 2. Jhs. v. Chr. Variante 2 - Fundament U früher errichtet als der Ringkanal des 2. Viertel des 2. Jhs. v. Chr.

Variante 1: Diese Möglichkeit basiert auf der Hypothese Wilbergs, berücksichtigt aber die aktuelle Datierung und geht von einer zeitgleichen Entstehung von Ringkanal und Fundament U ab dem 2. Viertel des 2. Jhs. v. Chr. aus. Dabei fokussiert die Variante auf die oben angesprochene, besonders sorgfältig gesetzte Kreisinnenseite des Fundaments $\mathrm{U}^{67}$. Diese Innenkante könnte auf eine Grenze zwischen unterschiedlichen Materialien

\footnotetext{
${ }^{65}$ Kap. 3.2.2.4.

${ }^{66}$ Heberdey u. a. 1912, 14.

${ }^{67}$ Eine Parallele dafür findet sich am unteren Diazoma in der gleichfalls aus hellenistischer Zeit stammenden Fundamentschar unter der Wand des Umgangs. Mit dem kaiserzeitlichen Umbau wurde der Umgang verbreitert, indem man die Diazomawand um etwa 0,5 m hangwärts versetzte. Dadurch ist die Oberfläche der Fundamente heute deutlich sichtbar. Während die zum Zuschauerraum weisende Seite zugerichtet ist und einen Kreisbogen beschreibt, ist die zum Hang gewandte Rückseite der Blöcke mehr oder weniger unbearbeitet geblieben. Manche Blöcke haben Abarbeitungen für den an sie anschließenden Plattenbelag. Die Linie des Kreisbogens bildete die Grenze zwischen den unterschiedlichen Bauelementen der aufgehenden Wand und des Fußbodens; vgl. zu diesem Befund STYHLER-Aydin (in Vorbereitung).
} 
bei der Bodengestaltung hinweisen. Konkret erfordert dies die Annahme einer nicht erhaltenen Blockreihe über Fundament $\mathrm{U}^{68}$, welche einen >Tanzplatz` aus gestampftem Lehm eingerahmt hätte, und eines Plattenbelags zwischen dem Steinkreis U und dem hellenistischen Ringkanal mit der unmittelbar dahinter befindlichen Sitzreihe. Der Durchmesser der Orchestra beträgt in diesem Fall 22,21 m innerhalb der Einfassung.

Lösungen dieser Art sind an mehreren Theaterbauten des griechischen Mutterlands zu erkennen. In allen Fällen gibt es einen Niveauunterschied zwischen Orchestra und Umgangsbereich, wobei das vornehmlich für die skenenferne Seite der Orchestra gilt ${ }^{69}$. Im Bereich der Parodoi und der jeweils ersten Kerkides befindet sich auch der Umgangsbereich auf dem etwas höheren Niveau der eigentlichen Orchestra. Damit ist eine für den Besucher weitgehend sichere Zugangslösung geboten, ohne Stufen im Bereich der Analemmata oder ohne Engstelle zwischen Analemma und Orchestraeinfassung. Ein allfällig im tiefer liegenden Umgangsbereich befindlicher Kanal ist im höher liegenden Umgangsbereich gedeckt. Eine Situation, die im Theater von Ephesos durch den Befund nicht bestätigt werden kann. Der Umgang mit dem offen geführten Ringkanal reicht bis an die Analemmata. Östlich davon kann es folglich keinen Niveausprung gegeben haben. Auch im Bereich der Analemmata und der Parodoi ist eine Stufe zwischen einem tieferliegenden und einem erhöhten Niveau aufgrund des Befunds auszuschließen. Wenn also nur die Orchestra selbst innerhalb ihrer Einfassung erhöht gewesen wäre, hätte das eine wenig elegante Engstelle von etwas mehr als $1 \mathrm{~m}$ Breite im Bereich der Analemmata ergeben. Die Oberfläche der Orchestra, deren Einfassung und der Umgang mit den Zugängen über die Parodoi müssten also weitgehend auf demselben Niveau gelegen haben. In diesem Fall wäre zwischen der Einfassung und der inneren Kanalwandung mit einem Plattenboden zu rechnen, während die Orchestra aus gestampftem Lehm oder einem Lehmestrich bestanden hätte.

Wie der untere Abschluss des Koilon in hellenistischer Zeit aussah, kann heute nicht mehr beantwortet werden. Fest steht aber, dass die untere Sitzreihe recht nahe an den Ringkanal herangereicht haben muss. Entfernt man aus der Rekonstruktion W. Wilbergs (Taf. 431 Abb. 760) alle späteren Elemente, so ist ein deutlicher Niveauunterschied zwischen der Kanaloberseite und der Sitzreihe bemerkbar. Vielleicht erklärt das auch die besondere Ausführung der Prohedrie-Sessel. Das eine noch erhaltene Exemplar hat eine halbrunde Lehne (Taf. 431 Abb. 761). Seine beiden Seiten sind flächig mit Reliefs dekoriert. Hier kann es folglich keine baulichen Anschlusszonen gegeben haben. An der Rückseite ist der Stuhl aber blockförmig gearbeitet und könnte vor einem leicht erhöhten, schmalen Umgang vor der ersten Sitzreihe positioniert gewesen sein. Als möglicher Aufstellungsort der Prohedrie-Sessel kommen die Mittelachsen der Kerkides nahe am Ringkanal in Betracht. Der geringe Abstand zwischen unterem Koilonabschluss und Ringkanal würde einen Umgang zwischen Ringkanal und der Orchestraeinfassung über dem Fundament U plausibel machen.

Variante 2: Aber auch eine zweite Interpretationsmöglichkeit soll in Betrachtung gezogen werden. Zwischen der Stadtgründung und der Errichtung der Skene erstreckt sich ein Zeitraum von gut 100 Jahren. Wenn man davon ausgeht, dass Theater zum festen Bestandteil einer (neu)gegründeten Stadt gehörten, und ein solches Gebäude daher auch mit Sicherheit bei der Planung der lysimachischen Gründung beabsichtig und im Stadtgefüge vorgesehen war, darf man wohl berechtigt die Frage nach dem architektonischen Erscheinungsbild einer solchen frühen Einrichtung stellen.

Wir wissen nicht, wann man mit dem Bau des Zuschauerraums am Berghang begonnen hat. Es ist jedoch davon auszugehen, dass das allein schon aus arbeitstechnischen Gründen bereits vor der Errichtung der Skene geschah. Vielleicht ist in dem Steinkreis daher auch eine ältere Phase eines womöglich einfacheren Theaters erhalten, schließlich bildete er die planimetrische Grundlage aller nachfolgenden Phasen. Führt man in der Schnittzeichnung (Taf. 431 Abb. 760) eine Linie am Fußpunkt der Sitzreihen im unteren Rang geradlinig weiter nach unten, so würde diese Linie etwa die Mitte des Ringkanals treffen und die Position der ersten Sitzreihe bezeichnen. Zwischen der untersten Sitzreihe und der Innenseite des Fundaments U

${ }^{68}$ Wogegen aber die Gestaltung der Oberflächen an der Oberseite der Blöcke spricht.

${ }^{69}$ Das von Heberdey u. a. 1912, 16 angeführte Vergleichsbeispiel, das Theater von Epidauros, besitzt einen tieferliegenden Umgangsbereich ohne zusätzlichen Kanal. Zum Wasserabfluss diente der Umgang selbst, erst an dessen Ende fließt das Wasser in unterirdische Kanäle. Bei anderen Theatern, z. B. in Eretria (Pickard-Cambridge 1946, Abb. 64. 65; Isler 2007, Planbeil. 1), Stratos, Oiniadai (Gogos 2009, Abb. 9 Plan 2) oder Sikyon ist der tieferliegende Umgangsbereich mit einem offenen bzw. teilgedeckten Ringkanal kombiniert. Aber auch an diesen Theatern wird der Kanal am Ende des tiefer gelegenen Umgangs unterirdisch weitergeführt; vgl. z. B. Epidauros: Gogos 2011, Abb. 1. 2. 
bliebe Platz für einen Umgang von etwa 1,5 m Breite. Das könnte auch die differierende Gestaltung der Außenseite des Fundaments U, wie in S 1/2005 angetroffen, erklären. Nur dort lässt sich auch an der AuBenseite der Blöcke ein Kreisbogen feststellen. Anders als im Süden tritt das Theater im Bereich des Schnitts S 1/2005 bereits aus dem Berghang heraus. Das Koilon musste in älterer Zeit nicht zwangsläufig bis an das spätere Analemma (Parodosmauer P) herangereicht haben. In den Bereichen des Berghangs, wo der Zuschauerbereich anschloss, muss es auch einen Umgang um den eigentlichen >Tanzplatz gegeben haben, der mit einem Plattenbelag versehen war, wodurch die unbearbeitete Außenseite des Steinkreises U nicht von Bedeutung war. Außerhalb des Berghangs gab es dann auch keinen Umgang mehr und die Funktion des Fundaments $\mathrm{U}$ bestand einzig in der baulichen Markierung der Orchestra ${ }^{70}$.

Besonders die beengten Verhältnisse zwischen Ringkanal und unterem Koilonabschluss im 2. Jh. v. Chr. in der Variante 1 legen (gegenüber der klar gestalteten Raumsituation zwischen Orchestra und Koilon in Möglichkeit 2) eine Vorgängervariante nahe.

\subsubsection{Orchestra in der Kaiserzeit}

Die im 1. Jh. n. Chr. begonnenen tiefgreifenden Umbauten am Theater folgten einem Gesamtkonzept, welches den hellenistischen Bau in ein zeitgemäßes Theater römischen Typus transferieren sollte. Dementsprechend komplex sind die Zusammenhänge zwischen den Bereichen Bühnengebäude, Bühne, Orchestra und Zuschauerraum. Die Lage des Bühnengebäudes hat sich nicht geändert und den Kern bildete nach wie vor der hellenistische Bau. An der Westseite wurde eine zusätzliche Reihe von Räumen angefügt, im Osten errichtete man an der Stelle des hellenistischen Proskenion eine mehrgeschossige Fassadenwand (Taf. 430 Abb. 758). Die daran anschließende Bühne reichte weit in die Orchestra hinein und bedingte die Aufgabe der hellenistischen Parodoi. Man musste eine neue Zugangsmöglichkeit schaffen. Dies geschah einerseits durch gedeckte Korridore, die jetzt hinter den Resten der einstigen Analemmata (Mauern P und Q) zur Orchestra führten (Taf. 3 Abb. 3), andererseits führten Rampen über diesen Korridoren zum unteren Umgang der ima cavea im Bereich der Orchestrawand X, die durch die Abtragung der untersten Sitzreihen entstand ${ }^{71}$. Nach R. Heberdey und W. Wilberg hätte sich die Entfernung der Sitzreihen in zwei Schritten vollzogen; bis etwa in den Bereich des Profils J in vortrajanischer Zeit, später bis an die Orchestrawand $\mathrm{X}^{72}$. Am heutigen Bestand lässt sich das nicht mehr nachvollziehen ${ }^{73}$.

Der Umbau in flavischer Zeit hatte keine Auswirkungen auf das Orchestraniveau. Das belegen die Türschwellen in der Proskenioenfront. Der hellenistische Ringkanal blieb sogar weiterhin in Verwendung; schadhafte Stellen wurden ergänzt und das Kanalinnere mit opus signinum versehen. Im Unterschied zu früheren Zeiten war der Kanal der flavischen Phase über die ganze Länge gedeckt. Wenn es stimmt, dass die Beseitigung der Sitzreihen tatsächlich bereits in flavischer Zeit bis an die Orchestrawand X erfolgte, muss auch der Profilring J, der zwischen dem Niveau des Ringkanals und dem höhergelegenen Umgang zwischen J und X vermittelte, aus derselben Zeit stammen und man kann über dem Profilring J eine Abschrankung erwarten.

Mit der Neugestaltung der Bühnenfront um die Mitte des 2. Jhs. n. Chr., die zu einer geschlossenen Wand mit Marmorverkleidung führte, muss auch die Anhebung des Orchestraniveaus einhergegangen sein. Der alte, aus hellenistischer Zeit stammende Kanal wurde dabei aufgegeben. An seiner statt legte man darüber einen neuen Kanal an, der dem aktuellen Niveau entsprach. Er blieb wieder ungedeckt und war von geringer Tiefe. Die äußerst geringen Reste im Norden der Orchestra erlauben keine sicheren Rückschlüsse auf die Fließrichtung und die Entwässerung. Die runde Ausarbeitung an der Bodenplatte und am Sockel der Bühnenfront (Taf. 89 Abb. 177) lässt darauf schließen, dass der hellenistische Kanal zumindest ab hier noch zur Ableitung des Wassers diente, was ein Gefälle von Süd nach Nord erwarten lässt.

Mit der neuen Bühnenfront und dem Anheben des Orchestraniveaus muss sich ein völlig geänderter Eindruck des Theaters ergeben haben. Der letzte augenfällige Bezug zum hellenistischen Theater - das

\footnotetext{
${ }^{70}$ Auch in den bereits angeführten Theatern von Epidauros, Oiniadai etc. wird zwischen dem Umgangsbereich vor den Sitzreihen und dem Zugangsbereich in der Nähe der Parodoi in der Gestaltung des Fußbodens variiert. Zu Epidauros vgl. Gogos 2011, Abb. 1. 2; zu Oiniadai vgl. Gogos 2009, Abb. 9 Plan 2. 3 , 1.

${ }^{71}$ Kap. 10.2.4.2, s. auch die Abschlusspublikationen STYHLER-Aydin (in Vorbereitung) u. ÖZTÜRK (in Vorbereitung).

${ }^{72}$ Herberdey u. a. 1912, Abb. 59. 94.

${ }^{73}$ Kap. 10.2.4.2.
} 
Proskenion mit Säulengliederung - ist verschwunden und hat einer niedrigeren Wand, die möglicherweise auch optisch stärker die Horizontale betonte, Platz gemacht. Auffällige Veränderungen späterer Zeit sind die Beseitigung der Abschrankung über dem Profilring J, die Treppen im Norden und Süden, die um 1900 abgetragenen Treppen zu beiden Seiten der Bühnen-Mitteltür und die Abmauerungen einzelner Durchgänge in der Bühnenwand.

So manche Maßnahme wurde hypothetisch mit Veranstaltungen in Verbindung gebracht, die eine Wasserbefüllung der Orchestra voraussetzten ${ }^{74}$. Für diese Annahme haben sich während der aktuellen Untersuchungen keine Belege gefunden. Zwar könnten in diesem Zusammenhang jene beiden Rohrstränge, die mit einem Innendurchmesser von 22,5 cm von der Aristion-Leitung im Bereich der media cavea unter den Treppen T11 und T13 zur Orchestra führen ${ }^{75}$, durchaus ausgereicht haben, um die gesamte Orchestra in wenigen Stunden zu füllen. Und auch der Ost-West-Kanal, dessen Beginn sich tatsächlich am tiefsten Punkt der Orchestra befindet und der keine nachweisbaren Verbindungen zu anderen wasserableitenden Einrichtungen innerhalb der Orchestra hatte, könnte wie auch der Kanal im Süden der kaiserzeitlichen Bühne (Plan 10. 18) im Kontext der postulierten Wasserbefüllung der Orchestra eine plausible Erklärung erfahren. Doch so wie sich der Befund heute präsentiert, müssen die Orchestrawand $\mathrm{X}$ und die Bühnenfront die Beckenbegrenzung gebildet haben. Aufgrund der spätesten Nutzungsgeschichte, die nichts mehr mit Schauveranstaltungen zu tun hatte, lassen sich aber keine baulichen Beweise für einen wasserdichten Verschluss der Bühnenwand erbringen. Die beiden Rohrleitungen könnten zudem durchaus mit Brunneneinbauten in Verbindung gestanden haben, wie es am mittleren Diazoma belegt ist ${ }^{76}$. Darüber hinaus lässt die vielfältige Nutzung des Theaters, zu der auch Tierhetzen und Gladiatorenkämpfe gezählt haben, eine leistungsfähige Wasserleitung zu Reinigungszwecken nicht unwahrscheinlich erscheinen, wodurch auch der Einbau des großen OstWest-Kanals in die Orchestra erklärt werden kann.

\subsection{AUDITORIUM}

Partiell war das Auditorium bereits im Zuge der Grabungstätigkeit um 1900 ausgegraben worden (Textabb. 10). Die vollständige Freilegung erfolgte bis in die 1970er Jahre. Fast die gesamte Marmorverkleidung der Sitzreihen war bereits ausgeraubt. Die wenigen erhaltenen Teile der einstigen Verkleidung sind heute, trotz (oder in Folge) mannigfacher Restaurierungsarbeiten, als disloziert anzusehen. Bei den heute sichtbaren Strukturen im Zuschauerraum handelt es sich um den originalen bzw. restaurierten Unterbau der Sitzstufen. Dieser wurde entweder durch den natürlich anstehenden Felsen oder durch zusätzlich eingeschobene Quader sowie durch gänzlich aufgebaute Bereiche gebildet. Für die archäologischen Untersuchungen boten sich daher die drei Diazomata an. Die Grabungen sollten die Bauforschung begleiten und erbrachten zusätzliche Aufschlüsse zur Konstruktion des Zuschauerbereichs. Die Ergebnisse flossen 2006 in die Planung zur Gestaltung der Diazomata für die Revitalisierung des Theaters als modernen Veranstaltungsort ein.

\subsubsection{Unteres Diazoma}

\subsubsection{SONDAGE S 2/2006}

Bei Vermessungsarbeiten in der Aristion-Leitung unter der media cavea wurden 2004 im Bereich der Treppen T11 und T13 nach Westen abzweigende Tonrohrleitungen entdeckt (Taf. 463 Abb. 827). Doch wohin führten diese Leitungen und welcher Bereich sollte von diesen Stellen aus mit Wasser versorgt werden? Es lag nahe, den weiteren Verlauf der beiden Rohrleitungen unter den genannten Treppen zu suchen. Deshalb wurde ein Schnitt im Kreuzungsbereich der durch alle drei Ränge laufenden Treppe T13 und dem unteren Diazoma angelegt (Taf. 92 Abb. 183; 93 Abb. 184. 185; 94 Abb. 186). Bereits an der Oberfläche waren die Reste eines Tonrohrs zu erkennen, das unter der stark zerstörten ersten Stufe von T13 zur media cavea hervorragte (TRL

\footnotetext{
${ }^{74}$ Vgl. De Bernardi Ferrero 1970, 63.

${ }^{75}$ Kap. 3.4.1.1. u. 3.4.1.5.

${ }^{76}$ Kap. 3.4.2.1.
} 


\begin{tabular}{|c|c|c|c|c|c|}
\hline Schicht & OK in $\mathrm{m}$ & UK in $\mathbf{m}$ & Beschreibung/Interpretation & Keramik & Münzen \\
\hline SE D16 & 20,26 & 20,21 & rezente Kiesschüttung & - & - \\
\hline SE D17 & 20,21 & $\begin{array}{l}20,12- \\
19,63\end{array}$ & braune Erde & - & - \\
\hline SE D18 & $\begin{array}{l}20,12- \\
20,03\end{array}$ & 19,95 & hellbrauner Lehm & - & - \\
\hline Se D21 & \begin{tabular}{|l|}
$19,95-$ \\
19,63
\end{tabular} & - & Fels & - & - \\
\hline
\end{tabular}

Tab. 19

3). Mit ca. 1,90 m Länge wurde, begrenzt von zwei marmornen Bodenplatten, ein Schnitt über die gesamte Breite zwischen der Diazomawand und der obersten Stufe der ima cavea angelegt. Der für den Bau des Umgangs eben vorbereitete Felsboden SE D21 (rote Brekzie) ist teilweise mit einer festgetretenen, fundleeren Lehmschicht SE D18 bedeckt und liegt kapp unter dem heutigen Laufniveau aus Schotter. Die dünne Ausgleichsschicht SE D17 aus brauner Erde zwischen dem gewachsenen Boden und der Kiesschüttung SE D16 ist antik, doch aufgrund der wenigen Funde zeitlich nicht einzuordnen. In Verlängerung des bereits genannten Tonrohrs kam ein zweites Rohrfragment zum Vorschein. Es ist direkt auf dem Felsuntergrund verlegt. Unmittelbar an das äußerste Rohrfragment schließt im Westen eine kleine Vertiefung im Felsen an. Die Fortsetzung der Leitung nach Westen ist nicht mehr nachzuvollziehen. Zu tief reichen hier die Eingriffe durch die Restaurierungsarbeiten. Zwar könnte man die kleine Grube im Fels als eine syphonartige Einrichtung interpretieren, wie sie etwa aus dem Stadion von Magnesia am Mäander bekannt ist, doch handelt es sich dort um eine horizontal geführte Leitung. Der am unteren Diazoma des ephesischen Theaters verbleibende Raum zwischen der Fels-/Lehmoberfläche und dem Fußbodenbelag ist zu gering für eine vergleichbare Lösung.

\subsubsection{SONDAGE S 3/2006}

\begin{tabular}{|l|l|l|l|l|l|}
\hline Schicht & OK in $\mathbf{m}$ & UK in $\mathbf{~ m}$ & Beschreibung/Interpretation & Keramik & Münzen \\
\hline SE D16 & 20,11 & 19,98 & rezente Kiesschüttung & - & - \\
\hline SE D19 & 19,98 & $\begin{array}{l}19,77- \\
19,65\end{array}$ & mittelbraune Erde & - & - \\
\hline SE D20 & $\begin{array}{l}19,77- \\
19,65\end{array}$ & 19,23 & Verwitterungslehm (fundleer) & - & - \\
\hline SE D21 & 19,23 & - & Fels & - & - \\
\hline
\end{tabular}

Tab. 20

Schnitt S 3/2006 liegt im Kontaktbereich des Gebäudes zum natürlich abfallenden Hang (Taf. 94 Abb. 187; 95 Abb. 188. 189). Der Felsboden (SE D21) ist von einer stark verwitterten Schicht bedeckt und reicht durch den natürlichen Hangverlauf im Nordwesten merkbar tiefer als im Südosten. Die Fundamente der Diazomawand sind auf den horizontal vorbereiteten Verwitterungslehm SE D20 gesetzt und nach Bedarf mit kleinen Steinen unterfüttert (Taf. 96 Abb. 190). Das Fundament besteht aus einer einzelnen Steinschar von grob zugerichteten Blöcken. Trotz einzelner Spuren von Restaurierungsarbeiten befinden sich die Quader in situ. An der Oberseite sind deutliche Risslinien zu erkennen. Sie verlaufen im Abstand von ca. 0,5 m konzentrisch vor der Diazomawand. Weitere Risslinien und dazu passende Abarbeitungen an der Felsoberfläche-immer im Abstand von $0,5 \mathrm{~m}$ vor der Diazomawand - treten mehrfach über die gesamte Länge des unteren Diazoma auf. Aus diesem Grund kann von einer Zweiphasigkeit ausgegangen werden. Der einst schmalere Umgang wurde im Zuge einer Umgestaltung in einer zweiten Bauphase um rund $0,5 \mathrm{~m}$ verbreitert ${ }^{77}$.

\footnotetext{
${ }^{77}$ STYHLER-Aydin (in Vorbereitung).
} 
Über dem fundleeren Verwitterungslehm SE D20 wurde zwischen den Fundamenten der Diazomawand und der obersten Sitzreihe der ima cavea eine Schicht aus brauner Erde (SE D19) aufgebracht, die ursprünglich als Bettung für den Marmorboden gedient hatte. Von den Platten selbst ist jedoch nichts mehr erhalten. Um den Weg für die Besucher gangbarer zu machen, wurde über SE D19 die Kiesschüttung SE D16 aufgebracht. Die spärlichen Funde aus SE D19 lassen keine Aussagen über die zeitliche Stellung zu.

\subsubsection{Sondage $S$ 4/2006}

\begin{tabular}{|l|l|l|l|l|l|}
\hline Schicht & OK in $\mathbf{m}$ & UK in $\mathbf{m}$ & Beschreibung/Interpretation & Keramik & Münzen \\
\hline SE D22 & 20,23 & 19,84 & $\begin{array}{l}\text { rote, bröselige Erde mit Ziegelschutt und } \\
\text { kleinen Steinen }\end{array}$ & - & - \\
\hline SE D21 & 19,84 & - & Fels & - & - \\
\hline
\end{tabular}

Tab. 21

Im Kreuzungsbereich mit Treppe T17 wurde Schnitt S 4/2006 angelegt (Taf. 96 Abb. 191). Mit einer Länge von 3,60 m erfasst dieser zu beiden Seiten der Treppe eine größere Fläche auf dem Umgang, der sich an dieser Stelle noch ganz im Hangbereich befindet. Nach Nordwesten hin wird der Schnitt durch die stark mit Beton restaurierte oberste Stufe der ima cavea begrenzt. Die zweite Langseite reicht an die Diazomawand heran. Von dem in den zweiten Rang führenden Treppenteil T17 nach Norden zog sich ein schmaler Fußbodenstreifen bestehend aus Steinen unterschiedlicher Größe. Die Fugen bzw. freien Flächen wurden im Zuge der Restaurierungsarbeiten mit Beton vergossen, wobei grober Schotter in die Betonoberfläche gedrückt wurde (Taf. 97 Abb. 193). Die Grabungsfläche befindet sich im Hangbereich. Den Untergrund bildet wieder die rote Brekzie SE D21, die unter anderem auch zum Bau der hellenistischen Skene verwendet wurde. Der Fels ist stark zerklüftet und von rotem, bröseligem Material (SE D22) bedeckt. Wieweit es sich dabei um den natürlichen Boden oder um bereits durch die Bautätigkeit am Theater umgelagertes Material handelt, lässt sich nicht genau bestimmen. Abgesehen von dürftigen Keramikfunden und einem Rohrfragment, beides an der Schichtoberfläche gefunden, ist der Aushub fundleer. Der Fußbodenrest im Nordosten mit seiner grob eingerichteten Oberfläche gehörte ursprünglich zum Unterbau der Diazomawand, die einst um 0,50 m weiter in den Umgang ragte ${ }^{78}$. Der Sockel der späteren Wand ruht direkt auf SE D22 oder dem Fels (Taf. 97 Abb. 192). Nur an wenigen Stellen fanden kleine Steine zum Unterfüttern Verwendung. Die Sockelzone überragte den Fußboden und bildete im Treppenbereich die unterste Stufe. Die starken Abriebspuren zeugen von einer langen Verwendung. In späterer Zeit wurde eine neue Stufe einfach darauf gesetzt.

\subsubsection{Sondage $\mathrm{S} 5 / 2006$}

\begin{tabular}{|l|l|l|l|l|l|}
\hline Schicht & OK in $\mathbf{m}$ & UK in $\mathbf{m}$ & Beschreibung & Keramik & Münzen \\
\hline SE D23 & 20,30 & 19,94 & $\begin{array}{l}\text { braune, lockere Erde mit kleinen Steinen und } \\
\text { Ziegelbruch }\end{array}$ & - & - \\
\hline SE D21 & 19,94 & - & Fels & - & - \\
\hline
\end{tabular}

Tab. 22

Der kleine Schnitt S 5/2006 (Taf. 98 Abb. 195; 99 Abb. 196.) in der Achse der Treppe T19 unterscheidet sich kaum von S 4/2006. Teils dienten der zugerichtete Fels SE D21, teils die verwitterte Brekzie (SE D23) als Untergrund für den Fußboden und die Diazomawand (Taf. 98 Abb. 194), deren Konstruktion gleichfalls identisch mit S 4/2006 ist. Der Sockel, der auch hier als unterste Stufe zur media cavea gedient hatte, ist mit reichlich Beton rekonstruiert. Wiederum erlauben die äußerst spärlichen Funde im Aushubmaterial keine Datierung des Untergrunds.

\footnotetext{
${ }^{78}$ Kap. 3.4.1.2.
} 
3.4.1.5 SONDAGE $S$ 6/2006

\begin{tabular}{|l|l|l|l|l|l|}
\hline Schicht & OK in $\mathbf{m}$ & UK in $\mathbf{m}$ & Beschreibung/Interpretation & Keramik & Münzen \\
\hline SE D24 & 20,10 & $\begin{array}{l}19,92- \\
19,88\end{array}$ & $\begin{array}{l}\text { mittelbraune, lockere Erde mit kleinen } \\
\text { Steinen (rezentes Laufniveau) }\end{array}$ & - & - \\
\hline SE D27 & 19,92 & 19,60 & $\begin{array}{l}\text { mittelbraune, sandige Erde mit kleinen } \\
\text { Steinen und Ziegelstücken }\end{array}$ & 5./6. Jh. n. Chr. & M 128 (Licinius I.) \\
\hline SE D29 & 19,88 & 19,46 & gelbbraune Erde & hell.-kaiserzeitlich & M 18 (hell.) \\
\hline SE D32 & 19,46 & 19,10 & gelbbraune, sandige Erde & kaiserzeitlich & - \\
\hline SE D28 & $\begin{array}{l}20,19- \\
19,60\end{array}$ & - & Fels & - & - \\
\hline
\end{tabular}

Tab. 23

Ausgehend von den Ergebnissen in S 2/2006 wurde im Kreuzungsbereich von T11 und dem unteren Diazoma der Schnitt S 6/2006 mit einer Länge von 2,50 m angelegt (Taf. 99 Abb. 197; 100 Abb. 198. 199). Auch hier zweigt im Kanal der Aristion-Leitung eine Rohrleitung nach Westen ab. In der nördlichen Schnitthälfte steht der Fels (SE D28 = Serizitphyllit) bis knapp unter das Oberflächenniveau an. Während die Fundamentquader der Diazomawand hier direkt auf die Felsoberfläche gesetzt wurden (Taf. 101 Abb. 201), musste im Süden, wo der Fels abrupt abbricht, ein Unterbau über der Anplanierung SE D29 geschaffen werden, der dem aus S 4/2006 bekannten gleicht (Taf. 101 Abb. 200). Der senkrechte Abbruch im Fels wirkt künstlich hergestellt und wurde für die Errichtung der Diazomawand verfüllt. Unter SE D29 wird das Material feiner (SE D32). Beide Straten reichen vom Späthellenismus bis in die Kaiserzeit ${ }^{79}$. Aus SE D29 stammt die hellenistische Münze M 18. Im Westprofil ist unterhalb der Treppe T11 zur ima cavea in Schicht SE D27 aus dem 5./6. Jh. n. Chr. eine Münze des frühen 4. Jhs. n. Chr. (M 128 Taf. 358) und ein beschädigtes Tonrohr erhalten (Taf. 102 Abb. 203). Es handelt sich um das einzige Rohr im Schnitt. Doch scheint ein massiver Kalkmörtelklumpen unter der Treppe am Ostprofil (Taf. 102 Abb. 202), wie er für die Verlegung von Tonrohrleitungen verwendet wurde, zusammen mit der leichten, rinnenförmigen Vertiefung der Felsoberfläche für eine einst das Diazoma kreuzende Tonrohrleitung zu sprechen. Eine Vertiefung im Fels, wie in S 2/2006, gibt es hier nicht. Dennoch belegen die Befunde von T11 und T13 zusammengenommen Leitungsstränge im Bereich der Treppen, die aus der Aristion-Leitung gespeist wurden und nach unten auf die Orchestra zuführen. Ohne die Restaurierungen an der Orchestrawand an den entsprechenden Stellen zu beseitigen, lässt sich der Verlauf im unteren Teil der Cavea nicht mehr verfolgen. Sollten die Rohrleitungen hinter der Orchestrawand nach Norden bzw. nach Süden umgeschwenkt haben, etwa um anderswo die Wasserversorgung zu gewährleisten, wäre dies mit baulichen Problemen bei der Leitungsführung verbunden gewesen. So wird das herbeigeleitete Wasser entweder für die Trinkwasserversorgung, wobei sich allerdings keine Hinweise auf einen Laufbrunnen in der Orchestrawand erhalten haben, oder zu Reinigungszwecken (für die zur Arena umgebauten Orchestra) gedient haben.

\subsubsection{SONDAGE $S$ 7/2006}

\begin{tabular}{|l|l|l|l|l|l|}
\hline Schicht & OK in $\mathbf{m}$ & UK in $\mathbf{m}$ & Beschreibung/Interpretation & Keramik & Münzen \\
\hline SE D25 & 20,19 & 19,96 & $\begin{array}{l}\text { mittelbraune, etwas sandige Erde mit } \\
\text { wenigen kleinen Steinen }\end{array}$ & $\begin{array}{l}\text { hellenistisch- } \\
\text { frühkaiserzeitl.? }\end{array}$ & - \\
\hline SE D26 & 19,96 & 19,66 & $\begin{array}{l}\text { Baugrube für die oberste Stufenreihe der ima } \\
\text { cavea; braune Erde }\end{array}$ & frühkaiserzeitl. & - \\
\hline
\end{tabular}

Tab. 24

\footnotetext{
${ }^{79}$ Kap. 4.4.1.
} 
Schnitt S 7/2006 liegt im einstigen Hangbereich des Theaters. Hier musste der Fels für die Anlage des Auditorium und des Umgangs abgearbeitet werden (Taf. 103 Abb. 204). Beim Felsuntergrund handelt es sich um grünlich grauen Serizitphyllit (SE D28). Hinter den Blöcken der obersten Sitzreihe der ima cavea ist der Fels teilweise etwas großzügiger in Form einer Stufe abgearbeitet (Taf. 103 Abb. 204. 205). Der Spalt zwischen Fels und Quader ist mit brauner Erde (SE D26) verfüllt. Das darin enthaltene Fundmaterial bezeugt bauliche Aktivitäten in der Kaiserzeit. Unter der Fundamentierung der einstigen Diazomawand, die wie in S 3/2006 aus einer einfachen Quaderlage gebildet ist, dienten Erde und kleine Steine als Ausgleich zwischen Fundament und Fels (Taf. 104 Abb. 206). Über der Felsoberfläche befand sich eine dünne, braune Erdschicht SE D25 als Ausgleich. Die wenigen Keramikfragmente gehören der hellenistischen Zeit an.

\subsubsection{Sondage S 8/2006}

\begin{tabular}{|l|l|l|l|l|l|}
\hline Schicht & OK in $\mathbf{m}$ & UK in $\mathbf{m}$ & Beschreibung/Interpretation & Keramik & Münzen \\
\hline SE D30 & $\begin{array}{l}20,13- \\
19,77\end{array}$ & $\begin{array}{l}19,79- \\
19,74\end{array}$ & braune Erde (Oberfläche), rezent umgelagert & - & - \\
\hline SE D31 & $\begin{array}{l}19,79- \\
19,74\end{array}$ & 19,34 & $\begin{array}{l}\text { mittelbraune, lockere Erde mit kleineren } \\
\text { Steinen }\end{array}$ & frühkaiserzeitl. & M 13 (frühhell.) \\
\hline
\end{tabular}

Tab. 25

Schnitt S 8/2006 mit einer Größe von 3,4 × 2 m wurde am Nordflügel des Theaters, westlich des Zugangs EN1 angelegt (Taf. 104 Abb. 207; 105 Abb. 208). Der Befund wird vor allem von Gussmauerwerk geprägt, das durch eine dünne Lage rezenter, brauner Erde (SE D30) bedeckt ist. Nur das westliche Drittel ist tief mit Erde verfüllt (SE D31). Aufgrund der umfangreichen Restaurierungsarbeiten lässt sich die ursprüngliche Situation nur schwer fassen. Es ist unklar, inwiefern es sich bei der Schicht SE D31 um eine Zerstörung oder um eine Aufbringung im Zuge einer konstruktiven Maßnahme, etwa einer mit Erde aufgefüllten Substruktion, handelt. Die Dichte der Verfüllung macht die letztere Vermutung durchaus wahrscheinlich. Das Fundmaterial ist gemischt und reicht bis in die frühe Kaiserzeit ${ }^{80}$. Vom Gussmauerwerk kann nur mehr ein etwa 0,5 m breiter Streifen im Süden dem Diazoma bzw. der Diazomawand zugerechnet werden. Nördlich dieses Streifens überragt das opus caementitium die Oberfläche des Diazoma bereits deutlich. Wir befinden uns hier also bereits in der Unterkonstruktion des mittleren Rangs. Da der Umgang unmöglich in seiner ursprünglichen Form so schmal sein kann, ist von einer fehlerhaften Restaurierung beim Aufbau der Sitzreihen auszugehen. Dafür sprechen auch die Beobachtungen am Südflügel ${ }^{81}$.

\subsubsection{Mittleres Diazoma}

Das mittlere Diazoma ist von besonderem Interesse, weil auf dieser Ebene eventuelle Anhaltspunkte für die Rekonstruktion der Ausdehnung des hellenistischen Theaters zu erwarten waren ${ }^{82}$. Die in der Folge beschriebenen Schnitte haben dazu leider keine brauchbaren Hinweise erbracht. Anders sieht es für die Frischwasserversorgung des Auditorium aus, zu der die mehrfach auf Höhe des mittleren Diazoma dokumentierten Tonrohrwasserleitungen zu rechnen sind. Im Rahmen der archäologischen Untersuchungen war nicht zu erwarten, das gesamte Leitungssystem verstehen zu können. Sicher ist aber anzunehmen, dass die Versorgung durch ein weiteres, von der Aristion-Leitung unabhängiges Leitungssystem (von der summa cavea oder vom Hang her) erfolgte ${ }^{83}$.

\footnotetext{
${ }^{80}$ Kap. 4 u. 5.

${ }^{81}$ STHYLER-Aydin (in Vorbereitung).

${ }^{82}$ STHYLER-Aydin (in Vorbereitung).

${ }^{83}$ STHYLER-Aydin (in Vorbereitung).
} 
3.4.2.1 SONDAGE S 1/2008

\begin{tabular}{|c|c|c|c|c|c|}
\hline Schicht & OK in $\mathrm{m}$ & UK in $\mathbf{m}$ & Beschreibung/Interpretation & Keramik & Münzen \\
\hline \multicolumn{6}{|l|}{ Diazoma } \\
\hline SE 49 & 30,24 & $\begin{array}{l}30,21- \\
30,07\end{array}$ & rezentes Laufniveau & - & - \\
\hline SE 50 & $\begin{array}{l}30,19- \\
30,07\end{array}$ & $\begin{array}{l}30,04- \\
29,50\end{array}$ & $\begin{array}{l}\text { fester, gelber Sand mit kleineren Steinen und } \\
\text { Ziegelstücken (Verfüllung TRL-Graben) }\end{array}$ & 1. Jh. v. Chr. & - \\
\hline SE 51 & 30,21 & $\begin{array}{l}30,20- \\
30,00\end{array}$ & $\begin{array}{l}\text { brauner Sand mit Ziegelstücken (Verfüllung } \\
\text { TRL-Graben) }\end{array}$ & $\begin{array}{l}\text { 1. Viertel 1. Jh. } \\
\text { n. Chr. }\end{array}$ & - \\
\hline SE 54 & 30,21 & $\begin{array}{l}30,18- \\
30,11\end{array}$ & $\begin{array}{l}\text { gelbbraune, sandige Erde mit Steinen und } \\
\text { Ziegelbruch, wenig Fundmaterial, tlw. rezent } \\
\text { gestört }\end{array}$ & - & - \\
\hline SE 55 & $\begin{array}{l}30,18- \\
30,11\end{array}$ & $\begin{array}{l}30,08- \\
30,04\end{array}$ & $\begin{array}{l}\text { feste, sandige Erde mit wenigen Steinen und } \\
\text { Ziegelbruch }\end{array}$ & - & - \\
\hline SE 56 & - & - & anstehender Fels (Serizit-Phyllit) & - & - \\
\hline SE 72 & 30,24 & 30,06 & $\begin{array}{l}\text { hellbraune Erde mit Steinen und } \\
\text { Ziegelstücken, oberer Bereich von SE } 73 \\
\text { (rezent gestört) }\end{array}$ & - & - \\
\hline SE 73 & 30,18 & $\begin{array}{l}29,95- \\
29,90\end{array}$ & $\begin{array}{l}\text { gelbes, sehr hartes, sandiges Material } \\
\text { mit kleinen Steinen und Ziegelstücken, } \\
\text { Mörtelbrocken und Holzkohle (Verfüllung } \\
\text { der Felsarbeitung) }\end{array}$ & $\begin{array}{l}\text { 1. Jh. v. Chr.- } \\
\text { frühes 1. Jh. n. Chr. }\end{array}$ & - \\
\hline SE 74 & $\begin{array}{l}29,77- \\
29,75\end{array}$ & $\begin{array}{l}29,67- \\
29,64\end{array}$ & $\begin{array}{l}\text { helles, sandiges Material mit zahlreichen } \\
\text { Steinen; etwas Ziegelbruch und } \\
\text { Steinabschlag (Verfüllung der Felsarbeitung) }\end{array}$ & 2. H. 1. Jh. v. Chr. & - \\
\hline SE 75 & 29,48 & 29,35 & $\begin{array}{l}\text { dunkle, lehmige Erde mit wenigen Steinen, } \\
\text { vermutlich verunreinigt }\end{array}$ & $\begin{array}{l}\text { nur ein signifikantes } \\
\text { Fragment, 6. Jh. n. } \\
\text { Chr. (intrusiv) }\end{array}$ & - \\
\hline SE 76 & 29,73 & 29,64 & weiße Mörtelschicht & - & - \\
\hline SE 77 & 30,16 & 30,13 & harter, weißer Mörtel & - & - \\
\hline SE 78 & 29,48 & - & $\begin{array}{l}\text { feine, dünne, weiße Mörtelschicht; direkt auf } \\
\text { dem anstehenden Fels }\end{array}$ & - & - \\
\hline \multicolumn{6}{|c|}{ Umgang vor erster Sitzreihe } \\
\hline SE 47 & 31,73 & 31,66 & $\begin{array}{l}\text { sehr hartes, rötlich braunes Niveau am } \\
\text { Umgang vor der ersten Sitzreihe; enthält } \\
\text { TRL, kaum aussagekräftiges Material }\end{array}$ & - & - \\
\hline SE 48 & 31,68 & 30,92 & $\begin{array}{l}\text { braunes, leicht rötliches, relativ festes } \\
\text { sandiges Material mit größeren Ziegelbruch } \\
\text { und Steinen }\end{array}$ & 2.-3. Jh. n. Chr. & - \\
\hline SE 52 & 30,92 & $\begin{array}{l}30,73- \\
30,64\end{array}$ & $\begin{array}{l}\text { rötlich braunes, kompaktes Erdmaterial mit } \\
\text { zahlreichen rosafarbenen Mörtelbrocken } \\
\text { (Brunnenfüllung) }\end{array}$ & $\begin{array}{l}\text { 3. Viertel 1.- } \\
\text { 1. H. 2. Jh. n. Chr. }\end{array}$ & - \\
\hline SE 56 & - & - & anstehender Fels (Serizit-Phyllit) & - & - \\
\hline
\end{tabular}

Tab. 26

Als die media cavea im Jahr 2004 für die Bauaufnahme einer umfassenden Reinigung unterzogen wurde, fiel auf dem schmalen Umgang vor der untersten Sitzreihe in Kerkis M12 ein vertikal im Boden steckendes Tonrohr auf (Taf. 108 Abb. 214). Es schien Teil einer Wasserleitung zu sein. Mit diesen Rohren korrespon- 
dierte im Bereich der Sockelzone der Diazomawand eine rechteckige Öffnung in Fußbodenhöhe (Taf. 111 Abb. 222). Bereits damals lag die Vermutung nahe, dass es sich dabei um einen kleinen Brunnen handeln könnte. 2008 erfolgte eine nähere Untersuchung. Dazu wurde ein Schnitt sowohl über den Umgang vor der untersten Sitzreihe als auch über dem Diazoma angelegt. Die Diazomawand ist in besagtem Bereich stellenweise restauriert, doch lässt sich folgende Situation deutlich erkennen: Im Quadermauerwerk zeichnen sich zwei vertikale Kanten ab. Diese reichen vom oberen Rand der Diazomawand bis hinunter zum Sockel, auf dem einst die Orthostaten der Wandverkleidung standen (Taf. 111 Abb. 222; 112 Abb. 223). Der Abstand zwischen diesen vertikalen Kanten ist mit Bruchsteinen unterschiedlicher Größe vermauert. Von der Orthostatenverkleidung sind rechts und links des Schnitts noch Reste vorhanden. Im Abschnitt zwischen den beiden vertikalen Kanten wurde im Zuge der Restaurierungsarbeiten auch der Sockel neu verlegt. Das belegt ein Betonbett unter dem Sockel (Taf. 112 Abb. 223). Kein Zweifel aber besteht an der richtigen Anordnung der Sockelblöcke.

Der Umgang vor der ersten Sitzreihe besteht in der südlichen Hälfte von Kerkis M12 überwiegend aus dem anstehenden Fels. Knapp hinter der Diazomawand ist der Fels senkrecht abgearbeitet. Der Spalt zwischen dem Fels und der Diazomawand ist mit hartem, rötlich braunem Material (SE 47) verfüllt (Taf. 105 Abb. 209). Nach Norden hin, wo der Fels etwas zurückweicht, ist nur die Verfüllung zu erkennen. Im Schnittbereich ist der Fels nischenförmig abgearbeitet, wobei es sich nur bei der südlichen Nischenwand um Fels handelt, während im Norden eine kleine Mauer angesetzt wurde. Die beiden künstlich hergestellten Felsecken, bzw. das Mäuerchen im Norden, korrespondieren mit den vertikalen Kanten an der Diazomawand (Taf. 106 Abb. 210; 108 Abb. 215; 109 Abb. 216). Damit liegt ein rechteckiges Brunnenbecken vor, von dem die dem Hang zugewendete Seite im Osten einschließlich der Wasserinstallation erhalten ist. Die Westhälfte ist von einer massiven Betonschicht über der mit Bruchsteinen ergänzten Diazomawand bedeckt. Die Bruchsteinwand an der Front dürfte nicht dem originalen Bestand des kleinen Brunnens angehören. Ursprünglich muss man sich auf Höhe der Orthostaten wohl eine Abschrankung vorstellen, die nicht bis an das zu ergänzende Abschlussprofil der Diazomawand gereicht hat und einen Blick in das Brunnenbecken sowie die Wasserentnahme ermöglichte. Die nischenförmige Anlage muss überdeckt gewesen sein, sodass der Umgang vor der untersten Sitzreihe durchgehend begehbar war. Ein Beispiel eines solchen, in eine niedere Wand integrierten Brunnens ist etwa jüngst im Stadion von Magnesia am Mäander in fast vollständiger Ausgestaltung freigelegt worden. Die Bruchsteinmauer vor dem Brunnen ist demnach später anzusetzen und gehört der Zeit nach der Aufgabe des Brunnens an.

Das Innere des Brunnenbeckens war mit Marmorplatten verkleidet. Einzelne Reste sowie Abdrücke im Mörtel sind erhalten (Taf. 107 Abb. 211-213; 109 Abb. 217. 218; 110 Abb. 219. 220). Recht aufwendig ist das Rohrsystem gestaltet (Taf. 111 Abb. 221). Die von Norden heranführende Tonrohrleitung (Taf. 105 Abb. 209; 106 Abb. 210) versorgt im Brunnenbereich eine vertikal angebrachte Leitung aus zwei Tonrohren, die mittig, hinter der Beckenwandung angebracht ist. Diese ist unten verschlossen und besitzt in der Mitte des oberen Rohrs eine größere Öffnung in Richtung des Brunnenbeckens. Zu beiden Seiten des vertikalen Rohrs befinden sich zwei weitere Stränge, die senkrecht nach unten führen. Über dem nördlichen Strang verläuft die Zuleitung. Das oberste Rohr dieser Leitung ist deshalb kürzer. Es ist komplett mit Kalkmörtel verschlossen. Die südliche Rohrleitung erreicht dieselbe Höhe wie die mittlere. Ein Verschluss der Oberseite ist nicht mehr festzustellen. Auf Höhe der zum Becken gewandten Ausgussöffnung sind die drei Rohrstränge durch kleine Bleirohre miteinander verbunden.

Am Diazoma selbst wurde der 3,0 m lange Schnitt vor dem Brunnen in der Diazomawand angelegt (Taf. 106 Abb. 210; 112 Abb. 224; 113 Abb. 225). Die Felsoberfläche befindet sich relativ tief unter dem Bodenniveau des Diazoma. Vor der Wand ist der Fels wannenförmig abgearbeitet. Die östliche Wandung befindet sich in einer vertikalen Ebene mit der Sockelzone der Diazomawand. Dennoch ruht der Sockel nicht auf dem Fels, sondern auf der Ausgleichsschicht SE 73 mit Funden aus dem späten 1. Jh. v. Chr. bis ins frühe 1. Jh. n. Chr. Diese Schicht erstreckte sich auch über die Felswanne, die mit großen Steinbrocken als Teil des Stratums SE 74 aus späthellenistischer Zeit angefüllt war. Darunter befand sich ein dunkelbraunes, lehmiges Niveau (SE 75). Es enthielt kaum signifikantes Fundmaterial. Einzig ein Fragment eines Topfs ließ sich dem 6. Jh. n. Chr. zuweisen. Aufgrund der darüber befindlichen Schichtfolge (SE 74 - SE 73 - Diazomawand) und der großen Homogenität des Fundmaterials der Schichten SE 73 und 74, muss das einzelne Fragment aus SE 75 als Verunreinigung gelten, zumal zwischen dem Abhub der Schicht SE 74 und dem Abhub der Schicht SE 75 ein Zeitraum von etwa einer Woche lag. Fels und Felswanne sind mit einem dün- 
nen Kalkmörtelüberzug versehen. Die Wanne könnte, wie das Becken vor der scaenae frons ${ }^{84}$, mit den Bauarbeiten im Theater in Verbindung stehen.

Über der Ausgleichsschicht SE 73 verlief SE $54=72$. Dabei handelt es sich weniger um ein eigenes Stratum, als viel mehr um den oberen Bereich der Ausgleichsschicht, der wohl im Zuge der Restaurierungsarbeiten an der Diazomawand in Mitleidenschaft gezogen worden war, wie eindeutig rezentes Material aus SE $54=72$ nahelegt. Von einer wirklichen Umlagerung kann nicht die Rede sein. Eine entlang des Sockels bis in SE 73 reichende Rinne scheint die Bettung jener Tonrohrleitung zu sein, die mehrfach am mittleren Diazoma zu erkennen ist. Die Verfüllung SE 50 (Nord) und SE 51 (Süd) enthält Fundmaterial vom Ende des 1. Jhs. v. Chr. bis ins 1. Viertel des 1. Jhs. n. Chr.

\subsubsection{SONDAGE $\mathrm{S} 2 / 2008$}

\begin{tabular}{|l|l|l|l|l|l|}
\hline Schicht & OK in $\mathbf{m}$ & UK in m & Beschreibung/Interpretation & Keramik & Münzen \\
\hline SE 49 & 30,15 & 29,98 & rezentes Laufniveau & - & - \\
\hline SE 115 & 29,98 & $\begin{array}{l}29,82- \\
29,80\end{array}$ & $\begin{array}{l}\text { mittelbraune, feste Erde mit Ziegelbruch und } \\
\text { kleinen Steinen }\end{array}$ & 3./2. Jh. v. Chr. & - \\
\hline
\end{tabular}

Tab. 27

In der 3,0 m langen, vor Kerkis S18 liegenden S 2/2008 wurde gerade soweit abgetieft, um die Sockelzone freizulegen. Das Füllmaterial SE 115 besteht aus fester, rötlicher Erde mit sehr viel Steinen, Ziegelbruch, Keramikfragmenten und Muschelschalen. Etwa mittig im Schnitt verläuft TRL 5. Die Sockelquader ruhen auf einer Schicht aus Erde mit Steinen (Taf. 113 Abb. 226; 114 Abb. 227). Stellenweise wurde mit flachen, plattenartigen Steinen unterfüttert. Die etwa 0,36 bis 0,38 m hohen Quader sind an der Unterseite falzartig abgearbeitet (Fußbodenanschluss?), wobei die Kante selbst sehr exakt ausgeführt ist. Die Front ist geglättet und am oberen Abschluss ist eine wulstartige Randbosse verblieben. Die Verklammerungen an der Oberseite weisen einen ungleichmäßigen Abstand von der Vorderseite auf. Insgesamt weist der ganze Bereich starke Risse und Brüche auf und ist stellenweise stark restauriert. Ohne Zweifel sind die Blöcke aber an ihrem Ort belassen. Das zeigt die passgenaue Position der Verklammerung. Bei Kabelverlegungsarbeiten für eine 2006 neu installierte Beleuchtung wurden die Blöcke über längere Abschnitte untergraben und drohten 2008 auf das Diazoma zu kippen. Diese Bereiche wurden 2008 und 2009 saniert.

Im Sondagenbereich kann von einer einheitlichen Sockelzone gesprochen werden, wohingegen das darüberliegende Mauerwerk, das seiner Verkleidung beraubt ist, eine scheinbare Fuge erkennen lässt (Taf. 114 Abb. 227). Längliche, flache Blöcke treffen hier auf große, quadratische Quader. Es handelt sich dabei aber eher um eine Fuge im Verband der Quader als um eine Baufuge im Sinn von unterschiedlichen Bauabschnitten. Auch oberhalb der Diazoma-Stützwand ist kein Wechsel in der Materialität des Sitzstufenunterbaus zu erkennen. In den unteren Reihen laufen die grauen Kalksteinquader durch; oberhalb schließen restaurierte bzw. wieder aufgebaute Stufen an.

\subsubsection{SONDAGE S 3/2008}

S 3/2008 wurde mit einer Länge von 3,0 m vor Kerkis S16 angelegt (Taf. 114 Abb. 228). Bereits nach wenigen Zentimetern kam unter SE 49 graue Brekzie zutage. Die Oberfläche ist horizontal abgearbeitet und für das Diazoma vorbereitet worden. Nahe der Diazomawand sind in der hergerichteten Felsoberfläche zwei annähernd quadratische $(32 \times 38 \mathrm{~cm})$ Vertiefungen zu erkennen (Taf. 114 Abb. 228; 115 Abb. 229). Sie stehen möglicherweise mit den Bauarbeiten am Koilon in Verbindung. Die Sockelschicht unter der Diazomawand ruht nicht auf dem vorbereiteten Fels. Zwischen Fels und Sockel befindet sich ein schmaler Streifen brauner Erde. Entlang der Wand sind - auch außerhalb des Schnitts - immer wieder größere Steine vorhanden. Sie reichen aber kaum unter den Sockel (Taf. 115 Abb. 230).

\footnotetext{
${ }^{84}$ Kap. 3.2.3.
} 


\begin{tabular}{|l|l|l|l|l|l|}
\hline Schicht & OK in $\mathbf{m}$ & UK in $\mathbf{m}$ & Beschreibung/Interpretation & Keramik & Münzen \\
\hline SE 49 & 30,47 & $\begin{array}{l}30,42- \\
30,21\end{array}$ & rezentes Laufniveau & - & - \\
\hline SE 101 & $\begin{array}{l}30,42- \\
30,21\end{array}$ & $\begin{array}{l}30,17- \\
30,11\end{array}$ & $\begin{array}{l}\text { sandige, braune Erde mit Bruchsteinen, } \\
\text { Kiesel und Ziegelbruch }\end{array}$ & $\begin{array}{l}\text { 1. Jh. v.-1. Jh. n. Chr. } \\
\text { (?) }\end{array}$ & - \\
\hline SE 102a & 30,42 & 30,05 & $\begin{array}{l}\text { rötlich braune Erde (Grubenverfüllung), } \\
\text { fundleer }\end{array}$ & - & - \\
\hline SE 102b & 30,21 & 30,02 & $\begin{array}{l}\text { rötlich braune Erde (Grubenverfüllung), } \\
\text { fundleer }\end{array}$ & - & - \\
\hline SE 103 & 30,23 & $\begin{array}{l}30,10- \\
30,08\end{array}$ & $\begin{array}{l}\text { dunkelbraune, sandige (Verfüllung zwischen } \\
\text { Fels und oberster Sitzreihe der ima cavea), } \\
\text { fundleer }\end{array}$ & - & - \\
\hline
\end{tabular}

Tab. 28

\subsubsection{SONDAGE $S$ 4/2008}

\begin{tabular}{|l|l|l|l|l|l|}
\hline Schicht & OK in $\mathbf{m}$ & UK in $\mathbf{m}$ & Beschreibung/Interpretation & Keramik & Münzen \\
\hline SE 49 & 30,15 & $\begin{array}{l}30,12- \\
30,07\end{array}$ & rezentes Laufniveau & - & - \\
\hline SE 96 & 29,82 & $\begin{array}{l}29,79- \\
29,65\end{array}$ & $\begin{array}{l}\text { gelbbraune Erde mit vereinzelt Ziegelbruch } \\
\text { und Mörtelbrocken }\end{array}$ & 1. H. 2. Jh. n. Chr. & - \\
\hline SE 97 & 29,82 & $\begin{array}{l}29,87- \\
29,74\end{array}$ & ockerfarbene Erde mit etwas Ziegelbruch & kaiserzeitlich & - \\
\hline
\end{tabular}

Tab. 29

Unmittelbar vor Treppe T8 fiel eine unterschiedliche Bearbeitung der Sockelzone auf (Taf. 116 Abb. 232; 118 Abb. 235). Die südlichen Quader wirken deutlich gröber ausgeführt als die nördlichen. Sie sind im Gegensatz zu letzteren auch ohne Wulst gearbeitet. Verfolgt man die Oberfläche der Sockelzone in beide Richtungen, fällt eine unterschiedliche Ausführung der Verklammerung auf. Der 2,0 m lange Schnitt (Taf. 116 Abb. 231; 117 Abb. 233. 234) sollte den in der Sockelzone sichtbaren Unterschied auch im Fundamentbereich überprüfen. Bereits nach Abhub einer dünnen, stark mit rezentem Müll durchmischten Schicht SE 49 ist die Unterkante der Sockelzone freigelegt. TRL 6 verläuft etwa in der Mitte zwischen Wandsockel und der obersten Stufenreihe der media cavea. Die Leitung ist in das gleiche rötliche Material gebettet, wie es auch aus S 2/2008 bekannt ist. Bis auf zwei Rohre ist die Leitung erhalten. Östlich der TRL wird zwischen teilweise großen Stein- und Brekziebrocken bis unterhalb der Fundamente abgetieft (SE 96. 97). Die ursprüngliche Vermutung, dass es sich bei den zwischen Rohrleitung und Sockel entstanden Vertiefungen um relativ groß dimensionierte Pfostenlöcher handelt (Taf. 117 Abb. 233), konnte nicht bestätigt werden. Es dürfte sich um vereinzelt im Aufschüttmaterial liegende Gesteinsbrocken handeln, die bei der Bearbeitung des Felsbodens angefallen sind. Die Fundamentschar ist auf einem festen Grund aus einer Mischung aus lehmiger Erde und Steinen errichtet. Wie an der Sockelzone zeigt sich auch bei den Fundamentquadern ein deutlicher Unterschied. Der im Schnitt unter den südlichen Sockelquadern sichtbare Fundamentblock weist eine kaum bearbeitete, weit herausragende Form auf (Taf. 118 Abb. 235). An einigen Stellen, wo die Oberfläche des Diazoma gerade bis zur Fundamentoberkante reicht, lässt sich dieser Umstand mehrfach beobachten. Unter den Sockelblöcken mit Wulst ist eine Fundamentschar aus zwar groben, aber mit vertikal ebener Fläche gearbeiteten Quadern erkennbar. An der Oberfläche lässt sich auch dieser Umstand nach Norden weiter verfolgen. Im Anschlussbereich der beiden unterschiedlichen Sockelzonen befindet sich ein schmälerer Quader mit geradlinig gearbeiteter Vorderseite, über dem flache Steine das unterschiedliche Niveau der Sockelunterkante beider Ausführungen überbrücken. Der südliche Quader wirkt an der Unter- 
seite leicht nachgearbeitet. Die differierende Bearbeitung sowohl der Fundamente als auch des Sockels findet seine Fortsetzung im Aufbau der summa cavea (Taf. 118 Abb. 236) ${ }^{85}$. Treppe T8 trennt die auf Fels gegründete Kerkis S8 von der gänzlich aufgemauerten Kerkis S7. Ein Blick zum oberen Abschluss der summa cavea lässt südlich der Treppe T8 gerade noch den Berghang erkennen. Dies erklärt die Unterschiede im Aufbau der Kerkides. Die Fuge im Sockel- und Fundamentbereich dürfte deutlich zeigen, dass es sich hierbei auch um zeitlich unterschiedliche Bauvorgänge handelt. Allem Anschein nach reichte der dritte Rang ursprünglich nur bis zu Treppe T8, war also noch nicht bis an das Nord-Analemma herangeführt.

\subsubsection{SONDAGE S 5/2008}

\begin{tabular}{|c|c|c|c|c|c|}
\hline Schicht & OK in $\mathbf{m}$ & UK in $\mathbf{m}$ & Beschreibung/Interpretation & Keramik & Münzen \\
\hline SE 049 & 29,55 & 29,38 & rezentes Laufniveau & - & - \\
\hline SE 085 & $\begin{array}{l}29,47- \\
29,34\end{array}$ & $\begin{array}{l}29,07- \\
28,91\end{array}$ & $\begin{array}{l}\text { graubraune, sandige, kompakte Erde mit } \\
\text { wenigen Ziegeln und kleinen Steinen; } \\
\text { vereinzelt rezente Betoneinschlüsse, rezent } \\
\text { umgelagert }\end{array}$ & frühe Kaiserzeit & - \\
\hline SE 086 & $\begin{array}{l}29,49 \\
29,33\end{array}$ & 28,74 & $\begin{array}{l}\text { sandiger Schutt mit kleinen Steinen } \\
\text { und Ziegelstücken; im nördlichen } \\
\text { Bereich gelegentlich rez. gestört und mit } \\
\text { Betonbrocken vermischt }\end{array}$ & 5. Jh. n. Chr.; & - \\
\hline SE 087 & $\begin{array}{l}29,56- \\
29,54\end{array}$ & 29,49 & $\begin{array}{l}\text { sandige, braune Erde mit vielen kleinen } \\
\text { Steinen und Ziegelstücken; rez. gestört und } \\
\text { vereinzelt mit Betonstücken vermischt }\end{array}$ & (1. H.) 1. Jh. n. Chr. & - \\
\hline SE 088 & 28,79 & $\begin{array}{l}28,95- \\
28,37\end{array}$ & $\begin{array}{l}\text { gelbbraune, sandige Schicht mit kleinen } \\
\text { Steinen und Ziegelbruch, fundleer }\end{array}$ & - & - \\
\hline SE 089 & $\begin{array}{l}29,20 \\
29,13 \\
\end{array}$ & $\begin{array}{l}29,07- \\
28,80\end{array}$ & $\begin{array}{l}\text { gelbbraune, sandige Schicht mit kleinen } \\
\text { Steinen und Ziegelbruch }\end{array}$ & frühe Kaiserzeit & - \\
\hline SE 090 & 28,71 & 28,40 & hellbraune Erde mit Bruchsteinen & frühe Kaiserzeit & - \\
\hline SE 091 & $\begin{array}{l}28,99 \\
28,93\end{array}$ & - & $\begin{array}{l}\text { Fundament in Verlängerung der } \\
\text { Diazomawand im Platzbereich von N2 (= } \\
\text { Zone 1), fundleer }\end{array}$ & - & - \\
\hline SE 092 & $\begin{array}{l}29,07- \\
28,91\end{array}$ & - & $\begin{array}{l}\text { caementitium-Aufbau unter dem } \\
\text { Zugangsbereich zwischen EN2 und } \\
\text { mittlerem Diazoma (= Zone 2), fundleer }\end{array}$ & - & - \\
\hline $\begin{array}{l}\text { SE } 93= \\
\text { SE } 094= \\
\text { SE } 95\end{array}$ & $\begin{array}{l}29,13- \\
2837\end{array}$ & - & $\begin{array}{l}\text { caementitium-Aufbau unter dem mittleren } \\
\text { Diazoma (= Zone 3), fundleer }\end{array}$ & - & - \\
\hline
\end{tabular}

Tab. 30

Der Zugang von EN2 auf das mittlere Diazoma wurde bereits 1998 von St. Karwiese untersucht ${ }^{86}$. Mit S 5/2008 sollte auch das Diazoma im Zugangsbereich erfasst werden. Die Stelle befindet sich bereits deutlich vom Hang entfernt und musste künstlich errichtet werden. Der Schnitt zieht sich L-förmig vom Zugangsweg auf das nach Westen führende Diazoma (Taf. 119 Abb. 237). Aufgrund der massiven Restaurierungen (Taf. 120 Abb. 239) sollte der Schnitt Auskunft über die originale Bausubstanz geben. Wie auf allen Umgängen ist kein Marmorbelag vorhanden. Im Unterbau lassen sich klar drei Zonen unterscheiden (Taf. 119 Abb. 237; 120 Abb. 238). In Verlängerung der Diazomawand führt deren Fundamentierung (Zone 2) zunächst gut erkennbar weiter unter dem Zugangsniveau nach Osten, wird aber nach etwa einem Meter vom Unterbau des Zugangs

\footnotetext{
${ }^{85}$ STYHLER-AYdin (in Vorbereitung)

${ }^{86}$ Kap. 3.5.
} 
überdeckt. Während die Fuge zu Zone 1 (Zugangsbereich aus Richtung des Zugangs EN2) weiter deutlich auszumachen ist, wird die Trennung zwischen den Zonen 2 und 3 (Diazoma) durch den Unterbau der einstigen Pflasterung verdeckt. Der Zugangsbereich ist aus einer Mischung großer Steine und caementitium befestigt. Im mittleren Bereich der Südseite, zu den Sitzreihen der media cavea hin, konnte eine Erdverfüllung mit einem großen Architekturblock und einer Platte des Diazomabelags (?) festgestellt werden (Taf. 120 Abb. 240). Es sieht also so aus, als wäre hier aufgrund einer Zerstörung ein Stück des Diazoma und vermutlich auch ein Teil der Kerkis abgerutscht und später wieder aufgefüllt worden, ohne jedoch die verstürzten Bauteile zu entfernen. Mit Ausnahme der untersten Schichten SE 88 und SE 90 in der mit Erde gefüllten Störstelle sind alle anderen Straten deutlich mit rezenten Funden und Betonstücken durchmischt.

\subsubsection{Oberes Diazoma}

\subsubsection{Sondage $S 6 / 2008$}

\begin{tabular}{|l|l|l|l|l|l|}
\hline Schicht & OK in $\mathbf{m}$ & UK in m & Beschreibung/Interpretation & Keramik & Münzen \\
\hline SE 49 & $\begin{array}{l}40,69- \\
40,61\end{array}$ & $\begin{array}{l}40,66- \\
40,53\end{array}$ & rezentes Laufniveau & - & - \\
\hline SE 107 & $\begin{array}{l}40,66- \\
40,53\end{array}$ & $\begin{array}{l}40,09- \\
39,57\end{array}$ & gelbbraune Erde mit Steinen & 2./1. Jh. v. Chr. & - \\
\hline SE 111 & 40,66 & 40,00 & mörteldurchsetzte, graubraune bis rötliche Erde & $\begin{array}{l}\text { hell.- } \\
\text { frühkaiserzeitlich }\end{array}$ & - \\
\hline SE 112 & 40,66 & $\begin{array}{l}40,37- \\
40,33\end{array}$ & $\begin{array}{l}\text { graubraune, etwas sandige Erde mit } \\
\text { Bruchsteinen und Mörtelbrocken }\end{array}$ & frühkaiserzeitlich & - \\
\hline SE 113 & $40,33-$ & $\begin{array}{l}40,13- \\
40,03\end{array}$ & $\begin{array}{l}\text { graubraune bis rötliche Erde mit } \\
\text { Mörtelbrocken }\end{array}$ & vorhellenistisch & - \\
\hline SE 114 & 40,00 & - & Fels; teils rötliche, teils gelbliche Brekzie & - & - \\
\hline
\end{tabular}

Tab. 31

Der Schnitt wurde am oberen Ende der Treppe T16 angelegt und befindet sich im Hangbereich unmittelbar unter einer 1,60 m hohen, rezent restaurierten Wand, über der die Säulenstellung der summa porticus zu ergänzen ist (Taf. 121 Abb. 241. 242; 122 Abb. 243. 244; 123 Abb. 245). Gewählt wurde diese Stelle wegen des plötzlichen Endes einer Reihe großer Steinquader, die als Fundamentierung eines Teils der Diazomawand dienten. Die Wand selbst, aus Bruchsteinen errichtet, läuft zwar nach Norden weiter, nicht jedoch die Fundamentquader der einstigen Orthostatenverkleidung. Sie sind der Bruchsteinwand vorgelagert. Die Fundamente der Bruchsteinwand ruhen auf der stark zerklüfteten Brekzieoberfläche. Für die Fundamentquader wurde eine dünne opus caementitium-Bettung aufgebracht. Diese endet gleichfalls mit dem letzten Quader. Die Situation ist kaum verständlich und hängt wahrscheinlich mit den massiven Zerstörungen der Diazomawand, vermutlich im Zuge des byzantinischen Festungsbaus zusammen ${ }^{87}$. Vieles ist ergänzt, wie Fotos vom Zustand des Koilon vor den Restaurierungsarbeiten der 1960er und 1970er Jahre belegen ${ }^{88}$.

Die wenigen Keramikfragmente aus der in den Felsvertiefungen abgelagerten SE 113 gehören vorhellenistischer Zeit an. Der Großteil des Fundmaterials stammt aber aus der darüber liegenden Schicht SE 107 aus dem Späthellenismus. SE 107 wird durch den Graben des ausgerissenen Fundaments entlang der Diazomawand nördlich der Fundamentquader gestört. Die Verfüllung des Fundamentgrabens (SE 112) weist in die frühe Kaiserzeit bzw. das 1. Jh. n. Chr. Der gleichen Zeit gehört die Grabenverfüllung SE 111 entlang des Nordprofils an.

\footnotetext{
${ }^{87}$ Kap. 11.

${ }^{88}$ De Bernardi Ferrero 1970, Abb. 55.
} 
3.4.3.2 SONDAGE $S$ 8/2008

\begin{tabular}{|l|l|l|l|l|l|}
\hline Schicht & OK in $\mathbf{~ m}$ & UK in $\mathbf{m}$ & Beschreibung/Interpretation & Keramik & Münzen \\
\hline SE 119 & 40,39 & $\begin{array}{l}40,27- \\
40,25\end{array}$ & $\begin{array}{l}\text { gelbbraune, sandige Erde mit wenigen } \\
\text { kleinen Steinchen. }\end{array}$ & spätantik & - \\
\hline
\end{tabular}

Tab. 32

S 8/2008 sollte vorrangig baulichen Fragestellungen dienen. Der Schnitt wurde in Verlängerung von T16 vor einer kleinen Treppe, die das obere Diazoma mit der summa porticus verbindet, angelegt (Taf. 123 Abb. 246; 124 Abb. 247. 248). Hier fehlte der Marmorbelag des Fußbodens. Im Bereich der Fehlstellen und in den Fugen des an den Schnitt grenzenden Pflasters hatte sich eine humose Schicht gebildet (SE D49). Die Auffüllung SE 119 dient als Bettung für den Marmorbelag. Das Material wurde bis in 0,60 m Tiefe ausgehoben. Es handelt sich um einen umgelagerten Komplex mit keramischem Fundmaterial, das von der archaischen Zeit bis in die Spätantike reicht.

\subsubsection{Zusammenfassung Auditorium}

Die Ausgrabungen auf den drei Diazomata erbrachten vor allem ein besseres Verständnis der Konstruktion und der Bauabfolge im Auditorium. Absolute Datierungen dagegen sind nur sehr bedingt möglich. Das hellenistische Fundmaterial ist in der Regel umgelagert und meist mit kaiserzeitlicher Keramik vergesellschaftet. Es scheint mit dem hellenistischen Bau zu tun zu haben, kann diesem aber nicht zugeordnet werden $^{89}$. Auf dieser Höhe ist der obere Abschluss des hellenistischen Theaters anzunehmen ${ }^{90}$. Hingegen lässt sich ein Schwerpunkt in der frühen und mittleren Kaiserzeit feststellen, der mit der Umgestaltung und dem Ausbau des Koilon bis ins frühe 2. Jh. n. Chr. zusammenhängt. Eine präzise Unterscheidung zu eventuellen mittel- oder spätkaiserzeitlichen Renovierungen lässt sich aber nicht ausmachen. Doch belegen einzelne Fundkomplexe sehr wohl Maßnahmen bis in die Spätantike. Im Zuge der 2009 begonnen Restaurierungsarbeiten wurde 2011 die Aufplanierung über dem Fels am unteren Diazoma entfernt ${ }^{91}$. Dabei wurden zwei Steinblöcke mit quadratischen Pfostenlöchern an der Oberseite freigelegt (Taf. 125 Abb. 249. 250).

M. HofBAuer

\subsection{NORDFLÜGEL DES THEATERS}

Die folgende Ausführung bezieht sich auf die Ergebnisse der unter St. Karwiese (Gesamtleitung, Archäologie) und I. Ataç (Bauforschung) vorgenommenen Untersuchungen am Nordflügel des Theaters in den Jahren 1993 bis 1998. Als Grundlagen dienten die im Archiv des ÖAI vorliegende Grabungsdokumentation ${ }^{92}$ sowie neue Ergebnisse der Bauforschung ${ }^{93}$ und der archäologischen Untersuchungen ${ }^{94}$. Ein Großteil der Fundauswertung wurde bereits 1998/1999 abgeschlossen. Die übrige Keramik wurde im Zuge der Aufarbeitungen 2010 aufgenommen. Die angeführten Datierungen beziehen sich auf die abschließenden Ergebnisse der Fundbearbeitung ${ }^{95}$. Im Zentrum der Forschungen der Jahre 1993 bis 1998 standen vor allem die

\footnotetext{
${ }^{89}$ Vgl. die Überlegungen zum hellenistischen Bau in STYHLER-Aydin (in Vorbereitung).

${ }^{90}$ STYHLER-Aydin (in Vorbereitung), dort auch zur Wasserver- und -entsorgung in hellenistischer Zeit.

${ }^{91}$ Durch die Beseitigung der antiken Auffüllung sollte eine Oberflächenfestigung des Felsgrunds ermöglicht werden. Die archäologischen Arbeiten wurden von R. Yazıcı beaufsichtigt.

${ }^{92}$ Folgende Unterlagen standen zur Verfügung: publizierte und unpublizierte Zwischenberichte, Grabungstagebücher 1997/1998, Fotodokumentation, Fundzettel, Fundbearbeitung, Plana und Profile, Münzliste. Die Schichtnummern wurden von der Autorin im Zuge der Aufarbeitung vergeben.

${ }^{93}$ Kap. 1.

${ }^{94}$ Kap. 3.

${ }^{95}$ Kap. 4
} 


\begin{tabular}{|c|c|c|c|c|c|}
\hline \multicolumn{2}{|l|}{ Bereich } & \multirow{2}{*}{$\begin{array}{l}\text { Sondagen, } \\
\text { St. Karwiese }\end{array}$} & \multirow{2}{*}{$\begin{array}{l}\text { Bezeichnung } \\
\begin{array}{l}\text { EN1, Korridor mit sekun- } \\
\text { därem Wasserbecken }\end{array}\end{array}$} & \multirow{2}{*}{ 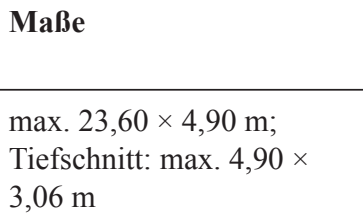 } & \multirow{2}{*}{$\begin{array}{l}\text { Grabungs- } \\
\text { jahr }\end{array}$} \\
\hline $\begin{array}{l}\text { Zugangssystem } \\
\text { EN1 }\end{array}$ & EN1, nördlich & & & & \\
\hline & EN1, südlich & $\begin{array}{l}\text { sog. Doppel- } \\
\text { stiegenhaus/97 }\end{array}$ & $\begin{array}{l}\text { EN1, südlicher Korridor- } \\
\text { bereich, teilweise KN3 u. } \\
\text { KN4 }\end{array}$ & $\begin{array}{l}\text { ca. } 12 \times 15 \mathrm{~m} \text {; } \\
\text { Tiefschnitt: } 2,00 \times 1,50 \mathrm{~m}\end{array}$ & 1998 \\
\hline & KN1 & KB 1/97 & $\begin{array}{l}\text { EN1, Kammer 1, westlich } \\
\text { angrenzend an EN1 }\end{array}$ & $\begin{array}{l}\max .10,90 \times 2,30 \mathrm{~m} \text {; Tief- } \\
\text { schnitt: } \max .1,33 \times 2,42 \mathrm{~m}\end{array}$ & 1997 \\
\hline & KN2 & KB 2/97 & $\begin{array}{l}\text { EN1, Kammer 2, westlich } \\
\text { angrenzend an EN1 }\end{array}$ & $\max .8,50 \times 2,51 \mathrm{~m}$ & 1997 \\
\hline & $\begin{array}{l}\text { EN1 West, } \\
\text { nördlicher } \\
\text { Treppenaufgang }\end{array}$ & S $1 / 98$ & $\begin{array}{l}\text { EN1 West, Treppenaufgang } \\
\text { zum unteren Diazoma, } \\
\text { oberes Podest }\end{array}$ & $3,00 \times 1,60 \mathrm{~m}$ & 1998 \\
\hline & & S 2/98 & $\begin{array}{l}\text { EN1 West, Treppenaufgang } \\
\text { zum unteren Diazoma, } \\
\text { mittleres Podest }\end{array}$ & $3,60 \times 2,20 \mathrm{~m}$ & 1998 \\
\hline \multirow[t]{2}{*}{$\begin{array}{l}\text { Zugangssystem } \\
\text { EN2 }\end{array}$} & EN2, südlich & S 4/98 & $\begin{array}{l}\text { EN2, mittleres Diazoma } \\
\text { und vomitorium }\end{array}$ & $\begin{array}{l}5,20 \times 2,30-1,50 \mathrm{~m} \text {; Nord- } \\
\text { Erweiterung: } 4,00 \times 1,20 \mathrm{~m}\end{array}$ & 1998 \\
\hline & EN2, nördlich & S 5/98 & $\begin{array}{l}\text { EN2, nördlich vor } \\
\text { vomitorium }\end{array}$ & ca. $5,50 \times 4,70 \mathrm{~m}$ & 1998 \\
\hline $\begin{array}{l}\text { Areal westlich } \\
\text { des Nord- } \\
\text { Analemma }\end{array}$ & & $\begin{array}{l}\text { sog. Nord- } \\
\text { Parodos }\end{array}$ & $\begin{array}{l}\text { obere, untere Terrasse, } \\
\text { Freitreppe, Sockel- } \\
\text { monument, BR } 4\end{array}$ & - & 1998 \\
\hline
\end{tabular}

Tab. 33: Sondagen-Übersicht. St. Karwiese interpretiert das Areal von KN3 u. KN4 als Doppelstiegenhaus bzw. als Aufgang/Zugangssystem zu EN1. Bei den beiden Torbögen im mittleren Abschnitt der Analemma-Mauer handelt es sich um Scheinöffnungen, weshalb hier die Bezeichnung sog. Doppelstiegenhaus gewählt wurde. Zugleich bezeichnet er Bereich vor den Nord-Analemma in seiner Grabungsdokumentation als Nord-Parodos, was bautypologisch zu Missverständnissen führen kann, weshalb der Bereich als sog. Nord-Parodos angeführt ist.

Klärung der Auf- und Zugangssysteme zum Koilon sowie die Erforschung der funktionalen Lösungen der Zuschauerführung (Taf. 9 Abb. 15) ${ }^{96}$. Auf Anfrage der türkischen Antikenverwaltung wurde 1993 mit Restaurierungs- und Konservierungsmaßnahmen am Theater begonnen. Der ruinöse Gesamtzustand des Bauwerks stellte eine besondere Herausforderung dar, weshalb in den Jahren 1993 bis 1996 vor allem die Sicherung der Bausubstanz im Zentrum der Bemühungen stand ${ }^{97}$. Umfassende Reinigungsarbeiten und das partielle Abtragen des Zerstörungsschutts im ersten Jahr bildeten die Grundlage zur Erstellung eines Schaden- und Gefahrenkatalogs. Auf diesem aufbauend wurden in den Jahren 1994 bis 1996 die notwendigen Sanierungs- und Restaurierungsmaßnahmen eingeleitet ${ }^{98}$. Ab 1997 konnte verstärkt mit dem Abtragen des massiven Versturzes über dem Nordflügel fortgefahren werden. Zusammen mit den im folgenden Jahr angelegten Sondierungen an den neuralgischen Punkten konnten weitere Informationen zum Grundriss des Theaters und der baugeschichtlichen Zusammenhänge im Norden gewonnen werden ${ }^{99}$. Die Sondagen S 1/98,

\footnotetext{
${ }^{96}$ Karwiese Archiv ÖAI; AtaÇ 1999a; AtaÇ 1999b.

${ }^{97}$ KARWIESE ARChIV ÖAI.

${ }^{98}$ KARWIESE 1994, 28-31; KARWIESE 1995a, 30-33; KARWIESE 1996, 29-31; KarWIESE 1997, 44-48.

${ }^{99}$ Die dabei entfernten Quader und Architekturfragmente wurden nördlich des Theaters deponiert bzw. an ihren Originalstandort transportiert, s. KARWIESE 1998a, 25 Anm. 38; KARWIESE 1999.
} 
S 2/98, S 4/98 und S 5/98 stellten eine erste wissenschaftliche Erforschung des Theater-Nordflügels und der Zugangssysteme dar und waren als kleinflächige Sondierungsschnitte gedacht, die einen ersten Überblick über die Situation schaffen sollten (Taf. 125 Abb. 251; 126 Abb. 252. 253).

\subsubsection{Zugangssystem EN1}

\subsubsection{1 voMITORIUM EN1}

\subsection{EN1, nördlicher Bereich}

\begin{tabular}{|l|l|l|l|}
\hline Schicht & Konsistenz/Interpretation & Datierung & Münzen (vgl. Kap.8) \\
\hline SE N1 & Versturz mit Bauteilen und Erde & $\begin{array}{l}\text { Anfang 7. Jh. n. Chr. } \\
\text { (Dat. Keramik: } \\
\text { 6. Jh. n. Chr.) }\end{array}$ & $\begin{array}{l}\text { M 39 (27 v. Chr./14. n. Chr., } \\
\text { aus dem Bereich von KN4), } \\
\text { M 116 (262 n. Chr., aus dem } \\
\text { Bereich von KN3) }\end{array}$ \\
\hline SE N2 & $\begin{array}{l}\text { unregelmäßig mit Mörtel verlegte Steinplatten } \\
\text { unterschiedlicher Form und Größe (Reste der } \\
\text { Plattenabdeckung) }\end{array}$ & - & - \\
\hline SE N3 & Übergangsschicht mit Sand und kleinteiligem Schutt & (spätes) 6. Jh. n. Chr. & $\begin{array}{l}\text { M 241 (572/573 n. Chr.) } \\
\text { M 78 (244/249 n. Chr.) }\end{array}$ \\
\hline SE N4 & lehmig-sandige Schicht über dem Ziegelplattenboden & 6. Jh. n. Chr. & - \\
\hline SE N5 & Ziegelplattenboden des Beckens & - & - \\
\hline SE N6 & Abflusskanal, Reinigungsloch & - & - \\
\hline SE N7 & Steinquader vor dem Abflusskanal & - & - \\
\hline SE N8 & $\begin{array}{l}\text { abgerundete Vormauerungen entlang der Korridorwände } \\
\text { bzw. Wände des Wasserreservoirs }\end{array}$ & - & - \\
\hline SE N9 & $\begin{array}{l}\text { Leitungsrohr in der Nord-Wand des Wasserreservoirs } \\
\text { (Überlaufschutz) }\end{array}$ & - & - \\
\hline
\end{tabular}

Tab. 34

\begin{tabular}{|l|l|}
\hline Tonrohrleitung & Bezeichnung/Interpretation \\
\hline TRL N1 & Tonrohrleitung (Zuleitung des Wasserreservoirs) \\
\hline
\end{tabular}

Tab. 35

Im Bereich des Nord-Süd verlaufenden, ursprünglich hoch überwölbten Korridors (max. Maße: 23,60 × $4,90 \mathrm{~m}$ ) wurde bereits 1997 begonnen, den Versturz zu entfernen (Taf. 127 Abb. 254). 1998 wurden die Arbeiten fortgesetzt und im nördlichen Abschnitt (Tiefschnitt: max. Maße: 4,90 × 3,06 m), wie auch in der Südostecke $^{100}$ (Tiefschnitt: max. Maße: 2,0 × 1,50 m) bis zum Plattenbodenniveau abgetieft ${ }^{101}$. Im Bereich nördlich der Verschlussmauer wurde die Schuttschicht bis zur Außenkante der Fassadenverstärkung ca. $1 \mathrm{~m}$ abgetragen.

Der mit weißem Marmor ausgekleidete, in Orthostaten-Binder-Technik ausgeführte Korridor wurde im Zuge der Umbau- bzw. Erweiterungsmaßnahmen im Nordtrakt des Theaters angelegt. Laut der Bauinschrift waren diese 92 n. Chr. vollendet ${ }^{102}$. Nach St. Karwiese und I. Ataç gelangten die Zuschauer durch den Kor-

\footnotetext{
${ }^{100}$ In der Grabungsdokumentation als östlicher Bereich des sog. Doppelstiegenhauses bezeichnet (vgl. dazu südl. Bereich von EN1)

${ }^{101}$ Die Architekturblöcke wurden beschriftet und nördlich des Theaters aufgereiht, s. KARWIESE 1998a, 24-29; KARWIESE Schlussbericht, 4 f.; s. Kap. 10.2.4.2 u. 10.3.2.

${ }^{102}$ IvE 2035. Vgl. Heberdey u. a. 1912, 36; s. auch Kap. 10.2.4.2.
} 
ridor, vorbei an vier Gewölbekammern (KN1-KN4) ${ }^{103}$ (Taf. 127 Abb. 255), durch die Nord-Außenschale des Theaters zum zweiten vomitorium (EN2), durch welches sie über eine steile Treppe das mittlere Diazoma erreichen konnten (Textabb. 16-18) ${ }^{104}$. St. Karwiese nimmt analog zum Süden eine Freitreppe entlang der Theateraußenwand an, über welche die oberen Ränge erschlossen wurden ${ }^{105}$. Die Erschließung der summa cavea bleibt bislang unklar.

Umbaumaßnahmen, vermutlich im Zuge von Stabilisierungsmaßnahmen, führten zu einer Umgestaltung des Gewölbes im Korridor EN1 ${ }^{106}$. Durch westlich und östlich vor die Korridorwand gesetzte Pfeilerreihen beabsichtigte man ein wesentlich niedrigeres Gewölbe einzuziehen, wenngleich derzeit nicht abschließend geklärt werden kann, ob das sekundäre Gewölbe vollständig zur Ausführung kam (Textabb. 21; Taf. 470 Abb. 840. 841; 472 Abb. 845) ${ }^{107}$. Bislang konnten drei Pfeiler ausgemacht werden ${ }^{108}$.

Das Theater hatte im späteren 4. Jh. n. Chr., vermutlich aufgrund von folgenschweren Erdbeben, massive Schäden erlitten, auf die im Nordflügel des Gebäudes mit einer Reihe von baulichen Sicherungen reagiert wurde ${ }^{109}$. Nach Analyse der aktuellen Bauforschung erfolgte die Ausführung der Sicherungsmaßnahmen offenbar etwas zeitlich versetzt in mehreren Schritten. Zu diesen Maßnahmen gehörten der Verschluss der nördlichen Fassadenöffnung von EN2, der Bau von zwei Strebemauern seitlich von EN2 sowie die Vorlagerung einer zusätzlichen Wandschale im Bereich zwischen den vomitoria EN1 und EN2.

Eine weitere Konsolidierungsmaßnahme ist im Bereich der Fassadenöffnung von EN1 anhand eines ca. $1 \mathrm{~m}$ breiten und 6,30 m hohen Negativabdrucks im opus caementitium-Kern der sekundär vorgelagerten Wandschale sichtbar. Dieser Abdruck zeigt, dass die Fassadenverstärkung bereits gegen ein vorhandenes bauliches Volumen im Bereich der Fassadenöffnung von EN1 gesetzt wurde (Taf. 472 Abb. 844). Es könnte sich dabei z. B. um eine unmittelbare statische Sicherung der hohen Öffnungslaibungen handeln. Der nördliche Eintritt in das vomitorium EN1 wäre dadurch zwar verschmälert worden, aber weiterhin zugänglich geblieben. Da der untere nördliche Außenbereich vor der Abschlussmauer in EN1 noch nicht freiliegt, lässt sich diese Hypothese derzeit jedoch nicht weiter verifizieren.

Klar ersichtlich ist hingegen, dass der Korridor in einer weiteren Umbauphase aufgegeben und im Norden durch eine 6,85 m starke und 4,50 m hohe Mauer verschlossen wurde (Taf. 128 Abb. 256). Diese Baumaßnahme steht entweder ebenfalls in Verbindung mit einer statischen Konsolidierung des Korridorbereichs oder mit der Umwandlung des Korridors EN1 in ein Wasserbecken. Die Mauerstärke spricht hingegen eher für eine statische Sicherungsmaßnahme, welche dann in Zusammenhang mit den Konsolidierungsmaßnahmen des späten 4. Jhs. n. Chr. stehen dürfte.

Durch die Stilllegung des Korridors (EN1) wurde jedenfalls auf den direkten Zugang von Norden verzichtet und der Zugang erfolgte nun ausschließlich über den L-förmigen Treppenaufgang von Westen her auf das untere Diazoma (EN1 West).

Vermutlich um die Mitte des 5. Jhs. n. Chr. wurde der nördliche und mittlere Bereich des Korridors EN1 in ein Wasserbecken umgebaut ${ }^{110}$. Dazu mussten die Toröffnungen der Kammern sowie der Durchgang zum südlichen Korridorabschnitt verschlossen werden ${ }^{111}$.

1998 konnte der Gang EN1 im nördlichen Bereich (max. 4,90× 3,06 m) sowie ein kleiner Ausschnitt im südlichen Teil vor dem verschlossenen Durchgang 1 zum südlichen Korridorabschnitt bis zum Boden des

\footnotetext{
${ }^{103}$ Die beiden nebeneinander liegenden, westlich an den Korridor EN1 angrenzenden Kammern (KN1-KN2) waren jeweils über ein Tor mit demselben verbunden. Aufgrund des Erhaltungszustands des Korridors im Süden und des noch hoch anstehenden Versturzes ist die Situation der Kammern KN3 und KN4 noch weitgehend unklar.

${ }^{104}$ KarWIESE ArChiv ÖAI, 4 f.; Karwiese 1998a, 25.

${ }^{105} \mathrm{Im}$ archäologischen Befund gibt es bisher keine Hinweise auf eine Freitreppe, dennoch erscheint die Vermutung des Ausgräbers wahrscheinlich.

${ }^{106}$ Laut St. Karwiese fanden diese etwa im 3. Jh. n. Chr. statt, s. KARwiese Archiv ÖAI, 5

${ }^{107}$ Vgl. Kap. 10.3.2. Es gibt keine Spuren von Verklammerungen oder Verdübelungen der Bauelemente miteinander oder zu den Korridorwänden. Vermutlich diente das sekundäre Gewölbe der zusätzlichen Aussteifung des Korridors oder sollte Bereiche des beschädigten Korridors ersetzen.

${ }^{108}$ Im südlichen Bereich des Korridors konnte der Versturz noch nicht abgetragen werden.

${ }^{109}$ Vgl. auch Karwiese Schlussbericht, 4; s. Kap. 10.3.2 u. Sondage 5/98.

${ }^{110}$ Kap. 10.3.2.

${ }^{111}$ Die Tore wurden mit Mörtelmauerwerk aus Bruchsteinen, Spolien und Ziegeln vermauert und mit hydraulischem Mörtel verputzt, die Wände des Korridors blieben hingegen unverputzt.
} 
Wasserbeckens freigelegt werden (Taf. 128 Abb. 257; 129 Abb. 258. 259) ${ }^{112}$. Aus diesen beiden Tiefschnitten ging hervor, dass das Wasserbecken über die gesamte Länge des Korridors EN1 angelegt war und ein Fassungsvermögen von mehr als $350 \mathrm{~m}^{3}$ besa ${ }^{113}$. Da der Bereich im Südwesten des Korridors noch mit Versturz verfüllt ist, bleibt unklar, wie dieser ausgebildet war.

Massive, abgerundete Vormauerungen aus Steinen und Ziegeln mit Mörtelputz ziehen sich entlang der Beckenseitenwände des Korridors (SE N8). Diese zeigen an, dass der ursprüngliche Boden des Gangs abgetieft und der dadurch offen liegende Fundamentbereich mit abgerundeten Vormauerungen bzw. Sockeln im Nordbereich des Beckens abgedeckt und gesichert wurde.

Der Boden des Beckens (SE N5) besteht soweit sichtbar aus rechteckigen Ziegelplatten in den Maßen $74 \times 74 \mathrm{~cm}$ bzw. $32 \times 32 \mathrm{~cm}$. Das nördliche Niveau des Ziegelplattenbodens ${ }^{114}$ liegt um 0,24 m tiefer als im Süden und gewährleistete somit das problemlose Abfließen des Wassers.

Wasserzulauf $^{115}$ (TRL N1), Ablauf bzw. Überlauf (SE N9) und Reinigungsloch (SE N6) des Wasserverteilers befinden sich in der nördlichen Verschlussmauer (Taf. 129 Abb. 260; 472 Abb. 845). Falls die Verschlussmauer bereits vor dem Bau des Wasserbeckens bestand, würde das bedeuten, dass die Mauer zumindest im mittleren Bereich teilweise abgetragen werden musste, um die Leitungsrohre zu verlegen ${ }^{116}$.

Vor dem Wasserauslass (Breite: $46 \mathrm{~cm}$ [unten], $54 \mathrm{~cm}$ [oben], Höhe: 45,5 cm) (SE N6) an der Nordseite des Beckens befindet sich ein quaderförmiger Stein (SE N7), der das Verstopfen des Kanals verhindern sollte und Verunreinigungen abhielt.

Der Zugang zum Wasserbecken erfolgte von Norden ${ }^{117}$ über einen schmalen Gang, der von Spolienmauern (Maße: 1,46 × 3,70 m [westliche Mauer]; 1,62 × 3,70 m [östliche Mauer]) flankiert wurde, die den Arkadenwänden der zweiten Phase vorgeblendet worden waren (Taf. 130 Abb. 261). Beide Mauern sind aus wiederverwendeten Architekturteilen und Bruchsteinen in Mörtelbindung errichtet.

Unmittelbar an der Oberseite der Abschlussmauer sind im Durchgangsbereich zwischen den Spolienmauern Teile der ursprünglichen Plattenabdeckung (SE N2) im östlichen Bereich und die Reste einer Tonrohrleitung (TRL N1) erhalten, die als Wasserzuleitung des Beckens diente (Taf. 130 Abb. 262; 131 Abb. 263) und entlang der Theateraußenmauer von Osten heranführte ${ }^{118}$.

Da die Wasserleitung allem Anschein nach entlang der Fassadenverstärkung der nördlichen Außenwand des Theaters verlief, kann das Becken erst nach der Errichtung der Fassadenverstärkung angelegt worden $\operatorname{sein}^{119}$. Diese Mauer ist durch zwei Inschriften ins späte 4. Jh. n. Chr. datiert, weshalb sich für das Wasserbecken ein terminus post quem für diese Zeit ergibt. Sofern die Kammer KN1 vor der Abmauerung des Verbindungstors zum Korridor verfüllt wurde, deren Verfüllungsschichten ans Ende des 4. bis zur Mitte des 5. Jhs. n. Chr. datieren, ergibt sich für den Umbau des Wasserbeckens eine Datierung um die Mitte des 5. Jhs. n. Chr.

Das Becken diente vermutlich der Versorgung der Theater-Therme oder als Wasserverteiler für die zahlreichen Brunnenanlagen, die in der Spätzeit im Bereich vor dem Nord-Analemma errichtet worden waren $^{120}$.

Über dem Ziegelboden des Wasserbeckens lagerte sich eine feine ca. $20 \mathrm{~cm}$ dicke Sandschicht (SE N4) ab, die ins 6. Jh. n. Chr. datiert (Taf. 131 Abb. 264). Darüber befand sich eine dünne Übergangsschicht mit Sand und kleinteiligem Schutt, die Keramik und Tierknochen enthielt (SE N3). Anpassungsscherben aus Schicht SE N4 mit SE N3 belegen, dass es sich hierbei wohl um eine Schicht handelt, welche an der Oberkante gröberes Material beinhaltete. Das Fundmaterial weist ins 6. Jh. n. Chr., wobei die in SE N3 gefun-

\footnotetext{
${ }^{112}$ Bodenniveau des Wasserbeckens (absolut) 16,56 m (N)/16,80 m (S).

${ }^{113}$ Vgl. Kap. 10.3.2. Das von St. Karwiese und I. Ataç errechnete Fassungsvermögen von 850.000 Liter lässt sich heute nicht mehr nachvollziehen, s. KARWIESE SCHLUSSBERICHT, 4.

$11416,56 \mathrm{~m}$

${ }^{115}$ Unterhalb des Wasserzulaufs hat sich eine massive Sinterspur gebildet, die bis zum Boden des Beckens reicht.

${ }^{116}$ Die Südseite der Verschlussmauer ist verputzt und nur an einigen Fehlstellen ist das dahinterliegende Mauerwerk sichtbar, weshalb hier keine Baumaßnahmen an der Verstärkungsmauer erkennbar sind.

117 Über die Verschlussmauer.

${ }^{118}$ UK (absolut) 20,6 m (Zulauf-Rinne).

${ }^{119}$ Erkennbar durch eine Aussparung in der westlichen Kante der Fassadenverstärkung auf Höhe der Tonrohrleitung.

${ }^{120}$ Weitere Wasserabflüsse, die vielleicht auf der Westseite des Beckens vorhanden waren, sind bislang nicht ergraben, s. KARWIESE SCHLUSSBERICHT, 4; vgl. Kap. 10.3.2.
} 
dene Münze M 241 (Taf. 359; 572/573 n. Chr.) den terminus post quem im letzten Viertel des 6. Jhs. n. Chr. angibt. Außerdem fand sich in SE N3 die für die Datierung nicht relevante Münze M 78 (244/249 n. Chr.).

St. Karwiese geht davon aus, dass der gesamte Korridor einschließlich des Beckens sowie die angrenzenden Kammern am Anfang des 7. Jhs. n. Chr. in Folge schwerer Erdbeben ab der Mitte des 6. Jhs. n. Chr. durch herabstürzende Bauteile des Korridorgewölbes bzw. der obersten Ränge verfüllt wurden (SE N1), was durch die Münzfunde aus dem Versturz über der Kammer KN1 bestätigt wird (SE N12) ${ }^{121}$.

Zwischen den verstürzten Architekturteilen konnten neben einigen Geisa und Statuenfragmenten zwei erwähnenswerte Gladiatoren-Pfeiler mit Inschrift und Relief geborgen werden ${ }^{122}$ (Taf. 132 Abb. 265-267). St. Karwiese nimmt aufgrund dieser Funde an, dass in der summa cavea hinter den letzten Sitzstufen kleine Altäre und Statuen aufgestellt waren und im Theater schon im 2. Jh. n. Chr. Gladiatorenkämpfe stattfanden ${ }^{123}$.

\subsection{EN1, südlicher Bereich ${ }^{124}$}

\begin{tabular}{|l|l|}
\hline Schicht & Konsistenz/Interpretation \\
\hline SE N10 & Schutt mit verstürzten Blöcken und Gewölbeteilen, entspricht vermutlich SE N1 \\
\hline SE N11 & lehmige Schicht, entspricht SE N4 \\
\hline SE N8 & $\begin{array}{l}\text { abgerundete Vormauerungen entlang der Korridorwände bzw. Wände des Wasserreservoirs, } \\
\text { Bodenkehle }\end{array}$ \\
\hline SE N5 & Ziegelplattenboden des Beckens \\
\hline
\end{tabular}

Tab. 36

Da es sich im südlichen Bereich von EN1 um eine großflächige Abnahme des Versturzes mit großen Architekturfragmenten und Erdmaterial handelte, wurden keine genauen Grabungsgrenzen definiert (Taf. 133 Abb. 268. 269) ${ }^{125}$. Im Schutt fanden sich massive Blöcke des eingestürzten Korridorgewölbes. Die Schuttschichten konnten nicht näher differenziert werden, dürften jedoch analog zum nördlichen Bereich von EN1 ${ }^{126}$ gegen Anfang des 7. Jhs. n. Chr. datieren (SE N10).

In der Nordostecke des südlichen Teils des Korridors EN1 vor dem zugemauerten Tor wurde in einem 2,0 × 1,50 m großen Bereich bis zum Plattenboden des Wasserbeckens (SE N5) abgetieft (Taf. 129 Abb. 258.

\footnotetext{
${ }^{121}$ Folgende Schichten gehören zur selben Zerstörungsphase bzw. Endphase: vgl. SE N1, SE N10, SE N12, SE N18; zu den Münzen s. Kap. 5; die Keramikfunde aus dem Versturz datieren zwar durchgehend ins 6./späte 6. Jh. n. Chr., dennoch geben die Münzfunde einen terminus post quem für die Zerstörung des Theaters an (M 201. M 242 Taf. 359; M 243. M 245 Taf. 360), zur Keramik s. Kap. 4.

${ }^{122}$ SK 54: Fragment von linkem Fuß auf Plinthe; Gladiatoren-Pfeiler: SK 55 (Taf. 389 Abb. 641-643); SK 56 (Taf. 390 Abb. 644. 645), s. Kap. 7 (Reliefs); Kap. 8 (Inschrift IN 4 Taf. 412; IN 5 Taf. 411) u. Kap. 6.2.2 (Beinring B 61 Taf. 380).

${ }^{123}$ Karwiese Archiv ÖAI, 5; Karwiese 1998b, 4.

${ }^{124}$ In der Dokumentation von St. Karwiese als Sondage sog. Doppelstiegenhaus/98 bezeichnet. Dies umfasst den Südteil des Korridors sowie den Bereich von KN3 und KN4. Die Grabungsfläche am sog. Doppelstiegenhaus wurde von St. Karwiese in ein südliches und nördliches Treppenhaus geteilt.

${ }^{125}$ St. Karwiese und I. Ataç interpretieren diesen Bereich (KN3 und KN4) als parallel angelegte Treppenhäuser, die durch zwei Bogenaufgänge in der Analemma-Mauer zugänglich waren. Der südliche Aufgang bog laut Ausgräber auf Höhe des Korridors nach Süden ab und führte zum untersten Rang. Der nördliche Treppenaufgang führte in den hoch überwölbten Korridor (EN1), von wo aus man durch die Nord-Außenschale des Theaters auf eine Freitreppe gelangte. St. Karwiese nimmt an, dass durch den Einbau des Beckens »zumindest auch der nördliche der beiden Aufgänge von der Parodos her zugemauert werden musste. Vielleicht wurde auch der Parallele zur selben Zeit verschlossen. Am Ende gab es jedenfalls auf dieser Seite nur noch einen überwölbten Aufgang zum 1. Rang, wobei noch nicht klar ist, wozu der dafür benutzte Raum gedient haben könnte« (KARWIESE 1998a, 25). Bei den verschlossenen Bogenaufgängen in der Analemma-Mauer handelt es sich allerdings um Scheintüren, wonach die beiden sogenannten parallelen Treppenaufgänge wohl als Kammern (KN3 und KN4) angesprochen werden können (Kap. 10.2.4.2). Ob diese zugänglich waren oder als bloße Substruktionskammern anzusprechen sind, kann beim jetzigen Wissensstand nicht geklärt werden, da der Bereich noch massiv mit Versturz verfüllt ist. Zu dem Fund eines Terrakottafragments einer nackten weiblichen Figur (TK 16 Taf. 362, Aphrodite); genauer Fundort ist unklar, s. Kap. 6.1.

${ }^{126}$ Vgl. Sondage KK/97/98.
} 
$259)^{127}$. Entlang der Korridorwände ließ sich analog zum Norden eine Bodenkehle aus Mörtel ausmachen, die im südlichen Bereich des Beckens allerdings um einiges weniger massiv ausgebildet war als im Norden $^{128}$. Unter dem Versturz (SE N10) kam auch hier eine feuchte, sandige Schicht zum Vorschein (SE N11). Schicht SE N10 enthielt sehr heterogenes Material, dessen jüngste Funde ins 2. Jh. n. Chr. datieren. Die Funde der darunterliegenden Schicht SE N11 datieren später, konnten allerdings aufgrund des sehr kleinen Fundkomplexes nicht genau eingeordnet werden. Es handelt sich bei beiden Schichten um umgelagertes Material, weshalb analog zum nördlichen Bereich von EN1 eine Datierung ins 6. bzw. Anfang des 7. Jhs. n. Chr. anzunehmen ist (vgl. SE N1 und SE N4).

\subsubsection{KAMMER KN1 ${ }^{129}$}

\begin{tabular}{|l|l|l|l|}
\hline Schicht & Konsistenz/Interpretation & Datierung & Münzen \\
\hline SE N12 & Versturz mit Bauteilen und Erde & Anfang 7. Jh. n. Chr. & $\begin{array}{l}\text { M 246 (aus dem Bereich } \\
\text { zwischen KN1 u. KN2) } \\
(613 / 614 \mathrm{n} . \text { Chr. }), \\
\text { M 242 (615/16 n. Chr.) } \\
\text { M 243 (615/616 n. Chr.) } \\
\text { M 245 (612/613 n. Chr.). }\end{array}$ \\
\hline SE N13 & lehmiger Erdschutt (Verfüllung) & & - \\
\hline SE N14 & $\begin{array}{l}\text { Schutt mit Mörtelfragmenten, Schotter, Keramik und } \\
\text { kompakten Mörtelstellen (Verfüllung) }\end{array}$ & 3.-4. Jh. n. Chr. & M 94 (197/217 n. Chr.) \\
\hline SE N15 & $\begin{array}{l}\text { dichte Lage von Keramikfragmenten unterschiedlicher } \\
\text { Größe mit etwas Mörtelgrieß und lockerer Erde } \\
\text { (Verfüllung) }\end{array}$ & Ende 4.-Mitte 5. Jh. n. Chr. & $\begin{array}{l}\text { M 49 (141/161 n. Chr.), } \\
\text { M 53 (161/180 n. Chr.), } \\
\text { M 59 (218/222 n. Chr.), } \\
\text { M 141 (347/348 n. Chr.), } \\
\text { M 160 (364/367 n. Chr.). }\end{array}$ \\
\hline SE N16 & Lehm & & - \\
\hline SE N17 & Boden der Kammer KN1 & - & - \\
\hline
\end{tabular}

Tab. 37

Nachdem die oberste Schicht des Versturzes mit teils großen Architekturteilen (SE N12) ${ }^{130}$ bis auf ein Niveau von ca. 19,77 m großflächig abgenommen wurde, konnte im Nordosten der Kammer eine Sondage in den max. Maßen 1,33 × 2,42 m für eingehendere Untersuchungen angelegt werden (Taf. $134 \mathrm{Abb} .270)^{131}$. Die Münzfunde, fast ausschließlich Prägungen des Heraklius, geben für die Schicht des Versturzes SE N12 einen terminus post quem im frühen 7. Jh. $\mathrm{n}$. Chr. $\mathrm{an}^{132}$.

Das Bodenniveau der nördlichsten Kammer KN1 bildet ein Steinboden (SE N20) ${ }^{133}$. Der Raum konnte ursprünglich über ein Tor mit Oberlichte vom Korridor EN1 aus betreten werden (Taf. 134 Abb. 271; 470 Abb. 841).

In einer zweiten Phase wurde den ursprünglichen Wänden der Kammern KN1 bis KN3 ${ }^{134}$ ein neues, unregelmäßiges, pseudoisodomes Mauerwerk vorgelagert, auf dem ein Ziegelgewölbe auflag (Taf. 135 Abb.

\footnotetext{
$12716,80 \mathrm{~m}$ (absolut).

${ }^{128}$ Bedingt durch das Gefälle des Beckenbodens nach Norden und die Funktion der Vormauerungen, die dazu dienten, das Wasser und die Verunreinigungen Richtung Auslasskanal zu leiten.

${ }^{129}$ In der Dokumentation von St. Karwiese als Sondage KB 1/97 bezeichnet (KB steht für Kuzeybatı = Nordwest).

${ }^{130}$ Es konnte keine nähere Differenzierung des verstürzten Materials vorgenommen werden; der obere Bereich gehört vermutlich zu SE N1 = SE N18.

${ }^{131}$ Maße der Kammer KN1 (aufgrund der fehlenden West-Wand sind nur ungefähre Angaben möglich): ca. 10,90 × 2,21/2,30 m. Es konnte keine Trennung zwischen dem Versturz des Kammergewölbes und dem darüberliegenden Versturz gemacht werden.

${ }^{132}$ Münzfunde aus diesem Paket: M 246 (Taf. 360; 613/614 n. Chr.), M 242 (Taf. 359; 615/16 n. Chr.), M 243 (Taf. 360; 615/16 n. Chr.), M 245 (Taf. 360; 612/13 n. Chr.).

${ }^{133}$ Zwei langrechteckige Kalksteinplatten/-quader sind erkennbar; nach Westen schließt eine Ziegelplatte an (Ausbesserung).

${ }^{134}$ Erkennbar an der noch erhaltenen nördlichen Mauer der Kammer KN3.
} 
272. 273; 136 Abb. 274). Diese Baumaßnahme steht vielleicht mit den umfassenden Konsolidierungsmaßnahmen am Nord-Flügel des Theaters am Ende des 4. Jhs. n. Chr. in Verbindung. Das Mauerwerk besteht bis auf eine Höhe von etwa 21,80 m aus größeren Steinquadern in Mörtelbindung. Zwischen den Quadern wurde bei Bedarf eine Ausgleichsschicht aus kleinen Bruchsteinen eingefügt. Im oberen Bereich kamen zunehmend auch Bruchsteine und Spolien zum Einsatz. Vom ehemaligen Gewölbe ist nur mehr die Hinterfüllung aus opus caementitium mit Bruchsteinen zu erkennen.

Die Tore der Kammern wurden im Zuge des Umbaus des Korridors in ein Wasserbecken bis zur Oberlichte vermauert ${ }^{135}$. Ob die Kammern im Zuge der Abmauerung der Tore oder zu einem späteren Zeitpunkt, als die Kammergewölbe nicht mehr intakt waren, mit Erdmaterial verfüllt wurden, kann nicht mit Sicherheit geklärt werden. Die Verfüllung der Kammer KN1 besteht aus heterogenem Material (3. Jh.-Mitte 5. Jh. n. Chr.) (Taf. 136 Abb. 275).

Über dem Plattenboden der Kammer KN1 befand sich eine Schicht aus Lehm (SE N16), die nicht abgetragen wurde. Darüber fand sich ein Stratum mit zahlreichen Keramikfragmenten (SE N15), die ans Ende des 4. bis in die Mitte des 5. Jhs. n. Chr. datieren, sowie fünf Münzfunden aus dem mittleren 2. bis in die 2. Hälfte des 4. Jhs. n. Chr. ${ }^{136}$.

Darauf folgte eine Schicht mit Mörtelfragmenten, Schotter und Keramik (SE N14), die nach Osten hin abfällt ${ }^{137}$. Zu den Wänden hin fand sich harter Mörtel. Die vom 3. bis ins 4. Jh. n. Chr. datierende Keramik gibt an, dass es sich um umgelagertes älteres Material handelt, wie es in der Spätzeit auch im Süden des Theaters vorkommt.

Nach Osten, zum verschlossenen Tor hin, konnte ein Bereich mit lehmiger Erde ausgemacht werden (SE N13), der ebenfalls nach Osten abfällt.

Wie große Teile des Nordflügels (EN1), stürzten in Folge schwerer Erdbeben auch die Gewölbe der Kammern KN1 bis KN3 ein (SE N12. N18).

Geht man davon aus, dass die Kammer KN1 im Zuge des Umbaus des Korridors in ein Wasserbecken verfüllt wurde, ergibt dies für das Wasserreservoir eine Datierung um die Mitte des 5. Jhs. n. Chr.

\subsubsection{KAMMERN KN2 UND KN3 ${ }^{138}$}

\begin{tabular}{|l|l|}
\hline Schicht & Konsistenz/Interpretation \\
\hline SE N18 & Versturz mit Architekturblöcken und Erde \\
\hline
\end{tabular}

Tab. 38

1997 wurde in KN2, wie in Kammer KN1, die oberste Schicht SE N18 bis auf ein Niveau von ca. 19,78 m abgenommen ${ }^{139}$.

Im Bereich von KN3 wurde die oberste aus Erde und Architekturteilen bestehende Schicht des Versturzes abgetragen (SE N1). Darin fand sich die Münze M 15/1998 (262 n. Chr.).

Der Befund von KN2 entspricht, soweit untersucht, dem von Kammer KN1, weshalb an dieser Stelle auf weitere Ausführungen verzichtet wird ${ }^{140}$.

Der Einbau der vorgeblendeten Mauern und die teilweise Verfüllung der Kammer KN2 ist als zeitgleich mit den Umbaumaßnahmen der Kammer KN1 bzw. KN3 zu sehen (Taf. 137 Abb. 276. 277).

\footnotetext{
${ }^{135}$ St. Karwiese nimmt an, dass die Kammern KN1 und KN2 als Folge eines Erdbebens im späteren 4. Jh. n. Chr. bis zur Hälfte verfüllt und durch kleinere Räume ersetzt wurden, s. KARWIESE 1998a, 25.

${ }^{136}$ Kap. 5: M 49 (141/161 n. Chr.); M 53 (161/180 n. Chr.); M 59 (Taf. 356; 218/222 n. Chr.); M 141 (347/348 n. Chr.); M 160 (364/367 n. Chr.); s. auch Kap. 6.2.2 (Fund B 47 Taf. 379).

${ }^{137}$ Darin fand sich die Münze M 94 (197/217 n. Chr.).

${ }^{138}$ In der Dokumentation von St. Karwiese als Sondage KB 2/97 bezeichnet.

${ }^{139}$ Maße der Kammer KN2 (aufgrund der fehlenden West-Wand nur ungefähre Längenmaße möglich): ca. 8,50 × 2,45/2,51 m. Es konnte keine nähere Differenzierung des verstürzten Materials vorgenommen werden, der obere Bereich gehört vermutlich zu dem massivem Versturz SE N1 = SE N12.

${ }^{140} \mathrm{Zu}$ dem Fund eines männlichen Groteskenkopfes aus Terrakotta (TK 8 Taf. 361 aus KN2), s. Kap. 6.1.
} 


\subsubsection{EN1 West, NöRdLicher Treppenaufgang}

\subsection{Sondage $S 1 / 98$}

\begin{tabular}{|l|l|l|}
\hline Schicht & Konsistenz/Interpretation & Datierung \\
\hline SE N19 & rezente Betonschicht & - \\
\hline SE N20 & erdiges Material auf der Rollierung & frühe Kaiserzeit \\
\hline SE N21 & $\begin{array}{l}\text { vermörteltes Bruchsteinmauerwerk (opus caementitium) } \\
\text { (Fundamentierung des Treppenabsatzes - 2. Phase) }\end{array}$ & - \\
\hline SE N22 & erdiges Material (Störung) & - \\
\hline SE N23 & Stufenunterbau & - \\
\hline SE N24 & $\begin{array}{l}\text { vermörteltes Bruchsteinmauerwerk (opus caementitium) } \\
\text { (Fundamentierung des Treppenabsatzes - 1. Phase) }\end{array}$ & - \\
\hline SE N25 & drei Marmorplatten im Süden der Sondage (1. Phase) & - \\
\hline
\end{tabular}

Tab. 39

Die Sondage 1/98 wurde im nördlichen Treppenaufgang (EN1 West) am oberen Podest, welches sich zum unterem Diazoma hin öffnet, in den Maßen 3,00 × 1,60 m angelegt (Taf. 137 Abb. 278).

Die Ergebnisse der Grabung sprechen laut Ausgräber für zwei Bauphasen des oberen Treppenabsatzes ${ }^{141}$. $\mathrm{Zu}$ einer ersten Phase gehören drei Marmorplatten, die das ungefähre ursprüngliche Bodenniveau anzeigen (SE N25) ${ }^{142}$. An die drei im südlichen Abschnitt der Sondage sichtbaren Marmorplatten schließt Richtung Norden eine Lage vermörteltes Bruchsteinmauerwerk an (SE N24) ${ }^{143}$, welches das ursprüngliche Fundament des Treppenabsatzes bildete (Taf. 138 Abb. 279; 139 Abb. 281).

An der östlichen Schnittgrenze wurde ein Art Mauerzug (Nord-Süd-Ausrichtung) aus vermörtelten Bruchsteinen freigelegt, welcher der Fluchtlinie der östlichen Mauer des Treppenaufgangs folgt. Dieser gehörte vermutlich zur ersten Phase des Aufgangs. Er läuft nach 2,14 m aus und bildet keinen geraden Abschluss.

In einer Umbauphase wurde das ursprüngliche Niveau des oberen Treppenabsatzes zum untersten Diazoma um ca. $23 \mathrm{~cm}$ angehoben ${ }^{144}$. Über das Gussmauerwerk und den Mauerzug der ersten Phase wurde eine weitere opus caementitium-Füllung (SE N21) ${ }^{145}$ eingebracht. Im Bereich zwischen dem Stufenunterbau und dem Gussmauerwerk fand sich eine 0,50 × 7,50 m große Störung. Diese war mit erdigem Material verfüllt $(\mathrm{SE} \mathrm{N} 22)^{146}$. Der Treppenunterbau besteht aus Bruchsteinen (SE N23) (max. Größe 35-45 cm) ${ }^{147}$ (Taf. 138 Abb. 280). Über der Einfüllung lag eine dünne Schicht aus Erde (SE N20) ${ }^{148}$. Die stratigrafisch jüngste Schicht bildet der Betonboden (SE N19) ${ }^{149}$.

\footnotetext{
${ }^{141}$ Karwiese 1998b; Karwiese 1998 c.

142 OK (absolut) 19,41-19,68 m, UK nicht ergraben.

143 OK (absolut) 19,57-19,41 m, UK nicht ergraben.

144 Diese Angaben beziehen sich auf die opus caementitium-Oberkanten. Darüber waren die Platten des Bodens versetzt, weshalb das ursprüngliche Gehniveau dementsprechend höher lag.

${ }^{145}$ OK (absolut) 19,77 m, UK (absolut) 19,57 m.

${ }^{146} \mathrm{OK}$ (absolut) ca. 19,80 m.

${ }^{147}$ OK (absolut) ca. 19,80 m.

${ }^{148}$ OK (absolut) 19,80 m, UK (absolut) 19,77 m.

${ }^{149}$ OK (absolut) 19,86 m, UK (absolut) 19,80 m.
} 
3.5.1.4.2. Sondage $S 2 / 98$

\begin{tabular}{|l|l|l|l|}
\hline Schicht & Konsistenz/Interpretation & Datierung & Münzen \\
\hline SE N26 & rezente Betonschicht & - & - \\
\hline SE N27 & vier Rinnsteine & - & - \\
\hline SE N28 & $\begin{array}{l}\text { Erdschicht mit Bruchsteinen (Fundament für die } \\
\text { Rinnsteine) }\end{array}$ & 5. Jh.-Mitte 6. Jh. n. Chr. & - \\
\hline SE N29 & $\begin{array}{l}\text { kompakte Erde, die teils in die Oberfläche des ver- } \\
\text { mörtelten Bruchsteinmauerwerks (opus caementitium) } \\
\text { eingedrückt war }\end{array}$ & 4. Jh. n. Chr. & M 183 ca. $318 / 378$ n. Chr. \\
\hline SE N30 & $\begin{array}{l}\text { vermörteltes Bruchsteinmauerwerk (opus caementitium) } \\
\text { (Fundamentierung des Treppenabsatzes - 2. Phase) }\end{array}$ & (1. H.) 1. Jh. n. Chr. & - \\
\hline SE N31 & dünne Erdschicht, Bauhorizont & kaiserzeitlich & - \\
\hline SE N32 & $\begin{array}{l}\text { vermörteltes Bruchsteinmauerwerk (opus caementitium) } \\
\text { (Fundamentierung des Treppenabsatzes - 1. Phase) }\end{array}$ & (1. H.) 1. Jh. n. Chr. & - \\
\hline SE N33 & $\begin{array}{l}\text { erdiges Material im Westen der Sondage über dem Fels } \\
\text { (Tiefschnitt) }\end{array}$ & (1. H.) 1. Jh. n. Chr. & - \\
\hline
\end{tabular}

Tab. 40

Die Sondage 2/98 wurde mit den Maßen 3,60 × 2,20 m in der Nordostecke des Mittelpodestes des westseitigen L-förmigen Zugangs zum untersten Diazoma angelegt (EN1 West) (Taf. 139 Abb. 282). In einem Tiefschnitt im westlichen Teil der Sondage (ca. 1,7 × $1 \mathrm{~m}$ ) konnte bis zum anstehenden Fels abgetieft werden (Taf. 140 Abb. 283) $)^{150}$.

Das Fundament der nördlichen, Ost-West ausgerichteten Mauer des Treppenaufgangs reicht bis an den anstehenden Felsen. Es besteht aus großen, grob behauenen, quaderförmigen Steinblöcken, die in unregelmäßigen horizontalen Lagen versetzten wurden.

Über dem Fels befand sich eine braune Erdschicht SE N33 mit einigen Bruchsteinen, die nach Ausweis des Fundmaterials ins 1. Jh. n. Chr. datiert ${ }^{151}$. Auf diesen Baugrund wurde das Gussmauerwerk (opus caementitium) der ersten Phase als Fundamentierung für den Treppenabsatz eingebracht (SE N32) (1. Hälfte des 1. Jhs. n. Chr.) (Taf. 140 Abb. 284).

Die Abgrenzung zur jüngeren Bodenfundamentierung ist durch eine dünne Erdschicht (SE N31) gegeben. Über diesem Bauhorizont wurde eine weitere opus caementitium-Schicht eingefüllt (SE N30) und das ursprüngliche Niveau um ca. $20 \mathrm{~cm}$ erhöht (Taf. 141 Abb. 285) ${ }^{152}$. Das Keramikmaterial datiert in die 1. Hälfte des 1. Jhs. n. Chr. Unklar ist, ob es sich hierbei um eine Baumaßnahme oder eine Umbauphase des Bodens des Treppenabsatzes handelt.

Nachdem die Platten des Bodens des Treppenabsatzes in jüngerer Zeit herausgerissen worden waren, bildete sich auf der jüngeren Fundamentierung eine Schicht aus fester Erde (SE N29), die teils in die Fundamentierung eingedrückt war ${ }^{153}$. Diese datiert ins 4 . Jh. n. Chr.

Im Laufe des 5. bis in die Mitte des 6. Jhs. n. Chr. wurden Rinnsteine (SE N27) entlang der Ost- bzw. Süd-Mauer des Treppenaufgangs auf einem Fundament aus Erde und Bruchsteinen verlegt (SE N28) (Taf. 141 Abb. 286). Ihre konkrete Funktion bleibt bislang unklar. Drei Rinnsteine konnten bei den Grabungen sichergestellt werden, die restlichen wurden zu einem früheren Zeitpunkt entfernt. Einer dieser Steine befand sich zu Grabungsbeginn disloziert auf dem Betonboden. Die stratigrafisch jüngste Schicht bildet der Betonboden (SE N26), der im Zuge von modernen Restaurierungsmaßnahmen eingebracht wurde.

\footnotetext{
${ }^{150}$ Aufgrund des darüberliegenden massiven opus caementitium wurde lediglich in einem kleinen Bereich bis auf den anstehenden Felsen abgetieft.

${ }^{151}$ Zur Auswertung der Keramikfunde s. Kap. 4.

${ }^{152}$ Diese Angaben beziehen sich auf die opus caementitium-Oberkanten. Darüber waren die Platten des Bodens versetzt, weshalb das ursprüngliche Gehniveau dementsprechend höher lag.

${ }^{153}$ Aus dieser Schicht konnte im Nordosten der Sondage die Münze M 183 geborgen werden. Sie ist stark abgegriffen und datiert ca. 318/378 n. Chr.
} 


\subsubsection{Zugangssystem EN2}

\subsubsection{VOMITORIUM EN2}

\subsection{Sondagen $S 4 / 98$ und Norderweiterung}

\begin{tabular}{|l|l|l|}
\hline Schicht & Konsistenz/Interpretation & Datierung \\
\hline SE N34 & oberstes braunes, lockeres Erdmaterial (Oberfläche/Ausgangsniveau) & - \\
\hline SE N35 & Erdmaterial mit Ziegelfragmenten, Keramik direkt über dem Gussmauerwerk & 6. Jh. n. Chr. \\
\hline SE N36 & vermörteltes Bruchsteinmauerwerk (opus caementitium) (Fundamentierung) & - \\
\hline Sondage S 4/98, Norderweiterung & 6. Jh. n. Chr. & 6. Jh. n. Chr. \\
\hline SE N37 & grober, lockerer Ziegelschutt (Verfüllungsschutt) & 6. Jh. n. Chr. \\
\hline SE N38 & $\begin{array}{l}\text { sehr lockerer, sandiger Schutt mit kleinen Steinen und Ziegelfragmenten } \\
\text { (Verfüllungsschutt) }\end{array}$ & spätes 6./1. H. 7. Jh. n. Chr. \\
\hline SE N30 & graubraunes, lockeres Erdmaterial mit kleinen Steinen und Ziegelfragmenten & \\
\hline
\end{tabular}

Tab. 41

Die Grabungsfläche befindet sich südlich vor dem vomitorium EN2, welches zum mittleren Diazoma führt (Taf. 142 Abb. 287). Nachdem die vor dem vomitorium lagernden Architekturteile entfernt worden waren, konnte im östlichen bzw. außerhalb liegenden Bereich von EN2 die Sondage mit den max. Maßen $5,20 \times 2,30-1,50 \mathrm{~m}$ mit einer anschließenden Norderweiterung des Schnitts in den max. Maßen 4,00× $1,20 \mathrm{~m}$ angelegt werden ${ }^{154}$.

In Sondage 4/98 wurde bis zum Bodenunterbau aus Bruchsteinen und Mörtel abgetieft (SE N36). Vom einstigen Plattenboden ist nichts mehr erhalten geblieben. Den Unterbau bedeckte eine harte, braune Erdschicht mit Keramik- und Ziegelfragmenten (SE N35), die ins 6. Jh. n. Chr. datiert (Taf. 142 Abb. $288 ; 143$ Abb. 289) ${ }^{155}$. Die stratigrafisch jüngste Schicht bildete modern umgelagertes, braunes, lockeres Erdmaterial (SE N34).

In der Norderweiterung, 3,5 m vom Eingang des vomitorium entfernt, wurden insgesamt sieben Stufen einer Treppe freigelegt (Taf. 143 Abb. 290). Sie überwand im vomitorium (EN2) den Niveauunterschied zwischen der Gasse im Norden und dem mittleren Diazoma.

Der Nord-Zugang zum vomitorium EN2 wurde im 4. Jh. n. Chr. aufgrund statischer Sicherungsmaßnahmen mit einer Mauer verschlossen und im Laufe der folgenden Jahrhunderte mit Schutt verfüllt. Lediglich die jüngsten Verfüllungen im Bereich der Norderweiterung wurden abgetragen (Taf. 144 Abb. 291. 292). Anhand des Fundmaterials wird deutlich, dass diese erst in der 1. Hälfte des 7. Jhs. n. Chr. eingebracht wurden. Insgesamt ließen sich folgende Verfüllungen unterscheiden (Taf. 145 Abb. 293): Über der siebten Stufe fand sich eine Schicht aus dunkelbrauner, sehr feiner, lockerer Erde mit kleinen Steinen (SE N40). Darüber kam eine weitere eingefüllte Schicht aus graubraunem, lockerem Schutt mit vereinzelten kleinen Steinen und Ziegelfragmenten zum Vorschein, die vermutlich von Süden her angeschüttet worden war und an der obersten Stufe anstieß (SE N39). Im Nordosteck der Sondage wurde eine weitere Schicht aus sehr lockerem, sandigem Schutt mit kleinen Steinen, Ziegel- und zahlreichen Keramikfragmenten erkannt (SE N38). Über SE N39 und SE N40 fand sich eine Schicht aus grobem, lockerem Ziegelschutt mit Steinen und Marmorsplittern (SE N37).

\footnotetext{
${ }^{154}$ Da es aufgrund der Aufzeichnungen nicht möglich war, eine zusammenhängende Stratigrafie der Sondage und deren NordErweiterung zu rekonstruieren, werden die beiden Teilbereiche jeweils für sich behandelt.

${ }^{155}$ Zum Fund eines Bleigewichts (MF 73 Taf. 377) s. Kap. 6.2.1.
} 
3.5.2.1.2 Sondage $S 5 / 98$

\begin{tabular}{|l|l|l|}
\hline Schicht & Konsistenz/Interpretation & Datierung \\
\hline SE N41 & oberflächige Schuttschicht - modern umgelagert (Abhub von Altgrabungen) & - \\
\hline SE N42 & Schuttmaterial & 6. Jh. n. Chr. \\
\hline
\end{tabular}

Tab. 42

Die Grabungsfläche liegt vor dem nördlichen Eingang EN2 und lässt sich durch den verschlossenen Eingang im Süden und den zu seinen beiden Seiten errichteten Stützmauern umgrenzen (Taf. 146 Abb. 294. 295). Bei den Grabungen durch St. Karwiese wurde das modern umgelagerte Schuttmaterial ${ }^{156}$ großzügig abgenommen (SE N41). Dabei wurde die sog. Messalinus-Inschrift, die R. Heberdey bei seinen Grabungen bereits zwischen 1897 und 1904 gefunden hatte, von St. Karwiese wiederentdeckt (Taf. 147 Abb. 296). Darunter kam das antike Niveau der Schuttschichten zum Vorschein (SE N42). Der Bereich wurde in einem schmalen Schnitt bis auf 23,17 m abgetieft. Das ursprüngliche Gehniveau sollte laut Höhenniveaus erreicht worden sein, jedoch zeichnete sich dieses nicht mehr ab oder wurde aufgrund der fehlenden Pflasterung nicht erkannt (Taf. 147 Abb. 297. 298).

Ursprünglich gelangten die Zuschauer durch das vomitorium über eine steile Treppe ${ }^{157}$ zum mittleren Diazoma (Textabb. 17. 18; Taf. 143 Abb. 290; 145 Abb. 293). St. Karwiese nimmt an, dass das Theater durch mehrere Erdbeben im 4. Jh. n. Chr. massiv beschädigt wurde, weshalb der Nordzugang des vomitorium aufgrund statischer Sicherungsmaßnahmen mit einer $5,0 \mathrm{~m}$ starken Mauer vollständig verschlossen wurde ${ }^{158}$. Die Mauer besteht aus uneinheitlich großen Bruchsteinen und vermutlich auch Spolien in Mörtelbindung mit vorgeblendeter Orthostatenverkleidung, die zumindest sekundär verwendet wurden. Der Verschluss über dem Profil besteht aus Gussmauerwerk hinter den Orthostaten.

Eine zusätzliche Konsolidierungsmaßnahme stellten die beiden das Tor flankierenden, orthogonal zur Nordfassade des Theaters angesetzten Strebemauern dar. Diese sind sorgfältig aus Bruchsteinen mit Ausgleichsschichten aus Ziegeln im Mörtelverband aufgebaut und auf Sicht gearbeitet (Taf. 148 Abb. 299. 300). Die Verstärkungsmauer entlang der Nordfassade des Theaters bindet in die westliche Strebemauer ein, weshalb diese Baumaßnahmen als gleichzeitig angesehen werden können. Anhand der bereits erwähnten Inschriftentafel, die von R. Herberdey an der Außenseite des vermauerten Tors des vomitorium EN2 »in situ über dem Kämpfergesimse in der Mitte des Bogens ${ }{ }^{159}$ gefunden wurde, und einer zweiten Inschrift in der östlichen Strebemauer ${ }^{160}$ können diese Konsolidierungsmaßnahmen ins späte 4. Jh. n. Chr. datiert werden ${ }^{161}$.

\subsubsection{Areal westlich des Nord-Analemma}

Im Zuge der Arbeiten von 1998 wurden mehrere Bereiche gereinigt, z. T. freigelegt und fotografisch dokumentiert. Dies betrifft die obere Terrasse (D) vor dem Nord-Analemma und das opus caementitium, das als Fundamentierung für die Bodenplatten diente (Taf. 149 Abb. 301. 303) ) $^{162}$. Hierzu gehören ebenso der nördliche Bereich der unteren Terrasse (Taf. 149 Abb. 302), der südwestliche Abschnitt des Treppenaufgangs vor dem Nord-Analemma und das Postament vor den Treppen (sog. Sockelmonument), östlich des antiken Prozessionswegs (Taf. 150 Abb. 304) ${ }^{163}$.

\footnotetext{
${ }^{156}$ Der obere Bereich des vermauerten Tors wurde bei Altgrabungen gewaltsam geöffnet, um einen Weg für den Abtransport des Schuttmaterials aus dem Theater zu gewinnen.

${ }^{157}$ Die südlichsten Treppenstufen konnten in Sondage 4/98 erfasst werden, vgl. Kap. 10.2.4.2.

${ }^{158}$ Karwiese ArChiv ÖAI, 4.

${ }^{159}$ Heberdey u. a. 1912, Nr. 43.

${ }^{160}$ Ebenfalls von HeBERDEY u. a. 1912, Nr. 44.

${ }^{161} \mathrm{Vgl}$. Kap. 10.3.2.

${ }^{162}$ Bei den Reinigungsarbeiten konnte die Münzen M 244 (Taf. 360; 613/614 n. Chr.) und M 80 (Taf. 357; 238/244 n. Chr.) geborgen werden; vgl. Kap. 5.2.5.

${ }^{163}$ Sog. Sockelmonument: max. 6,72 × 6,13 m. Das Monument wird vom Ausgräber als Naiskos des Dionysos angesprochen (vgl. Grabungstagebuch 1998). Zum Fund eines Gewandfragments SK 60 (Taf. 392 Abb. 655), s. Kap. 7.
} 


\subsubsection{BRUNNEN BR4}

\begin{tabular}{|l|l|l|}
\hline Schicht & Konsistenz/Interpretation & Datierung \\
\hline SE N43 & halbkreisförmige Aufmauerung aus Bruchsteinen in der Freitreppe (Brunnenbecken) & - \\
\hline SE N44 & Verfüllung des halbkreisförmigen Brunnenbeckens & 5.-6. Jh. n. Chr. \\
\hline SE N45 & Wasserleitungskanal & - \\
\hline SE N46 & Verfüllung des Wasserleitungskanals & 5. Jh. n. Chr. \\
\hline SE N47 & Erdmaterial oberhalb des Unterbaus der Freitreppe entlang des Wasserleitungskanals & 6. Jh. n. Chr. \\
\hline
\end{tabular}

Tab. 43

Bei der halbkreisförmigen Aussparung im Stufenunterbau südöstlich des Sockelmonuments handelt es sich um eine spätantike Brunnenanlage (BR4; Maße: max. 2,37 × 1,21 m) (Taf. 150 Abb. 305; 151 Abb. $306)^{164}$. Vom Brunnenbecken an sich hat sich nichts mehr erhalten. Von Norden führt ein steil abfallender Wasserleitungskanal (SE N45) zum Brunnenbecken (SE N43), welcher aus Ziegelplatten im Mörtelverband besteht (Taf. 151 Abb. 307; 152 Abb. 308).

Die Verfüllung der Wasserleitung (SE N46) wurde im Zuge der Reinigungsarbeiten entfernt und kann ins späte 5. Jh. n. Chr. datiert werden. Ebenso wurde ein Teil der Verfüllung des Brunnenbeckens entnommen (SE N44), welche ins 5. bis 6. Jh. n. Chr. datiert. Demzufolge wurde der Brunnen spätestens in dieser Zeit aufgegeben. Das Erdmaterial, das bei den Reinigungsarbeiten oberhalb des Unterbaus der Freitreppe entfernt wurde (SE N47), datiert ins 6. Jh. n. Chr.

B. ÖHLINGER

\subsection{SÜDFLÜGEL DES THEATERS}

\subsubsection{Aristion-Leitung}

\begin{tabular}{|l|l|l|l|}
\hline Schicht & Beschreibung/Interpretation & Keramik & Münzen \\
\hline SE D8 & $\begin{array}{l}\text { feines Schwemmmaterial; sehr dünne Schicht über } \\
\text { dem Wasserleitungsboden, keine Keramikfunde }\end{array}$ & - & $\begin{array}{l}\text { M 61 (Antoninus IV.) } \\
\text { (Elagabal) M 121 (Aurelian) }\end{array}$ \\
\hline $\begin{array}{l}\text { SE D9 }= \\
\text { SE D12 }\end{array}$ & feine, braune Erde mit Schutteinschlüssen & 5./6. Jh. n. Chr. & - \\
\hline SE D10 & feine, braune Erde & 5./6. Jh. n. Chr. & - \\
\hline $\begin{array}{l}\text { SE D11 } \\
\text { SE D15 }\end{array}$ & grober Schutt & 6. Jh. n. Chr. & M 48 (Antoninus Pius) \\
\hline SE D13 & feine, braune Erde & 4./5. Jh. n. Chr. & M 43 (Augustus) \\
\hline SE D14 & sandige Einschwemmung & kaiserzeitlich & - \\
\hline
\end{tabular}

Tab. 44

Diese Fernwasserleitung gehört in das aufwendige System der römischen Aquädukte, die das Stadtgebiet von Ephesos mit Frischwasser versorgte ${ }^{165}$. Das Quellgebiet liegt im unteren Kaystros-Tal nahe der heutigen Siedlung Büyükkale. Das Aquädukt führt von den Südhängen des Kaystros in das Marnastal. Nach der Querung der Ebene südlich von Ephesos zieht es in weitem Bogen um den Panayırdağ in das Stadtgebiet und endet schließlich am Nymphaeum Traiani ${ }^{166}$, wo die Bauinschrift den Stifter Ti. Claudius Aristion und seine Gattin Iulia Lydia Laterane nennt und seine Länge mit 210 Stadien angibt ${ }^{167}$. Die innerstädtische Tras-

${ }^{164}$ Die Brunnenanlage wurde 2007 erneut gereinigt und fotografisch dokumentiert.

${ }^{165}$ FORCHHEIMER 1923; WIPLINGER 2006c.

${ }^{166}$ Quatember 2011, 79 f. mit Lit.

${ }^{167}$ Diese selbstbewusste Längenangabe ist ein deutlicher Hinweis auf das Planungsprinzip der Freispiegelleitung, die aufwendige Kunstbauten wie Brücken und Tunnels zu vermeiden wusste und dafür eine bedeutend längere Streckenführung in Kauf nahm. Die angegebene Länge entspricht fast $40 \mathrm{~km}$, die heutige Stadt Ephesos ist von Büyükkale 24 Straßenkilometer entfernt. 
se des Aquädukts, die das Stadion und das Theater zu berücksichtigen hat, ist ein hervorragendes Beispiel für die geglückte Integration von notwendiger Infrastruktur und Leistungen der öffentlichen Monumentalarchitektur, für die es in der frühen Kaiserzeit viele gute Beispiele gibt.

Die Wasserleitung trifft von Norden auf das Theater, wird unterhalb von N2 in das Gebäude geführt und folgt - ganz konsequent als freies Gerinne ausgebaut - unterhalb der achten bis neunten Sitzstufenreihen der media cavea, dem Bogensegment des Koilon ${ }^{168}$. Im Bereich der Kerkides M10 und M13 wurden bei den Detailvermessungen im Jahr 2004 zwei Wartungsschächte festgestellt, über welche offensichtlich auch die Frischwasserversorgung des Theaters geregelt war $^{169}$. Bei S1, hinter der Ostmauer des zum unteren Diazoma führenden Treppenaufgangs, konnten die Bautechnik und der Verlauf des Gerinnes genau untersucht werden. Es nimmt an dieser Stelle in einem engen Bogen die radiale Richtung der Treppenstufe T21 auf und führt unter dem südlichen Analemma durch die äußere Mauerschale des Theaters und liegt unter der südlichen Freitreppe, wo eine spätere Veränderung den ursprünglichen Zustand verunklärt. Der weitere Verlauf in südöstlicher Richtung unterhalb der dortigen Wohnbauten ist archäologisch nicht untersucht.

Über die gesamte, unter dem Theater verlaufende Strecke, ist der Aquädukt begehbar. Die Leitung ist etwa $1 \mathrm{~m}$ breit und bis zu 1,90 m hoch (Taf. 152 Abb. 309. 310; 160 Abb. 327). Die aus Bruchstein errichteten Wände sind verputzt und mit einem Bruchsteingewölbe gedeckt. An Stellen, an denen der Wasserleitungskanal unter Mauern hindurchführt, ist die Decke aus Kalkstein- bzw. Marmorquadern gebildet (Taf. 158 Abb. 322-325). In Bodennähe sind an den Wänden starke Versinterungen erhalten. Wie an manchen Stellen zu sehen ist, wurden diese im Rahmen von Wartungsarbeiten gelegentlich auch entfernt (Taf. 156 Abb. 318) ${ }^{170}$. Generell ist nur eine dünne Schwemmschicht am Wasserleitungsboden vorhanden. Nur im Bereich der Wartungsöffnungen in den Kerkides M10 und M13 sowie an den zerstörten Bereichen im Norden und Süden - beim Ein- bzw. Austritt - sowie im Bereich des Knicks beim vomitorium ES1 sind größere Schuttmassen in den Kanal gestürzt. Gerade in letzterem Bereich ist das Mauerwerk über mehrere Meter stark zerstört (Taf. 153 Abb. 311). Bei Instandsetzungsarbeiten in den 1950er Jahren wurde diese Stelle missinterpretiert (Taf. 153 Abb. 312. 313) und die rezenten Stützmauern erst 2006 bis zur Originalsubstanz beseitigt (Taf. 154 Abb. 314. 315; 155 Abb. 316). Die hier vorgefundene Verfüllung der Wasserleitung (S 1/2006; Taf. 155 Abb. 317) stammt aus der Zeit nach den Restaurierungsarbeiten und gibt somit keinerlei Hinweise auf die Aufgabe der Leitung. Anders sieht es im Leitungsabschnitt an der Südseite des Theaters aus. Durch die Zerstörung der angrenzenden Stiegengasse ist die Wasserleitung auf den letzten 7,75 m von Nord nach Süd ansteigend, schließlich bis zum Gewölbe mit Schutt verfüllt (Taf. 156 Abb. 319; 157 Abb. 320. 321; 158 Abb. 322-325; 160 Abb. 328; 161 Abb. 329). Das Material ist größtenteils durch eine Öffnung der zerstörten Treppe unmittelbar an der südlichen Theateraußenmauer in den Kanal gelangt (Taf. 162 Abb. 331; 163 Abb. 333; 166 Abb. 339). Wie sich bei der Freilegung der Stiegengasse zeigte, hatte der Wasserleitungskanal über eine Länge von etwa $1 \mathrm{~m}$ ab der Theateraußenmauer keine Abdeckung (Taf. 162 Abb. 330; 163 Abb. 333; 164 Abb. 335; 167 Abb. 340. 341). Er war an dieser Stelle weder durch ein Gewölbe, wie im weiteren Verlauf nach Süden (Taf. 164 Abb. 335; 165 Abb. 336. 337; 166 Abb. 338), noch durch Steinplatten überdeckt. Dieses könnte auf einen funktionalen Zusammenhang (zur Wasserentnahme) hindeuten. Aufgrund der geringen Höhendifferenz zwischen Kanaloberkante und Stufenbelag bildeten die Treppensteine selbst diesen Abschluss. Die Wasserleitung schwenkt gleich nach dem Austritt aus dem Theater nach Südosten (Taf. 162 Abb. 330. 331). Unmittelbar an der Theatersüdmauer wirkt das Mauerwerk der westlichen Kanalwange geflickt (Taf. 164 Abb. 334). Das dürfte mit dem Einbau von einigen Tonrohrleitungen zusammenhängen, die unter Stufe 10 der Treppe zum Vorschein kamen (Taf. 272 Abb. 556; 273 Abb. 557) ${ }^{171}$. Im Zuge der Entfernung der Stufensteine entstand daher diese Öffnung. Mittels einiger Treppensteine wurde die gesamte Wasserleitung an dieser Stelle über eine Länge von 1,30 m verschlossen. Die Blöcke sind bis zu drei Reihen hoch längs und quer geschichtet (Taf. 162 Abb. 330. 331; 163 Abb. 332; 166 Abb. 339; 167 Abb. 341). Dabei wurde zusätzlich Mörtel verwendet. Obzwar die Öffnung in der Südmauer des Theaters nicht voll-

\footnotetext{
${ }^{168}$ Weitere Arbeiten an der Leitung fanden bereits durch F. Hueber statt (Kap. 2.4).

${ }^{169}$ STYHLER-AYDIN (in Vorbereitung).

${ }^{170}$ Wartungsarbeiten an der Aristion-Leitung ließen sich auch im Abschnitt um das Mausoleum von Belevi feststellen; vgl. dazu RugGendoRfer (im Druck), Kap. »Die Sondagen 12 und 13 an der Südseite« u. »Die Sondagen 7, 8, 11 und 14-16 an der Westseite/Die Spätzeit«).

${ }^{171}$ Kap. 3.7.1.5.
} 
ständig bis oben hin verschlossen vorgefunden wurde, ist in dieser späten baulichen Maßnahme eine massive Barriere zu sehen, die einen Zugang über den Kanal ins Theater unmöglich machen sollte. Damit ist ein Zusammenhang mit der byzantinischen Stadtbefestigung gegeben, in die das Theater eingebunden war. Auf alle Fälle aber bedeutet diese Abriegelung die völlige Aufgabe der Wasserleitung nach Süden, also in Richtung des Nymphaeum Traiani und der Kuretenstraße. Einige Stufensteine lagen auch nördlich der Barriere im Leitungskanal (Taf. 156 Abb. 319; 157 Abb. 320. 321; 158 Abb. 323-325). Sie waren teils vom eingedrungenen Schutt bedeckt, teils aber auch freiliegend etliche Meter vom Schuttverschluss entfernt vorgefunden worden. Wie in vielen anderen Abschnitten ist der Leitungsboden nördlich des Verschlusses nur von einer sehr dünnen und feinen Schwemmschicht SE D8 bedeckt. Daraus konnten zwar nur marginale Reste von stark zerkleinerten Keramikgefäßen geborgen werden, aber immerhin auch zwei Münzen (M 61 Taf. 357, Elagabal; M 121, Aurelian). Die Einschwemmung SE D8 lässt sich weiter nach Süden unter der Schuttverfüllung kaum fassen. Hier liegt die sehr grobe Schuttschicht SE D11 bis zu 0,84 m hoch über dem Leitungsboden (Taf. 161 Abb. 329). Sie ist eindeutig durch den verbleibenden Raum zwischen der Kanalöffnung in der Außenmauer des Theaters und der Barriere eingedrungen. SE D11 enthielt eine große Menge an Tierknochen und unterscheidet sich damit deutlich von den Schuttmassen über der ausgerissenen Treppe. Die über SE D11 liegenden Schichten SE D9, D10, D12, D13, D14 und D15 sind deutlich feiner. Es handelt sich meist um rötlich braune Erdlagen, die aber gleichfalls einen hohen Anteil an Tierknochen enthielten. Mehrfach wurden zu ein und demselben Individuum gehörende Knochen sowohl in den unteren als auch in den oberen Schichten gefunden. Dafür scheinen größere Wassermassen verantwortlich zu sein, die bei heftigen Regenfällen in den bereits aufgegebenen Leitungskanal gedrungen sind, einerseits selbst Material mitgebracht, andererseits aber auch kleinere Knochenteile aus dem Schuttmaterial vor der Barriere nach oben geschwemmt haben. Auffallend ist die Vielfalt an Tierarten, zu denen nicht nur verschiedene Haustiere gehören, deren Reste mit dem Schutt entsorgt worden waren, sondern auch eine ganze Reihe von Wildtieren, darunter Fuchs, Stachelschwein, Goldschakal und der Zahn einer Hyäne ${ }^{172}$. Das lässt darauf schließen, dass das Areal zwischen Theater, Marmor- und Kuretenstraße in frühbyzantinischer Zeit tatsächlich kaum mehr besiedelt war und sich Wildtiere vereinzelt bis and die Stadt heranwagten.

Anpassende Keramikfragmente sind, wie auch die Tierknochen, auf verschiedene Schwemmebenen verteilt aufgefunden worden ${ }^{173}$. Das Keramikspektrum umfasst Material bis in das 6. Jh. n. Chr. und belegt in Verbindung mit den Befunden am Wasserbecken nördlich des Nymphaeum Traiani eine Aufgabe der Wasserleitung im Abschnitt zwischen Theater und Kurentenstraße in diesem Zeitraum ${ }^{174}$.

Wenn der Verschluss der Wasserleitung an der südlichen Außenmauer des Theaters, der ja mit der Entfernung der Stufensteine und damit mit der Aufgabe der Stiegengasse einhergegangen ist, tatsächlich fortifikatorisch verstanden werden soll, muss die Integration des Theaters in die byzantinische Stadtmauer zur selben Zeit wie der Einbau der Barriere im Kanal erfolgt sein. Darauf weist auch die Vermauerung der Theatereingänge ES1 und ES2, die ebenfalls mit den Stufenblöcken beider Treppenabschnitte gemacht ist. Weiters dienten die Stufensteine auch der Wiederherstellung der alten, hellenistischen Terrassierung östlich des Eingangs ES3 ${ }^{175}$. Diese wiederum stellt den Anschluss der byzantinischen Stadtmauer an das Theater im Südosten dar. Somit ist die Aristion-Wasserleitung neben dem baulichen Aspekt und der Wasserversorgung des Theaters im 2. Jh. n. Chr. auch für die Dokumentation der Spätnutzung des Bauwerks von besonderem Interesse.

\subsubsection{Süd-Analemma}

Die Beseitigung der gewaltigen Versturzmasse im südlichen Abschnitt von vomitorium ES1 sollte einer der großen Programmpunkte des Jahres 2007 sein. Beinahe $10 \mathrm{~m}$ hoch war die Verfüllung des $5 \mathrm{~m}$ breiten Korridors (Taf. 168 Abb. 342-344). Große Steinquader und tonnenschwere massive caementitium-Brocken,

\footnotetext{
${ }^{172}$ Kap. 9.

${ }^{173}$ Kap. 4.6.1 u. 9.1.

174 Quatember u. a. 2008, 269; Quatember 2011, 82.

${ }^{175}$ Kap. 3.7.2.
} 
in deren Zwischenräume sich grauer, lockerer Mörtelschutt abgelagert hat, bestimmte das eindrucksvolle Bild der Zerstörung (Taf. 169 Abb. 345. 346; 170 Abb. 347. 348; 171 Abb. 349. 350; 172 Abb. 351). Als bereits nach wenigen Arbeitstagen die oberste Kuppe abgetragen war, zeigte sich der desolate Zustand der östlichen Korridormauer im Bereich unterhalb der Zwischenwand der beiden Substruktionskammern SK 10 und SK 12 (Taf. 171 Abb. 350). Damit musste von dem Vorhaben abgelassen werden. Eine umfassende statische Klärung der Situation war unumgänglich. Damit konzentrierten sich die Arbeiten am Süd-Analemma auf den Streifen zwischen der Korridorwestmauer und der Außenfassade, während der Schuttberg im Korridor belassen wurde. Die Schuttmasse, die sich vom Korridor nach Westen erstreckte, unterschied sich nicht von der des vomitorium: große Blöcke in lockerem Mörtelschutt. Im Westen, unmittelbar an der Fassade, war bereits für die Errichtung eines Schutzzauns ein schmaler Streifen des Zerstörungsschutts beseitigt worden (Taf. $170 \mathrm{Abb} .348 ; 171 \mathrm{Abb}$. 349). Vor allem innerhalb (östlich) des Zauns hatte sich über die Jahrzehnte hinweg der durch die Erosion herabgeschwemmte und stark mit Müll durchmischte Humus über die bereits freigelegten Abschnitte der Analemma-Mauer abgelagert. Dieses Material sowie die humose Oberfläche des noch in situ befindlichen Zerstörungsschutts wurden beseitigt. Bereits nach der Reinigung ließen sich mehrere Wandfluchten erahnen (Taf. 172 Abb. 351). Die herumliegenden Quader wurden mit Nummern versehen, lagerichtig dokumentiert und entfernt. Sehr bald zeigte sich der Grundriss von drei Kammern mit Zugängen von Osten, also aus dem großen Korridor ES1. Der Erhaltungszustand der drei Räume ist annähernd gleich. Die Ostmauer ist jeweils am besten erhalten (Taf. 172 Abb. 352). Die mehr als $2 \mathrm{~m}$ starken Nord- und Südmauern reißen nach Westen hin zunehmend aus. Keine der drei Kammern besitzt heute auch nur ansatzweise ein Stück der westlichen Außenmauer. Sie sind durchgehend bis auf das Bodenniveau zerstört. Eine kleine Kante im Boden der südlichsten Kammer KS3 könnte einen Hinweis auf die Westmauer, und damit auf die Tiefe der Räume geben. Ob die Kammern durch irgendwelche Fensteröffnungen Licht erhalten haben, kann aufgrund des Erhaltungszustands nicht mehr gesagt werden. Architekturteile, die darauf hinweisen könnten, wurden nicht gefunden. Das ist nicht weiter verwunderlich. Das Gros des Baumaterials der Kammern ist nach Westen gestürzt und lag demnach über der Marmorstraße, wo es bereits um die vorige Jahrhundertwende entfernt worden war. Gewölbesteine in Kammer KS1 könnten aber zum Gewölbe der Kammer gehört haben (Taf. 173 Abb. 355).

\subsubsection{KAMMER KS1}

Die Kammer KS1 schließt direkt an das heute pfeilerartige Mauerstück südlich des Tors im Süd-Analemma an (Taf. 2 Abb. 2). Wie auch bei den beiden anderen Kammern ist der Fußboden aus Stein. Es handelt sich dabei wohl um die Oberfläche der das Analemma bildenden Quader, nicht um einen zusätzlichen Plattenboden (Taf. 176 Abb. 360). Die Oberfläche ist nur grob hergerichtet, zeigt aber deutliche geglättete Abriebspuren. KS1 ist die am schlechtesten erhaltene Kammer (Plan 11), doch enthält sie als einzige deutliche Hinweise einer Nutzung. KS1 wurde im südlichen und im nördlichen Drittel freigelegt. An wenigen Stellen waren über dem Steinboden noch Reste einer harten Kalkmörtelschicht vorhanden, die vermutlich einem Fußbodenniveau zuzurechnen sind (Taf. 176 Abb. 360; 177 Abb. 363). Über einer sehr inhomogenen, dünnen, kaiserzeitlichen Schuttschicht, bestehend aus SE 60, SE 65-68 und SE 81, konnte ein fast flächig erhaltener Estrich festgestellt werden, zu dem in der Südostecke ein aus Ziegeln errichtetes Podest gehört (Taf. 175 Abb. 358; 176 Abb. 361; 177 Abb. 362). Eine ebenfalls inhomogene, stark mit Asche durchsetzte Schicht aus dem 3. Jh. n. Chr. (SE 53. 61-63. 80) bedeutete das Ende der Phase mit dem Podest (Taf. 174 Abb. 357). Die Schicht enthielt zahlreiche gut erhaltene Gefäße (Taf. 174 Abb. 356; 175 Abb. 359), aber keine Münzen. Dagegen stammen 21 Münzen ${ }^{176}$ aus dem Stratum darüber (SE 46). Die Münzen gehören dem späten 4. und frühen 5. Jh. n. Chr. an, während die Keramik bis in das 6. Jh. n. Chr. weist. Der Zerstörungsschutt des Theaters, dazu gehören einige Gewölbesteine (Taf. 173 Abb. 355) und caementitiumBrocken (Taf. 173 Abb. 354), ist nur mehr in Resten erhalten und stark mit rezentem Müll vermischt.

\footnotetext{
${ }^{176}$ Münzen der Kammer KS1, SE 46: M 113 Taf. 358; M 122. M 138; M 140 Taf. 359; M 147. M 150. M 157. M 164. M 169. M 170. M 174; M 176 Taf. 359; M 177. M 178. M 180. M 181; M 190 Taf. 359; M 214. M 215. M 229. M 255. Vgl. Kap. 5.2.6 u. 5.4.
} 


\begin{tabular}{|c|c|c|c|c|c|}
\hline Schicht & OK in $\mathbf{m}$ & UK in $\mathbf{m}$ & Beschreibung & Datierung & Münzen \\
\hline \multicolumn{6}{|c|}{ Gesamte Fläche von KS1 } \\
\hline SE 26 & - & - & rezenter Humus & - & - \\
\hline SE 27 & - & - & $\begin{array}{l}\text { Zerstörungsschutt vom Theater: } \\
\text { Quaderversturz mit grauem Schutt }\end{array}$ & - & - \\
\hline SE 46 & - & $\begin{array}{l}20,61- \\
20,60\end{array}$ & graubraune, lockere Erde & 6. Jh. n. Chr. & $\begin{array}{l}\text { M 122. 138. 140. } \\
\text { 147. 150. 157. } 164 . \\
\text { 169. 170. 174-178. } \\
\text { 180.181. 190. } 214 . \\
\text { 215. 229. 255 } \\
\text { (Aurelianus- } \\
\text { Theodosius II. oder } \\
\text { Valentinianus III.) }\end{array}$ \\
\hline \multicolumn{6}{|c|}{ südliches Drittel von KS1 } \\
\hline $\begin{array}{l}\text { SE } 53= \\
\text { SE } 61= \\
\text { SE } 82\end{array}$ & 20,60 & 20,43 & $\begin{array}{l}\text { dunkelbraunes, sandiges Niveau mit } \\
\text { Ziegelsplitt }\end{array}$ & 4./5. Jh. n. Chr. & - \\
\hline SE 60 & 20,66 & 20,23 & $\begin{array}{l}\text { Ziegelpodest in der SO-Ecke der Kammer } \\
\text { KS1 }\end{array}$ & kaiserzeitl. & - \\
\hline SE 63 & 20,57 & $\begin{array}{l}20,43- \\
20,22\end{array}$ & dunkelgraue Asche & 2.-3. Jh. n. Chr. & - \\
\hline SE 80 & 20,43 & 20,22 & rötlicher Schutt mit Verputzresten & 1. Jh. n. Chr. & - \\
\hline $\begin{array}{l}\mathrm{SE} 83= \\
(\mathrm{SE} 64)\end{array}$ & 20,30 & 20,23 & rötlich brauner Estrich & - & - \\
\hline SE 84 & $\begin{array}{l}20,29- \\
20,23\end{array}$ & 20,23 & Unterlage für Estrich & - & - \\
\hline \multicolumn{6}{|c|}{ nördliches Drittel von KS1 } \\
\hline SE 62 & 20,61 & $\begin{array}{l}20,35- \\
20,34\end{array}$ & rötlicher, sehr sandiger Schutt & 3. Jh. n. Chr. & - \\
\hline $\begin{array}{l}\text { SE 64 = } \\
(\text { SE 83) }\end{array}$ & 20,69 & 20,33 & rötlich brauner Estrich & - & - \\
\hline SE 65 & 20,33 & 20,22 & $\begin{array}{l}\text { dunkelgraue, feste und kompakte Schicht mit } \\
\text { kleinen Steinen, Holzkohle, Ziegelsplitt und } \\
\text { Kalk, fundleer }\end{array}$ & - & - \\
\hline SE 66 & 20,32 & 20,31 & $\begin{array}{l}\text { hellbrauner Lehm. Sehr dünn, nur mehr } \\
\text { stellenweise erhalten, fundleer }\end{array}$ & - & - \\
\hline SE 67 & 20,37 & 20,20 & brauner, sandiger Schutt mit Steinen & - & - \\
\hline SE 68 & 20,28 & 20,27 & brauner, sandiger Schutt mit kleinen Steinen & $\begin{array}{l}\text { Mitte-Ende 1. Jh. n. } \\
\text { Chr. }\end{array}$ & - \\
\hline SE 69 & 20,32 & 20,23 & $\begin{array}{l}\text { weißer Mörtel über dem Steinplattenboden. } \\
\text { Nur in Resten erhalten, fundleer }\end{array}$ & - & - \\
\hline SE 81 & $\begin{array}{l}20,35- \\
20,34\end{array}$ & $\begin{array}{l}20,23- \\
20,20\end{array}$ & rötlich brauner Sand mit Steinen und Ziegel & frühkaiserzeitl. & - \\
\hline $\begin{array}{l}\mathrm{SE} 82= \\
(\mathrm{SE} 53= \\
\mathrm{SE} \mathrm{61)}\end{array}$ & 20,39 & 20,29 & $\begin{array}{l}\text { dunkelbraunes, sandiges Niveau mit } \\
\text { Ziegelsplitt }\end{array}$ & 4./5. Jh. n. Chr. & - \\
\hline
\end{tabular}

Tab. 45 


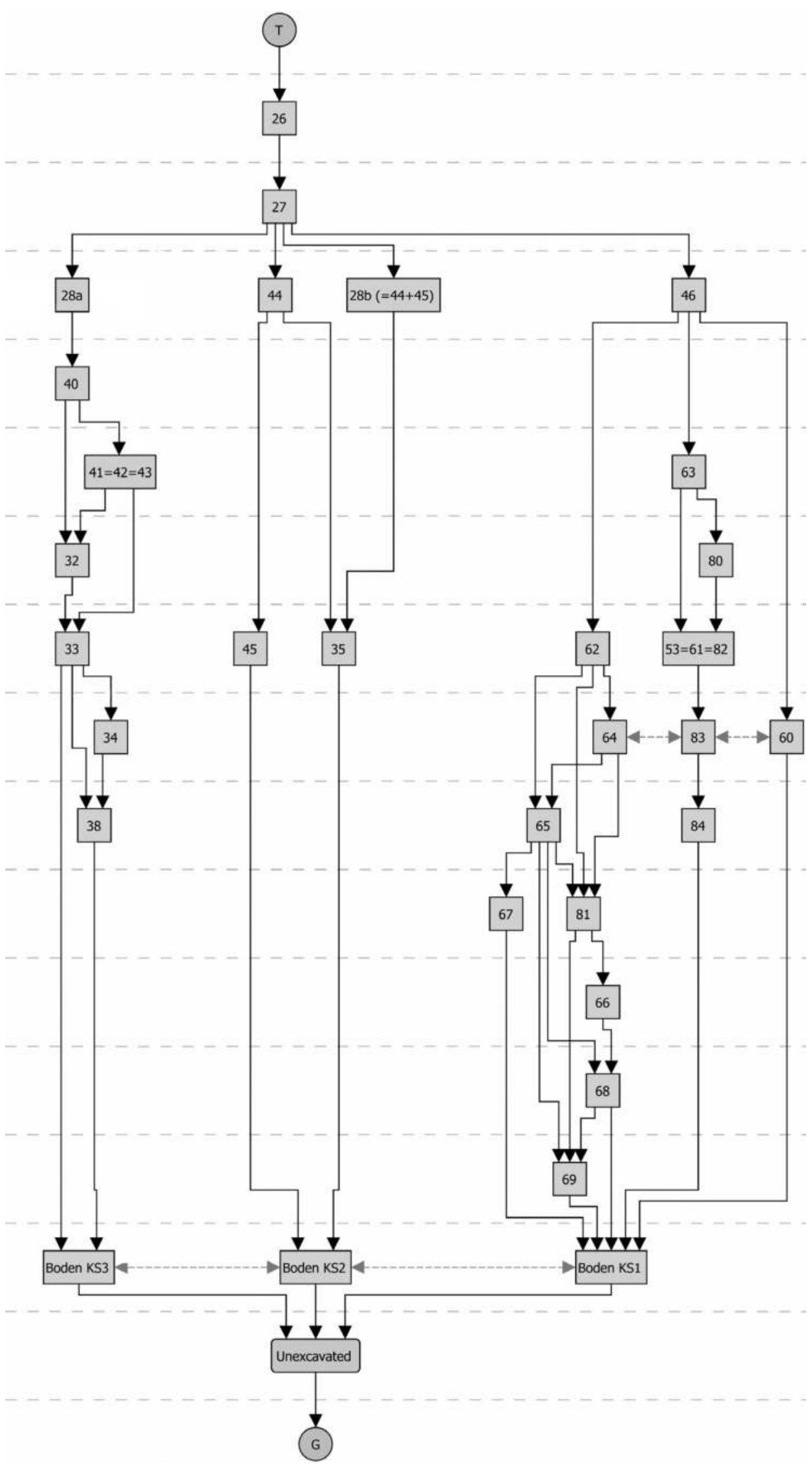




\subsubsection{KAMMER KS2}

\begin{tabular}{|c|c|c|c|c|c|}
\hline Schicht & OK in $\mathbf{m}$ & UK in $\mathbf{m}$ & Beschreibung/Interpretation & Keramik & Münzen \\
\hline SE 26 & - & - & rezenter Humus & - & - \\
\hline SE 27 & - & - & $\begin{array}{l}\text { Zerstörungsschutt vom Theater: } \\
\text { Quaderversturz mit grauem Schutt }\end{array}$ & - & - \\
\hline $\begin{array}{l}\text { SE } 28 b= \\
\text { SE } 44 \text { und } \\
\text { SE } 45\end{array}$ & 21,03 & $\begin{array}{l}20,49- \\
20,22\end{array}$ & $\begin{array}{l}\text { lockere, graubraune Erde mit Mörtelbändern } \\
\text { und Ziegelbruch, rez. Keramik }\end{array}$ & $\begin{array}{l}\text { 6. Jh. n. Chr./ } \\
\text { byzantinisch }\end{array}$ & $\begin{array}{l}\text { M 56. 58. 76. 79. } 95 . \\
\text { 117. 148. 151. } 152 . \\
\text { 153. 158. 168. } 186 . \\
\text { 192. 194-196. } 203 . \\
\text { 210. 218. 220. } 222 . \\
\text { 225. 226. 228. 230. } \\
\text { 235. 236. 249. 260 } \\
\text { (Antoninus III. } \\
\text { [Caracalla] - } \\
\text { Anastasius I.) }\end{array}$ \\
\hline SE 35 & 20,49 & 20,23 & feine, dunkle Erde & (2. H.) 3. Jh. n. Chr. & - \\
\hline SE 44 & 21,51 & 20,49 & lockere, graubraune Erde mit Mörtelbändern & spätes 5./6. Jh. n. Chr. & $\begin{array}{l}\text { M 109. 118. 136. } \\
\text { 142. 165. 171. } 179 . \\
\text { 182. 187. 191. } 199 . \\
\text { 200. 202. 205. } 209 . \\
\text { 216. 221. 223. } 227 . \\
\text { 232. 234. 258. } 259 \\
\text { (Gallienus-Zeno od. } \\
\text { Anastasius I.) }\end{array}$ \\
\hline SE 45 & 20,49 & 20,22 & $\begin{array}{l}\text { mörteliger Schutt mit Steinen und } \\
\text { Ziegelbruch }\end{array}$ & 3. Viertel 3. Jh. n. Chr. & $\begin{array}{l}\text { M 37. 38. 52. 54. } 64 . \\
68.69 .72 .83 .88 . \\
113.173 .254 \\
\text { (Marcus Aurelius- } \\
\text { Gratianus) }\end{array}$ \\
\hline
\end{tabular}

Tab. 46

KS2 ist die am besten erhaltene Kammer im Süd-Analemma (Grafik 5; Taf. 2 Abb. 2). Die Mauern bestehen aus großen Kalksteinquadern und sind im Osten bis zu einer Höhe von 2,10 m erhalten. Dennoch gibt es keinen Abschluss mehr im Westen. Die Analemma-Mauer ist bis unter das Fußbodenniveau der Kammer zerstört. Der befindet sich wie bei den anderen beiden Kammern in der Mitte der Ostwand. Die Türgewände sind teilweise stark in Mitleidenschaft gezogen (Taf. 178 Abb. 365; 179 Abb. 366. 367; 180 Abb. 368; Plan 11).

Auch in den Kammern KS2 und KS3 (Taf. 178 Abb. 364) konnten Reste eines Mörtelniveaus über dem Steinboden festgestellt werden (Taf. 181 Abb. 370). Im Gegensatz zu Kammer KS1 war aber kein vergleichbarer Nutzungshorizont vorhanden. Die Kammern wurden als Schuttablage verwendet. Interessant ist vor allem KS2 wegen der zahlreichen Münzfunde, die aus zwei Schuttstraten unterschiedlicher Zeitstellung stammen. Die den Boden bedeckende Schicht SE 45 enthielt zahlreiche gut erhaltene Keramikfragmente (Taf. 179 Abb. 366; 180 Abb. 369) mit einem Fundspektrum, das bis in die 2. Hälfte des 3. Jhs. n. Chr. reicht. Dazu fügen sich die 13 Münzen (M 37. M 38. M 52. M 54 Taf. 356; M 64. M 68. M 69. M 72 Taf. 357; M 83. M 88. M 113 Taf. 358; M 173 Taf. 359; M 254) der Zeit vor 270 n. Chr. recht gut ${ }^{177}$. Der Schutt scheint nach dem gallienischen Erdbeben hier deponiert worden zu sein. Am Übergang zur darüber befindlichen SE 44 gibt es kein wirklich nivelliertes oder verfestigtes Niveau, wie bei einer weitergehenden Nutzung der Kammer eventuell zu erwarten wäre. Im Gegenteil, nach Westen hin verläuft die eigentliche Schichtgrenze zuweilen sehr verschwommen und wurde zunächst gar nicht erkannt. Die als SE $28 \mathrm{~b}$ bezeich-

\footnotetext{
${ }^{177}$ Kap. 5.2.6.
} 
nete Schicht entspricht weitgehend SE 44, enthält aber auch Anteile an der tieferliegenden Schicht SE 45. In der ganzen östlichen Hälfte der Kammer konnte aber gut zwischen den Schuttniveaus unterschieden werden (Taf. 178 Abb. 365; 179 Abb. 366; 180 Abb. 368). SE 44 ist von der Keramik und den Fundmünzen (23 Stück: M 109; M 118. M 136 Taf. 358; M 142. M 165. M 171. M 179. M 182; M 187. M 191 Taf. 359; M 199; M 200. M 202 Taf. 359; M 205. M 209; M 216. M 221 Taf. 359; M 223. M 227. M 232. M 234. M 258. M 259) dem 6. Jh. n. Chr. zuzurechnen. Das Material aus SE 28b (30 Münzen: M 56. M 58 Taf. 356; M 76. M 79 Taf. 357; M 95. M 117. M 151-153. M 158. M 168; M 186. M 192 Taf. 359; M 194; M 195. M 196. M 203. M 210 Taf. 359; M 218. M 220; M 222. M 225. M 226 Taf. 359; M 228; M 230. M 235 Taf. 359; M 236. M 248. M 249. M 260), obzwar mit älteren Funden vermischt, bestätigt diese Datierung. Mit SE 27 ist der Zerstörungshorizont des Theaters erreicht.

\subsubsection{KAMMER KS3}

\begin{tabular}{|c|c|c|c|c|c|}
\hline Schicht & OK in $\mathrm{m}$ & UK in $\mathbf{m}$ & Beschreibung/Interpretation & Keramik & Münzen \\
\hline SE 26 & - & - & rezenter Humus & - & - \\
\hline SE 27 & - & 21,82 & $\begin{array}{l}\text { Zerstörungsschutt vom Theater: } \\
\text { Quaderversturz mit grauem Schutt }\end{array}$ & - & - \\
\hline SE 28a & 21,82 & 21,45 & graubraune Erde mit Mörtel & 5./6. Jh. n. Chr & $\begin{array}{l}\text { M } 73 \text { (Gallienus) } \\
\text { M } 110 \text { (Gordianus III.) }\end{array}$ \\
\hline SE 40 & 21,45 & 21,30 & feine, lockere, graue Erde (fundleer) & - & - \\
\hline $\begin{array}{l}\text { SE } 41= \\
42=43\end{array}$ & 21,30 & 21,15 & $\begin{array}{l}\text { sehr inhomogener Schutt mit Asche und } \\
\text { Mörtel (fundleer) }\end{array}$ & - & - \\
\hline SE 32 & $\begin{array}{l}21,30- \\
21,15 \\
\end{array}$ & 20,96 & mörteliger Schutt mit kleinen Steinen & 6. Jh. n. Chr. & - \\
\hline SE 33 & $\begin{array}{l}21,17- \\
20,96\end{array}$ & 20,79 & $\begin{array}{l}\text { feine, braune Erde mit Ziegeln und kleinen } \\
\text { Steinen }\end{array}$ & 6. Jh. n. Chr. & $\begin{array}{l}\text { M } 143 \\
\text { M 100. 213. } 251 \\
\text { M 2. 57. 63 } \\
\text { Antoninus III. } \\
\text { (Caracalla) oder Anto- } \\
\text { ninus IV (Elagabal)- } \\
\text { Constans I. oder } \\
\text { Constantius II. }\end{array}$ \\
\hline SE 34 & $\begin{array}{l}20,79 \\
20,41\end{array}$ & $\begin{array}{l}20,29 \\
20,25\end{array}$ & $\begin{array}{l}\text { braune Erde mit Ziegelbruch und kleineren } \\
\text { Steinen }\end{array}$ & 5. Jh. n. Chr. & $\begin{array}{l}\text { M 120. 123. } 256 \\
\text { (Aurelianus) }\end{array}$ \\
\hline SE 38 & $\begin{array}{l}20,29 \\
20,25\end{array}$ & 20,25 & feine, schwarze Lage - verbrannt & kaiserzeitlich & - \\
\hline
\end{tabular}

Tab. 47

Neben äußerst spärlichen, mörteligen Resten über dem Steinboden (Taf. 181 Abb. 370) konnte in KS3 (Taf. 2 Abb. 2; Plan 11) vereinzelt eine feine, schwarze Aschenschicht (SE 38) festgestellt werden (Grafik 5). Darüber war der Raum bis zu 0,70 m hoch mit Erde verfüllt (Taf. 181 Abb. 371; 182 Abb. 372. 373; 183 Abb. 374. 375; 184 Abb. 376. 377), wobei sich zwei Straten unterscheiden ließen: die über dem Boden bzw. über SE 38 liegende Schicht SE 34 mit Funden aus dem 5. Jh. n. Chr. und die darüber liegende SE 33, die anhand der Keramikfunde bereits dem 6. Jh. n. Chr. angehört. Die darin enthaltenen Münzen (M 2 Taf. 355; M 57 Taf. 356; M 63 Taf. 357; M 100. M 120. M 123. M 143. M 213. M 251. M 256) sind weit gestreut und reichen lediglich in das 5. Jh. n. Chr. Aus der Lage der Ziegelfragmente lässt sich eine Schüttrichtung von West nach Ost ablesen. Wie im Türbereich zu erkennen ist, reichten SE 33 und SE 34 zumindest in vomitorium ES1 hinein. Anders verhält es sich mit dem darauf verlaufenden Band aus Mörtelgrieß (SE 32). Seine massivste Stelle ist mit bis zu 0,5 m Stärke im Türbereich festzustellen. Nach Westen hin dünnt das Mörtelband zuneh- 
mend aus. Das gilt auch für die Bereiche nördlich und südlich der Eingangstür. Wie es scheint, dringt SE 32 vom vomitorium her in die Kammer ein. Das wenige Fundmaterial unterscheidet sich kaum von dem aus SE 34, datiert also ebenfalls ins 6. Jh. n. Chr. Im Türbereich folgen auf SE 32 die Schichten SE 41, SE 42 und SE 43. Sie reichten gerade noch durch die Tür in den Raum KS3 hinein, stammen also aus dem vomitorium. Dasselbe gilt auch für das schmale Band SE 40. Die angeschnittenen Reste der Niveaus enthielten kein Fundmaterial. SE 28a erstreckte sich innerhalb der Kammer über die gesamte Fläche und ist - wie es scheint - bis in das vomitorium hinein gelaufen. SE 28a kann nur allgemein ins 5./6. Jh. $\mathrm{n}$. Chr. datiert werden, wobei die beiden Münzen (M 73 Taf. 357; M 110) dem 3. Jh. n. Chr. angehören. Mit SE 27 und SE 26 ist wieder der Zerstörungsschutt vom Einsturz des Theaters erreicht.

Von den Mauern ist deutlich weniger erhalten als in Kammer KS2. Von der Südwand existieren gerade noch zwei Quader. Die westliche Abschlussmauer ist wieder gänzlich bis auf das Fußbodenniveau zerstört (Taf. 181 Abb. 370; 184 Abb. 377; 185 Abb. 378; Plan 11).

\subsubsection{Zugangssystem ES1}

\begin{tabular}{|l|l|l|l|}
\hline Schicht & Beschreibung/Interpretation & Keramik & Münzen \\
\hline SE 27 & $\begin{array}{l}\text { Zerstörungsschutt vom Theater: Quaderversturz mit } \\
\text { grauem Schutt (nur in der S-Hälfte vorhanden gewesen) }\end{array}$ & - & - \\
\hline FK 46/98 & graubrauner Schutt, rez. Verunreinigung & $5 . / 6$. Jh. n. Chr. & - \\
\hline FK 47/98 & hellbraune Stampfschicht & - & - \\
\hline FK 48/98 & Lehm & - & - \\
\hline
\end{tabular}

Tab. 48

Die Erschließung des ersten Diazoma erfolgte durch den Zugang ES1 und war sowohl von Westen durch das Analemma (ES1-W) als auch von Süden über das Zugangspodest ES1 zugänglich (Taf. 2 Abb. 2; Plan 13. 17). Der Westeingang wurde geschickt am Übergang zweier zeitlich differierender Bauabschnitte des Südflügels errichtet ${ }^{178}$. Über eine steile Stiege erreichte man zunächst einen annähernd quadratischen Treppenverteiler, von dem eine Treppe nach Norden auf das untere Diazoma führte, während spiegelbildlich dazu eine zweite Treppe nach Süden in ein hohes vomitorium zum Eingang ES1 in der südlichen Außenmauer des Theaters leitet (Taf. 168 Abb. 343. 344). Der einst hohe Korridor war etwa $10 \mathrm{~m}$ hoch mit einer eindrucksvollen Schuttmasse SE 26 und SE 27 bedeckt. Sie stammt vom Einsturz des Theaters und enthielt dementsprechend große Marmor- und Kalksteinblöcke sowie teils riesige opus caementitium-Brocken (Taf. 169-173). In der Kampagne von 2007 war die Entfernung des Schutts geplant. Aufgrund statischer Probleme an der Ostwand des vomitorium wurde von einer vollständigen Freilegung Abstand genommen, die Höhe des Schuttbergs wurde lediglich um zwei Meter reduziert ${ }^{179}$. Unter St. Karwiese wurde 1998 am nördlichen Ende des Korridors, nahe der Stiege zum Treppenverteiler bei ES1-W, das Bodenniveau des vomitorium freigelegt (Taf. 168 Abb. 344; 185 Abb. 379. 380; 186 Abb. 381. 382). Bis hierher fiel der Zerstörungsschutt stark ab und war nur mehr in einer verhältnismäßig dünnen Schicht vorhanden. Im Grabungsbereich wurden keine Fußbodenplatten mehr vorgefunden. In der Plattenbettung hatte sich Lehm festgesetz ${ }^{180}$. Der einzige Fund, ein schlecht erhaltenes Fragment eines Amphorenhenkels, lässt keine zeitliche Bestimmung zu. Dasselbe gilt für die Stampfschicht darüber ${ }^{181}$. Da im gesamten Grabungsbereich kein einziger Rest des Plattenbodens erhalten war, könnte man auf eine Demontage des Marmorfußbodens schließen. Wie weit eine solche den gesamten Fußboden des Korridors betroffen hatte, kann nicht gesagt werden. Doch weist die Stampfschicht auf eine weitere Nutzung, auch nach dem Ausriss zumindest eines Teils der Fußbodenplatten.

\footnotetext{
${ }^{178}$ STYHLER-Aydin (in Vorbereitung).

${ }^{179} \mathrm{Vgl}$. dazu die Angaben in Kap. 3.7.

${ }^{180}$ Vgl. Kap. 4.6.3, Ki 98/48.

${ }^{181}$ Vgl. Kap. 4.6.3, Ki 98/47.
} 
Zwischen dem Stampfboden und dem Theaterschutt SE 26/27 erstreckt sich eine weitere Schuttschicht ${ }^{182}$. Obzwar rezent ein wenig verunreinigt, weisen die antiken Fundstücke auf das 5./6. Jh. n. Chr. und passen damit gut zu den Schuttniveaus aus den Kammern KS1 bis KS3 und der Treppe im Süden des Theaters ${ }^{183}$. Wie im Fall der beiden Kammern KS2 und KS3 festgestellt werden konnte, reichen die unterhalb des Theater-Zerstörungsschutts befindlichen Schichten immer wieder durch die Kammertüren in das vomitorium hinein. Vermutlich hatten die Räume im Südflügel nach der Schließung des Zugangs ES1 keine größere Bedeutung mehr und wurden zum Deponieren von Schutt verwendet ${ }^{184}$.

\subsubsection{Zugangssystem ES3}

Das Zugangspodest vor dem Zugang ES3 ist identisch mit dem Ende des Südabschnitts der Akademiegasse (Taf. 2 Abb. 2; Plan 17). Gleichzeitig existierte entlang der Theatersüdseite eine Stiegengasse ${ }^{185}$, welche die Theatereingänge ES1, ES2 und ES3 untereinander verband. Der Torzugang ist überwölbt (Taf. 187 Abb. 383; $213 \mathrm{Abb}$. 439) und 3,80 m lang. Er verläuft neben einer alten, aus hellenistischer Zeit stammenden Hangmauer entlang der Straße, dürfte aber erst mit dem ersten kaiserzeitlichen Ausbau im 1. Jh. n. Chr. zusammenhängen (Taf. 187 Abb. 384; 188 Abb. 385) ${ }^{186}$. Eine im Jahr 2008 erfolgte Grabung unter das Niveau des Zugangspodests ES3 ergab eindeutig eine Gleichzeitigkeit des Zugangs und Theateraußenmauer bis ES2 (Taf. 212 Abb. 438; 217 Abb. 447). In hellenistischer Zeit hat an Stelle des überwölbten Tors vermutlich ein offener Zugang auf das obere Diazoma geführt, vergleichbar der Rampenlösung am Theater von Epidauros. Dass der oberste Rang bis in die Nähe der Akademiegasse geführt hat, ist sehr wahrscheinlich ${ }^{187}$.

\subsubsection{Sondage S 3/1998}

\begin{tabular}{|l|l|l|l|}
\hline Schicht & Beschreibung/Interpretation & Keramik & Münzen \\
\hline FK 98/30 & Schutt mit Ziegelbruch & - & - \\
\hline FK 98/31 & harte Erde, rezente Verunreinigung & $5 . / 6 . \mathrm{Jh} . \mathrm{n}$. Chr. & - \\
\hline FK 98/35 & mörteliger Schutt mit vielen Ziegeln und Dachziegeln & 2./3. Jh. n. Chr & - \\
\hline- & erdiger Schutt & - & - \\
\hline
\end{tabular}

Tab. 49

Der Schnitt S 3/1998 (Taf. 188 Abb 386; 189 Abb. 387. 388; 190 Abb. 389. 390; 191 Abb. 391. 392) umfasst die östliche Hälfte der Fläche zwischen dem Torverschluss von ES3 und dem oberen Diazoma. Bis auf das Niveau von Stufe 4 besteht die Einfüllung aus etwas grobem Schutt (Taf. 192 Abb. 393) ${ }^{188}$, der in der Nähe des Torverschlusses stark mit Dachziegeln durchmischt ist (Taf. 189 Abb. 388). Das darin enthaltene Keramikspektrum ist relativ homogen aus dem 2./3. Jh. n. Chr. und in einem teilweise recht guten Erhaltungszustand, der auf keine mehrmalige Umlagerung des Materials weist. Eine vergleichbare Situation wurde in Kammer KS2 vorgefunden ${ }^{189}$, wo auch eine Reihe von Münzen ein Datum im Zusammenhang mit dem Erdbeben in der Regierungszeit des Gallienus nahe legt. Muss man also für die Aufgabe des Zugangs ES3

\footnotetext{
${ }^{182}$ Vgl. Kap. 4.6.3, Ki 98/46.

${ }^{183}$ Kap. 3.7.

${ }^{184}$ Kap. 3.7.2

${ }^{185}$ Kap. 3.7.

${ }^{186}$ IvE 2033. Bereits W. Wilberg spricht sich aufgrund der fehlenden Kaisertitulaturen für die Zeit »um die Wende unserer Zeitrechnung« aus (HeBERDEY u. a. 1912, 157). MAYER 1995, 68 Nr. 36 Abb. 64 weist die Inschrift nach Vergleichen mit anderen Inschriften spätaugusteischer bzw. frühtiberischer Zeit zu. Vgl. auch Kap. 3.7.1.1; 8.6.1, Nr. 1 u. Kap. 8.6.2.

${ }^{187}$ STYHLER-AYDIN (in Vorbereitung).

${ }^{188}$ Vgl. Kap. 4.6.4, Ki 98/35.

${ }^{189}$ Kap. 3.6.2.2
} 
dieses für das ganze Areal südlich des Theaters einschneidende Ereignis annehmen ${ }^{190}$ ? Die beiden oberen Schichten ${ }^{191}$ unterstreichen diese Datierung. Eine einzelne LRC-Wandscherbe, die zu Ki 98/30 gehört, könnte von der Oberfläche stammen und dürfte an dieser Datierung nichts ändern. Darüber hinaus unterscheidet sich der Verschluss des Eingangs ES3 sowohl durch das verwendete Material als auch die Mauertechnik von den Verschlüssen anderer Eingänge. Handelt es sich bei dem Verschluss von EN2 aus dem ausgehenden 4. Jh. n. Chr. ${ }^{192}$ um Schalen aus großen Quadern, die als Orthostaten vor einen Gussmauerkern gesetzt sind (Taf. 146 Abb. 294), so finden wir bei den Verschlüssen der südlichen Zugänge ES1 und ES2 aus dem 6. Jh. n. Chr. eine ähnliche Technik ${ }^{193}$. Allerdings werden hier die Schalen nicht von großen Quadern gebildet, sondern aus den Stufensteinen der Treppe südlich des Theaters. Der Zugang ES3 ist fast über die gesamte Torlänge unter Verwendung von Säulentrommeln in Längsrichtung und Bruchsteinen massiv vermauert (Taf. 191 Abb. 392). Diese Unterschiede könnten tatsächlich ein zusätzliches Indiz für eine von den anderen Zugängen zeitliche Unabhängigkeit darstellen. Dennoch sei auf die Situation an der Südseite des Eingangs ES3 hingewiesen ${ }^{194}$. Hier befinden sich immer wieder Schichten des 2./3. Jhs. n. Chr. über dem Niveau des Zugangspodests von ES3. Doch keine dieser Schichten kann vor dem 6. Jh. n. Chr. dort hingekommen sein.

\subsection{AREAL SÜDLICH DES THEATERS, STIEGENGASSE}

Ein Hauptcharakteristikum der Erschließung des ephesischen Theaters stellen mehrere Radialkorridore dar, die von außen auf die einzelnen Diazomata führen (Taf. 2 Abb. 2; Plan 17). Der Begriff Radialkorridor ist im Zusammenhang mit dem ephesischen Theater streng genommen nicht ganz richtig. Die einzelnen Zugänge weichen von der idealen radialen Ausrichtung ab. Gründe dafür sind in der Geländesituation sowie in konstruktiven Ursachen zu sehen. Dennoch soll die Bezeichnung als ein terminus technicus hier Verwendung finden, charakterisiert er doch einen Erschließungstypus, der an den Theatern Kleinasiens mehrfach anzutreffen ist. Voraussetzung für eine derartige Lösung ist die Erschließung dieser Eingänge durch dazugehörige Straßen oder Gassen, die aus der Umgebung auf das Theater zuführen oder die Theateraußenmauer begleiten (Taf. 1 Abb. 1; Plan 17). Nun ist das für die Eingänge EN2 und ES3 offensichtlich. Beide Zugänge befinden sich in der Achse der Akademiegasse, der ersten Parallelstraße östlich der Marmorstraße. EN1 und ES1 befinden sich unweit der Marmorstraße bzw. der Straße zum Stadion, doch waren sie nicht direkt über diese Straßen zugäng$\operatorname{lich}^{195}$. Im besonderen Maße trifft das aber für den Eingang ES2 zu, der von keinem bekannten Straßenzug erschlossen wird (Plan 17) ${ }^{196}$. St. Karwiese hatte im Jahr 1993 auf Höhe des Zugangs ES2 jedoch eine nach Osten den Hang hinaufführende Treppe (Stiegengasse) angeschnitten, die - den Hang abwärts nach Westen ergänzt - eine durchgehende Erschließung aller drei südlichen Eingänge vermuten ließ (Taf. 193 Abb. 395. 396; 194 Abb. 397-399). Ergänzende Schnitte vor den Zugängen ES1 (Taf. 195 Abb. 400) und ES3 (Taf. 195 Abb. 401) wurden 1998 angelegt und gaben einen ersten Eindruck von den gewaltigen Schuttmassen, die über der Treppe auf einer Länge von immerhin $45 \mathrm{~m}$ lagerten. Überlegungen hinsichtlich der Einbindung der wieder freigelegten Treppe in die moderne wegetechnische Erschließung des Theaters für Veranstaltungen stellten den entscheidenden Impuls für die aktuellen Grabungen dar (Plan 2) ${ }^{197}$. Diese erfolgten in den Jahren 2007 bis 2009

\footnotetext{
${ }^{190}$ Kap. 3.7.2.1.

${ }^{191}$ Vgl. Kap. 4.6.4, Ki 98/30 und Ki 98/31.

${ }^{192}$ IvE 2043. 2044; s. auch Kap. 8.6.1, Nr. 12. 13 u. Kap. 8.6.2.

${ }^{193}$ Kap. 3.7.2.

${ }^{194}$ Kap. 3.7.2.1

${ }^{195}$ Kap. 3.7.1.5.

${ }^{196}$ Bei einer von S. Seren 2008 durchgeführten Georadarmessung am Hang südlich des Theaters wurden keine Hinweise auf eine Gasse in Höhe des Eingangs ES2 nachgewiesen. Die von M. Tschannerl im Jahr 2008 durchgeführten Grabungen schließen eine solche sogar aus. Stattdessen wurden südlich von Mauer MA38 die Reste von wenigstens zweigeschossigen Räumen der Insula angeschnitten. Diese begrenzte die Südseite des Podests. Die Zwischendecke befand sich bereits tiefer als das Bodenniveau von ES2. Beide Geschosse waren mit Wandmalerei ausgestattet und scheinen bis in die Spätzeit bestanden zu haben.

${ }^{197}$ Alle Eingangsöffnungen wurden in spätantik/frühbyzantinischer Zeit verschlossen. Aber auch um die Eingänge ES1, ES2 oder ES3 überhaupt erreichen zu können, gibt es heute keine natürliche Zugangslösung mehr. Eine über $7 \mathrm{~m}$ hohe Terrassenmauer trennt ES1 von der Marmorstraße. Eine in der Antike vermutlich existierende Verbindung zwischen der Marmorstraße und dem Zugangspodest ES1 (Kap. 3.7.1.5) ist durch späte Verbauung nicht mehr wieder herstellbar. Die zweite Zugangsmöglichkeit über die weiter östlich verlaufende Akademiegasse erschließt zwar den Eingang ES3, stellt aber einen großen Umweg für die Besucher
} 
in zwei großen Etappen: 2007/2008 oberer Abschnitt der Treppe zwischen den Zugängen ES2 und ES3 (Treppe-Ost) (Taf. 235 Abb. 485; 236 Abb. 486. 487; 237 Abb. 488; 238 Abb. 489) und 2009 unterer Abschnitt der Treppe zwischen den Zugängen ES1 und ES2 (Treppe-West) (Taf. 192 Abb. 394; 256 Abb. 522. 523; 257 Abb. 524; 258 Abb. 525) ${ }^{198}$. Eine besondere grabungstechnische Herausforderung stellte der Schuttkegel im Bereich des oberen Theaterzugangs ES3 dar, der die Theateraußenmauer deutlich überragte und sich weit nach Süden erstreckte (Taf. 196 Abb. 402. 403; 197 Abb. 404. 405; 198 Abb. 406. 407; 199 Abb. 408).

\subsubsection{Die Treppe und ihre Zugangspodeste vor den Zugängen ES1 bis ES3}

Oberer und unterer Treppenabschnitt (Taf. 288 Abb. 585; 289 Abb. 586) unterscheiden sich in wesentlichen Punkten, weshalb im Folgenden jeder Abschnitt sowie die Zugangspodeste vor den Eingängen gesondert behandelt werden sollen. Im Folgenden wird von Ost nach Westen vorgegangen, was zwar entgegen der Nummerierung der Theaterzugänge ist, aber der chronologischen Bauabfolge sowohl des Theaters als auch der Treppe selbst entspricht.

\subsubsection{ZugangSPODEST ES3}

Das Zugangspodest ES3 wird durch die Akademiegasse erschlossen, die zu beiden Seiten von Häuserfluchten begrenzt wird, und vor dem Eingang ES3 eine Kreuzung mit der Stiegengasse südlich des Theaters ausbildet (Plan 14. 17). Das Zugangspodest ist stark überformt und entspricht nicht mehr der Anlage aus der Zeit der Errichtung der Treppe. Wie die Oberflächenbearbeitung der Stufensteine 34 und der Niveauunterschied zu den Pfeilern des Theaterzugangs vermuten lassen, dürfte das einstige Niveau um das Maß einer Stufe höher gelegen sein. Das vor allem in der südlichen Hälfte erhaltene Tuffpflaster ${ }^{199}$ befindet sich bereits auf dem etwas tieferen Niveau von Stufe 34 (Taf. 220 Abb. 454), im Norden hingegen hat sich die Tuffpflasterung nur in wenigen Resten erhalten. Diese zeigen aber einen deutlichen Höhenunterschied zu den Unterkanten der Pfeiler des Eingangs (Taf. 213 Abb. 439; 217 Abb. 447). Die östliche Begrenzung des Zugangpodests bildet eine aus grob zugerichteten Quadern bestehende Mauer (MA2) gegen den Hang (Taf. 213 Abb. 440; 214 Abb. 441). Die Quader sind ohne Mörtel verlegt und gehören einer hellenistischen Hangstützmauer an, die älter ist als die Theateraußenmauer. Der obere Teil der Mauer wurde in späterer Zeit unter Verwendung von Spolien, darunter auch zahlreiche Treppensteine, ergänzt ${ }^{200}$.

Von der Ecke zwischen Theateraußenmauer und Hangmauer im Osten führt ein Kanal in die Straßenmitte und verläuft von hier weiter nach Süden, unter einer späteren Mauer MA3a hindurch (Taf. 216 Abb. 446; 217 Abb. 447. 448; 218 Abb. 449. 450; 219 Abb. 451). In der Spätzeit wurde der Kanal aus Richtung Theater aufgegeben. Mehrere Tonrohrstränge, die alle unmittelbar westlich der späteren Mauer MA3a verlaufen, werden im Kreuzungsbereich Kanal-MA3a zum Teil in den ab hier noch intakten Kanal geleitet. Andere Leitungen sind in der Auffüllung unter der Pflasterung verlegt und wurden ursprünglich von den Tuffplatten des Pflasters bedeckt. MA3a wurde über einem älteren Tuffbelag errichtet (Taf. 219 Abb. 452; 220 Abb. 453). Sie setzt am östlichen Pfeiler des Eingangs ES3 an, verläuft im Abstand von 1,75 m parallel zur Hangmauer MA2a. Nach 9,50 m endet die Mauer, doch ließen sich geringe Reste einer Ost-West-Mauer (MA3b) feststel-

\footnotetext{
dar. Deshalb wurden mehrere Lösungsvorschläge für das neues Erschließungskonzept vorgeschlagen. Zum einen dachte man an eine Zugangsmöglichkeit über eine bauliche Konstruktion von der Marmorstraße bis zum Eingang ES1 und dann weiter über den Hang zum Eingang S2. Zum anderen sah man im Zugang ES1-West - dem Eingang durch das Süd-Analemma - eine praktikable Lösung. Der Besucherstrom hätte sich hier aufgeteilt: nach Norden in Richtung unteres Diazoma und damit zu den Sitzreihen der ima cavea und nach Süden durch den Eingang ES1-(Süd) und wiederum über den Hang zum Eingang ES2, um das mittlere Diazoma und die media cavea zu erreichen. Bei beiden Überlegungen wurde sowohl an eine Wegeführung über die Hangoberfläche - bzw. eine Treppenkonstruktion am Hang - gedacht als auch an eine Freilegung und Sanierung der antiken Stiegengasse, um diese für die Erschließung zu nutzen. Die Entscheidung fiel, zumindest was die Treppe selbst betraf, zugunsten letzterer Lösung aus.

${ }^{198}$ In 30 Arbeitswochen wurden die Stiegengasse auf einer Länge von 45,0 m und einer durchschnittlichen Breite von 8,0 m zwischen den Eingängen ES1 und ES3 sowie das vomitorium ES1 (Kap. 3.6.2) freigelegt.

${ }^{199}$ Niveau der Tuffpflasterung: $\mathrm{T}^{\mathrm{a}} 38,42 \mathrm{~m}$.

${ }^{200}$ Kap. 3.7.2.1.
} 
len (Taf. 210 Abb. 434; 211 Abb. 436). Sie bildet mit MA3a eine rechtwinkelige Mauerecke und schließt an MA2a an. Der Verschluss der Mauerfugen im unteren Teil der Terrassenmauer MA2a zwischen dem Theater und der kleinen Ost-West-Mauer MA3b sowie ein Wasserzufluss in MA2a/2b belegen eine Brunnenanlage, zu der MA3a und MA3b das Becken gebildet haben (Taf. 213 Abb. 440; 214 Abb. 441. 442). Dazu gehört ein an der Südseite an MA3b gesetzter Marmorquader mit deutlichen Abriebspuren an der Südseite (Taf. 208 Abb. 430; 210 Abb. 434; 211 Abb. 435. 436). Es dürfte sich um einen in situ befindlichen Überrest einer um das Brunnenbecken herumlaufenden Stufe handeln. Dübellöcher und Sinterspuren an der Theateraußenmauer belegen ein zweites, kleineres Brunnenbecken unmittelbar westlich des Eingangs ES3. Mit Ausnahme einer Tonrohrleitung sind davon aber keine baulichen Reste mehr erhalten (Taf. 221 Abb. 455. 456).

\subsubsection{Oberer Treppenabschnitt ZWISChEn den Eingängen ES2 und ES3}

Der östliche Abschnitt der Treppe zwischen den Eingängen ES2 und ES3/Akademiegasse (= Treppe-Ost) ist $11,32 \mathrm{~m}$ lang und überwindet mit 34 Stufen eine Höhendifferenz von 8,06 m (Taf. 244 Abb. 502; 245 Abb. 503; 246 Abb. 504; 247 Abb. 505. 506; Plan 14. 17). Das entspricht einer Neigung von 35,45․ Die Breite variiert: 7,60 m liegen bei ES2 zwischen dem Theater und der Insulamauer, während es bei ES3 8,90 m sind. Hier vermittelt die Treppe zwischen der gekrümmten bzw. polygonalen Theateraußenmauer und dem rechtwinkeligen Rastersystem der Stadt. Auch die Nordmauer der Insula steht nicht im rechten Winkel zur Akademiegasse und verhindert somit eine zu starke Verjüngung der Stiegengasse nach Westen. Der Treppenabschnitt ist deutlich breiter als viele Straßen und Gassen der Stadt und vermittelt einen sehr monumentalen Eindruck.

Rund zwei Drittel der Stufensteine sind in situ erhalten, wobei sich die Fehlstellen auf die nördliche Hälfte der Treppe entlang der Theateraußenmauer beschränken (Taf. 244 Abb. 502; 245 Abb. 503; 246 Abb. 504). Der an diesen Stellen sichtbare Unterbau (Taf. 229 Abb. 473; 230 Abb. 474) besteht aus Bruchsteinen in grauer Mörtelbindung. Von der Mörtelbettung der Stufensteine ist fast nichts mehr erhalten. Für den Treppenbelag wurde grauer Marmor verwendet. Die Steine sind durch die oftmals verbliebenen Bossen zwischen $21,5 \mathrm{~cm}$ und 27,5 cm hoch und von sehr unterschiedlicher Länge. Das Maß variiert von $0,68 \mathrm{~m}$ bis 3,97 m. In der Tiefe messen die Blöcke zwischen $35,5 \mathrm{~cm}$ und $65,0 \mathrm{~cm}$. Aus der Länge und dem Höhenunterschied ergibt sich ein durchschnittliches Maß für die Höhe der Stufen von $24,0 \mathrm{~cm}$ und eine Länge der Trittflächen von $34,7 \mathrm{~cm}$. Alle senkrechten Sichtflächen sind sorgfältig mit dem Zahneisen hergerichtet. An den Trittflächen wurden Bossen dagegen vielfach nicht abgearbeitet. Insgesamt zeigen die Stufen starke Abnützungsspuren. Die Frontseiten weisen im oberen Teil der Treppe (Stufen 24 u. 29-33) Versatzmarken im System A-B, В-Г, Г- $\Delta, \Delta-\ldots$ auf (Taf. 291 Abb. 589; 292 Abb. 590; 293 Abb. 591; 294 Abb. 592). Unterhalb von Stufe 24 gibt es keine einzige Versatzmarke. Das könnte auf einen Abbau mit anschließender Neuverlegung des oberen Treppenabschnitts hindeuten. Dort ist auch der erhaltene Unterbau in einem deutlich schlechteren Zustand; in jenen Bereichen, wo die Treppensteine noch erhalten sind, lassen sich teilweise große Absenkungen auszumachen. Das kann, muss aber nicht zwingend mit Umbaumaßnahmen zusammenhängen. Wie sich bei den Grabungen gezeigt hat, wurde der oberste Teil der Treppe, wie auch der nachträglich durch die Errichtung der Halle vor dem Eingang ES3 entstandene Vorplatz, länger genutzt als die Treppe selbst ${ }^{201}$.

Abgesehen von den Versatzmarken ist in unregelmäßigen Abständen eine Buchstabenkombination in die Oberfläche, also die Trittfläche, eingemeißelt (Taf. 291 Abb. 589; 292 Abb. 590; 293 Abb. 591; 294 Abb. 592). Vereinzelt kommen diese auch an den senkrechten Sichtflächen vor. Generell handelt es sich um die Kombination EY, im Fall der Stufen 11/1, 10/1 um die Buchstaben АП und auf 11/2 ist ПА zu erkennen.

Steinmetzzeichen fanden sich auch auf einigen dislozierten Stufen des oberen Treppenabschnitts, die für den Verschluss des Eingangs ES2 verwendet wurden. Dabei handelt es ausschließlich um die Kombinationen EY und АП (Taf. 294 Abb. 592).

Der Stufenbelag erstreckt sich von der Theateraußenmauer bis an die Nordmauer der Insula. Später wurden entlang der Nordmauer der Insula MA10 Tonrohrleitungen über der Treppe verlegt (Taf. 237 Abb. 488; 238 Abb. 489. 490; 239 Abb. 491. 492) und durch eine geböschte Mauer MA16 gesichert (Taf. 240 Abb. 493; 252

\footnotetext{
${ }^{201}$ Kap. 3.7.2.1.
} 
Abb. 514). Die Leitungen führen von der Nordostecke des Zugangspodests ES3 heran und werden unter Stufe 34 hindurchgeleitet. TRL16 wird bereits an der Nordostecke der Insula ins Innere von Raum RN1 geführt (Taf. 231 Abb. 476. 477; 232 Abb. 478). Die beiden Stränge TRL17 und TRL18 verlaufen bis Mauer MA14 (Taf. 239 Abb. 492; 242 Abb. 499) auf Höhe von Stufe 8/9, wo sie nach unten in die geböschte Mauer MA16 schwenken, die im Westen an MA14 anschließt (Taf. 241 Abb. 496; 242 Abb. 497). Aus noch späterer Zeit stammt die Ziegelmauer MA15 (Taf. 242 Abb. 498; 243 Abb. 500) auf Höhe von Stufe 5/6. Wie MA14 wurde sie direkt auf den Marmorstufen errichtet, setzt aber MA16 bereits voraus ${ }^{202}$. Bei beiden Mauern handelt es sich um kurze Mauerstücke, deren Aufgabe wohl in der Stabilisierung der beschädigten Insulamauer MA10 bestand.

\subsubsection{ZugANGSPODEST ES2}

Die beiden Treppenabschnitte West und Ost sind mit ihrer jeweiligen mittleren Querachse annähernd radial auf die gekrümmte Außenmauer des Theaters ausgerichtet (Plan 13. 14). Daraus ergeben sich unterschiedliche Treppenfluchten und es kommt dem Zugangspodest vor dem Eingang ES2 zu, diese unterschiedlichen Verläufe auszugleichen. Das bedingt die trapezförmige Form des Podests ES2, das ursprünglich bis an Mauer MA38 im Süden heranreichte. Mit Ausnahme eines etwa $1 \mathrm{~m}$ breiten Streifens im Süden und dem Anschluss an die Treppe-West, ist das Podest samt Originalpflasterung ${ }^{203}$ erhalten (Taf. 251 Abb. 513). Als Material wurde wie bei der Treppe-Ost grauer Marmor gewählt. Die Platten sind rechteckig bzw. leicht trapezförmig geschnitten und unregelmäßig verlegt.

Eine 2008 durchgeführte Messung mit Georadar sollte über eine eventuelle Erschließung des Podests ES2 durch einen nicht regulär im Straßenraster liegenden Zugang von Süden her Aufschluss geben (Taf. 295 Abb. 593). Das Ergebnis der Messung zeigt eine mächtige Mauer in Verlängerung von MA34, die etwa $38 \mathrm{~m}$ südlich des Theaters sogar über der Hangoberfläche sichtbar ist. Weiter nach Süden verlängert, trifft die Flucht exakt auf einen Mauerzug in der Insula M/1, dem sog. Freudenhaus ${ }^{204}$. Wie dort lassen sich auch im Georadar Ost-West verlaufende Mauern zu beiden Seiten der mächtigen Nord-Süd-Mauer erkennen. Die Nord-Süd-Mauer diente der Terrassierung innerhalb der Häuserzeile und stellt keine straßenbegleitende Mauer dar. Auffallend ist, dass die Ost-West-Mauern im Georadar in ihrer Orientierung der Insula-Nordmauer MA10 folgen, nicht den Mauern der Insula M/1.

\subsubsection{Unterer Treppenabschnitt ZWISChEn den EIngängen ES1 und ES2}

Der westliche Treppenabschnitt zwischen den Eingängen ES1 und ES2 (= Treppe-West) unterscheidet sich deutlich vom östlichen (Taf. 279 Abb. 570; 280 Abb. 571; Plan 13). Mit 15,33 m ist er deutlich länger als die östliche Treppe (Plan 14). Auf eine Höhendifferenz von 9,99 m kommen insgesamt 44 Stufen, wobei auf Höhe von Stufe 30 ein kleiner Treppenabsatz (Taf. 281 Abb. 572) im Bereich einer Nische in der TheaterauBenmauer angelegt ist (Taf. 277 Abb. 563). Der Neigungswinkel von $33,76^{\circ}$ ist geringfügig flacher als bei Treppe-Ost. Die ursprüngliche Breite der Treppe konnte nicht festgestellt werden. Sie wurde bei den Grabungen nicht erreicht, da im Abstand von durchschnittlich 6,50 m von ES2 bis nahe an die Terrassenmauer an der Marmorstraße ein stabiler Zaun zum Schutz vor Steinschlag verläuft. Zu diesem musste aus Sicherheitsgründen ein gut $1 \mathrm{~m}$ breiter Streifen belassen werden, hinter dem die eigentliche Insula-Nordmauer zu erwarten ist. Eine Breite von 4,77 m lässt sich immerhin am westlichen Ende zwischen der Theatersüdmauer und MA27 messen. Jedoch wurde MA27 bereits über der Treppe errichtet (Taf. 270 Abb. 552) und scheidet damit als treppenbauzeitliche Insula-Begrenzung aus. Würde man die Flucht von Mauer MA10 entlang von TreppeOst bis ES1 verlängern, ergäbe sich eine Breite von $6,82 \mathrm{~m}$ am östlichen und 8,22 $\mathrm{m}$ am westlichen Abschluss von Treppe-West. Das würde auch der Breite von Treppe-Ost entsprechen. Die gesamte Stiegengasse besäße damit einen geradlinigen Abschluss im Süden. Die Breite an den beiden Enden wäre mit 8,22 m (West) und $8,90 \mathrm{~m}$ (Ost) annähernd vergleichbar, während sich der mittlere Bereich durch die gekrümmte bzw. polygo-

\footnotetext{
${ }^{202}$ Kap. 3.7.2.1.

${ }^{203}$ Niveau der Pflasterung: Ta 30,36 m (Ost); Ta 30,22 m (West).

${ }^{204}$ Boulasikis 2003, $34 \mathrm{f}$.
} 
nale Form der Theateraußenmauer auf bis zu 6,50 m verengt. Für eine solche Konzeption ließen sich aber keine Hinweise finden. Allerdings verlaufen auch die im Georadar erkennbaren Ost-West-Mauern südlich der Terrassenmauer in der Orientierung von MA10 ${ }^{205}$. Soweit sich aber feststellen lässt, knickt die Insula-Nordseite mit MA38 auf Höhe von ES2 leicht nach Norden (Plan 13. 14). Würde man MA38 in der Flucht nach Westen verlängern, ergäben sich folgende Breiten für Treppe-West: 6,07 m (Westen) und 6,73 m (Osten). Infolge der gekrümmten Theatermauer würden die $0,66 \mathrm{~m}$ Differenz kaum zu bemerken sein, sodass man von einer eigens auf den Abschnitt ES1 bis ES2 abgestimmten Ausrichtung der Insula-Nordmauer schließen könnte. Doch beide Varianten sind bloße Denkmodelle. Es wurde keine Verlängerung von MA10 südlich des Zugangpodests ES2 gefunden und eine Verlängerung des gerade einmal angeschnittenen Teilstücks von MA38 bis ES1 hinunter kann nur mit einem gebotenen Maß an Skepsis erfolgen.

Als Material für Treppe-West fand weißer Marmor Verwendung (Taf. 277 Abb. 565; 278 Abb. 566-568). Die Länge der erhaltenen Stufensteine liegt zwischen 71,5 und 141,5 cm, ist also deutlich kürzer als im Falle der Treppe-Ost. Die Höhe differiert zwischen 21 und $23 \mathrm{~cm}$. Die Tiefe der Steine liegt bei 43 bis $47 \mathrm{~cm}$, die Auftritte sind 32 bis $33 \mathrm{~cm}$ tief. Die Stoßfugen sind vorwiegend rechtwinkelig ausgeführt. Schräge Stoßfugen sind die Ausnahme. Die senkrechte Sichtfläche ist fein mit dem Zahneisen hergestellt, Versatzmarken kommen nicht vor. Die Trittflächen sind gespitzt. Von knapp neben dem Theater bis etwa $3 \mathrm{~m}$ Entfernung sind die Abriebspuren deutlich ausgeprägter als im weiteren Verlauf nach Süden. Die Stirnseiten sind grob mit dem Zahneisen gearbeitet und mit einer Anathyrose versehen (Taf. 278 Abb. 569). Der Anschluss an das Theater ist sehr sorgfältig hergestellt (Taf. 277 Abb. 565; 278 Abb. 566). Die Steine sind in ein Mörtelbett über dem Unterbau verlegt. Der Unterbau besteht aus Bruchsteinen in grauer Mörtelbindung. Westlich von MA23 ist der Unterbau teilweise abgetragen (Taf. 272 Abb. 555; 273 Abb. 557. 558; 274 Abb. 559; 275 Abb. 560). Hier sind unmittelbar neben der Theateraußenmauer mehrere Tonrohrleitungen im Profil erkennbar, die aus dem Wasserleitungskanal unter der Stufe 10 nach Westen führen (Taf. 272 Abb. 556; 273 Abb. 557; 274 Abb. 559). Ein weiterer Rest einer Rohrleitung wurde am Zugangspodest ES1 unter die Pflasterung geführt. Diese Leitung muss allerdings über den marmornen Stufen verlaufen sein (Taf. 283 Abb. 577). Sie dürfte aus der Zeit nach der Aufgabe der Treppe stammen, als das Zugangspodest selbst aber noch in Verwendung war.

\subsubsection{ZugangSPODEST ES1}

Durch den Eingang ES1 gelangte man in ein gewaltiges vomitorium, das heute, obzwar es von schweren Zerstörungen stark in Mitleidenschaft gezogen ist, dennoch einen imposanten Anblick bietet. Auch die Pfeiler des Eingangstors zeigen zahlreiche Risse und Sprünge von hoher Druckbelastung (Taf. 284 Abb. 578. 579; 285 Abb. 580. 581), und man ist geneigt, die etwa 2,5 m starke Mauer (Taf. 286 Abb. 582), die den Zugang verwehrt, unter statischen Gesichtspunkten zu sehen. Das ist nicht auszuschließen. Doch sei auch darauf hingewiesen, dass das Theater einen Teil der byzantinischen Stadtbefestigung darstellte und somit auch die Vermauerung von ES1 in diesem Zusammenhang zu verstehen ist ${ }^{206}$.

Am Zugangspodest ES1 ist die weiße Marmorpflasterung ${ }^{207}$ entlang des vermauerten Theatereingangs und des westlichen Abschnitts der Treppe erhalten (Taf. 282 Abb. 575; 283 Abb. 576). Große Bereiche im Westen und Süden sind jedoch nicht mehr vorhanden. Aufgrund des großen Niveauunterschieds von 9,60 m zwischen dem Zugangspodest ES1 und der Marmorstraß $\mathrm{e}^{208}$ musste eine mächtige Terrassenmauer errichtet werden (Taf. 286 Abb. 583). Diese stellte gleichzeitig die westliche Begrenzung des Podests dar. Als Abschluss ist hier wohl eine Brüstung zu ergänzen. Etwa 2,40 m fehlen heute vom oberen Teil der Terrassenmauer.

Dieser Teil der Mauer ist vermutlich durch ein Erdbeben, das auch zum Einsturz des Süd-Analemma geführt hatte, gemeinsam mit einem Teil des Podests ES1 und der im Süden angrenzenden Insula nach Westen abgerutscht. Daher lässt sich vom Süden des Podests ES1 nur bedingt eine Vorstellung gewinnen.

An der Ostseite der Marmorstraße lassen sich zwischen Theater und Kuretenstraße zahlreiche Umbaumaßnahmen aus späterer Zeit feststellen. Wie an der Westseite ist auch an der Ostseite des Zugangpodests

\footnotetext{
205 Kap. 3.7.1.3.

${ }^{206}$ Kap. 3.6.1 u. 3.7.2.

${ }^{207}$ Niveau der Pflasterung: Ta $20,23 \mathrm{~m}$.

${ }^{208}$ Niveau Marmorstraße vor der Terrassenmauer: $\mathrm{T}^{\mathrm{a}} 10,55 \mathrm{~m}$.
} 
ES1 das Gelände bis in eine Tiefe von 2,70 m unter das ursprüngliche Niveau abgerutscht. Es ist vermutlich von einem weiteren Treppenabschnitt auszugehen, der den Theatereingang ES1 und die Stiegengasse mit der Marmorstraße verbunden hat. Damit ließen sich auch die großzügigen Maße der Treppe erklären, mittels derer die Stiegengasse neben der Erschließung des Theaters auch eine übergeordnete, verbindende Funktion im Straßensystem der Stadt erfüllte. In diesem Zusammenhang muss erneut betont werden, dass die baulichen Dimensionen des Theaters in keiner Weise Rücksicht auf die Grenzen der Insulae und das innerstädtische Straßensystem nehmen. Auf Grundlage des theoretischen Rastersystems, das für die hellenistische Stadt angenommen wird, wären an der Position des Theaters bereits zwei Ost-West verlaufende Straßenzüge vorauszusetzen ${ }^{209}$. Da durch den Theaterbau sowohl mehrere Ost-West- als auch Nord-Süd-Verbindungen >blockiert` werden, könnte man spätestens mit dem kaiserzeitlichen Ausbau mit einer Verbindung zwischen Marmorstraße und Akademiegasse rechnen. Die Überwindung des Höhenunterschieds zwischen Zugangspodest ES1 und Marmorstraße wird aufgrund der Hanglage nur durch eine Treppe oder eine Rampe erfolgt sein. Ein Beleg für diese Erschließungsmöglichkeit ist m. E. in Form von massiven Abriebspuren an der Oberfläche der ES1-Pflasterung gegeben. Vom westlichen Torpfeiler des Eingangs ES1 nach Südwesten verlaufend, ist eine deutliche Linie am noch erhaltenen Pflaster zu erkennen (Plan 13). Östlich dieser Linie ist das Pflaster stark abgetreten, westlich davon kaum (Taf. 283 Abb. 576). Die Spuren der Abnutzung im Osten sind deutlich stärker ausgeprägt als vom Eingang ES1 in Richtung der Treppe-West. Daraus lässt sich eine starke Frequentierung und Nutzung der westlichen Hälfte des Zugangspodests ES1 vom Eingang in Richtung Südwesten erschließen. Dies ist nur dann sinnvoll zu erklären, wenn der Bewegungsverlauf im Süden nicht etwa an einer Abmauerung des Podests ES1 endete, sondern sich weiter nach Süden über eine Treppe zur Marmorstraße fortsetzen konnte. Andere Hinweise als die Abnutzungsspuren am Pflaster von ES1 konnten im Zuge der Grabungen 2008 und 2009 leider nicht gewonnen werden.

Der Bereich östlich der Marmorstraße ist stark überbaut. In seinem nördlichen Abschnitt grenzt dieser unmittelbar an das Zugangspodest ES1 an. Es fällt auf, dass von dem Abschluss der großen Terrassenmauer bis zur Gebäudefront hinter der Straßenhalle an der Ostseite der Marmorstraße eine schräg verlaufende Verlängerung der Terrassenmauer existiert, die mit Sicherheit eine spätere Ergänzung darstellt. Wie in den folgenden Kapiteln aufgezeigt werden soll, wurden sowohl die Theaterzugänge ES1 bis ES3 als auch die Stiegengasse in der Spätzeit aufgegeben, wohingegen das Zugangspodest ES1 noch länger in Verwendung war. $\mathrm{Ob}$ diese über einen hypothetisch erschlossenen dritten Treppenabschnitt erfolgte oder über einen Teil der Wohnverbauung, kann freilich nicht gesagt werden. Die Aufgabe der Stiegengasse bedeutete über kurz oder lang auch keine weitere Notwendigkeit, einen Treppenabschnitt zwischen ES1 und Marmorstraße zu unterhalten, was die massive Überbauung erklären würde.

\subsubsection{Aufgabe der Stiegengasse}

Die gesamte Stiegengasse südlich des Theaters war mit 2,0 bis 5,0 m hohen Schuttmassen bedeckt (Taf. 196 Abb. 402. 403; 197 Abb. 404; 199 Abb. 408. 409; 200 Abb. 410. 411; 201 Abb. 412. 413; 202 Abb. 414-416), die aufgrund der Eigenart des Geländes, aber auch durch Zerstörung und bewusste Eingriffe des Menschen drei unterschiedliche Fließrichtungen aufwiesen. Da ist zum einen die Hauptrichtung nach Westen, was der Orientierung der Treppe entspricht. Durch teilweise starke Schäden der Wohnverbauung südlich der Treppe, was mit dem Abrutschen ganzer Teile der Insula verbunden gewesen sein dürfte, ergibt sich für den westlichen Treppenabschnitt auch eine Fließrichtung nach Süden, von der Treppe in die ehemalige, angrenzende Verbauung. Für den Abschnitt Treppe-Ost ist eine bewusst angelegte Schüttung nach Norden, also von der Insula in Richtung auf das Theater festzustellen (Taf. $235 \mathrm{Abb}$. 484). Im Einzelnen lässt sich aber oft nicht mehr genau feststellen, inwiefern die Verschüttungen durch Erosion und Abrutschen des Materials entstanden sind - was mittels quer zum Hang verlaufende Mauern verhindert werden sollte - oder inwiefern die Schuttmassen als Hinterfüllung einer Terrasse aufgebracht wurden (Taf. 295 Abb. 593; 296 Abb. 594). Es ist nicht anzunehmen, dass das Material von weiter entfernt herangeschafft wurde. Es stammt wohl, wie die Auswertung der Funde zeigte, im Großen und Ganzen aus der theaternahen Wohnbebauung. Durch die Steilheit des Geländes sind aber Verlagerungen um teilweise viele Meter vorauszusetzen.

\footnotetext{
${ }^{209}$ SCHERRER 2001, Abb. 3-20; GroH 2006, 70 Abb. 10.
} 


\subsubsection{Oberer Treppenabschnitt und ZugangsPodest ES3}

\begin{tabular}{|c|c|c|c|}
\hline Schicht & Beschreibung/Interpretation & Keramik & Münzen \\
\hline SE 0 & alter Grabungsschutt, 1960/70er Jahre & - & - \\
\hline SE 1 & Oberflächenhumus & - & - \\
\hline SE 2 & hellbraune, lockere Erde & 2. H. 3. Jh. n. Chr. & - \\
\hline SE 4 & grauer, humoser Schutt & 3.-4. Jh. n. Chr. & $\begin{array}{l}\text { M } 92 \\
\text { (Gordianus III.) }\end{array}$ \\
\hline SE 5a & graubraune, sandige Erde mit Ziegeln & 2. H. 3. Jh. n. Chr. & - \\
\hline $\mathrm{SE} 5 \mathrm{~b}$ & graubrauner Ziegelschutt & - & - \\
\hline SE 6 & dichte Lage von kleinen Steinen & - & - \\
\hline SE 7 & - & 2. H. 4. Jh. n. Chr. & $\begin{array}{l}\text { M 20. 85. 112. 114. } 115 \\
\text { (Gordianus III.-- } \\
\text { Trebonianus Gallus) }\end{array}$ \\
\hline SE 8 & - & kaiserzeitlich? & - \\
\hline SE 9 & kleinteiliger Ziegelschutt mit Mörtelbrocken & 5.-6. Jh. n. Chr. & $\begin{array}{l}\text { M } 6 \\
\text { (hellenistisch) }\end{array}$ \\
\hline SE 11 & braune, sandige feste Erde über dem Platzniveau von S3 & 2. H. 4. Jh. n. Chr. & - \\
\hline SE 12 & $\begin{array}{l}\text { graubraune, sandige Erde mit Ziegelbruch, Mörtelgrieß } \\
\text { und Holzkohle }\end{array}$ & $\begin{array}{l}\text { 2. H. 4. Jh.- } \\
\text { 1. Viertel 5. Jh. n. Chr. }\end{array}$ & $\begin{array}{l}\text { M 75. } 198 \\
\text { (2./3. Jh. n. Chr.- } \\
\text { Honorius) }\end{array}$ \\
\hline SE 14 & Ziegelschutt & $\begin{array}{l}\text { 2. H. 4./ } \\
\text { Anfang 5. Jh. n. Chr. }\end{array}$ & $\begin{array}{l}\text { M 104. } 105 \\
\text { (prinzipatszeitl.) }\end{array}$ \\
\hline SE 14a & Ziegelschutt mit rötlich brauner Erde & 3.-5. Jh. n. Chr. & - \\
\hline SE $14 b$ & sandiger Schutt mit Ziegelbruch & - & - \\
\hline $\begin{array}{l}\text { SE } 36= \\
\text { SE } 37= \\
\text { SE } 71= \\
\text { SE } 120\end{array}$ & Kanalverfüllung & 3. Jh. n. Chr. & - \\
\hline SE 39 & Verfüllung zwischen Kanal und byzantinischer Stadtmauer & 3.-4. Jh. n. Chr. & - \\
\hline SE 99 & dünnes Band aus mittelbrauner Erde & - & - \\
\hline SE 100 & feine, rötliche Erde mit Ziegelbruch & kaiserzeitlich & - \\
\hline SE 106 & Mörtelniveau im westlichen Kanal (Kanalboden) & - & - \\
\hline SE 109 & feste, hellbraune Schicht & - & - \\
\hline SE 110 & stark verfestigte hellbraune Schicht & - & - \\
\hline SE 156 & Verfüllung des TRL-Grabens & - & - \\
\hline SE 160 & Mörtelbettung für Straßenpflasterung & - & - \\
\hline SE 164 & feinkörniges Material mit kleinen Steinen & kaiserzeitlich & - \\
\hline SE 165 & rötlich braune, sandige Erde & $\begin{array}{l}\text { 3. Viertel 1. Jh.- } \\
\text { 1. Viertel 2. Jh. n. Chr. }\end{array}$ & - \\
\hline SE 166 & $\begin{array}{l}\text { hellbraune kompakte Schicht mit kleinen Steinen und } \\
\text { Ziegelbruch }\end{array}$ & - & - \\
\hline SE 167 & braune, lehmige Erde mit Steinen und Ziegelbruch & - & - \\
\hline
\end{tabular}

Tab. 50 


\begin{tabular}{|c|c|c|c|}
\hline Schicht & Beschreibung/Interpretation & Keramik & Münzen \\
\hline SE 0 & alter Grabungsschutt, 1960/70er Jahre & - & - \\
\hline SE 1 & Oberflächenhumus & - & - \\
\hline SE 2 & hellbraune, lockere Erde & 2. H. 3. Jh. n. Chr. & - \\
\hline SE 3 & braune Erde mit einer dichten Lage großer Bruchsteine & - & - \\
\hline SE 4 & grauer, humoser Schutt & 3.-4. Jh. n. Chr. & - \\
\hline $\begin{array}{l}\text { SE } 7= \\
\text { SE } 143\end{array}$ & lockerer Ziegelschutt & spätantik & - \\
\hline SE 9 & kleinteiliger Ziegelschutt mit Mörtelbrocken & 5.-6. Jh. n. Chr. & - \\
\hline SE 12 & $\begin{array}{l}\text { graubraune, sandige Erde mit Ziegelbruch, Mörtelgrieß } \\
\text { und Holzkohle. Ist die Fortsetzung von SE12 (Tab. 50). }\end{array}$ & $\begin{array}{l}\text { 2. H. 4. Jh. }-1 \text {. Viertel } 5 \text {. } \\
\text { Jh. n. Chr. }\end{array}$ & $\begin{array}{l}\text { M 75, M } 198 \\
\text { (2.-3. Jh. n. Chr.- } \\
\text { Honorius) }\end{array}$ \\
\hline SE 13 & Versturz MA 4 & - & - \\
\hline SE 14 & Ziegelschutt. Ist die Fortsetzung von SE14 (Tab. 50). & 2. H. 4./5. Jh. n. Chr. & $\begin{array}{l}\text { M 104. } 105 \\
\text { kaiserzeitlich }\end{array}$ \\
\hline SE 16 & feste, mörtelige Schuttschicht & kaiserzeitlich & - \\
\hline SE 19 & Mörtelniveau & 3. Viertel 1.-2. Jh. n. Chr. & - \\
\hline $\begin{array}{l}\text { SE } 20= \\
\text { SE } 132 a-c\end{array}$ & Ziegelschutt & spätes 5.-6. Jh. n. Chr. & - \\
\hline $\begin{array}{l}\text { SE } 29= \\
\text { SE } 131= \\
\text { SE } 144\end{array}$ & dünne Sandschicht & kaiserzeitlich & - \\
\hline SE 30 & graue, sandige Erde & kaiserzeitlich & - \\
\hline $\begin{array}{l}\text { SE } 31= \\
\text { SE } 133\end{array}$ & Erde mit Ziegelsplitt über Stufenausriss & 2. H./spätes 3. Jh. n. Chr. & - \\
\hline $\begin{array}{l}\text { SE } 104= \\
\text { SE } 108\end{array}$ & Zerstörungsschutt von MA7 & - & - \\
\hline SE 105 & rötlich braune Erde & - & - \\
\hline SE 134 & kompakte, lehmige Erde mit kleinen Schneckenhäusern & 3.-4. Jh. n. Chr. & - \\
\hline SE 135 & $\begin{array}{l}\text { sandige, graubraune Erde in der Fuge zwischen Theater } \\
\text { und Treppenunterbau }\end{array}$ & frühkaiserzeitlich ? & - \\
\hline SE 136 & $\begin{array}{l}\text { feste, kompakte Erde in der Vertiefung zwischen } \\
\text { Stufenoberfläche/-bosse bis zur nächsten } \\
\text { Stufenvorderkante }\end{array}$ & 3. Viertel 3. Jh. n. Chr. & - \\
\hline SE 137 & feiner, sandiger Ziegelschutt & 2. Jh. n. Chr. & - \\
\hline SE 138 & brauner Schutt mit Bruchsteinen und Ziegelstücken & 1.-3. Jh. n. Chr. & - \\
\hline SE 139 & $\begin{array}{l}\text { sandig-mörteliger Schutt zwischen Theatermauer und } \\
\text { Stufen }\end{array}$ & 1. H. 3.-Jh. n. Chr. & - \\
\hline SE 140 & graubraune Erde & 2. H. 3. Jh. n. Chr. & - \\
\hline $\begin{array}{l}\text { SE } 141= \\
\text { SE } 142\end{array}$ & $\begin{array}{l}\text { kompakte, braune, sandige Schicht mit hohem Anteil an } \\
\text { Holzkohle }\end{array}$ & 3.-Anfang 4. Jh. n. Chr. & - \\
\hline SE 146 & graubraune Erde; sehr locker und sandig & kaiserzeitlich? & - \\
\hline SE 150 & Verfüllung einer Vertiefung im Treppenunterbau & spätantik? & - \\
\hline
\end{tabular}




\begin{tabular}{|c|c|c|c|}
\hline Schicht & Beschreibung/Interpretation & Keramik & Münzen \\
\hline SE 152 & $\begin{array}{l}\text { Ziegelschutt mit lockerer, orange gefärbter Erde und } \\
\text { Mörtelbröckchen }\end{array}$ & $\begin{array}{l}\text { 2. H. 3. Jh. n. Chr., } \\
\text { einzelne Fragmente 4.-7. } \\
\text { Jh. n. Chr. (intrusiv) }\end{array}$ & - \\
\hline SE 153 & $\begin{array}{l}\text { feine, braune Erde mit kleinteiliger Keramik. Ähnlich wie } \\
\text { SE } 136\end{array}$ & kaiserzeitlich & $\begin{array}{l}\text { M } 108 \\
\text { (Marcus Aurelius) }\end{array}$ \\
\hline $\begin{array}{l}\text { SE } 154= \\
\text { SE } 157\end{array}$ & Ziegelschutt mit zahlreichen Fensterglasscherben & $\begin{array}{l}\text { 2. H. 1.- } \\
\text { 1. H. 2. Jh. n. Chr. } \\
\end{array}$ & - \\
\hline SE 155 & lockere Erde mit Holzkohle & $\begin{array}{l}\text { 2. H. 3. Jh. n. Chr., } \\
\text { einzelne Fragmente 2. H. } \\
\text { 4. Jh. n. Chr. (intrusiv) }\end{array}$ & - \\
\hline SE 158 & graubraune Erde & - & - \\
\hline SE 159 & Ziegelschutt & kaiserzeitlich & - \\
\hline SE 162 & graubrauner, sandiger Schutt & (1. H.) 3. Jh. n. Chr. & - \\
\hline SE 163 & graue Erde mit kleinen Mörtelbrocken und Ziegelbruch & - & - \\
\hline
\end{tabular}

Tab. 51

Wie bereits festgestellt wurde, ist am östlichen Treppenabschnitt eine eigenartige Form des Steinraubs zu erkennen. Sowohl im oberen als auch im unteren Bereich ist jeweils die theaternahe nördliche Hälfte der Treppe ihrer Marmorblöcke beraubt, während die zur Insula gewandte Seite vollständig erhalten ist (Taf. 244-246). Die fehlenden Quader wurden zum Verschluss des Eingangs ES2 (Taf. 251 Abb. 512) und zur Wiederherstellung der Mauer MA2 verwendet (Taf. 213 Abb. 440; 214 Abb. 441). Insofern ist das Ausrissmuster im Bereich des Zugangs ES2 noch verständlich, wo auch die weiter entfernt verbauten Steine nur treppenabwärts geschafft werden mussten. Im Falle des Ausrisses zum Zugangspodest ES1 hin ist es jedoch verwunderlich, dass man hier eher die tiefer liegenden Treppensteine in der nördlichen Hälfte nach oben geschafft haben soll, um sie in der Mauer MA2 zu verwenden, während man die weiter oben befindlichen in der südlichen Treppenhälfte an Ort und Stelle belassen hätte. Dies ist um so erstaunlicher, als man die Steine aus dem nordöstlichen Bereich der Treppe ja gar nicht in Richtung des Eingangs ES3 gebracht hatte, sondern eben zur ehemaligen Stützmauer nach Osten, um diese wiederherzustellen. Da wären die in der südlichen Hälfte, weiter oben gelegenen Steine mit weitaus weniger Mühe zu beschaffen gewesen als die tieferliegenden Steine im Norden. Wie ist dieser Sachverhalt zu erklären? Eine Antwort darauf könnte das Schuttpaket entlang der Insulamauer MA10 geben (Taf. 193 Abb. 396; 194 Abb. 398. 399). Im Gegensatz zu anderen Schuttschichten über der Stiegengasse waren hier einzelne, nicht vollständig zerbröckelte Mauerteile noch erhalten. Dazu kommen die Funde von Fenstergittern, die wohl verformt, aber teilweise als Ganzes aus dem Schutt geborgen werden konnten (Taf. 232 Abb. 479; 233 Abb. 480. 481; 234 Abb. 482. 483). Dieser Umstand weist recht deutlich auf einen kaum umgelagerten Zerstörungshorizont, der nur von der angrenzenden Insula stammen $\mathrm{kann}^{210}$. Vermutlich gehört auch SE 155 dazu, die vor allem oberhalb der Tonrohrleitungen an SE 152 anschließt, sowie SE 162 und eventuell auch SE 138. Aufgrund der Stratigrafie sind auch die Schichten SE 158 und 163 dazu zu rechnen (Plan 15. 16). SE 136 und 153 befanden sich in dem Spalt zwischen der Bosse an der Stufenoberseite und der Front der nächst höheren Stufe. Die Schicht enthielt vor allem kleinformatige Keramikfragmente in großer Menge und zeichnete sich durch große Festigkeit aus. Es dürfte sich hierbei um Material handeln, das sich im Laufe der Zeit an diesen Stellen der Stufen abgelagert hatte, und auch beim Fegen der Stiege an diesen >geschützten ২ Stellen verblieben war. Das Fundmaterial ist relativ homogen und gehört dem 3. Viertel des 3. Jhs. n. Chr. an. Wie die Fundauswertung des Zerstörungsschutts SE 152 und die Datierung der jüngsten Funde aus dem Keramikspektrum in der darunterliegenden Schicht SE 136 belegen, ist die Zerstörung der Insula mit dem gallienschen Erdbeben um $262 \mathrm{n}$. Chr. in Zusammenhang zu bringen. Das bedeutet aber auch, dass die Treppe seit diesem Ereignis in der südlichen Hälfte nicht mehr frei geräumt wurde. Diesem Umstand ist es wohl zu verdanken, dass im oberen Bereich des liegen gebliebenen Zerstörungsschutts wenige Fundstücke späterer Zeit gefunden

\footnotetext{
${ }^{210}$ Kap. 4.7.2. Vgl. Furger 2011, 295-300.
} 
wurden. Die Anzahl an jüngeren Funden fällt im quantitativen Vergleich zu den Keramikfragmenten des 3. Jhs. n. Chr. gering aus. Dies spricht m. E. gegen eine Zugehörigkeit des Häuserschutts zu einem Erdbeben jüngerer Zeit. Das (teilweise) Belassen des Schutts hatte zur Folge, dass der darunterliegende Teil der Treppe erhalten blieb. Als man späterer daran ging, die Theatereingänge zu verschließen und die Stützmauer MA2 zu ergänzen, konnte man ohne große Freilegungsarbeit eben nur auf die in der nördlichen Hälfte nicht vom Schutt bedeckten Steine der Treppe zurückgreifen, was die Tatsache der Beraubung von Steinen aus eben dieser Hälfte erklärt.

Wie die Situation am Zugangspodest ES2 ausgesehen hat, lässt sich nicht mehr feststellen. Bereits vor den Ausgrabungen am westlichen Abschluss der Treppe-Ost durch St. Karwiese hat es hier Steinraub und später Sicherungs- und Restaurierungsmaßnahmen gegeben. Dabei ist es zu großen Materialumlagerungen gekommen, sodass heute kein stratigrafischer Zusammenhang zwischen Treppe und Podest herzustellen ist. Wie die Grabungen südlich der Mauer MA38 gezeigt haben, dürften zumindest Teile der Wohnverbauung nach dem Erdbeben von 262 n. Chr. wieder benutzt worden sein. Es ist denkbar, dass die Ziegelmauer MA15 auf Treppe-Ost (Taf. 242 Abb. 498; 243 Abb. 500) auch der Zeit nach dem Erdbeben entstammt und die Aufgabe hatte, eine aus dem Erdbeben resultierende Beschädigung der Nordmauer der Insula MA10 zu sichern. Bei der aus Bruchsteinen errichteten Mauer MA14 ist das nicht so klar. Es kann aber festgestellt werden, dass westlich von MA14 die geböschte Mauer MA16 beginnt (Taf. 240 Abb. 493; 242 Abb. 497. 498; 243 Abb. 500), die früher anzusetzen ist als MA15.

Östlich von MA14 dagegen lassen sich zwei Tonrohrstränge TRL17 und TRL18 fassen, die entlang der Nordmauer der Insula MA10 verlaufen (Taf. 168 Abb. 343. 344; 169 Abb. 345. 346). Sie wurden unter dem Pflaster des Zugangspodests ES3 auf die Nordostecke der Insula zu geführt und verlaufen ab Stufe 33 über der Oberfläche der Treppe (Taf. 240 Abb. 494; 241 Abb. 495). Eine dritte Leitung (TRL16) schwenkt gleich nach dem Austritt aus Stufe 33 an der Nordostecke der Insula nach Süden in die Mauer MA10 (Taf. 231 Abb. 476. 477; 240 Abb. 494). TRL17 und TRL18 verlaufen im Treppenbereich über einem Schuttpaket und man ist somit geneigt, deren Installation erst nach dem Erdbeben in gallienischer Zeit als möglich zu erachten. An manchen Stellen jedoch kann man den Eindruck gewinnen, dass es eine Oberflächenbefestigung mit Mörtel gegeben haben könnte, die vergleichbar ist mit den geböschten Mauern MA16 und MA17 (Taf. 253 Abb. 517) entlang der Nordmauer der Insula MA10 weiter im Westen oder auch mit der Trasse für die Wasserleitung MA29 an der Mauer MA27 am unteren Treppenabschnitt bei ES1. Demnach können die Leitungen auch vor dem Erdbeben verlegt worden sein. Der Erhaltungszustand des gesamten Materials um die Tonrohrleitungen TRL17 und TRL18 ist jedoch derartig schlecht, dass eine gesicher-

Grafik 6: Harris-Matrix über dem Zugangspodest ES3

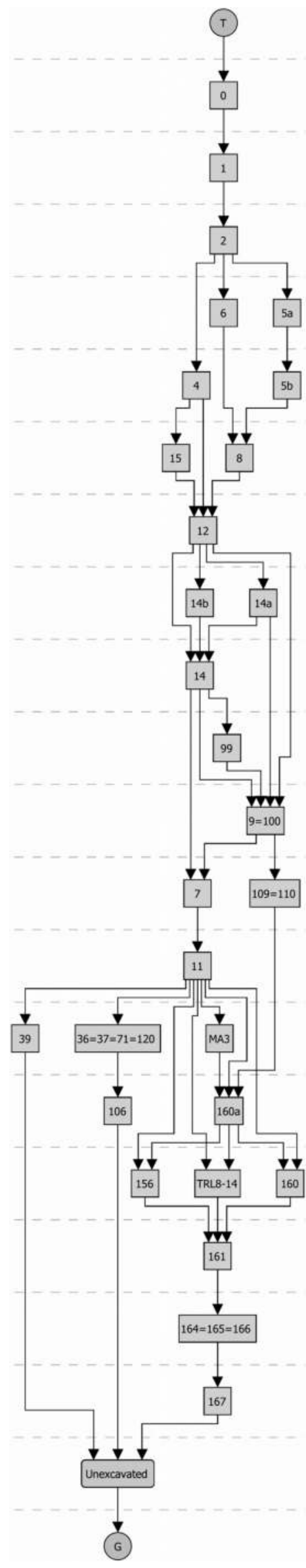


te Aussage nicht gemacht werden kann. Ab Mauer MA14 lassen sich die Rohrstränge nicht mehr weiter verfolgen. Sie biegen dort aber stark nach unten und sind im weiteren Verlauf durch Mauer MA16 geschützt (Taf. 241 Abb. 496; 242 Abb. 497).

Eine vergleichbare Situation gibt es am unteren Ende von Treppe-West. Hier dient die ebenfalls geböschte Mauer MA29 an der späten Insula(?)-Mauer MA27 der Führung von TRL20. Aus dem Gesamtbefund von Treppe-Ost lässt sich mit einiger Vorsicht aber doch folgendes Bild zeichnen. Die Mauer MA14 (Taf. 239 Abb. 492; 242 Abb. 499) diente zur Stabilisierung der durch das schwere Erdbeben im 3. Jh. n. Chr. in Mitleidenschaft gezogenen Mauer MA10 der Insula. Wie vermutlich die Häuser ${ }^{211}$, wurde auch die Stiegengasse im östlichen Abschnitt nicht mehr vollständig vom Erdbebenschutt befreit. MA14 bildete nach ihrer Errichtung zunächst die untere Schuttgrenze. Zeitgleich oder später erfolgte die Verlegung der Rohrleitungen. Diese wurden östlich der Mauer MA14 in den dort lagernden Schutt eingegraben, westlich von MA14 aber hinter der zu diesem Zweck errichteten Mauern MA16 und MA17 geführt.

Im Gegensatz zur Treppe-Ost scheint die Akademiegasse, zusammen mit dem Podest ES3 (Taf. 215 Abb. 444), nach dem Erdbeben vom Schutt befreit worden zu sein. Dafür sprechen die Umgestaltung des Zugangspodests und die lange Nutzung des Vorplatzes, wie im Folgenden noch näher erläutert wird. Mit der Entfernung der Stufensteine, die zur Schließung des Eingangs ES2 führten, wurde auch die Treppe selbst praktisch unpassierbar. Sie hatte also ihre Bedeutung nicht nur hinsichtlich der Erschließung der Theatereingänge verloren, sondern auch ihre Funktion als Straßenverbindung eingebüßt. Das Gelände blieb aber nicht gänzlich sich selbst überlassen. Der zwischen dem gallienschen Erdbebenschutt und der Theatermauer verbleibende Streifen wurde im 5./6. Jh. n. Chr. mit einem groben Schuttpaket, bestehend aus den Straten SE $154=157$, SE 30, SE $29=131=144$, SE 141 $=142$, SE $20=132 \mathrm{a}-\mathrm{c}$ und SE 137, angefüllt. Westlich des Podests ES3 wurde der Schutt eben abgezogen und eine $8,0 \times 4,0 \mathrm{~m}$ große Halle darauf errichtet (Taf. 222 Abb. 457; 223 Abb. 460; 224 Abb. 461. 462; Plan 12). Das Gebäude ist aus Ziegeln und Ziegelbruch in sekundärer Verwendung errichtet. Für das kurze Stück der Ziegelmauer MA4a wurden die Stufen 32 und 33

\footnotetext{
${ }^{211}$ LAdSTÄtTER 2002, 37-39.
}

Grafik 7:

Harris-Matrix über dem oberen Treppenabschnitt (ES2-ES3)

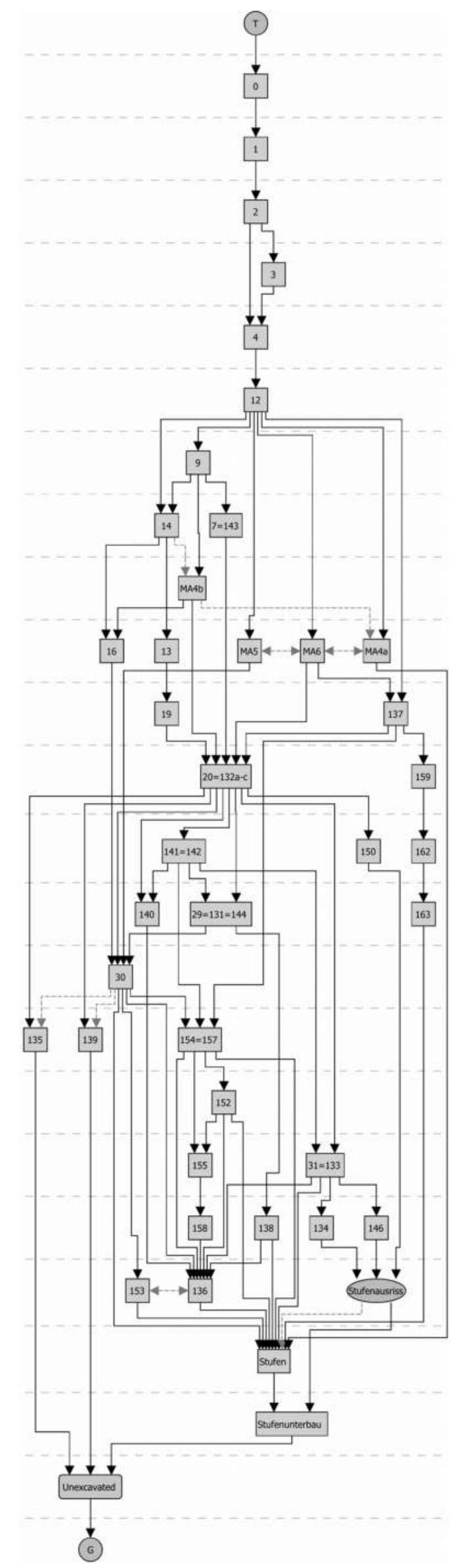


als Unterbau verwendet (Taf. 226 Abb. 465; 229 Abb. 472). Die Mauern MA5 (Taf. 223 Abb. 459; 228 Abb. 470) und MA6 (Taf. 226 Abb. 466; 227 Abb. 467. 468; 228 Abb. 469) dagegen wurden direkt auf die Schuttplanierung gestellt. Dementsprechend zeigen sich gerade an MA6 Verformungen über die gesamte Länge. Dabei handelt es sich um Senkungen, die im mittleren Bereich mit einer horizontalen Verschiebung einhergehen. Entlang der Theateraußenmauer gab es keine Mauer (Taf. 227 Abb. 468). Das Hallendach - sofern vorhanden - muss hier direkt an die Theatermauer angeschlossen haben. Die Ostseite war allem Anschein nach zunächst offen. Nur im Bereich der Südmauer MA5 gab es das kurze Wandstück MA4a von 1,30 m Länge (Taf. 226 Abb. 465). Zwischen MA4a und der Theateraußenmauer dürften offensichtlich Stützen aus Holz das Dach getragen haben. Später wurde dieser Bereich durch eine aus Spolien, Ziegelbruch und Wandstücken bestehende Mauer MA4b geschlossen (Taf. 224 Abb. 461; 225 Abb. 463. 464; 226 Abb. 465; 228 Abb. 471). Innerhalb der Halle wurden die verstürzten Reste der Mauern MA4a und b vorgefunden (Taf. 222 Abb. 458). Der Schutt der Westmauer MA6 ist in Richtung des Zugangspodests ES2 abgerutscht. Die Halle zeigt jedenfalls deutlich, dass auch nach der Aufgabe der Stiegengasse die Akademiegasse bis zum Theater intakt gewesen sein dürfte. Wieweit das auch für den Theaterzugang ES3 (Taf. 213 Abb. 439) gilt, kann nicht gesagt werden. Der Verschluss von ES3 unterscheidet sich deutlich von den Verschlüssen der Eingänge ES1 (Taf. 286 Abb. 582) und ES2 (Taf. 251 Abb. 512). Daraus könnte also durchaus ein unterschiedliches Alter der Torverschlüsse abgeleitet werden.

Das Keramikmaterial der Schuttverfüllung an der Innenseite von ES3 (S 3/1998) reicht allerdings kaum über das 3. Jh. n. Chr. hinaus ${ }^{212}$. Die Verbringung des Materials könnte mit dem Erdbeben in der Regierungszeit des Gallienus in Verbindung gebracht werden. Der Eingang ES3 wäre folglich bereits verschlossen gewesen, als man die Halle am oberen Ende der Stiegengasse errichtete. Damit ist eine gleichzeitige Nutzung des Eingangs ES3 und des nunmehr eingerichteten Vorplatzes mit der Halle auszuschließen. Jedoch finden sich auch in den meterhohen Schuttschichten an den Außenseiten von ES3 Schichten, die zwar den Vorplatz und die Halle bedeckten, aber das Produkt einer inversen Stratigrafie darstellen und somit deutlich älter als der Hallenbau sind. Diese inversen Schichten wurden wohl im Laufe der Zeit durch immense Hangrutschungen und Erosion gebildet.

Die Mauern MA3a und MA3b waren bereits beseitigt, als SE 11 über dem Vorplatz zu liegen kam (Plan $15)^{213}$. Die Schicht dürfte mit SE 31 über den Aufrissstellen der Treppe-Ost zusammengehören und muss der Zeit nach der Aufgabe der Treppe und der Errichtung der Halle angehören. Dasselbe gilt für den darüber liegenden Schutt SE $7=143$. Die Keramikfunde weisen ihn frühestens in das 2. Viertel des 4. Jhs. n. Chr. Dazu gesellen sich Münzen mit Prägezeiten bis in die Mitte des 3. Jhs. n. Chr. ${ }^{214}$. An der Schichtgrenze zwischen SE 11 und SE 7 wurde die Büste SK 81 gefunden ${ }^{215}$. SE 11 könnte eventuell ein spätes Bodenniveau darstellen, das der Zeit der Halle über Treppe-Ost angehört. SE $7=143$ dagegen setzt die Aufgabe der Halle bereits voraus. Aus dieser massiven Ziegel-Schuttschicht kamen außer einer vollständig erhaltenen Marmorsäule mit einer antiken Reparaturstelle keine anderen Architekturfragmente zum Vorschein (Taf. 208 Abb. 430; 209 Abb. 431. 432; 210 Abb. 433). SE 9 überdeckt bereits die Mauer MA4 und den Zerstörungsschutt dieser Mauer SE 13. Die Keramikfunde von SE 9 reichen bis in das 6. Jh. n. Chr., während alle darüberliegenden Schuttberge (SE 14; SE 12; SE 4) in ihrer Datierung variieren. Auf SE 4 aufliegend, umgeben von einer Schicht aus Mörtelgrieß, kleineren Steinen und humosen Einschlüssen, fanden sich zwei Brüstungspfeiler mit der Darstellung von Gladiatoren ${ }^{216}$. Sie sind mit den Namen Stephanos (SK 85, Taf. 398 Abb. 677-680; 399 Abb. 681-683) und Aithales (SK 86, Taf. 400 Abb. 685-688; 401 Abb. 689-691) gekennzeichnet. Bis in die 1970er Jahre lagen die Pfeiler dicht unter der Hangoberfläche. SK 85 ragte mit einer Ecke sogar aus der Humusschicht SE 1 heraus. Zu den jüngsten Befunden gehört eine kleine Ziegelmauer über SE 4, im Anschluss an das südliche Ende von MA2 (Taf. 207 Abb. 427; 216 Abb. 445). Ein sehr schlecht erhaltenes Mauerstück der Insula-Ostmauer MA9 ragte aus der Hangoberfläche heraus (Taf. 207 Abb. 428; 208 Abb. 429) und wurde durch den Grabungsschutt aus den 1970er Jahren stark in Mitleidenschaft gezogen. Der Schuttkegel wurde in den Jahren 1998, 2007 und 2008 vollständig abgetragen ${ }^{217}$. Bei der Freilegung eines kleinen Teils des Raums an der Nordostecke der Insula wurden die obersten losen Ziegel der Mauer MA9 entfernt (Taf. 232 Abb. 478).

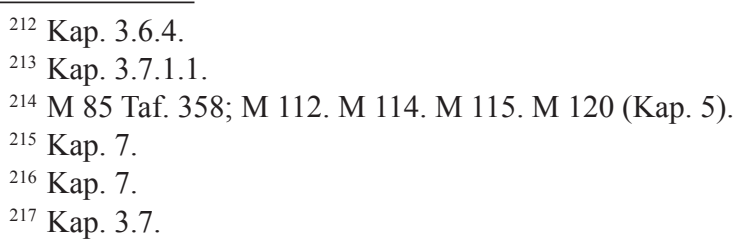


Zumindest SE 9 beweist, dass die Schuttmassen über dem Zugangspodest ES3 und der Halle nicht vor dem 6. Jh. n. Chr. abgelagert wurden. Das passt zu den Erkenntnissen aus der Freilegung der AristionLeitung ${ }^{218}$ : Das Areal im Süden des Theaters war bereits seit dem 4. oder 5. Jh. n. Chr. nicht mehr vollflächig genutzt. Zwischen dem Theater und der noch immer dekorativen Kuretenstraße scheint es große, brachliegende Bereiche gegeben zu haben. Hier gab es stellenweise auch kein jüngeres Material, das in die Zerstörungsschichten hätte gelangen können. Wie die Grabungen im Bereich des sogenannten byzantinischen Palasts und des Hafengymnasiums gezeigt haben, kam es ab dieser Zeit zu einer zunehmenden Verlagerung des städtischen Zentrums nach Nordwesten. Der Bau des byzantinischen Stadtmauerrings, an dessen Südseite das Theater eingebunden war, zeugt klar von diesem Vorgang. Während, mit Ausnahme der Kuretenstraße selbst, die südlichen Stadtteile eine zunehmend untergeordnete Rolle spielen, kommt es zu einem regen Ausbau des Gebiets nördlich und nordwestlich des Theaters. Die aus dem späten 4. Jh. n. Chr. stammenden gewaltigen Sicherungs- und Umbaumaßnahmen am Nordflügel des Theaters ${ }^{219}$, die wie eine imposante Fassade nach Norden hin gewirkt haben müssen, kündigen dieses Phänomen bereits an.

\subsubsection{ZugANGSPODEST ES2}

\begin{tabular}{|c|c|c|c|}
\hline Schicht & Beschreibung/Interpretation & Keramik & Münzen \\
\hline SE 168 & $\begin{array}{l}\text { mittelbraune Erde mit Mörtelbrocken, Steinen und } \\
\text { Ziegelbruch }\end{array}$ & $\begin{array}{l}\text { 2. H. 4. Jh. n. Chr.-- } \\
\text { byzantinisch }\end{array}$ & - \\
\hline SE 169 & lockerer Ziegelschutt mit Sand und Mörtelgrie $\beta$ & 3.-4. Jh. n. Chr. & - \\
\hline SE 170 & $\begin{array}{l}\text { mittelbrauner, sandiger Schutt mit grauem Mörtel, } \\
\text { Ziegelstücken und Steinen }\end{array}$ & 4.-1. H. 7. Jh. n. Chr. & $\begin{array}{l}\text { M } 66 \\
\text { (Severus Alexander) }\end{array}$ \\
\hline SE 171 & $\begin{array}{l}\text { dunkelbraune Erde mit Holzkohle, Ziegelstücken, Steinen, } \\
\text { Austernschalen und Schneckenhäusern }\end{array}$ & $\begin{array}{l}\text { 2. H. 4./Anfang 5. Jh. n. } \\
\text { Chr. }\end{array}$ & - \\
\hline SE 172 & dunkelbraune Erde mit Holzkohle und Ziegelstücken & 2.-3. Jh. n. Chr. & - \\
\hline SE 173 & braune Erde mit Ziegelbruch, Steinen und Mörtelbrocken & 2.-3. Jh. n. Chr. & - \\
\hline SE 174 & grauer, verfestigter Schutt & $\begin{array}{l}\text { Ende 4.-Mitte 5. Jh. n. } \\
\text { Chr. }\end{array}$ & $\begin{array}{l}\text { M } 70 \\
\text { (Gordianus III.) }\end{array}$ \\
\hline SE 175 & braune Erde mit Ziegelbruch, Steinen und Mörtelbrocken & 4. -5 . Jh. n. Chr. & - \\
\hline SE 176 & $\begin{array}{l}\text { hellbrauner, sandiger Schutt mit Mörtel u. kleinteiligem } \\
\text { Ziegelbruch }\end{array}$ & $\begin{array}{l}\text { Ende 2.-3. Jh. n. Chr.- } \\
\text { spätantik }\end{array}$ & - \\
\hline SE 179 & $\begin{array}{l}\text { Schicht aus Bruchsteinen verschiedener Größe; wenig } \\
\text { Ziegel; alles in sehr losem Mörtelgrieß; sehr locker }\end{array}$ & 5.-6. Jh. n. Chr. & - \\
\hline SE 181 & graubrauner Sand mit ganz wenigen Ziegelstückchen & 2. H. 4. Jh. n. Chr. & - \\
\hline SE 182 & dünnes, sandiges Niveau direkt über der Platzpflasterung & $\begin{array}{l}\text { 1. Jh. v. Chr.-1. Jh. n. } \\
\text { Chr. }\end{array}$ & - \\
\hline SE 183 & hartes, sandiges Niveau im Bereich von Pflasterfehlstellen & 2.-3. Jh. n. Chr. & - \\
\hline SE 184 & lockerer Sand über dem Treppenansatz im Westen & um 400 n. Chr. & - \\
\hline SE 187 & massiver Ziegelversturz & 2.-3. Jh. n. Chr. & - \\
\hline SE 190 & Mörtelschicht über Pflasterung & - & - \\
\hline SE 191 & einlagige Steinsetzung aus Bruchsteinen & - & - \\
\hline SE 204 & $\begin{array}{l}\text { feste, sandige Schicht mit wenigen Steinen und } \\
\text { Mörtelgrieß }\end{array}$ & - & - \\
\hline SE 205 & Ausgleichsschicht aus Mörtel über dem Treppenunterbau & - & - \\
\hline
\end{tabular}

Tab. 52

\footnotetext{
${ }^{218}$ Kap. 3.6.1.

${ }^{219}$ IvE 204. 2044; s. auch Kap. 8.6.1, Nr. 12 u. 13 u. Kap. 8.6.2.
} 
An der Südwestecke wurde 2008 Schnitt S 7/2008 angelegt. Damit konnte der Ausriss des Pflasters und eine späte Mauer MA36 festgestellt werden (Taf. 248 Abb. 508). Im selben Jahr erfolgte die Freilegung der östlichen Hälfte (Grabungsflächen E1 und E2). Die westliche Hälfte (F1 und F2) wurde 2009 vom Schutt befreit. Das Zugangspodest ES2 ist stratigrafisch mit der Treppe-Ost nicht mehr zu verbinden. Es fehlen die direkten Anschlüsse im Osten und auch nach Westen und Süden hin ergeben sich durch jüngere Aktivitäten, wie z. B. Steinraub und Restaurierung sowie die durch den Schutzzaun entstandenen Geländeveränderungen, Unklarheiten. Der antike Bodenbelag ist hier größtenteils erhalten (Taf. 251 Abb. 513). Lediglich nach Süden und Westen hin lässt sich ein massiver Ausriss feststellen. Vereinzelte Fehlstellen im Pflaster sind mit einem sehr festen, sandigen Material SE 183 geschlossen. Das spärliche Fundmaterial lässt allerdings keine Datierung zu. Der Anschluss an die TreppeWest ist nicht mehr erhalten (Taf. 251 Abb. 513). Wie im folgenden Unterkapitel noch genauer dargestellt werden soll, wurden die Marmorquader der Treppe demontiert, sodass nur mehr der Unterbau der Treppe erhalten blieb. Reste des Mörtelbetts SE 205 geben die Lage der obersten Stufe an. Von hier beginnt sich eine lockere, sandige Schuttschicht SE 184 (entspricht SE 193 auf Treppe-West) über den Treppenunterbau bis zum Treppenabsatz hinunter zu ziehen. Einer Zeit vor der Aufgabe der Treppen gehört Mauer MA18 an (Taf. 250 Abb. 510. 511). Die kleine Mauer befindet sich nahe der Nordostecke des Podests. Diese wurde direkt über dem Pflaster errichtet und reicht bis zu der die Insulamauer begleitenden, geböschten Mauer MA17 heran. Mit den Mauern MA34 und MA35 dürfte sie aber nichts zu tun haben. MA18 scheint wie MA14 und MA15 zur Stabilisierung der Insula-Außenmauer errichtet worden zu sein ${ }^{220}$. Über Teilen der intakten Pflasterung sowie den durch SE 183 gebildeten >Reparaturstellen` war eine dünne Sandschicht SE 182 festzustellen (Taf. 249 Abb. 509; Plan 15. 16). Im Bereich der Südwestecke des Podests haben sich Reste eines verfestigten Kalkmörtelniveaus SE 190 direkt über dem Pflaster erhalten. Die Schicht ist bis etwa $10 \mathrm{~cm}$ stark und enthielt keinerlei Fundmaterial. Interessant ist die im Süden des Podests teils über dem Pflaster, teils über dem Mörtel SE 190 befindliche Schicht SE 187. Es handelt sich dabei um ein bis zu 0,60 m hohes, dichtes Niveau aus Brocken an Ziegelmauerwerk. Diese Situation erinnert stark an den

\footnotetext{
${ }^{220}$ Kap. 3.7.2.1.
}

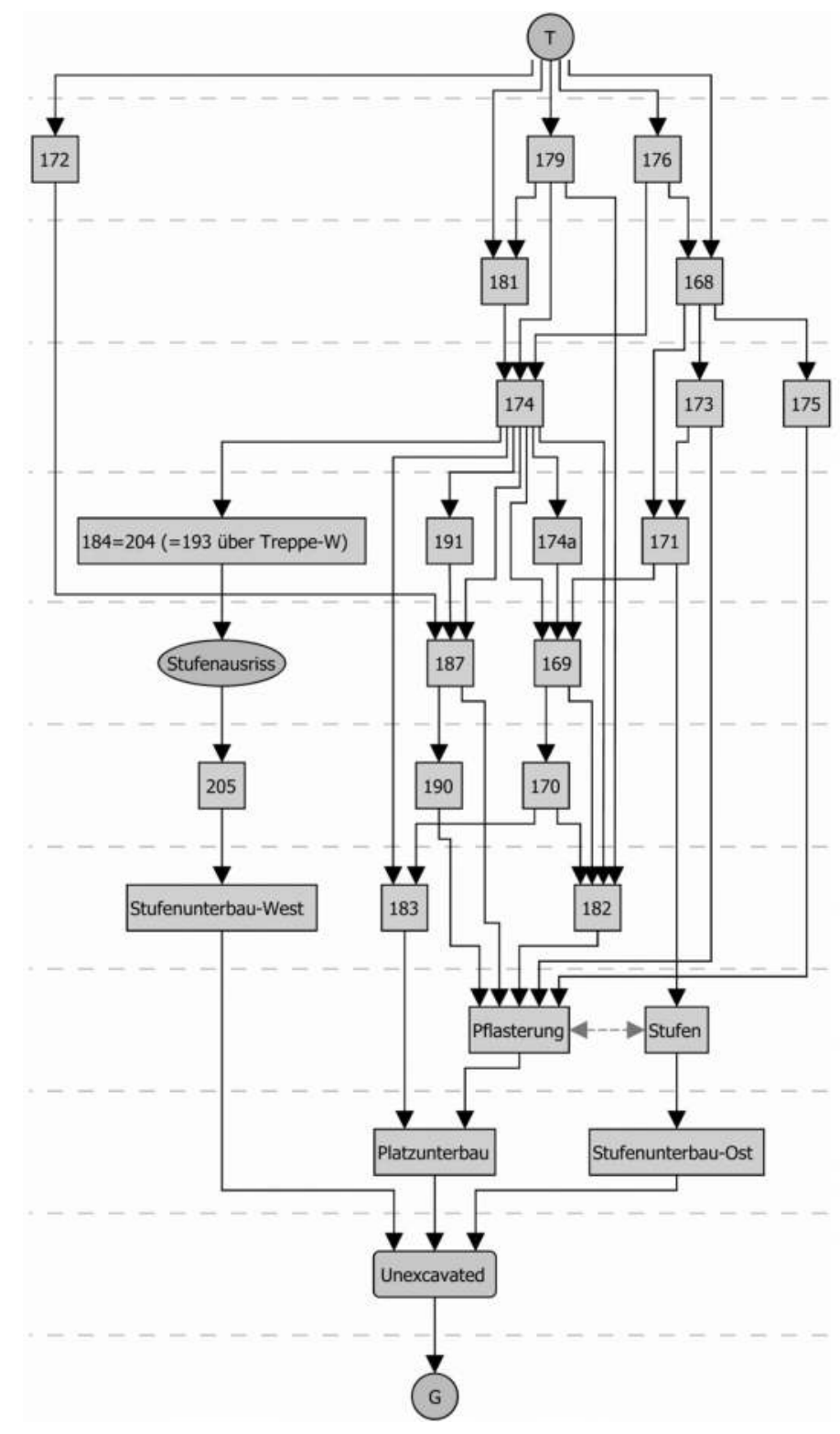

Grafik 8: Harris-Matrix über Zugangspodest ES2 
Zerstörungsschutt über dem Südteil der Treppe-Ost. Auch die Zeitstellung, die sich aus dem Fundmaterial ablesen lässt, ist entsprechend. Gleiches trifft auch auf die Schichten SE 171 (über den unteren beiden Stufen von Treppe-Ost) und - mit Vorbehalt - auch auf die westlich von MA 18 gelegenen Schichten SE 187 und $172 \mathrm{zu}$. Alle befanden sich an der Südseite des Podests ES2. Haben sich somit - wie über der Südseite von Treppe-Ost - weitere Spuren von teilweise nicht mehr beseitigtem Zerstörungsschutt des gallienischen Erdbebens gefunden? Hier ist doch Vorsicht geboten. Für das Material östlich von MA 18 (SE 171. 172) dürfte das zutreffend sein. Es handelt sich um Reste des Schutts, der sich über der Treppe befand und durch die Mauer MA18 an einer weiteren Ausbreitung nach Westen gehindert wurde. SE 187 und 172 dagegen befinden sich westlich der Mauer MA18. Von beiden Straten konnten nur mehr Reste festgestellt werden. Dementsprechend gering ist auch das darin enthaltene Keramikmaterial. Der Übergang zu dem nach Norden hin verlaufenden Schuttpaket (SE 170. 169. 174a. 174. 176) stellte sich als so fließend dar, dass man von keiner exakten Schichtgrenze sprechen kann. Einzig die im Verband verbliebenen Ziegelbrocken kommen nördlich von SE 187 nicht vor. Das Fundmaterial aus dem Paket darüber (SE 170. 169. 174a. 174. 176) gehört im Wesentlichen späterer Zeit an und reicht jedenfalls bis in das 5. Jh. n. Chr. Über SE 187 fanden sich Reste einer einfachen Steinsetzung (SE 191), vermutlich eine Schuttsperre. Sie verläuft von Ost nach West und schloss vermutlich an Mauer MA18 an (Taf. 248 Abb. 507).

Von den im 6. Jh. n. Chr. über der Treppe-Ost abgelagerten Schuttmassen muss auch das Podest ES2 betroffen gewesen sein. Zumindest gibt es keine Hinweise auf bauliche Einrichtungen, die den Schutt über der Treppe vom Podest fernhalten hätten können. Nach Aufgabe der Treppe und des Zugangs ES2 war auch das zugehörige Podest nicht mehr von Nöten.

\subsubsection{Unterer Treppenabschnitt und ZugangSPODEST ES1}

Mit Ausnahme der untersten dreieinhalb Stufen und Stufe 10 wurde die Treppe-West sämtlicher Marmorblöcke beraubt (Taf. 272 Abb. 555; 287 Abb. 584). Es lassen sich somit keine Aussagen über den Zeitraum vor der Demontage der Treppenoberfläche machen. Somit wissen wir auch nicht, ob es hier nach dem gallienischen Beben eine mit Treppe-Ost vergleichbare Situation gegeben hat, was den Erdbebenschutt betrifft. Die Tatsache jedoch, dass die Demontage der Treppensteine konsequent über die gesamte Breite erfolgen konnte, spricht $\mathrm{m}$. E. für keinerlei Nutzungsbeschränkungen in der Zeit zwischen dem Erdbeben und der Aufgabe des Treppenabschnitts. Die Steine wurden zum Verschluss von ES1 und der Barriere im Wasserleitungskanal verwendet ${ }^{221}$. Lediglich am unteren Abschnitt sind die bereits erwähnten dreieinhalb Stufen in situ erhalten geblieben. Auch an Stufe 10, über der die Mauer MA23 (Taf. 271 Abb. 554; 272 Abb. 555. 556) errichtet wurde, und am Treppenabsatz im oberen Abschnitt von Treppe-West (Taf. 281 Abb. 572) blieb die Marmoroberfläche bestehen. Ausnehmungen für die Stufen sind auch immer wieder an der Außenmauer des Theaters sichtbar (Taf. 275 Abb. 561; 276 Abb. 562; 277 Abb. 564).

Man kann davon ausgehen, dass MA23 nicht vor dem Ausriss der Treppensteine errichtet wurde. Sonst müsste auch an Stufe 11 der Marmorbelag verblieben sein. Das ist aber nicht der Fall (Taf. 271 Abb. 554). Die Aufgabe der Treppe mit Demontage der Stufen und die Errichtung von Mauer MA23 müssen zeitlich zusammenfallen, sonst hätte man sich wohl nicht entschieden, den Belag von Stufe 10 als Unterbau für die Mauer MA23 zu belassen. Die Mauer bestand ursprünglich aus einer Steinlage über Stufe 10 und einigen Ziegellagen, die eine Zone mit mehreren Entwässerungsrohren bildeten (Taf. 272 Abb. 556; 274 Abb. 559). Drei dieser Rohre sind erhalten. Darüber ändert sich das Material abermals; größere Bruchsteine, die mit kleineren, flachen Steinen als Ausgleich wechseln. Insgesamt ist das Mauerwerk sehr sorgfältig ausgeführt, was aber nicht für die gesamte Mauer MA23 gilt. Etwa $1 \mathrm{~m}$ südlich der Theateraußenmauer ändert sich das Bild. Von hier, zunächst bis Rohr drei über der Ziegelschicht, schließlich bis auf das Niveau von Stufe 10 verlaufend, zeigt sich das Mauerwerk recht unregelmäßig. Bruchsteine verschiedenster Größe sind willkürlich übereinandergeschichtet. Horizontal verlaufende Steinlagen sind nicht erkennbar. Allem Anschein nach wurde MA23 zerstört oder zerfiel und wurde wieder aufgebaut.

\footnotetext{
${ }^{221}$ Kap. 3.6.1.
} 


\begin{tabular}{|c|c|c|c|}
\hline Schicht & Beschreibung/Interpretation & Keramik & Münzen \\
\hline SE 21 & Oberflächenhumus; umgelagert und rez. gestört & - & - \\
\hline SE 21a & dünne Lage aus kleinen Steinchen & - & - \\
\hline SE 22 & $\begin{array}{l}\text { sehr lockerer Schutt mit Steinen, Erde, Sand und } \\
\text { Mörtelgrieß; rezent umgelagert }\end{array}$ & - & - \\
\hline SE 23 & $\begin{array}{l}\text { Zerstörungsschutt vom Theater: sehr lockere, weißgraue } \\
\text { - stellenweise auch rötliche - Mörtelschicht mit wenigen } \\
\text { Steinen und Mauerquadern }\end{array}$ & - & - \\
\hline SE 24 & $\begin{array}{l}\text { Zerstörungsschutt vom Theater: sehr harte, weißgraue - } \\
\text { stellenweise auch rötliche - Mörtelschicht }\end{array}$ & - & - \\
\hline SE 25 & rötlich brauner Ziegelschutt. Enthält sehr viel Ziegelbruch & kaiserzeitlich & - \\
\hline $\begin{array}{l}\text { SE } 122= \\
\text { SE } 210\end{array}$ & $\begin{array}{l}\text { verfestigte graubraunes Erde mit zahlreichen Ziegelstücken } \\
\text { und Steinen. }\end{array}$ & 6. Jh. n. Chr. & - \\
\hline SE 123 & dünnes, weißgraues Mörtelband & 5.-6. Jh. n. Chr. & - \\
\hline $\begin{array}{l}\text { SE } 124= \\
\text { SE } 219\end{array}$ & $\begin{array}{l}\text { verfestigte graubraune Erde mit Ziegelstücken und } \\
\text { Bruchsteinen. Ähnlich wie SE } 122\end{array}$ & 6. Jh. n. Chr. & - \\
\hline SE 179 & $\begin{array}{l}\text { Schicht aus Bruchsteinen verschiedener Größe. Wenig } \\
\text { Ziegel. Alles in sehr losem Mörtelgrieß; sehr locker }\end{array}$ & 5.-6. Jh. n. Chr. & - \\
\hline SE 180 & $\begin{array}{l}\text { Zerstörungsschicht zu Mauer MA 19: dichte Lage aus } \\
\text { Ziegelbruch um und über MA19 }\end{array}$ & kaiserzeitlich? & - \\
\hline SE 185 & Grubenverfüllung: lockere, braune Erde mit Steinen & - & - \\
\hline SE $185 \mathrm{a}$ & Grube & - & - \\
\hline SE 186 & $\begin{array}{l}\text { Zerstörungsschutt von MA 20: Ziegel- und Steinversturz in } \\
\text { teilweise harter, rötlich brauner Mörtelbindung }\end{array}$ & 6. Jh. n. Chr. & - \\
\hline $\begin{array}{l}\text { SE } 188= \\
\text { SE } 199 a\end{array}$ & $\begin{array}{l}\text { braune, sandige Erde; sehr fest; wahrscheinlich von SE } 198 \\
\text { abgesacktes Material }\end{array}$ & - & - \\
\hline SE 189 & braune, sandige Erde & 5. Jh. n. Chr. & - \\
\hline SE 192 & $\begin{array}{l}\text { lockere, braune Erde mit kleinen Ziegelstücken, Keramik } \\
\text { und wenigen Marmorplattenfragmenten }\end{array}$ & 3. Viertel 3. Jh. n. Chr. & - \\
\hline $\begin{array}{l}\text { SE } 193= \\
\text { SE } 194\end{array}$ & $\begin{array}{l}\text { graubraunes, leicht sandiges Material. Locker, mit kleinen } \\
\text { Ziegelstücken, Steinen und Holzkohle; kleinteilige Keramik }\end{array}$ & 3. Viertel 3. Jh. n. Chr. & $\begin{array}{l}\text { M } 35 \\
\text { (Antoninus Pius) }\end{array}$ \\
\hline SE 195 & $\begin{array}{l}\text { grau und braun gesprenkelte Schicht; feines, lockeres } \\
\text { Material }\end{array}$ & 6. Jh. n. Chr. & $\begin{array}{l}\text { M } 127 \\
\text { (Maximianus I.) }\end{array}$ \\
\hline SE 196 & $\begin{array}{l}\text { Versturz von MA 20: Schutt aus vielen großen } \\
\text { Bruchsteinen und Ziegeln }\end{array}$ & $\begin{array}{l}\text { spätantik- } \\
\text { frühbyzantinisch }\end{array}$ & $\begin{array}{l}\text { M } 47 \\
\text { (Antoninus Pius) }\end{array}$ \\
\hline SE 197 & $\begin{array}{l}\text { Ziegelschutt westlich von MA 21. Sehr lockeres Material } \\
\text { mit großen Ziegelfragmenten und kleineren Steinen; } \\
\text { vermutlich Versturz von MA21 }\end{array}$ & 6. Jh. n. Chr. & - \\
\hline $\begin{array}{l}\text { SE } 198= \\
\text { SE } 207\end{array}$ & $\begin{array}{l}\text { braune, sandige Erde mit Ziegelstücken, Steinen und } \\
\text { Mörtelbrocken, teilweise sehr fest }\end{array}$ & 1. H. 5. Jh. n. Chr. & $\begin{array}{l}\text { M } 19 \\
\text { (2. Jh. n. Chr.) }\end{array}$ \\
\hline SE 199 & Hohlraum unter SE 198 = SE207 entstanden & - & - \\
\hline SE 200 & feiner, loser Sand & spätes 2./3. Jh. n. Chr. & $\begin{array}{l}\text { M } 87 \\
\text { (Philippus I.) }\end{array}$ \\
\hline $\begin{array}{l}\text { SE } 201= \\
\text { SE } 206\end{array}$ & massiver Ziegelschutt mit Bruchsteinen & 3./4. Jh. n. Chr. & - \\
\hline
\end{tabular}




\begin{tabular}{|c|c|c|c|}
\hline Schicht & Beschreibung/Interpretation & Keramik & Münzen \\
\hline SE 202 & graubraune Erde zwischen MA 21 und MA 23 & 5./6. Jh. n. Chr. & - \\
\hline SE 203 & $\begin{array}{l}\text { sandige, braune Schicht aus kleinteiligem Ziegelbruch, } \\
\text { Mörtelstückchen und Holzkohle; sehr locker }\end{array}$ & 6. Jh. n. Chr. & - \\
\hline SE 208 & brauner, sandiger Schutt mit Steinen und Ziegelfragmenten & - & - \\
\hline SE 209 & $\begin{array}{l}\text { Versturz von MA 26: Rötlich brauner Schutt aus großen } \\
\text { Bruchsteinen, Ziegeln und fester Erde }\end{array}$ & Ende 4.-5. Jh. n. Chr. & - \\
\hline SE 209a & rötlich brauner Schutt. & - & - \\
\hline SE 209b & brauner Schutt Steinen und Ziegelstücken & - & - \\
\hline SE 211 & $\begin{array}{l}\text { Fundamentgrube unter MA25: Braune, sandige Erde mit Mör- } \\
\text { telgrieß, Holzkohle, Ziegelfragmenten und kleinen Steinen }\end{array}$ & - & - \\
\hline SE 212 & $\begin{array}{l}\text { graubraunes, sandiges Material mit Holzkohle und } \\
\text { Mörtelbrocken; kaum Ziegel oder Steine }\end{array}$ & $\begin{array}{l}\text { kaiserzeitlich-3. Jh. n. } \\
\text { Chr. }\end{array}$ & - \\
\hline SE 213 & $\begin{array}{l}\text { Fundamentgrube unter MA26 und MA28: Brauner Schutt } \\
\text { mit kleinen Steinen }\end{array}$ & - & - \\
\hline SE 214 & Schotter & - & - \\
\hline SE 215 & braune, feste Schicht mit kleinen Steinen & - & - \\
\hline $\begin{array}{l}\text { SE } 217= \\
\text { SE } 218\end{array}$ & rötlicher Schutt & 2. Jh. n. Chr. & - \\
\hline SE 222 & $\begin{array}{l}\text { braune, feine Erde zwischen MA } 20 \text { und MA 30. Sehr } \\
\text { homogen }\end{array}$ & 5./6. Jh. n. Chr. & $\begin{array}{l}\text { M } 247 \\
\text { (byzantinisch) }\end{array}$ \\
\hline SE 223 & Steinsetzung aus großen Bruchsteinen ohne Mörtelbindung & - & - \\
\hline $\begin{array}{l}\text { SE } 225= \\
\text { SE } 230\end{array}$ & $\begin{array}{l}\text { kompaktes, braunes Material mit wenig Ziegelbruch, } \\
\text { Mörtelbrocken und Holzkohle }\end{array}$ & - & - \\
\hline SE 227 & $\begin{array}{l}\text { schwarzbraunes, lockeres Material mit vielen kleinteiligen } \\
\text { Keramikfragmenten und Ziegelsplitt }\end{array}$ & 4.-1. H. 7. Jh. n. Chr. & - \\
\hline SE 228 & $\begin{array}{l}\text { braunes, lockeres Material mit vielen Mörtelbrocken, } \\
\text { kleinen Ziegelstücken und kleinen Steinen. Ähnelt SE } 207\end{array}$ & - & - \\
\hline SE 229 & $\begin{array}{l}\text { Versturz von MA22. Lockerer Schutt mit vielen Steinen } \\
\text { und Mörtelgrieß }\end{array}$ & - & - \\
\hline
\end{tabular}

Tab. 53

Eine ganz ähnliche Situation lässt sich bei Mauer MA20 feststellen (Taf. 263 Abb. 538; 264 Abb. 539. 540). Im Gegensatz zu MA23 wurde MA20 jedoch nicht über den Stufensteinen errichtet, sondern direkt auf den Stufenunterbau gesetzt. Der nördliche Abschnitt besteht von Grund auf aus Bruchsteinen, wobei immer wieder mittels einzelner Ziegellagen ein horizontaler Ausgleich vorgenommen wurde. Eine Entwässerung ist, wie bei MA23, nicht vorhanden. Das alles könnte auf eine zeitlich versetzte Errichtung von Mauer MA20 deuten. In der südlichen Hälfte ist ganz klar eine vertikale Fuge zu erkennen, von der aus das Mauerwerk gegen Süden deutlich unregelmäßiger wird und womöglich in Zusammenhang mit der Wiederherstellung des Mauerzugs (MA20) steht. Unregelmäßiges Mauerwerk findet sich auch auf einem kleinen Mauerstück nördlich der Vertikalfuge. Hier ist jedoch nur der unterste Bereich erhalten, und zwar dort, wo die Mauer sich im Übergang auf eine tiefere Stufe des Treppenunterbaus befindet. Wie im Fall der Mauer MA23 wird man aber von einer Zweiphasigkeit ausgehen können. Das Zerstörungsbild von MA20, geprägt von einem zunehmenden Ausriss gegen Süden, deckt sich mit dem von MA23. Es ist daher plausibel, das gleiche Ereignis für die Zerstörung anzunehmen. Aus dem Befund ergibt sich keine Erklärung für die Vertikalfuge in MA20. Allerdings schloss an der Westseite unmittelbar nördlich der Vertikalfuge von MA20 eine Mauer (MA30) an (Taf. 265 Abb. 541. 542), die aber nicht mehr auf dem Stufenunterbau gründet, 


\begin{tabular}{|c|c|c|c|}
\hline Schicht & Beschreibung/Interpretation & Keramik & Münzen \\
\hline SE 21 & Oberflächenhumus; umgelagert und rezent gestört & - & - \\
\hline SE 22 & $\begin{array}{l}\text { sehr lockerer Schutt mit Steinen, Erde, Sand und } \\
\text { Mörtelgrieß. Rezent umgelagert }\end{array}$ & - & - \\
\hline SE 23 & $\begin{array}{l}\text { Zerstörungsschutt vom Theater: sehr lockere, weißgraue } \\
\text { - stellenweise auch rötliche - Mörtelschicht mit wenigen } \\
\text { Steinen und Mauerquadern }\end{array}$ & - & - \\
\hline SE 24 & $\begin{array}{l}\text { Zerstörungsschutt vom Theater: sehr harte, weißgraue - } \\
\text { stellenweise auch rötliche - Mörtelschicht }\end{array}$ & - & - \\
\hline $\begin{array}{l}\text { SE } 122= \\
\text { SE } 210\end{array}$ & $\begin{array}{l}\text { verfestigte, graubraune Erde mit zahlreichen Ziegelstücken } \\
\text { und Steinen }\end{array}$ & 6. Jh. n. Chr. & - \\
\hline SE 123 & dünnes, weißgraues Mörtelband & 5.-6. Jh. n. Chr. & - \\
\hline $\begin{array}{l}\text { SE } 124= \\
\text { SE } 219\end{array}$ & $\begin{array}{l}\text { verfestigte, graubraune Erde mit Ziegelstücken und } \\
\text { Bruchsteinen; ähnlich SE } 122\end{array}$ & 6. Jh. n. Chr. & - \\
\hline SE 125 & Ziegelschutt & 6. Jh. n. Chr. & - \\
\hline SE 126 & dünnes Mörtelband & 5. Jh. n. Chr. & - \\
\hline SE 127 & $\begin{array}{l}\text { massive, graubraune bis rötliche Erde mit etwas Ziegel und } \\
\text { Bruchsteinen }\end{array}$ & 5. Jh. n. Chr. & $\begin{array}{l}\text { M } 99 \\
\text { (2.-3. Jh. n. Chr.) }\end{array}$ \\
\hline SE 130 & $\begin{array}{l}\text { hellbraune, leicht sandige Verfüllung mit Bruchsteinen und } \\
\text { Ziegel }\end{array}$ & spätantik & $\begin{array}{l}\text { M 10.19 } \\
\text { (Gallienus) }\end{array}$ \\
\hline SE 215 & $\begin{array}{l}\text { braune, feste Schicht mit kleinen Steinen. Konnte nur mehr } \\
\text { im Profil erfasst werden }\end{array}$ & - & - \\
\hline SE 216 & lockerer, sandiger Schutt mit Ziegelbruch und Steinen & 5.-6. Jh. n. Chr. & - \\
\hline SE 220 & $\begin{array}{l}\text { braune, leicht lehmige Erde über dem Pflaster von S1; sehr } \\
\text { homogen }\end{array}$ & spätantik/5. Jh. n. Chr.? & - \\
\hline
\end{tabular}

Tab. 54

sondern auf Schicht SE 198/207 gesetzt wurde. Sie gleicht im Aufbau zwar dem Abschnitt der MA20 südlich der Vertikalfuge, bindet aber in diese nicht ein. Die südliche Seite der Mauer MA30 ist auf Ansicht gearbeitet, während die nördliche in das Erdreich gesetzt ist.

Die nur mehr in Resten erhaltenen Mauern MA25 und MA28 liegen deutlich höher und haben mit MA20 nichts zu tun. Am ehesten sind die beiden Mauern MA20 und MA23 als Terrassierungen zu verstehen (Taf. 295 Abb. 593; 296 Abb. 594). Sie sollten das Gelände stabilisieren und das Zugangspodest ES1 vor herabrutschendem Schutt bewahren. Dieses Podest war, wie die parallelen Mauerzüge MA11 und MA12 zeigen (Taf. 282 Abb. 574), auch nach der Aufgabe des westlichen Treppenabschnitts und dem Verschluss des Theatereingangs ES1 weiterhin in Verwendung. Möglicherweise gehen mit der Anlage der Terrassierungen über der Treppe aber auch Arbeiten zur Wiederinstandsetzung in die Wohneinheiten der Insula südlich des Theaters einher. Einerseits konnte dadurch Schutt entsorgt werden, zum anderen ermöglichten die Terrassen eine wie auch immer geartete Vergrößerung der Nutzfläche, sei es in Form kleinerer Annexräume, in Form von Höfen oder kleinen Gärten. Die beiden Verfüllungen SE 189 und SE $198=207$ hinter MA23 wurde im 5./6. Jh. n. Chr. aufgebracht.

Die auf dem Podest ES1 errichteten Mauern MA11 und MA12 setzten am Torverschluss des Eingangs ES1 an (Taf. 282 Abb. 574). Wie bereits erwähnt, ist der Verschluss aus den Treppensteinen errichtet (Taf. 286 Abb. 582). Es gibt keine Hinweise, wozu die Mauern gedient haben und wie es um die Zugänglichkeit des Podests bzw. des darüber errichteten Gebäudes (?) bestellt war. Es fällt jedoch auf, dass gerade zwischen den Mauern MA11 und MA12 der Plattenbelag des ehemaligen Podests bis knapp vor den Theatereingang fehlt, während er östlich von MA11 bis zur Treppe vollständig erhalten ist und auch westlich von 


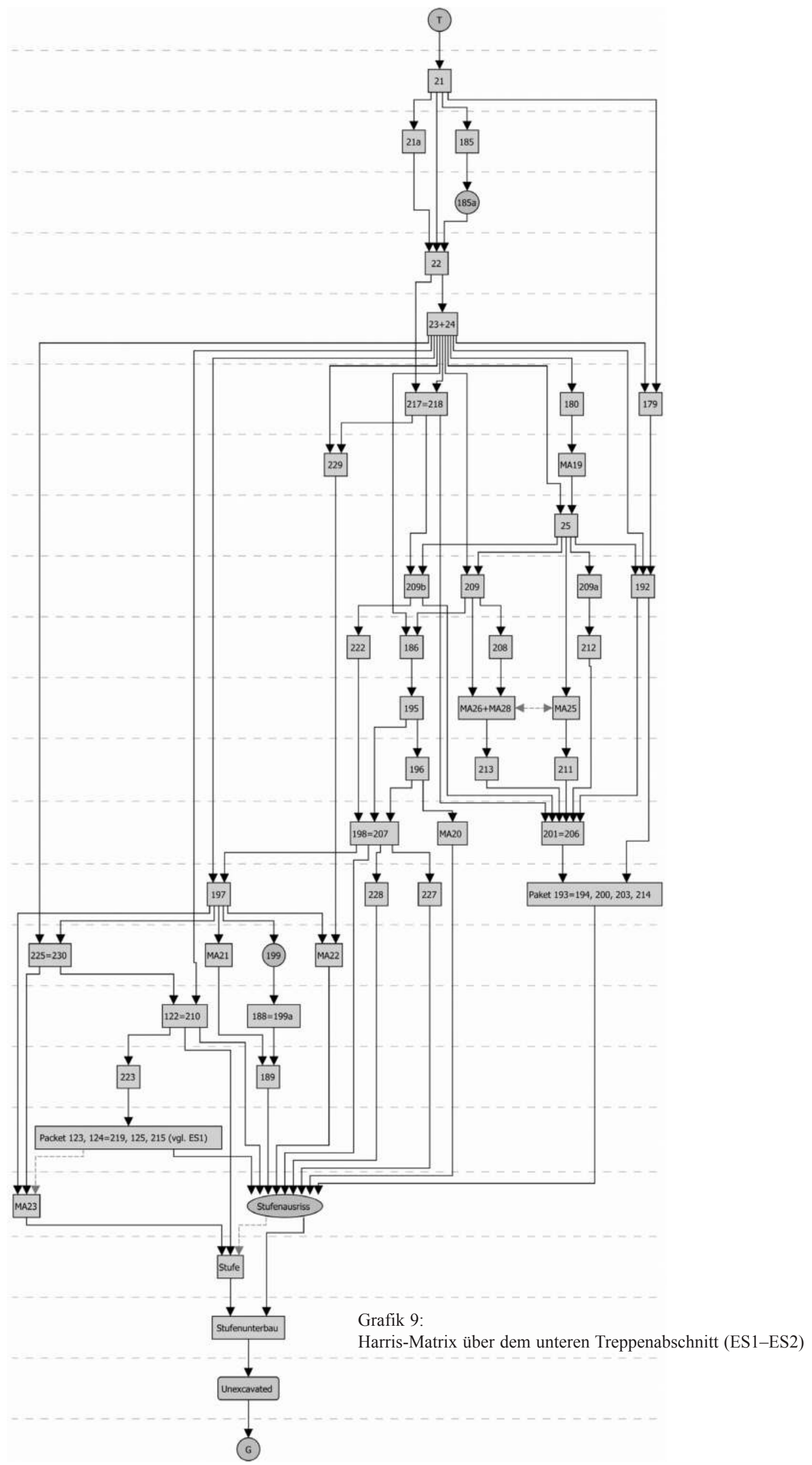


MA11 noch ein Stück weiter nach Süden reicht. MA11 ist über die gesamte Breite vom Theater bis zur Ost-West verlaufenden Mauer MA27 und der geböschten Wasserleitungstrasse MA29 erhalten. Wie aus den wenigen erhaltenen Resten der Treppensüdseite abzulesen ist, wurde die Mauer MA27 über der Treppe errichtet (Taf. 270 Abb. 551. 552; Plan 13. 16) ${ }^{222}$. Der kleine Mauerrest MA22 (Taf. 268 Abb. 548) weiter östlich bildet mit MA27 eine Flucht. Es ist sehr wahrscheinlich, dass sie ein und demselben Mauerzug angehörten, der nach der Aufgabe der Treppe hier errichtet worden war. MA11 lässt sich bis zum erhaltenen Abschluss des Plattenbelags fassen. MA12 wird beidseitig von sehr lockerem Schutt SE 216 (Plan 16) aus Steinen und Ziegeln bedeckt. Es handelt sich hierbei um den Zerstörungsschutt der Mauer MA12, der anhand des keramischen Fundmaterials in das 5./6. Jh. n. Chr. zu datieren ist. Im Süden befindet sich SE 125 ebenfalls zu beiden Seiten der Mauer MA12, liegt aber über SE 216 und reicht bis an die Oberkante von MA27 (Taf. 269 Abb. 549. 550). Nach Norden fällt das Niveau ab und ist schließlich nur mehr westlich von MA12 vorhanden. SE 125 ist als Zerstörung von MA27 zu interpretieren. Das Fundmaterial gehört bereits dem 6. Jh. n. Chr. an. Das gilt auch für das recht kompakte Stratum SE $124=219$, das MA27 bereits bedeckt. Die Oberfläche verläuft stellenweise auffallend horizontal oder weist nur ein geringes Gefälle auf. Das darüber verlaufende Mörtelniveau SE 123 sowie eine einfache Steinsetzung SE 223 (Taf. 275 Abb. 560) deuten auf eine zumindest kurzzeitige Nutzung des Niveaus über SE 124 $=219$. Fundmaterial aus dem 6 . Jh. $n$. Chr. ist aber genauso im Schutt SE 122 enthalten, der einer Zerstörung von Mauer MA23 angehören könnte.

Die Mauern MA20 und MA23 sowie MA11 und MA12 auf dem Podest ES1 bildeten nicht den letzten Hinweis auf bauliche Aktivitäten. Die Mauern MA20 und MA23 wurden entweder zerstört oder verfielen. SE 196 ist der Zerstörungsschutt der Mauer MA20, der auf die durch SE $198=207$ gebildete Terrasse fiel (Taf. 296 Abb. 594). SE195 dagegen ist Material, das einst hinter der Mauer MA20 lag und nach der Zerstörung über dem Mauerschutt SE 196 und die Terrassenoberfläche SE $189=207$ zu liegen kam. Ähnlich verhält es sich mit den Schichten SE $122=210$, SE $225=230$ und SE 197, die über den bereits besprochenen Schichten SE $124=219$, SE 125, SE 127, SE 215, SE 216 auf dem Podest ES1 und den Mauern MA11 und MA27 liegen.

Nach dem endgültigen Verfall der Mauern MA20, MA30 und MA23 wurde jedenfalls weiterhin der Versuch

\footnotetext{
${ }^{222}$ Kap. 3.7.1.4.
}

Grafik 10: Harris-Matrix über Zugangspodest ES1

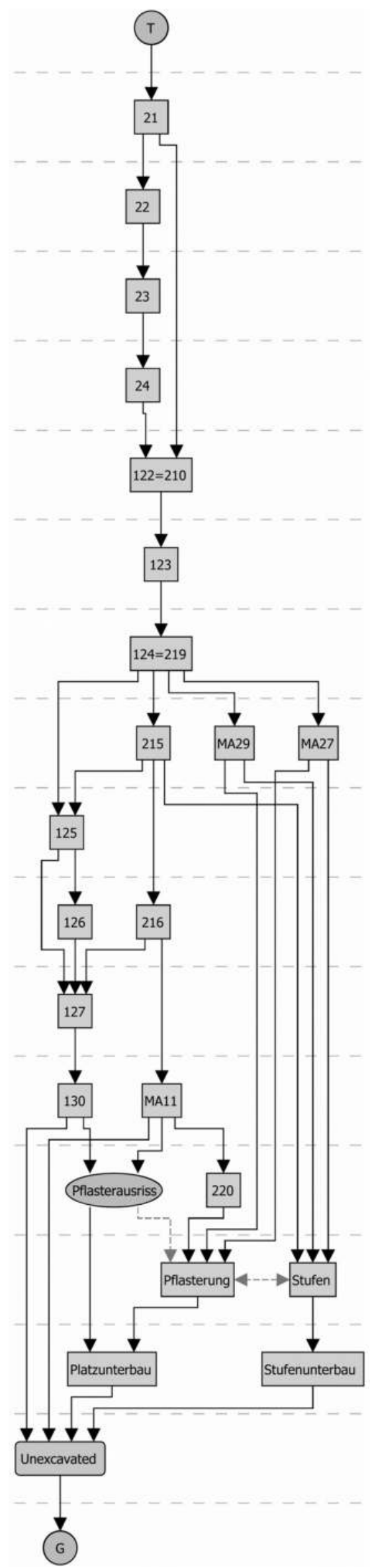


unternommen, das Gelände zu sichern. Mehrere kleine Mauern wurden gegen die Schuttmassen gesetzt. Dazu dürfte MA21 gehören (Taf. 266 Abb. 544; 268 Abb. 547), sicher aber MA25 und MA26. Alle diese Mauern zeigen eine sehr unregelmäßige Ostseite, die nie auf Sicht gearbeitet wurde. An MA26 (Taf. 262 Abb. 534. 535) schließt im rechten Winkel MA28 (Taf. 263 Abb. 536. 537) an. Diese ist nach Norden gleichfalls gegen den Hangschutt gesetzt gewesen. SE 222 wurde daher nur südlich von MA28 gefunden und liegt über einer späten Terrassierung. MA25 (Taf. 261 Abb. 532. 533) bildet in geringem Abstand quasi treppenförmig - eine weitere Terrassierung zu MA26 (Taf. 260 Abb. 530. 531). Mit MA19 (Taf. 258 Abb. 526; 259 Abb. 527-529) ist ein Rest der jüngsten Hangmauer gegeben, die über SE 25 errichtet wurde. SE 25 bedeckt den Mauerrest von MA25 bereits.

Alle über der Treppe-West befindlichen Schichten werden komplett von den Mörtelschichten SE 23 und SE 24 bedeckt. Diese sehr massive, im Fall von SE 24 teils sehr harte Schicht entlang des Theaters dünnt zunehmend nach Süden hin aus und kann nur vom Theater selbst stammen. Einige große Quader der Außenschale des Theaters wurden auch aus diesen Straten geborgen. Dennoch fehlt die große Masse an Quadern und Bruchsteinen, die aus dem caementitium-Mauerwerk hinter der Außenschale zu erwarten wäre. Es ist daher davon auszugehen, dass hier bereits ein massiver Steinraub stattgefunden hatte. Die dichte Bruchsteinschicht SE 22, wahrscheinlich identisch mit SE 179, ist vermutlich der verbliebene, aber umgelagerte Rest der Steinraubaktivitäten. Oberhalb von SE $22=179$ konnte nur mehr eine bereits umgelagerte, sehr humose Schicht SE 21 und SE 21a festgestellt werden.

\subsubsection{Zusammenfassung Areal südlich des Theaters, Stiegengasse}

Mit dem großen Ausbau des Theaters in der Zeit zwischen den Kaisern Domitian und Trajan ${ }^{223}$ entstand eine großzügig angelegte Treppe an der Südseite des Theaters, deren Aufgabe die Verbindung der drei südlichen Zugänge ES1 bis ES3 war, die auch mit großer Wahrscheinlichkeit eine Verbindung zwischen der Marmorstraße und der Akademiegasse darstellte (Taf. 288 Abb. 585; 289 Abb. 586). Rund 150 Jahre nach ihrer Fertigstellung wurde der östliche Treppenabschnitt teilweise nicht mehr von dem Schutt befreit, der durch das Erdbeben in gallienischer Zeit verursacht wurde. Eine etwa 3 bis $4 \mathrm{~m}$ breite begehbare Passage entlang der Theatermauer blieb aber weiterhin erhalten.

Eine exakte zeitliche Einordnung der Ereignisse der Spätzeit kann anhand der Befunde nicht vorgenommen werden. Das ältere Material, wie beispielsweise die Schicht SE 201 in der Verfüllung hinter Mauer MA20, stammt aus dem 3. Jh. n. Chr. Es handelt sich dabei um umgelagerten Schutt, vermutlich aus der Wohnverbauung im Süden der Stiegengasse. Es wurde aber mit Sicherheit nicht früher hier abgelagert als das Material der Terrassierung östlich der Mauer MA23. Funde des 4. Jhs. n. Chr. fallen kaum ins Gewicht. Den Schwerpunkt stellen Schichten mit Fundmaterial des 5./6. Jhs. n. Chr. dar. Diese bilden die großen Terrassierungen über der Treppe-West und geben einen terminus post quem für ihre Errichtung. Der letzte zeitliche Abschnitt wird durch die Zerstörung praktisch aller baulichen Strukturen im untersuchten Areal südlich des Theaters gekennzeichnet. Die Fundkeramik reicht bis in das 6. Jh. n. Chr. Die Münzfunde unterstreichen den keramischen Befund ${ }^{224}$. Ein Unterschied zwischen den beiden Treppenabschnitten West und Ost ist nicht gegeben. Die große erste Serie endet in beiden Abschnitten mit Gallienus. Danach ist eine Zäsur bis Theodosius I. festzustellen. Die verhältnismäßig geringe Zahl an Münzen dieser Epoche reicht zwar über Honorius bzw. Theodosius II. nicht hinaus ${ }^{225}$, macht aber die allgemeine Renovierungsphase, die in theodosianischer Zeit in Ephesos einsetzt und sich am Theater vor allem durch die Baumaßnahmen des Messalinus ${ }^{226}$ bemerkbar macht, auch in der Wohnverbauung südlich des Theaters fassbar. Warum aber enden die Münzfunde der Stiegengasse bereits mit Theodosius II., während sie im Norden des Theaters bis Heraklius reichen? Abgesehen davon, dass die geringe Anzahl an späteren Münzen im Süden des Theaters auch rein zufällig so früh enden kann, sei an den Bau der byzantinischen Stadtmauer erinnert, wonach sich

\footnotetext{
${ }^{223}$ Etwa IvE 2037 an der Außenarchivolte des Eingangs ES2; s. auch Kap. 8.6.1, Nr. 5 u. Kap. 8.6.2.

${ }^{224}$ Kap. 4 u. 5.

${ }^{225}$ Nur in Münze M 247 könnte ein byzantinisches Exemplar des frühen 6. Jhs. n. Chr. erhalten sein. Doch ist es unleserlich und in einem äußerst schlechten Erhaltungszustand, sodass sein Aussagewert begrenzt ist.

${ }^{226}$ IvE 2043. 2044; s. auch Kap. 8.6.1, Nr. 12. 13 u. Kap. 8.6.2.
} 
das gesamte Gebiet südlich des Theaters extra muros befand, was auch zu einer geringen Dichte der Besiedlung beitrug. Dagegen befanden sich das Theater selbst und das gesamte nördliche und nordöstlich anschließende Areal innerhalb der Mauern. Die massive Zunahme an Wohnbauten in der befestigten Stadt wird durch die in den letzten Jahren durchgeführten Ausgrabungen im Hafengymnasium belegt. Womöglich war aber nicht der Stadtmauerbau selbst der Auslöser für die Verlagerung des städtischen Zentrums. Der Vorgang scheint bereits mit dem Bauboom in theodosianischer Zeit einzusetzen ${ }^{227}$. Die Errichtung der Stadtmauer trägt dem nur Rechnung.

Damit bleibt die entscheidende Frage: Wann wurde die byzantinische Stadtmauer errichtet? Vorschläge für eine Datierung zwischen dem 5. und dem 8. Jh. n. Chr. wurden bereits seit dem Anfang des 20. Jhs. gemacht und oftmals mit dem Hinweis auf den unzulänglichen Forschungsstand wiedergegeben. Die untere Eingrenzung ist plausibel. Die Mauer verläuft über den Südkammern der Arkadiane, kann also folglich erst nach deren Anlage errichtet worden sein. Für die obere Grenze geben die Kaiserakklamationen an den Torgewänden des unmittelbar westlich des Theaters gelegenen Stadttors einen terminus ante quem (Taf. 51 Abb. 97; 290 Abb. 587. 588). Der Stadtmauerbau erfolgte also noch vor 609/610 n. Chr. ${ }^{228}$. Im Befund über der Stiegengasse offenbart sich zwar sehr schlüssig dieser Transformationsprozess zwischen Zentrum und Peripherie, allein die Funde ergeben dafür nur einen groben Zeitrahmen. Wie bereits dargelegt wurde ${ }^{229}$, hängen die einzelnen Umbaumaßnahmen im Süden des Theaters zusammen: Demontage der Treppen, Errichtung der Barriere in der Aristion-Leitung aus Stufensteinen, Verschluss der Theatereingänge und Renovierung der alten hellenistischen Terrassenmauer bei ES3 als Adaptierung für die byzantinische Stadtmauer ebenfalls aus Stufensteinen. Aus dem Fundmaterial erschließt sich für diese Maßnahmen ein terminus post quem in der Zeit vom ausgehenden 5. bis in das 6. Jh. n. Chr. Diese Beobachtung korreliert mit dem angenommenen Zeitraum für die Aufgabe des Wasserbeckens hinter dem Nymphaeum Traiani ${ }^{230}$, welche in Zusammenhang mit der der Aristion-Leitung zwischen Theater und Kuretenstraße stehen dürfte.

Obzwar weiterhin vereinzelte menschliche Aktivitäten festzustellen sind, hat das Areal südlich und östlich des Theaters im 6. Jh. n. Chr. außerhalb der Stadtmauer gelegen. Es lag wohl weitgehend brach, wie zahlreiche Wildtierknochen in der Verfüllung der aufgelassenen Aristion-Leitung belegen.

M. HOFBAUER

\subsection{GRABUNG ÖSTLICH DER SUMMA CAVEA}

\subsubsection{Aufgabenstellung und Methode}

Die Sondierung östlich der summa cavea (ETH 09-Ost) widmete sich der Untersuchung der hier an die Portikusmauer angesetzten Bebauung und sollte Fragen nach der Funktionalität der Räume sowie nach deren wegetechnischen Erschließung durch das städtische Straßennetz nachgehen (Plan 2) ${ }^{231}$. Die Entscheidung, den Schnitt etwas südlich der sekundär in die summa cavea eingebauten West-Ost-Treppe zu positionieren, beruht auf dem Nachweis eines Marmorbodens, dessen Reste zwischen den sogenannten Radialmauern ${ }^{232}$ im schrägen Erdprofil des Hangs bereits bei einer Begehung vor Beginn der Grabung erkennbar waren. Die bauhistorische Dokumentation umfasste das digitale Einmessen der Mauerzüge und die zeichnerische, fotografische und deskriptive Aufnahme relevanter Maueransichten (Taf. 297 Abb. 595).

\footnotetext{
${ }^{227}$ PüLZ 2011, 56 f.

${ }^{228}$ Während an vielen anderen Stellen an der Kuretenstraße, der Arkadiane und der Plateia in Koressos Kaisernamen, wie z. B. Phokas oder Heraklius, genannt werden, verzichten die beiden Akklamationen darauf. Doch ist auffällig, dass sie sowohl die Kaiser im Plural nennen als auch die Zirkuspartei der Grünen. Eine ganz ähnlich Inschrift am Hadrianstor wurde von H. Thür in die Zeit des Regierungsantritts des Heraklius datiert, vgl. dazu THür 1989, 74 f.

${ }^{229}$ Kap. 3.6.1.

${ }^{230}$ QuATEMBer u. a. 2008, 269; Quatember 2011, 82.

${ }^{231}$ Die Grabung fand von 20.7. bis 21.8. 2009 statt. Neben dem Autor waren M. Grebien als studentischer Mitarbeiter sowie neun türkische Arbeiter bei den Untersuchungen beschäftigt.

${ }^{232}$ ATAÇ 1999b, 3.
} 


\subsubsection{Grabungsbefund}

\subsubsection{Mauerzüge}

Rückwand des Theaters, Mauerzug MAl

Die sogenannte Portikusmauer, welche das Theater gegen Osten begrenzt, ist nur in ihren unteren Zonen im Original erhalten, der größte Teil des aufgehenden Mauerwerks wurde im Zuge von Konsolidierungsmaßnahmen rezent aufgemauert ${ }^{233}$.

\section{Mauerzug ThO-MA2}

Die südliche der radial orientierten Mauern lässt sich im Westen des Schnitts bis zu dem orthogonal ansetzenden Mauerzug ThO-MA4 nachweisen, wobei ihre vollständige Breite nur vor der Portikusmauer (MA1) auf einer Länge von etwa 2,3 m fassbar ist (Taf. 297 Abb. 596). Die ThO-MA2 reißt zwar ca. 1,0 m vor der MA1 aus, doch ist davon auszugehen, dass sie ehemals in die Portikusmauer eingebunden hat bzw. an diese angesetzt war. Sollte die ThO-MA2 nach der Ecke mit der Quermauer ThO-MA4 über eine Fortsetzung gegen Osten verfügt haben, so kann diese nach dem Grabungsbefund nicht in der direkten Flucht des westlichen Mauerabschnitts gelegen haben, sondern müsste nach Süden versetzt, außerhalb des Grabungsbereichs verlaufen sein.

Der unterste, etwa 0,4 m hohe Abschnitt der ThO-MA2 besteht aus kleineren Steinen, darüber findet sich eine Lage mit Steingrößen bis durchschnittlich 0,35 m. Am Westende der Mauer ist über dieser Lage auch eine Spolie in Form eines Quaders verbaut $(0,82 \times 0,55 \times 0,37 \mathrm{~m})$, der als einziger Mauerstein in diesem Bereich Versinterungen aufweist. Ab einer Mauerhöhe von 1,20 m nimmt die Größe der Mauersteine wieder $\mathrm{ab}$, wobei sie nun gleichmäßiger geformt und in horizontalen Lagen geschichtet sind. Ca. 1,0 m nach Osten findet sich ein bis zu 0,06 m starker vertikaler Riss, der über einem quadratischen (Balken-)Loch seinen Ausgang nimmt. Rund 2,3 m östlich der MA1 ist das Gefüge der Mauer durch von Ost nach West verlaufende, starke Versinterungen nur noch schlecht zu erkennen. Zudem ist die OK der Mauer in diesem Bereich mit flachen und relativ ebenen Feldsteinen rezent abgemauert.

\section{Mauerzug ThO-MA3}

Die nördliche Radialmauer ThO-MA3 ist bis etwa 1,7 m vor die MA1 erhalten. Ihr stark beschädigter westlicher Abschnitt wurde restauriert und an der OK mit Beton gegen weiteren Verfall gesichert (Taf. 297 Abb. 597). Ihre OK ist heute deutlich niedriger als die der ThO-MA2. Rund 0,9 m östlich zweier großer, übereinander auf der rezenten OK versetzter Feldsteine wird die Mauer von einer Baufuge durchlaufen. Eine weitere Baufuge, die sich auch in der darüberliegenden ThO-MA9 fortsetzt, zeigt sich nochmals 0,9 m (drei römische Fuß) weiter östlich. Zwischen diesen beiden Fugen liegt ein bis zu 1,23 m hoch aufgemauerter Bereich bestehend aus annähernd quaderförmigen Feldsteinen, die jedoch im oberen Bereich mit einer dikken Mörtelschicht mit gezacktem Bürstenstrich verputzt sind. Östlich der östlichen Baufuge sind die Steine mit einer Kantenlänge bis zu 0,35 m durchgehend weit größer, auch ist die Mauer hier etwa 0,7 m höher als in ihrem westlichen Bereich und schließt mit einer Art Plattform für die Objekte 1 und 2 ab.

\section{Mauerzug ThO-MA4}

ThO-MA4 begrenzt die beiden radialen Mauerzüge ThO-MA2 und ThO-MA3 im Osten und trennt damit Raum 1 von Raum 2 (Taf. 298 Abb. 598). Im Norden sind der im Baumaterial sehr heterogenen Mauer die zum Teil aus Ziegeln gestalteten Strukturen der Objekte 1 und 2 vorgelagert, wobei in der Mauer bis zu einer Höhe von rund 0,4 m ebenfalls Ziegel verbaut waren (Taf. 299 Abb. 601. 602). Darüber ändern sich Material und Gefüge der Mauer und es folgen annähernd gleichförmige Steinquader. Nach Süden schließt ein mit 0,2 m schmälerer Mauerteil, ebenfalls aus Steinquadern errichtet, an; allerdings scheint dieser angesetzt und die Fuge mit kleinen Steinen ausgeglichen worden zu sein. Der schmale Südteil von ThO-MA4 ist auf einer Länge von 2,20 m erhalten und von Westen gesehen inhomogen mit unbehauenen Bruchsteinen

\footnotetext{
${ }^{233}$ Vgl. zum architektonischen Befund die Ausführungen zur porticus in summa cavea in Kap. 10.2.4.2.
} 
und Ziegeln aufgemauert. 1,2 m vom Südabschluss entfernt findet sich eine mit Ziegeln eingefasste tropfenförmige Öffnung, die jedoch an der Ostseite über keine Entsprechung verfügt. Der südlich daran anschlieBende Abschnitt weist in den unteren Bereichen Bruchsteinmauerwerk auf. Darüber deuten Ziegellagen eine wohl nachträglich eingebaute Schwelle und später verschlossene Öffnung an. Die Ostseite der Mauer vermittelt dagegen mit den verwendeten Quadersteinen einen sehr homogenen Eindruck, wobei die oberste Steinreihe mittig aufgesetzt zu sein scheint.

\section{Mauerzug ThO-MA5}

Die mehrphasige ThO-MA5 ist bis zu einer Höhe von 3,2 m über die Grabungsunterkante erhalten, wobei in der obersten erhaltenen Steinlage auch Ziegel verwendet wurden und ein Balkenloch eingelassen ist (Taf. 298 Abb. 599). In den regelmäßigen Lagen der darunterliegenden Mauerzonen kamen hingegen ausschließlich grob behauene und annähernd gleich formatierte Quadersteine zur Anwendung. Es ist auffällig, dass in der freigelegten Wandfläche in unregelmäßigen Abständen Ausnehmungen unterschiedlicher Größe und Funktion, etwa in Form von Durchlässen zur Ableitung des Hangwassers, sowie Balkenlöcher auftreten. Unterhalb der Austrittsöffnung für das Hangwasser im unteren Drittel der Mauer zeigen sich starke Sinterspuren, während die Funktion der nördlich darunterliegenden, etwa $0,4 \times 0,2 \mathrm{~m}$ großen Öffnung unklar bleibt.

\section{Mauerzug ThO-MA9}

Die aus durchwegs größeren Feldsteinen errichtet ThO-MA9 sitzt auf der für die ThO-MA3 beschriebenen Plattform auf (Taf. 298 Abb. 600) und bindet in die ThO-MA4 ein. Ihr Aufbau ist bis 1,50 m oberhalb der Nische erhalten und besteht aus kaum behauenen Feldsteinen unterschiedlicher Größe $(<0,45 \mathrm{~m}$ Kantenlänge). Der relativ große Zwischenraum zwischen den Steinen ist mit Mörtel aufgefüllt.

\subsubsection{Weitere bauliche Strukturen}

\section{Objekt 1: Herd}

In der Nische zwischen den Mauern ThO-MA3/ThO-MA9 und ThO-MA4 fanden sich unter einem Versturz die Reste eines Ziegelherdes mit den Maßen 1,06 m in Ost-West-Richtung und 0,87 m in Nord-Süd-Richtung (Taf. 299 Abb. 601. 602). In situ erhalten sind neben Resten des Gewölbes, das im Osten in ThO-MA4 integriert ist und im Westen frei steht, noch der Boden des Gewölbes des Unterbaus sowie ein die Rückwand der Öffnung anzeigender, aufrecht stehender Ziegel. Dieser lehnt nicht direkt an ThO-MA9, sondern steht etwa $0,33 \mathrm{~m}$ davor, wohingegen die Ziegel des Gewölbes sehr wohl bis an ThO-MA9 reichen. Vom Marmorplattenboden des Raums ist die UK des Herdes durch eine niedrige, profilierte Steinleiste abgesetzt (Taf. 299 Abb. 603). Ziegelreste in ThO-MA4 markieren die OK des etwa 0,90 m hohen Herdes.

\section{Objekt 2: Feuerstelle}

Unter dem Herd (Objekt 1) findet sich eine Steinsetzung, die mit ihren Ausmaßen von 0,62 $\times 0,99 \mathrm{~m}$ die gesamte Nische zwischen den Mauern ThO-MA3/ThO-MA9 und ThO-MA4 ausfüllt (Taf. 299 Abb. 603). Sie zieht sowohl unter ThO-MA4 im Osten als auch unter den untersten Ziegel des Herdgewölbes sowie unter die profilierte Leiste und gehört somit einer früheren Bauphase des Raums an. In der Mitte der Setzung zeigt sich eine annähernd kreisrunde Aussparung, die mit Asche verfüllt ist, wodurch die Interpretation als Feuerstelle klar wird.

\section{Objekt 3: Wasserbecken und Kanal}

Westlich vor ThO-MA4 wurden die Reste eines Kanals und eines Wasserbeckens freigelegt (Taf. 300 Abb. 604. 605). Letzteres ist an Boden und Rändern mit kleinen Marmorplatten ausgelegt, die an der Westseite an einer Ziegelschar angebracht sind. Die nördliche und einzige vollständige Platte weist in ihrer Nordwestecke eine kreisrunde Öffnung auf, die bei der Freilegung mit einer noch in situ befindlichen steinernen Halbkugel verschlossen war. Die Ziegelschar wiederum ist durch eine ähnliche Steinleiste wie der Herd vom Marmorboden 


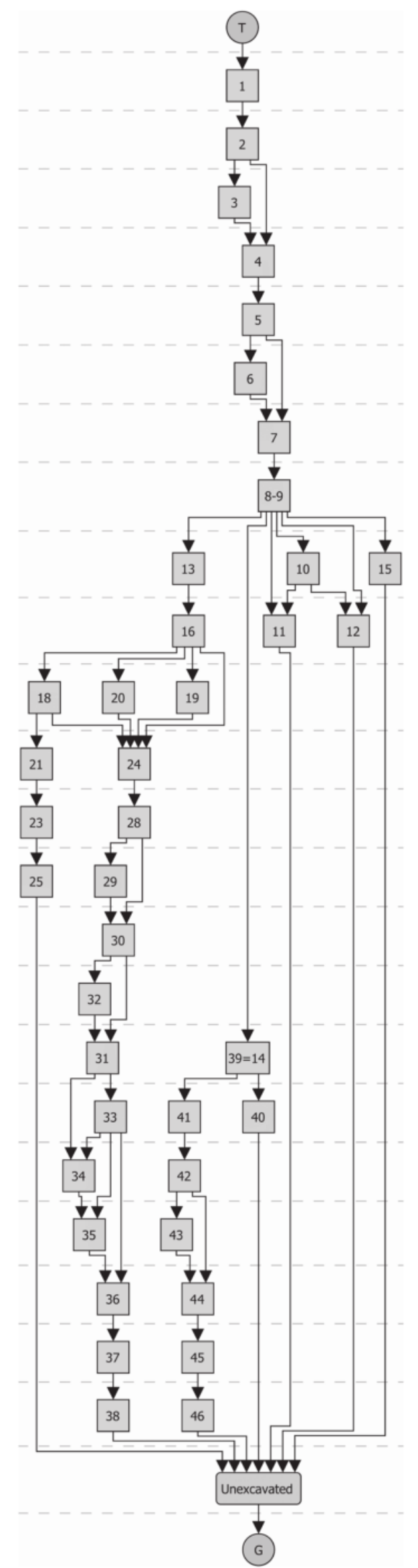

des Raums abgetrennt. Die ursprüngliche Größe des Wasserbeckens lässt sich nicht mehr eruieren. Seine Breite beträgt $0,39 \mathrm{~m}$, in Nord-Süd-Richtung ist es nur mehr auf einer Länge von $0,53 \mathrm{~m}$ erhalten. In seiner weiteren Fortsetzung nach Süden wurde das Becken in West-OstRichtung auf einer Breite von 0,15 m grob durchschlagen. Nach dieser Ausnehmung, die von der Öffnung in der ThO-MA4 etwas schräg nach Norden versetzt liegt, folgt nochmals ein $0,51 \mathrm{~m}$ breiter Mörtelblock, der wohl gleichfalls den Unterbau für den Beckenboden gebildet hat; jedoch fehlt die Marmorauflage.

Das Becken wurde über einem nur geringfügig schmaleren Gerinne errichtet, welches auf 0,85 m erhalten und ebenfalls mit Steinplatten ausgelegt ist. Es weist ein starkes Gefälle von Süd nach Nord auf, wobei der höchste Punkt seiner Sohle im Süden etwa um 0,7 m höher als die OK der ThO-MA2 liegt. Auch wurde das Gerinne nicht durch eine Ziegelschar vom Marmorboden des Raums getrennt, sondern durch eine Lage unbehauener Feldsteine, die am südlichen Ende nach Westen umzuknicken scheint, wobei dies jedoch nicht mit Sicherheit geklärt werden konnte.

\subsubsection{Stratigrafischer Befund}

Der Schnitt ETH 09-Ost wurde etwa 5,3 m südlich der sekundär eingebauten Treppenanlage auf einer Fläche von 6,57 $\times 4,13 \mathrm{~m}$ angelegt. Die Platzwahl erfolgte aufgrund steinerner Bodenreste, die sich zwischen den Mauern ThO-MA2 und ThO-MA3 abzeichneten. Diese beiden Mauern bilden somit auch die Nord- und Südbegrenzung des Schnitts. Den Westabschluss markiert die Portikusmauer, im Osten wurde hingegen darauf geachtet, den Schnitt in einer überschaubaren Größe zu halten und dabei ein durch das starke Hanggefälle zu erwartendes, allzu hohes Ostprofil zu vermeiden.

\subsubsection{Raum 1}

Das älteste fassbare, jedoch nicht datierbare Nutzungsniveau bilden die marginalen Reste eines nicht mit einer SE-Nummer versehenen Estrichbodens in der Ecke zwischen ThO-MA3 und ThO-MA4 (OK 47,82 m; UK 47,69 m), der auf demselben Niveau liegt wie die UK der abgemauerten Tür in ThO-MA3. Dieser Boden der ersten Nutzungsphase wurde im Zuge einer Niveauerhöhung gänzlich entfernt. $\mathrm{Zu}$ dieser Niveauerhöhung gehört der Boden SE 32 (OK 48,22 m; UK 48,11 m), wiederum ein

Grafik 11: Harris-Matrix für die Räume 1 (1.) und 2 (r.) 


\begin{tabular}{|c|c|c|c|c|}
\hline Schicht & OK (Absolut) & UK (Absolut) & Lage & Konsistenz/Interpretation \\
\hline $16=13$ & 49,54 & 49,08 & von MA4 ca. $1 \mathrm{~m}$ nach $\mathrm{W}$ & Schuttschicht \\
\hline $18=14$ & 49,08 & 48,775 & im S-Drittel des Raums & Ziegelschuttschicht \\
\hline 19 & 49,08 & 48,571 & im $\mathrm{O}$ von $\mathrm{R} 1$, mittlerer Bereich & stark mit Mörtelgrieß versetzte Erde \\
\hline 20 & 48,94 & 48,38 & in Ecke MA3/MA4 & Ziegelversturz \\
\hline 21 & 48,57 & 48,38 & N-Teil von R1 & Ofenversturz \\
\hline 22 & 48,53 & 48,38 & südl. des Ofens & Aschehaufen \\
\hline 23 & 48,67 & 48,34 & im $\mathrm{N}$ d. Schnitts zw. MA9 und MA4 & Ofen Obj. 1 \\
\hline 24 & 48,38 & 48,29 & flächig in erhaltenem Bereich von R1 & Marmorplattenboden \\
\hline 25 & 48,34 & 48,16 & unter Ofen Objekt 1 & Feuerstelle \\
\hline 26 & 48,54 & 48,41 & $\begin{array}{l}\text { in der Ecke der Schalungen von } \\
\text { MA4, über Becken }\end{array}$ & Bodenrest \\
\hline 27 & 48,38 & $\begin{array}{l}48,29(\mathrm{~S}) \\
48,14(\mathrm{~N})\end{array}$ & westlich von MA4 & Kanalverfüllung/Abfluss \\
\hline 28 & 48,29 & 48,17 & unter Boden SE24 & $\begin{array}{l}\text { Bodenunterbau/ } \\
\text { Aufplanierung }\end{array}$ \\
\hline 29 & 48,17 & 48,04 & an südl. W-Profil & Verfüllung V03 \\
\hline 30 & 48,17 & 48,09 & flächig westl. des N-S-Kanals in R1 & Aufplanierung \\
\hline 31 & 48,09 & 47,81 & unter SE30 & Planierschicht \\
\hline 32 & 48,22 & 48,11 & in Ecke zw. Feuerstelle und Becken & Estrichrest \\
\hline 33 & 47,81 & 47,75 & $\begin{array}{l}\text { flächig westl. des Kanals und nördl. } \\
\text { der Flucht von MA2 }\end{array}$ & Planierschicht \\
\hline 34 & 47,81 & 47,80 & über MA2 & Planierschicht \\
\hline 35 & 47,80 & 47,74 & über MA2 & Planierschicht mit viel Steinsplitt \\
\hline 36 & 47,74 & 47,61 & $\begin{array}{l}\text { flächig westl. des N-S- } \\
\text { Kanals }\end{array}$ & teils verbrannte lockere Erde \\
\hline 37 & 47,61 & 47,61 & $\begin{array}{l}\text { flächig westl. des N-S- } \\
\text { Kanals }\end{array}$ & Planierschicht \\
\hline 38 & 47,31 & 46,90 (künstlich) & im NW von R1 & Grube V04 \\
\hline
\end{tabular}

Tab. 55

Estrich. Auch hierbei handelt es sich nur um den - diesmal etwas größeren - Rest eines Horizonts, welcher zugunsten einer Niveauerhöhung im Raum aufgegeben wurde (Taf. 300 Abb. 606). Beiden Böden ist gemein, dass sie nahezu gänzlich entfernt wurden, um so einen neuen Unterbau für den Marmorplattenboden SE 24 zu schaffen, dessen Einfüllungen aus verschiedenen teils homogen, teils vermischten Materialien bestehen.

Bei dem Marmorplattenboden SE 24 (OK 48,38; UK 48,29; Taf. 300 Abb. 607. 608) handelt es sich nun um jene Schicht, die erstmals auch eine chronologische Einordnung zulässt. Die Platten sind zum großen Teil annähernd quadratisch mit Seitenlängen von ca. 0,3 m (1 römischer Fuß). Nur im Bereich vor der Feuerstelle findet sich eine etwa viermal so große, und südlich anschließend eine etwa doppelt so große Platte. 
Von der Feuerstelle ist der Boden durch eine fein gearbeitete Profilleiste abgetrennt. Auffällig ist auch ein etwa $0,8 \times 0,3 \mathrm{~m}$ großer Abschnitt, der exakt vor der abgemauerten und erhöhten Schwelle in ThO-MA4 liegt, in dem drei größere und an der Oberfläche eher flache Steine eine Art Unterlage formen.

Südlich an den Boden schließt eine gemeinsam mit SE 29 abgetragene Ost-West verlaufende Verfüllung aus lockerer Erde und viel Steinsplitt an (OK 48,17; UK 48,04), bei der es sich wohl um einen Ausriss handelt. Diese Schicht liegt exakt über der Mauer ThO-MA2 und lässt sich bis zum Abriss im Westen des Raums verfolgen. Der Abflusskanal an der ThO-MA4 ist mit einer rötlich verbrannten, stark mit Ziegelbruch angereicherten Erdschicht SE 27 (OK 48,38; UK 48,14) verfüllt. Zu erwähnen ist weiters auch noch ein Bodenrest SE 26 (OK 48,54; UK 48,41), der in der Nordostecke des Wasserbeckens liegt, und unter dem sich zwei Münzen fanden, mit deren Hilfe sich die Aufgabe des Wasserbeckens datieren lässt, sowie der unmittelbar vor der Gewölbeöffnung des Herdunterbaus liegende Aschehaufen SE 22 (OK 48,53; UK 48,38). Ebenso sollte der verstürzte Teil des Herdes nicht unerwähnt bleiben, da aus dieser Schicht SE 20 (OK 48,94; UK 48,38) mehrere Öllampenfragmente geborgen werden konnten.

\subsubsection{RAUM 2}

\begin{tabular}{|c|c|c|c|c|}
\hline Schicht & OK (Absolut) & UK (Absolut) & Lage & Konsistenz/Interpretation \\
\hline 1 & 52,53 & 51,46 & flächig über R2 & Planierschicht \\
\hline 2 & 52,48 & 51,00 & flächig über R2 & Schuttschicht \\
\hline 3 & 52,19 & 50,96 & flächig über R2 & Planierschicht \\
\hline 4 & 52,19 & 51,28 & in SO-Ecke & Grube V01 \\
\hline 5 & 52,19 & 50,83 & flächig außer V01 & Planierschicht \\
\hline 6 & 51,35 & 50,57 & über R2 & Schuttverfüllung \\
\hline 7 & 50,83 & 50,49 & flächig & Planierschicht \\
\hline 8 & 50,94 & 49,69 & westl. Teil von R2 & Planierschicht \\
\hline 9 & 50,57 & 49,57 & östl. Teil von R2 & Schuttlage \\
\hline 10 & 50,79 & 50,11 & mittig N-S verlaufend & Schuttlage \\
\hline 11 & 50,11 & 49,54 & unter SE10 & Schuttlage \\
\hline 12 & 50,34 & 49,98 & an N-Profil in Flucht MA3 & Schuttlage \\
\hline 13 & 50,00 & 48,92 & in NO-Bereich & Schuttlage \\
\hline 14 & 49,57 & 48,90 & über R2 & Grube V02 im NO von R2 \\
\hline 15 & 49,57 & 49,45 & östl. Bereich entlang MA5 & Streukies aus Kanal in MA5 \\
\hline 39 & 49,14 & 49,01 & östl. Teil des Suchschnitts & SE $39=$ SE 14 \\
\hline 40 & 49,01 & 48,64 & östl. Teil des Suchschnitts & $\begin{array}{l}\text { Ascheschicht, evtl. Zerstörungslage } \\
\text { des Kanalüberbaus }\end{array}$ \\
\hline 41 & 49,01 & 48,77 & Mitte bis W des Suchschnitts & $\begin{array}{l}\text { Estrichunterbau mit leichter } \\
\text { Erhöhung für Schranke vor Kanal }\end{array}$ \\
\hline 42 & 48,77 & 48,63 & flächig im Suchschnitt & Planierschicht für Boden SE41 \\
\hline 43 & 48,63 & 48,49 & westl. MA5, in Flucht unter SE40 & Schuttauffüllung \\
\hline 44 & 48,63 & 48,50 & zw. MA4 und SE43 & Planierung \\
\hline 45 & 48,53 & 48,50 & flächig im Schnitt bis $\sim 1 \mathrm{~m}$ vor MA5 & Bodenrest? \\
\hline 46 & 48,50 & 48,19 & östl. MA4 & $\begin{array}{l}\text { weiche Erde an MA4 - steht im } \\
\text { Zusammenhang mit dem Kanal in } \\
\text { dieser Mauer }\end{array}$ \\
\hline
\end{tabular}


Der hangseitig gelegene Raum 2 war von massiven, etwa 3 m hohen Schuttschichten überlagert, ehe man ein erstes, für die Funktion des Raums Erkenntnis bringendes Stratum erreichte. Bei diesem handelte es sich um die Kieslage SE 15 (OK 49,57; UK 49,45), die exakt in der Verlängerung des aus ThO-MA5 führenden Kanalrohrs liegt und sich von der Mauer Richtung Westen ausbreitete.

Da sich die Grabung hauptsächlich auf Raum 1 konzentrierte, musste zur Untersuchung von Raum 2 ein zwischen den Mauern ThO-MA4 und ThO-MA5 verlaufender, etwa $1 \mathrm{~m}$ breiter Suchschnitt genügen. Einen ersten Hinweis auf eine Nutzung liefert die SE 40 (OK 49,01; UK 48,64), eine Aschelage, die, ca. 1,4 m westlich von ThO-MA5 beginnend, zu dieser hin knapp 0,25 m abfällt und sich an dieser verdickt. Sie liegt auf einer Mörtel-Ziegelbruch-Schicht SE41 (OK 49,01; UK 48,77), die über den gesamten Verlauf des Suchschnitts zwischen den Mauern ThO-MA4 und ThO-MA5 zu verfolgen ist und bei der es sich offensichtlich um den Unterbau des jüngsten Gehniveaus handelt. Der darüberliegende eigentliche (Estrich-) Boden ist jedoch nur noch in Form kleiner Mörtelbrösel in der sie bedeckenden SE 39 (OK 49,14; UK 49,01) zu erahnen. Erwähnenswert ist in diesem Zusammenhang auch eine wulstartige Verdickung der SE 41 in jenem Bereich, der an die Aschelage SE 40 anschließt (Taf. 301 Abb. 609. 610). Zur Mauer ThO-MA5 hin fällt die Schicht, ebenso wie die Aschelage, ab, besteht hier aber aus reinem, glattgestrichenem Mörtel.

Unter einer weiteren Schuttschicht SE 44 (OK 48,63; UK 48,50) findet sich schließlich der älteste ergrabene Estrich (SE 45, OK 48,53; UK 48,50) sowie an ThO-MA4 die aus weicher Erde bestehende, rund $0,25 \mathrm{~m}$ breite Baugrube derselben (SE 46, OK 48,50; ergrabene UK 48,19). Letztere wurde bis auf ein unförmiges, und damit wohl nachträglich in ThO-MA4 eingefügtes, sich auf den darunter verlaufenden Kanal öffnendes Loch verfolgt.

Außerhalb des Schnitts wurde nördlich der Mauer ThO-MA3 noch die oberste rezente Schicht abgetragen, wobei sich unmittelbar darunter die Reste einer den Hang hinaufführenden Treppe zeigten (Taf. 301 Abb. 611). Diese reißt in einer Flucht mit dem Marmorplattenboden des Raums 1 ab, eine etwaige Fortsetzung nach Westen konnte ebenfalls nicht verfolgt werden.

\subsubsection{Bauphasen}

Die Betrachtung der Strukturen in Raum 1 ergab das Vorhandensein von fünf unterschiedlichen Bauphasen, die allesamt im Zusammenhang mit der Erhöhung von Gehniveaus stehen bzw. durch eine solche bedingt sind. Die Gründe für die Niveauerhöhungen sind nicht mehr zu erfassen, jedoch kann es sich nur um funktionale Aspekte handeln, wobei auch die Wasserversorgung durch den Kanal eine Rolle gespielt haben mag. Raum 2 kann zur allgemeinen Relativchronologie nur wenig beitragen, da hier nur die Böden Anhaltspunkte liefern, diese jedoch in keinen Zusammenhang mit den Phasen in Raum 1 gebracht werden können.

\section{Phase 1}

Das Gehniveau wird hier vom nicht benannten Estrichboden in Raum 1 gebildet, dessen Reste ein Niveau mit jenem Bereich der Tür in ThO-MA3 markieren, ab dem nach oben hin eine grobe, aber dünne Putzschicht erkennbar ist. Es ist anzunehmen, dass es sich hierbei um eine Art gemauerte Türschwelle handelte, über die der Raum von einem im Norden anzunehmenden Treppenhaus betreten werden konnte. Die Nische, die durch die weiter hinten auf ThO-MA3 aufgesetzte ThO-MA9 entstand, war schon zu dieser Zeit vorhanden, weshalb auch damit zu rechnen ist, dass der Bereich der Feuerstelle bereits in der ersten Phase des Raums genutzt wurde, als sie noch auf einem Sockel über dem nicht benannten Boden lag.

Der Kanal kam zu dieser Zeit von Süden, traf etwa mittig in ThO-MA2 und lief auf dieser entlang nach Osten, wo er vor ThO-MA4 nach Norden umknickte. Er lief parallel zur ThO-MA4 und verließ - leicht nach Westen versetzt - unter der Feuerstelle den Raum.

\section{Phase 2}

In Phase 2 erfolgte eine der markantesten Änderungen an Raum 1, indem die Tür im Norden des Raums abgemauert und stattdessen eine neue Öffnung im Süden von ThO-MA4 eingefügt wurde. Da sich aber 
unmittelbar hinter der Tür im Inneren des Raums der Kanal befand, war es notwendig, diesen mit Hilfe einer vermutlich aus Holz bestehenden Konstruktion zu überqueren, deren Auflager unmittelbar westlich des Kanals in Form der größeren, abgeflachten Feldsteine zu erkennen sind. Weiters wurde der erste Boden entfernt, das Niveau erhöht und ein neuer Estrich verlegt.

\section{Phase 3}

Der dritte Umbau brachte den Einbau des bekannten Marmorplattenbodens mit sich, für den der jüngere Estrich ebenfalls abgetragen und das Niveau mit Füllmaterial angehoben wurde. Kanal und Feuerstelle bestanden weiterhin, wobei letztere nun durch einen Herd ersetzt wurde, den eine profilierte Leiste vom Marmorboden trennte.

\section{Phase 4}

In Phase 4 erfolgte der Einbau des Beckens, welches direkt auf den Marmorplattenboden gesetzt wurde. Damit wurde auch die Wasserversorgung des Raums nachhaltig verändert. Der Kanal über ThO-MA2 wurde offensichtlich entfernt, worauf der Ausriss hindeutet. An seiner Stelle wurde das Wasserbecken installiert, welches nun über eine nachträglich in ThO-MA4 eingebaute Öffnung gespeist wurde. Abfließen konnte das Wasser über das im Nordosten in den Marmorboden geschlagene kreisrunde Loch, das durch die in situ gefundene steinerne Halbkugel verschlossen werden konnte.

Durch die Erhöhung des Niveaus wurde es auch notwendig, das Niveau des Eingangsbereichs um ca. 0,7 $\mathrm{m}$ anzuheben, was durch die Aufmauerung der Schwelle in ThO-MA4 erzielt wurde. Auch hier ist wiederum eine nur noch in der rot verbrannten SE 27 fassbare Holzkonstruktion, evtl. in Form einer Treppe, anzunehmen, um in den Raum zu gelangen. In diesem Zusammenhang ist nun auch der jüngere Boden in Raum 2 zu sehen, der hinsichtlich des Niveaus zur Oberkante der Schwelle passt, von dem allerdings nur noch marginale Reste und der Unterbau SE 41 zu erkennen waren.

\section{Phase 5}

Phase 5 stellt die letzte der fassbaren Baumaßnahmen dar, in der das Becken aufgegeben und von einem weiteren Estrich überbaut wurde.

\begin{tabular}{|l|l|}
\hline Phasen & Baumaßnahmen \\
\hline 1 & $\begin{array}{l}\text { erster Estrichboden, Eingang im Norden über MA3; Kanal läuft aus Süden kommend auf MA2 nach Osten und } \\
\text { MA4 entlang nach Norden }\end{array}$ \\
\hline 2 & $\begin{array}{l}\text { zweiter Estrichboden, die Tür wird nun abgemauert und statt dessen eine neue in MA4 eingefügt; (vermutlich) } \\
\text { hölzerner Übergang über Kanal }\end{array}$ \\
\hline 3 & Einbau des Marmorplattenbodens; Einbau des Ofens \\
\hline 4 & $\begin{array}{l}\text { Einbau des Beckens und Aufgabe des ursprünglichen Kanals, die Wasserversorgung erfolgt nun aus Osten über eine } \\
\text { Leitung in MA4; Erhöhung des Eingangsniveaus, dazu passend auch Unterbau des jüngsten Bodens in Raum2 }\end{array}$ \\
\hline 5 & Aufgabe des Beckens, das nun durch einen Estrich abgedeckt wird \\
\hline
\end{tabular}

Tab. 57

\subsubsection{Datierung}

Zur Einordnung der letzten Bauphase kann auf eine Münzdatierung für den Estrich SE 26 über dem Becken zurückgegriffen und die Zeit um 300 n. Chr. angeben werden ${ }^{234}$. Die Keramik deutet in diesem Fall einzig in die Spätantike - dabei ist jedoch die Möglichkeit einer Fundvermischung nicht auszuschließen. Hierbei

\footnotetext{
${ }^{234}$ Zur Datierung vgl. auch Kap. 4 u. 5.
} 


\begin{tabular}{|l|l|l|}
\hline Schicht & Beschreibung & Datierung \\
\hline 21 & Versturz des Ofens & 2. H. 1. Jh. n. Chr. \\
\hline 23 & Ofen Objekt 1 & 1. H.-Mitte 2. Jh. n. Chr. \\
\hline 25 & Feuerstelle Objekt 2 & Mitte 1.-3. Jh. n. Chr. \\
\hline 26 & Bodenrest über Becken & spätes 3. Jh. n. Chr. \\
\hline 27 & Kanalverfüllung & späthellenistisch-kaiserzeitlich \\
\hline 32 & Unterbau Marmorplattenboden & kaiserzeitlich (1.-2. Jh. n. Chr.) \\
\hline 36 & Estrichrest & 1. H. 1. Jh. n. Chr.? \\
\hline 40 & Planierschicht & flavisch \\
\hline 41 & Zerstörungslage & 2. Jh. n. Chr. \\
\hline 43 & Estrichunterbau & 4.-5. Jh. n. Chr. \\
\hline 44 & Schuttauffüllung & frühes (?) 5. Jh. n. Chr. \\
\hline 46 & Planierschicht & spätantik \\
\hline
\end{tabular}

Tab. 58

sind weniger Fehler im Zuge der Grabung gemeint, sondern vielmehr die Tatsache, dass sich der Befund unmittelbar unter der Oberfläche eines über die Jahre abrutschenden Hangs befand.

Hinsichtlich der Verfüllung der älteren Feuerstelle (Objekt 2) sowie der Errichtung des darüber liegenden Herdes (Objekt 1) belegen die Ergebnisse eine chronologisch schlüssige Abfolge zwischen etwa der Mitte des 1. Jhs. und der Mitte des 2. Jhs. n. Chr. Die Aufgabe der Herdstelle dürfte hingegen erst im 4. oder 5. Jh. n. Chr. erfolgt sein, womit auch das Ende der Nutzungsdauer des Raums festgelegt sein dürfte. Dem entspricht auch die Nutzungsdauer des Kanals über die gesamte Kaiserzeit sowie die Auswertung der Funde des Unterbaus des Marmorplattenbodens, die an die Wende vom 1. zum 2. Jh. n. Chr. deuten.

Früher scheint der kleine Estrichrest SE 32 mit seiner darunterliegenden Materialaufbringung SE 36 anzusetzen zu sein. Die Datierung dieser beiden Schichten in die 1. Hälfte des 1. Jhs. n. Chr. bzw. flavische Zeit legt nahe, dass die Umbauten in Raum 1 über einen Zeitrahmen von etwa 70 Jahren stattgefunden haben.

Die Tatsache, dass aus den Schichten in Raum 2 nur wenige aussagekräftige Stücke stammen, die allesamt frühestens in das 2./3. Jh. n. Chr. datiert werden können, beweist, dass an dieser Stelle nicht die ältesten Schichten erreicht wurden.

\subsubsection{Auswertung und Interpretation}

Die beiden freigelegten Räume sind Teil der Bebauung, deren flankierende Radialmauern von Osten an die Ringmauer der Cavea angeschlossen sind ${ }^{235}$. Raum 1 diente vermutlich schon ab der ersten, gesichert aber ab der zweiten Bauphase im späten 1. bzw. 2. Jh. n. Chr. als Thermopolion ${ }^{236}$. Dies wird durch die Verwendung einer Feuerstelle und später eines Herdes in einer Nische in der Nordostecke des Raums deutlich. Die Herdstelle findet hinsichtlich ihrer typologischen Einordnung am ehesten in dem »Type ST, `Stoveく Subtype (2)« Entsprechung, wie ihn P. W. Foss für die Küchen von Pompeji definierte ${ }^{237}$. Der Aschehaufen vor

\footnotetext{
${ }^{235}$ Vgl. zu den an die Portikus-Rückwand angesetzten Räume Kap. 10.2.4.2.

${ }^{236}$ Es ist dies einer der wenigen Nachweise für eine Garküche als Versorgungseinrichtung im Bereich des Theaters, wenngleich SEAR 2006, 9 bereits darauf hinwies, dass in Substruktionen Lager- oder Verkaufsräume zu suchen seien. Ebenso CALZA BINI 1953, $11 \mathrm{f}$. für das Marcellustheater.

${ }^{237}$ Foss 1997, 80: $\gg$... this kind of stove has its top tiled cooking surface supported by one or more masonry or brick arches. It measures ca. $0,85-3,70 \mathrm{~m}$ long, $0,42-1,29 \mathrm{~m}$ deep, and $0,50-0,90 \mathrm{~m}$ high. The arches range from a perfect semicircle to being
} 
der Gewölbeöffnung des Herdunterbaus belegt eine durchgehende Verwendung der Kochstelle bis zur Aufgabe des Raums im 4./5. Jh. n. Chr.

Raum 1 wird von Süden nach Norden von einer zum Teil entlang der Ostwand geführten Abwasserleitung durchlaufen, wobei anhand der Grabungsergebnisse weder deren ursächlicher Beginn noch deren intendierter Endpunkt erschlossen werden können. Ebenso bleibt unklar, ob mit ihrer Hilfe auch Regenwasser von den Dachflächen und vom Hang abgeleitet wurde. Die Leitung entwässerte jedenfalls das Marmorbecken an der Ostwand des Raums, welches durch die nachträglich eingearbeitete Öffnung in ThO-MA4 und eine vom Hang kommende neue Leitung gespeist wurde. Das Becken verfügte über einen verschließbaren Abfluss und diente damit möglicherweise auch zum Frischhalten von Nahrungsmitteln, wie gefundene Muschelschalen nahelegen.

Der Einbau des Beckens sowie des Marmorplattenbodens und die Errichtung des Herdes im späten 1. oder frühen 2. Jh. n. Chr. fallen in die Zeit eines allgemeinen großen Umbaus des Theaters und dokumentieren die nachhaltige Umgestaltung des Raums. Auffällig ist, dass man vor der Verlegung des neuen Bodens den alten bis auf wenige Reste nahezu vollständig entfernte und das Laufniveau mittels Aufschüttung erhöhte. Möglicherweise steht diese Maßnahme im Zusammenhang mit der fortgesetzten Nutzung der Wasserleitung, auf die auch der neue Marmorboden Rücksicht nimmt.

Hand in Hand mit der Erhöhung des Bodens ist auch die Veränderung der Eingangssituation in Raum $1 \mathrm{zu}$ sehen. Befand sich die Tür in der ersten Bauphase noch im Norden des Raums und führte in ein nach Osten führendes Treppenhaus, so musste sie durch die höherliegenden Gehniveaus der zweiten Phase anschließend nach Osten verlegt werden. Der Eingang befand sich nun im Südosten des Raums, was eine Behelfskonstruktion zum Übersteigen des Kanals notwendig machte. Die Reste des Auflagers dieser Konstruktion waren in Form von abgeflachten Feldsteinen noch erhalten. Mit dem Einbau des Beckens wurde auch der Eingang erhöht, sodass nun mit einer (hölzernen) Treppe zu rechnen war, mittels derer man in den Raum gelangte.

Bei dem im Osten des Schnitts liegenden Raum 2 handelt es sich um einen Nord-Süd verlaufenden Gang, der die Radialkammern hinter dem Theater von Osten erschloss. Bei den kleinen Öffnungen in der Ostmauer handelt es sich nicht um Gerüstlöcher, vielmehr stehen diese gemeinsam mit der großen Ausnehmung im unteren Mauerbereich offenbar im Zusammenhang mit der Ableitung des Hangwassers des Panayırdağ. Dieses Wasser wurde in der Spätphase in einer entlang der Mauer verlaufenden Rinne gesammelt und abgeleitet. Leider erlaubte es die Zeit nicht, in diesem Bereich tiefer zu gehen und ältere Böden und Strukturen, wie etwa jene das Becken in Raum 1 speisende Wasserleitung, zu erforschen. Eine annähernd quadratische Öffnung im obersten Bereich der Ostmauer diente vermutlich als Balkenloch. Es ist als Hinweis auf eine Dachkonstruktion mit einem auf der Rückwand der Portikus ansetzenden und zum Hang hin geneigtem Pultdach zu sehen, das Dach der Halle selbst war zum Theater hin geneigt ${ }^{238}$.

Die Räumlichkeiten stehen zwar funktional im Zusammenhang mit dem Theaterbetrieb, sind aber architektonisch vom eigentlichen Theaterbau zu trennen und können am ehesten als Annex zu diesem aufgefasst werden. Womit auch von der These von I. Ataç, wonach es sich bei den am Hang an der Rückwand der porticus in summa cavea abzeichnenden Radialmauern um Substruktionen für zusätzliche hölzerne Sitzbänke handle, Abstand genommen werden kann ${ }^{239}$. Die Rückwand der Portikus verfügte - wie an ihrer Westseite zu erkennen ist - über mehrere nachträglich zugesetzte Zugangsöffnungen, wobei der aus der Mittelachse verschobene, korridorartige Zugang mit seiner steil ansteigenden Treppe den Höhenunterschied zwischen dem Oberflächenniveau in den Radialkammern überwand. Wie verwendete Spolien belegen, wurde der heute sichtbare Zugang mit dem vorgelagerten unteren Treppenansatz sekundär angelegt. Der obere Abschluss ist verschüttet, die Treppe mündete vermutlich in den Umgang (Raum 2) ${ }^{240}$.

Die urbanistische Erschließung des hangseitig über dem Theater anschließenden Areals erfolgte über die Badgasse bzw. die Straße $46^{241}$, wobei die Erforschung der sich hier abzeichnenden Bebauung nicht mehr Teil der gegenständlichen Untersuchungen war und ein Desiderat für zukünftige Forschungsvorhaben dar-

nearly flat, and some are even pointed or triangular in shape. It is generally accepted that the open spaces formed by the arches beneath the stove were used for the storage of fuel.«

${ }^{238}$ Vgl. Kap. 10.2.4.2. Ich danke G. Styhler-Aydın und M. Hofbauer für den regen Gedankenaustausch und die hilfreichen Hinweise.

${ }^{239}$ ATAÇ 1999b, 3.

${ }^{240} \mathrm{Vgl}$. STYHLER-AYDIN (in Vorbereitung).

${ }^{241}$ Zur Einbindung der Hangzonen in das hellenistische Stadtgebiet s. Scherrer 1995, 172; Hueber 1997b, 252-255; GroH $2006,70$. 
stellt $^{242}$. Dies betrifft im Besonderen jene Architektur, die sich über einem langrechteckigen Fundament auf einer deutlich aus der Mittelachse des Theaters gegen Süden situierten Felsterrasse erhob und deren chronologische Stellung, genaue Gestalt und Funktion noch nicht untersucht und geklärt sind ${ }^{243}$. Dass der Westabhang des Panayırdağ neben diesen Strukturen jedoch sicherlich bereits in hellenistischer Zeit bebaut war, ergibt sich aus den aktuellen Forschungen an dem großflächigen, villenartigen Gebäudekomplex auf der ausgedehnten Geländekuppe oberhalb des Theaters ${ }^{244}$. So verweist die chronologische Stellung der Bauornamentik auf eine Errichtung der ältesten Teile der Anlage um die Mitte des 2. Jhs. v. Chr. ${ }^{245}$.

M. TSCHANNERL

\subsection{ZUSAMMENFASSUNG ARCHÄOLOGISCHER BEFUND}

Im Folgenden werden die Ergebnisse der archäologischen Untersuchungen besonders hinsichtlich ihrer Konsequenzen für die Bauforschung zusammengefasst, wobei aber nochmals auf die teils ausführlichen Resümees zu den Grabungen im Bereich der Bühnen des Theaters ${ }^{246}$, im Auditorium ${ }^{247}$ und an der Stiegengasse im Süden des Theaters hingewiesen $\operatorname{sei}^{248}$.

\section{Bühnengebäude}

Die Grabungsbefunde aus den beiden Kammern D3 und D8 gestatten - zumindest für das hellenistische Bühnengebäude - eine Datierung in die Zeit ab dem 2. Viertel des 2. Jhs. v. Chr. Das ist doch deutlich später als die Ausgräber um 1900 postulierten. Wie sich diese mehr als 100-jährige Lücke zwischen der Neugründung der hellenistischen Stadt und dem sich aus den jüngeren Grabungsergebnissen ermittelten Datum in konkreter baulicher Gestalt manifestierte, wissen wir nicht. Man kann jedoch davon ausgehen, dass zumindest der Bauplatz und eine vorläufige Gestaltung des Theaters mit der lysimachischen Neugründung festgelegt wurden.

Bei der Planung des Theaters machte man sich eine natürliche Geländeformation in den unteren Zonen des Panayırdağ in Form eines engen, nach Nordwesten auslaufenden Geländeeinschnitts mit steil abfallendem Schuttkegel zunutze. Daher können jene Quaderreste, die 1969 unter dem Logeion-Bereich freigelegt wurden, möglicherweise im Zusammenhang mit baulichen Maßnahmen interpretiert werden, mit deren Hilfe die Niveauunterschiede zwischen der Ebene des kleinen Brunnenhauses an der nordwestlichen Ecke des Bühnengebäudes aus der Zeit um 280 v. Chr. und der späteren Orchestra gestaltet wurden. Oder die Blöcke waren für die Errichtung des Sockels der scaenae frons bereitgelegt, der ausschließlich aus sekundär verwendetem Baumaterial errichtet ist. Hinsichtlich der Anlage des Zuschauerraums konnten keine datierenden Hinweise gefunden werden, sodass wir nicht wissen, wie zeitnah oder -fern das Koilon und die Orchestra - für die Gleiches gilt - zum Bühnengebäude stehen. Man kann aber berechtigterweise von einem Baubeginn vor der Errichtung der Skene ausgehen.

Für die Errichtung des Bühnengebäudes musste eine bis zu 4,5 m hohe Terrasse angelegt werden. Ihre Fundamente reichen bis auf den felsigen Untergrund und wurden gleichzeitig mit der dazwischen aufgebrachten Verfüllung schrittweise errichtet.

\footnotetext{
${ }^{242} \mathrm{Zu}$ den älteren Forschungen am Westabhang des Panayırdağ s. KeIL 1930, 31 f.; KeIL 1932, 12-15.

${ }^{243}$ Eine erste Begehung der Ruine wurde seitens des ÖAI in der Kampagne 2013 durchgeführt. Die Erforschung der mit der Frontseite nach Nordwesten orientierten Gebäudereste wird mit der damit einhergehenden Klärung der inhaltlichen Bezüge zwischen dem Theater und den im Osten anschließenden Architekturen zweifellos auch zu übergeordneten Fragenstellungen nach der Konzeption von Theater-Tempel-Komplexen in hellenistischer Zeit beitragen; vgl. zu dieser Problematik etwa MERT 2002, 187-203; Gros 2009, 53-63 und die Rezension dieses Beitrags von CAVALIER 2010.

244 ÖAI-BERICht 2012, 11-14; ÖAI-BERICHT 2013, 11 f. Zu den vorläufigen Ergebnissen der aktuellen Forschungen an der domus s. auch BAIER 2013.

${ }^{245}$ ÖAI-BerICht 2013, 12 (mit der Periodisierung in mindestens drei Hauptphasen); vgl. ThÜR 2002, 257-274; ÖAI-BERICHT $2012,13$.

${ }^{246}$ Kap. 3.2.3.

${ }^{247}$ Kap. 3.4.4.

${ }^{248}$ Zur Periodisierung s. Kap. 11.
} 
Dieselbe Konstruktionstechnik konnte für die kaiserzeitlichen Kammern zwischen hellenistischer Westmauer und Terrassenmauer festgestellt werden. Aus den Funden in der Auffüllung ist ersichtlich, dass das gesamte in hellenistischer Zeit aufgebrachte Material bis hinab zur Felsoberfläche abgetragen wurde. Die neuen Fundamente und die neuerlich aufgebrachte Verfüllung wurden wiederum Hand in Hand errichtet. In der kaiserzeitlichen Kammerreihe E konnten Nutzungsspuren von der Errichtungszeit im 1. Jh. n. Chr. bis in byzantinische Zeit hinein festgestellt werden.

Der Grundriss des kaiserzeitlichen Bühnenhauses konnte um einige wesentliche Details ergänzt werden. Es zeigte sich, dass das hellenistische Gebäude, das weiterhin erhalten blieb, von dem kaiserzeitlichen Umbau zwischen Bühnenfassade und Westerweiterung umfasst wird. Dies geschah an den Schmalseiten nicht mittels einer durchgehenden geschlossenen Mauer, sondern durch eine mit Pfeilern aufgelockerte Wand. Dadurch blieb das hellenistische Mauerwerk an diesen Stellen sichtbar. Der T-förmige Grundriss der Pfeiler und das in gleicher Weise zurückspringende Mauerwerk an den Westecken lassen eine Rekonstruktion von Bögen zu, die von Pfeilern mit darüber verlaufendem Architrav gerahmt werden.

\section{Orchestra}

Für die oft nur knapp über dem abgearbeiteten Fels errichtete Orchestra konnte der Befund der Altgrabungen bestätigt werden. Form und Niveau der älteren hellenistischen Orchestra lassen sich gut rekonstruieren. Lediglich für den Anschluss zu den Sitzreihen des Koilon muss es bei Vermutungen bleiben. Durch die kaiserzeitliche Umgestaltung der Orchestra wurden die untersten Sitzreihen entfernt. Der erste kaiserzeitliche Umbau des Theaters in flavischer Zeit hatte keine Auswirkungen auf das Niveau der Orchestra. Auch der hellenistische Ringkanal stand weiterhin in Verwendung, wie Reparaturstellen und die Auskleidung mit opus signinum belegen. Abarbeitungen an der Oberkante der Kanalwandungen sprechen für die Anbringung einer Kanalabdeckung. Um die Mitte des 2. Jhs. n. Chr. wurde der alte Ringkanal aufgegeben, das Orchestraniveau um rund 0,3 $\mathrm{m}$ angehoben und ein neuer, deutlich seichterer Abwasserkanal über dem alten errichtet.

Das Fundament U liegt mit seiner Oberkante deutlich tiefer als der hellenistische Ringkanal und scheint einen Hinweis auf eine ältere Phase eines einfacheren Theaters darzustellen. Es dürfte mit seiner sorgsam gesetzten Innenseite den >Tanzplatz` begrenzt haben und war hangseitig von einem Plattenbelag bedeckt, wodurch die unterschiedlich vorspringende Außenkante des Fundaments erklärt werden kann.

\section{Proskenion}

Vom hellenistischen Proskenion konnten keine Spuren nachgewiesen werden. An seiner Stelle erhebt sich der aus mächtigen Polsterquadern errichtete Sockel der kaiserzeitlichen scaenae frons.

Als komplexe Baumaßnahme präsentiert sich die Umgestaltung der römisch-kaiserzeitlichen Bühne. Die zunächst mit nur einer mittleren Stützenreihe errichtete Bühne wurde später mit zwei Stützenreihen ausgestattet. Die Umgestaltung der Front von einer hellenistisch anmutenden \Säulenhalle` aus flavischer Zeit zu einer geschlossenen, marmorgetäfelten Wand um die Mitte des 2. Jhs. n. Chr., die auch einer Inschrift zufolge als tiefreichender Eingriff zu verstehen ist, könnte mit der Verdoppelung der Stützen im Inneren einhergegangen sein.

\section{Koilon}

Die Ausgrabungen auf den drei Diazomata erbrachten vor allem ein besseres Verständnis der Konstruktion und der Abfolge der Baumaßnahmen im Auditorium. Absolute Datierungen sind kaum möglich. Das hellenistische Fundmaterial ist in der Regel umgelagert und meist mit kaiserzeitlicher Keramik vergesellschaftet. Hingegen lässt sich ein Schwerpunkt in der frühen und mittleren Kaiserzeit feststellen, der mit der Umgestaltung und dem Ausbau des Koilon bis in das frühe 2. Jh. n. Chr. zusammenhängt. Eine präzise Differenzierung der mittel- oder spätkaiserzeitlichen Renovierungen kann nicht vorgenommen werden, einzelne Fundkomplexe belegen weitere Baumaßnahmen bis in die Spätantike.

Die beiden Tonrohrstränge, die 2006 auf dem unteren Diazoma festgestellt wurden, könnten mit dem Umbau der Orchestra in eine Arena zusammenhängen, wobei das herbeigeleitete Wasser wohl zu Reinigungszwecken oder als Trinkwasser und nicht für die Veranstaltung von Wasserspielen verwendet wurde. 
Die Tonrohrleitungen führten von der unter der media cavea verlaufenden Aristion-Leitung, an welcher der Beginn der Leitungen zu sehen ist, durch den Zuschauerraum nach unten, queren das Diazoma und verlaufen unter der ima cavea weiter Richtung Orchestra ${ }^{249}$.

Die hangseitige Ausdehnung des Theaters im Osten ist durch die Rückwand der porticus in summa cavea klar definiert. Die östlich an die Rückwand der Portikus angesetzten Räumlichkeiten stehen funktional im Zusammenhang mit dem Theaterbetrieb, so wird einer der beiden in diesem Abschnitt freigelegten Räume als Thermopolion interpretiert. Architektonisch sind diese Räumlichkeiten aber vom eigentlichen Theaterbau zu trennen und können am ehesten als Annex zu diesem aufgefasst werden.

\section{Analemmata mit Zugangssystemen und Stiegengasse im Süden des Theaters}

Die Untersuchung der Analemmata erbrachte einen aufschlussreichen Einblick in die Konstruktion dieser gewaltigen Gebäudeflügel mit ihren hochüberwölbten Zugangssystemen und den entlang der vomitoria anschließenden Raumfluchten. Beide Analemmata wurden abschnittsweise ab spätflavischer bis in trajanische Zeit errichtet, ausgebaut und dann in spätantik/frühbyzantinischer Zeit aufgegeben. Im nördlichen Teil des Gebäudes waren es die schweren Erdbebenschäden des 3. und 4. Jhs. n. Chr., die umfangreiche Sanierungsarbeiten nach sich zogen. Dabei kam es zur Umgestaltung des vomitorium EN1 und im späten 4. Jh. n. Chr. zur Aufgabe des Zugangs EN2. Im 5. Jh. n. Chr. erfolgte der Einbau eines Wasserspeichers in EN1. Die Kammern westlich des vomitorium waren zu diesem Zeitpunkt bereits verschlossen. Der Südflügel des Theaters scheint hingegen von den Erdbebenzerstörungen des 3. und 4. Jhs. n. Chr. weniger stark betroffen gewesen zu sein. Schwere Schäden wiesen jedoch die Wohnhäuser südlich des Theaters auf, deren Schutt auch die Stiegengasse zwischen den Eingängen ES1 und ES3 großflächig bedeckte. Man unterließ es, die Treppe gänzlich vom Erdbebenschutt zu befreien. Am oberen Abschnitt der Stiegengasse, zwischen den Eingängen ES2 und ES3, wurde der nahe der Insula lagernde Schutt nicht mehr entfernt, wie die nur mehr an dieser Stelle in situ erhaltenen Stufensteine zeigen.

Auch die im frühen 2. Jh. n. Chr. errichtete Aristion-Leitung, die unter der media cavea des Theaters zum Nymphaeum Traiani führt, scheint im Laufe des 6. Jhs. n. Chr. aufgegeben worden zu sein, wie zahlreiche daraus geborgene Wildtierknochen nahelegen. Dass es sich dabei um eine intendierte Maßnahme handelte, zeigt eine Steinsetzung nahe der südlichen Außenmauer des Theaters. Diese aus Stufenblöcken der Treppe errichtete Sperre sollte wohl den Zugang ins Theater durch den Wasserleitungskanal unterbinden, was auf einen fortifikatorischen Aspekt verweist. Eine Maßnahme, die in Zusammenhang mit der Errichtung der byzantinischen Stadtmauer und mit der Integration des Theaters in das byzantinische Befestigungssystem zu sehen ist, wobei die wuchtigen Mauern zwischen dem Zugang ES3 und der Kammer E5 des kaiserzeitlichen Bühnengebäudes als Teil der Befestigung genutzt wurden. Damit verbunden waren die Zusetzung der südlichen Eingänge ES1, ES2 und ES3 sowie die Aufstockung einer aus hellenistischer Zeit stammenden Terrassenmauer entlang der Akademiegasse östlich des Eingangs EN3 unter Verwendung zahlreicher Stufensteine der großen Treppe. Am Bühnengebäude führten diese Maßnahmen zur Aufgabe einiger Kammern, deren Türen gleichfalls vermauert wurden. Zusätzlich verstärkte man die Westmauern der Kammern E7 und E8 durch eine Mauer im Inneren der Kammern. Die Südmauer des hellenistischen Bühnenhauses erhielt zudem eine Verstärkung aus großen Quadern. Wie Inschriften an einem Torgewände der Stadtmauer in unmittelbarer Nähe des Bühnengebäudes zeigen, ist mit der Errichtung der Stadtmauer bis spätestens in die Zeit des Heraklios zu rechnen.

Die Stiegengasse, die einst die südlichen Theaterzugänge und mit großer Wahrscheinlichkeit auch die Marmorstraße und die Akademiegasse verband, lag nun außerhalb der befestigten Stadt. Sie versank nach und nach unter meterhohem Schutt, wobei man offenbar zunächst noch versucht hatte, die Erdmassen mittels quer zur Treppe bzw. zu deren Unterbau verlaufenden Mauern abzufangen.

M. HOFBAUER

\footnotetext{
${ }^{249}$ Vgl. Kap. 3.3 u. 3.3.2.
} 


\section{Keramik-und Glasfunde}

Bei den stratifizierten Keramik- und Glasfunden aus den Grabungen im Theater handelt es sich um rund 30.000 statistisch erfasste, nach Gattungen und - wo möglich - Waren klassifizierte Fragmente oder Ganzgefäße aus unterschiedlichen, von 1997 bis 2009 durchgeführten Sondagen ${ }^{1}$.

Der zeitliche Rahmen der Funde reicht von der hellenistischen Periode über die römische Kaiserzeit bis in die frühbyzantinische Zeit ${ }^{2}$. Neben der Präzisierung des Chronologiegerüsts für das Theater und sein urbanistisches Umfeld konnten die Datierung des Bühnengebäudes sowie Mehrphasigkeiten der Einzelstrukturen und sekundäre Beeinträchtigungen des Gebäudes bzw. seine Nachnutzungsphasen verifiziert und enger zeitlich gefasst werden ${ }^{3}$.

Da die Datierung der einzelnen Bereiche und Straten anhand der keramischen Evidenz als vordergründiges Ziel galt, werden in erster Linie chronologisch relevante keramische Gattungen herangezogen, um die zeitliche Einordnung der einzelnen Strukturen und Straten zu untermauern. Diese umfassen Bestandteile des Tafelgeschirrs, also Produkte der östlichen Sigillataproduktionen Eastern Sigillata A (ESA), Eastern Sigillata B (ESB), Eastern Sigillata C (ESC), Pergamenische ESC, Late Roman C (LRC), zypriotische Sigillata (CRS), aber auch Importe italischer Sigillata (ITS) und sog. African Red Slip Ware (ARS). Es ist außerdem Tafelgeschirr lokal-regionaler Provenienz vertreten, dessen Formen oftmals Imitationen von Gefäßen importierter Sigillatagattungen darstellen. In diesem Zusammenhang ist v. a. die sog. Ephesische Red-Slip-Ware (ERSW) hervorzuheben. Weitere späthellenistische bis frühbyzantinische Gefäßgattungen des Tafelgeschirrs, die in einen engeren chronologischen Rahmen zu betten sind, werden mit einbezogen. Dazu zählen z. B. späthellenistische Firnisware, Graue Ware mit Schwarzem Überzug (GWSÜ), weißgrundige Keramik, Reliefkeramik und dünnwandige Keramik (DWK). Auch Gebrauchskeramik (GK), Küchenware (KW), Amphoren, Lampen und ausgewählte Glasgefäße finden Eingang in die chronologische Auswertung.

Alle Keramikfunde enthaltenden Fundkomplexe wurden chronologisch ausgewertet. Die enorme Fundquantität, die unterschiedliche Aussagekraft und die meist starke Heterogenität der Fundkomplexe bedingte zum einen eine Konzentration auf die jeweils jüngsten Keramikfunde. Zum anderen schien für die meisten Bereiche aufgrund ihrer Stratigrafie und stark heterogenen Schichtzusammensetzung und letztendlich aufgrund ihrer nicht immer klar zu erschließenden Aussagekraft für die Chronologie des Theaters eine tabellarische Darstellung und Charakterisierung der Fundkomplexe als zielführend für eine übersichtliche Vorlage. Der Aufbau des Textes folgt dabei jener des Befundkapitels ${ }^{4}$. Nur signifikante Funde aus ausgewählten, für die Chronologie des Theaters relevanten Fundkomplexen wurden in den Katalog aufgenommen und abgebildet und werden im Text ausführlicher erläutert.

\footnotetext{
${ }^{1} \mathrm{Zu}$ den einzelnen Grabungen und den jeweils zugrunde liegenden Fragestellungen s. Kap. 3. Die Kampagnen zur Dokumentation des Fundmaterials begannen 1998 (P. Turnovsky), wurden 2005 wieder aufgenommen und dauerten - mit Unterbrechung 2007 und 2008 - bis September 2011 an. Bis 2006 erfolgte die Bearbeitung durch M. Gessl, seit 2009 hat die Autorin die Bearbeitung inne. 2010 und 2011 erfolgte die örtliche Leitung der Fundbearbeitung durch J. Struber-Ilhan. Sie zeichnet außerdem für die Überarbeitung des Katalogs verantwortlich, sowie für die grafische Gestaltung bzw. für die Digitalisierung der Funde. Ihr gebührt großer Dank für ihren Einsatz und ihre Verlässlichkeit.

${ }^{2}$ Die Funde vorhellenistischer Zeit stammen aus späteren Einschüttungen und werden hier nicht näher behandelt, da sie nicht unmittelbar mit der Chronologie des Theaters in Verbindung stehen. Unter diesen nehmen die archaischen Keramikfunde den größten Anteil ein, während Funde der geometrischen und klassischen Zeit nur sporadisch belegt sind. Da archaische Keramik im Stadtgebiet von Ephesos - abgesehen von den Siedlungsresten unter der Tetragonos Agora und zwei Gräbern - bislang nur im geringem Ausmaß angetroffen wurde, wurden diagnostische Fragmente aus den Einschüttungen im Theater von A. von Miller zur Bearbeitung übernommen und im Rahmen ihrer Dissertation ergänzend ausgewertet s. vON MiLler (in Druck).

${ }^{3}$ Kap. 10 u. 11.

${ }^{4}$ Kap. 3.
} 
Der Anteil an Glasfunden ist mit lediglich 222 diagnostischen Fragmenten im Vergleich zur Keramik (rund 9.000 diagnostische Fragmente) deutlich in der Unterzahl ${ }^{5}$. Da die vorhandenen Glasgefäße feinchronologisch meist unempfindlicher sind als die vergesellschafteten Keramikfunde bzw. längere Laufzeiten aufweisen, und die Fragmente zudem meist kleinteilig gebrochen sind und sich somit einer exakten Klassifizierung entziehen, werden nur die für die Datierung relevanten oder besonders gut erhaltenen Stücke angeführt.

\subsection{BÜHNENGEBÄUDE}

\subsubsection{Funde aus den Sondagen im hellenistischen Bühnengebäude}

In den Kammern D3 und D8 konnten in den Grabungskampagnen 2002 und 2005 von späteren Bau- und früheren Grabungsaktivitäten ungestörte Fundkomplexe aus dem Fundamentbereich geborgen werden. Diese Funde sind ausschlaggebend für die Datierung der Errichtung der Kammern - und in weiterer Folge des Bühnengebäudes und des gesamten Theaters. Die Fundzusammensetzung der einzelnen Befunde ist chronologisch heterogen; der Anteil an vorhellenistischen Fragmenten ${ }^{6}$ ist auffallend hoch. Sämtliches Fundmaterial ist klein bis sehr kleinteilig gebrochen und oft sehr abgerieben, was insgesamt auf eine mehrmalige Umlagerung hindeutet. Für die Datierung der Kammern sind nur die jüngsten zu bestimmenden Funde relevant, die im Folgenden diskutiert werden.

\subsubsection{KAMMER D3}

In der obersten Aufschüttung SE B3 wurden insgesamt 271, davon 57 diagnostische, ausnahmslos kleinteilig gebrochene Keramikfragmente erfasst. Die heterogene Fundzusammensetzung entspricht einem Zeitrahmen beginnend mit der archaischen Zeit ${ }^{7}$ über die hellenistische Periode und die 2. Hälfte des 1. Jhs. sowie den Anfang des 2. Jhs. n. Chr. bis in das 5. Jh. n. Chr. Die jüngsten Stücke sind Vertreter der Küchenware und eine Lampe: Es handelt sich um einen für das ausgehende 4. und die 1. Hälfte des 5. Jhs. n. Chr. charakteristischen Rand eines Kochtopfs (K 1 Taf. 302) ${ }^{8}$, einen aufgrund seines fabrics ebenfalls als spätantik zu bewertenden gerippten Bandhenkel eines Kochtopfs und um einen Pfannengriff. Eine Lampe, von der zwei Bodenstücke und ein Wandstück mit vollem Griff erhalten sind, und die auf der Bodenunterseite eine Töpfermarke zwischen drei konzentrischen Rillen aufweist (K 2 Taf. 302. 345), dürfte aufgrund dieser Töpfermarke der 2. Hälfte des 6. Jhs. n. Chr. zuzuordnen sein".

In der kleinen Feuerstelle SE B4 wurden 32 Fragmente geborgen, davon 22 diagnostische. Mit Ausnahme eines bis auf Rand und Hals komplett erhaltenen, allerdings stark versinterten Unguentariums oder Amphoriskos mit niedrigem Standfuß (K 8 Taf. 302. 345) ${ }^{10}$ und einer ganz erhaltenen Spule (?) $)^{11}$ sind die meisten Fragmente kleinteilig gebrochen. In die 2. Hälfte des 1. Jhs. v. Chr. bis in die augusteische Zeit weist eine graue Platte mit schwarzem Überzug, von der neun Randfragmente geborgen wurden (K 3 Taf. 302), sowie ein Teller der GWSÜ mit Palmettenstempel, von dem sechs Fragmente geborgen wurden (K 4 Taf. 302), ein Randstück eines Reliefbechers (K 5 Taf. 302) sowie ein kleines, nicht in den Katalog

\footnotetext{
${ }^{5}$ Das Phänomen, dass Glasfunde in Fundkontexten oft unterrepräsentiert sind, kann mit der Möglichkeit des Recycling von GlasgefäBen erklärt werden: Glas wurde aufgesammelt, eingeschmolzen und wieder verwertet. s. z. B. FünFsChILLING 2011; Keller 2005.

${ }^{6}$ Vergleichbar sind diese Funde u. a. mit dem Repertoire aus dem Vediusgymnasium (Kerschner u. a. 2008), mit den Funden aus dem Siedlungsgebiet im Nordosten des Panayırdağ (Grabung M. Kerschner 2008-2009, ÖAI-Bericht 2010; Kerschner [in Vorbereitung]) und mit dem Material aus den Grabungen unter der Tetragonos-Agora (TrinkL - ScherRer 2006; GASSNER 1997; VON Miller in Druck). Für fachliche Diskussionen danke ich M. Kerschner (Wien), I. Kowalleck (Wien/Berlin) und A. von Miller (Wien/Halle).

${ }^{7}$ VON MiLLER (in Druck), Tabelle 7.

${ }^{8}$ LAdSTÄTter 2008, 187 Abb. 31; K 176. K 179; TURnovsky 2005a, Abb. 1, 5.

${ }^{9}$ LAdSTÄTter 2008, 119 Abb. 25 Typ II-IV.

${ }^{10}$ Vgl. Mitsopoulos-Leon 1991, O9-13.

${ }^{11}$ MF 39 Taf. 374 (Kap. 6.2.1).
} 
aufgenommenes Fragment einer Ephesoslampe. Auch die vorhandenen Fragmente von dünnwandigen Bechern (K 6. K 7 Taf. 302) fügen sich in die Datierung ein. Ein Fragment eines Glasröhrchens (G 1 Taf. 302) dürfte zu einem Balsamarium gehören ${ }^{12}$ und dem Kosmetikbereich entstammen. Aus der Reihe fällt ein Wandfragment eines ARS-Gefäßes. Dieses dürfte auf eine sekundäre Kontamination zurückzuführen bzw. der über SE B4 liegenden SE B3 zuzurechnen sein.

37 diagnostische Fragmente wurden in SE B5 geborgen. Es handelt sich durchwegs um kleinteilig gebrochene Fragmente, teilweise sind Anpassungen an Stücke aus SE B4 zu beobachten, was für die Zusammengehörigkeit beider Schichten spricht. Die jüngsten bestimmbaren Stücke können in das 1. Viertel des 1 . Jhs. n. Chr. datiert werden, die ältesten Funde reichen bis in die archaische Zeit zurück. Feinchronologisch aussagekräftig ist in erster Linie das ESA-Spektrum: Es umfasst u. a. Fragmente eines Tellers der Form Atlante 4B (K 9 Taf. 302) und einer Schale der Form Atlante 22B (K 10 Taf. 302). Letztere dürfte in das ausgehende 1. Jh. v. Chr. und das 1. Jahrzehnt des 1. Jhs. n. Chr. zu datieren sein. Neben einem Fragment einer Grauen Platte, das zu der Platte aus SE B4 gehören dürfte, sind ein Fragment eines Reliefbechers ohne erhaltenen Dekor (K 11 Taf. 303) und ein Wandfragment mit Blattschuppendekor (K 12 Taf. 303) vorhanden. Das Spektrum der Firnisware umfasst neben einem kleinen Kantharosfragment, das nicht in den Katalog aufgenommen wurde, hauptsächlich Schalen bzw. offene Gefäße (K 13-17 Taf. 303). Die aus B5 stammenden drei kleinen Fragmente von Ephesos-Lampen (K 18 Taf. 303) sind ebenfalls charakteristisch für das 1. Jh. v. Chr. und die augusteische Zeit. In tiberischer Zeit werden Ephesoslampen von ROW-Lampen abge1 öst ${ }^{13}$. Ein kleines Bodenfragment einer solchen Lampe (K 19 Taf. 303) stellt den jüngsten datierbaren Fund in dieser Schicht dar. Ein Münzfund aus SE B5 datiert in das 1. Jh. v. Chr. bis 1. Jh. n. Chr. ${ }^{14}$.

Aus SE B6 stammen 90 diagnostische Funde, die kleinteilig gebrochen und demnach mehrmals umgelagert worden sind. Die Zusammensetzung der Funde ist zeitlich heterogen. Ein Teil der Funde aus B6 ist der vorhellenistischen Zeit zuzuordnen. In die frühhellenistische Zeit bzw. in das 3./2. Jh. v. Chr. gehören vermutlich zwei kleine Wandfragmente von Gefäßen der Westabhangware (K 20 Taf. 345; K 21 Taf. 303), zwei Randfragmente von Tellern der Firnisware mit breitem, leicht gebogenem Rand ${ }^{15}$ (K 22. K 23 Taf. 303), eine Echinusschale (K 24 Taf. 303), zwei Randfragmente von Schalen mit eingebogenem Rand (K 25. K 26 Taf. 304), ein Schälchen mit geschwungener Wand (K 27 Taf. 304) ${ }^{16}$ und ein Fragment eines Unguentariums (K 28 Taf. 304). Die jüngsten Funde dürften jedoch mindestens in die 2. Hälfte des 1. Jhs. v. Chr. weisen. Es sind dies ein Henkel und ein abgebrochener Knauf einer Amphore mit einem dem Typs Peacock - Williams $45^{17}$ sehr ähnlichen fabric (K 29 Taf. 304) und zwei Fragmente eines massiven, abgesetzten Standrings aus Glas (G 2 Taf. 304), der aufgrund seines kleinteiligen Erhaltungszustands allerdings keiner bestimmten Form mehr zuzuweisen ist ${ }^{18}$. Aus SE B6 stammt eine Münze, die der Zeit 387 bis 295 v. Chr. zuzuordnen ist ${ }^{19}$.

SE B7 enthält insgesamt zahlreiche Fragmente (140 diagnostische Stücke), die allerdings zu einem großen Teil der vorhellenistischen Zeit, insbesodere der Archaik, zugerechnet werden können. Der Erhaltungszustand der Gefäße ist jeweils sehr fragmentarisch. Zu den jüngsten bestimmbaren Funden zählen ein Fragment eines Kantharos der Westabhangware (K 30 Taf. 304. 345), ein profilierter Standfuß eines Skyphos oder Kantharos (K 31 Taf. 304) und Wandfragmente sogenannter Riefelkantharoi. Vertreten sind außerdem eine frühe Echinusschale (K 32 Taf. 304), ein Fischteller (K 33 Taf. 304) und ein Teller der Firnisware mit Palmettenstempel (K 34 Taf. 304). Eine Randfragment einer graeco-italischen Amphore (K 35 Taf. 304) und ein koischer Amphorenknauf (K 36 Taf. 304) weisen ebenfalls in die frühhellenistische Zeit. Zu einer Steilschulterlampe dürfte ein oxidierend gebranntes, flächig überzogenes Fragment mit langem, abgesetztem Schnauzengang (K 37

${ }^{12}$ Vgl. SснÄтZSCHOCK 2010a, A-G 50-52.

${ }^{13}$ LADSTÄTter 2005, 235 f. 238 f.; LAdstätTer 2007, 211.

${ }^{14} \mathrm{M} 82$ (Kap. 5).

${ }^{15} \mathrm{Vgl}$. Gassner 1997, Nr. 96.

${ }^{16}$ Vgl. Ladstätter 2010c, KatNr. 25-30. Die Form ist in Ephesos v. a. im späten Hellenismus verbreitet, s. LAdSTÄTter u. a. 2003, Abb. 4.

${ }^{17}$ Peacock - Williams 1986, 188-190. Zum Amphorentyp in Ephesos s. Ladstätter 2005, 235; Ladstätter 2007, 212; LadSTÄtTer 2008, 180 f.; OutsChar 1996, 58; BEZECZKY 2004, 87.

${ }^{18}$ Vgl. Czurda-Ruth 2007, 143-146.

${ }^{19}$ M 5 (Kap. 5). 
Taf. 304. 345) gehören. Eine Datierung in die 1. Hälfte des 2. Jhs. v. Chr. ist anzunehmen ${ }^{20}$. Ein Henkel einer spätantiken Glaslampe ${ }^{21}$ (G 3 Taf. 304) dürfte hingegen sekundär in die Schicht gelangt sein.

Die jüngsten der insgesamt 88 kleinteilig gebrochenen diagnostischen Funde aus SE B8 weisen in das 3./2. Jh. v. Chr., enthalten sind aber auch in diesem Stratum Residuals vorangegangener Epochen. Zu den frühhellenistischen Funden zählen etwa ein Wandfragment eines Kantharos der Westabhangware (K 38 Taf. 305. 345), ein Wandfragment eines Riefelkantharos (K 39 Taf. 305) und ein Echinusschälchen (K 40 Taf. 305). Ein Teller mit breitem Rand (K 41 Taf. 305) und insbesondere ein Teller mit innen verdicktem Rand und innen metallisch glänzendem schwarzem Überzug (K 42 Taf. 305) gehören in die 1. Hälfte des 2. Jhs. v. Chr. Ein Rand eines Kochtopfs (K 43 Taf. 305) ist dem späten 3. und frühen 2. Jh. v. Chr. zuzuordnen ${ }^{22}$.

Unter den insgesamt 77 in SE B10 geborgenen diagnostischen Keramikfunden ist der Anteil an vorhellenistischen Funden besonders hoch. Allerdings kam hier aber auch ein Fragment eines Reliefbechers zum Vorschein (K 44 Taf. 305. 345). Das Dekorschema des Bechers lässt sich nicht mehr vollständig rekonstruieren. Erhalten sind die Reste eines vegetabilen Dekors, der aus herzförmig gruppierten Langblättern bestehen dürfte. Das linke Blatt wird durch einen Steg begrenzt. Darüber liegt eine umlaufende, feine Leiste, über der der Rest eines plastischen Dekors erhalten blieb. Insgesamt handelt es sich um ein für Ephesos bislang singuläres Stück: Die Außenseite ist rot, die Innenseite schwarz überzogen. Diese Art der Oberflächenbehandlung sowie die Machart insgesamt erinnern an die Beschaffenheit von Gefäßen hellenistischer Firnisware und lassen auf eine gewisse Experimentierfreude des Töpfers schließen. Es dürfte sich insgesamt um eines der frühesten Exemplare eines ephesischen Reliefbechers handeln ${ }^{23}$.

Unter den vergesellschafteten Funden sind Teller der Firnisware mit breitem Rand (K 45 Taf. 305), Fragmente von Schalen mit leicht eingebogenem Rand (K 46 Taf. 305) und ein intentionell gelochter Boden eines Tellers oder einer Schale mit hohem Standfuß zu nennen (K 47 Taf. 305). Diese Gefäße sind Bestandteil des Tafelgeschirrs im 3. und 2. Jh. v. Chr. Auch die Formen gebrauchskeramischer Schüsseln (K 48 Taf. 305; K 49 Taf. 306) sind vergleichbar mit jenen aus bereits bekannten ephesischen Fundkomplexen (früh)hellenistischer Zeitstellung ${ }^{24}$. $\mathrm{Zu}$ ergänzen ist außerdem eine Lekane mit breitem Rand und einem plastischen Wellenbanddekor auf der Randoberseite (K 50 Taf. 306) ${ }^{25}$. Die Form eines pithosartigen Gefäßes (K 51 Taf. 306) nimmt jene der in hellenistischer Zeit gängigen Kasserollen mit Wandknick im oberen Gefäßdrittel vorweg, kann allerdings auch schon in früheren Kontexten beobachtet werden ${ }^{26}$. Eine Amphore mit überhängender Randlippe (K 52 Taf. 306) dürfte zur sog. Nikandros-Gruppe gehören und kann dem späten 3. und der 1. Hälfte des 2. Jhs. v. Chr. zugeordnet werden ${ }^{27}$. Insgesamt kann SE B10 aufgrund der jüngsten Funde in das ausgehende 3. und die 1. Hälfte des 2. Jhs. n. Chr. datiert werden, das Reliefbecherfragment rückt die Datierung mindestens in das 2. Viertel des 2. Jhs. v. Chr. vor.

Aus SE B11 wurden 32 diagnostische Funde registriert, ihr fragmentarischer Erhaltungszustand weist sie als mindestens einmal umgelagert aus. Das Stratum enthält zwar ebenfalls ältere Residuals, es treten darin aber auch Funde auf, die eindeutig der hellenistischen Zeit zuzuordnen sind. Hervorzuheben ist in erster Linie ein Randfragment eines Reliefbechers mit figürlichem Dekor (K 53 Taf. 306. 345). Zu erkennen sind mindestens zwei männliche Figuren, die sich nach rechts bewegen. Die Kopfbedeckung des rechten Jünglings zeigt eine Art Helmbusch, jene der hinteren Figur blieb nicht mehr erhalten. Es dürfte sich um einen Fries mit der Darstellung von Kriegern oder Jägern handeln (Kentauromachie?) ${ }^{28}$. Auffällig ist das Fehlen einer Randbordüre. Die qualitätvolle Ausführung sowie die feine, dünnwandige Machart und der stark profilierte Körper mit ausgebogenem Rand weisen den Becher als zur frühen Produktion gehörig aus. Der Ton

\footnotetext{
${ }^{20}$ Scheibler 1976, 16; Gassner 1997, Nr. 783-785; Ladstätter 2010c, K 641.

${ }^{21}$ Vgl. TuRnovsKy 2003; CzURDA-Ruth 2007, Kap. $27 \mathrm{~b}$.

22 TRAPICHLER 2010, Abb. 3, 22; LADSTÄTter 2010c, K 38 (Gebrauchskeramik).

${ }^{23} \mathrm{Zu}$ chronologischen Fragen der Reliefbecher in Ephesos s. u. (SE B11, K 51)

${ }^{24}$ Vgl. LadSTÄTter 2003, L 333; Ladstätter 2010c, K 49.

${ }^{25}$ Rotroff 2006, Abb. 48, 277; 49, 281 (Lekane Form 4); Wellenbanddekor vgl. z. B. WaLdner 2009, K 55 (hellenistisches Brunnenhaus).

${ }^{26}$ z. B. am Panayırdağ, freundliche Information I. Kowalleck und A. von Miller; zur hellenistischen Kasserollenform vgl. LADSTÄTTER 2003, K 329.

${ }^{27}$ LaWall 2007, 48-53; vgl. Lawall 2004, 181 Abb. 5. 6; Gassner 1997, Nr. 408; Ladstätter 2005, K 68; LaWall 2004, 181 Abb. 5. 6 .

${ }^{28}$ Vgl. GASSNER 1997, Nr. 208. 209 Taf. 14. Profil vgl. auch Nr. 213.
} 
des Bechers ist sehr fein geschlämmt, hart gebrannt, kompakt und enthält etwas Glimmer. Möglicherweise wurde er im regionalen Umfeld von Ephesos hergestellt, was allerdings ohne mineralogisch-petrografische und chemische Analysen nicht zu beweisen ist. Eine Zuweisung zu einer bestimmten Werkstätte muss aufgrund der Kleinteiligkeit des Fragments ebenfalls unterbleiben. Mit dem Auftreten der Reliefbecher wird in Ephesos frühestens ab dem 2. Viertel des 2. Jhs. v. Chr. gerechnet ${ }^{29}$. Der Beginn der Produktion in Ephesos wurde nach bisherigem Forschungsstand in die 2. Hälfte des 2. Jhs. v. Chr. gesetzt, der Höhepunkt der Herstellung und des Exports von ephesischen Reliefbechern liegt eindeutig im ausgehenden 2. und in der 1. Hälfte des 1. Jhs. v. Chr. ${ }^{30}$. Das vorliegende Stück dürfte insgesamt - zusammen mit jenem Fragment aus SE B 11 - eines der frühesten Zeugnisse eines Reliefbechers in Ephesos darstellen. Es soll hier eine Datierung in das 2. Viertel des 2. Jhs. v. Chr. vorgeschlagen werden.

Dem ausgehenden 3. und 2. Jh. v. Chr. ist hingegen ein reduzierend gebrannter, matt grauschwarz überzogener Teller mit zentralem, vierfachem Palmettenstempel und konzentrischem Roulettdekor zuzuordnen (K 54 Taf. 306) ${ }^{31}$. Der Boden ist intentionell gelocht, was im Fundmaterial von Belevi in Zusammenhang mit der Spende von Trankopfern interpretiert wird ${ }^{32}$. Ein weiterer Teller mit Resten eines durch zwei konzentrische Rillen >gerahmten` Palmettenstempels in der Bodenmitte (K 55 Taf. 306) ist zu verzeichnen. Der Überzug des Stücks ist beinahe vollständig abgerieben. Drei Ränder von Schüsseln mit breitem, an der Oberseite gerilltem Rand (K 56. K 57 Taf. 307) finden Entsprechungen im Fundmaterial aus der Terrassierung des Prytaneions ${ }^{33}$, es handelt sich aber um eine sehr langlebige Form, deren früheste Vertreter bereits im 5. Jh. v. Chr. zu beobachten sind. Möglicherweise ist auch ein partiell überzogener Pithos mit Deckelfalz und hochgeschwungenem Rand ${ }^{34}$ der hellenistischen Zeit zuzurechnen (K 58 Taf. 307).

Insgesamt ist für die Entstehung des Stratums B11 aufgrund der jüngsten darin enthaltenen Keramikfunde - speziell des Reliefbecherfragments K 53 - und unter der Prämisse, dass zwischen deren Herstellung, Gebrauch und Entsorgung im Fundamentbereich von Kammer D3 eine bestimmte Zeitspanne liegt ${ }^{35}$, ein terminus post quem gegeben, der mindestens in das 2. Viertel des 2. Jhs. v. Chr. weist.

Das unterste Stratum SE B12 enthält 28 kleinteilig gebrochene Keramikfragmente, die vorwiegend der vorhellenistischen Zeit zuzurechnen sind. Ein einziges Fragment gehört zu einer außen schwarzbräunlich, innen rot überzogenen Schale mit eingebogenem Rand (K 59 Taf. 307), einer langlebigen Form, die in Gestalt der halbkugeligen Fußschalen und der Echinusschalen ${ }^{36}$ auch in der späteren hellenistischen Firnisware noch weit verbreitet ist. Mit Sicherheit kann der Großteil der Funde aus SE B12 der Vorgängernutzung des Theaterareals zugerechnet werden, gelangte nach mehrmaliger Umlagerung in die Aufschüttung und gibt daher lediglich einen terminus post quem für die Datierung des Theaters.

\subsubsection{KAMMER D8}

Die insgesamt 27 diagnostischen Funde aus SE B14 sind kleinteilig gebrochen. Indikativ für die Datierung sind ein Skyphos/Kantharos der Westabhangware mit zwei Rillen außen unter dem Rand und dem Rest einer

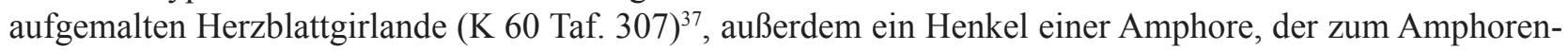

\footnotetext{
${ }^{29}$ LadstÄtter 2003, 73; PÜLZ - Ladstätter 2006, 80 f.; Rogl 2001. In Fundkontexten von der Tetragonos-Agora, die um $200 / 190$ v. Chr. geschlossen wurden, fehlen Reliefbecher bislang, s. Rogl 2003, 175-82; Rogl 2008, 28. Zur Einführung der Reliefbecher in Athen bereits in den Jahren 224/223 v. Chr. s. Rotroff 2006, 359. Das vorliegende Stück weicht aber in seiner Profilgestaltung deutlich von den athenischen Bechern ab. Mit einem früheren Produktionsbeginn (Ende 3./frühes 2. Jh. v. Chr.) als in Ephesos wird auch in Pergamon gerechnet, s. SchÄFER 1968, 17; RADT - DE LuCA 1999, 123-125. Zu RADT - DE LuCA 1999 s. allerdings die Rezension Rotroff 2001, 129 f., in der eine spätere Datierung (150 v. Chr. und später) des Fundmaterials aus dem Fundamentbereich des Großen Altars von Pergamon befürwortet wird.

${ }^{30}$ Ladstätter u. a. 2003, 26-28; Rogl 2008, 28; Rotroff 1982, 2-13; GÜNAY TuluK 2001, 51-57.

${ }^{31}$ LadstÄtter 2010c, K 8. K 9. K 16. K 17; Ladstätter 2003, K 312-314.

32 Vgl. Trapichler 2010, Abb. 3, 28. 29.

${ }^{33}$ LADSTÄTter 2010c, K 49.

34 Rotroff 2006, 94 (Vorratsgefäß Form 1).

${ }^{35}$ Vgl. RadT - DE LuCA 1999, 124 für die Sondagen im Großen Altar von Pergamon.

36 LADSTÄtTER 2003, 71.

37 Vgl. Mitsopoulos-Leon 1991, B52-54.
} 
typ mit Mushroom-rim gehören dürfte und mit einem Namensstempel `Ekataiou< versehen ist (K 61 Taf. $345)^{38}$, sowie ein Bandhenkelfragment einer weißgrundigen Lagynos. Ein Randfragment gehört zu einer Amphore mit verdickter Lippe (K 62 Taf. 307) ${ }^{39}$, dem zweiten in der mittel- und späthellenistischen Zeit verbreiteten Amphorentyp ${ }^{40}$.

Insgesamt kann SE B14 aufgrund der jüngsten Funde in das ausgehende 2. Jh. n. Chr. datiert werden. Der heterogene Fundkomplex enthielt außerdem Residuals der vorhellenistischen Zeit ${ }^{41}$. Auffällig ist zudem das Auftreten von 16 Muscheln, fünf Tierknochen, einer Schnecke und einer Austernschale.

Die unter SE B14 angetroffene Aufschüttung SE B15 enthielt 53 diagnostische Funde, erneut sind archaische Residuals vorhanden. Zwei kleine Wandfragmente von Reliefbechern aus SE B15 weisen mindestens in das 2. Viertel des 2. Jhs. v. Chr. Auf einem Fragment sind Reste eines zoomorphen Dekors in Form eines Delphins erhalten (K 63 Taf. 307. 345), das zweite Wandfragment zeigt den Rest einer Randbordüre, bestehend aus einem Rautenmuster zwischen Stegen (K 64 Taf. 307. 345) ${ }^{42}$. Ein sog. Fischteller ist charakteristisch für das 3. und 2. Jh. v. Chr. (K 65 Taf. 307) ${ }^{43}$. Ein Skyphos der Westabhangware, der außen einen auf rot überzogenem Grund schwarz aufgemalten Herzblattdekor zwischen eingeritzten Linien aufweist ${ }^{44}$ (K 66 Taf. 308), ein Wandfragment eines Riefelkantharos (K 67 Taf. 308) und ein gebrauchskeramisches Unguentarium (K 68) sind für das ausgehende 3. und 2. Jh. v. Chr. charakteristisch. Ein Rand einer Amphore mit Mushroom-rim $^{45}$ (K 69 Taf. 308) weist in dieselbe Zeit. Zwei Münzen datieren hingegen in das ausgehende 4. und 1. Viertel des 3. Jhs. v. Chr. ${ }^{46}$.

In SE B16 wurden 20 diagnostische, feinchronologisch allerdings meist nicht aussagekräftige Fragmente geborgen. Mit Ausnahme einer gebrauchskeramischen Schale, die eventuell der 1. Hälfte des 3. Jhs. v. Chr. zuzurechnen ist, ist nur Fundmaterial vorhanden, das der vorhellenistischen Zeit zugewiesen werden kann.

Auch die meisten der 62 diagnostischen Keramikfunde aus SE B17 sind der vorhellenistischen Zeit zuzurechnen. Die jüngsten bestimmbaren Stücke - ein reduzierend gebrannter, schwarz überzogener und ein oxidierend gebrannter, rot überzogener Kantharos oder Skyphos, jeweils mit Griffplatten (K 70. K 71 Taf. 308. 345) ${ }^{47}$ sind dem 2. Jh. v. Chr. zuzuordnen, ebenso eine Knickwandschale mit partiellem Überzug (K 72 Taf. 308).

Insgesamt 58 diagnostische Fragmente stammen aus SE B18. Ein Rand- und ein Wandfragment von Skyphoi der Westabhangnachfolgeware mit Mal- und Ritzdekor (K 73. K 74 Taf. 308), ein Teller der Glanztonware/Firnisware mit innen verdicktem Rand (K 75 Taf. 308) ${ }^{48}$ und ein runder, schwach eingedrückter

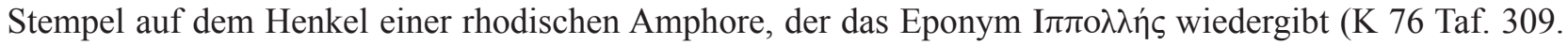
$345)^{49}$, machen eine Datierung von SE B18 in das späte 3. Jh. v. Chr. wahrscheinlich. Ein Fragment eines Kochtopfs (K 77 Taf. 309) findet ebenfalls Entsprechungen in Fundkomplexen aus der 2. Hälfte des 3. Jhs. v. Chr..$^{50}$ Auch in dieser Schicht finden sich ältere Residuals.

In der untersten Schicht B19 wurden nur vier gebrauchskeramische Fragmente geborgen, die feinchronologisch allerdings nicht relevant sind. Relativchronologisch muss SE B19 älter sein als SE B18. Eine

\footnotetext{
${ }^{38}$ EKATAIOY stellt die Genitivform von EKATAIO $\Sigma$ dar, das Y ist auf den Kopf gestellt, was bei lokalen Stempeln häufig vorkommt. Für die Bestimmung sei M. Lawall (Manitoba) herzlichst gedankt. Zu den Amphoren dieses Typs s. Lawall 2004; LADSTÄTTER u. a. 2003, 1987.

${ }^{39}$ Vgl. GASSNER 1997, Nr. 394 (ähnlich).

${ }^{40}$ BeZeCZKy 2003, 87.

${ }^{41}$ Eine Übersicht der archaischen Residuals in von Miller (in Druck), Tabelle 8.

${ }^{42}$ Gassner 1997, Nr. 232; Laumonier 1978, Taf. 11, 4705. 4727. 4731. 8640; Taf. 3, 1343.

${ }^{43}$ Ladstätter u. a. 2003, 34 mit Anm. 147-149; Mitsopoulos-Leon 1991.

${ }^{44}$ Vgl. LiKo 2001, Nr. 48.

${ }^{45}$ Vgl. LAdSTÄTter 2003, K 341. K 342; Gassner 1997, Nr. 409.

${ }^{46}$ M 8. M 21 (Kap. 5).

${ }^{47} \mathrm{Vgl}$. LADSTÄTter 2010c, K 124

${ }^{48}$ Vgl. LAdSTÄTter 2003, K 31. K 32.

${ }^{49}$ M. Lawall (Manitoba) sei wiederum herzlich für die Bestimmung gedankt. Zu Stempeln dieses Typs s. Finkielsztejn $2001,76$. 190 (Periode Ib). Stempel dieser Periode sind in Kontexten der Mitte bis zum späten 3. Jh. v. Chr. in ganz Ephesos verbreitet (freundliche Information M. Lawall).

${ }^{50}$ LADSTÄTter 2003, K 330; LAdSTÄTter 2010c, K 51.
} 
Münze aus SE B19 weist in die Zeit um 295/280 v. Chr. ${ }^{51}$, eine zweite, prinzipatszeitliche Münze ist wohl sekundär hierher gelangt und für die Datierung der Kammer nicht von Bedeutung ${ }^{52}$.

\subsubsection{AUSWERTUNG UND INTERPRETATION}

Die zeitliche Einordnung der Fundkomplexe aus dem Fundamentbereich der Kammern D3 und D8 wird einerseits durch ihre starke Heterogenität erschwert, andererseits weist der ausnahmslos kleinteilige Erhaltungszustand auf mehrere Umlagerungsprozesse nach dem Gebrauch der Gefäße hin, bevor das Material als Schutt eingefüllt wurde. In erster Linie ist aufgrund des Auftretens von Reliefbecherfragmenten in den untersten Auffüllungen des Fundamentbereichs der Kammer D3 (SE B10. B11) von einer Entstehungszeit der Kammern frühestens im 2. Viertel des 2. Jhs. v. Chr. auszugehen. Sie geben einen terminus post quem für die Einfüllungen und einen wichtigen Anhaltspunkt für die Datierung des Bühnengebäudes. Für die 2. Hälfte des 2. Jhs. und das 1. Jh. v. Chr. charakteristische Keramikgattungen, z. B. weißgrundige Keramik, ESA, GWSÜ, Ephesoslampen, Applikenware und typische Spätformen der Firnisware, fehlen im Fundspektrum. Ein in seiner Zusammensetzung ähnlicher Fundkomplex stammt aus der Wohneinheit 1 des Hanghauses $2^{53}$. Dieser wird von 170 bis 130 v. Chr. datiert, enthält aber eine größere Quantität an Reliefbecherfragmenten und vereinzelt auch Gattungen aus der 2. Hälfte des 2. Jhs. v. Chr. Die im Funddamentbereich der Kammer D3 vergesellschafteten Funde sind ausnahmslos - sofern sie nicht der vorhellenistischen Zeit zuzuordnen sind - vergleichbar mit jenen aus den wenigen bisher in Ephesos bekannten Fundkomplexen des späten 3. Jhs. und der 1. Hälfte des 2. Jhs. v. Chr.: Dabei handelt es sich um die älteste Füllung eines Brunnens im HH1/SR 9c (ausgehendes 3. Jh. v. Chr.) $)^{54}$, um einen hellenistischen Fundkomplex im HH1/SR 12 (ausgehendes 3. Jh. v. Chr.) ${ }^{55}$, um das Fundmaterial aus dem Bereich des Maussoleions in Belevi (SE 94B; SE 152/153, ca. 300-200 v. Chr.) ${ }^{56}$ und aus dem Prytaneion (fortgeschrittenes 3. Jh. v. Chr.) ${ }^{57}$ sowie um das Fundmaterial aus dem Bereich des sog. hellenistischen Brunnenhauses an der Kuretenstraße (spätes 3./1. Hälfte 2. Jh. v. Chr. $)^{58}$. Parallelen lassen sich auch zum Fundmaterial des späten 3. Jhs. v. Chr. aus einem versiegelten Kontext aus Lehmziegelguss auf dem Panayırdağ ziehen ${ }^{59}$. Bemerkenswert ist zum anderen der bis in die obersten Auffüllungen beider Kammern zu beobachtende hohe Anteil an vorhellenistischen Residuals. Dieser dürfte mit der Vorgängernutzung des Areals am Fuße des Panayırdağ zusammenhängen ${ }^{60}$.

\subsubsection{Funde aus den Sondagen im kaiserzeitlichen Bühnengebäude}

Die in den Kammern E1, E3, E5, E7 und E8 durchgeführten Sondagen geben Auskunft über die Chronologie des römischen Bühnengebäudes ${ }^{61}$. Die Zusammensetzung der Fundkomplexe muss in den meisten Fällen als heterogen bezeichnet werden.

\footnotetext{
${ }^{51}$ M 9 (Kap. 5).

${ }_{52}^{52} 77$ (Kap. 5). Freundliche Information M. Hofbauer.

${ }_{53}^{53}$ LAdSTÄTter 2010a, 3 Fundkomplex A-H/2 - SR 8, Lehmstratum. Vgl. auch LAdSTÄTter - LANG-Auinger 2001, 71-81.

${ }^{54}$ LADSTÄTteR u. a. 2003, 42 (Brunnenfüllung 3).

${ }^{55}$ LADSTÄTTER 2003.

56 TRAPICHLER 2010.

${ }^{57}$ LADSTÄTter 2010c.

${ }^{58}$ WALDNER 2009.

${ }^{59}$ Freundliche Mitteilung I. Kowalleck.

${ }^{60}$ Auf der Nordostseite des Panayırdağ wurde 2008 bis 2009 unter der Leitung von M. Kerschner ein befestigtes Siedlungsareal untersucht, nach bisherigem Kenntnisstand dürfte dieses im 3. Jh. v. Chr. aufgegeben worden sein Die ältesten Funde stammen aus einer Aufschüttung, die der spätgeometrisch-archaischen Epoche zuzurechnen ist (ÖAI-BERICHT 2010; KerSCHNER [in Vorbereitung]). Zu den geometrischen bis klassischen Keramikfunden aus den Grabungen im Bereich des Vediusgymnasium s. KERSCHNER u. a. 2008.

${ }^{61}$ Kap. 3.1.2
} 


\subsubsection{KAMMER E1}

Aus SE B23 wurden 67 diagnostische Keramikfunde erfasst, die meist kleinteilig gebrochen sind (erhaltene Höhe 1-5 cm). Die Zusammensetzung ist zeitlich heterogen. Feinchronologisch relevant sind eine ESB-Steilrandschale mit Spiralapplik und Roulettdekor am Rand, die der Form Atlante $30^{62}$ entspricht (K 78 Taf. 309), sowie ein Teller der Form Atlante $18^{63}$ (K 79 Taf. 309) und ein zu einer Schale der Form Atlante 40 (K 80 Taf. 309) ${ }^{64}$ gehöriges Bodenfragment. Die vergesellschafteten Funde - bestehend u. a. aus einem ESA-Teller der Form Atlante 11, fünf Fragmenten von Reliefbechern, drei Fragmenten von Ephesoslampen, einer runden, grauen Platte mit schwarzem Überzug, zwei Fragmenten weißgrundiger Lagynoi sowie spezifischen Amphoren und Küchenware-Gefäßen - sind der späthellenistischen Zeit zuzurechnen. Durch die erstgenannten jüngsten Funde kann die Datierung von SE B26 in das 2. Viertel des 1. Jhs. n. Chr. allerdings als gesichert gelten.

SE B25 kann als heterogen hellenistisch bezeichnet werden, unter den dort geborgenen sieben diagnostischen Fragmenten sind aber keine feinchronologisch relevanten Funde.

Insgesamt rund 70, meist kleinteilig gebrochene, diagnostische Fragmente stammen aus SE B26. Das Stratum dürfte in das 2. Viertel des 1. Jhs. n. Chr. zu datieren sein. Dafür sprechen ein ESB-Teller der Form Atlante 18 (K 81 Taf. 309) sowie vier kleine Bruchstücke von rot überfangenen Lampen, von denen zumindest eines einer Volutenschnauzenlampe (K 86 Taf. 309) zugeordnet werden kann ${ }^{65}$. Zwei weitere Lampenfragmente gehören zu Ephesoslampen, die bis in die tiberische Zeit den Lampenmarkt in Ephesos mit nahezu alleiniger Monopolstellung beherrschen (K 87 Taf. 309). Die Fragmente der dünnwandigen Becher (K 82-84 Taf. 309) finden gute Parallelen in Fundkontexten der Bauphase I im Hanghaus $2^{66}$. Auch ein kleines Fragment eines Deckelknaufs von einem tongrundigen Thymiaterion ist in das 1 . Jh. $\mathrm{n}$. Chr. zu datieren. Die übrigen - zahlreichen - Funde sind der späthellenistischen bis augusteischen Zeit zuzurechnen.

In SE B27 wurden 11 diagnostische Fragmente kleinteiligen Erhaltungszustands geborgen. Ein flaches Bodenfragment eines ESB-Tellers der Form Atlante 19/60 (K 88 Taf. 310) weist in das 2. Viertel des 1. Jhs. n. Chr. ${ }^{67}$, ein Feinwarebecher mit kurzem, ausgebogenem Rand ist der 1. Hälfte des 1. Jhs. n. Chr. zuzuordnen (K 89 Taf. 310). Die restlichen Funde sind etwas älter: Vertreten sind beispielsweise ein Wandfragment eines Reliefbechers und eine hellenistische Lampenschnauze. Die vorhandenen gebrauchskeramischen Gefäße sind innerhalb des ausgehenden Hellenismus und der frühen Kaiserzeit bzw. dem 1. Jh. n. Chr. nicht näher einzuordnen.

SE B28 enthält umfangreiches Fundmaterial (insgesamt 147 diagnostische Keramikfragmente) heterogener Zeitstellung. Das Spektrum der ESB (K 90-100 Taf. 310) ist ausschlaggebend für die Datierung: Vertreten sind die Formen Atlante 29, 30, 31, 38, 40, 56, 58 und 70. Die beiden letztgenannten Gefäße sind am Steilrand jeweils mit Spiralappliken dekoriert und weisen demnach in die Mitte und das 3. Viertel des 1. Jhs. n. Chr. Zahlreiche Funde (u. a. ein Teller Atlante 4B der ESA und ein Reliefbecher mit Bodensignatur) sind der späthellenistischen Zeit zuzurechnen, also nicht unmittelbar relevant für die Datierung. Beachtlich ist die große Anzahl an Metall-, speziell an Bronze(blech)funden aus dieser Schicht ${ }^{68}$.

Die jüngsten der insgesamt 51 diagnostischen Funde aus SE B40 sind ein Fragment einer ESB-Schale der Form Atlante 30 (K 101 Taf. 310) und ein Bodenfragment, das eventuell zu einer Schale der Form Atlante 53 (K 102 Taf. 310) gehört. Diese Funde weisen in die 1. Hälfte des 1. Jhs. n. Chr. Die restlichen Funde sind ältere Residuals, sie reichen von der archaischen bis in die späthellenistische Zeit.

\subsubsection{Kammer E3, Verfüllung der Pithoi 1 und 2}

Hervorzuheben sind zwei in Kammer E3 vorgefundene, mit keramischem Hausrat verfüllte Pithoi (SE 33. 34), die in weiterer Folge durch die Anlage eines jüngeren Ziegelplattenbodens mit entsprechendem Mör-

\footnotetext{
${ }^{62}$ HAYes 1985, 59.

${ }^{63}$ HAYES $1985,56 \mathrm{f}$.

${ }^{64}$ HAYES 1985, 61.

${ }^{65}$ Vgl. Ladstätter - Steskal 2009, A-K 146.

${ }^{66}$ Vgl. z. B. LADSTÄTter 2005, K 146-153.

${ }^{67}$ LADSTÄTTER 2005, 238.

${ }^{68}$ MF 61 Taf. 376 (Kap. 6.2.1); Kap. 7.2.
} 
telbett >versiegelt wurden ${ }^{69}$. Da es sich um zwei geschlossene, nahezu homogene Fundkomplexe handelt, die zudem eine beachtliche Anzahl an gut erhaltenen Gefäßen aufwiesen, werden sie vollständig diskutiert. Aus den restlichen Straten werden nur die jeweils für die Datierung relevanten Funde besprochen.

Aus SE B29b stammen nur drei, zudem feinchronologisch nicht aussagekräftige Fragmente. Ein sehr kleines Schulter- und Diskusfragment einer ROW-Lampe kann generell dem 1. bis 3. Jh. n. Chr. zugerechnet werden.

In SE B30, dem Schutt unmittelbar unter dem Mörtelbett über den Pithoi, wurden insgesamt 46 diagnostische Funde klein- bis mittelteiligen Erhaltungszustands und heterogener Zeitstellung (es treten späthellenistische Residuals auf) geborgen. Mit Ausnahme eines hohen Standfußes mit abgebrochener Unterseite, der zu einem Teller der ESC gehört (K 103 Taf. 311) und vermutlich der Form Atlante L19 oder Hayes 1 zuzuordnen ist, sowie einer dünnwandigen Schale mit leicht eingebogenem Rand und ESB-ähnlichem rotem Überzug (K 104 Taf. 311) und drei nicht näher zu datierenden Rand- und Bodenfragmenten von dünnwandigen Bechern kam keine Feinkeramik zum Vorschein. Es stammen aber mehrere Lampenfunde aus dieser Schicht, von denen zwei rot überfangene Exemplare nahezu vollständig erhalten blieben (K 105 . K 106 Taf. 311. 345). Beide haben einen runden Körper und einen gelochten Griff, die runde Schnauze ist jeweils durch zwei feine Rillen abgesetzt. Der Diskus ist jeweils mit einem figuralen Dekor um das zentrale Füllloch versehen. K 105 zeigt einen nach links schreitenden Greif $^{70}$. K 106, deren Schulter mit feinen Kreisaugen dekoriert ist, weist in der Mitte des Diskus eine Büste Helios/Sol mit Strahlenkranz auf ${ }^{71}$. Was die Form und Beschaffenheit betrifft, finden beide Lampen Entsprechungen in den Wohneinheiten $2^{72}$ und $4^{73}$ in Fundkontexten des 2. und 3. Jhs. n. Chr. Die Datierung von SE B30 aufgrund des keramischen Fundmaterials weist demnach mindestens in das 2. Jh. n. Chr. Eine vergesellschaftete Münze wurde unter Marcus Aurelius geprägt $^{74}$. Insgesamt ist durch das keramische Fundmaterial und die Münze aus SE B30 ein terminus ante quem für die Verfüllung der Pithoi und ein terminus post quem für die Errichtung des Ziegelplattenbodens darüber gegeben, der in das späte 2. Jh. n. Chr. weist.

Aus dem Pithos 1 (SE B33) im Osten der Kammer E3 stammen Fragmente von 39 keramischen Gefäßen, die bisweilen sehr gut erhalten sind (erhaltene Höhe der Fragmente: 1-30 cm), teilweise allerdings auch erhebliche Sinterspuren aufweisen. Mit Ausnahme weniger Einzelstücke, wie einem Wandfragment klassischer Zeitstellung, ist das Material aus der Füllung des Pithos zeitlich homogen. Das ESB-Spektrum (K 107-109 Taf. 311. 346; K 110. 111 Taf. 311; Grafik 12. 13) umfasst drei Schalen der Form Atlante 70, eine Schale der Form Atlante 32 und einen beinahe zur Gänze erhaltenen Miniaturbecher der Form Atlante 65 (K 108 Taf. 311). Die Schalen der Form Atlante 70 weisen ESB 1-Qualität auf, auf K 109 hat sich außerdem am roulettverzierten Rand die Applike einer S-Spirale erhalten. Die Schalen Atlante 70 und der Becher Atlante 65 dürften in das 3. Viertel des 1. Jhs. n. Chr. datieren, während für die Schale Atlante 32 (K 107 Taf. 311) ein etwas früherer Ansatz gilt (2. Viertel/Mitte 1. Jh. n. Chr.). Gesondert hinzuweisen ist außerdem auf eine knidische Schale in ESB-Qualität mit einem aufgemalten weißen Punktdekor (K 112 Taf. 311. 346) ${ }^{75}$. An dünnwandiger Keramik fanden sich in dem Pithos flache Böden von Bechern (K 113. K 114 Taf. 311), außerdem ein kleines Wandfragment mit Kerbdekor eines knidischen Bechers augusteischer Zeitstellung.

Unter den gebrauchskeramischen Gefäßen ist ein ganz erhaltener Krug mit innen abgesetztem, profiliertem Rand, ausladender Schulter und blockartigem Bandhenkel hervorzuheben (K 115 Taf. 312. 346). Ein Fragment eines Krugs weist einen leicht eingebogenen Rand auf (K 116 Taf. 312), zu ergänzen sind außerdem ein bauchiges Töpfchen mit leicht schräg nach unten abstehendem Rand und einfach gerillter Wand (K

${ }^{69} \mathrm{Zu}$ Befund und Stratigrafie sowie der genauen Beschreibung der Pithoi selbst s. Kap. 3.1.2.2.

${ }^{70}$ Zum Greif-Motiv vgl. HeimerL 2001, Motiv 83. 84 (ähnlich, allerdings Greif mit erhobenem Vorderhuf nach rechts schreitend).

${ }^{71}$ Vgl. BaIley 1988, 370 Q 3067 (modelgleiches Stück). Loeschcke Schulter VIIb, Schnauzenform Bailey, Eph. B 3. Helios/SolDarstellung vgl. auch Broneer 1930, Kat. 489 (1. Jh. n. Chr.); Heimerl 2001, Kat. 974 (2. Jh. n. Chr.). Beil. 5 Motiv 9.

72 Ladstätter 2010a, K 480-482. K 497. K 499.

${ }^{73}$ LADSTÄTtER 2005, K 416. K 796. K 799.

${ }^{74}$ M 50 Taf. 356 (Kap. 5.2).

${ }^{75}$ Die Produktion von Hybridformen mit der Beschaffenheit der ESB, kombiniert mit hellenistischen Dekorelementen kann in Ephesos besonders in augusteischer Zeit beobachtet werden, s. LADSTÄTter 2007, 208. Besonders zahlreiche frühe ESB- und Hybridgefäße finden sich in der WE 7 des Hanghauses 2: z. B. Lätzer 2009, 139 Kat. 66. 179 Taf. 1, 14-21 und WaLdNER 2016, 360-362. Vgl. auch WALDNER 2009, K 887. 
117 Taf. 312) und ein Standfuß eines geschlossenen Gefäßes (K 118 Taf. 312). Eine Schüssel mit flachem Boden und breitem, ausladendem Rand ist bis auf Teile des Rands ganz erhalten (K 119 Taf. 312. 346). Sie ist innen und teilweise auch außen mit Kalkmörtel behaftet, vielleicht wurde sie sekundär zu dessen Mischung verwendet. Die langlebige Schüsselform ist in ephesischen Fundkomplexen ab dem 1. Jh. ${ }^{76}$ bis in das 3. Jh. n. Chr. ${ }^{77}$ zu finden. Die restlichen Fragmente von Schüsseln entfallen auf solche mit breitem, ausgebogenem, innen durch einen kleinen Wulst abgesetzten Rand (K 120-124 Taf. 313) oder innen abgeschrägtem massivem Rand (K 125 Taf. 313). Abgesehen von einem flachen Boden (K 126 Taf. 313) und einem Standfuß von Schüsseln (K 127 Taf. 314) runden zwei Deckelfragmente (K 128. 129 Taf. 314) das Spektrum der Gebrauchskeramik ab. Gesondert hinzuweisen ist auf ein Miniaturgefäß, vermutlich ein Salbtöpfchen, von dem sowohl in Pithos 1 als auch in Pithos 2 je ein Fragment geborgen wurde (K 130 Taf. 314. 347). Die im Pithos vertretene Küchenware besteht aus einem Krug oder einer Flasche, von der ein großes Fragment des bauchigen, leicht gerippten Körpers und des hohen Halses mit Halswulst erhalten blieb (K 131 Taf. 314. 347) ${ }^{78}$. Vertreten sind außerdem zwei Randfragmente von Töpfen oder Kasserollen (K 132. K 133 Taf. 315).

Unter den Amphorenfunden aus dem Pithos 1 befinden sich ein Randfragment und ein geöffneter Knauf sowie mehrere Wandfragmente von lokalen Amphoren des Typs Peacock - Williams 45 (K 134. K 135 Taf. 315) ${ }^{79}$. Der Herstellungsraum von K 136 und K 137 (Taf. 315) ist nicht zu eruieren, dasselbe gilt für einen Doppelrundstabhenkel und zwei Wandfragmente. Ein Randfragment der Form Dressel 1B bezeugt einen italischen Import (K 138 Taf. 315) ${ }^{80}$, ist allerdings als Altstück aus dem 1. Jh. v. Chr. zu interpretieren. Hervorzuheben ist außerdem ein Fragment einer Amphore mit vollem Knauf, der seitlich einen rechteckigen Stempel [NO..ANDO?] aufweist (K 139 Taf. 316. 347). Die vulkanischen Komponenten im fabric lassen auf eine italische Herkunft schließen, eine Zuordnung zum Typ Dressel 2-4 scheint aufgrund der Knaufform gerechtfertigt ${ }^{81}$.

Von einer Lampe mit gelochtem Griff blieben vier Fragmente erhalten (K 140 Taf. 316. 347). Auf dem Diskus ist der Rest einer zoomorphen Darstellung in Form eines Adlers ${ }^{82}$ zu erkennen, auf der Schulter ein Dekor aus (Myrten)blättern und Knospen. Die Form und der Dekor der Lampe ist mit ROW-Lampen aus der flavischen Füllung des Brunnens am Staatsmarkt vergleichbar ${ }^{83}$. Der Überzug der Lampe aus dem Pithos zeigt allerdings keine ROW-Technik, sondern ist vielmehr matt dunkelbraun. Es dürfte sich um einen Import handeln, möglicherweise aus Kampanien ${ }^{84}$.

Bislang singulär für Ephesos ist das Auftreten des Wandfragments eines konischen, formgeblasenen Glasbechers der Form Isings $31^{85}$ mit einem Dekor aus mandelförmigen Tropfen (G 4 Taf. 316. 347). Vergleichsbeispiele, u. a. aus Syrien ${ }^{86}$ und Pompeji ${ }^{87}$, belegen die weite Verbreitung dieser Becher im gesamten Römischen Reich im 1. Jh. n. Chr.

Erwähnenswert ist auch das zur Füllung des Pithos 1 gehörige Fragment einer Gewandstatuette ${ }^{88}$. Außerdem wurde darin ein Fragment eines Dachziegels mit plastischer Kerbleiste geborgen.

Insgesamt ist der Inhalt des Pithos aufgrund der jüngsten keramischen Funde in die Mitte/das 3. Viertel des 1. Jhs. n. Chr. zu datieren.

\footnotetext{
${ }^{76}$ z. B. Meriç 2002, K 702; LadstätTer 2005, K 353. K 390. K 391.

77 z. B. GASSNER 1997, Nr. 657; LADSTÄTTER 2005, K 456. K 858.

${ }^{78}$ Vgl. eventuell LADSTÄTtER 2005, K 255.

79 Peacock - Williams 1986, 188-190; zur Entwicklung des Amphorentyps s. Ladstätter 2005, 235; Ladstätter 2007, 212; LADSTÄTter 2008, 180 f.; BEZECZKY 2004, 87.

${ }^{80}$ Peacock - Williams 1986, 89 f. (Class 4).

${ }^{81}$ Peacock - Williams 1986, 89 f. (Class 4). Die Stempelung des Knaufs ist allerdings innerhalb der italischen Amphorenproduktion nicht geläufig. Für Informationen zur vorliegenden Amphore danke ich T. Bezeczky (Wien) und H. Gonzales (Madrid/Berlin/ Wien).

${ }^{82}$ Vgl. Bailey 1980, Taf. 59, Q 1226 (Diskus allerding ohne Dekor).

${ }^{83}$ Meriç 2002, L 91 (mit Blattdekor auf der Schulter); L 103 (mit Adlerdarstellung auf dem Diskus).

${ }^{84}$ BAILEY 1980, 305.

${ }^{85}$ IsINGS 1957, $45 \mathrm{f}$.

${ }^{86}$ PrICE 1991, 56-75, bes. 72 Taf. XIX b.

${ }^{87}$ Scatozza Höricht 1991, 76-85 Abb. 16 a. b.

${ }^{88}$ TK 19 Taf. 363 (Kap. 6.1).
} 


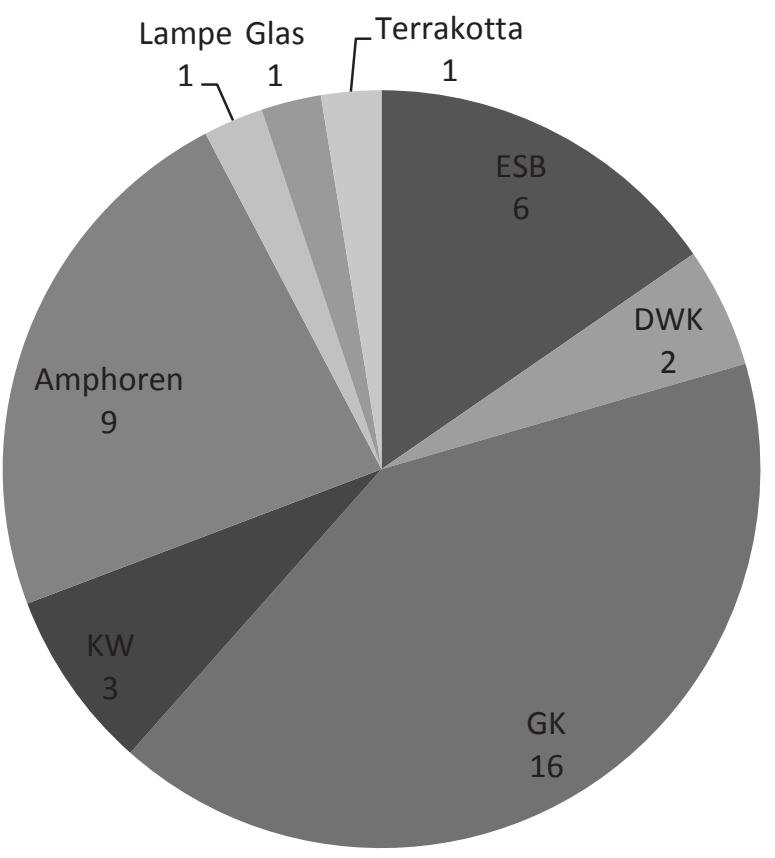

Grafik 12: Fundgattungen im Pithos 1 (SE B33, diagnostische Stücke)

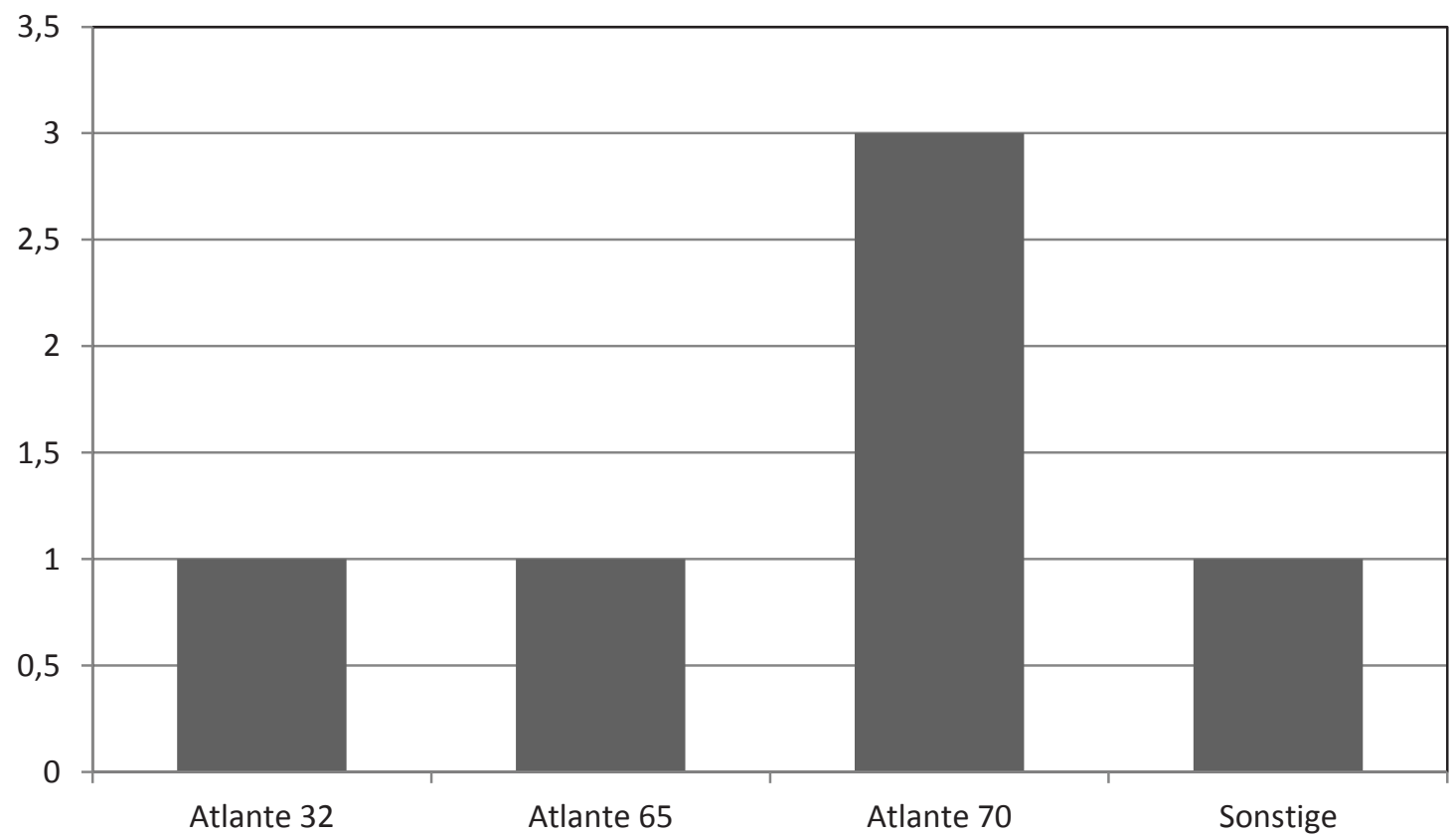

Grafik 13: ESB-Spektrum im Pithos 1 (SE B33) 
Noch umfangreicher ist der Inhalt des zweiten Pithos (SE B34) im Westen der Kammer E3. Es wurde darin ein keramischer Hausrat entsorgt, der aus rund 97 Gefäßen und drei Terrakotten bestand (Grafik 14). Auffällig ist der gute Erhaltungszustand der in dem Pithos entsorgten Gefäße, von denen 11 als Ganzformen hinein gelangten. Hervorzuheben ist eine ganz erhaltene Steilrandschale der italischen Sigillata (K 141 Taf. 316. 348), die der Form Conspectus 23 zuzuordnen ist und in das 2. bis 3. Viertel des 1. Jhs. n. Chr. datiert. Die Bodeninnenseite ist mit einem Planta pedis-Stempel versehen, der in abgekürzter Form [L.R.P] den Töpfernamen L. RASINIVS PISANVS ${ }^{89}$ enthält. Das ESB-Spektrum (Grafik 15) umfasst vier vollständig erhaltene Gefäße der Formen Atlante 36 (K 144 Taf. 317. 348) mit Radialstempel auf der Bodeninnenseite und Atlante 70 (K 149-151 Taf. 317). Die drei letzteren Exemplare weisen ESB1-Qualität auf und haben einen Dekor aus applizierten S-Spiralen, gerahmt von Roulettreihen, an der Randaußenseite, was sie als früh innerhalb der Produktionsserie ausweist und auf eine Datierung in das 3. Viertel des 1. Jhs. n. Chr. schließen lässt ${ }^{90}$. K 151 weist an der Bodenunterseite ein Graffito auf, das wohl den Besitzer nennt. Vertreten sind außerdem Fragmente der Formen Atlante 18 (K 142 Taf. 316. 348), Atlante 19 (K 143 Taf. 316), Atlante 38 (K 145. K 146 Taf. 317. 348, letzteres ist reduzierend gebrannt), Atlante 58 mit Spiralapplik (K 147 Taf. 317), Atlante 64B (K 148 Taf. 317), und zwei unvollständig erhaltene Schalen Atlante 70 (K 152 Taf. 348; K 153 Taf. 317), von denen K 152 ein Graffito auf der Bodenuntseite und Reste eines weiteren Graffito auf der Wand aufweist. Einer bislang nicht definierten Red Slip-Ware entspricht hingegen die Schale (K 154 Taf. 318. 348) mit breitem, ausgebogenem, innen leicht verdicktem Rand und einem Dekor aus spitzen, aneinandergereihten Ovuli an der Randinnenseite.

Bei K 155 (Taf. 318. 348) handelt es sich hingegen um zwei Randfragmente einer flächig matt rot überzogenen Schale mit Ansätzen breiter, plastischer Vertikalrippen an der Außenseite. Sie imitiert offensichtlich das - wesentlich geläufigere - gläserne Vorbild der speziell in claudisch-neronischer Zeit gebräuchlichen flachen Rippenschale Isings $3 a^{91}$.

Ein rot überzogener, bauchiger, kleiner Einhenkelkrug mit Trichterrand, der bis auf den Henkel und Teile des Rands ganz erhalten blieb (K 156 Taf. 318. 348), kann jener Gruppe lokaler Red Slip-Gefäße zugewiesen werden, die S. Ladstätter für eine Gruppe von Gefäßen flavischer Zeitstellung aus der Wohneinheit 1 definierte ${ }^{92}$. Speziell am unteren Teil des Gefäßkörpers sind Glimmereinschlüsse und weiße Einschlüsse, fast sandbewurfartig, an der Oberfläche sichtbar. Zu ergänzen ist schließlich ein Randfragment einer knidischen Schale mit ESB-artigem rotem Überzug (K 157 Taf. 318).

Von den insgesamt 21 dünnwandigen Gefäßen aus dem Pithos 2 blieben zwei Becher ganz erhalten (K 158. K 159 Taf. 318. 349). Sie gehören zu eiförmigen Henkelbechern mit ausgebogenem, kurzem Rand, leicht abgesetzter Schulter und flachem, leicht abgesetztem Boden ${ }^{93}$, wie sie in ephesischen Fundkontexten neronischer bis flavischer Zeitstellung auftreten ${ }^{94}$. Neun weitere Randfragmente (K 160-163 Taf. 318; K 164-168 Taf. 319) können diesem Bechertyp zugeordnet werden. Vertreten sind außerdem bauchige Becher mit kurzem, spitz abgestrichenem Rand und weniger akzentuierter Schulter (K 169. K 170 Taf. 319). Für sie ist derselbe zeitliche Ansatz anzunehmen wie für den vorherigen Bechertyp. In die 1. Hälfte des 1 . Jhs. n. Chr. dürfte hingegen der Becher K 171 (Taf. 319) gehören, der durch einen Steilrand und die profilierte Schulter charakterisiert is $\mathrm{t}^{95}$. Die restlichen Fragmente dünnwandiger Keramik sind durchwegs leicht abgesetzte, flache Böden von Bechern (K 172-179 Taf. 319). Das Spektrum der Gebrauchskeramik setzt sich zusammen aus Krügen (K 180-183 Taf. 319), einem Unguentarium (K 184 Taf. 319) und zwei Bodenfragmenten kleinformatiger Gefäße (K 185. K 186 Taf. 320). Vertreten sind außerdem ein Topf (K 187 Taf. 320) und Schüsseln mit breitem, gebogenem Rand, die jenen aus Pithos 1 (SE 33) ähneln (K 188 Taf. 349; K 189-192 Taf. 320; K 193. K 194 Taf. 321). Zwei Bodenfragmente gehören zu geschlossenen Gefäßen (K 195. K 196 Taf. 321). Zu erwähnen ist außerdem ein flacher Deckel der Gebrauchskeramik (K 197 Taf. 321. 349) mit verdicktem Rand und einem Dekor aus Rillen und spitz zulaufenden Wellen an der Ober-

\footnotetext{
${ }^{89}$ Vgl. OXÉ - COMFort 2000, 363-365, bes. 364, Stempel 45-49.

${ }^{90}$ HAYES 1985, 66.

${ }^{91}$ IsINGS 1957, 18 f.; vgl. z. B. CzURDA-Ruth 2007, 37-47 KatNr. 43-81.

${ }^{92}$ LadSTÄTter 2010a, 184. Das vorliegende Stück ist besonders gut zu vergleichen mit LAdSTÄTter 2010a, A-K 367. A-K 368.

${ }_{93}$ LAdSTÄTtER 2010a, 184 f. (Variante 1 der eiförmigen oder bauchigen Becher mit ausladendem Rand und akzentuierter Schulter).

${ }^{94}$ LadstätTer 2010a, 185.

${ }^{95}$ Vgl. LadSTÄTter 2005, K 329. K 346.
} 


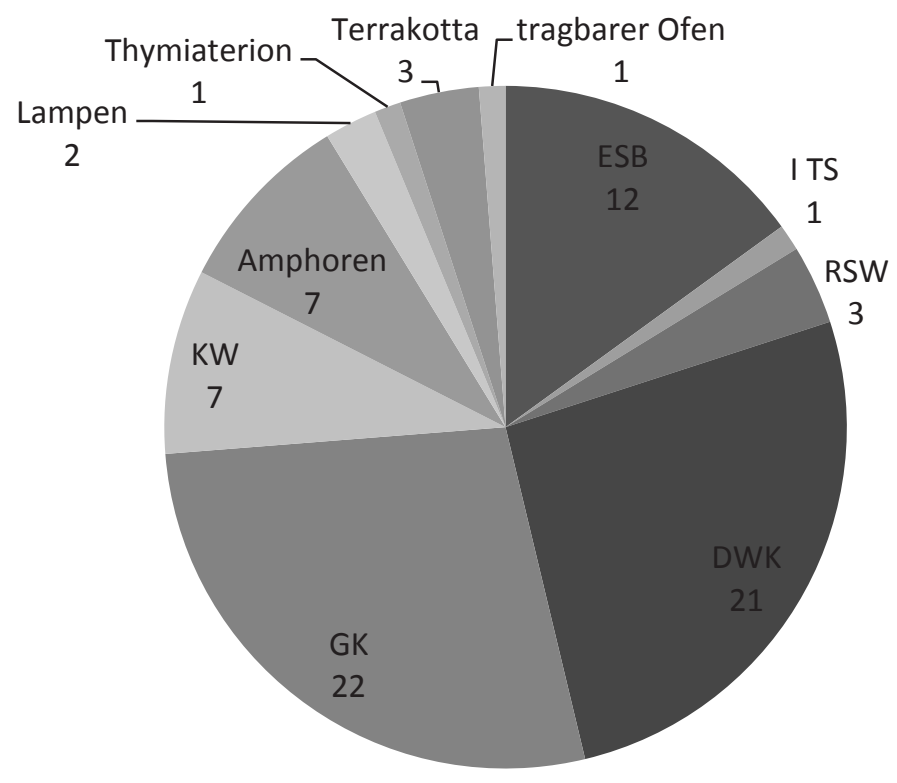

Grafik 14: Fundgattungen im Pithos 2 (SE B34, diagnostische Stücke)

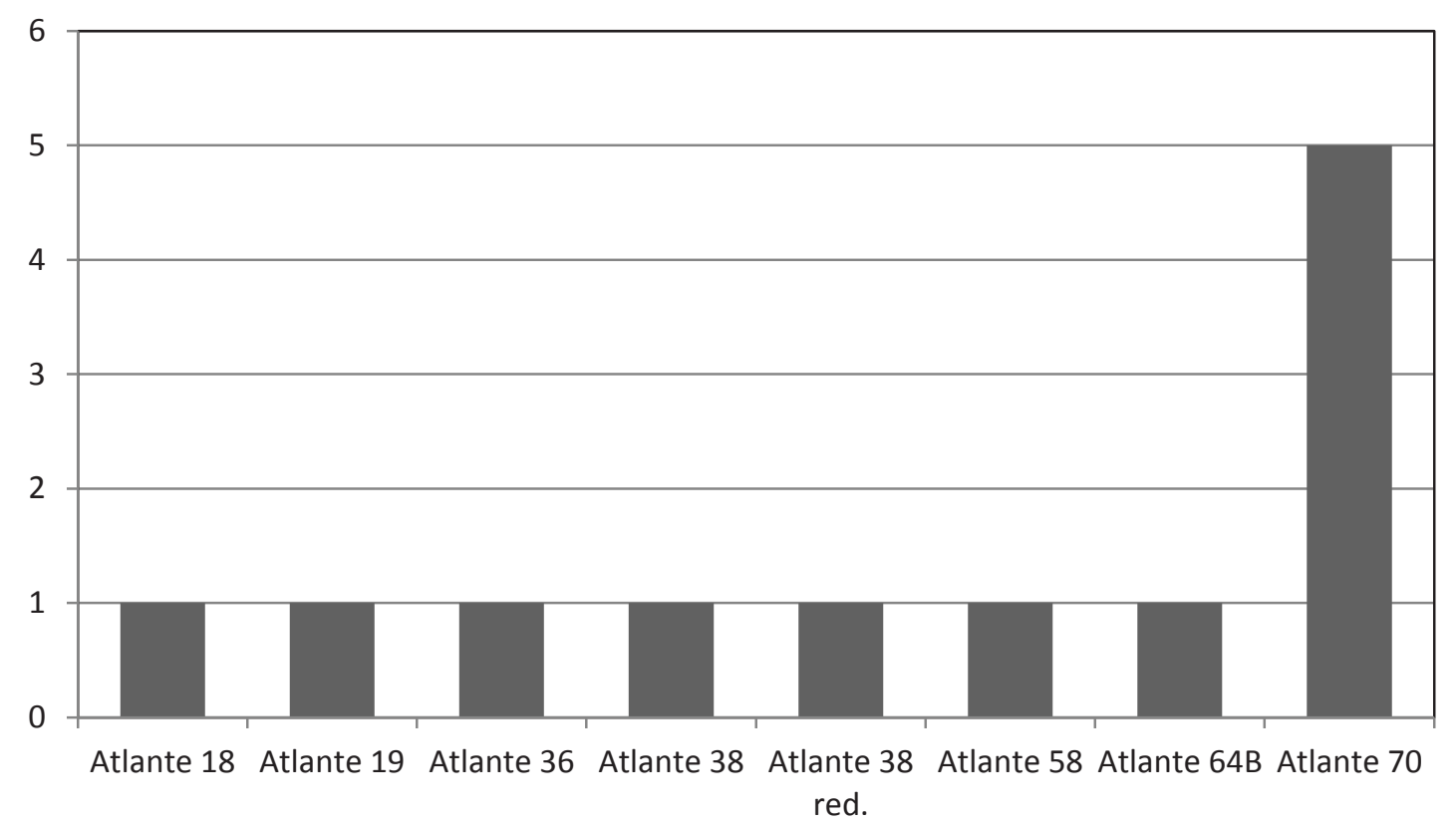

Grafik 15: ESB-Spektrum im Pithos 2 (SE B34) 
seite. Weitere gewöhnliche Deckelfragmente (K 198-202 Taf. 321) runden das Spektrum der Gebrauchskeramik aus dem Pithos 2 ab.

Unter den wenigen Vertretern von Kochgeschirr aus dem Pithos 2 ist ein Topf mit breitem, ausgebogenem Rand und abgerundeter Standfläche hervorzuheben, der vollständig erhalten geblieben ist (K 203 Taf. 322. 349). Es handelt sich um eine im 1. Jh. n. Chr. geläufige, v. a. ab der Mitte des 1. Jhs. n. Chr. häufig auftretende Form. Zwei weitere Kochtöpfe (K 204. K 205 Taf. 322), eine Kasserolle (K 206 Taf. 322) und drei Fragmente von Pfannen (K 207-209 Taf. 322) zählen zum Kochgeschirr.

Der Großteil der bestimmbaren Amphorenfragmente gehört zum Typ Peacock - Williams 45 (sog. onehandle-jar, K 210-212 Taf. 323). Vertreten sind außerdem ein vermutlich knidischer Import (K 213 Taf. 323) und drei nicht näher zuzuweisende Knäufe (K 214-216 Taf. 323).

Zwei Lampen treten in Pithos 2 auf, auch sie sind nahezu ganz erhalten. Es handelt sich zum einen um eine Lampe mit zwei sich gegenüberliegenden Volutenschnauzen dreieckiger Form ${ }^{96}$ und einem Herzblattdekor auf der Schulter (K 217 Taf. 323. 350), deren Diskus ausgebrochen ist. Zum anderen ist eine rot überfangene Lampe mit einem alternierenden Dekor aus Herzblättern und Punkten auf der Schulter (K 218 Taf. 323. 350 $)^{97}$ vertreten. Zu ergänzen sind schließlich noch ein kleines Fragment eines Thymiateriondeckels (K 219 Taf. 324) und ein Fragment eines tragbaren Ofens (K 220 Taf. 324. 350), die ebenfalls in dem Pithos entsorgt wurden. Ein Fragment einer männlichen Terrakottafigur, ein Fragment mit Gewandfalten und ein Maskenfragment ${ }^{98}$ ergänzen das Spektrum aus dem Pithos SE 34.

Die jüngsten Funde aus dem zweiten Pithos lassen darauf schließen, dass - analog zu Pithos 1 - ein Haushalt aus der Mitte bis 3. Viertel des 1. Jhs. n. Chr. entsorgt wurde ${ }^{99}$.

Die Zusammensetzung der Gefäße, welche in den beiden Pithoi in Kammer E 3 entsorgt wurden, ist zeitlich weitgehend homogen. Es ist v. a. in Pithos 2 (SE 34) ein hoher Anteil an Tafelgeschirr, Gebrauchskeramik und Amphoren zu beobachten, wohingegen der Anteil an Kochgeschirr jeweils vergleichsweise gering ausfällt. Der Inhalt der Pithoi ist partiell zwar vergleichbar mit dem ephesischen Tafelservice flavischer Zeitstellung, das man beispielsweise aus den Wohneinheiten $1^{100}$ und $6^{101}$ des Hanghauses 2 kennt. Die starke Präsenz von ESB-Gefäßen des 2. bis 3. Viertels des 1. Jhs. n. Chr. lässt allerdings auf eine frühere Datierung des Inhalts beider Pithoi schließen ${ }^{102}$. Es ist demnach davon auszugehen, dass beide Gefäße gleichzeitig mit Hausrat neronischer Zeitstellung aufgefüllt wurden, womit ein terminus post quem für die Aufgabe und Verfüllung der Pithoi gegeben ist. Zahlreiche Gefäße in den Pithoi waren noch sehr gut bis ganz erhalten, sodass nicht auszuschließen ist, dass die Kammer E3 selbst als primärer Nutzungskontext in Frage kommt. Möglich wäre aber auch eine Herkunft aus der im Süden an das Theater angrenzenden Insula oder aus dem Bereich der römischen Bebauung oberhalb des Theaters (sog. Peristylvilla).

\subsubsection{KAMMER E5}

Aus der Füllung des nördlichen Beckens SE B41, die insgesamt 20 diagnostische Keramikfragmente umfasst (erh. H 1-13 cm), wurden mit Ausnahme eines hellenistischen Pinienzapfenbechers aus dem 2. Jh. v. Chr. und einer frühkaiserzeitlichen Lampe nur spätrömisches bis spätantikes Fundmaterial geborgen. Vertreten sind ein Bodenfragment eines LRC-Tellers der Form Hayes $1^{103}$ (K 221 Taf. 324) und ein kleines, abgebrochenes Randfragment der Form Hayes 1A (nicht in den Katalog aufgenommen). Ferner wurden zwei Fragmente afrikanischer Sigillata geborgen, die den Formen Hayes $32^{104}$ (K 222 Taf. 324) und Hayes $33^{105}$

\footnotetext{
${ }^{96}$ Loeschcke Typus $1 \mathrm{C}$.

${ }^{97}$ Vgl. Mitsopoulos-Leon 2007, L 166.

${ }_{98}$ TK 7 Taf. 361; TK 29 Taf. 365; TK 41 Taf. 367 (Kap. 6.1).

${ }_{99}$ Auch die Tatsache, dass von dem Miniaturgefäß K 130 anpassende Fragmente in Pithos 1 und 2 geborgen wurden, zeugt von der gleichzeitigen Verfüllung beider Pithoi.

${ }^{100}$ LADSTÄTter 2010a, 182 Textabb. 5.

${ }^{101}$ WALDNER 2014, 455-457; 458 (Fundkomplexe BII/12 und BII/15).

102 Vgl. LadSTÄTter 2005, 238 f. (Fundkomplexe BI'/1 und BI'/2).

${ }^{103}$ HAYES 1972, 325-327.

${ }^{104}$ HaYes 1972, 54-56.

${ }^{105}$ HaYes 1972, 54-56.
} 
(K 223 Taf. 324) zugeordnet und somit früher - in das 3. Jh. n. Chr. - datieren. Zwei Töpfe der Küchenware sind mit ihrem jeweils ausgebogenen Rand und dem ausgeprägten Deckelfalz sowie dem typischen schwarzgrauen fabric Vertreter des Kochgeschirrs des 5. bis 6. Jhs. n. Chr. (K 224. K 225 Taf. 324). Das Amphorenspektrum besteht aus einem Knauf einer lokalen Amphore Peacock - Williams 45/LRA 3 (K 226 Taf. 324) ${ }^{106}$ und einem Knauf eines Spatheions Typ 1 (K 227 Taf. 324) ${ }^{107}$, das in das ausgehende 4./beginnende 5. bis Mitte des 5. Jhs. n. Chr. datiert werden kann. Eine kleine, runde Lampe kleinasiatischen Typs mit Griffzapfen und Kreisaugendekor auf der Schulter (K 228 Taf. 324) ${ }^{108}$ und ein Lampenfragment mit einem Dekor aus abgesetzten Rillen auf dem Diskus und dem Rest eines Kreisaugendekors auf der Schulter (K 229 Taf. 324) sind ebenfalls dem 4. bis 5. Jh. n. Chr. zuzuordnen. Aufgrund der jüngsten Funde kann für die Füllung des nördlichen Beckens SE B41 in der Kammer E7 eine Datierung in das 5. Jh. n. Chr. als gesichert gelten. Eine vergesellschaftete Münze weist in die 2. Hälfte des 4. Jhs. n. Chr. ${ }^{109}$.

In dem sehr kleinen Fundkomplex SE B42 wurden nur ein Randfragment eines gebrauchskeramischen Krugs (K 230 Taf. 325) sowie eine ganze (K 231 Taf. 325) und eine fragmentarische Lampe (K 232 Taf. 325) geborgen. Das kleine Randfragment des gebrauchskeramischen Krugs, das außen braun überzogen ist, kann innerhalb der Kaiserzeit nicht näher eingeordnet werden. Die ganz erhaltene, rot überfangene Lampe K 231 (Taf. 325) ist hingegen Loeschcke Typ VIII mit rundem Körper, kurzer, runder Schnauze und rundem Diskus zuzuweisen ${ }^{110}$. Letzterer ist in der Regel dekoriert, das vorliegende Exemplar zeigt allerdings nur zwei dezentrale Fülllöcher im vorderen Diskusbereich und ist undekoriert. Die Lampe kann in das 2. bis 3. Jh. n. Chr. datiert werden. Von der zweiten Lampe (K 232 Taf. 325) blieb ein kleines Schulterstück erhalten, das einen Eierstab als Dekor aufweist. Es ist in ROW-Technik gefertigt und kann allgemein in das 1. (ab tiberisch) bis in das 3. Jh. n. Chr. datiert werden. Zwei Münzen aus dieser Schicht datieren an das Ende des 3. Jhs. bis 334 n. Chr. ${ }^{111}$ und geben einen demnach einen terminus post quem für deren Entstehung. $\mathrm{Zu}$ erwähnen ist außerdem ein kleinformatiger Tritontorso, der in SE B42 geborgen wurde ${ }^{112}$.

SE B43 enthält 12 diagnostische, kleinteilig gebrochene Keramikfragmente (erh. H 1-4 cm). Feinchronologisch relevant ist lediglich ein sehr kleines ESB-Bodenstück, das wohl einer Schale der Form Atlante 31 zuzuordnen ist (K 233 Taf. 325). Diese tritt v. a. im 2. Viertel des 1. Jhs. n. Chr. auf ${ }^{113}$. Ein dünnwandiger Becher mit geschwungenem Trichterrand (K 234 Taf. 325) kann in die 2. Hälfte des 1. Jhs. n. Chr. datiert werden. Die restlichen Funde - darunter fünf gebrauchskeramische Deckel, ein Randfragment eines Kochtopfs bzw. einer Kasserolle ${ }^{114}$ und ein Rand einer Amphore vom Typ Peacock - Williams 45 - sind generell der Kaiserzeit zuzurechnen.

In den zusammengehörigen Straten SE B44 und SE B45 wurden 17 diagnostische Fragmente geborgen. Hervorzuheben ist ein zu drei Vierteln erhaltener ESB-Teller der Form Atlante 80 aus dem 2. Jh. n. Chr. (K 235 Taf. 325. 350) ${ }^{115}$. Ebenso ist auf ein ungewöhnliches, bislang typologisch nicht bekanntes ESBGefäß hinzuweisen, das eine trichterförmige Gestalt aufweist und einen breiten, umgebogenen Rand hat (K 236 Taf. 325. 350). Der Boden des Gefäßes ist geschlossen. Die Form ist etwas verzogen, außen weist es unter dem breiten Rand eine recht breite Rille auf. Das Stück wurde in der Qualität ESB 2 (ab ca. 70 n. Chr.) ${ }^{116}$ gefertigt. Möglicherweise ist das Gefäß Bestandteil eines Thymiaterions oder kann als Deckelschale interpretiert werden. Zwei Stücke aus B45 sind anpassend, weshalb von einer Zusammengehörigkeit beider Schichten auszugehen ist ${ }^{117}$. Zum ESB-Spektrum der Schichten B44 und B45 gehören ferner ein Becher der Form Atlante 29 (K 237 Taf. 325), eine Schale der Form Atlante 37 (K 238 Taf. 325) und zwei fragmentarisch erhaltene Steilrandschalen der Form Atlante 70 (K 239 Taf. 325; K 240 Taf. 326). Bei einem

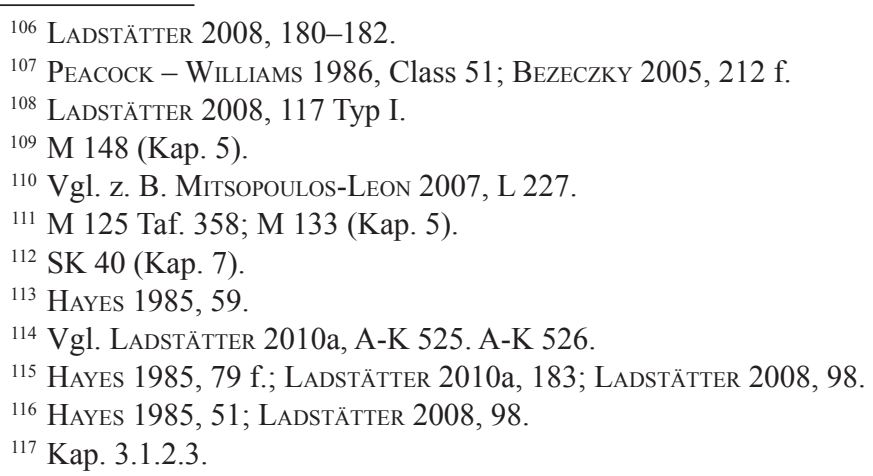


Wandfragment eines sog. Aco-Bechers (K 241 Taf. 326) handelt es sich um ein Residual augusteischer Zeitstellung. Von einem runden Kochtopf mit breitem, nach außen abfallendem, profiliertem Rand haben sich mehrere Fragmente erhalten (K 242 Taf. 326). Das Gefäß dürfte nach Analogiefunden ${ }^{118}$ in die 2. Hälfte des 1. Jhs. n. Chr. zu setzen sein. Auch hier gibt es Anpassungen aus B45. Die restlichen Funde, bestehend aus zwei weiteren Kochtopfrändern, fünf Fragmenten von Gebrauchskeramik (Krug, Schüssel, Deckel und zwei Bodenfragmente geschlossener Gefäße) und einem kleinen ROW-Lampenfragment sind innerhalb des 1. und 2. Jhs. n. Chr. nicht näher zeitlich einzuordnen. Insgesamt soll für SE B44/45 eine Datierung in die 1. Hälfte des 2. Jhs. n. Chr. vorgeschlagen werden.

Da unter den in SE B46 geborgenen acht diagnostischen Fragmenten bis auf ein kleines Fragment eines dünnwandigen Bechers (K 243 Taf. 326) keine Feinkeramik vorhanden war, muss das Spektrum der Küchenware und Gebrauchskeramik für die zeitliche Einordnung der Schicht herangezogen werden. Ein Schüsselrand (K 244 Taf. 326) und zwei Kochtopfränder (K 245. 246 Taf. 326) weisen in die flavische Zeit. Die restlichen Funde sind zeitlich innerhalb des ausgehenden Hellenismus und der Kaiserzeit nicht näher einzugrenzen.

\subsubsection{KAMMER E7}

Der sehr lockere Schutt mit zahllosen Ziegeln SE B36 enthielt ein Fragment eines Tellers der ESC, das der Form Hayes 4 entspricht (K 247 Taf. 327). Diese ist dem Ende des 2. und 3. Jhs. n. Chr. zuzuweisen. Vergesellschaftet war eine zu zwei Dritteln erhaltene Amphore mit gerippter Wand und kleinem Knauf (K 248 Taf. 327), die nach Analogiefunden aus dem Hanghaus $2^{119}$ demselben Zeitraum zuzuordnen ist.

In der Ziegelschuttschicht im oberen Bereich der Verfüllung (SE B37) wurden insgesamt 17 diagnostische Keramikfunde heterogener Zeitstellung geborgen, die - mit Ausnahme einer fast vollständigen Amphore kleinteilig gebrochen sind. Es ist ein Bodenfragment eines ESA-Tellers der Form Atlante 28 vorhanden ${ }^{120}$ (K 249 Taf. 327), außerdem ein typologisch nicht näher zuzuweisendes Wandfragment italischer Sigillata. Ein Bodenfragment einer weißgrundigen Lagynos ist dem ausgehenden 2. und 1. Jh. v. Chr. zuzuordnen, ebenso ein Wandfragment eines Reliefbechers. Bemerkenswert ist eine nahezu vollständig erhaltene sog. Forlimpopoli-Amphore (K 250 Taf. 328. 351). Dieser Amphorentyp wird zwar ab dem ausgehenden 1. Jh. v. Chr. in Nordostitalien produziert ${ }^{121}$, tritt in Ephesos bislang aber erst in späteren Fundkontexten ab dem 3. Jh. n. Chr. auf ${ }^{122}$. Die restlichen Amphorenfunde umfassen ein Randfragment des Typs Lamboglia 2, eine Amphore mit Mushroom-rim und eine Amphore mit verdicktem Rand, also eindeutig späthellenistische Typen. Eine Amphore mit kurzem, ausgebogenem Rand und außen darunter umlaufender, flacher Rille sowie ein runder, grober, über dem Boden abgearbeiteter Knauf sind hingegen nicht näher zuzuordnen. Eine Münze aus SE B37 wird in die augusteische Zeit datiert ${ }^{123}$. Aus SE B37 stammen u. a. auch eine Speer-/Lanzenspitze $^{124}$, ein Nagel ${ }^{125}$ sowie ein Konvolut aus 22 unverzierten Eisenblechfragmenten ${ }^{126}$.

Für die zusammengehörigen Straten der Schuttauffüllung SE B35-37 soll insgesamt aufgrund der jüngsten Funde aus SE B36 eine Datierung in das 3. Jh. n. Chr. vorgeschlagen werden. Ein großer Teil der Funde ist allerdings dem ausgehenden 1. Jh. v. und dem 1. Viertel des 1. Jhs. n. Chr. zuzuordnen. Bemerkenswert ist der vollständige Erhaltungszustand der sog. Forlimpopoli-Amphore. Ihr ursprünglicher Nutzungskontext wird nicht allzu weit entfernt vom Fundort zu postulieren sein.

In der Ascheschicht SE B38 wurden lediglich sechs kleinteilig gebrochene, diagnostische Keramikfragmente geborgen, die zudem zeitlich stark heterogen sind. Ein ESC-Bodenfragment gehört zu einem Teller der Form Hayes 4 (K 251 Taf. 329). Eine gebrauchskeramische Schale mit Steilrand, ausgezogenem Rand-

\footnotetext{
${ }^{118}$ Vgl. z. B. LadSTÄTter 2010a, A-K 527.

119 LADSTÄTteR 2010b, B-K 413; LADSTÄTter 2010b, 26: Fundkomplex B-Z/8-SR 25, SO-Ecke.

${ }^{120}$ HAYES 1985, 27 (Datierung: 11/10 v. Chr.-15/30 n. Chr.).

${ }^{121}$ Peacock - Williams 1986, 180 f.; Aldini 1996; Aldini 2000; Panella 2002; Riley 1979, 91-467.

${ }^{122}$ LAdSTÄTter 2005, 260 K 888 (Fundkomplex Z/17); s. auch unten Tab. 35, SE 179.

${ }^{123}$ M 36 Taf. 356 (Kap. 5).

${ }^{124}$ MF 54 Taf. 375 (Kap. 6.2.1).

${ }^{125}$ MF 62 Taf. 376 (Kap. 6.2.1).

${ }^{126}$ MF 58 Taf. 375 (Kap. 6.2.1).
} 
knick und abgerundetem Gefäßunterteil (K 252 Taf. 329) kann nach Analogiefunden aus Fundkomplexen der Erdbebenzerstörung des Hanghauses $2^{127}$ in das letzte Viertel des 3. Jhs. n. Chr. datiert werden. Eine Lampe mit gelochtem, an der Oberseite doppelt gerilltem Griff (K 253 Taf. 329) ist demselben Zeitrahmen zuzuordnen. Die restlichen drei Funde sind als spätklassische bis hellenistische Residuals anzusprechen.

Aus SE B39 stammen vier kleinteilig gebrochene, diagnostische Keramikstücke und ein Glasfragment. Ein Randstück einer ESB-Steilrandschale der Form Atlante 70 (K 254 Taf. 329) ist aufgrund seiner Beschaffenheit der späten Produktion zuzurechnen, möglicherweise handelt es sich auch um eine Imitation. Das Stück dürfte in das 2. Jh. n. Chr. datieren ${ }^{128}$. Ein weiteres kleines, nicht in den Katalog aufgenommenes Randfragment kann aufgrund seiner Kleinteiligkeit und der Unbestimmbarkeit des Durchmessers nur als Atlante 58 oder 70 bestimmt werden. Ein Fragment einer kleinen, runden Lampe mit abgesetzter Schnauze, deren Diskus von der Schulter durch Rillen abgesetzt ist und am Schnauzenansatz Reste eines Kreisdekors zeigt, gehört vermutlich in das 2./3. Jh. n. Chr. (K 255 Taf. 329). Ein sehr kleines Fragment einer ROWLampe und ein kleines Fragment eines Glasbechers oder einer Schale mit verdicktem Rand können nur allgemein in die Kaiserzeit datiert werden.

Insgesamt soll für B39 aufgrund der ESB-Funde und der Lampe eine Datierung in das 2. Jh. n. Chr. vorgeschlagen werden.

\subsubsection{KAMMER E8}

SE B48 kann nur allgemein als kaiserzeitlich eingestuft werden, die zwei daraus geborgenen diagnostischen Keramikfunde - ein Randstück eines gebrauchskeramischen Topfs und ein kleines Fragment einer ROWLampe - sind feinchronologisch nicht genauer einzuordnen.

Aus SE B49 stammen lediglich vier diagnostische Keramikfragmente. Ein Randfragment einer Schale oder eines Bechers der Westabhangnachfolgeware (K 256 Taf. 329) ist dem 2./1. Jh. v. Chr. zuzuordnen. Ein Boden eines dünnwandigen Bechers (K 257 Taf. 329) ist vermutlich augusteisch, ein Kochtopf mit nach außen abfallendem, profiliertem Rand (K 258 Taf. 329) ebenso. Es kamen in SE B49 auch eine kleine Bronzeglocke und ein ganzer Nagel ${ }^{129}$ zum Vorschein.

Es stammen 18 diagnostische, kleinteilig gebrochene Keramikfunde aus SE B51. Ein Randstück eines Skyphos der Westabhangnachfolgeware (K 259 Taf. 329), ein Becher (K 260 Taf. 329) und eine Echinusschale (K 261 Taf. 329) sowie ein Fragment einer Griffplatte eines Kantharos der Firnisware weisen in die (spät)hellenistische Zeit. Ein Fragment eines dünnwandigen, bauchigen Töpfchens mit ausgebogenem Rand (K 262 Taf. 329) datiert vermutlich in das ausgehende 1. Jh. v. Chr. und beginnende 1. Jh. n. Chr., die restlichen Stücke sind nicht näher einzuordnen. Da die Fragmente feinchronologisch nicht aussagekräftig sind, kann SE B51 innerhalb der späthellenistischen Zeit und des beginnenden 1. Jhs. n. Chr. nicht näher eingeordnet werden.

In SE B52 sind nur drei diagnostische Fragmente vorhanden, die chronologisch nicht zugeordnet werden können.

Aus SE B53 stammen sechs diagnostische Fragmente. Diese Schicht kann aufgrund eines Tellers mit breitem Rand (K 263 Taf. 329), eines Schalen- oder Tellerbodens mit Roulettdekor (K 264 Taf. 330) der Firnisware sowie von zwei Amphorenfunden (K 265. K 266 Taf. 330) in das 2. Jh. v. Chr. datiert werden.

In SE B54 wurden sechs diagnostische Fragmente geborgen. Ein kleines Bodenfragment der ESB, das zu einem Becher Atlante 40 gehört (K 267 Taf. 330), lässt darauf schließen, dass die Schicht nicht vor dem frühen 1. Jh. n. Chr. entstand. Ein Kochtopf mit nach außen abfallendem, profiliertem Rand (K 268 Taf. 330 ) ist ebenfalls der augusteischen Zeit zuzuordnen. Die restlichen Funde haben einen weiteren Datierungsrahmen.

\footnotetext{
${ }^{127}$ LAdSTÄTter 2005, K 754. K 787. K 788. K 794. K 854; LAdSTÄtTER 2010a, K 487; die Langlebigkeit der Form wird illustriert durch das Auftreten bis in das 1. Viertel des 6. Jhs. n. Chr., wie aus einem Fundkomplex des Nymphaeums des C. Laecanius Bassus hervorgeht, s. REMBART (in Vorbereitung).

${ }^{128}$ Vgl. z. B. LAdSTÄTter 2005, 241 K 608. 609; LADSTÄTter 2010a, A-K 760. A-K 761.

${ }^{129}$ MF 20 Taf. 371 (Kap. 6.2.1).
} 


\subsubsection{Funde aus Raum RN1, nördlich des Bühnengebäudes}

In dem nördlich an die Kammerreihe D anschließenden Raum RN1 wurde ausschließlich kleinteilig gebrochenes Fundmaterial geborgen (Tab. 59). Ein Stratum (SE B57) enthält Keramik aus dem 1. Jh. n. Chr., eine Münze weist allerdings in das 6. Jh. n. Chr. ${ }^{130}$. Die keramischen Funde aus SE B56 weisen allgemein in die Kaiserzeit, eine vergesellschaftete Münze datiert hingegen in das 6. Jh. $\mathrm{n} . \mathrm{Chr} .{ }^{131}$. Die keramischen Funde aus zwei Straten (SE B58 und SE B62) dokumentieren eine (Nach-)Nutzung des Raums im 6. und der 1. Hälfte des 7. Jhs. n. Chr. ${ }^{132}$.

\begin{tabular}{|c|c|c|c|c|c|c|}
\hline $\begin{array}{l}\text { Fläche, } \\
\text { KiNr. }\end{array}$ & Stratum & $\begin{array}{l}\text { Anzahl } \\
\text { diagnost. } \\
\text { Funde }\end{array}$ & $\begin{array}{l}\text { Charakterisierung } \\
\text { Fundkomplex }\end{array}$ & Datierung & $\begin{array}{l}\text { Datierungskriterien: } \\
\text { jüngste Keramik (u. Glas) }\end{array}$ & $\begin{array}{l}\text { Münzen } \\
\text { (Kap. 8) }\end{array}$ \\
\hline $\begin{array}{l}\text { S 5/2005 } \\
\text { KiNr. } 88\end{array}$ & SE B56 & 8 & $\begin{array}{l}\text { kleiner Fundkomplex } \\
\text { keine feinchronologisch } \\
\text { relevanten Funde }\end{array}$ & $\begin{array}{l}\text { kaiserzeitlich } \\
\text { 522/527 n. Chr. } \\
\text { (M 238) }\end{array}$ & $\begin{array}{l}\text { - Amphoren Peacock - Williams } 45 \\
\text { - KW Kleeblattkanne }\end{array}$ & $\begin{array}{l}\text { M } 238 \\
\text { M } 250\end{array}$ \\
\hline $\begin{array}{l}\text { S 5/2005 } \\
\text { KiNr. } 90\end{array}$ & SE B57 & 5 & kleiner Fundkomplex & $\begin{array}{l}\text { Anf. 1. Jh. n. Chr. } \\
\text { 518-527 n. Chr. } \\
\text { (M 237) }\end{array}$ & $\begin{array}{l}\text { - ESA Atlante } 31 \\
\text { - ESB (WS) } \\
\text { - GK Schale }\end{array}$ & M 237 \\
\hline $\begin{array}{l}\text { S 5/2005 } \\
\text { KiNr. } 91\end{array}$ & SE B58 & 4 & sehr kleiner Fundkomplex & $\begin{array}{l}\text { 6. Jh./ } \\
\text { 1. H. 7. Jh. n. Chr. }\end{array}$ & $\begin{array}{l}\text { - ERSW Imitation ARS Hayes } 105 \\
\text { - GK-Topf }\end{array}$ & - \\
\hline $\begin{array}{l}\text { S 5/2005 } \\
\text { KiNr. } 93\end{array}$ & SE B59 & 4 & $\begin{array}{l}\text { sehr kleiner Fundkomplex } \\
\text { keine feinchronologisch } \\
\text { relevanten Funde }\end{array}$ & - & - & - \\
\hline $\begin{array}{l}\text { S 5/2005 } \\
\text { KiNr. } 94\end{array}$ & SE B60 & 3 & $\begin{array}{l}\text { sehr kleiner Fundkomplex } \\
\text { keine feinchronologisch } \\
\text { relevanten Funde }\end{array}$ & $\begin{array}{l}\text { 193/211 n. Chr. } \\
\text { (M 55) }\end{array}$ & - & M 55 \\
\hline $\begin{array}{l}\text { S } 6 / 2005 \\
\text { KiNr. } \\
103\end{array}$ & SE B62 & 9 & kleiner Fundkomplex & 6. Jh. n. Chr. & $\begin{array}{l}\text { - ERSW Imitation LRC Hayes } 3 \\
\text { - KW Pfanne } \\
\text { - KW Topf (gerippter Bandhenkel) }\end{array}$ & - \\
\hline
\end{tabular}

Tab. 59

\subsection{FUNDE AUS DEN SONDAGEN IM BEREICH DER KAISERZEITLICHEN BÜHNEN}

Die Zusammensetzung der kleinen bis mittelgroßen Fundkomplexe aus den Sondagen im Bereich der kaiserzeitlichen Bühnen (Logeion) ist zeitlich meist heterogen (Tab. 60-65) ${ }^{133}$. Zusammengefasst kann festgehalten werden, dass das keramische Fundmaterial - abgesehen von den Fundkomplexen mit vorhellenistischen Residuals - mit jenem aus dem Fundamentgraben der Mauer Q (SE L62; Tab. 4. 63) ab dem 3./2. Jh. v. Chr. einsetzt. Einige Fundkomplexe enthalten späthellenistische Keramik (SE L11. 14. 17 Tab. 60; SE L35. 40 Tab. 62; SE L61 Tab. 63). Vom 1. Jh. v. Chr. bis in das frühe 1. Jh. n. Chr. ist eine Fundverdichtung zu verzeichnen (SE L8. 8a. 9-11. 14 Tab. 60; SE L24. 39 Tab. 62; SE L84. 85 Tab. 66). Eine weitere Fundkonzentration ist in der flavisch-trajanischen Zeit zu konstatieren, v. a. in Sondage 4/2003 (SE L47. 48.

\footnotetext{
${ }^{130}$ M 237 Taf. 359 (Kap. 5).

${ }^{131}$ M 238 Taf. 359 (Kap. 5).

132 Kap. 3.1.3.

${ }^{133}$ Zur - bisweilen schwierigen, da häufig auch rezent gestörten - Stratigrafie der einzelnen Grabungen im Bereich des Logeion s. Kap. 3.2.2.
} 
49=57? 55? 56? Tab. 64, außerdem SE L81a Tab. 65). Die späteste (Nach-)Nutzung des Logeion ist in das 5. Jh. n. Chr. zu setzen, was durch die jüngsten Keramikfunde in den Straten SE L5, SE L7 in Sondage 2001/1 (Tab. 60), SE L1 in Sondage 1/2002 (Tab. 61), SE L42 in Sondage 3/2003 (Tab. 62) und SE L80 in Sondage 4/2005 (Tab. 66) nahegelegt wird. Das keramische Fundmaterial aus den Sondagen im Logeion ist in der Regel kleinteilig gebrochen. Eine Ausnahme bildet die Kanalverfüllung SE L42 in Sondage 3/2003 (Tab. 63). Dort wurde verhältnismäßig zahlreiches Fundmaterial heterogener Zeitstellung geborgen. Unter anderem kamen vier nahezu ganz erhaltene Lampen kleinasiatischen Typs zum Vorschein ${ }^{134}$. Diese lassen zusammen mit den jüngsten vergesellschafteten Funden - Fragmenten von LRC-Tellern der Formen Hayes $2 \mathrm{~A}^{135}$ und Hayes $8^{136}$-, spezifischen Kochtopfrändern ${ }^{137}$ sowie Fragmenten von Amphoren des Typs LRA $3^{138}$ darauf schließen, dass der Kanal in der 2. Hälfte des 5. Jhs. n. Chr. endgültig verfüllt und aufgegeben wurde.

\section{Sondage S 1/2001, Nord}

\begin{tabular}{|c|c|c|c|c|c|c|}
\hline $\begin{array}{l}\text { Fläche, } \\
\text { KiNr. }\end{array}$ & Stratum & $\begin{array}{l}\text { Anzahl } \\
\text { diagnost. } \\
\text { Funde }\end{array}$ & $\begin{array}{l}\text { Charakterisierung } \\
\text { Fundkomplex }\end{array}$ & Datierung & $\begin{array}{l}\text { Datierungskriterien: } \\
\text { jüngste Keramik (u. Glas) }\end{array}$ & $\begin{array}{l}\text { Münzen } \\
\text { (Kap. 8) }\end{array}$ \\
\hline $\begin{array}{l}\text { Logeion } \\
\text { S } 1 / 2001 \\
\text { Nord } \\
\text { KiNr. } 19\end{array}$ & SE L4a & 1 & $\begin{array}{l}\text { insignifikant, aufgrund } \\
\text { geringer Fundquantität }\end{array}$ & 1.-2. Jh. n. Chr. & ESB, BS & - \\
\hline $\begin{array}{l}\text { Logeion } \\
\text { S } 1 / 2001 \\
\text { Nord } \\
\text { KiNr. } 9\end{array}$ & SE L5 & 43 & $\begin{array}{l}\text { heterogen: } \\
\text { späthell.-frühkaiserzeitli- } \\
\text { che Residuals (ESA, ESB, } \\
\text { ESB-Imitation, GWSÜ) } \\
\text { kaiserzeitliche Residuals } \\
\text { (DWK, rot überfangene } \\
\begin{array}{l}\text { Lampe: Teil eines Räu- } \\
\text { chergefäßes) }\end{array}\end{array}$ & 5. Jh. n. Chr. & $\begin{array}{l}\text { - LRC Hayes 3C } \\
\text { - LRC Hayes } 3 \\
\text { - GK-Krug } \\
\text { Glas: Schale mit Schliffrille, innen }\end{array}$ & - \\
\hline $\begin{array}{l}\text { Logeion } \\
\text { S } 1 / 2001 \\
\text { Nord } \\
\text { KiNr. } 10\end{array}$ & SE L6 & - & rezent gestört & - & - & - \\
\hline $\begin{array}{l}\text { Logeion } \\
\text { S } 1 / 2001 \\
\text { Nord } \\
\text { KiNr. } 11\end{array}$ & SE L7 & 13 & $\begin{array}{l}\text { heterogen: } \\
\text { späthellenistisch-frühkai- } \\
\text { serzeitliche Residuals }\end{array}$ & 5. Jh. n. Chr. & $\begin{array}{l}\text { - LRC Hayes } 3 \\
\text { - KW Töpfe } \\
\text { Glas: Becher/Schale mit echtem } \\
\text { Standring }\end{array}$ & - \\
\hline $\begin{array}{l}\text { Logeion } \\
\text { S } 1 / 2001 \\
\text { Nord } \\
\text { KiNr. } 12\end{array}$ & SE L7a & 7 & kleiner Fundkomplex & $\begin{array}{l}\text { späthellenistisch- } \\
\text { frühkaiserzeitlich }\end{array}$ & $\begin{array}{l}\text { - Echinusschale } \\
\text { - Firnisware-Teller mit Kerbdekor } \\
\text { - Amphore Peacock - Williams } 45 \\
\text { - GK-Schüssel }\end{array}$ & - \\
\hline
\end{tabular}

\footnotetext{
${ }^{134}$ MiLtner 1937; vgl. die Funde aus der Kanalfüllung SE 126/130 im Keller des Vediusgymnasiums: Ladstätter 2008, 117 Typ I.2-3.

${ }^{135}$ HaYes 1972, 328.

${ }^{136}$ HAYES 1972, 340.

137 Vgl. LADSTÄTter 2008, K 212-214.

${ }^{138}$ Zur Entwicklung des Amphorentyps s. LADSTÄTter 2008, 180-182.
} 


\begin{tabular}{|c|c|c|c|c|c|c|}
\hline $\begin{array}{l}\text { Fläche, } \\
\text { KiNr. }\end{array}$ & Stratum & $\begin{array}{l}\text { Anzahl } \\
\text { diagnost. } \\
\text { Funde }\end{array}$ & $\begin{array}{l}\text { Charakterisierung } \\
\text { Fundkomplex }\end{array}$ & Datierung & $\begin{array}{l}\text { Datierungskriterien: } \\
\text { jüngste Keramik (u. Glas) }\end{array}$ & $\begin{array}{l}\text { Münzen } \\
\text { (Kap. 8) }\end{array}$ \\
\hline $\begin{array}{l}\text { Logeion } \\
\text { S } 1 / 2001 \text {, } \\
\text { Nord } \\
\text { KiNr. } 13\end{array}$ & SE L8 & 17 & homogen & $\begin{array}{l}\text { späthellenistisch- } \\
\text { frühkaiserzeitlich } \\
(?)\end{array}$ & $\begin{array}{l}\text { - ESA Teller } \\
\text { - Firnisware Teller } \\
\text { - Firnisware Schalen } \\
\text { - Amphoren } \\
\text { - weißgrundige Keramik-Krug } \\
\text { - DWK Becher } \\
\text { Glas: Schale mit Schliffrille, innen } \\
\text { (1 RS) }\end{array}$ & - \\
\hline $\begin{array}{l}\text { Logeion } \\
\text { S } 1 / 2001 \text {, } \\
\text { Nord } \\
\text { KiNr. } 16\end{array}$ & \begin{tabular}{|l|} 
SE L8a \\
entspricht \\
SE L14
\end{tabular} & 9 & - & $\begin{array}{l}\text { späthellenistisch- } \\
\text { frühkaiserzeitlich }\end{array}$ & $\begin{array}{l}\text { ESA Atlante 5B } \\
\text { GWSÜ Platte } \\
\text { KW Topf } \\
\text { Amphore }\end{array}$ & - \\
\hline $\begin{array}{l}\text { Logeion } \\
\text { S 1/2001, } \\
\text { Nord } \\
\text { KiNr. } 14\end{array}$ & SE L9 & 9 & kleiner Fundkomplex & $\begin{array}{l}\text { späthellenistisch- } \\
\text { frühkaiserzeitlich }\end{array}$ & $\begin{array}{l}\text { ESB Atlante 29 } \\
\text { Reliefbecher } \\
\text { Westabhangware } \\
\text { Amphore }\end{array}$ & - \\
\hline $\begin{array}{l}\text { Logeion } \\
\text { S 1/2001, } \\
\text { Nord } \\
\text { KiNr. } 20\end{array}$ & SE L9? & 21 & $\begin{array}{l}\text { heterogen } \\
\text { kaiserzeitlich } \\
\text { spätantik } \\
\text { (2 RS Kochtopfränder) }\end{array}$ & $\begin{array}{l}\text { 2. Jh. n. Chr. } \\
\text { spätantik }\end{array}$ & $\begin{array}{l}\text { ESB Atlante 76A } \\
\text { ESA Atlante 22A } \\
\text { DWK Becher } \\
\text { GK Schüssel } \\
\text { KW Töpfe }\end{array}$ & - \\
\hline $\begin{array}{l}\text { Logeion } \\
\text { S 1/2001, } \\
\text { Nord } \\
\text { KiNr. } 15\end{array}$ & SE L10 & 8 & kleiner Fundkomplex & späthellenistisch & $\begin{array}{l}\text { Amphoren } \\
\text { Firnisware-Schale } \\
\text { GK Schüssel }\end{array}$ & - \\
\hline $\begin{array}{l}\text { Logeion } \\
\text { S 1/2001, } \\
\text { Nord } \\
\text { KiNr. } 17\end{array}$ & \begin{tabular}{|l|} 
SE L11 \\
entspricht \\
SE L16
\end{tabular} & 9 & homogen & $\begin{array}{l}\text { 1. Jh. v. Chr.-frü- } \\
\text { hes 1. Jh. n. Chr. }\end{array}$ & $\begin{array}{l}\text { ESA Atlante 4A } \\
\text { Reliefbecher } \\
\text { GK Krug } \\
\text { DWK Becher } \\
\text { Applikenware } \\
\text { Lampe, knidisch }\end{array}$ & - \\
\hline $\begin{array}{l}\text { Logeion } \\
\text { S 1/2001, } \\
\text { Nord } \\
\text { KiNr. 18, } \\
21\end{array}$ & SE L12 & 11 & $\begin{array}{l}\text { heterogen: } \\
\text { vereinzelt klassische } \\
\text { Residuals }\end{array}$ & $\begin{array}{l}\text { 1. Jh. v. Chr.- } \\
\text { 1. H. 1. Jh. n. Chr. } \\
\text { (?) }\end{array}$ & $\begin{array}{l}\text { ESA Atlante 4A } \\
\text { Reliefbecher } \\
\text { DWK Becher }\end{array}$ & - \\
\hline $\begin{array}{l}\text { Logeion } \\
\text { S } 1 / 2001 \text {, } \\
\text { Nord } \\
\text { KiNr. } 22\end{array}$ & SE L13 & 3 & $\begin{array}{l}\text { sehr kleiner Fundkomplex } \\
\text { heterogen: } \\
\text { archaisch/klassisch/ } \\
\text { frühkaiserzeitlich } \\
\text { insignifikant, aufgrund } \\
\text { geringer Fundquantität }\end{array}$ & frühkaiserzeitlich & KW Topf & - \\
\hline $\begin{array}{l}\text { Logeion } \\
\text { S } 1 / 2001 \text {, } \\
\text { Nord } \\
\text { KiNr. } 48\end{array}$ & SE L20 & - & $\begin{array}{l}\text { keine feinchronologisch } \\
\text { relevanten Funde }\end{array}$ & $\begin{array}{l}\text { spätklassisch- } \\
\text { hellenistisch }\end{array}$ & - & - \\
\hline
\end{tabular}

Tab. 60 
Sondage 1/2002

\begin{tabular}{|c|c|c|c|c|c|c|}
\hline $\begin{array}{l}\text { Fläche, } \\
\text { KiNr. }\end{array}$ & Stratum & $\begin{array}{l}\text { Anzahl } \\
\text { diagnost. } \\
\text { Funde }\end{array}$ & $\begin{array}{l}\text { Charakterisierung } \\
\text { Fundkomplex }\end{array}$ & Datierung & $\begin{array}{l}\text { Datierungskriterien: } \\
\text { jüngste Keramik (u. Glas) }\end{array}$ & $\begin{array}{l}\text { Münzen } \\
\text { (Kap. 8) }\end{array}$ \\
\hline $\begin{array}{l}\text { Logeion } \\
\text { S } 1 / 2002 \\
\text { KiNr. } \\
2.3\end{array}$ & SE L1 & 21 & $\begin{array}{l}\text { heterogen } \\
\text { hellenistisch/kaiserzeitlich/ } \\
\text { spätantik (vereinzelt) }\end{array}$ & $\begin{array}{l}\text { 1. H. 2. Jh. n. Chr. } \\
\text { 4./frühes 5. Jh. } \\
\text { n. Chr. } \\
1966 \text { (Münze) }\end{array}$ & $\begin{array}{l}\text { ESC Atlante L26B } \\
\text { KW Topf } \\
\text { Glas: Kelchfuß mit hohlem Rand } \\
\text { (vgl. z. B. CzURDA-RuTH 2007, } 152 \\
\text { KatNr. 626-663) }\end{array}$ & $\begin{array}{l}\text { M } 82 \\
\text { M } 1 \\
\text { M } 271\end{array}$ \\
\hline $\begin{array}{l}\text { Logeion } \\
\text { S } 1 / 2002 \\
\text { KiNr. } \\
8.9\end{array}$ & SE L5 & 16 & homogen & $\begin{array}{l}\text { späthellenistisch- } \\
\text { frühkaiserzeitlich }\end{array}$ & $\begin{array}{l}\text { ESA Atlante 22A } \\
\text { ESB Atlante } 40 \\
\text { Firnisware-Teller mit beidseitig } \\
\text { verdickter Lippe } \\
\text { KW Topf } \\
\text { Amphore Peacock - Williams } 45\end{array}$ & - \\
\hline $\begin{array}{l}\text { Logeion } \\
\text { S 1/2002 } \\
\text { KiNr. } 11 . \\
13.14 . \\
17\end{array}$ & SE L11 & 52 & $\begin{array}{l}\text { vereinzelt Residuals aus } \\
\text { archaischer Zeit und dem } \\
\text { 3./2. Jh. v. Chr. }\end{array}$ & 1. Jh. v. Chr. & $\begin{array}{l}\text { Firnisware-Teller mit gedrechsel- } \\
\text { tem Rand } \\
\text { Echinusschalen } \\
\text { Applikenware Becher } \\
\text { GK-Schüsseln } \\
\text { KW Töpfe/Kasserollen } \\
\text { Amphoren mit verdicktem Rand } \\
\text { Lampe, knidisch (?) }\end{array}$ & - \\
\hline $\begin{array}{l}\text { Logeion } \\
\text { S } 1 / 2002 \\
\text { KiNr. } 9\end{array}$ & \begin{tabular}{|l|} 
SE L14 \\
entspricht \\
SE L8a
\end{tabular} & 4 & kleiner Fundkomplex & 2. H. 1. Jh. v. Chr. & $\begin{array}{l}\text { ESA Atlante } 11 \mathrm{~A} \\
\text { Amphore Peacock - Williams } 45\end{array}$ & - \\
\hline $\begin{array}{l}\text { Logeion } \\
\text { S } 1 / 2002 \\
\text { KiNr. } 10\end{array}$ & \begin{tabular}{|l|} 
SE L16 \\
entspricht \\
SE L11
\end{tabular} & 12 & $\begin{array}{l}\text { homogen } \\
\text { keine feinchronologisch } \\
\text { relevanten Funde }\end{array}$ & hellenistisch & $\begin{array}{l}\text { Firnisware-Teller } \\
\text { Skyphos/Kantharos mit Griffplatte } \\
\text { GK Schüssel }\end{array}$ & - \\
\hline $\begin{array}{l}\text { Logeion } \\
\text { S } 1 / 2002 \\
\text { KiNr. } 15 . \\
16\end{array}$ & SE L17 & 18 & $\begin{array}{l}\text { heterogen: } \\
\text { archaisch/klassische } \\
\text { Residuals } \\
\text { wenig feinchronologisch } \\
\text { relevante Funde }\end{array}$ & 2. Jh. v. Chr. & $\begin{array}{l}\text { Echinusschale } \\
\text { Riefelkantharos } \\
\text { Amphore, rhodisch } \\
\text { Amphore mit verdicktem Rand }\end{array}$ & - \\
\hline
\end{tabular}

Tab. 61 
Sondage 1/2003

\begin{tabular}{|c|c|c|c|c|c|c|}
\hline $\begin{array}{l}\text { Fläche, } \\
\text { KiNr. }\end{array}$ & Stratum & $\begin{array}{l}\text { Anzahl } \\
\text { diagnost. } \\
\text { Funde }\end{array}$ & $\begin{array}{l}\text { Charakterisierung } \\
\text { Fundkomplex }\end{array}$ & Datierung & $\begin{array}{l}\text { Datierungskriterien: } \\
\text { jüngste Keramik (u. Glas) }\end{array}$ & $\begin{array}{l}\text { Münzen } \\
\text { (Kap. 8) }\end{array}$ \\
\hline $\begin{array}{l}\text { Logeion } \\
\text { S } 1 / 2003 \\
\text { KiNr. } 23\end{array}$ & SE L1 & 9 & $\begin{array}{l}\text { Oberflächenreinigung, } \\
\text { wenige feinchronologisch } \\
\text { aussagekräftige Funde, }\end{array}$ & $\begin{array}{l}\text { 1. Jh. v. Chr.-1. } \\
\text { Viertel 1. Jh. n. } \\
\text { Chr. }\end{array}$ & $\begin{array}{l}\text { Kantharos, pergamenisch } \\
\text { KW Topf } \\
\text { Ephesoslampe (oxidierend } \\
\text { gebrannt) }\end{array}$ & - \\
\hline $\begin{array}{l}\text { Logeion } \\
\text { S } 1 / 2003 \\
\text { KiNr. } 20 . \\
21.25 \\
26.73 . \\
74\end{array}$ & $\begin{array}{l}\text { SE L32 } \\
\text { SE L34 }\end{array}$ & 75 & $\begin{array}{l}\text { heterogen: } \\
\text { viel 2./1. Jh. v. Chr.-au- } \\
\text { gusteisch, jüngster Fund } \\
\text { aber ca. Mitte 1. Jh. n. } \\
\text { Chr. }\end{array}$ & $\begin{array}{l}\text { augusteisch-Mitte } \\
\text { 1. Jh. n. Chr. }\end{array}$ & $\begin{array}{l}\text { ESB Atlante 18 } \\
\text { ESA Atlante 4B } \\
\text { GWSÜ Platten } \\
\text { GWSÜ Krug }\end{array}$ & - \\
\hline $\begin{array}{l}\text { Logeion } \\
\text { S } 1 / 2003 \\
\text { KiNr. } 94 . \\
95\end{array}$ & SE L35 & 6 & kleiner Fundkomplex & 1. Jh. v. Chr. & $\begin{array}{l}\text { ESA } \\
\text { Ephesoslampe }\end{array}$ & - \\
\hline $\begin{array}{l}\text { Logeion } \\
\text { S } 1 / 2003 \\
\text { KiNr. } 24 . \\
70\end{array}$ & SE L39 & 6 & kleiner Fundkomplex & $\begin{array}{l}\text { 1. Jh. v. Chr.-1. } \\
\text { Viertel 1. Jh. n. } \\
\text { Chr. }\end{array}$ & $\begin{array}{l}\text { ESC, pergamenisch } \\
\text { GK Schüssel } \\
\text { Amphore mit Mushroom-rim } \\
\text { Amphore mit verdicktem Rand }\end{array}$ & - \\
\hline $\begin{array}{l}\text { Logeion } \\
\text { S } 1 / 2003 \\
\text { KiNr. } \\
27-30\end{array}$ & SE L40 & & $\begin{array}{l}\text { homogen } \\
\text { wenig feinchronologisch } \\
\text { relevante Funde }\end{array}$ & $\begin{array}{l}\text { (2. H.) 1. Jh. v. } \\
\text { Chr. }\end{array}$ & $\begin{array}{l}\text { Schale frühe ESB? } \\
\text { Echinusschale, spät } \\
\text { GWSÜ } \\
\text { DWK Becher } \\
\text { GK Krüge } \\
\text { GK Schüssel } \\
\text { KW Becken } \\
\text { Ephesoslampe }\end{array}$ & - \\
\hline
\end{tabular}

Tab. 62

Sondage 2/2003

\begin{tabular}{|l|l|l|l|l|l|l|}
\hline $\begin{array}{l}\text { Fläche, } \\
\text { KiNr. }\end{array}$ & Stratum & $\begin{array}{l}\text { Anzahl } \\
\text { diagnost. } \\
\text { Funde }\end{array}$ & $\begin{array}{l}\text { Charakterisierung } \\
\text { Fundkomplex }\end{array}$ & Datierung & $\begin{array}{l}\text { Datierungskriterien: } \\
\text { jüngste Keramik (u. Glas) }\end{array}$ & $\begin{array}{l}\text { Münzen } \\
\text { (Kap. 8) }\end{array}$ \\
\hline $\begin{array}{l}\text { Logeion } \\
\text { S 2/2003 } \\
\text { KiNr. } 68\end{array}$ & SE L53 & 3 & $\begin{array}{l}\text { insignifikant aufgrund } \\
\text { geringer Fundquantiät }\end{array}$ & augusteisch (?) & KW Topf & - \\
\hline $\begin{array}{l}\text { Logeion } \\
\text { S 2/2003 } \\
\text { KiNr. 85 }\end{array}$ & SE L61 & 10 & - & 1. Jh. v. Chr. & $\begin{array}{l}\text { ESA Atlante 4A } \\
\text { GWSÜ Platte } \\
\text { Amphore mit Mushroom-rim }\end{array}$ & - \\
\hline $\begin{array}{l}\text { Logeion } \\
\text { S 2/2003 } \\
\text { KiNr. 89 }\end{array}$ & SE L62 & 4 & sehr kleiner Fundkomplex & 3./2. Jh. v. Chr. (?) & Westabhang-Nachfolge-Ware & - \\
\hline
\end{tabular}

Tab. 63 
Sondage 3/2003

\begin{tabular}{|c|c|c|c|c|c|c|}
\hline $\begin{array}{l}\text { Fläche, } \\
\text { KiNr. }\end{array}$ & Stratum & $\begin{array}{l}\text { Anzahl } \\
\text { diagnost. } \\
\text { Funde }\end{array}$ & $\begin{array}{l}\text { Charakterisierung } \\
\text { Fundkomplex }\end{array}$ & Datierung & $\begin{array}{l}\text { Datierungskriterien: } \\
\text { jüngste Keramik (u. Glas) }\end{array}$ & $\begin{array}{l}\text { Münzen } \\
\text { (Kap. 8) }\end{array}$ \\
\hline $\begin{array}{l}\text { Logeion } \\
\text { S 3/2003 } \\
\text { KiNr. } \\
46 a-b\end{array}$ & $\begin{array}{l}\text { SE L44b } \\
\text { SE L45 }\end{array}$ & & rezent gestört & $\begin{array}{l}\text { 1909-1918 } \\
\text { (Münze) }\end{array}$ & - & M 265 \\
\hline $\begin{array}{l}\text { Logeion } \\
\text { S 3/2003 } \\
\text { KiNr. } 40 . \\
41.42 . \\
43\end{array}$ & SE L42 & 63 & $\begin{array}{l}\text { heterogen } \\
\text { viele kaiserzeitliche } \\
\text { Residuals } \\
\text { tw. gut erhaltene Gefäße } \\
\text { (zahlreiche Lampen, da- } \\
\text { von vier ganz erhalten) }\end{array}$ & 2. H. 5. Jh. n. Chr. & $\begin{array}{l}\text { LRC Hayes 2A } \\
\text { LRC Hayes } 8 \\
\text { KW Töpfe } \\
\text { KW Pfanne } \\
\text { Amphoren LRA } 3 \\
\text { Lampen, kleinasiatisch } \\
\\
\text { Glas: Becher mit ausgestelltem } \\
\text { Rand, drei Kelchfüße mit hohlem } \\
\text { Rand (CZURDA-RUTH 2007, 152.) }\end{array}$ & $\begin{array}{l}\text { M } 131 \\
\text { M } 132 \\
\text { M } 159 \\
\text { M } 163 \\
\text { M } 204\end{array}$ \\
\hline $\begin{array}{l}\text { Logeion } \\
\text { S 3/2003 } \\
\text { KiNr. } 45\end{array}$ & SE L43 & 1 & $\begin{array}{l}\text { insignifikant aufgrund } \\
\text { geringer Fundquantität }\end{array}$ & $\begin{array}{l}1 / 10-50 / 60 \mathrm{n} . \\
\text { Chr. }\end{array}$ & ESA Atlante 45 & - \\
\hline
\end{tabular}

Tab. 64

Sondage 4/2003

\begin{tabular}{|c|c|c|c|c|c|c|}
\hline $\begin{array}{l}\text { Fläche, } \\
\text { KiNr. }\end{array}$ & Stratum & $\begin{array}{l}\text { Anzahl } \\
\text { diagnost. } \\
\text { Funde }\end{array}$ & $\begin{array}{l}\text { Charakterisierung } \\
\text { Fundkomplex }\end{array}$ & Datierung & $\begin{array}{l}\text { Datierungskriterien: } \\
\text { jüngste Keramik (u. Glas) }\end{array}$ & $\begin{array}{l}\text { Münzen } \\
\text { (Kap. 8) }\end{array}$ \\
\hline $\begin{array}{l}\text { Logeion } \\
\text { S 4/2003 } \\
\text { KiNr. } 74\end{array}$ & SE L32 & 3 & $\begin{array}{l}\text { insignifikant aufgrund } \\
\text { geringer Fundquantität }\end{array}$ & 1. Jh. v. Chr. (?) & $\begin{array}{l}\text { Reliefbecher } \\
\text { Firnisware-Schale } \\
\text { KW Topf }\end{array}$ & - \\
\hline $\begin{array}{l}\text { Logeion } \\
\text { S 4/2003 } \\
\text { KiNr. } 70\end{array}$ & SE L39 & 6 & $\begin{array}{l}\text { kleiner Fundkomplex } \\
\text { heterogen: } \\
1 \text { spätantike Lampen- } \\
\text { schulter }\end{array}$ & $\begin{array}{l}\text { augusteisch } \\
\text { spätantik }\end{array}$ & $\begin{array}{l}\text { ESB Atlante } 22 \\
\text { DWK Becher } \\
1 \text { Lampe }\end{array}$ & - \\
\hline $\begin{array}{l}\text { Logeion } \\
\text { S 4/2003 } \\
\text { KiNr. } 57\end{array}$ & SE L46 & 36 & $\begin{array}{l}\text { heterogen: } \\
\text { späthellenistische Resi- } \\
\text { duals }\end{array}$ & 1. Jh. n. Chr. & $\begin{array}{l}\text { ESB } \\
\text { ESC, pergamenisch } \\
\text { GK Steilrandschälchen }\end{array}$ & - \\
\hline $\begin{array}{l}\text { Logeion } \\
\text { S 4/2003 } \\
\text { KiNr. } 58\end{array}$ & SE L47 & 12 & $\begin{array}{l}\text { heterogen: } \\
\text { viele späthellenistisch-au- } \\
\text { gusteische Residuals }\end{array}$ & $\begin{array}{l}\text { flavisch-hadria- } \\
\text { nisch }\end{array}$ & $\begin{array}{l}\text { ESB Atlante } 60 \\
\text { KW Töpfe }\end{array}$ & - \\
\hline $\begin{array}{l}\text { Logeion } \\
\text { S 4/2003 } \\
\text { KiNr. } 59\end{array}$ & SE L48 & 19 & homogen & $\begin{array}{l}\text { 2. H. 1.-1. V. } 2 . \\
\text { Jh. n. Chr. }\end{array}$ & $\begin{array}{l}\text { ESB Atlante } 60 \\
\text { ESB Atlante } 58 \\
\text { DWK Becher } \\
\text { GK Krüge } \\
\text { KW Töpfe } \\
\text { Amphoren Peacock - Williams } 45 \\
\text { ROW-Lampen }\end{array}$ & - \\
\hline
\end{tabular}




\begin{tabular}{|c|c|c|c|c|c|c|}
\hline $\begin{array}{l}\text { Fläche, } \\
\text { KiNr. }\end{array}$ & Stratum & \begin{tabular}{|l|} 
Anzahl \\
diagnost. \\
Funde
\end{tabular} & $\begin{array}{l}\text { Charakterisierung } \\
\text { Fundkomplex }\end{array}$ & Datierung & $\begin{array}{l}\text { Datierungskriterien: } \\
\text { jüngste Keramik (u. Glas) }\end{array}$ & $\begin{array}{l}\text { Münzen } \\
\text { (Kap. 8) }\end{array}$ \\
\hline $\begin{array}{l}\text { Logeion } \\
\text { S } 4 / 2003 \\
\text { KiNr. } 60\end{array}$ & $\begin{array}{l}\text { SE L49 = } \\
\text { L57? }\end{array}$ & 11 & $\begin{array}{l}\text { homogen } \\
\text { teilweise zusammengehö- } \\
\text { rig mit L } 57\end{array}$ & $\begin{array}{l}\text { 2. H. 1. Jh.-1. H. } \\
\text { 2. Jh. n. Chr. }\end{array}$ & $\begin{array}{l}\text { ESB Atlante } 60 \\
\text { DWK Becher mit Karniesrand } \\
\text { Amphore Peacock - Williams } 45 \\
\text { Fragmente einer großformatigen } \\
\text { tongrundigen Lampe }\end{array}$ & - \\
\hline $\begin{array}{l}\text { Logeion } \\
\text { S } 4 / 2003 \\
\text { KiNr. } 78 . \\
81\end{array}$ & $\begin{array}{l}\text { SE L57 = } \\
\text { L49? }\end{array}$ & 39 & $\begin{array}{l}\text { homogen } \\
1 \text { WS LRC, sekundäre } \\
\text { Kontamination }\end{array}$ & $\begin{array}{l}\text { flavisch-trajanisch } \\
\text { 4./5. Jh. n. Chr. }\end{array}$ & $\begin{array}{l}\text { RS ESB Atlante } 58 \\
\text { rot überfangener Krug mit Trich- } \\
\text { terrand } \\
\text { Kleeblattkanne } \\
\text { DWK Becher } \\
\text { Fragmente tongrundiger großer } \\
\text { Lampen (vgl. L 049, wohl zusam- } \\
\text { mengehörig, aber nicht anpassend) } \\
\text { GK Pithos } \\
\text { KW Topf } \\
\text { LRC (1 WS) }\end{array}$ & - \\
\hline $\begin{array}{l}\text { Logeion } \\
\text { S } 4 / 2003 \\
\text { KiNr. } 61 . \\
62\end{array}$ & SE L50 & 8 & $\begin{array}{l}\text { heterogen: } \\
\text { hellenistische Residuals }\end{array}$ & 1. Jh. n. Chr. & $\begin{array}{l}\text { ESB Atlante } 6 \\
\text { KW Topf } \\
\text { großformatige Lampe mit Lanzett- } \\
\text { blattdekor } \\
\text { Glas: konischer Becher mit nach } \\
\text { außen gewölbtem Rand }\end{array}$ & - \\
\hline $\begin{array}{l}\text { Logeion } \\
\text { S } 4 / 2003 \\
\text { KiNr. } 79\end{array}$ & SE L51 & 5 & sehr kleiner Fundkomplex & 1. Jh. v. Chr. (?) & $\begin{array}{l}\text { ESA Atlante } 3 \\
\text { Firnisware-Becher }\end{array}$ & - \\
\hline $\begin{array}{l}\text { Logeion } \\
\text { S } 4 / 2003 \\
\text { KiNr. } 71\end{array}$ & SE L54a & 3 & heterogen & 2. H. 4. Jh. n. Chr. & ARS Hayes 60 & - \\
\hline $\begin{array}{l}\text { Logeion } \\
\text { S 4/2003 } \\
\text { KiNr. } 71 . \\
72\end{array}$ & SE L54b & 21 & heterogen & 2. H. 1. Jh. n. Chr. & $\begin{array}{l}\text { ESB Atlante } 26 \\
\text { DWK Becher } \\
\text { ROW-Lampen }\end{array}$ & - \\
\hline $\begin{array}{l}\text { Logeion } \\
\text { S } 4 / 2003 \\
\text { KiNr. } 83 \text {. } \\
84\end{array}$ & SE L55 & 12 & $\begin{array}{l}\text { heterogen: } \\
\text { 1. Jh. v. Chr./1. Jh. n. } \\
\text { Chr./flavisch-trajanisch } \\
\text { DWK Becher, zusam- } \\
\text { mengehörig mit weiteren } \\
\text { Frgten. S 4/2003, Kiste } 76\end{array}$ & flavisch-trajanisch & $\begin{array}{l}\text { DWK Becher } \\
\text { ESC, pergamenisch } \\
\text { ROW Lampengriff }\end{array}$ & - \\
\hline $\begin{array}{l}\text { Logeion } \\
\text { S } 4 / 2003 \\
\text { KiNr. } 76\end{array}$ & SE L55a & 1 & $\begin{array}{l}\text { sehr kleiner Fundkomplex } \\
\text { insignifikant aufgrund } \\
\text { geringer Fundquantität, } \\
\text { feinchronologisch nicht } \\
\text { relevant }\end{array}$ & 2.-4. Jh. n. Chr. & KW Kasserolle & M 102 \\
\hline $\begin{array}{l}\text { Logeion } \\
\text { S } 4 / 2003 \\
\text { KiNr. } 77\end{array}$ & SE L56 & 4 & $\begin{array}{l}\text { sehr kleiner Fundkomplex } \\
\text { Schnauze einer großfor- } \\
\text { matigen Lampe wie in SE } \\
\text { L49/SE L57 }\end{array}$ & kaiserzeitlich & KW Töpfe & - \\
\hline
\end{tabular}




\begin{tabular}{|c|c|c|c|c|c|c|}
\hline $\begin{array}{l}\text { Fläche, } \\
\text { KiNr. }\end{array}$ & Stratum & \begin{tabular}{|l|} 
Anzahl \\
diagnost. \\
Funde
\end{tabular} & $\begin{array}{l}\text { Charakterisierung } \\
\text { Fundkomplex }\end{array}$ & Datierung & $\begin{array}{l}\text { Datierungskriterien: } \\
\text { jüngste Keramik (u. Glas) }\end{array}$ & $\begin{array}{l}\text { Münzen } \\
\text { (Kap. 8) }\end{array}$ \\
\hline $\begin{array}{l}\text { Logeion } \\
\text { S 4/2003 } \\
\text { KiNr. } 80\end{array}$ & SE L58 & 13 & heterogen & $\begin{array}{l}\text { 1. Jh. v. Chr. } \\
\text { 2. H. 1. Jh.-3. Jh. } \\
\text { n. Chr. }\end{array}$ & $\begin{array}{l}\text { ESA Atlante 4B } \\
\text { Firnisware-Becher } \\
\text { Ephesoslampe } \\
\text { GWSÜ Platten } \\
\text { DWK Becher }\end{array}$ & - \\
\hline $\begin{array}{l}\text { Logeion } \\
\text { S 4/2003 } \\
\text { KiNr. } 82\end{array}$ & SE L59 & 5 & kleiner Fundkomplex & 1. Jh. v. Chr. (?) & Ephesoslampe & - \\
\hline $\begin{array}{l}\text { Logeion } \\
\text { S 4/2003 } \\
\text { KiNr. } 91 . \\
93\end{array}$ & SE L64 & 11 & $\begin{array}{l}\text { heterogen } \\
\text { späthellenistisch/flavisch- } \\
\text { trajanisch/3.-4. Jh. n. Chr. } \\
\text { (sekundäre Kontamina- } \\
\text { tion?) }\end{array}$ & $\begin{array}{l}\text { 1. Jh. v. Chr. } \\
\text { flavisch-trajanisch } \\
\text { 3/4. Jh. n. Chr. }\end{array}$ & $\begin{array}{l}\text { GWSÜ Platte } \\
\text { ESA Atlante 4B } \\
\text { ESB Atlante } 58 \\
\text { ARS (1 WS) }\end{array}$ & - \\
\hline
\end{tabular}

Tab. 65

\section{Sondage $4 / 2005$}

\begin{tabular}{|c|c|c|c|c|c|c|}
\hline $\begin{array}{l}\text { Fläche, } \\
\text { KiNr. }\end{array}$ & Stratum & $\begin{array}{l}\text { Anzahl } \\
\text { diagnost. } \\
\text { Funde }\end{array}$ & $\begin{array}{l}\text { Charakterisierung } \\
\text { Fundkomplex }\end{array}$ & Datierung & $\begin{array}{l}\text { Datierungskriterien: } \\
\text { jüngste Keramik (u. Glas) }\end{array}$ & $\begin{array}{l}\text { Münzen } \\
\text { (Kap. 8) }\end{array}$ \\
\hline $\begin{array}{l}\text { Logeion } \\
\text { S 4/2005 } \\
\text { KiNr. } 38 . \\
41.45 . \\
55\end{array}$ & $\begin{array}{l}\text { SE L80 } \\
=\text { SE } \\
\text { L82 }\end{array}$ & 84 & $\begin{array}{l}\text { heterogen } \\
\text { vereinzelt späthellenisti- } \\
\text { sche Residuals } \\
1 \text { LRC-Boden (sekundäre } \\
\text { Kontamination) }\end{array}$ & $\begin{array}{l}\text { 2. H. 2.-3. Jh.n. } \\
\text { Chr. } \\
\text { 5. Jh. n. Chr. }\end{array}$ & $\begin{array}{l}\text { ESC Hayes } 2 \\
\text { ESC Hayes } 3 \\
\text { ESC L26B } \\
\text { ESC Atlante L19 } \\
\text { ESB2: } \\
\text { ESB Atlante } 58 \\
\text { ESB Atlante } 70 \\
\text { ESB Atlante } 60 \\
\text { ESB (reduzierend gebrannt) } \\
\text { DWK Becher } \\
\text { KW Töpfe } \\
\text { ROW-Lampen } \\
\\
\text { LRC 1 BS mit Stempel } \\
\text { (figürlich, Hayes III) }\end{array}$ & - \\
\hline $\begin{array}{l}\text { Logeion } \\
\text { S 4/2005 } \\
\text { KiNr. } 39\end{array}$ & SE L81a & 26 & $\begin{array}{l}\text { vereinzelt frühkaiser- } \\
\text { zeitliche Residuals }\end{array}$ & flavisch-trajanisch & $\begin{array}{l}\text { ESB Atlante } 60 \\
\text { ESB Atlante } 58 \\
\text { ESB Atlante } 70 \\
\text { ESB Atlante } 22 \\
\text { ESC } \\
\text { DWK Becher mit Trichterrand } \\
\text { KW Töpfe } \\
\text { ROW-Lampen }\end{array}$ & - \\
\hline $\begin{array}{l}\text { Logeion } \\
\text { S 4/2005 }\end{array}$ & SE L81b & - & - & - & - & - \\
\hline
\end{tabular}




\begin{tabular}{|c|c|c|c|c|c|c|}
\hline $\begin{array}{l}\text { Fläche, } \\
\text { KiNr. }\end{array}$ & Stratum & $\begin{array}{l}\text { Anzahl } \\
\text { diagnost. } \\
\text { Funde }\end{array}$ & $\begin{array}{l}\text { Charakterisierung } \\
\text { Fundkomplex }\end{array}$ & Datierung & $\begin{array}{l}\text { Datierungskriterien: } \\
\text { jüngste Keramik (u. Glas) }\end{array}$ & $\begin{array}{l}\text { Münzen } \\
\text { (Kap. 8) }\end{array}$ \\
\hline $\begin{array}{l}\text { Logeion } \\
\text { S } 4 / 2005 \\
\text { KiNr. } 46\end{array}$ & SE L83 & 5 & $\begin{array}{l}\text { sehr kleiner Fundkomplex } \\
\text { heterogen }\end{array}$ & $\begin{array}{l}\text { 1. Jh. v. Chr.-1. } \\
\text { H. 2. Jh. n. Chr. }\end{array}$ & $\begin{array}{l}\text { ESA Atlante 4B } \\
\text { ESB } 2 \text { Atlante 60, spät }\end{array}$ & - \\
\hline $\begin{array}{l}\text { Logeion } \\
\text { S 4/2005 } \\
\text { KiNr. } 52\end{array}$ & SE L84 & 9 & homogen & $\begin{array}{l}\text { 1. Jh. v. Chr.-frü- } \\
\text { hes } 1 \text {. Jh. n. Chr. }\end{array}$ & $\begin{array}{l}\text { Firnisware-Teller mit beidseitig } \\
\text { verdicktem Rand } \\
\text { pompejanisch-rote Platte } \\
\text { weißgrundige Keramik } \\
\text { KW Töpfe } \\
\text { Ephesoslampe }\end{array}$ & - \\
\hline $\begin{array}{l}\text { Logeion } \\
\text { S } 4 / 2005 \\
\text { KiNr. } 62 . \\
65\end{array}$ & SE L85 & 8 & kleiner Fundkomplex & $\begin{array}{l}\text { 1. Jh. v. Chr.-frü- } \\
\text { hes } 1 . \text { Jh. n. Chr. }\end{array}$ & $\begin{array}{l}\text { ESA Atlante } 3 \\
\text { ESA Atlante 4B } \\
\text { ESA Atlante 12 } \\
\text { ESB Krug ESB } 1 \\
\text { Firnisware-Becher } \\
\text { Amphore } \\
\text { Ephesoslampe }\end{array}$ & - \\
\hline $\begin{array}{l}\text { Logeion } \\
\text { S 4/2005 } \\
\text { KiNr. } 66\end{array}$ & SE L86 & 2 & $\begin{array}{l}\text { sehr kleiner Fundkomplex } \\
\text { insignifikant aufgrund } \\
\text { geringer Fundquantität }\end{array}$ & - & - & - \\
\hline $\begin{array}{l}\text { Logeion } \\
\text { S } 4 / 2005 \\
\text { KiNr. } 67 . \\
68\end{array}$ & SE L87 & 25 & homogen & 1. Jh. v. Chr. & $\begin{array}{l}\text { ESA Atlante } 3 \\
\text { GWSÜ Platten } \\
\text { Firnisware: } \\
\text { Fischteller } \\
\text { Teller } \\
\text { Schale } \\
\text { Becher } \\
\text { Amphore Peacock - Williams } 45 \\
\text { Amphorenhenkel, rhodisch } \\
\text { Amphorenhenkel, koisch } \\
\text { Glas: Becher mit geradem, leicht } \\
\text { eingebogenem Rand }\end{array}$ & - \\
\hline
\end{tabular}

Tab. 66

\subsection{FUNDE AUS DEN SONDAGEN IN DER ORCHESTRA}

Die Schichten O0-O6 aus der Sondage 3/2004 sowie O10-13 aus der Sondage 1/05 waren mangels feinchronologisch relevanter Keramikfunde - sie enthielten ausschließlich kleinteilig gebrochene Wandfragmente von Amphoren und Gebrauchskeramik - nicht näher zu datieren ${ }^{139}$. In dem kleinen Ausschnitt im Südwesten der Orchestra, der in Sondage 1/2005 erfasst wurde, können anhand des keramischen Fundmaterials lediglich Aktivitäten des ausgehenden 2. und 1. Jhs. v. Chr. (SE O17) und der augusteischen Zeit (SE O16) konstatiert werden (Tab. 67).

\footnotetext{
${ }^{139}$ Auch ein Münzfund aus SE O12 weist einen so schlechten Erhaltungszustand auf, dass er kein Datierungskriterium bildet, s. Kap. 5.2.3.
} 


\begin{tabular}{|l|l|l|l|l|l|l|}
\hline $\begin{array}{l}\text { Fläche, } \\
\text { KiNr. }\end{array}$ & Stratum & $\begin{array}{l}\text { Anzahl } \\
\text { dia- } \\
\text { gnost. } \\
\text { Funde }\end{array}$ & $\begin{array}{l}\text { Charakterisierung } \\
\text { Fundkomplex }\end{array}$ & Datierung & $\begin{array}{l}\text { Datierungskriterien: } \\
\text { jüngste Keramik (u. Glas) }\end{array}$ & $\begin{array}{l}\text { Münzen } \\
\text { (Kap. 8) }\end{array}$ \\
\hline $\begin{array}{l}\text { S 1/2005 } \\
\text { KiNr. } \\
83.87\end{array}$ & SE O16 & 35 & heterogen: & augusteisch & $\begin{array}{l}\text { ESA Atlante 2B } \\
\text { ESA, BS mit Rouletting u. Rosetten- } \\
\text { stempel } \\
\text { ESB (früh) } \\
\text { ITS (WS) } \\
\text { GWSÜ Teller } \\
\text { Desiduals (wenig) } \\
\text { Amphoren Peacock - Williams } 45 \\
\text { Ephesoslampen }\end{array}$ & - \\
\hline $\begin{array}{l}\text { S 1/2005 } \\
\text { KiNr. } \\
84.85\end{array}$ & SE O17 & 8 & $\begin{array}{l}\text { kleiner Fundkomplex } \\
\text { heterogen: } \\
\text { vereinzelt klassische } \\
\text { Residuals }\end{array}$ & $\begin{array}{l}\text { Ende 2./1. Jh. v. } \\
\text { Chr. }\end{array}$ & $\begin{array}{l}\text { ESA (WS) } \\
\text { Reliefbecher } \\
\text { Ephesoslampen }\end{array}$ & $\begin{array}{l}\text { - } \\
\end{array}$ \\
\hline
\end{tabular}

Tab. 67

\subsection{FUNDE AUS DEN SONDAGEN IM AUDITORIUM}

\subsubsection{Unteres Diazoma}

Aufgrund der geringen Fundquantität aus den Sondagen im unteren Diazoma sind nur begrenzt Aussagen über die Chronologie dieses Bereichs des Auditorium möglich ${ }^{140}$.

Die Erdverfüllung SE D31 (Tab. 69) enthält einen spätantiken Kochtopfrand, der allerdings sekundär in die aufgrund des keramischen Fundmaterials der frühen Kaiserzeit zuzuordnende Schicht gelangt sein dürfte. Die Keramikfunde aus den Straten SE D29 und SE D32 (Tab. 10) sind innerhalb der hellenistischen Zeit und der Kaiserzeit nicht näher einzuordnen. Dasselbe gilt für SE D25 und SE D26 (Tab. 69). Eine (Nach-)Nutzung im 5./6. Jh. n. Chr. ist über SE D27 (Tab. 68) nachzuweisen. Dies legen ein Bodenfragment eines LRC-Tellers der Form Hayes $3^{141}$ und zwei geschlossene Amphorenknäufe des Typs LRA $3^{142}$ aus dieser Schicht nahe.

\section{Sondage 6/2006}

\begin{tabular}{|l|l|l|l|l|l|l|}
\hline $\begin{array}{l}\text { Fläche, } \\
\text { KiNr. }\end{array}$ & Stratum & $\begin{array}{l}\text { Anzahl } \\
\text { diagnost. } \\
\text { Funde }\end{array}$ & $\begin{array}{l}\text { Charakterisierung } \\
\text { Fundkomplex }\end{array}$ & Datierung & $\begin{array}{l}\text { Datierungskriterien: } \\
\text { jüngste Keramik (u. Glas) }\end{array}$ & $\begin{array}{l}\text { Münzen } \\
\text { (Kap. 8) }\end{array}$ \\
\hline $\begin{array}{l}\text { S 6/2006 } \\
\text { KiNr. 22 }\end{array}$ & SE D27 & 11 & homogen & 5./6. Jh. n. Chr. & $\begin{array}{l}\text { LRC Hayes 3 } \\
\text { KW Topf } \\
\text { Amphoren LRA 3 }\end{array}$ & - \\
\hline $\begin{array}{l}\text { S 6/2006 } \\
\text { KiNr. 27 }\end{array}$ & SE D29 & 2 & $\begin{array}{l}\text { insignifikant aufgrund } \\
\text { geringer Fundquantität }\end{array}$ & $\begin{array}{l}\text { späthellenistisch- } \\
\text { kaiserzeitlich }\end{array}$ & $\begin{array}{l}\text { Echinusschale } \\
\text { Thymiaterion }\end{array}$ & - \\
\hline $\begin{array}{l}\text { S 6/2006 } \\
\text { KiNr. 41 }\end{array}$ & SE D32 & 7 & $\begin{array}{l}\text { kleiner Fundkomplex } \\
\text { heterogen: } \\
\text { hellenistische Residuals } \\
\text { keine feinchronologisch } \\
\text { relevanten Funde }\end{array}$ & kaiserzeitlich & $\begin{array}{l}\text { Thymiaterion } \\
\text { Amphoren }\end{array}$ & - \\
\hline
\end{tabular}

Tab. 68

\footnotetext{
${ }^{140}$ In den Sondagen S 2/2006-S 5/2006 fehlen feinchronologisch aussagekräftige Keramikfunde zur Gänze, s. Kap. 3.4.1.1-3.4.1.4.

${ }^{141}$ Hayes 1972, 329-338; LAdSTÄTter - SaUer 2005, 149 f.

${ }^{142}$ LAdSTÄTter 2008, 180-182; BEZECZKKy 2005, 204.
} 
Sondage 7/2006

\begin{tabular}{|c|c|c|c|c|c|c|}
\hline $\begin{array}{l}\text { Fläche, } \\
\text { KiNr. }\end{array}$ & Stratum & $\begin{array}{l}\text { Anzahl } \\
\text { diagnost. } \\
\text { Funde }\end{array}$ & $\begin{array}{l}\text { Charakterisierung } \\
\text { Fundkomplex }\end{array}$ & Datierung & $\begin{array}{l}\text { Datierungskriterien: } \\
\text { jüngste Keramik (u. Glas) }\end{array}$ & $\begin{array}{l}\text { Münzen } \\
\text { (Kap. 8) }\end{array}$ \\
\hline $\begin{array}{l}\text { S 8/2006, } \\
\text { KiNr. } 32 . \\
36\end{array}$ & SE D31 & 32 & $\begin{array}{l}\text { heterogen } \\
\text { (vor)hellenistische Re- } \\
\text { siduals (z. B. Lampen- } \\
\text { schnauze) } \\
1 \text { RS KW Topf spätantik- } \\
\text { frühbyzantinisch (sekun- } \\
\text { däre Kontamination) }\end{array}$ & $\begin{array}{l}\text { frühe Kaiserzeit } \\
\\
\text { spätantik- } \\
\text { frühbyzantinisch }\end{array}$ & $\begin{array}{l}\text { ESB Atlante } 6 \\
\text { ESA Atlante 2A } \\
\text { Echinusschale } \\
\text { DWK Becher } \\
\text { KW Töpfe } \\
\text { Amphore mit Mushroom-rim } \\
\text { Amphore mit verdickter Lippe } \\
\text { Glas: Becher/Krug mit einfachem } \\
\text { gerundetem Rand (CzURDA-RUTH } \\
\text { 2007, Kap. 15b.) } \\
\text { KW Topf }\end{array}$ & - \\
\hline
\end{tabular}

Tab. 69

\subsubsection{Mittleres Diazoma}

Das bei den Grabungen im Jahr 2008 im mittleren Diazoma geborgene Fundmaterial ist ausnahmslos kleinteilig gebrochen. Es handelt sich meist um sehr kleine bis kleine Fundkomplexe. In manchen Straten war kein oder feinchronologisch nicht aussagekräftiges diagnostisches Fundmaterial vorhanden, einige Fundkomplexe sind rezent gestört. Das früheste Fundmaterial jedoch stammt aus einem homogenen Fundkomplex des 3./2. Jhs. v. Chr. (SE 115 Tab. 74). Keramisches Fundmaterial aus dem 1. Jh. v. Chr. (SE 50. 74 Tab. 70) bis in das frühe/mittlere 1. Jh. n. Chr. ist in den Straten SE 51, 73 (Tab. 70), SE 87, 89, 90 (Tab. 71) und SE 101? (Tab. 73) belegt. SE 52 (Tab. 70) enthielt Keramikfunde des 3. Viertels des 1. Jhs. n. Chr. bis in die 1. Hälfte des 2. Jhs n. Chr., ebenso SE 96 (Tab. 72). In zwei Straten, SE 75 (Tab. 70) und SE 86 (Tab. 71), wurde schließlich Keramik aus dem 5. und 6. Jh. n. Chr. entsorgt.

\section{Sondage 1/2008}

\begin{tabular}{|c|c|c|c|c|c|c|}
\hline $\begin{array}{l}\text { Fläche, } \\
\text { KiNr. }\end{array}$ & Stratum & $\begin{array}{l}\text { Anzahl } \\
\text { diagnost. } \\
\text { Funde }\end{array}$ & $\begin{array}{l}\text { Charakterisierung } \\
\text { Fundkomplex }\end{array}$ & Datierung & $\begin{array}{l}\text { Datierungskriterien: } \\
\text { jüngste Keramik (u. Glas) }\end{array}$ & $\begin{array}{l}\text { Münzen } \\
\text { (Kap. 8) }\end{array}$ \\
\hline $\begin{array}{l}\text { S } 1 / 2008 \\
\text { KiNr. } 2\end{array}$ & SE 48 & 6 & kleiner Fundkomplex & 2.-3. Jh. n. Chr. & $\begin{array}{l}\text { ESC Hayes } 4 \\
\text { ESC Atlante L19 } \\
\text { ESB Atlante 60, spät } \\
\text { ESB Atlante 76A }\end{array}$ & - \\
\hline $\begin{array}{l}\text { S } 1 / 2008 \\
\text { KiNr. } 5\end{array}$ & SE 50 & 3 & $\begin{array}{l}\text { sehr kleiner Fundkomplex } \\
\text { insignifikant aufgrund } \\
\text { geringer Fundquantität }\end{array}$ & 1. Jh. v. Chr. & $\begin{array}{l}\text { DWK Becher } \\
\text { Ephesoslampe }\end{array}$ & - \\
\hline $\begin{array}{l}\text { S } 1 / 2008 \\
\text { KiNr. }\end{array}$ & SE 51 & 6 & kleiner Fundkomplex & $\begin{array}{l}\text { 1. Viertel 1. Jh. } \\
\text { n. Chr. }\end{array}$ & $\begin{array}{l}\text { DWK Becher } \\
\text { Ephesoslampen } \\
\text { ROW-Lampe }\end{array}$ & - \\
\hline
\end{tabular}




\begin{tabular}{|l|l|l|l|l|l|l|}
\hline $\begin{array}{l}\text { Fläche, } \\
\text { KiNr. }\end{array}$ & Stratum & $\begin{array}{l}\text { Anzahl } \\
\text { diagnost. } \\
\text { Funde }\end{array}$ & $\begin{array}{l}\text { Charakterisierung } \\
\text { Fundkomplex }\end{array}$ & Datierung & $\begin{array}{l}\text { Datierungskriterien: } \\
\text { jüngste Keramik (u. Glas) }\end{array}$ & $\begin{array}{l}\text { Münzen } \\
\text { (Kap. 8) }\end{array}$ \\
\hline $\begin{array}{l}\text { S 1/2008, } \\
\text { KiNr. 7. } \\
16\end{array}$ & SE 52 & 8 & homogen & $\begin{array}{l}\text { 3. Viertel 1. Jh.-1. } \\
\text { Hälfte 2. Jh. n. } \\
\text { Chr. }\end{array}$ & $\begin{array}{l}\text { ESC } \\
\text { ESB Atlante 70 } \\
\text { Pontische Sigillata } \\
\text { DWK Becher }\end{array}$ & - \\
\hline $\begin{array}{l}\text { S 1/2008 } \\
\text { KiNr. 9. } \\
19\end{array}$ & SE 73 & 57 & $\begin{array}{l}\text { homogen } \\
\text { viel GK, späthelleni- } \\
\text { stisch-frühkaiserzeitlich } \\
\text { 6 Fragmente Ephesoslam- } \\
\text { pen }\end{array}$ & $\begin{array}{l}\text { 1. Jh. v. Chr--frü- } \\
\text { hes 1. Jh. n. Chr. }\end{array}$ & $\begin{array}{l}\text { ESB Atlante 8 } \\
\text { ESA Atlante 3 } \\
\text { DWK Becher } \\
\text { KW Töpfe } \\
\text { Amphore Peacock - Williams 45 } \\
\text { Ephesoslampen } \\
\text { Volutenschnauzenlampe }\end{array}$ & - \\
\hline $\begin{array}{l}\text { S 1/2008 } \\
\text { KiNr. 10 }\end{array}$ & SE 74 & 19 & $\begin{array}{l}\text { homogen } \\
\text { eine vollständig erhaltene } \\
\text { Ephesoslampe }\end{array}$ & $\begin{array}{l}\text { 2. H. 1. Jh. v. Chr. } \\
\text { insignifikant aufgrund } \\
\text { geringer Fundquantität }\end{array}$ & $\begin{array}{l}\text { ESA Atlante 3 } \\
\text { Amphore Peacock - Williams 45 } \\
\text { Ephesoslampen }\end{array}$ & - \\
\hline $\begin{array}{l}\text { S 1/2008 } \\
\text { KiNr. 21 }\end{array}$ & SE 75 & 1 & & $\begin{array}{l}\text { 6. Jh. Chr. } \\
\text { KW Topf }\end{array}$ & \\
\hline
\end{tabular}

Tab. 70

\section{Sondage $\mathbf{5 / 2 0 0 8}$}

\begin{tabular}{|l|l|l|l|l|l|l|}
\hline $\begin{array}{l}\text { Fläche, } \\
\text { KiNr. }\end{array}$ & Stratum & $\begin{array}{l}\text { Anzahl } \\
\text { diagnost. } \\
\text { Funde }\end{array}$ & $\begin{array}{l}\text { Charakterisierung } \\
\text { Fundkomplex }\end{array}$ & Datierung & $\begin{array}{l}\text { Datierungskriterien: } \\
\text { jüngste Keramik (u. Glas) }\end{array}$ & $\begin{array}{l}\text { Münzen } \\
\text { (Kap. 8) }\end{array}$ \\
\hline $\begin{array}{l}\text { S 5/2008 } \\
\text { KiNr. 12 }\end{array}$ & SE 85 & 16 & homogen & 1. Jh. v. Chr. & $\begin{array}{l}\text { ESA Atlante 4 } \\
\text { GK Krug } \\
\text { KW Topf } \\
\text { Ephesoslampen }\end{array}$ & - \\
\hline $\begin{array}{l}\text { S 5/2008 } \\
\text { KiNr. 11 }\end{array}$ & SE 87 & 9 & heterogen & $\begin{array}{l}\text { (1. H.) 1. Jh. n. } \\
\text { Chr. }\end{array}$ & $\begin{array}{l}\text { ESB Atlante 5 } \\
\text { ESA Atlante 26 } \\
\text { DWK Becher }\end{array}$ & - \\
\hline $\begin{array}{l}\text { S 5/2008 } \\
\text { KiNr. 18 }\end{array}$ & SE 89 & 14 & homogen & frühe Kaiserzeit & $\begin{array}{l}\text { ESA Atlante 28 } \\
\text { Firnisware-Teller }\end{array}$ & - \\
\hline
\end{tabular}

Tab. 71

\section{Sondage 4/2008}

\begin{tabular}{|l|l|l|l|l|l|l|}
\hline $\begin{array}{l}\text { Fläche, } \\
\text { KiNr. }\end{array}$ & Stratum & $\begin{array}{l}\text { Anzahl } \\
\text { diagnost. } \\
\text { Funde }\end{array}$ & $\begin{array}{l}\text { Charakterisierung } \\
\text { Fundkomplex }\end{array}$ & Datierung & $\begin{array}{l}\text { Datierungskriterien: } \\
\text { jüngste Keramik (u. Glas) }\end{array}$ & $\begin{array}{l}\text { Münzen } \\
\text { (Kap. 8) }\end{array}$ \\
\hline $\begin{array}{l}\text { S 4/2008 } \\
\text { KiNr. 23 }\end{array}$ & SE 96 & 11 & heterogen & 1. H. 2. Jh. n. Chr. & $\begin{array}{l}\text { ESB Atlante } 80 \\
\text { DWK Becher } \\
\text { KW }\end{array}$ & - \\
\hline $\begin{array}{l}\text { S 4/2008 } \\
\text { KiNr. }\end{array}$ & SE 97 & 8 & $\begin{array}{l}\text { kleiner Fundkomplex } \\
\text { keine feinchronologisch } \\
\text { relevanten Funde }\end{array}$ & kaiserzeitlich & DWK Becher & - \\
\hline
\end{tabular}

Tab. 72 
Sondage $3 / 2008$

\begin{tabular}{|l|l|l|l|l|l|l|}
\hline $\begin{array}{l}\text { Fläche, } \\
\text { KiNr. }\end{array}$ & Stratum & $\begin{array}{l}\text { Anzahl } \\
\text { diagnost. } \\
\text { Funde }\end{array}$ & $\begin{array}{l}\text { Charakterisierung } \\
\text { Fundkomplex }\end{array}$ & Datierung & $\begin{array}{l}\text { Datierungskriterien: } \\
\text { jüngste Keramik (u. Glas) }\end{array}$ & $\begin{array}{l}\text { Münzen } \\
\text { (Kap. 8) }\end{array}$ \\
\hline $\begin{array}{l}\text { S 3/2008 } \\
\text { KiNr. 24 }\end{array}$ & SE 101 & 13 & $\begin{array}{l}\text { stark verwaschen } \\
\text { keine feinchronologisch } \\
\text { relevanten Funde }\end{array}$ & $\begin{array}{l}\text { 1. Jh. v. Chr.- } \\
\text { 1. Jh. n. Chr. (?) }\end{array}$ & $\begin{array}{l}\text { KW Topf } \\
\text { GK Schüssel }\end{array}$ & - \\
\hline
\end{tabular}

Tab. 73

Sondage $2 / 2008$

\begin{tabular}{|l|l|l|l|l|l|l|}
\hline $\begin{array}{l}\text { Fläche, } \\
\text { KiNr. }\end{array}$ & Stratum & $\begin{array}{l}\text { Anzahl } \\
\text { diagnost. } \\
\text { Funde }\end{array}$ & $\begin{array}{l}\text { Charakterisierung } \\
\text { Fundkomplex }\end{array}$ & Datierung & $\begin{array}{l}\text { Datierungskriterien: jüngste } \\
\text { Keramik (u. Glas) }\end{array}$ & $\begin{array}{l}\text { Münzen } \\
\text { (Kap. 8) }\end{array}$ \\
\hline $\begin{array}{l}\text { S 4/2008 } \\
\text { KiNr. 23 }\end{array}$ & SE 96 & 11 & heterogen & 1. H. 2. Jh. n. Chr. & $\begin{array}{l}\text { ESB Atlante } 80 \\
\text { DWK Becher } \\
\text { KW }\end{array}$ & - \\
\hline $\begin{array}{l}\text { S 4/2008 } \\
\text { KiNr. 24 }\end{array}$ & SE 97 & 8 & $\begin{array}{l}\text { kleiner Fundkomplex } \\
\text { keine feinchronologisch } \\
\text { relevanten Funde }\end{array}$ & kaiserzeitlich & DWK Becher & - \\
\hline
\end{tabular}

Tab. 74

\subsubsection{Oberes Diazoma}

Im Bereich des dritten Diazoma, das in Sondage 6/2008 untersucht wurde, dokumentieren SE 85, 107, 111 und SE 112 Aktivitäten im 2./1. Jh. v. Chr. und in der frühen Kaiserzeit (Tab. 75). Es ist ein hoher Anteil an spätgeometrischen bis archaischen Residuals gegeben ${ }^{143}$. SE 113 ist gänzlich der vorhellenistischen Zeit zuzuordnen, während es sich bei SE 119 um ein mit Fundmaterial aus der archaischen bis spätantiken Zeit durchmischtes Stratum handelt, das zusätzlich rezent gestört ist. Für die Chronologie des Theaters sind die letztgenannten Straten nicht von unmittelbarer Relevanz ${ }^{144}$.

\section{Sondage S 6/2008 und Sondage S 8/2008}

\begin{tabular}{|l|l|l|l|l|l|l|}
\hline $\begin{array}{l}\text { Fläche, } \\
\text { KiNr. }\end{array}$ & Stratum & $\begin{array}{l}\text { Anzahl } \\
\text { diagnost. } \\
\text { Funde }\end{array}$ & $\begin{array}{l}\text { Charakterisierung } \\
\text { Fundkomplex }\end{array}$ & Datierung & $\begin{array}{l}\text { Datierungskriterien: jüngste } \\
\text { Keramik (u. Glas) }\end{array}$ & $\begin{array}{l}\text { Münzen } \\
\text { (Kap. 8) }\end{array}$ \\
\hline $\begin{array}{l}\text { S 6/2008 } \\
\text { KiNr. 26 }\end{array}$ & SE 107 & 98 & $\begin{array}{l}\text { heterogen: } \\
\text { spätgeometrisch-archa- } \\
\text { isch/späthellenistisch }\end{array}$ & 2./1. Jh. v. Chr. & $\begin{array}{l}\text { Reliefbecher } \\
\text { weißgrundige Lagynos }\end{array}$ & - \\
\hline $\begin{array}{l}\text { S 6/2008 } \\
\text { KiNr. 28 }\end{array}$ & SE 111 & 26 & $\begin{array}{l}\text { heterogen: } \\
\text { spätgeometrisch-archa- } \\
\text { isch/späthellenistisch }\end{array}$ & $\begin{array}{l}\text { hellenistisch- } \\
\text { frühkaiserzeitl. }\end{array}$ & Reliefbecher & - \\
\hline
\end{tabular}

\footnotetext{
${ }^{143}$ Eine Übersicht der archaischen Residuals in von MilLER (in Druck), Tab. 9.

${ }^{144}$ Vgl. die Situation in den Auffüllungen der Kammern D3 und D8 (Kap. 4.1.1.3).
} 


\begin{tabular}{|l|l|l|l|l|l|l|}
\hline $\begin{array}{l}\text { Fläche, } \\
\text { KiNr. }\end{array}$ & Stratum & $\begin{array}{l}\text { Anzahl } \\
\text { diagnost. } \\
\text { Funde }\end{array}$ & $\begin{array}{l}\text { Charakterisierung } \\
\text { Fundkomplex }\end{array}$ & Datierung & $\begin{array}{l}\text { Datierungskriterien: jüngste } \\
\text { Keramik (u. Glas) }\end{array}$ & $\begin{array}{l}\text { Münzen } \\
\text { (Kap. 8) }\end{array}$ \\
\hline $\begin{array}{l}\text { S 6/2008 } \\
\text { KiNr. 29 }\end{array}$ & SE 112 & 9 & kleiner Fundkomplex & frühe Kaiserzeit? & $\begin{array}{l}\text { DWK Becher } \\
\text { GWSÜ Platte } \\
\text { GK Krug } \\
\text { GK Becher }\end{array}$ & - \\
\hline $\begin{array}{l}\text { S 6/2008 } \\
\text { KiNr. 30 }\end{array}$ & SE 113 & 23 & - & vorhellenistisch & - & - \\
\hline $\begin{array}{l}\text { S 8/2008 } \\
\text { KiNr. 31 }\end{array}$ & SE 119 & 48 & $\begin{array}{l}\text { rezent gestört (lt. Fund- } \\
\text { zettel) } \\
\text { archaisch/klassisch/spät- } \\
\text { hellenistisch-kaiserzeit- } \\
\text { lich/spätantik durchmischt }\end{array}$ & $\begin{array}{l}\text { archaisch/ } \\
\text { spätantik }\end{array}$ & - & - \\
\hline
\end{tabular}

Tab. 75

\subsection{FUNDE AUS DEN SONDAGEN IM NORDFLÜGEL DES THEATERS}

\subsubsection{Funde aus dem Zugangssystem EN1}

\subsubsection{EN1, NÖRDLICHER BEREICH}

\begin{tabular}{|c|c|c|c|c|c|c|}
\hline $\begin{array}{l}\text { Fläche, } \\
\text { KiNr. }\end{array}$ & Stratum & $\begin{array}{l}\text { Anzahl } \\
\text { diagnost. } \\
\text { Funde }\end{array}$ & $\begin{array}{l}\text { Charakterisierung } \\
\text { Fundkomplex }\end{array}$ & Datierung & $\begin{array}{l}\text { Datierungskriterien: } \\
\text { jüngste Keramik (u. Glas) }\end{array}$ & $\begin{array}{l}\text { Münzen } \\
\text { (Kap. 8) }\end{array}$ \\
\hline $\begin{array}{l}\text { EN1 } \\
\text { nördlich } \\
(1998) \\
\text { KiNr. } 40\end{array}$ & SE N 1 & 27 & $\begin{array}{l}\text { heterogen } \\
\text { vereinzelt späthellenisti- } \\
\text { sche Residuals, Großteil } \\
\text { des Fundmaterials kaiser- } \\
\text { zeitlich, vereinzelt 5./6. } \\
\text { Jh. n. Chr. }\end{array}$ & 6. Jh. n. Chr. & $\begin{array}{l}\text { KW Topf } \\
\text { KW Pfannengriff } \\
\text { Glas: Kelchfuß mit hohlem Rand } \\
\text { (CZURDA-RUTH 2007, Kap. 26.) }\end{array}$ & $\begin{array}{l}\text { M } 241 \\
\text { M } 116\end{array}$ \\
\hline $\begin{array}{l}\text { EN1 } \\
\text { nördlich } \\
\text { (1998) } \\
\text { KiNr. } 12\end{array}$ & SE N 3 & 21 & $\begin{array}{l}\text { heterogen } \\
\text { kaiserzeitlich-6. Jh. n. } \\
\text { Chr. }\end{array}$ & $\begin{array}{l}\text { (spätes) 6. Jh. n. } \\
\text { Chr. }\end{array}$ & $\begin{array}{l}\text { ERSW LRC Hayes } 3 \\
\text { ERSW LRC Hayes } 5 \\
\text { LRA } 3\end{array}$ & $\begin{array}{l}\text { M } 78 \\
\text { M } 241\end{array}$ \\
\hline $\begin{array}{l}\text { EN1 } \\
\text { nördlich } \\
(1998) \\
\text { KiNr. } 15 . \\
16.19\end{array}$ & SE N 3? & 80 & $\begin{array}{l}\text { heterogen } \\
\text { späthellenistisch-kaiser- } \\
\text { zeitliche Residuals }\end{array}$ & 6. Jh. n. Chr. & $\begin{array}{l}\text { ARS Hayes 104A } \\
\text { LRC Hayes 3F } \\
\text { ERSW LRC Hayes } 5 \\
\text { frühbyzantinische Ampulle } \\
\text { LRA } 3\end{array}$ & \\
\hline $\begin{array}{l}\text { EN1 } \\
\text { nördlich } \\
(1998), \\
\text { KiNr. } 20\end{array}$ & $\begin{array}{l}\text { SE N } 4= \\
\text { SE N } 11\end{array}$ & 5 & $\begin{array}{l}\text { homogen (Angabe nur lt. } \\
\text { FJ Turnovsky) }\end{array}$ & 6. Jh. n. Chr. & $\begin{array}{l}\text { KW Topf } \\
\text { Amphore Peacock - Williams } 43 \\
\text { Lampe (?) }\end{array}$ & \\
\hline
\end{tabular}

Tab. 76

Im nördlichen Bereich von EN1 (Tab. 76) konnten Fundkomplexe nachgewiesen werden, die allesamt mit der Zeit nach einer Umbauphase und Umwandlung des Korridors in ein Wasserbecken in Verbindung zu 
bringen sind ${ }^{145}$. Die Versturzschicht SE N1 sowie die über dem Ziegelbecken des Wasserbeckens im nördlichen Bereich des Zugangskorridors EN1 befindlichen zusammengehörigen Straten SE N3 und SE N4 können aufgrund der bisweilen umfangreichen - wenn auch heterogenen - keramischen Fundkomplexe und einer Münze ${ }^{146}$ in das (späte) 6. Jh. n. Chr. datiert werden. Vertreten sind u. a. spezifische Formen der LRC ${ }^{147}$ und deren Imitationen in ERSW ${ }^{148}$, außerdem ein Teller der ARS, welcher der Form Hayes 104A zuzuweisen ist ${ }^{149}$, sowie eine frühbyzantinische Ampulle ${ }^{150}$ (SE N3?), Kochgeschirr ${ }^{151}$ und Amphoren vom Typ LRA $3^{152}$.

\subsubsection{EN1, SÜDLICHER BEREICH}

In der Südostecke des Beckens im Nordkorridor ${ }^{153}$ konnte in der Versturzschicht SE N10 ein heterogener keramischer Fundkomplex geborgen werden, dessen jüngste Funde in das 2. Jh. n. Chr. weisen (Tab. 77). Aus der darunterliegenden lehmigen Schicht SE N11 stammen Funde, die möglicherweise einen späteren terminus post quem geben, allerdings handelt es sich um einen sehr kleinen Fundkomplex, dessen Einzelkomponenten nicht eindeutig zu datieren sind. Insgesamt ist aufgrund der analogen Stratigrafie zum nördlichen Bereich von EN1 ohnehin davon auszugehen, dass es sich bei beiden Fundkomplexen um umgelagertes Material handelt und die nicht näher zu differenzierenden Schuttschichten mit teils großen Teilen des eingestürzten Korridorgewölbes in das 6. und frühe 7. Jh. n. Chr zu datieren sind ${ }^{154}$.

\begin{tabular}{|l|l|l|l|l|l|l|}
\hline $\begin{array}{l}\text { Fläche, } \\
\text { KiNr. }\end{array}$ & Stratum & $\begin{array}{l}\text { Anzahl } \\
\text { diagnost. } \\
\text { Funde }\end{array}$ & $\begin{array}{l}\text { Charakterisierung Fund- } \\
\text { komplex }\end{array}$ & Datierung & $\begin{array}{l}\text { Datierungskriterien: } \\
\text { jüngste Keramik (u. Glas) }\end{array}$ & $\begin{array}{l}\text { Münzen } \\
\text { (Kap. 8) }\end{array}$ \\
\hline $\begin{array}{l}\text { EN1 } \\
\text { nördlich } \\
\begin{array}{l}1998) \\
\text { KiNr. } 31\end{array}\end{array}$ & $\begin{array}{l}\text { SE N10 } \\
\text { = SE N1 }\end{array}$ & 18 & $\begin{array}{l}\text { heterogen } \\
\text { späthellenistische Residuals } \\
\text { tw. versintert } \\
\text { ROW Lampe fast vollstän- } \\
\text { dig erhalten }\end{array}$ & 2. Jh. n. Chr. & $\begin{array}{l}\text { ESC WS } \\
\text { ESB Atlante 14 } \\
\text { ROW-Lampe }\end{array}$ & - \\
\hline $\begin{array}{l}\text { EN1 } \\
\text { nördlich } \\
\begin{array}{l}\text { 1998 }) \\
\text { KiNr. 32 }\end{array}\end{array}$ & $\begin{array}{l}\text { SE N11 } \\
\text { SE N4 }\end{array}$ & 4 & sehr kleiner Fundkomplex & (späte) Kaiserzeit & $\begin{array}{l}\text { DWK Becher } \\
\text { KW Pfanne }\end{array}$ & - \\
4.-7. Jh. n. Chr.? & $\begin{array}{l}\text { Amphore LRA 1? (1 } \\
\text { WS Peacock - Williams 44, } \\
\text { Angabe nur lt. FJ Turnovsky) }\end{array}$ & \\
\hline
\end{tabular}

Tab. 77

\subsubsection{KAMMER KN1}

Im Verfüllungsschutt der Nordkammer 1 (KN1) kann keramisches Fundmaterial von der Kaiserzeit (SE N13) bis in das 5. Jh. n. Chr. (SE N15) nachgewiesen werden (Tab. 78). Hervorzuheben ist SE N15, die umfangreiches Fundmaterial enthielt, allerdings keine ganz erhaltenen Gefäße. Die jüngsten Funde - hauptsächlich Kochtöpfe, eine Amphore und Lampen - sind dem ausgehenden 4. und 5. Jh. n. Chr. zuzuordnen. Es sind

\footnotetext{
${ }^{145}$ Zur Auswertung der Grabungsbefunde s. Kap. 3.5.1.1.

${ }^{146}$ M 241 Taf. 359 (Kap. 5.2).

147 Vgl. LADSTÄTter - SAuer 2005, 144-152.

$148 \mathrm{Zu}$ Definition, Formen- und Dekorspektrum der ERSW s. LADSTÄTTER - SAUER 2005, 152-154.

149 Hayes 1972, 162.

${ }^{150}$ Metaxas 2005.

${ }^{151}$ LAdSTÄTter 2008, 186-189.

152 BeZECZKY 2005, 204; LAdSTÄtTer 2008, 180-182.

${ }^{153}$ Zum Befund s. Kap. 3.5.1.2.

${ }^{154}$ Kap. 3.5.1.2.
} 
in demselben insgesamt als heterogen zu bezeichnenden Fundkomplex aber auch spezifische Sigillatagefäße des 3. Jhs. n. Chr. vorhanden, die gut vergleichbar sind mit jenen aus den Erdbeben-Zerstörungsschichten aus dem Hanghaus $2^{155}$. Dieses Phänomen - also die Vergesellschaftung von bisweilen gut erhaltenen Gefäßen aus Inventaren, die vermutlich bei dem schweren Erdbeben im 3. Viertel des 3. Jhs. n. Chr. zerstört wurden, mit Material aus dem späten 4. bis 6. Jh. n. Chr. kann sowohl in den Südkammern KS1 bis KS3 ${ }^{156}$ als auch in den Verfüllschichten im Süden über der Freitreppe ${ }^{157}$ beobachtet werden. Die Münzreihe aus SE N15 endet in der 2. Hälfte des 4. Jhs. n. Chr. ${ }^{158}$.

\begin{tabular}{|c|c|c|c|c|c|c|}
\hline $\begin{array}{l}\text { Fläche, } \\
\text { KiNr. }\end{array}$ & Stratum & \begin{tabular}{|l} 
Anzahl \\
diagnost. \\
Funde
\end{tabular} & $\begin{array}{l}\text { Charakterisierung } \\
\text { Fundkomplex }\end{array}$ & Datierung & $\begin{array}{l}\text { Datierungskriterien: } \\
\text { jüngste Keramik (u. Glas) }\end{array}$ & $\begin{array}{l}\text { Münzen } \\
\text { (Kap. 8) }\end{array}$ \\
\hline $\begin{array}{l}\text { KN } 1 \\
(1998) \\
\text { KiNr. } 2\end{array}$ & SE N13? & 5 & $\begin{array}{l}\text { kleiner Fundkomplex } \\
\text { keine feinchronologisch } \\
\text { relevanten Funde } \\
1 \text { GK-Deckel zu } 3 / 4 \text { er- } \\
\text { halten }\end{array}$ & - & - & - \\
\hline $\begin{array}{l}\text { KN 1 } \\
(1998) \\
\text { KiNr. } 4 . \\
4 a\end{array}$ & SE N14 & 2 & $\begin{array}{l}\text { insignifikant aufgrund } \\
\text { geringer Fundquantität }\end{array}$ & 3./4. Jh. n. Chr. & ARS WS & - \\
\hline $\begin{array}{l}\text { KN 1 } \\
\text { (1997) } \\
\text { KiNr. } 5 . \\
\text { 5a. 5b. } \\
\text { 5c. 6. 6a. } \\
\text { 6b }\end{array}$ & SE N15 & 143 & $\begin{array}{l}\text { heterogen } \\
\text { hellenistisch-spätantik } \\
\text { viel Material 3./4. Jh. n. } \\
\text { Chr.: ähnlich Zerstörungs- } \\
\text { Fundkomplexe im HH2 }\end{array}$ & $\begin{array}{l}\text { 3. Viertel 3. Jh. } \\
\text { n Chr. } \\
\\
\text { Ende 4.-Mitte } 5 . \\
\text { Jh. n. Chr. }\end{array}$ & $\begin{array}{l}\text { ARS Hayes 50A } \\
\text { ARS Hayes 48B } \\
\text { ESC Hayes } 3 \\
\text { ESC Hayes } 4 \\
\text { ESC Atlante L26A } \\
\text { ESC Atlante L26B } \\
\text { ESC Atlante L19 } \\
\text { ERSW Imitation ESC Hayes } 4 \\
\text { ESB 2: Atlante 54. Atlante 58, } \\
\text { Atlante 60, Atlante 71, Atlante 77 } \\
\text { Glas: Konischer Becher (CzURDA- } \\
\text { RuTH 2007, Kap. 14. a.) } \\
\text { Becher/Teller mit echtem Stand- } \\
\text { ring (CzURDA-RUTH 2007, } \\
\text { Kap. 25. d.) } \\
\text { Becher/Schale mit tropfenför- } \\
\text { migem Standring (CzURDA-RUTH } \\
\text { 2007, 624.) } \\
\text { Fensterglas } \\
\text { ARS Hayes 50 B } \\
\text { KW Töpfe } \\
\text { KW Kasserolle } \\
\text { Amphore LRA } 3 \\
\text { Lampen }\end{array}$ & - \\
\hline
\end{tabular}

Tab. 78

\footnotetext{
${ }^{155}$ LAdSTätter 2005, 242-262 (Fundkomplexe Z/1-Z19?); LAdstätter 2010a, 193 (Fundkomplex A-Z/1-A//3); LADSTÄTtER 2010b, 535-540 (Fundkomplex B-Z/1-B-Z/15); LAdstätter 2014, 467-470 (Fundkomplexe Z/1-Z/6 u. Textabb. 6).

${ }^{156}$ Kap. 4.6.2.1-4.6.2.3.

${ }_{157}$ Kap. 4.7.

${ }^{158}$ Kap. 5.2.5.
} 


\subsubsection{EN1 West, Nördlicher Treppenaufgang}

\section{Sondage S 1/1998}

In Sondage S 1/1998 konnte nur in dem erdigen Material auf der Rollierung des Treppenunterbaus (SE N20) Keramik geborgen werden (Tab. 79). Der sehr kleine Fundkomplex dürfte in die frühe Kaiserzeit zu datieren sein.

\begin{tabular}{|l|l|l|l|l|l|l|}
\hline $\begin{array}{l}\text { Fläche, } \\
\text { KiNr. }\end{array}$ & Stratum & $\begin{array}{l}\text { Anzahl } \\
\text { diagnost. } \\
\text { Funde }\end{array}$ & $\begin{array}{l}\text { Charakterisierung } \\
\text { Fundkomplex }\end{array}$ & Datierung & $\begin{array}{l}\text { Datierungskriterien: } \\
\text { jüngste Keramik (u. Glas) }\end{array}$ & $\begin{array}{l}\text { Münzen } \\
\text { (Kap. 8) }\end{array}$ \\
\hline $\begin{array}{l}\text { S 1/1998 } \\
\text { KiNr. 1 }\end{array}$ & SE N20 & 3 & $\begin{array}{l}\text { sehr kleiner Fundkomplex } \\
\text { tw. versintert }\end{array}$ & frühe Kaiserzeit & $\begin{array}{l}\text { GK Krug } \\
\text { Ephesoslampe }\end{array}$ & - \\
\hline
\end{tabular}

Tab. 79

\section{Sondage 2/1998}

Die wenigen Keramikfunde aus dem Unterbau des Treppenabsatzes ${ }^{159}$ (SE N32. 33 Tab. 80) sind der (frühen) Kaiserzeit zuzuordnen, ebenso die jüngsten Funde aus der opus caementicium-Schicht SE N30. Die Abgrenzungsschicht zur jüngeren Bodenfundamentierung (SE N31) ist nicht näher als kaiserzeitlich zu datieren. Das restliche keramische Fundmaterial aus Sondage 2/1998 zeugt von Umbaumaßnahmen des 4. Jhs. n. Chr. (SE N29) bis in das späte 5. und 6. Jh. n. Chr. (SE N28. 30?).

\begin{tabular}{|c|c|c|c|c|c|c|}
\hline $\begin{array}{l}\text { Fläche, } \\
\text { KiNr. }\end{array}$ & Stratum & $\begin{array}{l}\text { Anzahl } \\
\text { diagnost. } \\
\text { Funde }\end{array}$ & $\begin{array}{l}\text { Charakterisierung } \\
\text { Fundkomplex }\end{array}$ & Datierung & $\begin{array}{l}\text { Datierungskriterien: } \\
\text { jüngste Keramik (u. Glas) }\end{array}$ & $\begin{array}{l}\text { Münzen } \\
\text { (Kap. 8) }\end{array}$ \\
\hline $\begin{array}{l}\text { S 2/1998 } \\
\text { KiNr. } 7\end{array}$ & SE N28 & 3 & sehr kleiner Fundkomplex & $\begin{array}{l}\text { 5.-Mitte 6. Jh. n. } \\
\text { Chr. }\end{array}$ & LRC Hayes 3E & - \\
\hline $\begin{array}{l}\text { S 2/1998 } \\
\text { KiNr. } 2\end{array}$ & SE N29 & 14 & $\begin{array}{l}\text { kleiner Fundkomplex } \\
\text { heterogen }\end{array}$ & 4. Jh. n. Chr. & $\begin{array}{l}\text { ARS Hayes 50B } \\
\text { Amphore LRA } 1\end{array}$ & M 183 \\
\hline $\begin{array}{l}\text { S } 2 / 1998 \\
\text { KiNr. } \\
3.8\end{array}$ & SE N30 & 18 & $\begin{array}{l}\text { heterogen } \\
\text { kleinteilig gebrochen } \\
\text { späthellenistisch-1. Jh. } \\
\text { n. Chr. }\end{array}$ & $\begin{array}{l}\text { (1. H.) 1. Jh. n. } \\
\text { Chr. }\end{array}$ & $\begin{array}{l}\text { ESA Atlante 22B } \\
\text { ESB } \\
\text { ITS }\end{array}$ & - \\
\hline $\begin{array}{l}\text { S } 2 / 1998 \\
\text { KiNr. } \\
\text { 4. } 6\end{array}$ & SE N31 & 10 & $\begin{array}{l}\text { kleiner Fundkomplex } \\
\text { kleinteilig gebrochen } \\
\text { feinchronologisch nicht } \\
\text { zuordenbar }\end{array}$ & $\begin{array}{l}\text { kaiserzeitlich } \\
\text { 4.-7. Jh. n. Chr.? }\end{array}$ & $\begin{array}{l}\text { Amphoren Peacock - Williams } 45 \\
\text { Amphore LRA 1? (Angabe nur } \\
\text { nach FJ Turnovsky) }\end{array}$ & - \\
\hline $\begin{array}{l}\text { S 2/1998 } \\
\text { KiNr. } 9\end{array}$ & SE N32 & 4 & sehr kleiner Fundkomplex & $\begin{array}{l}\text { (1. H.) 1. Jh. n. } \\
\text { Chr. }\end{array}$ & ESB Atlante 34 & - \\
\hline $\begin{array}{l}\text { S 2/1998 } \\
\text { KiNr. } 9\end{array}$ & SE N33 & 12 & homogen & $\begin{array}{l}\text { (1. H.) 1. Jh. n. } \\
\text { Chr. }\end{array}$ & $\begin{array}{l}\text { Soldatenbecher } \\
\text { KW Töpfe }\end{array}$ & - \\
\hline
\end{tabular}

Tab. 80

\footnotetext{
${ }^{159}$ Zur Auswertung und Interpretation der Befunde s. Kap. 3.5.1.4.
} 


\subsubsection{Funde aus dem Zugangssystem EN2}

Im Bereich des Zugangssystems EN2, das zum mittleren Diazoma führt, wurden 1998 weitere Sondagen durchgeführt ${ }^{160}$. Die keramischen Fundkomplexe aus dem Ausgangsniveau SE N34, aus dem Bereich direkt über dem Gussmauerwerk (SE N35) sowie aus den Straten des Verfüllungsschutts (SE N37/39) datieren in das späte 6. Jh. n. Chr. (Tab. 81). In der bei der Nord-Erweiterung der Sondage angetroffenen, mit Keramik heterogener Zeitstellung durchsetzten Verfüllschicht SE N40 (Tab. 82) wurden mitunter die spätesten Keramikfunde aus dem Nordbereich des Theaters geborgen, die jüngsten Funde sind dem späten 6. Jh. bis 1 . Hälfte des 7. Jhs. n. Chr. zuzurechnen. Darunter befindet sich ein Randfragment eines Tellers der sog. Mäandertalsigillata, einer feinkeramischen Ware mit hohem Glimmergehalt. Dieser lässt auf eine eventuelle Herkunft aus dem großen Mäandertal schließen, ohne dass bislang allerdings eine genauere Produktionsregion gefasst werden konnte ${ }^{161}$. Vertreten sind außerdem spezifische Kochtopfränder ${ }^{162}$ und Amphorenknäufe vom Typ LRA 3 sowie Ephesos $56^{163}$.

\section{Sondage 4/1998}

\begin{tabular}{|l|l|l|l|l|l|l|}
\hline $\begin{array}{l}\text { Fläche, } \\
\text { KiNr. }\end{array}$ & Stratum & $\begin{array}{l}\text { Anzahl } \\
\text { diagnost. } \\
\text { Funde }\end{array}$ & $\begin{array}{l}\text { Charakterisierung } \\
\text { Fundkomplex }\end{array}$ & Datierung & $\begin{array}{l}\text { Datierungskriterien: } \\
\text { jüngste Keramik (u. Glas) }\end{array}$ & $\begin{array}{l}\text { Münzen } \\
\text { (Kap. 8) }\end{array}$ \\
\hline $\begin{array}{l}\text { S 4/1998 } \\
\text { KiNr. 52 }\end{array}$ & $\begin{array}{l}\text { SE N } \\
34 / 35\end{array}$ & 37 & heterogen & 6. Jh. n. Chr. & $\begin{array}{l}\text { LRC Hayes 3 } \\
\text { ERSW Hayes 3 } \\
\text { KW Töpfe } \\
\text { Amphore LRA 3 } \\
\text { Lampen }\end{array}$ & - \\
\hline $\begin{array}{l}\text { S 4/1998 } \\
\text { KiNr. 33 }\end{array}$ & SE N35 & 5 & sehr kleiner Fundkomplex & 6. Jh. n. Chr. & $\begin{array}{l}\text { LRC Hayes 3F } \\
\text { Amphore Eph. 56 }\end{array}$ & - \\
\hline
\end{tabular}

Tab. 81

\section{Sondage 4/98, Nord-Erweiterung}

\begin{tabular}{|l|l|l|l|l|l|}
\hline $\begin{array}{l}\text { Fläche, } \\
\text { KiNr. }\end{array}$ & Stratum & $\begin{array}{l}\text { Anzahl } \\
\text { diagnost. } \\
\text { Funde }\end{array}$ & $\begin{array}{l}\text { Charakterisierung } \\
\text { Fundkomplex }\end{array}$ & Datierung & $\begin{array}{l}\text { Datierungskriterien: } \\
\text { jüngste Keramik (u. Glas) } \\
\text { (Kap. 8) }\end{array}$ \\
\hline $\begin{array}{l}\text { S 4/1998 } \\
\text { KiNr. 43 }\end{array}$ & $\begin{array}{l}\text { SE N } \\
37 / 39\end{array}$ & 20 & homogen & 6. Jh. n. Chr. & $\begin{array}{l}\text { LRC Hayes 3 } \\
\text { ERSW Hayes 3 } \\
\text { KW Töpfe } \\
\text { LRA 3 }\end{array}$ \\
\hline $\begin{array}{l}\text { S 4/1998 } \\
\text { KiNr. 45 }\end{array}$ & SE N0 & 23 & $\begin{array}{l}\text { heterogen } \\
\text { späthellenistisch bis früh- } \\
\text { byzantinisch }\end{array}$ & $\begin{array}{l}\text { Jh. n. Chr. } \\
\text { spätes 6./1. H. 7. }\end{array}$ & $\begin{array}{l}\text { Mäandertalsigillata } \\
\text { Teller } \\
\text { KW Topf } \\
\text { Amphoren LRA 3 }\end{array}$ \\
& & & & $\begin{array}{l}\text { Glas: konischer Becher mit nach } \\
\text { innen gebogenem, gerundetem Rand } \\
\text { Boden mit echtem Standring }\end{array}$ \\
\hline
\end{tabular}

Tab. 82

\footnotetext{
${ }^{160}$ Kap. 3.5.1.

161 Zur sog. Mäandertalsigillata s. Hayes 1972, 408-410; LAdSTÄtter 2008, 115; vgl. WaLdNER u. a. 2008 , 284 Kat. 72. 73; LAdSTÄTTER 2014, 471 f.; WALDNER - LADSTÄTTER 2014b, $51 \mathrm{f}$.

Waldner - Ladstätter 2014b=A. Waldner - S. Ladstätter, Ephesus - local vs import: The Early Byzantine fine ware, in: H. Meyza (Hrsg.), Late Hellenistic to mediaeval fine wares of the Aegean coast of Anatolia (Warschau 2014) 49-58.

162 Vgl. Ladstätter 2008, K 270; Turnovsky 2005b, 4 (ähnlich).

163 LADstÄtTER 2008, 180-182; BEZECZKy 2005, 204 f.
} 


\section{Sondage 5/1998}

Der keramische Fundkomplex aus dem antiken Niveau der Schuttschichten (SE N42) ${ }^{164}$ ist aufgrund der jüngsten Funde in das 6. Jh. n. Chr. zu datieren.

\begin{tabular}{|l|l|l|l|l|l|l|}
\hline $\begin{array}{l}\text { Fläche, } \\
\text { KiNr. }\end{array}$ & Stratum & $\begin{array}{l}\text { Anzahl } \\
\text { diagnost. } \\
\text { Funde }\end{array}$ & $\begin{array}{l}\text { Charakterisierung } \\
\text { Fundkomplex }\end{array}$ & Datierung & $\begin{array}{l}\text { Datierungskriterien: } \\
\text { jüngste Keramik (u. Glas) }\end{array}$ & $\begin{array}{l}\text { Münzen } \\
\text { (Kap. 8) }\end{array}$ \\
\hline $\begin{array}{l}\text { S 5/1998 } \\
\text { KiNr. 39. }\end{array}$ & SE N42 & 25 & heterogen & 6. Jh. n. Chr. & $\begin{array}{l}\text { LRC Hayes 3 } \\
\text { LRC Hayes 5A } \\
\text { Amphore Eph. 56 } \\
\text { Amphore LRA 3 } \\
\text { GK Deckel }\end{array}$ & - \\
\hline
\end{tabular}

Tab. 83

4.5.3 Funde aus dem Areal westlich des Nord-Analemma

\begin{tabular}{|c|c|c|c|c|c|c|}
\hline $\begin{array}{l}\text { Fläche, } \\
\text { KiNr. }\end{array}$ & Stratum & $\begin{array}{l}\text { Anzahl } \\
\text { diagnost. } \\
\text { Funde }\end{array}$ & $\begin{array}{l}\text { Charakterisierung } \\
\text { Fundkomplex }\end{array}$ & Datierung & $\begin{array}{l}\text { Datierungskriterien: } \\
\text { jüngste Keramik (u. Glas) }\end{array}$ & $\begin{array}{l}\text { Münzen } \\
\text { (Kap. 8) }\end{array}$ \\
\hline $\begin{array}{l}\text { BR4 } \\
\text { KiNr. } 46 . \\
48\end{array}$ & SE N46 & 13 & $\begin{array}{l}\text { heterogen } \\
\text { kaiserzeitliche Residuals }\end{array}$ & 5. Jh. n. Chr. & $\begin{array}{l}\text { ARS Hayes 50B } \\
\text { ARS Hayes } 59 \\
\text { KW Töpfe } \\
\text { KW Kasserolle } \\
\text { Bildlampe mit Traube } \\
\text { (FJ Turnovsky) }\end{array}$ & - \\
\hline $\begin{array}{l}\text { BR4 } \\
\text { KiNr. } 50\end{array}$ & SE N47 & 21 & $\begin{array}{l}\text { homogen } \\
\text { nur vereinzelte, eventuell } \\
\text { kaiserzeitliche Residuals }\end{array}$ & 6. Jh. n. Chr. & $\begin{array}{l}\text { LRC Hayes 3F } \\
\text { LRC Hayes } 6 \\
\text { LRC Hayes 1D } \\
\text { ERSW Hayes } 1 \\
\text { Lampe } \\
\text { Glas: Kelchfuß mit Hohlrand } \\
\text { Becher mit leicht ausgebogenem, } \\
\text { verdicktem Rand }\end{array}$ & - \\
\hline $\begin{array}{l}\text { BR4 } \\
\text { KiNr. } 51\end{array}$ & SE N44 & 9 & homogen & 5./6. Jh. n. Chr. & $\begin{array}{l}\text { LRC Hayes } 3 \\
\text { ERSW Teller? }\end{array}$ & - \\
\hline
\end{tabular}

Tab. 84

Die jüngste Keramik aus der Verfüllung des Wasserleitungskanals (SE N46), des Erdmaterials auf dem Unterbau der Freitreppe am Beckenrand (SE N47) und der Verfüllung des Brunnenbeckens weist in das 5.

${ }^{164}$ Kap. 3.5.2.1.2. 
bis 6. Jh. n. Chr. (Tab. 84). Besonders aussagekräftig in Bezug auf die Datierung von SE N46 sind die vorhandenen Gefäße der Küchenware, welche an das Ende des 4. und in das 5. Jh. n. Chr. weisen. Ausschlaggebend für die Datierung von SE N47 in das 6. Jh. n. Chr. sind Randfragmente der LRC, die den Formen Hayes 3 und 6 zuzuweisen sind. Zu verzeichnen sind außerdem eine ERSW-Imitation der LRC-Form Hayes 1 und spätantik-frühbyzantinische Küchenware.

\subsection{FUNDE AUS DEN SONDAGEN IM SÜDFLÜGEL DES THEATERS}

\subsubsection{Funde aus der Aristion-Leitung}

\begin{tabular}{|c|c|c|c|c|c|c|}
\hline $\begin{array}{l}\text { Fläche, } \\
\text { KiNr. }\end{array}$ & Stratum & $\begin{array}{l}\text { Anzahl } \\
\text { diagnost. } \\
\text { Funde }\end{array}$ & $\begin{array}{l}\text { Charakterisierung } \\
\text { Fundkomplex }\end{array}$ & Datierung & $\begin{array}{l}\text { Datierungskriterien: } \\
\text { jüngste Keramik (u. Glas) }\end{array}$ & $\begin{array}{l}\text { Münzen } \\
\text { (Kap. 8) }\end{array}$ \\
\hline $\begin{array}{l}\text { S } 1 / 2006 \\
\text { KiNr. } 28 . \\
30.37 .40 . \\
44.47 .51 . \\
55.65 .75 . \\
79\end{array}$ & $\begin{array}{l}\text { SE D9 } \\
=\mathrm{D} 12\end{array}$ & 114 & $\begin{array}{l}\text { heterogen } \\
\text { späthellenistisch-kaiser- } \\
\text { zeitlich/5.-6. Jh. n. Chr. }\end{array}$ & 5./6. Jh. n. Chr. & $\begin{array}{l}\text { LRC Hayes } 2 \\
\text { LRC Hayes } 3 \\
\text { ARS Hayes } 57 \\
\text { ARS Hayes 51B } \\
\text { ARS Hayes 50 } \\
\text { ARS Hayes 50A } \\
\text { KW Töpfe } \\
\text { Amphore } \\
\text { Peacock - Williams } 20 \\
\text { Glas: } 1 \text { BS Becher }\end{array}$ & - \\
\hline $\begin{array}{l}\text { S } 1 / 2006 \\
\text { KiNr. } 39 . \\
43.46 .53 . \\
63\end{array}$ & SE D10 & 50 & $\begin{array}{l}\text { heterogen } \\
\text { späthellenistisch-kaiser- } \\
\text { zeitlich/5.-6. Jh. n. Chr. }\end{array}$ & 5./6. Jh. n. Chr. & $\begin{array}{l}\text { LRC Hayes 1A } \\
\text { LRC Hayes } 2 \\
\text { ARS Hayes 50B } \\
\text { ARS Hayes } 45 \text { Variante } \\
\text { KW Töpfe }\end{array}$ & - \\
\hline $\begin{array}{l}\text { S } 1 / 2006 \\
\text { KiNr. } 29 . \\
31,38.42 . \\
52.56 .66 . \\
72.73 .76 . \\
77.80 .81 \\
\end{array}$ & $\begin{array}{l}\text { SE D11 } \\
=\text { D15 }\end{array}$ & 114 & $\begin{array}{l}\text { heterogen } \\
\text { späthellenistisch-kaiser- } \\
\text { zeitlich/5.-6. Jh. n. Chr. }\end{array}$ & 6. Jh. n. Chr. & $\begin{array}{l}\text { LRC Hayes 3F } \\
\text { KW Töpfe } \\
\text { Amphore LRA } 5 \\
\text { Lampe } \\
\text { Glas: } 1 \text { RS Becher od. Krug }\end{array}$ & - \\
\hline $\begin{array}{l}\text { S } 1 / 2006 \\
\text { KiNr. } 50 . \\
54.64 .70\end{array}$ & SE D13 & 16 & $\begin{array}{l}\text { heterogen } \\
\text { späthellenistisch/4.-5. Jh. } \\
\text { n. Chr. }\end{array}$ & 4./5. Jh. n. Chr. & $\begin{array}{l}\text { ARS BS } \\
\text { KW Töpfe } \\
\text { Glas: } 1 \text { RS Becher }\end{array}$ & - \\
\hline $\begin{array}{l}\text { S } 1 / 2006 \\
\text { KiNr. } 74 . \\
78\end{array}$ & SE D14 & 5 & $\begin{array}{l}\text { kleiner Fundkomplex } \\
\text { keine feinchronologisch } \\
\text { relevanten Funde }\end{array}$ & kaiserzeitlich & - & - \\
\hline
\end{tabular}

Tab. 85

Sämtliche Schichten im Kanal der Aristion-Leitung sind in ihrer Zusammensetzung mehr oder weniger stark heterogen (Tab. 85). Sie können allerdings aufgrund der jüngsten darin auftretenden Funde einheitlich in das 5. und 6. Jh. n. Chr. datiert werden. Bis in diese Zeit war sie also vermutlich in Betrieb oder wurde abschnittsweise genutzt, bzw. die Zisterne mit Wasser befülltt ${ }^{165}$. SE D9 und SE D12 sind aufgrund von LRC-Tellern der Form Hayes 3 und Kochtöpfen mit innen profiliertem Rand und/oder Deckelfalz ${ }^{166}$ dem 5. bis 6. Jh. $n$. Chr. zuzuordnen, während die darin vorhandenen ARS-Teller durchwegs etwas früher, in die 2. Hälfte des 4. Jhs. n. Chr.

\footnotetext{
${ }^{165}$ Kap. 3.6.1.

166 Vgl. Ladstätter 2008, Abb. 31, 1-3.
} 
datieren. Zudem sind späthellenistische und kaiserzeitliche Residuals vorhanden. Auch D10 datiert aufgrund der jüngsten Funde - wiederum LRC-Fragmente, aber auch spezifische Vertreter der Küchenware - in das 5. Jh. n. Chr. Hier sind ebenfalls späthellenistische bis kaiserzeitliche Residuals zu beobachten. LRC-Randfragmente, die u. a. der Form Hayes $3 \mathrm{~F}^{167}$ zuzuordnen sind, und Küchenware ${ }^{168}$ machen eine Datierung von SE D11/SE D15 in das 6. Jh. n. Chr. wahrscheinlich. Auch SE D13 kann durch entsprechende Funde von Kochtöpfen in das 5. Jh. n. Chr. datiert werden. SE D14 enthält nur allgemein der Kaiserzeit zuzuweisende Funde.

\subsubsection{Funde aus dem Süd-Analemma}

In den nordwestlich an ES1 anschließenden Kammern KS1 bis KS3, die 2007 archäologisch untersucht wurden ${ }^{169}$, konnten keine keramischen Fundkomplexe geborgen werden, die mit der Errichtung der Kammern in Verbindung zu bringen sind. Aufgrund bauhistorischer Kriterien kann allerdings vom Abschluss ihrer Erbauung zwischen 102 und $112 \mathrm{n}$. Chr. ausgegangen werden ${ }^{170}$, was auch mit der Münzreihe korrespondiert ${ }^{171}$. Die keramischen Fundkomplexe beinhalten hingegen verstärkt Fundmaterial, das als Schutt des Erdbebens des 3. Viertels des 3. Jhs. n. Chr. interpretiert werden kann, vermischt mit Funden aus dem 5. und 6. Jh. n. Chr. Dasselbe Phänomen findet seinen Niederschlag in den Münzfunden ${ }^{172}$ und kann auch auf der Freitreppe im Süden des Theaters ${ }^{173}$ sowie im Bereich einer 1998 untersuchten Kammer im Norden des Theaters (KN1) $)^{174}$ konstatiert werden. Die jüngsten Funde geben einen terminus post quem für die endgültige Verfüllung und Aufgabe der Kammern, wohl im späten 6. Jh. n. Chr.

\subsubsection{KAMMER KS1}

In der Kammer KS1 konnten mangels feinchronologisch relevanter Keramikfunde nicht alle Straten datiert werden (Tab. 86). Hervorzuheben ist allerdings die umfangreiches Fundmaterial enthaltende Schuttschicht SE 46 über einem Estrich ${ }^{175}$, deren Entstehung aufgrund der jüngsten Keramikfunde in das 6. Jh. n. Chr. datiert werden kann. Es wurden hier allerdings auch zahlreiche sehr gut erhaltene Gefäße aus dem 3. Jh. n. Chr. geborgen. Exemplarisch soll anhand der Fundzusammensetzung von SE 46 daher jenes Phänomen veranschaulicht werden, das im Theater immer wieder zu beobachten is $\mathrm{t}^{176}$ : Gut erhaltene Bestandteile jenes Geschirrs, das vor der Zerstörung durch das große Erdbeben im letzten Viertel des 3. Jhs. v. Chr. in Benutzung stand, gelangen vergesellschaftet mit Gefäßen, die einen deutlich späteren Zeithorizont umfassen, in diverse Schuttschichten. In SE 46 sind also Gefäße vertreten, die eindeutig dem Horizont des 3. Jhs. n. Chr. zugeordnet werden können. Eine Schüssel der ARS konnte im Profil vollständig rekonstruiert werden, sie entspricht der Form Hayes $15^{177}$ (K 269 Taf. 330. 352). Vertreten sind außerdem ARS-Teller der Form Hayes $50 \mathrm{~A}^{178}$ (K 270-272 Taf. 330) als typische Vertreter des Tafelgeschirrs im 3. Jh. n. Chr. Die ESC umfasst mit der Form Hayes $4^{179}$ (K 273-276 Taf. 331) ebenfalls charakteristische Schalen dieses Zeitraums. Eine Schale, die vollständig erhalten blieb, deren Überzug allerdings stark abgerieben ist, ist der lokalen Feinware zuzurechnen (K 277 Taf. 331. 352). Auch die Formen der dünnwandigen Becher (K 278 Taf. 352; K 279. K 280 Taf. 331. 352) sind bestens bekannt aus den Fundkomplexen im Hanghaus 2, die der letzten Wohnpha-

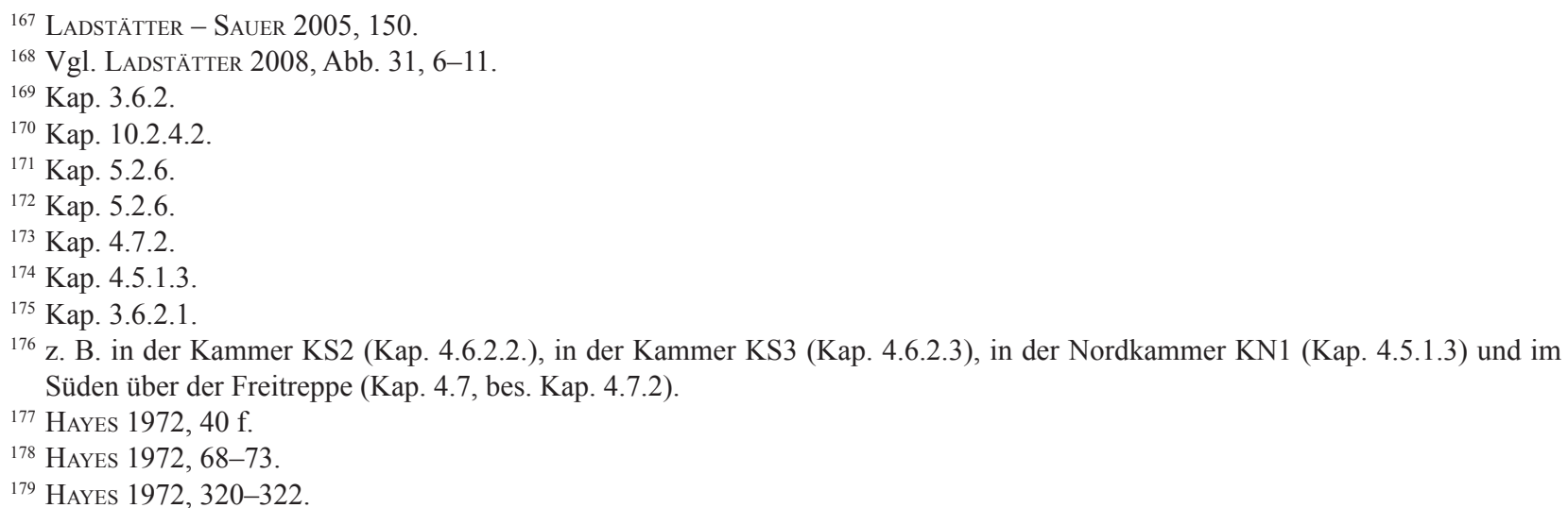


se und der Nutzung unmittelbar vor dem Erdbeben zuzurechnen sind ${ }^{180}$. Von einem gebrauchskeramischen Henkeltopf mit ausbiegendem Rand und geripptem Gefäßkörper blieben sechs Randfragmente, Wandfragmente sowie ein Henkelansatz erhalten (K 281 Taf. 332. 352) ${ }^{181}$. Auch von charakteristischen gebrauchskeramischen Schüsseln (K 282. K 283 Taf. 332; K 284 Taf. 333) und Kochtöpfen (K 285 Taf. 333) blieben große Stücke erhalten. Mehrere gut erhaltene, bauchige Amphoren mit geripptem Körper, zylindrischem Hals und kleinem Knauf (K 286 Taf. 334. 353; K 287. K 288 Taf. 335; K 289 Taf. 336) finden Parallelen in Inventaren aus der Bauphase IV und den Zerstörungskontexten des Hanghauses $2^{182}$. Hervorzuheben ist v. a. eine aus mehreren Fragmenten fast vollständig zusammengesetzte Amphore dieses Typs (K 286 Taf. 334). $\mathrm{Zu}$ ergänzen sind außerdem zwei Fragmente von afrikanischen Importamphoren, die dem Typ Africana IIB (K 290 Taf. 336) ${ }^{183}$ zugeordnet werden können, sowie charakteristische lokale Amphoren vom Typ Peacock - Williams 45 (K 291-294 Taf. 336), für die allerdings auch eine Zugehörigkeit zum späteren Zeithorizont in SE 46 nicht auszuschließen ist ${ }^{184}$. Das Lampenspektrum beinhaltet u. a. ein Fehlprodukt (K 295 Taf. 336. $353)^{185}$, das möglicherweise aber auch sekundär (durch Feuereinwirkung) deformiert wurde. Es handelt sich um eine verzogene runde Lampe mit gelochtem, zweifach gerilltem Griff, unverzierter Schulter und einer Girlande auf dem Diskus. Das kleine Fragment K 296 (Taf. 336. 353) zeigt einen Doppelaulos spielenden Eroten auf dem Diskus ${ }^{186}$. Ein Arm einer Gladiatorenstatuette dürfte ebenfalls zum spätkaiserzeitlichen Inventar gehören $^{187}$, ebenso eine Nadel und zwei beinerne Griffe ${ }^{188}$.

Der zweite in SE 46 durch das Fundmaterial fassbare Zeithorizont ist wesentlich später anzusetzen: Ein Teller der LRC der Form Hayes 1A ${ }^{189}$ (K 297 Taf. 336) ist dem ausgehenden 4. und 5. Jh. n. Chr. zuzurechnen. Es sind allerdings auch Teller der Form Hayes 3 (K 298. K 299 Taf. 336) vertreten, wobei speziell für die Variante H, wie sie mit K $298^{190}$ vorliegt, eine Datierung in das 6. Jh. n. Chr. zu postulieren ist ${ }^{191}$. Dasselbe gilt für ein Randfragment eines afrikanischen Sigillatatellers der Form Hayes 93B (K 300 Taf. 337) ${ }^{192}$. Die Gefäße der Küchenware sind in erster Linie dem ausgehenden 4. und 5. Jh. zuzuordnen, was speziell für die vorhandenen Kochtopfformen (K 301-309 Taf. 337) gilt ${ }^{193}$. Auch ein Krug (K 310 Taf. 337) und die Kasserollen K 311 (Taf. 337), K 312-315 (Taf. 338) ${ }^{194}$ sowie zwei Pfannenfragmente ${ }^{195}$ (K 316. K 317 Taf. 338) zeigen typische Merkmale des 5. Jhs. n. Chr. Die Amphoren umfassen mit den Typen LRA 2 (K 318 Taf. 338. 354; K 319 Taf. 339) ${ }^{196}$ und LRA 3 (K 320 Taf. 339) (97 $^{19}$ eindeutige Vertreter des 5. und 6. Jhs. n. Chr. Gesondert hinzuweisen ist auf ein Wandfragment mit Dipinto einer vermutlich spätantiken Importamphore (K 322 Taf. 339). Ein ägyptischer Import (K 321 Taf. 339. 354) ${ }^{198}$ datiert hingegen wieder etwas früher, in das späte 4. bis ins 5. Jh. n. Chr. Auf einem Lampenfragment (K 323 Taf. 339. 354) schließlich blieb der Rest einer Bodenmarke mit Monogramm erhalten. Es ist in die 2. Hälfte des 6. Jhs. n. Chr. zu datieren ${ }^{199}$. Ein zweites kleines Lampenfragment zeigt auf dem Diskus zwei Tauben, die einen Krater flankieren (K 324 Taf. 339. 354) $)^{200}$.

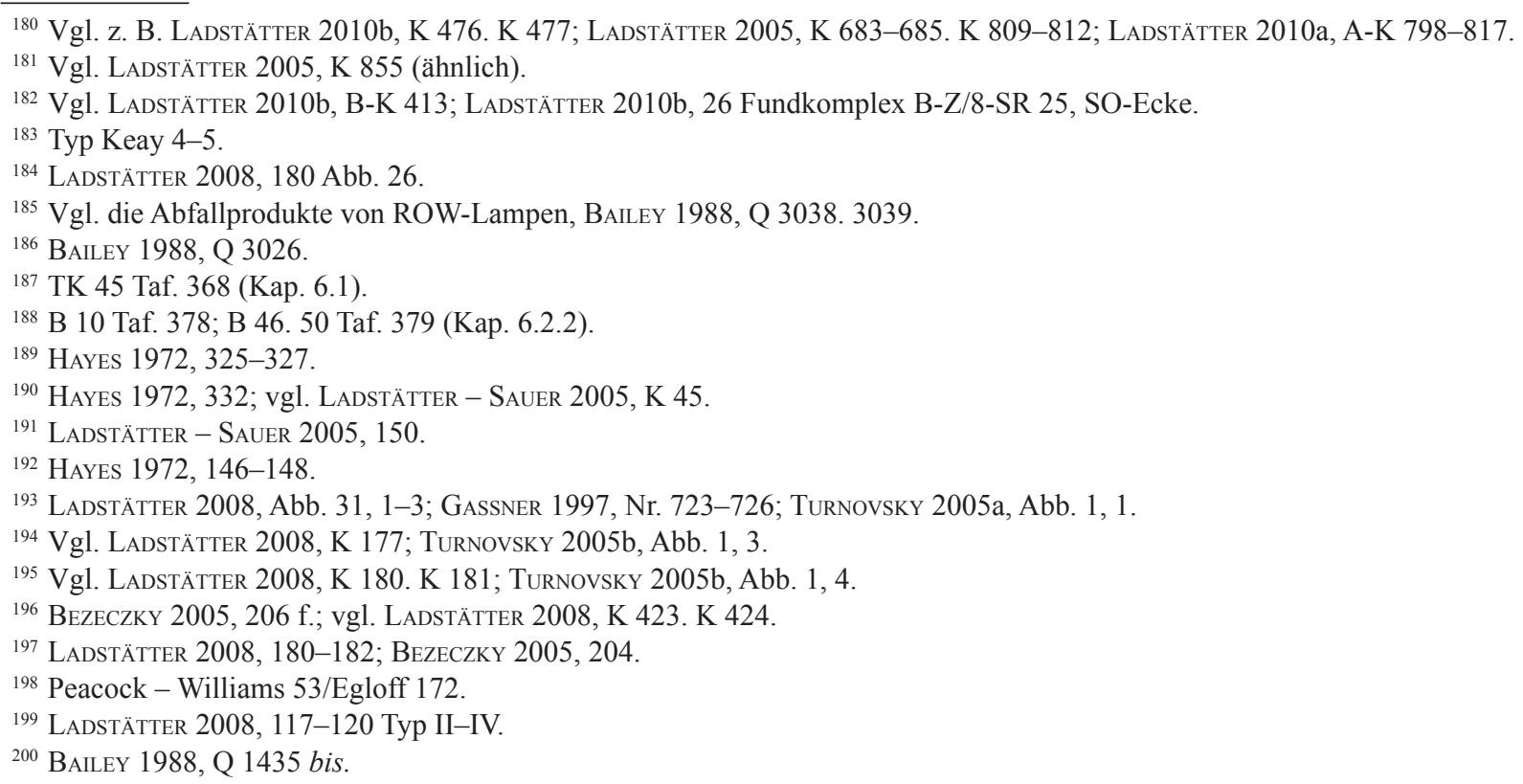


Von jenen Glasfunden aus SE 46, die typologisch zuzuweisen sind, ist ein Randfragment einer Flasche mit vertikalem Rand ${ }^{201}$ zu erwähnen (G 5 Taf. 339), außerdem ein Kelchglas, von dem der Hohlfuß erhalten blieb (G 6 Taf. 339) 202. Beide Fragmente sind dem 4. bis 6. Jh. n. Chr. zuzurechnen. Zu ergänzen ist außerdem ein Fragment eines Bechers oder Töpfchens mit eingeschnürtem Rand und einfachem gerundetem Rand (G 67 Taf. 339) ${ }^{203}$. Hervorzuheben ist die Vergesellschaftung der genannten Keramik- und Glasfunde aus SE 46 mit 23 Münzen, die eine Prägezeit vom Ende des 4. bis in die 1. Hälfte des 5. Jhs. n. Chr. haben ${ }^{204}$.

$\mathrm{Zu}$ erwähnen ist außerdem die unter dem Estrich befindliche SE 62, die aufgrund der Fundzusammensetzung in das 3. Jh. n. Chr. datiert werden kann und ebenfalls gut erhaltene Keramikfunde beinhaltet. Ein Zusammenhang mit SE 46 ist nicht auszuschließen ${ }^{205}$.

\begin{tabular}{|c|c|c|c|c|c|c|}
\hline $\begin{array}{l}\text { Fläche, } \\
\text { KiNr. }\end{array}$ & Stratum & $\begin{array}{l}\text { Anzahl } \\
\text { diagnost. } \\
\text { Funde }\end{array}$ & $\begin{array}{l}\text { Charakterisierung } \\
\text { Fundkomplex }\end{array}$ & Datierung & $\begin{array}{l}\text { Datierungskriterien: } \\
\text { jüngste Keramik (u. Glas) }\end{array}$ & $\begin{array}{l}\text { Münzen } \\
\text { (Kap. 8) }\end{array}$ \\
\hline $\begin{array}{l}\text { KS1 } \\
(2007) \\
\text { KiNr. } \\
171\end{array}$ & SE 46 & 140 & $\begin{array}{l}\text { großer Fundkomplex } \\
\text { heterogen } \\
\text { Ende 2.-3. Jh. n. Chr./4.- } \\
\text { 5.Jh. n. Chr./6. Jh. n. Chr. } \\
\text { z. T. gut erhaltene Gefäße } \\
\text { (speziell des 3. Viertels } \\
\text { des 3. Jhs. n. Chr.), eine } \\
\text { vollständig erhaltene } \\
\text { Lampe (Fehlbrand), } \\
\text { mehrere halb bis nahezu } \\
\text { vollständig erhaltene } \\
\text { Amphoren }\end{array}$ & $\begin{array}{l}\text { (3. Viertel) 3. Jh. } \\
\text { n. Chr. } \\
\text { 2. H. 4./5. Jh. n. } \\
\text { Chr. } \\
\text { 6. Jh. n. Chr. }\end{array}$ & $\begin{array}{l}\text { ARS Hayes 50A } \\
\text { ARS Hayes } 15 \text { ( } 8 \text { Fragmente, } \\
\text { zur Hälfte erhalten) } \\
\text { ESC Hayes } 4 \\
\text { DWK Trichterbecher } \\
\text { Amphoren } \\
\text { Bildlampen } \\
\\
\text { Glas: Flasche Isings 102b mit } \\
\text { vertikalem Rand } \\
\text { Kelch mit Hohlfuß } \\
\text { LRC Hayes 1 } \\
\text { LRC Hayes 1A } \\
\text { Amphore, ägyptisch } \\
\text { LRC Hayes 3H } \\
\text { ARS Hayes 93B } \\
\text { KW Töpfe, Kasserollen, Pfannen } \\
\text { Amphoren LRA } 2 \\
\text { Amphoren LRA } 3 \\
\text { Lampe }\end{array}$ & $\begin{array}{l}\text { M } 122 \\
\text { M } 140 \\
\text { M } 138 \\
\text { M } 147 \\
\text { M } 150 \\
\text { M } 157 \\
\text { M } 164 \\
\text { M } 169 \\
\text { M } 174 \\
\text { M } 175 \\
\text { M } 176 \\
\text { M } 177 \\
\text { M } 180 \\
\text { M } 170 \\
\text { M } 181 \\
\text { M } 190 \\
\text { M } 229 \\
\text { M } 214 \\
\text { M } 255\end{array}$ \\
\hline $\begin{array}{l}\text { KS1 } \\
(2007) \\
\text { KiNr. } 51 . \\
52.65\end{array}$ & $\begin{array}{l}\text { SE } 53= \\
\text { SE 61 = } \\
\text { SE } 82\end{array}$ & 31 & $\begin{array}{l}\text { heterogen } \\
\text { frühkaiserzeitlich-3. Jh. } \\
\text { n. Chr./4.-5. Jh. n. Chr. }\end{array}$ & $\begin{array}{l}\text { 3. Viertel 3. Jh. } \\
\text { n. Chr. } \\
\text { 4./5. Jh. n. Chr. }\end{array}$ & $\begin{array}{l}\text { ARS Hayes 50A } \\
\text { KW Töpfchen } \\
\text { KW Topf } \\
\text { Glas: voller Standknopf }\end{array}$ & - \\
\hline $\begin{array}{l}\text { KS1 } \\
(2007) \\
\text { KiNr. } 68\end{array}$ & SE 60 & 3 & $\begin{array}{l}\text { insignifikant aufgrund } \\
\text { geringer Fundquantität }\end{array}$ & & $\begin{array}{l}\text { Glas: kleiner umgefalteter } \\
\text { Standfuß }\end{array}$ & - \\
\hline
\end{tabular}

\footnotetext{
${ }^{201}$ Isings 102B; vgl. CzuRDA-Ruth 2007, KatNr. 868.869 (4.-5. Jh. n. Chr.).

${ }^{202}$ Vgl. Czurda-Ruth 2007, KatNr. 664-680. Zur Verbreitung dieser Kelchgläser im östlichen Mittelmeerraum s. ÇAKMAKÇı 2009, Tab. 1-3.

${ }^{203}$ Czurda-Ruth 2007, 108 KatNr. 383-403.

${ }^{204}$ Tab. 8; Kap. 5.2.6.

${ }^{205}$ Kap. 3.6.2.1.
} 


\begin{tabular}{|c|c|c|c|c|c|c|}
\hline $\begin{array}{l}\text { Fläche, } \\
\text { KiNr. }\end{array}$ & Stratum & \begin{tabular}{|l} 
Anzahl \\
diagnost. \\
Funde
\end{tabular} & $\begin{array}{l}\text { Charakterisierung } \\
\text { Fundkomplex }\end{array}$ & Datierung & $\begin{array}{l}\text { Datierungskriterien: } \\
\text { jüngste Keramik (u. Glas) }\end{array}$ & $\begin{array}{l}\text { Münzen } \\
\text { (Kap. 8) }\end{array}$ \\
\hline $\begin{array}{l}\text { KS1 } \\
(2007) \\
\text { KiNr. } 53\end{array}$ & SE 62 & 63 & $\begin{array}{l}\text { heterogen } \\
\text { späthellenistisch } \\
\text { (vereinzelt)-3. Jh. n. Chr. } \\
\text { teilweise gut bis vollstän- } \\
\text { dig erhaltene Gefäße (KW } \\
\text { Töpfchen mit Henkel, } \\
\text { Unguentarium, Topf/ } \\
\text { Eimer, Lampen) Fragment } \\
\text { Sieb (magnesisch) }\end{array}$ & 3. Jh. n. Chr. & $\begin{array}{l}\text { RSW Askos (Vgl. LADSTÄTTER } \\
\text { 2010a, A-K787.) } \\
\text { RSW Teller (reduzierend gebrannt, } \\
\text { vgl. LADSTÄTTER 2005, K 711. Tab. } \\
\text { 86) } \\
\text { ESB Atlante } 79 \\
\text { ESB Atlante } 8 \\
\text { DWK Becher } \\
\text { GK Schüsseln } \\
\text { KW Töpfchen } \\
\text { KW Kasserolle } \\
\text { Lampen } \\
\\
\text { Glas: } 1 \text { RS }\end{array}$ & - \\
\hline $\begin{array}{l}\text { KS1 } \\
(2008) \\
\text { KiNr. } 56\end{array}$ & SE 63 & 24 & $\begin{array}{l}\text { keine feinchronologisch } \\
\text { relevanten Funde }\end{array}$ & 2.-3. Jh. n. Chr. & $\begin{array}{l}\text { KW Töpfchen } \\
\text { GK Schüssel } \\
\text { Amphore Peacock - Williams } 45 \\
\text { Glas: } 1 \text { BS }\end{array}$ & - \\
\hline $\begin{array}{l}\text { KS1 } \\
(2008) \\
\text { KiNr. } 59\end{array}$ & $\begin{array}{l}\text { SE 64= } \\
\text { SE 83= } \\
\text { SE 84 }\end{array}$ & 1 & $\begin{array}{l}\text { insignifikant aufgrund } \\
\text { geringer Fundquantität }\end{array}$ & & GK Schüssel & \\
\hline $\begin{array}{l}\text { KS1 } \\
(2008) \\
\text { KiNr. } 60\end{array}$ & SE 68 & 1 & sehr kleiner Fundkomplex & $\begin{array}{l}\text { Mitte-Ende 1. Jh. } \\
\text { n. Chr.? }\end{array}$ & ESC Atlante L20 & \\
\hline $\begin{array}{l}\text { KS1 } \\
(2008) \\
\text { KiNr. } 62\end{array}$ & SE 80 & 5 & kleiner Fundkomplex & 1. Jh. n. Chr. & ESB Atlante 57 & \\
\hline
\end{tabular}

Tab. 86

\subsubsection{KAMMER KS2}

Die Straten der Kammer KS2 enthielten wiederum keramisches Fundmaterial aus dem 3. Jh. n. Chr., das - mit Ausnahme von SE 35 - mit Funden vermischt ist, die in das 5./6. Jh. n. Chr. zu datieren sind (Tab. 87). Hervorzuheben ist SE 45, wo mitunter sehr gut erhaltene Gefäße vorhanden sind. Das Stratum enthält nahezu ausschließlich Schuttmaterial, das aufgrund von Parallelinventaren im Hanghaus 2 eindeutig mit dem Erdbeben des 3. Viertels des 3. Jhs. n. Chr. in Zusammenhang gebracht werden kann. Der gute Erhaltungszustand vieler Gefäße lässt an eine nur einmalige Umlagerung denken. Zwei Fragmente frühbyzantinischer Ampullen bilden die einzigen > Verunreinigungen < des 5./6. Jhs. n. Chr., in Bezug auf die Gesamtanzahl von 147 diagnostischen Fragmenten aus der Schicht dürfte ihnen allerdings geringere Aussagekraft beigemessen werden. Vermutlich sind sie der darüberliegenden, gemischten SE 44 zuzurechnen $^{206}$. Ein grün glasiertes Wandfragment aus SE 28b (= SE 44+SE 45) weist in die byzantinische Zeit, kann allerdings zeitlich nicht näher eingegrenzt werden. Der Fundkomplex, aus dem es stammt, ist zudem rezent gestört.

\footnotetext{
${ }^{206}$ Dies entspräche auch dem Münzbefund, wo die nach-erdbebenzeitlichen Münzen ausschließlich in SE 44 auftreten, nicht aber in SE 45, s. Tab. 10. 11 (Kap. 5.2.6).
} 


\begin{tabular}{|c|c|c|c|c|c|c|}
\hline $\begin{array}{l}\text { Fläche, } \\
\text { KiNr. }\end{array}$ & Stratum & $\begin{array}{l}\text { Anzahl } \\
\text { diagnost. } \\
\text { Funde }\end{array}$ & $\begin{array}{l}\text { Charakterisierung } \\
\text { Fundkomplex }\end{array}$ & Datierung & $\begin{array}{l}\text { Datierungskriterien: } \\
\text { jüngste Keramik (u. Glas) }\end{array}$ & $\begin{array}{l}\text { Münzen } \\
\text { (Kap. 8) }\end{array}$ \\
\hline $\begin{array}{l}\text { KS2 } \\
(2007) \\
\text { KiNr. } \\
145 . \\
150\end{array}$ & $\begin{array}{l}\text { SE } 28 b \\
(=\text { SE } \\
44+\text { SE } \\
45)\end{array}$ & 128 & $\begin{array}{l}\text { rezent gestört } \\
\text { heterogen } \\
\text { z. T. guter Erhaltungszu- } \\
\text { stand (eine vollständig } \\
\text { erhaltene Lampe) }\end{array}$ & $\begin{array}{l}\text { 3. Viertel 3. Jh. } \\
\text { n. Chr. } \\
\text { 6. Jh. n. Chr. } \\
\text { byzantinisch }\end{array}$ & $\begin{array}{l}\text { ARS Hayes 50A } \\
\text { ARS Hayes } 44 \\
\text { ARS Hayes } 49 \\
\text { ESC Hayes } 4 \\
\text { ESC Atlante H1 } \\
\text { Lampe } \\
\text { LRC Hayes 3F } \\
\text { LRC Hayes } 3 \\
\text { grün glasierte Keramik (1WS) }\end{array}$ & $\begin{array}{l}\text { M } 56 \\
\text { M } 58 \\
\text { M } 76 \\
\text { M } 79 \\
\text { M } 95 \\
\text { M } 117 \\
\text { M } 151 \\
\text { M } 152 \\
\text { M } 153 \\
\text { M } 158 \\
\text { M } 168 \\
\text { M } 186 \\
\text { M } 192 \\
\text { M } 194 \\
\text { M } 195 \\
\text { M } 196 \\
\text { M } 203 \\
\text { M } 210 \\
\text { M } 222 \\
\text { M } 225 \\
\text { M } 226 \\
\text { M } 228 \\
\text { M } 218 \\
\text { M } 220 \\
\text { M } 230 \\
\text { M } 235 \\
\text { M } 236 \\
\text { M } 248 \\
\text { M } 249 \\
\text { M } 260\end{array}$ \\
\hline $\begin{array}{l}\text { KS2 } \\
(2007) \\
\text { KiNr. } \\
154\end{array}$ & SE 35 & 24 & homogen & $\begin{array}{l}\text { (2. H.) 3. Jh. n. } \\
\text { Chr. }\end{array}$ & $\begin{array}{l}\text { ARS Hayes 50A } \\
\text { ESB Atlante 58? } \\
\text { GK Becher } \\
\text { KW Töpfchen }\end{array}$ & - \\
\hline $\begin{array}{l}\text { KS2 } \\
(2007) \\
\text { KiNr. } \\
169\end{array}$ & SE 44 & 75 & $\begin{array}{l}\text { heterogen } \\
\text { 2.-3. Jh. n. Chr.-spätes } \\
\text { 5./6. Jh. n. Chr. }\end{array}$ & $\begin{array}{l}\text { 3. Jh. n. Chr. } \\
\text { spätes 5./6. Jh. n. } \\
\text { Chr. }\end{array}$ & $\begin{array}{l}\text { ARS Hayes } 49 \\
\text { ESC Hayes } 4 \\
\text { ESC Hayes } 5 \\
\\
\text { Glas: } 3 \text { RS, } 3 \text { BS } \\
\text { LRC Hayes } 3 \text { F } \\
\text { LRC Hayes } 3 \text { mit Kreuzstempel } \\
\text { Hayes } 77 \\
\text { ARS Hayes 50B } \\
\text { Lampen } \\
\text { KW Töpfe } \\
\text { Amphore Peacock - Williams } 44 \text { / } \\
\text { Keay LIII } \\
\text { Amphore, pontisch } \\
\text { frühbyzantinische Ampullen (aus } \\
\text { SE 45, lt. mündlicher Information } \\
\text { M. Hofbauer vermutlich zu SE } 44 \\
\text { gehörig) }\end{array}$ & $\begin{array}{l}\text { M } 109 \\
\text { (Tab. } \\
\text { 105 Kap. } \\
8.2 .6 \text { ) } \\
\text { M } 118 \\
\text { M } 136 \\
\text { M } 142 \\
\text { M } 165 \\
\text { M } 179 \\
\text { M } 171 \\
\text { M } 182 \\
\text { M } 187 \\
\text { M } 191 \\
\text { M } 199 \\
\text { M } 200 \\
\text { M } 202 \\
\text { M } 205 \\
\text { M } 209 \\
\text { M } 221 \\
\text { M } 223 \\
\text { M } 227\end{array}$ \\
\hline
\end{tabular}




\begin{tabular}{|c|c|c|c|c|c|c|}
\hline $\begin{array}{l}\text { Fläche, } \\
\text { KiNr. }\end{array}$ & Stratum & $\begin{array}{l}\text { Anzahl } \\
\text { diagnost. } \\
\text { Funde }\end{array}$ & $\begin{array}{l}\text { Charakterisierung } \\
\text { Fundkomplex }\end{array}$ & Datierung & $\begin{array}{l}\text { Datierungskriterien: } \\
\text { jüngste Keramik (u. Glas) }\end{array}$ & $\begin{array}{l}\text { Münzen } \\
\text { (Kap. 8) }\end{array}$ \\
\hline & & & & & ARS Hayes 49 & $\begin{array}{l}\text { M } 216 \\
\text { M } 232 \\
\text { M } 234 \\
\text { M } 258\end{array}$ \\
\hline & & & & & $\begin{array}{l}\text { ESC Hayes } 4 \\
\text { ESC Hayes } 5 \\
\text { Glas: } 3 \text { RS, } 3 \text { BS }\end{array}$ & M 259 \\
\hline $\begin{array}{l}\text { KS2 } \\
(2007) \\
\text { KiNr. } \\
170\end{array}$ & SE 45 & 147 & $\begin{array}{l}\text { großer Fundkomplex } \\
\text { heterogen } \\
\text { (spät)hellenistische Re- } \\
\text { siduals } \\
\text { Großteil 3. Jh. n. Chr., } \\
\text { sehr gut vergleichbar mit } \\
\text { den Zerstörungs-Fund- } \\
\text { komplexen im HH2 } \\
\text { zahlreiche gut erhaltene } \\
\text { Gefäße }\end{array}$ & $\begin{array}{l}\text { 3. Viertel 3. Jh. } \\
\text { n. Chr. }\end{array}$ & $\begin{array}{l}\text { ARS Hayes 45A } \\
\text { ARS Hayes 46? } \\
\text { ARS Hayes 50A } \\
\text { ESC Hayes } 4 \\
\text { ESB Atlante 60, spät } \\
\text { ESA Atlante 65B } \\
\text { DWK Becher } \\
\text { Amphoren Kapitän II Peacock - } \\
\text { Williams 45 } \\
\\
\text { Glas: } 8 \text { Frgte., hauptsächlich Bö- } \\
\text { den mit (zartem) echtem Standring } \\
\text { (CzURDA-RuTH 2007, Kap. 25. d. e) } \\
\text { mit hohem Standring (CzURDA- } \\
\text { RuTH 2007, Kap. 25. f) o. mit } \\
\text { Standplatte (CzURDA-RUTH 2007, } \\
\text { Kap. 25. c) }\end{array}$ & $\begin{array}{l}\text { M } 38 \\
\text { (Tab. } \\
\text { 106 Kap. } \\
8.2 .6 \text { ) } \\
\text { M } 37 \\
\text { M } 52 \\
\text { M } 54 \\
\text { M } 64 \\
\text { M } 68 \\
\text { M 69 } \\
\text { M } 72 \\
\text { M } 83 \\
\text { M } 88 \\
\text { M } 113 \\
\text { M } 173 \\
\text { M } 254\end{array}$ \\
\hline
\end{tabular}

Tab. 87 


\subsubsection{KAMMER KS3}

In den Einfüllungen der Kammer KS3 überwiegt der Fundanteil aus dem 5. und dem 6. Jh. n. Chr. (Tab. 88). Hervorzuheben ist SE 33, die den größten Fundkomplex bildet und ähnlich wie die Straten aus den beiden vorher besprochenen Kammern neben einem überwiegenden Anteil an Funden aus dem 6. Jh. n. Chr. wieder eine beachtliche Quantität an Keramik aus dem 3. Viertel des 3. Jhs. n. Chr. aufweist.

\begin{tabular}{|c|c|c|c|c|c|c|}
\hline $\begin{array}{l}\text { Fläche, } \\
\text { KiNr. }\end{array}$ & Stratum & $\begin{array}{l}\text { Anzahl } \\
\text { diagnost. } \\
\text { Funde }\end{array}$ & $\begin{array}{l}\text { Charakterisierung } \\
\text { Fundkomplex }\end{array}$ & Datierung & $\begin{array}{l}\text { Datierungskriterien: } \\
\text { jüngste Keramik (u. Glas) }\end{array}$ & $\begin{array}{l}\text { Münzen } \\
\text { (Kap. 8) }\end{array}$ \\
\hline $\begin{array}{l}\text { KS3 } \\
(2007) \\
\text { KiNr. } \\
146\end{array}$ & SE 28a & 30 & $\begin{array}{l}\text { heterogen } \\
\text { späthellenistische Residu- } \\
\text { als/kaiserzeitlich/spätantik } \\
\text { z. T. gut erhaltene Gefäße } \\
\text { (1 KW Topf zu drei Vier- } \\
\text { teln erhalten) }\end{array}$ & 5./6. Jh. n. Chr. & $\begin{array}{l}\text { Amphore Ephesos } 56 \\
\text { KW Töpfe } \\
\text { GK Krug mit Wellenbanddekor }\end{array}$ & $\begin{array}{l}\text { M } 73 \\
\text { (Tab. } \\
107 \text { Kap. } \\
8.2 .6 \text { ) } \\
\text { M } 110\end{array}$ \\
\hline $\begin{array}{l}\text { KS3 } \\
(2007) \\
\text { KiNr. } \\
147.158\end{array}$ & SE 32 & 19 & $\begin{array}{l}\text { heterogen } \\
\text { kaiserzeitlich/spätantik }\end{array}$ & 6. Jh. n. Chr. & $\begin{array}{l}\text { LRC Hayes 3E } \\
\text { LRC Hayes 3F } \\
\text { KW Schale } \\
\text { Lampe }\end{array}$ & - \\
\hline $\begin{array}{l}\text { KS3 } \\
(2007) \\
\text { KiNr. } \\
148.156\end{array}$ & SE 33 & 180 & $\begin{array}{l}\text { großer Fundkomplex } \\
\text { heterogen } \\
\text { hellenistische Residuals/ } \\
\text { kaiserzeitlich/spätantik }\end{array}$ & $\begin{array}{l}\text { 3. Viertel 3. Jh. } \\
\text { n. Chr. } \\
\text { 6. Jh. n. Chr. }\end{array}$ & $\begin{array}{l}\text { ESC Hayes } 3 \\
\text { ESC Hayes } 4 \\
\text { ESC Atlante L1 ESC Atlante L } 19 \\
\text { DWK Becher } \\
\text { DWK Töpfchen } \\
\\
\text { Glas: konischer Becher mit einfa- } \\
\text { chem gerundetem Rand } \\
\text { Böden mit echtem Standring } \\
\\
\text { LRC Hayes 3E } \\
\text { LRC Hayes 3F } \\
\text { LRC Hayes 3H } \\
\text { ARS Hayes 58B? } \\
\text { KW Töpfe } \\
\text { GK Topf } \\
\text { Amphore LRA } 3\end{array}$ & $\begin{array}{l}\text { M 2 } \\
\text { (Tab. } \\
\text { 108 Kap. } \\
8.2 .6 \text { ) } \\
\text { M 63 } \\
\text { M 57 } \\
\text { M 100 } \\
\text { M 143 } \\
\text { M 213 } \\
\text { M 251 }\end{array}$ \\
\hline $\begin{array}{l}\text { KS3 } \\
(2007) \\
\text { KiNr. } \\
149\end{array}$ & SE 34 & 31 & $\begin{array}{l}\text { heterogen } \\
\text { kaiserzeitlich/spätantik }\end{array}$ & 5. Jh. n. Chr. & $\begin{array}{l}\text { ARS Hayes 50B } \\
\text { LRA } 3 \\
\text { KW Töpfe }\end{array}$ & $\begin{array}{l}\text { M } 120 \\
\text { M } 123 \\
\text { M } 256\end{array}$ \\
\hline $\begin{array}{l}\text { KS3 } \\
(2007) \\
\text { KiNr. } \\
164\end{array}$ & SE 38 & 2 & $\begin{array}{l}\text { insignifikant aufgrund } \\
\text { geringer Fundquantität }\end{array}$ & kaiserzeitlich & - & - \\
\hline
\end{tabular}

Tab. 88 


\subsubsection{Funde aus der Sondage im Zugangssystem ES1}

Im Südflügel des Theaters ist im Bereich des vomitorium mit dem Eingang ES1 ${ }^{207}$ eine spätantik-frühbyzantinische Nutzung (5./6. Jh. n. Chr.) bezeugt (Tab. 89). Der entsprechende Fundkomplex ist allerdings rezent gestört. Die restlichen beiden Fundkomplexe enthalten kein feinchronologisch relevantes Keramikmaterial.

\begin{tabular}{|l|l|l|l|l|l|l|}
\hline $\begin{array}{l}\text { Fläche, } \\
\text { KiNr. }\end{array}$ & Stratum & $\begin{array}{l}\text { Anzahl } \\
\text { diagnost. } \\
\text { Funde }\end{array}$ & $\begin{array}{l}\text { Charakterisierung } \\
\text { Fundkomplex }\end{array}$ & Datierung & $\begin{array}{l}\text { Datierungskriterien: } \\
\text { jüngste Keramik (u. Glas) }\end{array}$ & $\begin{array}{l}\text { Münzen } \\
\text { (Kap. 8) }\end{array}$ \\
\hline $\begin{array}{l}\text { Südauf- } \\
\text { gang Ki } \\
46\end{array}$ & FK 46/98 & 7 & rezent gestört & 5./6. Jh. n. Chr. & LRC Hayes 3 & - \\
\hline $\begin{array}{l}\text { Südauf- } \\
\text { gang Ki } \\
47\end{array}$ & FK 47/98 & 1 & $\begin{array}{l}\text { insignifikant aufgrund } \\
\text { geringer Fundquantiät }\end{array}$ & - & Amphore & - \\
\hline $\begin{array}{l}\text { Südauf- } \\
\text { gang Ki } \\
48\end{array}$ & FK 48/98 & 1 & $\begin{array}{l}\text { insignifikant aufgrund } \\
\text { geringer Fundquantität }\end{array}$ & - & Amphorenhenkel & - \\
\hline
\end{tabular}

Tab. 89

\subsubsection{Funde aus der Sondage im Zugangssystem ES3}

Die keramischen Funde aus dem Bereich des oberen Theatereingangs im Süden, ES3 ${ }^{208}$, können, mit Ausnahme eines Wandstücks der LRC, dessen Vorkommen aber auch sekundär bedingt sein kann, hauptsächlich in das ausgehende 2. bis 3. Jh. n. Chr. datiert werden (Tab. 90). Hervorzuheben ist der teilweise gute Erhaltungszustand mancher Gefäße.

\begin{tabular}{|c|c|c|c|c|c|c|}
\hline $\begin{array}{l}\text { Fläche, } \\
\text { KiNr. }\end{array}$ & Stratum & $\begin{array}{l}\text { Anzahl } \\
\text { diagnost. } \\
\text { Funde }\end{array}$ & $\begin{array}{l}\text { Charakterisierung } \\
\text { Fundkomplex }\end{array}$ & Datierung & $\begin{array}{l}\text { Datierungskriterien: } \\
\text { jüngste Keramik (u. Glas) }\end{array}$ & $\begin{array}{l}\text { Münzen } \\
\text { (Kap. 8) }\end{array}$ \\
\hline $\begin{array}{l}\text { S 3/1998 } \\
\text { Ki } 30\end{array}$ & FK 30/98 & 12 & $\begin{array}{l}\text { kleiner Fundkomplex } \\
\text { heterogen } \\
\text { hellenistisch-kaiserzeit- } \\
\text { lich (Großteil)/spätantik } \\
\text { (vereinzelt) }\end{array}$ & $\begin{array}{l}\text { 2./3. Jh. n. Chr. } \\
\text { 5. Jh. n. Chr.? }\end{array}$ & $\begin{array}{l}\text { KW Töpfchen } \\
\text { GK Schüssel } \\
\text { LRC (1 WS)? }\end{array}$ & - \\
\hline $\begin{array}{l}\text { S 3/1998 } \\
\text { Ki } 31\end{array}$ & FK 31/98 & 6 & $\begin{array}{l}\text { kleiner Fundkomplex } \\
\text { heterogen }\end{array}$ & 2.-3. Jh. n. Chr. & $\begin{array}{l}\text { ESC Hayes } 1 \\
\text { Glas: } 1 \text { RS Becher }\end{array}$ & - \\
\hline $\begin{array}{l}\text { S 3/1998 } \\
\text { Ki } 35\end{array}$ & FK 35/98 & 17 & $\begin{array}{l}\text { homogen } \\
\text { z. T. gut erhaltene Gefäße } \\
\text { (Schale ESC Hayes 3, zu } \\
\text { zwei Dritteln erhalten) }\end{array}$ & $\begin{array}{l}\text { Ende 2.-3. Jh. n. } \\
\text { Chr. }\end{array}$ & $\begin{array}{l}\text { ESC Hayes } 3 \\
\text { ESC Altante L19/Hayes } 3 \\
\text { Glas: Becher mit einfachem, } \\
\text { gerundetem Rand } \\
\text { Boden mit echtem Standring }\end{array}$ & - \\
\hline
\end{tabular}

Tab. 90

\footnotetext{
${ }^{207}$ Kap. 3.6.3.

${ }^{208}$ Kap. 3.6.4.
} 


\subsection{FUNDE AUS DEN SONDAGEN IN DER STIEGENGASSE}

In den Jahren 2007 bis 2009 wurde die Freitreppe im Süden des Theaters freigelegt ${ }^{209}$. Im Folgenden wird die Datierung der teils massiven Schuttschichten, welche die Treppe bisweilen meterhoch bedeckten, tabellarisch dargelegt. Es erfolgt eine Charakterisierung des jeweiligen Fundkontexts und die Hervorhebung der als Datierungskriterien zu bewertenden Funde. Dabei wird - in Übereinstimmung mit der Diskussion der Befunde - nach definierten Abschnitten vorgegangen, vom Osten (dem oberen Zugang, ES3) nach Westen (bis zum unteren Zugang, ES1). Innerhalb der Unterteilung der Abschnitte folgt die Darstellung der Reihenfolge der Schichtbezeichnungen. Vorangestellt ist jeweils ein kurzes Resümee der Straten pro Abschnitt.

\subsubsection{Zugangspodest ES3}

Das Fundmaterial südlich des Theaterzugangs ES3 (Tab. 91) setzt mit SE 165 im ausgehenden 1. Jh. v. Chr. bis 1. Viertel des 1. Jhs. n. Chr. ein. SE 161 datiert in die Mitte des 2. bis in das 3. Jh. n. Chr. Der 2. Hälfte des 3. Jhs. n. Chr. zuzuordnen und vermutlich mit der Erdbebenzerstörung des 3. Viertels des 3. Jhs. n. Chr. in Zusammenhang zu bringen sind die keramischen Funde aus SE 2, SE 4?, SE 5a, eventuell auch SE 39. Die 1. Hälfte des 4. Jhs. n. Chr. ist, wie in ganz Ephesos zu beobachten, nicht bezeugt. Frühestens in die 2. Hälfte des 4. Jhs. n. Chr. datiert SE 7 (= SE 143), die allerdings auch Fundmaterial späthellenistischer und kaiserzeitlicher Zeitstellung enthält. Ähnlich verhält es sich mit der Fundzusammensetzung in SE 11. Die Entstehung der sehr umfangreichen, zeitlich heterogenes Fundmaterial enthaltenen Straten SE 12, SE 14 und SE 20 ist aufgrund der jüngsten Keramikfunde in die 2. Hälfte des 4. bis Mitte des 5. Jhs. n. Chr. zu datieren. SE 20 setzt sich allerdings in Form von SE 132a-c (Tab. 92) auch über den Bereich Treppe-Ost fort. Das jüngste Fundmaterial aus SE 132a-c datiert vom ausgehenden 5. bis in das 6. Jh. n. Chr., sodass auch für SE 20 im Bereich des Zugangspodests ES3 aufgrund der Zusammengehörigkeit mit SE 132a-c mit einer späteren Datierung zu rechnen sein wird. Die Datierung von SE 14a kann nur etwas weiter gefasst werden (3. bis 5. Jh. n. Chr.). Die Kanalverfüllung SE 36. 37. 71. 120 enthält sehr viel Fundmaterial aus dem 3. Jh. n. Chr., vermischt mit vereinzelten Funden aus dem 4./5. Jh. n. Chr. und mit wenigen älteren Residuals. Ähnlich verhält es sich mit SE 15. In SE 9 wurde Fundmaterial aus dem 5. bis 6. Jh. n. Chr. geborgen, wobei es sich um das jüngste Fundmaterial im gesamten Bereich vor ES 3 handelt.

\begin{tabular}{|c|c|c|c|c|c|c|}
\hline $\begin{array}{l}\text { Fläche, } \\
\text { KiNr. }\end{array}$ & Stratum & $\begin{array}{l}\text { Anzahl } \\
\text { diagnost. } \\
\text { Funde }\end{array}$ & $\begin{array}{l}\text { Charakterisierung } \\
\text { Fundkomplex }\end{array}$ & Datierung & $\begin{array}{l}\text { Datierungskriterien: } \\
\text { jüngste Keramik (u. Glas) }\end{array}$ & $\begin{array}{l}\text { Münzen } \\
\text { (Kap. 8) }\end{array}$ \\
\hline $\begin{array}{l}\text { B2 } \\
\text { C1 } \\
\text { C2 } \\
\mathrm{KiNr} . \\
27 / 07 . \\
35 / 09 . \\
50 / 07 . \\
60 / 07\end{array}$ & SE 2 & 61 & $\begin{array}{l}\text { heterogen } \\
\text { späthellenistisch-2. H. } 3 . \\
\text { Jh. n. Chr. } \\
\text { tw. versintert }\end{array}$ & 2. H. 3. Jh. n. Chr. & $\begin{array}{l}\text { ARS Hayes 50A } \\
\text { ESC Atlante Hayes } 4 \\
\text { ESB Atlante } 70 \\
\text { DWK Becher } \\
\text { Glas: Rippenschale (CZURDA-RUTH } \\
\text { 2007, 37-42) }\end{array}$ & M 92 \\
\hline $\begin{array}{l}\mathrm{B} 2 \\
\mathrm{KiNr} . \\
8 / 07 . \\
54 / 08\end{array}$ & SE 4 & 11 & $\begin{array}{l}\text { heterogen } \\
\text { kaiserzeitlich/3.-4. Jh. } \\
\text { n. Chr. }\end{array}$ & 3.-4. Jh. n. Chr. & $\begin{array}{l}\text { ARS WS grob } \\
\text { GK Schale } \\
\text { KW Teller }\end{array}$ & - \\
\hline
\end{tabular}

\footnotetext{
${ }^{209} \mathrm{Zu}$ den Sondagen s. Kap. 3.7.1-3.7.3.
} 


\begin{tabular}{|c|c|c|c|c|c|c|}
\hline $\begin{array}{l}\text { Fläche, } \\
\text { KiNr. }\end{array}$ & Stratum & \begin{tabular}{|l|} 
Anzahl \\
diagnost. \\
Funde
\end{tabular} & $\begin{array}{l}\text { Charakterisierung } \\
\text { Fundkomplex }\end{array}$ & Datierung & $\begin{array}{l}\text { Datierungskriterien: } \\
\text { jüngste Keramik (u. Glas) }\end{array}$ & $\begin{array}{l}\text { Münzen } \\
\text { (Kap. 8) }\end{array}$ \\
\hline $\begin{array}{l}\mathrm{B} 2 \\
\mathrm{KiNr} \\
57 / 07\end{array}$ & SE 5a & 19 & nahezu homogen & 2. H. 3. Jh. n. Chr. & $\begin{array}{l}\text { ARS Hayes 50A } \\
\text { ESC Hayes } 1 \\
\text { ESC Hayes } 3 \\
\text { DWK Becher }\end{array}$ & - \\
\hline $\begin{array}{l}\text { B1 } \\
\text { B2 } \\
\text { KiNr. } 12 . \\
79 / 07 \\
81 / 07 \\
87 / 07 \\
88 / 07 \\
107 / 07 \\
108 / 07 \\
109 / 08\end{array}$ & $\begin{array}{l}\text { SE } 7 \\
(=\mathrm{SE} \\
143)\end{array}$ & 103 & $\begin{array}{l}\text { heterogen } \\
\text { 2.-1. Jh. v. Chr./1.-2. Jh. } \\
\text { n. Chr./2. H. 4. Jh. n. Chr. }\end{array}$ & 2. H. 4. Jh. n. Chr. & $\begin{array}{l}\text { ARS Hayes 50B } \\
\text { Imitation Sigillata } \\
\text { KW Topf } \\
\text { KW Pfanne } \\
\text { KW Deckel }\end{array}$ & $\begin{array}{l}\text { M } 20 \\
\text { M } 85 \\
\text { M } 112 \\
\text { M } 114 \\
\text { M } 115\end{array}$ \\
\hline $\begin{array}{l}\mathrm{B} 1 \\
\mathrm{KiNr} \\
18 / 07\end{array}$ & SE 8 & 1 & $\begin{array}{l}\text { insignifikant aufgrund } \\
\text { geringer Fundquantität }\end{array}$ & kaiserzeitlich? & GK Schüssel & - \\
\hline $\begin{array}{l}\text { B1 } \\
\text { B2 } \\
\text { KiNr. } \\
49 / 07 . \\
54 / 07 . \\
71 / 07\end{array}$ & SE 9 & 55 & $\begin{array}{l}\text { heterogen } \\
\text { 2.-1. Jh. v. Chr./kaiser- } \\
\text { zeitlich/5.-6. Jh. n. Chr. }\end{array}$ & 5./6. Jh. n. Chr. & $\begin{array}{l}\text { LRC Hayes 1B } \\
\text { LRC Hayes } 3 \\
1 \text { BS ARS } \\
\text { RSW Teller } \\
\text { KW Topf } \\
\text { KW Kasserolle }\end{array}$ & M 106 \\
\hline $\begin{array}{l}\text { B1 } \\
\text { B2 } \\
\text { KiNr. } \\
\text { 26/07. } \\
72 / 07 . \\
85 / 07 . \\
91 / 07\end{array}$ & SE 11 & 23 & $\begin{array}{l}\text { heterogen } \\
\text { späthellenistisch-kaiser- } \\
\text { zeitlich/2. H. 4. Jh. n. Chr. }\end{array}$ & 2. H. 4. Jh. n. Chr. & ARS Hayes 50B & - \\
\hline $\begin{array}{l}\text { B1 } \\
\text { B2 } \\
\text { C1 } \\
\text { C2 } \\
\mathrm{KiNr} . \\
13 / 07 . \\
31 / 07 . \\
38 / 07 . \\
52 / 07 . \\
55 / 08 \\
59 / 07 . \\
66 / 07 . \\
70 / 08 . \\
71 / 08 . \\
74 / 07\end{array}$ & SE 12 & 105 & $\begin{array}{l}\text { heterogen } \\
\text { späthellenistisch-mittel- } \\
\text { kaiserzeitlich/2. H. 4.-1. } \\
\text { Viertel 5. Jh. n. Chr. }\end{array}$ & $\begin{array}{l}\text { 2. H. 4. Jh. n. } \\
\text { Chr.-1. Viertel } 5 . \\
\text { Jh. n. Chr. }\end{array}$ & $\begin{array}{l}\text { LRC Hayes } 1 \\
\text { ARS Hayes 50B } \\
\text { ESC Hayes } 4 \\
\text { ERSW } \\
\text { Glas: Schale mit breitem, nach } \\
\text { außen überhängendem Rand (Har- } \\
\text { ter Form A14) } \\
\text { Boden mit tropfenförmigem } \\
\text { Standring (CzURDA-RUTH 2007, } \\
\text { Kap. 25l) }\end{array}$ & $\begin{array}{l}\text { M } 75 \\
\text { (Tab. } \\
110 \text { Kap. } \\
8.2 .7 \text { ) } \\
\text { M } 198\end{array}$ \\
\hline
\end{tabular}




\begin{tabular}{|c|c|c|c|c|c|c|}
\hline $\begin{array}{l}\text { Fläche, } \\
\text { KiNr. }\end{array}$ & Stratum & $\begin{array}{l}\text { Anzahl } \\
\text { diagnost. } \\
\text { Funde }\end{array}$ & $\begin{array}{l}\text { Charakterisierung } \\
\text { Fundkomplex }\end{array}$ & Datierung & $\begin{array}{l}\text { Datierungskriterien: } \\
\text { jüngste Keramik (u. Glas) }\end{array}$ & $\begin{array}{l}\text { Münzen } \\
\text { (Kap. 8) }\end{array}$ \\
\hline $\begin{array}{l}\text { B1 } \\
\text { B2 } \\
\text { C2 } \\
\text { KiNr. } \\
7 / 07 . \\
14 / 07 \\
36 / 07 \\
37 / 07 \\
41 / 07 \\
48 / 07 \\
53 / 07 \\
57 / 08 \\
61 / 07 \\
64 / 07 \\
65 / 07 \\
72 / 07 \\
131 / 07 . \\
140 / 07 \\
159 / 07\end{array}$ & SE 14 & 144 & $\begin{array}{l}\text { heterogen } \\
\text { mittelkaiserzeitlich/2. H. } \\
\text { 4.-Anf. 5. Jh. n. Chr. }\end{array}$ & $\begin{array}{l}\text { 2. H. 4/.Anf. 5. Jh. } \\
\text { n. Chr. }\end{array}$ & $\begin{array}{l}\text { LRC Hayes 1A } \\
\text { ARS Hayes 50B } \\
\text { LRA 3 } \\
\text { LRA 2 } \\
\text { RSW Schale } \\
\text { RSW Becher } \\
\text { KW Topf }\end{array}$ & $\begin{array}{l}\text { M } 104 \\
\text { M } 105\end{array}$ \\
\hline $\begin{array}{l}\text { B1 } \\
\text { B2 } \\
\text { KiNr. } \\
32 / 07 \\
44 / 07 \\
45 / 07 \\
55 / 07\end{array}$ & SE 14a & 32 & $\begin{array}{l}\text { heterogen } \\
\text { kaiserzeitlich/3.-5. Jh. } \\
\text { n. Chr. } \\
\text { keine Feinkeramik }\end{array}$ & 3.-5. Jh. n. Chr. & $\begin{array}{l}\text { DWK Becher } \\
\text { Amphore, afrikanisch } \\
\text { KW Topf } \\
\text { GK Krug } \\
\text { KW Teller } \\
\text { Glas: Lampe (1 Henkel, CZURDA- } \\
\text { RUTH 2007, Kap. 27) }\end{array}$ & - \\
\hline $\begin{array}{l}\mathrm{B} 2 \\
\mathrm{KiNr} \\
2 / 07 \\
3 / 07 \\
24 / 07\end{array}$ & SE 15 & 19 & $\begin{array}{l}\text { heterogen } \\
\text { späthellenistisch-kaiser- } \\
\text { zeitlich/1. H. 5. Jh. n. Chr. } \\
\text { wenig Feinkeramik }\end{array}$ & $\begin{array}{l}\text { spätes 4./1. H. } 5 . \\
\text { Jh. n. Chr. }\end{array}$ & LRC Hayes 4 & - \\
\hline $\begin{array}{l}\text { B2 } \\
\text { C1 } \\
\text { C2 } \\
\text { D1 } \\
\mathrm{KiNr} . \\
37 / 08 . \\
141 / 07 . \\
162 / 07\end{array}$ & $\begin{array}{l}\text { SE 20 } \\
(=\mathrm{SE} \\
132 \mathrm{a}-\mathrm{c}, \\
\text { Tab. 92) }\end{array}$ & 52 & $\begin{array}{l}\text { heterogen } \\
\text { späthellenistisch (wenig)- } \\
\text { kaiserzeitlich/4.-Mitte 5. } \\
\text { Jh. n. Chr. (wenig) }\end{array}$ & $\begin{array}{l}\text { spätes 1.-1. H. } 2 . \\
\text { Jh. n. Chr. } \\
\\
\text { 4.-Mitte 5. Jh. n. } \\
\text { Chr. }\end{array}$ & $\begin{array}{l}\text { ESC Atlante L } 19 \\
\text { ESB Atlante 64B/65 } \\
\text { ESB Atlante 71 } \\
\text { ESB Atlante 58/70 } \\
\text { DWK Becher } \\
\text { DWK Topf } \\
\text { KW Kasserolle } \\
\text { GK Askos } \\
\text { Amphoren Peacock - } \\
\text { Williams 45 } \\
1 \text { ROW-Lampe } \\
\\
\text { ARS grob } \\
\text { Spatheion } 1\end{array}$ & M 84 \\
\hline
\end{tabular}




\begin{tabular}{|c|c|c|c|c|c|c|}
\hline $\begin{array}{l}\text { Fläche, } \\
\text { KiNr. }\end{array}$ & Stratum & $\begin{array}{l}\text { Anzahl } \\
\text { diagnost. } \\
\text { Funde }\end{array}$ & $\begin{array}{l}\text { Charakterisierung } \\
\text { Fundkomplex }\end{array}$ & Datierung & $\begin{array}{l}\text { Datierungskriterien: } \\
\text { jüngste Keramik (u. Glas) }\end{array}$ & $\begin{array}{l}\text { Münzen } \\
\text { (Kap. 8) }\end{array}$ \\
\hline $\begin{array}{l}\text { B1 } \\
\text { C1 } \\
\text { KiNr. } \\
123 / 08 . \\
135 / 08\end{array}$ & $\begin{array}{l}\text { SE } 31= \\
\text { SE } 133 \\
\text { (s. u. } \\
\text { Tab.92) }\end{array}$ & 71 & $\begin{array}{l}\text { heterogen } \\
\text { späthellenistisch/2.-4. Jh. } \\
\text { n. Chr. } \\
\text { keine Feinkeramik }\end{array}$ & 2.-4. Jh. n. Chr. & Amphore Kapitän II & - \\
\hline $\begin{array}{l}\text { B1 } \\
\text { B2 } \\
\text { KiNr. } \\
76 / 08 \\
79 / 08 \\
87 / 08 \\
163 / 07 \\
165 / 07 \\
167 / 07\end{array}$ & $\begin{array}{l}\mathrm{SE} 36= \\
37=71= \\
120\end{array}$ & 134 & $\begin{array}{l}\text { heterogen } \\
\text { späthellenistisch-3. Jh. } \\
\text { n. Chr.- 4./5. Jh. n. Chr. } \\
\text { (vereinzelt) } \\
\text { viel DWK, viel GK } \\
1 \text { DWK Becher zu drei } \\
\text { Vierteln erh., } 1 \text { GK Dek- } \\
\text { kel vollständig erh. }\end{array}$ & $\begin{array}{l}\text { 3. Jh. n. Chr. } \\
\text { 4./5. Jh. n. Chr. }\end{array}$ & $\begin{array}{l}\text { ARS Hayes 50A } \\
\text { ESB Atlante } 60 \\
\text { ESB Atlante } 70 \\
\text { DWK Töpfchen } \\
\text { DWK Becher mit Ritzung } \\
\text { GK Schüssel } \\
\text { KW Topf/Kasserole } \\
\\
\text { Glas: Facettenbecher (Vgl. z. B. } \\
\text { SCHÄTZSCHOCK 2005, G } 90 \text { (AR } \\
\text { 60.1-I 96b1); BARKÓcZI 1986, } \\
\text { Abb. 4, 1. 2) } \\
\text { voller hoher Standfuß } \\
\text { voller flacher Standfuß } \\
\text { Fensterglas }\end{array}$ & - \\
\hline $\begin{array}{l}\text { B1 } \\
\text { KiNr. } \\
168 / 07\end{array}$ & SE 39 & 16 & $\begin{array}{l}\text { heterogen } \\
\text { späthellenistisch/3.-4. Jh. } \\
\text { n. Chr. }\end{array}$ & 3.-4. Jh. n. Chr. & $\begin{array}{l}\text { ARS, } 1 \text { BS } \\
\text { Amphore Kapitän II }\end{array}$ & - \\
\hline $\begin{array}{l}\mathrm{B} 2 \\
\mathrm{KiNr} \\
73 / 08\end{array}$ & SE 100 & 6 & $\begin{array}{l}\text { heterogen } \\
\text { späthellenistisch-kaiser- } \\
\text { zeitlich } \\
\text { keine feinchronologisch } \\
\text { relevanten Funde }\end{array}$ & - & - & - \\
\hline $\begin{array}{l}\text { B1 } \\
\text { KiNr. } \\
167 / 08\end{array}$ & SE 161 & 18 & $\begin{array}{l}\text { heterogen } \\
\text { späthellenistisch/Mitte } \\
\text { 2.-3. Jh. n. Chr }\end{array}$ & $\begin{array}{l}\text { Mitte 2.-3. Jh. n. } \\
\text { Chr. }\end{array}$ & $\begin{array}{l}\text { ESC Hayes } 3 \\
\text { KW Töpfe }\end{array}$ & - \\
\hline $\begin{array}{l}\text { B1 } \\
\text { KiNr. } \\
168 / 08\end{array}$ & SE 164 & 4 & $\begin{array}{l}\text { klein, keine feinchronolo- } \\
\text { gisch relevanten Funde }\end{array}$ & kaiserzeitlich & & - \\
\hline $\begin{array}{l}\text { B1 } \\
\text { KiNr. } \\
172 / 08\end{array}$ & SE 165 & 11 & nahezu homogen & $\begin{array}{l}\text { 3. Viertel 1. Jh. v. } \\
\text { Chr.-1. Viertel } 1 . \\
\text { Jh. n. Chr. }\end{array}$ & $\begin{array}{l}\text { ESB } \\
\text { Prä-ESB } \\
\text { Krug hell. FW } \\
\text { Reliefbecher }\end{array}$ & - \\
\hline
\end{tabular}

Tab. 91 


\subsubsection{Treppe-Ost}

Im Abschnitt Treppe-Ost sei das Stratum SE 136 hervorgehoben (Tab. 92), das sehr viel Fundmaterial enthielt, welches dem 3. Viertel des 3. Jhs. n. Chr. zugeordnet werden kann. Mit Sicherheit bezeugen die z. T. gut erhaltenen Gefäße ein Inventar aus mindestens einem Gebäude, welches durch das große Erdbeben in dieser Zeit zerstört wurde. Weitere Straten enthalten Fundmaterial ähnlicher Zeitstellung und Beschaffenheit (SE 132a-c $=\mathrm{SE} 20$ [Tab. 91], SE 133 = SE 31, SE 140), bisweilen auch vergesellschaftet mit jüngerem Material (SE 152, SE 155). Die jüngsten Funde aus SE 132a-c belegen Aktivitäten, welche in das späte 5. und 6. Jh. n. Chr. zu datieren sind und demnach die späteste Nutzung dieses Bereichs anzeigen.

\begin{tabular}{|c|c|c|c|c|c|c|}
\hline $\begin{array}{l}\text { Fläche, } \\
\text { KiNr. }\end{array}$ & Stratum & \begin{tabular}{|l|} 
Anzahl \\
diagnost. \\
Funde
\end{tabular} & $\begin{array}{l}\text { Charakterisierung } \\
\text { Fundkomplex }\end{array}$ & Datierung & $\begin{array}{l}\text { Datierungskriterien: } \\
\text { jüngste Keramik (u. Glas) }\end{array}$ & $\begin{array}{l}\text { Münzen } \\
\text { (Kap. 8) }\end{array}$ \\
\hline $\begin{array}{l}\mathrm{C} 2 \\
\mathrm{KiNr} . \\
128 / 07 \\
130 / 07 \\
132 / 07 \\
155 / 07\end{array}$ & SE 13 & 68 & $\begin{array}{l}\text { heterogen } \\
\text { späthellenistisch (wenig)/ } \\
\text { kaiserzeitlich/4.-5. Jh. n. } \\
\text { Chr. (vereinzelt, ev. durch } \\
\text { Vermischung mit SE } 14 \\
\text { zu erklären) }\end{array}$ & $\begin{array}{l}\text { Ende 1./1. H. } 2 . \\
\text { Jh. n. Chr. } \\
\text { 4./5. Jh. n. Chr. }\end{array}$ & $\begin{array}{l}\text { ESC Atlante Hayes } 4 \\
\text { ESC Atlante L } 19 \\
\text { ESB Atlante } 60 \\
\text { ESB Atlante } 70 \\
\text { ESB Atlante } 76 \mathrm{~A} \\
\text { DWK Becher } \\
\text { LRC Hayes 2A } \\
\text { ARS Hayes 50B }\end{array}$ & - \\
\hline $\begin{array}{l}\mathrm{C} 1 \\
\mathrm{KiNr} . \\
161 / 07\end{array}$ & SE 19 & 8 & $\begin{array}{l}\text { homogen } \\
\text { wenige feinchronologisch } \\
\text { relevante Funde }\end{array}$ & $\begin{array}{l}\text { 3. Viertel 1.-2. Jh. } \\
\text { n. Chr. }\end{array}$ & $\begin{array}{l}\text { ESB 76A } \\
\text { DWK Becher } \\
\text { GK Schüssel }\end{array}$ & - \\
\hline $\begin{array}{l}\text { C1 } \\
\text { D1 } \\
\text { KiNr. } \\
139 / 08 \\
\end{array}$ & SE 30 & 11 & $\begin{array}{l}\text { homogen } \\
\text { keine feinchronologisch } \\
\text { relevanten Funde }\end{array}$ & kaiserzeitlich & - & - \\
\hline $\begin{array}{l}\mathrm{D} 2 \\
\mathrm{KiNr} . \\
127 / 08\end{array}$ & SE $124 ?$ & 15 & - & $\begin{array}{l}\text { kaiserzeitlich/2. } \\
\text { Jh. n. Chr. (?) }\end{array}$ & RSW Imitation ESB Atlante 60 & M 62 \\
\hline $\begin{array}{l}\mathrm{C} 1 \\
\mathrm{C} 2 \\
\text { KiNr. } \\
97 / 08 . \\
100 / 08 . \\
106 / 08 . \\
110 / 08\end{array}$ & $\begin{array}{l}\text { SE } 132 \mathrm{a} \\
=132 \mathrm{~b} \\
=132 \mathrm{c} \\
=20 \\
(\text { Tab. } 91)\end{array}$ & 59 & $\begin{array}{l}\text { heterogen } \\
\text { späthellenistisch } \\
\text { (vereinzelt) 3. Jh. n. Chr./ } \\
\text { 5.-6. Jh. n. Chr. } \\
\text { (vereinzelt) }\end{array}$ & $\begin{array}{l}\text { 2. H. 3. Jh. n. Chr. } \\
\text { spätes 5-6. Jh. n. } \\
\text { Chr. }\end{array}$ & $\begin{array}{l}\text { ARS Hayes 50A } \\
\text { ESC Hayes } 3 \\
\text { ESC Atlante L } 19 \\
\text { LRC Hayes } 3 \\
\text { ERSW Hayes 1C } \\
\text { ERSW Hayes } 3 \\
\text { KW Kasserolle } \\
\text { Glas: Boden mit Standplatte }\end{array}$ & M 84 \\
\hline $\begin{array}{l}\mathrm{C} 1 \\
\mathrm{KiNr} . \\
43 / 08\end{array}$ & $\begin{array}{l}\text { SE } 133= \\
\text { SE 31 } \\
\text { (s. o. Tab. } \\
\text { 91) }\end{array}$ & 69 & $\begin{array}{l}\text { heterogen } \\
\text { frühkaiserzeitlich-2. } \\
\text { Hälfte } 3 . \text { Jh. n. Chr. } \\
\text { vgl. Zerstörungs-Fund- } \\
\text { komplexe aus dem HH } 2\end{array}$ & $\begin{array}{l}\text { 2. Hälfte-spätes } 3 . \\
\text { Jh. n. Chr. }\end{array}$ & $\begin{array}{l}\text { ARS Hayes 45A } \\
\text { ESC Hayes } 4\end{array}$ & - \\
\hline $\begin{array}{l}\mathrm{C} 1 \\
\mathrm{KiNr} \\
95 / 08\end{array}$ & SE 134 & 1 & - & 3./4. Jh. n. Chr. & $\begin{array}{l}\text { Glas: Flasche Isings 102b (CZURDA- } \\
\text { RuTH 2007, 203, Kap. 30. A. IV.) } \\
\text { mit trichterförmiger Mündung und } \\
\text { gerundetem Rand }\end{array}$ & - \\
\hline
\end{tabular}




\begin{tabular}{|c|c|c|c|c|c|c|}
\hline $\begin{array}{l}\text { Fläche, } \\
\text { KiNr. }\end{array}$ & Stratum & \begin{tabular}{|l|} 
Anzahl \\
diagnost. \\
Funde
\end{tabular} & $\begin{array}{l}\text { Charakterisierung } \\
\text { Fundkomplex }\end{array}$ & Datierung & $\begin{array}{l}\text { Datierungskriterien: } \\
\text { jüngste Keramik (u. Glas) }\end{array}$ & $\begin{array}{l}\text { Münzen } \\
\text { (Kap. 8) }\end{array}$ \\
\hline $\begin{array}{l}\mathrm{C} 1 \\
\mathrm{KiNr} \\
94 / 08\end{array}$ & SE 135 & 1 & - & - & Glas: $1 \mathrm{BS}$ & - \\
\hline $\begin{array}{l}\mathrm{C} 1 \\
\mathrm{C} 2 \\
\mathrm{D} 1 \\
\mathrm{D} 2 \\
\mathrm{KiNr} \\
35 / 08 \\
47 / 08 \\
48 / 08 \\
96 / 08 \\
102 / 08 \\
103 / 08 \\
107 / 08 \\
108 / 08 \\
114 / 08 \\
115 / 08 \\
122 / 08 \\
129 / 08 \\
130 / 08 \\
131 / 08 \\
132 / 08 \\
138 / 08 \\
141 / 08 \\
152 / 08 \\
153 / 08 \\
157 / 08 \\
158 / 08 \\
159 / 08\end{array}$ & SE 136 & 303 & $\begin{array}{l}\text { vereinzelte späthellenisti- } \\
\text { sche und mittelkaiserzeit- } \\
\text { liche Residuals, ansonsten } \\
\text { homogen } \\
\text { z. T. gut erhaltene Gefäße } \\
\text { Zusammensetzung vgl. } \\
\text { Zerstörungs-Fundkomple- } \\
\text { xe aus dem HH } 2\end{array}$ & $\begin{array}{l}\text { 3. Viertel 3. Jh. } \\
\text { n. Chr. }\end{array}$ & $\begin{array}{l}\text { ARS Hayes 44 } \\
\text { ARS Hayes 45A } \\
\text { ARS Hayes 50A } \\
\text { ESC Hayes } 4 \\
\text { ESC Hayes } 3 \\
\\
\text { Glas: Krug Isings 126 (SCHÄTz- } \\
\text { scHOCK 2010b, B-G 40) mit } \\
\text { trichterförmiger Mündung und } \\
\text { horizontal umlaufender Glasfaden- } \\
\text { auflage } \\
\text { Becher mit einfachem, gerundetem } \\
\text { Rand } \\
\text { Boden mit hohem Standring }\end{array}$ & - \\
\hline $\begin{array}{l}\mathrm{C} 2 \\
\mathrm{D} 2 \\
\mathrm{KiNr} . \\
112 / 08 . \\
149 / 08 . \\
164 / 08 . \\
170 / 08\end{array}$ & SE 137 & 25 & homogen & 2. Jh. n. Chr. & $\begin{array}{l}\text { ESB Atlante } 60 \\
\text { ESA Atlante } 37 \text { B } \\
\text { DWK Töpfchen } \\
\text { DWK Becher } \\
\text { KW Topf } \\
\text { Glas: Boden mit hohem Standring }\end{array}$ & - \\
\hline $\begin{array}{l}\mathrm{C} 1 \\
\mathrm{C} 2 \\
\mathrm{KiNr} . \\
104 / 08\end{array}$ & SE 138 & 3 & $\begin{array}{l}\text { geringe Fundquantität } \\
\text { keine feinchronologisch } \\
\text { aussagekräftigen Funde }\end{array}$ & 1.-3. Jh. n. Chr. & & - \\
\hline $\begin{array}{l}\text { C1 } \\
\text { D1 } \\
\text { KiNr. } \\
99 / 08 . \\
137 / 08\end{array}$ & SE 139 & 13 & $\begin{array}{l}\text { ev. } 5 \text {. Jh. n. Chr., } \\
\text { vermutlich sekundär }\end{array}$ & $\begin{array}{l}\text { 1. H. 3. Jh. n. Chr. } \\
\text { 5. Jh. n. Chr.? }\end{array}$ & $\begin{array}{l}\text { ARS Hayes } 33 \\
\text { ESC Hayes } 3 \\
\text { KW Töpfchen } \\
\text { KW Kasserolle }\end{array}$ & - \\
\hline
\end{tabular}




\begin{tabular}{|c|c|c|c|c|c|c|}
\hline $\begin{array}{l}\text { Fläche, } \\
\text { KiNr. }\end{array}$ & Stratum & $\begin{array}{l}\text { Anzahl } \\
\text { diagnost. } \\
\text { Funde }\end{array}$ & $\begin{array}{l}\text { Charakterisierung } \\
\text { Fundkomplex }\end{array}$ & Datierung & $\begin{array}{l}\text { Datierungskriterien: } \\
\text { jüngste Keramik (u. Glas) }\end{array}$ & $\begin{array}{l}\text { Münzen } \\
\text { (Kap. 8) }\end{array}$ \\
\hline $\begin{array}{l}\text { C1 } \\
\text { D1 } \\
\text { D2 } \\
\text { KiNr. } \\
105 / 08 . \\
113 / 08 . \\
126 / 08 . \\
150 / 08\end{array}$ & SE 140 & 57 & $\begin{array}{l}\text { wenige späthellenistische } \\
\text { Residuals } \\
\text { Fundmaterial innerhalb } \\
\text { der Kaiserzeit feinchro- } \\
\text { nologisch meist nicht } \\
\text { zuordenbar }\end{array}$ & 2. H. 3. Jh. n. Chr. & $\begin{array}{l}\text { ARS Hayes 45A } \\
\text { ESC Hayes } 4 \\
\text { ESC Hayes 1-2 } \\
\text { DWK Becher } \\
\text { Amphoren Kapitän II } \\
\text { Glas: 1 BS }\end{array}$ & - \\
\hline $\begin{array}{l}\text { D2 } \\
\text { KiNr. } \\
154 / 08\end{array}$ & $\begin{array}{l}\text { SE } 141 \\
(=\mathrm{SE} \\
142)\end{array}$ & 2 & $\begin{array}{l}\text { insignifikant aufgrund } \\
\text { geringer Fundquantität }\end{array}$ & $\begin{array}{l}230 / 40-320 \mathrm{n} . \\
\text { Chr. }\end{array}$ & Hayes 45A & - \\
\hline $\begin{array}{l}\mathrm{C} 1 \\
\mathrm{KiNr} . \\
121 / 08\end{array}$ & SE 145 & 5 & $\begin{array}{l}\text { geringe Fundquantität } \\
\text { feinchronologisch nicht } \\
\text { aussagekräftige Funde }\end{array}$ & $\begin{array}{l}\text { kaiserzeitlich? } \\
\text { spätantik? }\end{array}$ & $\begin{array}{l}\text { DWK Becher } \\
\text { KW Kasserolle }\end{array}$ & - \\
\hline $\begin{array}{l}\text { D1 } \\
\text { KiNr. } \\
124 / 08\end{array}$ & SE 146 & 3 & $\begin{array}{l}\text { insignifikant aufgrund } \\
\text { geringer Fundquantität }\end{array}$ & kaiserzeitlich? & - & - \\
\hline $\begin{array}{l}\text { D2 } \\
\text { KiNr. } \\
147 / 08 . \\
148 / 08 . \\
165 / 08 . \\
166 / 08 . \\
173 / 08\end{array}$ & SE 152 & 51 & $\begin{array}{l}\text { homogen spätkaiser- } \\
\text { zeitlich, allerdings } 2 \text { RS } \\
\text { LRA } 2\end{array}$ & $\begin{array}{l}\text { 2. H. 3. Jh. n. Chr. } \\
\text { 4.-7. Jh. n. Chr. }\end{array}$ & $\begin{array}{l}\text { Hayes 45A } \\
\text { ESC Atlante Hayes } 4 \\
\text { ESC Hayes } 5 \\
\text { ERSW Teller } \\
\text { DWK Becher } \\
\text { Amphoren LRA } 2 \\
\text { Glas: } 1 \text { BS, } 1 \text { WS }\end{array}$ & - \\
\hline $\begin{array}{l}\mathrm{C} 1 \\
\text { D1 } \\
\text { KiNr. } \\
136\end{array}$ & SE 153 & 6 & $\begin{array}{l}\text { geringe Fundquantität } \\
\text { feinchronologisch inner- } \\
\text { halb der Kaiserzeit nicht } \\
\text { näher zuzuordnen }\end{array}$ & $\begin{array}{l}\text { kaiserzeitlich } \\
\text { 161/180 n. Chr. } \\
\text { (Münze) }\end{array}$ & - & M 108 \\
\hline $\begin{array}{l}\mathrm{C} 2 \\
\mathrm{D} 2 \\
\mathrm{KiNr} . \\
140 / 08 . \\
160 / 08 . \\
171 / 08\end{array}$ & $\begin{array}{l}\text { SE } 154= \\
\text { SE } 157\end{array}$ & 7 & $\begin{array}{l}\text { geringe Fundquantität } \\
\text { feinchronologisch nicht } \\
\text { näher zuzuordnen }\end{array}$ & $\begin{array}{l}\text { 2. H. 1. Jh.-1. H. } \\
\text { 2. Jh. n. Chr.? }\end{array}$ & $\begin{array}{l}\text { DWK Becher } \\
\text { Glas: } 1 \mathrm{BS}\end{array}$ & - \\
\hline $\begin{array}{l}\mathrm{C} 2 \\
\mathrm{D} 2 \\
\mathrm{KiNr} . \\
142 / 08 . \\
145 / 08 . \\
146 / 08\end{array}$ & SE 155 & 70 & $\begin{array}{l}\text { heterogen } \\
\text { viel 3. Jh. n. Chr. } \\
\text { jüngste Funde aber 2. } \\
\text { H. } 4 \text {. Jh. n. Chr., ev. mit } \\
\text { Fundvermischung mit SE } \\
458 \text { im unteren Bereich } \\
\text { zu erklären }\end{array}$ & $\begin{array}{l}\text { 3. Viertel 3. Jh. } \\
\text { n. Chr. } \\
\text { 2. H. 4. Jh. n. Chr. }\end{array}$ & $\begin{array}{l}\text { ARS Hayes 45A } \\
\text { ARS Hayes 50A } \\
\text { ESC Hayes } 4 \\
\text { ARS Hayes 50B } \\
\text { RSW Teller } \\
\text { Lampenfragmente } \\
\text { Glas: } 3 \text { RS, } 2 \text { BS }\end{array}$ & - \\
\hline
\end{tabular}




\begin{tabular}{|c|c|c|c|c|c|c|}
\hline $\begin{array}{l}\text { Fläche, } \\
\text { KiNr. }\end{array}$ & Stratum & $\begin{array}{l}\text { Anzahl } \\
\text { diagnost. } \\
\text { Funde }\end{array}$ & $\begin{array}{l}\text { Charakterisierung } \\
\text { Fundkomplex }\end{array}$ & Datierung & $\begin{array}{l}\text { Datierungskriterien: } \\
\text { jüngste Keramik (u. Glas) }\end{array}$ & $\begin{array}{l}\text { Münzen } \\
\text { (Kap. 8) }\end{array}$ \\
\hline $\begin{array}{l}\mathrm{D} 2 \\
\mathrm{KiNr} . \\
156 / 08\end{array}$ & SE 159 & 5 & $\begin{array}{l}\text { geringe Fundquantität } \\
\text { keine feinchronologisch } \\
\text { relevanten Funde }\end{array}$ & kaiserzeitlich & - & - \\
\hline $\begin{array}{l}\mathrm{C} 2 \\
\mathrm{KiNr} . \\
133 / 07\end{array}$ & SE 16 & 10 & $\begin{array}{l}\text { keine feinchronologisch } \\
\text { relevanten Funde }\end{array}$ & kaiserzeitlich & - & - \\
\hline $\begin{array}{l}\mathrm{D} 2 \\
\text { KiNr. } \\
176 / 08 . \\
177 / 08\end{array}$ & SE 162 & 25 & homogen & $\begin{array}{l}\text { (1. H.) 3. Jh. n. } \\
\text { Chr. }\end{array}$ & $\begin{array}{l}\text { ESC Hayes } 2 \\
\text { ESC Hayes } 3\end{array}$ & - \\
\hline $\begin{array}{l}\mathrm{C} 1 \\
\mathrm{C} 2 \\
\mathrm{KiNr} . \\
42 / 08 . \\
49 / 08\end{array}$ & $\begin{array}{l}\text { MA 4/ } \\
\text { MA } 5\end{array}$ & 7 & $\begin{array}{l}\text { kleiner Fundkomplex } \\
\text { Funde innerhalb der Kai- } \\
\text { serzeit meist nicht enger } \\
\text { einzugrenzen }\end{array}$ & 2.-3. Jh. n. Chr. & KW Töpfchen & - \\
\hline $\begin{array}{l}\mathrm{C} 1 \\
\mathrm{C} 2 \\
\mathrm{KiNr} \\
77 / 08\end{array}$ & MA 6 & 5 & $\begin{array}{l}\text { kleiner Fundkomplex } \\
\text { heterogen kaiserzeit- } \\
\text { lich/3.-4. Jh. n. Chr.? }\end{array}$ & 3.-4. Jh. n. Chr.? & ARS Hayes 50B oder Hayes 32/58 & - \\
\hline $\begin{array}{l}\text { C2 } \\
\text { C2-S } \\
\text { KiNr. } \\
75 / 08 . \\
78 / 08 \\
84 / 08\end{array}$ & MA 7 & 19 & $\begin{array}{l}\text { homogen kaiserzeitlich } \\
\text { wenige feinchronologisch } \\
\text { relevante Funde }\end{array}$ & 3. Jh. n. Chr. & $\begin{array}{l}\text { ESC Hayes } 4 \\
\text { KW Töpfchen }\end{array}$ & - \\
\hline
\end{tabular}

Tab. 92

\subsubsection{Zugangspodest ES2}

Das Areal vor ES2 war mit teilweise sehr massiven Straten bedeckt, die quantitativ umfangreiches Fundmaterial enthielten (Tab. 93). Hervorzuheben ist SE 168, wo Fundmaterial aus dem 3. Viertel des 3. Jhs. n. Chr. mit solchem aus der 2. Hälfte des 4. Jhs. n. Chr. vergesellschaftet war. Ein Wandfragment vermutlich byzantinischer Zeitstellung ist wohl auf eine sekundäre Kontamination zurückzuführen. Auch SE 171 und SE 173 enthielten jeweils viel Fundmaterial aus dem 3. Viertel des 3. Jhs. n. Chr., die Gefäße waren oft noch gut erhalten bzw. aus mehreren Fragmenten zu rekonstruieren. Die jüngsten Funde sind in beiden Straten aber in die 2. Hälfte des 4. und den Anfang des 5. Jhs. n. Chr. zu datieren. SE 179 barg das jüngste Fundmaterial aus dem Bereich vor ES2. Es ist in das 5. bis 6. Jh. n. Chr. zu datieren. 


\begin{tabular}{|c|c|c|c|c|c|c|}
\hline $\begin{array}{l}\text { Fläche, } \\
\text { KiNr. }\end{array}$ & Stratum & $\begin{array}{l}\text { Anzahl } \\
\text { diagnost. } \\
\text { Funde }\end{array}$ & $\begin{array}{l}\text { Charakterisierung } \\
\text { Fundkomplex }\end{array}$ & Datierung & $\begin{array}{l}\text { Datierungskriterien: } \\
\text { jüngste Keramik (u. Glas) }\end{array}$ & $\begin{array}{l}\text { Münzen } \\
\text { (Kap. 8) }\end{array}$ \\
\hline $\begin{array}{l}\text { E2 } \\
\text { KiNr. } \\
178.179\end{array}$ & SE 168 & 380 & $\begin{array}{l}\text { sehr großer Fundkom- } \\
\text { plex } \\
\text { heterogen } \\
\text { späthellenistisch } \\
\text { (wenig)/kaiserzeitlich/4. } \\
\text { Jh. n. Chr. } \\
\text { viel 2. H. 3. Jh. n. Chr. } \\
\text { (vgl. Fundkomplexe aus } \\
\text { der Zerstörung des HH2), } \\
\text { jüngste Funde aber 2. H. } \\
\text { 4. Jh. n. Chr., } \\
1 \text { byzantinisches Frag- } \\
\text { ment (wohl intrusiv) } \\
\\
\text { meist klein- bis mittel- } \\
\text { teilig gebrochen, einige } \\
\text { Gefäße zur Hälfte bis zu } \\
\text { drei Viertel erhalten }\end{array}$ & $\begin{array}{l}\text { 2. H. 4. Jh. n. } \\
\text { Chr. } \\
\text { byzantinisch }\end{array}$ & $\begin{array}{l}\text { ARS Hayes 45A } \\
\text { ARS Hayes 45C } \\
\text { ARS Hayes 50A } \\
\text { ESC Hayes 1 } \\
\text { ESC Hayes 4 } \\
\text { ESC Hayes 3A } \\
\text { Schale RSW } \\
\text { Amphoren Kapitän II } \\
\text { Amphoren Peacock - Williams 45/ } \\
\text { LRA 3 } \\
\text { zu drei Vierteln erhaltene Amphore } \\
\text { mit Dipinto } \\
\\
\text { Glas: Facettenbecher (zu drei Vier- } \\
\text { teln erhalten) (Vgl. z. B. ScHÄTz- } \\
\text { SCHOCK 2005, G 90, AR 60.1-I 96b1; } \\
\text { BARKÓczI 1986, Abb. 4, 1. 2) } \\
\text { ARS Hayes 50B } \\
\text { KW Topf } \\
\text { glasiertes WS mit zweifachem Wel- } \\
\text { lenbanddekor außen }\end{array}$ & - \\
\hline $\begin{array}{l}\text { E2 } \\
\text { KiNr. } 4 . \\
24.25 . \\
174\end{array}$ & SE 169 & 37 & $\begin{array}{l}\text { heterogen } \\
\text { späthellenistische } \\
\text { Residuals }\end{array}$ & 3./4. Jh. n. Chr. & $\begin{array}{l}\text { ARS Hayes } 45 \\
\text { ARS Hayes } 50 \\
\text { DWK Becher } \\
\text { Amphoren LRA } 3\end{array}$ & - \\
\hline $\begin{array}{l}\text { F1 } \\
\text { KiNr. } 9\end{array}$ & SE 170 & 4 & $\begin{array}{l}\text { kleiner Fundkomplex } \\
\text { keine feinchronologisch } \\
\text { relevanten Funde }\end{array}$ & $\begin{array}{l}\text { 4.-1. H. 7. Jh. n. } \\
\text { Chr.? }\end{array}$ & LRA 3 & M 66 \\
\hline $\begin{array}{l}\text { E2 } \\
\text { KiNr. } \\
180.186 . \\
190\end{array}$ & SE 171 & 274 & $\begin{array}{l}\begin{array}{l}\text { sehr großer Fundkom- } \\
\text { plex }\end{array} \\
\text { heterogen } \\
\text { 2. H. 3. Jh. n. Chr. (vgl. } \\
\text { Fundkomplexe aus der } \\
\text { Zerstörung des HH2), } \\
\text { jüngste Funde aber Ende } \\
\text { 4./Anfang 5. Jh. n. Chr. } \\
\\
\text { zahlreiche gut erhaltene } \\
\text { Gefäße, (nahezu) ganz } \\
\text { erhaltene Gefäße: 1 } \\
\text { Kleeblattkanne, 1 Lampe } \\
\text { (Vgl. LADSTÄTTER 2005, } \\
\text { K 847), } 1 \text { KW Askos, } \\
1 \text { GK Topf (zylindrisch) }\end{array}$ & $\begin{array}{l}\text { 3. Viertel 3. Jh. } \\
\text { n. Chr. } \\
\text { 2. H. 4./Anfang } \\
\text { 5. Jh. n. Chr. }\end{array}$ & $\begin{array}{l}\text { ARS Hayes 45A } \\
\text { ARS Hayes 49 } \\
\text { ARS Hayes 50A } \\
\text { ARS Hayes 50A } \\
\text { ESC Hayes 5 } \\
\text { ESC Hayes 1 } \\
\text { ESC Hayes 4 } \\
\text { ESB Atlante 60, spät } \\
\text { Amphoren Kapitän II } \\
\text { Bildlampen } \\
\text { ARS Hayes 50B } \\
\text { GK Steilrandteller } \\
\text { KW Topf } \\
\text { Lampen } \\
\\
\text { Glas: Schale mit Facettenschliff } \\
\text { (CZURDA-RUTH 2007, KatNr. } \\
\text { 158-160 (spätes 2.-3. Jh. n. Chr.); } \\
\text { ScHÄtZsCHOCK 2010a, A-G 78-80) }\end{array}$ & - \\
\hline
\end{tabular}




\begin{tabular}{|c|c|c|c|c|c|c|}
\hline $\begin{array}{l}\text { Fläche, } \\
\text { KiNr. }\end{array}$ & Stratum & $\begin{array}{l}\text { Anzahl } \\
\text { diagnost. } \\
\text { Funde }\end{array}$ & $\begin{array}{l}\text { Charakterisierung } \\
\text { Fundkomplex }\end{array}$ & Datierung & $\begin{array}{l}\text { Datierungskriterien: } \\
\text { jüngste Keramik (u. Glas) }\end{array}$ & $\begin{array}{l}\text { Münzen } \\
\text { (Kap. 8) }\end{array}$ \\
\hline & & & & & $\begin{array}{l}1 \text { RS Balsamarium mit ausgestelltem } \\
\text { Rand (CzURDA-RUTH 2007, KatNr. } \\
\text { 255. 256, 1.-2. Jh. n. Chr.) } \\
\text { Boden mit tropfenförmigem Standring } \\
\text { (CzURDA-RuTH 2007, KatNr. 614- } \\
\text { 625, spätes 2.-3. Jh. n. Chr.) } \\
\text { Böden mit hohem Standring (CzURDA- } \\
\text { RuTH 2007, KatNr. 512-532) } \\
\text { Teller mit gerundetem Rand (CzURDA- } \\
\text { RuTH 2007, KatNr. 428) } \\
\text { Konische Becher mit leicht ausge- } \\
\text { bogenem, gerundetem Rand (CzUR- } \\
\text { DA-RUTH 2007, 111 f.) } \\
\text { Böden mit Standplatte (CzURDA-RU- } \\
\text { TH 2007, 122-124 KatNr. 459-470, } \\
\text { 3. Viertel 3. Jh.-4./5. Jh. n. Chr.) }\end{array}$ & \\
\hline $\begin{array}{l}\text { E2 } \\
\text { KiNr. } \\
181\end{array}$ & SE 172 & 22 & $\begin{array}{l}\text { homogen kaiserzeitlich } \\
\text { keine feinchronologisch } \\
\text { relevanten Funde } \\
\text { späthellenistische Resi- } \\
\text { duals (wenig) }\end{array}$ & 2.-3. Jh. n. Chr. & $\begin{array}{l}1 \text { RS DWK Töpfchen } \\
\text { Glas: } 1 \text { BS }\end{array}$ & - \\
\hline $\begin{array}{l}\text { E2 } \\
\text { KiNr. } \\
182.183\end{array}$ & SE 173 & 199 & $\begin{array}{l}\text { großer Fundkomplex } \\
\text { viel 3.-4. Jh. n. Chr. (vgl. } \\
\text { Zerstörungskontexte } \\
\text { aus dem Hanghaus 2), } \\
\text { jüngste Funde allerdings } \\
\text { Ende 4./5. Jh. n. Chr. }\end{array}$ & $\begin{array}{l}\text { 3. Viertel 3. Jh. } \\
\text { n. Chr. } \\
\text { 2. H. 4./5. Jh. n. } \\
\text { Chr. } \\
\text { Ende 4./5. Jh. n. } \\
\text { Chr. }\end{array}$ & $\begin{array}{l}\text { ARS Hayes 45A } \\
\text { ARS Hayes 50A } \\
\text { ESC Atlante L } 9 \\
\text { ESC Hayes } 1 \\
\text { ESC Hayes } 4 \\
\text { Amphoren Kapitän II } \\
\text { ARS Hayes 50B } \\
\text { KW Töpfe } \\
\text { Amphore LRA } 2 \\
\text { GK Steilrandteller } \\
\\
\text { Glas: } 4 \text { RS, } 2 \text { BS }\end{array}$ & - \\
\hline $\begin{array}{l}\text { F1 } \\
\text { F2 } \\
\text { KiNr. } 1\end{array}$ & SE 174 & 7 & $\begin{array}{l}\text { kleiner Fundkomplex } \\
\text { heterogen } \\
\text { 1.-2. Jh. n. Chr./Ende } \\
\text { 4.-Mitte 5. Jh. n. Chr. } \\
\text { (vereinzelt) }\end{array}$ & $\begin{array}{l}\text { Ende 4.-Mitte } 5 . \\
\text { Jh. n. Chr. }\end{array}$ & KW Topf & M 70 \\
\hline $\begin{array}{l}\text { E2 } \\
\text { KiNr. } \\
184.185\end{array}$ & SE 175 & 27 & $\begin{array}{l}\text { heterogen } \\
\text { vereinzelt späthelle- } \\
\text { nistische Residuals/ } \\
\text { Kaiserzeit/2.-3. Jh. n. } \\
\text { Chr.; vereinzelt Ende 4./ } \\
\text { Anfang 5. Jh. n. Chr. } \\
\text { z. T. guter Erhaltungs- } \\
\text { zustand }\end{array}$ & $\begin{array}{l}\text { 2./3. n. Chr. } \\
\text { 4./5. Jh. n. Chr. }\end{array}$ & $\begin{array}{l}\text { ESC Hayes 1 } \\
\text { ESC Atlante 26A } \\
\text { KW Teller } \\
\text { GK Schüssel } \\
\\
1 \text { KW Topf }\end{array}$ & - \\
\hline
\end{tabular}




\begin{tabular}{|c|c|c|c|c|c|c|}
\hline $\begin{array}{l}\text { Fläche, } \\
\text { KiNr. }\end{array}$ & Stratum & $\begin{array}{l}\text { Anzahl } \\
\text { diagnost. } \\
\text { Funde }\end{array}$ & $\begin{array}{l}\text { Charakterisierung } \\
\text { Fundkomplex }\end{array}$ & Datierung & $\begin{array}{l}\text { Datierungskriterien: } \\
\text { jüngste Keramik (u. Glas) }\end{array}$ & $\begin{array}{l}\text { Münzen } \\
\text { (Kap. 8) }\end{array}$ \\
\hline $\begin{array}{l}\mathrm{E} 2 \\
\mathrm{KiNr} . \\
188\end{array}$ & SE 176 & 5 & $\begin{array}{l}\text { kleiner Fundkomplex } \\
\text { heterogen } \\
\text { hellenistisch- } \\
\text { kaiserzeitlich/ } \\
\text { 2.-3. Jh. n. Chr./ } \\
\text { spätantik }\end{array}$ & $\begin{array}{l}\text { Ende 2./3. Jh. n. } \\
\text { Chr. } \\
\text { spätantik (?) }\end{array}$ & $\begin{array}{l}\text { ESC Hayes } 3 \\
\text { KW Kasserolle }\end{array}$ & - \\
\hline $\begin{array}{l}\text { F1 } \\
\text { KiNr. } 3 . \\
13\end{array}$ & SE 179 & 18 & $\begin{array}{l}\text { heterogen } \\
\text { späthellenistisch-3. Jh. n. } \\
\text { Chr./5.-6. Jh. n. Chr. } \\
\text { tw. gut erhaltene } \\
\text { Gefäße: Forlimpopoli- } \\
\text { Amphore, zu drei Vier- } \\
\text { teln erhalten }\end{array}$ & 5.-6. Jh. n. Chr. & $\begin{array}{l}\text { LRC Hayes } 2 \text { C } \\
\text { LRA } 3 \\
\text { frühbyz. Ampulle } \\
\text { KW Kasserolle } \\
\text { KW Pfanne }\end{array}$ & - \\
\hline $\begin{array}{l}\text { F1 } \\
\text { KiNr. } 5 . \\
14\end{array}$ & SE 181 & 6 & $\begin{array}{l}\text { kleiner Fundkomplex } \\
\text { heterogen } \\
\text { späthellenistisch-- } \\
\text { kaiserzeitlich/ } \\
\text { 4. Jh. n. Chr. }\end{array}$ & $\begin{array}{l}\text { 2. H. 4. Jh. n. } \\
\text { Chr. }\end{array}$ & ARS Hayes 50B & - \\
\hline \begin{tabular}{|l} 
F2 \\
KiNr. 26
\end{tabular} & SE 182 & 7 & $\begin{array}{l}\text { kleiner Fundkomplex } \\
\text { heterogen } \\
\text { späthellenistisch-- } \\
\text { kaiserzeitlich }\end{array}$ & $\begin{array}{l}\text { 1. Jh. v. Chr.-1. } \\
\text { H. 1. Jh. n. Chr.? }\end{array}$ & $\begin{array}{l}\text { ESA Atlante 4A } \\
\text { Reliefbecher } \\
\text { GK Unguentarium }\end{array}$ & - \\
\hline $\begin{array}{l}\text { F1 } \\
\text { KiNr. } 10 . \\
17\end{array}$ & SE 183 & 23 & $\begin{array}{l}\text { heterogen } \\
\text { späthellenistisch (verein- } \\
\text { zelt)/kaiserzeitlich/2.-3. } \\
\text { Jh. n. Chr. }\end{array}$ & 2.-3. Jh. n. Chr. & $\begin{array}{l}\text { ESC Hayes } 3 \\
\text { ESC Atlante L19/Hayes } 3 \\
\text { ESC Atlante L 26A } \\
\text { ESC Atlante L19 } \\
\text { ESB Atlante } 60 \\
\text { ESB Atlante } 80\end{array}$ & - \\
\hline $\begin{array}{l}\text { F1 } \\
\text { KiNr. } 16\end{array}$ & SE 184 & 4 & $\begin{array}{l}\text { kleiner Fundkomplex } \\
\text { heterogen }\end{array}$ & um 400 n. Chr. & LRC Hayes 2A & - \\
\hline $\begin{array}{l}\text { F2 } \\
\text { KiNr. } 27\end{array}$ & SE 187 & 19 & $\begin{array}{l}\text { heterogen } \\
\text { späthellenistisch-augu- } \\
\text { steisch-kaiserzeitlich }\end{array}$ & 2.-3. Jh. n. Chr. & $\begin{array}{l}\text { DWK Töpfchen } \\
\text { GK Schüssel } \\
\text { KW Teller } \\
\text { Lampe } \\
\\
\text { Glas: } 1 \text { BS }\end{array}$ & - \\
\hline
\end{tabular}

Tab. 93 


\subsubsection{Treppe-West}

Auch im Abschnitt Treppe-West wurden Fundkomplexe geborgen, die Fundmaterial aus der Zerstörungszeit durch das Erdbeben im 3. Viertel des 3. Jhs. n. Chr. enthielten (Tab. 94). Hervorzuheben sind insbesondere SE 192, SE 193 (= SE 194) und SE 207 (= SE 198). Die letztgenannten beiden Straten bargen allerdings auch Fundmaterial aus dem ausgehenden 4. und der 1. Hälfte des 5. Jhs. n. Chr. In diesem Bereich sind insgesamt verstärkt Schichten mit Fundmaterial aus dem 5. bis 6. Jh. und speziell dem 6. Jh. $\mathrm{n}$. Chr. bezeugt. Bisweilen handelt es sich dabei um homogen zusammengesetzte Komplexe, wie bei SE 122 (= SE 210) und SE 203, oftmals sind aber auch hellenistische bis kaiserzeitliche Residuals enthalten (SE 124 = SE 219. 186. 195. 197).

\begin{tabular}{|c|c|c|c|c|c|c|}
\hline $\begin{array}{l}\text { Fläche, } \\
\text { KiNr. }\end{array}$ & Stratum & $\begin{array}{l}\text { Anzahl } \\
\text { diagnost. } \\
\text { Funde }\end{array}$ & $\begin{array}{l}\text { Charakterisierung } \\
\text { Fundkomplex }\end{array}$ & Datierung & $\begin{array}{l}\text { Datierungskriterien: } \\
\text { jüngste Keramik (u. Glas) }\end{array}$ & $\begin{array}{l}\text { Münzen } \\
\text { (Kap. 8) }\end{array}$ \\
\hline $\begin{array}{l}\text { G1 } \\
\text { KiNr. } 29\end{array}$ & SE 25 & 5 & $\begin{array}{l}\text { kleiner Fundkomplex } \\
\text { keine feinchronologisch } \\
\text { relevanten Funde }\end{array}$ & kaiserzeitlich & $\begin{array}{l}\text { ESB BS } \\
\text { DWK } \\
\text { GK Deckel } \\
\text { KW Pfanne }\end{array}$ & - \\
\hline $\begin{array}{l}\text { J1 } \\
\text { K2 } \\
\text { KiNr. } \\
28 / 09 . \\
55 / 09 . \\
56 / 09 . \\
69 / 09 . \\
86 / 09\end{array}$ & $\begin{array}{l}\text { SE } 122 \\
(=\text { SE 210) }\end{array}$ & 45 & $\begin{array}{l}\text { heterogen } \\
\text { kaiserzeitlich, 6. Jh. n. } \\
\text { Chr. }\end{array}$ & 6. Jh. n. Chr. & $\begin{array}{l}\text { LRC Hayes 3E } \\
\text { LRC Hayes 3F } \\
\text { LRC Hayes 3H } \\
\text { LRC Hayes 5A } \\
\text { ERSW Imitation LRC Hayes } 3 \\
\text { Amphoren LRA } 3 \\
\text { KW Töpfe, Pfanne, Kasserolle } \\
\\
\text { Glas: fünf Kelchgläser }\end{array}$ & - \\
\hline $\begin{array}{l}\mathrm{J} 1 \\
\mathrm{~K} 1 \\
\mathrm{KiNr} \\
80 / 09\end{array}$ & SE 123 & 4 & $\begin{array}{l}\text { kleiner Fundkomplex } \\
\text { heterogen }\end{array}$ & 5-6. Jh. n. Chr. & LRC Hayes 3 & - \\
\hline $\begin{array}{l}\text { J1 } \\
\text { K2 } \\
\text { KiNr. } \\
43 / 09 . \\
63 / 09 . \\
89 / 09 . \\
90 / 09\end{array}$ & $\begin{array}{l}\text { SE 124 } \\
(=\text { SE 219) }\end{array}$ & 91 & $\begin{array}{l}\text { heterogen } \\
\text { hellenistische Residuals/ } \\
\text { frühe u. späte Kaiser- } \\
\text { zeit/6. Jh. n. Chr. }\end{array}$ & 6. Jh. n. Chr. & $\begin{array}{l}\text { LRC Hayes 3F } \\
\text { LRC Hayes 3H } \\
\text { LRC Hayes 3 } \\
\text { LRC Hayes 1D } \\
\text { LRC Hayes 1 } \\
\text { Amphoren LRA } 3 \\
\text { KW Töpfe } \\
\text { KW Kasserolle } \\
\text { KW Pfanne } \\
\text { Lampen } \\
\\
\text { Glas: fünf Becher }\end{array}$ & - \\
\hline $\begin{array}{l}\mathrm{J} 2 \\
\text { KiNr. } 63\end{array}$ & $\begin{array}{l}\text { SE } 219 \\
(=\text { SE 124) }\end{array}$ & 15 & $\begin{array}{l}\text { heterogen } \\
\text { späthellenistische Resi- } \\
\text { duals/3.-4. Jh. n. Chr., } \\
\text { jüngste Funde aber 5./6. } \\
\text { Jh. n. Chr. }\end{array}$ & $\begin{array}{l}\text { 3.-4. Jh. n. Chr. } \\
\text { 5.-6. Jh. n. Chr. }\end{array}$ & $\begin{array}{l}\text { ARS Hayes 44 } \\
\text { ARS Hayes 50A } \\
\text { ESB, spät } \\
\\
\text { KW Töpfe } \\
\text { KW Kasserolle }\end{array}$ & - \\
\hline
\end{tabular}




\begin{tabular}{|c|c|c|c|c|c|c|}
\hline $\begin{array}{l}\text { Fläche, } \\
\text { KiNr. }\end{array}$ & Stratum & $\begin{array}{l}\text { Anzahl } \\
\text { diagnost. } \\
\text { Funde }\end{array}$ & $\begin{array}{l}\text { Charakterisierung } \\
\text { Fundkomplex }\end{array}$ & Datierung & $\begin{array}{l}\text { Datierungskriterien: } \\
\text { jüngste Keramik (u. Glas) }\end{array}$ & $\begin{array}{l}\text { Münzen } \\
\text { (Kap. 8) }\end{array}$ \\
\hline $\begin{array}{l}\text { G1 } \\
\text { KiNr. 2/09 }\end{array}$ & SE 180 & 3 & $\begin{array}{l}\text { sehr kleiner Fundkom- } \\
\text { plex } \\
\text { keine feinchronologisch } \\
\text { relevanten Funde }\end{array}$ & kaiserzeitlich? & - & - \\
\hline $\begin{array}{l}\mathrm{H} 1 \\
\mathrm{H} 2, \mathrm{KiNr} . \\
21 / 09 . \\
62 / 09 \\
76 / 09\end{array}$ & SE 186 & 10 & heterogen & 6. Jh. n. Chr. & $\begin{array}{l}\text { LRC Hayes } 3 \text { mit Rouletting und } \\
\text { Kreuzstempel } \\
\text { KW Topf } \\
\text { ARS, grob }\end{array}$ & - \\
\hline $\begin{array}{l}\mathrm{J} 2 \\
\mathrm{KiNr} \\
31 / 09\end{array}$ & SE 189 & 24 & $\begin{array}{l}\text { heterogen } \\
\text { späthellenistische Resi- } \\
\text { duals/Kaiserzeit/2-3. Jh. } \\
\text { n. Chr./5. Jh. n. Chr. }\end{array}$ & $\begin{array}{l}\text { 2-3. Jh. n. Chr. } \\
\text { 5. Jh. n. Chr. }\end{array}$ & $\begin{array}{l}\text { ESC Atlante L } 19 \\
\text { ESC Hayes } 1 \\
\text { Amphore Kapitän II } \\
\text { KW Pfanne } \\
\text { KW Töpfe }\end{array}$ & - \\
\hline $\begin{array}{l}\text { G1 } \\
\text { G2 } \\
\text { KiNr. } \\
8 / 09 . \\
33 / 09 . \\
47 / 09\end{array}$ & SE 192 & 35 & $\begin{array}{l}\text { nahezu homogen kaiser- } \\
\text { zeitlich, 1 Residual helle- } \\
\text { nistischer Zeit } \\
\text { vgl. Zerstörungs-Kontex- } \\
\text { te HH2 }\end{array}$ & $\begin{array}{l}\text { 3. Viertel 3. Jh. } \\
\text { n. Chr. }\end{array}$ & $\begin{array}{l}\text { ARS Hayes 50A } \\
\text { ESC Atlante L26A } \\
\text { ESC Atlante Hayes } 1 \\
\text { ESC Atlante Hayes } 4 \\
\text { RSW Teller } \\
\text { Amphoren Kapitän II } \\
\\
\text { Glas : } 1 \text { RS Becher }\end{array}$ & - \\
\hline $\begin{array}{l}\text { G1 } \\
\text { G2 } \\
\text { KiNr. } \\
38 / 09 . \\
39 / 09 . \\
58 / 09\end{array}$ & $\begin{array}{l}\text { SE } 193(= \\
\text { SE 194) }\end{array}$ & 60 & $\begin{array}{l}\text { heterogen } \\
\text { viel 3./4. Jh. n. Chr. (vgl. } \\
\text { Zerstörungs-Kontexte } \\
\text { HH2), jüngste Funde } \\
\text { aber Ende 4./5. Jh. n. } \\
\text { Chr. }\end{array}$ & $\begin{array}{l}\text { 3. Viertel 3. Jh. } \\
\text { n. Chr. } \\
\\
\text { Ende 4./5. Jh. n. } \\
\text { Chr. }\end{array}$ & $\begin{array}{l}\text { ARS Hayes 45A } \\
\text { ARS Hayes 50A } \\
\text { ARS Teller Hayes? } \\
\text { ESC L 26A } \\
\text { ESC Hayes 1 } \\
\text { ESC Atlante L19/Hayes } 3 \\
\text { ESC Hayes } 3 \\
\text { ESC Hayes } 4 \\
\text { Amphore Kapitän II } \\
\text { LRC Hayes 1? } \\
\text { ARS Hayes 50B } \\
\text { KW Topf } \\
\text { KW Kasserolle } \\
\text { Amphoren LRA } 3 \\
\\
\text { Glas: } 2 \text { BS }\end{array}$ & M 35 \\
\hline $\begin{array}{l}\mathrm{H} 1 \\
\text { J2 } \\
\text { KiNr. } \\
15 / 09 \\
18 / 09 . \\
2 / 09 . \\
42 / 09\end{array}$ & SE 195 & 57 & $\begin{array}{l}\text { heterogen } \\
\text { späthellenistisch-kaiser- } \\
\text { zeitlich/3.-4. Jh./6. Jh. } \\
\text { n. Chr. }\end{array}$ & 6. Jh. n. Chr. & $\begin{array}{l}\text { LRC Hayes 3E } \\
\text { LRC Hayes 3F } \\
\text { LRC Hayes } 3 \\
\text { Amphoren LRA } 3 \\
\text { KW Töpfe }\end{array}$ & M 14 \\
\hline
\end{tabular}




\begin{tabular}{|c|c|c|c|c|c|c|}
\hline $\begin{array}{l}\text { Fläche, } \\
\text { KiNr. }\end{array}$ & Stratum & $\begin{array}{l}\text { Anzahl } \\
\text { diagnost. } \\
\text { Funde }\end{array}$ & $\begin{array}{l}\text { Charakterisierung } \\
\text { Fundkomplex }\end{array}$ & Datierung & $\begin{array}{l}\text { Datierungskriterien: } \\
\text { jüngste Keramik (u. Glas) }\end{array}$ & \begin{tabular}{|l} 
Münzen \\
(Kap. 8)
\end{tabular} \\
\hline $\begin{array}{l}\mathrm{H} 1 \\
\mathrm{KiNr} \\
32 / 09\end{array}$ & SE 196 & 7 & $\begin{array}{l}\text { kleiner Fundkomplex } \\
\text { heterogen }\end{array}$ & $\begin{array}{l}\text { spätantik-frühby- } \\
\text { zantinisch }\end{array}$ & $\begin{array}{l}\text { Amphoren LRA } 3 \\
\text { frühbyzantinische Ampulle mit } \\
\text { intentionellem Loch }\end{array}$ & M 47 \\
\hline $\begin{array}{l}\mathrm{J} 1 \\
\mathrm{~J} 2 \\
\mathrm{KiNr} \\
34 / 09 . \\
84 / 09\end{array}$ & SE 197 & 45 & $\begin{array}{l}\text { heterogen } \\
\text { hellenistische Residuals, } \\
\text { Kaiserzeit, Großteil aber } \\
\text { spätantik-frühbyzanti- } \\
\text { nisch }\end{array}$ & 6. Jh. n. Chr. & $\begin{array}{l}\text { LRC Hayes 3F } \\
\text { LRC Hayes 2A } \\
\text { LRC Hayes 1A } \\
\text { frühbyzantinische Ampulle mit } \\
\text { Stempel } \\
\text { Amphoren LRA } 3 \\
\text { KW Töpfe } \\
\text { Kasserollen } \\
\text { Lampe }\end{array}$ & - \\
\hline $\begin{array}{l}\mathrm{G} 1 \\
\mathrm{KiNr} \\
35 / 09\end{array}$ & SE 200 & 10 & $\begin{array}{l}\text { heterogen } \\
\text { (spät)hellenistische Re- } \\
\text { siduals/Kaiserzeit/spätes } \\
\text { 2./3. Jh. n. Chr. }\end{array}$ & $\begin{array}{l}\text { spätes 2./3. Jh. n. } \\
\text { Chr. } \\
\text { 244-249 n. Chr. } \\
\text { (Münze). }\end{array}$ & ESC Hayes 3 & M 87 \\
\hline $\begin{array}{l}\mathrm{G} 2 \\
\mathrm{KiNr} . \\
37 / 09 . \\
53 / 09 \\
74 / 09\end{array}$ & $\begin{array}{l}\text { SE 201 (= } \\
\text { SE 206) }\end{array}$ & 13 & $\begin{array}{l}\text { kleiner Fundkomplex } \\
\text { heterogen }\end{array}$ & $\begin{array}{l}\text { (2. Hälfte) 3. Jh. } \\
\text { n. Chr. }\end{array}$ & $\begin{array}{l}\text { ARS Hayes 50A } \\
\text { ESC Hayes } 1 \\
\text { Glas: } 1 \text { BS }\end{array}$ & - \\
\hline $\begin{array}{l}\mathrm{J} 1 \\
\mathrm{~J} 2 \\
\text { KiNr. } \\
41 / 09 . \\
83 / 09 . \\
85 / 09\end{array}$ & SE 202 & 7 & $\begin{array}{l}\text { kleiner Fundkomplex } \\
\text { heterogen }\end{array}$ & 5./6. Jh. n. Chr. & $\begin{array}{l}\text { KW Töpfe } \\
\text { GK Schüssel }\end{array}$ & - \\
\hline $\begin{array}{l}\text { G1 } \\
\text { KiNr. } \\
44 / 09\end{array}$ & SE 203 & 16 & homogen & 6. Jh. n. Chr. & $\begin{array}{l}\text { LRC Hayes 3F } \\
\text { LRC Hayes } 6 \\
\text { KW Töpfe } \\
\text { Amphoren }\end{array}$ & - \\
\hline $\begin{array}{l}\text { H1 } \\
\text { H2 } \\
\text { J1 } \\
\text { KiNr. } \\
37 / 09 . \\
46 / 09 . \\
68 / 09 . \\
74 / 09 . \\
81 / 09\end{array}$ & $\begin{array}{l}\text { SE } 207= \\
\text { SE } 198\end{array}$ & 62 & $\begin{array}{l}\text { heterogen } \\
\text { viel 3.-4. Jh. n. Chr., } \\
\text { jüngste Funde aber } \\
\text { 1. H. 5. Jh. n. Chr. }\end{array}$ & $\begin{array}{l}\text { 3. Viertel 3. Jh. } \\
\text { n. Chr. } \\
\\
\text { (1. H.) 5. Jh. n. } \\
\text { Chr. }\end{array}$ & $\begin{array}{l}\text { ARS Hayes 45A } \\
\text { ARS Hayes 45B } \\
\text { ESC Hayes } 3 \\
\text { ESC Hayes } 4 \\
\text { Amphore Kapitän II } \\
\\
\text { Glas: } 1 \text { BS } \\
\text { LRC Hayes 2A } \\
\text { LRC Hayes 1 (?) } \\
\text { ARS Hayes 50B } \\
\text { Amphore LRA } 3 \\
\text { KW Topf } \\
\text { KW Kasserolle }\end{array}$ & M 19 \\
\hline $\begin{array}{l}\mathrm{H} 2 \\
\mathrm{KiNr} \\
64 / 09\end{array}$ & SE 209 & 7 & $\begin{array}{l}\text { kleiner Fundkomplex } \\
\text { heterogen }\end{array}$ & $\begin{array}{l}\text { Ende 4.-5. Jh. n. } \\
\text { Chr. }\end{array}$ & $\begin{array}{l}\text { LRC Hayes 1A } \\
\text { KW Topf }\end{array}$ & - \\
\hline
\end{tabular}




\begin{tabular}{|c|c|c|c|c|c|c|}
\hline $\begin{array}{l}\text { Fläche, } \\
\text { KiNr. }\end{array}$ & Stratum & $\begin{array}{l}\text { Anzahl } \\
\text { diagnost. } \\
\text { Funde }\end{array}$ & $\begin{array}{l}\text { Charakterisierung } \\
\text { Fundkomplex }\end{array}$ & Datierung & $\begin{array}{l}\text { Datierungskriterien: } \\
\text { jüngste Keramik (u. Glas) }\end{array}$ & $\begin{array}{l}\text { Münzen } \\
\text { (Kap. 8) }\end{array}$ \\
\hline $\begin{array}{l}\mathrm{G} 2 \\
\mathrm{KiNr} \\
50 / 09\end{array}$ & SE 212 & 5 & $\begin{array}{l}\text { kleiner Fundkomplex } \\
\text { Fundvermischung mög- } \\
\text { lich }\end{array}$ & $\begin{array}{l}\text { kaiserzeitlich-3. } \\
\text { Jh. n. Chr.? }\end{array}$ & DWK Kanne & - \\
\hline $\begin{array}{l}\mathrm{G} 2 \\
\mathrm{KiNr} \\
54 / 09 . \\
61 / 09\end{array}$ & $\begin{array}{l}\text { SE 217 }= \\
\text { SE 218) }\end{array}$ & 6 & $\begin{array}{l}\text { kleiner Fundkontext } \\
\text { heterogen }\end{array}$ & 2. Jh. n. Chr.? & ESC Atlante L26/H1 & - \\
\hline $\begin{array}{l}\mathrm{H} 2 \\
\mathrm{KiNr} . \\
70 / 09 . \\
87 / 09\end{array}$ & SE 222 & 13 & homogen & 5./6. Jh. n. Chr. & $\begin{array}{l}\text { LRC Hayes 3E/H } \\
\text { KW Töpfe }\end{array}$ & M 247 \\
\hline $\begin{array}{l}\mathrm{H} 1 \\
\mathrm{KiNr} . \\
91 / 09\end{array}$ & SE 227 & 1 & - & $\begin{array}{l}\text { 4.-1. H. 7. Jh. n. } \\
\text { Chr. }\end{array}$ & Amphore LRA 3 & - \\
\hline
\end{tabular}

Tab. 94

\subsubsection{Zugangspodest ES1}

Alle Straten, die dem Areal vor dem Südzugang ES1 zugerechnet werden können (Tab. 95), sind aufgrund der jüngsten Keramikfunde in das 5. oder 6. Jh. n. Chr. zu datieren. Mit Ausnahme von SE 126, die eine homogene Zusammensetzung aufweist, enthalten sämtliche Schichten Residuals aus der späthellenistischen und/oder der römischen Kaiserzeit.

Die massiven Schichten über dem Stiegenaufgang südlich von S1-S3 enthielten häufig gut erhaltenes Fundmaterial aus dem letzten Viertel des 3. Jhs. n. Chr., wenn auch meist vergesellschaftet mit Funden aus dem 5./6. Jh. n. Chr. Es handelt sich um weitere Belege der Zerstörungen in Folge des Erdbebens im 3. Viertel des 3. Jhs. n. Chr., was durch die gute Vergleichbarkeit mit sicher datierten Fundkomplexen aus den Zerstörungsschichten im Hanghaus $2^{210}$, aber auch aus dem Vediusgymnasium ${ }^{211}$ bestätigt wird. Das feinkeramische Material besteht nahezu ausschließlich aus späten ESC-Formen (Hayes 1-4), vergesellschaftet mit ARS-Tellern der Formen Hayes 45 und 50. Die Gefäßformen der dünnwandigen Keramik, der Gebrauchskeramik und Küchenware sowie das Amphorenspektrum und auch die Glasfunde sind bestens vergleichbar mit den bekannten Zerstörungskontexten dieser Zeit. Der bisweilen sehr gute Erhaltungszustand der Fragmente (Einzelgefäße aus mehreren Straten konnten fast vollständig zusammengefügt werden) lässt darauf schließen, dass das Material nicht mehrmals umgelagert und zur Planierung eingebracht wurde. Vielmehr ist es wahrscheinlich, dass der Schutt über der Treppe das vor der Erdbebenzerstörung benutzte Inventar aus der südlich angrenzenden Insula enthält. Die Bearbeitung der Fundkomplexe scheint das für andere Bereiche in Ephesos (z. B. Hanghaus 2 ${ }^{212}$, Kuretenstraße ${ }^{213}$ ) gewonnene Bild zu bestätigen, dass auf die Zerstörungen durch das Erdbeben des 3. Viertels des 3. Jhs. n. Chr. - in diesem Fall in der südlich angrenzenden Insula - kein unmittelbarer Wiederaufbau folgt, sondern erst frühestens im späten 4. und 5. Jh. n. Chr. eine Nachnutzung des Areals stattfindet ${ }^{214}$. In diesem Zusammenhang könnte der Erdbebenschutt dann auch aus Teilen

\footnotetext{
${ }^{210}$ LAdStätter 2005, 242-262 (Fundkomplexe Z/1-Z19?); LAdSTÄtter 2010a, 193 (Fundkomplex A-Z/1-2); LAdSTÄTter 2010b, 535-540 (Fundkomplex B-Z/1-15); LADSTÄTTER 2014, 467-470 (Fundkomplexe Z/1-6 Textabb. 6).

${ }^{211}$ LADSTÄTTER 2008, 111-113.

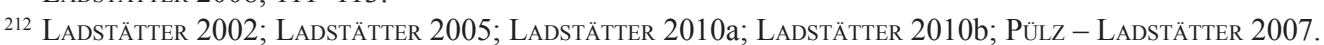

${ }^{213}$ IRO U. a. 2009; PÜLZ - LADSTÄTTER 2007.

${ }^{214}$ Kap. 4.5.1.3; Kap. 4.6.2.1.
} 
der Insula ausgeräumt und auf die Treppe im Süden des Theaters umgelagert worden $\operatorname{sein}^{215}$. Wann diese dadurch unbrauchbar wurde, muss allerdings offen gelassen werden ${ }^{216}$.

\begin{tabular}{|c|c|c|c|c|c|c|}
\hline $\begin{array}{l}\text { Fläche, } \\
\text { KiNr. }\end{array}$ & Stratum & $\begin{array}{l}\text { Anzahl } \\
\text { diagnost. } \\
\text { Funde }\end{array}$ & $\begin{array}{l}\text { Charakterisierung } \\
\text { Fundkomplex }\end{array}$ & Datierung & $\begin{array}{l}\text { Datierungskriterien: jüngste } \\
\text { Keramik (u. Glas) }\end{array}$ & $\begin{array}{l}\text { Münzen } \\
\text { (Kap. 8) }\end{array}$ \\
\hline $\begin{array}{l}\text { K1 } \\
\text { K2 } \\
\text { KiNr. } 49 . \\
82\end{array}$ & SE 125 & 29 & $\begin{array}{l}\text { heterogen } \\
\text { späthellenistisch-kaiser- } \\
\text { zeitlich/spätantik }\end{array}$ & 6. Jh. n. Chr. & $\begin{array}{l}\text { LRC Hayes } 3 \mathrm{H} \\
\text { LRC Hayes } 2 \\
\text { ARS Teller Hayes? } \\
\text { ERSW } \\
\text { Amphoren LRA } 3 \\
\text { KW Töpfe } \\
\text { KW Pfanne } \\
\text { GK Schüssel }\end{array}$ & - \\
\hline $\begin{array}{l}\text { K2 } \\
\text { KiNr. } 52\end{array}$ & SE 126 & 8 & homogen & 5. Jh. n. Chr. & $\begin{array}{l}\text { LRC Hayes 1D } \\
\text { KW Töpfe } \\
\text { KW Pfanne } \\
\text { LRA } 3\end{array}$ & - \\
\hline $\begin{array}{l}\text { K2 } \\
\text { KiNr. } 60 . \\
71\end{array}$ & SE 127 & 24 & $\begin{array}{l}\text { heterogen } \\
\text { kaiserzeitlich-spätantik }\end{array}$ & 5. Jh. n. Chr. & $\begin{array}{l}\text { LRC Hayes 1D } \\
\text { LRC Hayes } 4 \\
\text { ARS Hayes 50B } \\
\text { KW Töpfe } \\
\text { KW Teller } \\
\text { Glas: Teller mit gefaltetem Röhr- } \\
\text { chenrand }\end{array}$ & M 99 \\
\hline $\begin{array}{l}\text { K2 } \\
\text { KiNr. } 90\end{array}$ & SE 130 & 20 & heterogen & $\begin{array}{l}\text { 2./3. Jh. n. Chr. } \\
\text { spätantik } \\
\text { rezent (Münzen: } \\
\text { moderne Falsa) }\end{array}$ & $\begin{array}{l}\text { ESC Hayes } 3 \\
\text { ESC Atlante L 26B } \\
\text { KW Töpfe } \\
\text { GK Schüssel }\end{array}$ & $\begin{array}{l}\text { M } 282 \\
\text { M } 283\end{array}$ \\
\hline $\begin{array}{l}\text { K1 } \\
\text { K2 } \\
\text { KiNr. } 59 . \\
78.92\end{array}$ & SE 216 & 78 & $\begin{array}{l}\text { heterogen } \\
\text { kaiserzeitlich/5.-6. Jh. } \\
\text { n. Chr. }\end{array}$ & 5.-6. Jh. n. Chr. & $\begin{array}{l}\text { LRC Hayes 1D } \\
\text { LRC } 2 \\
\text { LRC Hayes } 3 \text { ? gestempelt, Stem- } \\
\text { pelstil } 1 \\
\text { KW Töpfe } \\
\text { Amphore LRA } 3 \\
\text { Amphore Keay } 34 \\
\\
\text { Glas: } 4 \text { Fragmente }\end{array}$ & - \\
\hline
\end{tabular}

Tab. 95

\footnotetext{
${ }^{215}$ Kap. 5.2.

${ }^{216}$ Kap. 3.7.3
} 


\subsection{FUNDE AUS DEN GRABUNGEN OBERHALB DER SUMMA CAVEA}

Im Jahr 2009 wurden Grabungen im Bereich oberhalb der summa cavea durchgeführt (Kap. 3.8). Im Folgenden werden die aussagekräftigsten Fundkomplexe und die datierenden Funde diskutiert, wobei dem Aufbau der Befundbeschreibung in Kap. 3.8 gefolgt wird.

\subsubsection{Raum 1}

Die Ziegelschuttschicht SE 18 enthält nur wenige diagnostische Funde. An Sigillaten sind lediglich ein Bodenfragment eines ESB-Tellers der Form Atlante 78 aus der 1. Hälfte des 2. Jhs. n. Chr. (K 325 Taf. 340) sowie ein ESC-Tellerfragment der Form Hayes 4 (K 326 Taf. 340) zu verzeichnen. Letzteres spricht - mit aller gebotenen Vorsicht, welche die zeitliche Einordnung eines Stratums mittels eines einzigen Fragments gebietet - für eine Datierung von SE 18 an das Ende des 2. bis in das 3. Jh. n. Chr. Weder die drei in dieser Schicht vorhandenen Amphorenränder noch ein Boden einer dünnwandkeramischen Schale, ein gebrauchskeramischer Deckel und ein Boden eines geschlossenen, gebrauchskeramischen Gefäßes können zu einer näheren Datierung beitragen.

Ausschlaggebend für die Datierung des Ziegelversturzes SE 20 sind drei Lampenfunde: Es handelt sich einerseits um eine ganz erhaltene, matt rot überzogene Lampe mit gelochtem Griff (K 327 Taf. 340. 354). Der Übergang zwischen Schulter und unverziertem Diskus ist gerillt. Jener zur durch eine Rille abgesetzten runden Schnauze ist durch vertikale Rillen, die von zwei Voluten flankiert werden, gegliedert. Auch der Griffansatz ist durch zwei kleine Kreisaugen betont. Die Unterseite der Lampe ist ebenfalls mit kreis- und winkelförmigen Elementen verziert, die Schnauze durch zwei Stege abgesetzt. Vergleichbare Exemplare aus Fundkomplexen der Bauphase IV und der Zerstörung der WE 4, WE 1 und WE 2 des Hanghauses $2^{217}$ legen eine Datierung in das 3. Jh. n. Chr. nahe. Bei dem Fragment K 328 (Taf. 340. 354) handelt es sich um eine Warzenlampe, wie sie ebenfalls in ephesischen Fundkomplexen ab dem 3. Jhs. n. Chr. zu beobachten sind ${ }^{218}$. Die Lampe entspricht dem Typ III.4 ${ }^{219}$, sie zeigt eine dreifache plastische Punktreihe auf der Schulter. Die Schnauze ist rund und nur leicht abgesetzt. Die dritte Lampe (K 329 Taf. 340. 354) ist rund und blieb bis auf die Schnauze und den ausgerissenen Diskus ganz erhalten. Sie kann aufgrund ihrer Beschaffenheit als korinthischer Import angesprochen werden und entspricht dem Typ XXVIII nach O. Broneer, der vom ausgehenden 2. Jh. n. Chr. bis in das 4. Jh. $\mathrm{n}$. Chr. produziert wird ${ }^{220}$. Die tongrundige Lampe zeigt einen plastischen Schulterdekor aus liegenden Spiralen, die untereinander durch erhabene Punkte und zwischen der vorderen und der hinteren Lampenhälfte durch jeweils einen breiten, durch zwei Kerben markierten Steg getrennt sind ${ }^{221}$. Vom plastischen Motiv auf dem Diskus haben sich nur spärliche, nicht interpretierbare Reste erhalten. Der Griff der Lampe ist gelocht und dreifach gerillt. Von der Benützung der Lampe zeugen Schmauchspuren am vorderen Teil des Diskus und am Ansatz der Schnauze.

Die restlichen Funde aus SE 20 datieren - sofern zuordenbar - in die frühe bis mittlere Kaiserzeit oder sind späthellenistische Residuals. Zu ergänzen sind eine vollständig erhaltene Lasche ${ }^{222}$ und zwei zylinderförmige Metallobjekte ${ }^{223}$.

Ausschlaggebend für die Datierung des Ofenversturzes SE 21 ist ein Randfragment eines kleinen ESBBechers der Form Atlante 65 (K 330 Taf. 340). Diese kann von 50 bis 80 n. Chr. datiert werden. Ein Wandfragment der ESC ist nicht näher zu klassifizieren. Ein Krug mit abgesetztem, außen leicht gekehltem Rand (K 331 Taf. 340) findet Parallelen in Fundkomplexen der 2. Hälfte des 1. Jhs. bis in die 1. Hälfte des 2. Jhs. n. Chr. Ein flacher Boden eines Unguentariums weist wiederum in die Kaiserzeit, ebenso ein flaches, über dem Boden gerilltes Fragment eines geschlossenen Gefäßes. Ein Kochtopfrand dürfte noch hellenistisch

\footnotetext{
${ }^{217}$ LAdSTÄTter 2005, K 720 (ähnlich); LAdSTÄTter 2010a, A-K923 (ähnlich); LADSTÄtTER 2010b, B-K 440 (ähnlich).

${ }^{218}$ LAdSTÄTtER 2010a, 539, B-K 165; B-K 166. Vergesellschaftet ist - wie im vorliegenden Fundkomplex - eine korinthische Lampe, allerdings eine sog. wine leaf lamp.

${ }^{219}$ LADStÄTter 2008, K 143.

${ }^{220}$ BRONEER 1930, 102-114.

${ }^{221}$ Vgl. Broneer 1930, 103 Abb. 48, 18 (Schulterdekor); 105 Abb. 49, 1 (Schnauzenansatz); vgl. insgesamt v. a. Nr. 1241. 1257; s. auch Perlzweig 1961, Taf. 20, 908. 924.

${ }^{222}$ MF 17 Taf. 371 (Kap. 6.2.1).

${ }^{223}$ MF 50 Taf. 374 (Kap. 6.2.1).
} 
sein, ein Knauf eines Kochtopfdeckels kann hingegen nicht näher zugeordnet werden. Ein Fragment einer Amphore vom Typ Peacock - Williams 45 (K 332 Taf. 340) weist generell in die Kaiserzeit.

Insgesamt sind die Funde im Versturz des Ofens also in erster Linie aufgrund des kleinen Becherfragments der ESB in die 2. Hälfte des 1. Jhs. n. Chr. zu datieren.

Aus dem Aschehaufen SE 22 wurden keine chronologisch aussagekräftigen Fragmente geborgen.

Ein Töpfchen (K 333 Taf. 340) aus dem Ofen (SE 23, Objekt 1) datiert in die 1. Hälfte bis Mitte des 2. Jhs. n. Chr. ${ }^{224}$, während ein Randfragment einer gebrauchskeramischen Schüssel (K 334 Taf. 340) vermutlich noch in das ausgehende 1. Jh. v. Chr. bis in das 1. Jh. n. Chr. zu datieren ist. Ein Rand eines Kochtopfs ist innen profiliert (K 335 Taf. 340). Ein Randfragment eines weiteren Kochtopfs passt an K 340 aus der Feuerstelle SE 25 an (s. u.). Aus dem Ofen SE 23 stammen im Übrigen auch eine Bronzeklinge ${ }^{225}$ und ein Fragment eines Metallgefäßes ${ }^{226}$.

Die Feuerstelle unter dem Ofen (SE 25, Objekt 2) enthält ein Randfragment einer Schale der ESC, das der Form Atlante L19 zuzuweisen ist (K 336 Taf. 341), und einen Rand eines ESB-Bechers der Form Atlante 39 (K 337 Taf. 341). Letzterer ist um die Mitte des 1. Jhs. n. Chr. zu datieren, während die ESC-Schale in die 2. Hälfte des 1. und in das 2. Jh. n. Chr. weist. Ein dünnwandiger Krug mit leicht gebauchtem Hals und einem vor dem Brand eingeritzten Graffito (K 338 Taf. 341.354) findet Parallelen in der mittleren Kaiserzeit ${ }^{227}$, v. a. aber in den Zerstörungskontexten des Hanghauses $2^{228}$. Neben einem der mittleren bis späten Kaiserzeit zuzuordnenden gebrauchskeramischen Schüsselrand (K 339 Taf. 341$)^{229}$ und einem flachen Boden einer Schüssel (K 340 Taf. 341) enthält SE 25 einen Kochtopf mit schräg gestelltem, innen profiliertem Rand, von dem insgesamt 15 Fragmente geborgen wurden, darunter zwei im Ofen >Objekt 1<(K 341 Taf. 341). Parallelen sind aus Fundkomplexen der Bauphase II der WE $4^{230}$ und WE $1^{231}$ belegt.

Insgesamt ist für die Feuerstelle unter dem Ofen >Objekt 1< eine Nutzung bis in das 2., vielleicht auch noch im 3. Jh. n. Chr. anzunehmen, eine exakte Datierung ist allerdings aufgrund der wenigen präzise datierenden Fragmente problematisch.

Der Bodenrest SE 26 enthält ausschließlich Küchenware, bestehend aus einem Teller oder einer Schale mit blockartigem, innen leicht abgesetztem Rand (K 342 Taf. 341) und einer Schüssel mit nach außen abfallendem, breitem, leicht profiliertem Rand (K 343 Taf. 341) sowie fünf Deckelrändern (K 344-348 Taf. 342). Die jüngste von drei Münzen aus SE 26 datiert in die Zeit um 295/299 n. Chr. ${ }^{232}$. Vertreten ist außerdem eine Klammer/Zange ${ }^{233}$.

In der Kanalverfüllung SE 27 wurde zeitlich inhomogenes Fundmaterial von der späthellenistischen bis in die mittlere/späte Kaiserzeit geborgen, was mit seiner langen Nutzung erklärt werden kann. Ein Randfragment einer Schale der ESB (K 349 Taf. 342) kann nur ganz allgemein in das 1. bis 2. Jh. n. Chr. datiert werden. Außerdem kamen ein Rand- und Henkelfragment einer Kasserolle zum Vorschein, deren Form typisch für das 2. bis 4. Jh. n. Chr. ist (K 350 Taf. 342). Ein Kochtopf oder eine Kasserolle mit breitem, ausgebogenem Rand ist in die mittlere Kaiserzeit zu datieren (K 351 Taf. 342). Ein Fragment einer Bildlampe mit einem vegetabilen Dekor (Zweige) auf der Schulter und Resten einer nicht näher zu identifizierenden Tierdarstellung auf dem Diskus kann innerhalb der Kaiserzeit nicht näher zugeordnet werden (K 352 Taf. 342), ebensowenig ein Bodenfragment eines dünnwandigen Bechers, ein gebrauchskeramischer Deckelknauf und der Knauf einer Amphore. Dasselbe gilt für zwei Glasfragmente - ein Randfragment einer Schale oder eines Tellers und ein Boden eines Bechers (G 8. G 9 Taf. 342). Zu verzeichnen sind außerdem späthellenistische Residuals. Ein Fragment eines Eisenmessers ${ }^{234}$ sowie ein Blechbeschlag ${ }^{235}$ ergänzen das Fundspektrum aus der Kanalverfüllung SE 27.

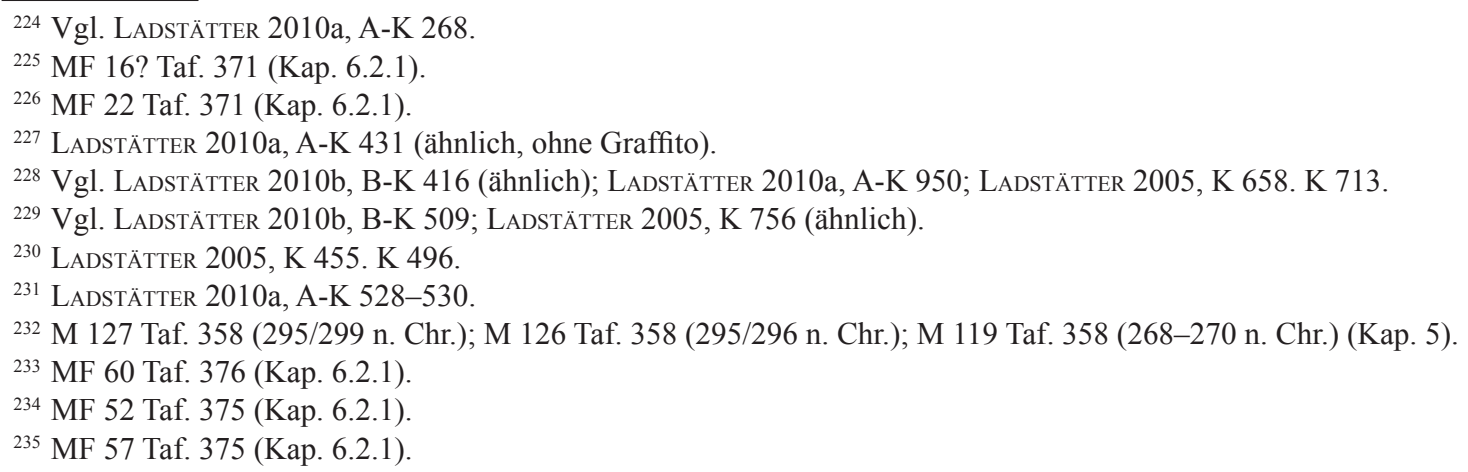


Aus dem Bodenunterbau SE 28 stammen ein Becher der ESB, welcher der Form Atlante 65 zuzuweisen und in das 3. Viertel des 1. Jhs. n. Chr. zu datieren ist (K 353 Taf. 342), und eine Schale derselben Gattung der Form Atlante 70 (K 354 Taf. 342), welche besonders in der Zeit von 50 bis $125 \mathrm{n}$. Chr. zum Standardinventar ephesischer Haushalte gehört. Ein Fragment einer Schale der ESA kann der Form Atlante 22B zugewiesen werden und datiert in das 2. Jh. v. Chr. bis ca. $10 \mathrm{n}$. Chr., ist also als Residual zu bewerten. Ebenso verhält es sich mit einer Schale, die in GWSÜ-Technik gefertigt ist und mit dem Fragment einer Ephesoslampe, auf deren Schnauzengang der Rest der Darstellung einer Maske in Form eines bärtigen Kopfs zu erkennen ist. Die vorhandene Küchenware und die gebrauchskeramischen Gefäße sind innerhalb des 1. bis 2. Jhs. n. Chr., bzw. ganz allgemein innerhalb der Kaiserzeit, meist nicht näher zuordenbar. Ebenso verhält es sich mit den drei Fragmenten von Amphoren aus SE 28, von denen sich lediglich ein halb geöffneter Knauf dem langlebigen Typ Peacock - Williams 45 zuweisen lässt.

Aus dem Rest des Estrichbodens SE 32 stammen nur zwei diagnostische Fragmente. Eine Schale der ESA (K 355 Taf. 342) ist der Form Atlante 46 zuzuweisen und datiert an den Anfang des 1. Jhs. n. Chr. Ein Kochtopf (K 356 Taf. 342) kann aufgrund von Analogiefunden ${ }^{236}$ in die 1. Hälfte des 1. Jhs. n. Chr. datiert werden. Es soll daher - mit aller gebotenen Vorsicht aufgrund der geringen Fundquantität - insgesamt eine Datierung in die 1. Hälfte des 1. Jhs. n. Chr. vorgeschlagen werden.

Die Planierschicht SE 36 enthielt zahlreiche Gefäße (insgesamt 48 diagnostische Stücke), die bisweilen sehr gut erhalten waren. Besonders aussagekräftig in Hinblick auf die zeitliche Einordnung der Schicht ist das ESB-Spektrum (K 357-366 Taf. 343): Es ließen sich mehrere Gefäße zu großen Teilen zusammenfügen, so z. B. ein Teller der Form Atlante 58 mit Rosettenstempel auf der Bodeninnenseite (K 358 Taf. 343. 354) und zwei Teller Atlante 60 mit früher Randausprägung (K 360 Taf. 343. 354; K 361 Taf. 343), letzerer allerdings im ab etwa $70 \mathrm{n}$. Chr. auftretenden fabric ESB 2. Außerdem sind weitere Rand- und/oder Bodenfragmente der Formen Atlante 58, 60, 70 (K 363 Taf. 343) bzw. Atlante 36/70 (K 364 Taf. 343) und Atlante 71 (K 366 Taf. 343) zu verzeichnen. Zusammengefasst kann festgehalten werden, dass die ESBGefäße einem flavischen Zeithorizont angehören. Die restlichen Fundgattungen (Grafik 16) fügen sich gut in diesen zeitlichen Rahmen ein, sind aber nicht so präzise einzuordnen. Anzumerken ist, dass die Fundzusammensetzung zeitlich nicht ganz homogen ist, vereinzelt treten frühkaiserzeitliche Residuals auf. $\mathrm{Zu}$ erwähnen sind außerdem ein Gewandfaltenfragment und eine Terrakottabasis ${ }^{237}$.

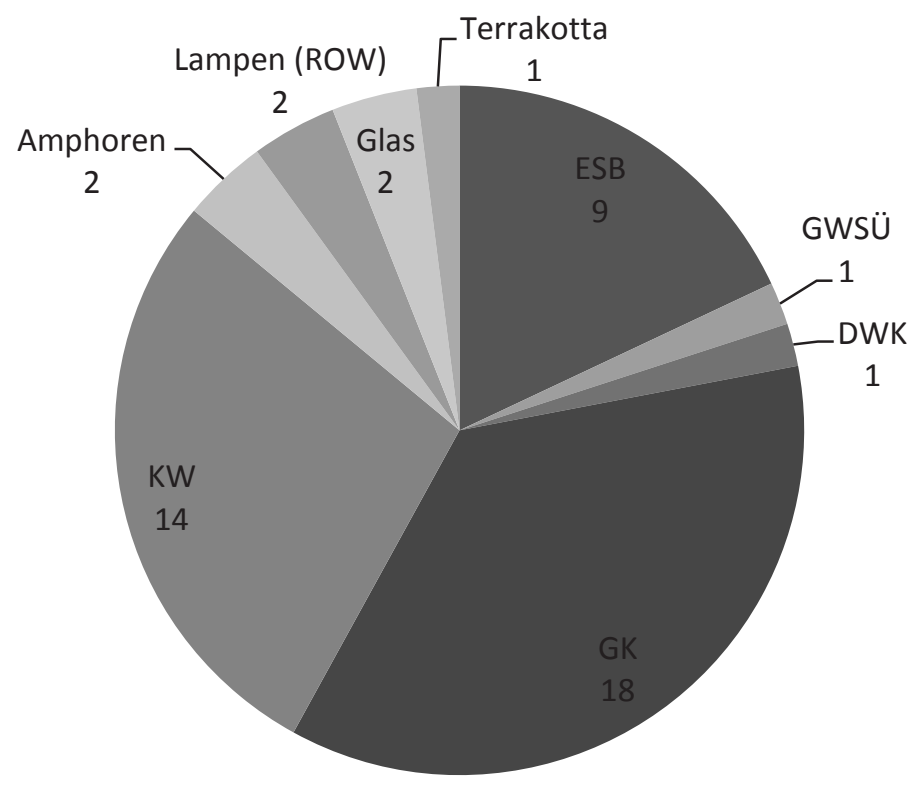

Grafik 16: Fundgattungen in der Planierschicht SE 36 (diagnostische Stücke)

\footnotetext{
${ }^{236}$ Vgl. z. B. LAdSTÄtTER 2005, K 316.

${ }^{237}$ TK 26 Taf. 365; TK 50 Taf. 369 (Kap. 6.1).
} 
In der Planierschicht SE 36 wurde also offensichtlich ein Hausrat flavischer Zeitstellung entsorgt, die zahlreichen Anpassungen bzw. die bisweilen gut zu rekonstruierenden Gefäße implizieren einen ursprünglichen Verwendungskontext in der Nähe des Fundorts, also vermutlich in Raum 1.

\subsubsection{Raum 2}

Aus der Schuttschicht SE 2 stammen 29 diagnostische Keramikfunde, die mehrheitlich in die spätantikfrühbyzantinische Zeit zu datieren sind. Es sind allerdings auch kaiserzeitliche Residuals vorhanden. Besonders aussagekräftig in Bezug auf die Datierung ist ein Fragment einer frühbyzantinischen Ampulle (K 367 Taf. 343). Diese im östlichen Mittelmeerraum produzierten ${ }^{238}$ massiven, mittelgroßen Gefäße wurden vom 5. Jh. bis in die Mitte des 7. Jhs. n. Chr. zahlreich nach Ephesos importiert und waren im gesamten Mittelmeerraum verbreitet. Das Randfragment K 368 (Taf. 343) gehört zu einem verwandten Produkt, einem sog. ephesischen frühbyzantinischen Amphoriskos ${ }^{239}$. Ein Kochtopf mit abgetrepptem Rand und gerippter Wand (K 369 Taf. 343) ${ }^{240}$ und ein zweiter mit nach innen abfallender, profilierter Lippe (K 370 Taf. 344) 241 $^{24}$ weisen in das ausgehende 4. bis 5. Jh. n. Chr. Ein gedrehter Pfannengriff ist ebenso als spätantikfrühbyzantinisch zu bewerten ${ }^{242}$. Eine gebrauchskeramische Schüssel (K 371 Taf. 344) mit breitem, nach außen abfallendem, profiliertem Rand ist nach Parallelen ${ }^{243}$ ab der Mitte des 5. Jhs. bis in das 7. Jh. n. Chr. zu datieren. Die bestimmbaren Fragmente von Amphoren sind dem Typ LRA 3 (K 372 Taf. 344) zuzuordnen.

Insgesamt lassen die jüngsten Funde aus der Schuttschicht SE 2 keinen Zweifel an deren Entstehung im (späten) 5. Jh. n. Chr.

In der Zerstörungslage SE 40 wurden lediglich vier diagnostische Fragmente geborgen. Es handelt sich um zwei gebrauchskeramische Schüsselränder, die allgemein in die Kaiserzeit bzw. in das 2. Jh. n. Chr. datiert werden können, sowie um einen innerhalb der Kaiserzeit nicht näher einzuordnenden Topfrand. Ein Deckelknauf weist ein fabric auf, das an spätantike Küchenware erinnert. Dies allein ist als Datierungskriterium aber auch nicht ausreichend. Insgesamt muss eine absolutchronologische Einordnung von SE 40 aufgrund der Fundkeramik also unterbleiben.

In dem Estrichunterbau SE 41 wurden nur zwei diagnostische Randfragmente geborgen, diese reichen aber aus, um eine Datierung in das späte 4. bis 5. Jh. n. Chr. zu gewährleisten. Es handelt sich um einen Rand eines Tellers der ARS (K 373 Taf. 344), der vermutlich eine Variante der Form Hayes 67 darstellt $^{244}$, und um einen Kochtopf (K 374) ${ }^{245}$.

In der Schuttauffüllung SE 43 waren drei diagnostische Fragmente vorhanden. Diese gehören zu Töpfen/ Pfannen mit gerippter Wand (K 375. K 376 Taf. 344) ${ }^{246}$, die jeweils in das (frühe) 5. Jh. n. Chr. datiert werden können. Die Amphore K 377 (Taf. 344) dürfte einen spätantiken Import darstellen, kann aber nicht näher klassifiziert werden.

Die Planierschicht SE 44 enthält lediglich zwei feinchronologisch nicht näher zuzuordnende diagnostische Fragmente: Es handelt sich um kleines Randstück eines Kochtopfs, der allgemein als spätantik bewertet werden kann, und um ein Bodenstück eines vermutlich kaiserzeitlichen geschlossenen Gefäßes.

In SE 46, der Baugrube des Estrichbodens SE 45, die in Zusammenhang mit dem Kanal in MA4 zu interpretieren ist, fand sich ein Fragment eines dünnwandigen Töpfchens der Küchenware (K 378 Taf. 344), das nach Analogiefunden ${ }^{247}$ in das 2. bis 3. Jh. n. Chr. datiert werden kann. Die restlichen Funde aus der Schicht sind innerhalb der späthellenistischen und der Kaiserzeit nicht näher einzuordnen.

\footnotetext{
${ }^{238}$ Aufgrund mineralogisch-petrografischer Analysen kommen Nordsyrien, Kilikien, Rhodos oder Zypern als Produktionsgegenden in Frage: SAUER - LADSTÄTTER 2005, 133.

${ }^{239}$ Metaxas 2005, 97-101.

${ }^{240}$ LADSTÄTter 2008, 186 f. K 176 Abb. 31, 1; K 179 Abb. 31, 2.

${ }^{241}$ LADSTÄtTER 2008, 187 Abb. 31, 3 (K 177).

${ }^{242}$ Turnovsky 2005b, Abb. 1, 5.

${ }^{243}$ Vgl. z. B. LAdSTÄTter 2008, K 414. K 415.

${ }^{244}$ HaYes 1972, 112-116.

${ }^{245}$ Vgl. LadSTÄTter 2008, K 177. K 212.

${ }^{246} \mathrm{Vgl}$. LAdSTÄtTer 2008, K 181; TuRnOvsky 2005b, Abb. 1, 5.

${ }^{247}$ LADSTÄTtER 2005, K 669. K 717.
} 


\subsection{KATALOG}

Die Farbbestimmung der keramischen Funde erfolgt nach Munsell, Soil Color Charts (New York, Edition 2000). Die Farbbestimmung für Glasfunde folgt H. Küppers, DuMont's Farbenatlas ${ }^{7}$ (Köln 1995).

\section{KAMMER D3}

\section{K 1 Topf}

Gattung: Küchenware

AO: GHD; InvNr. ETH02/49/5 (SE B3)

Ton: $10 \mathrm{YR} 4 / 1$

Farbe innen u. außen: Gley 1 4/N

Maße: RDm $17 \mathrm{~cm}$

Erh.: 1 RS

\section{K 2 Lampe}

AO: GHD; FO: SE B3; InvNr. ETH02/49/8 (SE B3)

Ton: 2.5 YR6/8

Farbe innen: 10YR5/4; Farbe außen: 2.5YR5/6

Überzug: außen, abgerieben

Dekor: Bodenmarke auf der Bodenunterseite

Maße: BDm ca. $5 \mathrm{~cm}$; erh. L ca. $5 \mathrm{~cm}$; erh. H 2,3 cm

Erh.: 3 BS+WS

\section{K 3 Platte}

Taf. 302

Gattung: GWSÜ

AO: GHD; FO: SE B4; InvNr. ETH02/24a/10 (SE B4)

Ton: 5YR6/4-7.5YR5/4

Farbe innen $u$. außen: 10YR2/1

Überzug: flächig, glänzend, kompakt

Maße: RDm $38 \mathrm{~cm}$

Erh.: 9 RS

\section{K 4 Teller}

Gattung: GWSÜ

AO: GHD; FO: SE B4; InvNr. ETH02/24a/7 (SE B4)

Ton: 7.5 YR5/4

Farbe innen u. außen: 7.5YR3/1; Oberfläche: 7.5YR6/4

Überzug: flächig, matt glänzend, abgerieben

Dekor: Palmettenstempel, Rouletting

Maße: BDm $14 \mathrm{~cm}$

Erh.: 6 BS+WS

\section{K 5 Reliefbecher}

Taf. 302

Gattung: hellenistische Reliefkeramik

AO: GHD; FO: SE B4; InvNr. ETH02/24a/3 (SE B4)

Ton: Gley $13 / 1$

Farbe innen: 5YR5/2; Farbe außen: Gley 1 2.5/N

Überzug: außen und Rand innen, matt glänzend, tw. abgerieben

Maße: RDm $11 \mathrm{~cm}$

Dekor: Palmette

Erh.: 1 RS

\section{K 6 Becher}

Taf. 302

Gattung: Dünnwandige Keramik

AO: GHD; FO: SE B4; InvNr. ETH02/24a/25 (SE B4)

Ton: $2.5 \mathrm{YR} 5 / 8$

Farbe innen: 2.5YR6/8; Farbe außen: 5YR5/1

Überzug: außen, matt, abgerieben
Taf. 302 Maße: RDm $13 \mathrm{~cm}$

Erh.: 1 RS

\section{K 7 Becher}

Taf. 302

Gattung: Dünnwandige Keramik

AO: GHD; FO: SE B4; InvNr. ETH02/24a/31 (SE B4)

Ton: 10R6/8

Farbe innen u. außen: 10R4/4

Maße: RDm $10 \mathrm{~cm}$

Erh.: 1 RS

K 8 Unguentarium/Amphoriskos

Taf. 302.345

Gattung: Gebrauchskeramik

AO: GHD; FO: SE B4; InvNr. ETH02/24a/8 (SE B4)

Ton: $10 \mathrm{R} 6 / 6$

Farbe außen: 2.5 YR6/6

Überzug: außen, matt, abgerieben

Maße: RDm 2,22 cm; BDm 2,84 cm

Erh.: 1 BS+WS

\section{G 1 Balsamarium}

Taf. 302

Gattung: Glas

AO: GHD; I FO: SE B4; InvNr. ETH02/24a/1 (SE B4)

Bruch: sehr fein, nur wenige sehr feine Bläschen

Farbe: farblos ds., weiß opak verwittert

Maße: Dm 0,6-0,8 cm; L 6,4 cm

Sekundäre Veränderungen: verwittert

Erh.: 1 RS

\section{K 9 Teller}

Taf. 302

Gattung: ESA, Typ: Atlante 4B

AO: GHD; FO: SE B5; InvNr. ETH02/25/2 (SE B5)

Ton: 5YR7/4

Farbe innen u. außen: $2.5 \mathrm{YR} 4 / 8$

Überzug: flächig, matt glänzend, kompakt

Maße: BDm $9 \mathrm{~cm}$

Dekor: feiner konzentrischer Roulettdekor, Boden innen Erh.: 1 BS

K 10 Schale

Taf. 302

Gattung: ESA, Typ: Atlante 22B

AO: GHD; InvNr. ETH02/25/4 (SE B5)

Ton: 7.5 YR7/4

Farbe innen u. außen: $2.5 Y R 4 / 8$

Überzug: flächig, matt glänzend, kompakt, abgesplittert

Maße: BDm $6 \mathrm{~cm}$

Erh.: 1 BS

\section{K 11 Reliefbecher?}

Taf. 303

Gattung: hellenistische Reliefkeramik?

AO: GHD; InvNr. ETH02/25/20 (SE B5)

Ton: Gley 1 5/N 
Farbe innen: Gley 1 2.5/N; Farbe außen: 10YR5/1

Überzug: flächig, glänzend, stark abgerieben

Maße: RDm $10 \mathrm{~cm}$

Erh.: 1 RS

\section{K 12 Reliefbecher}

Gattung: hellenistische Reliefkeramik

AO: GHD; InvNr. ETH02/25/11 (SE B5)

Ton: 2.5 YR7/8

Farbe innen u. außen: 2.5 YR7/8

Überzug: flächig, matt, kompakt

Dekor: Blattschuppen, an der Wand außen

Maße: $2 \times 2,6 \mathrm{~cm}$

Erh.: 1 WS

\section{K 13 Schale}

Gattung: hellenistische Firnisware

AO: GHD; InvNr. ETH02/25/43 (SE B5)

Ton: 10YR6/4

Farbe innen u. außen: 10YR3/1

Überzug: flächig, matt glänzend, tw. abgerieben

Maße: RDm $16 \mathrm{~cm}$

Erh.: 1 RS

\section{K 14 Echinusschale}

Gattung: hellenistische Firnisware

AO: GHD; InvNr. ETH02/25/1 (SE B5)

Ton: Gley $16 / \mathrm{N}$

Farbe innen u. außen: 2.5Y2.5/1; Farbe ohne Überzug: 10YR6/1

Überzug: flächig, glänzend, abgerieben

Maße: RDm $14 \mathrm{~cm}$

Erh.: 1 RS

\section{K 15 Offenes Gefäß}

Taf. 303

Gattung: hellenistische Firnisware

AO: GHD; InvNr. ETH02/25/21 (SE B5)

Ton: 5YR6/6

Farbe innen u. außen: 2.5YR3/1

Überzug: flächig, glänzend, kompakt, abgerieben

Maße: RDm $26 \mathrm{~cm}$

Erh.: 1 RS

\section{K 16 Offenes Gefäß}

Taf. 303

Gattung: hellenistische Firnisware

AO: GHD; InvNr. ETH02/25/44 (SE B5)

Ton: 10 YR6/3

Farbe innen u. außen: 2.5YR2.5/1

Überzug: flächig, matt glänzend, kompakt, tw. abgesplittert

Maße: BDm $6 \mathrm{~cm}$

Erh.: 1 BS

\section{K 17 Offenes Gefäß}

Taf. 303

Gattung: hellenistische Firnisware

AO: GHD; InvNr. ETH02/25/58 (SE B5)

Ton: 7.5 YR6/6

Farbe innen: 2.5YR4/8; Farbe außen: 5YR5/6

Überzug: flächig, matt glänzend, kompakt, stark abgerieben

Maße: BDm $7 \mathrm{~cm}$

Erh.: 1 BS

Taf. 303
K 18 Lampe

Taf. 303

Typ: Ephesoslampe

AO: GHD; InvNr. ETH02/25/18 (SE B5)

Ton: $2.5 \mathrm{Y} 6 / 1$

Farbe innen: 10YR6/4; Farbe außen: Gley 1 4/N

Taf. 303 Überzug: außen, matt, abgerieben, eher dünn

Maße: BDm $4 \mathrm{~cm}$

Erh.: $1 \mathrm{BS}$

K 19 Lampe

Taf. 303

Typ: ROW-Lampe

AO: GHD; InvNr. ETH02/25/33 (SE B5)

Ton: 2.5 YR6/4

Farbe innen: 10R6/4; Farbe außen: 10R5/8

Überzug: außen, matt glänzend, tw. abgerieben

Maße: BDm $5 \mathrm{~cm}$

Erh.: 1 BS

\section{K 20 Kantharos}

Taf. 303. 345

Gattung: Westabhangware

AO: GHD; InvNr. ETH02/32/37 (SE B6)

Ton: 5YR6/6

Farbe innen u. außen: Gley $12.5 / \mathrm{N}$

Überzug: flächig, glänzend, kompakt

Taf. 303 Dekor: Bemalung; Zacken und Punkte, Wand außen

Maße: Dm Hals $3 \mathrm{~cm}$

Erh.: 1 WS

\section{K 21 Offenes Gefäß}

Taf. 303

Gattung: Westabhangware

AO: GHD; InvNr. ETH02/32/38 (SE B6)

Ton: 5YR6/6-10YR5/2

Farbe innen u. außen: Gley 1 2.5/N

Überzug: flächig, glänzend, kompakt

Dekor: Bemalung, Efeublätter, an der Wand außen

Maße: $2 \times 2 \mathrm{~cm}$

Erh.: 1 WS

\section{K 22 Teller}

Taf. 303

Gattung: hellenistische Firnisware

AO: GHD; InvNr. ETH02/32/10 (SE B6)

Ton: $5 \mathrm{Y} 6 / 1$

Farbe innen u. außen: Gley 1 2.5/N; Farbe ohne Überzug: $2.5 \mathrm{Y} 6 / 2$

Überzug: flächig, matt glänzend, kompakt, abgerieben

Maße: RDm $21 \mathrm{~cm}$

Erh.: 1 RS

\section{K 23 Teller}

Taf. 303

Gattung: hellenistische Firnisware

AO: GHD; InvNr. ETH02/50/20 (SE B6)

Ton: 7.5 YR6/6

Farbe innen u. außen: 2.5YR5/6

Farbe außen (ohne Überzug): 10YR7/4; Farbe innen: 5YR5/6

Überzug: flächig, matt glänzend, abgerieben

Maße: RDm $32 \mathrm{~cm}$

Erh.: 1 RS

K 24 Echinusschale

Taf. 303

Gattung: hellenistische Firnisware

AO: GHD; InvNr. ETH02/50/17 (SE B6) 
Ton: $7.5 \mathrm{YR} 4 / 1$

Farbe innen: 7.5YR5/2; Farbe außen: 5YR4/1

Überzug: flächig, matt glänzend, tw. abgerieben

Maße: RDm $18 \mathrm{~cm}$

Erh.: 1 RS

\section{K 25 Schale}

Taf. 304

Gattung: hellenistische Firnisware

AO: GHD; InvNr. ETH02/50/22 (SE B6)

Ton: 7.5 YR5/2

Farbe innen: 10R5/1; Farbe außen: 5YR4/1

Überzug: flächig, matt glänzend, kompakt, abgesplittert

Maße: RDm $14 \mathrm{~cm}$

Erh.: 1 RS

\section{K 26 Schale}

Taf. 304

Gattung: hellenistische Firnisware

AO: GHD; InvNr. ETH02/32/11 (SE B6)

Ton: 2.5 YR6/8

Farbe innen u. außen: $2.5 \mathrm{YR} 4 / 8$

Überzug: flächig, matt glänzend, fleckig, tw. abgerieben

Maße: RDm 14,8 cm

Erh.: 1 RS

\section{K 27 Schälchen}

Taf. 304

Gattung: Gebrauchskeramik mit partiellem Überzug

AO: GHD; InvNr. ETH02/32/16 (SE B6)

Ton: $7.5 \mathrm{YR} 7 / 6$

Farbe innen: 7.5YR4/4; Farbe außen: 2.5YR5/6; Farbe außen ohne Überzug: 5YR6/6; Farbe innen ohne Überzug: 7.5YR $7 / 6$

Überzug: innen und Rand außen, matt, abgerieben

Maße: RDm $12 \mathrm{~cm}$

Sekundäre Veränderungen: versintert

Erh.: 1 RS

\section{K 28 Unguentarium}

Taf. 304

Gattung: Gebrauchskeramik

AO: GHD; InvNr. ETH02/26/1 (SE B6)

Ton: 2.5 YR6/8

Farbe innen u. außen: 7.5YR7/4; Farbe Überzug: 5YR5/6

Überzug: matt, abgerieben

Maße: RDm 2,9 cm

Erh.: 1 RS

\section{K 29 Amphore}

Typ: ähnlich Peacock - Williams 45?

AO: GHD; InvNr. ETH02/50/4 (SE B6)

Ton: 2.5 YR4/6

Farbe innen: 5YR5/3; Farbe außen: 7.5YR8/2

Maße: BDm 5,6 cm

Sekundäre Veränderungen: versintert

Erh.: 1 Knauf (abgebrochen)

\section{G 2 Offenes Gefäß}

Gattung: Glas

AO: GHD; InvNr. ETH02/50/25 (SE B6)

Farbe: $\mathrm{S}_{40} \mathrm{C}_{60} \mathrm{Y}_{40}$, wenige kleine Bläschen

Maße: BDm $3 \mathrm{~cm}$

Erh.: 2 BS

Taf. 304
K 30 Kantharos

Taf. 304. 345

Gattung: hellenistische Firnisware

AO: GHD; InvNr. ETH02/30/1 (SE B7)

Ton: $7.5 Y R 6 / 4$

Farbe innen u. außen: 10YR2/1

Überzug und Bemalung: flächig, glänzend, kompakt, abgesplittert

Maße: RDm 7,4 cm

Erh.: 1 RS

K 31 Skyphos/Kantharos

Taf. 304

Gattung: hellenistische Firnisware

AO: GHD; InvNr. ETH02/28/8 (SE B7)

Ton: $10 \mathrm{YR} 4 / 4$

Farbe innen u. außen: 2.5YR4/6; Farbe ohne Überzug: 2.5YR6/6

Überzug: flächig, matt glänzend, kompakt, abgesplittert

Maße: BDm $6 \mathrm{~cm}$

Erh.: 1 BS

K 32 Echinusschale

Taf. 304

Gattung: hellenistische Firnisware

AO: GHD; InvNr. ETH02/30/2 (SE B7)

Ton: 7.5 YR 5/4-10YR4/3

Farbe innen u. außen: Gley 1 2.5/N; Farbe ohne Überzug: 2.5Y $5 / 1-4 / 1$

Überzug: flächig, matt glänzend, abgerieben

Maße: RDm $13 \mathrm{~cm}$

Erh.: 1 RS

\section{K 33 Fischteller}

Taf. 304

Gattung: hellenistische Firnisware

AO: GHD; InvNr. ETH02/53/21 (SE B7)

Ton: 10 YR $7 / 1$

Farbe innen u. außen: Gley $13 / \mathrm{N}$

Überzug: flächig, glänzend, abgerieben

Maße: RDm $20 \mathrm{~cm}$

Erh.: 1 RS

\section{K 34 Teller}

Taf. 304

Gattung: hellenistische Firnisware

AO: GHD; InvNr. ETH02/53/8 (SE B7)

Ton: 2.5YR4/1

Farbe innen: 10YR3/1; Farbe außen: 10YR5/1

Überzug: flächig, matt glänzend, kompakt

Maße: BDm $10 \mathrm{~cm}$

Taf. 304 Dekor: in der Bodenmitte vier Palmettenstempel um zwei konzentrische Rillen

Erh.: 1 BS

\section{K 35 Amphore}

Typ: graeco-italisch

AO: GHD; InvNr. ETH02/28/1 (SE B7)

Ton: 5 YR7/4

Farbe innen $u$. außen: 10YR8/3

Überzug: flächig, matt, kompakt, abgerieben

Maße: RDm $15 \mathrm{~cm}$

Erh.: 1 RS

K 36 Amphore

Taf. 304

Typ: koisch

AO: GHD; InvNr. ETH02/37/3 (SE B7) 
Ton: 10YR5/1-5YR5/5

Farbe innen: 10YR5/1; Farbe außen: 10YR8/2; Farbe ohne Überzug: 5YR7/6

Überzug: außen, matt, kompakt

Maße: Dm $2 \mathrm{~cm}$

Erh.: 1 BS

\section{K 37 Lampe}

AO: GHD; InvNr. ETH02/53/6 (SE B7)

Ton: 2.5 YR6/6

Farbe innen: 5YR4/6; Farbe außen: 7.5YR7/4

Überzug: flächig, matt glänzend, abgerieben

Maße: BDm $5 \mathrm{~cm}$

Erh.: 1 Schnauze

\section{G 3 Glaslampe}

Gattung: Glas

AO: GHD; InvNr. ETH02/37/4 (SE B7)

Farbe: $\mathrm{Y}_{40} \mathrm{M}_{00} \mathrm{C}_{60}$

Maße: RDm ca. $15 \mathrm{~cm}$

Erh.: 1 RS+Henkel

\section{K 38 Kantharos}

Taf. 305. 345

Gattung: Westabhangware

AO: GHD; InvNr. ETH02/34/7 (SE B8)

Ton: 10YR6/4

Farbe innen u. außen: Gley 1 2.5/N; Farbe ohne Überzug: $2.5 \mathrm{YR} 3 / 2$

Überzug und Bemalung: flächig, glänzend, kompakt, abgerieben Dekor: Bemalung, vegetabil, an der Wand außen

Maße: Dm am Übergang Hals/Mündung $6 \mathrm{~cm}$

Erh.: $1 \mathrm{WS}$

\section{K 39 Kantharos}

Taf. 305

Gattung: hellenistische Firnisware

AO: GHD; InvNr. ETH02/52/6 (SE B8)

Ton: 7.5YR7/4-7.5YR6/6

Farbe innen u. außen: 5YR2.5/1

Überzug: flächig, glänzend, kompakt, abgesplittert

Dekor: Riefeldekor, an der Wand außen

Maße: Dm 4 cm

Erh.: 1 WS

\section{K 40 Echinusschälchen}

Taf. 305

Gattung: hellenistische Firnisware

AO: GHD; InvNr. ETH02/52/4 (SE B8)

Ton: $7.5 Y R 4 / 1-5 / 1$

Farbe innen u. außen: 7.5YR2.5/1

Überzug: flächig, matt glänzend, kompakt, abgesplittert

Maße: RDm $11 \mathrm{~cm}$

Erh.: 1 RS

\section{K 41 Teller}

Gattung: hellenistische Firnisware

Taf. 305

AO: GHD; InvNr. ETH02/35/2 (SE B8)

Ton: $2.5 \mathrm{Y} 5 / 1$

Farbe innen u. außen: Gley 1 2.5/N; Farbe ohne Überzug: 5Y5/1

Überzug: flächig, matt glänzend, abgesplittert

Maße: RDm $24 \mathrm{~cm}$

Erh.: 1 RS
K 42 Teller

Taf. 305

Gattung: hellenistische Firnisware

AO: GHD; InvNr. ETH02/54/9 (SE B8)

Ton: Farbe Rand: 5YR6/6; Farbe Kern: Gley 1 5/N

Farbe innen: Gley $13 / \mathrm{N}$; Farbe außen: 5Y2.5/1

Überzug: flächig, metallisch glänzend, kompakt

Maße: RDm $17 \mathrm{~cm}$

Erh.: 1 RS

K 43 Topf

Taf. 305

Gattung: Küchenware

AO: GHD; InvNr. ETH02/52/14 (SE B8)

Ton: 5 YR $4 / 6$

Farbe innen: 2.5YR6/6; Farbe außen: 5YR5/4

Maße: RDm 24,2 cm

Erh.: 1 RS

\section{K 44 Reliefbecher}

Gattung: hellenistische Reliefkeramik

AO: GHD; InvNr. ETH02/43/3 (SE B10)

Ton: 7.5YR7/6

Farbe innen: 7.5YR3/2; Farbe außen: 7.5YR7/6

Taf. 305.345

Überzug: flächig, matt glänzend, kompakt, abgerieben

Dekor: Langblätter, von vertikalem Steg begrenzt, darüber horizontaler Steg und Rest eines länglichen, plastischen Dekors Maße: KDm (max.) $10 \mathrm{~cm}$

Erh.: 1 WS

\section{K 45 Teller}

Taf. 305

Gattung: hellenistische Firnisware

AO: GHD; InvNr. ETH02/40/12 (SE B10)

Ton: 5YR6/6

Farbe innen u. außen: Gley 1 2.5/N

Überzug: flächig, matt glänzend, tw. abgerieben

Maße: RDm $22 \mathrm{~cm}$

Erh.: 1 RS

\section{K 46 Schale}

Taf. 305

Gattung: hellenistische Firnisware

AO: GHD; InvNr. ETH02/40/13 (SE B10)

Ton: 5YR7/6

Farbe innen u. außen: 2.5 YR5/6

Überzug: flächig, matt glänzend, tw. abgerieben

Maße: RDm $15 \mathrm{~cm}$

Erh.: 1 RS

\section{K 47 Kantharos}

Taf. 305

Gattung: hellenistische Firnisware

AO: GHD; InvNr. ETH02/40/8 (SE B10)

Ton: Gley $16 / \mathrm{N}$ und 2.5YR6/6

Farbe innen: 10R5/8; Farbe außen: 10R5/6

Überzug: flächig, matt glänzend, kompakt, tw. abgesplittert

Sekundäre Veränderungen: Lochung im Boden, intentionell

Maße: BDm $5 \mathrm{~cm}$

Erh.: 1 BS

K 48 Schüssel

Taf. 305

Gattung: Gebrauchskeramik

Sondage ETH D3; InvNr. 2002/40/16 (SE B10)

Ton: 5YR6/4

Farbe innen: 7.5YR6/3; Farbe außen: 5YR6/4 
Maße: RDm $26 \mathrm{~cm}$

Erh.: 1 RS

\section{K 49 Schüssel}

Gattung: Gebrauchskeramik

Sondage ETH D3; InvNr. 2002/56/5 (SE B10)

Ton: 5YR5/6

Farbe innen: 10R5/6; Farbe außen: 5YR7/6

Überzug: innen und Rand außen, matt, abgerieben

Sekundäre Veränderungen: versintert

Maße: RDm $32 \mathrm{~cm}$

Erh.: 1 RS

\section{K 50 Schüssel}

Gattung: Gebrauchskeramik

AO: GHD; InvNr. ETH02/44/2 (Z-Nr. 1) (SE B10)

Ton: 5YR6/6

Farbe innen: 5YR7/2; Farbe außen: 5YR8/4

Überzug: flächig, abgerieben

Dekor: plastischer Wellenbanddekor, Randoberseite

Maße: RDm $40 \mathrm{~cm}$

Erh.: 1 RS

\section{K 51 Pithos/Kasserolle}

Gattung: Küchenware

AO: GHD; InvNr. ETH02/56/10 (SE B10)

Ton: 5YR6/6

Farbe innen u. außen: 5YR7/4

Maße: RDm $56 \mathrm{~cm}$

Erh.: 1 RS

\section{K 52 Amphore}

AO: GHD; InvNr. ETH02/43/7 (SE B10)

Ton: 5YR7/6

Farbe innen u. außen: 7.5YR8/3

Überzug: flächig, matt, kompakt, abgerieben

Maße: RDm 15,4 cm

Erh.: 1 RS

\section{K 53 Reliefbecher}

Taf. 306. 345

Gattung: hellenistische Reliefkeramik AO: GHD; InvNr. ETH02/47/4 (SE B11)

Ton: 7.5 YR6/6

Farbe innen: 7.5YR3/2; Farbe außen: 7.5YR2.5/1

Überzug: flächig, glänzend, kompakt

Maße: RDm $11 \mathrm{~cm}$

Erh.: 1 RS

\section{K 54 Teller}

Taf. 306

Gattung: hellenistische Firnisware

AO: GHD; InvNr. ETH02/38/5 (SE B11)

Ton: Gley 2 4/1

Farbe innen u. außen: Gley 1 2.5/N

Taf. 306
Überzug: flächig, glänzend, kompakt, abgesplittert

Dekor: konzentrisches Rouletting und vierfacher Palmettenstempel

Taf. 306 Sekundäre Veränderungen: intentionelles Loch im Boden

Maße: BDm 6,3 cm

Erh.: 1 BS

K 55 Teller

Taf. 306

Gattung: hellenistische Firnisware

AO: GHD; InvNr. ETH02/47/01 (Z-Nr. 9) (SE B11)

Bemerkungen: Stempelverzierung

Ton: 7.5 YR7/4

Farbe innen: 10YR5/3; Farbe außen: 7.5YR7/2

Überzug: flächig, matt glänzend, abgerieben

Maße: BDm $7 \mathrm{~cm}$

Stempel: konzentrisch angeordnete Palmette(n), Boden innen Erh.: 1 BS

K 56 Schüssel

Taf. 307

Gattung: Gebrauchskeramik

AO: GHD; InvNr. ETH02/38/6 (SE B11)

Ton: 5YR5/6

Farbe innen: 7.5YR6/6; Farbe außen: 7.5YR8/4

Taf. 306 Überzug: innen und Rand außen, matt glänzend, abgerieben Maße: RDm $30 \mathrm{~cm}$

Erh.: 1 RS

K 57 Schüssel

Taf. 307

Gattung: Gebrauchskeramik

AO: GHD; InvNr. ETH02/38/8 (SE B11)

Ton: 5YR6/6

Taf. 306 Farbe innen: 7.5YR7/6; Farbe außen: 7.5YR8/4

Überzug: innen und Rand außen, matt, kompakt, abgerieben

Maße: RDm $38 \mathrm{~cm}$

Erh.: 1 RS

K 58 Topf

Taf. 307

Gattung: Color Coated Ware

AO: GHD; InvNr. ETH02/47/2 (Z-Nr. 6) (SE B11)

Ton: 7.5YR6/4; Kern: 5YR7/6

Farbe innen u. außen: 7.5YR8/2

Überzug: Rand innen und außen, matt glänzend, tw. abgerieben Maße: RDm $36 \mathrm{~cm}$

Erh.: 1 RS

K 59 Echinusschale

Taf. 307

Gattung: hellenistische Firnisware

AO: GHD; InvNr. ETH02/59/8 (SE B12)

Ton: $2.5 \mathrm{YR} 7 / 6$

Farbe innen: 2.5YR4/6; Farbe außen: 2.5YR3/2

Überzug: flächig, matt glänzend, abgerieben

Maße: RDm $20 \mathrm{~cm}$

Erh.: 1 RS 


\section{KAMMER D8}

\section{K 60 Skyphos/Kantharos}

AO: GHD; InvNr. ETH05/10/32 (SE B14)

Ton: Gley $14 / 1$

Farbe innen: Gley 1 2.5/N; Farbe außen: 7.5YR6/2

Überzug und Bemalung: flächig, glänzend, abgerieben

Dekor: Bemalung nach Brand, vegetabil, Wand außen

Maße: RDm $16 \mathrm{~cm}$

Erh.: 1 RS

\section{K 61 Amphore}

Taf. 307. 345

Typ: mit Mushroom-rim (Local Aegean 2)

AO: GHD; InvNr. ETH05/10/11 (SE B14)

Ton: 10 YR6/2-5YR7/8

Farbe innen: 5YR7/6; Farbe 10YR6/2

Stempel: Rechteckstempel EKATAIOY, auf der Henkeloberseite

Maße: erh. L $11 \mathrm{~cm}$; Stempel: $3,4 \times 1 \mathrm{~cm}$

Erh.: 1 Henkel

\section{K 62 Amphore}

Taf. 307

Typ: mit verdickter Lippe (Local Aegean 1)

AO: GHD; InvNr. ETH05/10/10 (SE B14)

Ton: 5YR6/6

Farbe innen: 7.5YR7/4-7/6; Farbe außen: 7.5YR7/4-5YR7/6

Maße: RDm $10 \mathrm{~cm}$

Erh.: 1 RS

\section{K 63 Reliefbecher}

Taf. 307. 345

Gattung: hellenistische Reliefkeramik

AO: GHD; InvNr. ETH05/19/15 (SE B15)

Ton: 7.5 YR6/4

Farbe innen u. außen: Gley $12.5 / \mathrm{N}$

Überzug: flächig, matt glänzend, kompakt, tw. abgerieben

Dekor: Rest eines Delphins, an der Wand außen

Maße: $3 \times 2,8 \mathrm{~cm}$

Erh.: $1 \mathrm{WS}$

\section{K 64 Reliefbecher}

Taf. 307. 345

Gattung: hellenistische Reliefkeramik

AO: GHD; InvNr. ETH05/18/16 (SE B15)

Ton: 7.5 YR7/6

Farbe innen u. außen: Gley 1 2.5/N

Überzug: flächig, glänzend, abgerieben

Dekor: Rautenbordüre, an der Wand außen

Maße: $2 \times 2 \mathrm{~cm}$

Erh.: 1 WS

\section{K 65 Fischteller}

Gattung: hellenistische Firnisware

AO: GHD; InvNr. ETH05/19/11 (SE B15)

Ton: $2.5 \mathrm{Y} 5 / 1$

Farbe innen u. außen: Gley $12.5 / \mathrm{N}$

Überzug: flächig, glänzend, abgesplittert

Maße: RDm $22 \mathrm{~cm}$

Erh.: 2 RS

\section{K 66 Skyphos}

AO: GHD; InvNr. ETH05/12/18 (SE B15)

Gattung: Westabhangware

Ton: 7.5YR7/4

Taf. 307

Taf. 308
Taf. 307 Farbe innen u. außen: 2.5YR4/4

Überzug und Bemalung: flächig, glänzend, kompakt

Dekor: Bemalung nach Brand, vegetabil, an der Wand außen

Maße: RDm $11 \mathrm{~cm}$

Sekundäre Veränderungen: tw. versintert

Erh.: 1 RS

\section{K 67 Kantharos}

Taf. 308

Gattung: hellenistische Firnisware

AO: GHD; InvNr. ETH05/20/8 (SE B15)

Ton: 5YR6/4-2.5Y5/2

Farbe innen u. außen: Gley $12.5 / \mathrm{N}$

Überzug: flächig, glänzend, abgerieben

Dekor: Riefeldekor, an der Wand außen

Maße: Dm $8 \mathrm{~cm}$

Erh.: 1 WS

\section{K 68 Unguentarium}

Taf. 308

Gattung: Gebrauchskeramik

AO: GHD; InvNr. ETH05/12/19 (SE B15)

Ton: 10YR6/4

Farbe innen: 10YR8/4; Farbe außen: 2.5YR5/6

Überzug: außen und Rand innen, matt, abgerieben

Maße: RDm 2,2 cm

Erh.: 1 RS

K 69 Amphore

Taf. 308

Typ: mit Mushroom-rim

AO: GHD; InvNr. ETH05/20/6 (Z-Nr. 1) (SE B15)

Ton: 10 YR7/4

Farbe innen u. außen: 10YR8/3

Überzug: flächig, matt, abgerieben

Maße: RDm ca. $15 \mathrm{~cm}$

Erh.: 1 RS

\section{K 70 Kantharos}

Taf. 308. 345

Gattung: hellenistische Firnisware

AO: GHD; InvNr. ETH05/74/5 (SE B17)

Ton: 2.5 YR6/6

Farbe innen u. außen: 2.5YR5/8

Überzug: flächig, matt glänzend, kompakt

Maße: RDm $10 \mathrm{~cm}$

Erh.: 1 RS

\section{K 71 Kantharos}

Taf. 308. 345

Gattung: hellenistische Firnisware

O: GHD; InvNr. ETH05/74/9 (SE B17)

Ton: Gley 1 5/N

Farbe innen u. außen: Gley 1 2.5/N

Überzug: flächig, matt glänzend, tw. abgerieben

Maße: RDm $14 \mathrm{~cm}$

Erh.: 1 RS

K 72 Schale

Taf. 308

Gattung: Color coated ware

AO: GHD; InvNr. ETH05/74/7 (SE B17)

Ton: 5YR6/6

Farbe innen: 2.5YR5/6; Farbe außen: 7.5YR7/4

Überzug: innen und Rand außen, matt, abgerieben 
Maße: RDm $13 \mathrm{~cm}$

Erh.: 1 RS

\section{K 73 Skyphos}

AO: GHD; InvNr. ETH05/76/27 (SE B18)

Gattung: Westabhangnachfolgeware

Ton: $5 \mathrm{Y} 5 / 2$

Farbe innen u. außen: Gley 1 2.5/1

Überzug: flächig, matt glänzend, kompakt, außen fleckig

Dekor: Ritzung und Bemalung; Ranken und Blätter/Knospen,

Wand außen

Maße: RDm $14 \mathrm{~cm}$

Erh.: 1 RS

\section{K 74 Skyphos}

Taf. 308

Gattung: Westabhangnachfolgeware

AO: GHD; InvNr. ETH05/76/40 (SE B18)

Ton: $10 \mathrm{YR} 6 / 2$

Farbe innen u. außen: Gley 1 2.5/N

Überzug: flächig, matt glänzend, kompakt

Dekor: Ritzung und Bemalung; Ranken und Efeublätter, Wand außen

Maße: Dm ca. $13 \mathrm{~cm}$

Erh.: $1 \mathrm{WS}$

Taf. 308
K 75 Teller

Taf. 308

Gattung: Glanztonkeramik/Firnisware

AO: GHD; InvNr. ETH05/76/32 (SE B18)

Ton: $7.5 Y R 8 / 4$

Farbe innen u. außen: 2.5YR4/6

Überzug: flächig, matt glänzend, kompakt, abgesplittert

Maße: RDm $22 \mathrm{~cm}$

Erh.: 1 RS

K 76 Amphore

Taf. 309. 345

Typ: rhodisch

AO: GHD; InvNr. ETH05/76/5 (SE B18)

Ton: 5YR7/6

Farbe innen u. außen: 5YR7/6

Uberzug: flächig, matt

Maße: erh. H 2,3 cm; erh. L 3,9 cm; Stempel Dm ca. 1,3 cm (nicht ganz rund, Konturen nur schwach eingedrückt)

Stempel: rund, Eponym 'I $\pi \pi$ $\pi \lambda \eta \dot{\zeta}$, Rand oben

Erh.: 1 Henkel

K 77 Topf

Taf. 309

Gattung: Küchenware

AO: GHD; InvNr. ETH05/76/7 (SE B18)

Ton: 5 YR $4 / 6$

Farbe innen: 2.5YR5/4-5YR5/6; Farbe außen: 2.5YR4/4

Maße: RDm $18 \mathrm{~cm}$

Erh.: 1 RS

\section{Kammer E1}

K 78 Schale

Gattung: ESB Atlante 30

Taf. 309

AO: GHD; InvNr. ETH04/18/1 (SE B23)

Ton: 5YR6/8

Farbe innen u. außen: 10YR5/8

Überzug: flächig, matt glänzend, kompakt

Dekor: Rouletting und Spiralapplike, Rand außen

Maße: RDm $10 \mathrm{~cm}$

Erh.: 1 RS

\section{K 79 Schale}

Gattung: ESB Atlante 18

AO: GHD; InvNr. ETH04/19/3 (SE B23)

Ton: 5 YR $7 / 8$

Farbe innen u. außen: 2.5YR5/8

Überzug: flächig, glänzend, kompakt

Maße: BDm $12 \mathrm{~cm}$

Erh.: 1 BS

\section{K 80 Schale}

Gattung: ESB, Typ: Atlante 40

AO: GHD; InvNr. ETH04/66/10 (SE B23)

Ton: 2.5 YR6/6

Farbe innen u. außen: 2.5YR6/8

Überzug: flächig, matt glänzend, tw. abgerieben

Maße: BDm $8 \mathrm{~cm}$

Erh.: 1 BS

\section{K 81 Schale}

Gattung: ESB Atlante 18
Taf. 309

AO: GHD; InvNr. ETH04/28/20 (SE B26)

Ton: 5 YR7/8

Farbe innen: 2.5YR3/6; Farbe außen: 2.5YR5/8

Überzug: flächig, matt glänzend, kompakt

Maße: RDm ca. $20 \mathrm{~cm}$

Erh.: 1 RS

K 82 Becher/Schale

Taf. 309

Gattung: Dünnwandige Keramik

AO: GHD; InvNr. ETH04/28/8 (SE B26) 7.5 YR5/6

Überzug: flächig, matt, kompakt

Maße: RDm $10 \mathrm{~cm}$

Erh.: 1 RS

K 83 Becher/Schale

Taf. 309

Gattung: Dünnwandige Keramik

Taf. 309

AO: GHD; InvNr. ETH04/28/9 (SE B26)

Ton: 10YR6/3

Überzug: flächig, matt, kompakt

Maße: RDm $16 \mathrm{~cm}$

Erh.: 1 RS

K 84 Becher

Taf. 309

Gattung: Dünnwandige Keramik

Taf. 309 AO: GHD; InvNr. ETH04/28/10 (SE B26)

Ton: 7.5 YR7/6
Taf. 309 Ton: 7.5 YR7/6

Farbe innen: 10YR3/2-5YR5/6; Farbe außen: 7.5YR3/2-6/6 u.

Farbe innen: 2.5Y4/1; Farbe außen: 7.5YR6/3 
Farbe innen u. außen: 2.5 YR4/8-3/2 u. 2.5YR3/4

Überzug: flächig, matt, kompakt

Maße: RDm $12 \mathrm{~cm}$

Erh.: 1 RS

\section{K 85 Becher/Töpfchen}

Gattung: Dünnwandige Keramik?

AO: GHD; InvNr. ETH04/28/18 (SE B26)

Ton: 2.5 YR5/8

Farbe innen u. außen: 10R5/6

Maße: RDm $5 \mathrm{~cm}$

Erh.: 1 RS

\section{K 86 Lampe}

Typ: Volutenschnauzenlampe

AO: GHD; InvNr. ETH04/28/25 (SE B26)

Ton: $2.5 \mathrm{YR} 5 / 4$

Farbe innen u. außen: 2.5YR4/8-2.5/1

Maße: erh. H 0,5 cm; erh. L $4 \mathrm{~cm}$

Erh.: 1 Schulter mit Schnauzenansatz

\section{K 87 Ephesoslampe}

Typ: Howland 49A

AO: GHD; InvNr. ETH04/28/28 (SE B26)

Ton: $10 \mathrm{YR} 4 / 1$

Farbe innen: 10YR6/1; Farbe außen: Gley 1 2.5/N

Überzug: außen, matt glänzend, kompakt

Maße: Dm Kragen 4 cm; erh. H 2 cm

Erh.: 1 Schulter

\section{K 88 Teller}

Gattung: ESB, Typ: Atlante 18/19

AO: GHD; InvNr. ETH04/35/8 (SE B27)

Ton: 2.56 YR6/8

Farbe innen u. außen: 2.5 YR5/8

Überzug: flächig, matt glänzend

Maße: BDm $15 \mathrm{~cm}$

Erh.: 1 BS

\section{K 89 Becher/Töpfchen}

Gattung: Dünnwandige Keramik

AO: GHD; InvNr. ETH04/35/6 (SE B27)

Ton: 2.5 YR $5 / 6$

Farbe innen: 2.5YR5/6; Farbe außen: 2.5YR6/4

Maße: RDm 4,2 cm

Erh.: 1 RS

\section{K 90 Becher}

Gattung: ESB, Typ: Atlante 40?

AO: GHD; InvNr. ETH04/73/10 (SE B28)

Ton: 5YR5/6

Farbe innen: 5YR6/6; Farbe außen: 2.5YR4/8

Überzug: flächig, matt glänzend, kompakt

Maße: BDm $10 \mathrm{~cm}$

Erh.: 1 BS

\section{K 91 Schale}

Gattung: ESB Atlante 29

AO: GHD; InvNr. ETH04/73/12 (SE B28)

Ton: 2.5 YR6/6

Farbe innen: 7.5YR7/6; Farbe außen: 5YR4/6

Überzug: flächig, matt glänzend, tw. abgerieben Maße: BDm 5,8 cm

Erh.: 1 BS

\section{K 92 Schale}

Taf. 310

Taf. 309

Gattung: ESB Atlante 29

AO: GHD; InvNr. ETH04/73/14 (SE B28)

Ton: 5YR6/6

Farbe innen u. außen: 2.5 YR 5/8-4/8

Überzug: flächig, matt glänzend, kompakt

Maße: RDm $13 \mathrm{~cm}$

Erh.: 1 RS

Taf. 309

\section{K 93 Schälchen}

Gattung: ESB Atlante 29

AO: GHD; InvNr. ETH04/73/15 (SE B28)

Ton: 5YR6/6

Farbe innen u. außen: 2.5 YR5/8-4/8

Überzug: flächig, matt glänzend, kompakt

Maße: RDm 7,4 cm

Erh.: 1 RS

Taf. 309

\section{K 94 Schale}

Gattung: ESB Atlante 29

AO: GHD; InvNr. ETH04/73/16 (SE B28)

Ton: 2.5 YR6/6

Farbe innen: 2.5YR4/8; Farbe außen: 2.5YR4/6

Überzug: flächig, matt glänzend, kompakt

Maße: RDm $8,8 \mathrm{~cm}$

Erh.: 1 RS

Taf. 310

\section{K 95 Schale}

Gattung: ESB Atlante 31

AO: GHD; InvNr. ETH04/73/22 (SE B28)

Ton: 2.5 YR6/8

Farbe innen u. außen: 2.5YR 4/8

Überzug: flächig, matt glänzend, tw. abgerieben

Dekor: feines Rouletting, Rand außen

Maße: RDm 8,4 cm

Taf. 310 Erh.: 1 RS

K 96 Schale

Gattung: ESB Atlante 68 (ähnlich)

AO: GHD; InvNr. ETH04/73/25 (SE B28)

Ton: 5YR6/6

Farbe innen u. außen: 2.5YR4/8

Überzug: flächig, matt glänzend, kompakt

Taf. 310 Dekor: Rouletting, Rand außen

Maße: RDm ca. $8,8 \mathrm{~cm}$

Erh.: 1 RS

K 97 Schale

Gattung: ESB Atlante 31

AO: GHD; InvNr. ETH04/73/28 (SE B28)

Ton: 2.5 YR6/8

Farbe innen u. außen: 2.5 YR5/8-4/8

Taf. 310 Überzug: flächig, matt glänzend, kompakt

Dekor: Rouletting, Rand außen

Maße: RDm 9,2 cm

Erh.: 1 RS
Taf. 310

Taf. 310

Taf. 310

Taf. 310

Taf. 310 


\section{K 98 Schale}

Gattung: ESB Atlante 70

AO: GHD; InvNr. ETH04/73/24 (SE B28)

Ton: 5YR6/6

Farbe innen u. außen: 2.5 YR5/8

Überzug: flächig, matt glänzend, kompakt

Dekor: Spiralapplik, Rand außen

Maße: RDm 10,6 cm

Erh.: 1 RS

\section{K 99 Teller}

Gattung: ESB Atlante 58

AO: GHD; InvNr. ETH04/74/1 (SE B28)

Ton: $2.5 \mathrm{YR} 6 / 8$

Farbe innen: 2.5YR5/8; Farbe außen: 2.5YR4/8

Überzug: flächig

Dekor: Spiralapplik, Rand außen

Maße: RDm $16 \mathrm{~cm}$; BDm $11 \mathrm{~cm}$

Erh.: 1 RS+BS

\section{K 100 Schale}

Gattung: ESB Atlante 56

AO: GHD; InvNr. ETH04/80/33 (SE B28)
Taf. 310

Ton: 2.5 YR6/6

Farbe innen u. außen: 2.5YR $4 / 8$

Überzug: flächig, matt glänzen, tw. abgerieben

Stempel: ATEI[VS] (?), Boden innen

Maße: RDm 4,3 cm

Erh.: 1 BS

\section{K 101 Schale}

Taf. 310

Gattung: ESB Atlante 30

AO: GHD; InvNr. ETH04/81/23 (SE B40)

Taf. 310

Ton: 5YR7/4-7.5YR6/2

Farbe innen: 2.5YR5/8; Farbe außen: 5YR6/6

Überzug: flächig, glänzend, kompakt

Maße: RDm ca. $14,4 \mathrm{~cm}$

Erh.: 1 RS

K 102 Teller

Taf. 310

Gattung: ESB Atlante 53

AO: GHD; InvNr. ETH04/81/16 (SE B40)

Ton: 5YR6/6

Taf. 310

Farbe innen u. außen: 2.5 YR4/8

Überzug: flächig, matt glänzend, kompakt

Maße: BDm ca. $18 \mathrm{~cm}$

Erh.: 1 BS

\section{Kammer E3}

\section{K 103 Teller}

Gattung: ESC Atlante L19/H1

AO: GHD; InvNr. ETH04/43/37 (SE B30)

Ton: 2.5 YR6/6

Farbe innen: 2.5YR5/8; Farbe außen: 2.5YR4/8

Überzug: flächig, matt glänzend, kompakt

Maße: BDm $12 \mathrm{~cm}$

Erh.: 1 BS

\section{K 104 Schale/Becher}

Gattung: Dünnwandige Keramik/ESB

AO: GHD; InvNr. ETH04/43/19 (SE B30)

Ton: 2.5 YR5/8

Farbe innen u. außen: 2.5 YR $4 / 6$

Überzug: flächig, matt glänzend, tw. abgerieben

Maße: RDm 12,6 cm

Erh.: 1 RS

\section{K 105 Lampe}

Typ: Bildlampe

Taf. 311. 345

AO: EM; InvNr. Envanterlik ETH FK 043/04/24 (SE B30)

Ton: 2.5 YYR6/6

Farbe außen: 10R6/8-5/8

Überzug: außen, abgerieben

Dekor: Greif nach links, auf dem Diskus

Maße: KDm 6,3 cm; L 9 cm; H 4,2 cm (inkl. Henkel); 3,2 cm (exkl. Henkel)

Sekundäre Veränderungen: Schnauze verbrannt

Erh.: vollständig

\section{K 106 Lampe}

Taf. 311. 345

Typ: Bildlampe

AO: EM; InvNr. ETH04/43/47 (SE B30)

Taf. 311

Taf. 311

\section{Ton: 5YR6/6}

Farbe außen: 2.5 YR5/8-4/8

Überzug: außen, abgerieben

Dekor: Helios, frontal, Diskus; Kreisaugen auf der Schulter, am Henkelansatz und am Schnauzenansatz

Maße: KDm 6,3 cm; L 8,2 cm; H 4,3 cm (inkl. Henkel); 2,5 cm (exkl. Henkel)

Erh.: bis auf Henkel vollständig erh.

\section{K 107 Schale}

Taf. 311.346

Gattung: ESB Atlante 32

AO: GHD; InvNr. ETH04/57/6 (SE B33 - Pithos 1)

Ton: 5YR6/6

Farbe innen u. außen: 2.5 YR5/8

Überzug: flächig, glänzend, kompakt

Dekor: Rouletting, Rand außen

Maße: RDm 10,6 cm

Erh.: 1 RS

\section{K 108 Becher}

Taf. 311.346

Gattung: ESB Atlante 65

AO: GHD; InvNr. ETH04/57/7 (SE B33 - Pithos 1)

Ton: 5YR7/8

Farbe innen u. außen: 2.5 YR5/8

Überzug: flächig, glänzend, kompakt

Maße: RDm 4,6 cm; BDm 4,6 cm

Erh.: RS+BS

\section{K 109 Schale}

Taf. 311.346

Gattung: ESB Atlante 70

AO: GHD; InvNr. ETH04/57/22 (SE B33 - Pithos 1)

Ton: 5YR6/8

Farbe innen u. außen: 2.5YR5/8 
Überzug: flächig

Dekor: Rouletting und Spiralapplike; Rand außen

Maße: RDm 10,4 cm

Erh.: 1 RS

\section{K 110 Schale}

Gattung: ESB Atlante 70

AO: GHD; InvNr. ETH04/57/23 (SE B33 - Pithos 1)

Ton: 5YR7/6

Farbe innen u. außen: $2.5 \mathrm{YR} 5 / 8$

Überzug: flächig, glänzend, kompakt

Dekor: Rouletting, Rand außen

Maße: RDm 7,2 cm

Erh.: 1 RS

\section{K 111 Schale}

Gattung: ESB Atlante 70

AO: GHD; InvNr. ETH04/57/24 (SE B33 - Pithos 1)

Ton: 5YR6/8

Farbe innen u. außen: 2.5 YR5/8

Überzug: flächig, matt glänzend, kompakt

Dekor: Rouletting, Rand außen

Maße: RDm 6,4 cm

Erh.: 1 RS

\section{K 112 Knidische Schale}

Gattung: ESB

Taf. 311.346

AO: GHD; InvNr. ETH04/57/8+21 (SE B33 - Pithos 1)

Ton: 5YR6/6

Farbe innen u. außen: $2.5 \mathrm{YR} 4 / 8$

Überzug: flächig, matt glänzend, tw. abgerieben

Dekor: Bemalung, Punktdekor, Rand außen

Maße: RDm ca. $8 \mathrm{~cm}$

Sekundäre Veränderungen: tw. versintert

Erh.: 2 RS mit Horizontalhenkelansätzen

\section{K 113 Becher}

Taf. 311

Gattung: Dünnwandige Keramik

Sondage ETH E3; InvNr. 2004/57/9 (SE B33 - Pithos 1)

Ton: 7.5 YR $4 / 1$

Farbe innen u. außen: 5 YR5/2-5/3 u. 5YR4/2

Maße: BDm $4 \mathrm{~cm}$

Erh.: 1 BS

\section{K 114 Becher}

Taf. 311

Gattung: Dünnwandige Keramik

Sondage ETH E3; InvNr. 2004/57/19 (SE B33 - Pithos 1)

Ton: 2.5 YR $5 / 8$

Farbe innen: 2.5YR5/6; Farbe außen: Gley 1 2.5/N; Farbe außen: 2.5YR5/6 (Boden)

Maße: BDm $5 \mathrm{~cm}$

Erh.: 1 BS

\section{K 115 Krug}

Taf. 312. 346

Gattung: Gebrauchskeramik

AO: EM; InvNr. ETH FK 57/04-21

Ton: $2.5 \mathrm{YR} 5 / 6$

Farbe innen: 2.5YR6/6-5/6-5/4; Farbe außen: 2.5YR6/6-5/6$5 / 4$

Maße: RDm 9,4 cm; BDm 5,6 cm; H 20 cm

Erh.: Ganzform
K 116 Krug

Taf. 312

Gattung: Gebrauchskeramik

Sondage ETH E3; InvNr. 2004/57/17 (SE B33 - Pithos 1)

Ton: 3.5 YR5 $/ 8$

Farbe innen: 10YR6/2-5/3

Maße: RDm ca. $6,4 \mathrm{~cm}$

Erh.: 1 RS mit Henkelansatz

K 117 Topf

Taf. 312

Gattung: Gebrauchskeramik

AO: GHD; InvNr. ETH04/57/x (SE B33 - Pithos 1)

Ton: 2.5 YR6/6

Farbe innen: 2.5YR6/4; Farbe außen: 10YR8/3

Überzug: außen, matt, kompakt

Maße: RDm $20 \mathrm{~cm}$

Erh.: 1 RS

\section{K 118 Geschlossenes Gefäß}

Taf. 312

Gattung: Gebrauchskeramik

Sondage ETH E3; InvNr. 2004/57/3 (SE B33 - Pithos 1)

Ton: 5YR5/6

Farbe innen u. außen: 5YR6/6

Maße: BDm 4,5 cm

Erh.: 1 BS

\section{K 119 Schüssel}

Taf. 312.346

Gattung: Gebrauchskeramik

AO: GHD; InvNr. ETH04/57/27 (SE B33 - Pithos 1)

Ton: 5YR6/6

Farbe innen u. außen: 7.5YR6/6

Maße: RDm ca. 26,8 cm; BDm 18 cm; H 16,5 cm

Sekundäre Veränderungen: flächig stark versintert

Erh.: 1 RS+BS

\section{K 120 Schüssel}

Taf. 313

Gattung: Gebrauchskeramik

Sondage ETH E3; InvNr. 2004/57/12 (SE B33 - Pithos 1)

Ton: 5YR6/6

Farbe innen $u$. außen: 5YR7/6

Maße: RDm ca. $39 \mathrm{~cm}$

Erh.: 1 RS

\section{K 121 Schüssel}

Taf. 313

Gattung: Gebrauchskeramik

Sondage ETH E3; InvNr. 2004/57/13 (SE B33 - Pithos 1)

Ton: 2.5 YR6/6

Farbe innen: 10YR8/4; Farbe außen: 5YR6/6

Maße: RDm ca. $38 \mathrm{~cm}$

Erh.: 1 RS

\section{K 122 Schüssel}

Taf. 313

Gattung: Gebrauchskeramik

Sondage ETH E3; InvNr. 2004/57/14 (SE B33 - Pithos 1)

Ton: 5YR6/6

Farbe innen u. außen: 7.5YR7/6

Maße: RDm $44,8 \mathrm{~cm}$

Erh.: 1 RS

K 123 Schüssel

Taf. 313

Gattung: Gebrauchskeramik

Sondage ETH E3; InvNr. 2004/57/25 (SE B33 - Pithos 1) 
Ton: 5YR7/6

Farbe innen: 10YR8/4; Farbe außen: 10YR7/4

Maße: RDm ca. $41 \mathrm{~cm}$

Erh.: 1 RS

\section{K 124 Schüssel}

Taf. 313

Gattung: Gebrauchskeramik

Sondage ETH E3; InvNr. 2004/57/26 (SE B33 - Pithos 1)

Ton: 5YR5/6

Farbe innen u. außen: 5YR6/4-6/6

Maße: RDm $38,8 \mathrm{~cm}$

Erh.: 1 RS

\section{K 125 Schüssel}

Taf. 313

Gattung: Gebrauchskeramik

Sondage ETH E3; InvNr. 2004/57/28 (SE B33 - Pithos 1)

Ton: 2.5 YR6/8

Überzug: Farbe innen: 2.5YR3/1-3/2; Farbe außen: 10YR6/4

Maße: RDm $52 \mathrm{~cm}$

Erh.: 1 RS

\section{K 126 Schüssel/Eimer}

Taf. 313

Gattung: Gebrauchskeramik

Sondage ETH E3; InvNr. 2004/57/30 (SE B33 - Pithos 1)

Ton: 5YR7/6

Farbe innen: 2.5YR3/3; Farbe außen: 7.5YR7/4-7/6

Maße: BDm ca. $20 \mathrm{~cm}$

Erh.: 1 BS

\section{K 127 Schüssel?}

Taf. 314

Gattung: Gebrauchskeramik

Sondage ETH E3; InvNr. 2004/57/37 (SE B33 - Pithos 1)

Ton: 2.5 YR $5 / 8$

Farbe innen: 5YR7/8; Farbe außen: 10R5/4-5YR7/1; Farbe

Überzug innen: 10R5/8

Überzug: innen, matt, tw. abgerieben

Maße: BDm 16,4 cm

Erh.: 1 BS

\section{K 128 Deckel}

Taf. 314

Gattung: Gebrauchskeramik

Sondage ETH E3; InvNr. 2004/57/20 (SE B33 - Pithos 1)

Ton: 5 YR $5 / 8$

Farbe innen u. außen: 5YR6/6

Maße: RDm $22 \mathrm{~cm}$

Erh.: 1 RS

\section{K 129 Deckel}

Taf. 314

Gattung: Gebrauchskeramik

Sondage ETH E3; InvNr. 2004/57/15 (SE B33 - Pithos 1)

Ton: 5YR6/6

Farbe innen u. außen: 5YR6/6

Maße: Dm 3,1 cm

Erh.: 1 Knauf

\section{K 130 Miniaturgefäß}

Taf. 314. 347

Gattung: Gebrauchskeramik

AO: GHD; InvNr. ETH04/57/32; ETH04/57/18; ETH04/63/54

(SE B33 - Pithos 1)

Ton: $10 \mathrm{YR} 4 / 1$
Farbe innen u. außen: 7.5YR5/3

Maße: RDm $5 \mathrm{~cm}$; $\mathrm{BDm} 3 \mathrm{~cm}$

Erh.: 1 RS+BS

K 131 Krug/Kanne

Taf. 314. 347

Gattung: Küchenware

ETH04/57/42 (SE B33 - Pithos 1)

Ton: $2.5 \mathrm{YR} 4 / 8$

Farbe innen: 2.5YR7/2; Farbe außen: 2.5YR3/1

Maße: KDm (max.) 24 cm; erh. H $21 \mathrm{~cm}$

Erh.: 1 WS

\section{K 132 Topf}

Taf. 315

Gattung: Küchenware

Sondage ETH E3; InvNr. 2004/57/10 (SE B33 - Pithos 1)

Ton: 5YR5/6

Farbe innen u. außen: 2.5YR5/6; Farbe Rand: 5YR3/1

Maße: RDm $25 \mathrm{~cm}$

Erh.: 1 RS

\section{K 133 Topf/Kasserolle}

Taf. 315

Gattung: Küchenware

Sondage ETH E3; InvNr. 2004/57/11 (SE B33 - Pithos 1)

Ton: 2.5 YR5 $/ 8$

Farbe innen u. außen: 2.5YR5/6; Farbe Rand: 5YR3/1

Maße: RDm $30 \mathrm{~cm}$

Erh.: 2 RS

\section{K 134 Amphore}

Taf. 315

Typ: Peacock - Williams 45

AO: GHD; InvNr. ETH04/57/36 (SE B33 - Pithos 1)

Ton: $2.5 \mathrm{YR} 5 / 8$

Farbe innen u. außen: 2.5YR5/6

Maße: RDm 4,6 cm

Erh.: 1 RS mit Henkelansatz

K 135 Amphore

Taf. 315

Typ: Peacock - Williams 45

AO: GHD; InvNr. ETH04/57/29 (SE B33 - Pithos 1)

Ton: 7.5YR6/6

Farbe innen u. außen: 7.5YR7/6

Maße: BDm 6,4 cm

Erh.: 1 BS

K 136 Amphore

Taf. 315

AO: GHD; InvNr. ETH04/57/31 (SE B33 - Pithos 1)

Ton: 7.5 YR6/6

Farbe innen u. außen: 10YR8/3

Maße: RDm 10,4 cm

Erh.: 1 RS

K 137 Amphore

Taf. 315

AO: GHD; InvNr. ETH04/57/33 (SE B33 - Pithos 1)

Ton: 5YR6/6

Farbe innen: 2.5YR7/4; Farbe außen: 10YR7/3

Maße: RDm 11,6 cm

Erh.: 1 RS mit Henkelansatz

K 138 Amphore

Taf. 315

Typ: Dressel 1B 
AO: GHD; InvNr. ETH04/57/38 (SE B33 - Pithos 1)

Ton: $2.5 \mathrm{YR} 6 / 6$

Farbe innen u. außen: 7.5YR7/6

Maße: RDm ca. $14,6 \mathrm{~cm}$

Erh.: 1 RS

\section{K 139 Amphore}

Taf. 316. 347

Typ: Dressel 2-4, italisch

AO: GHD; InvNr. ETH04/57/41 (SE B33 - Pithos 1)

Ton: $2.5 \mathrm{YR} 5 / 8$

Farbe innen: 2.5YR6/8; Farbe außen: 10YR8/3

Stempel: Rechteckstempel NO[.]AND[.]?, ca. $6 \times 1,7 \mathrm{~cm}$; Knauf außen

Maße: BDm 7 cm; erh. H $30 \mathrm{~cm}$

Erh.: $1 \mathrm{BS}$

\section{K 140 Lampe}

Taf. 316. 347

Typ: Bildlampe

AO: GHD; InvNr. ETH04/57/4 (SE B33 - Pithos 1)

Ton: 2.5 YR3/4 u. 2.5 Y $5 / 2$

Farbe innen u. außen: 7.5YR3/4

Überzug: außen, matt glänzend, tw. abgerieben

Dekor: Adler nach links auf dem Diskus; Myrtenblätter und

Knospen auf der Schulter

Maße: KDm ca. 6 cm; erh. H 4 cm (inkl. Henkel)

Erh.: 3 Schulterfragmente, 1 Diskus + Henkelfragment

\section{G 4 Becher}

Taf. 316. 347

Gattung: Glas; Typ: Isings 31

AO: GHD; InvNr. ETH04/57/2 (SE B33 - Pithos 1)

Farbe: $\mathrm{Y}_{40} \mathrm{M}_{00} \mathrm{C}_{50}$

Dekor: plastische Tropfen, an der Wand außen

Maße: erh. H 4,3 cm

Erh.: 1 Wandfragment

\section{K 141 Schale}

Taf. 316.348

Gattung: ITS; Typ: Consp. 23

AO: EM; InvNr. Envanterlik ETH FK/04/063-22 (SE B34 -

Pithos 2)

Ton: 5YR7/4

Farbe innen u. außen: 2.5YR4/6

Überzug: flächig, glänzend, kompakt

Stempel: Planta Pedis, eingeschrieben L.P.R, Boden innen

Maße: RDm 12,2 cm; BDm 6 cm

Sekundäre Veränderungen: versintert

Erh.: vollständig

\section{K 142 Teller}

Taf. 316. 348

Gattung: ESB Atlante 18

AO: GHD; InvNr. ETH04/63/9 (SE B34 - Pithos 2)

Ton: 5YR6/6

Farbe innen u. außen: 10R4/8

Überzug: flächig, glänzend, tw. abgerieben

Maße: RDm 16 cm; BDm 14 cm

Erh.: 1 RS+BS

\section{K 143 Teller}

Taf. 316

Gattung: ESB Atlante 19

AO: GHD; InvNr. ETH04/63/18 (SE B34 - Pithos 2)

Ton: 5YR7/6
Farbe innen u. außen: 2.5YR5/8

Überzug: flächig, matt glänzend, tw. abgerieben

Maße: RDm 15,8 cm

Erh.: 1 RS

\section{K 144 Schale}

Taf. 317.348

Gattung: ESB Atlante 36

AO: EM; InvNr. Envanterlik ETH FK 063/04-23 (SE B34 Pithos 2)

Ton: 5YR7/6

Farbe innen u. außen: 2.5 YR5/8-4/8

Überzug: flächig, glänzend, kompakt

Maße: RDm 13 cm; BDm 6 cm

Stempel: Radialstempel, Bodeninnenseite, Mitte

Sekundäre Veränderungen: versintert, verbrannt

Erh.: vollständig

\section{K 145 Becher}

Taf. 317. 348

Gattung: ESB Atlante 38

AO: GHD; InvNr. ETH04/63/10 (SE B34 - Pithos 2)

Ton: 5YR6/6

Farbe innen u. außen: 10R4/6

Überzug: flächig, matt glänzend, tw. abgerieben

Maße: BDm $8 \mathrm{~cm}$

Erh.: 1 BS

\section{K 146 Becher}

Taf. 317.348

Gattung: ESB (reduzierend gebrannt) Atlante 38

Sondage ETH E3; InvNr. 2004/63/11 (SE B34 - Pithos 2)

Ton: 10 YR5/1

Farbe innen u. außen: Gley 1 2.5/N

Überzug: flächig, matt glänzend, kompakt

Maße: BDm $8 \mathrm{~cm}$

Erh.: 1 BS

\section{K 147 Teller}

Taf. 317

Gattung: ESB Atlante 58

Sondage ETH E3; InvNr. 2004/63/15 (SE B34 - Pithos 2)

Ton: $2.5 \mathrm{YR} 6 / 8$

Farbe innen u. außen: 2.5YR4/8

Überzug: flächig, matt glänzend, kompakt

Dekor: Spiralapplike zwischen Rouletting, Rand außen

Maße: RDm $18 \mathrm{~cm}$

Erh.: 1 RS

K 148 Teller

Taf. 317

Gattung: ESB Atlante 64B

AO: GHD; InvNr. ETH04/63/16 (SE B34 - Pithos 2)

Ton: 5YR6/8

Farbe innen u. außen: 2.5YR $4 / 8$

Überzug: flächig, matt glänzend, kompakt

Maße: BDm ca. $10 \mathrm{~cm}$

Erh.: 1 BS

\section{K 149 Schale}

Taf. 317

Gattung: ESB Atlante 70

AO: EM; InvNr. ETH04/63/5 (SE B34 - Pithos 2)

Ton: 5YR6/6

Farbe innen u. außen: 2.5YR5/8

Überzug: flächig, glänzend, kompakt 
Dekor: Spiralapplike, Rand außen Graffito: eponym? Wand außen Maße: RDm $10 \mathrm{~cm}$; BDm 5,8 cm Erh.: vollständig

\section{K 150 Schale}

Gattung: ESB Atlante 70

AO: GHD; InvNr. ETH04/63/3 (SE B34 - Pithos 2)

Ton: $10 \mathrm{R} 5 / 6$

Überzug: flächig; Farbe innen u. außen: 2.5 YR5/8-4/8, glänzend, kompakt

Dekor: Rouletting, Spiralapplike, Rand außen

Maße: RDm $12 \mathrm{~cm}$; BDm $6 \mathrm{~cm}$

Erh.: bis auf Teile des Bodens vollständig erh.

\section{K 151 Schale}

Gattung: ESB Atlante 70

AO: EM; InvNr. ETH04/63/4 (SE B34 - Pithos 2)

Ton: 5YR6/6

Farbe innen u. außen: 2.5 YR4/8

Überzug: flächig, glänzend, kompakt

Dekor: Rouletting, Spiralapplike, Radialstempel

Maße: RDm $10 \mathrm{~cm}$; BDm $5 \mathrm{~cm}$

Erh.: vollständig

\section{K 152 Schale}

Taf. 317. 658

Gattung: ESB Atlante 70

AO: GHD; InvNr. ETH04/63/63 (SE B34 - Pithos 2)

Ton: 5YR7/8

Farbe innen u. außen: 2.5 YR5/8

Überzug: flächig, matt glänzend, tw. abgerieben

Graffito: Bodenunterseite (Ligatur), Wand außen

Maße: BDm 6,1 cm

Erh.: 1 BS

\section{K 153 Schale}

Taf. 317

Gattung: ESB Atlante 70

AO: GHD; InvNr. ETH04/63/93 (SE B34 - Pithos 2)

Ton: 2.5 YR6/8

Farbe innen u. außen: 2.5YR4/8

Überzug: flächig, matt glänzend, kompakt

Maße: RDm $12 \mathrm{~cm}$

Erh.: 1 RS

\section{K 154 Schüssel}

Taf. 318. 348

Gattung: RSW

AO: GHD; InvNr. ETH04/63/25 (SE B34 - Pithos 2)

Ton: schwarze und weiße Einschlüsse

Ton: 7.5YR6/6

Farbe innen: 10R5/4; Farbe außen: 10R5/6

Überzug: flächig, matt glänzend, kompakt

Maße: RDm $22 \mathrm{~cm}$

Erh.: 1 RS

\section{K 155 Rippenschale}

Taf. 318. 348

Gattung: RSW

AO: GHD; InvNr. ETH04/63/26 (SE B34 - Pithos 2)

Ton: 7.5 YR7 $7 / 6$

Farbe innen u. außen: 2.5 YR5/8

Maße: RDm $17 \mathrm{~cm}$
Erh.: 1 RS

K 156 Krug

Taf. 318. 348

Gattung: RSW

AO: GHD; InvNr. ETH04/63/68 (SE B34 - Pithos 2)

Ton: 5YR6/6

Taf. 317 Farbe innen u. außen: 2.5 YR5/6-1.5YR5/8

Überzug: außen matt, tw. abgerieben

Maße: RDm 4 cm; BDm 4,8 cm; H 14,5 cm

Erh.: beinahe vollständig mit Henkelansatz

K 157 Knidische Schale

Taf. 318

Gattung: RSW

AO: GHD; InvNr. ETH04/63/82 (SE B34 - Pithos 2)

Ton: 2.5 YR6/8

Farbe innen u. außen: 2.5 YR5/8

Taf. 317 Überzug: flächig, matt glänzend, kompakt

Maße: RDm $11 \mathrm{~cm}$

Erh.: 1 RS mit Horizontalhenkelansatz

K 158 Becher

Taf. 318. 349

Gattung: Dünnwandige Keramik

AO: GHD; InvNr. ETH04/63/83 (SE B34 - Pithos 2)

Ton: 2.5 YR5/4

Farbe innen: 7.5YR5/3; Farbe außen: Gley $12.5 / \mathrm{N}$

Überzug, außen, matt, tw. abgerieben

Maße: RDm 6,8 cm; BDm 4,4 cm; H 9,8 cm

Erh.: vollständig

\section{K 159 Becher}

Taf. 318. 349

Gattung: Dünnwandige Keramik

AO: GHD; InvNr. ETH04/63/84 (SE B34 - Pithos 2)

Ton: 5YR5/6

Farbe innen: 5YR6/6; Farbe außen: 2.5YR4/8

Maße: RDm 7 cm; BDm 4,3 cm; H 10,2 cm

Erh.: vollständig

K 160 Becher

Taf. 318

Gattung: Dünnwandige Keramik

Sondage ETH E3; InvNr. 2004/63/27 (SE B34 - Pithos 2)

Ton: 2.5 YR5 $/ 6$

Farbe innen: 2.5YR6/4-6/6; Farbe außen: 10R5/6

Maße: RDm $6,8 \mathrm{~cm}$

Erh.: 1 RS

\section{K 161 Becher}

Taf. 318

Gattung: Dünnwandige Keramik

Sondage ETH E3; InvNr. 2004/63/28 (SE B34 - Pithos 2)

Ton: 2.5 YR5/6

Farbe innen: 2.5YR5/6; Farbe außen: 2.5YR5/4

Maße: RDm 7,8 cm

Erh.: 1 RS

K 162 Becher

Taf. 318

Gattung: Dünnwandige Keramik

Sondage ETH E3; InvNr. 2004/63/29 (SE B34 - Pithos 2)

Ton: 2.5 YR5/8

Farbe innen: 2.5YR6/6; Farbe außen: 5YR5/6

Maße: RDm $7 \mathrm{~cm}$

Erh.: 1 RS 
K 163 Becher

Gattung: Dünnwandige Keramik

Sondage ETH E3; InvNr. 2004/63/30 (SE B34 - Pithos 2)

Ton: 2.5 YR5 $/ 8$

Farbe innen: 2.5YR6/6; Farbe außen: 2.5YR5/6; Farbe außen

Rand: 2.5 YR5/4

Maße: RDm 6,6 cm

Erh.: 1 RS

\section{K 164 Becher}

Taf. 319

Gattung: Dünnwandige Keramik

Sondage ETH E3; InvNr. 2004/63/31 (SE B34 - Pithos 2)

Ton: $2.5 \mathrm{YR} 5 / 8$

Farbe innen: 2.5YR6/6; Farbe außen: 10R5/6

Maße: RDm $7 \mathrm{~cm}$

Erh.: 1 RS

\section{K 165 Becher}

Taf. 319

Gattung: Dünnwandige Keramik

Sondage ETH E3; InvNr. 2004/63/32 (SE B34 - Pithos 2)

Ton: 5YR6/6

Farbe innen: 5YR6/6; Farbe außen: 2.5YR5/6

Maße: RDm $10 \mathrm{~cm}$

Erh.: 1 RS

\section{K 166 Becher}

Taf. 319

Gattung: Dünnwandige Keramik

Sondage ETH E3; InvNr. 2004/63/33 (SE B34 - Pithos 2)

Ton: Gley 1 2.5/N

Farbe innen u. außen: Gley 1 2.5/N

Maße: RDm 7,2 cm

Erh.: 1 RS

\section{K 167 Becher}

Taf. 319

Gattung: Dünnwandige Keramik

AO: GHD; InvNr. ETH04/63/36 (SE B34 - Pithos 2)

Ton: 5YR6/6

Farbe innen u. außen: 2.5 YR5/2-4/1

Maße: RDm $8,8 \mathrm{~cm}$

Erh.: 1 RS

\section{K 168 Becher}

Taf. 319

Gattung: Dünnwandige Keramik

AO: GHD; InvNr. ETH04/63/41 (SE B34 - Pithos 2)

Ton: 2.5 YR6/6

Farbe innen u. außen: 5YR6/6

Maße: RDm 6,8 cm

Erh.: 1 RS

\section{K 169 Becher}

Taf. 319

Gattung: Dünnwandige Keramik

AO: GHD; InvNr. ETH04/63/37 (SE B34 - Pithos 2)

Ton: 7.5 YR5/6

Farbe innen: 7.5YR6/4; Farbe außen: 5YR5/6

Maße: RDm 10,4 cm

Erh.: 1 RS

\section{K 170 Becher}

Taf. 319

Gattung: Dünnwandige Keramik

Sondage ETH E3; InvNr. 2004/63/35 (SE B34 - Pithos 2)
Ton: $2.5 \mathrm{YR} 5 / 6$

Farbe innen u. außen: 2.5YR5/6

Maße: RDm 6,6 cm

Erh.: 1 RS

\section{K 171 Becher}

Taf. 319

Gattung: Dünnwandige Keramik

AO: GHD; InvNr. ETH04/63/34 (SE B34 - Pithos 2)

Ton: 2.5 YR6/8

Farbe innen: 2.5YR6/8; Farbe außen: 10YR4/1

Maße: RDm 6,4 cm

Erh.: 1 RS

\section{K 172 Becher/Krug}

Taf. 319

Gattung: Dünnwandige Keramik

Sondage ETH E3; InvNr. 2004/63/8 (SE B34 - Pithos 2)

Ton: 5 YR7/8-2.5Y6/1

Farbe innen $u$. außen: 5YR6/4

Maße: BDm $5 \mathrm{~cm}$

Erh.: 1 BS

K 173 Becher

Taf. 319

Gattung: Dünnwandige Keramik

Sondage ETH E3; InvNr. 2004/63/60 (SE B34 - Pithos 2)

Ton: $2.5 \mathrm{YR} 5 / 8$

Farbe innen: 5YR6/6; Farbe außen: 2.5YR5/6

Maße: RDm $4 \mathrm{~cm}$

Erh.: 1 BS

\section{K 174 Becher}

Taf. 319

Gattung: Dünnwandige Keramik

Sondage ETH E3; InvNr. 2004/63/61 (SE B34 - Pithos 2)

Ton: 2.5 YR5/6

Farbe innen: 7.5YR6/4; Farbe außen: 2.5YR5/6-4/3

Maße: BDm 4,2 cm

Erh.: 1 BS

\section{K 175 Becher}

Taf. 319

Gattung: Dünnwandige Keramik

Sondage ETH E3; InvNr. 2004/63/62 (SE B34 - Pithos 2)

Ton: 5YR5/4

Farbe innen: 5YR6/4-6/6; Farbe außen: 2.5YR5/4-5/6

Maße: BDm 4,2 cm

Erh.: $1 \mathrm{BS}$

K 176 Becher

Taf. 319

Gattung: Dünnwandige Keramik

Sondage ETH E3; InvNr. 2004/63/64 (SE B34 - Pithos 2)

Ton: $2.5 \mathrm{YR} 5 / 4$

Farbe innen: 2.5YR5/4; Farbe außen: 2.5YR5/8

Maße: BDm 3,9 cm

Erh.: 1 BS

K 177 Becher

Taf. 319

Gattung: Dünnwandige Keramik

Sondage ETH E3; InvNr. 2004/63/56 (SE B34 - Pithos 2)

Ton: 2.5 YR6/8-4/1

Farbe innen u. außen: 2.5 YR7/8

Maße: BDm $4 \mathrm{~cm}$

Erh.: 1 BS 
K 178 Becher

Gattung: Dünnwandige Keramik

Sondage ETH E3; InvNr. 2004/63/57 (SE B34 - Pithos 2)

Ton: 5YR6/6-6/8

Farbe innen: 5YR6/6; Farbe außen: 2.5YR5/6

Maße: BDm $4 \mathrm{~cm}$

Erh.: 1 BS

\section{K 179 Becher}

Gattung: Dünnwandige Keramik?

Sondage ETH E3; InvNr. 2004/63/38 (SE B34 - Pithos 2)

Ton: Gley 1 4/5PB

Farbe innen u. außen: 5YR5/4

Maße: BDm $5 \mathrm{~cm}$

Erh.: 1 BS

\section{K 180 Becher}

Taf. 319

Gattung: Gebrauchskeramik

Sondage ETH E3; InvNr. 2004/63/39 (SE B34 - Pithos 2)

Ton: $2.5 \mathrm{Y} 4 / 1$

Farbe innen u. außen: 7.5YR4/1

Maße: RDm 8,4 cm

Erh.: 1 RS

\section{K 181 Krug}

Taf. 319

Gattung: Gebrauchskeramik

Sondage ETH E3; InvNr. 2004/63/77 (SE B34 - Pithos 2)

Ton: 5YR6/6

Farbe innen u. außen: 7.5YR6/6

Maße: RDm $8 \mathrm{~cm}$

Erh.: 1 RS mit Henkelansatz

\section{K 182 Krug}

Taf. 319

Gattung: Gebrauchskeramik

Sondage ETH E3; InvNr. 2004/63/43 (SE B34 - Pithos 2)

Ton: 2.5 YR5/6

Farbe innen u. außen: 7.5YR5/3

Maße: RDm 8,4 cm

Erh.: 1 RS

\section{K 183 Krug}

Taf. 319

Gattung: Gebrauchskeramik

Sondage ETH E3; InvNr. 2004/63/59 (SE B34 - Pithos 2)

Ton: 7.5 YR6/6

Farbe innen: $7.5 \mathrm{YR} 7 / 4-7 / 6$

Maße: $R D m$ 7,6 cm

Erh.: 1 RS

\section{K 184 Unguentarium}

Gattung: Gebrauchskeramik

Sondage ETH E3; InvNr. 2004/63/88 (SE B34 - Pithos 2)

Ton: Gley $14 / \mathrm{N}$

Farbe innen u. außen: 7.5YR7/6

Maße: Dm 4,4 cm

Erh.: 1 Standfuß abgebrochen

\section{K 185 Kännchen}

Taf. 320

Gattung: Gebrauchskeramik

Sondage ETH E3; InvNr. 2004/63/55 (SE B34 - Pithos 2)

Ton: 2.5 YR $5 / 8-10$ YR $4 / 2$
Farbe innen u. außen: 2.5YR5/6

Maße: BDm $3 \mathrm{~cm}$

Erh.: 1 BS

K 186 Becher

Taf. 320

Gattung: Gebrauchskeramik

Sondage ETH E3; InvNr. 2004/63/58 (SE B34 - Pithos 2)

Ton: 2.5 YR $5 / 8$

Farbe innen u. außen: 7.5YR6/4-6/6

Maße: BDm 4,4 cm

Erh.: 1 BS

\section{K 187 Topf}

Taf. 320

Gattung: Gebrauchskeramik

Sondage ETH E3; InvNr. 2004/63/80 (SE B34 - Pithos 2)

Ton: 5YR6/6-7.5YR5/1

Farbe innen: 10YR5/3; Farbe außen: 7.5YR6/4-6/6

Maße: RDm 24,4 cm

Erh.: 1 RS

\section{K 188 Schüssel}

Taf. 320. 349

Gattung: Gebrauchskeramik

Sondage ETH E3; InvNr. 2004/63/95 (SE B34 - Pithos 2)

Ton: 7.5 YR5/1

Farbe innen: 7.5YR7/6; Farbe außen: 7.5YR7/6; Farbe Überzug: 10R4/6

Überzug

Maße: RDm $20 \mathrm{~cm}$

Erh.: vollständig

K 189 Schüssel

Taf. 320

Gattung: Gebrauchskeramik

Sondage ETH E3; InvNr. 2004/63/75 (SE B34 - Pithos 2)

Ton: 5YR5/6

Farbe innen u. außen: 7.5YR6/6

Maße: RDm 40,4 cm

Erh.: 1 RS

\section{K 190 Schüssel}

Taf. 320

Gattung: Gebrauchskeramik

Sondage ETH E3; InvNr. 2004/63/90 (SE B34 - Pithos 2)

Ton: $10 Y R 7 / 4$

Farbe innen u. außen: 10YR8/4

Maße: RDm $39 \mathrm{~cm}$

Erh.: 1 RS

K 191 Schüssel

Taf. 320

Gattung: Gebrauchskeramik

Taf. 319 Sondage ETH E3; InvNr. 2004/63/91 (SE B34 - Pithos 2)

Ton: 5YR6/6

Farbe innen u. außen: 7.5YR7/6

Maße: RDm $51 \mathrm{~cm}$

Erh.: 1 RS

\section{K 192 Schüssel}

Taf. 320

Gattung: Gebrauchskeramik

Sondage ETH E3; InvNr. 2004/63/102 (93) (SE B34 - Pithos 2) Ton: 2.5 YR6/8

Farbe innen: 5YR3/2; Farbe außen: 10YR7/4

Überzug: partiell, matt, tw. abgerieben 
Maße: RDm $54 \mathrm{~cm}$

Erh.: 1 RS

\section{K 193 Schüssel}

Taf. 321

Gattung: Gebrauchskeramik

Sondage ETH E3; InvNr. 2004/63/47 (SE B34 - Pithos 2)

Ton: 2.5 YR6/8

Farbe innen: 10YR5/3; Farbe außen: 2.5YR6/6-5/6

Maße: RDm ca. 36,6 cm

Erh.: 1 RS

K 194 Schüssel

Taf. 321

Gattung: Gebrauchskeramik

Sondage ETH E3; InvNr. 2004/63/94 (SE B34 - Pithos 2)

Ton: 5YR6/4

Farbe innen u. außen: 5YR7/6

Maße: BDm $44 \mathrm{~cm}$

Erh.: 1 BS

K 195 Geschlossenes Gefäß

Taf. 321

Gattung: Gebrauchskeramik

Sondage ETH E3; InvNr. 2004/63/69 (SE B34 - Pithos 2)

Ton: 5YR6/6

Farbe innen u. außen: 7.5YR7/4

Maße: BDm 10,5 cm

Erh.: 1 BS

\section{K 196 Geschlossenes Gefäß}

Taf. 321

Gattung: Gebrauchskeramik

Sondage ETH E3; InvNr. 2004/63/70 (SE B34 - Pithos 2)

Ton: 7.5YR6/6-5YR6/6

Farbe innen u. außen: 7.5YR6/6

Maße: BDm $5 \mathrm{~cm}$

Erh.: 1 BS

\section{K 197 Deckel/Platte}

Taf. 321.349

Gattung: Gebrauchskeramik

Sondage ETH E3; InvNr. 2004/63/98 (SE B34 - Pithos 2)

Ton: 10YR6/4

Farbe innen: 10YR6/3; Farbe außen: 10YR5/3

Maße: RDm ca. $30 \mathrm{~cm}$

Dekor: Wellenband zwischen Rillen, Oberseite

Erh.: 1 RS

\section{K 198 Deckel}

Taf. 321

Gattung: Gebrauchskeramik

Sondage ETH E3; InvNr. 2004/63/65 (SE B34 - Pithos 2)

Ton: $2.5 \mathrm{YR} 4 / 2$

Farbe innen $u$. außen: 5YR6/6

Maße: Dm 3 cm

Erh.: 1 Knauf

\section{K 199 Deckel}

Taf. 321

Gattung: Gebrauchskeramik

Sondage ETH E3; InvNr. 2004/63/66 (SE B34 - Pithos 2)

Ton: 5YR5/6

Farbe innen: 5YR7/6; Farbe außen: 7.5YR6/4

Maße: Dm 3,5 cm

Erh.: 3 Knauffragmente
K 200 Deckel

Taf. 321

Gattung: Gebrauchskeramik

Sondage ETH E3; InvNr. 2004/63/50 (SE B34 - Pithos 2)

Ton: $2.5 \mathrm{YR} 5 / 8$

Farbe innen: 5YR7/6; Farbe außen: 7.5YR7/6-6/4

Maße: RDm $20 \mathrm{~cm}$

Erh.: 1 RS

\section{K 201 Deckel}

Taf. 321

Gattung: Gebrauchskeramik

Sondage ETH E3; InvNr. 2004/63/48 (SE B34 - Pithos 2)

Ton: 7.5 YR6/6

Farbe innen u. außen: 7.5YR7/6

Maße: RDm $18 \mathrm{~cm}$

Erh.: 1 RS

K 202 Deckel

Taf. 321

Gattung: Gebrauchskeramik

Sondage ETH E3; InvNr. 2004/63/49 (SE B34 - Pithos 2)

Ton: 5YR6/6

Farbe innen: 7.5YR7/6-4/2; Farbe außen: 7.5YR7/6-6/4

Maße: RDm $24 \mathrm{~cm}$

Erh.: 1 RS

\section{K 203 Topf}

Taf. 322.349

Gattung: Küchenware

AO: GHD; InvNr. ETH04/63/67 (SE B34 - Pithos 2)

Ton: 7.5 YR7/6

Farbe innen: 5YR6/4; Farbe außen: 7.5YR5/1-7/4

Maße: RDm $12,9 \mathrm{~cm}$

Erh.: vollständig

\section{K 204 Topf}

Taf. 322

Gattung: Küchenware

Sondage ETH E3; InvNr. 2004/63/42 (SE B34 - Pithos 2)

Ton: 10 YR $5 / 3$

Farbe innen u. außen: 7.5YR5/3-5/4

Maße: RDm $16 \mathrm{~cm}$

Erh.: 1 RS

\section{K 205 Topf}

Taf. 322

Gattung: Küchenware

Sondage ETH E3; InvNr. 2004/63/46 (SE B34 - Pithos 2)

Ton: 5YR5/6

Farbe innen: 5YR6/6; Farbe außen: 5YR5/3

Maße: RDm 26,6 cm

Erh.: 1 RS

\section{K 206 Kasserolle}

Taf. 322

Gattung: Küchenware

Sondage ETH E3; InvNr. 2004/63/52 (SE B34 - Pithos 2)

Ton: Gley 1 2.5/N

Farbe innen u. außen: 7.5YR6/4

Maße: RDm ca. $22 \mathrm{~cm}$

Erh.: 1 RS

K 207 Pfanne

Taf. 322

Gattung: Küchenware

AO: GHD; InvNr. ETH04/63/81 (SE B34 - Pithos 2)

Ton: $2.5 Y R 5 / 6$ 
Farbe innen u. außen: 5YR5/2

Maße: RDm $26 \mathrm{~cm}$

Erh.: 1 RS+BS

\section{K 208 Pfanne}

Taf. 322

Gattung: Küchenware

Sondage ETH E3; InvNr. 2004/63/89 (SE B34 - Pithos 2)

Ton: 2.5 YR5/3 und Gley $24 / 5 \mathrm{~PB}$

Farbe innen: 5YR6/6-5/3; Farbe außen: 5YR4/6

Maße: BDm ca. $20 \mathrm{~cm}$

Erh.: 1 BS+Henkelansatz

\section{K 209 Pfanne}

Taf. 322

Gattung: Küchenware

Sondage ETH E3; InvNr. 2004/63/53 (SE B34 - Pithos 2)

Ton: 7.5 YR7/6

Farbe innen u. außen: 5YR6/6

Maße: Dm 3,8 cm (Griffende)

Erh.: 1 Griff

\section{K 210 Amphore}

Taf. 323

Typ: Peacock - Williams 45

AO: GHD; InvNr. ETH04/63/76 (SE B34 - Pithos 2)

Ton: 2.5 YR5/8

Farbe innen: 5YR6/6; Farbe außen: 7.5YR6/4-6/6

Maße: RDm $5 \mathrm{~cm}$

Erh.: 1 RS mit Henkelansatz

\section{K 211 Amphore}

Taf. 323

Typ: Peacock - Williams 45

Sondage ETH E3; InvNr. 2004/63/20 (SE B34 - Pithos 2)

Ton: 2.5 YR5/8

Farbe innen u. außen: 2.5 YR5/4

Maße: RDm 5,8 cm

Erh.: 1 RS

\section{K 212 Amphore}

Typ: Peacock - Williams 45 (ähnlich)

Sondage ETH E3; InvNr. 2004/63/19 (SE B34 - Pithos 2)

Ton: $2.5 \mathrm{YR} 4 / 6$

Farbe innen u. außen: 2.5 YR5/6

Maße: RDm 7,8 cm

Erh.: 1 RS

K 213 Amphore

AO: GHD; InvNr. ETH04/63/74 (SE B34 - Pithos 2)

Taf. 323

Ton: 5YR7/6

Farbe innen: 5YR7/6; Farbe außen: 10YR8/3

Maße: RDm 9,6 cm

Erh.: 1 RS mit Henkelansatz
K 214 Amphore

Taf. 323

AO: GHD; InvNr. ETH04/63/85 (SE B34 - Pithos 2)

Bemerkungen: Durchmesser ist ungefähre Angabe

Ton: $10 \mathrm{R} 7 / 4-5 / 3$

Farbe innen: 10R6/3; Farbe außen: 2.5YR6/6

Maße: BDm $2 \mathrm{~cm}$

Erh.: 1 BS

K 215 Amphore

Taf. 323

AO: GHD; InvNr. ETH04/63/86 (SE B34 - Pithos 2)

Ton: 7.5YR6/6

Farbe innen: 5YR7/6; Farbe außen: 7.5YR8/6

Maße: BDm 4,2 cm

Erh.: 1 BS

K 216 Amphore

AO: GHD; InvNr. ETH04/63/87 (SE B34 - Pithos 2)

Ton: 5YR6/6

Farbe innen: 2.5YR7/8; Farbe außen: 7.5YR7/6-6/4

Maße: BDm 4,8 cm

Erh.: 1 BS

\section{K 217 Lampe}

Taf. 323. 350

Typ: Doppelschnauzenlampe

AO: GHD; InvNr. ETH04/63/6 (SE B34 - Pithos 2)

Ton: 5YR7/6

Farbe innen u. außen: 2.5 YR5/8

Überzug: außen, matt glänzend, kompakt

Dekor: Efeublätter/Herzblätter, auf Schulter

Maße: KDm 7,7 cm; L 15 cm; H 3,2 cm

Erh.: Boden und Diskus ausgebrochen

\section{K 218 Lampe}

Taf. 323. 350

Gattung: Lampe; Typ: ROW-Lampe

AO: GHD; InvNr. ETH04/63/7 (SE B34 - Pithos 2)

Ton: $2.5 \mathrm{YR} 5 / 8$

Farbe innen u. außen: 10R5/8

Überzug: außen, matt glänzend, tw. abgerieben

Dekor: Efeublätter alternierend mit Punkten, auf Schulter

Maße: BDm 4,4 cm; KDm 7,8 cm; L 9 cm; H 5,2 cm

Erh.: Schnauze abgebrochen, Diskus ausgebrochen

K 219 Thymiateriondeckel

Taf. 324

AO: GHD; InvNr. ETH04/63/51(SE B34 - Pithos 2)

Ton: Gley $13 / \mathrm{N}$

Farbe außen: 10YR8/4

Maße: Dm Knauf: $1,9 \mathrm{~cm}$

Erh.: 1 Fragment

\section{K 220 Tragbarer Ofen}

Taf. 324.350

AO: GHD; InvNr. ETH04/63/97 (SE B34 - Pithos 2)

Farbe innen: 2.5YR5/6-7.5YR6/4-6/6; Farbe außen: 2.5YR5/67.5YR6/4-6/6

Maße: L $9 \mathrm{~cm}$; H 5,3 cm

Erh.: 1 Fragment 


\section{KAMMER E5}

\section{K 221 Teller}

Gattung: LRC Hayes 1

AO: GHD; InvNr. ETH04/84/1 (SE B41)

Ton: 5YR7/6

Farbe innen: 2.5YR4/8; Farbe außen: 10R5/6

Überzug: flächig, matt, kompakt

Maße: BDm $8 \mathrm{~cm}$

Erh.: 1 BS

\section{K 222 Schale}

Gattung: ARS Hayes 32

AO: GHD; InvNr. ETH04/84/2 (SE B41)

Ton: 2.5 YR6/8

Farbe innen u. außen: 10R6/8

Überzug: flächig, matt glänzend, kompakt

Maße: RDm $16 \mathrm{~cm}$

Erh.: 1 RS

\section{K 223 Teller}

Gattung: ARS Hayes 33

AO: GHD; InvNr. ETH04/84/3 (SE B41)

Ton: 10R6/8

Farbe innen: 10R5/8; Farbe außen: 2.5YR6/8

Überzug: flächig

Maße: RDm ca. $19 \mathrm{~cm}$

Erh.: 1 RS

\section{K 224 Topf}

Gattung: Küchenware

AO: GHD; InvNr. ETH04/84/12 (SE B41)

Ton: 2.5 YR3/6

Farbe innen u. außen: Gley 1 2.5/N

Maße: RDm $22 \mathrm{~cm}$

Erh.: 1 RS

\section{K 225 Topf}

Gattung: Küchenware

AO: GHD; InvNr. ETH04/84/13 (SE B41)

Ton: 5YR4/6

Farbe innen: 5YR4/3; Farbe außen: 5YR4/1

Maße: RDm $16 \mathrm{~cm}$

Erh.: 1 RS

\section{K 226 Amphore}

Typ: Peacock - Williams 45/LRA 3

AO: GHD; InvNr. ETH04/84/10 (SE B41)

Ton: $2.5 \mathrm{YR} 4 / 6$

Farbe innen u. außen: 2.5 YR5/4

Maße: BDm 3,1 cm

Erh.: 1 BS

\section{K 227 Amphore}

AO: GHD; InvNr. ETH04/84/11 (SE B41)

Ton: $2.5 \mathrm{YR} 4 / 8$

Farbe innen: 2.5YR5/3; Farbe außen: 2.5YR5/6

Maße: Dm ca. $4,4 \mathrm{~cm}$

Erh.: 1 BS abgebrochen
Taf. 324

\section{K 228 Lampe}

Taf. 324

AO: GHD; InvNr. ETH04/84/5 (SE B41)

Ton: 2.5 YR5/6

Farbe innen u. außen: 10R5/4

Dekor: Kreisaugen, auf der Schulter

Maße: KDm 3,5 cm; erh. L 6,4 cm; erh. H 2,3 cm (inkl.

Griffzapfen); 1,1 cm (exkl. Griffzapfen)

Erh.: 1 Schulter-, Diskus und Henkelfragment

Taf. 324 K 229 Lampe

Taf. 324

AO: GHD; InvNr. ETH04/84/6 (SE B41)

Ton: $10 \mathrm{YR} 4 / 3$

Farbe innen: 2.5YR3/2; Farbe außen: 2.5YR4/4

Maße: erh. L 4,2 cm; erh. H $1 \mathrm{~cm}$

Dekor: abgesetzte Rillen auf dem Diskus, Kreisauge (?) auf der Schulter

Erh.: 1 Schulter- und Diskusfragment

Taf. 324

\section{K 230 Krug}

Taf. 325

Gattung: Gebrauchskeramik

AO: GHD; InvNr. ETH04/85/2 (SE B42)

Ton: 10 YR5/4

Farbe innen u. außen: 7.5YR6/4; Farbe Überzug: 7.5YR4/2

Überzug: außen, matt, tw. abgerieben

Maße: RDm $16 \mathrm{~cm}$

Erh.: 1 RS

Taf. 324

\section{K 231 Lampe}

Taf. 325

AO: GHD; InvNr. ETH04/85/3 (SE B42)

Ton: 7.5 YR6/6

Farbe innen u. außen: 5YR7/4-7/6

Maße: KDm 4,7 cm; L 10,4 cm (inkl. Griff); H 4,2 cm (inkl. Griff); $2.6 \mathrm{~cm}$ (exkl. Griff)

Erh.: vollständig

\section{K 232 Lampe}

Taf. 325

Taf. 324

Typ: ROW-Lampe

AO: GHD; InvNr. ETH04/85/1 (SE B42)

Ton: 7.5 YR6/4

Farbe innen u. außen: 5YR6/6; Farbe Überzug: 10R4/6

Überzug, außen, matt glänzend, tw. abgerieben

Dekor: Eierstab auf der Schulter

Maße: RDm $6 \mathrm{~cm}$

Erh.: 1 Schulter- und Diskusfragment

Taf. 324

\section{K 233 Schale}

Taf. 325

Gattung: ESB Atlante 31?

AO: GHD; InvNr. ETH04/87/12 (SE B43)

Ton: 2.5 YR6/6

Farbe innen u. außen: 2.5YR4/8

Überzug: flächig, matt glänzend, tw. abgerieben

Maße: BDm ca. $8 \mathrm{~cm}$

Taf. 324 Erh.: 1 BS

\section{K 234 Becher}

Taf. 325

Gattung: Dünnwandige Keramik

AO: GHD; InvNr. ETH04/87/2 (SE B43)

Ton: $2.5 \mathrm{YR} 5 / 8$

Farbe innen: 2.5YR5/6; Farbe außen: Gley $14 / \mathrm{N}$ 
Maße: RDm $7 \mathrm{~cm}$

Erh.: 1 RS

\section{K 235 Schale}

Gattung: ESB Atlante 80

AO: GHD; InvNr. ETH04/88/11 (SE B44)

Ton: 2.5 YR6/6

Farbe innen u. außen: 10R6/8-5/8

Überzug: flächig, matt glänzend, kompakt

Maße: RDm 19 cm; BDm 7,4 cm; H 5,5 cm

Erh.: zu 3 Vierteln erh.

\section{K 236 Deckel?}

Gattung: ESB (ESB 2)

AO: GHD; InvNr. ETH04/88/12 (SE B44)

Ton: 2.5 YR5 $/ 8$

Farbe innen u. außen: 10R4/8

Überzug: flächig, matt, tw. abgerieben

Maße: RDm ca. $15 \mathrm{~cm}$

Erh.: 3 RS

\section{K 237 Becher}

Gattung: ESB Atlante 29?

AO: GHD; InvNr. ETH04/88/10 (SE B44)

Ton: 5YR7/6-6/8

Farbe innen u. außen: 2.5YR5/8

Überzug: flächig, matt glänzend, kompakt

Maße: RDm $10 \mathrm{~cm}$

Erh.: 1 RS

\section{K 238 Schale}

Gattung: ESB Atlante 37

AO: GHD; InvNr. ETH04/89/2 (SE B45)

Ton: 2.5 YR5/8

Farbe innen u. außen: 10R4/8

Überzug: flächig, matt glänzend, kompakt

Maße: RDm 10,6 cm

Erh.: 1 Fragment

\section{K 239 Schale}

Gattung: ESB Atlante 70

AO: GHD; InvNr. ETH04/89/1 (SE B45)

Ton: 5YR6/6

Farbe innen u. außen: 2.5 YR5/8

Überzug: flächig, matt glänzend, kompakt

Dekor: Rouletting, Rand außen

Maße: RDm ca. $10 \mathrm{~cm}$

Erh.: 1 RS

\section{K 240 Schale}

Gattung: ESB Atlante 70

AO: GHD; InvNr. ETH04/88/8 (SE B44)

Ton: 5YR6/6
Farbe innen u. außen: 2.5YR5/8

Überzug: flächig

Maße: RDm ca. $14 \mathrm{~cm}$

Taf. 325. 350

Erh.: 1 RS

K 241 Becher

Taf. 326

Gattung: Dünnwandige Keramik; Typ: Aco-Becher

AO: GHD; InvNr. ETH04/89/4 (SE B45)

Ton: $7.5 Y R 7 / 6$

Farbe innen: 7.5YR7/6; Farbe außen: 2.5YR4/8

Maße: erh. H 2,4 cm

Erh.: 1 WS

Taf. 325. 350

\section{K 242 Topf}

Taf. 326

Gattung: Küchenware

AO: GHD; InvNr. ETH04/88/9 (SE B44)

Ton: 2.5 YR5/8

Farbe innen: 2.5YR5/6; Farbe außen: 2.5YR2.5/1-2.5/2

Maße: RDm $15 \mathrm{~cm}$

Erh.: 4 RS mit Henkelansatz

Taf. 325

\section{K 243 Becher}

Taf. 326

Gattung: Dünnwandige Keramik

AO: GHD; InvNr. ETH 04/94/4 (SE B46)

Ton: 2.5 YR7/6

Farbe innen u. außen: 10R5/8

Maße: RDm $12 \mathrm{~cm}$

Erh.: 1 RS

\section{K 244 Schüssel}

Taf. 326

Taf. 325

Gattung: Gebrauchskeramik

AO: GHD; InvNr. ETH 04/94/3 (SE B46)

Ton: 10R6/6

Farbe innen u. außen: 10R5/8

Maße: RDm $30 \mathrm{~cm}$

Erh.: 1 RS

\section{K 245 Topf}

Taf. 326

Taf. 325

Gattung: Küchenware

AO: GHD; InvNr. ETH 04/94/1 (SE B46)

Ton: $10 \mathrm{R} 5 / 6$

Farbe innen: 10R5/4; Farbe außen: 2.5YR4/2

Maße: RDm $13 \mathrm{~cm}$

Erh.: 1 RS

\section{K 246 Topf}

Taf. 326

Gattung: Küchenware

AO: GHD; InvNr. ETH 04/94/2 (SE B46)

Ton: 2.5 YR5/6

Taf. 326 Farbe innen: 10R6/6; Farbe außen: 2.5YR4/1

Maße: RDm $16 \mathrm{~cm}$

Erh.: 1 RS 


\section{KAMMER E7}

\section{K 247 Teller}

Gattung: ESC Hayes 4

AO: GHD; InvNr. ETH04/68/2 (SE B36)

Ton: $2.5 \mathrm{YR} 6 / 6$

Farbe innen u. außen: $2.5 \mathrm{YR} 4 / 8$

Überzug: flächig, glänzend, kompakt

Maße: RDm $24 \mathrm{~cm}$

Erh.: 1 Fragment

\section{K 248 Amphore}

AO: GHD; InvNr. ETH04/68/1(SE B36)

Ton: 10R6/6

Farbe innen: 2.5YR6/6; Farbe außen: 7.5YR7/3-7/4

Maße: BDm $3 \mathrm{~cm}$

Erh.: 2/3 erh.

\section{K 249 Teller}

Taf. 327

\section{Gattung: ESA Atlante 28}

AO: GHD; InvNr. ETH04/77/1(SE B37)

Ton: 7,5YR7/6

Farbe innen: 2.5YR4/6; Farbe außen: 10R5/6-5YR7/6

Überzug: flächig, matt glänzend, abgerieben

Sekundäre Veränderungen: abgesplittert

Maße: BDm $14 \mathrm{~cm}$

Erh.: 1 BS

\section{K 250 Amphore}

Taf. 328. 351

Typ: Forlimpopoli

AO: GHD; InvNr. ETH04/77/9 (SE B37)

Ton: 5YR6/4

Farbe innen: 5YR7/3; Farbe außen: 7.5YR7/3

Graffito: Motiv? Wand außen

Maße: RDm 6,3 cm; BDm 6 cm; H $47 \mathrm{~cm}$

Erh.: 1 RS+BS

\section{K 251 Teller}

Gattung: ESC Hayes 4

AO: GHD; InvNr. ETH04/82/5 (SE B38)

Ton: 2.5 YR6/6

\section{KAMMER E8}

\section{K 256 Schale/Skyphos}

Gattung: Westabhangnachfolgeware

Sondage ETH E8; InvNr. ETH05/36/2 (SE B49)

Ton: 10 YR6/4

Farbe innen u. außen: 10YR7/4; Farbe Überzug: Gley 1 2.5/N

u. 2.5 YR6/6 u. 10YR4/2

Überzug: Flächig, matt glänzend, tw. abgerieben

Dekor: Ritzung (Ranken), Wand außen

Maße: RDm 22,6 cm

Erh.: 1 RS

\section{K 257 Becher}

Gattung: Dünnwandige Keramik

Sondage ETH E8; InvNr. ETH05/36/3 (SE B49)

Ton: 2.5 YR6/8

Taf. 327 Farbe innen u. außen: 10R4/6

Überzug: flächig, matt glänzend, kompakt

Maße: RDm $22 \mathrm{~cm}$

Erh.: 1 RS

\section{K 252 Schale}

Taf. 329

Gattung: Gebrauchskeramik

AO: GHD; InvNr. ETH04/82/3 (SE B38)

Ton: 7.5 YR4/3; Kern: 7.5 YR5/3

Taf. 327 Farbe innen: 5YR6/3; Farbe außen: 5YR6/4

Maße: RDm $11 \mathrm{~cm}$

Erh.: 1 RS

K 253 Lampe

Taf. 329

AO: GHD; InvNr. ETH04/82/1 (SE B38)

Ton: 5YR4/4

Farbe innen: 5YR5/3; Farbe außen: 5YR4/1-7.5YR5/2

Maße: erh. L: 4,4 cm; erh. H 2,9 cm

Sekundäre Veränderungen: Oberfläche verbrannt

Erh.: 1 Fragment

K 254 Schale

Taf. 329

Gattung: ESB Atlante 70

AO: GHD; InvNr. ETH04/91/1 (SE B39)

Ton: 2.5 YR6/6

Farbe innen u. außen: 10R5/8

Überzug: flächig, matt, kompakt

Dekor: Rouletting, Rand außen

Maße: RDm $10 \mathrm{~cm}$

Erh.: 1 RS

K 255 Lampe

AO: GHD; InvNr. ETH04/91/2 (SE B39)

Taf. 329

Ton: $10 \mathrm{R} 5 / 3$

Farbe innen: 10R5/4; Farbe außen: 5YR6/3

Taf. 329 Dekor: Kreisauge (am Schnauzenansatz), Rillen am Übergang zum Diskus

Maße: RDm $7 \mathrm{~cm}$

Sekundäre Veränderungen: Oberfläche verbrannt

Erh.: 1 Fragment

Taf. 329

Taf. 329

Farbe innen: 5YR7/4; Farbe außen: 2.5YR6/6

Maße: BDm $4 \mathrm{~cm}$

Erh.: 1 BS

\section{K 258 Topf/Kasserolle}

Taf. 329

Gattung: Küchenware

Sondage ETH E8; InvNr. ETH05/36/1 (SE B49)

Ton: 2.5 YR5/6

Farbe innen: 2.5YR5/6-5YR4/1; Farbe außen: 5YR4/1

Maße: RDm 20,6 cm

Erh.: 1 RS

\section{K 259 Skyphos}

Taf. 329

Gattung: Westabhangnachfolgeware

Sondage ETH E8; InvNr. ETH05/50/1 (SE B51) 
Ton: 5 YR7/8

Farbe innen: 10R4/6; Farbe außen: Gley $12.5 / \mathrm{N}$

Überzug: flächig, matt glänzend, tw. abgerieben

Maße: RDm 10,4 cm

Dekor: Ritzung (Ranken) und Bemalung (Herzblätter), Wand außen

Erh.: 1 RS

\section{K 260 Becher/Schale}

Gattung: hellenistische Firnisware

Sondage ETH E8; InvNr. ETH05/50/3 (SE B51)

Ton: 5 YR7/4

Farbe innen: 2.5YR4/8; Farbe außen: 7.5YR6/6

Überzug: flächig, matt glänzend, kompakt

Maße: RDm 12,4 cm

Erh.: 1 RS

\section{K 261 Echinusschale}

Taf. 329

Gattung: hellenistische Firnisware

Sondage ETH E8; InvNr. ETH05/50/4 (SE B51)

Ton: 10YR6/4

Farbe innen: 7.5YR5/6; Farbe außen: 5YR5/6

Überzug: flächig, matt glänzend, kompakt

Maße: RDm $17 \mathrm{~cm}$

Erh.: 1 RS

\section{K 262 Töpfchen}

Gattung: Gebrauchskeramik/dünnwandige Keramik

Sondage ETH E8; InvNr. ETH05/50/5 (SE B51)

Ton: 2.5 YR6/6

Farbe innen $u$. außen: 5YR5/4-4/4

Maße: RDm ca. $12 \mathrm{~cm}$

Erh.: 1 Fragment

\section{K 263 Teller}

Gattung: hellenistische Firnisware

Sondage ETH E8; InvNr. ETH05/56/4 (SE B53)

Ton: 10 YR6/3

Farbe innen: Gley $13 / 1$ 5G; Farbe außen: Gley 1 2.5/N-5YR4/4

Überzug: flächig, matt glänzend, kompakt

Maße: RDm $18 \mathrm{~cm}$

Erh.: 1 RS

\section{KAMMER KS1}

\section{K 269 Schüssel}

Taf. 330. 352

Gattung: ARS Hayes 15

AO: GHD; InvNr. ETH07/171/14 (SE 46)

Ton: $10 \mathrm{R} 5 / 8$

Farbe innen: 10R5/6-2.5YR5/6; Farbe außen: 10R5/8-4/8

Überzug: außen, glänzend, kompakt

Maße: RDm 18 cm; BDm 9,4 cm; H 6,3 cm

Erh.: 8 RS+BS

\section{K 270 Teller}

Gattung: ARS Hayes 50A

Taf. 330

AO: GHD; InvNr. ETH07/171/9 (SE 46)

Ton: $10 \mathrm{R} 5 / 8$

Farbe innen: 10R5/8; Farbe außen: 10R5/8-10R5/6

Überzug: flächig, glänzend, kompakt

Taf. 329
K 264 Schale/Teller

Taf. 330

Gattung: hellenistische Firnisware

Sondage ETH E8; InvNr. ETH05/56/5 (SE B53)

Ton: 5YR7/6

Farbe innen u. außen: Gley $12.5 / \mathrm{N}$

Überzug: flächig, matt glänzend, kompakt

Dekor: konzentrischer Roulettdekor zwischen feinen Rillen, Bodeninnenseite

Taf. 329 Maße: BDm $7 \mathrm{~cm}$

Erh.: 1 BS

\section{K 265 Amphore}

Taf. 330

Sondage ETH E8; InvNr. ETH05/56/3 (SE B53)

Ton: 5YR6/6

Farbe innen: 5YR6/6; Farbe außen: 5YR7/3

Maße: RDm $8,8 \mathrm{~cm}$

Erh.: 1 RS

K 266 Amphore

Sondage ETH E8; InvNr. ETH05/56/2 (SE B53)

Taf. 330

Ton: 2.5 YR7/6

Farbe innen u. außen: 7.5YR8/4

Maße: RDm 11,2 cm

Erh.: 1 RS

\section{K 267 Becher}

Taf. 330

Gattung: ESB Atlante 40

Sondage ETH E8; InvNr. ETH05/58/5 (SE B54)

Ton: 5 YR7/8

Farbe innen u. außen: 2.5 YR5/8

Überzug: außen $\mathrm{u}$. innen

Maße: BDm ca. $8 \mathrm{~cm}$

Erh.: 1 BS

\section{K 268 Topf}

Taf. 330

Gattung: Küchenware

Sondage ETH E8; InvNr. ETH05/58/1 (SE B54)

Ton: 2.5 YR5/8

Farbe innen u. außen: 10R5/4

Maße: RDm 25,6 cm

Erh.: 3 RS

Maße: RDm ca. $37 \mathrm{~cm}$; BDm $28 \mathrm{~cm}$

Sekundäre Veränderungen: tw. versintert

Erh.: 3 RS+BS

K 271 Teller

Taf. 330

Gattung: ARS Hayes 50A/B

AO: GHD; InvNr. ETH07/171/11 (SE 46)

Ton: 2.5 YR5/8

Farbe innen u. außen: 10R5/8

Überzug: flächig, glänzend, kompakt

Maße: RDm ca. $30 \mathrm{~cm}$; BDm 22,4 cm

Erh.: 2 RS+BS

K 272 Teller

Taf. 330 
AO: GHD; InvNr. ETH07/171/10 (SE 46)

Ton: 10R5/8

Farbe innen u. außen: 10R6/8

Überzug: flächig, glänzend, tw. abgerieben

Maße: RDm 25,2 cm; BDm 14,4 cm

Erh.: 10 RS+BS

\section{K 273 Teller}

Gattung: ESC Hayes 4

AO: GHD; InvNr. ETH07/171/5 (SE 46)

Ton: 5YR6/6

Farbe innen: 10R5/6-5/8; Farbe außen: 10R5/6

Überzug: flächig, glänzend, tw. abgerieben

Maße: RDm 22,8 cm; BDm 11,4 cm; H 4,7 cm

Erh.: 2 RS+BS

\section{K 274 Teller}

Gattung: ESC Hayes 4

AO: GHD; InvNr. ETH07/171/6 (SE 46)

Ton: 5YR6/5

Farbe innen: 10R5/6-5/8; Farbe außen: 10R5/6

Überzug: flächig, glänzend, tw. abgerieben

Maße: BDm 11,2 cm; RDm 20 cm; H 3,9 cm

Erh.: 2 RS+BS

\section{K 275 Teller}

Gattung: ESC Hayes 4

AO: GHD; InvNr. ETH07/171/3 (SE 46)

Ton: 7.5YR6/6

Farbe innen u. außen: 10R5/6

Überzug: flächig, glänzend, tw. abgerieben

Maße: BDm 11,4 cm

Erh.: 1 BS

\section{K 276 Teller}

Gattung: ESC Hayes 4

AO: GHD; InvNr. ETH07/171/4 (SE 46)

Ton: 2.5 YR6/6

Farbe innen u. außen: 10R5/6

Überzug: flächig, glänzend, tw. abgerieben

Maße: BDm 11,6 cm

Sekundäre Veränderungen: tw. versintert

Erh.: 1 BS

\section{K 277 Schale}

Gattung: lokale RSW?

AO: GHD; InvNr. ETH07/171/39 (SE 46)

Ton: 7.5 YR6/4

Farbe innen: 5YR6/6-4/1; Farbe außen: 7.5YR6/4

Maße: RDm 14,5 cm; BDm 5,2 cm; H 5,8 cm

Sekundäre Veränderungen: stark verwittert

Erh.: vollständig

\section{K 278 Becher}

Taf. 331. 352

Gattung: Dünnwandige Keramik

AO: GHD; InvNr. ETH07/171/34 (SE 46)

Ton: 2.5 YR $4 / 6$

Farbe innen u. außen: 2.5 YR5/6

Maße: RDm 4 cm; BDm 3,5 cm

Sekundäre Veränderungen: tw. versintert

Erh.: bis auf Henkel und Teile des Randes ganz erh.

Taf. 331

Taf. 331

Taf. 331. 352
K 279 Becher

Taf. 331

Gattung: Dünnwandige Keramik

AO: GHD; InvNr. ETH07/171/35 (SE 46)

Ton: $2.5 \mathrm{YR} 4 / 8$

Farbe innen: 2.5YR4/8; Farbe außen: 5YR5/6-7.5YR6/4

Maße: RDm 7,4 cm

Sekundäre Veränderungen. tw. versintert

Taf. $331 \quad$ Erh.: 5 RS+WS

\section{K 280 Becher/Töpfchen}

Taf. 331. 352

Gattung: Dünnwandige Keramik

AO: GHD; InvNr. ETH07/171/37 (SE 46)

Ton: 10R5/6-10R5/1

Farbe innen: 10R5/4-5/6; Farbe außen: 5YR6/1-Gley $14 / \mathrm{N}$

Dekor: Dipinto [.] П (?) auf der Schulter; Farbe: 7.5YR8/1

Maße: ca. $7,4 \mathrm{~cm}$

Taf. 331 Erh.: 1 RS

\section{K 281 Topf}

Taf. 332. 352

Gattung: Gebrauchskeramik

AO: GHD; InvNr. ETH07/171/47 (SE 46)

Ton: 2.5 YR5/6

Farbe innen: 5YR6/6; Farbe außen: 2.5YR4/8

Maße: RDm $21 \mathrm{~cm}$

Sekundäre Veränderungen: tw. versintert

Erh.: 6 RS+WS+Henkelansatz

\section{K 282 Schüssel}

Taf. 332

Gattung: Gebrauchskeramik

AO: GHD; InvNr. ETH07/171/51 (SE 46)

Ton: 10R6/8-2.5YR6/4

Farbe innen: 10R6/4-6/6; Farbe außen: 7.5YR7/4

Überzug: innen und Rand außen, matt, tw. abgerieben

Maße: RDm $28 \mathrm{~cm}$

Erh.: 3 RS

\section{K 283 Schüssel}

Taf. 332

Gattung: Gebrauchskeramik

AO: GHD; InvNr. ETH07/171/50 (SE 46)

Ton: 10R8/4-2.5YR8/2

Farbe innen: 2.5YR8/2; Farbe außen: 7.5YR8/2

Maße: RDm ca. $51 \mathrm{~cm}$

Sekundäre Veränderungen: tw. versintert

Erh.: 15 RS+WS

K 284 Schüssel

Taf. 333

Gattung: Gebrauchskeramik

AO: GHD; InvNr. ETH07/171/49 (SE 46)

Ton: 5YR6/6

Farbe innen: 10R7/3; Farbe außen: 7.5YR7/3-10YR6/4

Überzug: innen, matt, fleckig, dünn, kompakt

Maße: BDm $28 \mathrm{~cm}$

Sekundäre Veränderungen: tw. versintert

Erh.: 3 WS+BS

\section{K 285 Topf}

Taf. 333

Gattung: Küchenware

AO: GHD; InvNr. ETH07/171/54 (SE 46)

Ton: 2.5 YR $5 / 8$

Farbe innen: 10R6/6; Farbe außen: 7.5YR6/2

Sekundäre Veränderungen. tw. versintert

Erh.: 4 RS+WS+Henkel 


\section{K 286 Amphore}

AO: GHD; InvNr. ETH07/171/128+129 (SE 46)

Ton: $2.5 \mathrm{YR} 5 / 6$

Farbe innen: 2.5YR5/6; Farbe außen: 10YR7/4-2.5Y7/3-7/4

Maße: RDm 13,5 cm; KDm 42 cm; KnaufDm 1,5 cm; H (re-

konstruiert) ca. $72 \mathrm{~cm}$

Erh.: 1 RS, 1 BS, WS (zu 3 Vierteln erh.)

\section{K 287 Amphore}

AO: GHD; InvNr. ETH07/171/124 (SE 46)

Ton: 2.5 YR5/6-7.5YR5/4

Farbe innen: 7.5YR5/6; Farbe außen: 5YR5/6

Maße: KDm 26-27 cm; KnaufDm ca. 2 cm

Sekundäre Veränderungen: tw. versintert, Oberfläche tw. stark beschädigt

Erh.: 9 WS+BS

\section{K 288 Amphore}

AO: GHD; InvNr. ETH07/171/126 (SE 46)

Ton: 5YR6/6

Farbe innen: 5YR7/4; Farbe außen: 10YR8/3

Maße: KDm ca. 43 cm; KnaufDm 1,5 cm; erh. H (rekonstruiert) ca. $70 \mathrm{~cm}$

Erh.: $1 \mathrm{WS}+\mathrm{BS}$

\section{K 289 Amphore}

AO: GHD; InvNr. ETH07/171/127 (SE 46)

Ton: 2.5 YR5/6

Farbe innen: 2.5YR5/6; Farbe außen: 10YR7/4

Maße: KDm $21 \mathrm{~cm}$; KnaufDm $1 \mathrm{~cm}$

Erh.: 18 WS+BS

\section{K 290 Amphore}

Typ: Africana IIB

AO: GHD; InvNr. ETH07/171/109 (SE 46)

Ton: $7.5 \mathrm{YR} 5 / 4$

Farbe innen: 2.5YR5/3; Farbe außen: 5YR5/6

Überzug: außen, matt, abgerieben

Maße: KnaufDm (max.) 6 cm; erh. H 18,6 cm

Sekundäre Veränderungen: versintert

Erh.: 1 Knauf

\section{K 291 Amphore}

Typ: Peacock - Williams 45

InvNr. ETH07/171/113 (SE 46)

Bruch: mittelviel, fein, dicht, viel feiner Glimmer, schiefrig brechend

Ton: 7.5 YR $4 / 3$

Farbe innen: 5YR5/2; Farbe außen: 2.5Y2.5/1

Maße: RDm 2,8 cm

Erh.: 1 RS

\section{K 292 Amphore}

AO: GHD; InvNr. ETH07/171/117 (SE 46)

Ton: 2.5 YR5/4-10R5/8

Farbe innen: 7.5YR5/2; Farbe außen: 10R5/6

Maße: BDm $4 \mathrm{~cm}$

Erh.: 1 BS

\section{K 293 Amphore}

Typ: Peacock - Williams 45
Taf. 336

Taf. 335 Farbe innen: nicht bestimmbar; Farbe außen: 7.5YR5/3-4/1

Dekor: Girlande, in der Mitte und an den Enden von Bändern eingeschnürt, auf dem Diskus

Maße: L ca. 8 cm; H 4,6 cm (inkl. Henkel) 3,2 cm (exkl. Henkel)

Sekundäre Veränderungen: deformiert (Fehlbrand)

Erh.: vollständig

\section{K 296 Lampe}

Taf. 336. 353

AO: GHD; InvNr. ETH07/171/23 (SE 46)

Ton: $2.5 \mathrm{YR} 5 / 8$

Farbe innen: 2.5YR6/6; Farbe außen: 10R4/3

Überzug: außen, innen hineingeronnen, matt, tw. abgerieben

Dekor: Doppelaulos spielender Erot auf dem Diskus

Maße: Dm Diskus ca. 5 cm; erh. $\mathrm{H} 1 \mathrm{~cm}$

Taf. 336 Sekundäre Veränderungen: verbrannt

Erh.: 1 Diskus

K 297 Teller

Taf. 336

Gattung: LRC Hayes 1A

AO: GHD; InvNr. ETH07/171/18 (SE 46)

Ton: 2.5 YR6/6

Farbe innen: 10R6/4; Farbe außen: 10R5/2-6/4

Überzug: flächig, matt, kompakt

Maße: BDm 7,4 cm

Taf. 336 Erh.: 1 BS

\section{K 298 Teller}

Taf. 336

Gattung: LRC Hayes $3 \mathrm{H}$

AO: GHD; InvNr. ETH07/171/20 (SE 46)

Ton: 2.5 YR6/6

Farbe innen u. außen: 10R5/8

Überzug: flächig, matt, tw. abgerieben

Maße: RDm 28,6 cm

Erh.: 1 RS

Taf. 336

\section{K 299 Teller}

Taf. 336

Gattung: LRC Hayes 3

AO: GHD; InvNr. ETH07/171/19 (SE 46)

Ton: $2.5 \mathrm{YR} 7 / 8$

Farbe innen: 2.5YR6/8; Farbe außen: 2.5YR6/8-10R5/8

Überzug: flächig, matt, kompakt

Taf. 336 Maße: RDm $25 \mathrm{~cm}$

Erh.: 1 RS 


\section{K 300 Teller}

Gattung: ARS Hayes 93B

AO: GHD; InvNr. ETH07/171/13 (SE 46)

Ton: 2.5 YR5/8

Farbe innen: 10R6/8; Farbe außen: 10R5/8

Überzug: flächig, matt glänzend, tw. abgerieben

Maße: RDm ca. $28 \mathrm{~cm}$

Erh.: 1 RS

\section{K 301 Topf}

Gattung: Küchenware

AO: GHD; InvNr. ETH07/171/70 (SE 46)

Ton: $10 \mathrm{R} 5 / 6$

Farbe innen: 2.5YR4/1; Farbe außen: 10R4/3-4/1

Maße: RDm 15,6 cm

Erh.: 2 RS

\section{K 302 Topf}

Gattung: Küchenware

AO: GHD; InvNr. ETH07/171/79 (SE 46)

Ton: 5YR4/3-5YR4/6

Farbe innen: 10YR6/2; Farbe außen: 7.5YR5/4

Maße: RDm 19,6 cm

Erh.: 2 RS

\section{K 303 Topf}

Gattung: Küchenware

AO: GHD; InvNr. ETH07/171/80 (SE 46)

Ton: 7.5YR4/4-10YR5/2

Farbe innen: 5Y5/1; Farbe außen: 5YR4/1

Maße: RDm 13,6 cm

Erh.: 5 RS+WS

\section{K 304 Topf}

Taf. 337

Gattung: Küchenware

AO: GHD; InvNr. ETH07/171/81 (SE 46)

Ton: 7.5 YR5/2-2.5YR4/6

Farbe innen: 10YR5/3-Gley 2 3/1; Farbe außen: 10YR4/1

Maße: RDm $18 \mathrm{~cm}$

Erh.: 1 RS

\section{K 305 Topf}

Taf. 337

Gattung: Küchenware

AO: GHD; InvNr. ETH07/171/77 (SE 46)

Ton: $2.5 \mathrm{YR} 5 / 2$

Farbe innen: 7.5YR4/1; Farbe außen: 7.5YR4/3-Gley $14 / \mathrm{N}$

Maße: RDm ca. $18 \mathrm{~cm}$

Erh.: 2 RS

\section{K 306 Topf}

Taf. 337

Gattung: Küchenware

AO: GHD; InvNr. ETH07/171/82 (SE 46)

Ton: 5 YR $4 / 6-5 / 2$

Farbe innen: 7.5YR5/3-10YR3/1; Farbe außen: 7.5YR5/3-

7.5YR4/3

Maße: RDm 21,4 cm

Erh.: 1 RS

\section{K 307 Topf}

Taf. 337

Taf. 337

Taf. 337

Taf. 337

Taf. 337
K 310 Krug

Taf. 337

Gattung: Küchenware

AO: GHD; InvNr. ETH07/171/65 (SE 46)

Ton: Gley $13 / \mathrm{N}$

Farbe innen u. außen: Gley $14 / \mathrm{N}$

Maße: RDm $6 \mathrm{~cm}$

Erh.: 1 RS

\section{K 311 Kasserolle}

Gattung: Küchenware

AO: GHD; InvNr. ETH07/171/74 (SE 46)

Ton: Gley $14 / \mathrm{N}$

Farbe innen: 10YR4/1; Farbe außen: Gley 1/3N

Maße: RDm $28 \mathrm{~cm}$

Erh.: 2 RS

\section{K 312 Kasserolle}

Taf. 338

Gattung: Küchenware

AO: GHD; InvNr. ETH07/171/72 (SE 46)

Ton: $10 \mathrm{R} 2.5 / 1-5 / 6$

Farbe innen: Gley $12.5 \mathrm{Y} / \mathrm{N}$; Farbe außen: Gley $13 / \mathrm{N}$

Maße: RDm 28,4 cm

Erh.: 1 RS

\section{K 313 Kasserolle}

Taf. 338

Gattung: Küchenware

AO: GHD; InvNr. ETH07/171/73 (SE 46)

Ton: 5YR4/3-2.5YR4/6

Farbe innen: 2.5YR4/2-Gley $12.5 \mathrm{~N}$; Farbe außen: Gley $13 / \mathrm{N}$

Maße: RDm $29 \mathrm{~cm}$

Erh.: 4 RS

\section{K 314 Kasserolle}

Taf. 338

Gattung: Küchenware

AO: GHD; InvNr. ETH07/171/63 (SE 46)

Ton: $10 \mathrm{R} 5 / 2$

Farbe innen: 7.5YR4/1; Farbe außen: 2.5Y4/1

Maße: RDm 23,6 cm

Erh.: 1 RS 
K 315 Kasserolle

Gattung: Küchenware

AO: GHD; InvNr. ETH07/171/71 (SE 46)

Ton: 10R5/6-2.5YR4/3

Farbe innen: 2.5YR4/3-Gley $12.5 / \mathrm{N}$; Farbe außen: Gley 1 2.5/N

Maße: RDm nicht bestimmbar

Erh.: 1 RS

\section{K 316 Pfanne}

Taf. 338

Gattung: Küchenware

AO: GHD; InvNr. ETH07/171/66 (SE 46)

Ton: 10R3/1-5YR4/6

Farbe innen: Gley1 4/N; Farbe außen: 10R5/ 1-Gley 1 3/N

Maße: RDm ca. $30 \mathrm{~cm}$

Erh.: 1 RS

\section{K 317 Pfanne}

Taf. 338

Gattung: Küchenware

AO: GHD; InvNr. ETH07/171/67 (SE 46)

Ton: Gley 2 5/1 10B-2.5YR5/6

Farbe innen: 2.5Y5/1; Farbe außen: 2.5Y4/1

Maße: RDm ca. $42 \mathrm{~cm}$

Erh.: 1 RS

\section{K 318 Amphore}

Typ: LRA 2

AO: GHD; InvNr. ETH07/171/125 (SE 46)

Ton: 7.5 YR6/4-5YR5/6

Farbe innen: 7.5YR6/6; Farbe außen: 10YR7/6

Maße: RDm 15,2 cm

Erh.: 1 RS

\section{K 319 Amphore}

Typ: LRA 2

AO: GHD; InvNr. ETH07/171/121 (SE 46)

Ton: $2.5 \mathrm{Y} 7 / 3$

Farbe innen u. außen: $2.5 Y 7 / 3$

Maße: RDm 12,4 cm

Erh.: 1 RS+Henkel+Schulteransatz

\section{K 320 Amphore}

Typ: LRA 3

AO: GHD; InvNr. ETH07/171/120 (SE 46)

Ton: 2.5 YR5/8

Farbe innen u. außen: 2.5YR6/6

Graffito A? L? I? S? am Boden

Maße: BDm 3,7 cm

Erh.: 1 BS

\section{K 321 Amphore}

Typ: Peacock - Williams 53/Egloff 172 AO: GHD; InvNr. ETH07/171/87 (SE 46)

Taf. 338

Taf. 338. 354

Taf. 339

Taf. 339
Ton: 7.5YR4/1-5/6

Farbe innen: 5YR5/4; Farbe außen: 5YR6/3-7.5YR7/1

Maße: RDm $10 \mathrm{~cm}$

Erh.: 1 RS

\section{K 322 Amphore}

AO: GHD; InvNr. ETH07/171/106 (SE 46)

Taf. 339. 354 Ton: 2.5 YR6/8

Farbe innen: 2.5YR6/6; Farbe außen: 5YR 6/6

Dipinto: $\Phi$ und Wellenband? Wand außen (10R6/6-5/6)

Maße: $9,6 \times 5 \mathrm{~cm}$

Sekundäre Veränderungen: tw. versintert

Erh.: 1 WS

K 323 Lampe

AO: GHD; InvNr. ETH07/171/25 (SE 46)

Taf. 339. 354

Ton: 2.5 YR6/6

Farbe innen: 2.5YR6/6; Farbe außen: 5YR5/2-10R5/6

Überzug: außen, matt, kompakt

Dekor: Töpfermarke (Monogramm) auf der Bodenunterseite

Maße: BDm 4 cm; erh. h 1,9 cm

Erh.: 1 BS

\section{K 324 Lampe}

Taf. 339. 354

AO: GHD; InvNr. ETH07/171/24 (SE 46)

Ton: 2.5 YR6/8

Farbe innen: 10R6/8; Farbe außen: 2.5YR7/6

Überzug: flächig hineingeronnen, matt, tw. abgerieben

Dekor: zwei Tauben, einen Krater flankierend

Maße: erh. H 0,8 cm

Erh.: 1 Diskus

G 5 Flasche

Taf. 339

Gattung: Glas

AO: GHD; InvNr. ETH07/171/140+135 (SE 46)

Farbe: $\mathrm{Y}_{20} \mathrm{M}_{00} \mathrm{C}_{20}$

Maße: RDm $7 \mathrm{~cm}$

Erh.: 2 RS mit Henkelansatz

\section{G 6 Kelch}

Taf. 339

Gattung: Glas

AO: GHD; InvNr. ETH07/171/139 (SE 46)

Farbe: nicht bestimmbar

Maße: BDm 4,6 cm

Erh.: 1 BS

G 7 Becher

Taf. 339

Gattung: Glas

InvNr. ETH07/171/132 (SE 46)

Taf. 339 Farbe: $\mathrm{S}_{00} \mathrm{C}_{20} \mathrm{Y}_{40}$

Maße: RDm 7,8 cm

Erh.: 1 RS 


\section{RAUM 1}

\section{K 325 Teller}

Gattung: ESB Atlante 78

AO: GHD; InvNr. ETH09-Ost/37/1 (SE 18)

Ton: 2.5 YR6/8

Farbe innen u. außen: 2.5 YR7/6-10R5/8

Überzug: flächig, glänzend, abgerieben

Maße: BDm $16 \mathrm{~cm}$

Sekundäre Veränderungen: tw. versintert

Erh.: 1 BS

\section{K 326 Teller}

Gattung: ESC Hayes 4

AO: GHD; InvNr. ETH09-Ost/34/1 (SE 18)

Ton: $10 \mathrm{R} 6 / 6$

Farbe innen: 10R5/8; Farbe außen: 10R5/8-6/8-5YR8/1

Überzug: flächig, matt glänzend, kompakt

Maße: BDm $16 \mathrm{~cm}$

Sekundäre Veränderungen: tw. versintert

Erh.: 1 BS

\section{K 327 Lampe}

Taf. 340. 354

Gattung: Lampe, Typ; Broneer XXV/Loeschcke VIII

AO: EM; InvNr. ETH09. SE 20 FK 36/09-28 (SE 20)

Ton: nicht bestimmbar

Farbe innen: nicht bestimmbar; Farbe außen: 10R6/8-5/8-2.5YR5/2 Maße: BDm 3,2 cm; L 9 cm; erh. H 4,1 cm (7 cm inkl. Griff)

Dekor: unregelmäßige konzentrische Rillen am Übergang Schulter/Diskus; Rillenbündel flankiert von kleinen Kreisaugen; Übergang zur Schnauze durch eine Kerbe abgetrennt; Kreisaugen am Griffansatz. Unterseite: Kreisauge in der Bodenmitte, weitere kleine Kreisaugen an der Unterseite des Griffs und der Schnauze; winkelförmige Dekorelemente an den Seiten; zwei Stege am Übergang zur Schnauze

Sekundäre Veränderungen: tw. verbrannt

Erh.: vollständig

\section{K 328 Lampe}

Taf. 340. 354

Typ: ephesische Warzenlampe

AO: GHD; InvNr. ETH09-Ost/36/12 (SE 20)

Ton: $10 \mathrm{YR} 4 / 2$

Farbe innen: 10R5/2; Farbe außen: 5YR5/4

Maße: erh. L 4,5 cm; erh. H 1,7 cm

Dekor: dreifache Warzenreihe auf der Schulter

Sekundäre Veränderungen: tw. verbrannt

Erh.: 1 Fragment

\section{K 329 Lampe}

Typ: korinthisch, Broneer XXIII

AO: GHD; InvNr. ETH09-Ost/36/19 (KF 7/09) (SE 20)

Ton: 10 YR7/2

Farbe innen u. außen: 10YR $8 / 3$

Maße: BDm 3 cm; KDm 7,7 cm; H 4,7 cm (inkl. Griff); 3,4 cm (exkl. Griff)

Dekor: in Viertelkreise unterteilte Schulter, je zwei von einem

Punkt getrennte Spiralen

Diskus: Reliefdekor, ausgebrochen

Griff nicht vollständig durchlocht

Sekundäre Veränderungen: Übergang zur Schnauze: Brandspuren

Erh.: bis auf Schnauze und Diskus vollständig erh.
K 330 Becher

Taf. 340

Gattung: ESB Atlante 65?

AO: GHD; InvNr. ETH09-Ost/39/2 (SE 21)

Ton: $2.5 \mathrm{YR} 5 / 8$

Farbe innen: 2.5YR6/8; Farbe außen: 2.5YR6/8-6/6

Maße: RDm 5,8 cm

Überzug: flächig, glänzend, kompakt

Erh.: 1 RS

\section{K 331 Krug}

Taf. 340

Gattung: Gebrauchskeramik

AO: GHD; InvNr. ETH09-Ost/39/5 (SE 21)

Ton: 2.5 YR6/8

Farbe innen: 5YR7/4; Farbe außen: 7.5YR7/3

Maße: RDm $13 \mathrm{~cm}$

Erh.: 1 RS

\section{K 332 Amphore}

Taf. 340

Typ: Peacock - Williams 45

AO: GHD; InvNr. ETH09-Ost/39/10 (SE 21)

Ton: 5YR4/3-5YR4/6

Farbe innen: 5YR6/2-8/1; Farbe außen: 5YR7/2-7.5YR6/2-3/1

Maße: RDm $3 \mathrm{~cm}$

Sekundäre Veränderungen: tw. versintert

Erh.: 1 RS+Henkel

\section{K 333 Töpfchen}

Taf. 340

Gattung: Küchenware/dünnwandige Keramik

AO: GHD; InvNr. ETH09-Ost/42/1 (SE 23)

Ton: 7.5YR4/1

Farbe innen: 2.5YR5/1; Farbe außen: 2.5YR5/1-7.5YR4/1

Maße: RDm (innen) $8 \mathrm{~cm}$

Sekundäre Veränderungen: tw. versintert

Erh.: 1 RS+Henkel

\section{K 334 Schüssel}

Taf. 340

Gattung: Gebrauchskeramik

AO: GHD; InvNr. ETH09-Ost/42/2 (SE 23)

Ton: 2.5 YR6/4

Farbe innen u. außen: 5YR7/4

Maße: RDm $26 \mathrm{~cm}$

Erh.: 1 RS

K 335 Topf

Taf. 340

Gattung: Küchenware

AO: GHD; InvNr. ETH09-Ost/42/3 (SE 23)

Ton: 2.5 YR $4 / 1$

Farbe innen $u$. außen: 10R4/1

Maße: RDm $13 \mathrm{~cm}$

Erh.: 1 RS

\section{K 336 Schale}

Taf. 341

Gattung: ESC Atlante L 19

AO: GHD; InvNr. ETH09-Ost/43/2 (SE 25)

Ton: 10R6/8

Farbe innen: 10R6/8-2.5YR8/1; Farbe außen: 10R6/8

Überzug: flächig, matt glänzend, kompakt

Maße; RDm 15,8 cm

Sekundäre Veränderungen: versintert

Erh.: 1 RS 
K 337 Becher/Schale

Gattung: ESB Atlante 39?

AO: GHD; InvNr. ETH09-Ost/43/1 (SE 25)

Ton: $10 \mathrm{R} 4 / 8$

Farbe innen: 10R5/8; Farbe außen: 10R5/8-6/8

Überzug: flächig, glänzend, tw. abgerieben

Maße: RDm $18 \mathrm{~cm}$

Sekundäre Veränderungen: versintert

Erh.: 1 RS

\section{K 338 Becher}

Taf. 341. 354

Gattung: Dünnwandige Keramik

AO: GHD; InvNr. ETH09-Ost/43/3 (SE 25)

Ton: $10 \mathrm{R} 4 / 8$

Farbe innen: 10R5/8; Farbe außen: 10R5/1

Graffito, Schulter außen

Maße: KDm am Übergang vom Hals zur Schulter $4 \mathrm{~cm}$

Sekundäre Veränderungen: tw. versintert

Erh.: 5 WS+Henkelansatz

\section{K 339 Schüssel}

Taf. 341

Gattung: Gebrauchskeramik

AO: GHD; InvNr. ETH09-Ost/43/4 (SE 25)

Ton: $2.5 \mathrm{YR} 6 / 8$

Farbe innen: 2.5YR7/6-6/2; Farbe außen: 2.5YR7/6-6/2

Maße: RDm $44 \mathrm{~cm}$

Erh.: 1 RS

\section{K 340 Schüssel}

Taf. 341

Gattung: Gebrauchskeramik

AO: GHD; InvNr. ETH09-Ost/43/5 (SE 25)

Ton: 10R5/6-10R5/2

Farbe innen: 2.5YR6/6-10R7/6; Farbe außen: 2.5YR6/6-

5YR7/6

Maße: BDm $26 \mathrm{~cm}$

Erh.: 6 BS

\section{K 341 Topf/Kasserolle}

Gattung: Küchenware

AO: GHD; InvNr. ETH09-Ost/43/6 (SE 25)

Ton: $10 \mathrm{R} 4 / 8$

Farbe innen: 5YR6/4; Farbe außen: 10R6/6

Maße: RDm 19,8 cm

Sekundäre Veränderungen: tw. versintert

Erh.: 15 RS+WS

\section{K 342 Teller}

Taf. 341

Gattung: Küchenware

AO: GHD; InvNr. ETH09-Ost/46/2 (SE 26)

Ton: $10 \mathrm{R} 4 / 1$

Farbe innen u. außen: 10R4/4

Maße: RDm $14 \mathrm{~cm}$

Erh.: 1 RS

\section{K 343 Schüssel}

Taf. 341

Gattung: Küchenware

AO: GHD; InvNr. ETH09-Ost/46/1 (SE 26)

Ton: $2.5 \mathrm{YR} 4 / 4$

Farbe innen u. außen: 2.5YR $4 / 4$

Maße: RDm $24 \mathrm{~cm}$

Erh.: 1 RS

Taf. 341
K 344 Deckel

Taf. 342

Gattung: Küchenware

AO: GHD; InvNr. ETH09-Ost/46/3 (SE 26)

Ton: $10 \mathrm{R} 4 / 6$

Farbe innen u. außen: 10R4/6

Maße: RDm $14 \mathrm{~cm}$

Erh.: 1 RS

\section{K 345 Deckel}

Taf. 342

Gattung: Küchenware

AO: GHD; InvNr. ETH09-Ost/46/4 (SE 26)

Ton: $2.5 \mathrm{YR} 3 / 3$

Farbe innen u. außen: $2.5 \mathrm{YR} 3 / 3$

Maße: RDm $31 \mathrm{~cm}$

Erh.: 1 RS

K 346 Deckel

Taf. 342

Gattung: Küchenware

AO: GHD; InvNr. ETH09-Ost/46/5 (SE 26)

Ton: $10 \mathrm{R} 3 / 4$

Farbe innen u. außen: 10R3/4

Maße: RDm $30 \mathrm{~cm}$

Erh.: 1 RS

\section{K 347 Deckel}

Taf. 342

Gattung: Küchenware

AO: GHD; InvNr. ETH09-Ost/46/6 (SE 26)

Ton: 2.5 YR $3 / 3$

Farbe innen u. außen: 2.5 YR3/3

$\mathrm{Ma0}$; RDm $31 \mathrm{~cm}$

Erh.: 1 RS

\section{K 348 Deckel}

Taf. 342

Gattung: Küchenware

AO: GHD; InvNr. ETH09-Ost/46/7 (SE 26)

Ton: 2.5 YR2.5/4

Farbe innen u. außen: 2.5YR2.5/4

Maße: RDm $12 \mathrm{~cm}$

Erh.: 1 RS

\section{K 349 Schale}

Gattung: ESB

AO: GHD; InvNr. ETH09-Ost/48/2 (SE 27)

Ton: 2.5 YR7/85/8-10R6/8

Farbe innen: 10R5/8-6/8; Farbe außen: 10R5/8

Überzug: außen u. innen, glänzend, tw. abgerieben

Maße: RDm $10 \mathrm{~cm}$

Erh.: 1 RS

\section{K 350 Kasserolle}

Taf. 342

Gattung: Küchenware

InvNr. ETH09-Ost/48/4 (SE 27)

Ton: $10 \mathrm{R} 5 / 3-10 \mathrm{R} 5 / 8$

Farbe innen: 10R5/8-5YR8/1; Farbe außen: 10R7/6-2.5YR6/4

Maße: RDm 14,2 cm

Sekundäre Veränderungen: etwas versintert

Erh.: 2 RS+Henkel

K 351 Topf

Taf. 342

Gattung: Küchenware

AO: GHD; InvNr. ETH09-Ost/48/3 (SE 27) 
Ton: $10 \mathrm{R} 6 / 8$

Farbe innen u. außen: 10R6/4-2.5YR5/4

Maße: RDm $18 \mathrm{~cm}$

Erh.: 3 RS+Henkelansatz

\section{K 352 Lampe}

AO: GHD; InvNr. ETH09-Ost/48/1 (SE 27)

Ton: $7.5 \mathrm{YR} 5 / 2$

Farbe innen: 5YR6/2; Farbe außen: 5YR7/3-5/1

Überzug: außen, matt, tw. abgerieben

Dekor: vegetabiler Dekor (Zweige) auf der Schulter, Tierdarstellung auf dem Diskus

Maße: KDm (Schulter) 6 cm; erh. H 2,4 cm

Erh.: 1 Fragment

\section{G 8 Becher?}

Taf. 342

Gattung: Glas

AO: GHD; InvNr. ETH09-Ost/48/7 (SE 27)

Farbe innen: $\mathrm{S}_{20} \mathrm{C}_{20} \mathrm{Y}_{20}$; Farbe außen: $\mathrm{S}_{00} \mathrm{M}_{00} \mathrm{C}_{00}-\mathrm{S}_{20} \mathrm{Y}_{00} \mathrm{M}_{00}$

Maße: BDm $3 \mathrm{~cm}$; erh. $\mathrm{H}$ 0,7 cm

Erh.: 1 BS

\section{G 9 Schale/Teller}

Taf. 342

Gattung: Glas

AO: GHD; InvNr. ETH09-Ost/48/8 (SE 27)

Farbe innen: $\mathrm{S}_{10} \mathrm{C}_{00} \mathrm{Y}_{10}$; Farbe außen: $\mathrm{S}_{10} \mathrm{C}_{00} \mathrm{Y}_{10}-\mathrm{S}_{10} \mathrm{C}_{00} \mathrm{Y}_{00}$

Maße: RDm 17 cm; erh. H 1,7 cm

Erh.: 1 RS

\section{K 353 Becher}

Taf. 342

Gattung: ESB Atlante 65

AO: GHD; InvNr. ETH09-Ost/49/4 (SE 28)

Ton: 2.5 YR6/8

Farbe innen u. außen: 10R6/8-2.5YR6/8

Überzug: flächig, glänzend, kompakt

Maße: BDm $8 \mathrm{~cm}$

Erh.: 1 BS

\section{K 354 Schälchen}

Taf. 342

Gattung: ESB Atlante 70

AO: GHD; InvNr. ETH09-Ost/49/5 (SE 28)

Ton: 2.5 YR6/8

Farbe innen: 10R5/8; Farbe außen: 10R5/8-2.5YR7/6

Überzug: flächig, glänzend, kompakt

Maße: RDm $10 \mathrm{~cm}$

Erh.: 1 RS

\section{K 355 Schale}

Gattung: ESA Atlante 46

AO: GHD; InvNr. ETH09-Ost/53/1 (SE 32)

Ton: $2.5 \mathrm{YR} 8 / 4$

Farbe innen: 7.5YR8/4-10R5/8; Farbe außen: 7.5YR8/4-10R5/8

Überzug: flächig, matt, tw. abgerieben

Mape: Dm nicht bestimmbar

Erh.: 1 WS

\section{K 356 Topf}

Taf. 342

Gattung: Küchenware

AO: GHD; InvNr. ETH09-Ost/53/2 (SE 32)

Ton: $2.5 \mathrm{YR} 4 / 6$

Farbe innen: 5YR5/1; Farbe außen: 2.5YR6/1-6/4
Maße; RDm $18 \mathrm{~cm}$

Erh.: 1 RS

K 357 Teller

Gattung: ESB, Typ: Form 56?

Taf. 343

AO: GHD; InvNr. ETH09-Ost/58/2 (SE 36)

Ton: $10 \mathrm{R} 5 / 6$

Farbe innen u. außen: 10R5/8

Überzug: flächig, glänzend, tw. abgerieben

Maße: BDm $12 \mathrm{~cm}$

Erh.: 1 BS

\section{K 358 Teller}

Taf. 343. 354

Gattung: ESB Atlante 58

AO: GHD; InvNr. ETH09-Ost/36/4 (SE 36)

Ton: 2.5 YR5/8

Farbe innen u. außen: 10R5/8

Überzug: flächig, glänzend, tw. abgerieben

Stempel: Rosette, Bodenmitte, innen

Maße: RDm 16 cm; BDm $12 \mathrm{~cm}$

Erh.: RS+BS

\section{K 359 Teller}

Taf. 343

Gattung: ESB Atlante 58

AO: GHD; InvNr. ETH09-Ost/36/5 (SE 36)

Ton: 2.5 YR5/8

Farbe innen u. außen: 10R5/8

Überzug: flächig, glänzend, tw. abgerieben Maße: BDm $12 \mathrm{~cm}$

Erh.: 1 BS

\section{K 360 Teller}

Gattung: ESB Atlante 60

AO: GHD; InvNr. ETH09-Ost/36/2 (SE 36)

Ton: 2.5 YR $5 / 8$

Farbe innen u. außen: 10R5/8

Überzug: flächig, glänzend, tw. abgerieben

Stempel EPM/H $\Sigma$, Bodenmitte, innen

Maße: RDm $17 \mathrm{~cm}$; BDm 12,5 cm

Erh.: 1 RS+BS

K 361 Teller

Taf. 343

Gattung: ESB Atlante 60

AO: GHD; InvNr. ETH09-Ost/36/3 (SE 36)

Ton: $2.5 \mathrm{YR} 5 / 8$

Farbe innen u. außen: 10R5/8

Überzug: flächig, glänzend, tw. abgerieben

Taf. 342 Maße: RDm ca. $28 \mathrm{~cm}$; BDm $24 \mathrm{~cm}$

Erh.: RS+BS

\section{K 362 Teller}

Gattung: ESB Atlante 60 früh (ähnlich)

Taf. 343

AO: GHD; InvNr. ETH09-Ost/36/11 (SE 36)

Ton: 5YR6/6

Farbe innen u. außen: 10R5/8

Überzug: flächig, glänzend, tw. abgerieben

Maße: RDm 30 cm (?)

Erh.: 1 RS

K 363 Schälchen

Taf. 343

Taf. 343. 354

Gattung: ESB Atlante 70 
AO: GHD; InvNr. ETH09-Ost/58/1 (SE 36)

Ton: $10 \mathrm{R} 6 / 6$

Farbe innen u. außen: 10R4/8

Überzug: flächig, glänzend, tw. abgerieben

Maße: RDm $8 \mathrm{~cm}$

Sekundäre Veränderungen: tw. versintert

Erh.: 2 RS

\section{K 364 Schale}

Gattung: ESB Atlante 36/70

AO: GHD; InvNr. ETH09-Ost/36/8 (SE 36)

Ton: 2.5 YR6/8

Farbe innen u. außen: 10R5/8

Überzug: flächig, glänzend, tw. abgerieben

Maße: RDm $12 \mathrm{~cm}$

Erh.: 1 RS

\section{Raum 2}

\section{K 367 Ampulle}

Gattung: Gebrauchskeramik

AO: GHD; InvNr. ETH09-Ost/3/8 (SE 2)

Ton: 7.5 YR6/8-10R6/8

Farbe innen: 10R6/8; Farbe außen: 7.5YR7/6

Überzug: außen herabgeronnen, matt, kompakt

Maße: KDm (max.) 4,8 cm

Erh.: 1 BS abgebrochen

\section{K 368 Amphoriskos}

Gattung: Gebrauchskeramik

AO: GHD; InvNr. ETH09-Ost/3/2 (SE 2)

Ton: $2.5 \mathrm{YR} 5 / 6$

Farbe innen: 2.5YR6/6; Farbe außen: 5YR6/6

Maße: RDm $3 \mathrm{~cm}$

Erh.: 1 RS

\section{K 369 Topf}

Gattung: Küchenware

AO: GHD; InvNr. ETH09-Ost/3/11 (SE 2)

Ton: 7.5 YR $4 / 1-5 / 3$

Farbe innen u. außen: 7.5YR4/1

Maße: RDm $14 \mathrm{~cm}$

Erh.: 1 RS

\section{K 370 Topf}

Gattung: Küchenware

AO: GHD; InvNr. ETH09-Ost/3/12 (SE 2)

Ton: 5 YR $4 / 4$

Farbe innen u. außen: 2.5YR4/1

Maße: RDm $20 \mathrm{~cm}$

Erh.: 1 RS

\section{K 371 Schüssel}

Gattung: Gebrauchskeramik

AO: GHD; InvNr. ETH09-Ost/3/5 (SE 2)

Ton: 5YR5/6

Farbe innen: 5YR8/3; Farbe außen: 5YR7/6

Überzug: außen, flächig, matt, kompakt

Maße: RDm $24 \mathrm{~cm}$

Erh: 1 RS
K 365 Teller

Taf. 343

Gattung: ESB Atlante 58/70

AO: GHD; InvNr. ETH09-Ost/36/6 (SE 36)

Ton: 2.5 YR6/8

Farbe innen u. außen: 10R6/8-2.5YR7/6

Überzug: flächig, glänzend, tw. abgerieben

Maße: BDm $14 \mathrm{~cm}$

Erh.: $1 \mathrm{BS}$

Taf. 343

\section{K 366 Schale}

Taf. 343

Gattung: ESB Atlante 71

AO: GHD; InvNr. ETH09-Ost/36/10 (SE 36)

Ton: 5YR6/6

Farbe innen u. außen: 10R5/8

Überzug: flächig, glänzend, tw. abgerieben

Maße: RDm $10 \mathrm{~cm}$

Erh.: 1 RS

Taf. 343

\section{K 372 Amphore}

Taf. 344

Typ: Peacock - Williams 45/LRA 3

AO: GHD; InvNr. ETH09-Ost/3/14 (SE 2)

Ton: 2.5 YR $4 / 8$

Farbe innen: 5YR5/6; Farbe außen: 5YR6/6

Maße: BDm ca. $1,5 \mathrm{~cm}$

Erh.: 1 BS

\section{K 373 Teller}

Taf. 344

Taf. 343

Gattung: ARS Hayes 67 (Variante)

AO: GHD; InvNr. ETH09-Ost/66/1 (SE 41)

Ton: 10R $4 / 8$

Farbe innen u. außen: 10R5/8

Überzug: flächig, matt glänzend, kompakt

Maße: RDm $30 \mathrm{~cm}$

Sekundäre Veränderungen: tw. verbrannt

Erh.: 1 RS

Taf. 343

\section{K 374 Topf}

Gattung: Küchenware

AO: GHD; InvNr. ETH09-Ost/66/2 (SE 41)

Ton: Gley $14 / \mathrm{N}$

Farbe innen: Gley $14 / \mathrm{N}$; Farbe außen: Gley $14 / \mathrm{N}-3 / \mathrm{N}$

Maße: RDm $18 \mathrm{~cm}$

Erh.: 1 RS

Taf. 344

K 375 Topf/Kasserolle

Taf. 344

Gattung: Küchenware

AO: GHD; InvNr. ETH09-Ost/68/1 (SE 43)

Ton: $10 \mathrm{YR} 4 / 1$

Farbe innen: 10YR4/2; Farbe außen: Gley 1 2.5/N

Maße: RDm $19 \mathrm{~cm}$

Erh.: 2 RS

Taf. 344

\section{K 376 Kasserolle/Pfanne}

Taf. 344

Gattung: Küchenware

AO: GHD; InvNr. ETH09-Ost/68/2 (SE 43)

Ton: 5YR3/3-2.5YR4/8

Farbe innen u. außen: Gley $13 / \mathrm{N}$

Maße: RDm $30 \mathrm{~cm}$

Erh.: 1 RS 
K 377 Amphore

AO: GHD; InvNr. ETH09-Ost/68/3 (SE 43)

Ton: 10YR6/4

Farbe innen: 10YR6/4; Farbe außen: 2.5Y7/4

Maße: RDm ca. $6 \mathrm{~cm}$

Erh.: 1 RS
Taf. 344

K 378 Töpfchen

Gattung: Küchenware

AO: GHD; InvNr. ETH09-Ost/71/2 (SE 46)

Ton: $10 \mathrm{R} 5 / 8$

Farbe innen u. außen: 2.5YR6/6

Maße: RDm $8 \mathrm{~cm}$

Erh.: 1 RS
Taf. 344

A. WALDNER 


\section{Münzfunde}

\subsection{AUSWERTUNG DES GESAMTBESTANDS}

\subsubsection{Stückzahlen und Fundgeschichte}

Der Gesamtbestand der aus dem Theater überlieferten Münzen beträgt in Summe 285 Stück. Davon konnten zwei Münzen nicht mehr für die Auswertung berücksichtigt werden (M 284. M 285). Zwei weitere Stücke sind die kuriosen Produkte lokaler 〉Fälscher<; bei den Münzen handelt es sich ganz offensichtlich um zeitgenössische Fabrikate, welche Touristen als Memorabilien dienen sollten (M 282. M 283 Taf. 360). Sie stammen von der Stiegengasse des Süd-Analemma, einer Oberflächenschicht, und wurden anscheinend dort verloren, als dieser Bereich des Theaters noch für Besucher frei zugänglich war, was also einen terminus ante quem vor 1992 ergibt.

Weiters gehören 16 Stücke moderner Zeit aus Europa und Russland zum Fundbestand des Theaters. Der Großteil davon fällt - wie zu erwarten - auf zeitgenössische türkische Münzen (M 270-280), vornehmlich aus den 1990er und 2000er Jahren. Es handelt sich dabei naturgemäß um Kleingeld; höhere Werte als 50-BinLira-Münzen wurden nicht gefunden. Bei den zwei älteren Stücken aus den Jahren 1966 und 1949 handelt es sich um 5- und 10-Kuruş-Stücke. Hinzu kommt Kleingeld aus Russland (M 269), aus Frankreich (M 266) und Großbritannien (M 267), sowie ein griechisches 5-Drachmen-Stück von 1994 (M 268).

Alle modernen Münzen wurden in der Orchestra im Zuge der Oberflächenreinigung aufgefunden und dokumentieren letztlich die modernen Besucherströme.

Auch die im Theater gefundenen fünf osmanischen Stücke sind vor diesem Hintergrund zu beurteilen (M 261-265 Taf. 360). Sie wurden alle im Zuge von Reinigungsarbeiten im Bereich des Logeion und der Cavea gefunden. Das älteste Stück, eine schlecht erhaltene osmanische Lokalbronze - vermutlich aus dem 15. Jh. - (M 261 Taf. 360) ${ }^{1}$, wurde in summa cavea verloren. Es handelt sich dabei um ein Mangir-Stück, das gängige Kupfernominale von der Mitte des 14. bis zum Beginn des 18. Jhs. Aufgrund des schlechten Erhaltungszustands kann die Münzstätte nicht mehr ausgemacht werden. Ob dieses Fundobjekt einen Zusammenhang mit der Schlacht von Ankara 1402 oder mit dem Aufstand gegen die osmanische Herrschaft 1451 hat, sei dahingestellt. Die übrigen Münzen - ausschließlich Kleingeld - stammen aus dem Zeitraum vom späten 18. bis ins beginnende 20. Jh. und bezeugen, dass das Gelände, aus dem sich später das Theater herausschälen sollte, in dieser Zeit begangen wurde. Die Stücke M 264 und M 265 (Taf. 360) könnten allerdings schon mit den Kampagnen des Österreichischen Archäologischen Instituts zusammenhängen.

Somit bleiben 260 antike Münzen, die nun näher untersucht werden sollen.

Zuvor sei noch in wenigen Worten auf die Fundgeschichte der Münzen aus dem Theater eingegangen. Alle Münzen stammen aus den Grabungskampagnen von 1993 bis 2010 und konnten dank der hervorragenden Dokumentation von St. Karwiese von 1993 bis 1998 und den Vorarbeiten von M. Pfisterer von 2001 bis 2006 alle - bis auf zwei Stücke - im Original identifiziert werden². Die Münzen befanden sich zum Teil im Grabungshaus, zum Teil im Efes Müzesi, wo ich vor Ort alle zum Theater gehörigen Stücke aufnehmen konnte. Lediglich für zwei Exemplare konnten keine technischen Daten genommen werden, da sie sich in den Vitrinen der ständigen Ausstellung befinden (M 22. M 23).

Die Münzen der Grabungsjahre 1993 bis 1998 stammen alle aus den Bereichen des Nord- und SüdAnalemma, welche im Zuge der Einsturzgefährdung baulich saniert wurden. Dabei wurden nicht nur große

\footnotetext{
${ }^{1}$ Gratias maximas refero Nikolao Schindel me semper adiuvanti. Für die Hilfestellung bei der Identifizierung der osmanischen Münzen bin ich N. Schindel zu Dank verpflichtet.

${ }^{2}$ Mein Dank gilt an dieser Stelle M. Pfisterer, der mir seine Aufzeichnungen bereitwillig überlassen hat. Weiters danke ich dem Institutsfotografen N. Gail für seine detaillierte Fotodokumentation sowie S. Ladstätter für die reibungslose Organisation vor Ort und letztendlich M. Hofbauer für die ständige Diskussionsbereitschaft hinsichtlich der Klärung der Fundzusammenhänge.
} 


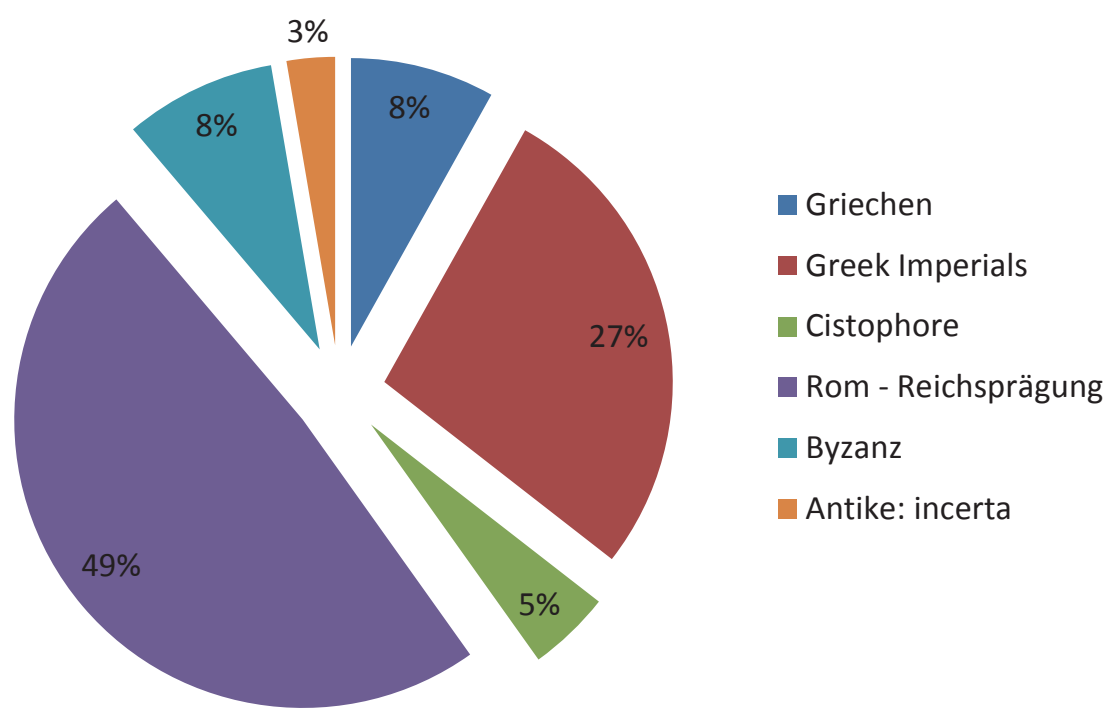

Grafik 17: Der Gesamtbestand aus dem Theater $(n=260)$

Massen Schutt entfernt, sondern es wurde auch das Einsturzmaterial freigelegt. Außerdem wurden Sondierungen in den nördlichen Stiegenhäusern durchgeführt. Die Münzen dieser Jahre stammen im NordAnalemma alle aus den Bereichen der Parodos, des Podiums D, der Kammern KN1 bis KN4 und des Korridors sowie aus den Stiegenaufgängen; jene des Süd-Analemma sind im Bereich der Süd-Parodos und der Eingangsplattformen aufgefunden worden. Einiges Material befand sich im Schutt und ist als Oberflächenoder Streufund anzusprechen. Die Münzen der Jahre von 2001 bis 2005 kamen im Zuge der Untersuchungen des Bühnengebäudes, des Logeion und der Orchestra zutage. Im Jahr 2006 wurde die Aristion-Leitung untersucht, und in den Jahren 2007 bis 2009 konzentrierte sich die archäologische Forschung auf den Südflügel des Theaters, wobei das Hauptaugenmerk der Arbeit der Stiegengasse und den Eingangsbereichen galt. Aus diesen Kampagnen stammt auch der größte Teil des Münzbestands. Im Jahr 2007 wurden in den Kammern im Bereich des vomitorium ES1 allein schon fast 100 Münzen gefunden. Auf diesen Komplex wird noch genauer einzugehen $\operatorname{sein}^{3}$.

Im Folgenden wird zunächst der Gesamtbestand analysiert und nach einzelnen chronologischen bzw. numismatisch relevanten Perioden interpretiert, sodann erfolgt eine archäologisch-historische Kontextualisierung. Die Nummernangaben der Münzen beziehen sich auf den Katalogteil, der alle Münzen chronologisch bzw. nach der numismatischen Ordnung anführt, wobei das Eckhel'sche System für die griechischen und die Göbl'sche Prägeabfolge für die römischen Münzen angewendet wurde ${ }^{4}$. Demnach beginnt der Katalog mit griechischen, auch autonomen Prägungen, setzt sich mit römischen Provinzialmünzen in geografisch-chronologischer Abfolge fort und schließt nach römisch-kaiserzeitlichen Reichsmünzen mit byzantinischen Prägungen. Die Fundliste führt alle Münzen nach ihren Fundkontexten an ${ }^{5}$, wobei hier die Ordnung von M. Hofbauer beibehalten wurde. Innerhalb der einzelnen Fundbereiche wurde nach der Abfolge der stratigrafischen Einheiten sortiert und innerhalb dieser nach dem numismatischen System. In Katalogteil werden zuerst die prägende Gemeinde bzw. der Prägeherr und die Münzstätte angegeben, sodann das Nominale und die Prägezeit, danach die technischen Daten (Gewicht, Durchmesser, Stempelstellung), die Beschreibung der Vorder- und Rückseite, gegebenenfalls technische Besonderheiten, die Erhaltung sowie zuletzt die Fundnummer und der Fundkontext. Die Fundliste der Münzen ist ähnlich aufgebaut, nur dass die Fundkontexte in den Überschriften genannt sind und zu den einzelnen Münzen nur mehr die Katalogund die Fundnummern sowie die Datierung angegeben werden. Die Abkürzungen richten sich wie gewohnt nach dem Wiener Kanon und brauchen an dieser Stelle nicht angeführt zu werden.

\footnotetext{
${ }^{3}$ Die Aufzeichnungen zu den Münzfunden von 1993 bis 1998 sind der Dokumentation von St. Karwiese entnommen, zu jenen von 2001 bis 2008 der von M. Pfisterer.

${ }^{4}$ Kap. 5.4.

${ }^{5}$ Kap. 5.5 .
} 


\subsubsection{Auswertung nach Perioden}

Zurück zum Gesamtbestand der antiken und byzantinischen Münzen aus dem Theater. Fast die Hälfte des antiken Münzmaterials (48 \%) entfällt auf reichsrömische Münzen (Grafik 17). An zweiter Stelle stehen römische Provinzial- bzw. Lokalmünzen - >Greek Imperials $<$ (32\%). Griechische Münzen aus hellenistischer Zeit sind mit $8 \%$ fast gleich stark vertreten wie byzantinische Objekte $(9 \%)$. Bei den >Incerta sich um ein prinzipatszeitliches Stück (M 254) und vier höchstwahrscheinlich spätantike bzw. frühbyzantinische Münzen. Nur bei zwei Münzen (M 259. M 260) bleibt ein non liquet. Es zeigt sich also schon hier ein eindeutiger Materialschwerpunkt auf der römischen Kaiserzeit.

\subsubsection{Griechische MünZeN}

Das Material der insgesamt 21 griechischen Prägungen zerfällt in 16 griechisch-hellenistische Münzen und fünf römisch-kaiserzeitliche, autonome Städteprägungen, welche weiter unten besprochen werden. Zunächst verdienen die hellenistischen Prägungen besondere Aufmerksamkeit. Es fällt auf, dass diese ausschließlich in Ephesos selbst hergestellt worden sind, mit Ausnahme einer makedonischen posthumen AlexanderDrachme. Diese nimmt überhaupt eine isolierte Stellung ein, da mir bislang keine makedonischen Silbermünzen aus ephesischen Einzelfunden bekannt sind.

Die ephesischen Stücke stammen alle aus der Zeit zwischen 387 und 27 v. Chr., wobei sich eine auffallende Häufung von Münzen der Periode 295/280 v. Chr. ergibt (Tab. 96). Dies könnte möglicherweise mit den Vorbereitungen im Areal für die Errichtung des Theaters in Zusammenhang stehen. Sehen wir uns die genauen Fundorte an, verdichtet sich dieser Befund. Die meisten Stücke stammen vom hellenistischen Bühnengebäude, das gleichzeitig mit der Errichtung der Theaterterrasse angelegt wurde. Die Münzen (M 8. M 9. M 12) weisen alle einen sehr starken Abnutzungsgrad auf, was für eine längere Umlaufdauer spricht. Sie können also durchaus mit der Bauzeit der Kammer D8 bzw. des Treppenfundaments zusammenhängen, was für eine Umlaufdauer von ca. 100 Jahren spricht. Die übrigen Münzen sind zum Großteil bei Oberflächenreinigungen zutage getreten; zwei Stücke stammen von der Stiegengasse im Südbereich des Theaters und wurden in spätantiken Kontexten aufgefunden (M 6. M 14). Da dieser Bereich des Theaters aber massive Einstürze aufwies, bleibt der Deutungsversuch der Münzen offen.

\begin{tabular}{|l|l|}
\hline Prägezeit & Stück \\
\hline $387 / 295$ v. Chr. & 1 \\
\hline $295 / 280$ v. Chr. & 8 \\
\hline $250 / 202$ v. Chr. & 2 \\
\hline $48 / 27$ v. Chr. & 1 \\
\hline unbestimmt & 2 \\
\hline
\end{tabular}

Tab. 96: Stückzahlen der hellenistischen Münzen nach Prägezeit

Als Vergleich kann an dieser Stelle der Münzbestand der Basilika auf dem Staatsmarkt herangezogen werden, dessen Anteil an ephesischen Lokalmünzen $17 \%$ des Gesamtbestands ausmacht. Dabei bilden wiederum Aes-Münzen der Periode 289/281 v. Chr. den größten Teil, gefolgt von Stücken des 4. Jhs. v. Chr. ${ }^{6}$ (Grafik 18). Dieses Material steht in unmittelbarem Zusammenhang mit den Planierungsarbeiten im Zuge der Errichtung der Stoa, des Vorgängerbaus der späteren Basilika, im ausgehenden 3. Jh. v. Chr.

\footnotetext{
${ }^{6}$ Für den Bestand der Basilika am Staatsmarkt berufe ich mich im Folgenden auf KARWIESE 2007.
} 


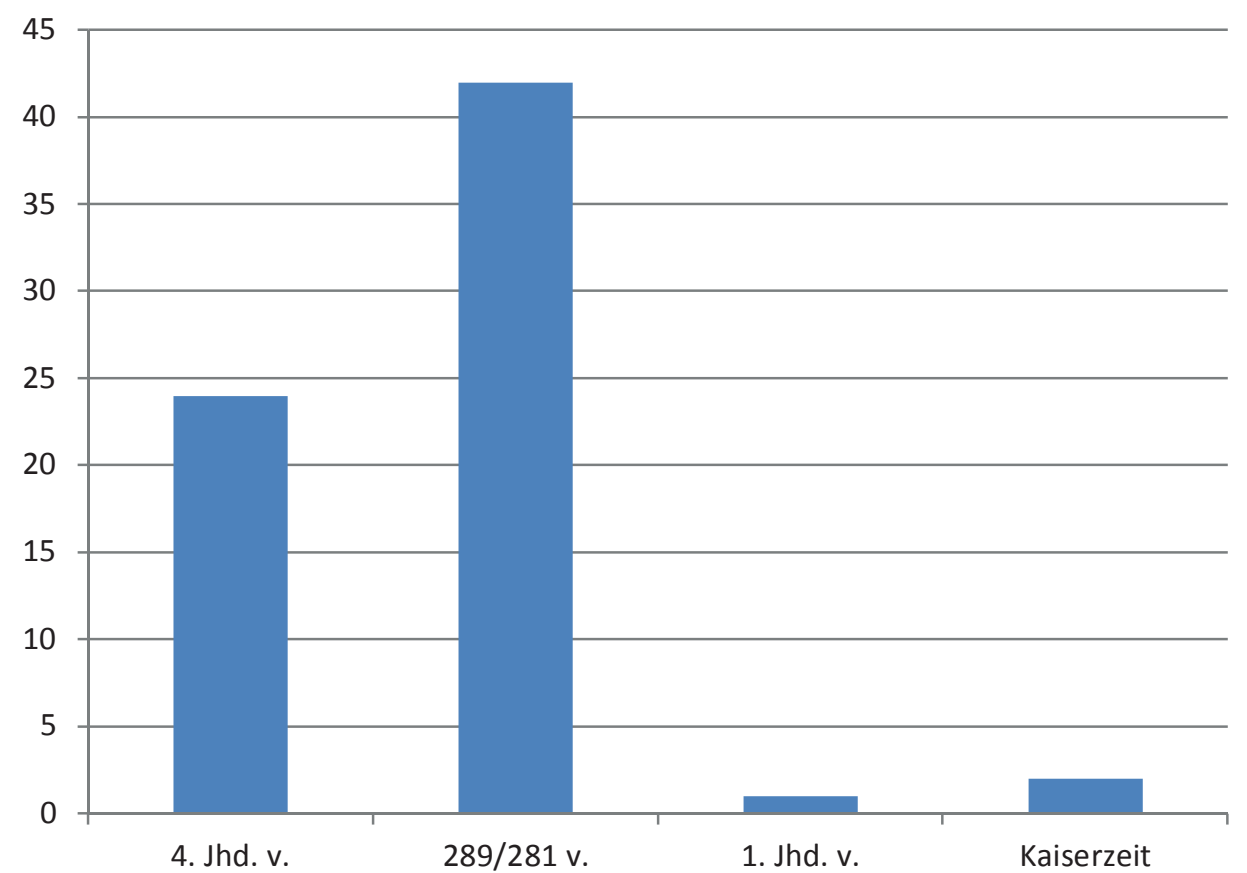

Grafik 18: Die hellenistischen Kupferprägungen aus Ephesos von der Basilika am Staatsmarkt (nach Karwiese 2007) (n=69)

\section{Nominalien}

Die Münztypen der hellenistischen Kleinbronzen lassen sich, obwohl die Beamtennamen aufgrund des hohen Abnutzungsgrads nicht mehr erkennbar sind, eindeutig nach stilistischen Kriterien identifizieren (Tab. 97). Die Nominalen beschränken sich auf drei differenzierbare Gewichtseinheiten, die vorherrschenden Nominalien im Nahverkehr. Dies wird durch den Münzbefund der Basilika am Staatsmarkt unterstrichen, wo Prägungen in drei bzw. vier Gewichtsklassen auftreten.

\begin{tabular}{|c|c|c|c|c|c|}
\hline KatNr. & Gewicht & Dm & Datierung & Zitat & Typ \\
\hline 5 & 1,25 & 11 & 387/295 v. Chr. & SNG Cop 254. 255 & $\begin{array}{l}\text { Biene/kniende Hirschkuh 1., Kopf zurückgewendet, 1.F.: } \\
\text { Beamtenname }\end{array}$ \\
\hline 6 & & 17 & \multirow[t]{8}{*}{ 295/280 v. Chr. } & SNG Cop 260. 261 & $\begin{array}{l}\text { Biene/kniende Hirschkuh 1., Kopf zurückgewendet, 1.F.: } \\
\text { Beamtenname, darüber Köcher }\end{array}$ \\
\hline 7 & 1,56 & 11 & & \multirow[t]{2}{*}{ SNG Cop 262} & \multirow{2}{*}{$\begin{array}{l}\text { Biene/kniende Hirschkuh 1., Kopf zurückgewendet, 1.F.: } \\
\text { Beamtenname, darüber Köcher }\end{array}$} \\
\hline 8 & 1,21 & 10 & & & \\
\hline 9 & & 19 & & SNG Cop 263. 264 & $\begin{array}{l}\text { Biene/st. Hirschkuh r., r.F.: Beamtenname, darüber } \\
\text { Köcher }\end{array}$ \\
\hline 10 & 1,23 & 11 & & SNG Cop 265. 266 & \multirow{2}{*}{$\begin{array}{l}\text { Biene/st. Hirschkuh r., Kopf zurückgewendet, r.F.: } \\
\text { Beamtenname, darüber Köcher }\end{array}$} \\
\hline 11 & 1,81 & 13 & & SNG Cop 266 & \\
\hline 12 & 5,13 & 16 & & \multirow[t]{2}{*}{ SNG Cop 268. 269} & \multirow{2}{*}{$\begin{array}{l}\text { Biene/äsende Hirschkuh r., i.A.: Beamtenname, darüber } \\
\text { Köcher }\end{array}$} \\
\hline 13 & & 17 & & & \\
\hline 14 & & 14 & \multirow[t]{2}{*}{ 258/202 v. Chr. } & SNG Cop 281. 282 & \multirow{2}{*}{$\begin{array}{l}\text { Artemisbüste r./Hirschprotome r., Kopf } \\
\text { zurückgewendet, 1.F.: Beamtenname, r.F.: Biene }\end{array}$} \\
\hline 15 & & 19 & & SNG Cop 281 & \\
\hline
\end{tabular}

Tab. 97: Die hellenistischen Kupfermünzen aus Ephesos vom Theater (wobei einzelne Gewichtsklassen farblich zusammengefasst sind) 
In Summe lässt sich feststellen, dass die vorliegenden hellenistischen Kleinbronzen aus dem Theater für dessen Nutzung in derselben Zeit sprechen. Weiters unterstreichen sie aufgrund der nominalienmäßigen Differenzierung das Bild einer durchgehenden Monetarisierung der Stadt - ein Bild, das wir schon aus anderen Fundkomplexen gewonnen haben. Denn es liegen aus dieser Zeit ausschließlich kleinere BuntmetallNominalien in verschiedenen Gewichtsklassen vor, was als Indiz für deren Verwendung im Nahhandel zu werten ist.

\section{Münzstätten}

Ob die Geldwirtschaft in hellenistischer Zeit stark lokal zentriert war, wird sich im Vergleich mit anderen Fundkomplexen zeigen. Zöge man allein die Münzen aus dem Theater heran, würde sich diese These bewahrheiten. Denn aus dem Theater sind ausschließlich ephesische Prägungen auf uns gekommen.

Die hellenistischen Münzen der Basilika am Staatsmarkt zeigen auf den ersten Blick eine differenziertere Zusammensetzung der Münzstätten (Grafik 19). Es stehen hier insgesamt 70 \% ephesische Münzen 30 $\%$ aus anderen Städten gegenüber. Diese umfassen, wie der Grafik zu entnehmen ist, Prägungen aus verschiedenen westkleinasiatischen Städten der unmittelbaren Umgebung (Magnesia, Priene, Milet, Smyrna), jedoch auch aus etwas weiter entfernten Regionen (Kyme, Pergamon, Sardes, Antiochia). Es zeigt sich allerdings, dass die geographische Nähe nicht unbedingt ein Überwiegen der Stückzahlen impliziert, denn aus Sardes stammen allein schon $16 \%$ der in der Basilika gefundenen hellenistischen Münzen. An zweiter Stelle steht Magnesia am Mäander mit $6 \%$. Man kann also keineswegs von einem ausschließlich lokal konzipierten Münzverkehr in Ephesos während der hellenistischen Periode sprechen, wenn er auch regional im Vergleich zurZirkulation der kaiserzeitlichen Lokalprägungen auf einen eingegrenzten Bereich Westkleinasiens beschränkt ist, der über einen Umkreis von 150 bis $200 \mathrm{~km}$ Luftlinie nicht hinausreicht. Bei allen Prägungen handelt es sich um Kupfermünzen, die in der Regel für den Nahverkehr bestimmt waren.

Aus Hanghaus 1 liegt eine geringere Materialbasis hellenistischer Kupfermünzen vor als aus der Basilika'; wir haben hier etwa einen Anteil von $13 \%$ des Gesamtbestands, von der Basilika doppelt so viel. Die Gründe sind in der Nutzung der Areale zu sehen und hängen insbesondere bei der Basilika mit deren Vorgängerbau bzw. dessen Errichtung zusammen. Die aus dem Fundbestand der Basilika gewonnenen Erkenntnisse zeigen sich auch tendenziell bei Hanghaus 1, Prägungen aus Ephesos selbst bilden den größten Teil des Umlauf-

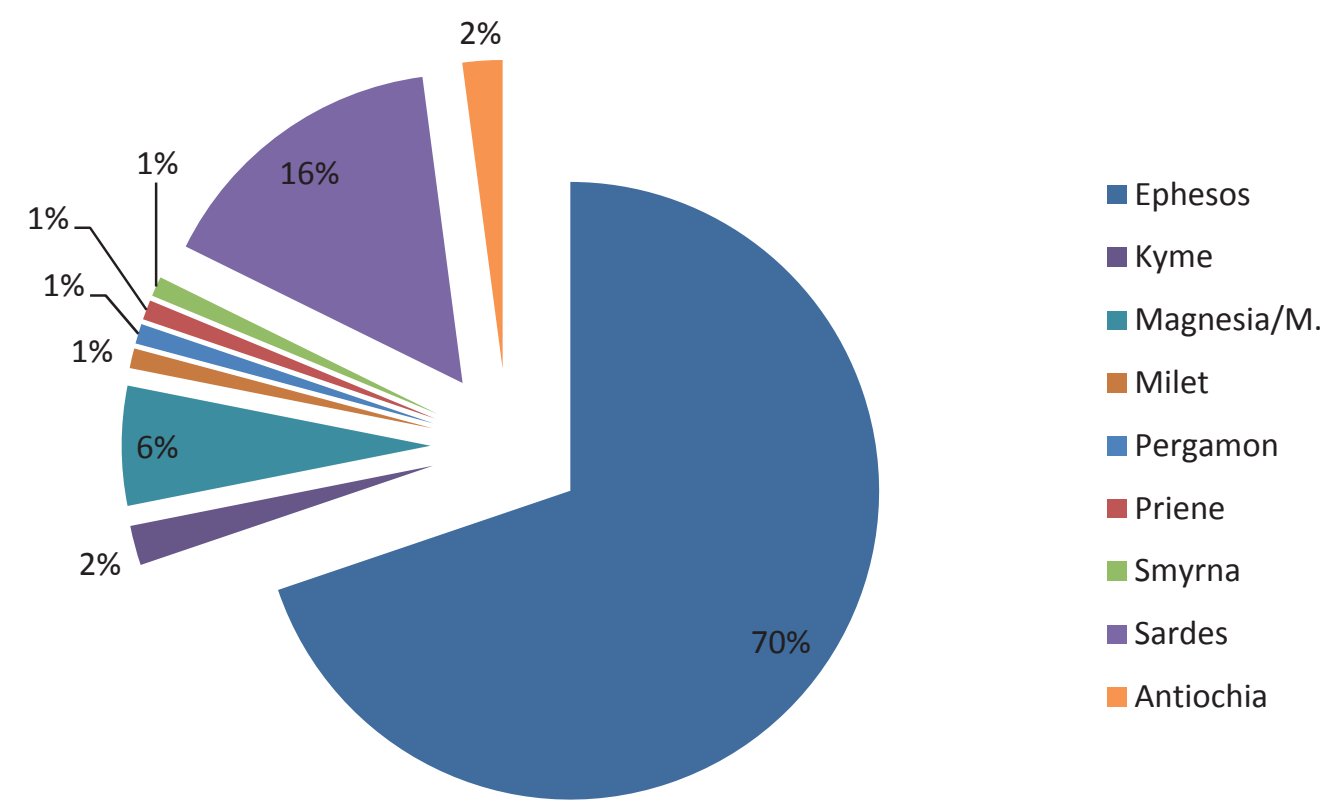

Grafik 19: Die hellenistischen Kupfermünzen aus der Basilika am Staatsmarkt ( $\mathrm{n}=106)$

\footnotetext{
${ }^{7}$ Für den Bestand des Hanghauses 1 beziehe ich mich im Folgenden auf KARWIESE 2003.
} 


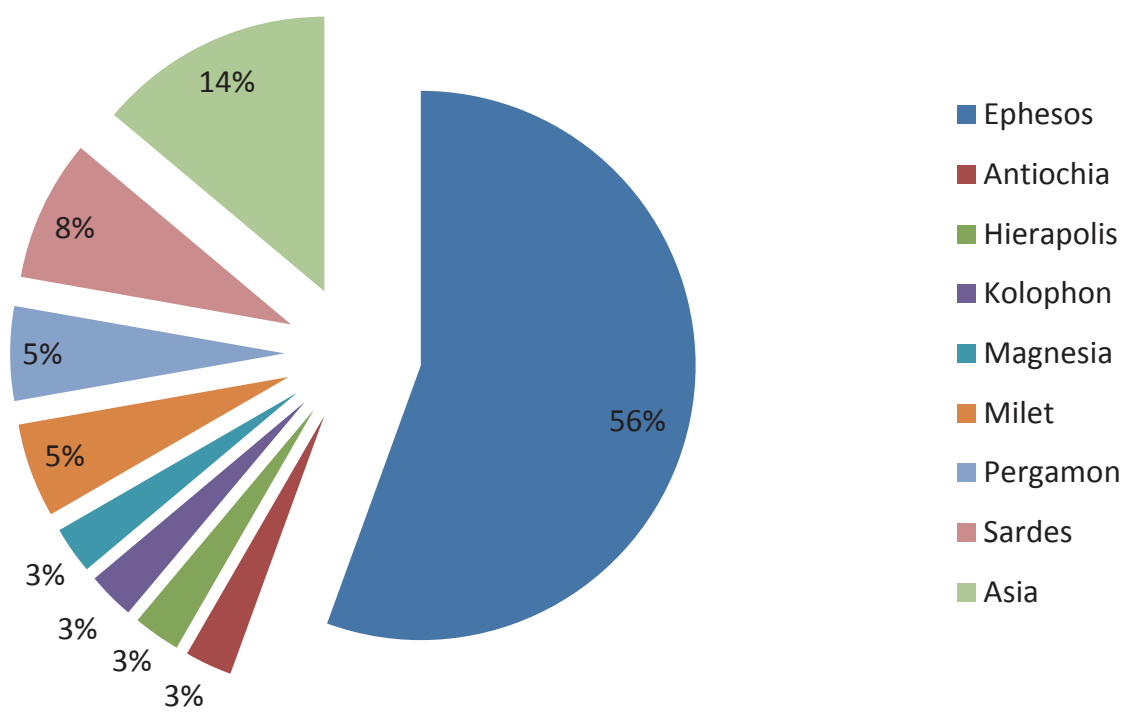

Grafik 20: Die hellenistischen Kupfermünzen aus Hanghaus 1 (n=36)

geldes (Grafik 20). Nimmt man die Münzen aus Asia hinzu, bei denen es sich meist um Stücke aus Ephesos handelt, beläuft sich der Anteil einheimischer Prägungen auf 70 \%. Die Zusammensetzung der restlichen Stücke weist ein ähnliches Bild auf wie jene von der Basilika: Sardes bildet den größten Anteil nach Ephesos, gefolgt von anderen Städten Westkleinasiens, die auch in der Basilika anzutreffen sind. Hinzu kommt jeweils eine späthellenistische Prägung aus Kolophon und Hierapolis, Städte, die ebenfalls zu dem genannten Liefergebiet zu rechnen sind.

Zusammenfassend kann konstatiert werden, dass Ephesos in hellenistischer Zeit mit zwei Drittel der Prägungen die Hauptmasse des in der Stadt verwendeten Geldes liefert; ein Drittel des Zirkulationsvolumens besteht aus Prägungen fremder Städte Westkleinasiens.

\subsubsection{Autonome StädteprägungeN}

An dieser Stelle sollen die fünf autonomen Städteprägungen aus der römischen Kaiserzeit angeführt werden, deren Provenienz etwas von den übrigen prinzipatszeitlichen `Greek Imperials` abweicht. Wir haben zwar mit Pergamon (M 4 Taf. 355) und Smyrna (M 19 Taf. 355) zwei Städte belegt, welche auch unter den Lokalprägungen mit Kaiserporträt auftreten; darüber hinaus findet sich ein Stück aus Bizya/Thrakien (M 2 Taf. 355), eines aus Alexandria Troas (M 3 Taf. 355) sowie eines aus Thyateira/Lydien (M 20). Alexandria Troas gehörte, wie schon K. Kraft nachgewiesen hat, zum Lieferbezirk von Pergamon, weshalb alexandrinische Stücke in Ephesos eher selten anzutreffen sind ${ }^{8}$. Thyateira hatte zeitweise Prägegemeinschaften mit Pergamon und Sardes, belieferte auch Ephesos, wobei Reverse mit der Darstellung der Artemis als Jägerin üblich waren'. Bei dem vorliegenden Stück handelt es sich um einen Adlertypus auf dem Revers und eine Darstellung der Artemis Boreitene auf dem Avers. Die Adlertypen treten auch mit Vorderseiten von Commodus ${ }^{10}$ und Caracalla sowie Iulia Mamaea auf ${ }^{11}$, jedoch auch mit anderen, wie beispielsweise Herakles, Tyche und Artemis. Sie werden ins 2./3. Jh. n. Chr. datiert.

\footnotetext{
${ }^{8}$ KRAFT 1972, 38-41.

${ }^{9}$ KRAFT 1972, 50-53.

${ }^{10}$ SNG Cop 602.

${ }^{11}$ SNG Mü 20 vgl. 653; SNG Cop 630.
} 


\subsubsection{KAISERZEITLICHE LOKALPRÄGUNGEN}

Insgesamt entfallen 71 Münzen des Gesamtbestands der antiken Münzen des Theaters auf 〉Greek Imperials〈, das sind in Summe 27 \% des Gesamtbestands. Sie treten vermehrt unter Augustus und danach ab Antoninus Pius bis Gallienus mit einer Spitze unter Gordianus III. auf (Grafik 21). Die Lücke zwischen Augustus und Antoninus Pius schließen zumindest vorerst Cistophore, welche weiter unten thematisiert werden.

Augusteische Prägungen sind gegenüber den späthellenistischen Serien relativ stark belegt, was mit der Installation des Statthaltersitzes zu tun hat. Danach kommt es zu einem Rückgang der Fundevidenz. Zwischen Antoninus Pius und Gallienus sind Lokalmünzen in gleichmäßiger Zahl vertreten, wobei unter Gordianus III. mit elf Stücken eine Spitze erreicht wird. Vergleicht man die Grafik der Lokalmünzen mit jener der Reichsmünzen, zeigt sich deutlich, dass vor Gordianus III. die Lokalmünzen den städtischen Geldverkehr getragen haben, erst danach setzen verstärkt Reichsprägungen ein, was naturgemäß seinen Grund im Niedergang der lokalen Prägung nach Gallienus hat ${ }^{12}$. Vergleiche mit den Münzbeständen des Hanghauses 1 (Grafik 22) und der Basilika am Staatsmarkt (Grafik 23) unterstreichen dieses Bild ${ }^{13}$. Im Hanghaus 1 sind augusteische Prägungen ebenfalls in relativ großer Zahl vertreten. Sie schließen unmittelbar an die helleni-

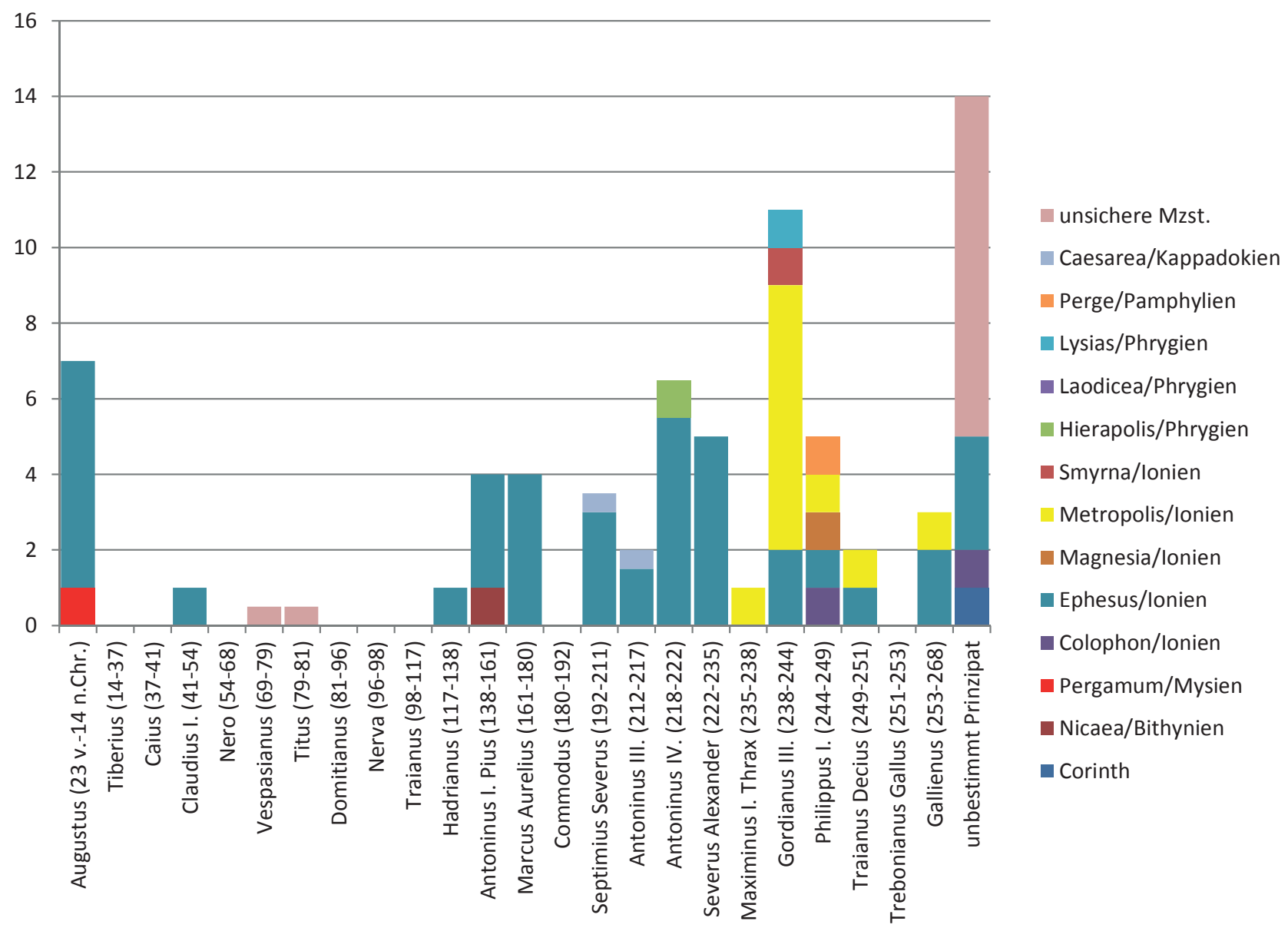

Grafik 21: Die kaiserzeitlichen Lokalprägungen aus dem Theater $(n=71)$

${ }^{12}$ Karwiese 1992, 139 nimmt eine Einstellung des Prägebetriebs in Ephesos kraft kaiserlichen Edikts zum Zwecke der Gewährleistung der Akzeptanz des reichsrömischen Antoninians an.

${ }^{13}$ Die Münzbestände des Hanghauses 1 und der Basilika am Staatsmarkt wurden aufgrund der zahlenmäßigen Repräsentativität als Vergleichsmaterial herangezogen. Ich beziehe mich dabei auf die Münzlisten von St. Karwiese (s. Anm. 4. 5). Andere Fundmünzenbestände, wie beispielsweise des Hanghauses 2 (Wohneinheiten 1 und 4) oder des Vediusgymnasiums sind aufgrund der geringen Fundzahl sowie des schlechten Erhaltungszustands der Münzen an dieser Stelle als Vergleichsmaterial wenig geeignet. 


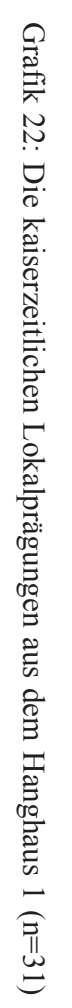

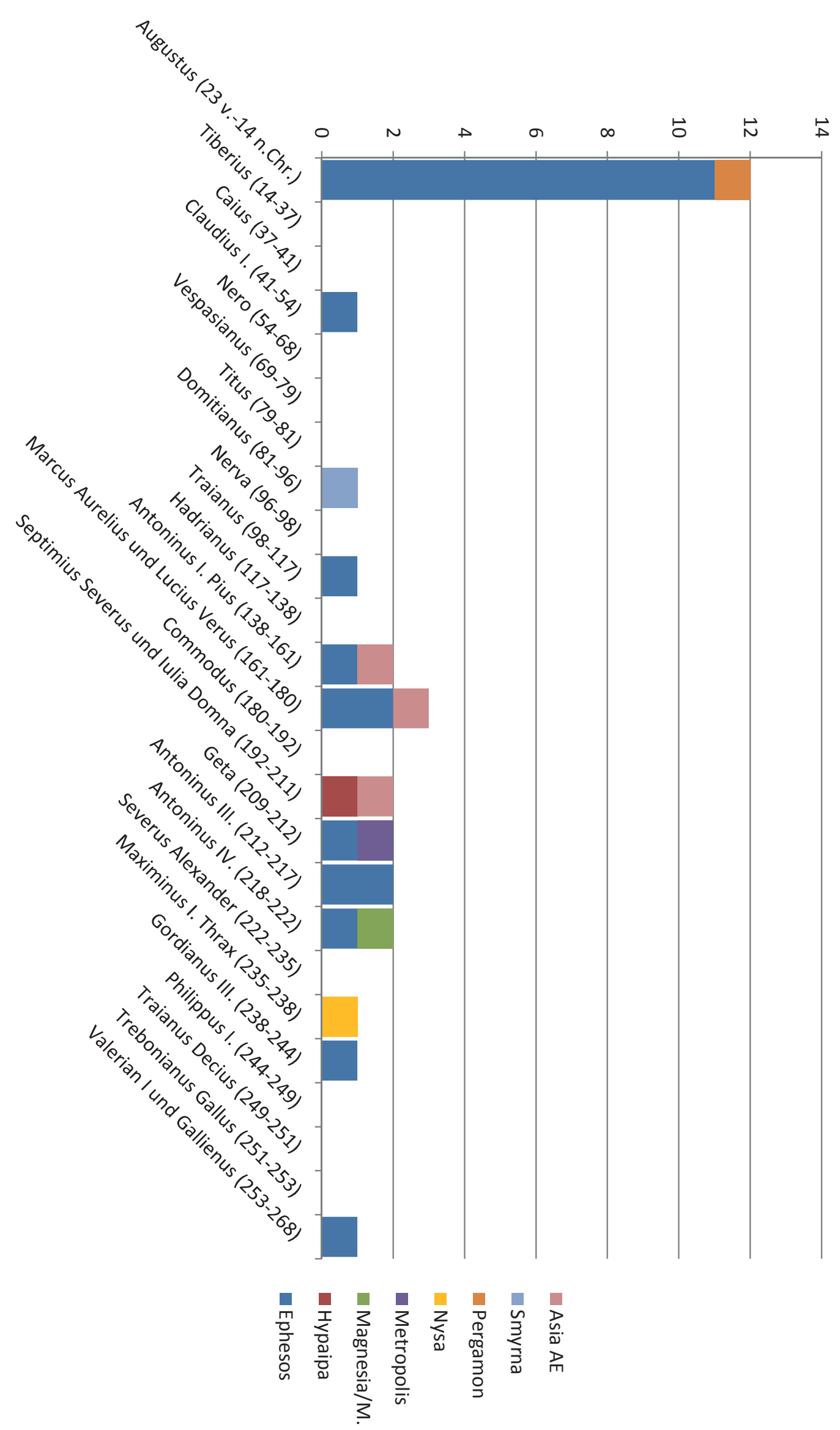




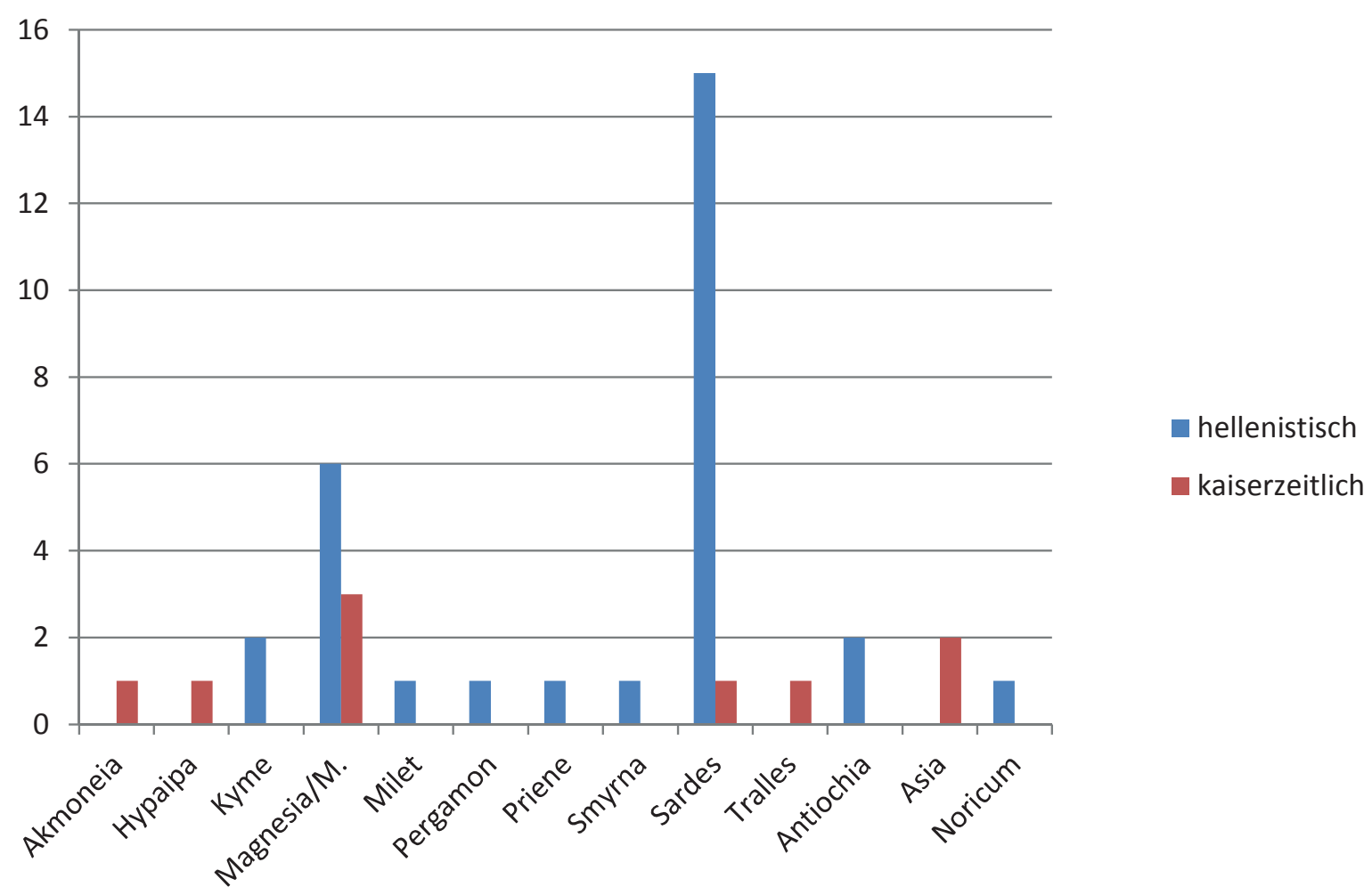

Grafik 23: Die hellenistischen Münzen und die kaiserzeitlichen Lokalprägungen aus der Basilika am Staatsmarkt (ohne Ephesos) $(n=39)$

stische Münzreihe an, welche sich hier stärker manifestiert als im Theater. Die Zeit zwischen Claudius I. und Gallienus ist ähnlich wie im Theater in gleichmäßiger Verteilung präsent. Erst ab der Mitte des 3. Jhs. n. Chr. steigt die Zahl der Funde an, wobei diese nur mehr aus Reichsmünzen bestehen.

Der Münzbestand der Basilika am Staatsmarkt zeigt eine ähnliche Verteilung, wenn auch der Anteil an kaiserzeitlichen Lokalprägungen ein geringerer ist als im Theater und im Hanghaus 1, was bei letzterem mit den baulichen Rahmenbedingungen zu tun hat. Für die ersten beiden Jahrhunderte sind in der Basilika ebenfalls ausschließlich Lokalmünzen belegt. Die Kurve der Reichsmünzen setzt ab der Mitte des 3. Jhs. n. Chr. ein und steigt dann stark im 4. Jh. n. Chr. an.

\section{Münzstätten}

An dieser Stelle empfiehlt es sich, die ephesischen von den übrigen Lokalprägungen zu trennen, um zu überprüfen, ob ein eventueller Rückgang der ephesischen Prägungen ein Einströmen von fremden Münzen bedingt. In Summe machen Münzen aus Ephesos selbst im Theater schon mehr als einen Anteil von 50 \% unter den kaiserzeitlichen Lokalprägungen aus. Der größte Anteil verteilt sich - mit Ausnahme der augusteischen Münzen - auf die Zeit zwischen Antoninus Pius und Severus Alexander; erst ab Maximinus I. gehen die ephesischen Prägungen zugunsten fremder Stücke zurück. In absoluten Zahlen ausgedrückt stehen in der Periode zwischen Hadrian und Severus Alexander 23 Lokalmünzen aus Ephesos drei Münzen aus anderen kleinasiatischen Städten gegenüber. Zwischen Maximinus I. und Gallienus hingegen verschiebt sich das Verhältnis zugunsten fremder Prägungen auf $6: 16$. Wir können hier folglich einen Zusammenhang zwischen dem Rückgang der ephesischen Münzen und einem zunehmenden Einströmen fremder Prägungen konstatieren. Ob diese Hypothese zu halten ist, soll ein Blick auf die Verteilungskurven des Hanghauses 1 und der Basilika am Staatsmarkt klären. In Hanghaus 1 ist der Anteil der ephesischen Münzen - anders als im Theater - mehr als doppelt so hoch wie jener der fremden kaiserzeitlichen Lokalprägungen (Grafik 22). Dabei verzerrt der große Bestand der augusteischen Münzen die Grafik ein wenig. Betrachtet man nur das 2. und 3. Jh. n. Chr., also die Zeit zwischen Trajan und Gallienus, stehen in Summe zehn ephesische 
Prägungen sieben Lokalmünzen anderer Städte gegenüber. Dies ist in Anbetracht des Gesamtbestands von Hanghaus 1 eine zu geringe Zahl, um eine stringente Argumentation aufzubauen. Zudem verteilen sich die ephesischen wie die anderen lokalen Prägungen etwa gleichmäßig über die ganze genannte Zeitspanne mit einer geringfügigen Materialverdichtung zwischen Antoninus Pius und Elagabal. Für die Basilika am Staatsmarkt ist zu bemerken, dass wir hier einen großen Anteil an hellenistischen Prägungen generell vorliegen haben, wobei die ephesischen Stücke einen Anteil von $17 \%$ ausmachen, jene anderer Städte $7 \%$. Die kaiserzeitlichen Lokalprägungen betragen inklusive der ephesischen lediglich $3 \%$ des Gesamtbestands, weshalb die Aussagemöglichkeiten in Bezug auf die genannte Fragestellung mehr als beschränkt sind. Zudem verteilen sich die Münzen etwa gleichmäßig auf die Zeit zwischen Augustus und Gallienus. Auffällig ist einzig die Tatsache, dass die ephesischen Prägungen gegenüber jenen anderer Städte in sehr geringem Ausmaß vertreten sind. In absoluten Zahlen bedeutet dies ein Verhältnis von $2: 7$.

Die weitere Frage, die sich in Bezug auf die Verteilung der >Greek Imperials` stellt, ist, ob die Versorgungslinien seit der hellenistischen Zeit dieselben geblieben sind, oder ob und inwieweit sie sich geändert haben.

Für die Münzen aus dem Theater können wir, wie schon erwähnt, aus der Grafik eine Spitze unter Gordianus III. ablesen (Grafik 21). Obwohl sich die These als nicht haltbar erwiesen hat, dass ein Zusammenhang zwischen dem Rückgang ephesischer Münzen und dem Zuströmen fremder Prägungen besteht, liegen gerade für das Theater ab dem 2. Viertel des 3. Jhs. n. Chr. mehr fremde als ephesische Prägungen vor. So erklärt sich der hohe Balken unter Gordianus III. durch die Präsenz von Stücken vor allem aus Metropolis. Mehr als die Hälfte aller kaiserzeitlichen Lokalprägungen fremder Städte entfallen zwischen Maximinus I. und Gallienus auf Prägungen aus Metropolis. Die übrigen vertretenen Städte sind jeweils nur mit einem bzw. maximal zwei Stücken vertreten. Dabei handelt es sich, wie schon für die hellenistische Periode ausgeführt, in erster Linie um Städte der unmittelbaren Umgebung, wie Magnesia, Tralleis, Kolophon, sowie der benachbarten Regionen Lydiens und Kariens. Lediglich drei Stücke kamen aus weiterer Entfernung, nämlich jeweils eines aus Nicaea/Bithyniae (M 35 Taf. 356), Perge/Pisidiae (M 93 Taf. 358) und Caesarea/Cappadociae (M 94). Hinzu kommt eine korinthische Prägung, die jedoch aufgrund des hohen Abnutzungsgrads nicht mehr zweifelsfrei zugewiesen werden kann (M 34 Taf. 356).

Dieselben Tendenzen zeigen sich auch am Befund des Hanghauses 1 sowie der Basilika am Staatsmarkt. Leider ist der Materialbestand in Summe zu gering und die einzelnen Stücke sind zu schlecht erhalten, sodass keine detaillierteren Aussagen in Bezug auf die Lieferbezirke möglich sind. Wir können an dieser Stelle lediglich festhalten, dass Ephesos in der Kaiserzeit auch von anderen, in der Regel nicht weiter als 100 bis $200 \mathrm{~km}$ entfernten Städten beliefert wurde, mitunter jedoch auch Münzen aus größerer Distanz hierher kamen. Dasselbe Bild zeigt sich im Münzspektrum der Stadtgrabung von Pergamon, wo ebenfalls hauptsächlich Prägungen von Städten aus dem pergamenischen Einflussbereich auftreten, andere wenige als Zufallsfunde zu bewerten sind ${ }^{14}$.

\section{Nominalien}

Bei den aus dem Theater vorliegenden kaiserzeitlichen Lokalprägungen handelt es sich ausschließlich um Münzen aus Buntmetall. Unabhängig von der Berechnung des Basisassarions durch St. Karwiese und R. Ziegler und von der Gewichtsreduzierung desselben bis zur Mitte des 3. Jhs. n. Chr. bzw. den unterschiedlichen Berechnungen für die einzelnen Städte ${ }^{15}$, ergibt sich aus den vorliegenden Stücken keine eindeutige Zuordnung der Nominalien. Aus Tabelle 98, die die Gewichte aufsteigend innerhalb der Prägeperioden ordnet, kann lediglich ersehen werden, dass sich die Gewichte gleichmäßig zwischen ca. 2,0 und 7,5 Gramm verteilen (Tab. 98). Schwerere Nominalien sind nur mehr spärlich vertreten. Erschwerend kommt hinzu, dass der Erhaltungsgrad der meisten Münzen mehr als unzureichend ist, sodass eine Ermittlung des Gewichts in diesem Fall kaum aussagekräftig sein kann. Die Grafik verdeutlicht diese unzureichende Evidenz einmal mehr (Grafik 24).

\footnotetext{
${ }^{14}$ Voegtli 1993, $5 \mathrm{f}$.

${ }^{15}$ Zum Assarion: KARWIESE 1992; ZIEGLER 1992.
} 


\begin{tabular}{|c|c|c|c|}
\hline KatNr. & Gew. & Datierung & Münzstätte \\
\hline 35 & 11,8 & 138/161 n. Chr. & Nicaea \\
\hline 37 & 4,07 & 198/268 n. Chr. & \multirow[t]{2}{*}{ Colophon } \\
\hline 38 & 4,62 & 244/249 n. Chr. & \\
\hline 39 & 2,95 & \multirow[t]{6}{*}{ Augustus } & \multirow[t]{36}{*}{ Ephesus } \\
\hline 40 & 4,63 & & \\
\hline 41 & 6,01 & & \\
\hline 43 & 6,15 & & \\
\hline 42 & 6,4 & & \\
\hline 44 & 6,92 & & \\
\hline 45 & 5,37 & 41/54 n. Chr. & \\
\hline 46 & 4,87 & 117/138 n. Chr. & \\
\hline 48 & 4,88 & \multirow[t]{2}{*}{ 138/161 n. Chr. } & \\
\hline 47 & 5,4 & & \\
\hline 49 & 12,48 & 141/161 n. Chr. & \\
\hline 51 & 3,86 & \multirow[t]{4}{*}{ 161/180 n. Chr. } & \\
\hline 52 & 5,34 & & \\
\hline 50 & 6,82 & & \\
\hline 53 & 20,72 & & \\
\hline 55 & 1,93 & \multirow[t]{3}{*}{ 193/211 n. Chr. } & \\
\hline 54 & 2,3 & & \\
\hline 56 & 13 & & \\
\hline 57 & 3,27 & 198/211 n. Chr. & \\
\hline 58 & 4,75 & \multirow[t]{4}{*}{ 218/222 n. Chr. } & \\
\hline 60 & 5,06 & & \\
\hline 61 & 6,73 & & \\
\hline 59 & 10,58 & & \\
\hline 62 & 7,63 & 221 n. Chr. & \\
\hline 63 & 2,63 & 197/222 n. Chr. & \\
\hline 64 & 4,6 & \multirow[t]{5}{*}{ 222/235 n. Chr. } & \\
\hline 67 & 5,23 & & \\
\hline 68 & 5,81 & & \\
\hline 66 & 11,6 & & \\
\hline 65 & 12,3 & & \\
\hline 70 & 3,23 & \multirow[t]{2}{*}{ 238/244 n. Chr. } & \\
\hline 69 & 6,38 & & \\
\hline 71 & 5,51 & 244/247 n. Chr. & \\
\hline 72 & 4,51 & 249/251 n. Chr. & \\
\hline 74 & 7,46 & \multirow[t]{2}{*}{ 253/268 n. Chr. } & \\
\hline 73 & 9,3 & & \\
\hline
\end{tabular}

\begin{tabular}{|c|c|c|c|}
\hline KatNr. & Gew. & Datierung & Münzstätte \\
\hline 78 & 4,83 & 244/249 n. Chr. & Magnesia/M. \\
\hline 79 & 4,99 & 235/238 n. Chr. & \multirow[t]{11}{*}{ Metropolis } \\
\hline 86 & 2,38 & \multirow[t]{7}{*}{ 238/244 n. Chr. } & \\
\hline 82 & 3,64 & & \\
\hline 81 & 5,36 & & \\
\hline 85 & 6,11 & & \\
\hline 84 & 6,76 & & \\
\hline 83 & 9,09 & & \\
\hline 80 & 9,6 & & \\
\hline 87 & 4,64 & 244/249 n. Chr. & \\
\hline 88 & 5,42 & 249/251 n. Chr. & \\
\hline 89 & 4,3 & 258/260 n. Chr. & \\
\hline 90 & 4,03 & 238/244 n. Chr. & Smyrna \\
\hline 91 & 4,86 & 221 n. Chr. & Hierapolis \\
\hline 92 & 11,3 & 238/244 n. Chr. & Lysias \\
\hline 93 & 7,03 & 244/247 n. Chr. & Perge \\
\hline 94 & 10,75 & 197/217 n. Chr. & Caesarea \\
\hline 98 & 14,6 & 138/161 n. Chr. & Kleinasien \\
\hline
\end{tabular}

Tab. 98: Die Gewichte der prinzipatszeitlichen Lokalprägungen aus dem Theater

In Summe kann festgestellt werden, dass größere Buntmetall-Nominalien nur spärlich vertreten sind, die kleineren, leichteren als der römische As jedoch häufig in unterschiedlichen Gewichtsstufen auftreten, was letztendlich wieder nur eine Bestätigung der durchgehenden Monetarisierung der Stadt ist.

\section{Münztypen}

Die kaiserzeitlichen Lokalprägungen sind von äußerst schlechtem Erhaltungszustand, sodass kaum Legenden mit einiger Genauigkeit vollständig aufgelöst werden können. Insbesondere die Beamtennamen auf den augusteischen Münzen sind kaum identifizierbar.

Auf den übrigen Lokalmünzen ist - soweit identifizierbar - der gängige Typenvorrat der einzelnen Städte repräsentiert. Wir haben generell festgestellt, dass mit Antoninus Pius der Niederschlag der städtischen Prägungen zunimmt und sich etwa gleichmäßig bis Gallienus verteilt. Unter den ephesischen Stücken fällt besonders unter Antoninus IV. (Elagabal) und Severus Alexander die starke 


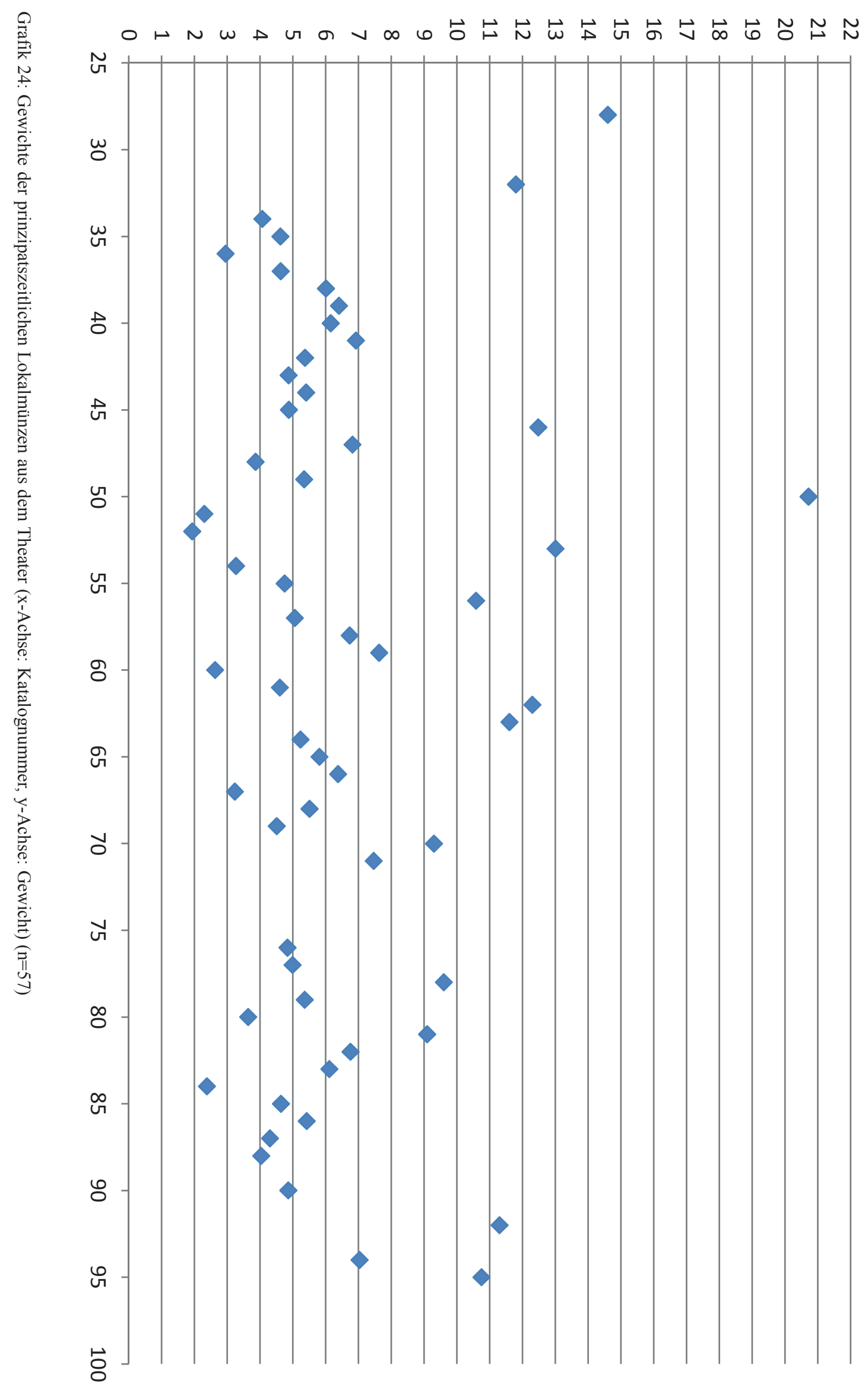


Präsenz von Neokorie-Prägungen und solchen mit Nennung der $\pi \rho \omega \hat{\omega} \tau \varepsilon 1 \alpha$ auf. So entfallen von den 25 mit einiger Sicherheit lesbaren Reverslegenden neun Stück auf Neokorie- und fünf Stück auf $\pi \rho \omega \hat{\tau} \varepsilon ı \alpha$-Legenden. Der Hintergrund für die relativ starke Präsenz dieser Münztypen hängt bekanntermaßen mit den anhaltenden Streitigkeiten der Städte Pergamon, Smyrna und Ephesos zusammen. Obwohl Antoninus Pius die Titulaturen und die Ränge der rivalisierenden Städte festgelegt hatte, mussten die Kaiser nach ihm ständig in die Zwiste eingreifen, um die Rangordnung erneut $\mathrm{zu}$ regeln ${ }^{16}$. Im Zusammenhang damit stehen die verschiedenen Homonoia-Prägungen mit unterschiedlichen Konstellationen sowie Münztypen mit der Nennung der jeweiligen Neokorien und der $\pi \rho \omega \epsilon \tau 1 \alpha$. Besonders nach Macrinus, der den ersten Rang an Ephesos verlieh, scheinen die Zwiste erneut entbrannt zu sein, was möglicherweise mit verstärkter Emission einschlägiger Münztypen einher ging ${ }^{17}$. So verwundert es auch nicht, dass gerade von den elf vorliegenden Stücken der Zeit von Antoninus IV. und Severus Alexander neun Stück auf solche Prägungen entfallen. Von Antoninus IV. weist die Mehrzahl der Münzen den Titel der vierten Neokorie auf (M 58. M 59 Taf. 356; M 60. M 62 Taf. 357), welche offensichtlich unter Severus Alexander unter Einflussnahme einer römischen Gesandtschaft aufgrund der damnatio memoriae Elagabals wieder rückgängig gemacht werden sollte. Dass die Stadt dem nicht entsprochen hat, ersieht man zunächst aus der weiterführenden Nennung dieser Zählung auf den Münzen Alexanders (M 68 Taf. 357). Auf den späteren Stücken sind dann nur mehr drei Neokorien genannt, aber unter Gallienus hat die Stadt ihre vierte Neokorie wieder zurückerlangt. Daher sind unter diesem Kaiser die dritte und die vierte Neokorie auf den Münzen belegt (M 73 Taf. 357: unsichere Lesung).

\subsubsection{Cistophoren-Prägungen}

Die zwölf vorliegenden Cistophore bilden einen Anteil von $5 \%$ des Gesamtbestands aus dem Theater, also eine relativ große Menge in Anbetracht der Tatsache, dass es sich hierbei aufgrund des hohen materiellen Werts dieser Stücke wohl nicht um Geld zur Deckung des täglichen Bedarfs handelt. Die Münzen stammen alle aus dem Bereich des Süd-AnalemmaundwurdenimZugederKampagnen der 1990erJahrewährend derAufräumungsarbeiten im Bereich des vomitorium ES1 aufgefunden. Die Zusammensetzung des Bestands ist relativ homogen, sodass die Annahme von einem verstreuten Hort nicht ganz von der Hand zu weisen ist. Die Münzen wurden alle zwischen 1993 und 1998 im Bereich des vomitorium ES1 im Schutt aufgefunden und stammen höchstwahrscheinlich aus der benachbarten Insula südlich des Theaters, aus der im Zuge der Aufräumarbeiten infolge der Erdbebenzerstörungen große Schuttmengen auf der Freitreppe deponiert worden waren ${ }^{18}$.

Sehen wir uns die Münzen und deren Streuung nun etwas genauer an, fällt auf, dass sie - abgesehen von zwei claudischen Stücken - zwischen Nerva und Hadrianus kontinuierlich zunehmen, und dass sich darunter ein vergleichsweise hoher Anteil an überprägten Münzen befindet (Tab. 99). Zudem sind zwei Typen belegt, die nach den Referenzwerken äußerst seltene Typen darstellen (M 26. M 29 Taf. 355). Bei den vorliegenden Cistophoren Hadrians handelt es sich ausnahmslos um Überprägungen. Die Cistophoren-Prägung unter Nerva und Trajan, die in einer sehr kurzen Zeitspanne zwischen 97 und 98 n. Chr. erfolgte, unterscheidet sich strukturell gravierend von jener unter Hadrian.

An dieser Stelle sollen nun einzelne Stücke aus dem erwähnten Komplex noch einmal genauer vorgestellt werden. Ich beziehe mich dabei in erster Linie auf das Referenzwerk von W. E. Metcalf zu Hadrian sowie auf die jüngsten und grundlegenden Forschungen von B. Woytek zu den Cistophoren Nervas und Trajans. Woytek hat nachgewiesen, dass die Prägung der Cistophore unter Nerva und Trajan in Bezug zur Reichsprägung standen und in der zentralen Prägeanstalt in Rom erfolgte ${ }^{19}$. Erstmals wurde von ihm auch eine fundierte metrologische Untersuchung durchgeführt, welche als Münzfuß für die Cistophore unter Nerva und Trajan exakt 1/96 des römischen Pfunds und somit ein errechnetes Gewicht von 10,22 g ergab. Demzufolge waren Cistophore gegenüber dem Denar um $15 \%$ überbewertet ${ }^{20}$. Sie wurden offenbar zielge-

\footnotetext{
${ }^{16}$ KLOSE 1987, 51-53; s. auch KarWIESE 1995b, $121 \mathrm{f}$.

${ }^{17}$ Selbstverständlich kann hier keine Untersuchung der Prägefrequenzen vorgenommen werden, was methodisch unvereinbar wäre.

${ }^{18}$ Kap. 5.2.6.

${ }^{19}$ WOYTEK 2010, 96-98.

${ }^{20}$ Wоутек 2010, 107-110. Ich danke an dieser Stelle B. Woytek sehr herzlich für seine hilfreichen Hinweise betreffend die Cistophoren-Prägung zwischen Nerva und Hadrian.
} 


\begin{tabular}{|c|c|c|c|c|}
\hline KatNr. & FundNr. & Prägeherr & Gewicht & Technicum \\
\hline 22 & $6 / 1993$ & \multirow[t]{2}{*}{ Claudius I. } & 9,6 & \\
\hline 23 & $10 / 1993$ & & 10 & \\
\hline 24 & IV/1997 & \multirow[t]{2}{*}{ Nerva } & 9,31 & \\
\hline 25 & V/1997 & & 8,35 & \\
\hline 26 & $12 / 1998$ & \multirow[t]{3}{*}{ Traian } & 8,94 & \\
\hline 27 & III/1997 & & 9,01 & \\
\hline 28 & II/1997 & & 8,37 & \\
\hline 29 & VI/1997 & \multirow[t]{5}{*}{ Hadrian } & 10,26 & Überprägung \\
\hline 30 & VII/1997 & & 9,57 & Überprägung \\
\hline 31 & VIII/1997 & & 10,19 & Km, Überprägung \\
\hline 32 & $5 / 1993$ & & 9,53 & Überprägung, unbelegter Typ \\
\hline 33 & 8a/1993 & & 9,58 & Überprägung \\
\hline
\end{tabular}

Tab. 99: Die Cistophore aus dem Schutt der Stiegengasse im Süden des Theaters

richtet für die Zirkulation in Westkleinasien produziert. Unter Hadrian ist die Typenvielfalt der Cistophore ungleich größer - unter Nerva und Trajan sind nur fünf unterschiedliche Reverse belegt -, sodass schon W. E. Metcalf für Hadrian von mehreren Produktionsstätten in Kleinasien ausging. Demzufolge stammen von den fünf hadrianischen Cistophoren zwei Stück aus Hierapolis Phrygiae und jeweils eines aus Ephesos und Laodicea Phrygiae. An einem Stück konnte die Münzstätte nicht eruiert werden, da es sich um einen bislang unbekannten Typ handelt (M 32 Taf. 355). Weiters identifizierte Metcalf ca. 80 bis $90 \%$ des von ihm bearbeiteten und damals bekannten Materials sicher als Überprägungen älterer Stücke, vorrangig von Augustus und Marc Anton. Deshalb nimmt es auch nicht Wunder, dass die in unserem Komplex enthaltenen hadrianischen Cistophore ausnahmslos Überprägungen darstellen.

Der trajanische Cistophor M 26 (Taf. 355) mit dem Tempel des Commune Asiae kommt in der vorliegenden Form im Standardzitierwerk (RIC) nicht vor. B. Woytek kennt acht Exemplare desselben Typs (Typ 4), wobei nur an zwei Exemplaren ein Band des Lorbeerkranzes am Porträt im Nacken herabhängt, das andere über die Halsbeuge nach vorne geführt ist. Wir haben es also mit einem äußerst seltenen Belegstück zu tun. Das bei Woytek zitierte Stück hat denselben Aversstempel wie unser Exemplar ${ }^{21}$. Dieser weist an dem zitierten Stück bereits im Bereich des Lorbeerkranzes, der Wange und des Halsausschnitts fehlerhafte Bereiche infolge von Stempelabnutzung auf. An unserem Stück zeigt sich die weitere Abnutzung des Stempels: Das Porträt ist bereits durchgehend vom Lorbeerkranz bis zu den Wangenknochen beschädigt. Hinzu kommt ein Schrötlingsfehler bzw. eine Blase, die sich beim Prägevorgang im Bereich der unteren Wangenpartie gebildet hat.

Das hadrianische Stück M 29 (Taf. 355) mit der Averslegende HADRIANVS AVGVSTVS P P und der Abbildung der Artemis Leukophryene auf dem Revers entspricht dem Typ 21 bei W. E. Metcalf, der diese Prägungen der Münzstätte Ephesos zuweist. Im Standardzitierwerk RIC ist diese Münze noch nicht belegt. Von den 105 im Jahre 1980 bekannten Cistophoren Hadrians, die Metcalf Ephesos zuschreibt, identifizierte er 88 Exemplare als Überprägungen, das sind nahezu $90 \%$. Das einzige ihm bekannte Exemplar des Typs 21 wies er als Überprägung eines Cistophors des Marc Anton aus. Ein stempelgleiches Stück kam in einer Münzauktion vor ${ }^{22}$. Ob dieses Stück eine Überprägung einer älteren Münze ist, kann nicht mehr verifiziert werden. An unserer Münze sind jedenfalls am Revers deutlich Spuren des Untergepräges erkennbar: Die Krone der Artemis ragt in den Bildrand des Untergepräges hinein.

\footnotetext{
${ }^{21}$ Auktion der CNG 57 vom 4.4.2001, Nr. 1210.
}

${ }^{22}$ Künker-Auktion 71, vom 12.3.2002, Nr. 853. 
Um eine Überprägung handelt es sich auch bei der Münze M 30 (Taf. 355). Metcalf schreibt diesen Typ Laodicea ad Lycum Phrygiae zu. Ihm waren zwei Exemplare bekannt, die beide als Überprägungen ausgewiesen wurden. Inzwischen sind zahlreiche weitere Stücke dieses Typs mit augusteischem Untergepräge bekannt. An unserem Stück erkennt man am Revers deutlich zwei wellenförmige Linien im Bereich der Standlinie der Jupiter-Figur. Diese könnten möglicherweise die Bänder des girlandengeschmückten Altars des bekannten augusteischen Cistophoren-Typs $\operatorname{sein}^{23}$.

Auch der Cistophor M 31 (Taf. 355) des Hadrian lässt sich als Überprägung identifizieren. Es handelt sich um den Typ 53 mit Apollo Citharoedus auf dem Revers, den W. E. Metcalf Hierapolis Phrygiae zuweist ${ }^{24}$. Metcalf kannte zum damaligen Zeitpunkt 21 Exemplare dieses Typs aus insgesamt 16 Avers- und 20 Reversstempeln. Zudem identifizierte er fast alle bekannten Stücke als Überprägungen, wobei der Großteil auf augusteische Untergepräge entfällt. Spuren des Untergepräges lassen sich am Avers vor dem Kinn des Porträts feststellen. Dabei sind die Spitzen der Ähren des augusteischen Typs mit sechs Ähren relativ gut sichtbar. Wir haben es also mit einer Avers-Revers- und Revers-Avers-Überprägung zu tun. Auf dem Revers lassen sich im linken Feld Reste der Legende IMP CAESAR erkennen, außerdem springt der geperlte Bildrand des Untergepräges ein wenig hervor, erkennbar an dem Knick links von der Standlinie der Figur. Auf dem Revers kann man außerdem noch deutlich eine Kontermarke des Vespasianus erkennen. Augusteische Cistophore des Ährentyps treten häufig mit vespasianischen Gegenstempeln auf. Auch hadrianische Überprägungen von in flavischer Zeit kontermarkierten augusteischen Cistophoren sind nicht selten ${ }^{25}$. Das vorliegende Stück weist jene bei C. J. Howgego unter der Nummer 840 auffindbare Kontermarke IMP VESP AVG auf, wobei das IMP, das VE und das AV jeweils in Ligatur ausgeführt sind. Dieser Gegenstempel findet sich häufig auf Cistophoren von Augustus, Marc Anton und Claudius. Er wurde zwischen 74 und 79 n. Chr. in Ephesos angebracht ${ }^{26}$. Das Stück hatte somit eine wechselvolle Geschichte. Es wurde unter Augustus in Ephesos produziert und blieb dann offenbar bis in die flavische Zeit vor Ort im Umlauf. Unter Vespasian wurde es hier zwischen 74 und $79 \mathrm{n}$. Chr. kontermarkiert und kam dann noch vor $128 \mathrm{n}$. Chr. nach Hierapolis. Dort wurde es neu beprägt und gelangte daraufhin wieder nach Ephesos, wo es vermutlich bis zum Erdbeben des 3. Jhs. n. Chr. in Verwendung war oder thesauriert wurde.

Ein bislang unbelegter Typ liegt mit der Münze M 32 (Taf. 355) vor. Auch hier handelt es sich wiederum um eine Überprägung. Auf dem Avers ist im rechten Feld der Rest des geperlten Bildrands des Untergepräges erkennbar, der in die Umschrift hineinläuft; auf dem Revers sind in dem Bereich zwischen dem Oberkörper der sitzenden Figur und der Legende COS Strukturen sichtbar, die zum Untergepräge gehören könnten. Der Aversstempel dieses Stücks weist schon sehr schlechte Qualität infolge von Abnutzung auf. Am Reversstempel fällt auf den ersten Blick die schlechte Erhaltung der Legende gegenüber der noch relativ unbeschädigten sitzenden Jupiterfigur auf. Der Bildtyp des nach links sitzenden Jupiter mit Patera und Szepter und einem Adler im rechten Feld zur Umschrift COS - III ist nicht belegt. Jupiter hält auf den Cistophoren Hadrians in der Regel eine Victoriola oder eine Statuette der Artemis. Der Adler hinter dem Thron tritt in der Form nicht auf. Die Typen 13 bis 15 bei W. E. Metcalf zeigen den sitzenden Jupiter nach links mit einer ArtemisStatuette, wobei kein Adler abgebildet ist und in der Legende IOVIS OLYMPIVS mit EPHESI oder EPHESIO auftritt. Die Typen 29 und 30 kommen unserem Stück schon näher. Zur Legende COS - III tritt der sitzende Jupiter zwar wieder mit einer Artemis- oder Victoria-Statuette und Szepter auf, davor sitzt im linken Feld ein Adler. Denkbar wäre, dass ein Stempel des Jupiter-Typus 29 oder 30 nachgeschnitten wurde, wobei die Statuette durch eine Patera ersetzt und der am Ursprungsstempel nicht mehr erkennbare Adler im rechten Feld hinter dem Thron hinzugefügt wurde. Dass der Adler im Nachhinein angebracht wurde, lässt sich daran erkennen, dass das Szepter in dessen rechten Flügel hineinläuft. Auch am Thron dürfte eine geringfügige Umarbeitung stattgefunden haben: Er weist eine rechteckige Verzierung an der Seite auf. Diese Hypothese, dass der Stempel umgeschnitten wurde, muss allerdings im Raum stehen bleiben, da zur Verifizierung eine fundierte Stempeluntersuchung durchgeführt werden müsste, denn gerade in den letzten Jahrzehnten sind zahlreiche neue Stempel hinzugekommen.

\footnotetext{
${ }^{23}$ RIC 479. 482 .

${ }^{24}$ Metcalf 1980, 66.

${ }^{25}$ Vgl. beispielsweise Metcalf 1980, Nr. 76a.

${ }^{26}$ THIRION 1963.
} 


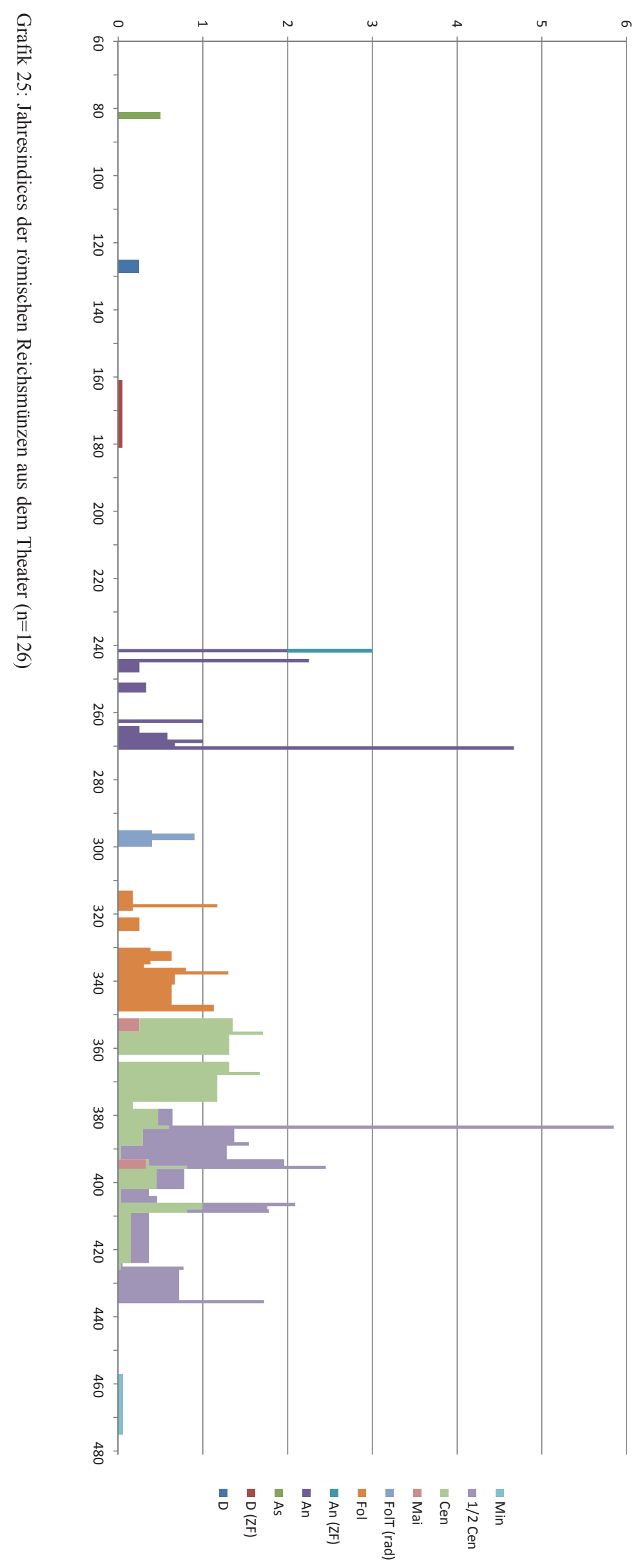


Bei dem Stück M 33 (Taf. 355) mit dem phrygischen Gott Men auf dem Revers dürfte es sich ebenfalls um eine Überprägung handeln. Auf der Vorderseite ist vor dem Porträt Hadrians der Schatten des Porträts des Untergepräges, vermutlich ein augusteischer Cistophor, sichtbar. Metcalf kannte ein Exemplar dieses Typs, der als Überprägung eines augusteischen Altar-Typs ${ }^{27}$ ausgewiesen ist.

\subsubsection{Römische Reichsprägungen (GrafiK 25)}

Der größte Teil der antiken Fundmünzen aus dem Theater entfällt mit nicht ganz $50 \%$ auf römische Reichsmünzen, ist also nicht in derselben Intensität vertreten wie beispielsweise im Hanghaus 1 (Grafik 26), in der Basilika (Grafik 27), der spätantiken Residenz in den Verulanushallen (Grafik 28) oder dem Domitianstempel, wo sich ein Prozentsatz um die 60 einstellt ${ }^{28}$. Die Münzreihe der römischen Reichsprägung setzt - abgesehen von drei Stücken aus dem 1. und dem 2. Jh. n. Chr. - mit Gordianus III. ein, erreicht aber erst im 4. Jh. n. Chr. ein kompaktes Gefüge. Dass die Reichsprägung erst im 3. Jh. n. Chr. einsetzt, ist auch an anderen Fundorten evident und geht - wie erwähnt - einher mit dem Rückgang der lokalen Prägung.

\section{Prägungen des 3. Jhs. n. Chr.}

Das 3. Jh. n. Chr. weist auf den ersten Blick nur geringe Geschlossenheit auf. Es setzt zwar mit Münzen des Gordianus III. relativ stark ein, geht jedoch in der Folgezeit wieder deutlich zurück, um erst wieder mit Gallienus und Claudius II. sowie der ersten Emission Aurelians (DIVO CLAVDIO-Prägungen) deutlich zuzunehmen. Zwischen Gordianus III. und Gallienus sind noch städtische Lokalprägungen präsent, woraus sich das niedrige Fundniveau der Reichsmünzen erklärt. Dieselbe Evidenz manifestiert sich im Bestand der Basilika am Staatsmarkt (Grafik 27), wo die Münzkurve zwischen 240 und 260 n. Chr. sehr unzusammenhängend ist. Zählt man aber auch hier die Lokalprägungen hinzu, ergibt sich tendenziell dasselbe Bild, obwohl die Zeit vor 260 n. Chr., wie überhaupt das 3. Jh. n. Chr., hier sehr spärlich belegt ist. Eine bessere Materialgrundlage liefert der Münzbestand von Hanghaus 1 (Grafik 26), wo das 3. Jh. n. Chr. relativ stark vertreten ist und sich in der Reichsmünzkurve ab $260 \mathrm{n}$. Chr. in regelmäßigem Anstieg niederschlägt. Für die Zeit vor $260 \mathrm{n}$. Chr. wird das Zirkulationsvolumen einigermaßen durch Lokalprägungen ergänzt. Anders als im Theater steigt die Münzkurve jedoch ab 260 n. Chr. stark an, was für eine Nutzung nach dem Erdbeben spricht ${ }^{29}$. Wir können also generell bei Hanghaus 1 eine schwache Zäsur ausmachen, die im Theater in dieser Form nicht auftritt. Ziehen wir nun auch den Bestand in der spätantiken Residenz in den Verulanushallen hinzu (Grafik 28), zeigt sich auch hier relativ klar, dass vor $260 \mathrm{n}$. Chr. das Zirkulationsvolumen hauptsächlich aus Lokalprägungen bestand, wenn auch die Anzahl von Münzen der Zeit vor 200 n. Chr. hier naturgemäß sehr gering ist. Der Großteil des Fundmaterials entfällt auf römische Reichsprägungen zwischen 335 und $425 \mathrm{n}$. Chr.

Sehen wir uns nun den Verlauf der Münzkurve des Theaters im 3. Jh. n. Chr. an (Grafik 25), zeigt sich ab 260 n. Chr. ein kontinuierlicher Anstieg und mit DIVO CLAVDIO-Prägungen ein Spitzenwert in der Grafik. Nach $270 \mathrm{n}$. Chr. bricht sie dann völlig ab und setzt erst wieder mit Prägungen der ersten Tetrarchie ein. Es stellt sich nun einerseits die Frage nach der Intensität des Münzverkehrs im 3. Jh. n. Chr., d. h. nach dem Umfang des Zirkulationsvolumens, und andererseits, ob das Abreißen der Münzkurve mit Prägungen des Jahrs $270 \mathrm{n}$. Chr. vor dem allgemeinen Hintergrund der historischen Stadtentwicklung zu beurteilen ist oder mit den Vorgängen im Theater zu tun hat. Die Frage nach dem Zirkulationsvolumen kann recht eindeutig beantwortet werden, wenn man sich beispielsweise die Fundbestände westlicher Städte ansieht, wo das 3. Jh. n. Chr. zahlenmäßig viel stärker vertreten ist als in Ephesos ${ }^{30}$. Dies erklärt sich aus der geldwirtschaftlichen Entwicklung, da sich in den Fundkurven der meisten westlichen Städte zwischen 264 und

\footnotetext{
${ }^{27}$ RIC 479. 482.

${ }^{28}$ Die Bestände der spätantiken Residenz in den Verulanushallen und des Domitianstempels wurden im Zuge der Grabungskampagnen 2011 bis 2013 bestimmt und sind noch unpubliziert. Der Bestand der Grabungskampagne 2011 bis 2013 aus dem spätantiken Gebäude in den Verulanushallen umfasst in Summe 2354 antike und byzantinische Münzen, jener aus dem Domitianstempel 95 Stück. Ich danke S. Ladstätter für ihr Entgegenkommen, die Ergebnisse hier bereits zu Vergleichszwecken heranziehen zu dürfen.

${ }^{29}$ Zur Datierung des Erdbebens: KARWIESE 1995b, 122-125; KARWIESE 1985.

${ }^{30}$ Vondrovec 2007 (Carnuntum); Schachinger 2006, 108-119 (Flavia Solva); Kos 1986, 92-111 (Slowenien).
} 

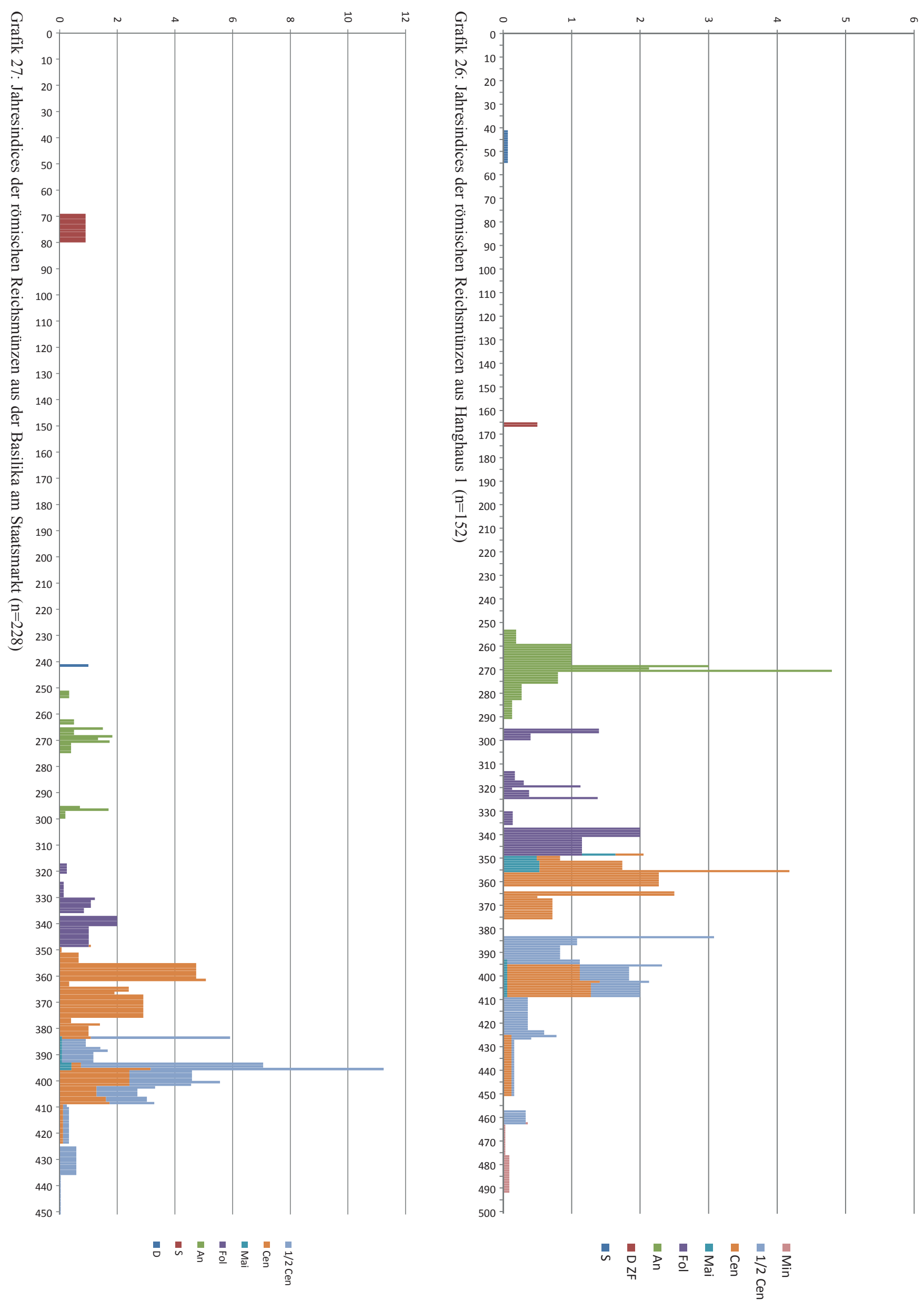


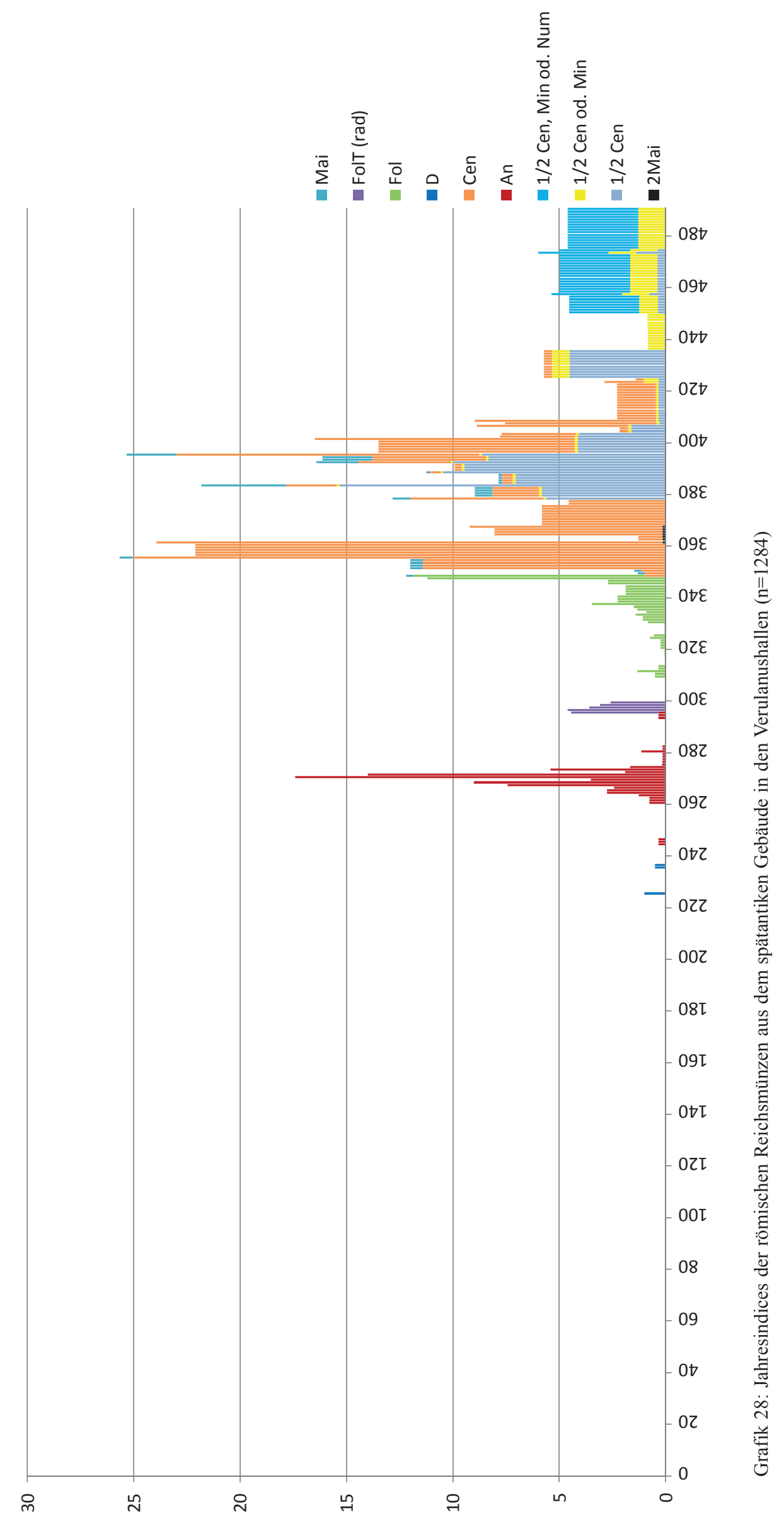


270 n. Chr. die Massenemissionen der Inflationsperiode niederschlagen. Wir haben also in Ephesos andere historische Rahmenbedingungen (Goteninvasionen), die einen Nachschub von Münzen im 3. Jh. n. Chr. eindämmten, sowie naturgegebene Faktoren (Erdbeben), die die Frequenzkurve beeinflussten. Das Fundniveau in Ephesos ist also im 3. Jh. n. Chr. grundsätzlich niedriger als im Westen. Für die Beantwortung der Frage nach dem Abreißen der Münzkurve um 270 n. Chr. müssen vergleichbare Fundbestände angeführt werden.

In Hanghaus 1 geht die Münzreihe von 260 bis 282 n. Chr. durch, wobei sie einen Spitzenwert mit Inflationsmünzen des Jahrs $270 \mathrm{n}$. Chr. erreicht und dann infolge der aurelianischen Münzreformen wieder abnimmt, ein Phänomen, das in dieser Form regelmäßig in den westlichen Städten auftritt. Der zwar zahlenmäßig geringe Bestand der Basilika am Staatsmarkt beinhaltet ebenfalls die starken Emissionen der Prägejahre zwischen 264 und $270 \mathrm{n}$. Chr., bricht dann aber mit gallischen Inflationsantoninianen der 270er Jahre ab. Ein Abbrechen der Münzreihe mit dem Ende der Regierungszeit des Claudius II. kann auch im Vediusgymnasium beobachtet werden; hier reicht die Zäsur, wie beim Theater, bis in die erste Tetrarchie ${ }^{31}$. Ein ähnlicher Verlauf zeigt sich am Münzspektrum der spätantiken Residenz in den Verulanushallen, wo die Inflationsperiode des 3. Jhs. n. Chr. relativ stark präsent ist. Nach DIVO CLAVDIO-Prägungen bzw. nach Tetricus I. scheint sich eine Zäsur in der Versorgung mit Reichsgeld abzuzeichnen - wenn man von den beiden Belegstücken des Probus absieht. Die Münzreihe setzt danach erst wieder mit Folles-Teilstücken (radiati) der Prägephase 295/299 n. Chr. ein. Wir können also mit einiger Vorsicht in vielen Fundkomplexen eine Zäsur zwischen 270/274 und ca. 295 n. Chr. feststellen. Diese erklärt sich wohl mit den Zerstörungen durch das Erdbeben und den Aufräumund Umbauarbeiten an zahlreichen Gebäuden in der Stadt. Gerade im Theater sind an vielen Stellen massive Einstürze belegt, die größere Restaurationen nach sich gezogen haben.

\section{,Follis-Perioder}

Die Münzreihe setzt nach dem Abreißen um 270 n. Chr. erst wieder mit Follis-Teilstücken (radiati) des Diocletianus (M 125 Taf. 358) und Maximianus I. (M 126. M 127 Taf. 358) der Periode 295/299 n. Chr. ein (Grafik 25). Die Emissionen der CONCORDIA MILITVM-Prägungen sind auch in dem spätantiken Gebäude in den Verulanushallen mit insgesamt 18 Stück relativ stark vertreten (Grafik 28). Der Großteil dieser Stücke stammt aus der Münzstätte Cyzicus, die restlichen kommen aus Heraclea. Auch im Bestand der Basilika und des Hanghauses 1 sind diese Typen vertreten. Vollgewichtige Folles der Tetrarchie sind an keiner der genannten Fundstellen belegt. Die Münzkurve weist danach wieder eine Zäsur bis etwa $320 \mathrm{n}$. Chr. auf. Im Theater beginnt sie mit bereits gewichtsreduzierten IOVI CONSERVATORI-Prägungen des Licinius und nimmt erst mit GLORIA EXERCITVS-Typen mit einem Feldzeichen, Roma- und Constantinopolis-Prägungen ab 330/335 n. Chr. wieder kompaktere Formen an. Die Münzen Konstantins und seiner Söhne sind vor der Reform von 348 n. Chr. gleichmäßig mit allen Haupttypen vertreten. Dazu gehören der Lagertor-Typ (316/328 n. Chr.), GLORIA EXERCITVS-Prägungen mit einem Feldzeichen (337/340 n. Chr.) und der östliche Haupttyp der VOT XX MVLT XXX-Münzen (341/348 n. Chr.) wie auch die beiden Divus Constantinus-Typen (Quadriga $337 / 340$ n. Chr. und VN-MR 341/348 n. Chr.) ${ }^{32}$. Der westliche VICTORIAE DD AVGQNN-Typ ist in einem Exemplar der Münzstätte Thessalonica vertreten. In Summe ist das Fundniveau der konstantinischen Zeit jedoch deutlich geringer als jenes der Postreformperiode. Noch deutlicher zeigt sich diese Evidenz am Fundbestand des spätantiken Gebäudes in den Verulanushallen (Grafik 28), wo die Typenvielfalt und die Stückzahl der Prägungen vor 348 n. Chr. verhältnismäßig gering sind; die Münzkurve steigt hier massiv mit Reitersturz-Typen ab $351 \mathrm{n}$. Chr. an, ähnlich wie in der Basilika (Grafik 27), wo zunächst ein Zuwachs mit GLORIA EXERCITVS-Typen mit zwei Feldzeichen (330/336 n. Chr.) zu verzeichnen ist. Ein stärkerer Zuwachs zeichnet sich dann auch hier mit Reitersturz-Prägungen ab $351 \mathrm{n}$. Chr. ab. Aus dem Hanghaus 1 wiederum liegen vor 337 n. Chr. nur wenige Funde vor (Grafik 26), das Niveau steigt markant mit DIVO CONSTANTINO-Quadriga- und GLORIA EXERCITVS-Typen mit einem Feldzeichen an, um gleichmäßig mit VOT XX MVLT XXX- und Reitersturz-Typen anzuschließen. Aus der Verteilung der Frequenzkurve der besprochenen Fundkomplexe lassen sich also zwei unterschiedliche Muster differenzieren. Wir haben auf der einen Seite ein niedriges Niveau vor der Reform von $348 \mathrm{n}$. Chr. und einen starken Anstieg mit Reitersturz-

\footnotetext{
${ }^{31}$ Pfisterer 2008.

${ }^{32}$ Zur Datierungsfrage hat sich auch Schindel 2009, 181 geäußert.
} 
Typen ab 351 n. Chr. (spätantike Residenz in den Verulanushallen, Basilika) und auf der anderen Seite ein relativ gleichmäßiges Niveau bzw. nur geringen Zuwachs zwischen der Periode 337/348 n. Chr. und dem Übergang zur \Postreform-Periode〈 (Theater, Hanghaus 1). Für das Theater bedeutet dies, dass die kontinuierlich verlaufende Münzkurve mit einer durchgehenden Nutzung im 4. Jh. n. Chr. korreliert. Zusammenfassend kann für die Follis-Periode festgehalten werden, dass das Fundniveau nach einem punktuellen Auftreten von Follis-Teilstücken der Periode 295/299 n. Chr. ab 330 n. Chr. kontinuierlich und ohne Unterbrechungen bis zur Reform von $348 \mathrm{n}$. Chr. ansteigt und auch darüber hinaus keine Unregelmäßigkeiten aufweist.

\section{,Postreform-Perioder bis 395 n. Chr.}

Nach 348 n. Chr. setzt sich die Münzkurve des Theaters in geringem, aber kontinuierlichem Anstieg fort und weist für die 2. Hälfte des 4. Jhs. n. Chr. ein sehr geschlossenes Bild auf (Grafik 25). Es zeichnet sich ein deutlicher Schwerpunkt in dieser Periode ab. Zudem sind alle Nominalien des Nahverkehrs vertreten.

Auffällig ist allein die Tatsache, dass aus der Periode 348/350 n. Chr. keine Münzen vorliegen, ein Phänomen, das sich auch im Bestand der spätantiken Residenz in den Verulanushallen (Grafik 28) und der Basilika am Staatsmarkt (Grafik 27) abzeichnet. Im Bestand der Verulanushallen und der Basilika kommen darüber hinaus überhaupt keine Maiorinen der früheren Prägeperiode von 348/355 n. Chr. vor. Dies hatte aber keinen unmittelbaren Einfluss auf das Zirkulationsvolumen jener Jahre, da die Münzen der konstantinischen Zeit weiterliefen. Der Münzbestand der 2. Hälfte des 4. Jhs. n. Chr. nimmt im Theater gegenüber der vorangehenden Periode zu und setzt sich vor allem aus Centenionales des Reitersturz- und des SPES REIPVBLICE-Typs zusammen ${ }^{33}$. Die Prägeperioden 351/355 und 355/361 n. Chr. sind etwa gleich stark vertreten, allerdings ist zu bedenken, dass ein Großteil der Reitersturz-Prägungen nicht mehr exakt datiert werden kann. Die Reitersturz-Typen sind in der doppelten Menge vertreten wie die SPES REIPVBLICEPrägungen. Dieser Befund zeigt sich auch in der spätantiken Residenz in den Verulanushallen und der Basilika am Staatsmarkt, wo - wie erwähnt - das Fundniveau in der Periode 351/361 n. Chr. stark ansteigt. In der Basilika ist aber die Periode 355/361 n. Chr. ungleich massiver vertreten. Das Spektrum von Hanghaus 1 weicht ein wenig von den genannten Befunden ab (Grafik 26): Reitersturz- und SPES REIPVBLICE-Typen sind hier in annähernd gleicher Intensität präsent, wobei sich die Periode 355/361 n. Chr. stärker niederschlägt. Hinzu kommen noch Reitersturz-Maiorinen, die die Prägeperiode 348/355 n. Chr. ergänzen.

Nach 361 n. Chr. zeigt sich ein kleiner Hiat im Münzspektrum des Theaters, was sich aus der fehlenden Präsenz von Prägungen des Iulianus III. erklärt. Dies mag ein wenig verwundern, wenn man bedenkt, dass dieser Kaiser Antiochia als seinen Ausgangspunkt für die Perserfeldzüge gewählt hatte, und sich die Mobilmachung von Truppenreserven im Osten des Reichs abspielte. Es stellt sich überhaupt die Frage, ob Münzen des Iulianus III. als Augustus einen Niederschlag im Spektrum von Ephesos gefunden haben oder nur im Theater fehlen; Prägungen seiner Caesarenschaft sind ja allerorts zahlreich vertreten. Von dem spätantiken Gebäude in den Verulanushallen sind zwei Stücke des VOT X MVLT XX-Typs belegt, von der Basilika, der Kuretenstraße und dem Hanghaus 1 ist kein Stück von Iulianus III. als Augustus vorhanden. Man könnte also annehmen, dass der Zustrom von Münzen des Iulianus III. generell schwach gewesen sein muss, was allerdings kaum einen Einfluss auf das zirkulierende Volumen gehabt hat, das sich sicher zu einem gewissen Teil aus früheren Prägungen speiste. Das Fundniveau des Theaters bleibt unter Valentinianus I. und Valens auf demselben Niveau wie unter Constantius II.; dabei verteilen sich die GLORIA ROMANORVM- und SECVRITAS REIPVBLICAE-Typen auf die Prägeperioden 364/367, 367/375 und 375/378 n. Chr. einigermaßen gleichmäßig - anders als beispielsweise auf der Kuretenstraße -, aber auch in Sardes, wo GLORIA ROMANORVM-Prägungen mehr als doppelt so stark vertreten $\operatorname{sind}^{34}$. In der Periode 378/383 n. Chr. sinkt das Fundniveau wieder etwas ab und erreicht ab $383 \mathrm{n}$. Chr. wieder seinen früheren Wert. Der geringfügige Rückgang ab 378 n. Chr. macht sich auch in Hanghaus 1, der Basilika am Staatsmarkt und der Kuretenstraße bemerkbar, ist also ebenso wie die relativ starke Präsenz von Vota-Prägungen des Gratianus ein großräumigeres Phänomen, das auch in Sardes anzutreffen ist ${ }^{35}$. Der hohe Balken in der Grafik für das Jahr $383 \mathrm{n}$.

\footnotetext{
${ }^{33}$ Obwohl der Datierungsansatz der SPES REIPVBLICE-Prägungen überdacht werden sollte, wird hier noch mit der im RIC vorgeschlagenen Datierung von 355/361 n. Chr. gearbeitet, s. auch SCHINDEL 2009, 181.

${ }^{34}$ SCHINDEL 2009, 179.

${ }^{35}$ SCHINDEL 2009, 179
} 
Chr. erklärt sich aus der Präsenz der Vota-Münzen des Gratianus, die im Katalog nach \LRBC $<$ datiert sind. Die >RIC-Datierung` verweist diese Prägungen generell in eine längere Zeitspanne, sodass sich der hohe Wert in der Grafik wieder relativiert. Über die gesamte Periode von 383 bis 395 n. Chr. erstrecken sich in gleichmäßigen Fundzahlen die in dieser Prägephase dominierenden Halbcentenionales vom Typ SALVS REIPVBLICAE, was durch die Prägepolitik der Zeit zu erklären ist, zumal diese Stücke auch andernorts die größte Menge darstellen. Nach 395 n. Chr. geht das Fundniveau des Theaters ein wenig zurück.

Zusammenfassend kann festgestellt werden, dass sich die Fundfrequenz zwischen 348 und $395 \mathrm{n}$. Chr. ohne größere Einbrüche etwa auf gleichmäßigem Niveau befindet, was für eine kontinuierliche Nutzung des Theaters spricht. Erst nach 395 n. Chr. kommt es zunächst zu einem geringfügigen Rückgang.

\section{Periode zwischen 395 und der Mitte des 5. Jhs. n. Chr.}

Nach 395 n. Chr. sinkt das Geldvolumen zwar etwas ab, bleibt jedoch bis 435 n. Chr. annähernd auf demselben Niveau, wenn man bedenkt, dass sich in der Grafik nur die Prägezeiten, nicht aber die Umlaufzeiten niederschlagen, und die Umlaufzeit länger anhielt. Es sind dabei alle Haupttypen in gleicher Intensität vertreten, lediglich der GLORIA ROMANORVM-2 Kaiser-Typ kommt etwas häufiger vor (Grafik 29). Das Spektrum unterscheidet sich in diesem Punkt ein wenig von jenem der Kuretenstraße und der spätantiken Residenz in den Verulanushallen (Grafik 28), wo der VIRTVS EXERCITI-Typ überwiegt. Im Theater ist die Prägeperiode 425/435 n. Chr. mit den gleichzeitig laufenden CONCORDIA AVG- und Kreuz in Kranz-Emissionen noch recht stark vertreten.

Kreuz in Kranz (425/435)

CONCORDIA AVG, Victoria (425/435)

GLORIA ROMANORVM, 3 Kaiser (406/408)

GLORIA ROMANORVM, 2 Kaiser (408/423)

SALVS REIPVBLICAE (395/403)

VIRTVS EXERCITI (395/401)
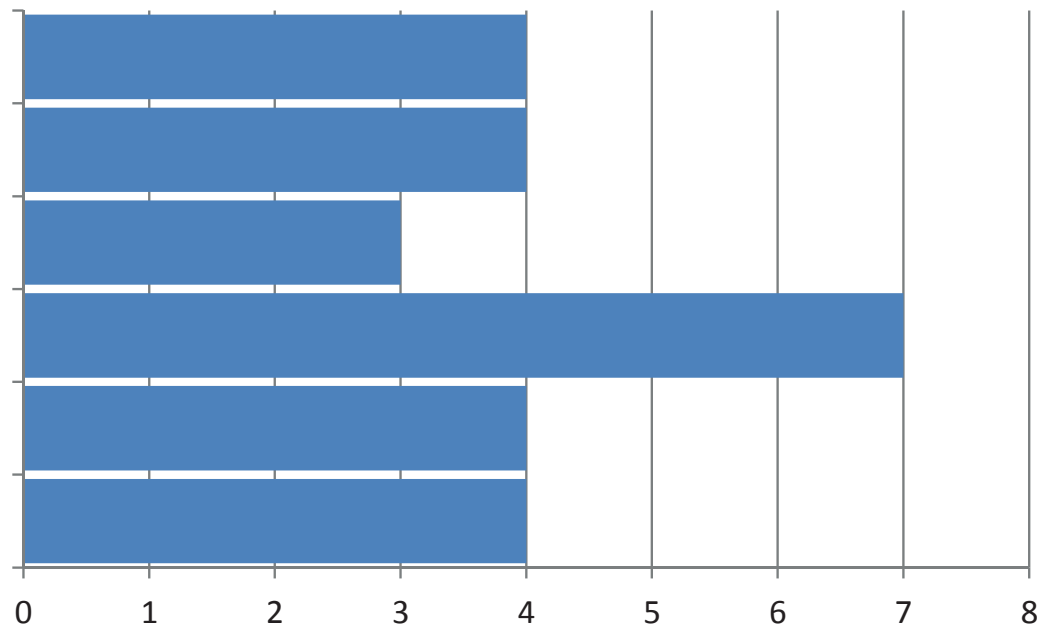

Grafik 29: Reverstypen der Periode 395/435 n. Chr. im Theater

Nach 435 n. Chr. bricht die Münzkurve ab; bis zur Regierungszeit des Anastasius I. (491/518 n. Chr.) sind lediglich zwei Minimi des Leo I. (457/474 n. Chr.) und Zeno (474/491 n. Chr.) belegt. Man könnte also für die Zeit zwischen 435 und 491 n. Chr. von einer markanten Zäsur sprechen. Allerdings ist zu bedenken, dass sich gerade in den letzten Jahren die Grabungstechniken derartig verfeinert haben, sodass die zahlreichen zutage getretenen Halbcentenionales, Minimi oder Nummi das Zirkulationsvolumen dieser Periode abdeckten. Leider ist der Großteil derselben von äußerst schlechtem Erhaltungszustand, sodass sie nicht genauer eingegrenzt werden können. In der spätantiken Residenz in den Verulanushallen beträgt der Anteil dieser nicht zuweisbaren Kleinkupferstücke sogar $40 \%$ des Gesamtbestands. Im Theater beträgt ihr Anteil immerhin $5 \%$; davon ist die Hälfte nicht mehr zuzuweisen. Auch im Hanghaus 1 ist ihre Präsenz recht hoch. Eine eindeutige Klärung des Geldverkehrs der 2. Hälfte des 5. Jhs. n. Chr. kann sich folglich erst aus einer Gesamtanalyse des ephesischen Fundspektrums ergeben. Einen ersten Ansatz hat schon N. Schindel durch die Analyse des Fundspektrums der Kuretenstraße vorgelegt, wo der Anteil an Halbcentenionales, Minimi oder Nummi vergleichsweise hoch ist ${ }^{36}$.

\footnotetext{
${ }^{36}$ SCHINDEL 2009.
} 


\subsubsection{ByZantinische MünZen}

Der byzantinische Münzbestand des Theaters beträgt $8 \%$ des Gesamtmaterials und weist in der Grafik auf den ersten Blick ein unzusammenhängendes Bild auf (Grafik 30). Die Periode von 491 bis $527 \mathrm{n}$. Chr. ist noch recht stark, allerdings nur mit kleineren Nominalien, vertreten (Minimi, Nummi, 5 Nummi-Stücke). Unter Iustinianus I. und Iustinus II. kommt es dann zu einem Rückgang im Fundspektrum, wobei hier jeweils eine 10-Nummi- und eine 40-Nummi-Prägung vorliegen. Nach $573 \mathrm{n}$. Chr. bricht die Verteilungskurve ab

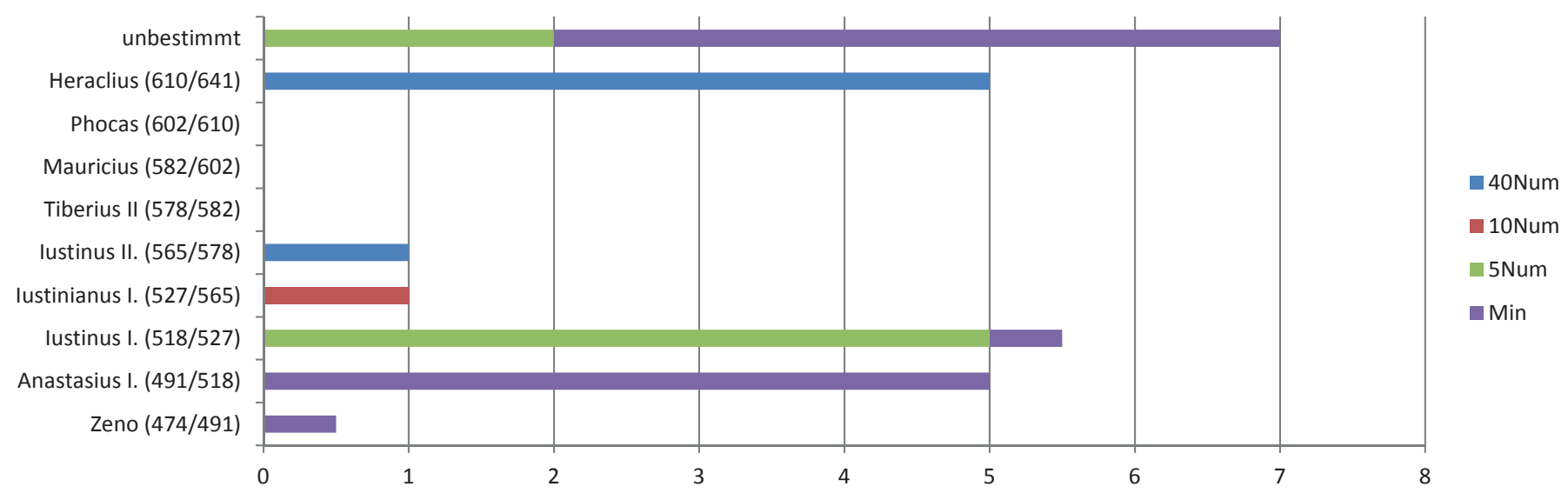

Grafik 30: Der byzantinische Fundbestand aus dem Theater $(n=25)$

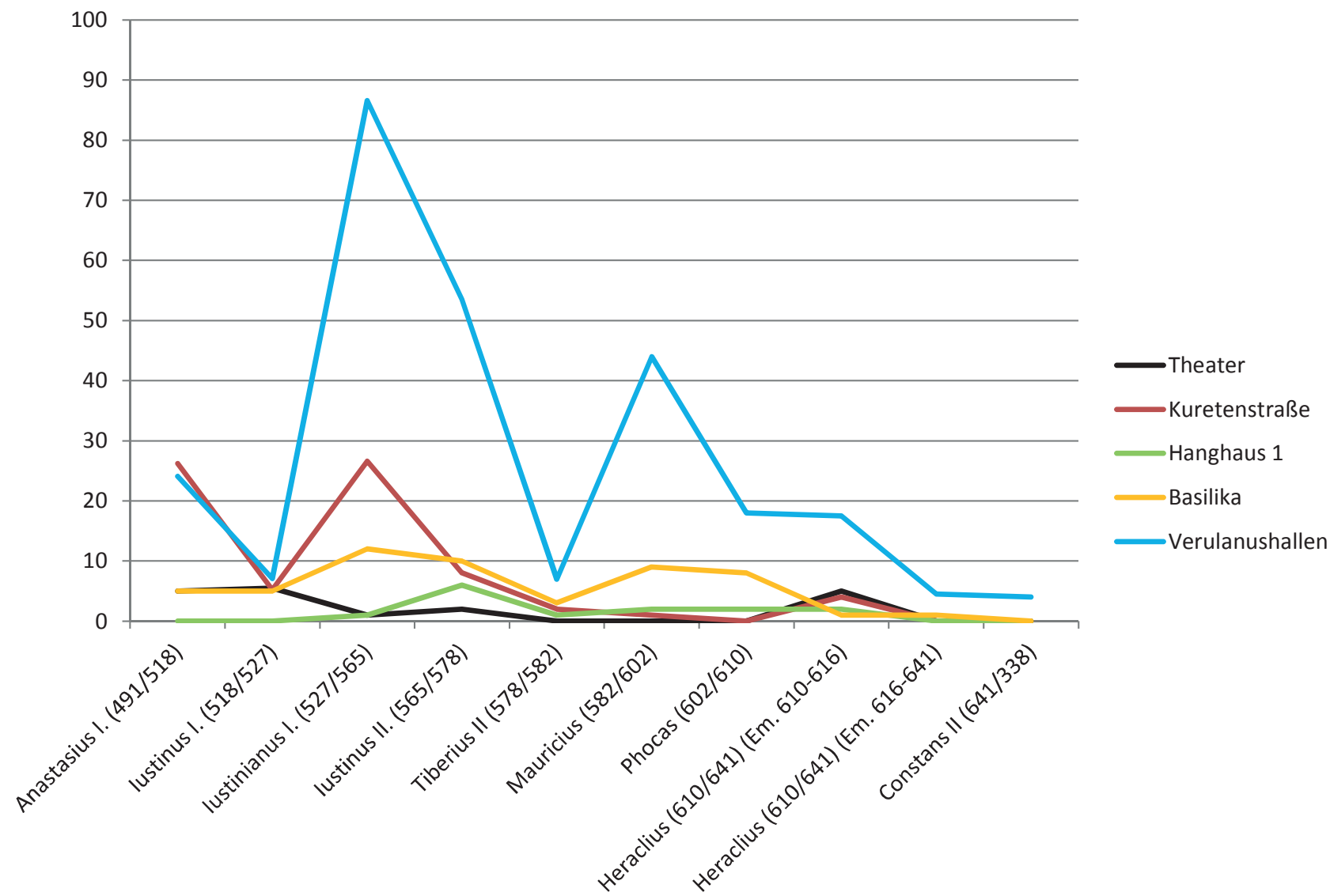

Grafik 31: Die byzantinischen Fundbestände des Theaters im Vergleich zu anderen ephesischen Fundbereichen $(n=426)$ 
und setzt erst wieder mit Heraclius ein, um danach gänzlich abzureißen. Es ergeben sich an dieser Stelle zwei Fragestellungen, die im Vergleich zu anderen ephesischen Münzspektren behandelt werden sollen. Zum einen fällt die markante Lücke zwischen Iustinus II. und Heraclius auf; die Kaiser Tiberius II., Mauricius und Phocas sind nicht belegt. Zum anderen der starke Anstieg zwischen 610 und $614 \mathrm{n}$. Chr. und das plötzliche Abreißen der Münzreihe nach $616 \mathrm{n}$. Chr.

In der Grafik sind die Fundbestände des Theaters, der Kuretenstraße, des Hanghauses 1, der Basilika und der spätantiken Residenz in den Verulanushallen im Vergleich dargestellt (Grafik 31). Dabei wurden die absoluten Fundzahlen verwendet, da ein Abbild der Jahresindices an dieser Stelle nicht notwendig erscheint. So unterschiedlich die einzelnen Linien en detail sein mögen, fallen auf den ersten Blick sofort zwei Aspekte auf, die allen Fundkomplexen gemein sind: erstens der Rückgang des Fundniveaus unter Tiberius II. und der Anstieg innerhalb der ersten sechs Regierungsjahre des Heraclius. Zweitens brechen nach Heraclius die Münzreihen aller angeführten Fundbereiche weitgehend ab, abgesehen von wenigen späteren Singulärfunden. Bezieht man die Münzkurven von Sardes, Pergamon und Antiochia in die Betrachtung mit ein, zeigt sich derselbe Abfall von Tiberius II. bis Phocas, wie schon N. Schindel ausgeführt hat ${ }^{37}$. Wenden wir uns nun den Heraclius-Münzen zu, bei denen es sich im Theater ausschließlich um 40-Nummi-Stücke der ersten sechs Regierungsjahre handelt (M 242 Taf. 359; M 243-246 Taf. 360); sie sind zudem alle als Überprägungen früherer Münzen identifiziert worden, wobei an zwei Stücken das Untergepräge festgestellt werden konnte. Bei diesen Stücken (M 242 Taf. 359; M 243 Taf. 360) handelte es sich um 40-Nummi-Prägungen des Phocas aus Constantinopolis. Beide sind jeweils Avers auf Revers und Revers auf Avers überprägt worden. Die übermäßige Präsenz von Heraclius-Überprägungen lässt letztendlich die Geschwindigkeit erahnen, mit der die Prägung in den frühen Jahren dieses Kaisers vonstatten ging. Man verzichtete offensichtlich auf den Prozess der Einschmelzung der alten Münzen, um die Produktion neuer zu beschleunigen. Alle HeracliusMünzen stammen aus dem Bereich der Kammern KN1 und KN2 sowie der oberen Terrasse D des NordAnalemma; der Großteil aus der Schicht SE N12, einer Versturzschicht, die sich mit den genannten Münzen nun genau eingrenzen lässt. Es ergibt sich für den Einsturz der Mauer ein terminus post quem von $616 \mathrm{n}$. Chr. Einen ähnlichen Befund hat schon N. Schindel für die Kuretenstraße festgestellt, wo sich die HeracliusStücke ebenfalls in einer Versturzschicht mit Brandspuren befanden. Weiters wies er nach, dass der Zustrom von Münzen nach $616 \mathrm{n}$. Chr. in Ephesos generell abriss, und stellte diese Evidenz in einen stringenten Zusammenhang mit dem Persersturm von $616 \mathrm{n}$. Chr. ${ }^{38}$.

\subsubsection{Münzstätten}

\section{Römische Reichsprägungen}

An dieser Stelle soll kurz umrissen werden, ob die Fundevidenz des Theaters mit weiteren ephesischen Komplexen hinsichtlich der Frage übereinstimmt, von welchen Münzstätten aus die Stadt in den verschiedenen Perioden versorgt worden ist, bzw. ob der Bestand des Theaters eine repräsentative Materialgrundlage liefert.

Für den relativ bescheidenen Anteil an Antoninianen von weniger als $10 \%$ des Gesamtbestands kann konstatiert werden, dass Rom als Hauptmünzstätte auch in den Funden des Theaters bestätigt wird. Hinzu kommt ein Stück des Gallienus aus der bedeutenden Emission 6/2 aus Mediolanum (M 117) sowie eine DIVO CLAVDIO-Prägung aus Cyzicus (M 124).

Für die Follis-Periode von 294 bis 348 n. Chr. lässt sich der Großteil des Fundbestands eindeutigen Münzstätten zuteilen, nur drei Stücke entfallen aufgrund mangelhafter Lesbarkeit der Sigle (Grafik 32). Anhand der Grafik ist ersichtlich, dass die näher gelegenen Münzstätten Cyzicus und Nicomedia überwiegen; ein großer Teil des Zustroms erfolgte auch von Heraclea aus, während Constantinopolis noch eine untergeordnete Rolle einnimmt. Vergleicht man die Verteilung mit den Fundbeständen des Hanghauses 1 (Grafik 35), der Basilika am Staatsmarkt(Grafik 34), der Kuretenstraße und des spätantiken Gebäudes in den Verulanushallen

\footnotetext{
${ }^{37}$ SCHINDEL 2009, 185.

${ }^{38}$ SCHINDEL 2009, 197-203.
} 


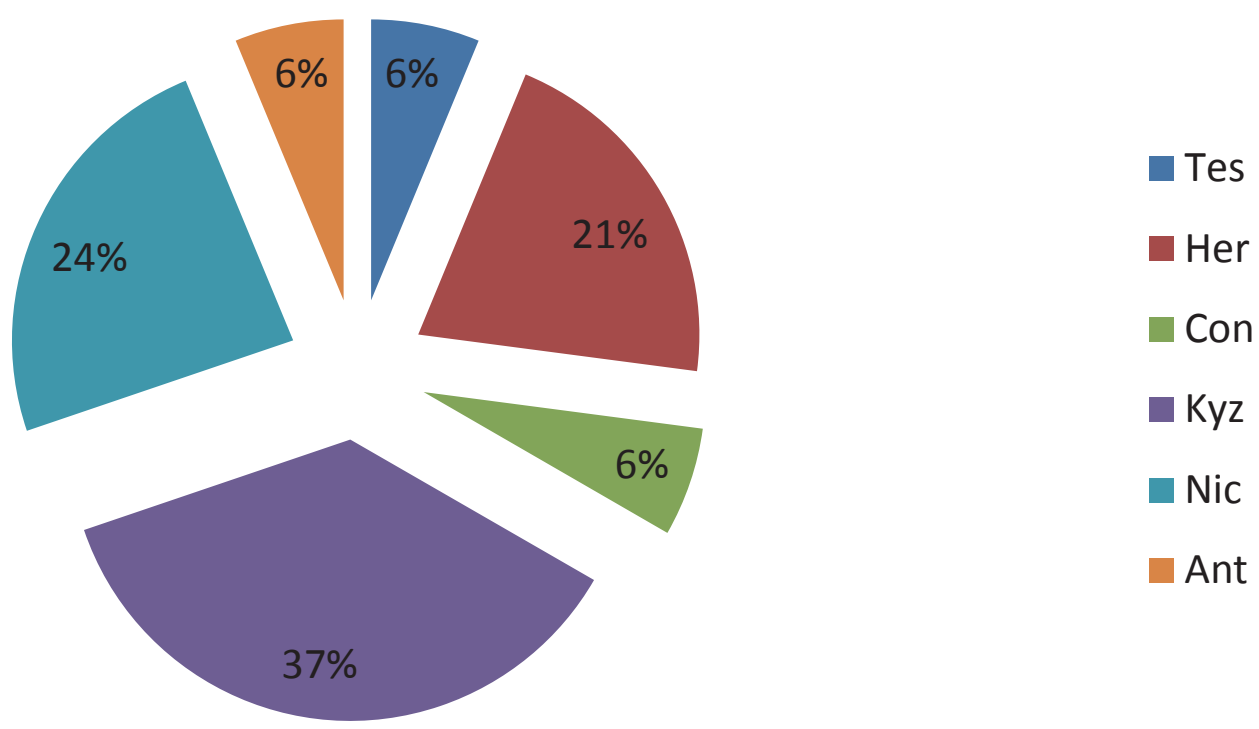

Grafik 32: Münzstättenverteilung der Periode 294/348 n. Chr. der Fundbestände aus dem Theater (n=19)

(Grafik 36), zeigt sich ein ähnliches Bild. In allen genannten Fundkomplexen überwiegen Prägungen aus Cyzicus mit Ausnahme der Basilika, wo alle östlichen Münzstätten in etwa derselben Intensität vertreten $\operatorname{sind}^{39}$. Von den Verulanushallen liegen fast ausschließlich Stücke aus Cyzicus vor. Generell fällt auf, dass der Hauptzustrom nach Ephesos von wenigen und dabei von nahe gelegenen Münzstätten aus erfolgte, wobei Cyzicus die größte Bedeutung zukommt.

Für die Periode nach der Reform von 348 n. Chr. ergibt sich ein etwas differenzierteres Bild (Grafik 33). Zwar können ca. 50 \% der Münzen keiner eindeutigen Münzstätte mehr zugewiesen werden, aber tendenziell steht Cyzicus noch an prominenter Stelle, wenngleich Constantinopolis zunehmend an Bedeutung zu gewinnen scheint. Ein nennenswerter Teil strömt auch aus Thessalonica und Heraclea ein, während Nicomedia seine Bedeutung in der Versorgung von Ephesos verloren zu haben scheint. Ob diese Aussage allgemein Gültigkeit hat, zeigt sich im Vergleich zu anderen Fundkomplexen. In Hanghaus 1 ist für die Periode 348/383 n. Chr. Constantinopolis mit den meisten Belegstücken vertreten, gefolgt von Cyzicus mit nicht einmal halb so vielen Münzen. In der Periode 383/491 n. Chr. verschiebt sich das Verhältnis dann zugunsten von Cyzicus und Nicomedia. Der Münzbestand der Basilika weist in der ganzen Periode bis $450 \mathrm{n}$. Chr. etwa gleich hohe Frequenzen aus Constantinopolis und Cyzicus auf, wobei in der späteren Phase Stücke aus Nicomedia und Antiochia zunehmen. Auch in der spätantiken Residenz in den Verulanushallen sind hauptsächlich Prägungen aus Constantinopolis und Cyzicus belegt; von Bedeutung ist auch Antiochia, während Nicomedia eine untergeordnete Stellung einnimmt. Letztendlich sei auch noch auf die Kuretenstraße verwiesen, die - wie schon N. Schindel ausgeführt hat - einen Schwerpunkt auf Constantinopolis und Cyzicus aufweist, wenn man von den Zeno-Minimi aus Nicomedia absieht ${ }^{40}$.

Es lässt sich also konstatieren, dass sich die vorrangige Präsenz von Münzen aus Cyzicus mit der Fundevidenz anderer Bereiche deckt. Für die Zeit nach der Reform von 348 n. Chr. übernahmen Constantinopolis und Cyzicus die Hauptversorgung der Stadt. Weiters strömte eine nennenswerte Menge aus Nicomedia und Antiochia ein.

\footnotetext{
${ }^{39}$ Die unsicheren Stücke sind hierbei nicht berücksichtigt, da sie die Grafiken verzerren würden. Trotzdem zeigen sich - auch in Anbetracht der zahlreichen unbestimmbaren Münzen - eindeutige Tendenzen.

${ }^{40}$ SCHINDEl 2009, 182-184.
} 


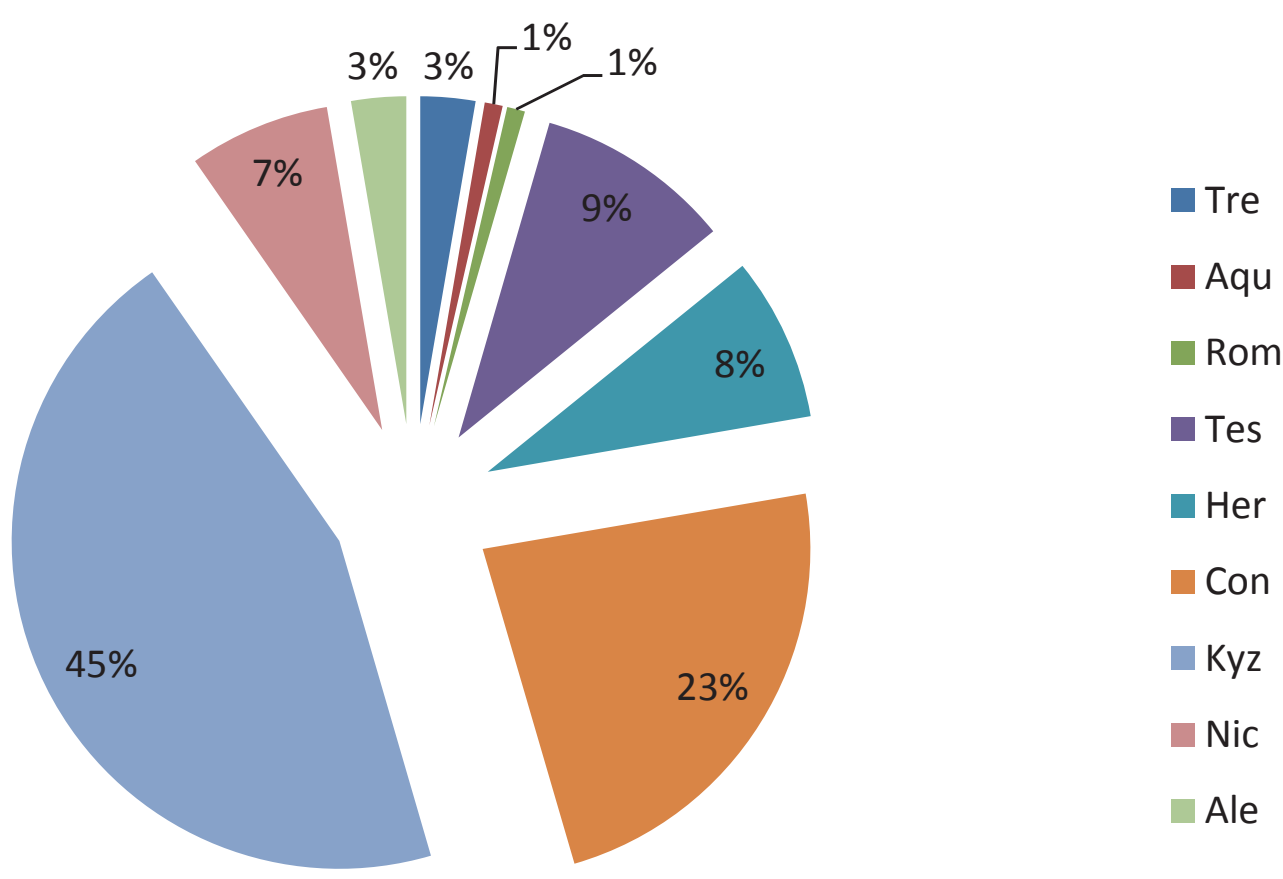

Grafik 33: Münzstättenverteilung der Periode 348/474 n. Chr. der Fundbestände aus dem Theater (n=29)

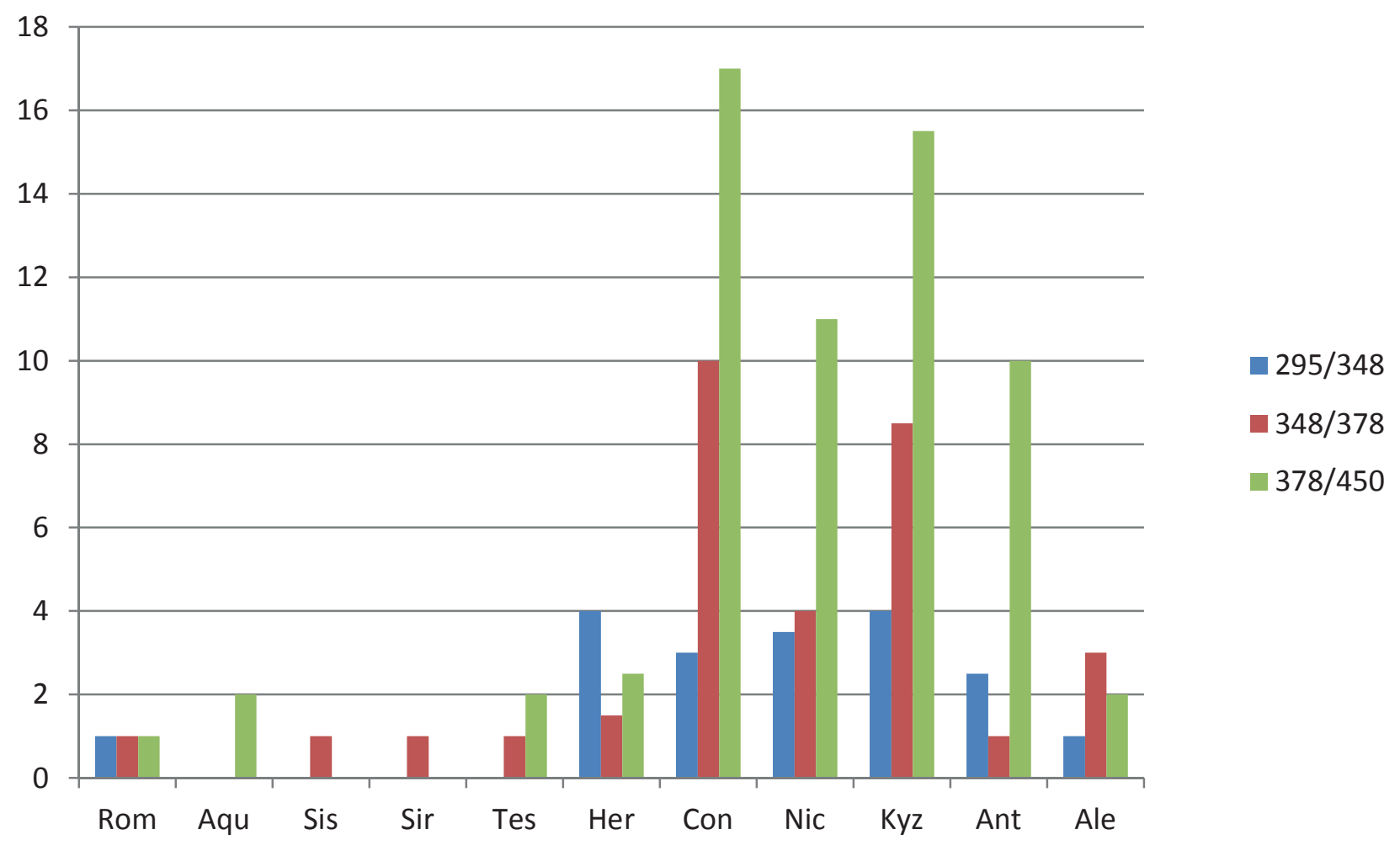

Grafik 34: Münzstättenverteilung der Bestände aus der Basilika am Staatsmarkt (n=114) 


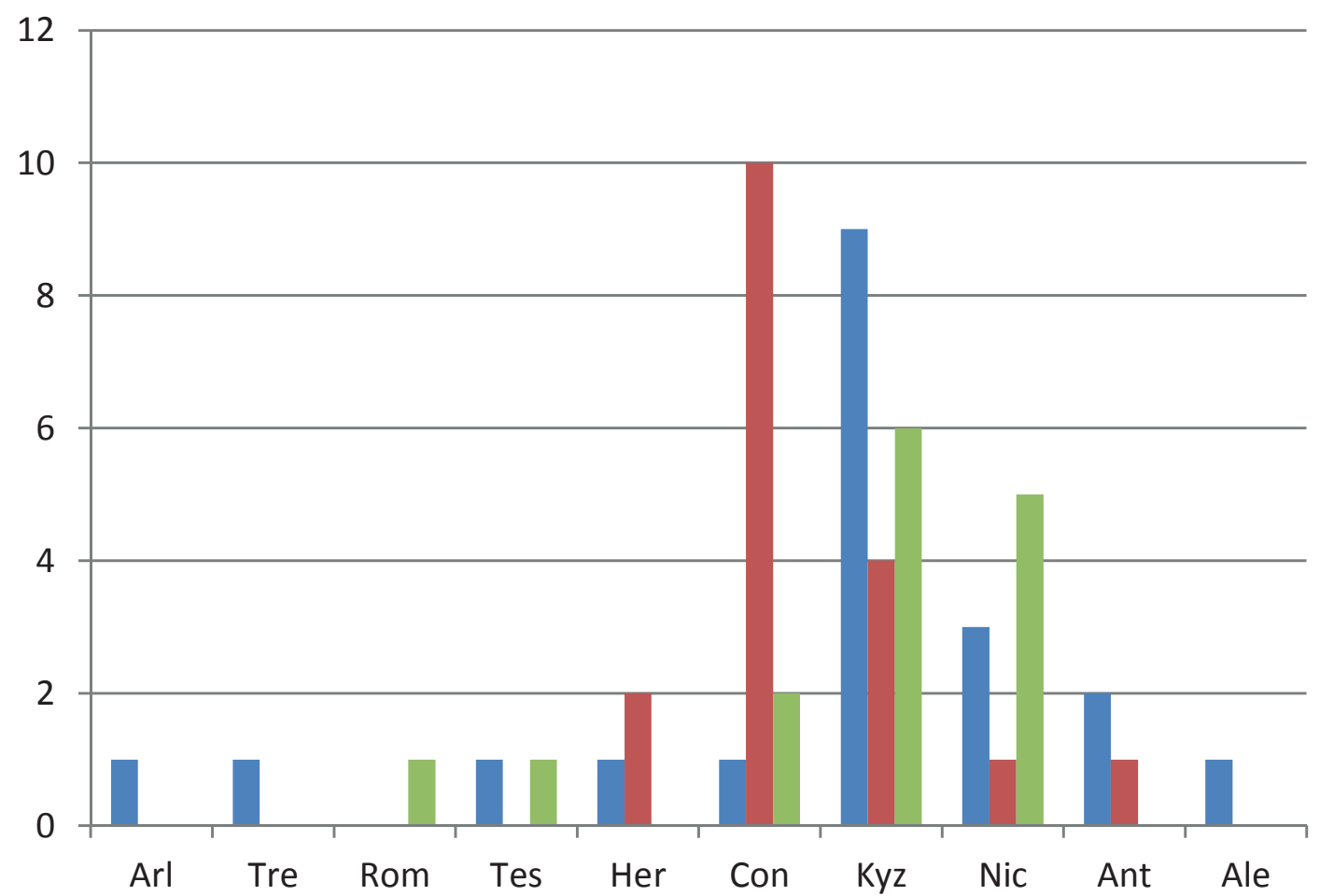

Grafik 35: Münzstättenverteilung der Bestände aus dem Hanghaus 1 ( $\mathrm{n}=53)$

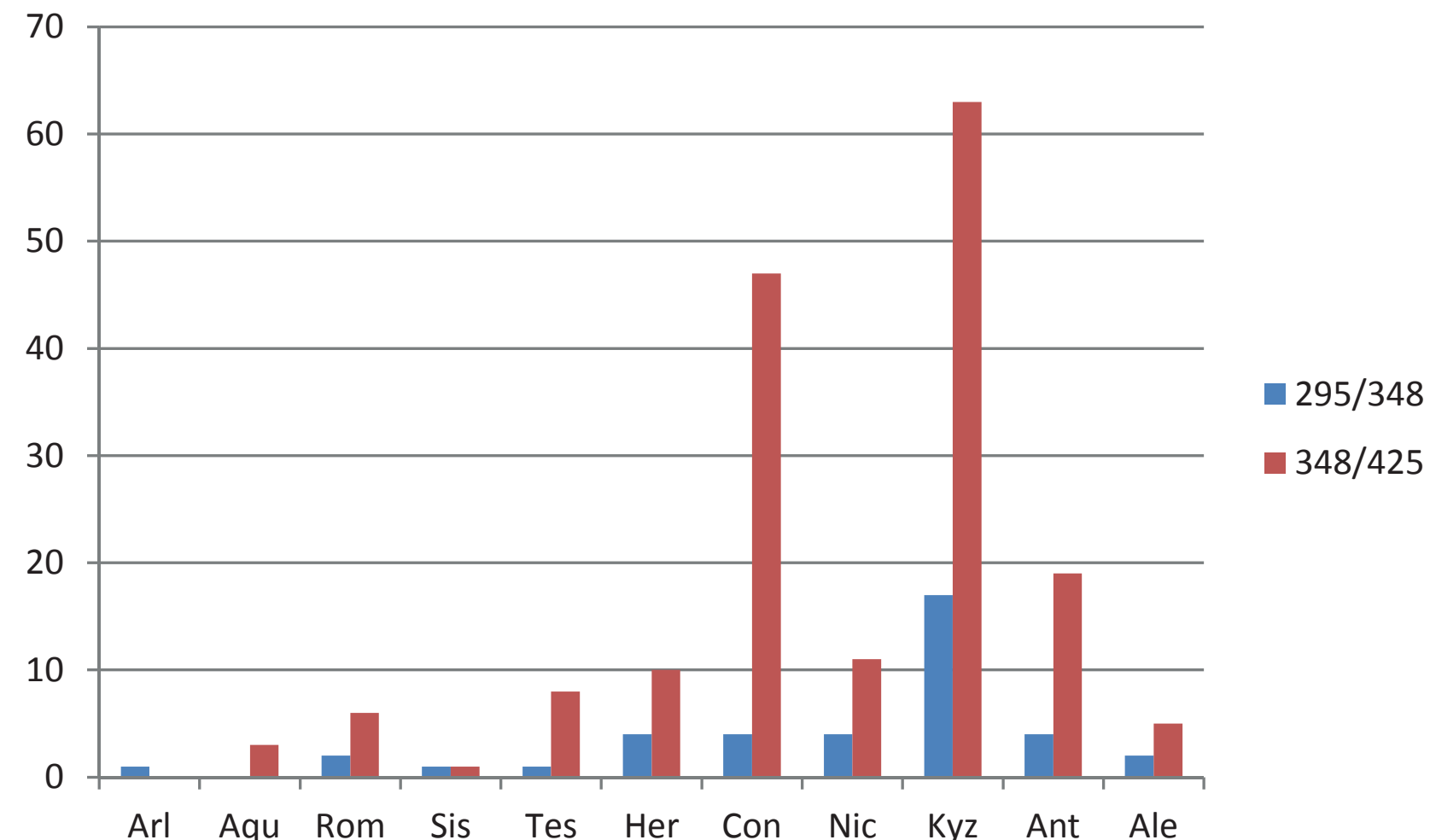

Grafik 36: Münzstättenverteilung der Bestände aus dem spätantiken Gebäude in den Verulanushallen (n=213) 


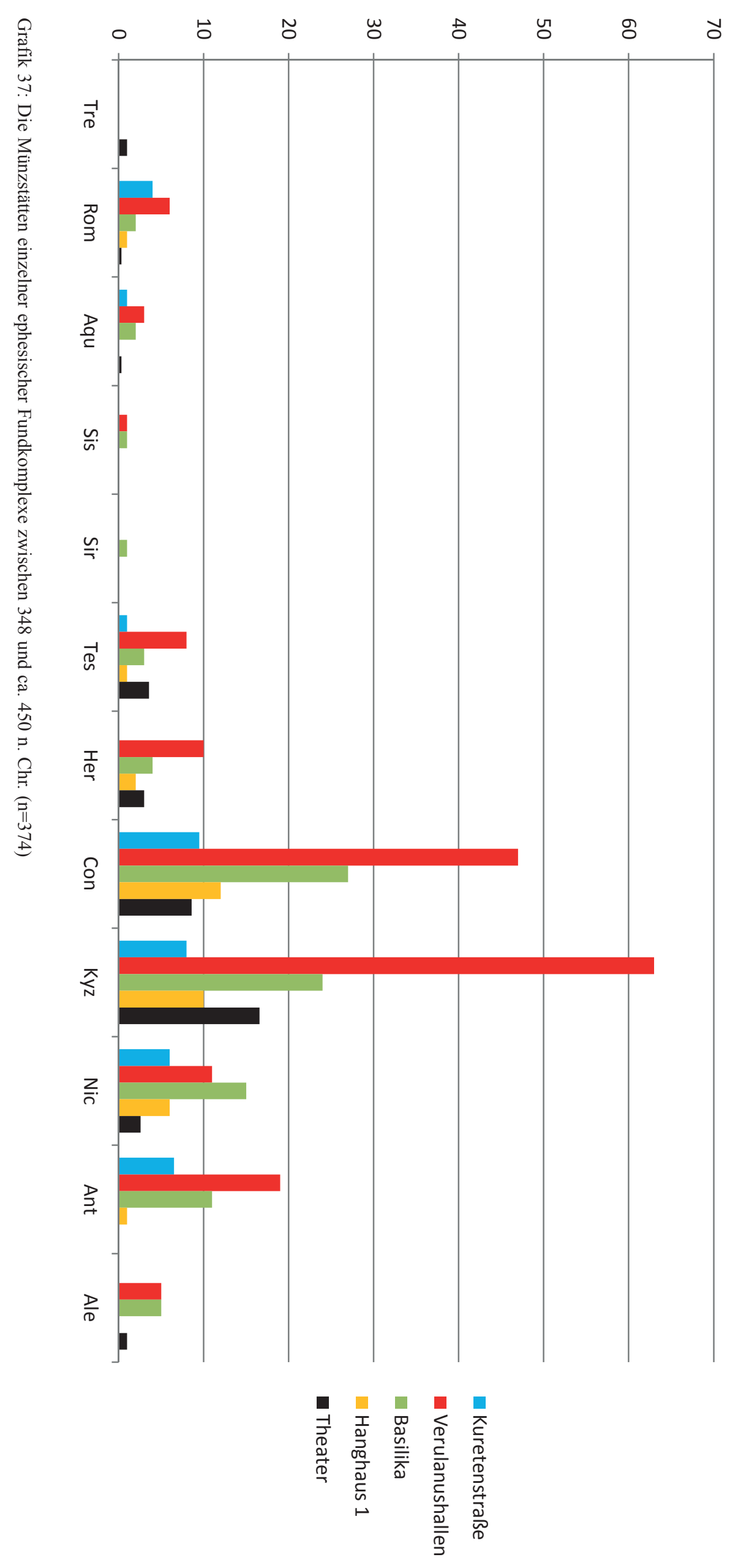




\section{Byzantinische Münzen (Grafik 38)}

Da an mehr als der Hälfte der byzantinischen Bestände des Theaters die Sigle nicht mehr lesbar ist, kann an dieser Stelle nur angeführt werden, dass Constantinopolis tendenziell überwiegt, gefolgt von Nicomedia. Dieser Trend stimmt weitgehend mit den Beständen anderer Fundkomplexe überein, wonach Constantinopolis in der Zeit zwischen Anastasius I. und Heraclius die meisten Bestände lieferte, ergänzt durch Prägungen aus Cyzicus und Nicomedia. Auch Thessalonica hat in dieser Zeit - dem Bestand der Basilika zufolge - noch einen bedeutenden Anteil an der Geldversorgung von Ephesos. Carthagische Prägungen kommen im Theater nicht vor.

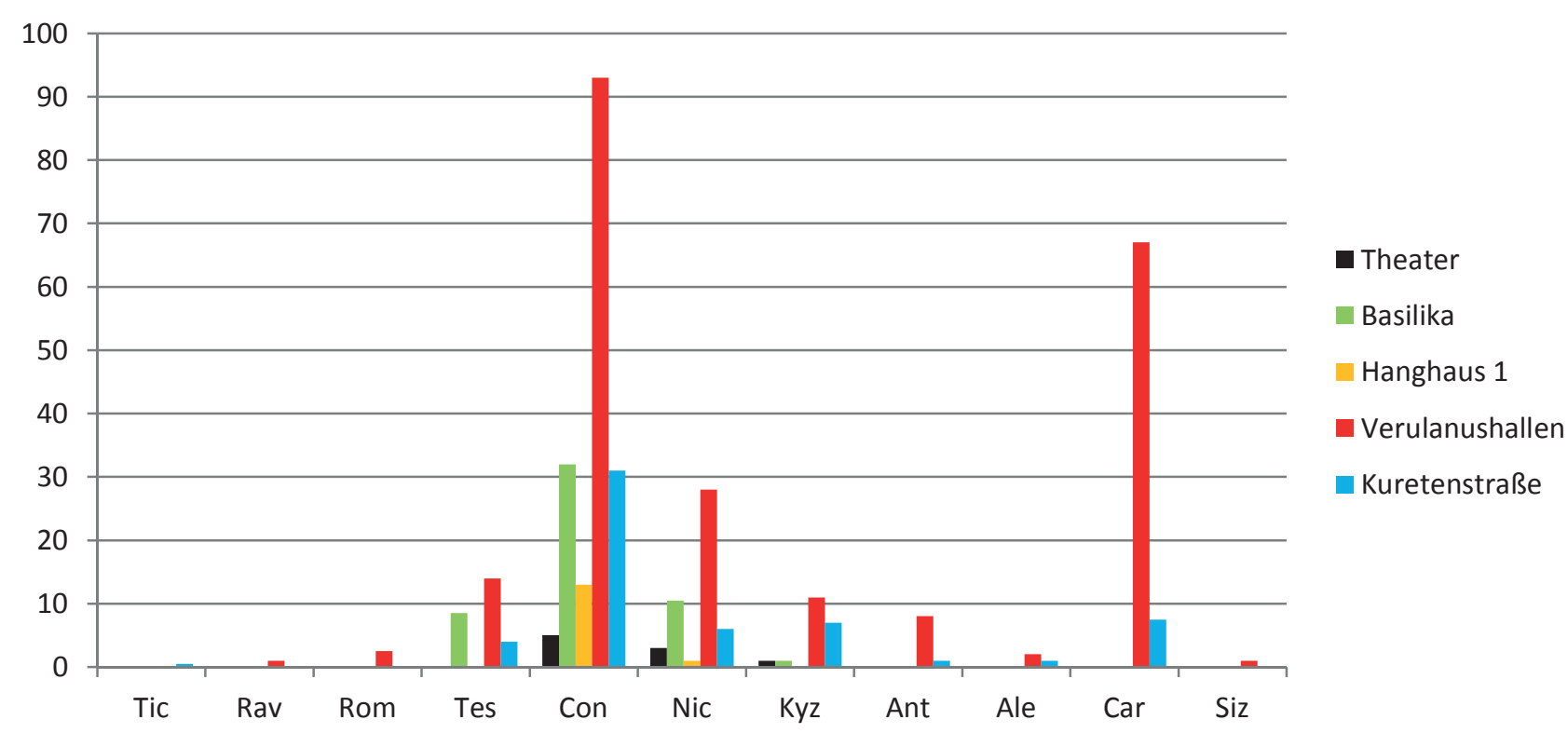

Grafik 38: Die Münzstätten der byzantinischen Stücke aus einzelnen ephesischen Fundbereichen ( $\mathrm{n}=361$ )

\subsection{ARCHÄOLOGISCH-HISTORISCHER KONTEXT}

Zum archäologisch-historischen Kontext der Münzfunde siehe Kapitel 5.5: Fundlisten der Münzen nach Fundbereichen.

\subsubsection{Münzfunde aus dem Bühnengebäude (Grafik 39)}

Die Grafik erfasst alle Funde aus dem Bereich des Bühnengebäudes. Unabhängig von der Umlaufzeit schlagen sich die markanten Eckpunkte trotz der relativ bescheidenen Anzahl von 26 Münzen deutlich nieder: Einerseits ersieht man schon vermehrte Aktivität am Beginn der Münzkurve, was mit der Errichtung der Terrasse für den Bau des Bühnengebäudes in Zusammenhang gebracht werden kann, anderseits schlagen sich die Baumaßnahmen in augusteisch-tiberischer Zeit in einer entsprechenden Verdichtung des Materials nieder. Zu Beginn des 4. Jhs. n. Chr. und im Verlauf desselben manifestieren sich wohl die im Zuge der Zerstörungen des 3. Jhs. n. Chr. notwendig gewordenen Restaurierungsmaßnahmen. Für das 6. Jh. n. Chr. ist erneut ein stärkerer Niederschlag in der Fundevidenz ersichtlich.

Wenden wir uns nun den einzelnen Befunden zu, mit dem Ziel zu überprüfen, ob sich die Münzevidenz mit den archäologischen Rahmenbedingungen deckt.

\section{Hellenistisches Bühnengebäude (Kammer D3 und D8)}

Der Bau des Bühnengebäudes wird mit der Errichtung der Kammern D3 und D8 bzw. deren Einfüllungen ab dem 2. Viertel des 2. Jhs. v. Chr. datiert ${ }^{41}$.

\footnotetext{
${ }^{41}$ Kap. 3.1.1.1; 3.1.1.2; 4.1.1.1 u. 4.1.1.2.
} 


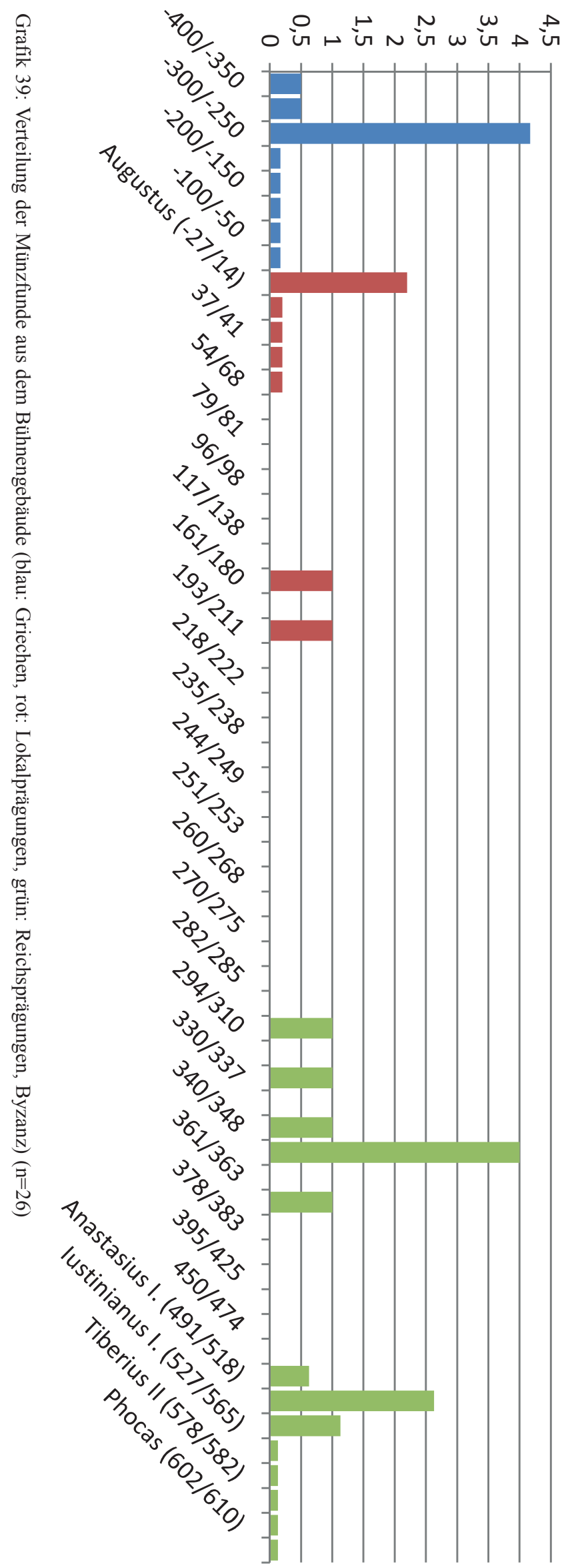


Die einzige Münze, die dafür relevant ist, ist M 8 aus Kammer D8, eine ephesische Aes-Prägung der Periode 295/280 v. Chr. Da sie eindeutig der Schicht B15, welche in die Mitte des 2. Jhs. v. Chr. datiert wird, jedoch auch Keramik des 3./2. Jhs. v. Chr. enthielt, zugeordnet wird, kann ihre Umlaufdauer mit ca. 80 bis max. 150 Jahren angenommen werden ${ }^{42}$. Ein weiteres aus diesem stratigrafischen Kontext stammendes Stück (M 21) kann aufgrund schlechter Erhaltung nur mehr approximativ in hellenistische Zeit datiert werden. Dieser Kontext ist der einzige Anhaltspunkt, der sich für eine mögliche Zirkulationsdauer einer hellenistischen Kupferprägung ergibt. Die übrigen hellenistischen Stücke aus den Kammern D3 und D8 sind wohl auch dem Geldverkehr dieser Periode zuzurechnen. Die Schichten B5 und B6, welche bereits Keramik des 1. Jhs. n. Chr. enthielten, wurden mit einem Umbau bzw. der Erneuerung des Fußbodens in Kammer D3 erklärt ${ }^{43}$. Darin finden sich eine ephesische Prägung der Zeit 387/295 n. Chr. (M 5) sowie eine nicht eingrenzbare Lokalmünze vermutlich des 1. Jhs. v. oder n. Chr. (M 96). Die erstgenannte Münze ist äußerst stark abgenutzt; unklar bleibt, ob sie entweder zum Zirkulationsvolumen zur Zeit der Errichtung des Bühnengebäudes oder früher gehörte, oder vielleicht viel länger im Umlauf blieb. Die erstgenannte These gewinnt jedoch an Plausibilität, wenn man berücksichtigt, dass in Schicht B6 auch keramisches Material des 3./2. Jhs. v. Chr. auftritt. Auch das Stück M 12 aus Schicht B13 der Kammer D8 könnte in diesen Zusammenhang gehören, doch leider weist sie keine Vergesellschaftung mit keramischen Funden auf; daher bleibt ein Unsicherheitsfaktor bestehen.

\section{Kaiserzeitliches Bühnengebäude}

Mit dem kaiserzeitlichen Bühnengebäude können in Summe 18 Münzen in Verbindung gebracht werden; davon sind elf Stück stratigrafisch relevant. Die ephesische Lokalmünze M 50 (Taf. 356) mit einer Prägezeit unter Marcus Aurelius weist nur mäßige Abnutzung auf, was für kürzere Verweildauer im Umlauf spricht. Das Stück könnte folglich für die Datierung des Mörtelbetts, durch das die unter dem späteren Ziegelplattenboden aufgefundenen Pithoi versiegelt wurden, schon um 200 n. Chr. sprechen ${ }^{44}$.

In Kammer E5 befanden sich drei Münzen der Maiorinen-Periode im Material aus den nachträglich eingebauten Becken (M 146. M 148. M 149) ${ }^{45}$. Ein Stück ist dabei mit Sicherheit der Schicht B41 zuzuordnen (M 148), die beiden anderen gehören mit großer Wahrscheinlichkeit der Nutzungszeit der Becken an. Bei den Münzen handelt es sich um einen Reitersturz- und einen SPES REIPVBLICE-Typ der Prägezeit 355/361 n. Chr. und eine nur mehr der Periode 351/361 n. Chr. zuweisbare Reitersturz-Prägung. Die Münzen sind mit spätantiker Keramik vergesellschaftet und für die Schichtdatierung wird das 5. Jh. n. Chr. angegeben $^{46}$, woraus vorsichtig eine mögliche Zirkulationsdauer dieser Prägungen abgeleitet werden könnte. Die Münzen passen einerseits nominalienmäßig zu dem im 5. Jh. n. Chr. neu hinzugekommenen Münzvorrat, andererseits würden diese Prägungen bei derartig langer Umlaufzeit eine im 5. Jh. n. Chr. angenommene Lücke im Geldnachschub auffüllen.

Westlich der Becken wurden in Schicht B42 zwei weitere Münzen aufgefunden, ein Stück der Zeit 295/299 n. Chr. und eine VRBS ROMA-Prägung der Phase 331/334 n. Chr. (M 125 Taf. 358; M 133); sie sind mit Keramikmaterial des 2. und 3. Jhs. n. Chr. vergesellschaftet ${ }^{47}$. Die beiden Münzen sind wenig abgegriffen, was für ein kurzes Verweilen im Umlauf spricht. Dies ergibt für die Schicht einen terminus post quem nicht viel später als $334 \mathrm{n}$. Chr..

In Kammer E7 wurde eine pergamenische Prägung des Augustus aufgefunden (M 36 Taf. 356), die der Schicht B37 zugehörig ist. Dabei handelt es sich um eine Ziegelschuttschicht, die mit der Auffüllung der Kammer in Verbindung gebracht wird. Die keramischen Objekte sprechen für eine Datierung ans Ende des 1. Jhs. v. Chr. bis ins 1. Jh. n. Chr., wobei es sich um umgelagerte Objekte zur Zeit der Schutteinfüllung nach Aufgabe der Kammer handelt ${ }^{48}$.

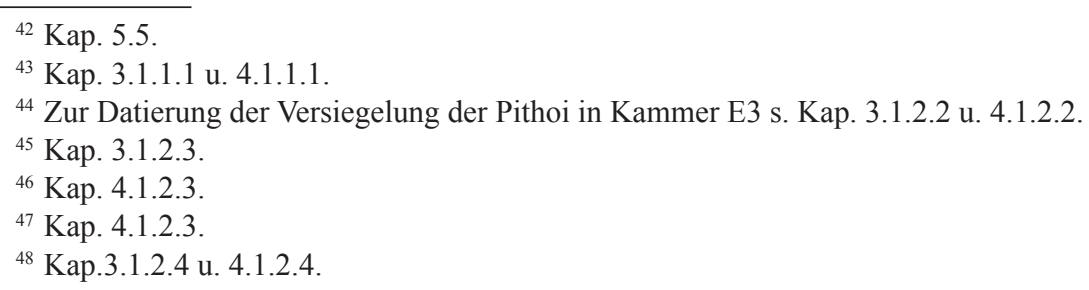


Im Norden reicht Raum RN1 direkt an das hellenistische Bühnengebäude heran ${ }^{49}$. Aus diesem Raum stammen sechs Münzen. Das Fundmaterial des Raums RN1 reicht bis ins 6. Jh. n. Chr., was dessen Nutzungszeit terminiert. Die Münzen passen großteils gut zu den übrigen Funden, lediglich die ephesische Kleinkupferprägung des Septimius Severus (M 55) scheint etwas aus dem Rahmen zu fallen. Dieses Stück stammt aus der Schicht B60, die als Verfüllschicht für den westlichen Rohrdurchlass klassifiziert wird ${ }^{50}$ und daher wenig aussagekräftig für die Zirkulationsdauer der darin enthaltenen Münze ist. Ein weiteres Stück, das nicht zur Datierung der Schicht passt, ist die Münze M 237 (Taf. 359) aus Schicht B57, welche ins frühe 1. Jh. n. Chr. datiert wird. Es handelt sich dabei um jene Schicht, in die die spätere Tonrohrleitung der östlichen Mauerausnehmung gelegt wurde; die Münze des Iustinus I. gibt somit einen terminus post quem für die Störung an. Die übrigen Münzen entstammen wohl alle dem Zirkulationsvolumen derselben Zeit, in der das Mörtelbett für den Marmorboden errichtet wurde (M 238. M 240 Taf. 359; M 250).

\begin{tabular}{|l|l|l|}
\hline KatNr. & Datierung & Schicht \\
\cline { 1 - 2 } M 240 & $556 / 557 \mathrm{n}$. Chr. & B55 \\
\cline { 1 - 2 } M 238 & $522 / 527 \mathrm{n}$. Chr. & B56 \\
\cline { 1 - 2 } M 250 & frühbyzantinisch & \\
\hline M 55 & 193/211 n. Chr. & B60 \\
\cline { 1 - 2 } M 237 & $518 / 522 \mathrm{n}$. Chr. & B57 \\
\cline { 1 - 2 } M 239 & $491 / 527 \mathrm{n}$. Chr. & B61 \\
\hline
\end{tabular}

Tab. 100: Münzfunde aus Raum RN1

\subsubsection{Münzfunde aus dem Bereich des Logeion (Grafik 40)}

Aus dem Bereich des Logeion stammen in Summe 27 Münzen. Die numismatischen Hauptaktivitäten in diesem Bereich spielten sich in hellenistischer Zeit ab, weiters in der flavischen Periode sowie im 3. und noch stärker im 5. Jh. n. Chr.

Die in der Grafik blau verzeichneten griechischen Prägungen (M 1 Taf. 355; M 11) stammen aus dem Oberflächenabhub (L1) und aus der Verfüllung der Altsondage von 1899 (L4) ${ }^{51}$. Sie gehörten wohl dem Zirkulationsvolumen des beginnenden 2. Jhs. v. Chr. an und könnten demnach mit dem hellenistischen Proskenion in Zusammenhang stehen ${ }^{52}$. Aus der Zeit der Errichtung des Logeion stammt lediglich eine nicht genauer datierbare Münze flavischer Zeit (M 97), die sich in der Verfüllung der Sondagen von 1969 befand.

Sechs Münzen sollen nun näher betrachtet werden, denn sie fanden sich in Schichten, die aufgrund des Keramikmaterials datiert werden konnten. Schicht L42, die antike Kanalverfüllung, wird aufgrund der Keramik in die 2. Hälfte des 5. Jhs. n. Chr. datiert ${ }^{53}$. Die Münzen streuen von 330 bis 388 n. Chr., wobei festzuhalten ist, dass die Prägungen der konstantinischen Zeit aufgrund ähnlichen Gewichts und Aussehens - die reduzierten Folles der 330er und 340er Jahre weisen dasselbe Gewicht und denselben Durchmesser auf wie Centenionales - sicher noch in der valentinianischen Periode zirkulierten, sofern sie den Rückfluss in die Münzanstalt überdauert hatten. Man kann also davon ausgehen, dass alle dieser Schicht zugehörigen Münzen aus dem Zirkulationsvolumen derselben Zeit stammen. Zieht man nun die Schichtdatierung in Betracht, kann man möglicherweise konstatieren, dass die mit Keramikmaterial des 5. Jhs. n. Chr. vergesellschafteten Münzen noch einige Zeit länger im Umlauf waren. Ihr durchwegs sehr abgetragenes

\footnotetext{
${ }^{49}$ Kap. 3.1.3.

${ }^{50}$ Kap. 3.1.3 u. 4.1.3.

${ }^{51}$ Kap. 3.2.2.

${ }_{52}$ Vgl. Kap. 3.2.1.

${ }^{53}$ Kap. 3.2.2.5 (Tab. 15) u. 4.2.
} 

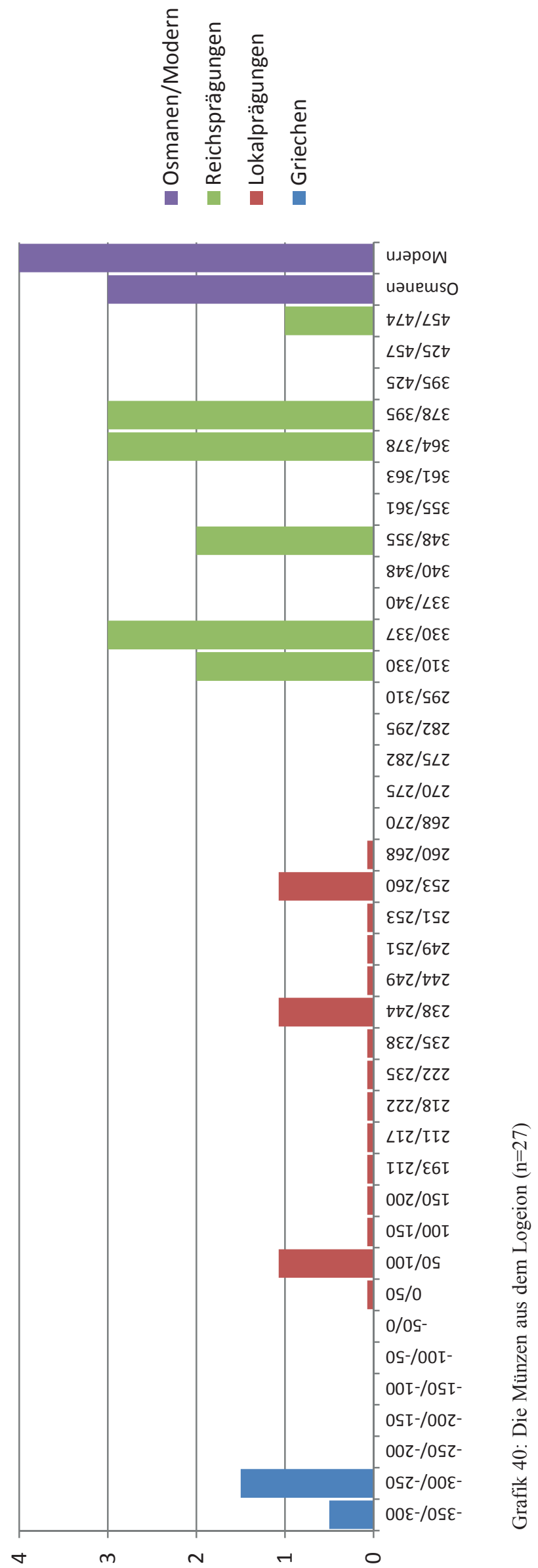


\begin{tabular}{|c|c|c|c|}
\hline KatNr. & Datierung & Schicht & Datierung \\
\hline M 1 & $320-275$ v. Chr. & \multirow[t]{4}{*}{ L1 } & \multirow[t]{4}{*}{ Oberflächenabhub, rezent } \\
\hline M 82 & 238/244 n. Chr. & & \\
\hline M 271 & 1966 & & \\
\hline M 269 & 1997 & & \\
\hline M 11 & 295/280 v. Chr. & \multirow[t]{6}{*}{ L4 } & \multirow[t]{6}{*}{ Verfüllung der Altsondage von 1899} \\
\hline M 130 & 317 n. Chr. & & \\
\hline M 134 & 330/337 n. Chr. & & \\
\hline M 144 & 351/355 n. Chr. & & \\
\hline M 212 & 383/395 n. Chr. & & \\
\hline M 231 & 457/474 n. Chr. & & \\
\hline M 264 & 1876 & L28 & Verfüllung der Altsondage von 1899 \\
\hline M 89 & 258/260 n. Chr. & L38 & Grubenverfüllung, undatiert \\
\hline M 132 & 330/333 n. Chr. & \multirow[t]{5}{*}{ L42 } & \multirow[t]{5}{*}{ 2. H. 5. Jh. n. Chr. } \\
\hline M 131 & 336/337 n. Chr. & & \\
\hline M 159 & 364/367 n. Chr. & & \\
\hline M 163 & 364/375 n. Chr. & & \\
\hline M 204 & 383/388 n. Chr. & & \\
\hline M 265 & 1910 & L45 & rezent \\
\hline M 102 & 27 v. Chr.-268 n. Chr. & L55a & 2.-4. Jh. n. Chr. \\
\hline M 97 & 69/81 n. Chr. & L65-L67 & Verfüllung der Sondage von 1969 \\
\hline M 145 & $351 / 355$ n. Chr. & L68-L75 & Verfüllung der Sondage von 1969 \\
\hline M 129 & 313/318 n. Chr. & L77 & Verfüllung der Altsondage von 1899 \\
\hline M 166 & 364/378 n. Chr. & Oberfläche & \\
\hline M 185 & 383/395 n. Chr. & Oberfläche & \\
\hline M 204 & 18./19. Jh. & Oberfläche & \\
\hline M 272 & 1995 & Oberfläche & \\
\hline M 275 & 1998 & Oberfläche & \\
\hline
\end{tabular}

Tab. 101: Die Münzen aus dem Logeion (Markierung der datierten Schichten)

Erscheinungsbild spricht jedenfalls dafür. Gehen wir nun noch einen Schritt weiter, könnten wir - wenn wir bei Schicht L42 von der 2. Hälfte des 5. Jhs. n. Chr. ausgehen - einen entsprechend langen coindrift voraussetzen.

Eine weitere Münze fand sich in einer Schicht mit gemischtem Keramikmaterial des 2. Jhs. bis zum 4. Jh. n. Chr. (L55a) ${ }^{54}$. Dieses Stück (M 102) ist jedoch aufgrund sehr schlechter Erhaltung nur mehr als kaiserzeitliche Lokalprägung anzusprechen und daher wenig aussagekräftig.

${ }^{54}$ Nach freundlicher Mitteilung von A. Waldner enthielt diese Schicht nur ein diagnostisches Fragment mit einem weiten Datierungsrahmen vom 2. bis zum 4. Jh. n. Chr., s. Kap. 4.2 (Tab. 65). 


\subsubsection{Münzfunde aus der Orchestra}

Der Orchestra können insgesamt 18 Münzen zugeschrieben werden, wobei der Großteil auf moderne Münzen entfällt, die selbstredend im Kontext rezenter `Sightseeing-Aktivitäten< stehen. Sie kamen alle bei Reinigungsarbeiten zutage. Bei den antiken Stücken handelt es sich ebenfalls um Oberflächenfunde. Die Münzen streuen von Claudius I. bis 388 n. Chr. Ein einziges Stück (M 257) lässt sich zwar einer Schicht zuordnen; diese ist allerdings nicht näher datierbar (Schicht O12, Sondage 1/2005). Die Münze ist völlig zersplittert und korrodiert, sodass keine Aussage zur Präge- und Zirkulationszeit getroffen werden kann ${ }^{55}$.

\subsubsection{Münzfunde aus dem Auditorium}

Eine ähnliche Situation herrscht bei den wenigen Münzfunden aus dem Auditorium; die sechs Stücke sind ausnahmslos als Streufunde zu bezeichnen und setzen sich vorrangig aus frühhellenistischen, ephesischen Prägungen und spätantiken Münzen zusammen.

\subsubsection{Münzfunde aus dem Nordflügel}

Die stratifizierten Münzfunde aus dem Nordflügel des Theaters konzentrieren sich im vomitorium EN1 und der Kammer KN1.

Die Grafik erfasst 18 Münzen, die sich von Augustus bis Heraclius erstrecken, wobei der hohe Balken unter Heraclius auffällt. Der Bau des Zugangskorridors EN1 wurde $92 \mathrm{n}$. Chr. vollendet und im 4. Jh. n. Chr. im Zuge von Stabilisierungsmaßnahmen, die auch die Kammern KN1 bis KN3 betrafen, stillgelegt ${ }^{56}$. Um die Mitte des 5. Jhs. n. Chr. baute man in den Korridor ein Wasserbecken ein, welches bis ins 6. oder frühe 7. Jh. n. Chr. genutzt wurde ${ }^{57}$.

Aus dem Korridor EN1 stammen zwei stratigrafisch der Schicht SE N3 zugeordnete Münzen; die Schicht wird ins 6. Jh. n. Chr. datiert und beinhaltet kleinteiligen Schutt und Tierknochen ${ }^{58}$. Bei den Münzen handelt es sich zum einen um eine Prägung des Iustinus II. (M 241 Taf. 359) des Jahres 572/573 n. Chr., die einen terminus post quem für die Schichtdatierung abgibt. Das Stück ist nur mäßig abgenutzt, sodass man einen nicht allzu großen Verzögerungsfaktor annehmen kann. Zum anderen wird dieser Schicht eine Münze des Philippus II. (M 78) zugeschrieben, die in diesem Kontext schwer zu interpretieren ist. Bei einem coindrift von 100 Jahren befinden wir uns noch immer in der Nutzungszeit des Korridors; die Stratigrafie spricht allerdings für einen Kontext im 5. bis 6. Jh. n. Chr., als der Korridor bereits als Zisterne diente. Man kann folglich nur feststellen, dass sich eine Münze des 3. Jhs. n. Chr. - offensichtlich als Altmaterial - im Fundzusammenhang der frühbyzantinischen Phase befindet. Da es sich um einen Einzelbefund handelt, können daraus keine allgemein gültigen Aussagen bezüglich der Zirkulationsdauer von Lokalmünzen des 3. Jhs. n. Chr. abgeleitet werden.

Der Befund der Kammer KN1 spricht wieder eine deutlichere Sprache ${ }^{59}$. Aus der Schicht SE N12, einer Versturzschicht, die aufgrund der Münzen an den Anfang des 7. Jhs. n. Chr. datiert wird, stammen vier Prägungen des Heraclius der Zeit vor 616 n. Chr. (M 242 Taf. 359; M 243. 245. 246 Taf. 360). Diese liefern für den Versturz des Gewölbes von KN1 einen terminus post quem von $616 \mathrm{n}$. Chr. Schicht SE N14 wird ins 3. bis 4. Jh. n. Chr. datiert und barg eine sehr stark abgenutzte Prägung der Iulia Domna (M 94), bei der wir infolge der stratigrafischen Daten wiederum einen entsprechenden Verzögerungsfaktor einberechnen müssten; allerdings enthielt diese Schicht auch viel umgelagertes Altmaterial. In der Kammer KN1 kamen noch fünf weitere Münzen zutage, die aus der vom Ende des 4. bis in die Mitte des 5. Jhs. n. Chr. datierten Schicht SE N15 stammen. Sie setzen sich aus zwei antoninischen Prägungen (M 49. M 53), einem severischen Stück (M 59 Taf. 356) und zwei Münzen des 4. Jhs. n. Chr. (M 141. M 160) zusammen. Der

\footnotetext{
${ }^{55}$ Kap. 4.3.

${ }^{56}$ Kap. 3.5.1.1.1.

${ }^{57}$ Kap. 3.5.1.1.1 u. 10.3.2.

${ }^{58}$ Kap. 3.5.1.1 u. 4.5.1.1.

${ }^{59}$ Kap. 3.5.1.2 u. 4.5.1.3.
} 
$\circ \mapsto N \omega \cap M \sigma$

$$
-27 / 14
$$

$37 / 41$

$41 / 54$

$54 / 68$

$69 / 79$

$79 / 81$

$81 / 96$

$96 / 98$

98/117

$117 / 138$

$138 / 161$

$161 / 180$

$180 / 192$

$193 / 211$

$211 / 217$

$218 / 222$

$222 / 235$

$235 / 238$

$238 / 244$

$244 / 249$

$249 / 251$

$251 / 253$

$253 / 260$

$260 / 268$

$268 / 270$

$270 / 275$

$275 / 282$

$282 / 295$

295/310

$310 / 330$

$330 / 337$

$337 / 340$

$340 / 348$

$348 / 355$

$355 / 361$

$361 / 363$

$364 / 378$

$378 / 395$

$395 / 425$

$425 / 457$

$457 / 474$

Zeno (474/491)

Anastasius I. (491/518)

lustinus I. (518/527)

lustinianus I. (527/565)

lustinus II. (565/578)

Tiberius II (578/582)

Mauricius (582/602)

Phocas (602/610)

Heraclius (610/641)

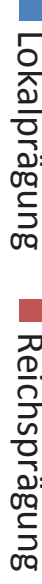




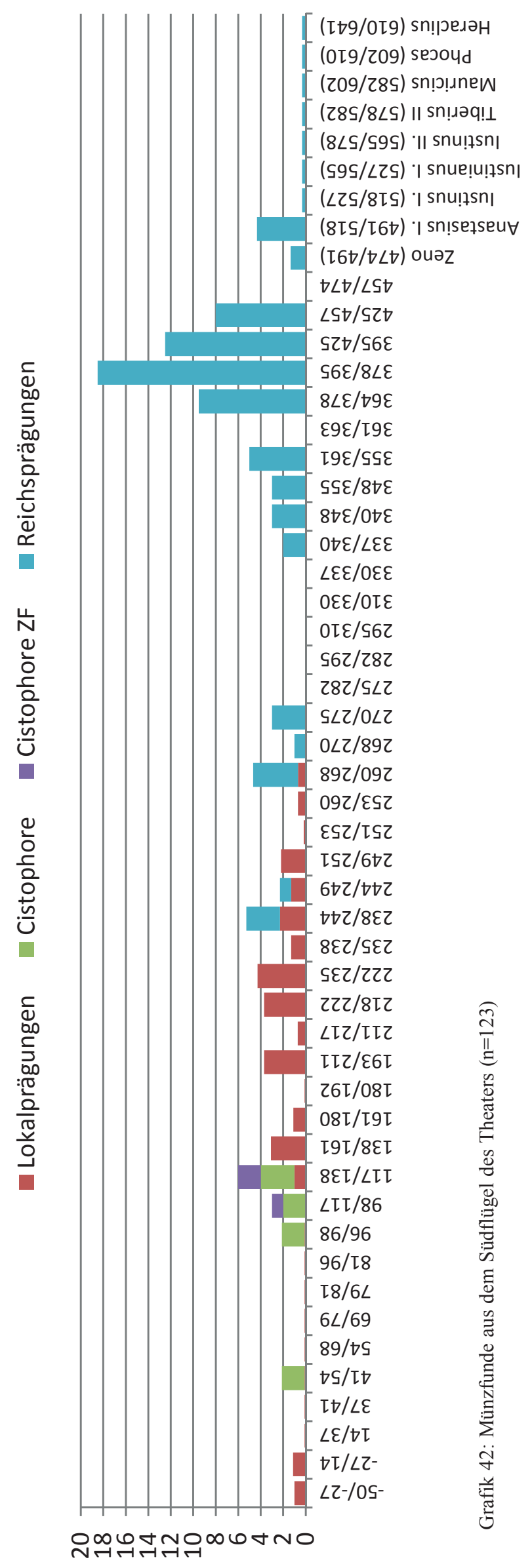


Verfüllungsschutt der Kammer KN1 besteht aus sehr inhomogenem Material, sodass an dieser Stelle nur vermutet werden kann, dass die älteren Münzen aus umgelagertem Altmaterial stammen und die Münzen des 4. Jhs. n. Chr. ab dem Ende des Jahrhunderts in die Erde gekommen sind.

Weitere Münzen, die aus dem im 6. bzw. frühen 7. Jh. n. Chr. herabstürzenden Material des Gewölbes stammen, sind ein Stück des Gallienus (M 116) aus der Kammer KN3 und eine augusteische Lokalmünze aus Ephesos (M 39 Taf. 356) aus der Kammer KN4; beide werden der Schicht SE N1 zugeschrieben ${ }^{60}$. Diese Stücke besitzen wenig Aussagekraft hinsichtlich der Datierung des Versturzes und der Zirkulationszeit ${ }^{61}$.

Zum Abschluss soll noch auf ein Stück hingewiesen werden, das stratigrafisch von Relevanz ist (M 183). Die Münze wurde in der Sondage 2/98 gefunden und wird der Schicht SE 29 zugeschrieben, einer Erdschicht über der (jüngeren) Bodenfundamentierung ${ }^{62}$ des nördlichen Treppenaufgangs, der im 5. bis ins 6. Jh. n. Chr. wieder eine Veränderung erfuhr ${ }^{63}$. Die Münze ist aufgrund schlechter Erhaltung nur mehr grob ins $4 . \mathrm{Jh} . \mathrm{n}$. $\mathrm{Chr}$. zu datieren. Man kann demzufolge zumindest konstatieren, dass das (jüngere) Treppenfundament vor der konstantinisch-valentinianischen Periode errichtet wurde.

Die restlichen drei Münzen aus dem Nordflügel sind Oberflächenfunde, darunter wieder eine HeracliusPrägung der Zeit vor 616 n. Chr., was einen terminus post quem für den Einsturz des Nordflügels des Theaters angibt $t^{64}$.

\subsubsection{Münzfunde aus dem Südflügel}

Aus dem Südflügel des Theaters stammen in Summe 127 Münzen, die sich zum Großteil in den westlichen Kammern von ES1 (KS1-KS3) fanden. In die Grafik wurden alle Funde mit Ausnahme der völlig unbestimmbaren Stücke eingearbeitet (Grafik 43). Auf den ersten Blick korrespondieren sie mit den baulichen Aktivitäten am Süd-Analemma und der Errichtung bzw. Nutzungszeit der Kammern. Diese wurden zwischen 102 und $112 \mathrm{n}$. Chr. fertiggestellt ${ }^{65}$, was sich in einem Anwachsen der Münzverluste in nach-trajanischer Zeit niederschlägt. Im 3. Jh. n. Chr. weist die Münzreihe eine Lücke von Aurelian bis in konstantinische Zeit auf, was mit dem nicht unmittelbar auf die Zerstörungen des Erdbebens folgenden Restaurierungen zu erklären ist. Der Wiederaufbau erfolgte erst im späten 4. und im 5. Jh. n. Chr.; dabei wurden die Eingänge ES2 und ES3 im Zuge der Errichtung der Stadtmauer verschlossen ${ }^{66}$. Die Münzfunde unterstreichen dieses Bild mit der Prämisse eines Verzögerungsfaktors, nach welchem sich das zirkulierende Geld in den Funden niederschlägt. Mit Anastasius I. brechen die Münzverluste ab; bei den niedrigen Balken in der Grafik von Iustinus I. bis Heraclius handelt es sich um unbestimmbare Minimi, die diesbezüglich wenig Aussagekraft besitzen.

Augenfällig sind allerdings die schon erwähnten Cistophoren-Funde, die von Claudius I. bis Hadrian streuen und mit großer Wahrscheinlichkeit zusammengehören ${ }^{67}$.

\section{Münzfunde aus der Aristion-Leitung}

Sehen wir uns nun die einzelnen Bereiche des Südflügels genauer an. Bei ES1 findet sich ein Leitungsquerschnitt der Aristion-Leitung ${ }^{68}$, die das vor $114 \mathrm{n}$. Chr. fertiggestellte Nymphaeum Traiani mit Wasser versorgte. Sie war bis ins 5./6. Jh. n. Chr. intakt. An der Oberfläche der Einschwemmung kamen vier Münzen zutage, die

\footnotetext{
${ }^{60}$ Kap. 3.5.1.1.1.

${ }^{61}$ Kap. 3.5.1.3 u. 4.5.1.1.

62 Öhlinger (Kap. 3.5.1.4.2, Sondage 2/98) bezweifelt, ob es sich überhaupt um zwei Bauphasen handelt.

${ }^{63}$ Kap. 3.5.1.4.2 u. 4.5.1.4 (Tab. 80).

${ }^{64}$ Die Münzen 17/1998, 19/1998 und 20/1998 aus dem Brunnen konnten weder im Original aufgefunden werden, noch ging die Erwähnung in der Grabungsdokumentation über die Nennung der Fundnummer hinaus, s. Kap. 3.5.3.1.

${ }^{65}$ Kap. 10.2.4.2.

${ }^{66}$ Kap. 10.3.2.

${ }^{67}$ Kap. 5.1.2.4.

${ }^{68}$ Kap. 10.2.4.2.
} 
mit der Benützungszeit der Leitung korrespondieren ${ }^{69}$. Münze M 43 (Taf. 356) kam logischerweise erst in nach-trajanischer Zeit in die Leitung und könnte durchaus dem Geldverkehr des 2./3. Jhs. n. Chr. entstammen.

\begin{tabular}{|l|l|}
\hline KatNr. & Datierung \\
\hline M 43 & Augustus \\
\hline M 48 & $138 / 161$ n. Chr. \\
\hline M 61 & 218/222 n. Chr. \\
\hline M 121 & 270 n. Chr. \\
\hline
\end{tabular}

Tab. 102: Die Münzen aus der Wasserleitung bei ES1

\section{Münzfunde aus dem vomitorium ES1}

Als ungewöhnliches Fundensemble traten im Zerstörungsschutt des vomitorium ES1 sieben Cistophore von Nerva bis Hadrian auf (M 22. M 23; M 24-33 Taf. 355) ${ }^{70}$. Alle Cistophore des Süd-Analemma gehören m. E. zusammen, also auch jene in der Fundliste der Münzen als Streufunde des Süd-Analemma angeführten fünf Stücke, da sie relativ konzentriert auftreten und in keinem anderen Bereich des Theaters derartiges Material zum Vorschein kam. Vier Cistophore kamen im ersten Jahr der wieder aufgenommenen Unternehmungen am Auditorium des Theaters zutage, denn 1993 begannen unter St. Karwiese die ersten Maßnahmen zur Sanierung des Gebäudes ${ }^{71}$. In diesem ersten Jahr stand neben der Schadensprotokollierung die Beseitigung von Unmengen von Schutt in den Analemmata im Mittelpunkt; daher sind die 1993 aufgefundenen Cistophore als \Streufundeく klassifiziert. Im Jahr 1997 wurden weitere sieben Stücke aufgefunden, wobei nun die Fundstelle (vomitorium ES1) bereits genauer klassifiziert werden konnte. 1998 fand sich schließlich noch ein Stück auf dem Zugangspodest von ES1. Auf der Freitreppe, die die südlichen Eingänge ES1 bis ES3 verband, wurde nach dem großen Erdbeben des 3. Jhs. im späten 4. und im 5. Jh. n. Chr. der Schutt der eingestürzten Häuser der benachbarten Insula deponiert. Man wird unser Cistophoren-Ensemble wohl mit dem Schutt aus der genannten Insula in Verbindung bringen und in einem der Privatquartiere einen Hort postulieren können, wovon dann eben ein Teil im Zuge der Aufräumungsarbeiten nicht bemerkt und daher gemeinsam mit dem Schutt entsorgt wurde ${ }^{72}$.

\section{Münzfunde aus den Kammern KS1-KS3}

Den größten Bestand des Südflügels bilden mit 99 Stück Münzen der Kammern KS1 bis KS3. In der Grafik sind alle Münzen der drei Kammern aus den einzelnen Schichten - mit Ausnahme der wenigen unzuordenbaren Stücke - erfasst (Grafik 43). Auf den ersten Blick fällt der deutliche Schwerpunkt in der 2. Hälfte des 4. und der 1. Hälfte des 5. Jhs. n. Chr. auf. Die Münzreihe läuft von der Mitte des 2. Jhs. n. Chr. bis Anastasius I. Für das 2. Jh. n. Chr. sind nur sehr wenige Stücke überliefert, deren Bestimmung zudem aufgrund des sehr schlechten Erhaltungszustands unsicher ist. Die Münzverluste steigen im 3. Jh. n. Chr. an, wobei sich die meisten davon in der untersten Schicht der Kammer KS2 fanden. Nach 270 n. Chr. bricht die Kurve wie erwartet $-a b$ und setzt dann erst wieder mit Prägungen nach dem Tod des Constantinus I. ein. Bis ca. 435 n. Chr. geht die Münzreihe durch; byzantinische Stücke finden sich nur sehr sporadisch. Die wenigen unbestimmbaren Minimi bzw. Nummi sind nicht in der Grafik erfasst. Die Münzen wurden in allen drei Räumen in Schuttschichten aufgefunden ${ }^{73}$.

\footnotetext{
${ }^{69}$ Kap. 3.6.1.

${ }^{70}$ Kap. 3.6.3.

${ }^{71}$ Kap. 1.3.

${ }^{72}$ Kap. 5.1.2.4. Laut St. Karwiese, dem ich für die ergiebigen wissenschaftlichen disputationes dankbar bin, handelt es sich bei diesen Münzen um Geldgeschenke im Zuge von Verteilungen (congiaria) seitens hochrangiger Würdenträger bzw. des Kaisers selbst.

${ }^{73}$ Kap. 3.6.2.
} 


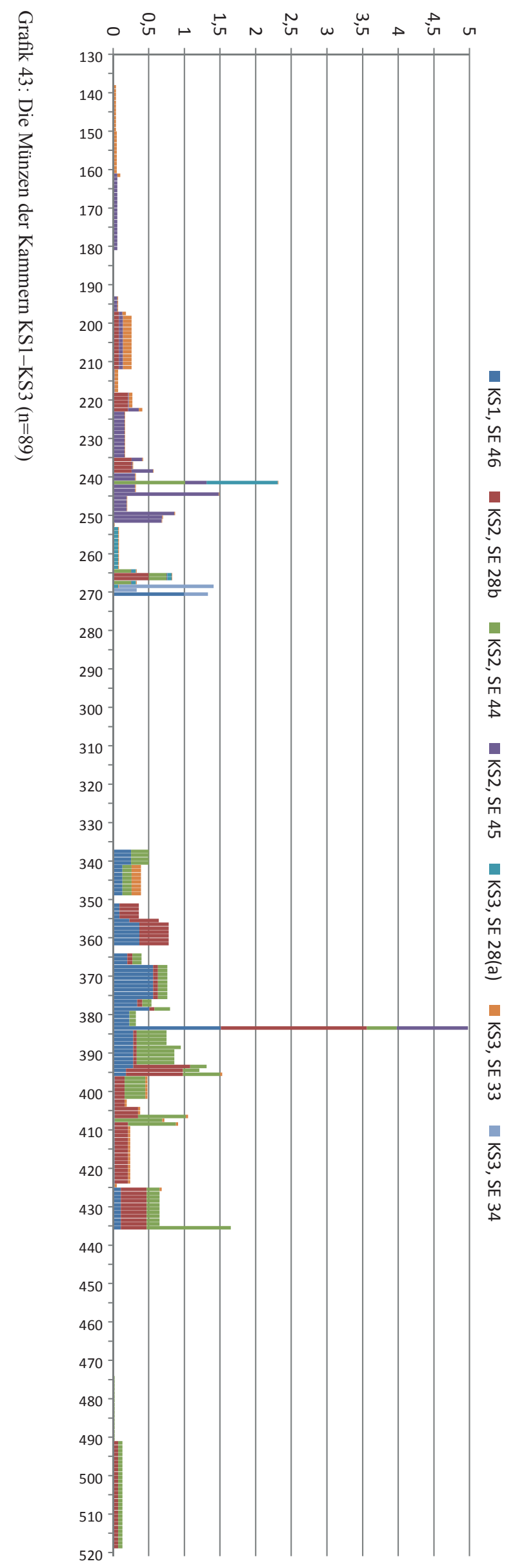




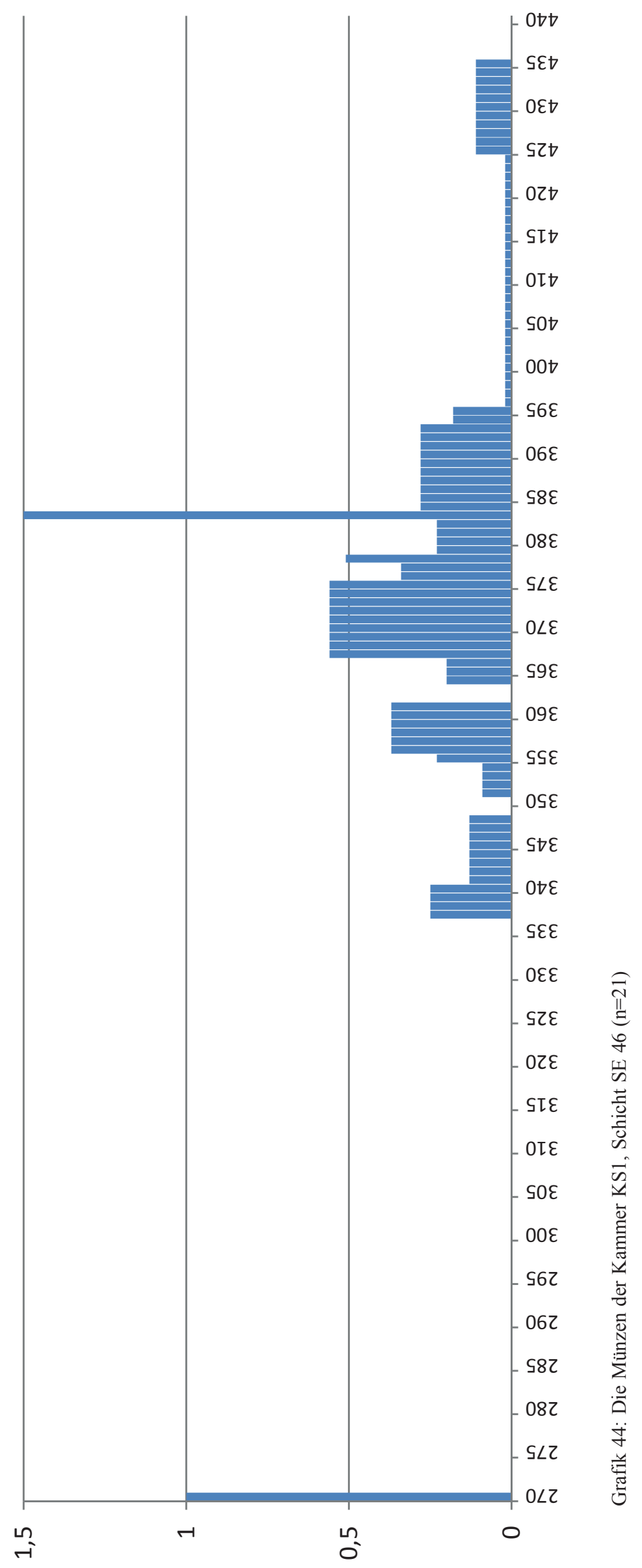




\begin{tabular}{|c|c|}
\hline KatNr. & Datierung \\
\hline M 122 & 270 n. Chr. \\
\hline M 140 & 337/340 n. Chr. \\
\hline M 138 & $341 / 348$ n. Chr. \\
\hline M 150 & 351/361 n. Chr. \\
\hline M 157 & \multirow[t]{2}{*}{ 355/361 n. Chr. } \\
\hline M 147 & \\
\hline M 169 & \multirow[t]{3}{*}{ 364/378 n. Chr } \\
\hline M 164 & \\
\hline M 170 & \\
\hline M 175 & \multirow[t]{2}{*}{ 367/375 n. Chr. } \\
\hline M 177 & \\
\hline M 178 & 367/378 n. Chr. \\
\hline M 180 & 367/383 n. Chr. \\
\hline M 174 & 378/383 n. Chr. \\
\hline M 181 & 383/392 n. Chr. \\
\hline M 190 & \multirow[t]{2}{*}{ 383/395 n. Chr. } \\
\hline M 214 & \\
\hline M 215 & 383/425 n. Chr. \\
\hline M 176 & 383 n. Chr. \\
\hline M 229 & 425/435 n. Chr. \\
\hline M 255 & kaiserzeitlich \\
\hline
\end{tabular}

Tab. 103: Die Münzen aus der Kammer KS1, Schicht SE 46 in chronologischer Abfolge
Im Folgenden sind die einzelnen Kammern unter Berücksichtigung der Stratigrafie ihrer Schutteinfüllungen noch einmal gesondert angeführt. Das Ziel dabei ist, zu untersuchen, ob sich frühere Prägungen des 2. und 3. Jhs. n. Chr. aus dem Geldverkehr der späteren Zeit erklären lassen, oder ob diese aus dem Zirkulationsvolumen vor dem großen Erdbeben des 3. Jhs. n. Chr. stammen. Die Nutzung der Kammern ab dem 4. Jh. n. Chr. hat jedenfalls nichts mehr mit dem Theater selbst zu tun.

Die Münzen aus der Kammer KS1 werden einer einzigen stratigrafischen Einheit (SE 46) zugeordnet, bei der es sich um eine Schuttschicht über dem Estrich handelt ${ }^{74}$. Bis auf ein Stück des Jahrs 270 n. Chr. bestehen die Verluste ausschließlich aus Münzen zwischen 337 und 435 n. Chr. (Grafik 44; Tab. 103). Die meisten Belegstücke sind der valentinianisch-theodosianischen Periode zuzuweisen. Die jüngsten Keramikfunde der Schicht SE 46 werden ins 6 . Jh. n. Chr. datiert, womit ein terminus post quem für die Einbringung des Schutts gegeben ist. Diese Schicht weist allerdings eine sehr heterogene Zusammensetzung mit Keramik vom 3. bis zum 6. Jh. n. Chr. auf ${ }^{75}$, sodass auch die Umlaufzeit der Münzen nicht mehr fassbar ist. Generell kann eine Zirkulation zumindest bis zum Ende des 4. und Anfang des 5. Jhs. n. Chr. postuliert werden. Das singuläre Stück des Aurelianus für Divus Claudius II. (M 122), das außerdem sehr stark abgenutzt ist, könnte zudem aus dem Geldverkehr der konstantinischen Zeit erklärt werden und bis ins späte 4. Jh. n. Chr. zirkuliert sein. Nach Aussage der Münzfunde müsste die Kammer KS1 schon im 5. Jh. n. Chr. oder - unter Annahme eines gewissen Verzögerungsfaktors - gegen Ende des Jahrhunderts mit Schutt verfüllt worden sein. Die Zirkulation der in Kammer KS1 aufgefundenen Münzen wird über 491/518 n. Chr. nicht hinausgegangen sein. Für eine Zirkulation der in der Schicht 46 auftretenden Münzen im 6. Jh. n. Chr. fehlen m. E. frühbyzantinische Prägungen; es müssten sich zumindest wenige Stücke von Anastasius I. finden.

Als etwas differenzierter manifestiert sich die Münzreihe von Kammer KS2 (Grafik 45; Tab. 104-106), die mit 66 Stücken auch den größten Teil des Fundbestands der drei Kammern lieferte. Die Münzen werden drei Schichten zugeschrieben, wobei die rezent gestörte Schicht 28b auch Material aus SE 44 und SE 45 enthält ${ }^{76}$. Die Münzkurve lässt auf den ersten Blick schon zwei unterschiedliche Verteilungsmuster erkennen. Die früheren Funde können dabei recht eindeutig der früher datierten Schicht SE 45 zugeordnet werden, die späteren dem Stratum SE 44. Aufgrund der recht zahlreichen Funde des 3. Jhs. n. Chr. müssen wir davon ausgehen, dass die Münzkurve bis Gallienus ein Abbild des Geldverkehrs um oder kurz vor 270 n. Chr. ist. Sie bildet relativ eindeutig das zirkulierende Volumen der Zeit vor dem großen Erdbeben des 3. Viertels des 3. Jhs. n. Chr. ab. Die Münzen befanden sich alle in einer einzigen Schuttschicht (SE 45), wobei auch der Großteil des keramischen Fundmaterials auf Erdbebenschutt des 3. Viertels des 3. Jhs. n. Chr. entfällt ${ }^{77}$.

Die Grafik zeigt für Kammer KS2 ferner die übliche Lücke von ca. 270 n. Chr. bis zur Zeit der Konstantinsöhne. Die konstantinisch-theodosianische Zeit weist auch hier den stärksten Niederschlag im Münzindex auf. Um 435 n. Chr. brechen die Verluste ab. Darüber hinaus ist der byzantinische Geldverkehr mit wenigen Stücken des Anastasius I. und/oder Zeno vertreten. Die Schicht SE 44 wird anhand der Keramik ins

\footnotetext{
${ }^{74}$ Kap. 3.6.2.1.

${ }^{75}$ Kap. 4.6.2.1

${ }^{76}$ Kap. 4.6.2.2.

${ }^{77}$ Die beiden frühbyzantinischen Fragmente gehören lt. freundlicher Mitteilung von A. Waldner und M. Hofbauer zu SE 44.
} 


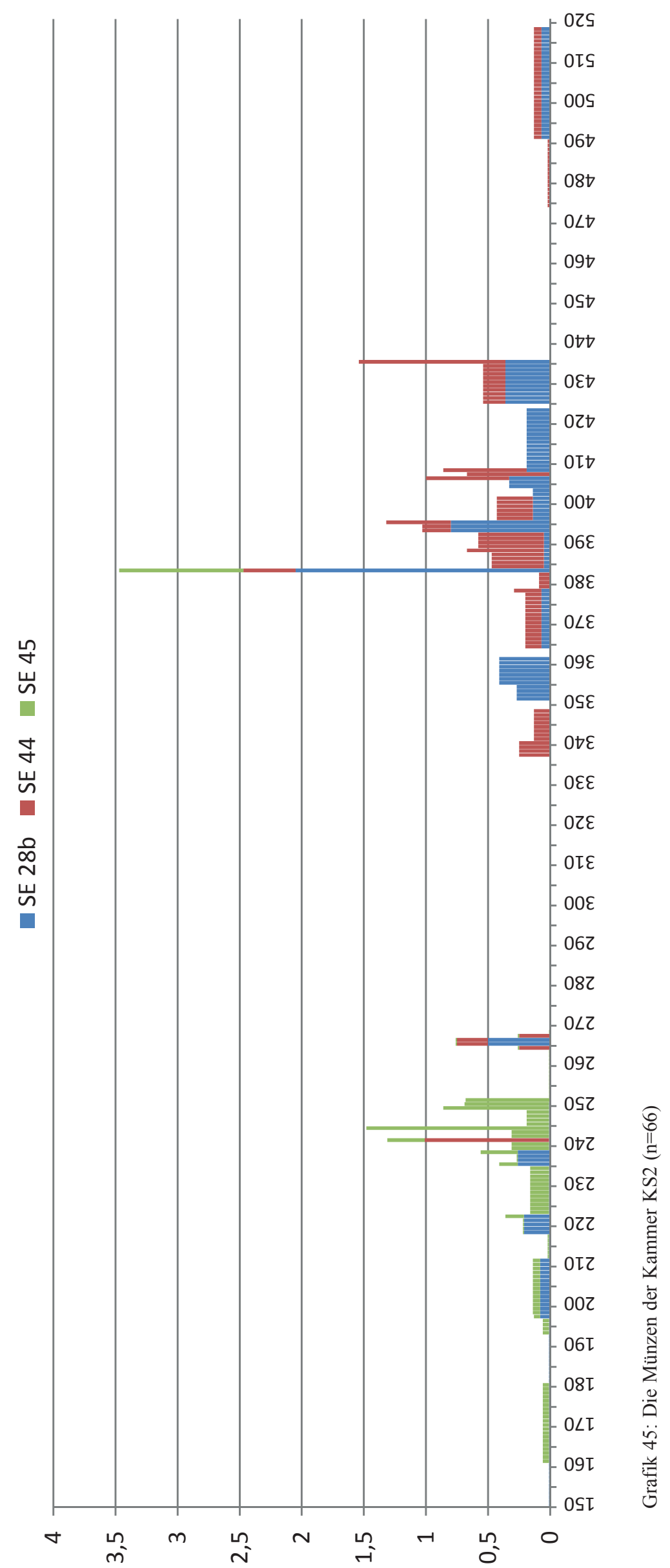




\begin{tabular}{|c|c|}
\hline KatNr. & Datierung \\
\hline M 95 & 23 v. Chr. -98 n. Chr. \\
\hline M 76 & 150/250 n. Chr. \\
\hline M 56 & 197/211 n. Chr. \\
\hline M 58 & 218/222 n. Chr. \\
\hline M 79 & 235/238 n. Chr. \\
\hline M 117 & 265/266 n. Chr. \\
\hline M 153 & \multirow[t]{3}{*}{ 351/361 n. Chr. } \\
\hline M 152 & \\
\hline M 151 & \\
\hline M 158 & 355/361 n. Chr. \\
\hline M 168 & 364/378 n. Chr. \\
\hline M 210 & 383/403 n. Chr. \\
\hline M 194 & \multirow[t]{2}{*}{383 n. Chr. } \\
\hline M 186 & \\
\hline M 195 & \multirow[t]{2}{*}{ 393/395 n. Chr. } \\
\hline M 192 & \\
\hline M 203 & 393/403 n. Chr. \\
\hline M 196 & 404/406 n. Chr. \\
\hline M 228 & \multirow[t]{3}{*}{ 408/423 n. Chr. } \\
\hline M 220 & \\
\hline M 218 & \\
\hline M 222 & \multirow[t]{4}{*}{ 425/435 n. Chr. } \\
\hline M 225 & \\
\hline M 226 & \\
\hline M 230 & \\
\hline M 236 & \multirow[t]{2}{*}{ 491/518 n. Chr. } \\
\hline M 235 & \\
\hline M 248 & \multirow[t]{2}{*}{ 5.-7. Jh. n. Chr. } \\
\hline M 249 & \\
\hline M 250 & unbestimmbar \\
\hline
\end{tabular}

Tab. 104: Die Münzen der Kammer KS2, Schicht 28b in chronologischer Abfolge

\begin{tabular}{|c|c|}
\hline KatNr. & Datierung \\
\hline M 109 & 241 n. Chr. \\
\hline M 118 & 264/267 n. Chr. \\
\hline M 136 & 337/340 n. Chr. \\
\hline M 142 & 341/348 n. Chr. \\
\hline M 171 & \multirow[t]{2}{*}{ 364/378 n. Chr. } \\
\hline M 165 & \\
\hline M 179 & 378/388 n. Chr. \\
\hline M 182 & 383/392 n. Chr. \\
\hline M 205 & \multirow[t]{3}{*}{ 383/395 n. Chr. } \\
\hline M 187 & \\
\hline M 209 & \\
\hline M 191 & 388/392 n. Chr. \\
\hline M 200 & \multirow[t]{2}{*}{ 395/401 n. Chr. } \\
\hline M 202 & \\
\hline M 199 & \multirow[t]{2}{*}{ 406/408 n. Chr. } \\
\hline M 216 & \\
\hline M 227 & \multirow[t]{2}{*}{ 425/435 n. Chr. } \\
\hline M 221 & \\
\hline M 223 & 435 n. Chr. \\
\hline M 232 & 474/518 n. Chr. \\
\hline M 234 & 491/518 n. Chr. \\
\hline M 258 & 5.-7. Jh. n. Chr. \\
\hline M 259 & unbestimmbar \\
\hline
\end{tabular}

\begin{tabular}{|c|c|}
\hline KatNr. & Datierung \\
\hline M 52 & 161/180 n. Chr. \\
\hline M 54 & 193/211 n. Chr. \\
\hline M 37 & 198/268 n. Chr. \\
\hline M 64 & \multirow[t]{2}{*}{ 222/235 n. Chr. } \\
\hline M 68 & \\
\hline M 83 & \multirow[t]{2}{*}{ 238/244 n. Chr. } \\
\hline M 69 & \\
\hline M 38 & 244/249 n. Chr. \\
\hline M 113 & 244 n. Chr. \\
\hline M 88 & \multirow[t]{2}{*}{ 249/251 n. Chr. } \\
\hline M 72 & \\
\hline M 173 & 383 n. Chr. \\
\hline M 254 & Lokalmünze \\
\hline
\end{tabular}

Tab. 106: Die Münzen der Kammer $\mathrm{KS} 2$, Schicht 45 in chronologischer Abfolge
Tab. 105: Die Münzen der Kammer KS2, Schicht 44 in chronologischer Abfolge

5./6. Jh. n. Chr. datiert. Diese Datierung deckt sich mit der Münzreihe, die ebenfalls bis ins 6. Jh. n. Chr. reicht. Ihr Schwerpunkt liegt auf Prägungen zwischen 383 und 435 n. Chr. Unter Einbeziehung eines coindrifts können wir annehmen, dass die meisten Münzen möglicherweise um die Mitte des 5. Jhs. n. Chr. in die Erde kamen, und die Einbringung der zweiten Schuttschicht in die Kammer KS2 im 6. Jh. n. Chr. erfolgt ist, wobei die spätesten in der Münzreihe überlieferten Stücke (M 232. M 234) hinzu kamen. Sie bilden gleichzeitig auch den terminus post quem für die Schuttablagerung in der Kammer.

Zusammenfassend kann festgehalten werden, dass nach Aussage der Münzreihe Schuttmaterial aus zwei unterschiedlichen Zeitperioden in der Kammer deponiert worden ist. Die erste Tranche bestand aus Schuttmaterial der Zeit vor dem großen Erdbeben; wann sie in die Kammer gebracht worden ist, bleibt unklar. Die zweite Schutttranche enthält Zirkulationsgeld der 1. Hälfte bis zur Mitte des 5. Jhs. n. Chr. und wurde nach $518 \mathrm{n}$. Chr. in der Kammer abgelagert. 


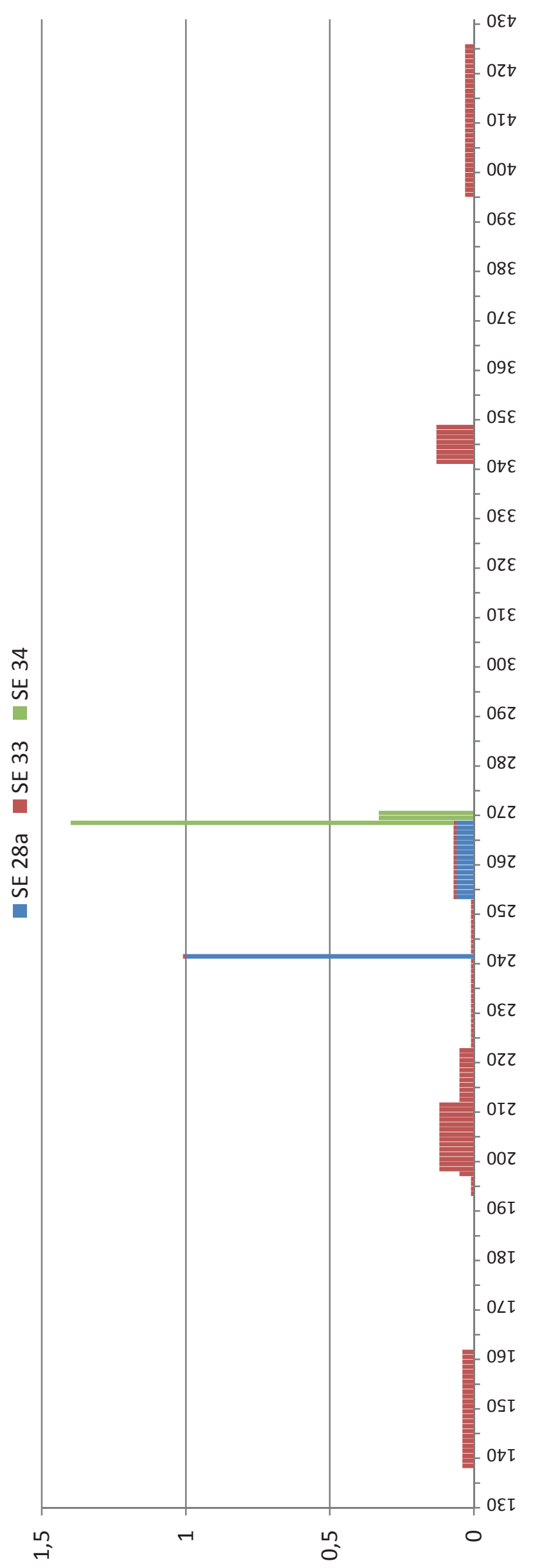

\begin{tabular}{|l|l|}
\hline KatNr. & Datierung \\
\hline M 110 & 241 n. Chr. \\
\hline M 73 & 253/268 n. Chr. \\
\hline
\end{tabular}

Tab. 107: Münzen der Kammer KS3, Schicht 28a

\begin{tabular}{|l|l|}
\hline KatNr. & Datierung \\
\hline M 2 & 138/161 n. Chr. \\
\hline M 100 & 193/268 n. Chr. \\
\hline M 63 & 197/222 n. Chr. \\
\hline M 57 & 198/211 n. Chr. \\
\hline M 143 & 341/348 n. Chr. \\
\hline M 213 & 395/425 n. Chr. \\
\hline M 251 & 5.-7. Jh. n. Chr. \\
\hline
\end{tabular}

Tab. 108: Münzen der Kammer KS3, Schicht 33

\begin{tabular}{|l|l|}
\hline KatNr. & Datierung \\
\hline M 120 & 268/270 n. Chr. \\
\hline M 123 & 270 n. Chr. \\
\hline M 256 & $192 / 425$ n. Chr. \\
\hline
\end{tabular}

Tab. 109: Münzen der Kammer KS3, Schicht 34 
Aus der größten der drei Kammern, KS3, sind am wenigsten Münzfunde überliefert (Grafik 46; Tab. 107-109). Es handelt sich um insgesamt zwölf Stück, die drei stratigrafischen Einheiten zugeordnet werden ${ }^{78}$. Die Münzfunde der Kammer erstrecken sich in Summe vom 2. bis ins beginnende 5. Jh. n. Chr. Die Keramikfunde sprechen für eine Datierung der Schichten ins 5. und 6. Jh. n. Chr., wobei die Schichten SE 28a und SE 34 ins 5. Jh. n. Chr. datiert werden. Die Münzen dieser Schichten stammen hauptsächlich aus dem 3. Jh. n. Chr., was allerdings aufgrund ihrer geringen Zahl wenig aussagekräftig ist. Aus der ins 6. Jh. n. Chr. reichenden Schicht SE 33 sind die meisten Objekte erhalten, sie streuen allerdings vom 2. bis zum 5. Jh. n. Chr., weisen jedoch auch die spätesten Münzen auf ${ }^{79}$. Summa summarum kann man lediglich festhalten, dass sich die Münzfunde der Kammer KS3 vom 2. bis zum 5. Jh. n. Chr. erstrecken, wobei sich ein Schwerpunkt der Funde im 3. Jh. n. Chr. manifestiert.

\subsubsection{Münzfunde an der Stiegengasse, im Süden des Theaters (Grafik 47)}

Über der Stiege südlich des Theaters befanden sich massive Schichten, die mit den Zerstörungen durch das große Erdbeben des 3. Jhs. n. Chr. in Verbindung gebracht werden ${ }^{80}$. Der Schutt stammte höchstwahrscheinlich aus der südlich angrenzenden Insula. In der Fundliste sind die Münzfunde nach Grabungsbereichen und Schichten geordnet. Zum Überblick sind sie nochmals mit ihren Prägezeiten angeführt (Tab. 110). Insgesamt stammen 45 Münzen aus dem Bereich der Stiegengasse. Die Grafik erfasst sowohl die stratifizierten als auch die Streufunde. Die unbestimmbaren Stücke sowie die beiden modernen Imitationen M 282 und M 283 (Taf. 360) wurden weggelassen.

Unter der Prämisse, dass die Münzfunde aus dem Bereich der Stiegengasse aus dem Schutt der benachbarten Insula stammen, lässt sich Folgendes feststellen: Die Münzreihe reicht von frühhellenistischer bis in spätrömische Zeit. Ein erster Schwerpunkt manifestiert sich mit Prägungen des 3. Jhs. v. Chr. Diese Münzen stehen vermutlich in Zusammenhang mit der Errichtung der Gebäude der Insula und bilden dafür einen terminus post quem. Die nächsten Aktivitäten lassen sich in augusteischer und flavischer Zeit feststellen. Die Münze M 4 (Taf. 355), die ca. von 40 bis 60 n. Chr. datiert, wird wohl zum Münzvolumen der flavischen Zeit gehört haben. Ab Hadrian geht die Münzreihe bis zur Mitte des 3. Jhs. n. Chr. durch, sodass wir von einer kontinuierlichen Entwicklung bzw. Nutzung der Gebäude ausgehen können. Nach Gallienus kommt es dann zu einem Einschnitt in der Münzkurve, der bis zur Mitte des 4. Jhs. n. Chr. reicht. Dies wird die Zeitspanne betreffen, in der die Gebäude durch das Erdbeben zerstört und verschüttet waren. Frühestens in der 2. Hälfte des 4. Jhs. n. Chr. - eher zu Beginn des 5. Jhs. n. Chr. - begann dann offenbar der Wiederaufbau. Die jüngsten Münzen (M 198; M 217 Taf. 359) könnten einen terminus post quem für die Beendigung der Aufräumarbeiten und der Schuttbeseitigung aus der Insula darstellen. Diese Hypothese wird durch die Tatsache gestützt, dass sich das 3. Jh. n. Chr. in den Münzverlusten der Stiegengasse ungewöhnlich stark im Vergleich zum 4. Jh. n. Chr. niederschlägt. In der Regel sind das 4. und 5. Jh. n. Chr. bzw. die Zeit bis Heraclius stärker vertreten (vgl. Hanghaus 1, Basilika, spätantikes Gebäude in den Verulanushallen). Diese fehlt hier völlig. Das Abreißen der Münzreihe mit 425 n. Chr. wäre anders kaum zu erklären.

Summa summarum werden für den Münzbestand der Freitreppe südlich des Theaters folgende Evidenzen deutlich: Es handelt sich bei dem Material höchstwahrscheinlich um Schutt, verursacht durch das Erdbeben des 3. Viertels des 3. Jhs. n. Chr. Die Münzreihe vor 270 n. Chr. gibt zum größten Teil ein Abbild des zirkulierenden Volumens zu diesem Zeitpunkt wieder. Die früheren Stücke im Spektrum sind mit Aktivitäten der vorangehenden Perioden bis zur flavischen Zeit in Verbindung zu bringen. Bis zum Beginn oder zur Mitte des 5. Jhs. n. Chr. war das Material unberührt, danach begann man, den Schutt aus der Insula zu entfernen und in der Stiegengasse zu deponieren. Einen terminus post quem für die Aufräumarbeiten geben die Münzen M 217 (Taf. 359), ein Streufund, und M 198; bei beiden handelt es sich um den GLORIA ROMANORVM-2 KaiserTyp der Prägeperiode 408/423 n. Chr. Das letzte Stück der Münzreihe bildet eine nicht zuordenbare 5-NummiMünze des 6. oder 7. Jhs. n. Chr. (M 247), die mit Keramikmaterial des 5. bis 6. Jhs. n. Chr. vergesellschaftet war (SE 222) und keine Aussagekraft mehr für die Aufräumungsarbeiten der Insula bietet.

\footnotetext{
${ }^{78}$ Kap. 3.6.2.3 u. 4.6.2.3.

${ }^{79}$ Kap. 4.6.2.3. Das Phänomen, dass Material des 3. Jhs n. Chr. mit Funden des 5. und 6. Jhs. n. Chr. vergesellschaftet ist, zeigt sich in diesem Zusammenhang auch in der Keramik.

${ }^{80}$ Kap. 3.7.2 u. 4.7.2.
} 


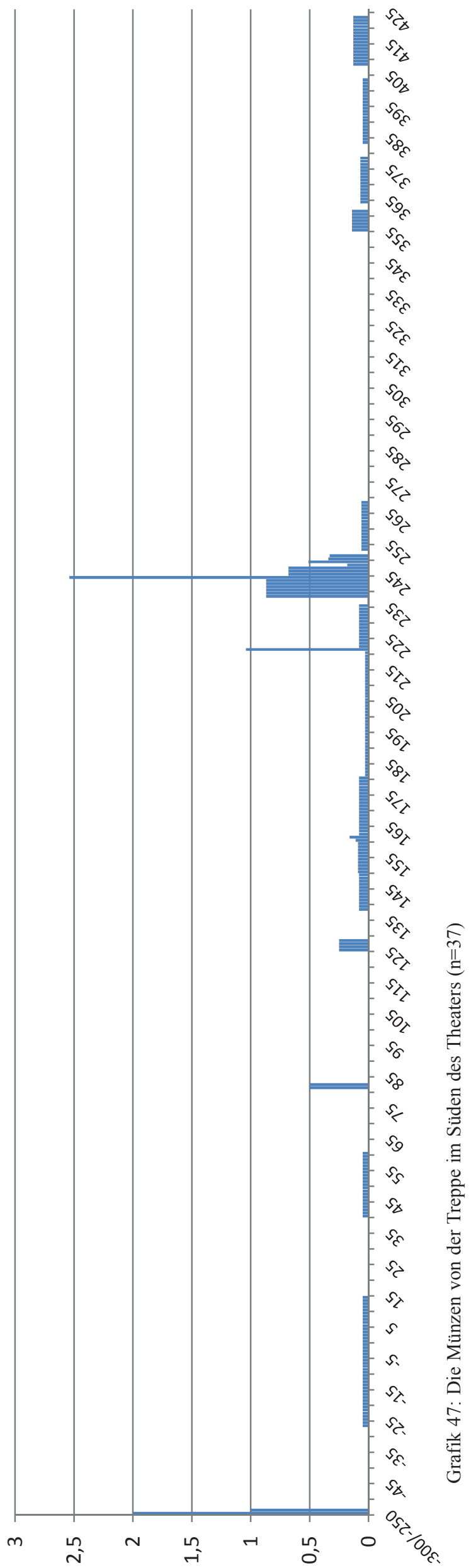

\begin{tabular}{|c|c|c|c|}
\hline $\begin{array}{l}\text { Grabungs- } \\
\text { fläche }\end{array}$ & SE & KatNr. & Prägezeit \\
\hline \multirow[t]{7}{*}{ B1 } & \multirow[t]{5}{*}{7} & M 20 & 150/250 n. Chr. \\
\hline & & M 85 & 238/244 n. Chr. \\
\hline & & M 114 & 244 n. Chr. \\
\hline & & M 112 & 244/247 n. Chr. \\
\hline & & M 115 & 251/253 n. Chr. \\
\hline & 9 & M 6 & 295-280 v. Chr. \\
\hline & 15 & M 106 & $81 / 82$ n. Chr. \\
\hline \multirow[t]{5}{*}{ B2 } & 4 & M 92 & 238/244 n. Chr. \\
\hline & \multirow[t]{2}{*}{12} & M 75 & $\begin{array}{l}\text { ca. } 150 / 250 \mathrm{n} . \\
\text { Chr. }\end{array}$ \\
\hline & & M 198 & 408/423 n. Chr. \\
\hline & \multirow[t]{2}{*}{14} & M 104 & $\begin{array}{l}\text { prinzipatszeitliche } \\
\text { Lokalprägung }\end{array}$ \\
\hline & & M 105 & $\begin{array}{l}\text { prinzipatszeitliche } \\
\text { Lokalprägung }\end{array}$ \\
\hline $\mathrm{C} 1 / \mathrm{C} 2$ & 132 & M 84 & 238/244 n. Chr. \\
\hline $\mathrm{C} 1 / \mathrm{D} 1$ & 153 & M 108 & $\begin{array}{l}\text { 161/180 n. Chr. } \\
\text { (zeitgenössisches } \\
\text { Falsum) }\end{array}$ \\
\hline \multirow[t]{2}{*}{ C2 Erw. } & \multirow[t]{2}{*}{$121 \mathrm{a}$} & M 107 & 125/128 n. Chr. \\
\hline & & M 103 & $\begin{array}{l}\text { prinzipatszeitliche } \\
\text { Lokalprägung }\end{array}$ \\
\hline $\mathrm{F} 1$ & 170 & M 66 & 222/235 n. Chr. \\
\hline \multirow[t]{2}{*}{ F2 } & 174 & M 70 & 238/244 n. Chr. \\
\hline & 231 & M 207 & 383/403 n. Chr. \\
\hline \multirow[t]{3}{*}{ G1 } & 193 & M 35 & 138/161 n. Chr. \\
\hline & 200 & M 87 & 244/249 n. Chr. \\
\hline & 222 & M 101 & $\begin{array}{l}\text { prinzipatszeitliche } \\
\text { Lokalprägung }\end{array}$ \\
\hline \multirow[t]{3}{*}{$\mathrm{H} 1$} & 195 & M 14 & 258-202 v. Chr. \\
\hline & $196=227$ & M 47 & 138/161 n. Chr. \\
\hline & $207=198$ & M 19 & 2. Jh. n. Chr. \\
\hline $\mathrm{H} 2$ & 222 & M 247 & frühbyzantinisch \\
\hline $\mathrm{J} 1$ & 124 & M 62 & $221 \mathrm{n} . \mathrm{Chr}$. \\
\hline \multirow[t]{3}{*}{ K2 } & 127 & M 99 & 98/268 n. Chr. \\
\hline & \multirow[t]{2}{*}{130} & M 282 & modernes Falsum \\
\hline & & M 283 & modernes Falsum \\
\hline
\end{tabular}

Tab. 110: Die stratifizierten Fundmünzen von der Treppe im Süden des Theaters 


\subsection{ZUSAMMENFASSUNG}

Die griechisch-hellenistischen Münzen stammen großteils aus dem 3. Jh. v. Chr. und gehörten wohl zum Umlaufvolumen in der 1. Hälfte des 2. Jhs. v. Chr. Die Funde wurden in erster Linie im Bereich des Bühnengebäudes gemacht, decken sich also mit dem Areal der Theaterterrasse. Die Fundmünzen geben aber keinerlei chronologische Anhaltspunkte für die Datierung der Bauphasen des Bühnengebäudes. Es handelt sich ausschließlich um Kleingeld, das im Zuge von Aktivitäten des Nahverkehrs verloren wurde. Der Geldverkehr dieser Zeit hatte lokalen Charakter, denn der Großteil der Münzen dieser Zeit wurde in Ephesos selbst produziert.

Im 1. Jh. v. Chr. nehmen die Münzfunde ab, um dann mit Augustus wieder stark anzusteigen. Diese Evidenz deckt sich mit den baulichen Aktivitäten im Theater in augusteisch-tiberischer Zeit. Ab dieser Periode ändert sich die Zusammensetzung des zirkulierenden Volumens grundsätzlich. Vom 1. bis zur Mitte des 3. Jhs. n. Chr. dominieren kaiserzeitliche Lokalprägungen den Geldverkehr. Sie setzen sich vor allem aus kleineren Buntmetall-Nominalien zusammen, die für Alltagsgeschäfte verwendet wurden. Größere Nominalien sind nur selten vertreten. Wie in anderen ephesischen Fundkomplexen geht das Verlustniveau nach Augustus wieder stark zurück, wobei davon auszugehen ist, dass sich das Zirkulationsvolumen noch längere Zeit aus augusteischen Prägungen speiste. Ab trajanisch-hadrianischer Zeit steigt die Münzkurve des Theaters, wie auch jene anderer ephesischer Fundstellen (z. B. Hanghaus 1), wieder an und geht bis in die 2. Hälfte des 3. Jhs. n. Chr. ohne Unterbrechung durch. Dies bedeutet für das Theater eine kontinuierliche Nutzung nach dem großen Umbau in flavisch-trajanischer Zeit. Das zirkulierende Geld setzt sich vor allem aus ephesischen Lokalprägungen zusammen, ein Drittel des Materials kam aus nicht mehr als $200 \mathrm{~km}$ Luftlinie entfernten Städten Kleinasiens. Im Fundbestand des Theaters nehmen ab Maximinus I. Thrax die ephesischen zugunsten fremder Prägungen ab, eine Evidenz, die jedoch an anderen Fundstellen nicht nachweisbar ist.

$\mathrm{Ab}$ der Mitte des 3. Jhs. n. Chr. schlagen sich aufgrund der Einstellung der Lokalprägungen ab Gallienus nur mehr Reichsmünzen im Fundbestand des Theaters nieder. Das Fundniveau steigt zwar mit den Massenemissionen zwischen Gallienus und Divus Claudius II. etwas an. Der Anstieg ist hier etwa gleich hoch wie in der Basilika am Staatsmarkt, im Hanghaus 1 jedoch ungleich höher. Man wird aber von kontinuierlicher Nutzung bis zum großen Erdbeben im 3. Jh. n. Chr. ausgehen können. Da die Münzreihe an vielen Stellen (Theater, Hanghaus 1, spätantike Residenz in den Verulanushallen, Basilika) jedoch ohne Unterbrechung mindestens bis $270 \mathrm{n}$. Chr. durchgeht, müsste die Übereinstimmung mit den Zerstörungen des für $262 \mathrm{n}$. Chr. postulierten Erdbebens noch einmal überdacht bzw. ein Einfluss der Gotenplünderungen von 261/262 n. Chr. und stärker von 267/268 n. Chr. eingehend überprüft werden.

Zwischen 270 und 295/299 n. Chr. manifestiert sich eine Lücke in der Münzkurve des Theaters, eine Evidenz, die an vielen Stellen in Ephesos auftritt. Die zahlreichen Follis-Teilstücke der Phase 295/299 n. Chr. stehen etwas isoliert, treten jedoch auch in mehreren Komplexen auf, sodass man von einem allgemeinen Phänomen sprechen kann.

Das 4. Jh. n. Chr. bildet einen Schwerpunkt im Fundmünzaufkommen nicht nur des Theaters, sondern allgemein in Ephesos. Die Münzreihe des Theaters setzt wieder verstärkt mit Prägungen ab $330 \mathrm{n}$. Chr. ein und verläuft durchgehend bis $435 \mathrm{n}$. Chr. Die stärkste Belegung ist zwischen 351 und $395 \mathrm{n}$. Chr. anzutreffen. Ab dieser Zeit fanden verstärkt Umbauten im Theater statt, insbesondere an den Analemmata in Form von Umgestaltungen von Kammern und vomitoria. An Nominalien ist der gängige Buntmetallvorrat vertreten. Ephesos wurde im 4. Jh. n. Chr. vor allem mit Material aus den näher gelegenen Münzstätten versorgt, allen voran Cyzicus. Während vor $348 \mathrm{n}$. Chr. noch Nicomedia und Heraclea eine bedeutende Rolle in der Versorgung der Stadt spielen, übernimmt nach $348 \mathrm{n}$. Chr. Constantinopolis diese Bedeutung.

Nach 435 n. Chr. manifestiert sich zwar eine Zäsur im Münzindex, die bis Zeno und Anastasius I. andauert, doch ist generell zu überdenken, ob nicht die überall zahlreich auftretenden unbestimmbaren frühbyzantinischen Minimi bzw. Nummi diese Lücke gefüllt haben könnten, sodass man von einem durchgehenden Münzverkehr von der spätrömischen bis in die frühbyzantinische Periode sprechen könnte. Die byzantinische Münzreihe läuft mit einem auch andernorts beobachtbaren Rückgang unter Tiberius II. bis Phocas bis in die ersten Regierungsjahre des Heraclius durch und bricht mit Prägungen von 615/616 n. Chr. ab. Diese Evidenz wird man - wie schon N. Schindel für die Kuretenstraße nachgewiesen hat - großräumig 
wohl mit dem Persersturm in Verbindung bringen können. Zuvor wurde das Theater in die byzantinische Verteidigungsanlage integriert. Der Abbruch der Münzreihe mit Prägungen von 615/616 n. Chr. manifestiert sich insbesondere im Nordbereich des Theaters, was hier allerdings nur einen terminus post quem für den Versturz des Nord-Analemma angibt. An Nominalien sind zunächst kleinere Einheiten (Minimi, Nummi, 5-Nummi-Stücke) vertreten; ab der Mitte des 6. Jhs. n. Chr. schlagen sich vorrangig 40-Nummi-Stücke in den Funden nieder. Der Großteil der Münzen wurde in der frühbyzantinischen Periode von Constantinopolis aus geliefert, aber auch Nicomedia sowie Cyzicus und Thessalonica übernahmen einen guten Teil der Versorgung.

Ein separat zu betrachtender Fundbestand ist jener von der Stiegengasse, der sich aus dem Schuttmaterial der südlich angrenzenden Insula zusammensetzt, das im 5. Jh. n. Chr. im Zuge des Wiederaufbaus derselben auf der Treppe südlich des Theaters deponiert wurde. Darin spiegelt sich einerseits ein Abbild des Münzvolumens der Zeit um ca. 270 n. Chr., andererseits das Ende der Aufräumarbeiten infolge der Zerstörungen des lange davor liegenden Erdbebens. Darüber hinaus fand sich in diesem Material auch ein Cistophoren-Hort mit terminus post quem unter Hadrian, der offensichtlich einem Bewohner der Insula als finanzielle Rücklage gedient hatte und aus unerfindlichen Gründen nicht mehr geborgen wurde.

\subsection{KATALOG DER FUNDMÜNZEN IN CHRONOLOGISCH-GEOGRAFISCHER ORDNUNG}

Der chronologisch-geografische Katalog ist nach rein numismatischen Kriterien geordnet. Die griechischen Münzen sind nach der Eckhel'schen Abfolge zuerst geografisch, dann chronologisch angeordnet. Danach sind als eigenes Kapitel die römisch-kaiserzeitlichen Cistophore eingeschoben, gefolgt von römisch-kaiserzeitlichen Provinzialprägungen, die wiederum dem geografischen Prinzip und innerhalb dessen chronologischer Ordnung folgen. Die römisch-kaiserzeitlichen Reichsmünzen sind nach der Göbl'schen Prägeabfolge angeordnet, die byzantinischen Prägungen nach Hahn. Es folgen die Münzen des Osmanischen Reichs; den Abschluss bilden moderne Stücke, die alphabetisch nach Staaten geordnet sind. Ganz zum Schluss sind moderne Falsa angeführt. Antike zeitgenössische Imitationen werden jeweils am Ende eines chronologischen Abschnitts aufgelistet.

Zu jeder Münze werden die Münzstätte und das Nominale nach den gängigen Abkürzungen von FMRÖ und TNRB angegeben, gefolgt von der Datierung des jeweiligen Stücks. Danach folgen die technischen Daten, die sich aus dem Gewicht in Gramm, dem Durchmesser in Millimeter und der Stempelstellung, d. h. der Abweichung der Vorderseiten- von der Rückseitenachse des Bilds, nach dem Zifferblatt der Uhr zusammensetzen. Nach einer summarischen Vorderseiten- und Rückseitenbeschreibung werden technische Besonderheiten sowie der Erhaltungsgrad der Münze angegeben. Dieser bezieht sich auf die Abnützung des Stücks ${ }^{81}$. Zum Schluss folgen die Fundnummer, die sich aus der Nummer und dem Fundjahr zusammensetzt, der Fundort sowie die näheren Fundumstände. Bei den Büstenbeschreibungen der Averse werden die gängigen Abkürzungen gemäß des Wiener Kanons nach TNRB und FRMÖ verwendet.

\footnotetext{
${ }^{81}$ Sie folgt dem Schema des Inventars der Fundmünzen der Schweiz. Abnutzung und Korrosion. Bestimmungstafeln zur Bearbeitung von Fundmünzen, Bulletin IFS ITMS IRMS 2, Supplément, 1995.
} 


\section{Griechen}

\section{Makedonien: Alexander III. (posthum)}

M 1 Mzst.?

Taf. 355

Dr

$320 / 275$ v. Chr.

3,23. 17.1

Av.: Leg. unlesbar, Herakleskopf r.

Rv.: Leg. unlesbar, Zeus 1. sitzend

gelocht, Erh. 4

1/2003; Logeion; S 2/2003; Oberflächenabhub

\section{ThrakiEn: Bizya (AUTONOM)}

M 2 AE

138/161 n. Chr.

4,22. 19. 12

Av.: keine Leg., Poseidonkopf 1.

Rv.: Leg. unlesbar, Artemis als Jägerin n. r., zieht Pfeil aus

Köcher, davor Hund

Erh. 5

RPC IV 9315

66/2007; Süd-Analemma; KS3; SE 33

Troas: Alexandria Troas (autonom), Conventus von Adramyteum

M 3 AE

160/220 n. Chr.

5,96. 25.7

Av.: Leg. unlesbar, Büste der Tyche mit Mauerkrone r.

Rv.: Leg. unlesbar, Fortuna 1. st. mit Apollonstatue und Standarte

Erh. 4

RPC IV 3174

12/2008; Stiegengasse Theater-Süd; ES2-ES3; Grabungsschutt

\section{Mysien: Pergamon (autonom)}

M 4 AE

$40 / 60$ n. Chr.

2,67. 16.7

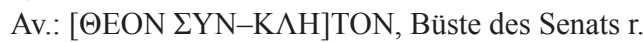

Rv.: $\Theta E A N ~ P \Omega-M H N$, Romabüste r.

RPC I 2374

Av dezentriert, Erh. 4

18/2007; Stiegengasse Theater-Süd; Treppe-Ost; C2; SE 1 (Oberfläche)

\section{IONIEN: EPHESOS}

\section{5 AE}

387/295 v. Chr.

1,25. 11.9

Av.: [E- $\Phi]$, Biene

Rv.: [Beamtenname], kniende Hirschkuh 1., Kopf r. korrodiert, aufgeglüht, Erh. 5
SNG Cop 254-255

2/2002; hellenistisches Bühnengebäude; Kammer D3; S 2/2002; B6

M 6 AE

$295 / 280$ v. Chr.

3,55. 17. 12

Av.: [E- $\Phi]$, Biene in Kranz

Rv.: [Beamtenname], kniende Hirschkuh 1., Kopf r., darüber Köcher

korrodiert, Erh. 5

SNG Cop 260-261

11/2007; Stiegengasse Theater-Süd; Zugangspodest ES3; B1; SE 9

M $7 \quad$ AE

$295 / 280$ v. Chr.

1,56. 11.7

Av.: [E- $\Phi]$, Biene?

Rv.: [Beamtenname], kniende Hirschkuh 1., Kopf r.

Erh. 5

SNG Cop 262

3/2004; Terrassenmauer nördl. der byzantinischen Stadtmauer; Oberflächenreinigung

M 8 AE

$295 / 280$ v. Chr.

1,21. 10. 12

Av.: [E- $\Phi]$, Biene?

Rv.: [Beamtenname], kniende Hirschkuh 1., Kopf r.

korrodiert, aufgeglüht, Erh. 4

SNG Cop 262

3/2005; hellenistisches Bühnengebäude; Kammer D8; S 2/2005; B15

M 9 AE

$295 / 280$ v. Chr.

3,02. 19. 12

Av.: $\mathrm{E}-\Phi$, Biene

Rv.: [Beamtenname], Hirschkuh r., darüber Köcher

Taf. 355 korrodiert, Erh.4

SNG Cop 263-264

6/2005; hellenistisches Bühnengebäude; Kammer D8; S

2/2005; SE B19 (Treppenfundament)

M $10 \quad$ AE

Taf. 355

$295 / 280$ v. Chr.

1,23. 11.12

Av.: E- $\Phi$, Biene in Kranz

Rv.: [Beamtenname], Hirschkuh r.

Erh. 3

SNG Cop 265-266

8/2009; summa cavea; Reinigung

M 11 AE

$295 / 280$ v. Chr.

1,81. 13. 9

Av.: [E- $\Phi]$, Biene

Rv.: [Beamtenname], Hirschkuh r. 
korrodiert, Erh. 5

SNG Cop 266

12/2003; Logeion; S 3/2003; L4

M 12 AE

295/280 v. Chr.

5,13. 16. 12

Av.: [E- $\Phi]$, Biene in Kranz

Rv.: [Beamtenname], äsende Hirschkuh r., darüber Köcher korrodiert, Erh. 4

SNG Cop 268. 269; SNG Tüв 2774/1

1/2005; hellenistisches Bühnengebäude; Kammer D8; S 2/2005; B13

M 13 AE

Taf. 355

295/280 v. Chr.

3,48. 17.1

Av.: [E- $\Phi]$, Biene in Kranz

Rv.: [Beamtenname], äsende Hirschkuh r., darüber Köcher

Erh. 4

SNG Cop 268. 269; SNG Tüв 2774/1

5/2006; unteres Diazoma, T1; S 8/2006

M 14 AE

258/202 v. Chr.

3,44. 14. 6

Av.: Leg. unlesbar, Artemisbüste r.

Rv.: [Beamtenname], Hirschkuhprotome r., Kopf 1.

Erh. 4

SNG Cop 281. 282; SNG Mü 20, 66. 67

3/2009; Stiegengasse Theater-Süd; Treppe-West; H1; SE 195

M 15 AE

258/202 v. Chr.

3,32. 19. ?

Av.: keine Leg., Artemisbüste r.

Rv.: [Beamtenname], Hirschkuhprotome r., Kopf 1.

verkrustet, Erh. 5

SNG Cop vgl. 281; BMC Ionia 118

1a/2009; Stiegengasse Theater-Süd; Zugangspodest ES2; E2;

Reinigung hinter oberem Diazoma

M 16 AE

$48 / 27$ v. Chr.

6,65. 19. 3

Av.: keine Leg., Artemisbüste r.

Rv.: [EФ, Beamtenname], Hirschkuhprotome r., Kopf 1.

Erh. 5

SNG Cop 338-341

9a/1993; Süd-Analemma; Streufund
M $17 \quad$ AE

ca. $300 / 23$ v. Chr.

0,6.9.?

Av.: Leg. unlesbar, Kopf

Rv.: Leg. unlesbar, Bild unkenntlich

Erh. 5

6/1998; Streufund

M 18 AE

ca. 300 v. Chr./14 n. Chr.

6,64. 20. ?

Av.: Leg. unlesbar, Bild unkenntlich

Rv.: Leg. unlesbar, Hirschkuh r.

korrodiert, aufgeglüht, Erh. 5

4/2006; unteres Diazoma, T11; S 6/2006

\section{IONIEN: SMYRNA (AUTONOM)}

M 19 AE

Taf. 355

ca. $100 / 200$ n. Chr.

2,9. 18.7

Av.: ZEY $\Sigma$ AKPAIO $\Sigma$, belorbeerter Zeuskopf r.

Rv.: $\Sigma$ MYPNAI $\Omega N$, Prora r.

Erh. 3

SNG Cop 1290. 1291

9/2009; Stiegengasse Theater-Süd; Treppe-West; H1; SE 207 = 198

\section{Lydien: ThyATEIRA (AUTONOM)}

M 20 AE

ca. $150 / 250$ n. Chr.

5,38. 23.6

Av.: Leg. unlesbar, Artemisbüste 1. (Artemis Boreitene)

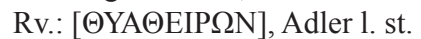

Erh. 5

SNG Cop 578; SNG Aul 3213; SNG Leyp 1269-1272

13/2007; Stiegengasse Theater-Süd; Zugangspodest ES3; B1; SE 7

\section{GRIECHEN: INCERTUM}

\section{M $21 \quad \mathbf{A E}$}

ca. $300 / 23$ v. Chr.

1,22. 11. ?

Av.: Leg. unlesbar, Bild unkenntlich

Rv.: Leg. unlesbar, Bild unkenntlich

korrodiert, aufgeglüht, Erh. 5

2/2005; hellenistisches Bühnengebäude; Kammer D8; S 2/2005; B15 


\section{Rom/Cistophore ${ }^{82}$}

Claudius I. (41-54 N. Chr.)

M 22 Cist

$50 / 51 \mathrm{n} . \mathrm{Chr}$

9,6. 27. ?

Av.: TI CLAVD CAES AVG AGRIPP AVGVSTA, gestaffelte

Büsten des Claudius u. der Agrippina 1.

Rv.: DIANA EFESIA, Statue der Artemis Ephesia

Erh. 2

RIC I² 119; RPC 2224 (Ephesos)

6/1993; Süd-Analemma (dzt. in Ausstellung, Museum Selçuk)

Claudius I. (41-54 n. Chr.)

für Claudius I. und Agrippina

M 23 Cist

41/42 n. Chr.

10. 28.6

Av.: TI CLAVD - CAESAR, $1 \mathrm{~K}$

Rv.: ROM ET AVG, COM - ASI, Tempel mit Statuen der Roma und des Augustus in militärischer Tracht mit Speer

Erh. 2

RIC I² 120; RPC 2221 (Pergamum)

10/1993; Süd-Analemma (dzt. in Ausstellung, Museum Selçuk)

\section{Nerva (96-98 n. Chr.)}

M 24 Cist

Taf. 355

97 n. Chr.

9,31.26. 7

Av.: IMP NERVA CAES AVG - P M TR POT P P, Lk2

Rv.: DIANA PERG, COS - III, Tempel mit Kultbild

Erh. 3

RIC II 116 (Asia minor); WoYTeK 2010, Typ 3a (Rom)

IV/1997; Süd-Analemma; vomitorium ES1

\section{25 Cist}

98 n. Chr.

8,35.27. 7

Av.: IMP NERVA CAES AVG - GERM P M TR POT P P, Lk2

Rv.: COS - IIII, 6 Ähren

Erh. 3

RIC II 125 (Asia minor); WoYTeK 2010, Typ 6 (Rom)

V/1997; Süd-Analemma; vomitorium ES1

\section{Traianus (98-117 n. Chr.)}

M 26 Cist

Taf. 355

98 n. Chr.

8,94.28. 6

Av.: IMP NERVA CAES TRAIAN AVG - GERM P M TR P P

P COS II, Lk1
Rv.: ROM ET AVG, COM - ASI, Tempel mit Statuen der Roma und des Augustus mit nacktem Oberkörper und Szepter Erh. 3

Woytek 2010, Typ 4 (Rom); RIC II vgl. 723 (Asia minor) (Av: IMP CAE NERVA TRAIAN AVG GERM P M, Rv: TR POT COS II, COM ASI (i.A.)

12/1998; Süd-Analemma; vomitorium SE1; Schutt auf Zugangspodest ES1

M 27 Cist

Taf. 355

98 n. Chr.

9,01.26. 7

Av.: IMP CAES NERVA TRAIA-N AVG GERM P M, Lk2

Rv.: TR POT - COS II, 6 Ähren

Erh. 3

RIC II 717 (Asia minor); Woytek 2010, Typ 9 (Rom)

III/1997; Süd-Analemma; vomitorium ES1

M 28 Cist

Taf. 355

98 n. Chr

8,37.27. 7

Av.: IMP CAES NERVA TRAIAN - AVG GERM P M, Lk2

Rv.: TR POT - COS II, Legionsadler zw. 2 Feldzeichen

Erh. 3

RIC II 719 (Asia minor); Woytek 2010, Typ 8 (Rom)

II/1997, Süd-Analemma; vomitorium ES1

\section{Hadrianus (117-138 N. Chr.)}

M 29 Cist

Taf. 355

128/129 n. Chr.

10,26. 26. 6

Av.: HADRIANVS - AVGVSTVS P P, K

Rv.: COS - III, Statue der Artemis von 2 Victorien bekränzt, flankiert von 2 Adlern (Artemis Leukophryene)

Überprägung, Erh. 2

RIC II - (unbelegt); Metcalf 1980, Type 21 (Ephesos); SNG Aul 6623

VI/1997; Süd-Analemma; vomitorium ES1

M 30 Cist

Taf. 355

128/132 n. Chr.

9,57.29.7

Av.: HADRIANVS - AVGVSTVS P P, PCh

Rv.: COS - III, Jupiter 1. st. mit Adler und Szepter

Vf: Büste (RIC), Überprägung, Erh. 2

RIC II 497 (b); Metcalf 1980, Type 58 (Laodicea ad Lycum)

VII/1997; Süd-Analemma; vomitorium ES1

M 31 Cist

Taf. 355

128/138 n. Chr.

10,19. 29. 6

Av.: HADRIANVS - AVGVSTVS P P, PCh

Rv.: COS - III, Apollo r. st. mit Lyra

\footnotetext{
${ }^{82}$ Die Cistophore sind chronologisch und nicht nach Münzstätten angeordnet, da die jüngsten Forschungen zu Nerva und Trajan von einer zentralen Produktion in Rom ausgehen. Aktuelle Untersuchungen zu den Cistophoren des Nerva und Trajan: s. WOYTEK 2010. Die Cistophore Hadrians folgen dem Standardwerk von Metcalf 1980.
} 
Km: IMP VESP AVG (lig.) (Rv), Überprägung, Erh. 2

RIC II 482 (b); Metcalf 1980, Type 53 (Hierapolis); Km: HowgEGO 1985, Nr. 840

VIII/1997; Süd-Analemma; vomitorium ES1

M 32 Cist

138 n. Chr.

9.53.29. 1

Av.: HADRIANVS - AVGVSTVS P P, Ph

Rv.: COS - III, Jupiter 1. sitzend mit Patera und Szepter, dahinter Adler

Überprägung, Erh. 3
RIC II - (unbelegt); MetCALF 1980 - (unbelegt) 5/1993; Süd-Analemma; Streufund

M 33 Cist

138 n. Chr.

Taf. $355 \quad 9,58.30 .7$

Av.: HADRIANVS - AVGVSTVS [P P], Ph

Rv.: COS - III, Men mit phrygischer Mütze 1. st. mit Patera und Szepter

Überprägung; Erh. 3

RIC II 502 (b) (Provinz Asia); MetCALf 1980, Type 54 (Hierapolis) 8a/1993; Süd-Analemma; Streufund

\section{Rom / Provinzialprägungen}

\section{Corinth Corinthiae \\ C. Iulius Caesar od. Caius - Commodus}

M 34 AE

Taf. 356

44 v. Chr./192 n. Chr.

6,13. 20. 12

Av.: Leg. unlesbar, Büste?

Rv.: Leg. unlesbar, Bellerophon auf Pegasos r. reitend

Erh. 5

RPC I vgl.1116 (Caes.); SNG Cop 222 (Cai.); RPC IV 9864 (Marc.)

12/2009; Stiegengasse Theater-Süd; Treppe-West, H2; Stufenunterbau; Reinigung

\section{Nicaea Bithyniae}

\section{Antoninus I. Pius (138-161 n. Chr.)}

M 35 AE

138/161 n. Chr.

11,8.33. 7

Av.: Leg. unlesbar, Büste?

Rv.: Leg. unlesbar, Dionysos (?) 1. st. mit langem Thyrsos

Erh. 4

RPC IV vgl. 5960 (Typ Faustina II.)

7/2009; Stiegengasse Theater-Süd; Treppe-West; G1; SE 193

\section{Pergamum Mysiae}

Augustus (27 v. Chr.-14 n. Chr.)

M 36 As

$30 / 20$ v. $\mathrm{Chr}$

9,8. 28. 12

Av.: Leg. unlesbar, Kopf r.

Rv.: AVGVSTVS in Kranz

Erh. 4

RIC I 53

7/2004; kaiserzeitliches Bühnengebäude; Kammer E7; B37

\section{Colophon Ioniae}

\section{Caracalla-Gallienus}

\section{M $37 \quad$ AE}

198/268 n. Chr.

4,07.26. 6

Av.: Leg. unlesbar, Kopf r.

Rv.: KO $\Lambda \mathrm{O}-\Phi$..., Apollo 1. sitzend mit Lyra

frg., Erh. 3

SNG Cop vgl. 190, 191 od. 194

103/2007; Süd-Analemma; KS2; SE 45

Philippus I. oder Philippus I. und Philippus II. FÜr PhILIPPUs I.

M $38 \quad \mathrm{AE}$

Taf. 356

244/249 n. Chr.

4,62.21. 1

Av.: ...ППО, Lk?PCh

Rv.: KO $\Lambda O \Phi-\Omega-N I \Omega N$, Tyche 1. st. mit Ruder und Füllhorn Erh. 3

SNG Cop vgl. 199 (Decius)

99/2007; Süd-Analemma; KS2; SE 45

\section{Ephesos Ioniae}

Augustus (27 v.-14 n. Chr.)

M 39 AE

Taf. 356

27 v. Chr./14 n. Chr.

2,95. 17.

Av.: keine Leg., $\mathrm{K}$

Rv.: [EФE, Beamtenname], Statue der Artemis Ephesia

Erh. 5

SNG Cop 359; MvE 11

7/1997; Nord-Analemma; Kammer KN4; SE N1

M 40 AE

27 v. Chr./14 n. Chr. 
4,63. 20. ?

Av.: Leg. unlesbar, K

Rv.: Leg. unlesbar, Bild unkenntlich

Rv völlig plan, Erh. 5

3/2010; Süd-Analemma; ES1; Oberflächenreinigung

\section{Augustus für Augustus und Livia}

M 41 AE

Taf. 356

27 v. Chr./14 n. Chr.

6,01.22. 11

Av.: keine Leg., gestaffelte Büsten des Augustus und der Livia r.

Rv.: ГPAMMA-TEY $\Sigma$ / API $\Sigma T \mathrm{~T}-\Omega \mathrm{N} / \mathrm{E} \Phi \mathrm{E} /$ ?-E $\Sigma \mathrm{B} \Omega \mathrm{N}$,

Hirschkuh $\mathrm{r}$.

Vf: Rv-Leg, Erh. 2

SNG Cop 362 (Rv-Leg: ...ГАAYK $\Omega N$ ); IMHOOF-BLUMER 1901/1902, 56; MvE 31

1/1996; Streufund

M 42 AE

Taf. 356

27 v. Chr./14 n. Chr.

6,4. 18.12

Av.: keine Leg., gestaffelte Büsten des Augustus und der Livia r.

Rv.: [EФE, Beamtenname], Hirschkuh r.

Erh. 4

SNG Cop 360-366

1b/2009; Stiegengasse Theater-Süd; Zugangspodest ES2; E2; Reinigung

M 43 AE

27 v. Chr./14 n. Chr

6,15.21. 12

Av.: keine Leg., gestaffelte Büsten des Augustus und der Livia r. Rv.: [EФE, Beamtenname], Hirschkuh r.

Erh. 4

SNG Cop 360-366.

10/2006; Südflügel; ES1; Wasserleitungskanal; an der Oberfläche der Einschwemmung

\section{44 AE}

Taf. 356

27 v. Chr./14 n. Chr.

6,92. 22. 1

Av.: keine Leg., gestaffelte Büsten des Augustus und der Livia r.

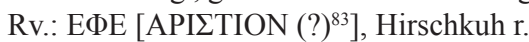

Vf: Beamtenname, Erh. 4

SNG Cop vgl. 360-366; MvE 31

7/2005; hellenistisches Bühnengebäude; Kammer D1; über Treppenfundament

Claudius I. (41-54 n. Chr.)

\section{für Claudius I. und Agrippina I.}

M 45 AE

49/54 n. Chr.

5,37. 19. ?

Av.: keine Leg., 2 gestaffelte Köpfe

Rv.: Leg. unlesbar, Bild unkenntlich
Rv plan, Erh. 4

SNG Cop 371-374; SNG TüB 2820 f.; MvE 68

63/2007; Orchestra; gedeckte Südparodos; Reinigung

\section{Hadrianus (117-138 n. Chr.)}

M $46 \quad \mathrm{AE}$

Taf. 356

$117 / 138$ n. Chr.

4,87. 21. 2

Av.: [AYT KAI TPA] -A $\triangle$ PIANOE, Lk?

Rv.: [EФE- $\Sigma I \Omega N]$, Hirschkuh 1.

Vf: Av-Leg, Erh. 4

SNG Cop vgl. 390 (Av-Leg: A $\triangle$ PIANO $\Sigma$ E); MvE 178

9/1993; Süd-Analemma; vomitorium ES2

\section{Antoninus I. Pius (138-161 n. Chr.)}

M $47 \quad$ AE

138/161 n. Chr.

5,4. 19. 6

Av.: Leg. unlesbar, Lk?

Rv.: [EФE- $\Sigma \mathrm{I} \Omega \mathrm{N}]$, Hirschkuh 1.

Erh. 4

SNG Cop 394; MvE 242

5/2009; Stiegengasse Theater-Süd; Treppe-West; H1; SE 196 $=227$

\section{48 AE}

138/161 n. Chr.

4,88. 23. 12

Av.: Leg. unlesbar, Kopf r.

Rv.: Leg. unlesbar, 4-säuliger Tempel mit Statue der Artemis Ephesia

korrodiert, Erh. 4

SNG Cop vgl. 389 (Hadrian)

7/2006; Südflügel; ES1; Wasserleitungskanal; an der Oberfläche der Einschwemmung

\section{Antoninus I. Pius für Marcus Aurelius}

M 49 AE

141/161 n. Chr.

12,48. 31. 11

Av.: Leg. unlesbar, Büste r.

Rv.: Leg. unlesbar, Statue der Artemis Ephesia

Erh. 5

SNG Cop 398; MvE 275

15/1997; Nord-Analemma; Kammer KN1; SE N15

Marcus Aurelius (161-180 n. Chr.)

M 50 AE

$161 / 180$ n. Chr

6,82.23. 6

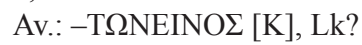

${ }^{83}$ Die Lesung dieses Beamtennamens ist unsicher. 
Rv.: EథE $\Sigma I \Omega N$ [B NEO], Tyche 1. st. mit Steuer und Füllhorn Erh. 3

SNG Cop 400; SNG Aul 1890; BMC IonIA 243; MvE 311

5/2004; kaiserzeitliches Bühnengebäude; Kammer E3; S 1/2004; B030

\section{51 AE}

161/180 n. Chr.

3,86. 23. ?

Av.: Leg. unlesbar, Lk?

Rv.: Leg. unlesbar, Tyche 1. st

Randausbruch, korrodiert, Erh. 4

SNG Cop 400; MvE 311

4/2008; Streufund

\section{52 AE}

161/180 n. Chr.

5,34. 22.6

Av.: Leg. unlesbar, Lk?

Rv.: EథE $\Sigma I \Omega N$ П-P $\Omega T \Omega N$ A $\Sigma I A \Sigma$, Artemis als Jägerin n. r., zieht Pfeil aus Köcher, davor Hund

Erh. 4

SNG Cop -

112/2007; Süd-Analemma; KS2; SE 45

\section{Marcus Aurelius od. Lucius Verus}

M 53 AE

161/180 n. Chr.

20,72. 34. 5

Av.: Leg. unlesbar, Büste r.

Rv.: Leg. unlesbar, Tempel mit Statue der Artemis Ephesia

Erh. 5

SNG Cop vgl. 397 (A. Pius); SNG Leyp 568

13/1997; Nord-Analemma; Kammer KN1; SE N15

\section{Septimius Severus (193-211 n. Chr.)}

M 54 AE

193/211 n. Chr.

2,3. 17.7

Av.: Leg. unlesbar, Lk?

Rv.: EФE $\Sigma I-\Omega N$, Hirschkuh $r$.

Erh. 4

SNG Cop 413; SNG Leyp 575; MvE 418

98/2007; Süd-Analemma; KS2; SE 45

M 55 AE

193/211 n. Chr.

1,93. 15.?

Av.: Leg. unlesbar, Kopf $\mathrm{r}$.

Rv.: [EథE $\Sigma \mathrm{I}-\Omega \mathrm{N}]$, Hirschkuh od. Eber r.

Randausbruch, Erh. 4

SNG Cop 413 od. 414; MvE 412 od. 418

11/2005; Raum RN1 nördlich des Bühnengebäudes; S 5/2005; B60

Taf. 356
Antoninus III. (Caracalla) (211-217 n. Chr.)

M 56 AE

197/211 n. Chr.

13. 28.6

Av.: M AYP ANT $\Omega N E I N O \Sigma$, Lk1

Rv.: ...N, Statue der Artemis Ephesia

Erh. 4

SNG Cop 419; MvE 470

24/2007; Süd-Analemma; KS2; SE 28 b

\section{Septimius Severus und Antoninus III. für Geta}

M 57 AE

Taf. 356

198/211 n. Chr.

3,27. 18.6

Av.: AYT K...ГETA $\Sigma$, Lk1

Rv.: E $\Phi E \Sigma-I \Omega N$, Hirsch r. st.

Vf: Av-Leg, Erh. 3

SNG Cop 428. 429 (Av-Leg: ПО ГЕ ГЕТА $\Sigma$ KAI); BMC

IoNIA 288 (Typ); MvE 578

65/2007; Süd-Analemma; KS3; SE 33

Antoninus IV. (Elagabal) (218-222 n. Chr.)

M 58 AE

Taf. 356

218/222 n. Chr.

4,75. 22. 12

Av.: AYT K M AYP AN-TSNEINOE, Lk1PCh

Rv.: EФE $\Sigma I \Omega N \Delta / N E \Omega K O P \Omega N$, Schiff mit Rudern r.

Erh. 3

SNG Cop 445; MvE 673

25/2007; Süd-Analemma; KS2; SE 28b

M 59 AE

218/222 n. Chr.

10,58.31. 7

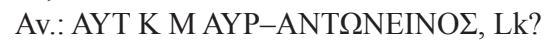

Rv.: E $\Phi E \Sigma I \Omega N \Delta-N E \Omega K O P \Omega N$, Artemis als Jägerin n. r.,

zieht Pfeil aus Köcher, davor Hund

Erh. 5

SNG Cop 447; MvE 643

14/1997; Nord-Analemma; Kammer KN1; SE N15

M 60 AE

218/222 n. Chr.

5,06. 23. 6

Av.: [AYT] K M AYP AN[T $\Omega N E] I N O \Sigma$, Lk?PCh

Rv.: $\mathrm{E} \Phi[\mathrm{E} \Sigma \mathrm{I} \Omega \mathrm{N}] \Delta \mathrm{NE} \Omega \mathrm{KOP} \Omega \mathrm{N}$, Tyche 1. st. m. Ruder und Füllhorn

Erh. 4

SNG Cop 448; MvE 686

1/2008; Streufund

M 61 AE

Taf. 357

218/222 n. Chr

6,73.23. 6

Av.: AYT K M AYP ANTSNEINO $\Sigma$, Lk?PCh

Rv.: ЕФЕ $\Sigma$ I $\Omega N$ ПР $[\Omega T \Omega N] A \Sigma I A \Sigma$, Tyche 1. st. mit Ruder und 
Füllhorn

Vf: Rv-Leg, Erh. 4

SNG Cop vgl. 448 (Rv-Leg: EФE $\Sigma \mathrm{I} \Omega \mathrm{N} \Delta \mathrm{NE} \Omega \mathrm{KOP} \Omega \mathrm{N}$ ); MvE 684

3/2006; Südflügel; ES1; Wasserleitungskanal; an der Oberfläche der Einschwemmung

\section{Antoninus IV. für Annia Faustina}

M $62 \quad \mathrm{AE}$

$221 \mathrm{n} . \mathrm{Chr}$.

7,63.29. 6

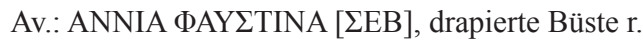

Rv.: EФE $\Sigma I \Omega N \Delta N E \Omega K O P \Omega N$, Artemis als Jägerin n. r., zieht

Pfeil aus Köcher, davor Hund

Erh. 3

SNG Aul vgl. 1908; SNG Mü 20 vgl. 187; Mionnet Suppl.VI 628; MvE 705

13/2009; Stiegengasse Theater-Süd; Treppe-West; J1; SE 124

\section{Antoninus III. (Caracalla) oder Antoninus IV. (Elagabal)}

M 63 AE

197/222 n. Chr.

2,63. 18. 6

Av.: ...- $\Omega$ NEINO $\Sigma$, Büste?

Rv.: E $\Phi E \Sigma-I \Omega N$, Eber von Speer aufgespießt

Erh. 4

SNG Cop 424, 441 od. 452; MvE 503 od. 666

67/2007; Süd-Analemma; KS3; SE 33

\section{Severus Alexander (222-235 n. Chr.)}

M 64 AE

Taf. 357

4,6.21. 6

222/235 n. Chr.

Av.: AYT K M AYP $\Sigma$ E[B A $\Lambda$ ]EXAN $\triangle \mathrm{PO} \Sigma$, Lk2Büste?

Rv.: ПP $\Omega T \Omega N-A \Sigma I A \Sigma$ / E $\Phi E \Sigma I \Omega N$, Kultbild in Tempel

Erh. 3

BMC Ionia 320; SNG Leyp 608; MvE 752

97/2007; Süd-Analemma; KS2; SE 45

M $65 \quad$ AE

Taf. 357

222/235 n. Chr.

12,3.30. 6

Av.: AYT K M AYP $\Sigma-$ EYH A $\Lambda$ EXAN $\triangle \mathrm{PO} \Sigma$, Lk2PCh

Rv.: E $\Phi E \Sigma I \Omega N ~ П P \Omega T \Omega N$ A $\Sigma I A \Sigma$, Artemis als Jägerin n. r., zieht Pfeil aus Köcher, davor Hund

Erh. 3

SNG Cop 457; MvE 758

8/1993; Süd-Analemma; vomitorium ES2

M $66 \quad \mathrm{AE}$

Taf. 357

222/235 n. Chr.

11,6.29. 6

Av.: AYT K M AYP- $\Sigma-E Y H ~ A \Lambda E X A N \triangle P O \Sigma, ~ L k 2 P C h$

Rv.: EФE $\Sigma I \Omega N$ ПP $\Omega T \Omega N$ A $\Sigma I A \Sigma$, Artemis als Jägerin n. r., zieht Pfeil aus Köcher, davor Hund

Erh. 3

SNG Cop 457; MvE 758

2/2009; Stiegengasse Theater-Süd; Zugangspodest ES2; F1; SE 170

M $67 \quad$ AE

Taf. 357

222/235 n. Chr.

5,23. 20. 6

Av.: M AYP $\Sigma E B$ A $\Lambda$ EXAN $\triangle \mathrm{PO} \Sigma$, Lk2PCh

Rv.: EФ-E $\Sigma I \Omega N$, Artemis n. r. Hirschkuh erlegend

Vf: Rv-Leg, Erh. 2

SNG Cop 459. 460 (Rv-Leg: EФE $\Sigma$ I $\Omega N \Delta$ NE $\Omega K O P \Omega N$ ); MvE 762

3/1993; Süd-Analemma; vomitorium ES2

M 68 AE

Taf. 357

222/235 n. Chr.

5,81.22. 6

Av.: AYT K M AYP $\Sigma E B$ A $\Lambda$ EXAN $\triangle \mathrm{PO} \Sigma$, Lk?PCh

Rv: $E \Phi E \Sigma I \Omega N \Delta-N E \Omega K O P \Omega N$, Tyche 1. st. mit Ruder und Füllhorn

Erh. 3

SNG Cop 462; MvE 791

100/2007; Süd-Analemma; KS2; SE 45

\section{Gordianus III. (238-244 n. Chr.)}

M 69 AE

Taf. 357

238/244 n. Chr.

6,38. 23. 6

Av.: AYT K M ANT-ГOPAIANO, Lk2PCh

Rv.: [EФE]- $\Sigma \mathrm{I} \Omega \mathrm{N} A \Lambda-\mathrm{EXA}-\mathrm{N} \Delta \mathrm{PE} \Omega \mathrm{N}$, Apisstier $\mathrm{r}$.

Lochversuch, Erh. 3

SNG Aul 1937; BMC Ionia 427; SNG Leyp 634; MvE 888

110/2007; Süd-Analemma; KS2; SE 45

M 70 AE

Taf. 357

238/244 n. Chr.

3,23. 18.6

Av.: ГOP $-\mathrm{IANO} \Sigma, \mathrm{Lk} 2 \mathrm{PCv}$

Rv.: EФE $\Sigma I \Omega N$, Artemis als Jägerin n. r., zieht Pfeil aus Köcher, davor Hund

kl. Schrötlingsriss, Erh. 3

SNG Cop 483

4/2009; Stiegengasse Theater-Süd; Zugangspodest ES2; F2; SE 174

\section{Philippus I. für Philippus II.}

M 71 AE

Taf. 357

244/247 n. Chr.

5,51.22. 6

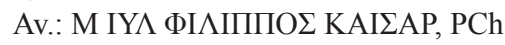

Rv.: EFESIWN NEWKORWN, Statue der Artemis Ephesia, 1.

u. r. zwei Kinder

Vf: Rv-Leg, Erh. 3

SNG Cop vgl. 489 (Rv-Leg: D); SNG TüB vgl. 2840 (Rv); MvE 961 
14/2007; Stiegengasse Theater-Süd; Zugangspodest ES3; B1; Reinigung

\section{Traianus Decius (249-251 n. Chr.)}

M 72 AE

249/251 n. Chr.

4,51.20. 7

Av.: ...TPAIANO $\triangle \mathrm{EKIO} \Sigma, \mathrm{Lk}$ ?PCh

Rv.: EФE $\Sigma$ I...KOP $\Omega N$, Tyche 1. st. mit Ruder und Füllhorn

Erh. 3

SNG Cop vgl. 538 (Valerianus II.); MvE 1000

111/2007; Süd-Analemma; KS2; SE 45

\section{Gallienus (253-268 n. Chr.)}

M 73 AE

Taf. 357

253/268 n. Chr.

9,3.26. 7

Av.: AYT К ПО $\Lambda$ IKI-N ГА $\Lambda \Lambda I H N O \Sigma$, Lk2PCh

Rv.: EФE $\Sigma I \Omega N[\Gamma]-N E \Omega K O P \Omega N$; Artemis als Jägerin n. r., zieht Pfeil aus Köcher, davor Hund

Vf: Av-Leg, Erh. 3

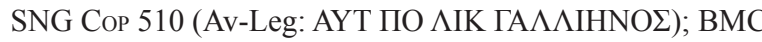
IoNIA 377 (Typ); MvE 1087

22/2007; Süd-Analemma; KS3; SE 28a

Valerianus I. und Gallienus bzw. Gallienus für Salonina

M 74 AE

253/268 n. Chr.

7,46. 28.6

Av.: [ $\Sigma \mathrm{A} \Lambda \Omega \mathrm{N} \Xi \mathrm{PY} \Sigma]-\mathrm{O} \Gamma \mathrm{ONH} \Sigma \mathrm{E}$, Büste r. auf Mondsichel

Rv.: [E $\Phi E \Sigma]-I \Omega N$, Statue der Artemis Ephesia

Rv dezentriert, kleiner Schrötlingsriss, Vf: Rv.-Leg. $(\Delta$ NE $\Omega K O P \Omega N)$, Erh. 4

SNG Cop vgl. 536 (Rv-Leg: $\Delta$ NE $\Omega$ KOP $\Omega N$ ); SNG LEYP vgl. 633

135/2007; Stiegengasse Theater-Süd, Zugangspodest ES1; K1; Reinigung

\section{Unbestimmbar: Prinzipatszeit}

M $75 \quad$ AE

ca. $150 / 250$ n. Chr.

7,35. 23. ?

Av.: Leg. unlesbar, Büste?

Rv.: Leg. unlesbar, Tyche 1. st. mit Ruder und Füllhorn

Erh. 5

SNG Cop vgl. 400 (M. Aurel) od. 406 (L. Verus) (Typ)

6/2007; Stiegengasse Theater-Süd; Zugangspodest ES3; B2; SE 12

\section{M $76 \quad$ AE}

ca. $150 / 250$ n. Chr.

6,02. 23.?
Av.: Leg. unlesbar, Büste?

Rv.: Leg. unlesbar, Tyche 1. st. mit Ruder und Füllhorn korrodiert, Erh. 5

SNC Cop vgl. 400 (M. Aurel) od. 406 (L. Verus) (Typ) 48/2007; Süd-Analemma; KS2; SE 28b

M $77 \quad$ Pb (Plombe)

200/250 n. Chr.

0,87. 11. ?

Av.: Leg. unlesbar, Bild unkenntlich

Rv.: Leg. unlesbar, Hirsch (?) in Incusum

frg., Erh. 4

GÜLBAY 2008, vgl. 118

4/2005; hellenistisches Bühnengebäude; Kammer D8; S 2/2005; SE B19 (Treppenfundament)

\section{Magnesia Ad Maeandrum Ioniae}

Philippus II. (244-249 n. Chr.)

M $78 \quad$ AE

244/249 n. Chr.

4,83.22. 6

Av.: AYT K M IOY-

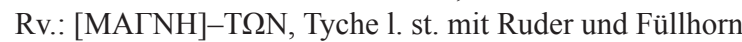

Erh. 4

SNG Cop 899

10/1998; vomitorium EN1; SE N3

\section{Metropolis Ioniae}

Maximinus I. (Thrax) (235-238 n. Chr.)

M 79 AE

235/238 n. Chr.

Taf. 357

4,99. 22.6

Av.: ...-MA...NOE, Lk2Büste?

Rv.: МНТРОПО- $\Lambda$ EI $[T \Omega N]$, Tyche 1 . st. mit Ruder und Füllhorn

Erh. 3

SNG Cop vgl. 913 (Severus Alexander)

26/2007; Süd-Analemma; KS2; SE 28b

\section{Gordianus III. (238-244 n. Chr.)}

M 80 AE

Taf. 357

238/244 n. Chr.

9,6.30. 5

Av.: AYT K M ANT ГOP $\triangle \mathrm{IANO} \Sigma$, Lk2PCh

Rv.: МНTPOПO $\Lambda$ EIT $\Omega$ N T $\Omega$ N EN I $\Omega$ NIA, Kybele 1. sitzend mit Patera und Tympanon, zu ihren Füßen 2 Löwen

Erh. 2

SNG Cop 922-924

16/1998; Nord-Analemma; obere Terrasse (D); Oberfläche

M 81 AE

Taf. 357

238/244 n. Chr.

$5,36.22 .6$ 


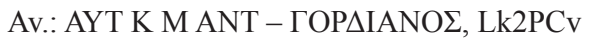

Rv.: MHTPO[ПO] $\Lambda E I T \Omega N$, Tyche 1. st. mit Ruder und Füllhorn Erh. 4

SNG Cop 929; SNG TÜв 2982

13/2008; Stiegengasse Theater-Süd; Treppe-Ost; Streufund bei Hangabtragung

\section{82 AE}

238/244 n. Chr.

3,64. 22. 6

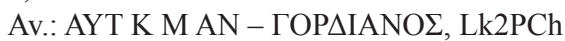

Rv.: МНТРОПО $\Lambda$ E-IT $\Omega N$, Tyche 1. st. mit Ruder und Füllhorn Erh. 3

SNG CoP 929; SNG TÜв 2982

1/2001; Logeion, Hyperskenion; S 1/2001; L1

M 83 AE

Taf. 358

238/244 n. Chr.

Av.: AYT K M AN - ГOPAIANO $\Sigma$, Lk2PCv

Rv.: MH[TPOПO] $-\Lambda$ EI-T $\Omega$ N EN I $\Omega$ N-IA, Tyche 1. st. mit Aresstatue und Füllhorn, 1.F.: Altar

Erh. 3

BMC Ionia 16

96/2007; Süd-Analemma; KS2; SE 45

M 84 AE

Taf. 358

238/244 n. Chr.

6,76. 24. 12

Av.: AYT K M AN-ГOPAIANO $\Sigma$, Lk?PCv

Rv.: MНTPO-ПO $\Lambda$ EIT[ $\Omega N]$, Tyche 1. st. mit Ruder und Füllhorn

Erh. 4

BMC Ionia 17; SNG Mü 20 vgl. 681 132

M 85 AE

Taf. 358

238/244 n. Chr.

6,11.22. 6

Av.: AYT K M AN - ГOP $\triangle \mathrm{IANO} \Sigma$, Lk2PCh

Rv.: MHTPOПO $\Lambda$ EIT $\Omega$ N A $\Sigma$-TPAIO $\Sigma$, Flußgott 1. liegend

Vf: Rv-Leg, Erh. 4

SNG Cop 930 (Rv-Leg: МНTPOПO $\Lambda$ EITSN)

12/2007; Stiegengasse Theater-Süd; Zugangspodest ES3; B1; SE 7

M $86 \quad$ AE

238/244 n. Chr.

2,38. 18.6

Av.: AYT ГOP $\triangle \mathrm{IANO \Sigma}, \mathrm{Lk}$ ?PCv

Rv.: MHTPO-ПO- $\Lambda$ EIT $\Omega N$, Flußgott 1. liegend

Erh. 3

SNG Cop 931; BMC IoNIA 18

64/2007, Orchestra; gedeckte Südparodos; Reinigung

Philippus I. (244-249 n. Chr.)

M 87 AE

244/249 n. Chr.

Taf. 358
9,09.31. 6

11/2008; Stiegengasse Theater-Süd; Treppe-Ost; C1/C2; SE

Av.: M IOY - ФІ $\Lambda$ IППО , Lk2Ph

Rv.: МНТРОПО $\Lambda$ EIT $\Omega N$, Tyche 1. st. mit Ruder und Füllhorn Erh. 4

SNG Cop 933

6/2009; Stiegengasse Theater-Süd; Treppe-West; G1; SE 200

\section{Traianus Decius (249-251 n. Chr.)}

$M 88$ AE

Taf. 358

249/251 n. Chr.

5,42. 22. 6

Av.: AYT K M AYP - TPAIAN $\triangle$ EKIO, Lk2PCh

Rv.: MHTPO-ПО $\Lambda$ EIT $\Omega N$, Tyche 1. st. mit Ruder und Füllhorn Erh. 3

SNG CoP vgl. 933 (Philippus I.)

108/2007; Süd-Analemma; KS2; SE 45

\section{Gallienus für Saloninus}

M 89 AE

258/260 n. Chr.

4,3. 19.7

Av.: [ $\Lambda \mathrm{IK} \Sigma \mathrm{A} \Lambda \Omega$ N OYA $\Lambda$ EPIANO $\Sigma$ ], Lk2

Rv.: [MНТРОПО $\Lambda$ EIT $\Omega N]$, Mars 1. st. mit Schild und Speer

korrodiert, Erh. 5

SNG Cop 941

2/2003; Logeion; S 1/2003; L38

\section{SMYrna IONIAE}

Gordianus III. (238-244 n. Chr.)

M $90 \mathrm{AE}$

238/244 n. Chr.

Taf. 358

4,03. 21.6

Av.: ...NOE, Lk?PC?

Rv.: ...E $\Omega$ KOP..., Herakles 1. st. mit Kantharos und Keule

Erh. 4

SNG Aul 2230

15/2007; Stiegengasse Theater-Süd; B1; Reinigung

\section{Hierapolis Phrygiae}

\section{Antoninus IV. für Annia Faustina}

M 91 AE

Taf. 358

221 n. Chr., Km: nach 260 n. Chr., Ionien

4,86. 24. 3

Av.: ANNIA $\Phi$..., Büste $r$.

Rv: IHPAПO $\Lambda$ EIT $\Omega N$ NE $\Omega K \Omega P \Omega N$, Kranz, darin Inschrift [A/KTI/A $]$

Riss, $2 \mathrm{Km}$ Av: B und Kopf, Erh. 5

BMC PhrYgia 148; SNG Mü 24 vgl. 245; Howgego 763 (Km B)

4,64.21. 6

2/1993; Süd-Analemma; vomitorium ES2 


\section{Lysias Phrygiae}

Gordianus III. (238-244 n. Chr.)

M 92 AE

238/244 n. Chr.

$11,3.30 .5$

Av.: [AYT K M AN-ГOPAIANO 2 ], Lk2PCv

Rv.: $\Lambda-Y \Sigma I A-\Delta E \Omega N$, Kybele 1. sitzend mit Patera und

Tympanon, 1.F. Löwe

Av dezentriert, Erh. 4

SNG Aul 3881; v. Aulock II 642

2/2007; Stiegengasse Theater-Süd; Zugangspodest ES3; B2; SE 4

\section{Perge Pamphyliae}

Philippus II. (247-249 n. Chr.)

M 93 AE

244/247 n. Chr.

7,03. 25. 11

Av.: Leg. unlesbar, Lk2PCv

Rv.: $\Gamma E P-\Gamma A I-\Omega N$, Preistisch mit 2 Urnen

Erh. 4

SNG Cop 350

I/1997; Streufund

\section{Caesaraea Cappadociae}

\section{Iulia Domna}

M 94 AE

197/217 n. Chr.

10,75. 30. ?

Av.: Leg. unlesbar, Büste r.

Rv.: Leg. unlesbar, Kranz mit Inschrift

Erh. 5

9/1997; Nord-Analemma; Kammer KN1; SE N14

\section{UNSICHERE Mzst.}

\section{Jh. v. Chr.-1. Jh. n. Chr.}

M 95 AE

ca. 23 v. Chr./98 n. Chr.

8,56. 22. ?

Av.: Leg. unlesbar, Kopf r.

Rv.: Leg. unlesbar, Bild unkenntlich

Erh. 5

59/2007; Süd-Analemma; KS2; SE 28b

\section{96 AE}

ca. 23 v. Chr./68 n. Chr.

4,88. 21.?

Av.: Leg. unlesbar, Kopf r.

Rv.: Leg. unlesbar, Bild unkenntlich

Av und Rv völlig plan, Erh. 5

Taf. 358
1/2002; hellenistisches Bühnengebäude; Kammer D3; S 2/2002; B5

\section{Vespasianus od. Titus}

M 97 AE

69/81 n. Chr.

11,4. 27. ?

Av.: Leg. unlesbar, Büste r.

Rv.: Leg. unlesbar, Bild unkenntlich

korrodiert, Erh. 5

1/2004; Logeion; S 5/2004; L66. L67

\section{Antoninus I. Pius (138-161 n. Chr.)}

\section{M $98 \quad \mathrm{AE}$}

138/161 n. Chr.

14,6. 30. ?

Taf. 358 Av.: Leg. unlesbar, Büste r.

Rv.: Leg. unlesbar, Bild unkenntlich

Erh. 5

4/1993; Süd-Analemma; Streufund

\section{2.-3. Jh. n. Chr.}

\section{99 AE}

Km: Anchialos, Apollonia/Thraciae; severisch ca. 98/268 n. Chr.

7,88. 22. ?

Av.: Leg. unlesbar, Büste?

Rv.: Leg. unlesbar, Bild unkenntlich

Km: Howego 1985, 183

$\mathrm{Km}(\mathrm{Rv})$ : behelmter Athenakopf 1 .

Erh. 5

11/2009; Stiegengasse Theater-Süd, Zugangspodest ES1; K2; SE 127

\section{Jh. n. Chr.}

\section{100 AE}

ca. $193 / 268$ n. Chr.

3,33. 21. ?

Av.: Leg. unlesbar, Büste r.

Rv.: Leg. unlesbar, Bild unkenntlich

korrodiert, Erh. 5

60/2007; Süd-Analemma; KS3; SE 33

\section{Unbestimmbar: Prinzipatszeit}

\section{101 AE}

ca. 27 v. Chr./268 n. Chr.

6,13. 24. ?

Av.: Leg. unlesbar, Büste r.

Rv.: Leg. unlesbar, Bild unkenntlich

Erh. 5

10/2007; Stiegengasse Theater-Süd; Treppe-West; G1 
M 102 AE

ca. 27 v. Chr./268 n. Chr.

5,36. 21.?

Av.: Leg. unlesbar, Büste?

Rv.: Leg. unlesbar, Bild unkenntlich

korrodiert, aufgeglüht, Erh. 5

20/2003; Logeion; S 4/2003; L55a

\section{M $103 \mathrm{AE}$}

ca. 27 v. Chr. $/ 268$ n. Chr.

5,04. 21.5

Av.: Leg. unlesbar, Büste $r$.

Rv.: Leg. unlesbar, Bild unkenntlich

korrodiert, Erh. 5

6/2008; Insula südlich des Theaters; Raum 1; C2; SE 121a

\section{Rom / Kaiserzeit}

\section{Domitianus (81-96 n. Chr.)}

\section{Rom}

M 106 As

$81 / 82$ n. Chr.

11,1.27. 6

Av.: IMP CAES DIVI VESP F DOMITIAN AVG PM, Lk2

Rv.: Leg. unlesbar, S-C, Minerva r. laufend

Erh. 3

RIC II 237 od. 242

1/2007; Stiegengasse Theater-Süd; Zugangspodest ES3; B1; SE 15

\section{Hadrianus (117-138 n. Chr.)}

\section{Rom}

M 107 D

$125 / 128$ n. Chr.

3,23. 19. 12

Av.: HADRIANVS-AVGVSTVS, Lk1

Rv.: COS - III, Libertas 1. st.

Erh. 3

RIC II 175 (c)

7/2008; Insula südlich des Theaters; Raum 1; C2; SE 121a

\section{Marcus Aurelius (161-180 N. Chr.)}

\section{(Rom)}

\section{108 (D)}

(161/180 n. Chr.)

2,6. 8. ?

Av.: ...-NINVS..., Lk?Büste?

Rv.: Leg. unlesbar, Bild unkenntlich

\section{104 AE}

ca. 27 v. Chr./268 n. Chr.

4,99. 20. ?

Av.: Leg. unlesbar, Büste r.

Rv.: Leg. unlesbar, Bild unkenntlich

Erh. 5

7/2007; Stiegengasse Theater-Süd; Zugangspodest ES3; B2; SE 14

\section{105 AE}

ca. 27 v. Chr./268 n. Chr.

4,72. 20.?

Av.: Leg. unlesbar, Büste r.

Rv.: Leg. unlesbar, Bild unkenntlich

Erh. 5

9/2007; Stiegengasse Theater-Süd; Zugangspodest ES3; B2; SE 14

ZF subärat/Anima; frg., Erh. 5

14/2008; Stiegengasse Theater-Süd; Treppe-Ost; C1/D1; SE 153

\section{Gordianus III. (238-244 N. Chr.)}

\section{Rom}

M 109 An

241 n. Chr.

3,08. 23.7

Av.: IMP GORDIANVS PIVS [FEL AVG], Stk2PCh

Rv.: [PM T]R P III C[OS II] PP, Apollo 1. sitzend

Erh. 3

RIC IV/III 87 (b)

88/2007; Süd-Analemma; KS2; SE 44

M 110 An

Taf. $358 \quad 241 \mathrm{n}$. Chr.

4,89.23. 7

Av.: IMP [GOR]DI[ANVS PIVS FEL AVG], Stk2PCh

Rv.: [PM TR P] IIII COS II PP, Apollo 1. sitzend

korrodiert, Erh. 4

RIC IV/III 88 (b)

23/2007; Süd-Analemma; KS3; SE 28a

\section{(Rom)}

M 111 (An)

(241 n. Chr.)

4,3. 23. 1

Av.: IMP GORDIANVS PIVS FEL AVG, Stk2PCh

Rv.: IOVI STATORI, Jupiter r. st. mit Szepter und Blitz

ZF: subärat, Erh. 2

RIC IV/III 84 (b)

7/1993; Süd-Analemma; vomitorium ES2 
Philippus I. Arabs (244-249 N. Chr.)

\section{Rom}

M 112 An

244/247 n. Chr.

4,22. 22.6

Av.: IMP M IVL PHILIPPVS AVG, Stk2PCh

Rv.: AE[QVIT]AS AVGG, Aequitas 1. st. mit Waage und Füllhorn korrodiert (Rv), Erh. 3

RIC IV/III 27b

3/2007; Stiegengasse Theater-Süd; Zugangspodest ES3; B1; SE 7

\section{113 An}

244 n. Chr.

3,91.24. 6

Av.: IMP M IVL PHILIPPVS AVG, Stk2PCh

Rv.: SECVRIT ORBIS, Securitas 1. sitzend mit Szepter

Erh. 2

RIC IV/III 48b (b)

107/2007; Süd-Analemma; KS2; SE 45

Philippus I. für Philippus II.

\section{Rom}

M 114 An

244 n. Chr.

4,19.23. 6

Av.: [M IVL PHILIPPVS CAES], Stk2PCh

Rv.: PRINCIPI IVVENT, Prinz 1. st. mit Globus und Feldzeichen

Erh. 4

RIC IV/III 218d (b)

4/2007; Stiegengasse Theater-Süd; Zugangspodest ES3; B1; SE 7

\section{Trebonianus Gallus (251-253 n. Chr.)}

Ant

M 115 An

251/253 n. Chr.

4,64. 24. 1

Av.: IMP C C VIB TREB GALLVS PF AVG, Stk2PCh

Rv.: MARTI - PACIFERO, Mars 1. st. mit Zweig und Speer

Erh. 4

RIC IV/III 85 (b)

5/2007; Stiegengasse Theater-Süd; Zugangspodest ES3; B1; SE 7

\section{Gallienus, Alleinherrschaft (260-268 n. Chr.)}

\section{Rom}

M 116 An

$262 \mathrm{n} . \mathrm{Chr}$

1,75. 18.7

Av.: GALLIENVS AVG, Stk1
Rv.: AEQVITAS AVG, Aequitas 1. st. mit Waage und Füllhorn (Göbl Typ 14)

$--/ /-$

Erh. 4

MIR 36 499f

15/1998; Nord-Analemma; Kammer KN3; SE N1

\section{Med}

\section{117 An}

265/266 n. Chr.

3,11. 22. 12

Av.: Leg. unlesbar, Stk1

Rv.: SALVS AVG, Salus 1. st. mit Patera und Füllhorn, 1.F.: Altar mit Schlange (Göbl Typ 511)

$--/ / \mathrm{P}$

korrodiert, Erh. 3

MIR $361286 f$

27/2007; Süd-Analemma; KS2; SE 28b

\section{Gallienus für Salonina}

\section{Rom}

M 118 An

Taf. 358

264/267 n. Chr.

2,4. 20.6

Av.: SALONINA AVG, Büste r

Rv.: FECVNDITAS AVG, Fecunditas 1. st. mit Füllhorn, vor ihr Kind (Göbl Typ 139)

$-\Delta / /-$

Erh. 3

MIR 36 580aa

87/2007; Süd-Analemma; KS2; SE 44

Claudius II. (Gothicus) (268-270 N. Chr.)

\section{Rom}

M 119 An

Taf. 358

268/270 n. Chr.

2,59. 19. 12

Av.: IMP C CLAVDIVS AVG, Stk2PCh

Rv.: IOVI STATORI, Jupiter 1. st.

$--/ /-$

Erh. 3

RIC V/1 52 (C); NoRmanby, 594-597

2P/2009; Portikus; FK 46/2009; SE 26

\section{Mzst.?}

M120 An

268/270 n. Chr.

3,1.20. 10

Av.: ...DIV ..., Stk?Büste?

Rv.: Leg. unlesbar, st. Fig.

Rv-Bz. ?

korrodiert, Erh. 4

56/2007; Süd-Analemma; KS3; SE 34 


\section{Aurelianus (270-275 n. Chr.) Für Divus Claudius II.}

\section{Rom}

M 121 An

270 n. Chr.

1,87. 17. 12

Av.: DIVO CLA[VDIO], Stk1

Rv.: [CONSECRATIO], Adler 1. Kopf r. (Göbl Typ CONSECRATIO

1a)

$--/ /-$

ovaler Schrötling, Erh. 4

MIR 47 9810a; RIC V/1 266 (K)

6/2006; Südflügel; ES1; Wasserleitungskanal; an der Oberfläche der Einschwemmung

M 122 An

270 n. Chr.

1,71. 19. 6

Av.: [DI]VO CLA[VDIO], Stk?

Rv.: [CONSECRATIO], Altartyp (Göbl Typ CONSECRATIO 2b)

$--/ /-$

ovaler Schrötling, Erh. 4

MIR 47 99; RIC V/1 261 (K)

113/2007; Süd-Analemma; KS1; SE 46

M 123 An

$270 \mathrm{n} . \mathrm{Chr}$

$3,11.21 .12$

Av.: [DIVO CLAVDIO], Stk?Büste?

Rv.: Leg. unlesbar, Altartyp

$--/ /-$

korrodiert, Erh. 4

MIR 47 99; RIC V/1 261 (K)

57/2007; Süd-Analemma; KS3; SE 34

\section{$K y z$}

M 124 An

270 n. Chr.

2,81.21. 11

Av.: DIVO CLAVDIO, Stk2PCv

Rv.: CONSECRATIO, Rogus (Göbl Typ CONSECRATIO 3)

$--/ /$ -

Randausbruch, Erh. 3

MIR 47 297e; RIC V/1 256 (K)

3/1998; Streufund

\section{Diocletianus (285-305 n. Chr.)} (NACH DER Reform von 294 N. Chr.)

\section{$K y z$}

M 125 FolT (rad.)

295/299 n. Chr.

3,29. 23.6

Av.: IMP C C VAL DIOCLETIANVS PF AVG, Stk2Cv

Rv.: CONCORDIA MI-LITVM, Kaiser und Jupiter halten Victoria
$\mathrm{KA} / /-$

Erh. 2

RIC VI 16a

9/2004; kaiserzeitliches Bühnengebäude; Kammer E5; außerhalb von S 7/2004; B42

Maximianus I. (286-305 n. Chr.) (NaCh der ReFORM VON 294 N. CHR.)

Her

M 126 FolT (rad.)

Taf. 358

295/296 n. Chr.

2,81. 23. 12

Av.: IMP C M A MAXIMIANVS PF AVG, Stk2Cv

Rv.: CONCORDIA MILITVM, Kaiser und Jupiter halten

Victoria

$\mathrm{H} \Delta / /-$

Erh. 2

RIC VI 14

4P/2009; Portikus; FK 46/2009; SE 26

$K y z$

M 127 FolT (rad.)

Taf. 358

295/299 n. Chr.

2,91.22. 6

Av.: IMP C M A MAXIMIANVS PF AVG, Stk2Cv

Rv.: CONCORDIA MILITVM, Kaiser und Jupiter halten

Victoria

$\mathrm{KE} / /-$

Erh. 2

RIC VI 16b

3P/2009; Portikus; FK 46/2009; SE 26

Licinius I. (308-324 N. Chr.)

Nic

M 128 Fol

Taf. 358

321/324 n. Chr.

2,16. 20. 12

Av.: IMP C VAL LICIN [LICINIVS PF AVG], Stk2PCv

Rv.: IOVI CONS-ERVATORI, Jupiter 1. st., Adler, Gefangener - X/III//SMN $\Delta$

Erh. 3

RIC VII 44

2/2006; unteres Diazoma, T11; S 6/2006

\section{Her, Nic od. Kyz}

\section{129 Fol}

Taf. $358 \quad 313 / 318 \mathrm{n}$. Chr

1,26. 21.6

Av.: IMP C VAL LICIN LIC[INIVS P F AVG], Büste?

Rv.: [IOVI CON-SERVATORI], Jupiter 1. st.

Rv-Bz. ? 
frg., korrodiert, Erh. 4

12/2004; Logeion; S 6/2004; L77

\section{Constantinus I. (306-337 n. Chr.)}

Her

M 130 Fol

317 n. Chr.

2,95. 20. 5

Av.: IMP CONSTA-NTINVS AVG, ILk2PhGbSzMp

Rv.: PROVIDEN-TIAE AVGG, Lagertor

$--/ /$ MHTB

korrodiert, Erh. 4

RIC VII 16

15/2003; Logeion; S 3/2003; L4

\section{Constantinus I. Für Constantius II.}

\section{Kyz}

\section{131 Fol}

336/337 n. Chr.

2,21. 19. 1

Av.: FL IVL CONSTANTIVS NOB C, Büste?

Rv.: [GLOR-IA EXER-CITVS], 2 Soldaten mit einem

Feldzeichen

- -//SMKГ

korrodiert, oblonger Schrötling, Erh. 4

RIC VII 126-128; LRBC 1263. 1264

7/2003; Logeion; S 3/2003; L42

\section{Constantinus I. FÜr Constantinopolis}

\section{Her}

\section{132 Fol}

330/333 n. Chr.

2,73. 18.6

Av.: CONSTAN-[TINOPOLIS],

Constantinopolis 1 .

Rv.: keine Leg., Victoria 1. auf Prora

- -//SMHA

korrodiert, Erh. 4

RIC VII 115; LRBC 903

8/2003; Logeion; S 3/2003; L42

\section{Constantinus I. Für Urbs Roma}

$\boldsymbol{K y z}$

M 133 Fol

331/334 n. Chr.

1,46. 20.7

Av.: VRBS - ROMA, Romakopf 1.

Rv.: keine Leg., Lupa 1.

- -//SMK?
Randausbruch, Erh. 3

RIC VII 90; LRBC 1232

14/2004; kaiserzeitliches Bühnengebäude; Kammer E5; außerhalb von S 7/2004; B42

\section{Mzst.?}

M 134 Fol

330/337 n. Chr.

2,65. 19.6

Av.: [VRBS - ROMA], Romakopf 1.

Rv.: keine Leg., Lupa

$--/ /$ ?

korrodiert, Erh. 5

RIC VII ?

13/2003; Logeion; S 3/2003; L4

\section{Konstantinische Dynastie (UnBestimmbar)}

Mzst.?

M 135 Fol

$335 / 340$ n. Chr.

1,03.14. 6

Av.: Leg. unlesbar, Büste?

Rv.: [GLOR-IA EXER-CITVS], 2 Soldaten mit 1 Feldzeichen $--/ /$ ?

Erh. 5

17/2007; Südflügel; Zugangspodest ES1; Streufund

\section{KonSTANTINSÖHNE}

\section{Con}

M 136 Fol

Taf. 358

$337 / 340$ n. Chr.

1,3.16. 7

Av.: DN CONSTAN-..., RDiad?

Av.: GLOR-IA EXERC-[ITVS], 2 Soldaten mit 1 Feldzeichen $--/ /$ CONSI

Erh. 3

RIC VIII 24, 27 od. 29; LRBC 1054 od. 1057

70/2007; Süd-Analemma; KS2; SE 44

Constans I. (337-350 N. Chr.)

(VOR Der Reform von 348 N. Chr.)

\section{Tes}

M 137 Fol

Taf. 359

341/348 n. Chr.

1,14. 19. 11

Av.: CONSTANS - PF AVG,

LRDiad2PCV

Rv.: VICTORIAE DD AVGGQNN, 2 Victorien

- -//SMTS?

Erh. 3 
RIC VIII 100; LRBC 860

6/2004; Terrassenmauer nördl. der byzantinischen Stadtmauer; vor Kammer E4; Reinigung

Nic

M 138 Fol

341/348 n. Chr.

1,75. 14. 12

Av.: DN CONSTA-[NS PF AVG], RDiad2

Rv.: VOT / XX / MVLT / XXX in Kranz

- -//SMNA

Erh. 3

RIC VIII 52; LRBC -

133/2007; Süd-Analemma; KS1; SE 46

\author{
östl. Mzst. \\ M 139 Fol \\ 341/348 n. Chr. \\ 2,06. 16.6 \\ Av.: Leg. unlesbar, PDiad? \\ Rv.: VOT / XX / MVLT / XXX in Kranz \\ $--/ /$ ? \\ Erh. 4 \\ 7/1998; Streufund
}

Constantius II. (337-361 N. Chr.)

(VOR DER REFORM VON 348 N. CHR.)

\section{Kyz}

M 140 Fol

$337 / 340$ n. Chr.

$1,71.16 .12$

Av.: [DN CONS]TAN-TIVS PF AVG, Lk1

Rv.: GLOR-IA EXERC-[ITVS], 2 Soldaten mit 1 Feldzeichen $--/ / \mathrm{SMK} \Gamma$

Erh. 3

RIC VIII 10; LRBC 1281

117/2007; Süd-Analemma; KS1; SE 46

\section{Constans I. und Constantius II.} für Divus Constantinus I.

\section{Nic}

M 141 Fol

$341 / 348$ n. Chr.

1,6. 15.5

Av.: [DV CONSTANTI]- PT AVGG, Schleier

Rv.: VN - MR, Kaiser mit Schleier r. st., r. Hand erhoben

- -//SMN?

Erh. 3

RIC VIII 57; LRBC 1155

12/1997; Nord-Analemma; Kammer KN1; SE N15
Constans I. od. Constantius II. (Follisperiode)

\section{Nic/Kyz}

M 142 Fol

341/348 n. Chr.

1,74. 14.6

Av.: Leg. unlesbar, ?Diad2

Rv.: VOT / XX / MVLT / XXX in Kranz

$--/ / \mathrm{SM}$ ?

Erh. 4

RIC VIII 49. 50 (Nic) od. 47-52 (Kyz)

84/2007; Süd-Analemma; KS2; SE 44

\section{Ant}

\section{143 Fol}

$341 / 348$ n. Chr.

1,11. 14. 6

Av.: Leg. unlesbar, PDiad?

Rv.: VOT / XX / MVLT / XXX in Kranz

- -//ANT?

Erh. 3

RIC VIII 118-120; LRBC 1401

46/2007; Süd-Analemma; KS3; SE 33

\section{Constantius II. (337-361 N. Chr.)}

(NACH DeR Reform von 348 N. Chr.)

\section{Con}

M 144 Cen

$351 / 355$ n. Chr.

Taf. $359 \quad 3,09.14 .12$

Av.: [D N CONSTAN-TIVS P F AVG], PDiad2Büste?

Rv.: [FEL TEMP RE-PARATIO], Reitersturz (Reiter mit ausgestreckter Hand)

$--/ /$ CONSI

korrodiert, Erh. 4

RIC VIII 118; LRBC 2039

14/2003; Logeion; S 3/2003; L4

M 145 Cen

351/355 n. Chr.

2,29. 17.6

Av.: DN CONSTAN-[TIVS PF AVG], PDiad2PCv

Rv.: FEL TEMP RE-PARATIO, Reitersturz (Reiter mit ausgestreckter Hand)

$--/ / \mathrm{CONS} \varsigma$

Erh. 3

RIC VIII 121; LRBC 2043

13/2004; Logeion; S 5/2004; L68-75

Kyz

M 146 Cen

355/361 n. Chr.

$1,51.20 .6$ 
Av.: [DN C]ONSTAN-TIVS PF AVG, PDiad2PCv Rv.: SPES-[REIPV]BLICE, Kaiser st. mit Globus $\Gamma-/ /[\mathrm{S}] \mathrm{MK} \Delta$

frg., Erh. 4

RIC VIII 119; LRBC 2506

11/2004; kaiserzeitliches Bühnengebäude; Kammer E5, mittleres sog. Becken

\section{Ale}

M 147 Cen

355/361 n. Chr.

2,4. 15.5

Av.: [DN CONSTAN-TIVS PF AVG], PDiad2Cv

Rv.: [SPES REI-PVBLICE], Kaiser st. mit Globus

- -//ALEB

kleiner Randausbruch, Erh. 4

RIC VIII 87; LRBC 2850

132/2007; Süd-Analemma; KS1; SE 46

\section{östl. Mzst.?}

M 148 Cen

355/361 n. Chr.

3,26. 18.11

Av.: DN CONSTAN-TIVS PF AVG,

PDiad2PCV

Rv.: FEL TEMP-[REPARATIO], Reitersturz (Reiter mit ausgestreckter Hand)

$\mathrm{M}-/ /$ ?

Erh. 3

8/2004; kaiserzeitliches Bühnengebäude; Kammer E5; S 7/2004; B41

\section{Mzst.?}

M 149 Cen

351/361 n. Chr.

1,78. 17.8

Av.: DN CONSTAN-[TIVS PF AVG], PDiad2PCv

Rv.: [FEL TEMP RE-PARATIO], Reitersturz (Reiter mit ausgestreckter Hand)

Rv-Bz. ?

Erh. 4

10/2004; kaiserzeitliches Bühnengebäude; Kammer E5; mittleres sog. Becken

\section{150 Cen}

351/361 n. Chr.

1,7. 17.9

Av.: Leg. unlesbar, PDiad2Büste?

Rv.: [FEL TEMP RE-PARATIO], Reitersturz (Typ)

Rv-Bz. ?

kleiner Randausbruch, Erh. 5

123/2007, Süd-Analemma; KS1, SE 46

\section{151 Cen}

351/361 n. Chr.

1,55. 13. 11
Av.: DN CO[NSTAN-TIVS PF AVG], PDiad2PCv Rv.: [FEL TEMP - REPARATIO], Reitersturz (Typ) Rv-Bz. ?

dezentriert, Erh. 4

47/2007; Süd-Analemma; KS2; SE 28b

\section{152 Cen}

351/361 n. Chr.

1,32. 17. ?

Av.: Leg. unlesbar, Büste?

Rv.: [FEL TEMP RE-PARATIO], Reitersturz (Typ)

Rv-Bz. ?

frg., Erh. 5

35/2007; Süd-Analemma; KS2; SE 28b

\section{153 Cen}

351/361 n. Chr.

$1,12.17 .6$

Av.: DN CONSTAN-TIVS PF [AVG], PDiad2PCv

Rv.: [FEL TEMP - REPARATIO], Reitersturz (Reiter mit ausgestreckter Hand)

- - //?

Randausbruch, Erh. 3

33/2007; Süd-Analemma; KS2; SE 28b

\section{Constantius II. für Constantius Gallus}

\section{Nic}

\section{154 Mai}

$351 / 354$ n. Chr

5,6. 22.5

Av.: [D N FL CL CONSTAN]TIVS NOB CAES, PCv

Rv.: FEL TEMP RE-PARATIO, Reitersturz (Reiter mit ausgestreckter Hand)

$\Gamma-/ / \bullet$ SMN $\Delta$

kleiner Randausbruch, Erh. 3

RIC VIII 87; LRBC 2303

14/2005; Bühnengebäude; Oberflächenfund

Mzst.?

M 155 Cen

351/354 n. Chr.

2,01. 16.12

Av.: Leg. unlesbar, PCv

Rv.: Leg. unlesbar, Reitersturz (Typ)

Rv-Bz. ?

Erh. 5

15/2009; Süd-Analemma; vomitorium ES1

\section{Constantius II. Für IUlianus III.}

\section{östl. Mzst.?}

M 156 Cen

$355 / 361$ n. Chr. 1,39. 17. 12 
Av.: Leg. unlesbar, PCv

Rv.: [FEL TEMP - REPARA]TIO, Reitersturz (Typ) $\mathrm{M}-/ /$ ?

frg., Erh. 4

106/2007; Stiegengasse Theater-Süd; ES2; Streufund

\section{Mzst.?}

M 157 Cen

355/361 n. Chr.

1,78. 15.9

Av.: Leg. unlesbar, Büste?

Rv.: [SPES REI-PVBLICE], Kaiser st. 1. mit Globus

Rv-Bz. ?

Erh. 5

125/2007; Süd-Analemma; KS1; SE 46

\section{158 Cen}

355/361 n. Chr.

1,19. 15.6

Av.: ...IV ..., PCv

Rv.: SPES RE[I PVBLICE], Kaiser 1. st. mit Globus

Rv-Bz. ?

Erh. 5

49/2007; Süd-Analemma; KS2; SE 28b

\section{VaLentinianus I. (364-375 N. Chr.)}

\section{Tes}

M 159 Cen

364/367 n. Chr.

2,7. 18.12

Av.: [DN VALENTINI]-ANVS PF AVG, Büste?

Rv.: [GLORIA RO-M]ANORVM, Kaiser und Gefangener

- *//(?)TESГ(?)

korrodiert, Erh. 4

LRBC 1711 od. 1715; RIC IX 16a (ii-v)

5/2003; Logeion; S 3/2003; L42

\section{160 Cen}

364/367 n. Chr.

1,47. 19. 12

Av.: DN VALENT[INI-ANVS] PF AVG, PDiad2PCv

Rv.: [GLORIA RO]-MANORVM, Kaiser und Gefangener

- *//TESГ

Av korrodiert, Erh. 4

LRBC 1715; RIC IX 16a (iv)

11/1997; Nord-Analemma; Kammer KN1; SE N15

\section{$K y z$}

\section{161 Cen}

364/375 n. Chr.

2,99. 20. 12

Av.: DN VALENTINI-ANVS PF AVG, PDiad2PCV

Rv.: GLORIA RO-MANORVM, Kaiser und Gefangener - -//SMKГ korrodiert, Erh. 3

LRBC 2517=2526; RIC IX 8a (3)=12a (3)

3/2002; Bühnengebäude, Terrassenmauer; Oberflächenreinigung

Valens II. (364-378 N. Chr.)

$K y z$

M 162 Cen

$364 / 375$ n. Chr.

2,95. 18.12

Av.: DN VALEN-S PF AVG, PDiad2PCv

Rv.: SECVRITAS - REIPVBLICAE, Victoria n. 1.

- -//SMK $\triangle$

Erh. 3

LRBC 2520=2530; RIC IX 11b (4) =13b (4)

1a/2006; Streufund

M 163 Cen

$364 / 375$ n. Chr.

2,12. 19.12

Av.: D N VALEN-S P F [AVG], PDiad2PCv

Rv.: [GLORIA RO-MANORVM], Kaiser und Gefangener

- -//SMKA

Erh. 4

LRBC 2518=2527; RIC IX 8b (1)=12b (1)

6/2003; Logeion; S 3/2003; L42

\section{östl. Mzst.?}

\section{164 Cen}

364/378 n. Chr.

1,74. 19. 12

Av.: DN VALEN-[S PF AVG], PDiad2PCv

Rv.: [SECVRITAS]-REIPV[BLICAE], Victoria n. 1.

? ?//SM?

Randausbruch, Erh. 4

128/2007; Süd-Analemma; KS1; SE 46

\section{Mzst.?}

M 165 Cen

364/378 n. Chr.

1,1. 16.12

Av.: [DN VALEN]-S PF AVG,

PDiad2PCV

Rv.: GLORIA RO-[MANORVM], Kaiser und Gefangener

$--/ /$ ?

frg., Erh. 3

95/2007; Süd-Analemma; KS2; SE 44

\section{166 Cen}

$364 / 378$ n. Chr.

1,86. 17. 12

Av.: DN VALEN-S PF AVG, PDiad2PCV

Rv.: SECVRITAS - REIPVBLICAE, Victoria n. 1.

$?-/ /$ ?

kleiner Randausbruch, Erh. 4

4/2004; Logeion; S 5/2004; Profilreinigung 
Valentinianus I. OD. VAlens II.

\section{Mzst.?}

M 167 Cen

364/378 n. Chr.

2,15. 14.5

Av.: Leg. unlesbar, PDiad2PCv

Rv.: [GLORIA RO-MANORVM], Kaiser und Gefangener

Rv-Bz. ?

Erh. 5

118/2007; Stiegengasse Theater-Süd; ES2; Streufund

M 168 Cen

364/378 n. Chr.

$1,95.15 .12$

Av.: Leg. unlesbar, PDiad2PCv

Rv.: [SECVRITAS - REIPVBLICAE], Victoria n. 1.

Rv-Bz. ?

Erh. 4

55/2007; Süd-Analemma; KS2; SE 28b

\section{169 Cen}

1,59. 15.6

Av.: Leg. unlesbar, PDiad2PCv

Rv.: [SECVRITAS - REIPVBLICAE], Victoria n. 1.

Rv-Bz. ?

kleiner Randausbruch, Erh. 4

364/378 n. Chr.

120/2007; Süd-Analemma; KS1; SE 46

\section{Valentinianus I., Valens II. OD. Gratianus}

\section{Mzst.?}

\section{170 Cen}

364/378 n. Chr.

1,62.17. 6

Av.: Leg. unlesbar, Büste?

Rv.: [GLORIA RO-MANORVM], Kaiser und Gefangener Rv-Bz. ?

kleiner Randausbruch, korrodiert, Erh. 4

131/2007; Süd-Analemma; KS1; SE 46

\section{171 Cen}

364/378 n. Chr.

1,43. 15.6

Av.: Leg. unlesbar, PDiad2PCv

Rv.: [GLORIA RO-MANORVM], Kaiser und Gefangener $--/ /$ ?

Erh. 4

92/2007; Süd-Analemma; KS2; SE 44

\section{Gratianus (367-383 n. Chr.)}

\section{Tes}

M 172 Cen

378/383 n. Chr. 1,74. 15.6
Av.: DN GRATIA-NVS PF AVG, PDiad2PCv

Rv.: VOT / XV / MVLT / XX in Kranz

$--/ /$ TES

Erh. 3

LRBC 1819; RIC IX 43

1/2010; Orchestra; Oberflächenreinigung

\section{$\mathrm{Her}$}

M 173 1/2 Cen

Taf. 359

383 n. Chr.

1,07. 14. 6

Av.: DN GRATIA-[NVS PF AVG], PDiad2PCV

Rv.: VOT / XX / MVLT / XXX in Kranz

$--/ / \mathrm{SMH} \Delta$

Erh. 3

LRBC 1957; RIC IX 20a (2)

101/2007; Süd-Analemma; KS2; SE 45

\section{Nic}

M 174 1/2Cen

$378 / 383$ n. Chr.

1,8.14. 12

Av.: [DN GRATIA-NVS PF AVG],

PDiad2PCV

Rv.: VOT / XV / MVLT / XX in Kranz

- -//SMNB

Erh. 4

LRBC 2350; RIC IX 35

116/2007; Süd-Analemma; KS1; SE 46

$K y z$

M 175 Cen

$367 / 375$ n. Chr.

2,05. 14.5

Av.: [DN GRATIA-NVS PF AVG], PDiad2PCV

Rv.: [SECVRITAS - REIPVBLICAE], Victoria n. 1.

- -//SMKA

ovaler Schrötling, Erh. 4

LRBC 2531; RIC IX 13c (1)

121/2007; Süd-Analemma; KS1; SE 46

M 176 1/2Cen

Taf. 359

383 n. Chr.

1. 16.12

Av.: DN GRATIA-NVS PF AVG,

PDiad2PCv

Rv.: VOT / XX / MVLT / XXX in Kranz

- -//SMKA

Erh. 3

LRBC 2552; RIC IX 22a (1)

134/2007; Süd-Analemma; KS1; SE 46 
Mzst.?

M 177 Cen

367/375 n. Chr.

1,15. 17. 12

Av.: [DN GRATIA]-NVS P F AVG,

PDiad2PCV

Rv.: [GLO]RIA RO-MANORVM, Kaiser st. mit Standarte,

Gefangener

Rv-Bz. ?

kleiner Randausbruch, Erh. 4

122/2007; Süd-Analemma; KS1; SE 46

\section{178 Cen}

367/378 n. Chr.

2,25. 17. 12

Av.: Leg. unlesbar, PDiad2PCv

Rv.: SECVRITAS - [REIPVBLICAE], Victoria n. 1.

$?-/ /$ ?

Erh. 5

115/2007; Süd-Analemma; KS1; SE 46

\section{179 Cen}

378/388 n. Chr.

1,25. 15.7

Av.: DN GR[ATI-ANVS PF AVG],

PDiad2PCV

Rv.: [CONCORDI-A AVGGG], Constantinopolis sitzend front. mit Globus und Szepter

$--/ /$ ?

Randausbruch, Erh. 4

76/2007; Süd-Analemma; KS2; SE 44

\section{180 Cen}

367/383 n. Chr.

1,84. 17. ?

Av.: [DN GRATIANVS PF AVG], Büste?

Rv.: Leg. unlesbar, Bild unkenntlich

Rv-Bz. ?

Erh. 5

127/2007; Süd-Analemma; KS1; SE 46

Valentinianus II. (375-392 N. Chr.)

\section{Con}

M $181 \frac{1 / 2 \text { Cen }}{3}$

383/392 n. Chr.

0,78. 14.12

Av.: DN VALENTINI-ANVS PF AVG, PDiad2PCV

Rv.: SALV[S REI-PVBLICAE], Victoria n. 1. mit Gefangenem $f-/ /$ CONST

Erh. 4

LRBC 2183; RIC IX 86a (2)

119/2007; Süd-Analemma; KS1; SE 46

\section{Mzst.?}

M 182 1/2Cen

383/392 n. Chr.
1,15. 13.1

Av.: DN VALENTINIANVS PF AVG, PDiad2PCv

Rv.: [SALVS REI-PVBLICAE], Victoria n. 1. mit Gefangenem $f-/ /$ ?

Erh. 3

72/2007; Süd-Analemma; KS2; SE 44

\section{Konstantinische-valentinianische Dynastie}

Mzst.?

M $183 \mathrm{Fol} / \mathrm{Cen}$

ca. $318 / 378$ n. Chr.

1,32.19. 6

Av.: Leg. unlesbar, Büste?

Rv.: Leg. unlesbar, Bild unkenntlich

frg., korrodiert, Erh. 5

2/1998; Sondage 2/98; SE 29

Theodosius I. (379-395 N. Chr.)

\section{Her}

M 184 Mai

Taf. 359

393/395 n. Chr.

6,76. 22.6

Av.: DN THEODO-SIVS PF AVG, PDiad2PCv

Rv.: GLORIA - ROMANORVM, Kaiser st. mit Labarum und Globus

- -//SMHA

Erh. 1

LRBC 1986; RIC IX 27b (1)

1/1993; Streufund

\section{Con}

M 185 1/2Cen

Taf. 359

383/395 n. Chr.

0,96. 14. 6

Av.: DN THEODO-SIVS P F AVG, PDiad2PCv

Rv.: [SALVS REI-PVBLICAE], Victoria n. 1. mit Gefangenem f-//CON?

Erh. 3

LRBC 2184=2192; RIC IX 86b=90a

16/2003; Logeion; S 3/2003; Profilreinigung

\section{$K y z$}

M 186 1/2Cen

Taf. 359

383 n. Chr.

1,66. 14.12

Av.: DN THEODO-SIVS PF AVG,

PDiad2PCv

Rv.: VOT / X / MVLT / XX in Kranz

- -//SMK?

Erh. 4

LRBC 2557; RIC IX 21c

43/2007; Süd-Analemma; KS2; SE 28b 
M $187^{1 / 2}$ Cen

383/395 n. Chr.

1,47. 14.7

Av.: DN THEOD[O-SIVS PF AVG],

PDiad2PCV

Rv.: SALVS REI-PVB[LICAE], Victoria n. 1. mit Gefangenem f-//SMK厂

Erh. 3

LRBC 2569=2577; RIC IX 26b=30a (3)

78/2007; Süd-Analemma; KS2; SE 44

\section{188 1/2 Cen}

383/395 n. Chr.

$0,95.13 .6$

Av.: DN THEODO-SIVS PF AVG,

PDiad2PCV

Rv.: SALVS REI-PVBLICAE, Victoria n. 1. mit Gefangenem

f- //SMKA

Erh. 3

LRBC 2569=2577; RIC IX 26b=30a (1)

1/2006; summa cavea; Streufund

\section{Mzst.?}

M 189 1/2Cen

383/395 n. Chr.

1,06. 13.11

Av.: DN THEODO-]SIVS PF AVG,

PDiad2PCV

Rv.: [SALVS REI-PVBLICAE], Victoria n. 1. mit Gefangenem

$f-/ /$ ?

kleiner Randausbruch, Erh. 4

3/2008; Streufund

\section{190 1/2 Cen}

383/395 n. Chr.

0,88. 15.7

Av.: DN THEODO-SIVS PF AVG,

PDiad2PCv

Rv.: [SALVS REI]-PVBLICAE, Victoria n. 1. mit Gefangenem f- $/ /$ ?

Erh. 3

114/2007; Süd-Analemma; KS1; SE 46

\section{Arcadius (383-408 N. Chr.)}

\section{Tre}

M 191 1/2Cen

388/392 n. Chr.

1,22. 13.1

Av.: DN AR[CADI-]VS PF AVG,

PDiad2PCV

Rv.: VICTOR-IA AVGGG, Victoria 1. laufend

- $-/ / \mathrm{TR}(?)$

Erh. 3

LRBC 164 od. 167; RIC IX 97c=107b

77/2007; Süd-Analemma; KS2; SE 44

Taf. 359

\section{Con}

M 192 1/2Cen

393/395 n. Chr.

1,58. 14.12

Av.: DN ARCADIVS PF AVG,

PDiad2PCV

Rv.: [SALVS REI-PVBLICAE], Victoria n. 1. mit Gefangenem f-//CONSГ

Erh. 3

LRBC 2193; RIC IX 86c (3)

40/2007; Süd-Analemma; KS2; SE 28b

\section{193 Cen}

Taf. 359

395/408 n. Chr.

2,05. 17. 12

Av.: DN ARCADI-VS PF AVG, PDiad2PCv

Rv.: VIRTVS-EXERCITI, Kaiser r. st. von Victoria 1. st. bekränzt

$--/ / C O N S ?$

Erh. 2

LRBC 2205; RIC X 60

1P/2009; Portikus; FK 25/2009; SE 16

\section{$K y z$}

\section{194 1/2Cen}

383 n. Chr.

0,79. 14. 6

Av.: DN ARCADIVS PF AVG, PDiad2PCv

Rv.: VOT / V in Kranz

$--/ / \mathrm{SMK}$ ?

Erh. 4

LRBC 2562; RIC IX 20d

Taf. 359 29/2007; Süd-Analemma; KS2; SE 28b

M 195 1/2Cen

393/395 n. Chr

1,5.14. 12

Av.: DN ARCADIVS PF AVG,

PDiad2PCV

Rv.: SALVS REI-[PVBLICAE], Victoria n. 1. mit Gefangenem f-//SMK?

Erh. 3

LRBC 2578; RIC IX 26c (1)

37/2007; Süd-Analemma; KS2; SE 28b

M 196 1/2Cen

Taf. 359

404/406 n. Chr.

$0,92.13 .12$

Av.: [DN AR]CADI-[VS PF AVG],

PDiad2PCv

Rv.: [CONCORDI-A AVGGG], Kreuz

f-//SMK?

frg., Erh. 3

RIC X 135

50/2007; Süd-Analemma; KS2; SE 28b

Taf. 359 


\section{östl. Mzst.?}

\section{197 Cen}

395/401 n. Chr.

1,5. 16. 11

Av.: [ARCA]-DI[VS PF AVG],

PDiad2PCV

Rv.: [VIRTVS - EXERCITI], Kaiser r. st. von Victoria 1. st. bekränzt

$--/ /$ ?

Erh. 5

91/2007; Südrampe; Reinigung

\section{Honorius (393-423 N. Chr.)}

\section{Her}

\section{198 Cen}

408/423 n. Chr.

1,48. 15.5

Av.: DN HONORI-VS PF AVG, PDiad2PCv

Rv.: [GLORIA RO]-MANORVM, Zwei Kaiser halten Globus * -; - - //SMHB

Erh. 3

RIC X 407

2/2008; Stiegengasse Theater-Süd; Zugangspodest ES3; B2; SE 12

\section{Con}

\section{199 Cen}

406/408 n. Chr.

1,12. 13.6

Av.: [DN H]ONORI-VS PF AVG,

PDiad2PCv

Rv.: [GLORI-A ROMA-NORVM], 3 Kaiser

$*-;--/ / C O N S ?$

frg., Erh. 4

RIC X 143

73/2007; Süd-Analemma; KS2; SE 44

\section{$K y z$}

M 200 Cen

395/401 n. Chr.

2,18. 18.6

Av.: DN HONORI-VS PF AVG,

PDiad2PCv

Rv.: [VIRTVS - EXERCITI], Kaiser r. st. von Victoria 1. st.

bekränzt

- -//SMKA

kleiner Randausbruch, Erh. 4

RIC X 68; LRBC 2581

86/2007; Süd-Analemma; KS2; SE 44

\section{201 Cen}

406/408 n. Chr.

1,21. 15.6

Taf. 359
Av.: DN HONORI-VS PF AVG,

PDiad2PCV

Rv.: GLORI-A ROMA-NORVM, 3 Kaiser

* -; - -//SMK?

ovaler Schrötling, Erh. 3

RIC X 149

1/1998; Nord-Analemma; Oberfläche

\section{Mzst.?}

M 202 Cen

Taf. 359

395/401 n. Chr.

$1,46.19 .5$

Av.: DN HON[ORI-VS P]F AVG,

PDiad2PCV

Rv.: [VIRTVS - EXERCITI], Kaiser r. st. von Victoria 1. st. bekränzt

$--/ /$ ?

frg., Erh. 3

94/2007; Süd-Analemma; KS2; SE 44

M 203 1/2Cen

$393 / 403$ n. Chr.

Taf. 359

1,4. 12.6

Av.: DN HONORI-[VS PF AVG],

PDiad2PCv

Rv.: [SALVS REI-PVBLICAE], Victoria n. 1. mit Gefangenem $f-/ /$ ?

Erh. 3

39/2007; Süd-Analemma; KS2; SE 28b

VALENTINIANUS II.,

Theodosius I. OD. Arcadius

\section{Aqu/Rom/Tes}

M 204 Cen

$383 / 388$ n. Chr.

2,01. 15. 6

Av.: Leg. unlesbar, Büste?

Rv.: [GLORIA RO-MANORVM], Kaiser und Gefangener

Rv-Bz. ?

korrodiert, Erh. 5

LRBC 768-774, 1084-1086, 1848 od. 1850-1852; RIC IX 45 (Aqu), 55 (Rom) od. 60 (Tes)

4/2003; Logeion; S 3/2003; L42

Valentinianus II., Theodosius I., ArCadius OD. Honorius

\section{Con}

M 205 1/2Cen

$383 / 395$ n. Chr.

0,82. 10.12

Taf. 359 Av.: Leg. unlesbar, PDiad2PCv

Rv.: [SALVS REI-PVBLICAE], Victoria n. 1. mit Gefangenem $f-/ / C O N$ ? 
Randausbruch, Erh. 4

RIC IX 86 od. 90; LRBC 2183-2185 od. 2192 od. 2194

69/2007; Süd-Analemma; KS2; SE 44

\section{Mzst.?}

M 206 1/2Cen

$383 / 403$ n. Chr.

1,28. 14. 11

Av.: Leg. unlesbar, PDiad2PCv

Rv.: [SALVS REI-PVBLICAE], Victoria n. 1. mit Gefangenem

$f-/ /$ ?

ovaler Schrötling, Erh. 4

90/2007; Südrampe; Reinigung

M $207 \frac{1}{2}$ Cen

383/403 n. Chr.

1,26. 13.12

Av.: Leg. unlesbar, Büste?

Rv.: [SALVS REIPVBLICAE], Victoria n. 1. mit Gefangenem

$[\mathrm{f}]-/ /$ ?

Erh. 4

14/2009; Stiegengasse Theater-Süd; Treppe-West; SE 231

M 208 1/2Cen

$383 / 395$ n. Chr.

1,17. 11.6

Av.: Leg. unlesbar, Büste?

Rv.: [SALVS REI-PVBLICAE], Victoria n. 1. mit Gefangenem

$f-/ /$ ?

Erh. 5

16/2004; Orchestra; S 3/2004; Oberfläche

M 209 1/2 Cen

383/395 n. Chr.

1,12. 11. ?

Av.: Leg. unlesbar, PDiad2PCV

Rv.: [SALVS REI-PVBLICAE], Victoria n. 1. mit Gefangenem $[\mathrm{f}]-/ /$ ?

Flächenschaden, Erh. 4

85/2007; Süd-Analemma; KS2; SE 44

M 210 1/2 Cen

Taf. 359

$383 / 403$ n. Chr.

1,11. 12. 5

Av.: Leg. unlesbar, PDiad2PCv

Rv.: [SALVS REI-PVBLICAE], Victoria n. 1. mit Gefangenem

$f-/ /$ ?

Erh. 4

42/2007; Süd-Analemma; KS2; SE 28b

VALENTINIANISChE OD. THEOdosianische Dynastie

\section{Mzst.?}

\section{211 Cen}

364/395 n. Chr.

0,75. 15. ?
Av.: Leg. unlesbar, Büste?

Rv.: Leg. unlesbar, Bild unkenntlich

Rv-Bz.?

frg., Bruchhälfte, Erh. 5

17/2004; Orchestra; S 3/2004; Oberfläche

\section{Unbestimmbar naCh 378 n. Chr.}

\section{Mzst.?}

M 212 1/2Cen

383/395 n. Chr.

1,81.14. 3

Av.: Leg. unlesbar, Büste?

Rv.: Leg. unlesbar, Victoria 1.

Rv-Bz. ?

korrodiert, Erh. 5

10/2003; Logeion; S 3/2003; L4

\section{213 Cen}

$395 / 425$ n. Chr.

1,67. 16,2. ?

Av.: Leg. unlesbar, Büste?

Rv.: Leg. unlesbar, Bild unkenntlich

Rv-Bz. ?

korrodiert, Erh. 5

62/2007; Süd-Analemma; KS3; SE 33

M 214 1/2Cen

$383 / 395$ n. Chr.

1,24. 12. ?

Av.: Leg. unlesbar, Büste?

Rv.: Leg. unlesbar, Victoria 1.

Rv-Bz. ?

korrodiert, Erh. 5

130/2007; Süd-Analemma; KS1; SE 46

M 215 1/2Cen

$383 / 425$ n. Chr.

0,68. 12. ?

Av.: Leg. unlesbar, Büste?

Rv.: Leg. unlesbar, Bild unkenntlich

Rv-Bz. ?

frg., Erh. 5

129/2007; Süd-Analemma; KS1; SE 46

Arcadius, Honorius oder Theodosius II.

östl. Mzst.?

M 216 Cen

Taf. 359

406/408 n. Chr.

1,5. 14. 2

Av.: Leg. unlesbar, PDiad2PCv

Rv.: [GLORI-A ROMA-NORVM], 3 Kaiser

$*-;--/ /$ ?

Erh. 4

RIC X 142-159

93/2007; Süd-Analemma; KS2; SE 44 
HoNORIUS ODER THEODOSIUS II.

Mzst.?

M 217 Cen

408/423 n. Chr.

1,58. 15.6

Av.: Leg. unlesbar, PDiad2PCv

Rv.: [GLOR-IA ROMA-NORVM], 2 Kaiser halten Globus

$--/ /$ ?

Erh. 5

RIC X 395-418

16/2007; Stiegengasse Theater-Süd; Treppe-Ost; C2; Oberfläche

\section{218 Cen}

408/423 n. Chr.

$0,89.15 .7$

Av.: ...S PF AVG, PDiad2PCV

Rv.: [GLORI]-A ROMA-[NORVM], 2 Kaiser halten Globus

$--/ /$ ?

frg., Erh. 3

RIC X 407-418

51/2007; Süd-Analemma; KS2; SE 28b

\section{219 Cen}

408/423 n. Chr.

1,31.11. 6

Av.: Leg. unlesbar, PDiad2PCv

Rv.: [GLOR-IA ROMA-NORVM], 2 Kaiser halten Globus

Rv-Bz. ?

Erh. 5

RIC X 395-418

11/2006; Südrampe; Oberflächenfund

\section{220 Cen}

408/423 n. Chr.

0,3. 11. ?

Av.: Leg. unlesbar, Büste?

Rv.: [GLORI-A ROMA-NORVM], 2 Kaiser halten Globus $--/ /$ ?

Randausbruch, Erh. 5

38/2007; Süd-Analemma; KS2; SE 28b

\section{Theodosius II. (408-450 N. Chr.)}

Kyz

M 221 1/2Cen

425/435 n. Chr.

1,01. 12. 1

Av.: DN THEODOSIVS PF AVG,

PDiad2PCV

Rv.: CONCOR-[DIA AVG], Victoria front. st. mit 2 Kränzen

- -//SMKA

Erh. 3

RIC X 437

83/2007; Süd-Analemma; KS2; SE 44

M 222 1/2 Cen

425/435 n. Chr.

1,99. 15.7

Taf. 359
Av.: DN THEO..., PDiad2PCv

Rv.: keine Leg., Kreuz in Kranz

- -//SMKA

Erh. 3

RIC X 449 od. 451

30/2007; Süd-Analemma; KS2; SE 28b

\section{Con/Nic/Kyz}

M 223 1/2Cen

$435 \mathrm{n}$. Chr.

0,8. 12.12

Av.: [DN THEODOSIVS PF AVG],

PDiad2PCV

Rv.: VT / XXX / V in Kranz

$--/ /$ ?

Erh. 4

RIC X 457-459

75/2007; Süd-Analemma; KS2; SE 44

\section{östl. Mzst.?}

M 224 1/2Cen

$425 / 435$ n. Chr.

$0,84.11 .6$

Av.: DN THEODO-[SIVS PF AVG],

PDiad2PCy

Rv.: [CONCOR-DIA AVG], Victoria front. st. mit 2 Kränzen

$--/ /$ ?

Av dezentriert, Erh. 3

RIC X 431-439

8/2007; Streufund

M $2251 / 2$ Cen

Taf. 359

425/435 n. Chr.

1,23. 13.6

Rv.: DN TH[EODOSIVS PF] AVG, PDiad2PCv

Rv.: [CONCOR-DIA AVG], Victoria front. st. mit 2 Kränzen

$--/ /$ ?

dezentriert (Av. und Rv.), Erh. 3

RIC X 431-434. 436.437 od. 439

36/2007; Süd-Analemma; KS2;SE 28b

M $2261 / 2$ Cen

Taf. 359

$425 / 435$ n. Chr.

0,76. 12.6

Av.: [DN T]HEODOSIV[S PF AVG], PDiad2PCv

Rv.: keine Leg., Kreuz in Kranz

$--/ /$ ?

Erh. 3

RIC X 440. 442. 443. 445. 448. 451. 453.454 od. 455

52/2007; Süd-Analemma; KS2; SE 28b

M $227 \frac{1}{2}$ Cen

$425 / 435$ n. Chr.

0,56. 9. ?

Av.: Leg. unlesbar, Büste?

Rv.: keine Leg., Kreuz in Kranz

$--/ /$ ?
Taf. 359 
Loch, Erh. 4

RIC X 440. 442. 443. 445. 448. 451. 453. 454 od. 455

81/2007; Süd-Analemma; KS2; SE 44

\section{Mzst.?}

M 228 Cen

408/423 n. Chr.

1,62.13. 7

Av.: IMP THEODO-SIVS PF AVG,

PDiad2PCv

Rv.: [GLORI-A ROMA-NORVM], 2 Kaiser halten Globus

$--/ /$ ?

Erh. 4

RIC X 395-418

28/2007; Süd-Analemma; KS2; SE 28b

\section{Theodosius II. od. Valentinianus III.}

östl. Mzst.

M 229 1/2Cen

425/435 n. Chr.

0,83. 11. ?

Av.: Leg. unlesbar, Büste?

Rv.: keine Leg., Kreuz in Kranz

$--/ /$ ?

Erh. 5

\section{Byzanz}

\section{Zeno (474-491 n. Chr.)}

od. Anastasius I. (491-518 N. Chr.)

Mzst.?

M 232 Min

474/518 n. Chr.

0,78. 9.?

Av.: Leg. unlesbar, Büste?

Rv.: Monogramm

Erh. 5

80/2007; Süd-Analemma; KS2; SE 44

\section{Anastasius I. (491-518 N. Chr.)}

\section{Mzst.?}

M 233 Min

491/518 n. Chr.

$0,61.8 .5$

Av.: Leg. unlesbar, Büste?

Erh. 4

Rv.: Monogramm

MIBE 40 (Typ)

2/1995; Süd-Analemma; vomitorium ES2
RIC X 440-455

126/2007; Süd-Analemma; KS1; SE 46

\section{Mzst.?}

M 230 1/2Cen

Taf. 359

$425 / 435$ n. Chr.

1,22. 11.6

Av.: Leg. unlesbar, PDiad2PCy

Rv.: [CONCOR-DIA AVG], Victoria front. st. mit 2 Kränzen

$--/ /$ ?

Erh. 3

RIC X 431-439

54/2007; Süd-Analemma; KS2; SE 28b

\section{LEO I. (457-474 N. CHR.)}

\section{Tes/Con/Nic/Kyz}

M 231 Min

457/474 n. Chr.

$0,43.10 .5$

Av.: Leg. unlesbar, Büste?

Rv.: b-E, Verina 1. st. mit Kreuzglobus und Szepter quer $--/ /-$

Erh. 5

RIC X 713-718

11/2003; Logeion; S 3/2003; L4

\section{234 Min}

491/518 n. Chr.

$0,52.8 .3$

Av.: Leg. unlesbar, PDiad2PCv

Rv.: Monogramm

Erh. 5

MIBE 40 (Typ)

79/2007; Süd-Analemma; KS2; SE 44

M 235 Min

Taf. 359

491/518 n. Chr.

0,46. 9.7

Av.: Leg. unlesbar, PDiad2PCv

Rv.: Monogramm

Erh. 5

MIBE 40 (Typ)

32/2007; Süd-Analemma; KS2; SE 28b

\section{236 Min}

491/518 n. Chr.

0,36. 8. ?

Av.: Leg. unlesbar, Büste?

Rv.: Monogramm

Erh. 5

MIBE 40 (Typ)

31/2007; Süd-Analemma; KS2; SE 28b 
IUSTINUS I. (518-527 N. CHR.)

\section{Con}

M 237 5Num

518/522 n. Chr.

1,68. 11.2

Rv.: [D N IVSTI-NVS P P] AV, Büste r.

Rv.: $C$ A

Erh. 4

MIBE 25

10/2005; Raum RN1 nördlich des Bühnengebäudes; S 5/2005; zu B58

M 238 5Num

$522 / 527$ n. Chr.

2. 13.6

Av.: [D N IVSTI-NVS P P AVC], Büste r.

Rv.: Christogramm, 1: A, r: $€$

Erh. 4

MIBE 32

8/2005; Raum RN1 nördlich des Bühnengebäudes; S 5/2005; B56

\section{Anastasius I. OD. IUstinus I.}

\section{Mzst.?}

\section{239 Min}

491/527 n. Chr.

$0,7.8 .12$

Av.: Leg. unlesbar, Büste $\mathrm{r}$.

Rv.: Monogramm

Erh. 5

12/2005; Raum RN1 nördlich des Bühnengebäudes; S 6/2005; B61

\section{IUSTINIANUS I. (527-565 N. CHR.)}

\section{Nic}

M 24010 Num

$556 / 557$ n. Chr.

3,61. 15.1

Av.: [D N IVSTINI-ANVS] P P AVC, Büste r.

Rv.: I, 1: ANNO, r: XXX, oben Kreuz

$--/ /$ NIK

Erh. 3

MIBE 118a

13/2005; Raum RN1 nördlich des Bühnengebäudes; westl. Schwelle, Mörteloberfläche; B55

IUSTINUS II. (565-578 N. Chr.)

$K y z$

M 241 40Num

572/573 n. Chr.

14,16. 31.12
Av.: DN IVSTI-NVS P P AVC, thronendes Kaiserpaar Rv.: M, 1: ANNO, r: CIII, Off: A

$--/ / \mathrm{KYZ}$

Erh. 3

Taf. 359 MIBE $50 \mathrm{~b}$

9/1998; vomitorium EN1; SE N3

\section{Heraclius (610-641 N. Chr.)}

\section{Con}

M 242 40Num

Taf. 359

$615 / 616 \mathrm{n}$. Chr.

9,7.30. 8

Av.: DDNN HERACLIVS ET HERA CONST P AV, 2 Kaiser

st. mit Kreuzstab

Rv.: M, 1: ANNO, r: Ч, Off: $\Gamma$

$--/ / \mathrm{CON}$

unregelmäßiger Schrötling, Überprägung eines 40Num des Phocas aus Con, Av-Rv, Erh. 3

MIB 160a

4/1997; Nord-Analemma; Kammer KN1; SE N12

M 243 40Num

Taf. 360

$11,34.35 .8$

Av.: DDNN HERACLIVS ET HERA CONST P AV, 2 Kaiser

st. mit Kreuzstab

Rv.: M, l: ANNO, r: Ч, Off: A

$--/ / \mathrm{CON}$

unregelmäßiger Schrötling, Überprägung eines 40Num des Phocas aus Con, Av-Rv, Erh. 3

615/616 n. Chr.

MIB 160a

5/1997; Nord-Analemma; Kammer KN1; SE N12

M 244 40Num

Taf. 360

$613 / 614$ n. Chr.

10,34. 32.8

Av.: DD NN HERACLIVS ET HERA CONST P AV, 2 Kaiser

st. mit Kreuzstab

Rv.: M, darüber Christogramm, 1: ANNO, r: II / II, Off: A

$--/ / \mathrm{CON}$

Überprägung, Erh. 3

MIB 160b

11/1998; Nord-Analemma; obere Terrasse (D); Oberfläche

\section{Nic}

M 245 40Num

Taf. 360

$612 / 613 \mathrm{n}$. Chr.

13,6.32. 6

Av.: DDNN HERACLIVS ET HERA CONS, 2 Kaiser st. mit Kreuzglobus

Rv.: M, l: ANNO, r: II / I, Off: A

$--/ / \mathrm{NIK}$

Taf. 359 Überprägung, Erh. 3

MIB 175a

6/1997; Nord-Analemma; Kammer KN1; SE N12 
M 24640 Num

613/614 n. Chr.

$11,75.30 .7$

Av.: DDNN HERACLIVS ET HERA CONS, 2 Kaiser st. mit

Kreuzglobus

Rv.: M, 1: ANNO, r: II / II, Off: B

$--/$ NIK

unregelmäßiger Schrötling, Überprägung, Erh. 3

MIB 175a

1/1997; Nord-Analemma; Kammer KN1/2; SE N12

\section{UNBESTIMMBAR: BYZANZ}

\section{Mzst.?}

M 247 5Num

518/648 n. Chr.

2,55. 12. ?

Av.: Leg. unlesbar, Bild unkenntlich

Rv.: E

dezentriert, Erh. 5

10/2009; Stiegengasse Theater-Süd; Treppe-West; H2; SE 222

\section{248 5Num}

ca. $500 / 700$ n. Chr.

1,97. 13.?

Av.: Leg. unlesbar, PDiad2PCv

Rv.: E

Erh. 5

41/2007; Süd-Analemma; KS2; SE 28b

\section{249 Min/Num}

ca. $500 / 700$ n. Chr.

0,91. 9. ?

Av.: Leg. unlesbar, Büste r.
Taf. 360

Rv.: Monogramm

Rv. korrodiert, Erh. 4

44/2007; Süd-Analemma; KS2; SE 28b

\section{M $250 \mathrm{Min} / \mathrm{Num}$}

ca. 500/700 n. Chr.

0,79. 9. ?

Av.: Leg. unlesbar, Büste r.

Rv.: Monogramm

Randausbruch, korrodiert, aufgeglüht, Erh. 5

9/2005; Raum RN1 nördlich des Bühnengebäudes; S 5/2005; B56

\section{M $251 \mathrm{Min} / \mathrm{Num}$}

ca. $500 / 700$ n. Chr.

0,76. 9. ?

Av.: Leg. unlesbar, Büste r.

Rv.: Monogramm

kleiner Randausbruch, Erh. 5

61/2007; Süd-Analemma; KS3; SE 33

\section{M $252 \mathrm{Min} / \mathrm{Num}$}

ca. 500/700 n. Chr.

0,38. 9. ?

Av.: Leg. unlesbar, Bild unkenntlich

Rv.: Leg. unlesbar, Bild unkenntlich

völlig plan, Erh. 5

5/2008; Streufund

\section{M $253 \mathrm{Min} /$ Num}

ca. $500 / 700$ n. Chr.

0,29. 6. ?

Av.: Leg. unlesbar, Büste?

Rv.: Monogramm

Erh. 5

15/2004; Orchestra; S 3/2004; Oberfläche

\section{Antike: Incerta}

\section{Unbestimmbar: 1.-3. Jh. N. Chr.}

\section{Mzst.?}

M 254 AE

ca. 23 v. Chr. $/ 250$ n. Chr.

14,6. 30.?

Av und Rv völlig plan, Erh. 5

109/2007; Süd-Analemma; KS2; SE 45

\section{Unbestimmbar: 1.-4. Jh. N. Chr.}

\section{Mzst.?}

\section{M $255 \mathrm{AE}$}

ca. 23 v. Chr./400 n. Chr.

0,87. 18.?

frg., Erh. 5

124/2007; Süd-Analemma; KS1; SE 46
Unbestimmbar: 3.-5. JH. N. Chr.

\section{Mzst.?}

M $256 \mathrm{AE}$

192/425 n. Chr.

1,91. 17.?

Av.: Kopf r.

korrodiert, Erh. 4

58/2007; Süd-Analemma; KS3; SE 34

\section{Unbestimmbar: ANTIKe}

\section{Mzst.?}

M 257 AE

ca. 300 v. Chr./600 n. Chr. völlig zersplittert, korrodiert, Erh. 5 5/2005; Orchestra; S 1/2005; O12 
Unbestimmbar: 5.-6. JH. N. Chr.

Mzst.?

M $258 \mathrm{Min} / \mathrm{Num}$

ca. $450 / 600$ n. Chr.

$0,87.10$. ?

Erh. 5

82/2007; Süd-Analemma; KS2; SE 44
UNBESTIMMBAR: ANTIKE

Mzst.?

M 259 AE

ca. 350 v. Chr. $/ 400$ n. Chr.

1,51. 12. ?

Erh. 5

89/2007; Süd-Analemma; KS2; SE 44

$M 260 \mathrm{AE}$

ca. 350 v. Chr./600 n. Chr.

1,69. 14.?

frg., Erh. 5

34/2007; Süd-Analemma; KS2; SE $28 b$

2,29

Av.: Büste $r$

Rv.: unkenntlich

Taf. 360

korrodiert, aufgeglüht, Erh. 5

14/1998; Streufund

15. Jh.

1,27. 13

Av.: Ornament

Rv.: 2-zeilige arab. Schrift, kein Bild

Erh. 3

1/1994; summa cavea; Reinigung

M 262 AE

18. Jh./19. Jh.

6,05

Av.: Leg. unlesbar, Bild unkenntlich

Rv.: Tughra

Erh. 5

4B/2003; Logeion; S 1/2003; Oberfläche

MaHMUd II. (1808-1839) OD.

ABdüLMECID (1839-1861)

Mzst.?

M $263 \mathrm{AE}$

1255 (=1839)

Taf. 360

18/2003; Logeion; S 2/2003; L28
Abdülhamid II. (1876-1909)

\section{Istanbul}

M 26410 Piaster

Taf. 360 $1293(=1876)$

1,94

Erh. 2

Мohammed V. (1909-1918)

\section{Istanbul}

M 26520 Para

$1328(=1910)$

3,88

Erh. 2

9/2003; Logeion; S 3/2003; L45
Taf. 360

\section{Moderne Münzen}

\section{FranKREICH}

Grossbritannien, George VI. (1936-1952)

M 26610 Francs, 1979

o.N./2004; Orchestra; S 3/2004; Oberflächenreinigung

M 2672 Shillings, 1948

2/2004; kaiserzeitliches Bühnengebäude; Kammer E4; Oberflächenreinigung 


\section{GriechenLand}

M 2685 Drachmen, 1994

o.N./2004; Orchestra; S 3/2004; Oberflächenreinigung

\section{RUSSLAND}

M 2691 Rubel, 1997

17/2003; Logeion; S 4/2003; L1

\section{TÜRKEI}

M 27010 Kurus, 1949

18/2004; Orchestra; S 6/2004; Oberflächenreinigung

M 2715 Kurus, 1966

19/2003; Logeion; S 4/2003; L1

M 27210 Bin Lira, 1995

21/2003; Logeion; Oberflächenreinigung

M 27310 Bin Lira, 1996

o.N./2004; Orchestra; S 3/2004; Oberflächenreinigung
M 27450 Bin Lira, 1998

o.N./2004; Orchestra; S 3/2004; Oberflächenreinigung

M 27525 Bin Lira, 1998

22/2003; Logeion; Oberflächenreinigung

M 27610 Bin Lira

23/2003; Orchestrakanal; Oberflächenreinigung

M 27710 Bin Lira

24/2003; Orchestrakanal; Oberflächenreinigung

M 27825 Bin Lira

25/2003; Orchestrakanal; Oberflächenreinigung

M 27925 Bin Lira

26/2003; Orchestrakanal; Oberflächenreinigung

M 28050 Bin Lira

27/2003; Orchestrakanal; Oberflächenreinigung

\section{USA}

M $281 \quad 1 / 4$ \$

28/2003; Orchestrakanal; Oberflächenreinigung

\section{Moderne Falsa}

\section{Samos (Ionische INSELN)}

Gallienus (253-268 n. Chr.)

M 282 AE

253/268 n. Chr.

20,29. 32,6. 5

Av.: AYТ К ПО $\Lambda$ ІГА $\Lambda \Lambda \mathrm{IHNO} \Sigma$ AYTO, 1Stk2PhLzSchd

Rv.: $\Sigma$ A-M-I- $\Omega$ N, 4-säuliger Tempel m. Kultbild der Hera von Samos

Erh. 2

SNG Cop vgl. 1806; SNG LeYP vgl. 779

8/2008; Stiegengasse Theater-Süd, Zugangspodest ES1; K2; SE 130
M 283 AE

Taf. 360 253/268 n. Chr.

18,92. 32,6. 5

Av.: AYТ К ПО $\Lambda$ IГА $\Lambda \Lambda$ IHNO $\Sigma$ AYTO, 1Stk2PhLzSchd

Rv.: $\Sigma$ A-M-I- $\Omega$ N, 4-säuliger Tempel m. Kultbild der Hera von Samos

Erh. 2

SNG Cop vgl. 1806; SNG LeYp vgl. 779

9/2008; Stiegengasse Theater-Süd, Zugangspodest ES1; K2; SE 130

\section{Unberücksicht $^{84}$}

M 284

13,4. 40.?

$10 / 2008$

M 285

15/2008; Stiegengasse Theater-Süd; Treppe-Ost; C1/D1; SE 153

\footnotetext{
${ }^{84}$ Dies resultiert daraus, dass die Münzen im Jahre 2008 nach Eingang ins Grabungshaus nicht mehr numismatisch betreut wurden.
} 


\subsection{FUNDLISTE DER MÜNZEN NACH FUNDBEREICHEN}

Die Liste nach Fundbereichen folgt den Kriterien der archäologischen Auswertung: Bühnengebäude, Logeion, Orchestra, Auditorium, Nordflügel des Theaters, Südflügel des Theaters und Stiegengasse im Süden des Theaters sowie die Funde aus der Portikus im Ostbereich des Theaters. Zum Schluss sind nicht stratifizierte Streufunde angeführt. Innerhalb dieser großen Fundbereiche sind die Fundorte und Fundumstände wie im archäologischen Auswertungsteil nach Sondagen, Fundstellen und stratigrafischen Einheiten angeordnet.

\section{Bühnengebäude}

Hellenistisches BühnengebäUde, Kammer D1, ÜBER HELLENISTISCHEM TREPPENFUNDAMENT

M $447 / 2005,27$ v. Chr./14 n. Chr.

Hellenistisches BühnengebäUde, S 2/2002, KaMmer D3, SChicht B5

M 96 1/2002, 1. Jh. v. Chr.-1. Jh. n. Chr.

Hellenistisches Bühnengebäude, S 2/2002, KAMMer D3, Schicht B6

M 5 2/2002, 387/295 v. Chr.

HeLlenistisches BühNENGEBäUde, S 2/2005, Kammer D8, SChicht B13

M 12 1/2005, 295/280 v. Chr.

HellenistisChes BüHNENGEBäUde, S 2/2005, KAMMER D8, SChicht B15

M $83 / 2005,295 / 280$ v. Chr.

M $212 / 2005$, ca. 300/23 v. Chr.

HELLENISTISCHES BÜHNENGEBÄUdE, S 2/2005, KAMmer D8, SE B19 (Treppenfundament)

M 9 6/2005, 295/280 v. Chr.

M 77 4/2005, 200/250 n. Chr.

KaiserZeitliChES BüHNENGEbäUde, S 1/2004, Kammer E3, SChicht B30

M $505 / 2004,161 / 180$ n. Chr.

Kaiserzeitliches BÜhnengebäUde, Kammer E4, ReINIGUNG

M 267 2/2004, 1948
Kaiserzeitliches BühNENGEBäUde, S 7/2004, KaMmer E5, SCHicht B41

M 148 8/2004, 355/361 n. Chr.

Kaiserzeitliches BühnengebäUde, Kammer E5, SCHICHT B42, AUSSERHALB VON S 7/2004

M 125 9/2004, 295/299 n. Chr.

M 133 14/2004, 331/334 n. Chr.

Kaiserzeitliches BÜHNEngebäUde, Kammer E5, MitTLERES SOG. BECKEN, OBERFLäChe

M 146 11/2004, 355/361 n. Chr.

M $14910 / 2004,351 / 361$ n. Chr.

Kaiserzeitliches BühnengebäUde, KaMmer E7, SCHICHT B37

M $367 / 2004$, 30/20 v. Chr.

RAUM RN1 NÖRdLICH DES BÜHNENGEBÄUdES, SCHIChT B55 (OBERfläChE des MörTelbetTS FÜR Marmorplatten) westl. Schwelle

M 240 13/2005, 556/557 n. Chr.

RAUM RN1 NÖRDLICH DES BÜHNENGEBäUdES, S 5/2005, SCHICHT B56

M $2388 / 2005,522 / 527$ n. Chr.

M 250 9/2005, ca. 500/700 n. Chr.

RAUM RN1 NÖRDLICH DES BÜHNENGEBäUdES, S 5/2005, SсHICHT B57

M 237 10/2005, 518/522 n. Chr.

RAUM RN1 NÖRDLICH DES BÜHNENGEBÄUdES, S 5/2005, SCHICHT B60

M $5511 / 2005,193 / 211$ n. Chr. 
RAUM RN1 NÖRDLICH DES BÜHNENGEBÄUdES, S 6/2005, SCHICHT B61

M 239 12/2005, 491/527 n. Chr.

Nordseite der Terrassenmauer, OberflächenREINIGUNG

\section{Römische Bühne (sog. Logeionbereich)}

Logeion, S 1/2001, SCHICHT L1

M 82 1/2001, Hyperskenion, 238/244 n. Chr.

Logeion, S 1/2003, Schicht L1

M $11 / 2003,320 / 275$ v. Chr.

Logeion, S 1/2003, SCHICHT L38

M $892 / 2003,258 / 260$ n. Chr.

Logeion, S 1/2003, OBERFLÄCHE

M 262 4B/2003, 18.Jh./19. Jh.

Logeion, S 2/2003, SChicht L28

M 264 18/2003, 1876

Logeion, S 3/2003, SCHICHT L4

M 11 12/2003, 295/280 v. Chr.

M 130 15/2003, 317 n. Chr.

M 134 13/2003, 330/337 n. Chr.

M 144 14/2003, 351/355 n. Chr.

M 212 10/2003, 383/395 n. Chr.

M 231 11/2003, 457/474 n. Chr.

\section{Logeion, S 3/2003, SCHicht L42}

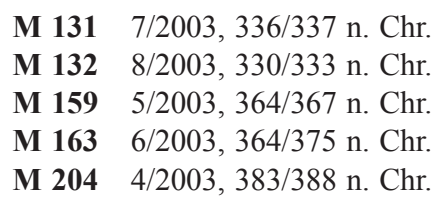

M 7 3/2004, 295/280 v. Chr.

M 137 6/2004, vor Kammer E4, 341/348 n. Chr.

M 161 3/2002, vor Mitteltor zum Westen, im Bühnengebäude des Theaters, 364/375 n. Chr.

Bühnengebäude, STreufund

M 154 14/2005, 351/354 n. Chr.

Logeion, S 3/2003, Schicht L45

M $2659 / 2003,1910$

Logeion, S 3/2003, Profilreinigung

M $18516 / 2003,383 / 395$ n. Chr.

LogEION, S 4/2003, L1

M 269 17/2003, 1997

M 271 19/2003, 1966

Logeion, S 4/2003, SCHICHT L55A

M 102 20/2003, ca. 27 v. Chr./268 n. Chr.

Logeion, S 5/2004, SCHICHT L65-L67

M 97 1/2004, 69/81 n. Chr.

Logeion, S 5/2004, Schicht L68-L 75

M $14513 / 2004,351 / 355$ n. Chr.

Logeion, S 5/2004, Profilreinigung

M $1664 / 2004$, 364/378 n. Chr.

Logeion, S 6/2004, Schicht L77

M 129 12/2004, 313/318 n. Chr.

Logeion, ObERFlächENREINIGUNG

M 272 21/2003, 1995

M 275 22/2003, 1998 


\section{Orchestra}

OrChestra, S 3/2004, ObERFLÄCHENREINIGUNG

M 208 16/2004, 383/395 n. Chr.

M 211 17/2004, 364/395 n. Chr.

M 253 15/2004, ca. 500/700 n. Chr.

M 266 o.N./2004, 1979

M 268 o.N./2004, 1994

M 273 o.N./2004, 1996

M 274 o.N./2004, 1998

OrChestra, S 6/2004, OBERfLÄChenreinigung

M 270 18/2004, 1949

Orchestra, S 1/2005, Schicht 012

M 257 5/2005, ca. 300v. Chr./600 n. Chr.

\section{Auditorium}

Unteres Diazoma, S 6/2006, Streufunde, T11

M 18 4/2006, ca. 300 v. Chr./14 n. Chr.

M 128 2/2006, 321/324 n. Chr.

Unteres Diazoma, S 8/2006, Streufund, T1

M $135 / 2006$, 295/280 v. Chr.

\section{Nordflügel}

Sondage 2/98, SChicht SE 29

M 183 2/1998, ca. 318/378 n. Chr.

\section{Vomitorium EN1, Schicht SE N3}

M 78 10/1998, 244/249 n. Chr.

M 241 9/1998, 572/573 n. Chr.

Nord-Analemma, obere Terrasse (D), OBErfläche

M 80 16/1998, 238/244 n. Chr.

M 244 11/1998, 613/614 n. Chr.

\section{Kammer KN1/2, Schicht SE N12}

M 242 4/1997, 615/616 n. Chr.

M $2435 / 1997,615 / 616$ n. Chr.

\section{Orchestra, Oberflächenreinigung}

M 45 63/2007, gedeckte Südparodos, Reinigung, 49/54

n. Chr.

M 86 64/2007, gedeckte Südparodos, Reinigung, 238/244 n. Chr.

M 172 1/2010, 378/383 n. Chr.

\section{Orchestrakanal, Oberflächenreinigung}

M 276 23/2003, modern, Türkei

M 277 24/2003, modern, Türkei

M 278 25/2003, modern, Türkei

M 279 26/2003, modern, Türkei

M 280 27/2003, modern, Türkei

M 281 28/2003, modern, USA

\section{Summa Cavea, Streufunde}

M 10 8/2009, Reinigung, 295/280 v. Chr.

M 188 1/2006, summa porticus Süd, 383/395 n. Chr.

M 261 1/1994, Reinigung, 15. Jh

M 245 6/1997, 612/613 n. Chr.

M 246 1/1997, 613/614 n. Chr.

\section{Kammer KN1, Schicht SE N14}

M 94 9/1997, 197/217 n. Chr.

\section{Kammer KN1, Schicht SE N15}

M 49 15/1997, 1,95 m tief, 141/161 n. Chr.

M 53 13/1997, 1,71 m tief, 161/180 n. Chr.

M 59 14/1997, 1,90 m tief, 218/222 n. Chr.

M 141 12/1997, 1,36 m tief, 347/348 n. Chr.

M 160 11/1997, 1,58 m tief, 364/367 n. Chr.

\section{Kammer KN3, Schicht SE N1}

M 116 15/1998, 262 n. Chr. 
Kammer KN4, SChICht SE N1

M 39 7/1997, 27 v. Chr./14 n. Chr.
Nord-Analemma, Oberfläche

M 201 1/1998, 406/408 n. Chr.

\section{Südflügel}

ES1, Wasserleitungskanal, an der Oberfläche Der Einschwemmung

M 43 10/2006, 27 v. Chr./14 n. Chr.

M $48 \quad 7 / 2006,138 / 161$ n. Chr.

M $613 / 2006,218 / 222$ n. Chr.

M $1216 / 2006,270$ n. Chr.

Süd-Analemma, Vomitorium ES1, ZerstörungSSCHUTT

M 24 IV/1997, 97 n. Chr.

M 25 V/1997, 98 n. Chr.

M 27 III/1997, 98 n. Chr.

M 28 II/1997, 98 n. Chr.

M 29 VI/1997, 128/129 n. Chr.

M 30 VII/1997, 128/132 n. Chr.

M 31 VIII/1997, 128/138 n. Chr.

\section{Süd-Analemma, Vomitorium ES2, STReufunde}

M 46 9/1993, 117/138 n. Chr.

M $658 / 1993,222 / 235$ n. Chr.

M 67 3/1993, 222/235 n. Chr.

M 91 2/1993, 221 n. Chr., Km: nach 260 n. Chr.

M 111 7/1993, (241 n. Chr.)

M 155 15/2009, 351/354 n. Chr.

M 233 2/1995, 491/518 n. Chr.

\section{SÜD-ANAlemma, KS1, SE 46}

M $122113 / 2007,270$ n. Chr.

M $138133 / 2007,341 / 348$ n. Chr.

M $140117 / 2007,337 / 340$ n. Chr.

M 147 132/2007, 355/361 n. Chr.

M $150123 / 2007,351 / 361$ n. Chr.

M $157 \quad 125 / 2007,355 / 361 \mathrm{n}$. Chr.

M 164 128/2007, 364/378 n. Chr.

M $169120 / 2007,364 / 378 \mathrm{n}$. Chr.

M $170131 / 2007,364 / 378$ n. Chr.

M 174 116/2007, 378/383 n. Chr.

M $175121 / 2007,367 / 375$ n. Chr.

M 176 134/2007, 383 n. Chr.

M 177 122/2007, 367/375 n. Chr.

M $178115 / 2007,367 / 378$ n. Chr.

M $180127 / 2007,367 / 383$ n. Chr.

M 181 119/2007, 383/392 n. Chr.

M $190114 / 2007,383 / 395$ n. Chr.

M 214 130/2007, 383/395 n. Chr.
M $215129 / 2007,383 / 425$ n. Chr.

M $229126 / 2007,425 / 435$ n. Chr.

M 255 124/2007, ca. 23 v. Chr./400 n. Chr.

SüD-Analemma, KS2, SE 28в (= SE 44 + SE 45)

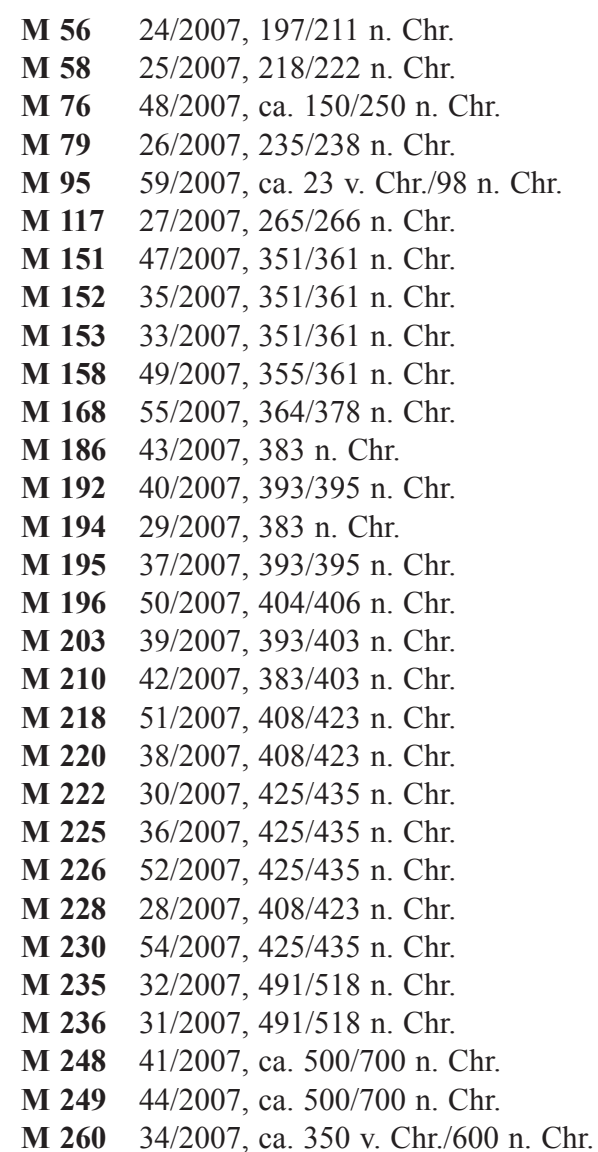

\section{SÜD-Analemma, KS2, SE 44}

$\begin{array}{ll}\text { M 109 } & 88 / 2007,241 \text { n. Chr. } \\ \text { M } 118 & 87 / 2007,264 / 267 \text { n. Chr. } \\ \text { M 136 } & 70 / 2007,337 / 340 \text { n. Chr. } \\ \text { M 142 } & 84 / 2007,341 / 348 \text { n. Chr. } \\ \text { M 165 } & 95 / 2007,364 / 378 \text { n. Chr. } \\ \text { M 171 } & 92 / 2007,364 / 378 \text { n. Chr. } \\ \text { M 179 } & 76 / 2007,378 / 388 \text { n. Chr. } \\ \text { M } 182 & 72 / 2007,383 / 392 \text { n. Chr. } \\ \text { M 187 } & 78 / 2007,383 / 395 \text { n. Chr. } \\ \text { M } 191 & 77 / 2007,388 / 392 \text { n. Chr. } \\ \text { M } 199 & 73 / 2007,406 / 408 \text { n. Chr. }\end{array}$ 
M $20086 / 2007,395 / 401$ n. Chr.

M 202 94/2007, 395/401 n. Chr.

M $20569 / 2007,383 / 395$ n. Chr.

M $20985 / 2007,383 / 395$ n. Chr.

M $21693 / 2007,406 / 408$ n. Chr.

M $22183 / 2007,425 / 435$ n. Chr.

M 223 75/2007, 435 n. Chr.

M $22781 / 2007,425 / 435$ n. Chr.

M $23280 / 2007,474 / 518$ n. Chr.

M 234 79/2007, 491/518 n. Chr.

M 258 82/2007, ca. 450/600 n. Chr.

M $25989 / 2007$, ca. 350 v. Chr./400 n. Chr.

\section{Süd-Analemma, KS2, SE 45}

M 37 103/2007, 198/268 n. Chr.

M 38 99/2007, 244/249 n. Chr.

M $52112 / 2007,161 / 180 \mathrm{n}$. Chr.

M 54 98/2007, 193/211 n. Chr.

M $6497 / 2007,222 / 235$ n. Chr.

M $68100 / 2007,222 / 235$ n. Chr.

M $69110 / 2007,238 / 244$ n. Chr.

M $72111 / 2007,249 / 251$ n. Chr.

M $8396 / 2007$, 238/244 n. Chr.

M $88108 / 2007,249 / 251$ n. Chr.

M $113107 / 2007,244$ n. Chr.

M 173 101/2007, 383 n. Chr.

M 254 109/2007, ca. 23 v. Chr./250 n. Chr.

Süd-Analemma, KS3, SE 28A

M $7322 / 2007,253 / 268$ n. Chr.

M 110 23/2007, 241 n. Chr.

\section{Stiegengasse Theater-Süd}

ZugangsPodest ES1, K2, SE 127

M 99 11/2009, ca. 98/200 n. Chr., Km: severisch

Zugangspodest ES1, K2, SE 130

M $2828 / 2008$, moderne Imitation

M 283 9/2008, moderne Imitation

\section{Treppe-West, G1, SE 193}

M $357 / 2009$, 138/161 n. Chr.

\section{Treppe-West, G1, SE 200}

M $876 / 2009$, 244/249 n. Chr.
SÜD-AnAlemma, KS3, SE 33

M 2 66/2007, 138/161 n. Chr.

M 57 65/2007, 198/211 n. Chr.

M 63 67/2007, 197/222 n. Chr.

M 100 60/2007, ca. 193/268 n. Chr.

M $14346 / 2007,341 / 348$ n. Chr.

M $21362 / 2007,395 / 425$ n. Chr.

M 251 61/2007, ca. 500/700 n. Chr.

SÜD-ANALEMma, KS3, SE 34

M 120 56/2007, 268/270 n. Chr.

M $12357 / 2007,270$ n. Chr.

M 256 58/2007, ca. 192/425 n. Chr.

\section{Süd-Analemma, Südrampe, Streufunde}

M 197 91/2007, Reinigung, 395/401 n. Chr.

M 219 11/2006, Oberflächenfund, 408/423 n. Chr.

M 206 90/2007, Reinigung, 383/403 n. Chr.

\section{Süd-Analemma, Streufunde}

M 16 9a/1993, 48/27 v. Chr.

M 22 6/1993, 50/51 n. Chr.

M 23 10/1993, 41/42 n. Chr.

M 26 12/1998, vomitorium ES1, Schutt auf Treppenabsatz in S1, 98 n. Chr.

M 32 5/1993, 138 n. Chr.

M 33 8a/1993, 138 n. Chr.

M 98 4/1993, 138/161 n. Chr.

Treppe-West, G1, SE 222

M 101 10/2007, ca. 27 v. Chr./268 n. Chr.

Treppe-West, H1, SE 195

M 14 3/2009, 258/202 v. Chr.

Treppe-West, H1, SE $196=227$

M 47 5/2009, 138/161 n. Chr.

Treppe-West, H1, SE $207=198$

M 19 9/2009, ca. 100/200 n. Chr. 
Treppe-West, H2, SE 222

M 247 10/2009, 518/648 n. Chr.

Treppe-West, H2, Stufenunterbau, Reinigung

M 34 12/2009, 44 v. Chr./192 n. Chr.

Treppe-West, J1, SE 124

M 62 13/2009, 221 n. Chr.

Zugangspodest ES2, F1, SE 170

M $662 / 2009,222 / 235 \mathrm{n}$. Chr.

ZugangSPODEST ES2, F2, SE 174

M $704 / 2009,238 / 244$ n. Chr.

Zugangspodest ES2, F2 Erweiterung, SE 231

M 207 14/2009, 383/403 n. Chr.

Treppe-Ost, C1/C2, SE 132

M $8411 / 2008$, 238/244 n. Chr.

\section{Treppe-Ost, C1/D1, SE 153}

M 108 14/2008, (161/180 n. Chr.)

M 285 15/2008, Fehlbestand

\section{ZugangsPodest ES3, B1, SE 7}

M $2013 / 2007$, ca. 150/250 n. Chr.

M 85 12/2007, 238/244 n. Chr.

M $1123 / 2007,244 / 247$ n. Chr.

M 114 4/2007, 244 n. Chr.

M 115 5/2007, 251/253 n. Chr.

\section{Zugangspodest ES3, B1, SE 9}

M $611 / 2007,295 / 280$ v. Chr.

\section{ZugangSPODEST ES3, B1, SE 15}

M $1061 / 2007,81 / 82$ n. Chr.

\section{ZugANGSPODEST ES3, B2, SE 4}

M 92 2/2007, 238/244 n. Chr.
ZugangSPodest ES3, B2, SE 12

M $756 / 2007$, ca. 150/250 n. Chr.

M 198 2/2008, 408/423 n. Chr.

ZugangSPOdest ES3, B2, SE 14

M 104 7/2007, ca. 27 v. Chr./268 n. Chr.

M 105 9/2007, ca. 27 v. Chr./268 n. Chr.

Insula SÜDlich des Theaters, Raum 1, C2-SÜDERWeiterung, SE 121A

M 103 6/2008, ca. 27 v. Chr./268 n. Chr.

M 107 7/2008, 125/128 n. Chr.

\section{Streufunde Stiegengasse Theater-Süd}

M 3 12/2008, ES2-ES3, Grabungsschutt, 160/220 n. Chr.

M 4 18/2007, C2, Oberfläche, 40/60 n. Chr.

M 15 1/2009, E2, hinter oberem Diazoma, 258/202 v. Chr.

M 40 3/2010, ES1, Oberflächenreinigung, 27 v. Chr./14 n. Chr.

M 42 1/2009, E2, Reinigung, 27 v. Chr./14 n. Chr.

M 71 14/2007, B1, Reinigung, 244/247 n. Chr.

M 74 135/2007, K1, Reinigung, 253/268 n. Chr.

M 81 13/2008, Streufund bei Hangabtragung, Grabungsschutt, 238/244 n. Chr.

M 90 15/2007, B1, Reinigung, 238/244 n. Chr.

M 135 17/2007, Südflügel, Treppenaufgang S1, Streufund, 335/340 n. Chr.

M 156 106/2007, ES2, Streufund, 355/361 n. Chr.

M 167 118/2007, ES2, Streufund, 364/378 n. Chr.

M 217 16/2007, C2, Grabungsschutt, 408/423 n. Chr.

\section{Streufunde Aus dem Theater}

M 17 6/1998, ca. 300/23 v. Chr.

M 41 1/1996, 27 v. Chr./14 n. Chr.

M $514 / 2008$, 161/180 n. Chr.

M $601 / 2008,218 / 222$ n. Chr.

M 93 I/1997, 244/247 n. Chr.

M 124 3/1998, 270 n. Chr.

M $1397 / 1998,341 / 348$ n. Chr.

M 162 1a/2006, 364/375 n. Chr.

M 184 1/1993, 393/395 n. Chr.

M $1893 / 2008,383 / 395$ n. Chr.

M $2248 / 2007,425 / 435$ n. Chr.

M $2525 / 2008$, ca. 500/700 n. Chr.

M 263 14/1998, 1839

\section{INCERTUM}

M 284 10/2008, Fehlbestand 


\section{Theater-Ost, Portikus}

\section{FK 25/2009, SCHICHT SE 16}

M 193 1/2009, 395/408 n. Chr.

\section{FK 46/2009, SCHICHT SE 26}

M $1192 / 2009$, 268/270 n. Chr.

M $1264 / 2009$, 295/296 n. Chr.

M 127 3/2009, 295/299 n. Chr.

U. SCHACHINGER 


\section{Terrakotten und Kleinfunde*}

\subsection{TERRAKOTTEN}

Die hier vorgestellten Terrakotten stammen aus den Grabungen, die von 1993 bis 2009 im Bereich des Theaters von Ephesos durchgeführt wurden. Da es sich um Funde aus Auffüllschichten handelt ${ }^{1}$, sind die ursprünglichen Nutzungskontexte nicht bekannt. Die Mehrzahl der Stücke besteht aus glimmerhältigem Ton und ist aus Modeln hergestellt. Während der weiße Überzug bei vielen zumindest noch teilweise erhalten ist, trifft dies für die farbige Bemalung nur sehr begrenzt $\mathrm{zu}^{2}$. An Themen kommen die aus Fundkomplexen des Hellenismus und der Kaiserzeit aus Ephesos, aber auch von anderen Orten bekannten vor: Bekleidete und unbekleidete weibliche Darstellungen (TK 17. TK 18 Taf. 362; TK 19. TK 20 Taf. 363; TK 21 Taf. 364), die Göttinnen ${ }^{3}$ und Frauen allgemein zeigen, männliche Figuren (TK 31 Taf. 365; TK 32 Taf. 366), vermutlich eine Eros-Psyche-Gruppe (TK 31 Taf. 365), Grotesken/Karikaturen ${ }^{4}$ (TK 9. TK 10 Taf. 361; TK 11. TK 12 Taf. 362), Schauspieler (TK 41 Taf. 367), Theatermasken ${ }^{5}$ (TK $42-44$ Taf. 367), (Glieder-)Puppen ${ }^{6}$ (TK 34?; TK 38 Taf. 366) und Tiere ${ }^{7}$ (TK 48 Taf. 368; TK 49 Taf. 369). Um ein Porträt der frühen Kaiserzeit handelt es sich vermutlich bei TK 5 (Taf. 361) ${ }^{8}$. Die beiden auf Gladiatorendarstellungen zu beziehenden Fragmente ${ }^{9}$ (TK 45. TK 46 Taf. 368) sind als Reflex auf die in der Kaiserzeit eingeführten Gladiatorenspiele und damit als Ausdruck der Romanisierung zu bewerten. Alle Terrakotten hatten Statuettengröße: Während jedoch für die Mehrzahl eine Höhe bis ca. $20 \mathrm{~cm}$ zu rekonstruieren ist, hatten TK 1, TK 3, TK 6, TK 7 (Taf. 361) und TK 17 (Taf. 362) eine Höhe zwischen 25 und $40 \mathrm{~cm}$. Von lebensgroßen Theatermasken stammen die Fragmente TK 43-45 (Taf. 367. 368).

\footnotetext{
* Die Aufnahme der Funde und die technischen Daten in den Katalogen fußen auf der Autopsie der Stücke durch D. Akar-Tanrıver. Die Beschreibung und Einordnung der Terrakotten in das ephesische Fundspektrum und die Vergleiche zu Terrakotten von anderen Fundorten erfolgte durch E. Rathmayr. Die entsprechende Bearbeitung der Kleinfunde lag in den Händen von A. M. Pülz.

${ }^{1} \mathrm{Zu}$ den Grabungen s. Kap. 3; zur zeitlichen Stellung der Keramik aus diesen Schichten s. Kap. 4.

${ }^{2}$ Als Malfarben wurden Schwarz (TK 4 Taf. 361; TK 45 Taf. 368; TK 60 Taf. 369), Grau (TK 58 Taf. 369), braune Töne (TK 12. TK 13 Taf. 362; TK 27 Taf. 365; TK 52. TK 57 Taf. 369), rote Töne (TK 23. TK 31 Taf. 365; TK 34 Taf. 366; TK 48 Taf. 368; TK 54 Taf. 369), Pink und Blau (TK 21 Taf. 364) beobachtet.

${ }^{3}$ Als Aphroditen anzusprechen sind wahrscheinlich die unbekleideten TK 17, TK 18 (Taf. 362) und TK 19 (Taf. 363), die die Göttin in Pudica-Typen wiedergegeben haben dürften. Zu Terrakotten der Aphrodite aus Ephesos s. Meriç 2002, 142; LANG-AuINGER 2003b, 213-217; LANG-Auinger 2003b, 126 f.; RATHMAYR 2014, 416 f. (TK 7-9); 420-422 (TK 31. TK 43. TK 47); zur Benennung von nackten weiblichen Figuren als Aphroditen s. RumscheID 2006, 217, der betont, dass bei den für diese Göttin belegten Typen wohl auch Aphrodite selbst und nicht etwa eine Hetäre gemeint war.

${ }^{4}$ Beide Begriffe werden synonym verwendet, da die unter diese Begriffe fallenden Figuren nicht voneinander zu unterscheiden sind; ebenso GiUliani 1987, 709 f.; Fischer 1994, 51 mit Anm. 2. Zu diesen Darstellungen aus Ephesos: Meriç 2002, 145; LANGAuinger 2003b, 221 f.; Rathmayr 2014, 415 f. (TK 4); 425 (TK 64); 428 f. (TK 80); besonders viele solcher Darstellungen stammen aus Smyrna: Besques 1972, 166-170 Kat. 1140-1183 Taf. 230-236; aber auch aus Ägypten: Fischer 1994, $200 \mathrm{f}$.

${ }^{5} \mathrm{Zu}$ Terrakotta-Masken aus Ephesos s. Meriç 2002, 145; Lang-Auinger 2003b, 224; Lang-Auinger 2007, 156-161; Lang-AuINGER 2010, 348. 679; RATHMAYr 2014, 417 (TK 10. TK 11); 421 (TK 37-39); 426 (TK 69); zu Masken von anderen Orten s. LeyenaAr-Plaisier 1979, 480-484 Kat. 1373-1384 Taf. 177. 178 (hellenistisch bis römisch); zu Theatermasken aus Priene s. Rumscheid 2006, 330-334; zu solchen aus Myrina s. Mollard-Besques 1963, 192 f. Kat. Myr 347. 349. 348. 353 Taf. 229; und aus Ägypten s. FisCHER 1994, 190-200.

${ }^{6}$ Meriç 2002, 144; Lang-Auinger 2003b, 222 f.; Lang-Auinger 2010, 680.

${ }^{7}$ Zu Terrakotta-Tieren aus Ephesos s. Lang-Aunnger 2003b, 232 f.; LANG-Auinger 2007, 165-167; Lang-Auinger 2010, 349; RathmaYr 2014, 418 (TK 12-17); 419 f. (TK 28); 421 (TK 40-42); 423 f. (TK 56. TK 57); 426 (TK 71); 428 (TK 78 ); 430 (TK 86).

${ }^{8}$ Zu Terrakotta-Porträts aus Ephesos s. RathmaYr 2014, 415 (TK 3); 424 (TK 60); 429 f. (TK 82. TK 89).

${ }^{9} \mathrm{Zu}$ Gladiatorenkämpfen und -darstellungen aus Ephesos s. Gladiatoren in Ephesos; zu Gladiatoren aus Terrakotta aus Ephesos s. Lang-Auinger 2003b, 224 f.; LANG-Auinger 2010, 349. 679 f.; Rathmayr 2014, 425 f. (TK 67).
} 


\section{KATALOG}

TK 1 Kopf

AO: GHD; Ki 07/10

FO/FJ: ETH; Stiegengasse-Süd; B1; SE 7; 2007

Maße: $\mathrm{H}$ 4,6 cm; B 2,5 cm; T 2,4 cm

Mat.: Ton mit feinem Glimmer u. Sand; zwischen 5YR7/4

(pink) u. 10YR4/1 (dunkelgrau)

Oberfläche: 7.5 YR8/3 (pink)

Technik: aus Model gezogen

Erh.: Gesicht mit Hals; weißer Überzug großteils erh. Frisur ist weggebrochen; abgenutzte Oberfläche

Beschreibung: TK 1 ist ein leicht nach rechts ${ }^{10}$ gewendeter Kopf auf einem breiten Hals. Das Gesichtsfeld ist oval, die Stirn schmal und hoch, das Kinn spitz und markant. Die schräg gestellten und von den Lidern überschnittenen Augen liegen unter wulstigen Orbitalen. Die Nase ist am Ansatz schmal und verbreitert sich zur Spitze hin stark. Der Mund ist klein und leicht geöffnet, die Mundwinkel sind nach oben gezogen. Ob es sich um den Kopf einer männlichen oder weiblichen Figur handelte, ist aufgrund des schlechten Erhaltungszustands nicht mehr zu beantworten.

\section{TK 2 Weiblicher Kopf}

AO: GHD; Ki 07/114

FO/FJ: ETH; Stiegengasse-Süd; B2; SE 5; 2007

Maße: $\mathrm{H} 2,4 \mathrm{~cm} ; \mathrm{B} 1,5 \mathrm{~cm} ; \mathrm{T} 2,1 \mathrm{~cm}$

Mat.: Ton mit feinem Glimmer; 5YR6/6 (rötlich gelb)

Oberfläche: 7.5 YR7/6 (rötlich gelb) erh.

Technik: aus Model gezogen

Erh.: Kopf mit Hals; weißer Überzug. Oberfläche stark abgenutzt

Beschreibung: TK 2 ist der Kopf einer jungen Frau mit Melonenfrisur und einem Haarknoten am Hinterkopf. Er ist gerade nach vorne gerichtet und sitzt auf einem langen, schmalen Hals. Das Gesicht hat ovale Form; an Details sind kleine Augen, eine schmale Nase, ein kleiner Mund und ein rundes, markantes Kinn zu erkennen. Vergleichbare Köpfe von Frauenfiguren sind ab dem frühen Hellenismus bis in die Kaiserzeit zu finden ${ }^{11}$

\section{TK 3 Weiblicher Kopf}

Taf. 361

\section{AO: EM; Ki 93/22}

FO/FJ: ETH; vomitorium ES2, Füllschutt; 1993

Maße: H 4,7 cm; B 3,3 cm; T 4 cm

Mat.: Ton

Technik: aus Model gezogen

Erh.: Kopf mit Hals

\footnotetext{
${ }^{10}$ Die Beschreibung erfolgt vom Betrachter aus; wenn nicht, wird dies mit zu seiner/ihrer rechten bzw. linken Seite benannt.

${ }^{11}$ Vgl. z. B. Leyenaar-Plaisier 1979, 104 f. Kat. 210 Taf. 36 (ca. 300 v. Chr.); 105 f. Kat. 212 Taf. 36 (Anfang 3. Jh. v. Chr.); 113 Kat. 227 Taf. 39 (2. Jh. v. Chr.); 168 f. Kat. 386 Taf. 63 (1. Jh. v. oder 1. Jh. n. Chr.); Kat. 885-897 Taf. 120 (2. Jh. v. Chr.); 455 Kat. 1280-1282 Taf. 166 (hellenistisch); Rumscheid 2006, 479 Kat. 229. 230 Taf. 94 (hellenistisch); BesQues 1972, Kat. D 3288-3290 Taf. 211.
}

Beschreibung: TK 3 ist ein weiblicher Kopf auf einem langen, schlanken Hals, der nach rechts gewendet und leicht nach rechts geneigt ist. Die langen Haare sind aus dem Gesicht in Wellen nach rückwärts frisiert und am Hinterkopf zu einem Haarknoten hochgenommen, sodass der Nacken frei bleibt ${ }^{12}$. Über der Stirn befindet sich ein Diadem, unter den Ohren liegen am Hals die Enden eines Bands auf. Das Gesichtsfeld ist oval. Die mandelförmigen Augen liegen unter leicht geschwungenen Brauen, die Nase ist schmal und der Mund klein. Vorder- und Rückseite sind von gleich hoher Qualität.

\section{TK 4 Kopf}

Taf. 361

AO: GHD; Ki 07/87

FO/FJ: ETH; Stiegengasse-Süd; G1; SE 7; 2007

Maße: H 3,7 cm; B 2,4 cm; T 2,2 cm

Mat.: Ton mit feinem Glimmer u. Sand; 2.5 YR5/8 (rot)

Oberfläche: 5YR5/6 (gelblich rot)

Wenig schwarze Malfarbe erh.

Technik: aus Model gezogen

Erh.: Kopf mit Hals; Reste von weißem Überzug. Oberfläche stark abgenutzt

Beschreibung: TK 4 ist ein Kopf auf einem breiten Hals ${ }^{13}$. Das Gesicht ist rundoval. Es wird von kleinen, unter geraden Brauen liegenden Augen, einer großen, breiten Nase, einem volllippigen Mund und einem spitzen Kinn bestimmt. Die Pupillen sind durch schwarze Farbe kenntlich gemacht. Über der niederen Stirn setzen die auf den Hinterkopf frisierten Haare einer Melonenfrisur (?) an.

TK 5 Kopf eines Knaben oder jungen Mannes Taf. 361 AO: GHD; Ki 07/120

FO/FJ: ETH; Stiegengasse-Süd; C1; SE 1; 2007

Maße: H 2,3 cm; B 2,1 cm; T 1,1 cm

Mat.: Ton mit viel feinem Glimmer; 2.5YR4/4 (rötlich braun) Oberfläche: 5YR5/4 (rötlich braun)

Erh.: rechte Kopfseite. Schräger Bruch geht durch den Kopf Dat. n. Stück: vermutlich frühe Kaiserzeit

Beschreibung: TK 5 ist der Kopf eines Knaben oder jungen Mannes mit einer Fransenfrisur und Porträtcharakter ${ }^{14}$. Die durch Kerben voneinander getrennten Strähnen fallen auf Stirn und Schläfenpartie. Das erhaltene rechte Auge ist mandelförmig und liegt unter einer geraden Braue.

TK 6 Kopf eines Knaben oder Eros Taf. 361 AO: EM; Ki 93/66 FO/FJ: ETH; Süd-Analemma; Substruktionsgewölbe; 1993 Maße: H 4,5 cm; B 3,2 cm

${ }^{12} \mathrm{Zu}$ vergleichbaren Frisuren s. LeYenAar-Plaisier 1979, 173 f. Kat. 401 (1. Jh. v. oder n. Chr.); 404 (tiberisch) Taf. 65.

${ }^{13}$ Vgl. aus Ephesos Lang-Auinger 2010, 355 A-TK 33 Taf. 159

${ }^{14} \mathrm{Zu}$ vergleichbaren Frisuren an Terrakotten aus Ephesos s. LANG-AuINGER 2003b, 239 TK 24 Taf. 125 (Dat. nach Fundkomplex: spätaugusteisch-tiberisch); RATHMAYR (in Druckvorbereitung), A-TK 26; vgl. ferner LeyenaAR-Plaisier 1979, 226 Kat. 573 Taf. 83 (iulisch-claudisch); 278 Kat. 725 Taf. 105 (frühes 1. Jh. n. Chr.). 
Mat.: Ton

Technik: aus Model gezogen

Erh.: Kopf mit Nacken; Reste von weißem Überzug

Beschreibung: TK 6 ist ein leicht nach links gewendeter Kopf mit einer Scheitelzopf-Frisur. Die Rückseite ist nur summarisch ausgeführt. Vermutlich war ein Knabe oder Eros dargestellt ${ }^{15}$.

\section{TK 7 Fragment von Stirn mit Haaransatz einer männlichen Figur}

Taf. 361

AO: GHD; Ki 04/63

FO/FJ: ETH; Skene; Kammer E3; S1/2004; SE B34; 2004

Maße: H 3,3 cm; B 8,1 cm; T 0,9 cm

Mat.: Ton mit viel feinem Glimmer; 2.5YR5/8 (rot)

Oberfläche: 5YR6/6 (rötlich gelb)

Technik: aus Model gezogen

Erh.: kleiner Teil der Stirn mit anschließenden kurzen Locken.

\section{TK 8 Männlicher Kopf}

AO: Efes. Müzesi, InvNr. 93/42/93, Th 93/93

FO/FJ: ETH, südlich der summa cavea, 1993

Maße: erh. H $1,9 \mathrm{~cm}$

Mat.: Ton mit viel Glimmer; 2.5YR6/4

Technik: aus Model gezogen

Erh.: VS des Kopfs

Beschreibung: Leicht nach links gewendeter Kopf, der auf einem schlanken Hals sitzt. Er hat eine kurze, breite Nase, breite Lippen mit Angabe des Philtrum, kleine, runde Augen, breite, bogenförmig geschwungene Brauen, hervortretende Backenknochen und eine wulstige Stirn. TK 8 trägt einen undekorierten, wulstförmigen Kranz, der die Ohren verdeckt.

Dargestellt ist der Kopf eines älteren Mannes mit realistischen Gesichtsmerkmalen. Er trägt einen Kranz, der jedoch keine genauen Aussagen über den Inhalt der Darstellung gibt, da vergleichbare Kränze von sehr unterschiedlichen Personengruppen getragen werden ${ }^{16}$. Realistische Darstellungen wie TK 8 treten ab der hellenistischen Zeit auf ${ }^{17}$. Im Terrakottaspektrum von Ephesos ist dieser Kopf bisher singulär.

${ }^{15}$ Vgl. Meriç 2002, 142 f. TK 16. TK 17 Taf. 108; Lang-AuINGER 2007, 154 TK 71 Taf. 50; LeyenaAR-Plaisier 1979, 216 Kat. 542.543 Taf. 79 (römisch).

${ }^{16} \mathrm{z}$. B. von Jünglingen im Mantel und Kindern, s. MollardBesques 1963, 120 KatNr. LY 1608. B 165, Myrina 979 Taf. 144 (Epheben im Mantel); 137 Myrina 1666. 1462 Taf. 167 (Kinder); Besques 1972, 32 D 169. 170 Taf. 39 (Jünglinge); FISCHER 1994, 186 f. KatNr. 309-312 Taf. 26 (Knaben).

${ }^{17}$ Vgl. den Realismus der Darstellung von TK 8 z. B. mit männlichen Terrakottaköpfen aus späthellenistischer Zeit. Davon ist einer bekrönt wie TK 8 aus Kleinasien, s. Besques 1972, 89 KatNr. D 521 Taf. 113; 149 KatNr. D/E 1035 Taf. 188 sowie einen weiteren späthellenistischen Kopf eines älteren Mannes mit wulstförmiger, runder Bekrönung aus Ägypten, s. Besques 1992, 136 KatNr. D/E 4572 Taf. 87, in dem ein Landmann/Bauer vermutet wird. Zum Realismus generell s. u. a. Himmelmann 1983; AnDREAE 1998.

\section{TK 9 Männlicher Kopf einer Groteske/}

Karikatur?

Taf. 361 AO: GHD; Ki 97/A

FO/FJ: ETH; Nord-Analemma; Kammer KN2; an der Oberfläche; 1997

Maße: H 3,6 cm; B 2,1 cm; T 1,7 cm

Mat.: Ton mit viel feinem Glimmer u. Sand; 2.5YR6/6 (lichtrot) Oberfläche: 5YR6/6 (rötlich gelb) und 10YR7/4 (blassbraun)

Technik: massiv; von Hand gemacht?

Erh.: Kopf mit Hals

Beschreibung: TK 9 ist der Kopf einer männlichen Figur auf einem kräftigen Hals. Das Gesicht ist oval. Es wird durch tief liegende Augen, eine sehr breite, lange Nase und einen leicht geöffneten Mund mit breiten, schlauchförmigen Lippen bestimmt. Der Kopf trägt eine Kurzhaarfrisur, die auch die Ohren bedeckt. Die Merkmale der sehr breiten Nase und der schlauchförmigen Lippen lassen annehmen, dass der Kopf zur Figur einer Groteske/Karikatur gehörte ${ }^{18}$.

\section{TK 10 Kopf einer Groteske/Karikatur}

Taf. 361

AO: GHD; Ki 08/180

FO/FJ: ETH, Stiegengasse-Süd; E2; SE 171; 2008

Maße: H 2,6 cm; B 2 cm; T 1,5 cm

Mat.: Ton mit feinem Glimmer; 2.5YR4/6 (rot)

Oberfläche: 2.5YR5/6 (rot)

Erh.: Hinterkopf und Hals

Beschreibung: TK 10 ist die Rückseite eines Glatzkopfs mit übertrieben groß dargestellten Ohren. Das Fragment gehörte diesen Merkmalen zufolge zur Gruppe der Grotesken/Karikaturen ${ }^{19}$.

\section{TK 11 Kopf einer Groteske/Karikatur}

Taf. 362

AO: EM; InvNr. 95/42/93, Ki 93/110

FO/FJ: ETH; vomitorium ES2; Südausgang; 1993

Maße: H 3,1 cm; B 3,2 cm; T 4,9 cm

Mat.: Ton, 10R6/6

Erh.: Kopf; Reste von weißem Überzug

Beschreibung: TK 11 hat einen stark gewölbten Hinterkopf, tief liegende, große Ohren, eine stark gebogene Hakennase mit einem nach oben gebogenen rechten Nasenflügel und einsehbaren linken Nasenloch, kleine, ovale Augen unter vortretenden Lidern und einen breiten, weit geöffneten Mund mit schlauchförmigen Lippen sowie eine am Gaumen aufliegende Zunge. Es ist der Kopf einer männlichen Groteske/Karikatur. Charakteristisch für diese Darstellungen sind die Tiefe des Kopfs und das im Verhältnis dazu schmale Gesicht, die Glatze, die großen, weit abstehenden Ohren, die kleinen Augen, die lange Hakennase und der weit geöffnete Mund mit den breiten, schlauchförmigen Lippen ${ }^{20}$.

${ }^{18}$ Vgl. LeyenaAr-Plaisier 1979, 244 Kat. 638 Taf. 89 (römisch); 246 Kat. 643 Taf. 90 (römisch).

${ }^{19} \mathrm{Vgl}$. Leyenaar-Plaisier 1979, 160 Kat. 360 Taf. 60 (römisch); 243 Kat. 632 Taf. 89 (römisch); 248 f. Kat. 651. 653 Taf. 91 (römisch).

${ }^{20} \mathrm{Zu}$ ähnlichen Köpfen aus Smyrna s. LeyenaAR-PLAISIER 1979, 152 Kat. 336 Taf. 56 (römisch); 240 Kat. 623 Taf. 88 (römisch); 248 Kat. 651 Taf. 91 (römisch); und aus »Ephesos-Tralles« und Smyrna s. Besques 1972, 125 Kat. E/D 843 Taf. 154 (frühhellenistisch); 230 Kat. E 136-E 139 Taf. 309. 
TK 12 Nase einer Groteske/Karikatur bzw. einer Maske einer Groteske

Taf. 362 AO: GHD; Ki 03/61

FO/FJ: ETH; Logeion; S4/2003; SE L50; 2003

Maße: L 3,2 cm: B 2 cm; T 1,7 cm

Mat.: Ton mit sehr feinem Glimmer; 7.5YR6/4 (lichtbraun)

Oberfläche: 7.5 YR7/4 (pink) u. 10YR6/8 (bräunlich gelb)

Malfarbe: 10YR3/2 (dunkelgrau braun)

Erh.: Nase und Teil der Oberlippe, einzelne Zähne; Reste von weißem Überzug

Beschreibung: TK 12 ist eine lange, breite, schiefe Nase, unter der noch ein Teil der breiten, schlauchförmig gebildeten Oberlippe erhalten ist. Da unterhalb der Oberlippe einzelne quaderförmig gebildete Zähne zu erkennen sind, war der Mund der Figur geöffnet. TK 12 gehörte aufgrund der übertrieben hässlichen Gestaltung von Nase und Mund zur Darstellung einer Groteske/Karikatur bzw. zur Maske, die eine solche zeigte ${ }^{21}$.

\section{TK 13 Kopf}

Taf. 362

AO: GHD; Ki 97/C

FO/FJ: ETH; 1997

Maße: H 3,5 cm; B 2,8 cm; T 1,4 cm

Mat.: Ton mit wenig feinem Glimmer u. Sand; 5YR5/8 (gelblich rot)

Oberfläche: 7.5YR6/4 (lichtbraun)

Malfarbe: 7.5YR3/1 (dunkelgrau)

Technik: aus Modeln gezogene VS und RS

Erh.: Hinterkopf und Teil der Haarpartie über der Stirn; Reste von weißem Überzug

Beschreibung: Das Fragment TK 13 umfasst den Hinterkopf und die Partie um Stirn und Schläfen einer Figur. Während die Haare am Hinterkopf nur summarisch gestaltet sind, sind sie über der Stirn und neben den Schläfen als Locken ausgeführt.

\section{TK 14 Hinterkopf}

AO: GHD; Ki 08/90

FO/FJ: ETH; Stiegengasse-Süd; K2; SE 130; 2008

Maße: $\mathrm{H} 4,8 \mathrm{~cm} ; \mathrm{B} 4,4 \mathrm{~cm}$; T $2 \mathrm{~cm}$

Mat.: Ton mit viel feinem Glimmer, wenig Kalk u. Sand; 10YR5/3 (braun)

Oberfläche: 2.5YR6/6 (lichtrot)

Aus Model gezogen

Erh.: halbkugelförmig gewölbtes Stück

Beschreibung: TK 14 ist wahrscheinlich ein Hinterkopf. Die punktförmigen Vertiefungen sind als summarisch dargestellte Haare aufzufassen.

\section{TK 15 Hinterkopf?}

Taf. 362

AO: GHD; Ki 08/79

FO/FJ: ETH; Stiegengasse-Süd; B2; SE 37; 2008

Maße: H 3,7 cm; B 2,6 cm; T 1,7 cm

Mat.: Ton mit feinem Glimmer u. Sand; 2.5YR5/6 (rot)

Erh.: stark gewölbtes Stück mit kleinerer mittiger Wölbung; Oberfläche abgenutzt

Beschreibung: Bei TK 15 dürfte es sich um einen Hinterkopf handeln, wobei der stärker gewölbte Teil vielleicht ein Haarknoten ist und die Ritzungen darauf Haare wiedergeben.

\footnotetext{
${ }^{21}$ Vgl. z. B. Meriç 2002, 145, 148 TK 39 Taf. 112.
}

TK 16 Hinterkopf

Taf. 362

AO: GHD; Ki 08/190

FO/FJ: ETH; Stiegengasse-Süd; E2; SE 171; 2008

Maße: H 2,9 cm; B 3,1 cm; T 1,9 cm

Mat.: Ton mit viel feinem Glimmer; 10YR5/6 (rot)

Oberfläche: 2.5 YR6/6 (lichtrot)

Technik: aus Model gezogen

Erh.: stark gewölbtes Stück.

\section{TK 17 Fragment einer nackten weiblichen} Figur/Aphrodite

Taf. 362

AO: GHD; Ki 98/17

FO/FJ: ETH; vomitorium EN1 (südliche Hälfte); Zerstörungsschutt, 1998

Maße: $\mathrm{H} 8,9 \mathrm{~cm}$; B $5 \mathrm{~cm}$; $2,5 \mathrm{~cm}$

Mat.: Ton 2.5YR6/6 (lichtrot)

Oberfläche: 7.5YR7/4 (pink) und 5Y8/1 (weiß)

Technik: aus Model gezogen

Erh.: Glutäen und rechter Oberschenkel

Dat.: späthellenistisch bis frühe Kaiserzeit

Beschreibung: Das Fragment TK 17 umfasst den rechten Gluteus, die Analfalte und einen Teil des linken Gluteus sowie die Rückseite des rechten Oberschenkels. Aufgrund der Ausführung der Glutäen und der schlanken Form des Oberschenkels dürfte TK 17 von einer weiblichen Figur, wahrscheinlich einer Aphrodite in einem unbekleideten Typus ${ }^{22}$, stammen.

\section{TK 18 Fragment einer nackten weiblichen} Figur/Aphrodite

Taf. 362 AO: GHD; Ki 09/36

FO/FJ: ETH-Ost; S1/2009; SE 20; 2009

Maße: H 4,2 cm; B 3,4 cm; T 1,5 cm

Mat.: Ton mit viel Glimmer; 5YR5/6 (gelblich rot)

Oberfläche: 7.5YR6/4 (lichtbraun) u. 10YR8/1 (weiß)

Technik: aus Model gezogen

Erh.: Oberkörper. Bruch an Hals und Bauch

Dat.: späthellenistisch bis frühe Kaiserzeit

Beschreibung: TK 18 ist der unbekleidete Oberkörper einer weiblichen Figur. Der Körper ist schlank, die Brüste groß. Der linke Arm ist neben dem Körper gesenkt und war vermutlich zur Scham geführt, der rechte Arm ist abgewinkelt und zur rechten Kopfseite gerichtet ${ }^{23}$. Nacktheit und Haltung von TK 18 lassen vermuten, dass es sich um einen nackten oder halbbekleideten Aphrodite Pudica-Typus handel ${ }^{24}$. Die rechte Hand könnte ins Haar gefasst oder einen am Rücken drapierten Mantel hoch gezogen haben ${ }^{25}$.

${ }^{22} \mathrm{Zu}$ Typen der nackten Aphrodite s. Delivorrias 1984, Nr. 349-525.

${ }^{23}$ Vgl. z. B. die Terrakotta einer Aphrodite aus Smyrna: LEYENAAR-Plaisier 1979, 135 Kat. 285 Taf. 48 (1. Jh. v. oder 1. Jh. n. Chr.).

${ }^{24}$ Zur den unterschiedlichen Typen der Aphrodite Pudica s. Delivorrias 1984, Nr. 349-786 s. v. Aphrodite.

${ }^{25} \mathrm{Vgl}$. für das Motiv des Hoch-Ziehens des Mantels eine hellenistische Terrakotta, die mit ihrer linken Hand einen Mantel hochzieht, der ihren Rücken und das rechte Bein verhüllt, wobei die rechte Hand einen Zipfel des Mantels vor der Scham hält (Delivorrias 1984, Nr. 705 mit Abb.); das gleiche Gewandmotiv, aber mit umgekehrter Armhaltung könnte TK 18 zugrunde gelegen haben. 
TK 19 Rückseite einer nackten weiblichen Figur/Aphrodite

Taf. 363 AO: GHD; Ki 09/16

FO/FJ: ETH-Ost; S1/2009; 2009

Maße: H $8,4 \mathrm{~cm}$; B 2,8 cm; T 1,3 cm

Mat.: Ton mit viel feinem Glimmer; 7.5YR5/4 (braun)

Oberfläche: 7.5YR6/4 (lichtbraun)

Technik: aus Model gezogen

Erh.: RS einer unbekleideten Figur bis auf Höhe der Ansätze der Oberschenkel

Dat.: späthellenistisch bis frühe Kaiserzeit

Beschreibung: TK 19 ist die Rückseite einer nackten weiblichen Figur. Nach der Anspannung der Glutäen zu urteilen, war das rechte Bein das Stand- und das linke das Spielbein. Die Oberarme waren seitlich des Körpers gesenkt, der Kopf ist etwas nach unten geneigt. Die Figur hat lange Haare, die im Nacken zu einem Zopf zusammengefasst sind, der unterhalb des Nackens am Rücken aufliegt. Wahrscheinlich zeigte TK 19 eine Aphrodite in einem Pudica-Typus ${ }^{26}$.

\section{TK 20 Weibliche Gewandfigur/Artemis? Nike/Victoria?}

Taf. 363

AO: GHD; Ki 04/57

FO/FJ: ETH; Skene; Kammer E3; S1/2004; SE B33 (Pithos 1); 2004

Maße: H 7,9 cm; B 4,3 cm; T 2 cm

Mat.: Ton mit viel feinem Glimmer u. Sand; 5YR5/6 (gelblich rot)

Oberfläche: 5YR6/6 (rötlich gelb)

Technik: aus Model gezogen

Erh.: Vorderseite einer bekleideten weiblichen Figur. Kopf und Füße weggebrochen

Beschreibung: TK 20 stellt eine wohl weibliche Figur dar, deren Beine eng und auf gleicher Höhe zusammenstehen und deren Arme neben dem Körper gesenkt sind. Sie trägt einen Peplos mit Überfall, der reiche Falten wirft und bis auf Höhe der Füße herabreicht. Zwischen den Beinen bildet das Gewand zwei parallele Steilfalten, über der Brustpartie übereinander angeordnete, bogenförmige Falten und über den Oberschenkeln Spannfalten. Unter dem Peplos zeichnen sich Knie und Unterschenkel ab. In Haltung und Gewandung wird auf archaische Stilmittel zurückgegriffen. Der hieratischen Pose zufolge dürfte TK 20 eine Göttin, vielleicht eine Artemis ${ }^{27}$ oder Nike ${ }^{28}$, gezeigt haben.

TK 21 Weibliche Gewandfigur

Taf. 364 AO: GHD; Ki 93/84

FO/FJ: ETH; vomitorium ES2; Südausgang; Füllschutt; 1993 Maße: $\mathrm{H} 8,6 \mathrm{~cm}$; B 4,6 cm; T 2,8 cm

Mat.: Ton mit viel Glimmer u. Sand; 5YR5/6 (gelblich rot)

Oberfläche: 5YR6/6 (rötlich gelb)

${ }^{26} \mathrm{Zu}$ nackten Aphroditedarstellungen s. Delivorrias 1984, Nr. 349-525 s. v. Aphrodite.

${ }^{27}$ Vgl. eine archaisierende Artemisstatue in einem hieratischen Typus späthellenistischer Zeit aus Aulis (KAHIL 1984, Nr. 525 mit Abb.) und eine als Athena oder Artemis gedeutete Figur (Meriç 2002, 142. 146 TK 3 Taf. 106).

${ }^{28}$ Vgl. die Figur einer Nike bei RumscheID 2006, 407 f. Kat. 3 Taf. 1 (2. H. 2. Jh. v. Chr.); Vollkommer 1997, Nr. 310.
Malfarbe: Reste von Pink und blauer Farbe erhalten

Technik: aus Model gezogen

Erh.: Unterkörper und linker Arm ohne Hand; Reste von weißem Überzug. Teil der linken Seite weggebrochen Dat. nach Stück: späthellenistisch bis frühkaiserzeitlich Beschreibung: TK 21 stellt den Unterkörper einer weiblichen Gewandfigur mit ausladender rechter Hüfte und einem neben dem Körper gesenkten linken Arm dar. Das rechte Bein ist das Standbein, das nicht erhaltene linke war das Spielbein ${ }^{29}$. Die Figur ist mit einem reich gefältelten Chiton und Himation bekleidet. Da die Falten nur auf der Vorderseite, nicht aber auf der nur summarisch ausgeführten Rückseite ausgeführt sind, war TK 21 für eine Ansicht von vorne bestimmt. Hier überziehen viele parallel nebeneinander angeordnete, vertikale Falten den Chiton, am Mantel ziehen Spannfalten über den rechten Oberschenkel und die rechte Hüfte. Auf dem teilweise erhaltenen weißen Überzug haben sich Reste von Pink und auf dem Gewand Reste von blauer Farbe erhalten, die die Farbigkeit der Figur erahnen lassen.

TK 22 Männlicher Torso

Taf. 365

AO: EM; Ki 93/100

FO/FJ: ETH; Süd-Analemma; Substruktionsgewölbe; 1993

Maße: H 5,7 cm; B 4,7 cm

Mat.: Ton

Erh.: Torso mit Resten von weißem Überzug

Beschreibung: Bei TK 22 handelt es sich um den Torso einer männlichen Figur mit athletischem Körper, der mit einem Lendenschurz bekleidet ist. Die Figur ist in Bewegung wiedergegeben: Der Oberkörper ist etwas nach rechts gedreht, die Oberarme waren den Ansätzen nach zur Seite gestreckt; der linke Oberschenkel war aufgrund des erhaltenen Ansatzes leicht nach links vorne und der rechte Oberschenkel gerade nach vorne gerichtet. Oberkörper und Gliedmaßen sind schlank und muskulös gestaltet, am Oberkörper treten ein schlauchförmiger Rippenbogen und die Ansätze von Rippen und Brustmuskeln hervor. Ähnliche athletische Darstellungen sind aus dem späteren Hellenismus und der Kaiserzeit bekannt ${ }^{30}$.

TK 23 Fragment einer Figur

Taf. 365

AO: GHD; Ki 09/97

FO/FJ: ETH; Stiegengasse-Süd; F2-S; SE 236; 2009

Maße: H 5,5 cm; B 3,3 cm; T 1,5 cm

Mat.: Ton mit feinem Glimmer u. Sand; 2.5YR5/6 (rot)

Oberfläche: 2.5YR6/8 (lichtrot) und 5Y8/1 (weiß)

Malfarbe: 10R7/6 (lichtrot)

Technik: aus Model gezogen

Erh.: Brustbereich mit Ansatz des rechten Oberarms und dem Ansatz des Halses.

${ }^{29}$ Figuren ähnlicher Ikonografie sind ab dem 2. Jh. v. Chr. häufig; vgl. z. B. RuMscheID 2006, Kat. 142 Taf. 62 (hellenistisch); LeyenaAR-Plaisier 1979, 261 Kat. 684 Taf. 97 (2. Jh. v. Chr.); vgl. für Ephesos: LANG-Auinger 2007, 140 TK 31.1 Taf. 44. (2. Jh. v. Chr.).

${ }^{30}$ Vgl. z. B. Leyenaar-Plaisier 1979, 149 Kat. 327. 328 Taf. 54 (römisch); 368 f. Kat. 1018-1020 Taf. 131 (2. Jh. v. Chr.); und folgende Terrakotten aus Smyrna: Besques 1972, 163 f. Kat. D 1111-1121 Taf. 225. 226 (alle hellenistisch). 
TK 24 Fragment einer Gewandfigur

Taf. 365

AO: GHD; Ki 09/114

FO/FJ: ETH; Stiegengasse-Süd; F2-S; SE 248; 2009

Maße: H: 5,9 cm; B 6,9 cm; T 2,1 cm

Mat.: Ton mit feinem Glimmer u. Sand; 7.5YR6/4 (lichtbraun)

Oberfläche: 5Y8/1 (weiß)

Erh.: kleiner Teil mit Gewand; links Rand erh.

TK 25 Fragment einer Gewandfigur

AO: GHD; Ki 07/127

FO/FJ: ETH; Stiegengasse-Süd; C2; SE 12; 2007

Maße: $\mathrm{H} 4,9 \mathrm{~cm} ; \mathrm{B} 4,8 \mathrm{~cm} ; \mathrm{T} 1,2 \mathrm{~cm}$

Mat.: Ton mit feinem Glimmer u. wenig Sand; 5YR5/8 (gelb-

lich rot)

Oberfläche: 5YR6/6 (rötlich gelb).

TK 26 Faltenfragment

Taf. 365

AO: GHD; Ki 07/64

FO/FJ: ETH; Stiegengasse-Süd; B2; SE 14; 2007

Maße: H 7,4 cm; B 9,6 cm; T 2,2 cm

Mat:: grober Ton mit viel Glimmer und Sand; 5YR6/6 (rötlich gelb)

Oberfläche: 5YR7/3 (pink).

TK 27 Gewandfaltenfragment

Taf. 365

AO: GHD; Ki 09/57

FO/FJ: ETH-Ost; S1/2009; SE 36; 2009

Maße: H 3,3 cm; B $3 \mathrm{~cm}$; T 0,9 cm

Ton: 5YR5/6 (gelblich rot)

Oberfläche: 5YR6/6 (rötlich gelb)

Farbe: 5YR3/2 (dunkel rötlich braun).

\section{TK 28 Gewandfaltenfragment}

Taf. 365

AO: GHD; Ki 03/43

FO/FJ: ETH; Logeion; S3/2003; SE L42; 2003

Maße: H 4,6 cm; B 2,6 cm; T 0,8 cm

Mat.: Ton mit feinem Glimmer; 5YR5/6 (gelblich rot)

Oberfläche: 5YR6/4 (lichtbraun).

TK 29 Fragment mit Gewandauflage?

AO: $08 / 186$

FO/FJ: ETH; Stiegengasse-Süd; E2; SE 171; 2008

Maße: H 4,3 cm; B 2,1 cm; T 1,6 cm

Mat.: Ton mit viel feinem Glimmer; 2.5YR5/8 (rot)

Oberfläche: 5YR6/6 (rötlich gelb).

\section{TK 30 Fragment mit Gewandfalten} oder säulenförmige Stütze?

AO: GHD; Ki 04/63

Taf. 365

FO/FJ: ETH; Skene; Kammer E3; S1/2004; SE B34; 2004

Maße: $\mathrm{H} 6 \mathrm{~cm}$; B 3,1 cm; T $1 \mathrm{~cm}$

Mat.: Ton mit viel feinem Glimmer; 2.5YR5/8 (rot)

Oberfläche: 2.5YR6/6 (lichtrot)

Technik: aus Model gezogen

Erh.: Fragment mit Querwulst und waagrecht darauf angeordneten Rillen

Beschreibung: Das Fragment TK 30 könnte die Falten eines Gewands darstellen, aber ebenso gut den Teil einer Säule ${ }^{31}$.

${ }^{31}$ Vgl. eine Säule bei Mollard-Besques 1963, 135 Kat. Myr 668 Taf. 165; 150 Kat. Myr 393 Taf. 187.
TK 31 Amor einer Amor-Psyche-Gruppe?

Taf. 365 AO: GHD, Ki 07/107

FO/FJ: ETH; Stiegengasse-Süd; B2; SE 7; 2007

Maße: H 5,7 cm; B 3,9 cm; T 1,3 cm

Mat.: Ton; 7.5YR6/4 (lichtbraun)

Oberfläche: 7.5YR7/3 (pink) u. 10R8/1 (weiß)

Malfarbe: 10R6/6 (lichtrot)

Erh.: Teil eines Oberkörpers und des rechten Arms sowie Halsansatz und größerer Ansatz auf der rechten Schulter Beschreibung: Bei TK 31 handelt es sich um den Oberkörper einer unbekleideten, männlichen Figur. Der rechte Arm weist Fettpolster auf, er ist über den Oberkörper zur linken Schulter gelegt. Auf die rechte Schulter fallen einerseits die Enden von langen Haarlocken herab, andererseits befindet sich hier ein größerer Ansatz, wahrscheinlich von einem Flügel. Etwas unterhalb des Halsansatzes ist ein Wulst, der zu einer Chlamys gehören könnte. Aufgrund der kindlichen Formen, der langen Haare und des Ansatzes eines Flügels ist in der Figur wohl Eros/Amor zu erkennen, der der Haltung des rechten Arms zufolge vermutlich zusammen mit Psyche dargestellt war $^{32}$.

\section{TK 32 Mit Mantel bekleidete Figur}

Taf. 366

\section{AO: GHD; Ki 07/32}

FO/FJ: ETH; Stiegengasse-Süd; B1; SE 14a; 2007

Maße: H 6,6 cm; B 3,3 cm; T 2,6 cm

Mat.: Ton mit feinem Glimmer u. Sand; 2.5YR5/8 (rot)

Oberfläche: 5YR6/4 (licht rötlich braun) und weiße Oberfläche Technik: aus Model gegossen

Erh.: VS und RS. Größeres Stück an VS ausgebrochen. Kopf mit Hals und Füße weggebrochen

Beschreibung: TK 32 ist eine Figur mit eng zusammenstehenden, durchgestreckten Beinen und einem gerade aufgerichteten Oberkörper. Der linke Arm ist neben dem Körper gesenkt. Die Figur scheint gänzlich von einem Mantel verhüllt zu sein und in der linken Hand einen Gegenstand zu halten ${ }^{33}$.

TK 33 Armfragment

Taf. 366 AO: GHD; Ki 02/30

FO/FJ: ETH; Skene, Kammer D3; S02/2002; SE B7; 2002

Maße: H 3,6 cm; B 1,4 cm; T 1,2 cm

Mat.: Ton mit Glimmer, Sand u. wenig Kalk; 2.5YR5/8 (rot)

Oberfläche: 2.5YR6/6 (lichtrot)

Technik: massiv

Erh.: Arm, Hand weggebrochen.

TK 34 Beine einer Figur / Eros? Puppe?

Taf. 366 AO: GHD; Ki 93/40

FO/FJ: ETH; vomitorium ES2; Füllschutt, von oben kommende Erde; 1993

Maße: H 3,7 cm; B 1,8 cm; T 1,2 cm

Mat:: Ton mit viel feinem Glimmer u. Sand; 5YR4/6 (gelblich rot) Oberfläche: 5YR6/6 (rötlich gelb)

${ }^{32} \mathrm{Zu}$ dieser hellenistischen Gruppe s. ICARD-Gianolio 1994, Kommentar zu Nr. 141a; zu Eros-Psyche-Gruppen aus Ephesos s. LANG-Auinger 2003b, 219 f. TK 3 (Fundkontext: spätaugusteisch-tiberisch); TK 4 (Fundkontext: spätaugusteisch-tiberisch); RATHMAYR 2014, 427 f. TK 76 (3. Jh. n. Chr.).

${ }^{33}$ Vgl. eine ähnliche Figur bei Meriç 2002, 143. 147 TK 24 Taf. 109. 
Malfarbe: 10R7/4 (blassrot)

Erh.: Unterschenkel und Füße; Reste von weißem Überzug Beschreibung: Bei TK 34 handelt es sich um eng zusammenstehende, nackte Unterschenkel einer Figur, die an Vorder- und Rückseite gleich gut ausgearbeitet sind. Das Fragment kann zu einer Erosfigur ${ }^{34}$ oder einer Puppe ${ }^{35}$ gehört haben, von denen es Darstellungen mit vergleichbarer Beinhaltung gibt.

TK 35 Beinfragment

Taf. 366

AO: GHD; Ki 04/63

FO/FJ: ETH; Skene, Kammer E3; S1/2004; SE B34; 2004

Maße: H 4,9 cm; Dicke: $1,8 \mathrm{~cm}$

Mat.: Ton mit viel feinem Glimmer; 5YR4/4 (rötlich braun)

Oberfläche: 5YR5/4 (rötlich braun)

Erh.: Fragment eines Beins. Bruch an beiden Enden.

TK 36 Gliedmaßenfragment

Taf. 366

AO: GHD; Ki 98/14

FO/FJ: ETH; über vomitorium EN3; 1998

Maße: H 7,2 cm; B 2,5 cm; T 2 cm

Mat.: Ton mit wenig Glimmer u. Sand; 2.5YR4/6 (rot)

Oberfläche: 2.5 YR5/6 (rot)

Erh.: Gliedmaßenfragment. Bruch am oberen und unteren Ende.

\section{TK 37 Gliedmaßenfragment}

Taf. 366

AO: GHD; Ki 08/182

FO/FJ: ETH; Stiegengasse-Süd; E2; SE 173; 2008

Maße: H 2,3 cm; Dicke 1,5 cm

Mat.: Ton mit feinem Glimmer; 2.5YR4/6 (rot)

Oberfläche: 2.5 YR5/6 (rot)

Erh.: Stück von Arm oder Bein.

\section{TK 38 Bewegliches Bein einer Puppe}

AO: EM; InvNr. 94/42/93; Th 93/117

FO/FJ: ETH; Süd-Analemma; Substruktionsgewölbe; 1993

Maße: L 6,7 cm; B 2,9 cm; T 1,4 cm

Mat.: Ton

Erh.: Bein mit Loch am Oberschenkel

Beschreibung: Die Innenseite des Beins TK 38 ist flacher als die Außenseite gearbeitet, die Fußunterseite ist flach und das obere Ende leicht abgeschrägt und ebenfalls flach. Es war über das Loch beweglich an einer Figur montiert und gehörte zu einer Puppe mit beweglichen Gliedmaßen ${ }^{36}$.

TK 39 Rücken einer unbekleideten Figur

Taf. 367

AO: GHD; Ki 93/127

FO/FJ: ETH; Süd-Analemma; Substruktionsgewölbe; 1993

\footnotetext{
${ }^{34} \mathrm{Vgl}$. die Stellung der Beine mit Erosfiguren aus Myrina, die mit einem Mantel bekleidet sind, der entweder nur den Oberkörper bedeckt oder knapp über den Knien endet; s. Mollard-Besques 1963, 61-63 Kat. 124-126. 129. 131. 132. 137. 143 Taf. 77-79.

${ }^{35} \mathrm{Zu}$ Sitzpuppen mit eng zusammenstehenden Beinen s. z. B. Rumscheid 2006, 433 Kat. 79-81 Taf. 32; für Ephesos s. LANG-AUINGER 2007, 155 f. TK 75 Taf. 50.

${ }^{36}$ Vgl. Leyenaar-Plaisier 1979, 380 Kat. 1053 Taf. 135 (3. Jh. n. Chr.); Besques 1972, 72 Kat. D 445 Taf. 97; zu Gliederpuppen aus Ephesos vgl. Meriç 2002, 144; LANG-AuinGER 2007, 155 f. Taf. 50
}

Maße: $\mathrm{H} 8,4 \mathrm{~cm}$; B 7,8 cm; T 2,4 cm

Mat.: Ton mit viel feinem Glimmer u. Sand; 2.5YR5/6 (rot) u. 7.5YR5/1 (grau)

Oberfläche: 2.5YR6/6 (lichtrot) u. 7.5YR8/1 (weiß)

Technik: aus Model gezogen

Erh.: Rücken mit Ansatz der Arme und des Halses

Beschreibung: TK 39 stellt den Rücken einer Figur mit nacktem Oberkörper und gesenkten Oberarmen dar. Dieser kann zu einer männlichen oder weiblichen Darstellung gehört haben.

TK 40 Rückseitenfragment?

Taf. 367 AO: GHD; Ki 98/33

FO/FJ: ETH; vomitorium ES3; S3/1998; 1998

Maße: H 6 cm; B 3,4 cm; T 1,3 cm

Mat.: Ton mit feinem Glimmer; 5YR5/8 (gelblich rot)

Oberfläche: 5YR6/6 (rötlich gelb)

Technik: aus Model gezogen.

TK 41 Kopf eines Schauspielers mit Maske AO: EM; Ki 04/19

FO/FJ: ETH; Skene; E1; S 2/2004: SE B23; 2004

Maße: H 4,7 cm; B 3,4 cm; T 2,3 cm

Mat.: Ton mit feinem Glimmer; 2.5YR5/8 (rot)

Oberfläche: 2.5YR6/6 (lichtrot) u. 5Y8/1 (weiß)

Technik: aus Model gezogen

Erh.: Kopf mit Hals; Reste von weißem Überzug

Beschreibung: TK 41 zeigt den Kopf eines Schauspielers mit einer Maske der Neuen Komödie ${ }^{37}$.

\section{TK 42 Fragment einer Maske der} Neuen Komödie

Taf. 367 AO: GHD; Ki 04/63

FO/FJ: ETH; Skene; E3; S1/2004; SE B34 (Pithos 2); 2004

Maße: H 5,3 cm; B 6,3 cm; T 1,3 cm

Mat.: Ton mit viel feinem Glimmer; 2.5YR5/8 (rot) u. 2.5YR5/1 (rötlich grau)

Oberfläche: 5YR6/6 (rötlich gelb)

Technik: aus Model gezogen

Erh.: Teil der linken Stirnpartie und des linken durchlochten Auges

Beschreibung: TK 42 ist das Fragment einer Maske mit stark gebogener rechter Braue und hervortretenden Stirnfalten sowie einem wulstförmig vortretenden Oberlid. Das erhaltene linke Auge ist durchlocht. TK 42 ist das Fragment einer lebensgroßen Maske, wahrscheinlich der Neuen Komödie ${ }^{38}$.

TK 43 Nase einer Maske der Neuen Komödie AO: GHD; Ki 04/63

FO/FJ: ETH; Skene; E3; S1/2004; SE B34 (Pithos 2); 2004

Maße: H 4,9 cm; B 3,1 cm; T 3,5 cm

Mat.: Ton mit feinem Glimmer; 5YR5/6 (gelblich rot)

Oberfläche: 5YR6/4 (licht rötlich braun) u. 2.5Y8/1 (weiß)

\footnotetext{
${ }^{37} \mathrm{Vgl}$. folgende hellenistische Köpfe von Schauspielern: Besques 1972, 121 D 806-808 Taf. 149; 252 D 1999 Taf. 326. Zu Schauspieler wiedergebenden Terrakotten s. auch FISCHER 1994, 189 f.; RUMSCHEID 2006, 286-289.

${ }^{38}$ Vgl. z. B. bei Rumscheid 2006, 528 f. Kat. 378 Taf. 157 (2. Jh. v. Chr.).
} 
Technik: aus Model gezogen

Erh.: Nase mit Resten von weißem Überzug

Beschreibung: Bei TK 43 handelt es sich um die Nase einer Maske, wahrscheinlich der Neuen Komödie ${ }^{39}$.

TK 44 Nase einer Maske der Neuen Komödie Taf. 367 AO: GHD; Ki 07/170

FO/FJ: ETH; Süd-Analemma; Kammer KS2; SE 45; 2007

Maße: H 5,3 cm; B 3,8 cm; T 2,5 cm

Mat.: Ton mit viel feinem Glimmer; 2.5YR4/8 (rot)

Oberfläche: 2.5 YR6/8 (lichtrot)

Erh.: lange Nase und leicht gebogener Rand der Mundöffnung Beschreibung: TK 44 umfasst die Nase und den oberen Rand der Mundöffnung einer Maske, wahrscheinlich der Neuen Komödie.

\section{TK 45 Gladiator}

Taf. 368

AO: GHD; Ki 07/15

FO/FJ: ETH; Stiegengasse-Süd, B1; Reinigung; 2007

Maße: H 6,2 cm; B 4,8 cm; T 1,9 cm

Mat.: mit sehr viel feinem Glimmer u. Sand; 2.5YR4/6 (rot)

Oberfläche: 2.5 YR5/6 (rot)

Malfarbe: 5YR2.5/1 (schwarz)

Erh.: Körper mit Arm- und Beinansätzen. Kopf und Hals sind weggebrochen.

Dat.: Kaiserzeit

Beschreibung: TK 45 ist eine Figur, deren rechter Arm zur Seite gestreckt war und deren linker Arm neben dem Körper gesenkt ist. Die Ansätze der Oberschenkel weisen nach außen, wobei der Ansatz des rechten Oberschenkels nach vorne und der des linken etwas zur linken Seite gerichtet ist. Während Arme und Beine unbedeckt sind, befindet sich unterhalb der Brust ein Lendenschurz mit breiter Gürtung. Am Oberkörper führt ein Riemen von der linken Schulter auf den Rücken ${ }^{40}$. Eine Terrakottafigur aus Ephesos, heute im Museum von Selçuk, stimmt mit TK 45 nicht nur in der Bekleidung und Ausrüstung, sondern auch in der Haltung der Arme und Beine überein ${ }^{41}$. Beide Figuren haben demnach denselben Gladiatorentypus wiedergegeben. Wahrscheinlich haben sie retiarii gezeigt, da diese über der manica, dem Armschutz, einen bronzenen Schirm auf der linken Schulter trugen, der mit einem um den Oberkörper geführten Schulterriemen gehalten wurde ${ }^{42}$.

\section{TK 46 Arm eines Gladiators}

Taf. 368

AO: GHD; Ki 07/171

FO/FJ: ETH; Süd-Analemma; Kammer KS1; SE 46; 2007

Maße: $\mathrm{H} 4 \mathrm{~cm}$; B $2 \mathrm{~cm}$; $1,5 \mathrm{~cm}$

Mat.: Ton mit feinem Glimmer; 2.5YR5/8 (rot)

Oberfläche: 2.5 YR6/8 (lichtrot)

Erh.: rechter Arm; an der Hand und am Ansatz zur Schulter Bruch

Dat.: Kaiserzeit

\footnotetext{
${ }^{39} \mathrm{Zu}$ vergleichen ist die lange, gerade Nase mit drei Theatermasken der Neuen Komödie aus Priene: s. RumscheID 2006, 531 f. Kat. 385. 386. 388 Taf. 159. Dies gilt auch für TK 44.

${ }^{40}$ Vgl. z. B. einzelne Gladiatoren auf einem Relief aus Ephesos in M. BÜYÜKKKOLANCI 2002, 87. 88 mit Abb.

${ }^{41}$ P. BÜYÜKKKolanci 2002, 93 mit Abb.

42 JuNKELMAN 2002, 31 Abb. 1. 3.
}

Beschreibung: TK 46, der mit einer manica geschützte Arm, gehörte zur Figur eines Gladiators ${ }^{43}$.

\section{TK 47 Stütze mit vorgeblendeter} Figur einer Chimaira?

AO: GHD; Ki 07/35

FO/FJ: ETH; Stiegengasse-Süd; B2; SE 2; 2007

Maße: H 5 cm; B 1,6 cm; T 2,5 cm

Mat.: Ton mit viel feinem Glimmer u. Sand; Ton: 7.5YR5/2 (braun)

Oberfläche: 7.5YR6/3 (lichtbraun)

Erh.: oberer Teil einer pfeilerartigen Stütze

Dat.: Hellenismus bis Kaiserzeit

Beschreibung: Bei TK 47 handelt es sich um den oberen Teil einer Stütze, deren Vorderseite als Tierfigur ausgeführt ist. Vom Tier ist der Kopf mit einem geöffneten Maul und ein Teil der Brust erhalten, die aber annehmen lassen, dass es sich nicht um ein reales, sondern ein Mischwesen handelt: Von der Ziege sind die Hörner inklusive der Torsionsrillen, von einem bulligen Hund oder Löwen die runde Kopfform und die beidseits ausladende, durch ein tiefes Philtrum geteilte Oberlippe ${ }^{44}$; von Ziege oder Löwe kommen die als schräge, nach oben als divergierende Schlitze dargestellten Nasenlöcher, während der Unterkiefer und die Unterlippe sowie die heraushängende Zunge sehr gut zu Löwe und Hund passen. Um ein Mischwesen aus Ziege und Löwe handelt es sich bei der Chimaira ${ }^{45}$, die hier wohl dargestellt war. Über ihrem Kopf verbreitert sich die Stütze bis zum oberen Ende. Als Tierfüße gestaltete Stützen sind aus der hellenistischen Periode und der Kaiserzeit von Möbeln gut bekannt ${ }^{46}$.

\section{TK 48 Rind}

Taf. 368

\section{AO: EM; Ki 93/72}

FO/FJ: ETH; Südseite; Theateraußenmauer; 1993

Maße: H 4,5 cm; B 7 cm; T 3,6 cm

Mat.: Ton

Erh.: fast vollständig. Bruch an Beinen und Hörern; Reste von weißem Überzug

Beschreibung: Bei TK 48 handelt es sich um die Figur eines stehenden Rinds ${ }^{47}$.

TK 49 Kopf eines Schweins?

Taf. 369

\section{AO: GHD; Ki 03/59}

FO/FJ: ETH; Logeion; S4/2003; SE L48; 2003

Maße: $\mathrm{H} 3 \mathrm{~cm}$; $2,4 \mathrm{~cm}$; T $1,2 \mathrm{~cm}$

Mat.: Ton mit viel Glimmer; 2.5 YR4/8 (rot)

Oberfläche: 2.5 YR6/6 (lichtrot)

Technik: aus Model gezogen

Erh.: Teil des Kopfs

\footnotetext{
${ }^{43}$ Bei Gladiatoren war der Waffen führende Arm mit einer manica, einem Schutz aus überlappenden Lederbändern oder gestepptem Leinen, geschützt s. JunKeLMAN 2002, 28.

${ }^{44}$ Für die Beschreibung sei G. Forstenpointner von der Veterinärmedizinischen Universität in Wien herzlichst gedankt.

${ }^{45} \mathrm{Zu}$ Darstellungen der Chimaira: JACQUEMIN 1986.

${ }^{46} \mathrm{Vgl}$. beispielsweise einen Tisch mit solchen Beinen aus Herkulaneum: RichteR 1966, 112 Abb. 572.

${ }^{47}$ Vgl. zwei ähnliche Rinder aus Priene: RumscheId 2006, 520 Kat. 351. 352 Taf. 146.
} 
Beschreibung: Bei TK 49 könnte es sich um den Kopf eines Schweins gehandelt haben ${ }^{48}$.

TK 50 Basis

AO: GHD; Ki 08/182

FO/FJ: ETH; Stiegengasse-Süd; E2; SE 173; 2008

Maße: H 5,3 cm; B 3,2 cm; T 6,1 cm

Mat.: Ton mit viel feinem Glimmer; 2.5YR6/6 (lichtrot)

Oberfläche: 2.5YR7/6 (lichtrot) und 5YR8/1 (weiß)

Erh.: von einer quaderförmige Basis mit Kopf- und Fußprofil ist eine Seite ganz und von zwei weiteren Seiten je ein Stück erh. Auf der OS Ansätze einer Figur.

\section{TK 51 Basis}

AO: GHD; Ki 09/57

FO/FJ: ETH-Ost; S1/2009; SE 36; 2009

Maße: $\mathrm{H} 1,3 \mathrm{~cm} ; \mathrm{B} 4,3 \mathrm{~cm} ; \mathrm{T} 4,5 \mathrm{~cm}$

Mat.: Ton mit viel feinem Glimmer; 5YR6/6 (rötlich gelb)

Oberfläche: 7.5YR7/4 (pink)

Erh.: Teil einer quaderförmigen Basis.

TK 52 Basis

Taf. 369

AO: GHD; Ki 09/113

FO/FJ: ETH; Stiegengasse-Süd; F2-S; SE 246; 2009

Maße: H 0,7 cm; B 6,6 cm; T 1,1 cm

Mat.: Ton mit feinem Glimmer; 10YR7/4 (blassbraun)

Malfarbe: 7.5 YR5/3 (braun)

Erh.: Ecke einer Basis; Reste von weißem Überzug.

TK 53 Basis

Taf. 369

AO: GHD; Ki 04/63

FO/FJ: ETH; Skene; Kammer E3; S1/2004; SE B34 (Pithos 2); 2004

Maße: H 4,2 cm; B 2,4 cm; T 5,6 cm

Mat.: Ton mit wenig feinem Glimmer; 2.5YR5/8 (rot)

Oberfläche: 2.5YR6/6 (lichtrot)

Erh.: Teil einer quaderförmigen Basis auf Füßchen in den Ecken erh.

\section{TK 54 Basis}

Taf. 369

AO: GHD; Ki 08/180

FO/FJ: ETH; Stiegengasse-Süd, E2; SE 171; 2008

Maße: H 3,5 cm; B 4 cm; T 3,4 cm

Mat.: Ton mit viel feinem Glimmer u. wenig Sand; 2.5YR5/6 (rot)

Oberfläche: 2.5 YR6/6 (lichtrot)

Malfarbe: 10R5/6 (rot)

Erh.: Teil einer quaderförmigen Basis.

\section{TK 55 Basis}

AO: GHD; Ki 08/180

FO/FJ: ETH; Stiegengasse-Süd, E2; SE 171; 2008

Maße: H 2,4 cm; B 7,1 cm; T 6,5 cm

Mat.: Ton mit viel feinem Glimmer u. wenigen Kalkstückchen; 2.5YR5/8 (rot)

Oberfläche: 7.5YR5/4 (braun)

Erh.: Ecke einer niedrigen quaderförmigen Basis; Reste von weißem Überzug.

Taf. 369
TK 56 Basis

Taf. 369

AO: GHD; Ki 08/180

FO/FJ: ETH; Stiegengasse-Süd, E2; SE 171; 2008

Maße: $\mathrm{H}$ 7,9 cm; B $3 \mathrm{~cm}$; $\mathrm{T} 5,8 \mathrm{~cm}$

Mat.: Ton mit viel feinem Glimmer; 2.5YR5/8 (rot)

Oberfläche: 2.5YR6/6 (lichtrot)

Technik: aus Model gezogen

Erh.: Teil einer hohen quaderförmigen Basis mit Kopf- und Fußprofil sowie den Zehen eines linken Fußes auf der Oberseite.

TK 57 Basis

Taf. 369 AO: GHD; Ki 08/87

FO/FJ: ETH; Stiegengasse-Süd; B2; SE 120; 2008

Maße: $\mathrm{H} 4 \mathrm{~cm}$; B 2,7 cm; T $2 \mathrm{~cm}$

Mat.: Ton mit Glimmer; 2.5YR4/6 (rot)

Oberflächenfarbe: 7.5YR6/3 (lichtbraun)

Erh.: zwei Seiten einer hohen quaderförmigen Basis.

TK 58 Basis

Taf. 369

AO: GHD; Ki 08/87

FO/FJ: ETH; Stiegengasse-Süd; B2; SE 120; 2008

Maße: H 3,7 cm; B 3 cm; T 1,2 cm

Mat.: Ton mit Glimmer; 10YR4/3 (braun)

Oberflächenfarbe: 10YR7/2 (lichtgrau)

Erh.: Stück einer profilierten Basis mit dem Fuß einer Figur.

TK 59 Fragment einer Basis?

Taf. 369

AO: GHD; Ki 09/31

FO/FJ: ETH; Stiegengasse-Süd; J2; SE 189; 2009

Maße: H 5,5 cm; B 2,4 cm; T 1,7 cm

Mat.: Ton mit feinem Glimmer u. Sand; 2.5YR5/6 (rot) mit 5YR6/4 (licht rötlich braun)

Erh.: Ecke mit Leiste, auf der ein kugelförmiger Gegenstand aufliegt; Reste von weißem Überzug.

TK 60 Basisfragment?

Taf. 369

\section{AO: GHD; Ki 98/22}

FO/FJ: ETH; über vomitorium EN3; 1998

Maße: H 3,9 cm; B 4,5 cm; T 2,4 cm

Mat.: Ton mit wenig Glimmer u. Sand; 7.5YR6/4 (lichtbraun) Oberfläche: 5YR6/6 (rötlich gelb)

Malfarbe: zwischen 7.5YR2.5/1 (schwarz) und 7.5YR4/2 (braun)

Technik: aus Model gezogen.

TK 61 Fragment, auf dem ein Blatt aufliegt AO: GHD; Ki 03/61

FO/FJ: ETH; Logeion; S4/2004; SE L50; 2003

Maße: H 6,4 cm; B 3,7 cm; T 1,4 cm

Mat.: Ton mit feinem Glimmer u. Sand; 10YR5/2 (gräulich braun) u. 10YR4/1 (dunkelgrau)

Oberfläche: 10YR6/3 (blassbraun)

Erh.: flaches TK-Stück, das mit einem Blatt verziert ist; unterer Rand erh.

E. RATHMAYR

D. AKAR-TANRIVER

${ }^{48}$ Vgl. zwei Schweinefiguren aus Priene: RumscheID 2006, 522 Kat. 358. 359 Taf. 150. 


\subsection{KLEINFUNDE}

Die hier präsentierten Funde aus Metall und Bein sowie wenige Einzelstücke aus Ton und Muschel stammen aus den Grabungen zwischen 1993 und 2009 im Theater von Ephesos ${ }^{49}$. Eine zeitliche Einteilung aufgrund stilistischer Merkmale lässt sich nur bei wenigen Stücken vornehmen und ist in der Einleitung sowie an entsprechender Stelle im Katalog vermerkt. Unter den im Katalog aufgenommenen Metallfunden sind die meisten Objekte aus Kupferlegierung gefertigt (MF 1-15 Taf. 370; MF 16-23 Taf. 371; MF 24-31/3 Taf. 372; MF 31/4-37 Taf. 373; MF 38-50/2 Taf. 374), der Rest ist aus Eisen (MF 51 Taf. 374; MF 52-58/2 Taf. 375; MF 59-67 Taf. 376) und Blei (MF 68-73 Taf. 377). Die Beinfunde umfassen 64 Objekte (B 1-42 Taf. 378; B 43-56 Taf. 379; B 57-62 Taf. 380), die unter dem Kapitel »Kleinfunde aus unterschiedlichen Materialen« zusammengefassten Funde beinhalten mehrere Objekte aus Ton (KF 1-4 Taf. 380; KF 5. KF 6 Taf. 381) sowie einen Anhänger aus Muschelschale (KF 7 Taf. 381).

\subsubsection{Metall}

Bei den Objekten MF 1-7 (Taf. 370) handelt es sich um Ringe. MF 1 und MF 2 (Taf. 370) gehören zu den Fingerringen mit abgeschrägten Seitenflächen. Aufgrund von Vergleichsbeispielen können die Ringe ab dem 3. Jh. n. Chr. datiert werden ${ }^{50}$. Auch aus Ephesos ist diese Ringform bekannt: So stammen beispielsweise zwei Fingerringe dieses Typs mit kantig abgeschrägten Seitenflächen aus spätantiken Kanalfüllungen vom Südtor der Tetragonos Agora ${ }^{51}$.

Die Ringform von MF 3 mit verbreiterter Platte ist zeitlich nicht näher eingrenzbar (Taf. 370) ${ }^{52}$.

Die unverzierten Ringe MF 4-7 (Taf. 370) besitzen alle einen runden oder ovalen Querschnitt und lassen sich aufgrund ihrer Form ebenfalls chronologisch nicht einordnen. Auch ist ihre Verwendung als Fingerringe nicht gesichert, vielmehr konnten sie beispielsweise auch als Verbindungsglieder verwendet worden sein.

Das Gürtelbeschläg MF 8 (Taf. 370) ist Teil einer vielteiligen Gürtelgarnitur vom Typ H1 nach M. Schulze-Dörrlamm, der der 2. Hälfte des 6. Jhs. n. Chr. zugeordnet wird ${ }^{53}$. Angeblich wurden diese Gürtelgarnituren nicht von Byzantinern, sondern von Barbaren getragen, wie aus bildlichen Darstellungen hervorgeht $^{54}$. Vergleichbar mit dem Beschläg MF 8 sind beispielsweise Riemenbeschläge aus Nikopolis in der Ukraine, die sich im Römisch-Germanischen Zentralmuseum in Mainz befinden ${ }^{55}$, sowie eine vielteilige Gürtelgarnitur aus dem Kammergrab 74 in Lutchistoe auf der $\mathrm{Krim}^{56}$, die, abgesehen von münzdatierten weiteren Exemplaren, auch aufgrund ihrer Ähnlichkeit zu den byzantinischen Schnallentypen mit festen und durchbrochen gearbeiteten Beschlägen (Typen D1 und D2) in die 2. Hälfte des 6. Jhs. n. Chr. datiert werden können ${ }^{57}$.

Bei der einzigen bekannten Fibel aus den Theatergrabungen (MF 10 Taf. 370) handelt es sich vermutlich nicht um einen römischen Fibeltypus, auch wenn eine genaue Zuordnung aufgrund des schlechten Erhaltungszustands nicht vorgenommen werden kann. Möglicherweise jedoch gehört MF $10 \mathrm{zu}$ den kleinen Bogenfibeln mit rundstabigem, symmetrischem Bügel, die in Ephesos vor allem im Artemision begegnen, jedoch in der gesamten östlichen Ägäis in spätgeometrischer und früharchaischer Zeit zu finden sind und auch über einen langen Zeitraum hin Verwendung fanden ${ }^{58}$.

\footnotetext{
${ }^{49}$ Die Aufnahme der Funde und der technischen Daten im Katalogteil erfolgte durch D. Akar-Tanriver. Zu den Grabungen s. Kap. 3.

${ }^{50}$ z. B. Henkel 1913, Kat. 390 Taf. 19 (Silberring) und S. 240 zur Datierung. Vergleichbare Schulter s. Bronzering in Trier: HenKeL 1913, Kat. 934 Taf. 36. - Olympia: PHILIPP 1981, Kat. 661 Taf. 43. - Zwei Bronzeringe aus dem Schatzfund aus der Insula 42 in Augst: Riнa 1990, 31 Kat. 2982. 2983 Taf. 79.

${ }^{51}$ JILEK 1997, 219 f. Kat. 916.917 Taf. 70: Datierung: 3. Jh. n. Chr. bis Spätantike.

${ }_{52}^{5}$ s. z. B. drei Bronzeringe mit vergleichbarer Form: Henkel 1913, Kat. 810-812 Taf. 32.

${ }^{53}$ SChUlze-DörRlamm 2009, II 265-268.

${ }^{54}$ Schmauder 2000, 15 f. Abb. 2. 3. 7; Bálint 2000, 99 f. Abb. 5. 6. 8-19.

${ }_{55}^{5}$ Schulze-Dörrlamm 2009, II 265 f. Kat. 578, Typ H1.

${ }^{56}$ Aibabin 1999, Abb. 44; abgebildet bei Schulze-Dörrlamm 2009, II Abb. 101.

${ }^{57}$ Schulze-Dörrlamm 2009, II 266. Zu den Typen D1 und D2 s. Schulze-Dörrlamm 2009, I 146-155.

${ }_{58}$ Artemision: Klebinder-Gauss 2007, 22-25, z. B. Kat. 1-3 Taf. 1 (Bronze); Pülz 2009, 67 f. Kat. 54 Taf. 14 Farbtaf. 9 (Gold).
} 
Bei MF 11 (Taf. 370) handelt sich vielleicht um eine römische Löffel- oder Hohlsonde, die als chirurgisches Hilfsinstrument, beispielsweise als Führungsschiene für das Skalpell, gedient haben könnte ${ }^{59}$. Auch MF 12 (Taf. 370) könnte ein medizinisches oder kosmetisches Instrument sein: Vergleichbare Spatelsonden, jedoch oftmals mit vierkantigem Stiel, stammen beispielsweise aus Augst ${ }^{60}$. Eine andere Möglichkeit wäre die Interpretation als Stilus, ähnlich einem Bronzestilus aus Korinth, der aus einem römischen Fundkontext stammt ${ }^{61}$.

Die Haarnadel MF 13 (Taf. 370) findet Parallelen in Augst, die ebenfalls ein schmales Kopfende besitzen und im oberen Schaftbereich unterschiedliche Verzierungen aus Wülsten und Ringen aufweisen, und die laut ihren Fundkontexten zwischen dem 2. und 4. Jh. n. Chr. datiert werden können ${ }^{62}$.

Bei MF 18-20 (Taf. 371) handelt es sich um kleine Glocken. Unterschiedliche Bronzeglocken stammen auch aus den Hanghäusern 1 und 2 in Ephesos ${ }^{63}$. Das Glöckchen MF 19 besitzt zusätzlich eine Inschrift zwischen umlaufendem Fischgrätmuster. Dies deutet auf eine Weihung, wie auch bei einer Glocke aus der WE 2 im Hanghaus 2, deren Fundkontext in das 3. Viertel des 3. Jhs. n. Chr. weist ${ }^{64}$.

MF 21-25 (Taf. 371. 372) sind Fragmente unterschiedlicher Gefäße. Das peltaförmige Gefäßfüßchen MF 25 war ursprünglich eines von drei Füßchen, die als Untersätze auf den Böden von Kasserollen und Griffschalen im 1. und 2. Jh. n. Chr. dienten ${ }^{65}$.

Unter den wenigen Bleiobjekten aus dem Theater befindet sich ein pyramidales Gewicht (MF 73 Taf. 377). Weitere aus Ephesos bekannte Bleigewichte stammen aus dem Hanghaus 1 in Ephesos, wobei eines der beiden aus einem frühkaiserzeitlichen Fundkontext stammt ${ }^{66}$, oder auch aus einer Verfüllung eines Brunnen am Staatsmarkt ${ }^{67}$.

A. M. PÜLZ

\section{KATALOG}

\section{Edelmetall}

MF 1 Ring

Silber

AO: EM; Ki 93/97; Inv. 100/42/93

FO/FJ: ETH; vomitorium ES2; Südausgang; 1993

Maße: Dm 2,2 × 2,5 cm; Dicke max. 0,4 cm

Erh.: vollständig

Dat:: ab dem 3. Jh. n. Chr.

Beschreibung: Der geschlossene Fingerring besitzt eine eckige Form, wobei sich die Schultern schräg nach außen, mit hervorgehobenen Schulterecken ziehen, während der Unterteil eher rund gehalten ist. Die Ringplatte ist oval erhaben und zeigt einen springenden Hirsch oder Rehbock.

Taf. 370
MF 2 Ring

Kupferlegierung

AO: GHD; Ki 93/101

FO/FJ: ETH; vomitorium ES2; Südausgang; 1993

Maße: Dm 2,0 × 2,2 cm; Dicke max. 0,6 cm

Erh.: vollständig (?)

Dat:: ab dem 3. Jh. n. Chr.

Beschreibung: Der offene und massive Fingerring ist einteilig hergestellt und gegossen. Die unverzierte Ringschiene ist, wie schon MF 1, an der Innenfläche rund und außen eckig gestaltet, d. h. die Schultern fallen schräg ab und die Schulterecken sind kräftig ausgeprägt, der Unterteil ist rund gehalten. Der Ringkopf ist oval erhaben (Fassung?).

\footnotetext{
${ }^{59}$ Vgl. beispielsweise Riнa 1986, 64. 71 Kat. 519. 523 Taf. 48.

${ }^{60}$ RiHa 1986, 77 Kat. 612 Taf. 55.

${ }^{61}$ Davidson 1952, 185 f. Kat. 1348 Taf. 83.

${ }^{62}$ Riнa 1990, 111, z. B. Kat. 2538. 2558 Taf. 59. 60.

${ }^{63}$ RathmaYr 2010, 323. 618 (WE 1 und 2); JILEK 2003, 272 mit zahlreichen Vergleichen, Verwendungszwecken und weiterführender Lit.

${ }^{64}$ Rathmayr 2010, Kat. B-B 21 Taf. 262. 271; sowie S. 618 und Anm. 187 mit Lit. zu Glöckchen mit Weihinschriften. Zur Inschrift TAEUBER 2010, 478 Kat. IKL 10.

${ }^{65}$ JILEK 1997, 222 mit Lit.- Korinth: DAvidson 1952, Kat. 539 Taf. 50: 4 Gefäßfüßchen aus Bronze aus byzantinischem Kontext, vielleicht aber kaiserzeitlich. - Olympia: FuRTwÄNGLER 1966, 197 Nr. 1270: Datierung kaiserzeitlich. - Sardis: WALDBAUM 1983, Taf. 58 Nr. 1011. - Ephesos, Südtor der Tetragonos Agora: JILeK 1997, Kat. 925 Taf. 70. - Ephesos, Byzantinischer Palast: Gefäßfüßchen mit konzentrischer Kreisaugenzier; unpubliziert.

${ }^{66}$ TRINKL 2003, 316 f. Kat. T 15. 48 Taf. 152.

${ }^{67}$ Meriç 2002, 138 f. M 28. 29 Taf. 87: 1. Viertel 1. Jh. n. Chr.
} 
MF 3 Ring

Kupferlegierung

AO: EM; Ki 08/85

FO/FJ: ETH; Stiegengasse-Süd; C2-S (Insula-Süd/R1); SE 121a; 2008

Maße: Dm 1,8 cm; Dicke 0,1 cm; B Ringplatte 0,4 cm

Erh.: vollständig

Beschreibung: Der geschlossene Fingerring hat einen runden Querschnitt mit abgeflachter Innenseite, d. h. einen D-förmigen Querschnitt. Die Ringplatte ist mit der Schiene aus einem Stück gemacht, leicht verbreitert und mit drei waagrechten Linien verziert.

\section{MF 4 Ring}

Taf. 370

Kupferlegierung

AO: GHD

FO/FJ: ETH; Südrampe; 1997

Maße: Dm 1,9 cm; D 0,3 cm

Erh.: vollständig

Beschreibung: Es handelt sich um einen unverzierten, geschlossenen Fingerring mit rundem Querschnitt.

\section{MF 5 Ring}

Kupferlegierung

AO: EM; Ki 08/94

FO/FJ: ETH; Stiegengasse-Süd; C1; SE 135; 2008

Maße: Dm 2,4 cm; Dicke 0,3 cm

Erh.: vollständig (?)

Beschreibung: Der geschlossene und unverzierte Ring hat einen runden Querschnitt mit abgeflachter Innenseite. An einer Stelle finden sich an der Außenfläche mehrere Einbuchtungen.

\section{MF 6 Ring}

Kupferlegierung

AO: GHD; Ki 07/80

FO/FJ: ETH; Stiegengasse-Süd; B1; SE 9; 2007

Maße: Dm 1,3 cm; Dicke 0,2 cm

Erh.: vollständig

Beschreibung: Es handelt sich um einen kleinen, geschlossenen und unverzierten Ring, der einen runden Querschnitt besitzt.

\section{MF 7 Ring}

Taf. 370

Kupferlegierung

AO: GHD; Ki 08/22

FO/FJ: ETH; mittleres Diazoma; S5/2008; SE 90; 2008

Maße: Dm 1,9 cm; Dicke 0,2-0,3 cm

Erh.: vollständig (?)

Beschreibung: Der offene, rundstabige und unverzierte Ring verdickt sich in der Mitte. Es könnte sich eventuell auch um einen einfachen halbmondförmigen Ohrring handeln, dessen Enden verbrochen sind.

\section{MF 8 Gürtelbeschläg}

Taf. 370

Kupferlegierung

AO: GHD; KF 09/2; Ki 09/69

FO/FJ: ETH; Stiegengasse-Süd; K1; SE 122; 2009

Maße: L 0,8 cm; B 2,6 cm; Dicke 1,3 cm

Erh.: vollständig

Dat.: 2. H. 6. Jh. n. Chr

Beschreibung: Das Gürtelbeschläg ist schild- oder wappenförmig mit abgeschrägten Randflächen. Die Verzierung besteht aus zwei kreisrunden, nebeneinander liegenden Durchlochungen, darunter befinden sich zwei halbmondförmige Auslassungen. An der gerade abgeschnittenen Kante sind zwei schräge Kerben, an der gegenüberliegenden Seite befindet sich ein Endknopf. Die Rückseite zeigt zwei Ösen.

MF 9 Gürtelbeschläg (?)

Taf. 370

Kupferlegierung

AO: GHD; Ki 04/100

FO/FJ: ETH; Skene, Kammer D8; Reinigung; 2004

Maße: erh. L 4,1 cm; max. B 2,3 cm; Dicke $0,2 \mathrm{~cm}$

Erh.: Fragment, stark korrodiert

Beschreibung: Vermutlich handelt es sich um das Fragment eines Gürtelbeschlägs, das ursprünglich Teil einer vielteiligen Gürtelgarnitur war. Eine Seite ist halbrund geformt und zeigt zwei parallel gesetzte Durchlochungen sowie den Ansatz einer Stecköse. Das Objekt ist stark korrodiert, von einer Verzierung ist nichts mehr erhalten.

MF 10 Fibel

Taf. 370

Kupferlegierung

AO: GHD; KF 09/12; Ki 09/114

FO/FJ: ETH; Stiegengasse-Süd; F2-Süd (Insula); SE 248; 2009

Maße: erh. L 1,8 cm; H $1 \mathrm{~cm}$; Dicke Bügel 0,3 cm

Erh.: Fragment: Teil vom Bügel mit Feder erhalten

Dat.: archaisch (?)

Beschreibung: Die halbkreisförmige Fibel ist massiv, der Bügel ist rundstabig. Da die Fibel nur zur Hälfte erhalten und der Anfang des Bügels stark korrodiert ist, kann über eine mögliche Verzierung keine Aussage getroffen werden. Ein Ende ist zu einer Spirale bzw. Feder gebogen. Aufgrund der geringen GröBe handelt es sich vermutlich um eine Miniaturfibel.

MF 11 Löffel- oder Hohlsonde (?)

Taf. 370

Kupferlegierung

AO: EM; KF 09/7; Ki 09/99

FO/FJ: ETH; Stiegengasse-Süd; J1/J2; SE 239; 2009

Maße: erh. H 8,7 cm; Kopf B 0,6 cm; Kopf Wulst Dm 0,5 cm; Schaft Dicke $0,3 \mathrm{~cm}$

Erh.: fast vollständig erhalten, Teile von der Laffe und vom Schaft verbrochen

Beschreibung: Der unverzierte Griffschaft ist rundstabig und verjüngt sich leicht nach unten. Die Laffe, die durch einen profilierten Ring deutlich vom Schaft abgesetzt ist, besitzt einen birnen- oder wulstartigen Ansatz, aus dem sie heraus wächst. Sie ist lanzettförmig mit scharfem Mittelgrat und weist einen dreieckigen oder dachförmigen Querschnitt auf.

MF 12 Spatelsonde/Stilus (?)

Taf. 370

Kupferlegierung

AO: EM; KF 09/4; Ki 09/86

FO/FJ: ETH; Stiegengasse-Süd; J1; SE 122; 2009

Maße: H 9,3 cm; Kopf B 0,8-0,5 cm; Kopf Dicke 0,1 cm; Schaft Dicke 0,3 cm

Erh.: vollständig

Beschreibung: Der rundstabige Griffschaft verjüngt sich zur Spitze hin und ist im unteren Drittel mit zwei kleinen Wülsten verziert. Der Kopf besteht aus einem trapezförmig geschnittenen, unverzierten Blech. 
MF 13 Nadel

Taf. 370

Kupferlegierung

AO: GHD

FO/FJ: ETH; Stiegengasse-Süd; K1; 2008

Maße: H 13,1 cm; Dicke 0,3 cm

Erh.: vollständig

Dat.: 2.-4. Jh. n. Chr.

Beschreibung: Die lange, dünne Nadel ist rundstabig und verjüngt sich leicht zur Spitze hin. Im oberen Drittel befindet sich eine Verzierung aus drei langgezogenen Wülsten alternierend mit je zwei Scheiben. Der Kopf ist länglich schmal und leicht konisch.

\section{MF 14 Kreuz (?)}

Taf. 370

Kupferlegierung

AO: GHD; Ki 04/100

FO/FJ: ETH; Skene, Kammer D8; Reinigung; 2004

Maße: erh. L 8,5 cm; erh. B 8,5 cm; Hasten B 2,1 cm; Dicke $0,2 \mathrm{~cm}$; Öse Dm $0,7 \mathrm{~cm}$

Erh.: Fragment

Beschreibung: Zwei rechteckige, dünne und unverzierte Bleche sind übereinander gelegt und in der Mitte durchbohrt. Darin steckt ein Splint, der beide Teile zusammenhält, wobei die Bleche beweglich bleiben.

MF 15 Kettenglieder

Taf. 370

Kupferlegierung

AO: EM; Ki 09/5

FO/FJ: ETH-Ost; S1/2009; SE 20; 2009

Maße: erh. L 9,1 cm; Öse Dicke 0,2 cm

Erh.: Fragment, 5 Kettenglieder erh.

Beschreibung: Jedes der fünf Kettenglieder besteht aus einer tropfenförmig gebogenen Öse mit rechteckigem Querschnitt, deren Enden zu je einer weiteren Öse geformt sind, die gerade darauf stehen und in welchen das nächste Kettenglied verhakt ist.

MF 16 Griff (?)

Taf. 371

Kupferlegierung

AO: EM; Ki 09/10

FO/FJ: ETH-Ost; S1/2009; 2009

Maße: H 3,7 cm; B 6,1 cm; Dicke 2,9 cm

Erh.: vollständig (?)

Beschreibung: Das T-förmige Objekt ist an der geraden Oberkante zu den Enden hin zunächst leicht eingezogen, darauf folgt ein langgezogener Wulst und endet in einem leicht kugelförmigen Abschluss. Der breitere und dicke Unterteil ist wulstförmig gestaltet und zeigt auf einer Seite einen applizierten Ring mit Strahlendekoration, von dessen Zentrum nach oben ein dreieckiges Element wegführt. Darunter befindet sich ein lanzettförmiges, nach unten gerichtetes Ornament.

MF 17 Lasche (?)

Taf. 371

Kupferlegierung

AO: GHD; Ki 09/36

FO/FJ: ETH-Ost; S1/2009; SE 20; 2009

Maße: L 14,3 cm; B max. 4,5 cm; Dicke 0,1 cm

Erh.: vollständig, das Blech ist schlampig geschnitten

Beschreibung: Es handelt sich um ein großes, laschenartiges

Blech, das sich auf einer Seite leicht verbreitert und einen gerundeten Abschluss besitzt, und auf der anderen Seite umgebogen ist. Das Blech ist unverziert und grob geschnitten.
MF 18 Glocke

Taf. 371

Kupferlegierung

AO: GHD

FO/FJ: ETH; Nord-Analemma; Reinigung; 1996

Maße: H 3,2 cm; Dm 3 cm

Erh.: fast vollständig, Blech an der Schulter zum Teil ausgerissen, Klöppel fehlt

Beschreibung: Das konisch geformte Blech ist mit feinen horizontalen Rillen verziert. In dem Loch im Scheitel sitzt eine große Öse, die zur Befestigung gedient hat.

MF 19 Glocke

Taf. 371

Kupferlegierung

AO: GHD; KF 08/109

FOFJ: ETH; SE 142; S3/C1-C2; 2008

Maße: H 2,2 cm; Dm 2,6 cm; Dicke 0,1 cm

Erh.: Fragment (?), Blech auf einer Seite eingerissen

Beschreibung: Das aus Blech gefertigte konische Objekt besitzt am Scheitel eine kleine Durchlochung. Die Verzierung, die das gesamte Blech dekoriert, besteht aus je einem umlaufenden Fischgrätmuster im Schulterbereich und im unteren Abschnitt des Blechs alternierend mit mehrfacher horizontaler Linienverzierung. In der Mittelzone findet sich ein Band aus griechischen Buchstaben (...E T Y X...)

MF 20 Glocke

Taf. 371

Kupferlegierung

AO: GHD; Ki 05/36

FO/FJ: ETH; Skene; Kammer E8; S3/2005; SE B49; 2005

Maße: erh. Dm 1,9 cm; erh. H 1 cm

Erh.: Fragment; stark korrodiert

Beschreibung: Es handelt sich um eine aus Blech gefertigte kleine Glocke. In der Mitte sitzt eine kleine Durchlochung für den Klöppel.

MF 21 Gefäß (?)

Taf. 371

Kupferlegierung

AO: GHD; Ki 04/100

FO/FJ: ETH; Skene, Kammer D8; Reinigung; 2004

Maße: größtes Fragment: erh. H 13,6 cm; erh. B 9,5 cm; Dicke $0,1 \mathrm{~cm}$

Erh.: 8 Fragmente

Beschreibung: Es handelt sich um acht Fragmente aus dünnem, unverziertem Blech, die vielleicht Teile eines Gefäßes waren.

MF 22 Gefäß

Taf. 371

Kupferlegierung

AO: GHD; KF 09/11

FO/FJ: ETH-Ost; S1/2009; SE 23; 2009

Maße: erh. Dm 15,7 cm; B 2 cm; Dicke 0,2 cm

Erh.: Fragment

Beschreibung: Es handelt sich um ein leicht gewelltes Randfragment eines Gefäßes mit großem Durchmesser.

MF 23 Gefäß (?)

Taf. 371

Kupferlegierung

AO: GHD; Ki 02/17

FO/FJ: ETH; Logeion; S1/2001; SE 11; 2002

Maße: erh. B 5,9 cm; erh. H 3,1 cm; Dicke 0,5-0,8 cm

Erh.: Fragment

Beschreibung: Das Blechfragment stammt vielleicht von einem Gefäß mit einer Auslassung. 
MF 24 Henkel

Taf. 372

Kupferlegierung

AO: GHD; Ki 07/145

FO/FJ: ETH; Süd-Analemma; KS2; SE 28b; 2007

Maße: B 5,2 cm; H 4,6 cm

Erh.: fast vollständig, ein Ende verbrochen

Beschreibung: Der Henkel besteht aus einem U-förmig gebogenen, dicken Stab mit quadratischem Querschnitt, dessen Enden nach außen gebogen sind.

\section{MF 25 Gefäßfüßchen}

Taf. 372

Kupferlegierung

AO: GHD; Ki 97/F

FO/FJ: ETH; Nord-Analemma; KN1; 1997

Maße: B 3,8 cm; H 1,7 cm

Erh.: vollständig

Dat.: 1.-2. Jh. n. Chr.

Beschreibung: Es handelt sich um ein unverziertes, peltaförmiges Gefäßfüßchen.

\section{MF 26 Beschlag}

Taf. 372

Kupferlegierung

AO: EM; Inv. 99/12/93

FO/FJ: ETH; Süd-Analemma; Substruktionsgewölbe; 1993

Maße: 2,6 × 2,6 cm; B 1,25 cm

Dat.: kaiserzeitlich

Erh.: vollständig

Beschreibung: Der swastika-förmig geschnittene Beschlag aus Bronzeblech zeigt auf der Rückseite zwei zu Haken gebogene Blechstege.

\section{MF 27 Beschlag}

Taf. 372

Kupferlegierung

AO: EM; Inv. 98/12/93

FO/FJ: ETH; Südseite; Theateraußenmauer; 1993

Maße: H 5 cm; B 4,7 cm

Dat.: kaiserzeitlich

Erh.: vollständig

Beschreibung: Das Blech ist halbrund geschnitten. Die gerade Kante weist einen gezahnten Dekor auf. Die Peltenverzierung ist durchbrochen gearbeitet. Drei große und runde Durchlochungen befinden sich einmal in der Mitte des halbrunden Blechabschlusses und je einmal in den Ecken vor der geraden Kante. In allen stecken noch Nägel. Vermutlich handelt es sich um einen Zaumzeugbeschlag.

\section{MF 28 Türschloss-Beschlag}

Taf. 372

Kupferlegierung

AO: GHD; Ki 04/100

FO/FJ: ETH; Skene, Kammer D8; Reinigung; 2004

Maße: erh. L 7,8 cm; erh. B 5,4 cm; Dicke 0,4 cm

Erh.: Fragment

Beschreibung: Das dicke, massive Blech ist L-förmig geschnitten, beide Arme sind verbrochen. An der Innenkante ist ein dünner Blechrest erhalten. An der Außenkante entlang ist der Buchstabe »L« eingeritzt. Vermutlich handelt es sich um einen Türschloss-Beschlag.

MF 29 Türschloss-Beschlag (?)

Taf. 372

Kupferlegierung

AO: GHD; Ki 04/80
FO/FJ: ETH; Skene, Kammer E1, S 2/2004; SE B28; 2004

Maße: erh. L 2,2 cm; erh. B $3 \mathrm{~cm}$; Dicke 0,2 cm

Erh.: Fragment

Beschreibung: Das massive, leicht halbkreisförmige Blech besitzt einen quadratischen Querschnitt und wirkt auf der geraden Kante wie abgeschnitten. Im Blech befindet sich mittig eine große, nierenförmige Auslassung, die vielleicht als Schlüsselloch interpretiert werden kann.

MF 30 Beschlag

Taf. 372

Kupferlegierung

AO: GHD; Ki 08/53

FO/FJ: ETH; Süd-Analemma; KS1; SE 62; 2008

Maße: erh. L 2,2 cm; erh. B 1,3 cm; Dicke 0,1 cm; Durchlochung Dm $0,2 \mathrm{~cm}$

Erh.: Fragment, Blech an zwei Seiten ausgerissen

Beschreibung: Das rechteckig erhaltene Blech zeigt in einer abgerundeten Ecke eine große, sorgfältig ausgeführte, runde Durchlochung. An der gegenüberliegenden Blechseite befindet sich eine runde Einlassung im Blech (?). Die verbrochene Breitseite zeigt möglicherweise eine rechteckige Auslassung.

MF 31 Beschläge

Taf. 372. 373

Kupferlegierung

AO: GHD; Ki 04/80

FO/FJ: ETH; Skene, Kammer E1, S 2/2004; SE B28; 2004

Erh.: 9 Fragmente von unterschiedlichen Beschlägen

1. Maße: erh. L 12,4 cm; erh. H 8,5 cm; Dicke $0,1 \mathrm{~cm}$ Beschreibung: Das große, dünne Blechfragment ist an drei Seiten ausgerissen. Erhalten ist die gerade geschnittene Unterkante, unter der sich mittig eine große runde Durchlochung in einem breiten und unverzierten Bildrahmen befindet. Weitere kleine Ausrisse im Blech könnten mögliche andere Durchlochungen darstellen. Die erhaltene Verzierung zeigt ein geprägtes Motiv in Form einer Rosette, bestehend aus einem großen Buckel im Zentrum umschlossen von einer Perlreihe und einem Ring aus freistehenden kleinen Buckeln. Ober- und unterhalb finden sich je drei lanzettartige Blätter. Die Rosette wird von einer Leiste gerahmt. Die jeweils mittleren Blätter zeigen ein männliches Gesicht im Inneren, das sich der Blattform anpasst. Deutlich zu erkennen sind die Punktaugen, eine wulstige Nase, runde Wangen sowie ein Vollbart, der die untere Gesichtshälfte verdeckt und das spitze Blatt zur Gänze ausfüllt. Die seitlichen Rosettenblätter werden durch je zwei sich zugewandte fischähnliche Motive ersetzt. Links und rechts der Rosette steht je eine nackte menschliche Figur.

2. Maße: erh. L 4,1 cm; erh. H 5,6 cm; Dicke $0,1 \mathrm{~cm}$ Beschreibung: Das an allen Seiten ausgerissene, dünne Blech zeigt an einem Rand eine quadratische Durchlochung. Reste eines Rosettenmotivs sowie einer männlichen Figur (?) sind erhalten. Vermutlich gehören die Fragmente 1 und 2 zusammen.

3. Maße: erh. L 6,2 cm; B 5,6 cm; Dicke $0,1 \mathrm{~cm}$ Beschreibung: Der vermutlich ursprünglich quadratisch geschnittene Blechbeschlag ist an zwei Seitenrändern ausgerissen. An den erhaltenen Kanten ist der Blechrand nach innen gebogen. An einer Kante befinden sich in regelmäßigen Abschnitten drei unterschiedlich große Durchlochungen. An der gegenüberliegenden Seite ist eine weitere Durchlochung am Rand erhalten. In der Blechmitte ist eine 
große, quadratische Auslassung zu erkennen. Vermutlich handelt es sich um einen Türschloss-Beschlag.

4. Maße: L 8,3 cm; H $4 \mathrm{~cm}$; Dicke $0,1 \mathrm{~cm}$

Beschreibung: Das rechteckig erhaltene Blech ist an den Rändern zum Teil ausgerissen. Es ist unverziert und zeigt mehrere Löcher im Blech.

5. Maße: L 6,5 cm; H 3,7 cm; Dicke $0,1 \mathrm{~cm}$

Beschreibung: Das unverzierte, vielleicht rechteckige Blech ist an den Rändern ausgerissen. In einer Ecke findet sich eine Durchlochung.

6. Maße: erh. L 7,3 cm; erh. H 4,9 cm; Dicke $0,1 \mathrm{~cm}$ Beschreibung: Es handelt sich vermutlich um den Rest eines Gitterblechs. Das dreieckig geschnittene Fragment ist durchbrochen gearbeitet, mit tropfenförmigen und halbrunden Durchbrüchen.

7. Maße: erh. L 5,1 cm; erh. H 2,8 cm; Dicke $0,1 \mathrm{~cm}$; Öse Dm $0,5 \mathrm{~cm}$

Beschreibung: Das rechteckige und unverzierte Blech zeigt in der Mitte eine Durchlochung, in welcher eine Öse verhakt ist. Die Blechränder sind zum Teil ausgerissen.

8. Maße: erh. L $4 \mathrm{~cm} ; \mathrm{H} \mathrm{2,4} \mathrm{cm}$; Dicke $0,1 \mathrm{~cm}$ Beschreibung: Das vermutlich rechteckige Blech ist an den Seitenrändern verbrochen. Es ist unverziert und ohne Durchlochungen.

\section{MF 32 Beschlag}

Taf. 37

Kupferlegierung

AO: GHD; Ki 93/37

FO/FJ: ETH; vomitorium ES2; Südausgang; 1993

Maße: Dm 2,7 cm; Dicke 0,1 cm

Erh.: Fragment, ca. zwei Drittel erh.

Beschreibung: Der kreisförmige Beschlag besteht aus einem großen, unverzierten Buckel, dessen Zentrum leicht nach innen eingezogen ist. Der Rand ist wulstartig verdickt.

\section{MF 33 Blech}

Taf. 373

Kupferlegierung

AO: GHD; Ki 08/116

FO/FJ: ETH; Stiegengasse-Süd; C2; SE 136; 2008

Maße: erh. L 4,6 cm; B 2,3 cm; Dicke 0,2 cm

Erh.: Fragment

Beschreibung: Nach drei Seiten verbrochenes, dünnes und unverziertes Blech mit einer geraden Kante, die sich nach innen wölbt.

\section{MF 34 Blech}

Taf. 373

Kupferlegierung

AO: GHD; Ki 04/100

FO/FJ: ETH; Skene, Kammer D8; Reinigung; 2004

Maße: erh. L 13,3 cm; erh. H 3,9 cm; Dicke 0,3 cm

Erh.: Fragment, an drei Seiten ausgerissen

Beschreibung: Das rechteckige Blech besitzt eine gerade abgeschnittene Breitseite mit einem breiten, unverzierten Rand. Darauf folgt ein Dekorband in Form eines lesbischen Kymations, von dem ca. die Hälfte erhalten ist.

\section{MF 35 Blech}

Taf. 373

Kupferlegierung

AO: GHD; Ki 09/47

FO/FJ: ETH; Stiegengasse-Süd; G2; SE 192; 2009

Maße: erh. L 4,6 cm; erh. B 3,4 cm; Dicke 0,2 cm; Durchlochung $0,4 \times 0,5 \mathrm{~cm}$
Erh.: Fragment

Beschreibung: Der unverzierte Blechbeschlag besitzt eine rechteckige Form und in einer Ecke eine große quadratische Durchlochung.

MF 36 Blech

Taf. 373

Kupferlegierung

AO: GHD; Ki 07/145

FO/FJ: ETH; Süd-Analemma; KS2; SE 28b; 2007

Maße: erh. L 9,8 cm; erh. B 7,8 cm; Dicke 0,3 cm

Erh.: Fragment

Beschreibung: Das flache Blech ist an allen Rändern ausgerissen und unverziert.

MF 37 Blech

Taf. 373

Kupferlegierung

AO: GHD; Ki 04/100

FO/FJ: ETH; Skene, Kammer D8; Reinigung; 2004

Maße: erh. L 6,3 cm; B 1,3 cm; Dicke 0,6 cm

Erh.: Fragment, an einer Seite verbrochen

Beschreibung: Es handelt sich um ein rechteckig geschnittenes, unverziertes, dickes Blech.

MF 38 Nagel

Kupferlegierung

Taf. 374

AO: GHD; Ki 05/35

FO/FJ: ETH; Skene; Kammer E8; S3/2005; SE B49; 2005

Maße: H 7,6 cm; Nagelkopf Dm 1,6 cm; Schaft 0,7-0,5 cm

Erh.: fast vollständig, Spitze verbrochen

Beschreibung: Der Schaft weist einen quadratischen Querschnitt auf und ist im unteren Drittel umgebogen. Der Nagelkopf ist scheibenförmig und unverziert.

MF 39 Spule (?)

Taf. 374

Kupferlegierung

AO: GHD; Ki 02/24a

FO/FJ: ETH; Skene; Kammer D3; S 2/2002; SE B4; 2002

Maße: H 7,1 cm; Schaft Dicke 0,6 cm; Kopf Dm 1,7 cm; 1,6 $\times 1,8 \mathrm{~cm}$

Erh.: vollständig

Beschreibung: Der Schaft weist einen quadratischen Querschnitt auf. An beiden Enden befindet sich je eine unverzierte Scheibe.

MF 40 Nagel

Taf. 374

Kupferlegierung

AO: GHD; Ki 08/33

FO/FJ: ETH; SE 31; C1; 2008

Maße: H $1 \mathrm{~cm}$; Kopf Dm 1,5 cm

Erh.: fast vollständig, Schaft verbrochen (?)

Beschreibung: Kurzer, gebogener Schaft (oder verbrochen?) mit einem scheibenförmigen, unverzierten Nagelkopf.

MF 41 Nagel

Taf. 374

Kupferlegierung

AO: GHD; Ki 09/57

FO/FJ: ETH; Stiegengasse-Süd; G2; SE 211; 2009

Maße: H 4,1 cm; Dicke 0,3 cm

Erh.: fast vollständig, Spitze und Kopf fehlen

Beschreibung: Der Schaft hat einen leicht ovalen Querschnitt und verjüngt sich zur Spitze hin. 
MF 42 Stift/Nagel

Taf. 374

Kupferlegierung

AO: GHD; Ki 07/145

FO/FJ: ETH; Süd-Analemma; KS2; SE 28b; 2007

Maße: erh. H 10,7 cm; max. Dicke 0,8 cm; min. Dicke 0,4 cm Erh.: vollständig (?)

Beschreibung: Der unverzierte Schaft besitzt einen quadratischen Querschnitt, der sich zur Spitze hin stark verjüngt, und am breiten Ende gerade abgeschnitten ist.

\section{MF 43 Öse}

Taf. 374

Kupferlegierung

AO: GHD; Ki 09/97

FO/FJ: ETH; SE 236; 2009

Maße: L 3,5 cm; B 2,1 cm; Dicke 0,5 cm

Erh.: Fragment

Beschreibung: Die Öse ist S-förmig gebogen und weist einen rechteckigen Querschnitt auf.

\section{MF 44 Reißnagel}

Taf. 374

Kupferlegierung

AO: GHD; KF 09/1; Ki 09/70

FO/FJ: ETH; Stiegengasse-Süd; H2; SE 222; 2009

Maße: Dm 2,8 cm; H 0,9 cm; Einbohrung 0,6 cm

Erh.: fast vollständig

Beschreibung: Der Kopf aus Blech ist kreisförmig konvex und unverziert. Die Rückseite besitzt im Zentrum eine Einbohrung, in der noch der Rest eines Nagels steckt.

\section{MF 45 Reißnagel}

Taf. 374

Kupferlegierung

AO: GHD; Ki 09/91

FO/FJ: ETH; Stiegengasse-Süd; F2-S (Insula); SE 232; 2009

Maße: Dm 2,8 cm; Dicke 0,2 cm; Einbohrung 1,3 cm

Erh.: fast vollständig erhalten

Beschreibung: s. MF 44.

MF 46 Haken

Kupferlegierung

AO: GHD; Ki 07/37

FO/FJ: ETH; Stiegengasse-Süd; B2; SE 14; 2007

Maße: L $8,5 \mathrm{~cm}$; Dicke $1,1 \times 0,6 \mathrm{~cm}$

Erh.: Fragment, beide Enden verbrochen

Taf. 374
MF 48 Blech

Kupferlegierung

AO: GHD; Ki 04/100

Nadel/Griff

Kupferlegierung; Silber (?)

AO: GHD; Ki 07/140

FO/FJ: ETH; Stiegengasse-Süd; C1; SE 14; 2007

Maße: erh. H 6,1 cm; Dicke 0,5 cm

Erh.: fast vollständig, Spitze und Kopfbereich verbrochen

Beschreibung: Es handelt sich um einen langen Stab mit rundem Querschnitt, der sich zur Spitze hin verjüngt und in regelmäßigen Abständen mit horizontalen Profilierungen verziert ist. Vom Kopf/Griff ist nur mehr ein unregelmäßiges Konglomerat erhalten.

FT: ETH; Skene, Kammer D8; Reinigung; 2004

Maße: erh. L 8,9 cm; B 1,5 cm; Dicke 0,3 cm

Erh.: Fragment

Beschreibung: Das langrechteckige Blech ist unverziert, es verbreitert sich zu beiden Seiten hin und ist dann verbrochen.

MF 49 Unterlegscheibe (?)

Taf. 374

Kupferlegierung

AO: GHD; Ki 09/62

FO/FJ: ETH; Stiegengasse-Süd; H2; SE 186; 2009

Maße: Dm 1,9 cm; Dicke 0,1 cm; Durchlochung 0,4 ×0,4 cm Erh.: fast vollständig

Beschreibung: Das scheibenartig geschnittene, unverzierte Blech zeigt im Zentrum eine quadratische Durchlochung.

MF 502 Objekte

Taf. 374

Kupferlegierung

AO: EM; Ki 09/40

FO/FJ: ETH-Ost; S1/2009; SE 20; 2009

Maße: 1. Blech: erh. L 15,6 cm; B 1,1-0,6 cm; Dicke 0,2 cm 2. Zylinder: Dm 2,8 cm; Dicke $0,1 \mathrm{~cm}$

Erh.: vollständig (?)

Beschreibung: 1. Das unverzierte Blech ist langrechteckig und verjüngt sich nach einer Seite hin.

2. Das unverzierte Blech ist in eine zylindrische Form gebogen, es ist oben und unten offen.

\section{Eisen}

\section{MF 51 Kreuz}

Eisen

AO: GHD; Ki 04/100

FO/FJ: ETH; Skene, Kammer D8; Reinigung; 2004

Maße: erh. L 8,5 cm; B 1,7-2,2 cm; Dicke 0,3 cm

Erh.: Fragment, eine Haste erh.

Dat.: vermutlich byzantinisch

Beschreibung: Die erhaltene Haste ist unverziert und besteht aus einem schmalen Blech, das sich an dem Hastenende trapezförmig verbreitert und einen geraden Abschluss besitzt. Der Rest einer Querhaste ist umgebogen.

Taf. 374
MF 52 Messer

Taf. 375

Eisen

AO: GHD; KF 09/15

FO/FJ: ETH-Ost; S1/2009; SE 27; 2009

Maße: Messer: L 6,9 cm; B 2,1 cm; Dicke 0,6 cm

Schaft: L $8,3 \mathrm{~cm}$; B 2,3 cm; Dicke $0,7 \mathrm{~cm}$

Erh.: 2 Fragmente, stark korrodiert, daher nicht anpassend Beschreibung: Ein Fragment ist eine spitze Messerklinge, das zweite Fragment ist der Rest der Klinge mit einem schmalen Heft. 
MF 53 Messer

Taf. 375

Eisen

AO: GHD; Ki 09/39

FO/FJ: ETH; Stiegengasse-Süd; G1; SE 193; 2009

Maße: erh. L 7,8 cm; B 1,1 cm; 0,5 cm

Erh.: Fragment, stark korrodiert

Beschreibung: Das langrechteckige Messer verjüngt sich zu beiden Enden hin.

\section{MF 54 Speer/Lanzenspitze}

Taf. 375

Eisen

AO: GHD; Ki 04/77

FO/FJ: ETH; Skene; Kammer E7; SE 37; 2004

Maße: erh. L 14,1 cm; max. B 2,4 cm; Dicke 0,2 cm

Erh.: fast vollständig, Spitze verbrochen

Beschreibung: Das lange, lanzettförmig geschnittene Blatt besitzt in der Mitte eine vertikale Kehlung. Am unteren Ende ist noch der Rest einer Durchlochung erhalten.

\section{MF 55 Schlüsselring}

Taf. 375

Eisen

AO: GHD; Ki 93/45

FO/FJ: ETH; 1993

Erh.: vollständig, stark korrodiert

Beschreibung: Es handelt sich um einen stark korrodierten Schlüsselring.

\section{MF 56 Fenster}

Eisen

AO: GHD; Ki 08/151

FO/FJ: ETH; Stiegengasse-Süd; C2; auf SE 157 liegend; 2008 Maße: L $86 \mathrm{~cm}$; B $43 \mathrm{~cm}$; horizontale Gitterstäbe D $5 \mathrm{~cm}$; vertikale Gitterstäbe D $2 \mathrm{~cm}$

Erh.: mehrere Fragmente, stark korrodiert

Beschreibung: Von dem Gitter/Fenster haben sich zwei Reihen vertikale und drei Reihen, in mehrere Teile gebrochene, horizontale Gitterstäbe erhalten. Die Öffnungen sind mit $10 \mathrm{~cm}, 15$ $\mathrm{cm}$ und $19 \mathrm{~cm}$ unterschiedlich groß.

\section{MF 57 Blechbeschlag}

Taf. 375

Eisen

AO: GHD; Ki 09/14

FO/FJ: ETH-Ost; S1/2009; SE 27; 2009

Maße: L 7,3 cm; B 8,5 cm; Dicke 0,3 cm

Große Durchlochung 0,5 cm; kleine Durchlochung 0,2 cm

Erh.: fast vollständig, der Rand fehlt zum Teil

Beschreibung: Das rechteckige, unverzierte Blech weist umgebogene Ränder auf. Am Rand sind mehrere unterschiedlich große Durchlochungen erhalten.

\section{MF 58.1 u. 58.2 Blech}

Taf. 375

Eisen

AO: GHD; Ki 04/77

FO/FJ: ETH; Skene; Kammer E7; SE 37; 2004

Maße: größtes Fragment: erh. L 6,5 cm; erh. B 5,5 cm; Dicke $0,1 \mathrm{~cm}(\mathrm{MF} 58.1)$

Erh.: 22 Fragmente

Beschreibung: Es handelt sich um 22 nicht anpassende, unverzierte Blechfragmente (MF 58.2: Gesamtaufnahme).
MF 59 Haken

Taf. 376

Eisen

AO: GHD

FO/FJ: ETH; Portikus-Rückwand; Streufund; 2009

Maße: L 12,2 cm; B 8,9 cm; runder Teil Dm 2,4 cm; Nagel L $2,1 \mathrm{~cm}$; Dicke $0,5 \mathrm{~cm}$

Erh.: vollständig

Beschreibung: Der L-förmige Haken aus Blech besitzt oben einen kreisförmigen Abschluss mit einer Durchlochung, in der noch ein Nagelrest steckt.

MF 60 Klammer/Zange

Taf. 376

Eisen

AO: GHD; Ki 09/13

FO/FJ: ETH-Ost; S1/2009; SE 26; 2009

Maße: erh. L 6,3 cm; B 2,2 cm; Dicke 0,6 cm

Erh.: Fragment, stark korrodiert

Beschreibung: Das stark korrodierte Objekt ist auf einer Seite zu einer Öse gebogen und am Ende vernietet. Die nach unten $\mathrm{zu}$ fortlaufenden Zangen sind unterschiedlich hoch verbrochen.

MF 61 Verankerung

Taf. 376

Eisen

AO: GHD; Ki 04/80

FO/FJ: ETH; Skene; Kammer E1, S 2/2004; SE B28; 2004

Maße: erh. L 2,8 cm; B 4,1 cm; Dicke 0,4 cm

Erh.: Fragment, stark korrodiert

Beschreibung: Es handelt sich um drei dicke Eisenstäbe mit höchstwahrscheinlich quadratischem Querschnitt (?), die in einer Öse ineinander geschlungen sind.

MF 62 Nagel (?)

Taf. 376

Eisen

AO: GHD; Ki 04/77

FO/FJ: ETH; Skene; Kammer E7; SE 37; 2004

Maße: erh. H 4,3 cm; Dm oben 0,8 cm; Schaft Dicke 0,6 cm Erh.: fast vollständig

Beschreibung: Der Schaft verjüngt sich nach unten, der Nagelkopf fehlt.

MF 63 Nagel

Taf. 376

Eisen

AO: GHD; Ki 09/39

FO/FJ: ETH; Stiegengasse-Süd; G1; SE 193; 2009

Maße: erh. H 4,1 cm; Kopf Dm 2 cm; Schaft Dicke 0,9 cm

Erh.: vollständig (?), stark korrodiert

Beschreibung: Auf dem quadratischen Schaft sitzt eine flache Scheibe als Nagelkopf.

MF 64 Nagel

Taf. 376

Eisen

AO: GHD; Ki 09/86

FO/FJ: ETH; Stiegengasse-Süd; J1; SE 122; 2009

Maße: H 7,5 cm; Kopf Dm 2,2 cm; Schaft Dicke 0,8 cm

Erh.: vollständig

Beschreibung: Der Schaft mit rechteckigem Querschnitt verjüngt sich stark zur Spitze hin. Den Nagelkopf bildet eine leicht konvexe Scheibe. 
MF 65 Nagel

Taf. 376

Eisen

AO: GHD; Ki 09/70

FO/FJ: ETH; Stiegengasse-Süd; H2; SE 222; 2009

Maße: erh. H 4,6 cm; Dicke 1,1 cm (oberer Bereich) - 0,3 cm (unterer Bereich)

Erh.: Fragment

Beschreibung: Der S-förmig verformte Schaft hat einen quadratischen Querschnitt. Spitze und Kopf sind verbrochen.

\section{MF 66 Verbindungsglied}

Taf. 376

Eisen und Blei

AO: GHD; Ki 09/70

FO/FJ: ETH; Stiegengasse-Süd; H2; SE 222; 2009

Maße: L 14,6 cm; B 3,8 cm (dicke Spitze) - 3,1 cm (dünne

Spitze); Eisen B 1,3 cm; Eisen Dicke 0,6 cm; Kopfteile mit Eisen und Blei B 2,5 cm;

\section{Blei}

MF 68 Tiegel

Taf. 377

Blei

AO: GHD; Ki 08/134

FO/FJ: ETH; Stiegengasse-Süd; B2/C2; SE 136; 2008

Maße: H 4,1 cm; B 8,3 cm; Dicke 0,1 cm

Erh.: vollständig, aber gequetscht

Beschreibung: Es handelt sich um einen kleinen Tiegel mit kreisförmiger Grundfläche und unverzierten Wänden.

\section{MF 69 Blech}

Blei

Taf. 377

AO: GHD; Ki 04/100

FO/FJ: ETH; Skene, Kammer D8; Reinigung; 2004

Maße: erh. L 7,1 cm; erh. B 4,3 cm; Dicke 0,2 cm

Erh.: Fragment

Beschreibung: Das rechteckig geformte, dicke Blech ist unverziert. Die Ränder sind zum Teil ausgerissen und nach innen gebogen.

\section{MF 70 Blech}

Blei

Taf. 377

AO: GHD; Ki 04/100

FO/FJ: ETH; Skene, Kammer D8; Reinigung; 2004

Maße: erh. L 5,7 cm; erh. B 2,2 cm; Dicke 0,3 cm

Erh.: Fragment

Beschreibung: Das rechteckige Blech ist an allen Seiten ausgerissen.
Einbohrung 0,6 × 0,6 cm; Durchlochung Dm 0,4 cm

Erh.: vollständig

Beschreibung: Es handelt sich um ein langrechteckiges Eisenstück mit quadratischem Querschnitt, das an seinen Enden in Bleifassungen eingebettet ist. Eine der Bleibettungen besitzt zwei quadratische Einbohrungen, die zweite weist eine quadratische Einbohrung sowie eine Durchlochung auf.

MF 67 Oinochoe, Ausguss (?)

Taf. 376 Eisen (?) AO: GHD; Ki 93/92

FO/FJ: ETH; Stiegengasse-Süd; über der östlichen Treppe im späteren Bereich D1/D2; 1993

Maße: erh. H 4,3 cm; B 5,8 cm; Dicke 0,5 cm

Erh.: Fragment

Beschreibung: Es handelt sich um den kleeblattförmigen Ausguss einer Oinochoe.
MF 71 Blech

Blei

AO: GHD; Ki 07/168

FO/FJ: ETH; Stiegengasse-Süd; B1; SE 39; 2007

Maße: L 10,1 cm; B 9,6 cm; Dicke 0,3 cm

Erh.: Fragment (?)

Beschreibung: Unregelmäßig rund geformtes Blech.

MF 72 Henkel (?)

Blei

AO: GHD; Ki 09/49

FO/FJ: ETH; Stiegengasse-Süd; K2; SE 125; 2009

Maße: L 3,1 cm; B 2,3 cm; Dicke 0,4 cm

Erh.: Fragment (?)

Beschreibung: Der massive Stab mit rundem Querschnitt ist gebogen wie die Zahl 3.

MF 73 Gewicht

Taf. 377

Blei

AO: GHD

FO/FJ: ETH; vomitorium EN2; S 4/1998; SE N35; 1998

Maße: $\mathrm{H} 4 \mathrm{~cm}$; B unten 0,4; B oben 1,4 cm

Erh.: vollständig

Dat.: frühe Kaiserzeit

Beschreibung: Es handelt sich um ein pyramidales, unverziertes Gewicht auf quadratischem Grundriss mit einfacher Bohrung ${ }^{68}$.

D. AKAR-TANRIVER

A. M. PÜLZ

\footnotetext{
${ }^{68}$ Laut Fundkontext Datierung in das 6. Jh. n. Chr. s. Kap.
} 3.5.2.1.1. 


\subsubsection{Bein}

Die Mehrzahl der im Theater gefundenen Beinobjekte sind unverzierte Nadeln (B 1-45 Taf. 378. 379). Die Nadeln ${ }^{69}$, die hauptsächlich zum Feststecken der weiblichen Frisuren gedient haben, besitzen einen Schaft, der sich zur Spitze hin verjüngt, und meist kugelförmige, ovale bzw. eiförmige oder konische Nadelköpfe. Jedoch sind auch andere Funktionen, wie beispielsweise für medizinische oder kosmetische Zwecke vorstellbar. Durch ihr zahlreiches Vorkommen, nicht nur im Theater, sondern auch an anderen Fundstellen in ganz Ephesos $^{70}$, sowie das zur Genüge vorhandene Material und die einfache und billige Herstellung kann von einer Massenproduktion ausgegangen werden. Eine zeitliche Einordnung aufgrund der Formen ist wegen der einfachen Gestaltung nicht möglich ${ }^{71}$.

B 43 und B 44 (Taf. 379) gehören zu den pfriemenförmigen Nadeln. Während B 43 einen konisch zugespitzten Abschluss aufweist, ist der Kopf von B 44 flach abgerundet. Eine vergleichbare Nadel mit konisch angespitztem Kopf aus Korinth stammt aus einem Kontext des 1. oder frühen 2. Jhs. n. Chr., eine weitere Nadel dieses Typus jedoch aus einem spätrömisch-byzantinischen Kontext ${ }^{72}$. Auf zahlreiche pfriemenförmige Nadeln trifft man auch in Augst; diese können nur grob zwischen dem 1. und 4. Jh. $n$. Chr. eingeordnet werden $^{73}$. Der Typus mit flach abgerundetem Kopf wurde auch in Korinth gefunden, wo er in das 1. oder 2. Jh. n. Chr. datiert wird ${ }^{74}$. Die Haarnadel B 45 gehört zum Typus der Nadeln mit zwiebelkopfförmigem Abschluss und kommt vom 3. Jh. n. Chr. bis zum Ende der römischen Periode vor (Taf. 379) ${ }^{75}$.

Bei den Objekten B 52-56 (Taf. 379) handelt es sich um Spielgeräte. Hohe, halbkugelförmige, zweiteilige Spielsteine, die mit schrägen Rillen verziert sind, wie B 52, treten erst ab der spätrömischen Zeit und hier vor allem in den östlichen Provinzen auf $^{76}$. Ein sehr ähnlicher Spielstein, ebenfalls mit schrägen Kanneluren verziert, jedoch mit einem kleinen Knopf an der Spitze, stammt aus dem Hanghaus 1 in Ephesos ${ }^{77}$.

Flache, scheibenförmige Tesserae, deren Vorderseiten mit konzentrischen Rillen verziert sind, wie B 54, hingegen finden sich in der gesamten römischen Kaiserzeit, wobei ihre Funktion als Spielsteine nicht hundertprozentig gesichert ist; sie könnten auch als Pyxidendeckel, Spinnwirtel oder Möbelbeschläge gedient haben $^{78}$. Ein vergleichbarer Spielstein, der aufgrund seines Fundkontexts in das 3. Viertel des 3. Jhs. n. Chr. datiert wird, stammt aus dem Hanghaus 2, WE $2^{79}$. Zahlreiche Spielsteine aus Bein, die in das 1. oder 2. Jh. n. Chr. gehören, wurden in Korinth gefunden ${ }^{80}$. Auch aus Augst stammen Tesserae mit zentralem Loch $^{81}$.

Vergleichbare Würfel aus Bein, wie B 55, ohne genauere Datierungsangaben, wurden beispielsweise in Augst $^{82}$ oder, auch aus dem 1. und 2. Jh. n. Chr. stammend, in Korinth ${ }^{83}$ gefunden.

Dem Astragal B 56 sehr ähnlich sind Fischwirbel aus Korinth, die vielleicht ebenfalls als Spielsteine Verwendung fanden ${ }^{84}$. Vergleichbar ist auch ein Knöchelchen aus dem sog. Byzantinischen Palast in Ephesos, das aufgrund des Fundkontexts in das 7. Jh. n. Chr. datiert werden kann ${ }^{85}$.

\footnotetext{
${ }^{69}$ s. auch RiHA 1990, 95-98; DeSCHLER-ERB 1998, 159-166.

${ }^{70}$ z. B. WE 4, HH 2: JileK 2005, Kat. B 8. B 9. B 16-18. B 26-29. B 48. B 79 Taf. 236. 237. 239. - WE 2, HH 2: RathmaYr 2010, Kat. B-B 3. B-B 26-28. B-B 41. B-B 128. B-B 145. B-B 146. B-B 206-213 Taf. 261. 262. 267. 269. 270. - WE 1, HH 2: RAтHMAYr 2010, A-B 1-4. A-B 9. A-B 10. A-B 12-20. A-B 26 Taf. 145.

${ }^{71}$ JILEK 2005, 391. Vgl. auch das teilweise sehr ähnliche Material aus Korinth, das in die gesamte römische Periode datiert werden kann: DAVIDSON 1952, Kat. 2300-2336 Taf. 118. 119.

${ }^{72}$ Davidson 1952, Kat. 2386. 2387 Taf. 120.

${ }_{73}$ Deschler-Erb 1998, 165 Kat. 3421-3669 Taf. 35. 36.

${ }^{74}$ Davidson 1952, Kat. 2385 Taf. 120.

${ }^{75}$ RiHA 1990, 102 (z. B. Kat. 1422).

${ }^{76}$ JILEK 2003, 271.

77 JILEK 2003, Kat. 136 Taf. 139: Schutteinfüllung über Peristylsüdumgang und Atrium.

${ }^{78}$ Deschler-Erb 1998, 147 f. 151.

79 Rathmayr 2010, WE 2, Kat. B-B 25 Taf. 262.

${ }^{80}$ DaVIDSON 1952, Kat. 1679-1684 Taf. 99.

${ }^{81}$ Deschler-Erb 1998, 151 Kat. 1953 Taf. 27.

${ }^{82}$ Deschler-Erb 1998, 147 Kat. 872-889 Taf. 24.

${ }^{83}$ Davidson 1952, z. B. Kat. 1740. 1744 Taf. 100.

${ }^{84}$ Davidson 1952, Kat. 1707 Taf. 99.

${ }^{85}$ Unpubliziert.
} 
Geräte, die zur Textilverarbeitung verwendet wurden, sind ein Stift, der als Spindel interpretiert werden kann (B 57 Taf. 380), und ein dreieckiges Webbrettchen (B 58 Taf. 380). Ob unter den im Katalog genannten Nadeln auch Nähnadeln waren, muss aufgrund des teilweise schlechten Erhaltungszustands der Objekte offen bleiben. Möglicherweise handelt es sich bei dem Objekt B 57 um eine langspitzige Spindel mit schrägem Einschnitt, wie sie auch beispielsweise in Augst aus der 1. Hälfte des 1. Jhs. n. Chr. gefunden wurde ${ }^{86}$. In Größe und Machart unterschiedliche Webbrettchen, wie B 58, stammen beispielsweise aus Augst, die zeitlich zwischen dem 1. und 4. Jh. n. Chr. eingeordnet werden ${ }^{87}$. Weitere unverzierte dreieckige Exemplare wurden in Verulamium in Großbritannien gefunden ${ }^{88}$.

B 59 (Taf. 380) kann als Beschlagknopf angesprochen werden. Vergleichbar ist ein beinerner Minibeschlag mit Gegenknopf aus Augst, der zwischen 70 und $110 \mathrm{n}$. Chr. datiert wird ${ }^{89}$ und ein weiterer aus Nessana ${ }^{90}$. Vom Südtor der Tetragonos Agora in Ephesos ist ein sehr ähnliches Stück, hier allerdings aus Bronze hergestellt, bekannt, das als Hilfe zum An- und Abknöpfen von Lederteilen interpretiert wurde ${ }^{91}$.

Fingerringe aus Bein sind aufgrund ihrer Fragilität relativ selten; sie werden hautsächlich anhand ihrer Form dem 3. Jh. n. Chr. zugewiesen ${ }^{92}$. Ob die beiden Ringe B 61 (Taf. 380) und B 62 (Taf. 380) tatsächlich auch als Fingerringe benutzt wurden, muss dahingestellt bleiben.

A. M. PÜLZ

\section{KATALOG}

B 1 Nadel

AO: GHD; Ki 08/179

FO/FJ: ETH; Stiegengasse-Süd; E2; SE 168; 2008

Maße: erh. H 7,1 cm; Schaft Dicke 0,4-0,3 cm; Kopf Dm 0,4 $\mathrm{cm}$

Erh.: fast vollständig - besteht aus zwei anpassenden Fragmenten, Spitze verbrochen

Beschreibung: Der rundstabige Nadelschaft ist unverziert und verjüngt sich zu beiden Enden hin. Der Kopf ist deutlich vom Schaft abgesetzt und kugelförmig mit abgeflachten Seiten.

\section{B 2 Nadel}

Taf. 378

AO: GHD; Ki 08/183

FO/FJ: ETH; Stiegengasse-Süd; E2; SE 173; 2008

Maße: erh. H 6,6 cm; Schaft Dicke 0,9-0,5 cm

Erh.: fast vollständig, Spitze verbrochen

Beschreibung: Der rundstabige, unverzierte Nadelschaft verjüngt sich zur Spitze hin. Der Nadelkopf besitzt eine leicht ovale Form und ist deutlich vom Schaft abgesetzt.
B 3 Nadel

AO: GHD; Ki 08/166

FO/FJ: ETH; Stiegengasse-Süd; D2; SE 152; 2008

Maße: erh. H 7 cm; Schaft Dicke 0,3 cm; Kopf Dm 0,25 cm

Erh.: fast vollständig, Spitze verbrochen; sehr schlechter $\mathrm{Zu}-$ stand

Beschreibung: Der rundstabige und unverzierte Nadelschaft verjüngt sich nach unten zu. Der Nadelkopf ist kugelförmig und vom Schaft abgesetzt.

\section{B 4 Nadel}

Taf. 378

AO: GHD; Ki 08/180

FO/FJ: ETH; Stiegengasse-Süd; E2; SE 171; 2008

Maße: erh. H 5,4 cm; Schaft Dicke 0,4 cm; Kopf Dm 0,4 cm Erh.: fast vollständig, unterer Teil des Nadelschafts verbrochen Beschreibung: Der rundstabige, unverzierte Nadelschaft verjüngt sich zu beiden Seiten hin. Der beinahe kugelförmige Kopf ist vom Schaft abgesetzt.

\footnotetext{
${ }^{86}$ Deschler-Erb 1998, 139 Kat. 344 Taf. 13 mit weiteren Vergleichsbeispielen.

${ }^{87}$ Deschler-Erb 1998, 140 (z. B. Kat. 394 Taf. 17).

${ }^{88}$ Frere 1972, 204 Abb. 55.

${ }^{89}$ Deschler-Erb 1998, 178 Kat. 4047 Taf. 44.

${ }^{90}$ Colt 1962, Taf. 25, 3.

${ }^{91}$ JILEK 1997, 220 Kat. 929 Taf. 70: Datierung: 2. Hälfte 2. bis 3. Jh. n. Chr.

${ }^{92}$ Rina 1990, 48 Kat. 293-294 Taf. 14; HeNKEl 1913, 255 f.
} 
B 5 Nadel

AO: GHD; Ki 07/80

FO/FJ: ETH; Stiegengasse-Süd; B1; SE 9; 2007

Maße: erh. H 3,9 cm; Schaft Dicke 0,5 cm; Kopf Dm 0,7 cm Erh.: fast vollständig, unterer Teil des Schafts verbrochen Beschreibung: Der rundstabige, unverzierte Nadelschaft verjüngt sich leicht zu beiden Seiten hin. Der ovale Nadelkopf ist vom Schaft deutlich abgesetzt.

\section{B 6 Nadel}

Taf. 378

AO: GHD; Ki 07/41

FO/FJ: ETH; Stiegengasse-Süd; B2; SE 14a; 2007

Maße: erh. H 6 cm; Schaft Dicke 0,3-0,4 cm; Kopf Dm 0,4 cm Erh.: fast vollständig, Spitze verbrochen; schlechter Zustand Beschreibung: Der rundstabige und unverzierte Schaft verjüngt sich zu beiden Seiten hin. Der Nadelkopf ist kugelförmig und ebenfalls unverziert.

\section{B $7 \quad$ Nadel}

Taf. 378

AO: GHD; Ki 07/145

FO/FJ: ETH; Süd-Analemma; Kammer KS2; SE 28b; 2007

Maße: erh. H 3,9 cm; Schaft Dicke 0,2-0,3 cm; Kopf Dm 0,4 $\mathrm{cm}$

Erh.: fast vollständig, Schaft im unteren Teil verbrochen Beschreibung: Der rundstabige, unverzierte Schaft verjüngt sich zu beiden Seiten hin. Der Nadelkopf ist leicht kugelförmig und ebenfalls unverziert.

\section{B 8 Nadel}

Taf. 378

AO: GHD; Ki 07/156

FO/FJ: ETH; Süd-Analemma; Kammer KS3; SE 33; 2007

Maße: erh. H 5,7 cm; Schaft Dicke 0,3-0,4 cm; Kopf Dm 0,6 $\mathrm{cm}$

Erh.: fast vollständig, Schaft im unteren Teil verbrochen Beschreibung: Der rundstabige, unverzierte Schaft verjüngt sich zu beiden Seiten hin. Der Nadelkopf ist kugelförmig und ebenfalls unverziert.

\section{B 9 Nadel}

Taf. 378

\section{AO: GHD; Ki 09/15}

FO/FJ: ETH; SE 9; 2009

Maße: erh. H 1,6 cm; Schaft Dicke 0,3-0,4 cm; Kopf Dm 0,4 cm Erh.: fast vollständig, Schaft im unteren Teil verbrochen Beschreibung: Der rundstabige, unverzierte Schaft verjüngt sich zu beiden Seiten hin. Der Nadelkopf ist oval und ebenfalls unverziert.

\section{B 10 Nadel}

Taf. 378

AO: GHD; Ki 07/171

FO/FJ: ETH; Süd-Analemma; Kammer KS1; SE 46; 2007

Maße: erh. H 4,7 cm; Schaft Dicke 0,3 cm; Kopf Dm 0,3 cm Erh.: fast vollständig, Schaft im unteren Teil verbrochen Beschreibung: Der rundstabige, unverzierte Schaft verjüngt sich zu beiden Enden hin. Der ovale Nadelkopf ist unverziert und stark vom Schaft abgesetzt.

B 11 Nadel

Taf. 378

AO: GHD; Ki 07/115

FO/FJ: ETH; Stiegengasse-Süd; C1/C2; SE 1; 2007

Maße: erh. H 8 cm; Schaft Dicke 0,3 cm; Kopf Dm 0,3 cm

Erh.: fast vollständig, Spitze verbrochen
Beschreibung: Der rundstabige, unverzierte Schaft verjüngt sich zu beiden Enden hin. Der Nadelkopf ist leicht tropfenförmig und stark vom Körper abgesetzt.

B 12 Nadel

Taf. 378

AO: GHD; Ki 09/34

FO/FJ: ETH; SE 18; 2009

Maße: erh. H 6,1 cm; Schaft Dicke 0,5 cm; Kopf Dm 0,6 cm Erh.: fast vollständig, Spitze verbrochen

Beschreibung: Der rundstabige, unverzierte Schaft verjüngt sich zu beiden Enden hin. Der Nadelkopf ist kugelförmig und stark vom Körper abgesetzt.

B 13 Nadel

Taf. 378

AO: GHD; KF 97/16; Ki 97/5

FO/FJ: ETH; 1997

Maße: erh. H 3,8 cm; Schaft Dicke 0,4 cm; Kopf Dm 0,4 cm Erh.: fast vollständig, Schaft im unteren Teil verbrochen

Beschreibung: Der Nadelschaft ist leicht polygonal (?), unverziert und verjüngt sich zu beiden Enden hin. Der ovale und unverzierte Kopf ist deutlich vom Schaft abgesetzt.

B 14 Nadel

Taf. 378

AO: EM; KF 08/22; Ki 08/143

FO/FJ: ETH; C2/D2; 2008

Maße: H 9,9 cm; Schaft Dicke 0,3 cm; Kopf Dm 0,3 cm

Erh.: vollständig

Beschreibung: Der rundstabige, unverzierte Nadelschaft verjüngt sich leicht zur Spitze hin. Der Nadelkopf besitzt eine ovale, leicht abgeflachte Form und ist vom Schaft abgesetzt.

B 15 Nadel

Taf. 378

AO: EM; KF 08/21; Ki 08/141

FO/FJ: ETH; C2/B2; 2008

Maße: H 9,9 cm; Schaft Dicke 0,4 cm; Kopf Dm 0,4 cm

Erh.: vollständig

Beschreibung: Der rundstabige, unverzierte Nadelschaft verjüngt sich leicht zu beiden Enden hin. Der Nadelkopf besitzt eine ovale, leicht abgeflachte Form und ist vom Schaft abgesetzt.

B 16 Nadel

Taf. 378

AO: GHD; Ki 08/176

FO/FJ: ETH; Stiegengasse-Süd; D2; SE 162; 2008

Maße: erh. H 3,8 cm; Dicke $0,3 \mathrm{~cm}$

Erh.: Fragment eines Nadelschafts, beide Enden verbrochen Beschreibung: Es handelt sich um einen rundstabigen, unverzierten Schaft, der sich zur Spitze hin leicht verjüngt.

B 17 Nadel

Taf. 378

AO: GHD; Ki 08/59

FO/FJ: ETH; Süd-Analemma; Kammer KS1; SE 64; 2008

Maße: erh. H 4 cm; Dicke $0,4 \mathrm{~cm}$

Erh.: Fragment eines Nadelschafts, beide Enden verbrochen

Beschreibung: Der rundstabige, unverzierte Schaft ist gleichbleibend breit.

B 18 Nadel

Taf. 378

AO: GHD; Ki 07/171

O/FJ: ETH; Süd-Analemma; Kammer KS1; SE 64; 2008

Maße: erh. H 5,8 cm; Dicke $0,3 \mathrm{~cm}$ 
Erh.: Nadelschaft vollständig, Kopf fehlt

Beschreibung: s. B 16.

B 19 Nadel

AO: GHD; Ki 08/186

FO/FJ: ETH; Stiegengasse-Süd; E2; SE 171; 2008

Maße: erh. H 6,1 cm; Dicke 0,4 cm

Erh.: Nadelschaft fast vollständig, oben verbrochen, Kopf fehlt

Beschreibung: s. B 16.

\section{B 20 Nadel}

Taf. 378

AO: GHD; Ki 08/53

F O/FJ: ETH; Süd-Analemma; Kammer KS1; SE 62; 2008

Maße: erh. H 6,9 cm; Dicke 0,3 cm

Erh.: Fragment eines Nadelschafts, beide Enden verbrochen

Beschreibung: s. B 16.

\section{B 21 Nadel}

Taf. 378

AO: GHD; Ki 08/53

F O/FJ: ETH; Süd-Analemma; Kammer KS1; SE 62; 2008

Maße: erh. H 4,8 cm; Dicke $0,3 \mathrm{~cm}$

Erh.: Fragment eines Nadelschafts, beide Enden verbrochen

Beschreibung: s. B 16.

B 22 Nadel

Taf. 378

AO: GHD; Ki 08/171

O/FJ: ETH; Süd-Analemma; Kammer KS1; SE 64; 2008

Maße: erh. H 7,3 cm; Dicke $0,3 \mathrm{~cm}$

Erh.: Nadelschaft vollständig, Kopf fehlt

Beschreibung: s. B 16.

\section{B 23 Nadel}

Taf. 378

AO: GHD; Ki 08/123

FO/FJ: ETH; Stiegengasse-Süd; C1; SE 31; 2008

Maße: erh. H 7,5 cm; max. Dicke $0,5 \mathrm{~cm}$

Erh.: Nadelschaft erh., Kopf verbrochen

Beschreibung: s. B 16.

\section{B 24 Nadel}

AO: GHD; Ki 08/123

FO/FJ: ETH; Stiegengasse-Süd; C1; SE 31; 2008

Maße: erh. H 6,1 cm; Dicke 0,4 cm

Erh.: Nadelschaft fast vollständig, beide Enden verbrochen,

Kopf fehlt

Beschreibung: s. B 16.

B 25 Nadel

Taf. 378

AO: GHD; Ki 08/123

FO/FJ: ETH; Stiegengasse-Süd; C1; SE 31; 2008

Maße: erh. H 5,8 cm; Dicke 0,5-0,3 cm

Erh.: Nadelschaft fast vollständig, beide Enden verbrochen,

Kopf fehlt

Beschreibung: s. B 16.

\section{B 26 Nadel}

Taf. 378

AO: GHD; Ki 08/123

FO/FJ: ETH; Stiegengasse-Süd; C1; SE 31; 2008

Maße: erh. H 3,5 cm; Dicke 0,4 cm

Erh.: Fragment eines Nadelschafts, beide Enden verbrochen,

Kopf fehlt

Beschreibung: s. B 16.
B 27 a u. 27 b 2 Nadeln

Taf. 378

AO: GHD; Ki 07/168

FO/FJ: ETH; Stiegengasse-Süd; B1; SE 139; 2007

Maße: a. erh. H $4 \mathrm{~cm}$; Dicke $0,4 \mathrm{~cm}$

Maße b. erh. H 3,2 cm; Dicke 0,3 cm

Erh.: 2 Schaftfragmente von 2 unterschiedlichen Nadeln - nicht anpassend, Spitzen und Köpfe verbrochen

Beschreibung: s. B 16.

\section{B 28 Nadel}

Taf. 378

AO: GHD; Ki 08/179

O/FJ: ETH; Stiegengasse-Süd; E2; SE 168; 2008

Maße: erh. H 3,1 cm; Dicke 0,3-0,2 cm

Erh.: Nadelschaft fast vollständig, Spitze verbrochen; Nadelkopf fehlt

Beschreibung: s. B 16.

B 29 Nadel

Taf. 378

AO: GHD; Ki 08/179

FO/FJ: ETH; Stiegengasse-Süd; E2; SE 168; 2008

Maße: erh. H 3,4 cm; Dicke 0,2 cm

Erh.: Nadelschaft fast vollständig; Nadelkopf verbrochen

Beschreibung: s. B 16.

\section{B 30 Nadel}

Taf. 378

AO: GHD; Ki 08/134

FO/FJ: ETH; Stiegengasse-Süd; B2/C2; SE 136; 2008

Maße: erh. H 8,1 cm; Dicke 0,3-0,2 cm

Erh.: Nadelschaft fast vollständig, Spitze verbrochen, Kopf fehlt

Beschreibung: Der rundstabige, unverzierte Nadelschaft verjüngt sich zu beiden Enden hin.

\section{B 31 Nadel}

Taf. 378

AO: GHD; Ki 08/134

FO/FJ: ETH; Stiegengasse-Süd; B2/C2; SE 136; 2008

Maße: erh. H 4,5 cm; Dicke $0,3 \mathrm{~cm}$

Erh.: Nadelschaftfragment, beide Enden verbrochen

Beschreibung: Der rundstabige, unverzierte Nadelschaft verjüngt sich zu beiden Enden hin.

B 32 Nadel

Taf. 378

AO: GHD; Ki 04/28

FO: ETH; Skene; Kammer E1; SE B26; 2004

Maße: erh. H 6,3 cm; Dm 0,5-0,3 cm

Erh.: Nadelschaft fast vollständig, Spitze verbrochen; Nadelkopf verbrochen.

Beschreibung: s. B 16.

B 33 Nadel

Taf. 378

AO: GHD; Ki 08/48

FO/FJ: ETH; Stiegengasse-Süd; D2; SE 136; 2008

Maße: erh. H 4,9 cm; Dicke 0,3-0,2 cm

Erh.: Nadelschaft vollständig; Kopf verbrochen

Beschreibung: s. B 16.

B 34 Nadel

Taf. 378

AO: GHD; Ki 09/35

FO/FJ: ETH; 2009

Maße: erh. H 3,9 cm; Dicke $0,3 \mathrm{~cm}$ 
Erh.: Nadelschaft fast vollständig, Spitze verbrochen, Kopf fehlt

Beschreibung: s. B 16.

B 35 Nadel

Taf. 378

AO: GHD; Ki 09/39

FO/FJ: ETH; 2009

Maße: H 6,3 cm; Dicke 0,4 cm

Erh.: Nadelschaft fast vollständig, Spitze verbrochen, Kopf fehlt

Beschreibung: Der rundstabige, unverzierte Schaft verjüngt sich stark zur Spitze hin und leicht nach oben zu. Im oberen Schaftbereich gibt es eine deutliche Verschmälerung.

B 36 Nadel

Taf. 378

AO: GHD; Ki 97/6A 36

FO/FJ: ETH; Nord-Analemma; Kammer KN1; SE N15; 1997

Maße: erh. H 6,8 cm; Dicke $0,4 \mathrm{~cm}$

Erh.: Nadelschaft fast vollständig, Spitze verbrochen, Kopf fehlt

Beschreibung: Der Nadelschaft hat einen leicht polygonalen Querschnitt (?), ist unverziert und verjüngt sich zu beiden Enden hin.

\section{B 37 Nadel}

Taf. 378

AO: GHD; Ki 08/166

FO/FJ: ETH; Stiegengasse-Süd; D2; SE 155; 2008

Maße: erh. H 6,4 cm; Dicke 0,2-0,4 cm

Erh.: Nadelschaft fast vollständig; Kopf verbrochen

Beschreibung: Der Nadelschaft ist rundstabig, unverziert und verjüngt sich zu beiden Enden hin.

B 38 Nadel

Taf. 378

AO: GHD; Ki 08/166

FO/FJ: ETH; Stiegengasse-Süd; D2; SE 155; 2008

Maße: erh. H 4,4 cm; Dicke 0,3-0,4 cm

Erh.: Schaftfragment, beide Enden verbrochen, Kopf fehlt

Beschreibung: s. B 16.

\section{B 39 Nadel}

Taf. 378

AO: GHD; Ki 08/180

FO/FJ: ETH; Stiegengasse-Süd; E2; SE 171; 2008

Maße: erh. H 6,8 cm; Dicke 0,3 cm

Erh.: Nadelschaft fast vollständig, Spitze verbrochen, Kopf fehlt

Beschreibung: Der unverzierte, rundstabige Nadelschaft verjüngt sich zu beiden Enden hin.

\section{B 40 Nadel}

Taf. 378

AO: GHD; Ki 03/33

FO/FJ: ETH; Logeion; S 2/2003; SE L36; 2003

Maße: erh. H 7,9 cm; Dicke 0,4-0,3 cm

Erh.: fast vollständig, Spitze und Kopf sind verbrochen

Beschreibung: Es handelt sich um eine lange, rundstabige und unverzierte Nadel, die sich zur Spitze hin verjüngt.

B 41 Nadel (?)

Taf. 378

AO: GHD; Ki 08/180

FO/FJ: ETH; Stiegengasse-Süd; E2; SE 171; 2008

Maße: erh. H 2,9 cm; Schaft Dicke 0,3 cm; Kopf B 0,5 cm

Erh.: Fragment
Beschreibung: Der Schaft besitzt einen leicht rechteckigen Querschnitt und ist innen hohl. Das eine Ende ist abgebrochen, das andere verbreitert sich und ist gerade abgeschnitten.

B 42 Nadel

Taf. 378 AO: GHD; Ki 08/26

FO/FJ: ETH; oberes Diazoma; S6/2008; SE 107; 2008

Maße: erh. H 3,9 cm; Kopf B 0,5 cm; Schaft Dicke $0,3 \mathrm{~cm}$

Erh.: fast vollständig, Schaft im unteren Bereich verbrochen Beschreibung: Der rundstabige, unverzierte Schaft verjüngt sich leicht nach unten zu. Der obere Abschluss ist unregelmäßig verbreitert.

B 43 Nadel

Taf. 379

AO: GHD; Ki 04/28

FO/FJ: ETH; Skene; Kammer E1; SE B26; 2004

Maße: erh. H 10,6 cm; Kopf Dm 0,8 cm; Schaft Dicke 0,5 cm Erh.: fast vollständig, Nadelspitze verbrochen

Beschreibung: Das Kopfende der pfriemenförmigen Nadel besitzt einen konischen oder kegelartigen Abschluss. Der unverzierte Schaft ist rundstabig und verjüngt sich zur Spitze hin.

B 44 Nadel

Taf. 379

AO: GHD; Ki 08/179

FO/FJ: ETH; Stiegengasse-Süd; E2; SE 168; 2008

Maße: erh. H 6 cm; Dicke 0,5-0,4 cm

Erh.: fast vollständig, Nadelspitze verbrochen

Beschreibung: Die pfriemenförmige Nadel besitzt einen unverzierten Schaft mit leicht polygonalem Querschnitt und verjüngt sich zur Spitze hin. Der Nadelkopf ist leicht abgerundet und flach.

B 45 Nadel

Taf. 379

AO: GHD; Ki 08/113

FO/FJ: ETH; Stiegengasse-Süd; C1; SE 140; 2008

Maße: erh. H 2,9 cm; Schaft Dicke 0,4-0,3 cm; Kopf Dm 0,4 $\mathrm{cm}$

Erh.: Fragment; untere Hälfte des Schafts ist verbrochen

Dat.: ab dem 3. Jh. n. Chr.

Beschreibung: Es handelt sich um eine Haarnadel mit Zwiebelkopf. Der tropfenförmige bzw. spitzovale Kopf ist durch eine deutliche Profilierung vom Schaft abgesetzt. Der Nadelschaft ist unverziert und rundstabig.

B 46 Griff (?)

Taf. 379

AO: EM; Ki 07/171

FO/FJ: ETH; Süd-Analemma; Kammer KS1; SE 46; 2007

Maße: erh. H 11,3 cm; Kopf: B und Dicke 1,1 cm; Griffbereich $0,6 \mathrm{~cm}$; Spitze Dm 0,7cm

Erh.: fast vollständig, der obere Teil verbrochen

Beschreibung: Das Objekt besteht aus einem sich nach unten zu verjüngenden Stab mit rundem Querschnitt, der in einem kugelförmigen Element endet, das durch zwei scheibenartige Wülste vom Stab getrennt ist, und dann verbrochen ist. Als oberer Abschluss finden sich ebenfalls Zierglieder, bestehend aus Scheiben alternierend mit Wülsten und dazwischen einem stark konkav eingezogenen Teil. Auf der abgeflachten Oberseite steht die Figur eines stilisierten Löwen. Der Schädel besitzt kleine runde und abstehende Ohren, von denen eines verbrochen ist. Die Gesichtsform wirkt dreieckig, die Augen sind rund, wobei die Pupillen als vertiefte Punkte angegeben sind. Die breite Nase 
wirkt durch zwei horizontale Ritzungen und soll die Schnauzenfalten andeuten. Die Barthaare sind durch Ritzungen gekennzeichnet. Das Löwenmaul wird durch eine runde Öffnung ersetzt. Der sehr stilisierte Körper besteht aus einem tropfenförmigen Leib, der in vereinfacht wiedergegebenen Krallen endet.

Am Kopf des Löwen befindet sich der Rest eines eckigen Aufbaus, der dann verbrochen ist.

\section{B 47 Griff}

Taf. 379

AO: GHD; Ki 97/D

FO/FJ: ETH; Nord-Analemma; Kammer KN1; SE N15; 1997 Maße: erh. H 3,8 cm; Kopf: H 1,7 cm; B 1,9 cm; Dicke 1,1 $\mathrm{cm}$; Schaft: Dicke 0,7 cm

Erh.: Fragment, nur Kopf und Schaftansatz erhalten Beschreibung: Das gesamte Objekt ist innen der Länge nach durchbohrt. Der zylindrische Kopf ist mit $2 \times 2$ scheibenartigen Wülsten jeweils getrennt durch eine scharfe Kerbung verziert, die durch eine konkav eingezogene Fläche voneinander abgesetzt sind. Der obere Teil des Kopfs ist verbrochen.

Der erhaltene Schaft ist rundstabig, unverziert und hohl.

\section{B 48 Griff (?)}

Taf. 379

AO: GHD; Ki 08/183

FO/FJ: ETH; Stiegengasse-Süd; E2; SE 173; 2008

Maße: erh. H 8,6 cm; Kopf Dm 0,4 cm; Schaft Dicke 0,3-0,2 $\mathrm{cm}$

Erh.: Fragment, unten verbrochen

Beschreibung: Es handelt sich um einen rundstabigen oberen Teil eines Griffs (?), der vielleicht vertikal profiliert ist. Der obere Abschluss ist spitzkonisch gebildet. Der Griff verjüngt sich leicht nach unten zu.

B 49 a u. 49 b 2 Griffe (?)

Taf. 379

AO: GHD; Ki 08/180

F FO/FJ: ETH; Stiegengasse-Süd; E2; SE 171; 2008

Maße: a. erh. H 4,4 cm; Dm 1,6 cm

Maße: b. erh. H 4,6 cm; Dm 1,3 cm

Erh.: 2 Fragmente, nicht anpassend, aufgrund des unterschiedlichen Farbtons sowie des unterschiedlichen Durchmessers Beschreibung: a. Es handelt sich um das Fragment eines dikken, hohlen Griffs mit rundem Querschnitt, der im unteren Teil verbrochen ist. Der obere Abschluss ist leicht konvex abgerundet und darunter zweifach scharf horizontal profiliert.

b. Der hohle Griff mit zylindrischer Form ist an einem Ende gerade abgeschnitten.

B 50 Griff

Taf. 379

AO: GHD; Ki 07/171

FO/FJ: ETH; Süd-Analemma; Kammer KS1; SE 46; 2007

Maße: erh. H 2,2 cm; Dm 1,1 cm

Erh.: Fragment (?)

Beschreibung: Es handelt sich um eine zylindrische Form, die Oberseite ist abgeflacht und weist eine Einbohrung auf.

\section{B 51 Griff}

Taf. 379

AO: EM; Ki 97/81

FO/FJ: ETH; 1997

Maße: erh. H 3,8 cm; Dm 1,4 cm

Erh.: Fragment

Beschreibung: Der rundstabige, hohle Griff ist mit Ziergliedern aus Wülsten und Scheiben dekoriert und dann verbrochen.
B 52 Spielstein

Taf. 379

AO: GHD; Ki 98/37

FO/FJ: ETH; 1998

Maße: H 2,8 cm; B 3 cm; Dm $1 \mathrm{~cm}$

Erh.: eine Hälfte erh.

Dat.: ab der spätrömischen Zeit

Beschreibung: Von dem ursprünglich zylindrisch geformten Objekt mit konvex gewölbter Oberseite hat sich eine Hälfte erhalten. Die Unterseite ist flach abgeschnitten. Der Körper ist mit tief gekerbten, schrägen Rillen durchgehend verziert und endet oben in zwei Profilierungen. Den unteren Abschluss der Verzierung bildet eine tiefe horizontale Kerbung. Das Objekt ist innen zylindrisch ausgehöhlt.

\section{B 53 Spielstein}

\section{AO: GHD; Ki 07/164}

FO/FJ: ETH; Süd-Analemma; Kammer KS3; SE 38; 2007

Maße: L 1,6 cm; Dm 1,1 cm

Erh.: vollständig

Beschreibung: Das Objekt besitzt eine langzylindrische Form und ist an der Unterseite gerade abgeschnitten. Die Seitenflächen sind unverziert. Die Oberseite ist mit tief gekerbten, konzentrischen Rillen verziert.

\section{B 54 Spielstein}

Taf. 379

AO: EM; Inv. 97/12/93

FO/FJ: ETH; Südseite außen Front Mauer, Füllschutt; 1993

Maße: Dm 4,3 cm; D 0,3 cm

Erh.: fast vollständig, an einer Seite verbrochen

Dat.: römische Kaiserzeit

Beschreibung: Es handelt sich um eine flache Scheibe, die auf der Vorderseite mit konzentrischen Rillen verziert ist. In der Mitte befindet sich eine Durchlochung. Die Rückseite ist glatt. Der Spielstein gehört zu den großen Tesserae mit zentralem Loch.

B 55 Würfel

Taf. 379

AO: GHD; Ki 08/48

FO/FJ: ETH; Stiegengasse-Süd; D2; SE 136; 2008

Maße: $0,6 \times 0,6 \mathrm{~cm}$

Erh.: vollständig

Beschreibung: Es handelt sich um einen kleinen Kubus, dessen sechs symmetrische Seitenflächen mit 1 bis 6 konzentrischen Kreisen verziert sind. Die Würfelkanten sind leicht abgerundet.

\section{B 56 Knöchelchen/Astragal}

AO: GHD; Ki 08/123

FO/FJ: ETH; Stiegengasse-Süd; C1; SE 31; 2008

Maße: Dm 1,8 cm; H 1,9 cm; Löcher 0,7 × 0,3 cm

Erh.: vollständig

Beschreibung: Das Objekt besitzt eine zylindrische Form. Die Ober- und Unterseite sind stark konkav eingezogen und mit feinen, konzentrischen Rillen verziert. Dies diente möglicherweise zur Befestigung einer Einlage aus einem anderen Material wie Glas oder Bernstein. Die Seitenflächen sind ebenfalls eingezogen und weisen je zwei sich gegenüberliegende längliche Einbohrungen zum Aufstecken auf ein anderes Objekt auf.

B 57 Stift/Spindel (?)

Taf. 380

AO: GHD; Ki 04/37

FO/FJ: ETH; Skene; Kammer E1; SE 28; 2004 
Maße: H 4,6 cm; Dicke 0,5-0,3 cm

Erh.: vollständig

Beschreibung: Der unverzierte Stift mit rundem Querschnitt verjüngt sich stark zur Spitze hin. Der obere Abschluss ist abgeflacht. Darunter befinden sich einander gegenüberliegend je eine tiefe waagrechte Kerbe.

\section{B 58 Webbrettchen}

Taf. 380

\section{AO: GHD}

FO/FJ: ETH; E7; 2004

Maße: L 3,5 cm; B 4,2 cm; Dicke 0,2 cm; Öffnung Dm 0,2 cm Erh.: fast vollständig, eine Spitze verbrochen

Dat.: 1.-4. Jh. n. Chr.

Beschreibung: Es handelt sich um ein dreieckig geschnittenes, unverziertes Webbrettchen, das drei gleichmäßig große Bohrlöcher in je einer Ecke aufweist.

B 59 Beschlagknopf mit Steg und Gegenknopf Taf. 380 AO: GHD; Ki 08/180

FO/FJ: ETH; Stiegengasse-Süd; E2; SE 171; 2008

Maße: $\mathrm{H} 1,1 \mathrm{~cm}$; oberer und unterer Dm 0,8 cm

Erh.: vollständig

Beschreibung: Das spulenförmige Objekt besteht aus einem schmalen, rundstabigen Verbindungssteg, der auf einer Seite von einer Scheibe abgeschlossen wird und auf der anderen Seite von einem halbkugelförmigen Element mit abgeflachter Mitte, in dessen Zentrum sich eine Einbohrung (?) findet, umgeben von einem Ring.
B 60 Objekt

Taf. 380

AO: GHD; Ki 08/16

FO/FJ: ETH; mittleres Diazoma; S1/2008; SE 51; 2008

Maße: L 2,9 cm; B 0,6 cm; Dicke 0,3 cm

Erh.: Fragment

Beschreibung: Es handelt sich um ein auf einer Seite spitz zulaufendes Objekt mit einem mandelförmigen (?) Querschnitt, das einer Klinge ähnelt. Auf der anderen Seite befindet sich ein waagrechter, scharfer Einschnitt, der in einem schmalen, rundstabigen (?) Fortsatz weiterläuft und dann verbrochen ist.

\section{B 61 Ring}

Taf. 380

(AO: GHD; Ki 97/B

FO/FJ: ETH; vomitorium EN1 (nördliche Hälfte); SE N1; 1997

Maße: Dm 4,1 cm; Dicke 0,9 cm

Erh.: vollständig

Beschreibung: Der große Ring weist einen runden Querschnitt auf und ist unverziert.

B 62 Ring

Taf. 380

AO: EM

FO: ETH; vomitorium EN1-Nord; SE N1; 1997

Maße: Dm 4,1 cm

Erh.: vollständig

Beschreibung: Der große Ring mit rundem Querschnitt ist unverziert.

D. AKar-T ANRIVER

A. M. PÜLZ 


\subsubsection{Varia}

Aus dem Theater sind drei Webgewichte aus Ton bekannt (Taf. 380), davon sind zwei von pyramidaler Form mit einfacher (KF 2) bzw. doppelter Bohrung (KF 1), sowie ein linsenförmiges Webgewicht (KF 3). Des Weiteren gibt es ein pyramidales Gewicht aus Blei, das unter den Metallfunden geführt wird (MF 73 Taf. 377). Linsenförmige Webgewichte, die in Kleinasien in klassischer und hellenistischer Zeit beliebt waren, sind auch aus den Hanghäusern, vom Staatsmarkt und der Tetragonos Agora in Ephesos bekannt, aber auch pyramidale Formen sowohl mit quadratischer als auch rechteckiger Grundfläche stammen beispielsweise aus dem Hanghaus $1^{93}$.

A. M. PÜLZ

\section{KATALOG}

\section{KF 1 Webgewicht}

Ton

AO: GHD; Ki 01/13

FO/FJ: ETH; Logeion; S1/2001; SE 8; 2001

Maße: H 10,2 cm; B oben 3,1 cm; B unten 5,6 cm; Öffnung Dm $0,5 \mathrm{~cm}$

Material: 7.5YR7/4 (pink); wenig Sand u. Glimmer

Erh.: vollständig

Beschreibung: Es handelt sich um ein pyramidales Webgewicht auf einer quadratischen Grundfläche mit zweifacher Bohrung.

\section{KF 2 Webgewicht}

Taf. 380

Ton

AO: GHD; Ki 04/36

FO/FJ: ETH; Skene; Kammer E1; S 2/2004; SE B28; 2004

Maße: H 12,7 cm; B oben 4,3 cm; B unten 7,3 cm; Öffnung Dm $1,1 \mathrm{~cm}$

Material: 5YR5/6 (gelbliches Rot); Sand, Kalkstücke, Glimmer Erh.: vollständig

Beschreibung: Das pyramidale Webgewicht auf rechteckiger Grundfläche weist eine Bohrung auf.

\section{KF 3 Webgewicht}

Ton

AO: GHD; Ki 09/90

FO/FJ: ETH; Stiegengasse-Süd; J2; SE 124; 2009

Maße: Dm 5,6 cm; Öffnung Dm 0,6 cm

Material: 2.5YR5/8 (rot); grober Ton mit grobem Glimmer u. wenig Sand

Erh.: vollständig

Beschreibung: Das linsenförmige Webgewicht ohne Dekor weist zwei hoch liegende Bohrungen auf.

\section{KF 4 Spielstein}

Ton

AO: GHD; Ki 97/E

FO/FJ: ETH; Theatergymnasium; 1997

Maße: Dm 3,2 cm; Dicke 0,6 cm

Material: 10R6/8 (lichtrot); Ton ohne Zusatzstoffe

Erh.: vollständig
Taf. 380

Taf. 380

\section{AO: GHD; Ki 09/1 \\ FO/FJ: ETH; 2009}

Maße: L 4,7 cm; B 4,5 cm; Öffnung 0,4 × 0,6 cm

Erh.: vollständig

Beschreibung: Es handelt sich um eine natürliche Muschelschale, die auf einer Seite eine Durchlochung aufweist und vermutlich als Anhänger getragen wurde.

D. AKar-TANRIVER

A. M. PÜLZ

\footnotetext{
${ }^{93}$ TRINKL 2003, 315 f. Taf. 150-152 zu linsenförmigen und pyramidalen Webgewichten.

${ }^{94}$ Ich danke T. Bezeczky für die Information. Zu Namensignaturen auf hellenistischen Lampen und Reliefbechern: RogL 2001; GUILIANI 2004
} 


\section{Skulpturen und Inventar: Funde aus den Jahren 1993 bis 2012}

\subsection{FUNDE UND AUSSTATTUNG AUS MARMOR}

\subsubsection{Einleitung}

Der vorliegende Beitrag umfasst die Funde ${ }^{1}$, welche bei den Sicherungs- und Freilegungskampagnen von St. Karwiese vor allem im Bereich des Nord- und Südflügels des Theaters in den 1990er Jahren zutage kamen, und jene Neufunde, die bei den Nachuntersuchungen von M. Hofbauer und M. Tschannerl an der Bühne, in den Kammern des Bühnengebäudes, oberhalb der summa cavea und im Süden des Theaters entdeckt wurden ${ }^{2}$. Es wurden Skulpturen aus Marmor sowie Fragmente von Marmorinventar aufgenommen. Auch die zahlreichen Fragmente von Gliedmaßen und Gewandteilen wurden dokumentiert, um besonders die Fülle des in der Kammer D8 des Bühnengebäudes deponierten Materials aufzuzeigen.

Die Katalogeinträge beinhalten einen technischen Teil, die Beschreibung und die Einordnung der einzelnen Denkmäler hinsichtlich Ikonografie, Funktion, Stil und Chronologie. Im Textteil werden übergreifende Themen behandelt ${ }^{3}$, und es wird der Versuch unternommen, die Ausstattungsstücke des Theaters von den theaterfremden< Objekten zu trennen.

\subsubsection{Erhaltungszustand und Fundorte der Skulpturen sowie des Inventars}

Alle hier vorgestellten Funde wurden in sekundärem Kontext angetroffen, alle bis auf die Gladiatorenpfeiler SK 55 (Taf. 389), SK 56 (Taf. 390), SK 85 (Taf. 398; 399 Abb. 681-683), SK 86 (Taf. 400. 401) kamen nur in fragmentarischem Zustand auf uns ${ }^{4}$. An vielen der Objekte sind Mörtelspuren festzustellen, sie waren also verbaut. Fundsituation und Erhaltungszustand der Denkmäler spiegeln den Zustand des Theaters nach dem Einbau einer Zisterne in das vomitorium EN1, welche mindestens bis in das frühe 7. Jh. n. Chr. in Verwendung war, nach der Verschließung der Zugänge im Norden sowie nach der Integration des Theaters in die byzantinische Stadtmauer im späten 6./frühen 7. Jh. n. Chr. (?). Zu diesem Zweck wurden die Zugänge im Süden verschlossen und die Kammern hinter der Bühne zugemauert bzw. teilweise verschüttet ${ }^{5}$.

Es folgen die wichtigsten Fundorte der Skulpturen und des Inventars: Die zwei Einzelfunde aus den Untersuchungen am Logeion stammen aus dem Schutt (SK 1 Taf. 382, Aphroditestatuette) bzw. wurden bei der Reinigung des Logeion entdeckt (SK 2, Fragment von Felidenpranke).

Unter den Funden aus den Kammern hinter dem Bühnengebäude sticht die große Materialmenge in der Kammer D8 hervor (SK 3-39 Taf. 383-385). Die Marmorfragmente wurden bei der Reinigung der Kammer bis zur Fundament-Oberkante entdeckt; sie wurden offenbar zu einem uns unbekannten Zeitpunkt dort deponiert. Laut M. Hofbauer lässt sich schwer sagen, inwieweit dieser Schutt zum Material aus dem Theater gehörte ${ }^{6}$. Solange die Kammer D8 über den Raum E8 von Westen her zugänglich war, ist eine Einbringung

\footnotetext{
${ }^{1}$ Die Bearbeitung der Skulpturenfragmente aus Bronze wurde mir nach Fertigstellung des Katalogs der Marmorfunde und des Tafellayouts von A. Pülz und P. Ruggendorfer übertragen. Deshalb werden der Katalog und die Auswertung der Bronzefunde (Kap. 7.2 u. 7.2.1) und die zugehörigen Tafeln hier an den Katalog (Kap. 7.1.8) und die Abbildungen der Marmorfunde angeschlossen. - Meinen Kolleginnen und Kollegen K. Herold, M. Hofbauer, St. Karwiese, G. Plattner, U. Quatember, G. Styhler-Aydın, H. Taeuber, M. Tschannerl, A. Waldner und N. Gail danke ich für Hinweise und Hilfe. - Der Beitrag wurde 2012 abgeschlossen.

${ }^{2}$ Vgl. Kap. 1.

${ }^{3}$ Kap. 7.1.2-7.

${ }^{4}$ Die Kybelestatuette SK 72 (Taf. 395 Abb. 668. 669) ist zwar zur Gänze erhalten, es handelt sich jedoch um eine Rohfassung aus einer Werkstatt.

${ }^{5}$ Vgl. Kap. 3.5.1 u. 10.3. Zur byzantinischen Stadtmauer vgl. LAdSTÄTter 2010d, 505 f. Abb. 16; PÜlz 2010, 556. 558-560 Abb. 15. 19. 20.

${ }^{6}$ Mündliche Auskunft.
} 
des Schutts von außen denkbar. Nach dem Verschluss der Kammer E7 war D8 nur mehr über eine Treppe aus dem Obergeschoss zu betreten. Ab diesem Zeitpunkt ist eine Einbringung des Schutts von außen eher auszuschließen.

Aus den Kammern der kaiserzeitlichen Westerweiterung stammen das flavische Tritonfragment SK 40 (Taf. 408) (Kammer E5), aus einer Schicht, die durch Münzfunde in das 4. Jh. n. Chr. datiert wird ${ }^{7}$, sowie eine kleine Gruppe von Skulpturenfragmenten aus der Kammer E7, aus einer Schuttauffüllung mit umgelagertem Material des 3. Jhs. n. Chr. ${ }^{8}$ Im Zuge der Integration des Theaters in die byzantinische Stadtmauer wurde die Kammer E7 mit Schutt aufgefüllt' 9

Aus den von St. Karwiese freigelegten, aber bislang nicht genauer untersuchten Räumen südlich des Bühnengebäudes stammen drei Skulpturenfragmente SK 48-50 (Taf. 386 Abb. 632; 387 Abb. 633-635), unter denen das Kopffragment SK 49 aufgrund seiner theodosianischen Zeitstellung hervorzuheben ist. Letzteres wurde in losem Schutt über dem Mosaikfußboden des 5./6. Jhs. n. Chr. gefunden, der einen saalartigen Raum südlich des Bühnengebäudes zierte ${ }^{10}$.

Die Abtragung des Hang- und Füllschutts entlang der nördlichen Umfassungsmauer der Cavea, welche als Vorarbeit für die Konsolidierung und Erforschung des Nordflügels unter St. Karwiese unternommen wurde $^{11}$, erbrachte auch eine kleine Gruppe von Skulpturen- und Inventarfragmenten unterschiedlicher Funktion (SK 51. SK 52 Taf. 388 Abb. 639. 640; SK 57-59 Taf. 391; 392 Abb. 653. 654). Die wichtigsten Funde aus dieser ersten Phase der Erforschung des Nordflügels sind die beiden Gladiatorenpfeiler SK 55 und SK 56 (Taf. 389. 390), die im Versturz einer Zisterne angetroffen wurden, welche wahrscheinlich in der Mitte des 5. Jhs. n. Chr. im nördlichen und mittleren Bereich des Korridors EN1 errichtet worden war ${ }^{12}$. Die Versturzschichten im Korridor bzw. in den westlich anschließenden Kammern sind nach Ausweis der Münzfunde in das frühe 7. Jh. n. Chr. zu datieren ${ }^{13}$. Außerdem wurden zwei freiplastische Fragmente (SK 53. SK 54) im Korridor gefunden.

Im Zuge der Reinigungsarbeiten im Areal westlich des Nord-Analemma unter St. Karwiese ${ }^{14}$ wurden ein Gewandfragment SK 60 (Taf. 392 Abb. 655) und ein weiblicher Idealkopf SK 61 (Taf. 392 Abb. 656; 393 Abb. 657. 658) flavischer Zeit entdeckt.

Aus den Grabungen oberhalb der summa cavea stammt nur ein kleines Skulpturenfragment, der Satyroder Silens(?)torso SK 62 (Taf. 393 Abb. 659): Es handelt sich um ein Fragment aus dem Verfüllschutt des Nord-Süd verlaufenden Gangs (Raum 2), der die Radialkammern hinter dem Theater erschloss ${ }^{15}$.

Im Bereich des Südflügels des Theaters umfassen die Altfunde aus den Grabungen von St. Karwiese zunächst wieder Objekte aus der Abtragung des Schutts entlang der Umfassungsmauer der Cavea (die Skulpturenfragmente SK 70; SK 71 Taf. 395 Abb. 665; SK 76 Taf. 410 Abb. 730; SK 77). Dazu kommen Funde aus der Reinigung der Kammer KS 3 (SK 63) und der Korridore ES1 und ES2: das Maskenfragment SK 64 (Taf. 393 Abb. 660) sowie die Skulpturen SK 72 (Taf. 395 Abb. 668. 669), SK 73 (Taf. 395 Abb. 666. 667) und SK 75 (Taf. 396 Abb. 670. 671). Die Freilegung der Treppe im Süden des Theaters durch M. Hofbauer erbrachte eine Reihe von weiteren Funden in diesem Bereich, zumeist aus Kontexten des 5. bis 6. Jhs. n. Chr.: die Skulpturenfragmente SK 66-68 (Taf. 394) und SK 69. Im Bereich des östlichsten Zugangs ES3 förderte St. Karwiese ein kleines Armfragment zutage (SK 79). Das im Zuge der Grabungen M. Hofbauers freigelegte Zugangspodest vor ES3 war besonders fundreich: Zwei Büstenfragmente SK 80 und SK 81 (Taf. 397), zwei kleine Fragmente aus Kalksinter SK 83 (Taf. 410 Abb. 731) und SK 84 (Taf. 410 Abb. 732) und, als für die Theaterausstattung wichtigster Fund, zwei weitere Gladiatorenpfeiler SK 85 (Taf. 398; 399 Abb. 681-683), SK 86 (Taf. 400. 401) samt Schrankenplattenfragment SK 85A (Taf. 399 Abb. 684) sowie zwei andere Schrankenpfeiler SK 87 (Taf. 402) und SK 88 (Taf. 403) stammen von dort.

\footnotetext{
${ }^{7}$ Vgl. Kap. 3.1.2.3 zu den SE B43 und SE B42; Kap. 4.1.2.3.

${ }^{8}$ SK 41-47 (Taf. 386 Abb. 629-631). Vgl. Kap. 3.1.2.4 zu den SE B35-SE B37; Kap. 4.1.2.4.

${ }^{9}$ Vgl. auch HofBaUer 2005, 335 unter 1.5.1.1.

${ }^{10}$ Vgl. Kap. 3.1.4.3 zum Bereich südlich des Bühnengebäudes. Datierung des Mosaiks: V. Scheibelreiter-Gail (mündliche Mitteilung).

${ }^{11}$ Vgl. dazu Kap. 3.5, Vorbemerkung.

${ }^{12} \mathrm{Vgl}$. dazu Kap. 3.5.1 u. 4.5.1.

${ }^{13}$ Vgl. Kap. 3.5.1 und 5.2.5.

${ }^{14}$ Vgl. Kap. 3.5.3.

${ }^{15}$ Vgl. Kap. 3.8.
} 
Die weit auseinanderliegenden Fundorte der beiden als Pendants gearbeiteten kleinformatigen Tritonen im Theater SK 40 (Taf. 408), Kammer E5 sowie >oberste Galerieく, also wohl Portikus, bestätigen wieder einmal, dass man mit der Auswertung der Fund- und Aufstellungsorte nicht vorsichtig genug sein kann.

\subsubsection{Material und Bearbeitung}

Der Großteil der Funde wurde aus dem in Ephesos zumeist verwendeten weißen bzw. hellgrauen Marmor gearbeitet. Buntmarmor tritt bei einer Gruppe von kleinformatigen Statuetten aus rötlichem Kalksinter, alabastro fiorito (SK 76 Taf. 410 Abb. 730; SK 83 Taf. 410 Abb. 731; SK 84 Taf. 410 Abb. 732), sowie bei dem Tritonenpaar auf (SK 40 Taf. 408 und Pendant aus bigio antico) ${ }^{16}$. Für das Fragment eines Tischfußes SK 38 (Taf. 385) wurde greco scritto verwendet. Ein kleines Armfragment SK 69 wurde aus Pavonazetto gearbeitet.

Von besonderer Wichtigkeit für den Nachweis von Bildhauerwerkstätten in Ephesos sind die beiden unfertigen, kleinformatigen Bildwerke der Aphrodite SK 7 (Taf. 384 Abb. 621) und der Kybele SK 72 (Taf. 395 Abb. 668. 669) aus weißem bzw. hellgrauem Marmor, die die Skulpturen in unterschiedlichen Stadien der Bearbeitung zeigen. Die Kybele ist in ihrer rohen Blockform auf uns gekommen, die Figur nur im Umriss angelegt. SK 71 (Taf. 395 Abb. 665) ist möglicherweise eine unfertige Panstatuette. Bislang kennen wir unfertige Freiplastik in einem fortgeschritteneren Bearbeitungsstadium aus dem kaiserzeitlichen Ephesos (abgesehen von den Halbfabrikaten der Girlandensarkophage) ${ }^{17}$.

\subsubsection{Formate der Skulpturen}

Die Formate der hier vorgestellten Skulpturen reichen vom Kleinformat der Statuetten über das Mittelformat von unterlebensgroßen Skulpturen bis zu den Fragmenten von lebensgroßen und etwas überlebensgroßen Skulpturen ${ }^{18}$. Bei den Statuetten handelt es sich um Figuren von Gottheiten und Mischwesen sowie um kleine Tierplastiken ${ }^{19}$. Ein Beispiel für das Mittelformat ist der Unterteil der weiblichen Gewandstatuette SK 67, die ihrer Sandalen wegen wohl auch eine Göttin darstellte (Taf. 394 Abb. 663. 664) ${ }^{20}$. Lebensgroß sind Fragmente von Porträtstatuen bzw. -büsten SK 3 (Taf. 383 Abb. 616), SK 66 (Taf. 394 Abb. 661), SK 80, SK 81 (Taf. 397), aber auch ideale Köpfe SK 4 von einer Herme (?) (Taf. 383 Abb. 617), SK 48 von einem Hochrelief (Taf. 387 Abb. 633. 634), und der flavische weibliche Kopf SK 61 (Taf. 392 Abb. 656; 393 Abb. 657. 658 $)^{21}$. Etwas überlebensgroß ist der Fuß auf dem Plinthenfragment SK 46.

\subsubsection{Zur Datierung der Skulpturen}

Aussagen zur Chronologie der Ausstattungsphasen des Theaters lassen sich im Rahmen dieses Beitrags nicht formulieren, da, wie im nächstfolgenden Abschnitt ausgeführt wird, nur sehr wenige der hier dokumentierten Denkmäler tatsächlich zur Ausstattung des Theaters zu zählen sind: die Maskenfragmente SK 64 (Taf. 393 Abb. 660) und SK 106 (Taf. 71 Abb. 139) sowie die Gladiatorenpfeiler. Das kaiserzeitliche Maskenfragment SK 64 lässt sich nicht genauer datieren, da der Onkos nicht erhalten ist; wahrscheinlich gehörte es aber zur Serie der Masken, die im Bereich der Portikus und ihrer Rückwand gefunden wurde ${ }^{22}$. Die Gladiatorenpfeiler

\footnotetext{
${ }^{16}$ Referenzen zu den Marmorsorten bei den einzelnen Katalogeinträgen.

${ }^{17} \mathrm{Zu}$ einem kleinen unfertigen Porträtbüstchen Hadrians in Selçuk, Efes Müzesi 126/59/80 vgl. Thür - RAthMAYR 2014, 368.372 Anm. 71 (E. Rathmayr).

${ }^{18}$ Vgl. FiLges 1999, 378 zur Trennung von Statuetten und unterlebensgroßen Statuen nach ihrer Höhe.

${ }^{19}$ Beispiele: SK 1 (Taf. 382 Abb. 612); SK 5 (Taf. 383 Abb. 619); SK 6 (Taf. 384 Abb. 620); SK 8 (Taf. 384 Abb. 622.623 ); SK 36 (Taf. 385 Abb. 624); SK 40 (Taf. 408); SK 44 (Taf. 386 Abb. 630); SK 52 (Taf. 388 Abb. 640); SK 62 (Taf. 393 Abb. 659 ); SK 71 (Taf. 395 Abb. 665); SK 72 (Taf. 395 Abb. 668. 669); SK 73 (Taf. 395 Abb. 666. 667); SK 75 (Taf. 396 Abb. 670. 671); SK 76? (Taf. 410 Abb. 730).

${ }^{20}$ Unterlebensgroß auch der Fuß in Sandale SK 47 (Taf. 386 Abb. 631), Fragment einer Porträtstatue, und der nackte männliche Torso SK 51 (Taf. 388 Abb. 639).

${ }^{21}$ Dazu vielleicht auch das theodosianische Kopffragment SK 49 (Taf. 387 Abb. 635) und der lebensgroße Fuß SK 50 (Taf. 386 Abb. 632 ).

${ }^{22}$ Vgl. dazu Kap. 7.1.6. Zum Fragment SK 106 vgl. Kap. 7.3.2.
} 
SK 55 (Taf. 389), SK 56 (Taf. 390), SK 85 (Taf. 398; 399 Abb. 681-683) und SK 86 (Taf. 400. 401) sind aufgrund der Inschriften in die 2. Hälfte des 2. Jhs. bzw. in die 1. Hälfte des 3. Jhs. n. Chr. zu datieren ${ }^{23}$.

Mindestens drei der Denkmäler aus dem Bereich bzw. Umkreis des Theaters entstanden in flavischer Zeit, der Errichtungszeit der scaenae frons ${ }^{24}$ : der weibliche Idealkopf SK 61 (Taf. 392 Abb. 656; 393 Abb. 657. 658), ein Streufund vom Areal westlich vor dem Theater, der kleinformatige Triton SK 40 (Taf. 408) und sein Pendant sowie wahrscheinlich auch der nackte männliche Torso SK 51 (Taf. 388 Abb. 639). Der Idealkopf steht stilistisch der weiblichen Idealplastik aus dem 78/79 n. Chr. errichteten C. Laecanius BassusNymphäum sehr nahe ${ }^{25}$. Das Tritonpaar wird aufgrund seines Formats und möglicherweise auch wegen seines Materials (Buntmarmor) nicht Teil der Ausstattung des Theaters gewesen $\operatorname{sein}^{26}$. Der Torso SK 51 wurde außerhalb der Umfassungsmauer der Cavea gefunden.

Soweit die Fragmente eine chronologische Einordnung zulassen, kann festgestellt werden, dass der Schwerpunkt des Fundspektrums im 2. bis 3. Jh. n. Chr. liegt ${ }^{27}$.

Das jüngste Bildwerk im Rahmen der hier dokumentierten Funde ist das theodosianische Kopffragment SK 49 (Taf. 387 Abb. 635) aus dem Raum südlich des Bühnengebäudes, das aufgrund seiner Zeitstellung ein weiteres wichtiges Denkmal in der Gruppe der spätantiken Plastik aus Ephesos darstellt ${ }^{28}$.

\subsubsection{Zur Ausstattung des Theaters anhand der Funde aus den Jahren von 1993 bis 2009}

Der Großteil der großformatigen Skulpturen aus dem Theater wurde bereits während der österreichischen Grabungen in den Jahren um 1900 geborgen, abgesehen von der kleineren Gruppe von Skulpturen, auf die J. T. Wood in den 1860er Jahren stie ${ }^{29}$. Die Reinigungs-, Konsolidierungs- und Forschungskampagnen St. Karwieses im Bereich des Nord- und Südflügels sowie die ergänzenden Untersuchungen M. Hofbauers zur Chronologie des Theaters erbrachten hingegen nur wenige Funde, die sich tatsächlich der Skulpturenausstattung zuweisen lassen. Streng genommen gehörten nur das Maskenfragment SK 64 (Taf. 393 Abb. 660) und die vier Gladiatorenpfeiler SK 55 (Taf. 389), SK 56 (Taf. 390), SK 85 (Taf. 398; 399 Abb. 681-683), SK 86 (Taf. 400; 401 Abb. 689-691) der Ausstattung an.

Das Maskenfragment wurde in einer Erdfüllung im Korridor ES1 gefunden. Aus ikonografischen Gründen liegt die Zugehörigkeit zum Theater nahe. Reinigungskampagnen des Efes Müzesi in den Jahren 1966, 1967 und 1972 erbrachten eine ganze Serie von gut erhaltenen, marmornen tragischen Masken unterschiedlicher Ikonografie und Ausführung ${ }^{30}$. Sie wurden im Bereich der Portikus, nördlich von der zentralen, hangaufwärts führenden Treppe, sowie hinter der Rückwand der Portikus gefunden und waren wahrscheinlich an dieser Wand angebracht. Es ist anzunehmen, dass auch das Maskenfragment SK 64 (Taf. 393 Abb. 660), an dem der Onkos nicht erhalten ist, zu dieser Serie gehörte.

Die Gruppe der in das 2. bzw. 3. Jh. n. Chr. zu datierenden Gladiatorenpfeiler, die wohl im Rahmen einer Brüstung im Bereich der Portikus aufgestellt waren, wird hier in einem eigenen Kapitel behandelt ${ }^{31}$.

\footnotetext{
${ }^{23}$ Vgl. Kap. 8.2, Inschriften IN 4 (Taf. 412); IN 5 (Taf. 411); IN 6.7 (Taf. 413).

${ }^{24}$ Vgl. dazu Kap. 10.2.

${ }^{25}$ Vgl. dazu im Katalogeintrag SK 61 (Taf. 392 Abb. 656; 393 Abb. 657. 658).

${ }^{26}$ Vgl. dazu Kap. 7.1.7.

${ }^{27}$ Vgl. z. B.: SK 3 (Taf. 383 Abb. 616); SK 41 (Taf. 386 Abb. 629); SK 48 (Taf. 387 Abb. 633. 634); SK 55 (Taf. 389 Abb. 641-643); SK 56 (Taf. 390 Abb. 644. 645); SK 67 (Taf. 394 Abb. 663. 664); SK 73 (Taf. 395 Abb. 666. 667); SK 80. SK 81 (Taf. 397 ); SK 85 (Taf. 398; 399 Abb. 681-683); SK 86 (Taf. 400. 401).

${ }^{28}$ Vgl. dazu Kap. 7.1.6 und den Katalogeintrag. Zur spätantiken Plastik aus Ephesos Auinger - Aurenhammer 2010, 663-696, zu Denkmälern aus dem Bereich des Theaters S. 688.

${ }^{29}$ Zur Skulpturenausstattung des Theaters s. vorläufig die Zusammenstellung und Auswertung der publizierten Funde bei ÖZREN 1996, 105. 107 f. 124-127. Die Verfasserin des vorliegenden Beitrags dokumentierte von 2004 bis 2011 alle Skulpturenfunde aus dem Theater, die in vier Museen aufbewahrt werden, inklusive des Eroten-/Satyrfrieses vom Bühnengebäude (letzteres in Kooperation mit der Antikensammlung des Kunsthistorischen Museums Wien, G. Plattner). Die Skulpturenfunde aus der Cavea werden in StyHLER-Aydin (in Vorbereitung), der Fries in einer eigenen Monografie zusammen mit G. Plattner vorgelegt werden.

${ }^{30}$ Atalay 1972, 47 Abb. 1. 2; Kayan 1972, 56-64 Abb. 1-6. Sie werden von der Verfasserin im Rahmen der Publikation der Cavea des Theaters erneut vorgelegt werden. Vgl. außerdem Kap. 7.3.2 (SK 106).

${ }^{31}$ Kap. 7.1.6.1
} 
Theoretisch könnten die Porträtfragmente SK 3 (Taf. 383 Abb. 616), SK 66 (Taf. 394 Abb. 661), SK 47 (Taf. 386 Abb. 631) zur Ausstattung des Theaters gehört haben, wobei nicht klar ist, ob das severische Porträtfragment SK 3 von einer Statue oder einer Büste stammt. Die flavische Datierung des weiblichen Idealkopfs SK 61 (Taf. 392 Abb. 656; 393 Abb. 657. 658), der im Areal vor dem Nord-Analemma gefunden wurde, lässt, wie schon oben gesagt, in Hinblick auf die Errichtung der scaenae frons in spätflavischer Zeit aufhorchen. Doch ist der Kopf stilistisch so eng mit Idealköpfen des 78/79 n. Chr. errichteten C. Laecanius Bassus-Nymphäums verbunden, dass eine Zugehörigkeit zu diesem Brunnen auch erwogen werden muss ${ }^{32}$. Mit Verschleppung von Bildwerken quer durch die Stadt ist immer zu rechnen. Bei dem theodosianischen Kopffragment SK 49 (Taf. 387 Abb. 635), dessen Funktion nicht ganz sicher ist, handelt es sich um einen Schuttfund aus dem (noch nicht genauer erforschten) Raum mit Mosaikboden südlich des Bühnengebäudes. Laut Auskunft von V. Scheibelreiter-Gail lag hier ein Mosaikboden des 5./6. Jhs. n. Chr. über einem kaiserzeitlichen Mosaik des 2. Jhs. n. Chr. Eine stilistisch eng mit dem Kopffragment verwandte Doppelherme, ein Oberflächenfund vom Areal zwischen Vediusgymnasium und Stadion, diente wahrscheinlich als Teil einer Brüstung oder Abgrenzung ${ }^{33}$.

\subsubsection{GLADIATORENPFEILER}

Im Versturz des nördlichen Korridors EN1, der im 5. Jh. n. Chr. zu einem Wasserbecken umgestaltet wurde, bzw. im Ziegelschutt vor dem Zugang zu ES3 wurden vier Gladiatorenpfeiler SK 55 (Taf. 389), SK 56 (Taf. 390), SK 85 (Taf. 398; 399 Abb. 681-683), SK 86 (Taf. 400. 401) gefunden. Unter diesen sind die Pfeiler des Stephanos SK 85 (Taf. 398; 399 Abb. 681-683) und des Aithales SK 86 (Taf. 400. 401) als Pendants gearbeitet; dazu gehörte eine Schrankenplatte SK 85A (Taf. 399 Abb. 684). Drei dieser Pfeiler aus dem Bereich des Theaters (SK 56 Taf. 390 Abb. 644. 645, der Pfeiler für Achilleus, sowie SK 85. SK 86) entsprechen in ihrer Form und der einfachen Profilierung mit der obersten, von Akroterien gerahmten Leiste sowie in der Einzelfigur eines kampfbereiten Gladiators auf einer Standleiste an der Vorderseite des Schafts einem in Kleinasien ${ }^{34}$ und auch in Ephesos verbreiteten altarähnlichen Typus von Gladiatoren-Denkmälern. Der bereits 1926 entdeckte Pfeiler für Prestor wurde im Bereich des Zugangs zu ES3 und damit in der Nähe von SK 85 und SK 86 im Schutt gefunden ${ }^{35}$.

Bei den weiteren ephesischen Beispielen dieses Typus, die auf der Marmorstraße vor dem Theater gefunden wurden, handelt es sich um folgende Exemplare ${ }^{36}$ :

1. Pfeiler des Hoplomachos Rhodios. Gefunden unter den Trümmern in der Mitte der Marmorstraße. 2011 noch an der Westseite der Straße aufgestellt ${ }^{37}$. Maximale Maße: H $77 \mathrm{~cm}$, B $56 \mathrm{~cm}$, T $50 \mathrm{~cm}$, B der Nuten an den Nebenseiten $12-13 \mathrm{~cm}$.

2. Pfeiler des secutor Asbolas. Gefunden vor dem Theater, auf der Marmorstraße. Selçuk, Efes Müzesi ${ }^{38}$. Maximale Maße: H $93 \mathrm{~cm}$, B $54 \mathrm{~cm}$, T $56 \mathrm{~cm}$, B der Nuten an den Nebenseiten 8-11 cm.

3. Pfeiler eines retiarius. Gefunden an der Marmorstraße? 2011 noch an der Westseite der Straße aufgestellt. Namensinschrift links über der Relieffigur stark verwittert, nicht lesbar ${ }^{39}$. Maximale Maße: H $90 \mathrm{~cm}$, B $68 \mathrm{~cm}$, T $46 \mathrm{~cm}$. Keine Nuten.

\footnotetext{
${ }^{32}$ Zu Stil und Datierung des Kopfs vgl. den Katalogeintrag SK 61.

${ }^{33}$ Vgl. dazu unter dem Katalogeintrag zu SK 49.

34 Vgl. u. a. Robert 1971, 59 f.; Günther 1985, 132 f. Nr. 4.5 Taf. 28, 1. 2 (Milet); Hrychuk Kontokosta 2008, 197-199. 203. 206-217 Nr. 4-21 (Aphrodisias); Uzunaslan 2010, 96 Abb. 17; 123 Abb. 24; 138 Abb. 29 (Antiochia in Pisidien); 161 f. Abb. 41 (Kibyra); 197 Abb. 55 (Resim ve Heykel Müzesi, Izmir).

${ }^{35}$ Selçuk, Efes Müzesi ohne InvNr., Fundangabe nach Skizzenbuch 2131 (»hoch oben außen neben der Südmauer der Cavea, in der Nähe des vermauerten obersten Eingangs im Schutte«). Maximale Maße: H $91 \mathrm{~cm}$, B $51 \mathrm{~cm}, \mathrm{~T} 47 \mathrm{~cm}$, B der Nuten an den Nebenseiten 11-12 cm. IvE 1174. Vgl. RoBert 1971, 199 Nr. 212 Taf. 11; ZüLKADíroĞLu - İçTen 2002, 82 (linker Pfeiler).

${ }^{36}$ Die Fundortangaben basieren auf den IvE bzw. den epigrafischen Skizzenbüchern im Archiv des ÖAI.

${ }^{37}$ IvE 1177. Vgl. Robert 1971, 199 Nr. 214 Taf. 3; Merkelbach 1998, 337 unter 03/02/53 Ephesos (»kaiserzeitlich«); JunkELMANN 2008, 361 f. Abb. 361.

${ }^{38}$ Selçuk, Efes Müzesi ohne InvNr., IvE 1181. Vgl. Robert 1971, 200 Nr. 215 Taf. 10; PfuHL - MöBIUs 1979, 296 Nr. 1203 Taf. 182 (»3. Jh. n. Chr.«); ZÜLKADíroĞLU - İçTEN 2002, 80 f.

${ }^{39}$ Unpubliziert?
} 
Bei weiteren Gladiatorenpfeilern dieses Typus ist der genaue Fundort in Ephesos nicht bekannt, bzw. er liegt außerhalb des Theaterbereichs. Im Folgenden sind die publizierten Exemplare angeführt ${ }^{40}$ :

4. Pfeiler des Hippolytos. Fundort »Sandgrube nordöstlich des Panayırdağ«. Selçuk, Efes Müzesi ${ }^{41}$. Maximale Maße: H $86 \mathrm{~cm}$, B $60 \mathrm{~cm}$, T $37 \mathrm{~cm}$. Keine Nuten.

5. Pfeiler des Polydoxos (fragmentarisch). Aus später Mauer nördlich der Johannesbasilika. Selçuk, Efes Müzesi 2261 ${ }^{42}$. Maximale Maße: H erh. $53 \mathrm{~cm}$, B $40 \mathrm{~cm}$, T erh. $18 \mathrm{~cm}$.

6. Pfeiler eines secutor. Gefunden in Ephesos. Selçuk, Efes Müzesi ${ }^{43}$. An der oberen Leiste völlig verwitterte Inschrift. Maximale Maße: H $92 \mathrm{~cm}$, B 48,5 cm, T $47 \mathrm{~cm}$, B der Nuten an den Nebenseiten $9 \mathrm{~cm}$.

Bei den meisten dieser Denkmäler ist der Name des Gladiators im Nominativ auf der obersten Leiste bzw. an der Vorderseite des Schafts neben der Relieffigur angebracht. An drei Pfeilern breitet sich die Inschrift über das obere Profil und den oberen Teil der Vorderseite des Schafts aus ${ }^{44}$.

Viele dieser Pfeiler weisen - wie die Neufunde von den Grabungen am Zugangspodest vor ES3 SK 85 (Taf. 398; 399 Abb. 681-683), SK 86 (Taf. 400. 401) sowie der Pfeiler des Prestor aus demselben Bereich - Einlassungen an den Nebenseiten zur Aufnahme von Schrankenplatten auf. Den Maßen des Pfeilers und der Nuten zufolge waren die Pfeiler des Stephanos und Aithales (SK 85. SK 86) sowie des Prestor vom gleichen Fundortbereich zu einer Brüstung verbunden. H. Taeuber datiert die Pfeiler für Stephanos und Aithales in die 1. Hälfte des 3. Jhs. n. Chr. ${ }^{45}$. Der Pfeiler eines secutor (obige Liste Nr. 6), dessen genauer Fundort nicht bekannt ist, könnte aufgrund der Maße, der Profilierung und der Relieffigur dazu gehört haben.

Die Pfeiler des Rhodios und des Asbolas (Nr. 1. 2) würden zwar in den Maßen ungefähr dazu passen ${ }^{46}$, heben sich aber durch den Charakter ihrer Inschrift - Grabepigramm bzw. -inschrift - von dieser Serie ab, welche nur den Namen des Gladiators nennt. Dazu gehört auch der Pfeiler des Achilleus mit Epigramm von EN1 SK 56 (Taf. 390), der außerdem stärker in den Maßen abweicht und (noch?) keine Nuten aufweist ${ }^{47}$. H. Taeuber datiert letzteren in die 2. Hälfte des 2. Jhs. n. Chr.

Der Pfeiler SK 55 (Taf. 389) für den Gladiator Pardos, nach H. Taeuber aus der 2. Hälfte des 2. Jhs. n. Chr., hebt sich aufgrund seiner reichen Profilierung, des langen Epigramms und der auf den Namen des Toten zugeschnittenen Reliefdarstellung (Pantherweibchen) von der Reihe aller dieser einfacher gestalteten Pfeiler $\mathrm{ab}^{48}$. Eine Nut ist aber auch hier, im rechten Teil der Rückseite, eingearbeitet.

Zwei der in der Liste erfassten Pfeiler sind aus einem größeren Block gearbeitet, der an den Nebenseiten vorspringt. Sie standen offenbar in einem Mauerverband und weisen daher keine Nuten auf (Nr. 3. 4).

Dem Fundort von drei Pfeilern (SK 85 Taf. 398; 399 Abb. 681-683; SK 86 Taf. 400. 401 und Pfeiler des Prestor) vor dem obersten südlichen Zugang zur Cavea zufolge war die Brüstung wohl in der Portikus aufgestellt. Dies wird durch den Fundort von SK 55 und SK 56 im Versturz von EN1 gestützt. Es könnte sich bei dieser Pfeilerserie um eine Stiftung zu Ehren eines munerarius bzw. aus Anlass eines erfolgreichen munus gehandelt haben ${ }^{49}$. Nach der Auflösung der Brüstung wurden die Pfeiler des Stephanos und des

\footnotetext{
${ }^{40}$ Weitere unpublizierte Beispiele im Efes Müzesi, Selçuk. Die umfassende Vorlage aller Gladiatoren-Denkmäler aus Ephesos ist ein Desiderat.

${ }^{41}$ Selçuk, Efes Müzesi ohne InvNr., Fundortangabe laut Skizzenbuch 3098, IvE 1174,4. Vgl. ZüLKAdíroĞLu - İçten 2002, 78.

${ }^{42} \operatorname{IvE} 1174,5$.

${ }^{43}$ Selçuk, Efes Müzesi ohne InvNr. Vgl. ZüLKAdíroĞLu - İçTen 2002, 82 (rechter Pfeiler).

${ }^{44}$ Vgl. oben Nr. 1 (Epigramm), Nr. 2 (Inschrift der Kyrilla für Asbolas) und Pfeiler des Achilleus mit Epigramm (SK 56 Taf. 390 Abb. 644. 645), zum letzteren s. Kap. 8.2, IN 5 (Taf. 411).

${ }^{45}$ Vgl. Kap. 8.2, IN 6. 7 (Taf. 413).

${ }^{46}$ Bei abweichenden Einzelmaßen.

${ }^{47}$ Vgl. Kap. 8.2, IN 5 (Taf. 411).

${ }^{48}$ Vgl. Kap. 8.2, IN 4 (Taf. 412).

${ }^{49}$ Vgl. RumscheID 2001, 130 zu den Funktionen der Gladiatoren-Denkmäler. Vgl. auch die Befunde in Milet, GüNTHER 1985, 133 zu Nr. 4 f. und Aphrodisias, HrychuK Kontoкоsтa 2008, 199 (hier Deutung der Pfeilergruppen als Ausstattung großer Grabkomplexe). In IvE IV, 114 f. sind 5 ephesische Gladiatoren-Denkmäler unterschiedlichen Fundorts zu einem präsumtiven »Monument eines Asiarchen« zusammengestellt. CARTER 2004, 41-68 zu den Asiarchen und Archiereis als Ausrichtern der Gladiatorenspiele im Osten, mit zahlreichen epigrafischen Belegen aus Ephesos.
} 
Aithales SK 85 und SK 86 zu einem unbekannten Zeitpunkt in den Schichten über dem Zugangspodest ES3 gelagert, wo sie sich bis in die 1970er Jahre dicht unter der Hangoberfläche befanden ${ }^{50}$.

Die sekundär an der Marmorstraße angetroffenen Pfeiler waren ursprünglich möglicherweise auch im Theater aufgestellt. Auf der Marmorstraße wurden außerdem weitere Inschriften gefunden, die sich auf die Gladiatur in Ephesos beziehen ${ }^{51}$.

Im Bereich der Portikus wurden auch reich profilierte Bekrönungen von zusammengesetzten Statuenbasen sowie Basen mit reliefierten Siegeskränzen an der Vorderseite, z. T. in Rohform, gefunden. G. StyhlerAydın denkt an eine Funktion der Portikus als Ehrenhalle ${ }^{52}$.

Gladiatorenspiele sind in Ephesos zum ersten Mal unter L. Lucullus nach seinem Sieg über Mithridates überliefert ${ }^{53}$. Die Inschrift einer Statuenbasis des T. Flavius Montanus, die an den Quadern des Mittelpfeilers des Süd-Analemma angebracht war, nennt den Mäzen als Vollender des Theaters in trajanischer Zeit, der das Gebäude in seiner Funktion als archiereus einweihte und Gladiatorenkämpfe und venationes abhielt ${ }^{54}$. Als Austragungsort dieser Spiele kommt (nicht nur) für Ephesos neben dem Theater auch das Stadion in Frage $^{55}$. Das Stadion war offensichtlich ein bevorzugter Schauplatz für derartige Spektakel im Osten des Reichs, wo sehr selten Amphitheater errichtet wurden ${ }^{56}$.

Eine umfassende Vorlage aller Gladiatoren-Denkmäler aus dem Bereich bzw. Umkreis des Theaters (und darüber hinaus) muss einer größeren Studie vorbehalten bleiben.

\subsubsection{Ikonografie, Funktion und präsumtive Aufstellungsorte der nicht zur Ausstattung des Theaters gehörenden Denkmäler}

Der Großteil der hier dokumentierten und interpretierbaren Funde gehörte aufgrund ihres kleinen Formats, aber auch ihrer Ikonografie bzw. ihrer Funktion wegen nicht zur Ausstattung des Theaters. Die meisten Denkmäler stammten ursprünglich aus privatem Ambiente. Diese Objekte gelangten möglicherweise aus den Wohnbezirken nördlich und südlich des Theaters oder durch Erosion des Berghangs des Panayırdağ in das Theater bzw. in die Umgebung der Umfassungsmauer der Cavea. Der Schutt über der Treppe im Süden des Theaters enthielt Reste des Haushaltsinventars, das vor dem Erdbeben im 3. Viertel des 3. Jhs. n. Chr. in der südlich angrenzenden Insula benutzt worden war $^{57} \mathrm{Am}$ Panayırdağ lagen über dem Theater eine große domus und ein Zentralbau, der mit jener offenbar in Verbindung stand, sowie weiter südlich das sog. Banketthaus $^{58}$. Seit 2009 erforscht C. Baier den Tetrakonchos, der in zwei Phasen (ab trajanisch-hadrianischer Zeit) Teil einer Gartenarchitektur bzw. eines Privatbads war und in der 2. Hälfte des 3. Jhs. n. Chr. zerstört wurde $^{59}$. Abgesehen davon muss man sich immer vor Augen führen, dass die Fundsituation im Theater die letzte Phase ab der frühbyzantinischen Zeit spiegelt, als das Gebäude in die Stadtmauer integriert wurde. Es ist immer auch mit Verschleppung von beweglichen Objekten im Bereich der ganzen Stadt zu rechnen.

Unter den kleinformatigen Statuetten sind Götterfiguren und Mischwesen vertreten, u. a. mehrere Darstellungen der Aphrodite ${ }^{60}$. Für einige dieser Statuetten lassen sich Parallelen aus den Hanghäusern anfüh-

${ }^{50}$ Zum Fundort vgl. Kap. 3.7.2.1.

${ }^{51} \mathrm{Vgl}$. IvE 1171. 1173 (Monomachoi und eine familia von Monomachoi).

${ }^{52}$ Vgl. Kap. 10.2.4.2. Weiteres zur Rekonstruktion dieser Portikus und ihrer Ausstattung in der Monografie zur Cavea des Theaters s. STYHLER-AYDIN (in Vorbereitung).

${ }^{53}$ Plut. Luc. 23,1. Vgl. Gelzer 1926, 395 zum Aufenthalt des Lucullus in Kleinasien 71/70 v. Chr.

${ }^{54}$ Heberdey u. a. 1912, 174-176 Nr. 61.62 (fragmentarischer Text); IvE 2061, II sowie 2062; vgl. Kap. 10.2.2.

${ }^{55}$ Zum Einbau von Stützwand und Abschrankung in der Orchestra im ephesischen Theater, die mit den epigrafisch bezeugten Umbauten antoninischer Zeit in Verbindung gebracht wird, vgl. Heberdey u. a. 1912, 44 f. Abb. 86. 92; Kap. 10.2.3. Allgemein zu kaiserzeitlichen Umbauten der Orchestra im Osten des Reichs, die auch als kleine Arenen für Spiele gedeutet werden, vgl. GoLviN 1988, 239-247, zu Ephesos vgl. die Tabellen auf den S. 239. 243.

${ }^{56}$ Zum ephesischen Stadion vgl. Alzinger 1972, 1638 f.; SCherrer 1995, 168 (St. Karwiese); zu den Austragungsorten im Osten vgl. Robert 1971, 35 f.; Welch 1998, 122-125. 127 f.; Rumscheid 2001, 132; Welch 2009, 166-185.

${ }^{57}$ Vgl. Kap. 4.7.2.

${ }^{58}$ KeIL 1932, 8-15; THÜr 2002, 257-264; GROH 2006, 87 f.

${ }^{59}$ Zum Zentralbau: BAIER 2009; BAIER 2010; vgl. zuletzt zum ganzen Areal: BAIER 2013.

${ }^{60}$ Götterfiguren: SK 1 (Taf. 382 Abb. 612); SK 5 (Taf. 383 Abb. 618. 619); SK 6 (Taf. 384 Abb. 620); SK 7 (Taf. 384 Abb. 621) (von Relief oder Gewicht?); SK 8 (Taf. 384 Abb. 622. 623); SK 44? (Taf. 386 Abb. 630); SK 52? (Taf. 388 Abb. 640); SK 73 (Taf. 395 Abb. 666. 667). Mischwesen: SK 40 (Taf. 408) und Pendant (Tritone); SK 62 (Taf. 393 Abb. 659) (Satyr?); SK 71 (Taf. 395 Abb. 665) (Pan?). 
ren $^{61}$. Eine Aufstellung im privaten Ambiente ist auch für die mittelformatige, vor dem Süd-Analemma angetroffene weibliche Gewandstatuette SK 67 anzunehmen. Das gleiche gilt für die kleinformatigen Tierstatuetten SK 36 (Taf. 385 Abb. 624) und SK 75 (Taf. 396 Abb. 670. 671). Als Aufstellungsort von Statuetten am Bühnengebäude bieten sich jedenfalls die Nischen am pulpitum an $^{62}$. In einer dieser Nischen war möglicherweise eine Poseidonstatuette platziert ${ }^{63}$.

Idealplastik aus Buntmarmor stammte laut $\mathrm{H}$. Gregarek zum überwiegenden Teil aus privatem Kontext ${ }^{64}$. Der kleinformatige Triton SK 40 (Taf. 408) und das Pendant aus bigio antico wären als Schmuck eines kleinen Brunnens im privaten Ambiente denkbar. Was die Statuettenfragmente aus rotbraunem Kalksinter SK 76 (Taf. 410 Abb. 730), SK 83 (Taf. 410 Abb. 731) und SK 84 (Taf. 410 Abb. 732) betrifft, so ist die Verwendung von verschiedenfarbigem Kalksinter für klein- und großformatige Porträtbüsten sowie für Porträtstatuetten in den Hanghäusern bezeugt ${ }^{65}$. Die Fragmente SK 76, SK 83 und SK 84 sind zu klein, um ihre Funktion bestimmen zu können; es wäre sowohl eine Interpretation als Götterstatuette als auch als weibliche Porträtstatuette in idealem Körpertypus möglich.

Die auf den Basen der Salutaris-Stiftung im Theater temporär aufgestellten kleinformatigen Bildwerke von Herrschern, Göttern, Heroen und Personifikationen aus Edelmetall sind in der Stiftungsinschrift dokumentiert ${ }^{66}$.

Porträtbüsten SK 41 (Taf. 386 Abb. 629), SK 80 (Taf. 397 Abb. 674. 675), SK 81 (Taf. 397 Abb. 676) sind sehr selten im römischen Theater bezeugt; die temporäre Aufstellung von Büsten des Kaisers und der kaiserlichen Familienmitglieder ist jedoch literarisch und inschriftlich überliefert ${ }^{67}$. Für die Aufstellung im ephesischen Theater ist wieder die Salutaris-Inschrift mit den silbernen »eikones« - was hier wohl leicht transportable Porträts in Büstenform meint - des Trajan und der Plotina anzuführen ${ }^{68}$. Die über dem Zugangspodest ES3 gefundene, am besten erhaltene Büste SK 80 mit dem rechten Arm in der `Mantelschlinge könnte aufgrund ihres Darstellungstypus auch aus dem sepulkralen Bereich stammen ${ }^{69}$.

Die Tischfüße mit Felidenprotomen waren ursprünglich im Wohnbereich aufgestellt; die besser erhaltenen Fragmente SK 59 (Taf. 392 Abb. 653. 654) und SK 78 (Taf. 396 Abb. 672. 673) lassen sich typologisch mit Exemplaren aus den Hanghäusern verbinden.

Aus dieser vor allem dem privaten Ambiente zuzuweisenden Gruppe fallen drei Denkmäler heraus: der von einem Hochrelief stammende bärtige ideale Kopf SK 48 (Taf. 387 Abb. 633. 634) vom Bereich südlich des Bühnengebäudes, das Sarkophagfragment SK 57 (Taf. 391 Abb. 646. 647) von der nördlichen Umfassungsmauer, und die aus einer Bildhauerwerkstatt stammenden kleinformatigen Bildwerke SK 72 (Kybele, Taf. 395 Abb. 668. 669), SK 7 (Aphrodite-Relief oder Gewicht? Taf. 384 Abb. 621) und SK 71 (Pan? Taf. 395 Abb. 665) ${ }^{70}$.

Insgesamt ist also die `Ausbeuteく an Denkmälern, die tatsächlich zur Ausstattung des Theaters gehörten, gering. Das Spektrum jener Denkmäler, die anderen ursprünglichen Aufstellungsorten zuzuweisen sind, bietet jedoch einen interessanten Ausschnitt aus der Fundsituation in einem öffentlichen Gebäude der kaiserzeitlichen Stadt, dessen Funktion in frühbyzantinischer Zeit verändert wurde. Viele der hier dokumentierten Objekte fallen jedoch schlicht in die Rubrik >abgelegter` oder >angesammelter Schutt.

\footnotetext{
${ }^{61}$ z. B. für SK 1 (Taf. 382 Abb. 612-615); SK 8 (Taf. 384 Abb. 622. 623); SK 73 (Taf. 395 Abb. 666. 667). Auch der sepulkrale Kontext ist für derartige Statuetten aus Kleinasien bezeugt, vgl. FILGES 1999, 425.

${ }^{62} \mathrm{Vgl}$. Heberdey u. a. 1912, 45 f. Abb. 91.

${ }^{63}$ Aurenhammer 1990, 26-28 Nr. 5 Taf. 4 f.

${ }^{64}$ Gregarek 1999, 20. In ihrer 1999 erschienenen Studie führt die Autorin keine aus Theatern stammende Idealplastik aus Buntmarmor an. Vgl. jedoch einen großformatigen Triton aus »marmo bigio«, wahrscheinlich aus dem Theater von Hierapolis, PENSABENE 2011, 56 Abb. 3. 23. Porträt: bichrome Statue der Matidia Minor (?) als Aura aus dem Theater von Sessa Aurunca, s. RugGI D’ARAGONA 2002, 325 f. Nr. 23.

${ }^{65}$ Büsten: Aurenhammer 2003, 187. 207 S 115 Taf. 117; Rathmayr 2005a, 228 S 7; Rathmayr 2005b, 284 f.; Christof $2010,660$. 665 B-S 9. B-S 10 Taf. 284. Statuette eines sitzenden Togatus aus der Wohneinheit 2 des Hanghauses 2 (Toga aus Kalksinter): AUINGer 2010, 666-669 Taf. 290. 493.

${ }^{66}$ Rogers 1991, 83-115 zur Prozession: S 101 zum Aufenthalt im Theater; 152-185 zur Stiftungsinschrift.

${ }^{67}$ PeKÁRy 1985, 47; Fuchs 1987, 176. 185 für den Westen des Reichs.

${ }^{68}$ Vgl. Rogers 1991, Text S. 158 f. (griechischer Originaltext Zeilen 150-153); Lahusen 1999, 158 f. Vgl. SturgeOn 2004a, 187189 Nr. 73 Taf. 64 zu einer vergoldeten Miniaturbüste des Antoninus Pius (?), ihrer Vermutung zufolge ein Objekt des Kaiserkults, das auf dem Weg in oder aus dem Theater von Korinth verlorenging.

${ }^{69} \mathrm{Vgl}$. FitTschen u. a. 2010, 172 zu Nr. 170.

${ }^{70}$ SK 7 (Taf. 384 Abb. 621) stammt aus dem Schutt in der Kammer D8, dessen Zugehörigkeit zum Theater nicht gesichert ist.
} 


\subsubsection{Katalog der Funde aus Marmor ${ }^{71}$}

\section{BÜHNENGEBÄUdE: LOGEION}

\section{SK 1}

Torso von Aphroditestatuette,

Typus Louvre/Neapel, 2. Jh. n. Chr.

Selçuk, GHD, FK 34/03

Logeion, S 2/2003, SE L36; 2003

Mittelkörniger weißer Marmor

$\mathrm{H} 5,3 \mathrm{~cm}$

Erh. Torso bis etwa in Hüfthöhe, mit Ansatz des 1. Oberarms Abgeschlagen Ansatz des r. Oberarms. Der Kopf war ursprünglich angesetzt. Bestoßungen an Inkarnat und Gewand. RS besonders im $r$. Teil beschädigt (hier ist der ursprünglich am Rücken herabfallende Mantel abgebrochen)

Das charakteristische Motiv der vom Chiton entblößten linken Brust, die sichtbare rechte Achsel und der somit einst angehobene rechte Oberarm weisen das Fragment als Nachbildung des Aphrodite-Typus Louvre/Neapel aus ${ }^{72}$. Der runde Chitonsaum unter der rechten Achsel und das Faltenbündel darunter entsprechen nicht dem Typus ${ }^{73}$. Der Bogen des Chiton fällt am ephesischen Fragment besonders tief unter die linke Brust hinab. Im Vergleich zu den von A. Filges zusammengestellten, z. T. aus Side stammenden kleinformatigen Statuetten nach dem Typus mit profilierten Basen ${ }^{74}$ ist der Chiton am ephesischen Fragment stofflicher wiedergegeben. Die von der rechten Brust ausgehenden, schematisch gekerbten Falten finden sich jedoch auch an dem Fragment; an den Exemplaren von der kleinasiatischen Südküste sind diese in das flach anliegende Gewand 'geritzt<. Angesichts der stärkeren Stofflichkeit des Gewands ist das ephesische Fragment wahrscheinlich früher zu datieren als die von Filges anhand der profilierten Basentypen in das spätere 2. bzw. in das 3. Jh. n. Chr. gesetzten Statuetten von der Südküste Kleinasiens ${ }^{75}$.

Zwei weitere kleinformatige Nachbildungen dieses AphroditeTypus in handwerklicher Manier wurden in den Hanghäusern von Ephesos gefunden ${ }^{76}$. Sie stammen offenbar aus der gleichen Werkstatt und sind aufgrund ihrer bescheidenen Qualität schwer zu datieren. Die Zerstörung des Hanghauses 2 durch das Erdbeben nach der Mitte des 3. Jhs n. Chr. gibt einen terminus ante quem. Wahrscheinlich sind die Statuetten in das fortgeschrittene 2. Jh. n. Chr. zu setzen ${ }^{77}$.

${ }^{71}$ Der technische Teil jeder Katalognummer umfasst: Aufbewahrungsort, Fundort und Fundjahr, Material, Maße, Erhaltungszustand, Technik bzw. Bearbeitung, Fundkontext sowie, falls vorhanden, Literaturangaben. Darauf folgt die Einordnung mit Beschreibung, Interpretation und Datierungsvorschlag.

${ }^{72}$ Zum Typus BrinKe 1991; BrinKe 1996.

${ }^{73}$ Vgl. die Statue im Louvre mit der V-förmigen Öffnung des Chitons, BRINKe 1996, 19 f. R 3 Taf. $1 \mathrm{f}$.

${ }^{74}$ Filges 1999, 378. 384 f. 427 Nr. 6-11 Taf. 34, 2-4; 35.

${ }^{75}$ Filges 1999, 402 f. zur Datierung der profilierten Statuenbasen.

${ }^{76}$ Aurenhammer 2003, 175. 203 S 77 Taf. 16; Rathmayr 2005a, 216-218. 220 f. 228 f. S 14 Taf. 142, 1

${ }^{77}$ Zur Datierung der Statuette aus der Wohneinheit 4 des Hanghauses 2 (auf nicht profilierter Basis): RATHMAYR $2005 \mathrm{a}, 216$.
Das neue Fragment aus dem Theater könnte ursprünglich auch aus dem Wohnbereich stammen. Statuetten dieses Typus wurden aber auch im sepulkralen Kontext gefunden ${ }^{78}$.

\section{SK 2}

Fragment von Tischfuß mit Felidenpranke

Selçuk, GHD; FK 10/06

Beim Reinigen des Logeion (Streufund); 2006

Grobkörniger hellgrauer Marmor

H $12 \mathrm{~cm}$, SockelH max. 2,5 cm, B am Sockel max. $6 \mathrm{~cm}, \mathrm{~T} 15 \mathrm{~cm}$ L. Teil abgeschlagen. Starke Mörtelspuren.

Erhalten haben sich zwei Krallen einer Felidenpranke auf niedrigem Sockel ${ }^{79}$.

\section{KAMMER D8}

SK 3

Taf. 383 Abb. 616

Fragment eines weiblichen Porträts, severisch

Selçuk, GHD; FK 100/04

Kammer D8, Reinigung bis OK der Fundamente; 2004

Feinkörniger weißer Marmor

$\mathrm{H} 10 \mathrm{~cm}, \mathrm{~B} 8 \mathrm{~cm}, \mathrm{~T} 8 \mathrm{~cm}$

Erh. Fragment mit Teil der 1. Hälfte der Stirn mit Braue, Rest des Oberlids und Ansatz des Augapfels. Rundum abgebrochen. Bestoßungen an Braue und Stirnhaar

Inkarnat fein geglättet, aber nicht poliert. Brauenhaar gespitzt. Haarsträhnen etwas rauer belassen.

Das Fragment gehörte zu einem lebensgroßen weiblichen Porträt. Es umfasst einen Teil der linken Stirnhälfte, das zur Seite und nach oben gestrichene Haar sowie die linke Braue mit dem Rest des schmalen, leicht vorkragenden Oberlids. Das Haar ist in Form von schmalen Strähnen gekerbt und geritzt, die Härchen an der stark ansteigenden Braue sind unregelmäBig gespitzt. Die Details sind in harter Manier gearbeitet. Eine vergleichbare Technik der Haarwiedergabe findet sich an severischen Porträts mit Nestfrisur und schlicht zurück- oder zur Seite gestrichenem $\mathrm{Haar}^{80}$. Eine Gruppe von weiblichen severischen Porträts dieser Art stammt auch aus Ephesos ${ }^{81}$.

SK 4

Taf. 383 Abb. 617

Fragment eines archaistischen Kopfs

Selçuk, GHD; FK 100/04

Kammer D8, Reinigung bis OK der Fundamente; 2004

Grobkörniger grauer Marmor

H $12 \mathrm{~cm}$, B 12,5 cm, T 5,5 cm

Erh. Scheibe des Gesichtsfelds; RS abgeschlagen. In Augenhöhe abgeschlagen; r. Auge ganz verloren, vom 1. Auge nur Rest des 1 . Augenwinkels sowie gekerbter Ansatz der ansteigenden

${ }^{78}$ FILGES 1999, 425.

${ }^{79}$ Bezüglich der Fragmente von Tischfüßen vgl. unter den besser erhaltenen Exemplaren SK 59 (Taf. 392 Abb. 653. 654); SK 78 (Taf. 396 Abb. 672. 673).

${ }^{80}$ z. B. FitTSChen - ZANKer 1983, Nr. 125 Taf. 157; Nr. 137 Taf. 163; Nr. 138 Taf. 164; Nr. 142 Taf. 169; Nr. 149 Taf. 178.

${ }^{81} \mathrm{Vgl}$. z. B. İNan - Rosenbaum 1966, Nr. 153 f. Taf. 89; Nr. 163 Taf. 95. Nr. 164 Taf. 96. 
Braue erh. Abgebrochen Nase, der Rand der r. Wange, entlang der 1. Wange und des Kinns. Lippen bestoßen, Inkarnat beschädigt. Oberfläche sehr angegriffen, verwittert.

Am Inkarnat stellenweise dichte Raspelarbeit. Mundspalte und Nasenlöcher gebohrt.

An dem lebensgroßen, runden Gesicht fällt der geöffnete Mund auf, der etwa gleich breit wie die Nase ist. Der Lippensaum ist nicht angegeben. Die vollen Wangen stauen sich an den Nasenflügeln. Ein Grübchen bildet sich unter der Unterlippe. Das Kinn geht in ein hängendes Doppelkinn über.

Das Gesichtsfragment entspricht in seiner breiten Form, den vollen Wangen, die von den Nasenflügeln und der Mundpartie in charakteristischer Weise abgesetzt sind, und dem offenbar schmalen linken Auge archaistischen Köpfen wie jenen des Typus Brüssel-Konservatorenpalast, dessen Repliken bis in das 1. Jh. v. Chr. zurückreichen ${ }^{82}$. Die Öffnung des Munds weist vielleicht darauf hin, dass es sich ursprünglich um den Kopf einer Herme handelte ${ }^{83}$. Von dem Kopf ist jedoch zu wenig erhalten, als dass er sich chronologisch genauer eingrenzen ließe.

\section{SK 5}

Taf. 383 Abb. 618. 619

\section{Statuette einer thronenden Gottheit}

Selçuk, GHD; FK100/04

Kammer D8, Reinigung bis OK der Fundamente; 2004

Grobkörniger hellgrauer Marmor

H $12 \mathrm{~cm}$, B 9,5 cm, T 10,5 cm

Erh. Unterkörper und Beine; ohne Füße. Parallel zur 1. Körperseite verläuft ein vertikaler, an der Außenseite abgebrochener stegartiger Ansatz. RS großteils abgebrochen, doch Reste der originalen Oberfläche erh. R. Seite des Sitzmöbels abgebrochen. Grob bearbeitete US in Höhe des Mantelsaums, auch zwischen den Beinen erh.

Mantel an beiden Knien, am r. Oberschenkel und an dessen Außenseite, am 1. Unterschenkel beschädigt. Bräunliche Patina, RS braungrau verwittert. Sinterspuren.

Die Gottheit thront auf einem niedrigen Sitz, der noch an der Rückseite (unter dem Ansatz des rechten Glutäus) und an der rechten Seite (dort als Bruchstelle) zu erkennen ist. Da die Rückseite zum Großteil abgebrochen ist, könnte es sich aber auch um einen Thron handeln. Das rechte Bein ist vorgeschoben. Der Unterkörper ist bedeckt. Der Mantel liegt über den Oberschenkeln und fällt über den Beinen, entlang der Außenseite des linken Beins und vom Sitz entlang der Außenseite des rechten Beins herab. Der untere Mantelsaum verläuft über den unteren Teil der Unterschenkel. Breite, brettartige Spannfalten ziehen schräg über die Vorderseite der Beine und über die $\mathrm{Au}$ ßenseite des rechten Beins, getrennt durch tiefe, muldenförmige Faltentäler. Derartige vertikale Faltentäler finden sich auch am Unterkörper. Neben der an der linken Körperseite herabfallenden Mantelbahn befindet sich ein langer, vertikaler, außen abgebrochener stegartiger Ansatz.

Deutung und Datierung fallen angesichts des schlechten Erhaltungszustands und der handwerklichen Bearbeitung schwer.

\footnotetext{
${ }^{82}$ HerdeJürgen 1972, 299-306; RumscheId 1992， 83-98; Fuchs 1999, 36.

${ }^{83}$ Vgl. die Doppelhermen in der Ny Carlsberg Glyptotek, Kopenhagen, und im Musée Rodin, Paris, HerdeJürgen 1972, 300-302 Abb. 4-6; RuMscheID 1992, 92 f. Abb. 13-16.
}

Der lange stegartige Ansatz an der linken Körperseite spricht - wenn es sich dabei um ein Attribut handelt - gegen die Interpretation als Kybele. Die bearbeitete Unterseite des Fragments in Höhe des Mantelsaums und zwischen den Beinen weist auf eine männliche Gottheit.

\section{SK 6}

Taf. 384 Abb. 620

Kleinformatiger männlicher Torso im Mäntelchen,

kaiserzeitlich

Selçuk, GHD; FK 100/04

Kammer D8, Reinigung bis OK der Fundamente; 2004

Grobkörniger hellgrauer Marmor

H $14 \mathrm{~cm}$

Erh. Fragment der r. Hälfte des Torsos mit r. Schulterlinie, Stück der r. Flanke und Fragment der r. Hälfte des Rückens. R. Oberarm abgeschlagen. Beschädigt Fibel, Gewandfalten. Abgebrochener hoher Ansatz entlang des Nackens. Auch Oberfläche an der VS unter diesem Ansatz abgebrochen. Oberfläche generell in schlechtem Zustand. Mörtelspuren.

Oberfläche war einst am Inkarnat der VS recht gut geglättet. Auch Inkarnat und Gewand an der RS geglättet.

Dargestellt war eine nackte männliche Statuette mit einem an der rechten Schulter mittels einer scheibenförmigen Fibel gehefteten Mäntelchen. Teile des Inkarnats sind am Brustansatz, an der rechten Flanke und dahinter zu sehen. Von der Fibel ziehen zwei schräge Falten an der Vorderseite abwärts. Das Gewand bedeckte die rechte Schulterlinie und in schräger Bahn den Großteil des Rückens; dort ist es in flachen Faltenbahnen summarisch gegliedert. Das Mäntelchen fiel also wohl in der Folge über den linken Arm herab. Bei dem abgebrochenen hohen >Ansatz « entlang des Nackens könnte es sich um einen Rest des Haars handeln.

Das Motiv des an der rechten Schulter gefibelten und über dem linken Arm herabfallenden Mantels wurde in der Kaiserzeit für eine Reihe von Götterfiguren, aber auch für Porträtstatuen verwendet. Chr. Landwehr spricht dabei von $>$ Konzeptfiguren ${ }^{84}$. Die Führung des Gewands über dem linken Arm wurde offenbar erst im Laufe des 2. Jhs. n. Chr. entwickelt ${ }^{85}$. Bei dem ephesischen Fragment wird es sich angesichts des Formats vielleicht eher um eine Götterfigur gehandelt haben. Für Ephesos sind z. B. Hermes- und Ganymedfiguren mit dieser Mantelführung bezeugt ${ }^{86}$.

\section{SK 7}

Taf. 384 Abb. 621

\section{Unfertige Figur einer Aphrodite Pudica}

Selçuk, GHD; FK 100/04

Kammer D8, Reinigung bis OK der Fundamente; 2004

Mittelkörniger weißer Marmor

H $16,5 \mathrm{~cm}, \mathrm{~B} 8 \mathrm{~cm}$, T $8 \mathrm{~cm}$

Block abgeschlagen in Höhe des Oberkopfs, unten etwa in Kniehöhe, an der r. NS und der ganzen RS. Ein Stück der 1. NS ist erh., an der Außenseite des 1. Oberarms bricht der schmale Streifen jedoch direkt zur RS um. Bräunliche Patina. Mörtelreste, vor allem an der RS.

\footnotetext{
${ }^{84}$ LANDwehr 1998, 147-171 Abb. 18-35.

${ }^{85}$ LANDWEHR 1998, 159.

${ }^{86}$ Vgl. Aurenhammer 1990, Nr. 6 Taf. 8 sowie Nr. 101 Taf. 71. Vgl. auch den Torso in Aurenhammer 1990, Nr. 118 Taf. 84 c. d.
} 
Grobe Meißelarbeit an der VS sowie an der zur RS umbrechenden 1 . Seite.

Die Figur der Aphrodite Pudica, in der Nachfolge der Capitolinischen Venus ${ }^{87}$, ist grob aus dem Block gehauen: Im Umriss sichtbar sind der Kopf und der Leib mit den Oberschenkeln sowie den Armen. Der rechte Arm ist unter den Brüsten quer über den Leib gelegt, der linke ist schräg über den Leib geführt und bedeckt die Scham. Die Beine sind eng nebeneinander gestellt, der rechte Oberschenkel ist vorgeschoben.

Der Kopf steht noch in Bosse, die Hände sind noch nicht ausgearbeitet. Außerdem sind die Oberschenkel und der Streifen neben der linken Seite des Kopfs und an der linken Flanke der Figur grob mit dem Meißel bearbeitet, während die Oberfläche der Arme und des Streifens an der rechten Seite der Figur bereits in einem fortgeschrittenen Bearbeitungsstadium erscheinen. Wahrscheinlich war die Figur als Teil eines Reliefs oder als Dekor eines Gewichts gedacht, wurde jedoch verworfen.

Diese Figur im Produktionsprozess ist wie SK 72 (Kybelestatuette, Taf. 395 Abb. 668. 669) wichtig für den ’handfesten Nachweis von Bildhauer-Werkstätten in Ephesos. Unfertige Aphrodite Pudica-Statuetten aus serienmäßiger Produktion wurden im Bereich der Stoa Philipps V. auf Delos sowie in der fabrica von Chemtou gefunden ${ }^{88}$.

\section{SK 8}

Taf. 384 Abb. 622. 623

\section{Torso einer Aphrodite Pudica-Statuette}

Selçuk, GHD; FK 100/04

Kammer D8, Reinigung bis OK der Fundamente; 2004

Mittelkörniger weißer Marmor

$\mathrm{H} 9,5 \mathrm{~cm}$

Erh. beide Oberschenkel und Teil der Glutäen. Abgebrochene Stellen an der VS des l. Oberschenkels, an der RS beider Schenkel, am 1. Glutäus, runder Ansatz an der Außenseite des 1. Oberschenkels unter dem Glutäus $(2,2 \times 2 \mathrm{~cm})$. Zwei horizontale, übereinander liegende Puntelli an der VS des 1. Oberschenkels. An der VS zahlreiche Wurzelfasern.

Material zwischen der oberen Partie der Schenkel nicht abgearbeitet. Glutäen grob von den Schenkeln abgesetzt.

Diese handwerkliche Arbeit in der Nachfolge der Knidischen Aphrodite stellte die nackte Aphrodite mit belastetem rechten Bein und vorgeschobenem linken Oberschenkel dar ${ }^{89}$. Die Schenkel sind lang. Die Puntelli am linken Oberschenkel stellen wohl den Rest der auf dem Schenkel aufliegenden rechten Hand dar.

SK 9

Fragment von unterlebensgroßem, nacktem männlichen Torso?

Selçuk, GHD; FK 100/04

Grobkörniger hellgrauer Marmor

Kammer D8, Reinigung bis OK der Fundamente; 2004

H $29 \mathrm{~cm}$

VS fast zur Gänze abgeschlagen und versintert, erh. Oberfläche

${ }^{87}$ Vgl. dazu Delivorrias 1984, $52 \mathrm{f}$

${ }^{88}$ Delos: Jockey 1993, 90-93; Chemtou: Rakoв 1994, 107. 116 Taf. 116 f.; RaKob 1997, 13. 17 Abb. 35; Gregarek 1999, 48 f. Abb. 14. 180 B8.

${ }^{89}$ Vgl. z. B. Delivorrias 1984, 51 Nr. 396; Jentel 1984, 155 Nr. 3. 7. stellenweise abgebrochen, abgeplatzt und bestoßen. Bräunlich grau verwittert.

Erhalten haben sich Außen- und Rückseite des Ansatzes eines rechten Arms sowie ein Teil des Rückens. Der Rücken ist flach gebildet und weist eine vertikale Mulde auf. Eine Staufalte bildet sich zwischen dem Ansatz des Oberarms und der rechten Flanke.

\section{SK 10}

Fragment von etwas überlebensgroßer

linker Hand mit Attribut

Selçuk, GHD; FK 100/04

Kammer D8, Reinigung bis OK der Fundamente; 2004

Grobkörniger hellgrauer Marmor

H $19,5 \mathrm{~cm}$

Zeige- und Mittelfinger sind nur im Ansatz, Daumen und Ringfinger sind fast zur Gänze erh. Kleiner Finger abgebrochen, nur im Umriss zu sehen. Erh. Oberfläche stellenweise stark beschädigt, stark verwittert, bräunlich grau verfärbt

Erhalten hat sich eine Hand mit dem Ansatz des Gelenks. Die Finger schließen sich um einen stabförmigen Gegenstand. Der Daumen liegt an der Unterseite des Attributs, die längeren Finger sind über die Rundung des Gegenstands gebogen.

SK 11

Fragment von etwas überlebensgroßer rechter Hand

Selçuk, GHD; FK 100/04

Kammer D8, Reinigung bis OK der Fundamente; 2004

Grobkörniger hellgrauer Marmor

L $11,5 \mathrm{~cm}$, B $10,5 \mathrm{~cm}$

Erh. haben sich ein Teil des Handrückens und der Ansatz der abgebogenen Finger (Mittel-, Ring- und kleiner Finger sowie Daumen), und die Innenfläche der Hand. Mörtelspuren, Wurzelfasern.

\section{SK 12}

Lebensgroßer Unterarm

Selçuk, GHD; FK 100/04

Kammer D8, Reinigung bis OK der Fundamente; 2004

Grobkörniger hellgrauer Marmor

L $18,5 \mathrm{~cm}$

Der Arm ist am Handgelenk gebrochen. An der Armbeuge ist gerade noch ein winziger Rest des Ansatzes des Oberarms erh. Oberfläche stark bestoßen, bräunlich grau verfärbt, Mörtelspuren.

\section{SK 13}

\section{Armfragment}

Selçuk, GHD; FK 100/04

Kammer D8, Reinigung bis OK der Fundamente; 2004

Feinkörniger weißer Marmor

L $8,5 \mathrm{~cm}$, Dm $16,5 \mathrm{~cm}$

Oberfläche stellenweise versintert. Leichte bräunliche Patina. Wurzelfasern. Bestoßungen.

Oberfläche mäßig geglättet.

Erhalten hat sich die etwa halbe Rundung eines Armfragments (wohl r. Oberarm) mit Gewandrest und darunter dem Ansatz des Inkarnats. Das Gewand weht zur Innenseite des Arms. Schräg geführte, flache Falten sind angegeben. Zur Innenseite des Arms zu 
werden die Falten immer breiter. An der äußersten Falte links hängt ein Gewicht. Der Gewandsaum ist durch eine Ritzlinie angegeben.

\section{SK 14}

Unterschenkel einer Statuette

Selçuk, GHD; FK 100/04

Kammer D8, Reinigung bis OK der Fundamente; 2004

Mittelkörniger hellgrauer Marmor

L $19 \mathrm{~cm}$

Erh. hat sich der rechte, durchgestreckte Unterschenkel ohne

Knie. Oben und unten sowie Teil der RS abgebrochen. An der

Außenseite 10,5 cm langer Ansatz. Mörtelspuren.

VS gut geglättet, an der RS Raspelarbeit.

\section{SK 15}

Unterschenkelfragment einer Statuette

Selçuk, GHD; FK 100/04

Kammer D8, Reinigung bis auf OK der Fundamente; 2004

Mittel- bis grobkörniger hellgrauer Marmor

L $19 \mathrm{~cm}$

Oben und unten gebrochen. Zwei abgebrochene Ansätze an der RS: ein länglicher, sehr schmaler Ansatz an der Außenseite (L $11 \mathrm{~cm})$; an der RS der Wade ovaler Puntello $(5 \times 3 \mathrm{~cm})$. Stark bestoßen, graubraun verfärbt.

\section{SK 16}

Gliedmaßenfragment

Selçuk, GHD; FK 100/04

Kammer D8, Reinigung bis auf OK der Fundamente; 2004

Grobkörniger hellgrauer Marmor

$\mathrm{L} 21 \mathrm{~cm}$

Oben und unten gebrochen, an einer originalen Seite großflächiger Bruch. Oberfläche versintert.

\section{SK 17}

\section{Gliedmaßenfragment (Bein?)}

Selçuk, GHD; FK 100/04

Kammer D8, Reinigung bis auf OK der Fundamente; 2004

Grobkörniger hellgrauer Marmor

$\mathrm{L} 14 \mathrm{~cm}$

Oben, unten und an einer Seite gebrochen. Oberfläche stark bestoßen, dunkelgrau verfärbt.

\section{SK 18}

Lebensgroßes Gliedmaßenfragment

Selçuk, GHD; FK 100/04

Kammer D8, Reinigung bis auf OK der Fundamente; 2004

Grobkörniger hellgrauer Marmor

$\mathrm{L} 13 \mathrm{~cm}$

Oben und unten gebrochen, an einer Seite offenbar abgebrochener Ansatz einer ansteigenden originalen Oberfläche. Oberfläche versintert, bräunlich grau verfärbt.

\section{SK 19}

Gliedmaßenfragment, gehörte vielleicht zu SK 15

Selçuk, GHD; FK 100/04

Kammer D8, Reinigung bis auf OK der Fundamente; 2004

Mittel- bis grobkörniger hellgrauer Marmor

$\mathrm{L} 13 \mathrm{~cm}$

Oben und unten gebrochen. Stellenweise versintert.

VS glatt poliert, an der weniger sichtbaren Seite Raspelarbeit.
SK 20

Gliedmaßenfragment?

Selçuk, GHD; FK 100/04

Kammer D8, Reinigung bis auf OK der Fundamente; 2004

Grobkörniger hellgrauer Marmor

$\mathrm{H} 9 \mathrm{~cm}$

Oben und unten gebrochen. Verwitterte Oberfläche.

\section{SK 21}

Gliedmaßenfragment (Arm?)

Selçuk, GHD; FK 100/04

Kammer D8, Reinigung bis auf OK der Fundamente; 2004

Grobkörniger hellgrauer Marmor

$\mathrm{L} 8,5 \mathrm{~cm}$

Oben und unten gebrochen. Oberfläche einst geglättet, jetzt leicht versintert.

\section{SK 22}

Gliedmaßenfragment

Selçuk, GHD; FK 100/04

Kammer D8, Reinigung bis auf OK der Fundamente; 2004

Grobkörniger hellgrauer Marmor

$\mathrm{L} 7 \mathrm{~cm}$

Oben und unten gebrochen. Oberfläche bestoßen. Grau verwittert, Mörtelspuren.

\section{SK 23}

Gliedmaßenfragment

Selçuk, GHD; FK 100/04

Kammer D8, Reinigung bis auf OK der Fundamente; 2004

Grobkörniger hellgrauer Marmor, kristallzuckerartig abbrechend

L $6 \mathrm{~cm}$

Oben und unten gebrochen.

Oberfläche gut geglättet.

\section{SK 24}

Plinthenfragment von Statuette mit Fußfragment

Selçuk, GHD; FK 100/04

Kammer D8, Reinigung bis auf OK der Fundamente; 2004

Mittelkörniger hellgrauer, blaustichiger Marmor

H 5,5 cm, PlinthenH 2-3 cm

Erh. hat sich nur ein Stück der Außenkante der Plinthe, darauf drei Zehen eines 1. Fußes (es fehlen die zwei kleinsten Zehen). Die OS der Plinthe fällt leicht von hinten nach vorne ab.

Raspelarbeit an OS der Plinthe. Zahneisen an der Plinthenkante. US grob gespitzt. Oberfläche stellenweise braun verfärbt.

\section{SK 25}

\section{Gewandfragment}

Selçuk, GHD; FK 100/04

Kammer D8, Reinigung bis auf OK der Fundamente; 2004

Mittelkörniger hellgrauer Marmor

H $19,5 \mathrm{~cm}$

Allseits abgebrochen. Faltenkanten bestoßen. Bräunlich grau verfärbt, versintert, Mörtelreste.

Es handelt sich um ein Fragment guter Qualität mit drei fein ausgearbeiteten, scharfkantigen Faltenbahnen.

\section{SK 26}

Gewandfragment

Selçuk, GHD; FK 100/04 
Kammer D8, Reinigung bis auf OK der Fundamente; 2004 Grobkörniger weißer Marmor

H $18,5 \mathrm{~cm}$

Rundum gebrochen. Auch an VS stark beschädigt. Nur Reste von drei Faltenbahnen erh. Oberfläche bräunlich verfärbt.

\section{SK 27}

\section{Gewandfragment}

Selçuk, GHD; FK 100/04

Kammer D8, Reinigung bis auf OK der Fundamente; 2004

Mittelkörniger hellgrauer Marmor

H $16,5 \mathrm{~cm}$

Erh. hat sich eine Partie mit einer Reihe von bogenförmigen, nach links schwingenden Falten mit scharfen Kanten. Rundum gebrochen. Faltenkanten bestoßen. Mörtelspuren.

\section{SK 28}

Gewandfragment, vollplastisch gearbeitet

Selçuk, GHD; FK 100/04

Kammer D8, Reinigung bis auf OK der Fundamente; 2004

Grobkörniger hellgrauer Marmor

H $15 \mathrm{~cm}$, B $8,5 \mathrm{~cm}$, T $8 \mathrm{~cm}$

Oben und unten gebrochen, eine Falte fast zur Gänze abgeschlagen. Faltenkanten bestoßen. Stellenweise leicht bräunliche Patina, Wurzelfasern.

An der Vorderseite haben sich zwei breite, lang herabfallende Falten erhalten sowie der Rest einer weiteren Falte. Die weniger sichtbare Seite weist eine breitere flache Faltenbahn auf, die durch parallele Kerben gegliedert ist.

\section{SK 29}

\section{Gewandfragment}

Selçuk, GHD; FK 100/04

Kammer D8, Reinigung bis auf OK der Fundamente; 2004

Mittelkörniger hellgrauer Marmor

L $15,5 \mathrm{~cm}$

Rundum Bruch, Faltenkanten beschädigt. Oberfläche versintert, Wurzelfasern.

Oberfläche ursprünglich gut geglättet.

Die Falten sind in zwei Etagen angeordnet: An einer Bahn der oberen Etage hängt ev. ein Gewicht, während der untere Rand der tiefer liegenden Gewandpartie von einer Rille begleitet wird.

\section{SK 30}

\section{Gewandfragment}

Selçuk, GHD; FK 100/04

Kammer D8, Reinigung bis auf OK der Fundamente; 2004

Mittelkörniger hellgrauer Marmor

H $14 \mathrm{~cm}$

Erh. sehr plastisch gearbeitetes Faltenbündel. Rundum angebrochen. Oberfläche versintert, Mörtelspuren.

\section{SK 31}

\section{Gewandfragment}

Selçuk, GHD; FK 100/04

Kammer D8, Reinigung bis auf OK der Fundamente; 2004

Grobkörniger hellgrauer, blaustichiger Marmor

H $13,5 \mathrm{~cm}$

Erh. Fragment mit zwei parallelen, unterschnittenen Falten.
Oben und unten gebrochen. VS großteils abgeschlagen. Oberfläche bräunlich verfärbt,

RS flach, nur schematisch durch Kerben gegliedert.

\section{SK 32}

\section{Gewandfragment}

Selçuk, GHD; FK 100/04

Kammer D8, Reinigung bis auf OK der Fundamente; 2004

Mittel- bis grobkörniger hellgrauer, blaustichiger Marmor

$\mathrm{H} 12,5 \mathrm{~cm}$

Erh. Reste von drei Falten; auf einer sitzt abgebrochener kleiner Puntello. Rundum abgebrochen. Falten beschädigt. Oberfläche bräunlich verfärbt. An RS Mörtelspuren.

\section{SK 33}

\section{Gewandfragment}

Selçuk, GHD; FK 100/04

Kammer D8, Reinigung bis auf OK der Fundamente; 2004

Grobkörniger hellgrauer Marmor

L $10,5 \mathrm{~cm}$

Oben, unten und an einer Seite gebrochen. Oberfläche bestoßen, grau verwittert.

\section{SK 34}

Gewandfragment?

Selçuk, GHD; FK 100/04

Kammer D8, Reinigung bis auf OK der Fundamente; 2004

Grobkörniger hellgrauer, blaustichiger Marmor

H $10 \mathrm{~cm}$, B 8,5 cm

An drei Seiten gebrochen. Erh. Oberfläche ursprünglich gut geglättet; leicht versintert.

\section{SK 35}

\section{Faltenfragment}

Selçuk, GHD; FK 100/04

Kammer D8, Reinigung bis auf OK der Fundamente; 2004

Mittelkörniger weißer Marmor

H $4 \mathrm{~cm}$, B $16 \mathrm{~cm}$

Erh. hat sich scheibenförmiges Fragment mit zwei sehr plastisch herausgearbeiteten Gewandfalten. Rundum abgebrochen. Mörtelspuren; z. T. bräunlich verfärbt.

Raspelarbeit an der Innen- bzw. Außenkante der Falten.

\section{SK 36}

Taf. 385 Abb. 624

\section{Fragment einer Tierstatuette}

Selçuk, GHD; FK 100/04

Kammer D8, Reinigung bis auf OK der Fundamente; 2004

Grobkörniger hellgrauer Marmor

L 11,4 cm, H 9,2 cm

Erh. Hinterleib mit Ansatz der Hinterbeine und kurzem Schwanz. Kein Geschlechtsteil erh. bzw. erkennbar.

Oberfläche verwittert und bestoßen, Mörtelspuren. Marmor an den Bruchflächen porös.

Dem kurzen Schwanz zufolge könnte es sich um die Statuette einer Hindin handeln.

SK 37

Taf. 385 Abb. 625

Fragment eines Tischfußes mit Felidenpranke,

kaiserzeitlich

Selçuk, GHD; FK 100/04

Kammer D8, Reinigung bis auf OK der Fundamente; 2004 
Grobkörniger hellgrauer Marmor, von grauen Bändern durchzogen

H 11,8 cm, SockelH 2,5-3 cm

Erh. Fragment des untersten Teils einer Felidenpranke auf niedrigem, gerundetem Sockel: Rest des Mittelteils mit zwei schmalen Krallen (davon die rechte nur im Ansatz erh.) sowie Teil der r. Seite mit der äußeren, breiteren Kralle und dahinter anschließender Fläche. Rundum Bruch. Oberfläche verwittert. Mörtelspuren.

Fläche hinter der äußeren Kralle an r. Seite grob bossiert. US grob gespitzt.

\section{SK 38}

Taf. 385 Abb. 626. 627

Beinfragment von Tischfuß, kaiserzeitlich

Selçuk, GHD; FK 100/04

Kammer D8, Reinigung bis auf OK der Fundamente; 2004 greco scritto $^{90}$

$\mathrm{H} 15 \mathrm{~cm}$

Oben und unten abgebrochen, Außenkanten unten abgebrochen. Oberfläche des Fragments und Kanten bestoßen. Ein Riss im Stein an der VS.

Erhalten hat sich der Rest eines Felidenbeins von einem Tischfuß (Taf. 385 Abb. 626. 627 zeigen die beiden Nebenseiten). Die Vorderkante wird von je einer vertikalen Kante/Kerbe seitlich begleitet. Die Außenkanten des Beins schwingen in ihrem unteren Teil aus. Die Mittelkante der Rückseite endet in einem (abgebrochenen) tropfenförmigen Gebilde, das von zwei vertikalen Kerben gerahmt wird.

\section{SK 39}

Taf. 385 Abb. 628

Sockelfragment mit Rest einer Felidenpranke, kaiserzeitlich Selçuk, GHD; FK 100/04

Kammer D8, Reinigung bis auf OK der Fundamente; 2004

Grobkörniger hellgrauer Marmor

H 8,5 cm, SockelH 5,5 cm, B 10,7 cm, T 9,5 cm

Erh. r. Ecke eines Sockels mit Felidenpranke: Teil von VS und 1. NS erh., an r. Seite und RS Bruch. Neben dem Prankenrest, an der Bruchkante der rechten Seite, Rest von rundem, abgebrochenen Ansatz. US zum Großteil abgeschlagen. Kanten des Sockels bestoßen, Krallen beschädigt. Oberfläche stellenweise bräunlich grau verfärbt.

Tiefe Bohrrillen (in >stop and go<-Manier) zwischen den Krallen und an der Außenseite der Pranke. Auch vor der Pranke verläuft eine Bohrrille.

Die Felidenpranke steht dicht an der Ecke des Sockels, leicht schräg zur linken Seite hin versetzt.

\section{KAMMER E5}

SK 40

Kleinformatiger Tritontorso, flavisch

Selçuk, Efes Müzesi 41/11/04, FK 85/04

Kammer E5, S 7/2004, SE B42; 2004

Bigio antico (dunkelgrau mit zahlreichen dunkleren Einsprengseln)

\footnotetext{
${ }^{90} \mathrm{Vgl}$. zum greco scritto-Vorkommen in der Nähe von Ephe-
} sos s. YAVUZ u. a. 2011, bes. $226 \mathrm{f}$.
H $12 \mathrm{~cm}$

Erh. Torso bis zur Leistenlinie mit den Ansätzen beider Oberarme und der Oberschenkel. Kopf und Oberarme (unterhalb der Ansätze) waren angesetzt (Stiftlöcher). Oberfläche der VS stark beschädigt. Kleinere Bestoßungen an den Flanken und an der RS. Rostspuren von Eisenstiften an allen angestückten Stellen sowie an der VS der r. Schulter.

Oberfläche glatt poliert.

Fundkontext: 2.-3. Jh. n. Chr. (Lampe); zwei Münzen des späten 3. bzw. frühen 4. Jhs. n. Chr. (Diocletian, Constantinus I.); vgl. Kap. 4.1.2.3.

Der qualitätvolle kleine Torso aus Buntmarmor (bigio antico $0^{91}$ ) gibt den muskulösen Rumpf eines nackten Mannes wieder. Die linke Schulter war angehoben, der linke Oberarm daher abgestreckt. Die rechte Schulter ist dagegen gesenkt und etwas nach hinten genommen. Das linke Bein war offenbar stärker belastet: Der linke Glutäus scheint stärker vorzuspringen (von diesem ist allerdings mehr erhalten als vom rechten Glutäus), die rechte Hüftpartie und der Ansatz des rechten Oberschenkels laden weiter aus. An der Vorderseite des Körpers sind Brust-, Rippen-, Bauchund Hüftpartie voneinander abgesetzt und modelliert. Halsgrube, Schlüsselbein und linea alba sind angegeben. An der angespannten linken Flanke drücken sich die einzelnen Rippen durch die Haut. Die Leistenlinie ist von den Oberschenkeln abgesetzt, unter den Hüften bilden sich Faltenwülste. Am Rücken sind die Nakken- und Schultermuskulatur, der Kapuzen- oder Trapezmuskel und die Rückenmuskeln angegeben, getrennt durch die Furche. Ein Pendant zu dieser Figur, ebenfalls aus spiegelglatt poliertem bigio antico, wurde 1972 bei Reinigungsarbeiten des Efes Müzesi an der »obersten Galerie«, also wohl der Portikus des Theaters gefunden (Taf. 409) ${ }^{92}$. H. Gregarek hat ihn in ihre Liste der Idealplastik aus Buntmarmor aufgenommen und als Gigant angesprochen $^{93}$. Dieser Torso weist jedoch an dem erhaltenen rechten Oberschenkel den charakteristischen Zackenkranz der Tritonen auf und erschließt daher auch für den Neufund eine Deutung als Triton. Die Rumpflänge der beiden Torsi stimmt überein ${ }^{94}$. Die

${ }^{91}$ Vgl. dazu u. a. Borghini 1989, 158 f.; Pensabene - LazzAriNi 1998, 141-154; GregareK 1999, 38; Koller 2000, 124; LAZZARINI 2006, 97-109 zum Vorkommen auf der Halbinsel Mani, 98-102 zur Verwendung der bigi antichi und morati. Zum bigio antico-Vorkommen am Panayırdağ und in den Steinbrüchen von Belevi und Hasancavuşlar vgl. zuletzt YavuZ u. a. 2011, 217. 220 f. 226-229. Eine genaue Herkunftsbestimmung des für die Torsi verwendeten Marmors kann nur eine naturwissenschaftliche Analyse erbringen.

${ }^{92}$ Efes Müzesi 6/1/73. Bigio antico (blaugrau mit dunkleren und weißen Einschlüssen sowie längeren weißen Adern). H $21 \mathrm{~cm}$. Es fehlen Kopf und Hals, beide Arme außer den Ansätzen, l. Oberschenkel außer Ansatz, r. Unterschenkel. Glied und VS des Ansatzes des 1. Oberschenkels abgebrochen. VS sehr gut erh., vor allem RS mit Wurzelfasern überzogen. Spiegelglatt poliert. Dieser Torso wird hier gemeinsam mit E. Bideci (Museum Selçuk) vorgestellt.

${ }^{93}$ Gregarek 1999, 96. 244 E9 (der kurzen Beschreibung zufolge wird es sich um diesen Torso handeln). Kurze Erwähnung mit Foto bei CANSEVER 2010, 32.

${ }^{94}$ Länge des Torsos InvNr. 6/1/73 vom Halsbruch bis zum Ansatz der Oberschenkel 10,5 cm; das entspricht etwa der Rumpflänge des Neufunds, des Torsos InvNr. 41/11/04. 
Haltung des früher (1972) gefundenen Tritons spiegelt die Haltung des Neufunds als Pendant: Ersterer streckte den rechten Oberarm zur Seite, während der Ansatz des linken Oberarms anliegt und etwas zurückgenommen ist. Dem Stiftloch an der Vorderseite der linken Schulter zufolge hielt der linke Arm ein Attribut. Der rechte Oberschenkel ist senkrecht aufgestellt, der linke Glutäus ist etwas vorgeschoben, der Ansatz des linken Oberschenkels ist angehoben und leicht nach außen gewendet, was sich auch in der Position des linken Glutäus widerspiegelt. Der Rumpf ist etwas nach hinten gelehnt. Der gute Erhaltungszustand dieses Torsos lässt die plastische Durchformung der Vorderseite des Rumpfs erkennen, mit der Angabe von Schlüsselbeinen, Brustmuskeln, Rippenbogen und inscriptiones (am Neufund ist die Muskulatur der Rückseite des Torsos und der Flanken im Vergleich zu dem Altfund detailreicher gestaltet). Eine lange Ader verläuft von der rechten Hüfte zur Scham.

Die prallen Formen der Muskulatur an Vorder- wie Rückseite des Rumpfs der Torsi weisen in flavische Zeit ${ }^{95}$. Das beste ephesische Vergleichsbeispiel sind die Tritonen vom Nymphäum des C. Laecanius Bassus, dessen Errichtung in das Jahr 78/79 n. Chr. fällt ${ }^{96}$. Die Armhaltung und das Attribut des gesenkten Arms lässt sich auch an einem der Tritonen des Nymphäums ablesen: Dieser hielt das Ruder im gesenkten Arm, das an den kleinen Tritonen wahrscheinlich aus Metall angesetzt war ${ }^{97}$. Der andere Oberarm war dagegen angehoben; dieser Arm hielt ein weiteres Attribut, etwa ein Muschelhorn, wie der großformatige Triton in der Ny Carlsberg Glyptotek ${ }^{98}$. Die Windungen der Beine müssen den Rumpf der kleinen Tritonen gestützt haben; auch der abgestreckte Arm muss durch eine Schwanzwindung bzw. durch eine Stütze fixiert gewesen sein. An der Rückseite von vier der Tritonen des C. Laecanius Bassus-Nymphäums führen Bettungen für Wasserleitungen zu den Attributen an den angehobenen Armen empor, aus denen Wasser spritzte ${ }^{99}$. Diese Vorrichtungen fehlen an den kleinen Tritonen. Auch mittelformatige Tritonen wurden jedenfalls als Brunnenfiguren verwendet ${ }^{100}$.

In H. Gregareks 1990 erschienener Liste sind keine Tritone aus Buntmarmor verzeichnet, dafür jedoch eine ganze Reihe von Gigantengruppen aus bichromem sowie dunklem Marmor und schwarzem Kalkstein, teilweise sicher aus privatem Ambiente $^{101}$.

\footnotetext{
${ }^{95}$ So schon Gregarek 1999, 244 E9.

${ }^{96}$ Aurenhammer 1990, Nr. 88-91 Taf. 62-64; Rathmayr 2011, 131-149 zur Skulpturenausstattung des Nymphäums, zu den Tritonen 134-139. Weiters RathmaYr (in Vorbereitung).

${ }^{97}$ Vgl. den Rest des Ruderblattes an der linken Schulter des Tritons: Aurenhammer 1990, Nr. 88 Taf. 62 und das Stiftloch an der linken Schulter des kleinen Torsos von 1972. An der Vorderseite der rechten Schulter des Neufunds (2007) Rostspuren.

${ }^{98}$ ICARD-GiANOLIO 1997, 77 Nr. 45.

${ }^{99}$ Aurenhammer 1990, Nr. 88. 98. 91. 92; Rathmayr 2011, $134 \mathrm{f}$.

${ }^{100} \mathrm{z}$. B. Statuette von halber Lebensgröße aus römischem Haus in Paestum: Icard-Gianolio 1997, 77 Nr. 46a; Neutsch 1956, 427 f. Nr. 4.

${ }^{101}$ Gregarek 1999, 96 f. 244-246 E8. E10-E19; Giganten in den Komplexen von Silahtarağa und Valdetorres $136 \mathrm{f}$.
}

\section{KAMMER E7}

SK 41

Taf. 386 Abb. 629

Büstenfragment, 2. Hälfte des 2.-3. Jh. n. Chr.

Selçuk, GHD; FK 99/04

Kammer E7, Ziegelschutt, SE B37; 2004

Feinkörniger weißer Marmor

H $14 \mathrm{~cm}$, B max. 9,5 cm, T max. 4,5 cm, B des Büstenrands $2,5 \mathrm{~cm}$

Erh. Fragment von r. Teil (vom Betrachter aus gesehen) einer Gewandbüste mit Rest der Randleiste an der r. Seite. RS leicht konkav gewölbt. Oben, unten und an 1. Seite abgebrochen. Faltenauge, Rand stellenweise bestoßen. Starke Mörtelreste.

Oberfläche der VS ursprünglich geglättet. Randleiste und RS rauer belassen.

Fundkontext: heterogen; 3. Jh. n. Chr. (vgl. Kap. 4.1.2.4)

Dieses Fragment fällt durch den feinkörnigen weißen Marmor auf. Die Oberfläche des leicht vorgewölbten Fragments einer bekleideten Büste ist nur wenig gegliedert. Eine breite, vertikale Falte nahe der linken Bruchkante endet unten in einem Faltenauge, das bis zur unteren Bruchkante reicht. Eine feine Rille zieht schräg über die ganze rechte Hälfte des Fragments.

Da die Außenkante der Büste nur ganz schwach gewölbt ist, wird die Büste auch zumindest den Ansatz der Oberarme umfasst haben und daher in der 2. Hälfte des 2. Jhs. bzw. im 3. Jh. n. Chr. entstanden sein.

\section{SK 42 Faltenfragment}

Selçuk, GHD; FK 99/04

Kammer E7, Ziegelschutt, SE B37; 2004

Grobkörniger hellgrauer Marmor

L $9 \mathrm{~cm}$

Oben, unten und an der RS gebrochen. Falten beschädigt und bestoßen. Oberfläche braungrau verfärbt.

An der Oberfläche der erh. Faltenbahn stellenweise dichte Raspelarbeit.

Fundkontext: heterogen; 3. Jh. n. Chr. (s. unter SK 41 Taf. 386 Abb. 629)

SK 43 Unterlebensgroße rechte Hand

Selçuk, GHD; FK 99/04

Kammer E7, Ziegelschutt, SE B37; 2004

Grobkörniger hellgrauer Marmor

L $12,5 \mathrm{~cm}$

Erh. r. Hand mit Ansatz des Unterarms. Daumenansatz erh., die anderen Finger alle abgebrochen. Stark verwittert und versintert.

Ursprüngliche Oberfläche geglättet.

Fundkontext: heterogen; 3. Jh. n. Chr. (s. unter SK 41 Taf. 386 Abb. 629)

Erhalten hat sich die rechte Hand mit dem Ansatz des Unterarms. Die Hand war im Gelenk leicht nach unten gebogen. Die Hand ist schmal und gehörte vielleicht zu einer weiblichen Statuette.

SK 44

Taf. 386 Abb. 630

Bekleideter Unterschenkel einer Statuette

Selçuk, GHD; FK 99/04

Kammer E7, Ziegelschutt, SE B37; 2004

Grobkörniger hellgrauer, blaustichiger Marmor 
$\mathrm{L} 11,5 \mathrm{~cm}$

Oben, unten und großteils an der RS abgebrochen. Bestoßungen. Dunkelgrau verfärbt. Stellenweise starke Mörtelreste.

Raspelspuren.

Fundkontext: heterogen; 3. Jh. n. Chr. (s. unter SK 41 Taf. 386 Abb. 629)

Erhalten sind linker Unterschenkel und Knie einer Statuette. Offensichtlich ist das Bein bekleidet: Von beiden Seiten laufen schräge Kerben nach Art des Fischgrätenmusters auf Knie und Schienbein zu. Es könnte sich um das Fragment einer Attisoder einer Barbarenstatuette handeln ${ }^{102}$.

SK 45 Gliedmaßenfragment (?) von Statuette

Selçuk, GHD; FK 99/04

Kammer E7, Ziegelschutt, SE B37; 2004

Grobkörniger hellgrauer Marmor

L $4,2 \mathrm{~cm}$

Oben, unten und an einer Seite abgebrochen.

Fundkontext: heterogen; 3. Jh. n. Chr. (s. unter SK 41 Taf. 386 Abb. 629)

\section{SK 46}

Etwas überlebensgroßer Fuß auf Plinthe

Selçuk, GHD; FK 99/04

Kammer E7, Ziegelschutt, SE B37; 2004

Grobkörniger hellgrauer Marmor

H 16,5 cm, PlinthenH 7-8 cm, B $21 \mathrm{~cm}, \mathrm{~T} 10 \mathrm{~cm}$

Erh. Stück der Plinthe rund um das Fußfragment. An der Außenseite des Fußes hat sich ein Rest der gerade verlaufenden NS der Plinthe erhalten. Fuß (und Plinthe) am Ansatz der Zehen sowie am Ansatz der Ferse abgeschlagen. Rückwärts vom winzigen Ansatz des Unterschenkels schräg durchgeschlagen bis zur US

OS des Fußes gut geglättet. Der Umriss des Fußes wird von einer Rille an der OS der Plinthe begleitet. NS gespitzt, mit Randschlag. US grob bossiert. OS der Plinthe mit grobem Zahneisen bearbeitet. Oberfläche bräunlich verfärbt.

Fundkontext: heterogen; 3. Jh. n. Chr. (s. unter SK 41 Taf. 386 Abb. 629)

\section{SK 47}

Taf. 386 Abb. 631

\section{Fuß in Sandale auf Plinthenfragment, kaiserzeitlich}

Selçuk, GHD; FK 99/04

Kammer E7, Ziegelschutt, SE B37; 2004

Grobkörniger hellgrauer Marmor

H $10 \mathrm{~cm}$, PlinthenH 5-6 cm, L $19 \mathrm{~cm}$

Erh. 1. Vorderfuß und Rist sowie an Vorderkante und an der 1. NS Reste der Plinthe. Ferse und RS sowie r. NS der Plinthe abgeschlagen. Zehen beschädigt (besonders große und kleine Zehe), Riemen der Sandale bestoßen. Oberfläche grau verwittert, an der Innenseite des Fußes grünlich verfärbt.

\footnotetext{
${ }^{102} \mathrm{Zu}$ Attis vgl. Vermaseren - de Boer 1986, 22-44; zu Attisdarstellungen in Kleinasien: Vermaseren 1987, $191 \mathrm{f}$. Nr. 638 f.; 199 Nr. 667; 203 Nr. 685? (Ephesos) = AurenhaMMER 1990, 133 f. Nr. 110 Taf. 78 a. b; vgl. MADERNA-LAUTER 1993, 571 f.; Aurenhammer 1990, 123 Nr. 103 Taf. 72 c. d (»Ganymed«, vgl. dazu LinfERT 1972, 424). Vgl. auch die Figur mit Mütze im Vierfigurenrelief für Meter aus Ephesos, BÜYÜKKOLANCI 1999, 19-21; VIKELA 2001, 109 Anm. 137.
}

US grob bossiert.

Fundkontext: heterogen; 3. Jh. n. Chr. (s. unter SK 41 Taf. 386 Abb. 629)

Der unterlebensgroße Fuß in einer Sandale gehörte zur Statue eines Himationträgers. Die Sandale bedeckt den Fuß bis auf die Zehen. Zwischen der großen und der nächstfolgenden Zehe ist der Oberteil der Sandale mit einem Riemen an der Sohle befestigt; dieser Riemen geht offenbar in den Zehenriemen über. Hinter diesem wiederum zieht ein Lederstreifen an beiden Seiten in Richtung Ferse, wobei die Partie vor dem gezackten Ende der über den Rist ziehenden Lederzunge wellig ausgeschnitten ist. Die Lederzunge bedeckt hier nicht, wie sonst üblich, den Zehenriemen. Die beiden schmalen Bänder rechts von der Lederzunge (vom Betrachter aus gesehen) könnten Teile der Schnürung der Sandale darstellen. Die Sandalenform entspricht keiner der von C. Hallett anhand der Himationträger aus Aphrodisias zusammengestellten Sandalentypen mit Zehenriemen in allen Details ${ }^{103}$.

Die Plinthenkanten sind unregelmäßig geformt: An der Vorderseite springt unter den Zehen ein Profil vor, an der Außenseite springt dagegen ein schmaler Streifen über der Unterkante zurück.

\section{BEREICH SÜDLICH DES BÜHNENGEBÄUDES: RS1-RS3}

\section{SK 48}

Taf. 387 Abb. 633. 634

Männliches Kopffragment von einem Relief, antoninisch

Selçuk, Efes Müzesi 61/8/97; FK 4/97

Südlich des Bühnengebäudes; 1997

Grobkörniger weißer Marmor

H $14,5 \mathrm{~cm}$, B 20,8 cm, T $12 \mathrm{~cm}$

Erh. Gesichtsfragment mit Stirn, Augenpartie und Nasenansatz und r. Kopfseite inkl. des r. Ohrs. Dabei haben sich nur ein schmaler Streifen der 1. Stirnhälfte, der Ansatz des 1. Augenwinkels und des 1 . Nasenflügels erhalten. Rundum abgebrochen. Oberfläche stark abgerieben und beschädigt.

Pupille des r. Auges (?) und innere Augenwinkel gebohrt. Tiefe Bohrungen in und zwischen den Haarbüscheln, mit Stegen zwischen den Bohrrillen. Ein dünner Steg am untersten Ende der r. Ohrmuschel.

Mehrere Details weisen darauf hin, dass dieses Kopffragment wahrscheinlich von einem Hochrelief stammt, die Vorderseite jedenfalls nicht die Haupt-Ansichtsseite war: Der Nasenansatz verläuft schräg, der Ansatz des linken Augenwinkels und der linke Nasenflügel liegen höher als die entsprechenden Partie in der rechten Gesichtshälfte. Dadurch wirkt der Nasenrücken schmal im Vergleich zu den breiten, raufgequollenen< Nasenflügeln. An der Nasenwurzel ist die `Zornesfalte` angegeben, über die Stirnmitte verlaufen zwei gebogene horizontale Falten. Das rechte Auge liegt tief unter der überhängenden Braue. Das Oberlid ist schmal und kragt vor, das Unterlid ist breit und hängend gebildet. Der vorliegende Erhaltungszustand zeigt eine große Bruchstelle am rechten Augapfel, was auf eine Markierung von Iris und Pupille hinweisen könnte. Die Haarbüschel

\footnotetext{
${ }^{103}$ Vgl. SмiтH 2006, 152-154 Abb. 22, Typus 1 und 3 (C. HaLLETT). Sicher auszuschließen ist jedenfalls Typus 2 ohne Zehenriemen, der einen großen Teil des Fußes freilässt.
} 
an der rechten Schläfe und über dem rechten Ohr liegen locker übereinander und fallen vor dem rechten Ohr herab, wobei sie letzteres freilassen. Sie sind von tiefen Bohrungen zwischen und in den Lockenbüscheln durchsetzt, was in antoninische Zeit weist. Der >unruhige< Eindruck wird aber sicher auch durch den Erhaltungszustand hervorgerufen. Über der Stirn ist im jetzigen Erhaltungszustand kein Haar zu sehen; entweder war es aus der Stirn gestrichen oder es lag eine Stirnglatze vor. Über den Rand der Ohrmuschel legt sich ein Kranz von kaum gebohrten Büscheln, die von einer glatten Fläche (dem Reliefgrund?) am Bruchrand ausgehen. Das Ohr selbst liegt zu tief unten und zu schräg im Vergleich zum Auge, was mit der Position des Kopfs vor dem Reliefhintergrund zusammenhängen wird.

Die mimische Bewegung der tief ansetzenden rechten Braue, welche über der Nasenwurzel kontrahiert ist, dort mit der linken Braue die `Zornesfalte < bildet und zur rechten Schläfe hin ansteigt, findet sich, im Verein mit den Stirnfalten, am griechischen Herrscherund Philosophenporträt, aber auch an idealen Köpfen von >wilden< Gestalten wie Silen, Satyr, Kentaur und Pan ${ }^{104}$. In römischer Zeit wird diese pathetische Bewegung der Brauen im Privatporträt ${ }^{105}$, an Barbarenköpfen ${ }^{106}$ und idealen Köpfen aufgegriffen. Das rechte $\mathrm{Ohr}$ des Fragments ist als menschliches Ohr gebildet. Angesichts des expressiven Ausdrucks des Fragments in der Vorderansicht wird es sich wohl um einen idealen oder um einen Barbarenkopf handeln. Die Vermutung der Zugehörigkeit zum Partherdenkmal drängt sich auf ${ }^{107}$. Von Bohrungen durchsetztes Haar findet sich auch an Köpfen dieses Denkmals ${ }^{108}$. Die Verbindungsstege zwischen den Bohrungen an dem Fragment sind nicht unterbohrt; der dünne Steg am unteren Rand der Ohrmuschel wurde nicht abgearbeitet. Augenbohrung an den Köpfen des Partherdenkmals tritt selten auf, ist meist schwach und unterschiedlich ausgeführt; die Markierung der Pupille sitzt meist dicht am oberen Lidrand ${ }^{109}$. Die große Bruchstelle am rechten Augapfel des Fragments könnte auf eine Kennzeichnung der Iris und eine andersartige Angabe der Pupille hinweisen, wobei aber über die Wiedergabe der Pupille nichts Sicheres ausgesagt werden kann. Für die Bestätigung der Zugehörigkeit des Fragments zum Denkmal bedarf es außerdem der Bestimmung des

${ }^{104}$ Vgl. Giuliani 1986, 140-144; HofF 1994, 146 zum Antisthenes-Porträt.

${ }^{105}$ Porträts: im republikanischen Porträt, vgl. z. B. ein männliches Porträt des 1. Jhs. v. Chr. im Museo Capitolino, Rom, FitTSCHEN u. a. 2010, 8 f. Nr. 6 Taf. 8. 10, oder ein antoninisches Porträt im Kunsthistorischen Museum, Wien, ZANKER 1995, 223 f. Abb. 127; Danguillier 2001, 87 f. 249 KatNr. 132 Abb. 37.

${ }^{106}$ Vgl. z. B. Köpfe des Großen Ludovisischen Schlachtsarkophags, Palazzo Altemps, Rom, und Köpfe vom Schlachtfries des Partherdenkmals im Kunsthistorischen Museum, Wien: Krierer 1995, 102 Taf. 46, Abb. 155 bzw. 106 f. Taf. 53, Abb. 182. 184 = OBERLEITNER 2009 FR 13 Abb. 144, sowie FR 9 Abb. 16. 122.

${ }^{107}$ Zum Denkmal OBerLeITNER 2009. W. Oberleitner danke ich für die Diskussion des Kopfs.

${ }^{108}$ Vgl. z. B. die Wassergottheit OberLeItNer 2009 FR 18 Abb. 174. 178; den Kopf der vexillaria FR 15 Abb. 159 f.; den Kopf des Apollon-Helios FR 23 Abb. 205 f. und des Windgotts Abb. 205 f.; das Kopffragment FR 26 Abb. 253-237. Zur Frage der Bohrungen FitTsChen 2009, 169-171.

$109 \mathrm{Vgl}$. FitTSChen 2009, 170 f.
Marmors. Der Fundort des Fragments liegt nicht im Umkreis der verschiedenen Fundorte der Platten und Fragmente des Denkmals ${ }^{110}$; es handelt sich bei dem südlich des Theaters gefundenen Fragment allerdings um einen Streufund.

\section{SK 49}

Taf. 387 Abb. 635

Fragment eines männlichen Kopfs, theodosianisch ${ }^{111}$

Selçuk, Efes Müzesi 60/8/97; FK 3/97

Loser Schutt südlich des Bühnengebäudes bzw. westlich der südlichen Parodos über Mosaikboden des 5./6. Jhs. n. Chr. ${ }^{12}$; 1997

Grobkörniger hellgrauer Marmor

H $19 \mathrm{~cm}$, B 15,3 cm, T 7,7 cm

Erh. scheibenförmiges Fragment eines Kopfs mit oberem Teil des Gesichts bis zum Nasenansatz und der oberen Partie sowie der gesamten Rundung der r. Wange, inkl. des r. Ohrläppchens, des Ansatzes des Kinns und des Halses darunter. Rundum abgeschlagen, schräger Bruch vom 1. Auge bis zum Kinn. Abgebrochene Ansatzfläche über dem Stirnhaar, über dem r. äußeren Augenwinkel bzw. der r. Schläfe. Nase abgebrochen, Bestoßungen am Haar, den Augen und Brauen, der r. Wange. Hellbraune Patina.

Pupillen sichelförmig gebohrt, Karunkel gebohrt.

Das etwa lebensgroße Gesichtsfragment umfasst Stirn, Augenpartie, Nasenansatz und einen Teil der rechten Wange, ein Stück des Halsansatzes an der rechten Seite und das rechte Ohrläppchen. Ein Kranz von rechtsläufigen, sichelförmigen Lockenbüscheln umrahmt bogenförmig die Stirn. Über dem linken äußeren Augenwinkel bildet sich eine Gabel; an der linken Schläfe drehen sich die Locken in die Gegenrichtung. Die schmalen, mandelförmigen Augen sind von breiten Oberlidern bedeckt, die mittels einer Kante vom Augapfel abgesetzt sind. Das spitz zulaufende Ende des rechten Lids überschneidet das vergleitend in die Wange hängende Unterlid. Die Pupillen sind sichelförmig am oberen Rand des Oberlids gebohrt; auch die Karunkel ist gebohrt. Die Brauengrate überspannen die Augen und sind weit, bis zum Ende des rechten Oberlids, herabgezogen. Die Orbitalfalte legt sich breit über das Oberlid. Das linke Auge sitzt näher am Nasenansatz; linkes Oberlid und linke Pupille sitzen etwas tiefer als jene Details am rechten Auge. Über dem rechten äußeren Augenwinkel bzw. über der rechten Schläfe befindet sich eine abgebrochene Ansatzfläche.

Die Form des Haarkranzes, die Bildung der Augenpartie und die flachen, unbewegten Wangen weisen in theodosianische Zeit ${ }^{113}$. Die engste ephesische Parallele für das Kopffragment sind die Köpfe einer Doppelherme, welche 1994 als Oberflächenfund zwischen Stadion und Vediusgymnasium entdeckt wurde (nur

${ }^{110}$ Vgl. zu den Fundorten OBerLeitner 2009, 36 f.

${ }^{111}$ Die Dokumentation des Fragments basiert auf Aufzeichnungen von J. Auinger.

${ }^{112}$ Datierung des Mosaiks durch V. Scheibelreiter-Gail (mündliche Mitteilung).

${ }^{113}$ Vgl. besonders zur Augenbildung ein Kaiserporträt in Berlin, Staatliche Museen, u. a. BECK - Bol 1983, 447-449 Nr. 57 und KiIlerich 1993, 89 f. Abb. 42; die Statue Valentinians II. oder des Arcadius aus Aphrodisias in Istanbul vgl. für die Augenbohrung und den Kranz von dicken Lockenbüscheln, Sмith 1999, 162 Taf. 12, 1. 2; KiILerich 1999, 27-30 Abb. 3 f., alle Literaturangaben mit früherer Lit. 
das Gesicht eines der Köpfe ist vollständig erhalten; Taf. 387 Abb. 636; 388 Abb. 637. 638) $)^{114}$. Augenbildung und Brauenführung stimmen hier eng überein, auch die etwas abweichende Lage des linken Auges. Die Lockenbüschel des Fragments sind in die andere Richtung (rechtsläufig) gestrichen und besser ausgearbeitet, die Stirnhaarlinie verläuft bogenförmig. Eine Gabel findet sich auch an der Frisur der Köpfe der Doppelherme (rechte Stirnecke). Das Haar dieser Köpfe ist nur in den Stirnlocken ausgearbeitet, die Kalotten sind summarisch behandelt. Das Fragment vom Bereich südlich der Bühne war im originalen Zustand wohl etwas größer als die Köpfe der Doppelherme. Dennoch könnte es, angesichts der großen Ähnlichkeiten im Detail, aus der gleichen Werkstatt stammen bzw. der gleichen Funktion zuzuweisen sein, wenn der fragmentarische Zustand des Objekts auch keine sicheren Schlüsse zulässt. Ungeklärt ist in diesem Zusammenhang die Deutung des abgebrochenen Ansatzes über der Lockenreihe des Fragments, über dem rechten äußeren $\mathrm{Au}-$ genwinkel (eventuell Ansatz einer 2. Lockenreihe?). Bei einer Funktion als Porträt könnte es sich um den Ansatz eines Diadems handeln. Auf eine Funktion als Porträt könnten auch die qualitätvollere Ausarbeitung und der schmälere Nasenansatz hinweisen. Die jugendlichen Köpfe der Doppelherme mit Kurzhaarfrisur (und vielleicht auch das Fragment vom Theater) gehören typologisch zu den »Porträtfiktionen« des 4 . Jhs. n. Chr., wie sie sich z. B. zahlreich unter den Hermen der Galerie der Villa von Welschbillig finden ${ }^{115}$. Hermenbalustraden waren in der Spätantike beliebte Abgrenzungen auch für Logen und $\mathrm{Zu}-$ schauerränge von Wettkampf- und Spielstätten wie Hippodrom, Amphitheater und Circus ${ }^{116}$. Die ephesische Doppelherme und das Fragment vom Theater sind Streu- bzw. Schuttfunde, daher wird sich ihre Funktion nicht sicher klären lassen. Die Doppelherme könnte als Teil einer Balustrade zu einer derartigen Abgrenzung gehört haben.

\section{SK 50}

Fragment von rechtem Fuß auf Plinthe

Selçuk, Efes Müzesi 62/8/97; TH 5/97

Südlich des Bühnengebäudes; 1997

Grobkörniger hellgrauer Marmor

H 17,5 cm, PlinthenH 8-9 cm, B $22 \mathrm{~cm}$, T $15 \mathrm{~cm}$

Erh. Vorderteil des Fußes. Plinthe rund um den Fuß schräg abgeschlagen, rückwärts entlang der höchsten Erhebung des Rists. Der auf dem Rist aufliegende Gewandsaum ist abgebrochen. Die große und die nächste Zehe sowie die Spitze der 3. Zehe sind abgeschlagen. Oberfläche grau verwittert, Beschädigungen, Mörtelspuren.

US gespitzt.

Der lebensgroße Fuß liegt auf einer hohen Sandalensohle. Die kleine Zehe hebt sich von der Sohle ab; der Zwischenraum zwischen dieser Zehe und der nächsten ist nicht ausgearbeitet. Über den Rist legt sich der Saum des Gewands, der am Rist und an den Außenkanten des Fußes durch einfache parallele Kerben gegliedert ist. Zu Seiten des Fußes haben sich an der Bruchkan-

${ }^{114}$ Selçuk, Efes Müzesi 69/43/94. Hanslmayr 2016, 61-64. 155-156 KatNr. A26 Taf. 30.

115 Wrede 1972, 61-67. 90-101 (Datierung der Hermengalerie): Regierungszeit Gratians (367-383 n. Chr.).

116 Wrede 1987, 139 f. Spätantiker Hermenzaun vom Nymphaeum Traiani in Ephesos: HansLmaYr 2016, 128-139 D2. te Reste von plastischeren Faltenbündeln mit tiefen Faltentälern erhalten. Insgesamt wirkt die Bildhauertechnik hart.

\section{Fundorte im Nordbereich des Theaters: VOMITORIUM EN1, NÖRDLICHER BEREICH VOR DER Umfassungsmauer der Cavea und Bereich west- LICH DES NORD-ANALEMMA}

\section{SK 51}

Männlicher Torso, flavisch?

Taf. 388 Abb. 639

Selçuk, Efes Müzesi 79/42/93; FK 29/93

An der nördlichen Umfassungsmauer, Füllschutt; 1993

Grobkörniger hellgrauer Marmor

$\mathrm{H} 33 \mathrm{~cm}$

Torso erh. bis in Nabelhöhe, mit Ansatz der Hüftpartie. Beide Armansätze abgeschlagen. Bruchstellen über dem 1. Schlüsselbein, an der 1. Brust, am r. Rückenmuskel. Stellenweise Mörtelspuren.

Oberfläche glatt poliert, an RS Raspelarbeit.

Da die linke Achsel sichtbar ist, war der linke Oberarm der etwas unterlebensgroßen Statue angehoben. Der Bruchstelle des rechten Oberarms zufolge lag dieser mehr am Körper an. An der Vorderseite des Torsos sind Knochenbau und Muskulatur herausgearbeitet: Schlüsselbeine, Brustmuskeln, linea alba, Rippenbogen, Bauchdecke und Hüften mit Leistenlinie - wobei die Hüftpartien nicht auf die stärkere Belastung eines bestimmten Beins schließen lassen. Der abgebrochene Rest neben dem Hals könnte auf Haarlocken zurückzuführen sein. Der Rücken ist durch die Furche geteilt. Im unteren Teil ist zu Seiten der Furche die Muskulatur herausgearbeitet, an der rechten Hälfte detailreicher. Die prallen, wulstigen Formen der Muskulatur machen eine Entstehung in flavischer Zeit wahrscheinlich ${ }^{117}$.

\section{SK 52}

Taf. 388 Abb. 640

Rumpffragment von männlicher Statuette

Selçuk, GHD; FK 74/93

Nördliche Umfassungsmauer, Hangschutt; 1993

Grobkörniger hellgrauer Marmor

H $5,5 \mathrm{~cm}$

Erh. Rumpffragment mit Rest des Rippenbereichs, Bauchdecke und Ansatz der r. Hüfte. Rundum Bruch. RS großteils abgebrochen und stark verwittert.

VS geglättet.

Am Rumpf dieser kleinen Statuette sind der Ansatz des Rippenbogens und die sich vorwölbende Bauchdecke mit den horizontalen und den seitlichen vertikalen inscriptiones zu sehen, geteilt durch die linea alba. Der rechte Hüftansatz mit dem Rest des Glutäus hat sich erhalten, jedoch nur mehr ein kleiner Ansatz der linken Hüfte.

\section{SK 53}

Arm einer Statuette

Selçuk, GHD; FK 21/93

EN1, Gewölbe, Innenseite, bei der Reinigung, oberer Füllschutt

\footnotetext{
${ }^{117}$ Vgl. z. B. eine Panstatue in Dresden, KNoll u. a. 2011, 950-955 Nr. 227 (H. Heres). Vgl. auch hier den Tritontorso SK 40 (Taf. 408) und sein Pendant.
} 
Fein- bis mittelkörniger weißer Marmor

L 7,5 cm

Unten abgebrochen. OS geglättet zur Anstückung; Stiftloch. Oberfläche fein geglättet.

Es handelt sich um eine feine Arbeit. Der Unterarm ist leicht abgebogen. Die Muskeln an der Innenseite des Arms sind modelliert.

\section{SK 54}

Fragment von linkem Fuß auf Plinthe

Aufbewahrungsort unbekannt; TH 2/97

EN1 nördlich; 1997

(Angaben nach dem Tagebuch)

\section{SK 55}

Pfeiler mit Epigramm für den Gladiator Pardos,

Taf. 389

\section{Hälfte des 2. Jhs. n. Chr.}

An der Nordfront des Theaters, westlich vom Zugang zu EN1 aufgestellt

EN1, im Versturz des sekundären Wasserbeckens, FundNr KK 26; 1998

Grobkörniger hellgrauer, blaustichiger Marmor mit dunkleren Streifen

H 1,245 m, H oberes Profil $22 \mathrm{~cm}$, unteres Profil $23 \mathrm{~cm}$, H Relieffeld max. $36 \mathrm{~cm}$, BuchstabenH 1,7-2,2 cm, B 56,5 am oberen Profil, B am Schaft 47-49 cm, T am oberen Profil 56,5 cm, T am Schaft $51 \mathrm{~cm}$.

Kanten bestoßen und stellenweise abgebrochen, ebenso Ecken stellenweise abgebrochen. Unteres Profil der 1. Seite abgearbeitet. Bestoßungen und lokale Beschädigungen an allen Seiten. Relieffeld: Oberfläche bestoßen, Kopf des Pantherweibchens und oberer Teil des Steines beschädigt. Besonders an RS Mörtelspuren.

An den NS Zahneisenarbeit, an der OS Zahneisen- und MeiBelarbeit. VS und Profile geglättet. RS grob bossiert, darin im r. Teil Nut eingearbeitet; breiter, mit dem Zahneisen bearbeiteter Streifen im oberen bzw. unteren Teil.

KARWIESE 1999, 26 Abb. 9; KNIBBE 1999, 34.

Die Gladiatorenpfeiler SK 55 (Taf. 389) und SK 56 (Taf. 390) wurden im Versturz des wahrscheinlich in der Mitte des 5. Jhs. n. Chr. sekundär in ein Wasserbecken umgestalteten vomitorium EN1 gefunden ${ }^{118}$. Der Typus des hohen, reich profilierten Inschriftpfeilers, wie er hier in SK 55 aufgegriffen wurde, ist in Ephesos mehrfach z. B. bei den an der Kuretenstraße aufgestellten Basen vertreten ${ }^{119}$. Das Epigramm erstreckt sich über drei Leisten des oberen Profils und den Großteil der Vorderseite des Schafts ${ }^{120}$. Der linke Teil der Reliefdarstellung im versenkten Bildfeld nimmt in dem zurück blickenden Pantherweibchen Bezug auf den Namen des phrygischen Gladiators Pardos, eines secutor ${ }^{121}$. Bei dem hohen gewölbten Objekt rechts davon

${ }^{118}$ Zum Fundort vgl. Kap. 3.5.1.1.

${ }^{119}$ Vgl. z. B. die Statuenbasis des Alexandros, MiLtNer 1959, 325. 363 Abb. 191; Roueché 2002a, 530 Nr. 1; AuINGer 2009, 35 f. Abb. 17. Die ephesischen Statuenbasen werden von A. Sokolicek bearbeitet.

${ }^{120}$ Vgl. Kap. 8.2, IN 4 (Taf. 412).

${ }^{121}$ Vgl. RITTI 1977, 289-310 zu onomastischen Darstellungen, die sich auf Tiere und Pflanzen beziehen, 301 Nr. 57 Grabinschrift der Leoparda mit entsprechender Darstellung. $\mathrm{Zu}$ könnte es sich - anstatt eines Schildes - um die Wiedergabe eines heiligen Steines handeln, vielleicht um den Meteorstein aus dem Kybele-Heiligtum aus Pessinus, in Anspielung auf die phrygische Herkunft des Pardos ${ }^{122}$. Am rechten Ende des Relieffelds ist ein länglicher, schmaler, leicht gebogener Stab dargestellt. Es kann sich nicht um eine Palme handeln, da die sonst immer dargestellten Blätter fehlen. Eine Lanze kommt aufgrund der leichten Biegung des Stabs und der fehlenden, abgesetzten Spitze auch nicht in Betracht; sie gehörte auch nicht zur Ausrüstung der Secutoren. Möglicherweise handelt es sich um die rudis, den Freilassungsstab ${ }^{123}$.

H. Taeuber datiert den Pfeiler aufgrund der Inschrift in die 2. Hälfte des 2. Jhs. n. Chr. ${ }^{124}$.

\section{SK 56}

Pfeiler mit Epigramm für den Gladiator Achilleus,

2. Hälfte des 2. Jhs. n. Chr.

An der Nordfront des Theaters, westlich vom Eingang zu EN1 aufgestellt

EN1, im Versturz des sekundären Wasserbeckens, FundNr KK 93; 1998

Grobkörniger hellgrauer, blaustichiger Marmor

H 1,03-1,04 m, H oberes Profil $17 \mathrm{~cm}$, unteres Profil $14 \mathrm{~cm}$, BuchstabenH 1,3-1,5 cm, B 66-68 cm am Profil, SchaftB 66 $\mathrm{cm}, \mathrm{T} 26-30 \mathrm{~cm}$.

Im unteren Teil schräg durchgebrochen, 1. untere Ecke ausgebrochen. Auch unteres Profil beschädigt. Zahlreiche Sprünge im Stein.

Oberfläche der VS besonders im r. Teil inkl. Relief stark beschädigt. Am Relief fehlen durch den Bruch der 1. Teil der Standleiste mit dem r. Unterschenkel und Fuß.

Beide NS, OS und RS grob bossiert.

KARWIESE 1999, 26; KNIBBE 1999, 34

Dieser profilierte Pfeiler mit Einzelfigur eines Gladiators auf niedriger Standleiste entspricht dem in Kleinasien geläufigen altarähnlichen Typus von Ehrendenkmälern für Gladiatoren. ${ }^{125}$. Der Gladiator Achilleus, laut Inschrift ${ }^{126}$ ein Pergamener, steht im rechten Teil des Relieffelds auf der Standleiste im Ausfallschritt nach rechts, leicht ins Profil gedreht. Er trägt einen Helm mit hohem Kamm und breiter Krempe, deren unteres Ende sichtbar ist. Möglicherweise handelt es sich bei diesem Helm -

ähnlichen Gladiatorennamen anhand einer Stele des Pardalas aus Hierapolis: RitTi - Yilmaz 1998, 523-526. Vgl. Kap. 8.2, IN 4 (Taf. 412)

${ }^{122}$ Diesen Vorschlag verdanke ich H. Taeuber. Vgl. z. B. die numismatischen Zeugnisse zu den Steinen des Zeus Kasios in Seleukia Pieria und des Elagabalos in Emesa: Herrmann 1959, 26 f. Abb. 3, 3. 4; Augé - Linant de Bellefonds 1986, 707 Nr. 14; CARstens 2008, 82 f. Abb. 9. Zum Meteor von Pessinus vgl. u. a. Kron 1992, 63 f.; Dalcher 2001, 83-89; STARK 2007, 67-87.

${ }^{123}$ Vgl. die Grabstele eines murmillo aus Hadrianopolis in Thrakien, Junkelmann 2008, 208 Abb. 348. Der Gladiator auf der von Junkelmann ebenda verglichenen Stele aus Kos (?) trägt allerdings einen Stab (rudis?) mit herabhängendem Ende: Pfunl - MöBius 1979, Nr. 1234 Taf. 185.

${ }^{124}$ Kap. 8.2, IN 4 (Taf. 412).

${ }^{125}$ Vgl. hier den Text zu den Gladiatorenpfeilern, Kap. 7.1.6.1.

${ }^{126}$ Zur Inschrift Kap. 8.2, IN 5 (Taf. 411). 
soweit der schlechte Erhaltungszustand eine Interpretation zulässt - um einen im Osten im 2.-3. Jh. n. Chr. auftretenden Sondertypus, der einen rundum laufenden, tief herabreichenden Kragen aufweist ${ }^{127}$. In der Linken hält Achilleus einen Rechteckschild vor dem Leib. In der Hand des abgebogenen rechten Arms schwingt er wohl ein Kurzschwert. Am Leib trägt er den Lendenschurz, dessen Gürtung unter der Brust sichtbar wird, die manica über dem rechten Arm und die kurze Beinschiene über dem linken Unterschenkel. Den Rüstungsteilen sowie dem charakteristischen Detail des hohen, geknickten Helmkamms zufolge handelt es sich um einen murmillo ${ }^{128}$. Murmillones sind auch auf zwei Grabstelen des ephesischen Gladiatorenfriedhofs aus dem späten 2./frühen 3. Jh. dargestellt ${ }^{129}$.

Dicht unter dem oberen Profil erstreckt sich die vierzeilige Inschrift, die H. Taeuber auch in die 2. Hälfte des 2. Jhs. n. Chr. datiert $^{130}$.

\section{SK 57}

Taf. 391 Abb. 646. 647

Widderkopf von Girlandensarkophag, kaiserzeitlich Selçuk, GHD; FK 17/93

An der nördlichen Umfassungsmauer, Hangschutt; 1993

Sehr grobkörniger hellgrauer Marmor

L $32 \mathrm{~cm}, \mathrm{H}$ max. 15,5 cm, T max. $15 \mathrm{~cm}$

Erh. Ecke von Sarkophag mit Widderkopf und längerem Reliefrest an der einen Längsseite. Oben in Stirnhöhe des Widders in etwa ebener Fläche abgeschlagen, unten in unregelmäßiger Linie ab dem Tiermaul. Spitze des Mauls abgeschlagen. Nur geringer Rest der 1. Kopfseite des Widders erh., dahinter durchgehend abgeschlagen. Mehrere Bruchstellen an der besser erh. Längsseite. Erhaltene originale Oberfläche generell bestoßen und beschädigt. Stark bräunlich grau verfärbt, Mörtelspuren. Reliefgrund an der VS gespitzt. Innere Augenwinkel gebohrt.

An der Ecke des Sarkophagfragments sitzt ein Widderkopf mit vorspringender Stirn und breitem Nasenrücken, der Kopf verjüngt sich stark zum Maul hin. Die Augen stehen schräg, sind groß und rund. Die Augenlider sind schmal und von der umliegenden Haut abgesetzt. Von den gebohrten inneren Augenwinkeln verläuft eine tiefe Kerbe zu Seiten des Nasenrückens herab. Hinter dem rechten Auge liegt die Windung des Horns, dessen Außenseite durch Kerblinien gegliedert ist. Unter dem Horn fallen offenbar Tänien in zwei übereinander liegenden Ebenen herab. Zwischen diesen Bändern und der Kinnlade des Tiers hat sich ein Stück des Reliefgrunds erhalten (ebenso ein kleiner Rest an der linken Seite der Kinnlade des Tiers). An der

\footnotetext{
${ }^{127}$ JunKeLmanN 2008, 66 ( $>$ Typus Tralles $\left.\triangleleft\right)$, vgl. ein Relief mit zwei kämpfenden Gladiatoren (Asteropaios und Drakon) aus Ephesos in Berlin, Staatliche Museen, Antikensammlung, JunKeLMANN 2008, Abb. 94.

${ }^{128}$ Vgl. dazu den Grabstein des Marcianus aus Marcianopolis, Angelov u. a. 1996, 135-144; JunKelmanN 2008, 106 f. Abb. 148. Inschriftlich ist Marcianus als secutor und murmillo bezeichnet, das Relief zeigt ihn mit dem Helm des murmillo; daneben ist der Helm des secutor abgebildet. Zum murmillo vgl. JunKELMANN 2002, 36 Abb. 9. 45 Abb. 5; JunKeLMANN 2008, 104-112.

${ }^{129}$ Pietsch - Trinkl 1995, 42-45 (Relief 1 und 2) Abb. 25 f.; Pietsch 2002, 15 f. zu S. 59; ZÜLKAdíroĞLU - Ị̇́TEN 2002, 76; JunKelmann 2008, 175 Abb. 307.

${ }^{130}$ Vgl. Kap. 8.2, IN 5 (Taf. 411).
}

oberen Bruchkante, hinter dem Horn, ist ein herabhängendes Eichenblatt zu sehen, wohl Teil der hoch ansetzenden Girlande. An der linken Seite des Kopfs haben sich nur ein schmaler Streifen der Wangenpartie mit der Kerbe entlang des Nasenflügels, das Bohrloch im inneren Augenwinkel sowie der Ansatz des Augapfels (?) erhalten. Eine chronologische Einordnung des Fragments ließe sich nur über das vergleichende Studium aller ephesischer Girlandensarkophage und -fragmente erzielen ${ }^{131}$.

\section{SK 58}

Taf. 391 Abb. 648- 652

Altärchen an Pfeiler, kaiserzeitlich

Selçuk, Efes Müzesi 81/42/93; FK 32/93

An der nördlichen Umfassungsmauer, Füllschutt; 1993

Grobkörniger hellgrauer Marmor

H 23-24 cm, B max. 13,5 cm, T max. 20,5 cm

US und zum Großteil auch Sockelleisten bzw. untere Profile abgeschlagen, ebenso oberes Profil des Altärchens stellenweise abgeschlagen; Bruchstelle an einer Seite des Pfeilers. Kanten bestoßen. Großflächig von Wurzelfasern überzogen.

An OS des Altärchens große seichte Ausnehmung, diese grob gespitzt; an der dem Pfeiler nächstliegenden Kante Rest von Bleiverguss. An der mit dem Zahneisen bearbeiteten RS des Pfeilers noch mit Blei gefüllter Gusskanal, an der OS des Pfeilers Dübelloch mit Bleiverguss ( $\mathrm{L}$ des Kanals insgesamt $9 \mathrm{~cm}$, Dübelloch $3 \times 2 \mathrm{~cm}$ ).

Die Nebenseiten dieses Objekts (Taf. 391 Abb. 651. 652) ähneln in der Zusammensetzung eines Sockels mit einem an dessen Rückseite ansetzenden Pfeiler Fragmenten von Tischfüßen mit figural verzierten Stützen aus Aphrodisias ${ }^{132}$. Im Fall der letzteren handelt es sich bei den Sockeln um Basen von Statuetten, deren Reste sich noch an der Oberseite der Basen erhalten haben. Der Sockel am ephesischen Fragment ist oben und unten einfach profiliert. Darüber liegt eine Deckleiste; an der (vom Betrachter aus gesehen) linken Seite zeichnet sich deutlich ein Eckakroter ab (Taf. 391 Abb. 652) ${ }^{133}$. In den versenkten Relieffeldern der drei sichtbaren Seiten ist ein rundes Objekt, wohl eine Phiale, abgebildet. Es handelt sich hier also wohl um einen Altar. Der sich dahinter erhebende Pfeiler weist ein vielfach gegliedertes unteres Profil auf, das an den Nebenseiten und der Rückseite sichtbar ist (Taf. 391 Abb. 649. 651. 652) ${ }^{134}$, und darüber, am Schaft, den Ansatz eines breiten versenkten Feldes zeigt. Die Rückseite dieses Schafts (Taf. 391 Abb. 649), schmaler als das Altärchen, ist ungegliedert und rauer belassen. In ihrer Mitte führt ein Kanal mit Bleiverguss empor zur Oberseite des Pfeilers, die mit dem Zahneisen bearbeitet ist und in ihrer Mitte ein mit Blei gefülltes Dübelloch aufweist (Taf. 391 Abb. 650). In die Oberseite des Altärchens (Taf. 391 Abb. 650) wiederum ist eine große, seichte Ausnehmung gearbeitet, deren Oberfläche gespitzt ist und die an der Kante zur Obersei-

\footnotetext{
${ }^{131}$ M. Heinz nahm alle Sarkophagfragmente in den Jahren 1999 bis 2006 auf. Eine Publikation der Girlandensarkophage ist nach der Vorlage der attischen Sarkophage (C. Kintrup) geplant.

${ }^{132}$ Philipps 2008, 265-267 Nr. 6 Abb. 11; 282 f. Nr. 23 Abb. 34.

${ }^{133}$ An dieser Seite ist die Oberseite des Pfeilers etwas höher als jene des Altärchens.

${ }^{134}$ An der Rückseite in unterschiedlichem Aufbau und gröber ausgeführt.
} 
te des Pfeilers Reste von Bleiverguss aufweist. Der obere Teil des Pfeilers war also angesetzt, und auch an der Oberseite des Altärchens muss ein weiteres Objekt angesetzt gewesen sein. Altärchen wie Pfeiler müssen von einem gemeinsamen Sockel getragen worden sein. Denkbar ist eine Funktion des Monuments als Teil eines Tischfußes oder einer Statuenstütze.

\section{SK 59}

Taf. 392 Abb. 653. 654

Unterteil eines Tischfußes mit Felidenpranke, kaiserzeitlich

Selçuk, GHD; FK 73/93

Nord-Analemma, Füllschutt; 1993

Grobkörniger hellgrauer, blaustichiger Marmor

H $33 \mathrm{~cm}$, PlinthenH $3 \mathrm{~cm}$, B $16,5 \mathrm{~cm}, \mathrm{~T} 10 \mathrm{~cm}$

Erh. Unterteil des Tischfußes. Beschädigt äußerste Kralle rechts und geschwungene Sockelpartie darunter. Sockel an RS leicht beschädigt. Kanten der oberen Partie stellenweise bestoßen. Wurzelfasern. Bräunlich grau verfärbt.

Mittellinie zwischen dem mittleren Krallenpaar und Innenseite der äußeren Krallen durch Bohrrillen hervorgehoben. Krallen hinterbohrt. In der Mitte der US Stiftloch.

Die niedrige Plinthe des freistehenden Tischfußes weist eine schmale, gerade Vorderseite unter den mittleren Krallen der Felidenpranke auf; unter den seitlichen Krallen schwingt der Sockelrand konkav ein und mündet schließlich in die bogenförmig gerundete Rückseite. Über dem Sockel erheben sich die vier von Fell bedeckten Krallen; die Fellbüschel sind durch Kerben gegliedert. Die Beinpartie ist an der Vorderkante und den Seiten konkav gerundet. An den Stellen der maximalen Breitenerstreckung der oberen Partie des Beins ist an beiden Seiten ein pfeilartiges Ornament angegeben (wobei die Spitze des Pfeils umgedreht ist). Über diesen Ornamenten schwingen die Seitenkanten des Beins nach innen. Die Vorderkante des Beins wird von je einer schräg verlaufenden Kante begleitet. Am oberen Bruchrand der Rückseite sitzt ein längliches, lanzettförmiges Ornament. Das Stiftloch an der Unterseite der Plinthe weist darauf hin, dass diese auf einem Sockel aufsaß. Die Form der niedrigen Plinthe sowie die Form des Beins und der Krallen entsprechen einem Typus, der sich in mehreren, aus alabastro fiorito gearbeiteten Exemplaren in den Hanghäusern gefunden hat ${ }^{135}$. Ein in der Form und dem pfeilartigen Ornament vergleichbares Exemplar aus weißem Marmor stammt aus Metropolis ${ }^{136}$. Der Bohrer wurde an den Fragmenten aus den Hanghäusern allerdings stärker eingesetzt, das Bein ist z. T. stärker durchgebogen, und die Krallenpartie lädt stärker aus. Die Gliederung der Fellbüschel durch einfache Kerben am Tischfuß aus dem Theater lässt sich mit dem Fragment aus alabastro fiorito aus dem Hanghaus 1 vergleichen ${ }^{137}$.

Tischfüße mit Tierprotomen haben sich in großer Zahl in ganz Kleinasien gefunden, doch erschwert die schlechte Publikationslage ihre typologische und chronologische Einordnung ${ }^{138}$.

\footnotetext{
${ }^{135}$ QuATEMBER 2006, 91-97.

${ }^{136}$ Аyвек 2009, 123 Nr. 252 Taf. 63.

${ }^{137}$ Quatember 2006, 91 f. KatNr. 1 Abb. 1. Zur Form des Beins vgl. auch den Tisch aus rosso brecciato aus der Wohneinheit 2 des Hanghauses 2: QuATEMBer 2010, 649 f. 653 KatNr. B-MI5, Taf. $276 \mathrm{f}$

${ }^{138}$ Vgl. zuletzt Feuser 2008, 230. Dort S. 231-235 zu Nutzung und Aufstellungsorten dieser Tische. Zu löwenköpfi-
}

Für die Tische und Fragmente aus dem Hanghaus 2 gilt als terminus ante quem die Zerstörung der Insula im 3. Viertel des 3. Jhs. n. Chr. ${ }^{139}$. Angesichts der Bohrungen am Fragment aus dem Theater könnte man an eine Datierung in das fortgeschrittene 2. Jh. bzw. in das 3. Jh. n. Chr. denken, doch muss man im Auge behalten, dass es sich hier um Massenprodukte handelt, bei denen andere Kriterien galten als bei der Freiplastik ${ }^{140}$.

\section{SK 60}

Taf. 392 Abb. 655

\section{Gewandfragment}

Selçuk, GHD; FK 44/98

Bereich westlich des Nord-Analemma, sog. Sockelmonument, Schutt ${ }^{141}$

Grobkörniger hellgrauer Marmor

L $21 \mathrm{~cm}, \mathrm{~B} 9 \mathrm{~cm}$, T erh. max. $8,5 \mathrm{~cm}$

Erh. langes Fragment mit Faltenbahnen. Rundum abgebrochen. Bräunlich grau verfärbt, Wurzelfasern, Mörtelspuren. Beschädigte Stelle am untersten Teil der VS.

Erhalten haben sich die Reste zweier langer, vertikal herabfallender, übereinander liegender Faltenbahnen. Die vertikalen Falten der oberen, längeren Bahn sind leicht modelliert. Beide Bahnen enden unten in einem abgesetzten Rand, der an der oberen Bahn unterschnitten ist. Beide Säume werden von einer wellenförmigen, parallel gezogenen Kerblinie begleitet. Unter dem Rand der unteren Bahn hat sich ein weiterer kleiner Rest der originalen Oberfläche erhalten.

SK 61

Taf. 392 Abb. 656; 393 Abb. 657.658

\section{Weiblicher Idealkopf, flavisch}

Selçuk, Efes Müzesi 31/18/98

Vor dem Theater (Areal westlich des Nord-Analemma), bei Aufräumungsarbeiten; 1998

Hellgrauer grobkörniger Marmor

H 22,5 cm, KopfH 20 cm, B max. 14,2 cm, T max. $18 \mathrm{~cm}$ (am Nackenknoten), T 12,5 cm (am Kopf)

Erh. Hals, 1. Teil des Kopfs mit Teil der 1. Gesichtshälfte, Haarwellen im hinteren Teil der r. Seite und ganze RS. Großteil des Gesichts mit Stirnhaar sowie Großteil des Haars an 1. Kopfseite abgeschlagen, Nackenknoten beschädigt und unten abgebrochen. Schräg sitzender Puntello an der OS des Kopfs in Höhe des 1. Auges $(2,5 \times 1,5 \mathrm{~cm})$. Kopf stark von Mörtel überzogen, stellenweise grau verfärbt.

Die über den Hals führenden Haarwellen sind durch eine grobe Rille vom Inkarnat getrennt.

Der nicht sehr sorgfältig ausgearbeitete, auf einem schmalen Hals sitzende Kopf war zu seiner Linken gewendet und gedreht. Vom Gesicht haben sich nur mehr der äußere Teil der linken Wange und der linke äußere Augenwinkel erhalten. Die

gen Tischfüßen mit Akanthusdekor aus der Antikengalerie des königlichen Museums in Stockholm, ihrer Datierung und ihren ursprünglichen Aufstellungsorten in Peristyl und Garten vgl. LANG 2006/2007, 167-188.

${ }^{139}$ Quatember 2006, 96.

${ }^{140}$ Zur Schwierigkeit der chronologischen Einordnung auch Quatember 2006, 90 f. 101.

${ }^{141}$ Dieses Monument wurde von St. Karwiese als »DionysosAltar« oder Naiskos des Dionysos angesprochen, vgl. Kap. 3.5.3. 
Haarwellen sind in einem für weibliche Idealköpfe sehr beliebten Schema von einem Mittelscheitel ausgehend entlang der Schläfen und über die Ohren hinweg zum Nacken geführt, wo sie in einem tief sitzenden Knoten von eckiger Form münden. Die breiten Haarwellen an der rechten Kopfseite sind grob gemeißelt. Das flache, leicht gewellte Kalottenhaar ist, ausgehend vom Scheitel, durch dünne Linien gegliedert. Der an der Oberseite des Kopfs sitzende Puntello könnte der Rest einer Haarschleife sein, wie sie z. B. von Aphrodite getragen wurde ${ }^{142}$. Stilistisch steht der Kopf den weiblichen Idealköpfen mit Mittelscheitelfrisur vom 78/79 n. Chr. errichteten Nymphäum des C. Laecanius Bassus in der Gestaltung der breiten, kantigen Wellen des Haars hinter den Ohren am nächsten ${ }^{143}$.

\section{Grabungen OBERHALb DER SUMMA CAVEA}

SK 62

Taf. 393 Abb. 659

Torso einer Satyr- oder Silenstatuette (?)

Selçuk, GHD; FK 28/09

Theater-Ost, $>$ Raum $<2$ = Umgang, Verfüllschutt (Abfallgrube) im Nordosten des Schnitts S1, SE 13 ${ }^{144} ; 2009$

Mittelkörniger weißer Marmor

H $11,5 \mathrm{~cm}$

Erh. Rumpf mit Ansätzen des r. Oberarms und kleinem Ansatz des 1. Oberarms sowie der r. Hüfte. Bruchstellen an 1. Brust, am Rücken, am Ansatz des 1. Oberarms. Mörtelspuren, Wurzelfasern, bräunliche Patina.

Originale Oberfläche geglättet. Nabel gebohrt.

Der Torso ist zu seiner Linken gedreht. Dies drückt sich auch in der schräg verlaufenden linea alba und in dem schräg sitzenden Nabel aus. Der Ansatz des rechten Oberarms ist an den Körper angelegt und zurückgenommen. Der Ansatz des linken Oberarms ist jedoch angehoben; die Rundung der linken Brust liegt höher, und neben der Brust wird die Achsel sichtbar. An dem muskulösen Torso sind Halsgrube, Brustmuskeln und Rippenkorb angegeben, die Bauchdecke ist von der rechten Hüfte abgesetzt. Der obere Teil des Rückens ist durch die Furche geteilt. Darunter sitzt ein abgebrochener Ansatz, der jedoch nichts mit den Glutäen zu tun hat - handelt es sich eventuell um das Schwänzchen eines Satyrn oder Silen? Wenn dies der Fall war, so wären etwa bewegte, tanzende Silensstatuen nach hellenistischem Vorbild zu vergleichen ${ }^{145}$. Ein etwas unterlebensgroßer Satyrtorso in Drehbewegung wurde von J. T. Wood im Theater gefunden ${ }^{146}$.

\footnotetext{
${ }^{142}$ Vgl. Aphroditen in der Nachfolge des Typus vom Kapitol, DelivorRias 1984, 52 f. Nr. 409-421.

${ }^{143}$ Vgl. besonders die Köpfe Efes Müzesi, Selçuk 2333 und 2459. InvNr. 2333: FLeISCHER 1972/1975, 432 Abb. 11. Zu beiden Köpfen und dem idealen Kopf eines Figuralpfeilers, der in der Brunnenfassade verbaut war: RATHMAYR (in Vorbereitung) im Katalog S 97 f. und S 120.

${ }^{144} \mathrm{Zu}$ diesem Gang und seiner Funktion vgl. Kap. 3.8.

${ }^{145}$ Vgl. z. B. den \Satyr Borghese aus der Casa del Fauno in Pompeji, Simon 1997, 1130 Nr. 214 bzw. 1131 Nr. 233.

${ }_{146}$ Aurenhammer 1990 Nr. 53 Taf. 36.
}

\section{Fundorte IM SÜDBEREICH des ThEATERS: KAMMERN, VOMITORIA UND TREPPE ENTLANG DER UMfassungsmauer der CaVEa}

\section{SK 63}

Kleines Gliedmaßenfragment?

Selçuk, GHD; FK 156/07

Kammer KS3; SE 33; 2007

Mittelkörniger hellgrauer Marmor

L $4 \mathrm{~cm}$

Rundum abgebrochen. Oberfläche poliert.

Fundkontext: heterogen; 6. Jh. n. Chr. (s. Kap. 4.6.2.3).

\section{SK 64}

Maskenfragment, kaiserzeitlich

Selçuk, GHD; FK 45/98

ES1, in Erdfüllung; 1998

Grobkörniger hellgrauer Marmor

H $22 \mathrm{~cm}$, B max. $19 \mathrm{~cm}, \mathrm{~T}$ erh. $12,5 \mathrm{~cm}$

Oben, unten und an den Seiten abgeschlagen. Die äußere r. Hälfte des Gesichts ist abgeschlagen; von der 1. Gesichtshälfte ist nur wenig erh. An der RS Bruch, aber auch eine größere, mit dem Meißel bearbeitete Fläche. Erh. Rest der Augenpartie (mit Fragment des 1. und unteren Teil des r. Auges), Teil des Mittelgesichts und r. Hälfte des Untergesichts. Nase abgebrochen, Kinn beschädigt. Mörtelreste; Oberfläche von weißer Schicht überzogen.

Iris und Mund ausgehöhlt.

Dieses offenbar sekundär verbaute Maskenfragment zeigt die charakteristische große Öffnung des Mundes und die ursprünglich in anderem Material eingelegte Iris der großen Augen. Die inneren Augenwinkel sind leicht ausgezogen. Der Ansatz des schmalen Oberlids hat sich am rechten äußeren Winkel erhalten. Die Unterlider sind kaum von den flachen Wangen abgegrenzt. Das kurze Philtrum ist leicht eingetieft. Leider ist nichts vom Onkos erhalten, sodass die Maske nicht näher bestimmt werden kann.

Eine Reihe von marmornen Masken fand sich bei Reinigungsund Restaurierungsarbeiten des Efes Müzesi im Bereich der Portikus und hinter deren Rückwand, an der sie offensichtlich angebracht waren. Diese Masken wurden bereits von E. Atalay und D. Kayan im Jahrbuch des Museums kurz vorgestellt ${ }^{147}$. Sie zeigen verschiedene Typen der Tragödie und sind auch stilistisch unterschiedlich ausgeführt. Es liegt nahe, dass auch das Maskenfragment SK 64 (Taf. 393 Abb. 660) zu dieser Serie gehörte. Dessen Augenbildung mit den nur schwach ausgeprägten Unterlidern und dessen unbewegtes Inkarnat lassen sich vielleicht an die weibliche Maske mit hohem, in der Art einer Mittelscheitelfrisur gestalteten Onkos anschließen ${ }^{148}$.

\section{SK 65}

Arm einer Statuette

Selçuk, GHD; FK 40/07

ES1, Oberflächenfund

Grobkörniger hellgrauer Marmor

$\mathrm{L} 11 \mathrm{~cm}$

\footnotetext{
${ }^{147}$ Atalay 1972, 47 Abb. 1. 2; Kayan 1972, 56-64 Abb. 1-6. Diese Masken werden in der Publikation der Cavea erneut vorgelegt werden. Vgl. außerdem Kap. 7.3.2 (SK 106).

148 Selçuk, Efes Müzesi 5/1/73. KaYAn 1972, 64 Abb. 6.
} 
Erh. Ansatz des Oberarms und leicht abgebogener Unterarm Oben und unten gebrochen. An US quer liegender Puntello (B 2,8 cm). An der Oberfläche schwarze Ablagerungen, etwas Wurzelfasern.

Innenseite des Arms gut geglättet.

SK 66

Taf. 394 Abb. 661

Gewandfragment mit Schwertscheide, kaiserzeitlich

Selçuk, GHD; FK 69/09

Sektor K1, SE 122 (= SE 210); 2009

Grobkörniger weißer Marmor

H $18 \mathrm{~cm}$, B 21,5 cm, T 13,5 cm

Fragment einer Schwertscheide mit seitlich ansetzenden Gewandfalten. Rundum Bruch. Kanten der Schwertscheide und Gewandfalten stellenweise bestoßen. Von Wurzelfasern überzogen. Oberfläche der Schwertscheide geglättet.

Fundkontext: heterogen; 6. Jh. n. Chr. (s. Kap. 4.7.4)

Es handelt sich offenbar um das Fragment einer lebensgroßen, nackten männlichen Porträtstatue mit der über die linke Schulter und den linken Unterarm geworfenen Chlamys. Vergleichbare Porträtstatuen mit originaler Schwertscheide zeigen, dass die linke Hand den Schwertgriff hielt und das Schwert in der Scheide am linken Oberarm lehnte ${ }^{149}$. Am ephesischen Fragment liegt die Schwertscheide schräg auf dem Gewand; sie neigt sich mehr zu dem kleineren, stärker beschädigten Faltenteil.

\section{SK 67}

Taf. 394 Abb. 663. 664

Unterteil von unterlebensgroßer weiblicher Gewandstatue, 2. Jh. n. Chr.

Selçuk, GHD; ET09/12

Zwischen den Zugängen zu ES1 und ES2, vor der Umfassungsmauer, Sektor H1, SE 195 (= SE 124); 2009

Grobkörniger weißer Marmor

H $20 \mathrm{~cm}$, PlinthenH 3-4 cm

Aus 3 Fragmenten zusammengesetzt. Erh. Plinthe mit Unterschenkeln und Füßen. Abgebrochen ganzer vorderer Rand, 1. NS und Großteil der r. NS der Plinthe, Spitze des 1. Fußes und an der Außenseite des 1. Beins herabfallende Faltenbahn, r. vordere Ecke der Plinthe mit r. Fuß, Stück an der RS der Plinthe. Faltenbahnen stellenweise beschädigt und bestoßen. Stellenweise Brandspuren, Bruchflächen sehr porös.

Fundkontext: heterogen; 6. Jh. n. Chr. (s. Kap. 4.7.4)

Die Statuette erhebt sich auf einer niedrigen, einfach gestalteten Plinthe. Das Gewand an der Rückseite sowie die Faltenbahnen an der rechten Körperseite fallen direkt auf die Plinthenkanten herab. Das rechte Bein ist belastet, der linke Unterschenkel ist abgebogen, der linke Fuß (auf einer Sandalensohle) ist etwas zurückgesetzt. Beide Füße sind schräg zur Vorderkante ausgerichtet; am linken Fuß ist noch die Sohle der Sandale zu sehen. Beide Unterschenkel treten unter dem Gewand vor, besonders das Spielbein. Die Schenkel sind sowohl innen wie außen von begleitenden, unterschnittenen Falten gerahmt. Drei entlang der Innenseite des linken Unterschenkels herabführende Falten streichen über den

\footnotetext{
${ }^{149}$ Vgl. z. B. die trajanische Porträtstatue aus Ostra in Genf, Hallett 2005, 191 f. 325 Nr. 219 Taf. 3, oder eine Porträtstatue des Hadrian aus Pergamon, Inan-Rosenbaum 1966, KatNr. 31 Taf. 19, 1. Vgl. auch das Fragment aus Aphrodisias, Sмith 2006, 144 Nr. 135 Taf. 25 (J. Lenaghan).
}

Rist des linken Fußes. Die Steilfalte vor dem rechten Unterschenkel endet in einer Schlangenlinie über dem rechten Fuß. Zwischen den Beinen fällt eine breite Mittelfalte herab. Die Außenseite des rechten Unterschenkels ist von einer breiten, abtreppenden Faltenbahn gerahmt, während die schmälere Faltenbahn an der Außenseite des linken Unterschenkels zu den flachen, schematischen vertikalen Faltenbahnen der Rückseite überführt.

Bestimmende Elemente dieses mittelformatigen Statuenfragments sind die zwischen den Beinen herabfallende Mittelfalte, die über den Spielbeinfuß streichenden Falten und die Faltenbahnen, welche die Außenseiten beider Beine rahmen. Diese Kombination findet sich, oft mit Verbreiterung der mittleren Faltenpartie, an zahlreichen hellenistischen und römischen $\mathrm{Ge}-$ wandstatuen.

Vergleichbar im Format und in der bescheidenen Ausführung ist z. B. eine Statuette von der Marmorstraße, die einen hellenistischen Fortunatypus aufgreift, den F. Rausa >Typus Claudia Iusta genannt hat ${ }^{150}$. Über dem hoch gegürteten Chiton trägt sie einen Mantel mit Hüftbausch und über dem linken Knie hochgezogenen Saum; auch der Kopf war bedeckt. Den beschuhten Füßen zufolge handelte es sich hier um eine Porträtstatuette ${ }^{151}$. Die Statuette vom Theater trug Sandalen, wie an der Sohle unter dem linken Fuß zu sehen ist, und stellte demnach wohl eine Göttin dar ${ }^{152}$. Die schweren, teigigen Falten des Fragments vom Theater, die durch tiefe Einschnitte getrennt sind, finden sich auch an antoninischen Athenastatuetten aus Griechenland, in Verbindung mit der schematischen Gestaltung der Rückseite ${ }^{153}$.

SK 68

Taf. 394 Abb. 662

Haarfragment

Selçuk, GHD; FK 56/09

Außerhalb der Umfassungsmauer zwischen ES1 und ES2, Sektor J2; 2009

Grobkörniger hellgrauer Marmor

H 8,5 cm, B 9,3 cm, T max. $2 \mathrm{~cm}$

Rundum abgebrochen. Stark versintert; Mörtelspuren.

Fundkontext: heterogen; kaiserzeitlich (s. Kap. 4.7.4)

Erhalten hat sich eine Reihe von parallel gewellten, kräftig gekerbten, herabfallenden Haarsträhnen.

\section{SK 69}

\section{Armfragment}

Selçuk, GHD; FK 15/09

Zwischen ES1 und ES2, vor der Umfassungsmauer, Sektor H1, SE 195 (= SE 124); 2009

Pavonazetto

H $6 \mathrm{~cm}, \mathrm{Dm} 7,8 \mathrm{~cm}$

${ }^{150}$ Selçuk, Efes Müzesi 1283. Fleischer 1974, 94 f.; Atalay 1989, 36. 92 Nr. 27 Abb. 64. Zum Typus Rausa 1997, 128. 139 Nr. 25-34.

${ }^{151}$ AleXANDridis 2004, 255 Bd 15.

${ }^{152}$ Zur Unterscheidung vgl. FILGES 1999, 185.

${ }^{153}$ Vgl. z. B. Karanastassis 1987, 404 B I 5 Taf. 37, 1-4, dazu die Rückseite einer Athenastatuette aus Philippi mit Taf. 57, 2-4. Zur schematischen Gestaltung der Rückseite vgl. auch hier SK 73 (Taf. 395 Abb. 666. 667). Vgl. aber auch Mittelfalte und Faltenwurf an der Innenseite des Spielbeins an der Figur der Demeter vom Parthermonument, OBerLeitner 2009, Abb. 223 
Oberfläche ursprünglich geglättet. Stiftloch in der Bruchfläche (L 4,5 cm, B 1,5 cm).

Fundkontext: heterogen; 6. Jh. n. Chr. (s. Kap. 4.7.4).

\section{SK 70}

Unterlebensgroßes Beinfragment mit Ansatz

Selçuk, GHD; FK 30/93

Südliche Außenmauer, oberer Füllschutt; 1993

Mittel- bis grobkörniger weißer Marmor

L $14,5 \mathrm{~cm}$

Oben und unten gebrochen. An der Außenseite großer abgebrochener Ansatz (L 9,5 cm, B max. $5 \mathrm{~cm}$ ).

Oberfläche gut geglättet. Stellenweise versintert.

\section{SK 71}

Taf. 395 Abb. 665

Torso von Panstatuette (?)

Selçuk, GHD; FK 50/93

Südliche Außenmauer, Schutt; 1993

Grobkörniger hellgrauer Marmor

$\mathrm{H} 13 \mathrm{~cm}$

Erh. Großteil des Rumpfs und Oberschenkel. Oberfläche an den Außenkanten der Schenkel beschädigt, generell stark bestoßen, bräunlich verfärbt.

An der VS Spalte zwischen den Beinen nicht getrennt. Glied und RS nicht ausgearbeitet, an letzterer Meißelspuren.

Der Aufbau des Torsos mit klobigen Oberschenkeln und schmalem Rumpf erinnert an Figuren des $\mathrm{Pan}^{154}$. Der Rumpf ist allerdings nicht gegliedert, keine inscriptiones sind angegeben, die Oberschenkel sind unbehaart (vielleicht setzten die Zotteln aber weiter unten an), das Glied ist nicht ausgearbeitet. Es sind keine Spuren von Armansätzen zu erkennen; an der linken Flanke ganz oben befindet sich jedoch eine Bruchstelle. Die Rückseite ist zur Gänze nicht ausgearbeitet.

Es könnte sich um eine noch nicht fertig ausgearbeitete oder verworfene Pan-Statuette handeln.

\section{SK 72}

\section{Kybelestatuette, unfertig}

Selçuk, Efes Müzesi 80/42/93; FK 31/93

ES2; 1993

Grobkörniger hellgrauer Marmor

H 26,5 cm, B $17 \mathrm{~cm}, \mathrm{~T} 12,5 \mathrm{~cm}$

Die Figur ist im Marmorblock angelegt. Oberfläche bossiert; RS und NS des Throns grob bossiert. Besonders an VS stark mit Mörtel überzogen.

Die Figur sitzt auf einem kastenförmigen Thron, dessen rechte Nebenseite an der rechten Körperseite vorragt. Die linke Seite des Throns springt (in diesem Stadium des Produktionsprozesses) im Gegensatz zur rechten Seite nicht vor. Auf dem Schoß der Figur ist der Umriss des quer liegenden Löwen angelegt. Der Ikonografie zufolge handelt es sich um die thronende Kybele. Diese Muttergottheit wurde als Meter in Ephesos am Nordostabhang des Panayırdağ in einem Felsheiligtum zusammen mit an-

\footnotetext{
${ }^{154}$ Vgl. Panstatuen mit schlankem, hoch aufgerichtetem Rumpf in Cherchel und Kyrene, Marquardt 1995, $24 \mathrm{Nr}$. 25 Taf. 2, 2 und 98 Nr. 4 Taf. 14, 2 sowie LandweHr 2006, 34 f. Nr. 194 Taf. 28 (zu Cherchel). Vgl. auch die Statue des Pan mit Dionysoskind, Aurenhammer 1990, Nr. 59 Taf. 40.
}

deren weiblichen und männlichen Gottheiten ab dem 5. Jh. v. Chr. verehrt ${ }^{155}$. In diesem Heiligtum wurden Reliefs der Göttin, welche diese stehend oder sitzend, mit oder ohne männliche Begleiter zeigen, von frühhellenistischer Zeit bis in die Kaiserzeit geweiht ${ }^{156}$. Die ephesischen freiplastischen Statuetten der Kybele von der Spätklassik bis zur Kaiserzeit folgen zumeist, so wie die thronenden Relieffiguren der Göttin (von verschiedenen Fundorten in der Stadt), dem spätklassischen attischen thronenden Typus mit einem oder mehreren Löwen und dem Tympanon in der Linken ${ }^{157}$. Auf den spätklassischen attischen Votivnaiskoi und Stelen tritt meistens die Variante des Typus mit dem lang gestreckten Löwen auf dem Schoß der Göttin auf, wie schon auf den archaischen Naiskoi aus Kyme ${ }^{158}$. Dieses Motiv wählte auch der Steinmetz der unfertigen Kybelefigur aus dem Theater. Der Löwe auf dem Schoß der Göttin findet sich auch auf einer Reihe von Votivreliefs aus Ephesos ${ }^{159}$. An einer der Kybelestatuetten dieses Typus aus Ephesos mit dem Löwen auf dem Schoß der Göttin fehlt offenbar das Tympanon - letzteres scheint auch an dem unfertigen Exemplar nicht angelegt gewesen zu sein ${ }^{160}$

SK 73

Taf. 395 Abb. 666. 667

\section{Basis einer Gewandstatuette,}

späteres 2. bis frühes 3. Jh. n. Chr.

Selçuk, Efes Müzesi 82/42/93; FK 25/93

ES2; 1993

Feinkörniger hellgrauer Marmor

H $5 \mathrm{~cm}$, Basis H 2,5 cm, Dm der Basis 7,5 cm

Erh. Basis mit Füßen und Ansatz der Unterschenkel der Gewandstatuette. Unteres Profil zum Großteil abgebrochen. RS durch Sinter beeinträchtigt.

Zwei Bohrlöcher unter dem Gewandsaum der VS.

Die kleine, runde Basis weist Rundstäbe als oberes und unteres, stärker vorspringendes Profil und eine Hohlkehle dazwischen

${ }^{155}$ KeIL 1915, 66-78; KeIL 1926, 256-261; Naumann 1983, 214-216; SOYKal 1998, 7-13. 22-121. 135-208. Die Resultate der ungedruckten Diss. von F. Soykal an der Universität Wien werden in die Publikation des Meterheiligtums und der Siedlung am Panayırdağ einfließen (Leitung M. Kerschner); SCHERRER - TrinKL 2006, 263 f. M. Kerschner entdeckte 2009 die oberste Terrasse dieses Heiligtums, was eine weitere Serie von Votivreliefs und Terrakotten erbrachte.

${ }^{156}$ NaUmann 1983, 225-229 zu den ephesischen Reliefs; VerMASEREN 1987, 184-203 mit Liste der Kybele- und Attisdenkmäler aus Ephesos; SoyKaL 1998, 74-121 zu den Meterreliefs aus Ephesos, wobei die Altfunde nur zu einem geringen Teil vom Heiligtum stammen. VIKELA 2001, 108-111.

${ }^{157}$ Vgl. Naumann 1983, 180-187, Vikela 94-107 zum spätklassischen Typus. Eine spätklassische Darstellung der thronenden Kybele aus Ephesos: die Terrakotta aus den Tiefgrabungen an der Tetragonos Agora, SoYKAL 1993, 53-56 Abb. 1-4; Soykal 1998, 98 Taf. 28. Thronende Kybele auf den ephesischen Votivreliefs: Soykal 1998, 100-106. Die freiplastischen Darstellungen der Kybele aus Ephesos werden in die Publikation des Meterheiligtums integriert werden.

${ }^{158}$ Naumann 1983, 181 f. Typ 2a, KatNr. 215-266; VikelA $2001,100$.

${ }^{159}$ SoYKal 1998, 98-106.

${ }^{160}$ Selçuk, Efes Müzesi 2/35/72, gefunden im sog. Byzantinischen Palast. Naumann 1983, 324 KatNr. 247. Unpubliziert. 
auf. Der obere Rundstab wird von einem weiteren, niedrigen Rundstab begleitet. Das obere Profil ist rund um die Basis angegeben. Die Statuette steht dicht an der rechten Nebenseite der Basis, am linken Teil der Oberseite der Basis findet sich keine Spur eines Attributs oder einer Nebenfigur. An der flachen Rückseite und an den Nebenseiten ist noch der Marmorblock zu erkennen, aus dem die Statuette gearbeitet wurde. Das linke Bein ist belastet, das rechte Bein zur Seite gesetzt. Die Füße stehen auf hohen Sohlen; am rechten Fuß ist der Sandalenriemen über dem Rist zu sehen. Zwischen den Beinen fallen Faltenbahnen mit eingetieften Tälern herab. Auf dem Rist des linken Fußes staut sich das Gewand. Hinter dem linken Fuß ist das Gewand glatt gearbeitet; an der Rückseite sind nur schematische vertikale Kerblinien eingetragen.

Dieses Fragment ist ein besonders kleinformatiger Vertreter der Statuetten auf hoher profilierter Basis, wie sie typisch für kleinasiatische Werkstätten des späteren 2. und des 3. Jhs. n. Chr. $\operatorname{sind}^{161}$. Die Basis aus dem Theater unterscheidet sich von den von A. Filges zusammengestellten Exemplaren durch ihre Rundform ${ }^{162}$. Wenn man Filges" Erkenntnisse bezüglich der chronologischen Entwicklung der profilierten Statuettenbasen auf die kleine Basis aus dem Theater anwendet, so entspricht diese in ihrer Profilierung am ehesten seinem Typus II, der eine hohe untere Leiste, eine höhere Kehlung sowie eine obere Leiste mit Absatz aufweist und für die der Autor eine Datierung in spätantoninischseverische Zeit vorschlägt ${ }^{163}$. Der Mantel der ephesischen Statuette reicht bis auf die Oberseite der Basis und lässt nur die Zehen der Füße frei. Die auf die Basis treffenden Falten sowie die Gestaltung des Mantelsaums lassen sich mit einer halbbekleideten Aphroditestatuette aus der Wohneinheit 2 des Hanghauses 2 vergleichen, welche eine längliche Basis des gleichen Typus aufweist und in die gleiche Zeit zu datieren ist ${ }^{164}$. Auch die Statuette aus dem Theater könnte eine halbbekleidete Aphrodite dargestellt haben, deren Mantel beide Beine (fast) zur Gänze bedeckte ${ }^{165}$.

\section{SK 74}

Fragment einer rechten Hand

Selçuk, GHD; FK 14/93

ES2, oberer Füllschutt; 1993

Grobkörniger hellgrauer Marmor

L $6 \mathrm{~cm}, \mathrm{~B} 7,5 \mathrm{~cm}$

Erh. Fragment des Handrückens mit Ansätzen von drei Fingern.

\section{SK 75}

Torso einer Tierstatuette

Selçuk, GHD; FK 3/93

ES2; 1993

${ }^{161}$ Filges 1999, 377-430.

${ }^{162}$ Vgl. die Rundbasis einer Hygieiastatuette aus der Wohneinheit 4 des Hanghauses 2, RathmaYr 2005a, 214. 228 S 11 Taf. 140, und eine etwa $50 \mathrm{~cm}$ hohe, reicher profilierte Hygieiastatuette in Dresden, KNoll u. a. 2011, 299-301 Nr. 46 aus dem 3. Jh. n. Chr.

${ }^{163}$ Filges 1999, 402 f. Abb. 1b. An der Basis aus dem Theater liegt unter dem breiteren oberen Rundstab ein schmälerer Rundstab.

${ }^{164}$ Christof 2010, 663 B-2 20, 667 Taf. 289.

${ }^{165}$ Vgl. Delivorrias 1984, 63-65 Nr. 526-545 zur Aphrodite von Arles und ihrer Nachfolge.
Mittel- bis grobkörniger hellgrauer Marmor

L $12 \mathrm{~cm}, \mathrm{H} 6 \mathrm{~cm}$ (ohne Stütze)

Erh. Torso eines Tierleibs mit Ansatz der Hinterbeine; am vorderen bzw. hinteren Ende des Körpers jeweils schräg abgebrochen. Ansatz der Stütze unter dem Leib abgebrochen. Ein großer Sprung im Stein verläuft horizontal durch den Körper. Bestoßungen. Oberfläche bräunlich grau verfärbt.

Bei diesem Fragment handelt es sich offenbar um die Statuette eines Vierbeiners mit einst erhobenen Vorderbeinen, das zeigt der Ansatz der Stütze unter dem Tierleib. Im Vergleich z. B. mit Reiterstatuen, die das Pferd in der Levade zeigen, ist an dem Fragment (noch) kein Ansatz der vorderen Läufe des Tiers zu sehen ${ }^{166}$. Die Flanken des Tiers sind modelliert.

\section{SK 76}

Taf. 410 Abb. 730

\section{Torso von Gewandstatuette, kaiserzeitlich}

\section{Selçuk, GHD; FK 91/93}

Südlich des Zugangs zu ES2 (vor der Umfassungsmauer), Füllschutt; 1993

Rötlich brauner Kalksinter

H $13 \mathrm{~cm}$

Erh. Unterteil der Statuette. VS zum Großteil abgeschlagen; ebenso oben, unten und an 1. Seite abgeschlagen. RS zumindest im unteren Teil abgeschlagen, im oberen Teil Oberfläche stark beschädigt; Mörtelspuren. Originale Oberfläche ist vor allem am r. Unterschenkel und den rahmenden Faltenbeinen erh.; Fuß nur im Ansatz erh.

Originale Oberfläche gut geglättet. Dicht gesetzte sekundäre Bearbeitungsspuren in Kniehöhe des r. Beins und, in geringem Ausmaß, im untersten Teil der VS an der glatten (abgebrochenen?) Fläche rechts neben dem rechten Fuß.

Von der einst durch ihr farbiges Material ansprechenden Statuette hat sich nur mehr ein geringer originaler Rest erhalten ${ }^{167}$. Der erhaltene rechte Unterschenkel der Statuette tritt stark unter dem Gewand hervor; es handelt sich also um das Spielbein. An seiner Oberseite sind feine, schräge Falten angegeben. An der Außenseite wird der Unterschenkel von einer vertikalen Falte begleitet; eine breitere Faltenbahn zieht vom Rücken herab und endet am rechten Knie. An der Innenseite des Schenkels bildet sich eine tiefe Mulde. Rechts daneben (vom Betrachter aus gesehen) schwingt eine breite Bahn zum rechten Fuß, rechts gefolgt von einem weiteren Faltental. Am rechten Rand des Fragments (vom Betrachter aus gesehen), seitlich der breiten abgebrochenen bzw. sekundär bearbeiteten Fläche, hat sich die originale Mulde eines vertikalen Faltentals erhalten.

\section{SK 77}

\section{Lebensgroßes Armfragment}

Selçuk, GHD, FK 107/93

Südlich des Zugangs zu ES2 (vor der Umfassungsmauer), Erdhaufen in der Nähe der Freitreppe; 1993

Mittelkörniger hellgrauer Marmor

$\mathrm{L} 18 \mathrm{~cm}$

Oben und unten gebrochen. An der Oberfläche Wurzelfasern, Mörtelspuren.

\footnotetext{
${ }^{166}$ Vgl. Bergemann 1990, 110-112 P53-54, 115 f. P63 Taf. 82-85.

${ }^{167}$ Vgl. zu den Statuetten aus Kalksinter unter dem besser erhaltenen Fragment SK 83 (Taf. 410 Abb. 731).
} 
An der sichtbaren Seite sehr gut geglättet, an der weniger sichtbaren Raspelarbeit.

\section{SK 78}

Unterteil von Tischfuß mit Felidenpranke,

kaiserzeitlich

Selçuk, GHD; FK 40/93

Südlich des Zugangs zu ES2 (vor der Umfassungsmauer); 1993

Grobkörniger hellgrauer Marmor

$H$ max. $20 \mathrm{~cm}$, PlinthenH 2,5 cm, B 8,5 cm, T 13, $5 \mathrm{~cm}$

Am Ansatz des Schenkels abgeschlagen; Bruchstelle an der VS. Oberfläche an der 1. NS stellenweise abgeplatzt. Grau verfärbt. Starke Mörtelreste.

Bohrrille in der Mitte zwischen den Krallen. In der Mitte der US tiefes Stiftloch.

Die schmale, hohe Felidenpranke erhebt sich über einer niedrigen Plinthe, die an der Vorderseite gerade abschließt und die einst auf einem Sockel stand. Die Nebenseiten laufen bogenförmig auf die Kante an der Rückseite zu. Das Fragment entspricht dem gleichen Typus wie SK 59 (Taf. 392 Abb. 653. 654) ${ }^{168}$, doch ist der ganze Tischfuß schmäler angelegt, die Krallenpartie daher sehr hoch. Die Kerbung der Fellbüschel findet sich ebenfalls an dem Tischfuß SK 59 (Taf. 392 Abb. 653. 654), der Bohrer ist jedoch hier nur zurückhaltend eingesetzt.

\section{SK 79}

\section{Arm von Statuette}

Selçuk, GHD; K 27/98

ES3; 1998

Grobkörniger weißer Marmor

L 7,5 cm

Erh. größerer Teil des Unterarms mit Ellbogen und Ansatz des Oberarms.

Oberfläche spiegelglatt poliert; Wurzelfasern.

\section{SK 80}

Taf. 397 Abb. 674.675

Büste eines Mannes im Himation,

um bzw. nach der Mitte des 3. Jhs. n. Chr.

Selçuk, Efes Müzesi 3/7/07, ET 07/9

Auf dem Zugangspodest ES3, Sektor B2, auf SE 11 (spätes Bodenniveau der Halle über Treppe-Ost?), bedeckt von SE 7 (= SE 143, Ziegelschutt) ${ }^{169} ; 2007$

Grobkörniger weißer Marmor

H $43,5 \mathrm{~cm}$, B $47 \mathrm{~cm}$.

Kopf und Zapfen an der US der Büste abgeschlagen. Abgebrochen die vorderen Glieder von Zeige- und Mittelfinger (siehe Puntello am Himation), Spitze des Daumens. Beschädigt und bestoßen Finger, Faltengrate, unterster Teil des Stegs an der RS. Oberfläche an VS poliert. RS rauer belassen (Zahneisen, Meißel). Im unteren Ende des Stegs an der RS Dübelloch.

Fundkontext: heterogen; hellenistisch bis 2. Hälfte 4. Jh. n. Chr. (s. Kap. 4.7.1)

Die bis auf den Kopf gut erhaltene, an der Schauseite sorgfältig gearbeitete lebensgroße Büste war einst mittels eines Dübels im Steg der Rückseite mit dem Büstenfuß verbunden. Die Büste umfasst den ganzen, in der Schlinge des Himations hängen-

\footnotetext{
${ }^{168}$ Zur Besprechung des Typus s. dort.

${ }^{169}$ Zum Fundort s. Kap. 3.7.2.1.
}

den rechten Arm, den Großteil des linken Oberarms und die Brustpartie. Der Kopf war dem stärker ausgeprägten rechten Kopfnicker zufolge zu seiner Linken gewendet. An der linken Seite des Halses hat sich offenbar der kleine Rest einer Bartlocke erhalten.

Die Büste gehört zur Gruppe der Himationbüsten mit zur Gänze dargestelltem, in der Mantelschlinge hängendem rechten Arm, wobei der rechte Unterarm hier vor dem Körper angelegt ist ${ }^{170}$. Eine Variante dieses Motivs zeigt den plastischer gearbeiteten rechten Arm, der über den Kontur der Büste hinausragt ${ }^{171}$. Büsten mit zur Gänze wiedergegebenem rechten Arm und unbedeckter Hand treten von nachseverischer Zeit bis nach der Mitte des 3. Jhs. n. Chr. auf und sind vor allem im Osten des Reichs beliebt $^{172}$. Die Wiedergabe der feinen Faltengrate des Himation an der Büste SK 80 lässt sich gut mit der Büste des nachgallienischen Porträts im Museo Capitolino vergleichen ${ }^{173}$, wobei die ephesische Büste in manchen Partien flacher und schematischer gestaltet ist. Aufgrund des Lockenrests an der linken Halsseite wird es sich um ein bärtiges Porträt gehandelt haben ${ }^{174}$.

Ein weiteres Exemplar dieser Gruppe mit (unverziertem) Indextäfelchen stammt aus der Marienkirche in Ephesos, welches starke Bohrungen aufweist ${ }^{175}$.

SK 81

Taf. 397 Abb. 676

Fragment von weiblicher Büste, 3. Jh. n. Chr.

Selçuk, GHD, FK 123/07

Auf dem Zugangspodest SE3, Sektor A2, SE 1, Oberflächenhumus; 2007

Grobkörniger hellgrauer Marmor

H 29 cm, B 20 cm, B des Rands hinter r. Schulter $6 \mathrm{~cm}$

Erh. r. Hälfte der Büste, an beiden Seiten und an der US abgeschlagen.

Oberfläche der VS beschädigt, besonders an den vorspringenden Falten; an der RS stark bräunlich verwittert, versintert. An den Bruchflächen kristallzuckerartig brechend.

Oberfläche an VS geglättet, an RS grob bearbeitet. Am Randstreifen hinter der r. Schulter leichte Meißelspuren.

Erhalten hat sich ein Teil der rechten Hälfte einer weiblichen Büste mit einem tiefen Halsausschnitt. Von der rechten Schulter fällt der Mantel in gebogenen Faltenbahnen herab. Strahlenförmige Falten des Untergewands ziehen vom Halsausschnitt nach unten. Eine gebogene Kante verläuft über der rechten Brust. Die Rückseite ist konkav gewölbt. Am Bruchrand in der Mitte der Büste ist gerade noch zu sehen, dass die Seitenflächen der Rückenstütze in ihrer mittleren Partie ebenfalls konkav gebildet waren.

\footnotetext{
${ }^{170} \mathrm{Zu}$ diesen Büsten vgl. Freyer-Schauenburg 1980, $118 \mathrm{f}$. Anm. 4; Goette 1990, 64 Anm. 312; Sмith 2006, 240 f. Nr. 130 mit Taf. 96; FitTsChen u. a. 2010, 172.

${ }^{171}$ Vgl. z. B. die Büste des Dion aus Pergamon, Horn - BoEHRINGER 1966, 473. 475 Abb. 55; FreYer-SChaUenburg 1980, 118 f. Anm. 4; die Büste in Aydın, İnan - Rosenbaum 1966, Nr. 235 Taf. 130, 3. 4 , Freyer-Schauenburg 1980, 118 f. Anm. 4 und J. Lenaghan in Smith 2006, $240 \mathrm{f}$.

${ }^{172}$ Freyer-Schauenburg 1980, 118 f. Anm. 4; Fittschen u. a. 2010, 172.

${ }^{173}$ Fittschen u. a. 2010, 171-173 Nr. 170 Taf. $211 \mathrm{f}$.

${ }^{174} \mathrm{Zu}$ Porträts des 3. Jhs. n. Chr. mit längeren Bärten FiтTSCHEN u. a. 2010, 165 f. mit Anm. 1.

175 İzmir, Arkeoloji Müzesi 917. Unpubliziert.
} 
Vergleichbare, zur Gänze erhaltene Büsten zeigen, dass der Mantel über beide Schultern gelegt und wahrscheinlich unter der Brust verschlungen war; strahlenförmige bzw. schräge Faltenführung charakterisiert das Untergewand ${ }^{176}$. Auch die Betonung der Brüste durch begleitende Falten lässt sich belegen ${ }^{177}$. Da Untergewand und Mantel stofflich nicht unterschieden sind, wird die Büste im 3. Jh. n. Chr. entstanden sein ${ }^{178}$.

\section{SK 82}

Linke Hand und Unterarm von Statuette

Selçuk, GHD; FK 43/07

Vor dem Zugang zu ES3, Sektor B1, SE 9; 2007

Feinkörniger weißer Marmor

L 8,3 cm, Dm des Arms 2,5 cm

Abgebrochen Daumen, Ringfinger, kleiner Finger; von den anderen Fingern nur Ansätze erh.

Am Handballen leichte Bestoßungen.

Am oberen Ansatz des Unterarms glatte Fläche mit Stiftloch.

Fundkontext: heterogen; jüngste Funde: 5./frühes 6. Jh. n. Chr. (s. Kap. 4.7.1)

Der Unterarm war durchgestreckt, die Hand leicht angehoben. Die Finger waren offenbar ausgestreckt. Falten sind an der Handwurzel und am Handballen angegeben.

\section{SK 83}

Taf. 410 Abb. 731

Fragment von weiblicher Gewandstatuette, kaiserzeitlich Selçuk, GHD; FK 141+161/07 (141/07 = unteres Fragment) Auf dem Zugangspodest ES3, Sektor C1, SE 20 (= SE 132a-c); 2007

Dunkelroter Kalksinter (alabastro fiorito) ${ }^{179}$

$\mathrm{H} 7,7 \mathrm{~cm}, \mathrm{~B} 8 \mathrm{~cm}, \mathrm{~T} 3 \mathrm{~cm}$

Aus zwei Fragmenten zusammengesetzt. Rundum abgebrochen, auch an der leicht konkav gerundeten RS. Stellenweise versintert, Kanten etwas bestoßen.

An der VS spiegelglatt poliert.

Fundkontext: heterogen; spätes 1.-3./Mitte 5. Jh. n. Chr. (s. Kap. 4.7.2)

Es handelt sich um ein Fragment der linken Hälfte einer qualitätvollen kleinen Mantelstatuette mit linkem Spielbein und über dem linken Oberschenkel in einem Bogen hochgezogenen Mantelsaum. Das linke Knie tritt unter dem Chiton vor. An der Außenseite des linken Oberschenkels fallen plastisch gestaltete Faltenbahnen herab; zwei von ihnen schwingen leicht nach außen. Vom oberen Bruchrand führt etwa in Mitte des Oberschenkels ein als Mulde eingetieftes Faltental herab. Links davon (vom Be-

\footnotetext{
${ }^{176}$ Vgl. z. B. FitTsChen - ZANKer 1983, 95 Nr. 138 Taf. 165 (frühestens frühseverisch), Nr. 162 Taf. 190 (severisch; K. Fittschen); Smith 2006, Nr. 138-140 Taf. 100 f. (J. LenaGHAN, 2.-3. Jh. n. Chr.)

${ }^{177}$ Vgl. z. B. FitTsChen - ZanKer 1983, 84 f. Nr. 115 Taf. 145 (K. Fittschen; mittelantoninisch) und Büste eines (nicht zugehörigen) Porträts der Julia Domna im Vatikan, WeGner 1976, 194 f. Taf. 26, 1 (an beiden Büsten dünne Tunica).

${ }^{178}$ Vgl. FitTSCHEN - ZANKER 1983, 95 zu Nr. 138 Taf. 165.

${ }^{179}$ Zum Material GregareK 1999, 41; LazZarini 2002, 241. 243; Koller 2005, 145 Taf. 105, 3 f.; Gagetti 2006, 64-72, alle Autoren mit weiterer Lit. LAZZARINI u. a. 2006 war mir nicht zugänglich.
}

trachter aus gesehen) fallen zwei lange Faltenkanten herab; am linken Bruchrand schwingt eine weitere Falte leicht nach außen. Wahrscheinlich handelte es sich um eine Statuette mit um die Hüften geschlungenem Mantel ${ }^{180}$. An den vergleichbaren Statuen und Statuetten ziehen die Falten des hochgezogenen Mantels meist schräg nach oben, während die entsprechenden Falten an dem ephesischen Fragment senkrecht verlaufen. Für die Interpretation des Fragments kommen die Statuette einer Göttin oder eine Porträtstatuette mit idealem Körpertypus in Frage. Verschiedenfarbiger Kalksinter wurde in den ephesischen Hanghäusern für kleinformatige und lebensgroße Porträtbüsten sowie für den Körper der Statuette eines Togatus verwendet (2.-3. Jh. n. Chr. $)^{181}$. Gagetti hat außerdem eine weitere Gruppe von kaiserzeitlichen, aus Alabaster und Marmor gearbeiteten weiblichen Porträtstatuetten zusammengestellt, die ihrer Meinung nach bereits Verstorbene sub speciae dearum darstellen ${ }^{182}$. Die Wahl des bunten Steins für die Darstellung von Kleidungsstücken sollte die Färbung und Verzierung des Stoffes zur Geltung bringen ${ }^{183}$. Das macht auch den Reiz dieses kleinen Fragments aus.

\section{SK 84}

Taf. 410 Abb. 732

\section{Gewandfragment, kaiserzeitlich}

Selçuk, GHD; FK 39/07

Auf dem Zugangspodest ES3, Sektor B1, SE 14; 2007

Rötlich brauner Kalksinter

$\mathrm{H} 7,7 \mathrm{~cm}$

Allseits abgebrochen, auch an der RS; Bestoßungen an der originalen Oberfläche.

Oberfläche der plastisch gestalteten Oberfläche spiegelglatt poliert. In der oberen Bruchfläche steckt ein quer liegender, großer, rostiger Eisenstift. Tiefer liegende Fläche unter diesem Bruch sowie eingearbeitete Rinne links neben den breiten, plastisch gestalteten Falten rauer belassen.

Fundkontext: heterogen; mittlere Kaiserzeit bis 2. Hälfte des 4./ Anfang des 5. Jhs. n. Chr. (s. Kap. 4.7.1)

Dieses kleine Gewandfragment aus - etwas andersfärbigem Kalksinter ist so hoch wie SK 83 (Taf. 410 Abb. 731), es ist jedoch in seinem Erhaltungszustand weniger aussagekräftig. $\mathrm{Zu}$ erkennen ist ein längliches, allseits abgebrochenes Fragment mit einer gerundeten \Kante $<$ an einer Seite (bei Position des Fragments wie auf Taf. 410 Abb. 732 an der linken Seite, vom Betrachter aus). Im oberen Teil des Fragments - immer von der Position auf Taf. 410 Abb. 732 ausgehend - befinden sich zwei

${ }^{180} \mathrm{Zu}$ den Statuen im Hüftmantel vgl. z. B. AleXANDRIDIS 2004, 248-256; als Vergleich zum ephesischen Fragment 254 unter >Bd ( (rechtes Standbein, Mantelsaum oberhalb des linken Knies). Ephesische Beispiele vgl. z. B. AtalaY 1989, 32 Nr. 22 Abb. 57 (Selçuk, Efes Müzesi 33, Hygieia aus dem Ostgymnasium) oder 36 Nr. 27 Abb. 64 (Selçuk, Efes Müzesi 1283, Porträtstatuette, da in Schuhen, nach dem Fortuna-Typus).

${ }^{181}$ Büsten: Aurenhammer 2003, 187. 207 S 115 Taf. 117; RATHMAYr 2005a, 228 S 7; RAthMAYr 2005b, 284 f.; Christof 2010, 660. 665 B-S 9. B-S 10 Taf. 284. Statuette eines sitzenden Togatus aus der Wohneinheit 2 des Hanghauses 2 (Toga aus Kalksinter): AUINGER 2010, 666-669 Taf. 290. 493.

182 Gagetti 2006, 69. 259 f. 299 f. E10 Taf. 34. 387 G161 Taf. 61.

${ }^{183}$ Gregarek 1999, 151 
breite, plastisch gearbeitete Falten, die obere verläuft in einem Bogen. Im größeren, gewölbten Teil darunter sind längliche, nach links orientierte Falten schwach angegeben. Im oberen Bruchrand steckt ein Eisenstift. Auch die darunter, rechts neben den plastischen Falten befindliche, aufgeraute Fläche weist auf eine Anstückung in anderem Material, wohl in Marmor. Ebenso war wohl auch die von links auf die plastischen Falten zulaufende und aufgeraute Rinne für eine Anstückung eingetieft ${ }^{184}$.

\section{SK 85}

Taf. 398 Abb. 677-680; 399 Abb. 681-683 Pfeiler für den Gladiator Stephanos, 1. Hälfte 3. Jh. n. Chr. Efes Müzesi, Selçuk 2/7/07. ET 07/1

Zugangspodest ES3, Sektor B2, SE 1/2, auf Ziegelschutt, in einer Schicht aus Mörtelgrieß, kleinen Steinen und humosen Einschlüssen, dicht unter der Hangoberfläche bzw. mit einer Ecke herausragend; 2007

Grobkörniger hellgrauer Marmor

H $91 \mathrm{~cm}, \mathrm{H}$ unteres Profil mit Sockel $17 \mathrm{~cm}, \mathrm{H}$ oberes Profil $19,5 \mathrm{~cm}, \mathrm{H}$ der Relieffigur mit Standleiste $46 \mathrm{~cm}$, BuchstabenH $3,5 \mathrm{~cm}, \mathrm{~B}$ am Sockel $54,5 \mathrm{~cm}, \mathrm{~B}$ an der Inschriftleiste $52,5 \mathrm{~cm}$, B am Schaft 46,5 cm, T am Sockel 42-42,5 cm, T am Schaft $38 \mathrm{~cm}$, T an oberer Leiste 43,5-44,5 cm, NutB an 1. NS 8,5-9,5 $\mathrm{cm}$, an $\mathrm{r}$. NS $11 \mathrm{~cm}$.

Ecken und UK der RS beschädigt bzw. abgebrochen: Kanten bestoßen. Abgebrochene 1. obere Ecke des Profils wieder angesetzt. An r. NS Stück des unteren Profils ausgebrochen. Relief gut erh.; nur leichte Bestoßungen. Ursprünglich zahlreiche Mörtelspuren.

Am Reliefgrund der VS Zahneisen. An der Sockelleiste durchgehend Zahneisen. Nut ist an r. NS in der Mitte durchbrochen: oben und unten bossiert, in der Mitte Zahneisen. RS grob bearbeitet, dichtes Zahneisen und Meißelarbeit. OS grob bossiert. Fundkontext: SE 1 = Humusschicht, SE 2 = 2. Hälfte des 3. Jhs. n. Chr. (s. Kap. 4.7.1 Tab. 91)

Hofbauer 2008, 410 unter 1.3.1.3; dort auch TAeUber 2008, 422 unter 3.13 .

Der Pfeilertypus entspricht - wie das Denkmal für Aithales SK 86 (Taf. 400 Abb. 685-688; 401 Abb. 689-691) vom gleichen Fundort sowie der Pfeiler des Achilleus SK 56 (Taf. 390) vom Versturz von EN1 - dem besonders in Kleinasien beliebten Typus von altarähnlichen Denkmälern für Gladiatoren mit einer Einzelfigur an der Vorderseite des Schafts ${ }^{185}$. Der Name des Gladiators ist an der oberen Profilleiste angegeben (Taf. 398 Abb. 680). Vom gleichen Fundort stammt auch der Altfund des Pfeilers des Prestor ${ }^{186}$. Die charakteristischen Akroterien der obersten Leiste sind am Pfeiler des Stephanos (und an jenem des Aithales) an drei Seiten ausgearbeitet.

Auf der unter dem rechten Fuß des Gladiators keilförmig vorspringenden Leiste ist der Gladiator Stephanos im Ausfallschritt nach rechts dargestellt, wobei die Figur nur leicht ins Profil gedreht ist.

\footnotetext{
${ }^{184}$ Vgl. zur Kombination Alabaster und Marmor an Büsten und einem Togatus aus dem Hanghaus 2: СнRISTOF 2010, 660; Aunnger 2010, 666-669 Taf. 290. 493; weitere Beispiele bei GagetTi 2006, 69. $259 \mathrm{f}$.

${ }^{185} \mathrm{Vgl}$. Kap. 7.1.6.1.

${ }^{186}$ Selçuk, Efes Müzesi ohne InvNr., Fundangabe nach Skizzenbuch 2131; IvE 1174; Vgl. RoBert 1971, 199 Nr. 212 Taf. 11; ZÜLKAdiroĞLU - İçTen 2002, 82 (linker Pfeiler).
}

Dem Krummschwert in der Rechten ${ }^{187}$, den Beinschienen an beiden Unterschenkeln und dem breitkrempigen Helm vom attischböotischen Typus mit Visier und sichelförmigen Kamm zufolge handelt es sich um einen thraex $^{188}$. Vor dem Leib hält Achilleus einen bis zum Knie reichenden Schild. Der rechte Arm ist von der manica bedeckt; am rechten Unterschenkel werden die Bandagen unter der Beinschiene sichtbar ${ }^{189}$. Auch der Oberkörper ist auffallenderweise von Bandagen umwickelt, wie an der rechten Flanke zu sehen ist ${ }^{190}$. Am Ansatz des rechten Oberschenkels liegt der Saum des Lendenschurzes. Weitere ephesische Pfeiler bzw. Stelen mit thraeces-Darstellungen sind bereits bekannt ${ }^{191}$.

Der Form der Buchstaben zufolge ist der Pfeiler in die 1. Hälfte des 3. Jhs. n. Chr. zu setzen ${ }^{192}$.

\section{SK 85A}

Taf. 399 Abb. 684

\section{Fragment von Schrankenplatte}

Gelagert südlich der Freitreppe vor dem Zugang zu ES3

Zugangspodest ES3, auf Ziegelschutt; 2007

Grobkörniger hellgrauer Marmor

H $71 \mathrm{~cm}$, B $89 \mathrm{~cm}$, T 8,3-12 $\mathrm{cm}^{193}$

Zwei originale Kanten der Platte haben sich z. T. erhalten (Teil einer Längs- und einer Breitseite), deren Ränder sind bestoßen. An den beiden anderen Seiten Bruch.

An einer Seite Risslinie etwa parallel zur erh. Breitseite (4,3$5,5 \mathrm{~cm}$ von der Kante entfernt).

Zahneisenspuren an der Oberfläche.

Aufgrund der (stark schwankenden) Dicke der Platte, die jedoch zur Breite der Nuten der im gleichen Bereich gefundenen Gladiatorenpfeiler passt, wird diese Schrankenplatte die beiden Pfeiler SK 85 (Taf. 398; 399 Abb. 681-683) und SK 86 (Taf. 400. 401) zu einer Brüstung verbunden haben.

SK 86 Taf. 400 Abb. 685-688; 401 Abb. 689-691 Pfeiler für den Gladiator Aithales, 1. Hälfte 3. Jh. n. Chr Efes Müzesi, Selçuk 1/7/07. ET 07/2

Zugangspodest ES3, Sektor B2, SE 1/2, auf Ziegelschutt, in einer Schicht aus Mörtelgrieß, kleinen Steinen und humosen Einschlüssen, dicht unter der Hangoberfläche; 2007

Grobkörniger hellgrauer Marmor

H 94 cm, H unteres Profil mit Sockel 17 cm, H oberes Profil 16 $\mathrm{cm}, \mathrm{H}$ der Relieffigur mit Standleiste $46 \mathrm{~cm}$, BuchstabenH an der VS 2,5-3 cm, an der RS 1-2 cm, B am Sockel $53 \mathrm{~cm}$, B an der oberen Leiste $49 \mathrm{~cm}, \mathrm{~B}$ am Schaft 43-46 cm, T am Sockel $45 \mathrm{~cm}, \mathrm{~T}$ am Schaft 38-39 cm, T an oberer Leiste 45,5 cm,

\footnotetext{
187 Vgl. dazu JunKeLMANn 2008, $92 \mathrm{f}$.

${ }^{188} \mathrm{Zu}$ diesem vgl. JunKelmann 2002, 38. 45 Abb. 5; JunKeLMANN 2008, $119 \mathrm{f}$.

${ }^{189} \mathrm{Zu}$ den Beinschienen und zum Einheitstypus der Beinschienen an östlichen Denkmälern des 2.-4. Jhs. n. Chr., vgl. JUNKELMANN 2008, 76

${ }^{190}$ Vgl. ein Relieffragment aus Benevent, Junkelmann 2008, 46 Abb. 60, die Stele eines essedarius aus Mylasa, RumSCHEID 2001, 127 f. Nr. 7 Abb. 10 und das Relieffragment eines thraex im Museum von Izmir, Robert 1971, $167 \mathrm{f}$. Taf. 9 = PetZl 1974, 293 Nr. 12.

${ }^{191}$ Vgl. den Pfeiler für Hippolytos, IvE 1174,4; ZüLKADiRoĞLU - İcTen 2002, 78 f. (und zur Stele für Seidonis).

${ }^{192}$ Vgl. Kap. 8.2, IN 6 (Taf. 413).

${ }^{193}$ Die Maßangaben verdanke ich M. Hofbauer.
} 
NutB an 1 . NS 8-11 cm, an r. NS 9-11 cm.

Gut erh. Ausgebrochen 1. Ecke an der RS und ein paar Stellen an den Kanten der RS. Kanten generell bestoßen. Ursprünglich dicht von Mörtel bedeckt.

Akroterien an allen Seiten außer an der RS. Profile an RS nicht voll ausgearbeitet. Zahneisen am Reliefgrund und am Sockel der VS, am Schaft der 1. NS. Nuten bossiert. Dichtes Zahneisen und Meißelspuren an der OS. Dichtes, grobes Zahneisen an der RS. Fundkontext: SE $1=$ Humusschicht, SE $2=2$. Hälfte des 3. Jhs. n. Chr. (s. Kap. 4.7.1 Tab. 91)

Hofbauer 2008, 410 unter 1.3.1.3; dort auch TAeuber 2008, 422 unter 3.13.

Die gleiche Profilierung, die großteils übereinstimmenden Maße der Pfeiler SK 85 (Taf. 398; 399 Abb. 681-683) und SK 86 (Taf. 400. 401) sowie der gleichartige Stil der Relieffiguren und der Duktus der Inschriften an der oberen Profilleiste erweisen die Pfeiler als Pendants. Der Gladiator Aithales ist in Ausfallstellung im Profil nach links dargestellt. Seine Figur wirkt durch den langen Schild, der einen Großteil des Körpers bedeckt und damit auch den rechten Arm verdeckt, statischer als Stephanos. Aithales trägt einen kammlosen Helm mit breiter, schräg abfallender Krempe ${ }^{194}$ und Stirngiebel mit seitlicher Volute. In der Rechten hält er das Kurzschwert. Unterkörper und Glutäen sind vom Lendenschurz bedeckt, der von einem breiten Gürtel gehalten wird. Der vorgesetzte rechte Unterschenkel ist von Bandagen umschnürt und (irrtümlicherweise) von der Beinschiene bedeckt ${ }^{195}$. Kniebinde und Fußschutz bedecken das linke Bein. Dem kammlosen Helm zufolge handelt es sich um einen provocator ${ }^{196}$. Die vom Gürtel hinter den Beinen lang herabfallenden Riemen sind offensichtlich ein spezielles Trachtdetail, das auch auf anderen Denkmälern von provocatores aus dem westlichen und südlichen Kleinasien auftritt ${ }^{197}$. Provocatores traten den bildlichen Darstellungen zufolge fast ausschließlich gegeneinander an ${ }^{198}$. Provocatores sind uns auch von weiteren ephesischen Denkmälern bekannt ${ }^{199}$.

Wie der Pfeiler des Stephanos, so ist auch jener des Aithales aufgrund der Buchstabenform in die 1. Hälfte des 3. Jhs. n. Chr. $\mathrm{zu}$ datieren ${ }^{200}$. Die ungelenke Künstlersignatur auf dem oberen

${ }^{194}$ Vgl. dazu Junkelmann 2008, 56 mit Abb. 70 (provocator auf einem Pfeiler aus Ephesos in Berlin, Staatliche Museen, Antikensammlung).

${ }^{195}$ Die Beinschiene sollte am linken Unterschenkel angebracht sein; vgl. JunKELMANN 2008, 75.

${ }^{196} \mathrm{Vgl}$. zu diesem JunKeLMANN 2002, 37.45 Abb. 5; JunKeLMANN 2008, 114-116, 55 f. (zum Helm); 56 (zum Helm im Osten).

${ }^{197}$ Vgl. dazu Robert 1948, 95-99 Nr. 173 Taf. 7, 2; GÜNTHER 1985, 130 f. Taf. 27, 2; RuMscheID 2001, 120 f. Abb. 3; RuMsCheID 2004, 633-635. 640. 643 f. Abb. 3-6; AYDAŞ 2006, 105 f. 108 f. Nr. 1. 2. 5; Нrychuk Kontokosta 2008, 219 f. Nr. 28 Abb. 29; JunKELMANN 2008, 185 Abb. 320; 213. Vgl. außerdem die Darstellung auf einem östlichen Pilgerfläschchen im Römisch-Germanischen Zentralmuseum in Mainz, Junkelmann 2008, 115 Abb. 169.

198 JUNKELMANN 2008, 116.

${ }^{199}$ Vgl. den Pfeiler aus Ephesos in Berlin, Staatliche Museen, Antikensammlung, und das Fragment eines Gladiatorenreliefs im Kunsthistorischen Museum, Wien, JunkelmanN 2008, 56 Abb. 70; 82 Abb. 116.

${ }^{200}$ Vgl. Kap. 8.2, IN 7 (Taf. 413).
Profil der Rückseite, welche Paris und Narkisianos nennt, ist für das kaiserzeitliche Ephesos ein seltener Fall (Taf. 401 Abb. 689).

SK 87

Taf. 402 Abb. 692-695

Fragment von Schrankenpfeiler, kaiserzeitlich

Selçuk, GHD; FK 57/08

Auf dem Zugangspodest ES3, Sektor B2, SE 14; 2008

Grobkörniger blaugrauer Marmor mit dunkleren Einschlüssen H $24 \mathrm{~cm}$, SockelH 5,5 cm, SockelB 12,5 cm, SchaftB 8,5 cm, SockelT 20,3 cm, SchaftT 14,5-14,8 cm, NutB 4,3-4,5 cm

Kanten bestoßen, Ecken teilweise abgebrochen. Mörtelreste.

Ansichtsseite A: Raspelarbeit; Schwache Meißelspuren am Schaft. Ansichtsseite B: Raspelarbeit; am Schaft Spiegel mit Zahneisenarbeit (Randstreifen nur unten und an einer Außenseite). Seite C: unterer Teil des Sockels mit `Füßchen , an den Ecken; Raspelarbeit, am Schaft Spiegel mit Zahneisen, Nut bossiert. Seite D: gröber bearbeitet, Raspelarbeit und Meißelspuren, Nut bossiert. US grob gespitzt.

Fundkontext: heterogen; mittlere Kaiserzeit bis 2. Hälfte des 4./ Anfang des 5. Jhs. n. Chr. (s. Kap. 4.7.1 Tab. 91).

\section{SK 88}

Taf. 403 Abb. 696-699

\section{Fragment von Schrankenpfeiler, kaiserzeitlich}

Selçuk, GHD; FK 57/08

Auf dem Zugangspodest ES3, Sektor B2, SE 14; 2008

Grobkörniger blaugrauer Marmor

H $48 \mathrm{~cm}$, SockelH 6,5 cm, SockelB $27 \mathrm{~cm}$, SchaftB $23 \mathrm{~cm}$, NutB 4,5 cm, SockelT $21 \mathrm{~cm}$, SchaftT 16,5 cm

Oben abgeschlagen. Kanten und Ecken bestoßen bzw. beschädigt. An zahlreichen Stellen Mörtelreste.

Ansichtsseite A: am Schaft Spiegel mit je einem seitlichen vertikalen Streifen mit Zahneisenarbeit; dazwischen breiter Streifen mit dicht gesetzten Meißelhieben. Unter dem Spiegel und am Profil des Sockels unregelmäßige (wohl sekundäre) Meißelhiebe. Ansichtsseite B: am Schaft Spiegel mit dichter Zahneisenarbeit und leichten Meißelhieben. Nebenseite A: Nut grob gespitzt; links davon Spiegel mit dichtem Zahneisen, am Rand Raspelarbeit; rechts von Nut glatt mit verstreuten Meißelhieben. An der 1. Kante der Nut führt schmaler, gespitzter Streifen über Profil und Sockel hinweg. Nebenseite B: glatt, Raspelarbeit; Nut grob gespitzt. US glatt.

Fundkontext: heterogen; mittlere Kaiserzeit bis 2. Hälfte des 4./ Anfang des 5. Jhs. n. Chr. (s. Kap. 4.7.1 Tab. 91)

Der - in den Grundmaßen größere - Pfeiler SK 88 (Taf. 403) weist zwei im rechten Winkel aneinander stoßende Seiten mit Nuten auf, d. h. es handelt sich um einen Eckpfeiler, an den von zwei Seiten Gitter bzw. Schrankenplatten anliefen. An dem kleineren Pfeiler SK 87 (Taf. 402) sind die Ansichtsseiten A und B schmäler als die Seiten mit den Nuten. Der Schwung des Profils verläuft an den Seiten dieses Pfeilers etwas unterschiedlich.

Vergleichbares Profil, Nutbreite und Bearbeitungsspuren an den Seiten beider Pfeiler legen die Zugehörigkeit der Pfeiler zu einem Zaun oder einer Brüstung nahe.

In der üblichen einfachen Profilierung zu vergleichen sind z. B. die Schrankenpfeiler aus dem Hanghaus 1, welche wahrscheinlich vom oberen Umgang des Atriums der domus stammen ${ }^{201}$.

M. Aurenhammer

${ }^{201}$ Jenewein 2003, 92. 110 A 96 f. Taf. 41 f. (Datierung: 1.frühes 2. Jh. n. Chr.). 


\subsection{SKULPTUREN AUS BRONZE: FUNDE AUS DEN JAHREN VON 1993 BIS 2009}

Es wurden vor allem Fragmente in den Katalog aufgenommen, die sicher oder mit einiger Wahrscheinlichkeit von Skulpturen stammen ${ }^{202}$. Die zahlreichen Bronzebleche werden summarisch in den Anmerkungen aufgelistet. Im Gegensatz zu den Fragmenten von Gliedmaßen aus Marmor werden hier die entsprechenden Objekte aus Bronze auch abgebildet, da sich Bronzeskulpturen in Ephesos generell selten erhalten haben.

Die Fundorte der Skulpturenfragmente aus Bronze bzw. der Bronzebleche verteilen sich auf die Kammern D8 und E7 hinter der Bühne sowie auf den Südbereich mit der Kammer KS1, die Aufschüttungen auf der Treppe im Süden sowie die Zugangspodeste vor ES2 und ES3. Einige Skulpturenfragmente aus Bronze (SK 89-91 Taf. 404 Abb. 700-702) sowie eine Anzahl von Bronzeblechen und zwei Schlackenfragmente stammen aus der Schuttdeponie in Kammer D8, wo sich auch eine große Zahl von Marmorfragmenten fand $^{203}$. Skulpturenfragmente aus Bronze (SK 92. SK 93 Taf. 404 Abb. 703. 704; SK 94 Taf. 405 Abb. 705) fanden sich weiters in der Steinabschlagschicht (der untersten Schicht) und der darüber liegenden Ascheschicht in Kammer E7, im Steinabschlag außerdem auch Rückstände einer metallverarbeitenden Werkstatt ${ }^{204}$. Zahlreich sind die Fragmente vom Südteil des Theaters. Neben zwei Fragmenten aus der Kammer KS1 ${ }^{205}$ stammt der Hauptteil aus den Schichten über der Treppe und den Podesten vor den Zugängen ES2 und ES3 (SK 97-99 Taf. 405 Abb. 708-710; SK 100 Taf. 406 Abb. 713; SK 101 Taf. 405 Abb. 711. 712; SK 102. SK 103 Taf. 406 Abb. 714. 715), wobei die Fundkontexte der Skulpturenfragmente und Bronzebleche vom 3. Jh. über das 4. Jh., die Mitte des 5. Jhs. bis in das 6. Jh. n. Chr. weisen ${ }^{206}$.

Die Fußfragmente (SK 89 Taf. 404 Abb. 700; SK 97. SK 98 Taf. 405 Abb. 708. 709; SK 102 Taf. 406 Abb. 714) stammen von lebensgroßen Skulpturen, wobei sich nicht entscheiden lässt, ob es sich um Porträtoder Idealstatuen handelte. Das Haarfragment SK 93 (Taf. 404 Abb. 704) könnte von einem Porträt stammen. Am interessantesten ist das kleine, beutelförmige Fragment SK 101 (Taf. 405 Abb. 711. 712) mit Spuren von Vergoldung, dessen Interpretation nicht ganz klar ist. Bei keinem dieser Fragmente lässt sich die Zugehörigkeit zur Ausstattung des Theaters beweisen. In vielen Theatern wurden Fragmente von Bronzestatuen gefunden, mit der Aufstellung derartiger Statuen im Rahmen des Programms ist jedenfalls zu rechnen ${ }^{207}$.

Was die Datierung der im Hohlguss hergestellten Fragmente betrifft, so werden diese aufgrund ihrer geringen Wandstärke (1-4 mm) der Kaiserzeit zuzuweisen $\operatorname{sein}^{208}$.

Stabfragmente im Vollguss wurden zahlreich angetroffen, drei davon sind hier angeführt (SK 95. SK 96 Taf. 405 Abb. 706. 707; SK 103 Taf. 406 Abb. 715). Manche wirken wie Wiedergaben von Rankenteilen oder Pflanzenstängeln (SK 96 Taf. 405 Abb. 707), es wird sich dabei aber hauptsächlich um Abfallprodukte (Gussstege, `Luftpfeifen`) mit nicht abgearbeiteten Gussrückständen handeln (vgl. SK 95. SK 103).

\footnotetext{
${ }^{202}$ Die Funde wurden von D. Akar-Tanriver und M. Aurenhammer dokumentiert, die Auswertung stammt von M. Aurenhammer.

${ }^{203}$ Vgl. Kap. 7.1.2. 30 Bronzefragmente bzw. Bleche und zwei Schlackenfragmente in Fundkisten 100/04 und 100/04A.

${ }^{204}$ Bronzefragmente und Bleche in den Fundkisten 82/04 (20 Fragmente) und 91/04 (5 Blechfragmente). 12 Stabfragmente (Gussstege) in FK 91/04. Zu beiden Schichten vgl. Kap. 4.1.2.4.

${ }^{205}$ GHD, FK 53/08, SE 62, dünnes Bronzeblech, Fundkontext: 3. Jh. n. Chr. (vgl. Kap. 4.6.2.1); FK 56/08, SE 63, stark gebogenes Bronzefragment, Fundkontext: 2.-3. Jh. n. Chr.

${ }^{206}$ Bronzefragmente und -bleche aus diesem Bereich: Fundort G1, SE 193 (westlich von ES2), FK 39/09: Bronzeblech, Fundkontext 3. Viertel des 3. Jhs. n. Chr.; Fundort F1, SE 174 (vor ES2), FK 1/09: Bronzefragment, Fundkontext Ende 4.-Mitte 5. Jh. n. Chr.; Fundort F1, SE 179 (vor ES2), FK 3/09: Blechfragment, Fundkontext Ende 4.-Mitte 5. Jh. n. Chr.; Fundort B2, SE 4 (vor ES3), FK 8/07: Blechfragment, Fundkontext 3.-4. Jh. n. Chr.

${ }^{207}$ Vgl. dazu Fuchs 1987, 184 zu Porträtstatuen in Theatern.

${ }^{208}$ Zur Wandstärke im Lauf der Epochen vgl. LAHUSEN - FormigLI 2001, 498.
} 


\subsubsection{Katalog der Skulpturen aus Bronze ${ }^{209}$}

\section{BÜHNENGEBÄUdE: KAMMERN}

\section{Kammer D8}

\section{SK 89}

Fußfragment

Taf. 404 Abb. 700

Selçuk, GHD; FK 100/04

Kammer D8, Schutt; 2004

Bronze, Hohlguss, dunkelgrüne Patina

L $16 \mathrm{~cm}$, B $7 \mathrm{~cm}$, Wandstärke $2 \mathrm{~mm}$

Allseits abgebrochen. Oberfläche korrodiert.

Von diesem lebensgroßen rechten Fuß haben sich ein großer Teil des Fußgewölbes, die Außenkante mit dem Ansatz der kleinen Zehe und ein winziger Ansatz der nächsten Zehe erhalten.

\section{SK 90}

Vier Faltenfragmente

Selçuk, GHD; FK 100/04

Kammer D8, Schutt; 2004

Bronze, Hohlguss, dunkelgrüne Patina

Oberfläche korrodiert.

Im Folgenden der Größe nach geordnet:

L $12,3 \mathrm{~cm}$, B 5,8 cm, Wandstärke 1-3 mm

Erh. haben sich zwei recht plastisch gearbeitete Faltenbahnen mit einem Faltental dazwischen.

L 9,8 cm, B 3,3 cm, Wandstärke $2 \mathrm{~mm}$

Erh. haben sich eine Faltenbahn sowie zwei seitliche Falten.

L $9 \mathrm{~cm}$, B 4,5 cm, Wandstärke 1-2 mm

Erh. hat sich eine nur gering aufwölbende Faltenbahn.

L 7,7 cm, B 4,3 cm, Wandstärke 1-3 mm

Erh. haben sich zwei nur wenig aufwölbende Faltenbahnen.

\section{SK 91}

Taf. 404 Abb. 702

Fragment mit Angabe von Haar

Selçuk, GHD; FK 100/04

Kammer D8, Schutt; 2004

Bronze, Hohlguss, dunkelgrüne Patina

H $11 \mathrm{~cm}$, B 19,8 cm, Wandstärke 3-4 mm

Allseits Bruch, an OS korrodiert.

Erhalten hat sich ein größeres, konvex gewölbtes Fragment mit kurzen, fein gekerbten Haarbüscheln an zwei Stellen des Bruchrands. Die Position des Fragments im ursprünglichen Zustand ist nicht klar. Bei einer Interpretation als Kopffragment mit Ansätzen von Haar (Stirnhaar an beiden Stellen oder Stirnhaar mit Rest von Nackenhaar) müssten entweder Reste des Augenpaars bzw. der Übergang der Wange zum Nacken zu sehen sein. Vielleicht handelte es sich um eine Tierplastik oder um einen gewölbten Gegenstand mit Ansatz von Haar oder Fell.

\section{Kammer E7}

SK 92

Taf. 404 Abb. 703

Haar(?)fragment

Selçuk, GHD; FK 91/04

${ }^{209}$ Dieser Katalog ist wie der Katalog der Marmorfunde nach Fundorten angeordnet.
Kammer E7, SE B39, Steinabschlag; 2004

Bronze, Hohlguss

H 8,2 cm, B $4 \mathrm{~cm}$, Wandstärke $2 \mathrm{~mm}$

Rundum abgebrochen. Oberfläche korrodiert.

Fundkontext: 2. Jh. n. Chr. (vgl. Kap. 4.1.2.4)

In die Oberfläche des Fragments sind, in großen Abständen, längliche, leicht gebogene Kerben gesetzt.

SK 93

Taf. 404 Abb. 704

Haarfragment

Selçuk, GHD; FK 91/04

Kammer E7, SE B39, Steinabschlag; 2004

Bronze, Hohlguss

H 6,5 cm, B 4,6 cm, Wandstärke 2-3 mm

Rundum abgebrochen.

Fundkontext: 2. Jh. n. Chr. (vgl. Kap. 3.1.2.4 u. 4.1.2.4)

Das Fragment mit den länglichen, schmalen, locker verteilten Haarsträhnen könnte von der Rückseite eines Kopfs stammen. SK 92 und SK 93 (Taf. 404 Abb. 703. 704) gehören wahrscheinlich zu demselben Kopf.

SK 94

Taf. 405 Abb. 705

Skulpturenfragment?

Selçuk, GHD; FK 82/04

Kammer E7, SE B38, Ascheschicht; 2004

Bronze, Hohlguss, dunkelgrüne Patina

H $10 \mathrm{~cm}$, B 14,1 cm, Wandstärke $1 \mathrm{~mm}$

Allseits Bruch. An einer >Schmalseite< abtreppender Rand, der auf eine Lötstelle hinweist ${ }^{210}$.

Fundkontext: heterogen; 2 Funde aus dem 3. Viertel des 3. Jhs. n. Chr. (vgl. Kap. 4.1.2.4)

SK 95

Taf. 405 Abb. 706

\section{Stabfragment}

Selçuk, GHD; FK 82/04

Kammer E7, SE B38, Ascheschicht, 2004

Bronze, Vollguss, dunkelgrüne Patina

L $8 \mathrm{~cm}$, Dm 6-8 mm

Fundkontext: heterogen; 2 Funde aus dem 3. Viertel des 3. Jhs. n. Chr. (vgl. Kap. 3.1.2.4 u. 4.2.1.4)

Leicht gebogenes Stabfragment mit tropfen- bzw. >schlierenförmigen $<$ Ansätzen.

\section{SK 96}

Taf. 405 Abb. 707

Stabfragment

Selçuk, GHD; FK 91/04

Kammer E7, SE B39, Steinabschlag; 2004

Bronze, Vollguss

L 8,9 cm, Dm 6,7 cm

Fundkontext: 2. Jh. n. Chr. (vgl. Kap. 3.1.2.4 u. 4.1.2.4)

Das Fragment ist von einem dünnen Band umwunden und mit zahlreichen kleinen Knötchen `besetztr.

\footnotetext{
${ }^{210}$ Vgl. z. B. das männliche Bronzeporträt aus dem Hanghaus 1, Aurenhammer 2003, 163. $195 \mathrm{~S} 18$ Taf. 88 f. Zum Verfahren LAHUSEN - FoRMIGLI 2001, 490.
} 
FUNDORTE IM SÜDFLÜGEL MIT KAMMERN, VOMITORIA UND TREPPEN IM SÜDEN

SK 97

Taf. 405 Abb. 708

Zehenfragment?

Selçuk, GHD; FK 86/09

J1 (westlicher Treppenabschnitt zwischen ES1 und ES2), SE

122 (= SE 210); 2009

Bronze, Hohlguss, dunkelgrüne Patina

L 5,4 cm, B 1,7 cm, Wandstärke 2-4 mm

Fundkontext: 6. Jh. n. Chr. (vgl. Kap. 4.7.4)

Erhalten hat sich die kleine Zehe eines lebensgroßen rechten Fußes (?). Die Außenkante ist erhalten, die Innenkante abgebrochen; an dieser sitzt neben dem Zehennagel ein abgebrochener Rest.

SK 98

Taf. 405 Abb. 709

Zehenfragment

Selçuk, GHD; FK 83/93

ES2, S-Ausgang, oberflächlicher Schutt; 1993

Bronze, Hohlguss, mittelgrüne Patina

L 4,8 cm, B $3 \mathrm{~cm}$, Wandstärke $1,5-2 \mathrm{~mm}$

Erhalten hat sich der rechte Teil einer Zehe; an der rechten Kante ist der kleine Ansatz der nächsten Zehe erhalten.

\section{SK 99}

Fragment, von Statue?

Selçuk, GHD; FK 83/93

ES2, S-Ausgang, oberflächlicher Schutt; 1993

Bronze, Hohlguss, dunkelgrüne Patina

L 9,3 cm, B 4,5 cm, Wandstärke 1,5-2 mm

Raspelspuren. An der OS rechteckige Vertiefung für Plattierung $(1 \mathrm{~cm} \times 7 \mathrm{~mm})$.

Erhalten hat sich ein gebogenes Bronzefragment, vielleicht von einer Statue.

\section{SK 100}

Fragment mit Finger

Selçuk, GHD; FK 106/93

Vor ES2, in Erde über Treppe; 1993

Bronze, Hohlguss, dunkelgrüne Patina

L 4,2 cm, B $5 \mathrm{~cm}$, Wandstärke $2 \mathrm{~mm}$

Erhalten hat sich der Rest eines Fingers an größerer Fläche (Gewand, Inkarnat?).
SK 101

Taf. 405 Abb. 711.712

Beutelförmiges Objekt

Selçuk, GHD; FK 106/93

Vor ES2, in Erde über Treppe; 1993

Bronze, Hohlguss, dunkelgrüne Patina, Spuren von Vergoldung H 7,2 cm, B 7,7 cm, Dm $5 \mathrm{~cm}$, Wandstärke 1,5-2 mm

An einer Seite abgebrochen. RS nur angelegt, quadratisches Montage(?)loch $(4 \times 4 \mathrm{~mm})$.

Bei diesem kleinen, an einer Seite rabgeschnittenen (Objekt könnte es sich um den Rest des Beutels einer Hermesstatuette gehandelt haben, wobei der Gegenstand in diesem Fall auf der Handfläche der Hand ruhte - eine seltenere Version im Vergleich zu jener häufiger dargestellten, bei der Hermes den Beutel mit einer Hand hältt ${ }^{21}$. Die umgekehrte Position des Fragments (mit dem unten liegenden, abgeschnürten Teil) erinnert an einen abgebundenen Haarschopf, doch ist der Haarschopf an weiblichen Porträts und Idealköpfen länger, außerdem müsste der Schopf mit dem Nacken verbunden sein.

\section{SK 102}

Taf. 406 Abb. 714

\section{Fußfragment}

Selçuk, Efes Müzesi 2/18/98. FK 32/98

ES3, Sondage, 1998

Bronze, Hohlguss, dunkelgrüne Patina

L 6,3 cm, B $7 \mathrm{~cm}$, Wandstärke $1-3 \mathrm{~mm}$

Fundkontext: Funde in der Sondage: vor allem 2.-3. Jh. n. Chr. (vgl. Kap. 4.6.4)

Erhalten haben sich vier Zehen (in unterschiedlicher Länge) eines lebensgroßen rechten Fußes. Zehen und Nägel sind sorgfältig wiedergegeben.

SK 103

Taf. 406 Abb. 715

\section{Stabfragment}

Selçuk, GHD; FK 79/09

Zugangspodest ES3, SE 220; 2009

Bronze, Vollguss

L 4,3 cm, Dm 6-9 mm

Oben und unten abgebrochen.

Erhalten hat sich ein leicht gebogenes, sich an einer Seite verbreiterndes Stabfragment mit einem tropfenförmigen Ansatz.

M. Aurenhammer

D. AKar-TanRIVER

${ }^{211}$ Vgl. die Bronzestatuetten SieberT 1990, 371 Nr. 975 und Simon - BauchHenss 1992, 548 Nr. 493. 


\subsection{APPENDIX}

\subsubsection{Addendum I}

Im Jahr 2012 wurden zwei Skulpturenfragmente aus den kleinen Treppen entnommen, die von der untersten Sitzreihe der Cavea an beiden Enden des Logeion in die Orchestra hinabführen. Der vorläufigen Einschätzung von R. Heberdey und W. Wilberg zufolge ist der Aufbau dieser Treppen möglicherweise der letzten Phase der Umgestaltung des Logeion zuzuweisen, nach den Reparaturen der frühantoninischen Zeit ${ }^{212}$.

Eine Auswertung der Funde aus dem Erdmaterial in der nördlichen Orchestrastiege im Jahr 2011 durch S. Ladstätter ergab das 5. Jh. n. Chr. als terminus post quem dieser Stiege ${ }^{213}$.

\section{SK $104 \quad$ Taf. 406 Abb. 716. 717; 407 Abb. 718.719 Unterer Teil einer sitzenden Musen(?)statuette,} antoninisch

Selçuk, Efes Müzesi

In der Außenwange der südlichen, in die Orchestra führenden Treppe verbaut (Spolienmauer); 2012

Grobkörniger hellgrauer Marmor

H $47 \mathrm{~cm}, \mathrm{H}$ der Statuette $40 \mathrm{~cm}$, PlinthenH 6,5-8 cm, B max. $31,5 \mathrm{~cm}$, T max. $32 \mathrm{~cm}$ (an der Plinthe).

Die Statuette ist in Hüfthöhe abgeschlagen; es fehlt der obere Teil. Der Rand der Plinthe ist an der VS und der 1. Seite abgebrochen bzw. beschädigt; der unterste Teil des Felsensitzes ist an der RS abgebrochen. Beschädigt sind die Gewandfalten, das 1. Knie, die Zehen des r. Fußes. Oberfläche korrodiert. Starke Mörtelspuren, Kalkablagerungen, Sinter.

Gewand an der VS poliert. Faltenbahnen stellenweise unterschnitten, Faltentäler z. T. gebohrt. US grob bossiert. An der 1. Seite der Plinthe vertikale Klammerbettung (B ca. $2 \mathrm{~cm}$ ), darüber an der OS der Plinthe neben den Chitonfalten seichte Vertiefung (B ca. $3 \mathrm{~cm}$ ). An der RS des Felsensitzes, im unteren Teil, tiefes Dübelloch $(2 \times 2,5 \times 3 \mathrm{~cm})$.

Die mittelformatige Statuette war in der Spolienmauer mit der Unterseite nach außen verbaut. Die Figur sitzt schräg auf einem kubischen Felsensitz, der an den Nebenseiten und auch an der Rückseite in Form von horizontalen Bändern und Buckeln mit dem Meißel gestaltet ist. Die Plinthe läuft von den Seiten auf den vor gestellten rechten Fuß zu; die Nebenseiten der Plinthe sind ebenfalls als Felsen gestaltet. Das linke Bein ist unter das rechte Bein geschlagen, der linke Fuß erscheint hinter dem rechten Fuß. An diesem Fuß sind noch die Sohle und die Schnürung der Sandale zu erkennen. Die Statuette trägt Chiton und Himation. Das Untergewand ist am Unterleib in schmalen, flachen Faltengraten sichtbar; unter dem Mantelsaum fällt es in Form von schmalen sowie breiteren, z. T. durch tiefe Täler getrennten Falten auf die Plinthe herab. Der Mantel ist um den Unterleib geschlungen und liegt in einem Bausch schräg über dem Ansatz der Oberschenkel. Der Bausch ist von tiefen Faltentälern durchzogen; auf einer Falte über dem Ansatz des linken Oberschenkels hat sich der längliche Ansatzrest eines Attributs erhalten, der sich nach unten zu verbreitert. Über den Oberschenkeln bildet der Mantel breite, in der mittleren Partie jeweils tief unterschnittene Faltenbahnen. An beiden Unterschenkeln liegt das

\footnotetext{
${ }^{212}$ Heberdey u. a. 1912, 50. Eine Auswertung des Befunds dieser Treppen und anderer Wände in der Orchestra wird in STYHLER-Aydin (in Vorbereitung) erfolgen. Ich danke G. Styhler-Aydın und M. Hofbauer für Hinweise.

${ }^{213}$ Vgl. Kap. 4.3.
}

Gewand eng an. Vom linken Knie fallen außen eine Steilfalte und zwei V-förmige, tief durchhängende Falten herab, gefolgt von einer breiten Faltenbahn, die vom Felsensitz herabfällt. Die entsprechende Partie an der Außenseite des rechten Beins ist schematischer gestaltet: Unter dem typischen dreieckigen Faltenmotiv, das vom rechten Knie ausgeht, liegt eine Reihe von parallelen Spannfalten, die zum rechten Unterschenkel ziehen. Hinter dem rechten Knie ist der Mantel am Felsensitz zu einem Bausch gerollt, der dann in einer Faltenbahn herabfällt, welche in einem Gewicht endet. An der Rückseite bildet der Mantel über den Glutäen horizontale Spannfalten.

Die Statuette erinnert aufgrund ihres vorstoßenden Fußes auf felsiger Plinthe, des Felsensitzes und der Kombination von dem eng am Unterleib anliegenden Chiton mit dem Mantel, der in einem Bausch über die Oberschenkel führt und entlang der Außenseite des linken Beins herabfällt, an die Statue der sitzenden Muse aus den Faustinathermen in Milet ${ }^{214}$. Das der milesischen Statue zugrunde liegende Vorbild wurde auch für eine ergänzte Statue aus der sog. Villa des Quintilius Varus in der Ermitage sowie für eine Statue in Kassel mit erhaltenem Kopf verwende $^{215}$. Eine weitere Statue in der Ny Carlsberg Glyptotek, Kopenhagen, wurde zu Isis umgestaltet, ein Torso ist in einer Zeichnung von G. Dosio überliefert ${ }^{216}$.

Die ephesische Statuette ist allerdings hinsichtlich der Position der Beine und des Faltenwurfs des Mantels verändert, auch ist die Faltenwiedergabe am Mantel im Vergleich zu den Statuen in der Ermitage und in Kassel stark vereinfacht, wie die kleinere ephesische Statuette überhaupt das bescheidenere Denkmal ist. Im Gegensatz zu den anderen Statuen ist hier das rechte Bein vorgeschoben und die Füße sind übereinander geschlagen; diese entspannte Sitzhaltung ist an Musenstatuen recht oft anzutreffen ${ }^{217}$. Besonders an der rechten Nebenseite der ephesischen Statuette ist die Gewandwiedergabe vereinfacht und schematisiert. Andererseits ist hinter dem rechten Knie der ephesischen Statuette ein eingerolltes Faltenbündel

\footnotetext{
${ }^{214}$ SCHNEIDER 1999, 9 f. 19 f. 123 f. Taf. 8 f.

${ }^{215}$ Ermitage: WaldhaUer 1936, 48 f. Nr. 292 Abb. 43; SChNeIDER 1999, 119 f. 123 Nr. 1; Kassel: SCHNEIDER 1999, 120 f. Nr. 2; 123 Taf. 35 b. 36 a.

${ }^{216}$ Isisstatue: SCHNEIDER 1999, 121 Nr. 4. 123 Taf. 36 b; Zeichnung des Dosio: SchNeIDER 1999, 121 Nr. 3; HÜlSEN 1912, 40 f. mit Abb.; HÜlSEN 1933, 23 Nr. 114 b. c.

${ }^{217}$ Vgl. z. B. eine der Musen aus der Villa Adriana im Prado, SCHRÖDER 2004, 206 f. 216. 229 KatNr. 142 Farbtaf. 16, und eine Muse aus der Gruppe in Wörlitz, Paul 1965, 44 f. 47 Abb. 24.
} 
neben dem rechten Knie als verspieltes Detail hinzugefügt. Der Rücken der ephesischen Statuette scheint aufgerichtet zu sein (zumindest nach Ausweis des erhaltenen Ansatzes), im Gegensatz zu dem leicht vorgeneigten und gedrehten Oberkörper der milesischen Statue.

An der ephesischen Statuette ist nur ein länglicher, schmaler Ansatzrest auf dem Bausch über dem linken Oberschenkel erhalten. Die Ansatzspuren bzw. Bruchstellen an den Statuen aus Milet, in der Ermitage und in Kassel sowie der Attributrest in der Zeichnung von Dosio lassen auf eine Kithara auf dem linken Oberschenkel schließen ${ }^{218}$. Die rechte Hand stützte sich nach Ausweis der Statuen aus Milet und in Kassel auf den rechten Oberschenkel und hielt wohl ein Plektron. Der Ansatzrest an der ephesischen Statuette ist klein, die Statuette ist nur fragmentarisch erhalten, sodass hier auch eine andere Armhaltung und ein anderes Attribut möglich sind.

Der durch die Statuen in Milet und Kassel und die Zeichnung des Dosio erschlossene Musentypus wurde mit der sitzenden Muse mit großer Kithara auf dem Archelaosrelief im British Museum in Verbindung gebracht ${ }^{219}$. Die Verbindung beruht aber vor allem auf den Grundzügen der Figuren, der Aktion der Arme, dem Attribut der Kithara, der Kleidung mit hoch gegürtetem Chiton und Mantel. Der Rumpf der Relieffigur ist jedoch aufgerichtet, das rechte Bein ist vorgeschoben und die Füße sind überkreuzt (wie an der ephesischen Statuette), das Mantelende fällt zwischen den Beinen herab, es fehlt das Motiv des von der Schulter gleitenden Chitons. Die Datierung des Reliefs wurde kontrovers diskutiert; in jüngerer Zeit wurde wieder auf die 30er Jahre des 2. Jhs. v. Chr. als untere Grenze für die Datierung hingewiesen ${ }^{220}$. Auch das Vorbild des milesischen Musentypus wurde zeitlich unterschiedlich angesetz ${ }^{221}$.

Wichtiger für die Einordnung der ephesischen Statuette ist die Datierung aller Statuen, die das Vorbild aufgreifen, in antoninische Zeit ${ }^{222}$. Dieser Ansatz kann auch für die ephesische Statuette gelten, wenn man z. B. die Statue einer thronenden Göttin in Antalya vergleicht, hinsichtlich der Kombination von tief gebohrten bzw. unterschnittenen Falten zwischen den Oberschenkeln, dem an den Unterschenkeln eng anliegenden Gewand, dem Kranz von gebohrten Chitonfalten unter dem Mantelsaum, und den breiteren Mantelbahnen, die außen an den Beinen herabfallen ${ }^{223}$. Die ephesische Statuette ist auch an ihrer Rückseite ausgearbeitet und weist an der linken Seite der Plinthe eine Klammerbet-

${ }^{218}$ SCHNEIDER 1999, 119-124.

${ }^{219}$ Vgl. Pinkwart 1965a, 136 f.; Schneider 1999, 122 Nr. 5; 123 f. Zur Figur auf dem Relief: Pinkwart 1965b, 62 Taf. 35. Die Figur tritt auch auf dem Relief aus der Villa des Herodes Atticus in Luku auf, vgl. SCHNEIDER 1999, 122-124 Nr. 5.

${ }^{220}$ Zur Datierung vgl. u. a. PINKWART 1965a, 48-64 (Datierung: 130-120 v. Chr.); SchNeider 1999, 185 (1. Hälfte 2. Jh. v. Chr.). In jüngerer Zeit: von Prittwitz von Graffon 2007, 257-260 (spätestens 30er Jahre des 2. Jhs. v. Chr.).

${ }^{221}$ PINKWART 1965a, 138 (gehört zu einer um 150-130 v. Chr. entstandenen Musengruppe); Косн 1994, 97 f. 217 f. (2. Hälfte des 2. Jhs. v. Chr.); SCHNEIDER 1999, 124: Datierung anhand der sitzenden Muse auf der Musenbasis von Mantineia (Ende 4. Jh. v. Chr. bzw. Frühhellenismus).

${ }^{222} \mathrm{Vgl}$. SCHNEIDER 1999, 120-123.

${ }^{223}$ Косн 1994, 227 KatNr. 108 Abb. 48 f. tung zur Fixierung auf einer Basis sowie an der Rückseite ein Dübelloch zur Verbindung mit einer Rückwand auf. Zahlreiche in Theatern aufgestellte Musengruppen bzw. Teile von Gruppen haben sich erhalten, die meisten dieser Statuen sind allerdings überlebensgroß, manche kolossal ${ }^{224}$. Als Aufstellungsort mittelformatiger Skulpturen im Theater kämen die Nischen im pulpitum in Frage ${ }^{225}$. Die Statuette wäre jedoch aufgrund ihres Formats auch zur Aufstellung in Thermen oder im privaten Ambiente geeignet ${ }^{226}$.

\section{SK 105}

Taf. 407 Abb. 720.721

\section{Fragment einer Herme, kaiserzeitlich?}

Selçuk, GHD

In der Außenwange der nördlichen, in die Orchestra führenden Treppe verbaut (Spolienmauer); 2012

Grobkörniger hellgrauer Marmor, bräunlich bzw. dunkelgrau verfärbt (durch Mikrokolonien bildende Pilze)

H 42,5 cm, B $26 \mathrm{~cm}, \mathrm{~T} 20 \mathrm{~cm}$, B der Nuten 7-7,5 cm

Erh. hat sich der obere Teil mit der Brustpartie sowie der Ansatz des Schaftes. Hals sowie Umgebung des Halses sind abgeschlagen. Mörtelspuren.

Brustpartie geglättet, vom Schaft durch Linie abgesetzt. Im Bruch der OS sitzt Stiftloch mit Bleirest. Zahneisenarbeit an der VS des Schafts, an den Rändern der NS; gröberes Zahneisen und Meißel in den Nuten. An der RS reicht die Bearbeitung mit dem Zahneisen höher hinauf. In die NS sind Nuten eingelassen; an deren oberen Rand sitzt ein viereckiges Dübelloch (an der 1. Seite 2,5-3 $\times 3 \times 3 \mathrm{~cm}$, an der r. Seite 2,5 $\times 4 \mathrm{~cm}$ ), wobei jenes an der $r$. Seite noch mit Blei verfüllt ist.

Das Fragment war mit der abgeschlagenen Oberseite nach außen in der Spolienmauer verbaut. Es handelt sich um das Fragment einer Schulterherme, an das einst von beiden Seiten Schrankenplatten oder Gitter anliefen; der Verbindung dienten die Nuten und die Dübellöcher darin. Das mit Blei gefüllte Stiftloch in der Bruchstelle der Oberseite weist auf eine Reparatur hin.

Hermenzäune dienten besonders in der späteren Kaiserzeit und im 4. Jh. n. Chr. auch in Spielstätten der Abgrenzung ${ }^{227}$. Da das Fragment aber als Spolie verwendet wurde, ist eine ursprüngliche Aufstellung im Theater nicht gesichert.

M. Aurenhammer

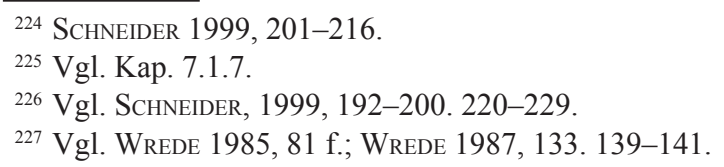




\subsubsection{Addendum II}

In S 1/2003, im südlichsten Bereich des Logeion, wurde in der Verfüllung eines alten Schnitts unter anderem auch das Fragment einer weiblichen tragischen Maske aus Marmor SK 106 geborgen ${ }^{228}$. Eine Serie von Masken wurde im Bereich der Rückwand der Portikus gefunden; die Rückseiten einiger dieser Masken sind leicht konkav gewölbt bzw. weisen eine konkave Eintiefung an ihrer Rückseite wie SK 106 auf ${ }^{229}$. Zwei der im Bereich der Portikus gefundenen weiblichen, in der Machart unterschiedlichen Masken zeigen Kerbstil in der Wiedergabe des Haars, ähnlich wie das Fragment SK 106 ${ }^{230}$. Ein weiteres Maskenfragment SK 64 wurde im Korridor ES1 gefunden und war offenbar sekundär verbaut ${ }^{231}$.

Aufgrund der Verwendung der Maske SK 106 als Auffüllung eines Schnitts im Bühnenbereich kann ihre ursprüngliche Anbringung an der scaenae frons auch theoretisch erwogen werden. G. Niemann hat in seinen zwei »Studien zum Aufbau der Bühnenwand« einzelne Masken, »jede für sich an Marmorplatte angearbeitet« über der Haupttür des ersten Geschosses angeordnet ${ }^{232}$. Diese Art der Anbringung lässt sich zumindest an den zwei Maskenfragmenten SK 64 und SK 106 sowie an den Masken von der Portikus nicht belegen; letztere weisen teilweise Spuren von Verklammerung auf ${ }^{233}$.

SK 106

Maskenfragment, kaiserzeitlich

Taf. 71 Abb. 139

Selçuk, Efes Müzesi ohne InvNr.

S 1/2003, in der Verfüllung eines alten Schnitts; 2003

Grobkörniger hellgrauer Marmor

H $21 \mathrm{~cm}$, B $20 \mathrm{~cm}$, T max. 12,5 cm

Erh. hat sich der obere Teil der Maske mit dem Onkos, der Stirn und einem Rest der Augen. Oberfläche beschädigt und bestoßen, bräunlich grau verwittert, Sprünge im Stein. Größere Bruchstelle hinter dem 1. Teil des Onkos. Die Iris war in anderem Material eingesetzt. RS grob bossiert, etwa in Stirnhöhe konkave Ausnehmung.

\begin{abstract}
Die niedrige Stirn der Maske ist durch eine horizontale Falte geteilt. Unter den Brauen haben sich noch die Bögen der schmalen Oberlider erhalten. Die Haarwellen werden durch einen Mittelscheitel geteilt und sind über dem schmalen, horizontalen Band hoch getürmt. Zu Seiten der Stirn sind sie abwärts gestrichen. Auch wenn die ephesische Maske nur fragmentarisch erhalten ist, so ist sie zumindest im oberen Teil typologisch etwa mit einer jugendlichen, weiblichen, tragischen Maske auf einem Rankenfries aus Pergamon in Berlin zu vergleichen ${ }^{234}$. Die Haarwellen an SK 106 sind nur mit dem Meißel herausgearbeitet und unterscheiden sich darin deutlich von der Maskenserie aus der Villa Adriana, die auf die kontrastreiche Wirkung von Licht und Schatten mit Hilfe des Bohrers abzielt ${ }^{235}$.
\end{abstract}

M. Aurenhammer

\footnotetext{
${ }^{228}$ Aufgrund einer Verwechslung wurde das Maskenfragment nicht in den Katalog unter Abschnitt 7.1.8 aufgenommen. Es konnte daher, im Stadium der Druckvorbereitung des Bands, nur mehr als Nachtrag angefügt werden. Vgl. zum Fundort Kap. 3.2.2.5.

${ }^{229}$ Vgl. Atalay 1972, 47 Abb. 1. 2; Kayan 1972, 56-64 Abb. 1-6; s. auch Kap. 7.1.5 u. 7.1.6. Diese Masken werden in StyhleRAYDIN (in Vorbereitung) erneut vorgelegt werden.

${ }^{230}$ KaYAn 1972, 62-64 Abb. 5. 6.

${ }^{231}$ Vgl. Kap. 7.1.5 u. 7.1.6.

${ }^{232}$ Heberdey u. a. 1912, 93 Taf. 8 f; 91-93 (zum Maskenfries am Sockel des dritten Geschosses).

${ }^{233}$ Weitere Maskenfragmente (Funde aus den frühen Grabungen) sind durch alte Grabungsfotos belegt bzw. werden in den Depots des Efes Müzesi, Selçuk und des Kunsthistorischen Museums, Wien aufbewahrt.

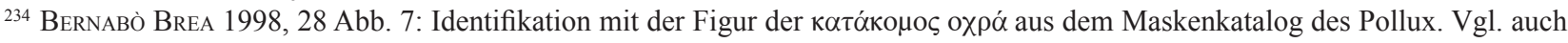
RUMSCHEID 1994, 282. 287. 294 Kat. S. 65 Nr. 258

${ }^{235}$ GaSPARRi 1996, 237-239. 248 Nr. 18 f.; 250 f. Nr. 21-26; 258 Nr. 57. Weiteres zur Datierung der ephesischen Masken in StYhLERAYDIN (in Vorbereitung).
} 


\section{Neue Inschriften aus dem Theater in Ephesos}

\section{VORBEMERKUNG}

Der folgende Beitrag enthält die Inschriften, welche seit 1995 im Theater teils bei regulären Grabungen, zumeist jedoch bei der architektonischen und epigrafischen Revision der am Ort befindlichen Blöcke zum Vorschein gekommen sind. Maßangaben durchwegs in Zentimeter. Epigrafische Sammelwerke werden nach dem Supplementum Epigraphicum Graecum abgekürzt.

\subsection{INSCHRIFTEN, DIE MIT DEM BAU ODER DEM BETRIEB DES THEATERS IN ZUSAMMENHANG STEHEN}

IN 1: Block einer Archivolte aus grauweißem Marmor. H 60; B 52 (oben); 42 (unten); D 120; Bh 12 (Z. 1); 10 (Z. 2); 4,5 (Z. 3); 3 (Z. 4). FO: S2 innen. Inv. 5645; hier: Taf. 411.

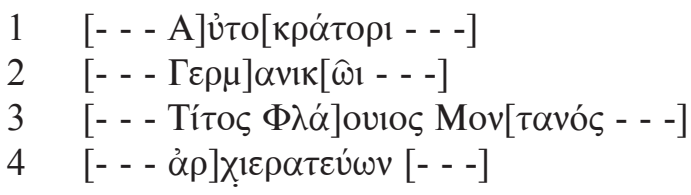

Der Block wiederholt die Inschrift IvE 2037, die an der Außenarchivolte des Südaufgangs zum zweiten Diazoma angebracht war:

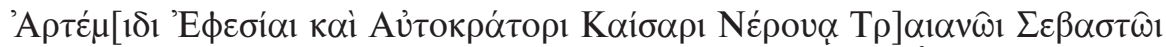

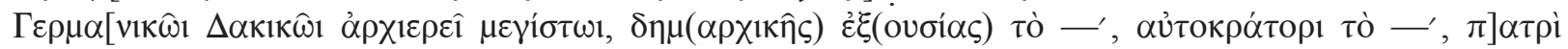

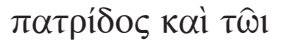

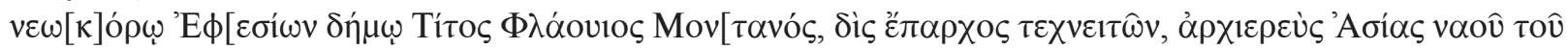

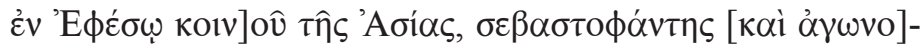

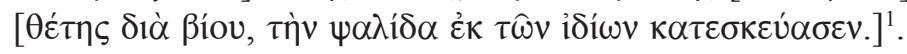

T. Flavius Montanus hat die Eingangsgewölbe des Theaters zwischen 102 und 112 herstellen lassen; zu seinen zahlreichen sonstigen Verdiensten um die Stadt s. IvE 206 III.

IN 2: Quaderfragment aus grauweißem Marmor; links und unten Originalrand; rechts grob behauen; oben abgebrochen. H 19+; B 47+; D 69+; Bh 4,5-5 (Z. 1); 3-3,5 (Z. 2). FO: S2 innen. Inv. 5646; hier: Taf. 411.

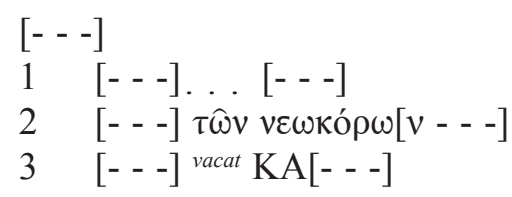

Z. 1: Im Anschluss an die Lücke ist an der unteren Zeilengrenze eine Längshaste erkennbar, die sich an ihrem linken Ende nach einem spitzen Winkel nach oben fortzusetzen scheint, sodass es sich um ein Sigma handeln dürfte. Die Schriftspuren daneben sind nicht deutlich genug, um sicher zugeordnet zu werden.

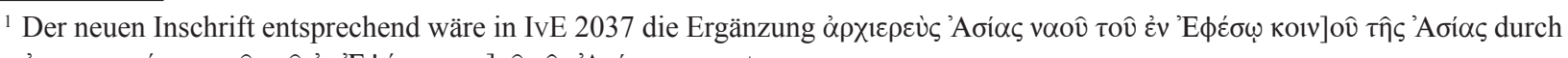

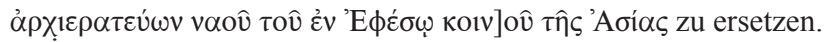




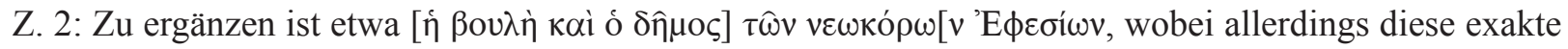
Wendung in Ephesos bisher nicht belegt ist. Jedenfalls ermöglichen die erhaltenen Reste eine Datierung in die Zeit zwischen erster (Domitian, 82, allenfalls schon Nero, 65²) und zweiter (Hadrian, 132) Neokorie.

Z. 3: $\kappa \alpha[\tau \varepsilon \sigma \kappa \varepsilon v-?$

\subsection{EHRENINSCHRIFTEN, DIE IM THEATER AUFGESTELLT WAREN}

IN 3: Zwei Blockfragmente aus grauweißem Marmor; an allen Seiten abgebrochen. H 36+; B 35+; D 34+ (Wulst), 27+ (Schriftfläche); Bh 3. FO: Süd-Parodos-Depot. Inv. 5584; hier: Taf. 411.

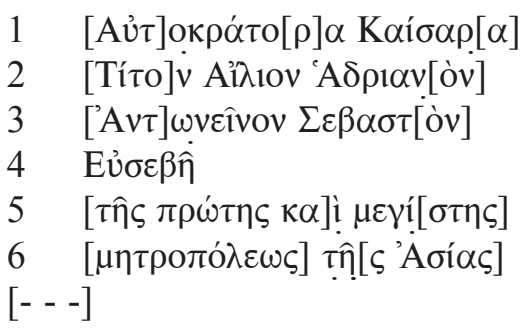

Es handelt sich um eine Basis für eine Statue des Antoninus Pius. Der Text wird nach Z. 6 folgenderma-

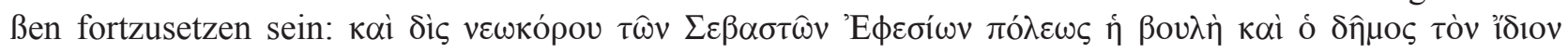

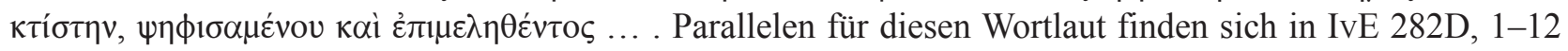
und 2050 I-VI, 1-11, zusammen insgesamt sieben Statuenbasen, die ebenfalls aus dem Theater stammen und dem Kaiser Antoninus Pius Ehre erweisen sollten. Im Falle von IvE 2050 I-VI wurden die sechs Statuen

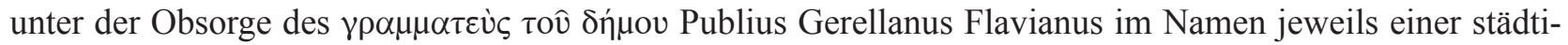
schen Phyle aufgestellt ${ }^{3}$; eine diesbezügliche Abstimmung war zuvor unter dem Vorsitz desselben Funktionärs erfolgt ${ }^{4}$. Im Fall von IvE 282D sind der für die Fassung des Ehrenbeschlusses und für dessen Umsetzung verantwortliche Amtsträger sowie die eventuelle Nennung einer Phyle wie im vorliegenden Fall nicht mehr erhalten ${ }^{5}$. Allerdings wird man davon ausgehen dürfen, dass die verlorenen Textabschnitte denselben Inhalt wie IvE 2050 aufwiesen, denn Ephesos war in acht Phylen gegliedert ${ }^{6}$, sodass die im ephesischen Theater aufgestellte Statuengruppe des Antoninus Pius mit IvE 282D und der neu hinzugekommenen Basis nunmehr komplett sein dürfte.

IN 4: Reliefierte Basis aus weißem Marmor, an den Rändern etwas beschädigt, sonst vollständig. FO: an der Nordseite des Theaters im Versturz. H 122; B 54,5; T 56; Bh 1,7-2,2 (Ф 4,3). Inv. 5325. Zum Relief s. Kap. 7 ; hier: Taf. $412^{7}$.

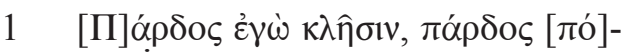

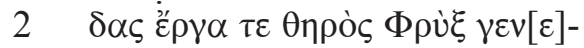

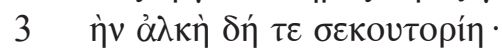

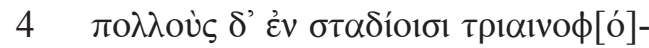

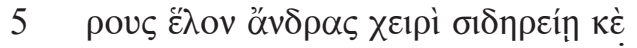

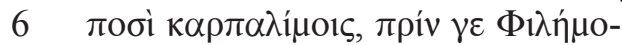

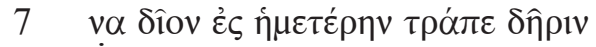

\footnotetext{
${ }^{2}$ Burrell 2004, 60 f.; eine Arbeit von R. Posamentir zu diesem Thema ist in Vorbereitung.

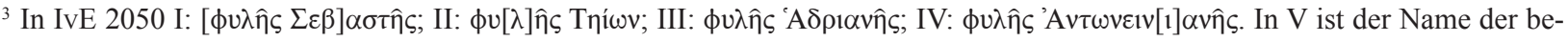

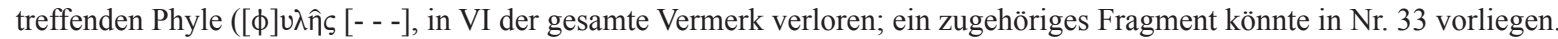

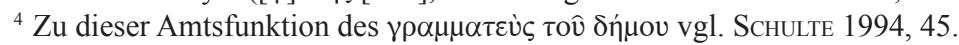

${ }^{5}$ Dazu aber Anm. 3 (s. o.).

${ }^{6}$ Vgl. KniBBe 1981, 107-109.

${ }^{7}$ Bei der Behandlung dieser und der folgenden Inschrift konnten wir dankenswerterweise auf Vorarbeiten von D. Knibbe zurückgreifen.
} 


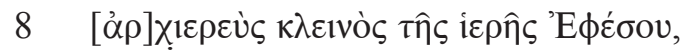

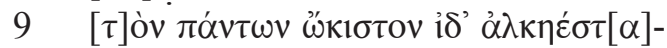

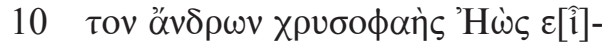

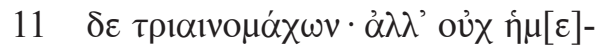

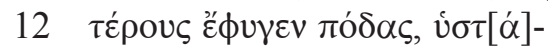

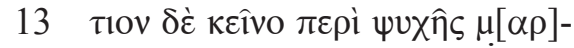

$14 v v^{\alpha} \mu \varepsilon \theta^{\prime} \dot{\eta} \mu \varepsilon \tau \varepsilon \dot{\varepsilon} \rho \varsigma, \dot{\omega} \varsigma \delta^{\prime} \varepsilon^{\prime} \theta[\alpha]-$

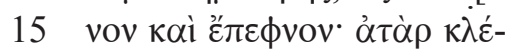

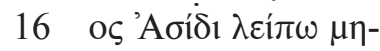

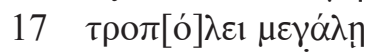

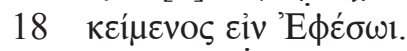

Ligaturen in Z. 5 (HKE), 11 (HM) und 18 (NE).

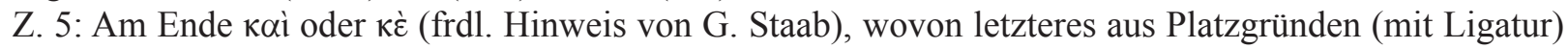
vorzuziehen ist.

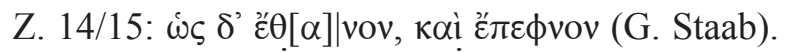

»(P)ardos bin ich von Namen, mit den Füßen eines Panthers und den Taten einer Bestie, Phryger von Abstammung, und bin wahrhaft die Stärke der Secutoren. Viele mit dem Dreizack kämpfende Männer habe ich mit eiserner Hand und schnellen Füßen in den Stadien überwältigt, bevor der berühmte Oberpriester des heiligen Ephesos den edlen Philemon in meinen Kampf entsandte, den die goldleuchtende Morgenröte als schnellsten und mutigsten aller mit dem Dreizack kämpfenden Männer sah. Doch er entfloh meinen Füßen nicht; danach kämpften wir zuletzt um unser Leben, und als ich starb, tötete ich auch ihn. Den Ruhm jedoch hinterlasse ich (der Provinz) Asia, (begraben) liegend in der großen Metropolis Ephesos.«

Epigramm bestehend aus sechs elegischen Distichen. Der Text in metrischer Anordnung:

[П]

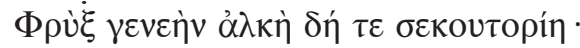

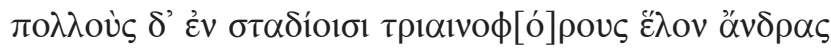

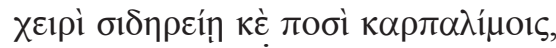

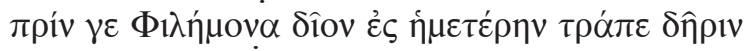

[ảo]X̣ı

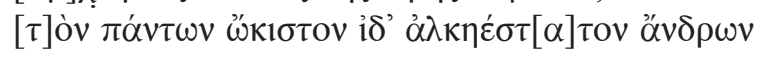

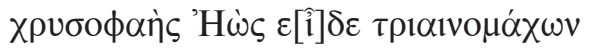

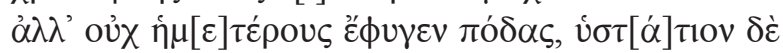

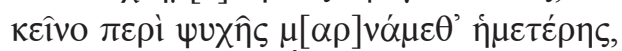

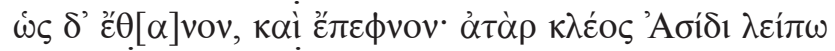

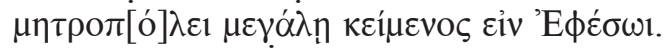

Am Beginn stand der Name des Gladiators, von dem nicht mehr als ein Buchstabe fehlen kann und der

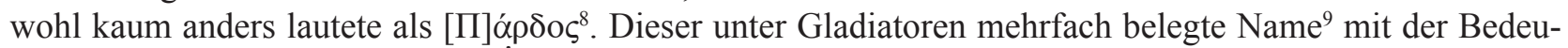
tung »männlicher Panther« ist eine wohl vom lat. pardus abgeleitete späte Nebenform von $\pi \alpha \dot{\alpha} \rho \delta \alpha \lambda 1 \varsigma^{10}$ (worauf das Relief Bezug nimmt).

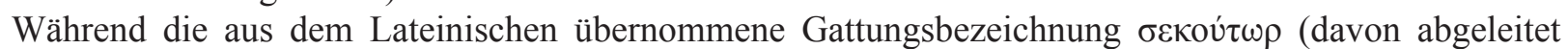

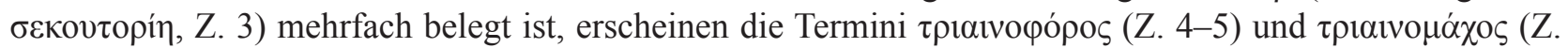

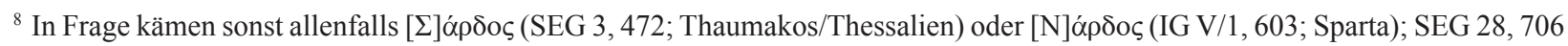
(IG XII/5, 464; Paros) und öfters in der lateinischen Form in Italien (LGPN I s. v.).

${ }^{9}$ Als solcher auch auf einem Relief aus der Zeit des Severus Alexander: IGBulg $1^{2} 70 b i s$ (Odessos/Thrakien). Vgl. a. ILS 5084 und 5122. Nicht in LGPN V (Asia Minor); in Maroneia/Thrakien: LouKopoulou 2005, E 308 Taf. 69. Vgl. a. П $\alpha \rho \delta \alpha \lambda \hat{\alpha} \varsigma$ in Hierapolis (SEG 46, 1668).

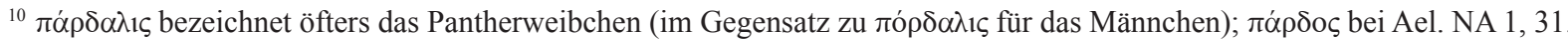




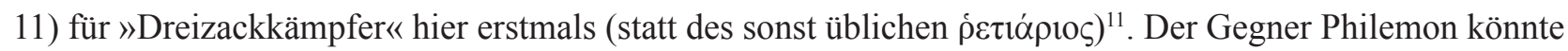
auf einem Relief aus Milet abgebildet sein, das ebenfalls einen Retiarius zeigt; dort erlitt er wie in Ephesos

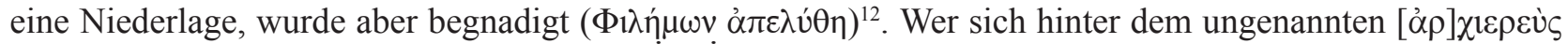

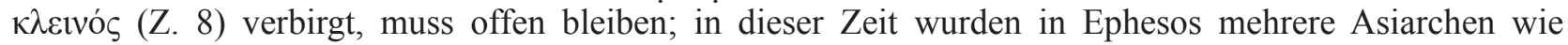
M. Aurelius Daphnus (IvE 3070) oder M. Aurelius Mindius Mattidianus Pollio (IvE 627) wegen ihrer üppigen Gladiatorenspiele gerühmt.

Denselben Gladiatoren-Namen wie der ephesische Text zeigt ein in Smyrna aufgenommenes, jetzt verschollenes Epigramm, das in der folgenden Form überliefert ist (ISmyrna 547):

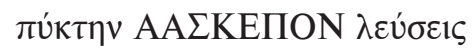

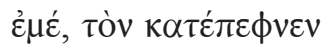

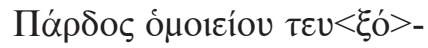

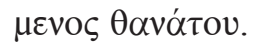

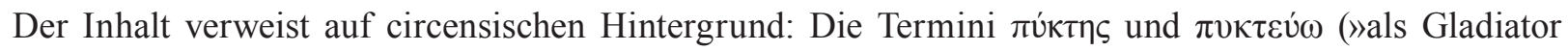
kämpfen«) sind in diesem Kontext durchaus geläufig ${ }^{13}$. Es handelt sich demnach um den Grabstein des Opfers eines Pardos, dem nach Auskunft der Inschrift dasselbe Schicksal wie seinem Gegner bereitet war, und zwar - wie schon L. Robert vermutete - sogar im selben Kampf ${ }^{14}$. Die Parallelität zu dem neuen Epigramm legt es nahe, in der smyrnäischen Inschrift den Grabstein des Philemon zu sehen, dessen Name dann freilich an anderer Stelle (etwa auf der Kopfleiste) angebracht gewesen sein musste. Ein Problem stellt

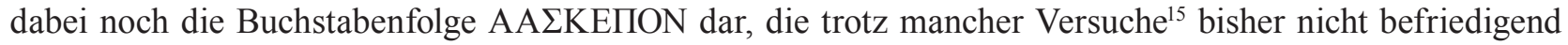

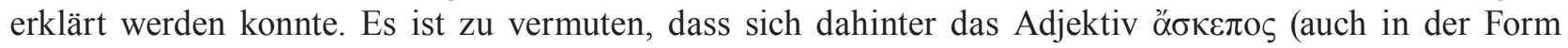

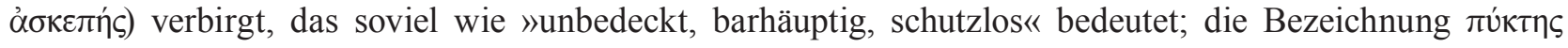

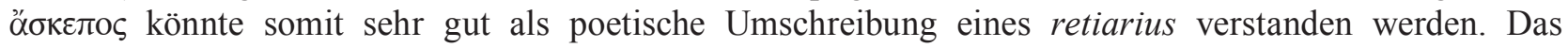
davorstehende Alpha, das das Versmaß als Länge erfordert, könnte die Interjektion $\hat{\alpha}$ darstellen. Das Alpha

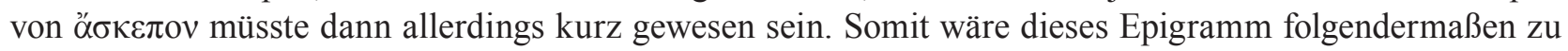
lesen:

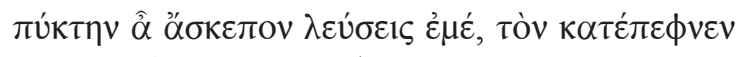

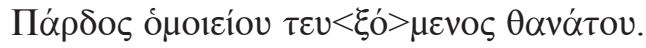

»Wehe, als ungeschützten Kämpfer erblickst du mich, welchen Pardos tötete, dem das gleiche Schicksal zuteil wurde.«

Die beiden Epigramme weisen noch zwei gemeinsame Besonderheiten auf: einerseits den Gebrauch des

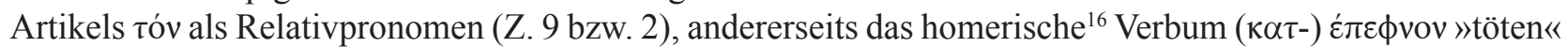
(Z. 15 bzw. 2). Möglicherweise lässt sich daraus auf einen gemeinsamen Verfasser schließen. Ein direkter Schriftvergleich zwischen den beiden Texten ist nicht möglich, da das Denkmal aus Smyrna verschollen ist; unser Monument ist wohl in die 2. Hälfte des 2. Jhs. n. Chr. zu datieren.

IN 5: Stele aus hellgrauem Marmor, in der Mitte gebrochen und an den Rändern beschädigt. H 97; B 66; T 31; Bh 1,3-1,5 (Ф: 3). FO: an der Nordseite des Theaters im Versturz. Inv. 5324. Zum Relief s. Kap. 7; hier: Taf. 411.

\footnotetext{
${ }^{11}$ ROBERT 1940, 65.

${ }^{12}$ SEG 35, 1138. - Ein Zusammenhang mit den in Aphrodisias zur Zeit des Commodus gestifteten Spielen $\Phi$ i $\lambda \mu$ movín $\alpha$ (REYNOLDS $1982,189)$ ist wohl auszuschließen.

${ }^{13}$ ROBERT 1940, 16-20.

${ }^{14}$ RoBert 1940, 305 Anm. 2.

${ }^{15}$ Zusammengefasst im kritischen Apparat zu ISmyrna 547.

${ }^{16}$ z. B. Hom. Il. 3, 281; Od. 3, 252.
} 


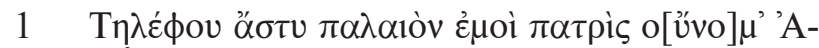

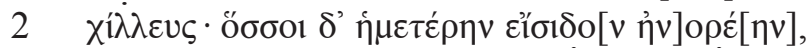

3 [

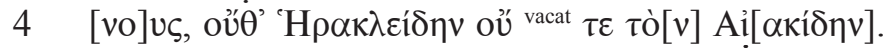

»Die alte Stadt des Telephos ist meine Heimat, mein Name ist Achilleus; wie viele unsere männliche Stärke sahen, alle bewunderten sie gleicherweise; und nicht beschämte ich jene, weder den Herakliden noch den Aiakiden.«

Epigramm bestehend aus zwei elegischen Distichen. Der Text in metrischer Anordnung:

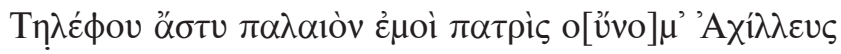

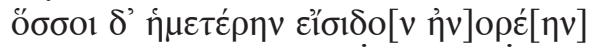

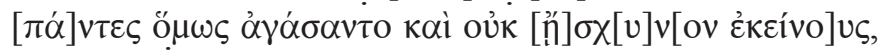

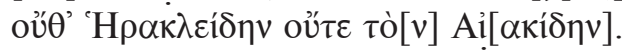

Z. 2: erg. Staab. Nach dem zweiten Iota folgen ein Delta oder Lambda, danach ein Omikron und eine Lücke von drei Buchstaben. Der erste wieder lesbare Buchstabe ist am ehesten ein Omega, allenfalls wären auch Omikron oder Theta in Betracht zu ziehen. Danach ein schmaler Buchstabe (Rho?) vor dem klaren Epsilon; vom Ende der Zeile ist kaum mehr etwas zu erkennen.

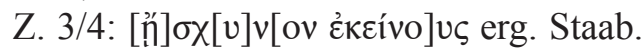

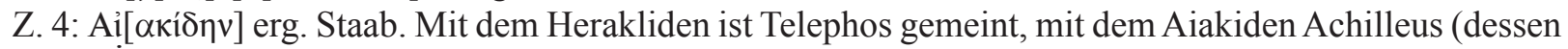
Großvater Aiakos war); der Gladiator musste demnach weder den Vergleich mit dem Gründer Pergamons scheuen noch jenen mit seinem Namensvetter.

Das Denkmal ist wohl ebenfalls in die 2. Hälfte des 2. Jhs. n. Chr. zu datieren.

IN 6: Basis aus grauweißem Marmor mit Gladiatoren-Relief; auf linker und rechter Seite (ca. $14,5 \mathrm{~cm}$ von der Schriftfläche) je eine ca. $11 \mathrm{~cm}$ breite Rille. H 90,5; B 53 (Schriftfläche), 46,5 (Relieffläche), 55 (Standfläche); D 43 (Schriftfläche), 36 (Relieffläche), 43,5 (Standfläche); Bh 3 (ф: 5). FO: An der Südseite des obersten Diazoma des Theaters. Inv. 5586. Zum Relief s. Kap. 7; hier: Taf. 413.

$\Sigma \tau \varepsilon ́ \phi \alpha \nu \circ \varsigma$

Stephanos ist ein häufiger Gladiatoren-Name ${ }^{17}$. Datierung: 1. Hälfte des 3. Jhs. n. Chr.

IN 7: Basis aus grauweißem Marmor; auf linker und rechter Seite (ca. $15 \mathrm{~cm}$ von der Schriftfläche) je eine ca. 10 cm breite Rille. H 93,5; B 49,5 (Schriftfläche), 43 (Relieffläche), 53 (Standfläche); D 45 (Schriftfläche), 38,5 (Relieffläche), 45,5 (Standfläche); Bh 2,5 (ı: 3); auf der Rückseite: 1-2. FO: An der Südseite des obersten Diazoma des Theaters. Inv. 5587. Zum Relief s. Kap. 7; hier: Taf. 413.

Vorderseite (A):

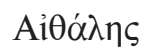

Der Name scheint unter Gladiatoren bisher nicht belegt zu sein und ist auch sonst nicht allzu häufig ${ }^{18}$; »der Feurige« ist aber ein durchaus passender nom de guerre.

Rückseite (B):

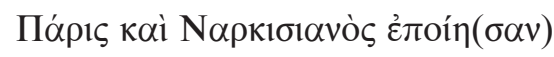

${ }^{17}$ RoBert 1940, 299.

${ }^{18}$ Nach LPGN siebenmal in Attika, sonst nur vereinzelt; in Kleinasien dreimal in Kyzikos. 
Wenig sorgfältig eingemeißelt; Epsilon und Sigma lunar. Bei koí ist das Iota über das Alpha hochgestellt.

Hier liegt der seltene Fall einer Künstlerinschrift bei einem Gladiatorenrelief vor. Beide Bildhauer sind ansonsten unbekannt. Datierung: 1. Hälfte des 3. Jhs. n. Chr.

IN 8: Quader aus weißem Marmor; unten gebrochen, sonst allseitig Rand; hinten roh belassen. H 112+; B 64,5; D 36; Bh 4,5-3,5. FO: ? Inv. 5301; hier: Taf. 414.

$$
\begin{aligned}
& \text { [- - - ] } \\
& 1 \text {. }
\end{aligned}
$$

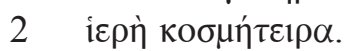
Platz.

Z. 1: Auf der abgeriebenen Fläche am Beginn der Zeile hätte vor Epsilon prinzipiell noch ein Buchstabe

Es handelt sich wahrscheinlich um das Fragment einer Ehreninschrift. Genannt wird eine Priesterin und

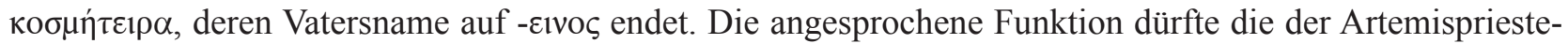

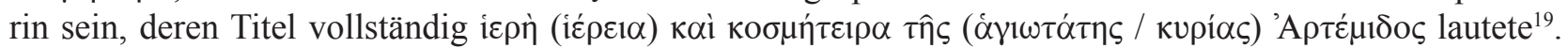
Die Titel sind in unserem Fall asyndetisch aneinandergereiht. Immerhin wird die Artemispriesterin in IvE

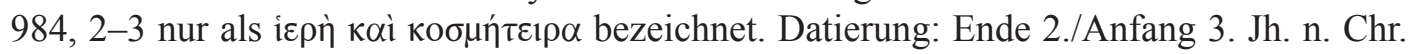

IN 9: Oberteil einer stark profilierten Statuenbasis aus weißem Marmor; oben runder Sockel mit Einlassspuren. H 51; B 90+; D 91; Bh 2,5. FO: Peristyl2 ${ }^{20}$ Inv. 5608; hier: Taf. 414.

'A $\gamma \alpha \theta \hat{n}$ Túxn

Datierung: 2. Jh. n. Chr.

IN 10: Oberteil einer stark profilierten und ornamentierten Statuenbasis aus weißem Marmor; oben runder Sockel mit Einlassspuren. H 48; B 86; D 85; Bh 2-2,5 (Z. 1); ansonsten 3,2-3,5; $\varphi$ : 6,5. FO: Peristyl ${ }^{21}$. Inv. 5611; hier: Taf. 414.

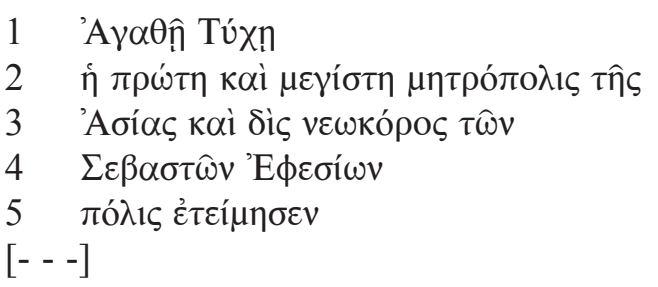

Erhalten ist die Bekrönung einer Ehrenbasis, welche bereits von R. Heberdey aufgenommen worden war (Skizzenbuchnummer 658). Allerdings hat er sich (wohl aus Zeitmangel) damit begnügt, jeweils nur die Zeilenanfänge und -enden abzuzeichnen; dementsprechend erscheinen die übrigen Textpassagen in IvE 1906 (2) als Ergänzung, sind jedoch tatsächlich auf dem Stein erhalten. Aufgrund des Verweises auf zwei Kaiserneokorien ist die Inschrift einem Zeitraum zuzuordnen, der von der Regierungszeit Hadrians bis zu jener des Septimius Severus reicht. Die Darstellung des Kopfs des Helios/Sol im Freiraum zwischen 'A $\gamma \alpha \theta \hat{n}$ und Túxn lässt eher das Ende der genannten Periode vermuten, da dieser Gott erst ab den Severern stark an Bedeutung gewonnen hat. Ungewöhnlicherweise ist an den beiden Ecken jeweils eine Galeere eingefügt, was auf die Bedeutung des Seehandels für Ephesos hinweisen könnte, möglicherweise aber auch auf einen Tätigkeitsbereich des Geehrten.

\footnotetext{
${ }^{19}$ Vgl. etwa IvE 892, 7-8; 980, 7-8; 983, 2-4; 1026, 4.

${ }^{20}$ Mit Peristyl ist hier die porticus in summa cavea bezeichnet.

${ }^{21}$ Wie die vorangehende Anm.
} 
IN 11: Blockfragment aus grauweißem Marmor; rechter Originalrand erhalten, sonst gebrochen. H 79+; B 39+; D 14+; Bh 4-5. FO: Peristy122; abgelagert auf Estrich. Inv. 5609 B; hier: Taf. 415.

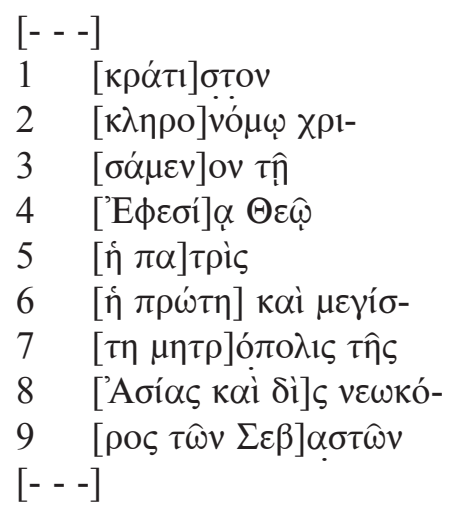

Z. 2: Am Ende der Zeile entweder eine itazistische Verschreibung oder eine (gemalte?) Ligatur von P und H.

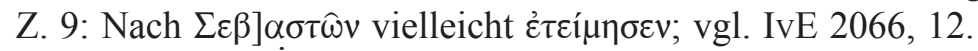

Zur Ergänzung der Inschrift kann IvE 731 als Parallele herangezogen werden:

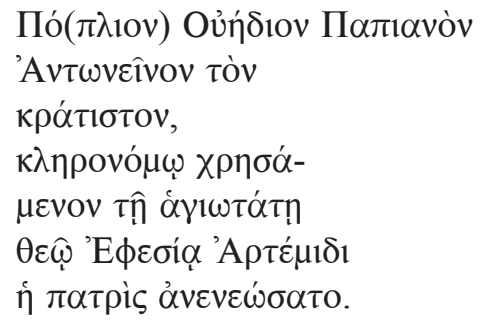

P. Vedius Papianus Antoninus, der sogenannte »Erblasser « ${ }^{23}$, lebte etwa in der 2. Hälfte des 2. Jhs. n. Chr. Sein moderner Beiname leitet sich von dem Umstand ab, dass er nach Ausweis mehrerer Inschriften das Heiligtum der Artemis Ephesia als Erbe seines Vermögens (oder zumindest eines erheblichen Teils davon) eingesetzt hat. Fünf dieser Texte ${ }^{24}$ beziehen sich allerdings in einem stereotypen Formular auf die Erneuerung von Statuenbasen, welche für Vorfahren des »Erblassers« und für diesen selbst errichtet worden waren; ein weiterer ehrt T. Flavius Apellas, einen späteren Nachkommen der Dynastie ${ }^{25}$. Lediglich einer ${ }^{26}$ stellt eine zeitgenössische Ehrung des »Erblassers « dar, jedoch in einem vom vorliegenden Text abweichenden Wortlaut: Es fehlt dort die städtische Titulatur mit Angabe der Neokoriezahl, dagegen ist vorgesehen, dass die

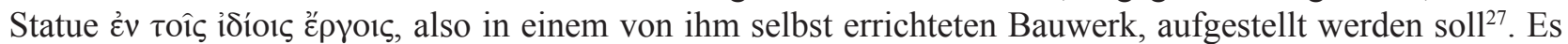
ist freilich nicht auszuschließen, dass in unserem Dokument eine andere Person als der Vedier geehrt wurde: So erhielt auch T. Flavius Aristion Iulianus eine Ehrenstatue mit sehr ähnlichem Wortlaut ${ }^{28}$ (T. $\Phi \lambda \alpha \dot{\alpha o v i o v}$

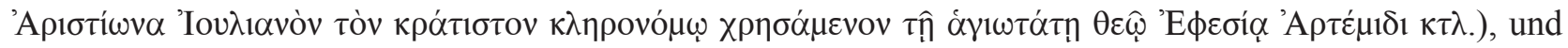
zumindest eine weitere Person ist ebenfalls noch als Erblasser zugunsten der Göttin bezeugt ${ }^{29}$. Unsere Inschrift hat jedenfalls als terminus ante quem die Verleihung der dritten Neokorie durch Septimius Severus, Caracalla und Geta (209 n. Chr.).

${ }^{22}$ Wie Anm. 20.

${ }^{23}$ Nach dem Stemma bei IvE 3085.

${ }^{24}$ IvE 725. 731. 3076. 3077. 3078.

${ }^{25}$ IvE 678

${ }^{26}$ KNIBBE - İPLIKÇıoĞLu 1981/1982, 125 Nr. 123; SEG 33, 939.

${ }^{27}$ Er wird auch in der zeitgenössischen Ehrung IvE 730 als Ktistes bezeichnet, was üblicherweise auf Bautätigkeit beruht. Der Fundort der Basis, an der Straße vom Theater zum Stadion in sekundärer Verwendung, lässt keine Rückschlüsse auf das Gebäude zu.

${ }^{28}$ IvE 669 .

${ }^{29} \mathrm{IvE} 612$. 


\subsection{INSCHRIFTEN, DIE SEKUNDÄR IM THEATER VERBAUT WAREN}

IN 12: Statuenbasis aus grauweißem Marmor; waagrecht und mit der frei liegenden Schriftfläche nach oben in der obersten Lage des Mauervorsprungs verbaut. H 123,8 (Schriftfl. 72); B 29+; T 48,5 (Schriftfl. 43); Bh 3,7. FO: nördliche Außenmauer. Inv. 5647; hier: Taf. 415.

Ed. pr: SÄNGER 2011, Nr. 1

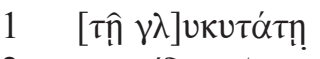

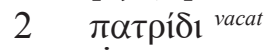

3 Ýyzíav

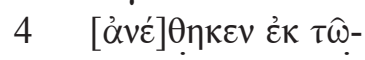

$5 \quad[v i] \delta i ́ \omega v$ vacat

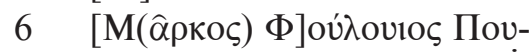

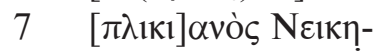

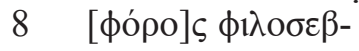

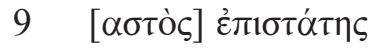

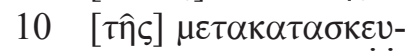

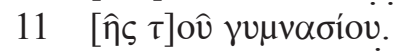

»Der dulcissima patria hat M. Fulvius Publicianus Nicephorus, Vorsteher der Reparatur bzw. Umgestaltung des Gymnasiums, aus dem eigenen Vermögen eine Statue der Hygieia aufgestellt.«

Der bereits bekannte und im Ephesos der Severerzeit als städtischer Würdenträger und Bauherr wirkende M. Fulvius Nikephoros weiht der >Gesundheitsgöttin< Hygieia eine Statue. Diese wird in dem Gymnasium aufgestellt gewesen sein, bei dessen >Reparatur〈 oder >Umgestaltung ( $\mu \varepsilon \tau \alpha \kappa \alpha \tau \alpha \sigma \kappa \varepsilon \cup \eta ́)$ er als Vorsteher

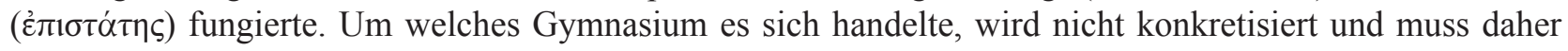
offenbleiben.

IN 13: Statuenbasis aus grauweißem Marmor; waagrecht und mit der frei liegenden Schriftfläche nach oben in der obersten Lage des Mauervorsprungs verbaut; erste und letzte Zeile durch Dübelloch gestört. H 105; B 37+; T 44; Bh 3,7. FO: nördliche Außenmauer. Inv. 5648; hier: Taf. 415.

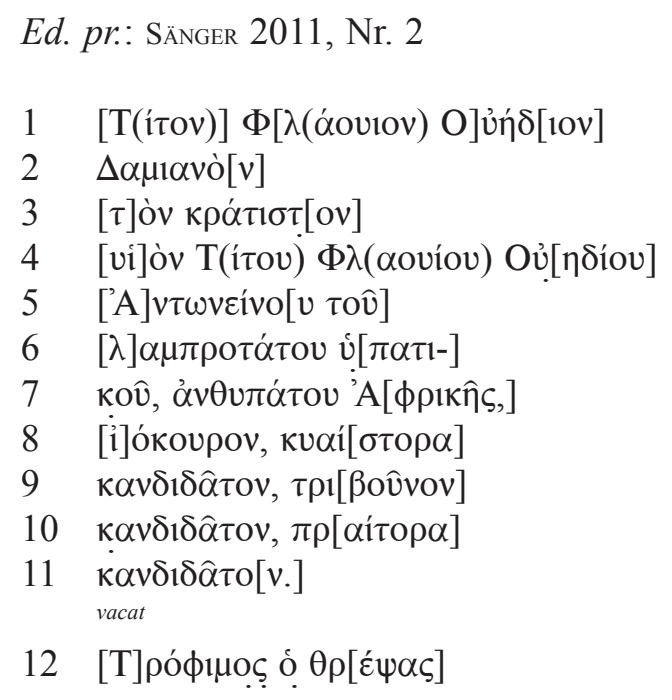

»Für T. Flavius Vedius Damianus, vir egregius, Sohn des T. Flavius Vedius Antoninus, des clarissimus Konsul und Prokonsul von Africa, den viocurus, quaestor candidatus, tribunus candidatus und praetor candidatus. Trophimus, der Ziehvater.« 
Vorliegende Statuenbasis aus der 1. Hälfte des 3. Jhs. n. Chr. ist T. Flavius Vedius Damianus (III.) gewidmet, der den späten Vediern zuzuordnen is ${ }^{30}$. Sein Vater ist - wie auch der Inschrift zu entnehmen - T. Flavius Vedius Antoninus (I.), der selbst Sohn des >Sophisten`T. Flavius Damianus (I.) ist. Damianus (III.) hatte zwei Brüder, und zwar T. Flavius Vedius Antoninus (II.) und T. Flavius Vedius Apellas. Zusammen sind die drei Brüder die letzten uns bekannten Vertreter der Vedierfamilie. Damianus (III.) fand bislang nur

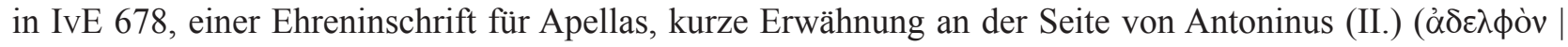

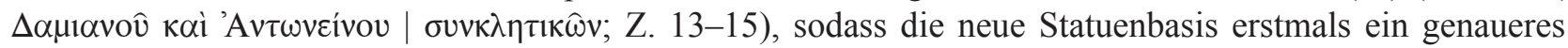
Licht auf seine senatorische Karriere wirft, die ihn - soweit es sich uns erschließt - bis zur Bekleidung der Prätur als candidatus des Kaisers führte.

Als Stifter der Statue tritt eine Person namens Trophimos auf, die sich selbst als ó $\theta \rho \varepsilon ́ \psi \alpha \varsigma$, also als »Ziehvater« bezeichnet. Er stiftete auch T. Flavius Vedius Antoninus (I.), dessen Frau Flavia Pasinike sowie Damianus' (III.) Brüdern Antoninus (II.) und Apellas jeweils eine Statue. Sein Verhältnis zu letzteren beiden drückt er ebenfalls mit der Umschreibung ó $\theta \rho \varepsilon ́ \psi \alpha \varsigma$ aus ${ }^{31}$. Dagegen weist er sich auf der Ehreninschrift für

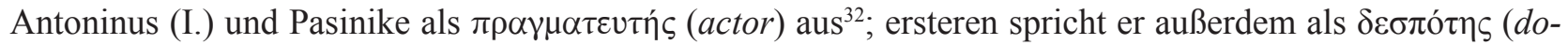
minus) an. Somit wird man Trophimos als (später wohl freigelassenen) Haussklaven zu identifizieren haben, der für Antoninus (I.) nicht nur in Verwaltungsangelegenheiten tätig war, sondern auch die erzieherische Betreuung der Söhne seines Herrn übernahm ${ }^{33}$.

Die vier bereits bekannten, von Trophimos gestifteten Statuenbasen wurden in der NO-Ecke der Agora gefunden; dort wird vermutlich auch die Basis für Damianus (III.) ursprünglich aufgestellt gewesen sein, bis sie schließlich sekundär in der Außenmauer des Theater verbaut wurde.

IN 14: Blockfragment (Basisbekrönung?) aus grauweißem Marmor; mit der Schriftfläche nach außen vermauert; in den oberen zwei Dritteln grob behauen. H 36; B 62,5; Bh 4; T 30. FO: nördliche Außenmauer. Inv. 5649; hier: Taf. 416.

\section{Ed. pr: SÄNGER 2011, Nr. 3}

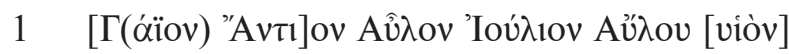

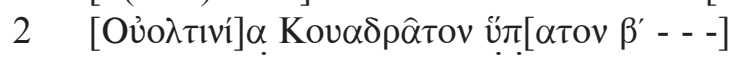

$[---]$

»Für C. Antius Aulus Iulius, Sohn des Aulus, aus der Tribus Voltinia, Quadratus, Konsul [zum 2. Mal $--] . \ll$

Es handelt sich um den Beginn einer Ehreninschrift. Die Person des C. Antius Aulus Iulius Quadratus und dessen Karriere, die in der zweimaligen Bekleidung des Konsulats (suffectus 94, ordinarius 105) und des Prokonsulats von Asia (ca. 109/110) gipfelte ${ }^{34}$, sind gut bekannt. Neben dem vorliegenden Zeugnis kennen wir aus Ephesos bereits drei Ehreninschriften für Quadratus, die auf Statuenbasen angebracht waren $^{35}$. Da nur auf IvE 3033 die Namensangabe des Quadratus erhalten ist, könnte das vermauerte Fragment ursprünglich Teil des verlorenen oberen Abschnitts einer der anderen beiden Inschriften gewesen sein.

IN 15: Grob in einen Quaderblock gehauene Inschrift. Maße konnten aufgrund der Lage nicht genommen werden. Inv. 5650; hier: Taf. 416.

$$
\text { [- - -]MENEK[- - - ] }
$$

\footnotetext{
${ }^{30}$ Stammtafeln der Vedier sind in PIR ${ }^{2}$ III, S. 178; KeIL 1923, 166 f. und IvE VII/1, S. 88-90, hier: S. 90 einzusehen.

${ }^{31} \operatorname{IvE} 3084,11 ; 3085,12$.

${ }^{32}$ IvE 3082, 6; 3083, 8.

${ }^{33}$ Vgl. bereits KeIL 1923, 164 (Komm. zu Nr. 82).

${ }^{34}$ Vgl. PIR ${ }^{2}$ IV 507; KReILER 1975, 113-115; HalfMANn 1979, 112-115.

${ }^{35}$ IvE 614, 1538. 3033.
} 
Das Schriftbild weist in die Spätantike. Es handelt sich wohl um den Beginn eines Namens, wie z. B.

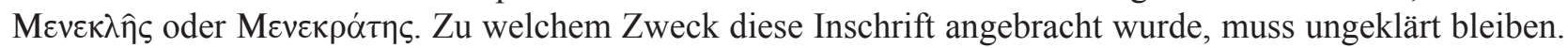

IN 16: Orthostatenplatte aus hellem Marmor; rechts und unten abgebrochen; untere Leiste noch teilweise erhalten; oben Abschlussleiste, Anschlussflächen und Dübellöcher. H 121; B 78; D 22; Bh 2-4. FO: Skene; nahe N-Ende. Inv. 5335; hier: Taf. 416.

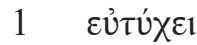

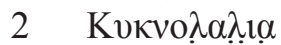

Z. 2: KYKNO ist klar, dann Delta oder Lambda, dann Alpha wieder deutlich, die letzten drei Buchstaben schwächer. In dieser Form unbelegt; der Name könnte etwa heißen: »die wie ein Schwan spricht«, also wohl

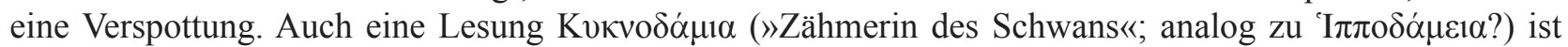
nicht auszuschließen. Datierung: 2.-3. Jh. n. Chr.

\subsection{FRAGMENTE UND STREUFUNDE}

IN 17: Blockfragment aus grauem Marmor; oberer und unterer Rand erhalten, sonst überall gebrochen. $H$ 48; B 37+; D 30+; Bh 2,5. Auf der Oberseite befinden sich zwei Dübellöcher zur Verankerung einer Statue. FO: Süd-Parodos-Depot. Inv. 5568; hier: Taf. 417.

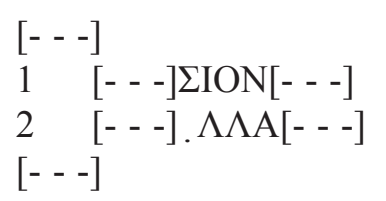

Z. 2: Der erste erkennbare Buchstabe könnte wegen seiner an der Zeilenobergrenze positionierten Querhaste ein Epsilon, Sigma oder Tau gewesen sein. Datierung: 1. Hälfte 3. Jh. n. Chr.

IN 18: Architravblock aus grauweißem Marmor; rechts abgebrochen; auf der Rückseite grob behauen. H 34; B 40+; D 25 (Wulst), 19 (Schriftfläche); Bh 10,5. Auf der Oberseite befindet sich ein Klammerloch. FO: Süd-Parodos-Depot. Inv. 5569; hier: Taf. 417.

$$
\text { [- - - ]OPNT[- - ] }
$$

Datierung: 2. Jh. n. Chr.

IN 19: Quaderblockfragment aus hellgrauem Marmor; oberer (?) und unterer Rand erhalten, sonst überall gebrochen. H 41; B 12+; D 63+; Bh 1,5-2. FO: Süd-Parodos-Depot. Inv. 5570; hier: Taf. 417.

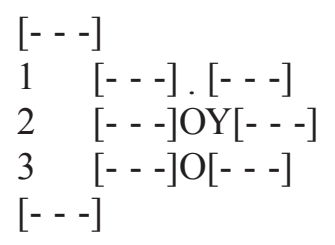

IN 20: Blockfragment aus grauweißem Marmor; oberer und rechter Rand erhalten, sonst überall abgebrochen. H 9,5+; B 29+; D 20,5+; Bh 2,5. FO: Süd-Parodos-Depot. Inv. 5571; hier: Taf. 417.

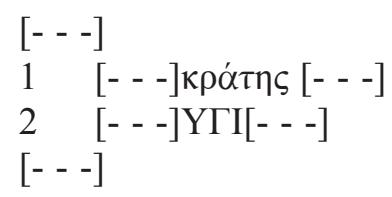


Z. 2: Man könnte an das Substantiv úyıía bzw. die >Gesundheitsgöttin` 'Yyıía denken.

Datierung: 1. Jh. n. Chr.

IN 21: Säulenfragment (?) aus grauweißem Marmor; Schriftfläche leicht nach außen gewölbt; allseitig abgebrochen. H 18,5+; B 23+; D 6+; Bh 2,5 (E), 6 ( $\Delta$ ), 9 (B). FO: Süd-Parodos-Depot. Inv. 5572; hier: Taf. 417.

$$
\begin{aligned}
& {[---]} \\
& {[---] \Delta E() \text { B [- - - }} \\
& {[---]}
\end{aligned}
$$

Das lunare Epsilon ist hochgestellt, was für eine Kürzung spricht. Datierung: 1. Hälfte 4./5. Jh. n. Chr.

IN 22: Plattenfragment aus grauweißem Marmor; unterer Rand erhalten, sonst allseitig abgebrochen. $\mathrm{H}$ 28+; B 24+; D 3-3,5; Bh 16. FO: Süd-Parodos-Depot. Inv. 5573; hier: Taf. 417.

$$
\begin{aligned}
& {[---]} \\
& {[---] E .[---]} \\
& {[--]}
\end{aligned}
$$

Von dem auf Epsilon folgenden Buchstaben ist eine Längshaste erhalten. Es könnte sich um ein Gamma, Eta oder Iota handeln. Datierung: 1. Hälfte 3. Jh. n. Chr.

IN 23: Blockfragment (?) aus grauweißem Marmor; unterer Rand erhalten, sonst allseitig abgebrochen. H 26+; B 21,5+; D 7,5-8 (untere Hälfte), 13+ (obere Hälfte); Bh 4,5-5. FO: Süd-Parodos-Depot. Inv. 5574; hier: Taf. 417.

$$
\begin{array}{ll}
{[---]} \\
1 & {[---] .[---]} \\
2 & {[---] \Sigma I \Omega[---]} \\
3 & {[---] . \Omega N[---]}
\end{array}
$$

Z. 1: Erhalten ist der Rest einer Schräghaste, die ursprünglich vielleicht zu einem Delta gehört hat. Z. 3: Vor dem Omega ist eine Längshaste erkennbar, die isoliert und ein Iota zu sein scheint.

Datierung: Ende 2. oder 1. Hälfte 3. Jh. n. Chr.

IN 24: Blockfragment aus grauweißem Marmor; allseitig abgebrochen. H 30+; B 23+; D 10+; Bh 3. FO: Süd-Parodos-Depot. Inv. 5575; hier: Taf. 417.

$$
\begin{aligned}
& \text { [- - - ] } \\
& 1 \quad[---] . \Delta[---] \\
& 2[---] \mathrm{O} \Sigma
\end{aligned}
$$

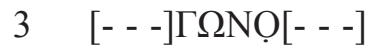

$$
\begin{aligned}
& 4 \text { [- - - ] NNI. [- - - ] } \\
& \text { [- - - ] }
\end{aligned}
$$

Z. 1: Vor dem Delta ist das durch Serifen geschmückte Ende eines nicht näher zu bestimmenden Buchstabens erkennbar.

Z. 4: Der auf Iota folgende Buchstabe endet in zwei sich in spitzem Winkel treffenden Linien; es dürfte sich um ein Alpha oder Delta handeln.

Datierung: 2. Jh. n. Chr. 
IN 25: Plattenfragment (?) aus grauweißem Marmor; oberer Rand erkennbar, sonst allseitig abgebrochen. H 15,5+; B 17+; D 3,5-6,5; Bh 2-3. FO: Süd-Parodos-Depot. Inv. 5576; hier: Taf. 417.

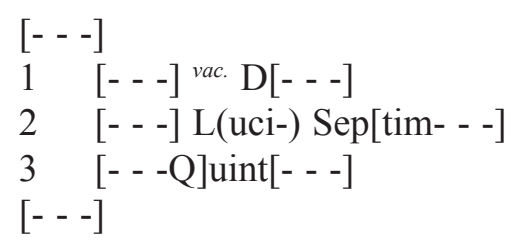

Z. 1: Sollte es sich um die erste Zeile bzw. den Beginn der Inschrift handeln, wäre die Ergänzung D[(is) m(anibus)] denkbar. In diesem Fall hätten wir ein Fragment einer verschleppten Grabinschrift vor uns, zu der die in den folgenden Zeilen aufgeführten Namen gut passen würden.

Z. 2: Vom letzten Buchstaben ist lediglich der Abschluss einer Längshaste erhalten, an die sich keine weitere Linie angeschlossen haben dürfte.

Z. 3: Das Wortfragment gehört vielleicht zum Cognomen Quintilianus.

Datierung: 1. Hälfte 3. Jh. n. Chr.

IN 26: Plattenfragment (?) aus grauweißem Marmor; linker Rand erhalten, sonst allseitig abgebrochen. H 19,5+; B 19,5+; D 4,8; Bh 3,5-4,5. FO: Süd-Parodos-Depot. Inv. 5577; hier: Taf. 418.

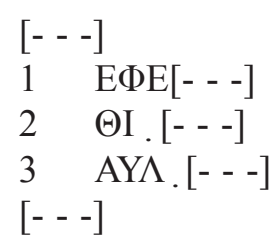

Z. 2 und 3: Nach dem Iota und dem Lambda befindet sich eine Längshaste im Bruch.

Datierung: 2. Jh. n. Chr.

IN 27: Blockfragment aus grauweißem Marmor; rechter Rand erhalten, sonst allseitig abgebrochen. $H$ 23,5+; B 14,5+; D 10+; Bh 3. FO: Süd-Parodos-Depot. Inv. 5578; hier: Taf. 418.

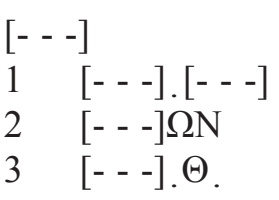

Z. 1: Erkennbar ist der untere, mit Serifen geschmückte Abschluss einer Längshaste.

Z. 3: Vor dem Theta ist eine runde Linie erhalten, welche entweder zu einem Omikron oder Omega gehört. Der letzte Buchstabe wird lediglich durch eine an der Zeilenobergrenze positionierte Querhaste repräsentiert. Zarte, bei gutem Lichteinfall sich abzeichnende Linien sprechen dafür, dass hier ein Epsilon gestanden hat. Vielleicht ist an dieser Stelle mit $[\hat{\alpha} \gamma \omega v] \mathrm{o} \theta \hat{c} \mid \tau-$ zu ergänzen.

Datierung: Ende 1. oder 1. Hälfte 2. Jh. n. Chr.

IN 28: Plattenfragment aus grauweißem Marmor; linker Rand erhalten, sonst allseitig abgebrochen. $\mathrm{H}$ 25+; B 20+; D 9,5; Bh 9,5+. FO: Süd-Parodos-Depot. Inv. 5579; hier: Taf. 418.

$$
\begin{aligned}
& {[---]} \\
& {[---] K[---]} \\
& {[---]}
\end{aligned}
$$


IN 29: Plattenfragment aus grauweißem Marmor; oben abgebrochen, sonst alle Ränder erhalten. H 16,5+; B 8; D 25+; Bh 2. Ein Klammerloch berührt die obere Hälfte des Epsilon in Z. 1. Die Bearbeitung des Steins deutet auf eine Zweitverwendung hin. FO: Süd-Parodos-Depot. Inv. 5580; hier: Taf. 418.

$$
\begin{array}{ll}
{[---]} \\
1 & {[---] . \mathrm{E}[---]} \\
2 & {[--] \Delta \mathrm{I} \Omega[---]} \\
3 & {[--] P O \Sigma[--]}
\end{array}
$$

Z. 1: Vor Epsilon treffen sich zwei Hasten in spitzem Winkel an der Zeilenuntergrenze. Wahrscheinlich handelte es sich hier um ein Ny. Nach Epsilon ist eine Längshaste erkennbar.

Datierung: 2. Jh. n. Chr.

IN 30: Blockfragment aus grauweißem Marmor; oberer Rand erhalten, sonst allseitig abgebrochen. $\mathrm{H}$ 29+; B 30+; D 16+; Bh 4. FO: Süd-Parodos-Depot. Inv. 5581; hier: Taf. 418.

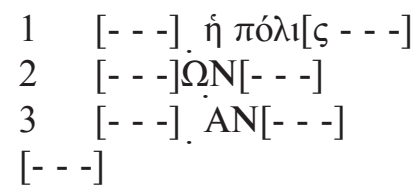

Z. 1: Vor dem Eta ist eine Längshaste zu erkennen.

Z. 3: Vor dem Alpha zeichnet sich eine Längshaste auf dem Stein ab.

Datierung: 2. Jh. n. Chr.

IN 31: Blockfragment aus grauweißem Marmor; oberer und rechter (?) Rand erhalten, sonst allseitig abgebrochen. H 12,5+ (Schriftfläche), 24+ (gesamt); B 16,5+; D 27+; Bh 2,5 (M), 5,5 (个). Links neben dem Pfeil befindet sich eine vertikale, ca. $2 \mathrm{~cm}$ breite Rille, ca. $4 \mathrm{~cm}$ unter der Schriftfläche ein Klammerloch. FO: Süd-Parodos-Depot. Inv. 5582; hier: Taf. 418.

$$
\uparrow \mathrm{M}[---]
$$

IN 32: Architravfragment aus grauweißem Marmor; rechter Rand erhalten, sonst überall abgebrochen. H 18,5+; B 45+; D 12,5+; Bh 12,5+. FO: Süd-Parodos-Depot. Inv. 5583; hier: Taf. 418.

$$
\begin{aligned}
& {[---]} \\
& {[---] Y .[--~-~} \\
& {[---]}
\end{aligned}
$$

Die sich nach dem Ypsilon in spitzem Winkel an der Zeilenobergrenze treffenden Hasten könnten zu einem Delta oder Lambda gehören.

IN 33: Basisfragment mit Fußprofil aus grauweißem Marmor; Standfläche erhalten, sonst allseitig abgebrochen. H 15+ (Schriftfläche), 43,5+ (gesamt); B 19+ (Schriftfläche), 29+ (Rahmen); D 5,5+ (Schriftfläche), 24+ (Rahmen); Bh 2+-2,5+. FO: Süd-Parodos-Depot. Inv. 5585; hier: Taf. 418.

$$
\begin{aligned}
& \text { [- - - ] } \\
& \text { [- - - ] Y. [- - ] }
\end{aligned}
$$

Nach dem Ypsilon ist der untere Abschluss einer schrägen Linie erhalten, die möglicherweise zu einem

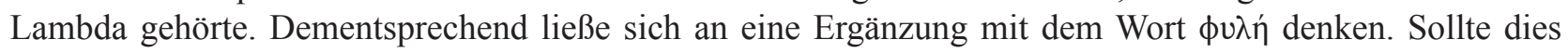


tatsächlich zutreffen, könnte das Fragment zu der weiter oben im Kommentar zu Nr. 3 erläuterten Statuengruppe des Antoninus Pius gehören.

IN 34: Fragment eines Marmorblocks; sekundär zu einer Platte mit glatten Seitenflächen (links und rechts) umgearbeitet; auf rechter Seite vier moderne Bohrlöcher. H 30+; B 8,5+; D 36,5+; Bh 3-3,3. FO: ? Inv. 5146; Depotnr. 3002; hier: Taf. 419.

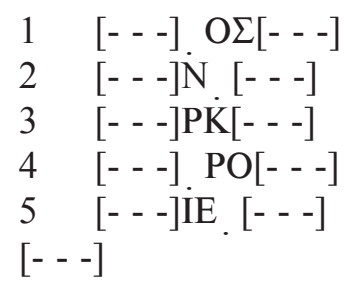

Z. 1: Vor Omikron ist der Abschluss einer Serife zu erkennen.

Z. 2: Nach Ny ist noch der Beginn einer Querhaste erhalten.

Z. 4: Vor Rho zeichnet sich eine Längshaste $a b$.

Z. 5: Nach Epsilon handelt es sich entweder um ein My oder ein $\mathrm{Ny}$.

Datierung: 2. Jh. n. Chr.

IN 35: Fragment einer Basis aus weißem Marmor; oben Profil und Rand, sonst Bruchfläche. H 20+; B 4+; D 9+; Bh 4,5. FO: ? Inv. 5271; Depotnr. 3109; hier: Taf. 419.

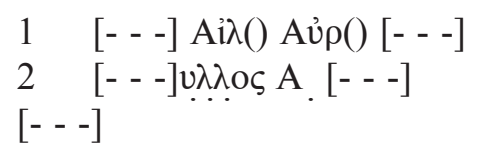

S. u. zu Nr. 36.

IN 36: Fragment aus weißem Marmor; rechts Rand, sonst allseitig Bruchfläche. H 21+; B 23+; D 5+; Bh 4,5-4. FO: ? Inv. 5270; Depotnr. 3108; hier: Taf. 419.

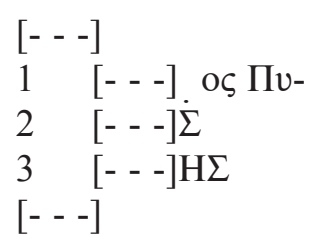

Z. 1: Vor Omikron zeigt sich am unteren Zeilenende noch eine Längshaste. Da sich zwischen Sigma und Pi ein Trennzeichen befindet, dürfte mit $\Pi Y$ ein neues Wort beginnen.

Z. 2: Nach Alpha deutet sich eine Längshaste an.

Die Fragmente IN 35 und IN 36 gehören zusammen und waren wahrscheinlich Teil der schon von R. Heberdey publizierten Basis des Auleten T. Aelius Aurelius Beryllos aus Aizanoi (IvE 1137; Inv. 528):

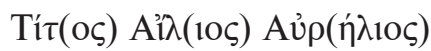

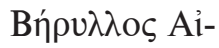

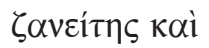

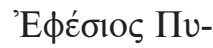

Өıкòs.

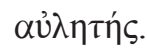


IN 37: Blockfragment aus weißem Marmor; unten und hinten gebrochen; links gewölbt; Schriftfläche nach vorne geneigt; links von der Schriftfläche verläuft eine schräge Rille. H 11,5+; B 9,5+ (oben), 7+ (unten); D 17+ (oben), 11+ (unten); Bh 3. FO: KK NA 10. Inv. 5303; hier: Taf. 420.

\section{$\Sigma \varepsilon \beta[\alpha \sigma \tau----]$}

Die Schrift verläuft von oben nach unten. Datierung: Ende 2. oder 1. Hälfte 3. Jh. n. Chr.

IN 38: Plattenfragment aus weißem Marmor; überall gebrochen. H 10+; B 8,5+; D 3,5; Bh 1-1,3. FO: Streufund. Inv. 5602; Taf. 420.

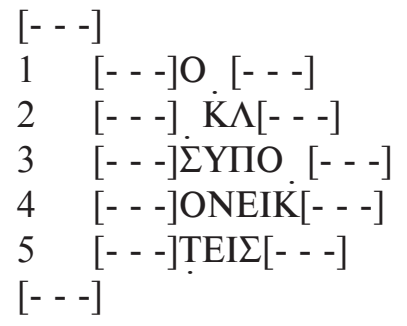

Z. 1: Nach Omikron ist der Abschluss einer Längshaste sichtbar. Es könnte sich um ein Iota handeln.

Z. 2: Vor Kappa hat sich das Ende einer Längshaste erhalten. Zwischen die Buchstaben ist ein Trennungszeichen gesetzt, sodass $\mathrm{K} \Lambda$ [ der Beginn eines neuen Worts sein dürfte.

Z. 3: Nach Omikron zeigt sich noch ein Hastenende.

IN 39: Blockfragment aus grauweißem Marmor; rechter Originalrand erhalten, sonst gebrochen. H 18+; B 23+; D 12,5+; Bh 4; ф: 8,5. FO: Peristy ${ }^{36}$; abgelagert auf Estrich. Inv. 5609 A; hier: Taf. 420.

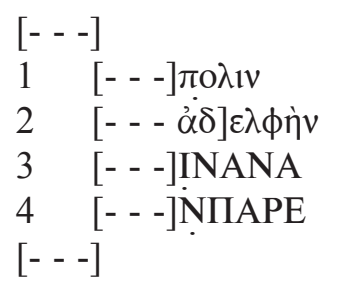

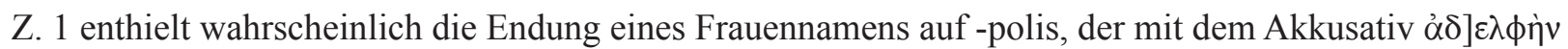
übereingestimmt war, wie z. B. in dem Gebet für die Familie des Prytanen Plutachos (IvE 1068, Z. 3f.): ...

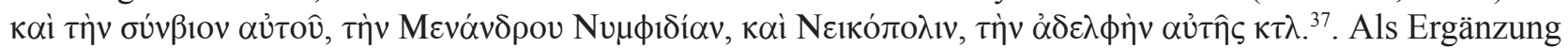

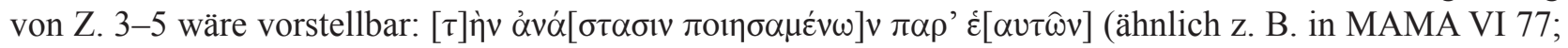
Attouda/Karien).

Datierung: 2. Jh. n. Chr.

IN 40: Architravfragment aus grauweißem Marmor. H 45; B 136+; 59+; Bh 9. FO: Diazoma; unterhalb des Peristy ${ }^{38}$. Inv. 5610; hier: Taf. 421.

$$
[---O] \dot{v} \alpha \lambda \varepsilon \rho[1----]
$$

\footnotetext{
${ }^{36}$ Wie Anm. 20.

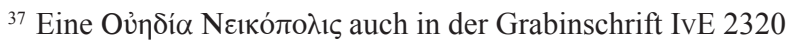

${ }^{38}$ Wie Anm. 20.
} 
Wahrscheinlich (trotz etwas abweichender Umzeichnung) identisch mit IvE 309A (3) = Inv. 656; damals war allerdings die Fortsetzung mit O]ن̉ $\alpha \lambda \varepsilon p i ́ \omega$. rung mit 284-305 n. Chr.

IN 41: Statuenbasis aus weißem Marmor; oben gebrochen; Oberkante hinten erhalten. H 149; B 56+; D 52; Bh 3. FO: Peristyl ${ }^{39}$ (ET 09/181); mit rechter Seite im Boden. Inv. 5612; hier: Taf. 421.

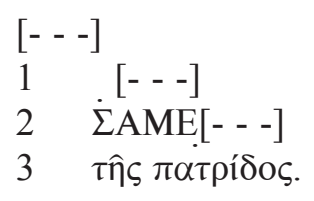

Z. 1: Sichtbar ist der Abschluss einer Längshaste.

Z. 2: Nach My ist noch ein rechtwinkliger Buchstabenrest erkennbar.

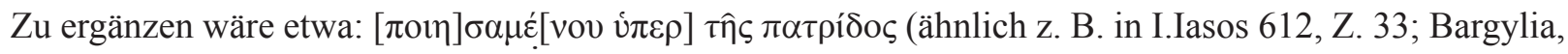
129 v. Chr.). Datierung: 2. Jh. n. Chr.

IN 42: Quaderfragment aus grauweißem Marmor; oben und unten Originalrand; sonst gebrochen. H 26; B 90+; D 60+; Bh 18. FO: S2 innen. Inv. 5651; hier: Taf. 421.

$$
[---] \mathrm{N} \varepsilon \rho \mathrm{o}[---]
$$

Das Fragment ist wahrscheinlich Teil einer großen Weihinschrift, die im Theater angebracht war. Parallelen dazu sind IvE 2035-2038. Aufgrund der erhaltenen Buchstaben dürfte die Dedikation, wie im Fall von

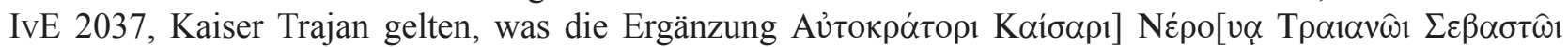
wahrscheinlich machen würde. Obwohl mit vorliegendem Fragment eine Lücke in IvE 2037 gefüllt werden könnte, dürfte es sich um zwei verschiedene Weihinschriften handeln: Erstens scheint unser neu gefundenes Bruchstück im Gegensatz zu IvE 2037 eine einzeilige Inschrift darzustellen. Zweitens sind beide Inschriften auf unterschiedlichen Architekturelementen angebracht: Nr. 42 auf einem Steinquader, IvE 2037 auf einer Außenarchivolte.

\subsection{ZUSAMMENFASSUNG}

Bei den neueren Grabungen und Untersuchungen im Theater sind insgesamt 42 Inschriften, großteils in fragmentierter Form, zutage gekommen. Je nach ihrer Relevanz für das Bauwerk wurden sie in vier Gruppen gegliedert: jene, die Aussagen über Bau und Verwendung des Theaters zulassen, dann Ehreninschriften, die dort ursprünglich aufgestellt waren, sowie solche, die sekundär dort vermauert wurden, und schließlich Texte, deren ursprünglicher Anbringungsort unbekannt ist. Aus der zweiten Gruppe stechen vor allem zwei Epigramme für Gladiatoren hervor, deren Fähigkeiten und Leistungen in sehr plastischer Weise verewigt wurden (Nr. 4. 5); diesen schließen sich zwei weitere Gladiatoren-Basen mit Reliefs an (Nr. 6. 7). Bemerkenswert sind außerdem zwei Ehrungen für Angehörige der Vedier-Dynastie (Nr. 11. 13), für den Stifter M. Fulvius Publicianus Nicephorus (Nr. 12) sowie für den Kaiser Antoninus Pius (Nr. 3).

P. SÄNGER

H. TAEUBER

${ }^{39}$ Mit Peristyl ist hier die porticus in summa cavea bezeichnet. 


\subsection{APPENDIZES}

\subsubsection{Appendix 1, Altbestand der Bauinschriften aus dem Theater}

Um dem Leser einen bequemen und vollständigen Einblick in die mehrfach zitierten epigrafischen Zeugnisse zu den verschiedenen Bauvorgängen im Theater zu ermöglichen, sind im Folgenden die schon länger bekannten einschlägigen Dokumente in chronologischer Reihenfolge zusammengestellt. Neben dem griechischen Text und der deutschen Übersetzung enthält das Dossier Angaben zu Datierung, früheren Editionen und Sekundärliteratur, eine Kurzbeschreibung sowie - soweit erforderlich und möglich - einen kurzen prosopografischen Kommentar ${ }^{40}$.

\section{Bauinschrift des Hieron Aristogiton}

Datierung Wende vom 1. Jh. v. Chr. zum 1. Jh. n. Chr. (nach Schriftart und Formular)

Kurzbeschreibung Drei Keilsteine, im oberen südlichen Zugang (ES3) verbaut

Editionen HeberdeY u. a. 1912, Nr. 33; IvE 2033

Literatur MAYER 2003, 80

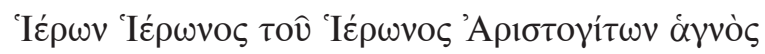

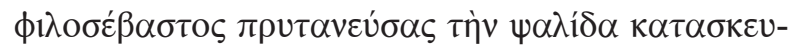

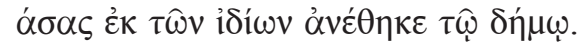

»Hieron Aristogiton, Hierons Sohn und Hierons Enkel, hat als ehrwürdiger und kaisertreuer Prytane auf eigene Kosten dieses Gewölbe errichten lassen und dem Volk gewidmet.«

\section{BaUinsChrift aUf einem ArChitraV der SCAENAE Frons}

Datierung $\quad 85-86 \mathrm{n}$. Chr. (nach der Kaisertitulatur)

Kurzbeschreibung Fragmente eines Architravs der scaenae frons, im Schutt gefunden

Editionen HEBERDEY u. a. 1912, Nr. 34; IvE 2034

Literatur Hörmann 1923/1924, 304-310; Halfmann 2001, 43; Sturgeon 2004b, 422

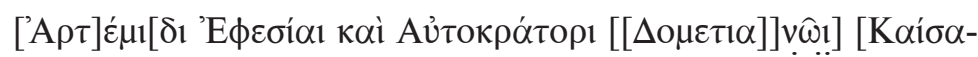

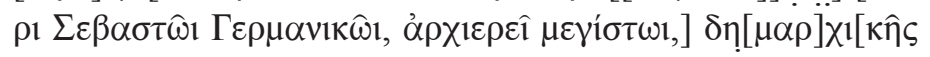

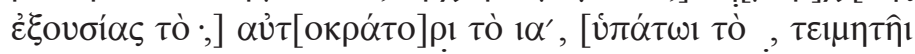

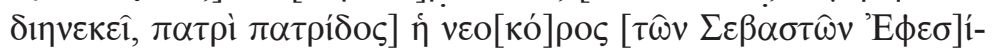

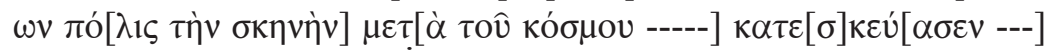

»Der Artemis von Ephesos und dem Imperator Domitianus Caesar Augustus Germanicus, pontifex maximus, tribuniciae potestatis --, imperator XI, consul --, censor perpetuus, pater patriae, hat als Tempelhüterin der Augusti in Ephesos die Stadt die Skene mitsamt der Ausschmückung errichtet -.."

\section{Weihinschrift vom Nord-ANalemma an Domitian}

Datierung $\quad 92 \mathrm{n}$. Chr. (nach der Kaisertitulatur)

Kurzbeschreibung 20 Fragmente von Wandquadern des Nord-Analemma

\footnotetext{
${ }^{40}$ Die Zusammenstellung hat T. Hobel unter Anleitung von H. Taeuber und unter Mitwirkung von V. Böhm durchgeführt.
} 
Editionen Heberdey u. a. 1912, Nr. 35; IvE 2035

Literatur Halfmann 2001, 43 Anm. 142; StuRgeon 2004b, 422

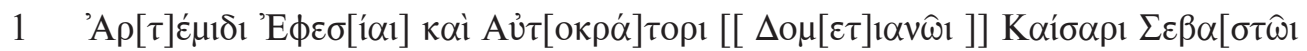

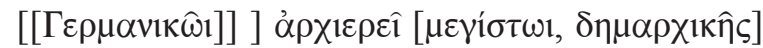

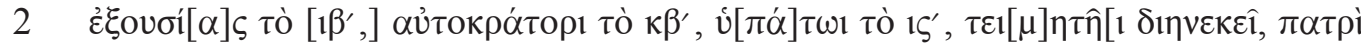

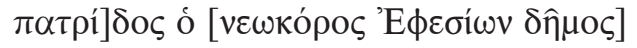

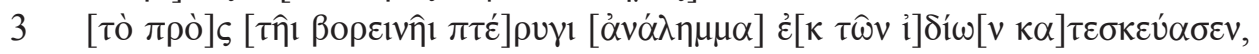
$\kappa \alpha \theta 1 \varepsilon[\rho \dot{\omega} \sigma \alpha \nu \tau \circ \varsigma----] \phi i \lambda \varepsilon \sigma[$

Kommentar:

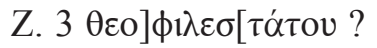

»Der Artemis von Ephesos und dem Imperator Domitianus Caesar Augustus Germanicus, pontifex maximus, tribuniciae potestatis XII, imperator XXII, consul XVI, censor perpetuus, pater patriae, hat der tempelhütende Demos der Ephesier die Stützmauer für den nördlichen Flügel aus eigenen Mitteln errichtet; geweiht hat $--\ldots .--. \ll$

\section{Stiftung des C. Vibius Salutaris}

Datierung 104 n. Chr. (nach dem Konsulat des Sex. Attius Suburanus, Z. 134)

Kurzbeschreibung Fragmente von 15 beschrifteten Quadern aus dem Süd-Analemma

Editionen IvE 27; Rogers 1991

Die umfangreiche Literatur zu dieser Inschrift kann hier ebenso wenig wiedergegeben werden wie ihr voller Text; nachstehend sind nur die auf das Theater bezüglichen Passagen angeführt. Übersetzungen: $\mathrm{H}$. WANKEL (IvE).

(Beschluss von Rat und Volk von Ephesos. Aufzählung der Verdienste des C. Vibius Salutaris, der u. a. versprochen hat, insgesamt 29 goldene und silberne Statuen der Artemis, des Kaiserpaars und verschiedener Personifikationen zu stiften);

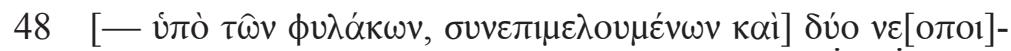

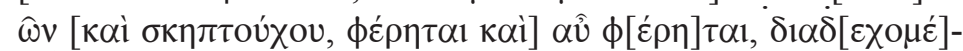

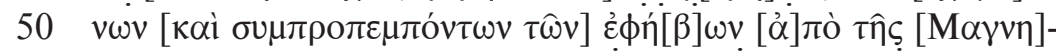

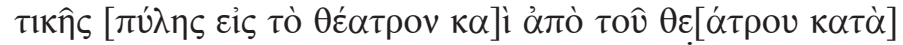

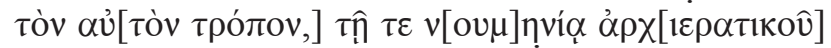

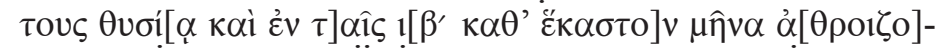

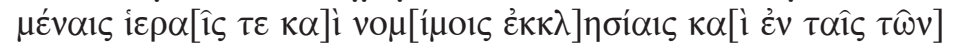

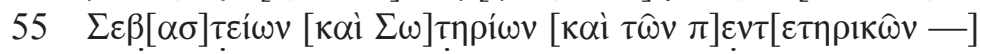
$[-] \omega[v$ ह่

»(Sie sollen von den Wächtern, unter Begleitung und Fürsorge) zweier Neopoioi (und eines Stabträgers hin- und) zurück(gebracht werden, d. h. ins Theater und ins Heiligtum der Artemis); die Epheben übernehmen sie und (und geleiten sie) vom (Magnesischen Tor zum Theater) und vom Theater (zurück auf) dieselbe (Weise); und zur Zeit des Neumondopfers des archieratischen Jahrs (- d. h. am 1. Januar - und während) der feierlichen und regulären (zwölf) monatlichen Volksversammlungen und (an den Festen) der Augusteen (und der So)terien (und der) penteterischen .... .

(Es folgen weitere Details der Stiftung) 


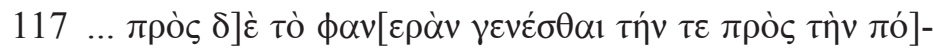

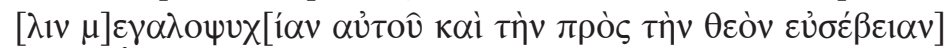

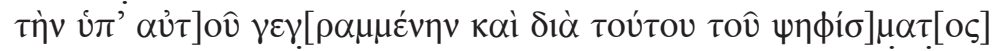

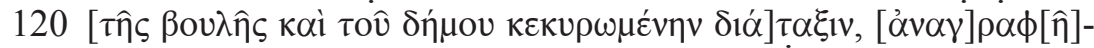

$[v \alpha 1-] \theta \alpha[\ldots] \varsigma[\ldots]$

$[-]$

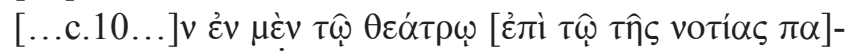

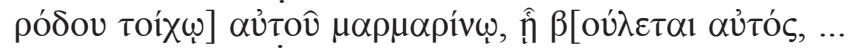

»... (und damit seine) großzügige Gesinnung (gegenüber der Stadt und seine Ehrfurcht vor der Göttin) bekannt (werden, soll die von ihm) verfügte (und durch diesen Beschluss des Rats und des Volks des Rats ratifizierte) Stiftung aufgezeichnet werden ... im Theater (an der) Marmor(wand) von dessen (südlicher Parodos), wo immer (er selbst will), ... «

(Salutaris stiftet goldene und silberne Statuen sowie einen Geldbetrag von 20.000 Denaren),

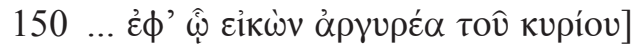

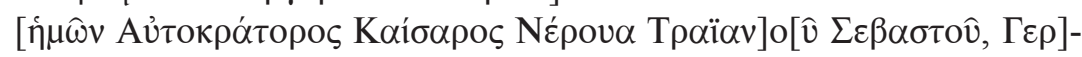

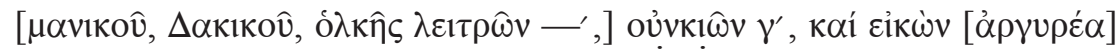

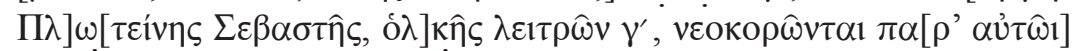

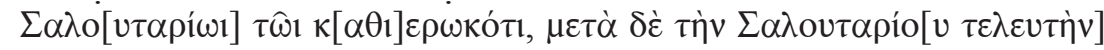

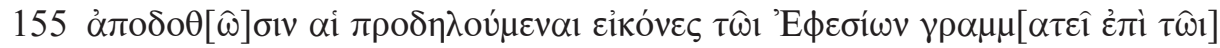

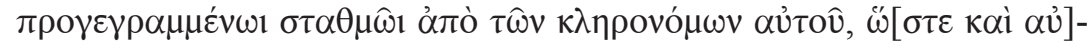

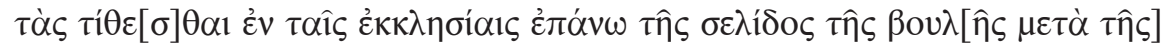

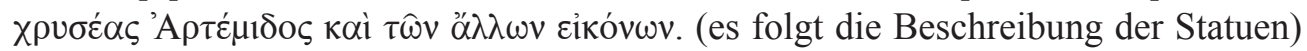

»... (unter der Bedingung, dass eine silberne Statue unseres Herrn, des Imperator Caesar Nerva Traianus Augustus Germanicus Dacicus, mit einem Gewicht von ... Pfund) und drei Unzen und eine (silberne) Statue (der Plotina Augusta) mit einem Gewicht von drei Pfund im Haus des Stifters Salutaris (selbst) verehrt und gewartet werden und dass nach dem (Tod) des Salutaris von seinen Erben die erwähnten Statuen (mit dem) angegebenen Gewicht dem Schreiber der Ephesier übergeben werden, damit sie während der Volksversammlungen oberhalb des Blocks (d. h. im Theater), in dem der Rat sitzt, (zusammen mit der) goldenen Artemis und den anderen Statuen aufgestellt werden.«

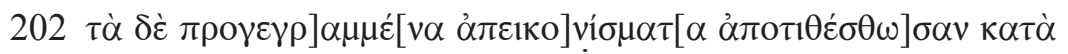

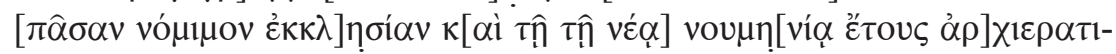

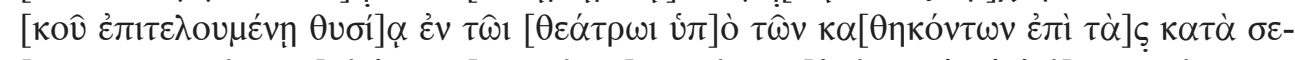

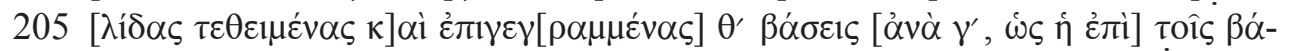

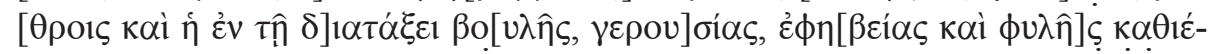

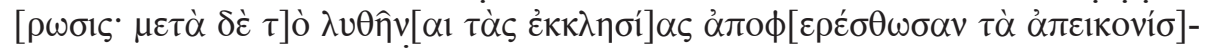

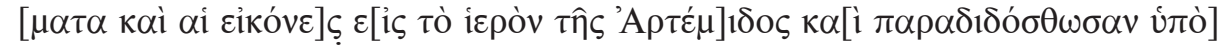

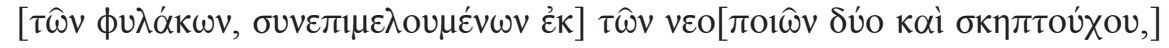

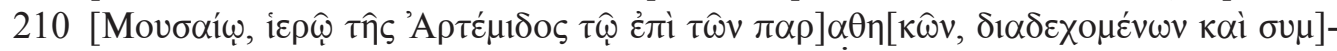

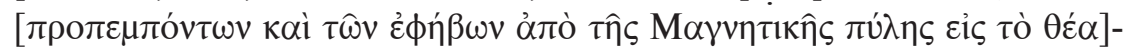

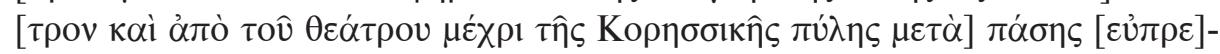

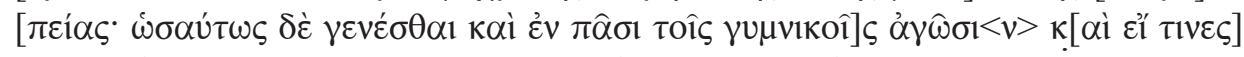

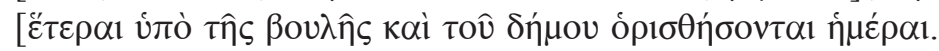

»(Die genannten) Statuenkopien (sollen) während (jeder regulären) Volksversammlung (und zur Zeit des) Neumond(opfers) des archieratischen Jahrs (- d. h. am 1. Januar - ) im (Theater) von den ... (auf den nach Blocks verteilten) und mit einer Aufschrift versehenen neun Basen (in Dreiergruppen aufgestellt werden, entsprechend der) Weihung (auf) den Basen (und in der Stiftung), nämlich für Rat, Gerusie, Ephebie und (die jeweilige) Phyle; nach dem Ende (der Volksversammlungen sollen die Statuenkopien und die Statuen) 
wieder zurückgebracht (werden in das Heiligtum der) Artemis und (von den Wächtern, unter Begleitung und Fürsorge zweier) Neopoioi (und eines Stabträgers, dem Musaios, einem Sklaven der Artemis, dem Betreuer der Deposita, übergeben werden; die Epheben übernehmen und begleiten sie vom Magnesischen Tor bis ins Theater und vom Theater bis zum Koressischen Tor mit) aller (Feierlichkeit; ebenso soll es auch an allen gymnischen) Agonen (geschehen und an anderen Tagen, falls Rat und Volk solche noch bestimmen).《

(Ergänzender Ratsbeschluss):

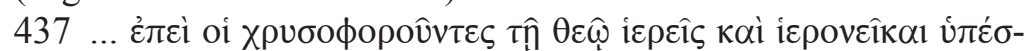

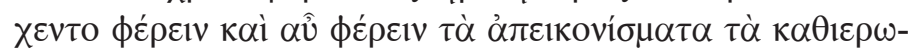

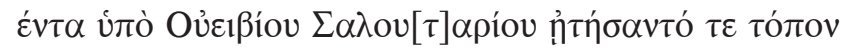

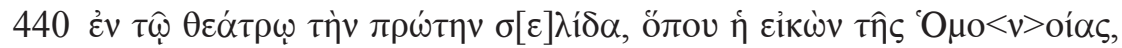

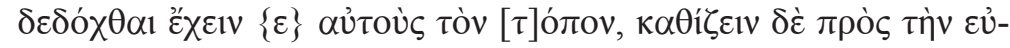

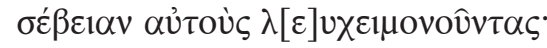

»Nachdem die Priester und Hieroniken, die Goldträger der Göttin sind, versprochen haben, die von Salutaris gestifteten Statuenkopien hin- und zurückzubringen, und um einen Platz im Theater im ersten Block gebeten haben, wo die Statue der Homonoia (Concordia) steht, möge beschlossen werden, dass sie auf diesem Platz sitzen und mit Rücksicht auf den Akt der Frömmigkeit weiße Gewänder tragen sollen.«

(Salutaris erweitert seine Stiftung)

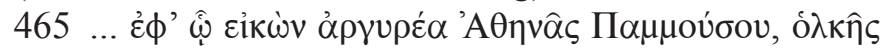

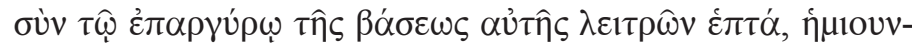

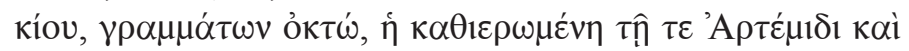

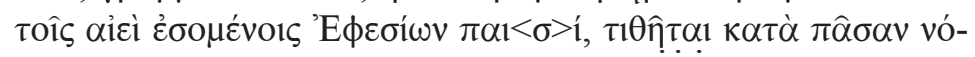

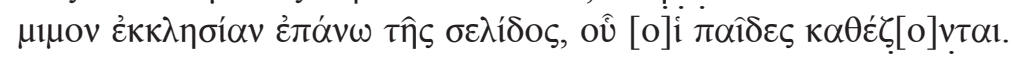

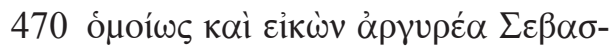

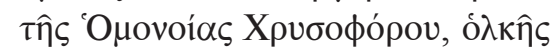

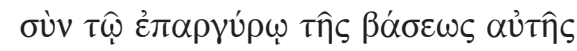

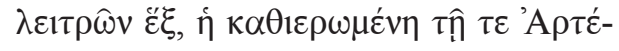

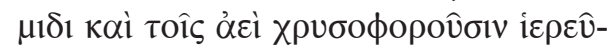

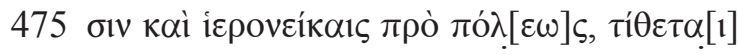

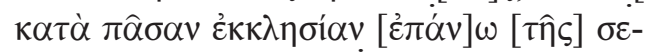

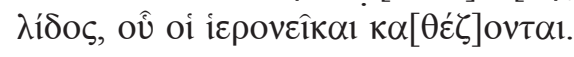

$» \ldots$ unter der Bedingung, dass eine silberne Statuette der Athena Pammusos mit einem Gewicht - einschließlich der Versilberung ihrer Basis - von sieben Pfund, einer halben Unze und acht Skrupel, die der Artemis und den jeweiligen Paides der Ephesier geweiht ist während jeder regulären Volksversammlung oberhalb des Blocks (d. h. im Theater) aufgestellt wird, wo die Paides sitzen.

Ebenso wird eine silberne Statue der Sebaste Homonoia (Concordia Augusta) Chrysophoros mit einem Gewicht - einschließlich der Versilberung ihrer Basis - von sechs Pfund, der Artemis und den jeweiligen Priestern und Hieroniken vor der Stadt geweiht, die Goldträger sind, während jeder regulären Volksversammlung (oberhalb des) Blocks (d. h. im Theater) aufgestellt werden, wo die Hieroniken sitzen.«

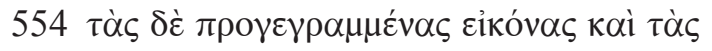

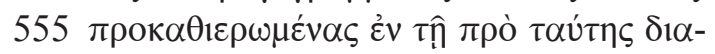

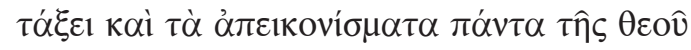

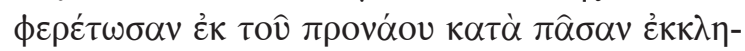

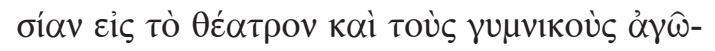

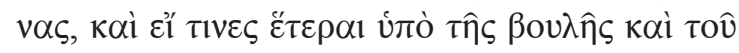

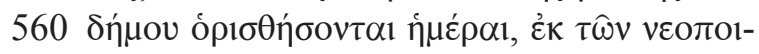

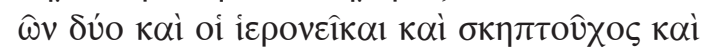




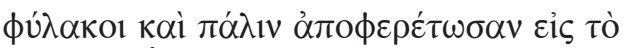

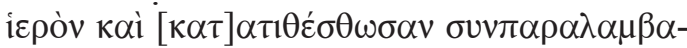

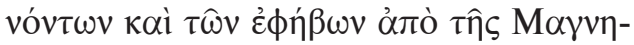

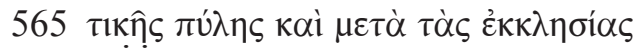

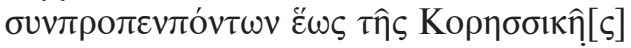

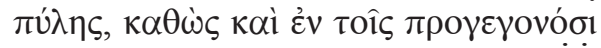

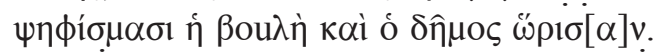

»Die genannten Statuen und die schon vorher in der früheren Stiftung gestifteten und alle Statuenkopien der Göttin sollen vom Pronaos ins Theater zu jeder regulären Volksversammlung und zu den gymnischen) Agonen und an anderen Tagen, falls Rat und Volk solche noch bestimmen, von zwei Neopoioi und den Hieroniken und einem Stabträger und den Wächtern gebracht und wieder ins Heiligtum zurückgebracht und aufgestellt werden; vom Magnesischen Tor an übernehmen sie die Epheben mit und begleiten sie nach den Volksversammlungen bis zum Koressischen Tor, so wie es Rat und Volk auch in den vorausgegangenen Beschlüssen bestimmt haben.«

\section{Bauinschrift des T. Flavius Montanus}

\section{Datierung 102-112 n. Chr. (nach der Kaisertitulatur)}

Kurzbeschreibung Sechs Keilsteine in der Außenarchivolte des vomitorium ES2:

Die Steine eins und drei bis sechs wurden in situ gefunden, der zweite lag »im Schutte auf der Straße an der Südecke des Zuschauerraumes « ${ }^{41}$

Editionen

HEBERDEY u. a. 1912, Nr. 37; IvE 2037

Literatur

Halfmann 2001, 43; Sturgeon 2004b, 419

1 'A

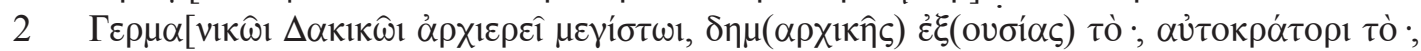

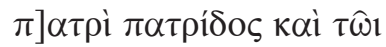

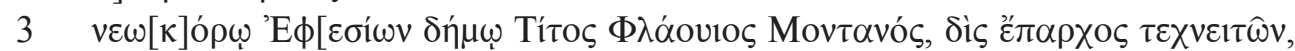

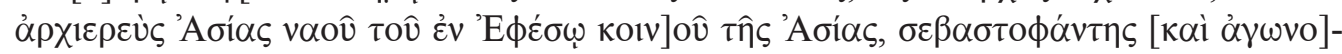

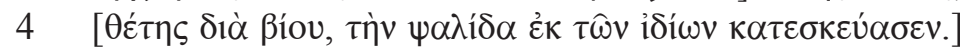

»Der Artemis von Ephesos und dem Imperator Caesar Nerva Traianus Augustus Germanicus Dacicus, pontifex maximus, tribuniciae potestatis --, imperator --, pater patriae, sowie dem tempelhütenden Demos der Ephesier hat Titus Flavius Montanus, zweimal praefectus fabrum, Oberpriester von Asia des Tempels des Koinons von Asia in Ephesos, Augustuspriester und Agonothet auf Lebenszeit, dieses Gewölbe auf eigene Kosten errichtet.«

T. Flavius Montanus stammte aus dem phrygischen Akmoneia und war in der Regierungszeit Trajans politisch tätig. Er war zweimal praefectus fabrum, Oberpriester von Asia des Tempels des Koinons von Asia in Ephesos, Augustuspriester, Sebastophant und Agonothet auf Lebenszeit. Er vollendete den Bau des Theaters und erhielt in Ephesos drei Ehrenstatuen.

Belegstellen: IvE 498; IvE 2037; IvE 2061; IvE 2062; IvE 2063; IGR IV 643 + 1696

Literatur: Witulski 2011, 64-65; HalfMANn 2001, 64; KeARSLEy 1988, 43-45; PIR² F 323; Rossner 1974, 129

\footnotetext{
${ }^{41}$ Heberdey u. a. 1912, 161
} 


\section{Ehreninschriften für L. Vibius Lentulus und T. Flavius Montanus}

Datierung $\quad 102-116 \mathrm{n}$. Chr. (nach der Kaisertitulatur)

Kurzbeschreibung 24 Fragmente von Quadern des Mittelpfeilers am Süd-Analemma

Editionen Heberdey u. a. 1912, Nr. 61; IvE 2061

Literatur HALFMANN 2001, 64

\section{Statue des L. Vibius Lentulus}

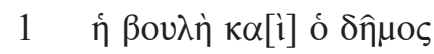

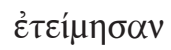

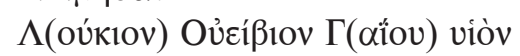

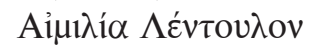

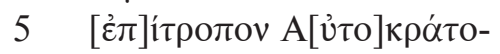

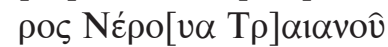

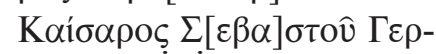
$\mu \alpha v ı \kappa o \hat{v} \dot{\Delta}[\alpha \kappa ı \kappa o \hat{v}, \grave{\alpha}] \pi \dot{o}$ $\tau \hat{\omega} v \lambda \hat{\gamma} \gamma \omega v[\lambda \omega \rho \mathrm{s} \alpha \dot{\tau} \tau] \eta \varsigma$,

10 'A $\alpha \dot{\alpha} \alpha \varsigma, \Pi \alpha v v[o v i \alpha \varsigma, \Delta \alpha \lambda]$ $\mu \alpha \tau i \alpha \varsigma, \mu o v[\dot{\eta} \tau \eta \varsigma$, हैं $\alpha \rho \chi 0 v]$

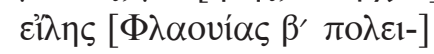
$\tau \omega \hat{~}{ }^{\mathrm{P}} \mathrm{P} \omega[\mu \alpha i \omega v, \chi \varepsilon i \lambda i \alpha \rho \chi 0 v]$

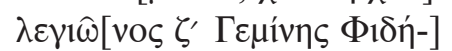

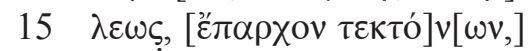

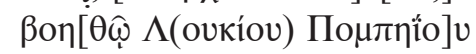
Oن̉[оті́бкоч K $\alpha \tau \varepsilon \lambda \lambda i ́ o] v$ $[\mathrm{K}] \varepsilon \dot{\lambda} \varepsilon[\rho \circ \varsigma \delta \delta \hat{\omega} v v \alpha \hat{\omega} v]$

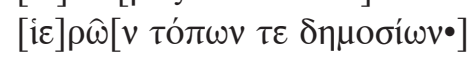

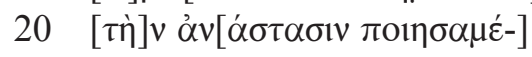
[vov - - - - . - - - - - ]

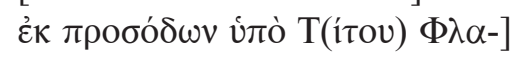

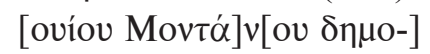

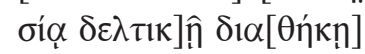

$25[\lambda \varepsilon \lambda \varepsilon 1 \mu \mu \varepsilon \dot{v} \omega \nu$.

Kommentar:

Z. $16 \beta$ o $[\theta \hat{\omega}]$ : Die Verwendung des Dativs anstatt des Akkusativs ist in den beiden Parallelexemplaren IvE 736 und IvE 3046 belegt.

$»$ Rat und Demos ehrten Lucius Vibius Lentulus, Sohn des Gaius, aus der Tribus Aemilia, procurator des Imperator Nerva Traianus Caesar Augustus Germanicus Dacicus a loricata, von Asia, Pannonia und Dalmatia, sowie der moneta, praefectus alae Flaviae II civium Romanorum, tribunus legionis VII Geminae Fidelis, praefectus fabrum, adiutor des L. Pompeius Vopiscus Catellius Celer, der die Erneuerung der Straßen, Tempel, Heiligtümer und öffentlichen Plätze durchführte aus Mitteln, die von T. Flavius Montanus durch öffentliches Vermächtnis hinterlassen wurden.«

L. Vibius Lentulus begann seine politische Karriere als adiutor des L. Pompeius Vopiscus Arruntius Catellius Celer und war wohl um $80 \mathrm{n}$. Chr. curator viarum aedium sacrarum locorumque publicorum. Als praefectus fabrum schlug er die militärische Laufbahn ein und wurde tribunus der legio VII Gemina 
sowie praefectus der ala II Flavia civium Romanorum. Danach trat Vibius als procurator monetae in die zivile Laufbahn über und bekleidete die Ämter des procurator a loricata, Dalmatiae, Pannoniae, und zuletzt Asiae.

Belegstellen: IvE 736. 2061 I, II; 3046

Literatur: Devijver 1976-1993, V 97; Pflaum 1970, Nr. 5; Pflaum 1960, Nr. 66; Hanslik 1958

L. Pompeius Vopiscus Arruntius Catellius Celer war consul suffectus im Jahr $77 \mathrm{n}$. Chr. gemeinsam mit M. Arruntius Aquila und ging danach als legatus Augusti pro praetore in die Provinz Lusitania. In den Jahren 75-91 n. Chr. gehörte er dem Kollegium der fratres arvales an.

Belegstellen: CIL II 5264 = ILS 261; CIL VI 2059 = CIL VI $32364=$ ILS 5033; CIL VI 2060. 2067. 2068. 2071. 32361. 32370; CIL X 8038; IvE 736. 2061. 3046

Literatur: PIR² P 662; GUNDEL 1964; vON ROHDEN 1895

\section{Statue des T. Flavius Montanus}

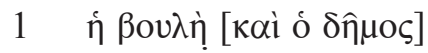

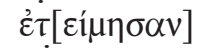

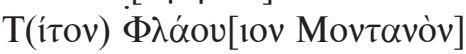

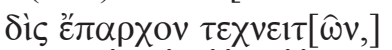

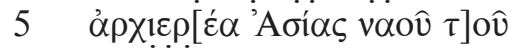

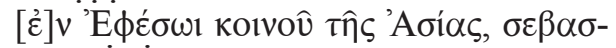

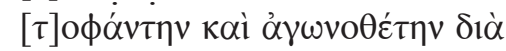

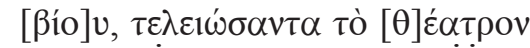

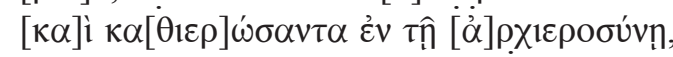

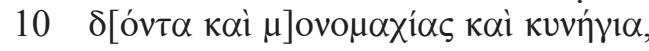

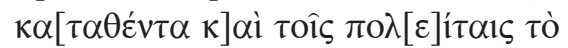

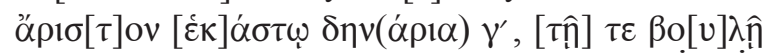

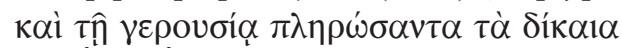

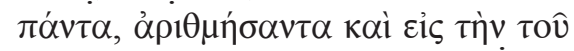

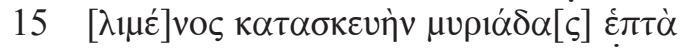

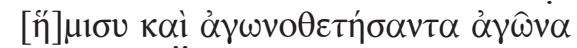

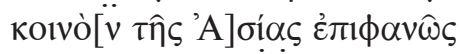

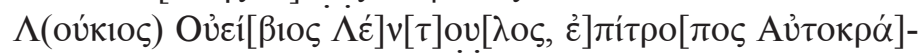

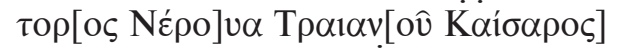

$20 \sum \varepsilon \beta \alpha[\sigma \tau о \widehat{v} \Gamma] \varepsilon \rho \mu \alpha v ı \kappa о[\hat{v} \Delta \alpha \kappa ı \kappa о \widehat{v}]$

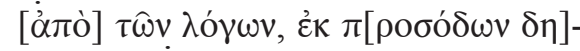

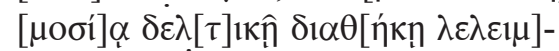

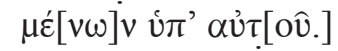

»Rat und Demos ehrten Titus Flavius Montanus, der zweimal praefectus fabrum war, Oberpriester des Asia-Tempels des Koinons von Asia in Ephesos, Augustuspriester und Agonothet auf Lebenszeit, der das Theater vollendete und im Amt des Oberpriesters einweihte, der Gladiatorenspiele und Tierhetzen veranstaltete, der den Bürgern eine Ausspeisung um je 3 Denare bezahlte, der dem Rat und der Gerusie alles Rechte erfüllte, der zur Ausstattung des Hafens 7 1/2 Myriaden bezahlte und als Agonothet den Wettkampf des Koinons von Asia ausgezeichnet durchführte.

Lucius Vibius Lentulus, procurator a rationibus des Imperators Nerva Traianus Caesar Augustus Germanicus Dacicus, aus den von diesem durch öffentlich verzeichnete Verfügung hinterlassenen Einnahmen.«

Zu T. Flavius Montanus s. o. Nr. 5. 


\section{Statue des T. Flavius Montanus}

Datierung $\quad 102-116 \mathrm{n}$. Chr.

Kurzbeschreibung Zwei Quader und drei Fragmente von der südlichen Gebäudeecke des Süd-Analemma; im Schutt gefunden

Editionen HeberdeY u. a. 1912, Nr. 62; IvE 2062

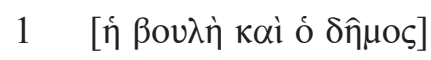

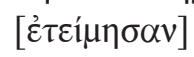

Títov $\Phi \lambda[\alpha ́$ oviov Moviavóv,]

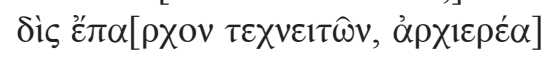

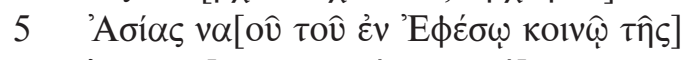

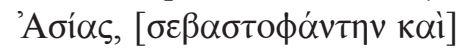

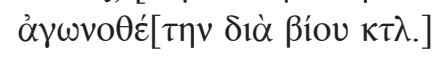

Kommentar:

Es handelt sich um einen mit IvE 2061 II gleichlautenden Text.

Zu T. Flavius Montanus s. o. Nr. 5.

\section{Bauinschrift des T. Flavius Montanus}

Datierung

Kurzbeschreibung Fragmente von Wandverkleidungsplatten des mittleren südlichen vomitorium ES2; im Schutt gefunden

Editionen $\quad \operatorname{IvE} 498$

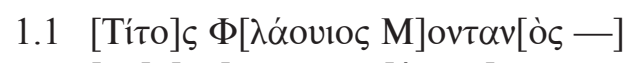

$[-] \tau[-] \pi \alpha \rho \alpha \lambda \alpha \beta[\omega v-]$

$[-] \mu \alpha[-] \tilde{\tau} 1 \kappa \alpha[-]$

$2.1[-] \lambda_{10}[-]$

$[-] \operatorname{cvov}[-]$

$[-\delta]$ טтıкаi $[-]$

Zu T. Flavius Montanus s. o. Nr. 5.

\section{Renovierung des Theaters unter P. Vedius Antoninus}

Datierung ca. $145-150$ n. Chr. (Grammatie des P. Vedius Antoninus)

Kurzbeschreibung Zwei gleichlautende Inschriften in der Verkleidung des Logeion, am Süd-Analemma auf zwei Quadern, am Nord-Analemma auf einem

Editionen Heberdey u. a. 1912, Nr. 39; IvE 2039

Literatur Moretri 1993b, 137-140 Abb. 2; Halfmann 2001, 76. 79 Anm. 259

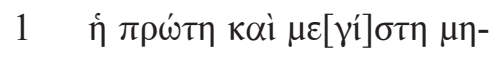

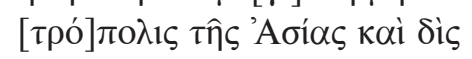
$[v \varepsilon]$ oкó $о \varsigma, \tau \hat{\omega} v \Sigma \varepsilon \beta \alpha \sigma \tau \hat{\omega} v$

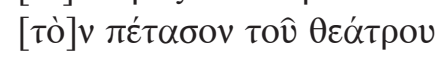




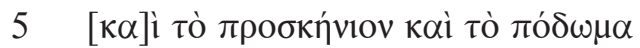

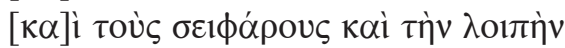

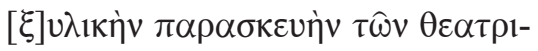

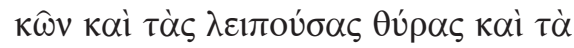

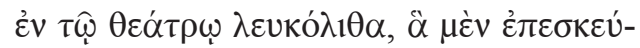

$10 \alpha \sigma \varepsilon v, \ddot{\alpha} \delta \varepsilon \dot{~ \kappa \alpha i ~ \kappa \alpha \tau \varepsilon \sigma \kappa \varepsilon v ́ \alpha \sigma \varepsilon v ~ \varepsilon ̇ \kappa ~ \tau \omega ิ \nu ~ i \delta ́ i ́-~}$

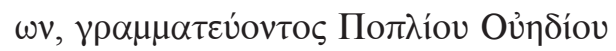

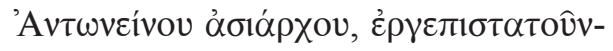

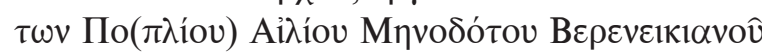

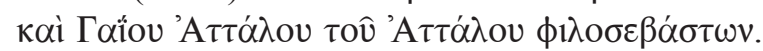

»Die angesehenste und größte Hauptstadt Asiens und zweifache Tempelhüterin der Augusti hat mit eigenen Mitteln das Schutzdach des Theaters, das Proskenion, die Orchestrawand, die Sonnensegel, die übrige hölzerne Ausstattung der Theatereinrichtung, die übrigen Türen und die Marmorteile im Theater teils renoviert und teils errichtet; Grammateus war der Asiarch Publius Vedius Antoninus, die Bauaufsicht führten die Kaisertreuen P. Aelius Menodotus Berenicianus und Gaius, der Sohn des Attalos und Enkel des Attalos.«

\section{Renovierung des Schutzdachs unter dem Prokonsul Tineius Sacerdos}

Datierung 200-210 n. Chr. (Tineius Sacerdos und die 2. Neokorie von Ephesos)

Kurzbeschreibung Zwei gleichlautende Inschriften auf zwei Quadern. Der eine Quader lag auf einem Schutthügel vor der Süd-Parodos, Fragmente des anderen im Schutt vor der NordParodos

Editionen Heberdey u. a. 1912, Nr. 40; IvE 2040

Literatur Moretti 1993b, 137-140; StURgeOn 2004b, 423

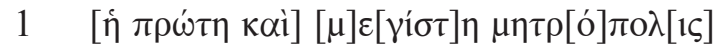

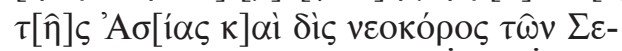

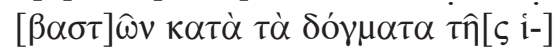

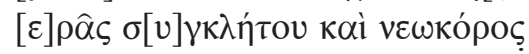

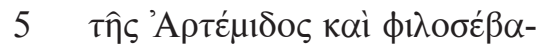

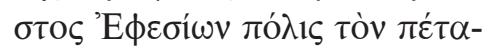

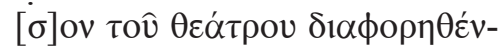

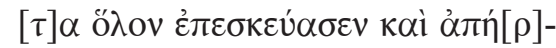

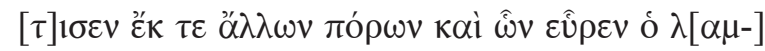

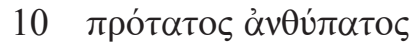

Tivéı́ $\Sigma \alpha \kappa \varepsilon ́ \rho \delta \omega \varsigma$

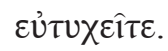

»Die angesehenste und größte Hauptstadt Asiens und zweifache Tempelhüterin der Augusti, die gemäß den Beschlüssen der heiligen Versammlung Tempelhüterin der Artemis und kaisertreue Stadt der Ephesier hat das gänzlich verfallene Schutzdach des Theaters ausgebessert und instand gesetzt sowohl aus anderen Einnahmen als auch aus denen, die der höchst angesehene Prokonsul Tineius Sacerdos fand. Möge es euch wohlergehen!«

Q. Tineius Sacerdos bekleidete im Jahr 192 n. Chr. den Suffektkonsulat gemeinsam mit P. Iulius Scapula Priscus. 198/199 n. Chr. war er legatus Augusti pro praetore Bithyniae et Ponti, 209/10 oder 210/211 n. Chr. proconsul Asiae. An der Spitze seiner Karriere war er im Jahr 219 n. Chr. consul II ordinarius gemeinsam mit Kaiser Elagabal.

Belegstellen: IvE 939. 2040; IGR IV = IGR VI 698 = MAMA IV 10; IGR III 82 + 1429; 
CIL IV 32319; CIL VI 865. 1978. $2104+32388.31162$; CIL XIII 5170. 6764; CIL XV 4111; 7365; CIL XVI 133; AE 1985, 804; AE 1984, 833; AE 1968, 422; AE 1967, 361; AE 1938, 158; AE 1931, 66; TAM IV 1, 13; CPL 138; P. Dura 100 col. 44; P. Dura 101 col. 31; P. Dura 116 co. 4

Literatur: PIR² T 229; ECK 2002; HANSLIK 1975; Fluss 1937

\section{Reparatur des Schutzdachs im Theater}

Datierung

Kurzbeschreibung

spätes 2. Jh. / frühes 3. Jh. n. Chr. (Familie der Iulia Pantima Potentilla)

Editionen

HEBerdey u. a. 1912, Nr. 41; IvE 2041

Literatur

Moretti 1993b, 137-140, Abb. 3; Sturgeon 2004b, 419

$1 \quad \dot{\alpha} \gamma \alpha \theta \hat{\eta} \tau u ́ x \eta$

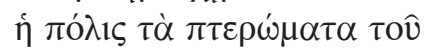

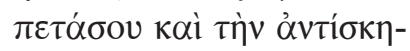

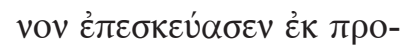

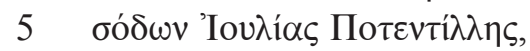

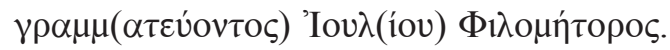

»Der wohlwollenden Glücksgöttin. Die Stadt hat die Flügel des Schutzdachs und den Bau gegenüber der Skene renoviert aus den Einkünften der Iulia Potentilla. Grammateus war Iulius Philometor.«

Iulia Pantima Potentilla war Priesterin und Kosmeteira der Artemis. Ihr Vater, Iulius Artemas (PIR ${ }^{2}$ I 177), fungierte zwischen 177 und 180 n. Chr. als Abgesandter der Ephesier zu den Kaisern Mark Aurel und Commodus, wie die an die Tochter gerichtete Inschrift IvE 983 belegt. Iulia Pantima Potentilla ließ das Theater und den Boden des Auditorium der Celsus-Bibliothek erneuern.

Belegstellen: IvE 983; IvE 2041; IvE 2042; IvE 3009

Literatur: PIR ${ }^{2}$ 686

\section{Epigramm auf Messalinus}

Datierung

Kurzbeschreibung

Editionen

Literatur
4. Jh. n. Chr. (Messalinus)

Quader, in der Verschlussmauer des nördlichen vomitorium EN2 verbaut

Heberdey u. a. 1912, Nr. 43; IvE 2043; Donderer 1996, Nr. C5;

Merkelbach 1998, Nr. 3.2.16

Heberdey 1898, 77; FeIsSel 1998, 130

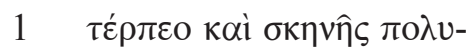

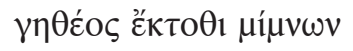

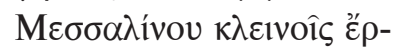

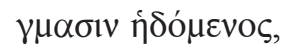

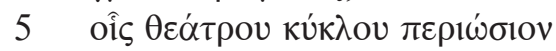

$\varepsilon \xi \xi \varepsilon \alpha \dot{\alpha} \omega \sigma \varepsilon v^{*}$

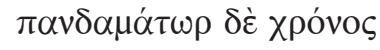

$\varepsilon \hat{i} \xi_{\varepsilon v} \alpha \grave{\alpha} \rho \eta \gamma 0 \sigma u ́ v \eta ̣$

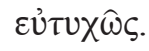

Alternative Lesungen:

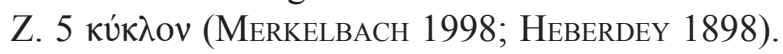


»Freue dich, indem du, auch wenn du außerhalb der viel Freude machenden Bühne bleibst, die ruhmvollen Taten des Messalinus genießt, durch die er das riesige Theaterrund erhalten hat. Die alles bezwingende Zeit aber wich der Rettungsmaßnahme. Möge es zum Glück gereichen.«

Messalinus war proconsul Asiae im 4. Jh. n. Chr.

Belegstellen: IvE 1307. 2043. 2044

Literatur: Jones u. a. 1971, 600; PIR² M 510; MALCus 1967, 130 f.; EnssLin 1931; FABRICIUs 1931

\section{Epigramm auf Messalinus}

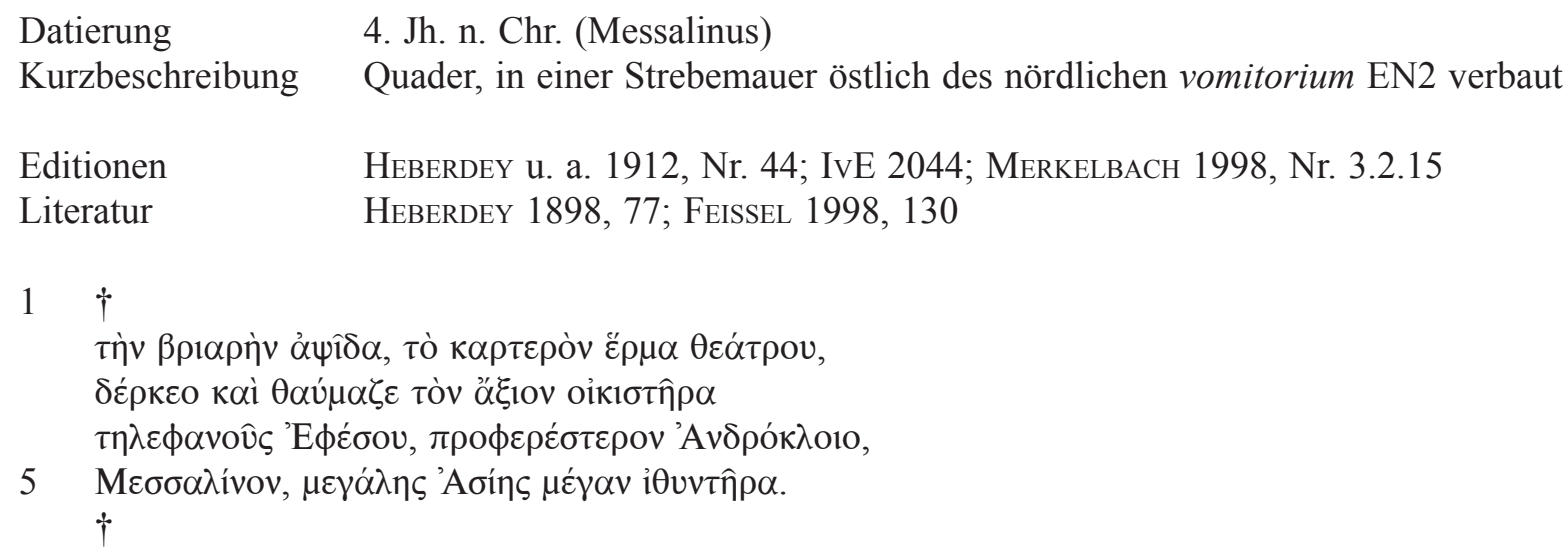

»Die wuchtige Wölbung, das feste Stützwerk des Theaters betrachte und bewundere den würdigen Gründer der weithin berühmten Stadt Ephesos, vorzüglicher als Androklos, Messalinus, der großen Asia großen Lenker.«

Zu Messalinus s. o. Nr. 12.

\subsubsection{Appendix 2, Gesamtverzeichnis der im Bereich des Theaters gefundenen Inschriften}

In der folgenden Tabelle sind alle früher im Bereich des Theaters gefundenen bzw. mit diesem in Zusammenhang stehenden Inschriften angeführt. Die erste Spalte enthält die IvE-Nummer, die zweite die Inventar(= Skizzenbuch-) Nummer. Die dritte Spalte gibt den Fundort an, die vierte eine kurze Inhaltsangabe zur leichteren Identifizierung. Die Nummern der in dieser Tabelle enthaltenen Zusammenstellung aus dem Appendix 1, Altbestand der Bauinschriften aus dem Theater sind hier angegeben. Die nicht in IvE enthaltenen Texte (Altfunde meist in Form kleinerer Fragmente) sind am Schluss angeführt ${ }^{42}$.

\begin{tabular}{|l|l|l|l|}
\hline IvE & Inv. & Fundort & Stichwort \\
\hline 4 & 684 & $\begin{array}{l}\text { auf Terrasse vor dem Nordflügel im Pflaster } \\
\text { verbaut }\end{array}$ & Beschluss über Schuldentilgung, Block 4 \\
\hline 9 & $\begin{array}{l}255,644,645,660- \\
663,674,755\end{array}$ & in Bühnenfront und Nord-Parodos verbaut & Agonothetenliste der Dionysia \\
\hline 10 & 2982 & im Pflaster vor dem Theater & Opfergesetz \\
\hline
\end{tabular}

\footnotetext{
${ }^{42}$ Die Tabelle wurde von Ch. Samitz unter Anleitung von H. Taeuber und auf der Basis der Datenbank von A. Sokolicek angefertigt.
} 


\begin{tabular}{|c|c|c|c|}
\hline IvE & Inv. & Fundort & Stichwort \\
\hline 15 & 555,557 & Theaterplatz, vor dem Nord-Analemma & Kaiserbrief des Antoninus Pius (?) \\
\hline 17 & $556,569,586$ & Theaterplatz vor und im Nord-Analemma & Edikt des Paullus Fabius Persicus \\
\hline $19 \mathrm{~A}$ & $352,368,370,411$ & Orchestra & Edikt des Paullus Fabius Persicus \\
\hline 19B & $77 \mathrm{~B}$ & Theaterstraße & Edikt des Paullus Fabius Persicus \\
\hline 21 & 554,1 & Nordaufgang zum 1. Diazoma & $\begin{array}{l}\text { Dekret über Geburtstagsfeier des Antoninus } \\
\text { Pius }\end{array}$ \\
\hline 25 & 268 & vor der Westfront & $\begin{array}{l}\text { Reskript des Mark Aurel und Lucius Verus } \\
\text { über die Gerusie }\end{array}$ \\
\hline 26 & $242,312,369,451$ & $\begin{array}{l}\text { Nord-Parodos, Orchestra, Logeion und } \\
\text { Theaterplatz }\end{array}$ & Dekret der Gerusie \\
\hline 27 & $\begin{array}{l}188,189,206,213, \\
214,217,219,222, \\
223,225-227,265, \\
278,314,336,341, \\
342,417,424,489, \\
490,604,634\end{array}$ & Süd-Analemma & Salutaris-Stiftung (Nr. 4) \\
\hline 28 & 398 & Orchestra bei der 1. Stiege im Süden & $\begin{array}{l}\text { Statue aus Salutaris-Stiftung für Phyle } \\
\text { Sebaste }\end{array}$ \\
\hline 29 & 394 & Orchestra nahe der Nord-Parodos & $\begin{array}{l}\text { Statue aus Salutaris-Stiftung für Phyle der } \\
\text { Teier }\end{array}$ \\
\hline 30 & $\begin{array}{l}338-340,377,457, \\
587\end{array}$ & Orchestra nahe der Süd-Parodos & Statue aus Salutaris-Stiftung \\
\hline 31 & 391 & Orchestra gegenüber dem Mitteleingang & $\begin{array}{l}\text { Statue aus Salutaris-Stiftung für Phyle der } \\
\text { Bembinaier }\end{array}$ \\
\hline 32 & 412,551 & Orchestra bei der 1. Stiege im Süden & Statue aus Salutaris-Stiftung \\
\hline 33 & 318 & auf den Sitzstufen an der Süd-Parodos & $\begin{array}{l}\text { Statue aus Salutaris-Stiftung für die Paides } \\
\text { und Phyle Hadriane }\end{array}$ \\
\hline 34 & 503 & auf den Sitzstufen, etwas südlich der Mitte & $\begin{array}{l}\text { Statue aus der Salutaris-Stiftung für die } \\
\text { Epheben }\end{array}$ \\
\hline 35 & 479 & vor der Westfront, nahe dem Brunnenhaus & $\begin{array}{l}\text { Statue aus der Salutaris-Stiftung für die } \\
\text { Gerusie }\end{array}$ \\
\hline $36 \mathrm{C}$ & 256 & $\begin{array}{l}\text { zwischen dem Hauptsaal des Bühnenhauses } \\
\text { und der Westterrasse }\end{array}$ & Götterstatue aus der Salutaris-Stiftung \\
\hline $36 \mathrm{~B}$ & 395 & auf den Sitzstufen, nahe dem Nordende & Götterstatue aus der Salutaris-Stiftung \\
\hline $36 \mathrm{D}$ & 396 & $\begin{array}{l}\text { im Norden der Orchestra, nahe den } \\
\text { Sitzstufen }\end{array}$ & Götterstatue aus der Salutaris-Stiftung \\
\hline $36 \mathrm{~A}$ & 461 & südlicher Teil der Orchestra & Götterstatue aus der Salutaris-Stiftung \\
\hline 37 & $328,337,450$ & Orchestra & Ehrung des Salutaris \\
\hline 47 & 2974 & im Pflaster vor dem Theater & $\begin{array}{l}\text { Spenden der Prytanen für Gerusie und } \\
\text { Kureten }\end{array}$ \\
\hline 220 & 619 & Theaterplatz & Brief des Marcus Aurelius \\
\hline 221 & 236,439 & Süd-Parodos & Kaiserbrief über die Neopoioi der Artemis \\
\hline 222 & 305 & vor der Skene & $\begin{array}{l}\text { Beginn eines Briefs des Septimius Severus } \\
\text { oder Caracalla }\end{array}$ \\
\hline
\end{tabular}




\begin{tabular}{|c|c|c|c|}
\hline IvE & Inv. & Fundort & Stichwort \\
\hline 243 & 389 & Orchestra & $\begin{array}{l}\text { Ehrung durch Thyateira anlässlich der dritten } \\
\text { Neokorie }\end{array}$ \\
\hline $256 \mathrm{~A}$ & 3388 & $\begin{array}{l}\text { Theaterplatz, in der byzantinischen } \\
\text { Abmauerung der Straße }\end{array}$ & Drusus Iulius Caesar, Agrippina Maior \\
\hline $263 \mathrm{~A}, 2$ & 577,1 & Theaterplatz & Domitian, Weihinschrift \\
\hline $264 \mathrm{~A}$ & 300 & Süd-Parodos & Weihung an Nerva oder Trajan \\
\hline $265 \mathrm{~A}$ & 243 & Nord-Parodos & Weihung an Trajan \\
\hline 270 & 509 & vor der Westfront & Hadrian als Zeus Olympios \\
\hline $271 \mathrm{E}$ & 294 & Süd-Parodos & Weihung an Hadrian \\
\hline $271 \mathrm{I}$ & $\begin{array}{l}330,333,375,447, \\
448\end{array}$ & im Schutt der Orchestra & Hadrian \\
\hline $280 \mathrm{~A}$ & 356 & gewölbter Gang & $\begin{array}{l}\text { Lucius Ceionius Commodus, der spätere } \\
\text { Kaiser Lucius Verus }\end{array}$ \\
\hline 282B & 2977 & in der linken Theatertreppe verbaut & Antoninus Pius \\
\hline $282 \mathrm{D}$ & & & Antoninus Pius \\
\hline $309 \mathrm{~A}, 3$ & 656 & oberstes Diazoma, in der Mitte & Diocletian \\
\hline 313 & 499 & westlich vor der Skene & Ehrung für Konstantin den Großen \\
\hline 322,3 & $210,293,1986$ I 17 & $\begin{array}{l}\text { Theaterplatz, nordwestlich des Theaters und } \\
\text { unterhalb der Skene }\end{array}$ & Bauinschrift \\
\hline 333 & 283 & Nord-Parodos & Bauinschrift? \\
\hline 334,1 & 291 & Nord-Parodos & Kaiserehrung \\
\hline 343 & 1939 & Brunnenhaus & Arsi[noe?] \\
\hline 417 & 480 & Brunnenhaus & $\begin{array}{l}\text { Aufschrift Marnas auf einer Säule vom } \\
\text { Brunnenhaus }\end{array}$ \\
\hline $425 \mathrm{~A}$ & $794,795,8$ & in der späten Mauer vor dem Theater verbaut & Bauinschrift des Claudius Aristion \\
\hline 460 & 1685,5 & Orchestra & $\begin{array}{l}\text { (Publius Vedius Antoninus) und Flavia } \\
\text { Papiane stiften das Bouleuterion }\end{array}$ \\
\hline 464 & 798 & im Schutt vor der Süd-Parodos & Architrav mit Bauinschrift einer Ausstattung \\
\hline $465 \mathrm{~A}$ & & & Fragment einer Bauinschrift; Servilius \\
\hline 471 & 497 & vor der Westfront & $\begin{array}{l}\text { Fragmente eines Gesimses; Ti. Claudius } \\
\text { Nysios }\end{array}$ \\
\hline 498 & $3485-3487$ & Zugang zum 2. Diazoma & $\begin{array}{l}\text { T. Flavius Montanus vollendet das Theater } \\
\text { (Nr. 8) }\end{array}$ \\
\hline 530 & 332 & Orchestra & der Prytanis Pollio \\
\hline 541 & 654 & 1. Diazoma, nördliches Drittel & $\begin{array}{l}\text { Platz des Timonax und der Verwalter der } \\
\text { Tempelgelder }\end{array}$ \\
\hline 542 & 795 & $\begin{array}{l}\text { Theaterplatz, zwischen Theater und Osttor } \\
\text { der Agora }\end{array}$ & Platz der Schiffsherren \\
\hline 544 & 3369,3370 & $\begin{array}{l}\text { Hanghaus 1; ursprünglich wohl aus dem } \\
\text { Theater }\end{array}$ & Platz des Q. Arellius Antiochus \\
\hline 551 & 435 & Nordteil der Orchestra & Platz des Pferdehändlers (?) Akakios \\
\hline
\end{tabular}




\begin{tabular}{|c|c|c|c|}
\hline IvE & Inv. & Fundort & Stichwort \\
\hline $557 \mathrm{~A}$ & 588 & im Schutt der Nord-Parodos & $\begin{array}{l}\text { Kassettenplatte mit Relief des Ebers, den } \\
\text { der Stadtgründer Androklos erlegte, mit } \\
\text { Beischrift Ktista }\end{array}$ \\
\hline $570,1 \mathrm{c}$ & 536 & vor der Nord-Parodos & Ziegelstempel \\
\hline $570,2 b$ & 307 & vor der Westfront & Ziegelstempel \\
\hline 570,4 & 3490 & unbekannt & Ziegelstempel \\
\hline 605 & 297,427 & Westfront, bei der unteren Tür & $\begin{array}{l}\text { Statue eines Dichters mit Fragment eines } \\
\text { Epigramms }\end{array}$ \\
\hline 606 & 670 & $\begin{array}{l}\text { Nordseite, in einer späten Mauer zwischen } \\
\text { dem untersten und dem mittleren Tor }\end{array}$ & Fragment eines Gedichtes in Distichen \\
\hline 630 & 565 & vor der Skene & -ius Bassus \\
\hline $650 \mathrm{~A}$ & 298 & vor der Westfront, bei der Tür & Tiberius Claudius (Tuendianus?) \\
\hline $666 \mathrm{C}$ & 578,2 & westlich vor dem Torbau & der proconsul Fabius Tatianus \\
\hline 676 & 299,426 & vor der Westfront & Siegerinschrift \\
\hline $676 \mathrm{~A}$ & 579 & Theaterplatz, nahe dem Torbogen & $\begin{array}{l}\text { Totenehren für Titus Flavius Papianus; aus } \\
\text { einem Gebäude, das sein Großvater errichtet } \\
\text { hat }\end{array}$ \\
\hline $677 \mathrm{~A}$ & 212,1896 I 14 & vor dem Bühnengebäude & der praefectus Aegypti Flavius Titianus \\
\hline 709 & & unbekannt & $\begin{array}{l}\text { Aufidius Proclus ehrt seinen Onkel Gnaeus } \\
\text { Pompeius Hermippus Aelianus }\end{array}$ \\
\hline 781 & 228,264 & Süd-Parodos & fragmentarisches Ehrendekret \\
\hline 791 & 591 & Theaterplatz & Ehrung \\
\hline 798,1 & 418 & vor der Westfront & Fragmente, wohl einer Statuenbasis \\
\hline 798,2 & 419 & vor der Westfront & Fragmente, wohl einer Statuenbasis \\
\hline 835 & 623 & $\begin{array}{l}\text { vor der Südfront des Zuschauerraums, nahe } \\
\text { der Südecke }\end{array}$ & Totenehren für einen Unbekannten \\
\hline 836 & 443 & Süd-Parodos & Fragment \\
\hline 851 & 625 & vor dem Stiegenaufgang im Pflaster & $\begin{array}{l}\text { Grab des Mithradates, Freigelassener des M. } \\
\text { Vipsanius Agrippa }\end{array}$ \\
\hline 860 & 221 & vor der Süd-Parodos & der Sklave Eperastus dankt dem Hercules \\
\hline 901 & 624 & Südfront des Zuschauerraums & Liste der Molpoi \\
\hline $903 a$ & 3063 & Badgasse, Theatereingang & Namensliste \\
\hline 908 & 350 & gewölbter Gang, Südende & Namensliste \\
\hline 908 & 378 & Orchestra & Namensliste \\
\hline $932 \mathrm{~A}$ & 5103 & unsicher & Inschrift für einen Agoranomos \\
\hline 944 & 386 & Nord-Parodos & Fragment, nennt einen Neopoios \\
\hline 970 & 216 & Süd-Parodos & Spenderliste? \\
\hline 974 & 2973 & Theaterplatz & Liste einer religiösen Vereinigung \\
\hline 975 & 273,343 & Nord-Parodos & $\begin{array}{l}\text { Liste römischer Bürger in griechischer } \\
\text { Sprache }\end{array}$ \\
\hline
\end{tabular}




\begin{tabular}{|c|c|c|c|}
\hline $\mathbf{I v E}$ & Inv. & Fundort & Stichwort \\
\hline $1105 \mathrm{~A}$ & 473 & vor der Westfront & Siegerinschrift \\
\hline 1069 & & unbekannt & Dank für den Prytanis Agathopous \\
\hline 1074 & & unsicher & die Prytanis Lollia \\
\hline 1096 & 455 & vor der Westfront & Siegerinschrift \\
\hline 1105 & & unsicher & Siegerinschrift \\
\hline 1108 & 771 & vor dem nördlichen Flügel & Siegerinschrift \\
\hline 1122 & 438 & beim Tor an der Westfront & Siegerinschrift \\
\hline 1135 & 581,1 & Südende des Theaterplatzes & Siegerinschrift \\
\hline 1147 & 349 & gewölbter Gang, Südende & Siegerinschrift \\
\hline $1147 \mathrm{~A}$ & 631 & vor der Südfront & Siegerinschrift \\
\hline 1147B & 262,306 & Süd-Parodos & Siegerinschrift \\
\hline 1148 & 296,428 & vor der Westfront & Siegerinschrift \\
\hline 1170 & 204 & im Schutt der Nord-Parodos & $\begin{array}{l}\text { Ritzzeichnung eines Gladiatorenkampfs; } \\
\text { Gladiator Alektor }\end{array}$ \\
\hline 1174,3 & 2131 & $\begin{array}{l}\text { Südmauer der Cavea, in der Nähe des } \\
\text { obersten vermauerten Eingangs; im Schutt }\end{array}$ & Gladiatoren-Relief, Prestor \\
\hline 1197 & 818 & Sitzstufen, im Süden & Fragment, erwähnt die Cancelli \\
\hline 1252 & 582 & Theaterplatz in später Mauer & $\begin{array}{l}\text { Orakelfrage und Antwort des Apollon von } \\
\text { Didyma }\end{array}$ \\
\hline 1303 & & in einem Sumpf nördlich des Theaters & Fragment eines Epigramms auf Damocharis \\
\hline 1331 & 310 & nahe der Skene & christliche Monogramme \\
\hline $1135 \mathrm{~A}$ & 581,2 & Südende des Theaterplatz & Prytanenliste \\
\hline 1366,1 & 665 & Orchestra & christliche Akklamation \\
\hline $1393 \mathrm{~A}$ & 270 & Nord-Parodos & Fragment eines Beschlusses der Presbyteroi (?) \\
\hline 1397 & 505 & Diazoma & Fragment eines Beschlusses \\
\hline 1406 & 263 & $\begin{array}{l}\text { Süd-Parodos; ursprünglich aus dem } \\
\text { Artemision }\end{array}$ & Fragmente von Volksbeschlüssen \\
\hline 1444 & 267 & $\begin{array}{l}\text { Nord-Parodos; ursprünglich aus dem } \\
\text { Artemision }\end{array}$ & Bürgerrechtsdekret \\
\hline 1448 & 201 & $\begin{array}{l}\text { Proskenion; ursprünglich aus dem } \\
\text { Artemision }\end{array}$ & Bürgerrechtsdekret \\
\hline 1449 & & $\begin{array}{l}\text { Proskenion; ursprünglich aus dem } \\
\text { Artemision }\end{array}$ & Bürgerrechtsdekret \\
\hline 1450 & & $\begin{array}{l}\text { Proskenion; ursprünglich aus dem } \\
\text { Artemision }\end{array}$ & Bürgerrechtsdekret \\
\hline 1451 & & $\begin{array}{l}\text { Proskenion; ursprünglich aus dem } \\
\text { Artemision }\end{array}$ & Bürgerrechtsdekret \\
\hline 1452 & & $\begin{array}{l}\text { Proskenion; ursprünglich aus dem } \\
\text { Artemision }\end{array}$ & Bürgerrechtsdekret \\
\hline 1453 & 203 & $\begin{array}{l}\text { Proskenion; Nord-Parodos; ursprünglich aus } \\
\text { dem Artemision }\end{array}$ & Bürgerrechtsdekret \\
\hline
\end{tabular}




\begin{tabular}{|c|c|c|c|}
\hline IvE & Inv. & Fundort & Stichwort \\
\hline 1454 & & $\begin{array}{l}\text { Proskenion; ursprünglich aus dem } \\
\text { Artemision }\end{array}$ & Bürgerrechtsdekret \\
\hline 1455 & & $\begin{array}{l}\text { Proskenion; ursprünglich aus dem } \\
\text { Artemision }\end{array}$ & Bürgerrechtsdekret \\
\hline 1456 & & $\begin{array}{l}\text { Proskenion; ursprünglich aus dem } \\
\text { Artemision }\end{array}$ & Bürgerrechtsdekret \\
\hline 1457 & & $\begin{array}{l}\text { Proskenion; ursprünglich aus dem } \\
\text { Artemision }\end{array}$ & Bürgerrechtsdekret \\
\hline 1458 & & $\begin{array}{l}\text { Proskenion; ursprünglich aus dem } \\
\text { Artemision }\end{array}$ & Bürgerrechtsdekret \\
\hline 1459 & & $\begin{array}{l}\text { Proskenion; ursprünglich aus dem } \\
\text { Artemision }\end{array}$ & Bürgerrechtsdekret \\
\hline 1460 & & $\begin{array}{l}\text { Proskenion; ursprünglich aus dem } \\
\text { Artemision }\end{array}$ & Bürgerrechtsdekret \\
\hline 1461 & & $\begin{array}{l}\text { Proskenion; ursprünglich aus dem } \\
\text { Artemision }\end{array}$ & Verkauf des Bürgerrechts \\
\hline 1462 & & $\begin{array}{l}\text { Proskenion; ursprünglich aus dem } \\
\text { Artemision }\end{array}$ & Bürgerrechtsdekret \\
\hline 1463 & & $\begin{array}{l}\text { Proskenion; ursprünglich aus dem } \\
\text { Artemision }\end{array}$ & Bürgerrechtsdekret \\
\hline 1464 & & $\begin{array}{l}\text { Proskenion; ursprünglich aus dem } \\
\text { Artemision }\end{array}$ & Bürgerrechtsdekret \\
\hline 1465 & & $\begin{array}{l}\text { Proskenion; ursprünglich aus dem } \\
\text { Artemision }\end{array}$ & Bürgerrechtsdekret \\
\hline 1466 & & $\begin{array}{l}\text { Proskenion; ursprünglich aus dem } \\
\text { Artemision }\end{array}$ & Ehrendekret \\
\hline 1467 & & $\begin{array}{l}\text { Proskenion; ursprünglich aus dem } \\
\text { Artemision }\end{array}$ & Fragment eines Bürgerrechtsdekrets \\
\hline 1468 & & $\begin{array}{l}\text { Proskenion; ursprünglich aus dem } \\
\text { Artemision }\end{array}$ & Ehren- oder Bürgerrechtsdekrete \\
\hline 1469 & & $\begin{array}{l}\text { Proskenion; ursprünglich aus dem } \\
\text { Artemision }\end{array}$ & Fragment eines Bürgerrechtsdekrets \\
\hline 1470 & & $\begin{array}{l}\text { Proskenion; ursprünglich aus dem } \\
\text { Artemision }\end{array}$ & Ehrendekret \\
\hline 1471 & & $\begin{array}{l}\text { Proskenion; ursprünglich aus dem } \\
\text { Artemision }\end{array}$ & Bürgerrechtsdekret \\
\hline 1472 & & $\begin{array}{l}\text { Proskenion; ursprünglich aus dem } \\
\text { Artemision }\end{array}$ & Fragment eines Bürgerrechtsdekrets \\
\hline 1473 & & $\begin{array}{l}\text { Proskenion; ursprünglich aus dem } \\
\text { Artemision }\end{array}$ & Fragment eines Bürgerrechtsdekrets \\
\hline 1474 & & $\begin{array}{l}\text { Proskenion; ursprünglich aus dem } \\
\text { Artemision }\end{array}$ & Fragment eines Bürgerrechtsdekrets \\
\hline 1475 & & $\begin{array}{l}\text { Proskenion; ursprünglich aus dem } \\
\text { Artemision }\end{array}$ & Fragment eines Bürgerrechtsdekrets \\
\hline
\end{tabular}




\begin{tabular}{|c|c|c|c|}
\hline IvE & Inv. & Fundort & Stichwort \\
\hline 1476 & & $\begin{array}{l}\text { Proskenion; ursprünglich aus dem } \\
\text { Artemision }\end{array}$ & Fragment eines Bürgerrechtsdekrets \\
\hline 1480 & $\begin{array}{l}190,199,202,205 \\
247,258\end{array}$ & & Kaiserbrief \\
\hline 1481 & & & agonistisches Fragment (?) \\
\hline 1486 & & & $\begin{array}{l}\text { Brief Hadrians vom 27. September } 120 \mathrm{n} . \\
\text { Chr. an die Gerousia }\end{array}$ \\
\hline 1501 & & & $\begin{array}{l}\text { [Tib.] Claudius Demostratus Caelianus stellt } \\
\text { eine Statue Hadrians auf }\end{array}$ \\
\hline 1534 & & & das Forum des Theodosius \\
\hline 1537 & & & Ehrung für Gaius Iulius Agrippa; Basis? \\
\hline 1538 & 460 & vor der Westfront & $\begin{array}{l}\text { Ehrenstatue des C. Antius A. Iulius } \\
\text { Quadratus (?) }\end{array}$ \\
\hline 1541 & & & $\begin{array}{l}\text { Ehrung für C. Iulius Lupus T. Vibius Varus } \\
\text { Laevillus, Quaestor pro praetore }\end{array}$ \\
\hline 1543 & & & $\begin{array}{l}\text { Ehren für A. Iunius Pastor L Caesennius } \\
\text { Sospes }\end{array}$ \\
\hline 1571 & & & $\begin{array}{l}\text { Fragmente von Inschriften religiöser } \\
\text { Funktionäre oder Priester }\end{array}$ \\
\hline 1573 & & & Liste der Neopoioi \\
\hline 1575 & & & zwei Neopoioi; Basis? \\
\hline 1577 & & & $\begin{array}{l}\text { die Deipnophoriake Pompe (Lectisternia); } \\
\text { Basis? }\end{array}$ \\
\hline 1587 & & & Dankinschrift zweier Beamter \\
\hline 1600 & & & Priesterliste \\
\hline 1601 & & $\begin{array}{l}\text { vielleicht zum Banketthaus oberhalb des } \\
\text { Theaters gehörig }\end{array}$ & $\begin{array}{l}\text { die Dionysosmysten }>\text { vor der Stadt }<\text {; mehrere } \\
\text { Fragmente }\end{array}$ \\
\hline 1602 & & $\begin{array}{l}\text { vielleicht zum Banketthaus oberhalb des } \\
\text { Theaters gehörig }\end{array}$ & Liste dionysischer Mysten \\
\hline 1603 & & $\begin{array}{l}\text { vielleicht zum Banketthaus oberhalb des } \\
\text { Theaters gehörig }\end{array}$ & Fragment einer Namensliste \\
\hline 1604 & & & Siegerinschrift \\
\hline 1605 & & & Siegerinschrift \\
\hline 1609 & & & Siegerinschrift \\
\hline 1611 & & & Siegerinschrift \\
\hline 1612 & & unsicher & Siegerinschrift \\
\hline 1615 & & & Siegerinschrift \\
\hline 1617 & & & agonistisches Fragment \\
\hline 1634 & & & $\begin{array}{l}\text { Grab des Aur. Zo[ ] ] us Saon und der } \\
\text { Aurelia Smyrna }\end{array}$ \\
\hline 1789 & 596 & Theaterplatz, in einer byzantinischen Mauer & Fragment \\
\hline
\end{tabular}




\begin{tabular}{|c|c|c|c|}
\hline IvE & Inv. & Fundort & Stichwort \\
\hline 1808 & 326 & Orchestra & Fragment einer Platte \\
\hline 1808 & 481,482 & Nord-Parodos & zugeschnittenes Fragment einer Basis \\
\hline 1857,1 & 431 & vor der Westfront & Fragment \\
\hline 1857,2 & 422 & Westfront & Fragment \\
\hline 1858 & 429 & im Westen, beim Pfeilerfundament & Fragment einer Rundbasis \\
\hline 1861 & 493 & in später Mauer vor dem Brunnenhaus & Fragment einer Archivolte \\
\hline 1862 & 320 & Orchestra & Fragment mit Nennung einer Erneuerung \\
\hline 1876 & 224 & Nord-Parodos & Fragment \\
\hline 1877 & 244 & Nord-Parodos & Fragment \\
\hline 1878 & 245 & Nord-Parodos & Fragment \\
\hline 1900,6 & 269 & Nord-Parodos & Archiereus tes Asias \\
\hline 1900,9 & 485 & Logeion Nord-Parodos & Archiereus \\
\hline 1901,2 & 250 & Nord-Parodos bei Inv. 275 (IvE 2071) & Statuenbasis \\
\hline 1902,2 & 484 & $\begin{array}{l}\text { Logeion Nord-Parodos, als Fußbodenbelag } \\
\text { wiederverwendet }\end{array}$ & Fragment einer Statuenbasis \\
\hline 1904,2 & 325 & Orchestra & Fragment; Neokorie \\
\hline 1906,2 & 658 & oberstes Diazoma, in der Mitte & Oberteilfragment einer Statuenbasis \\
\hline 1908,2 & 595 & Theaterplatz & Fragment einer Basis \\
\hline 1908,3 & 657 & oberstes Diazoma in der Mitte & Statuenbasis \\
\hline 1909,3 & 280 & Süd-Parodos & Fragment \\
\hline 1910,2 & 345 & Nord-Parodos & $\begin{array}{l}\text { Fragment einer Statuenbasis; auf Vorderseite } \\
\text { Darstellung eines Schiffs mit drei Ruderern }\end{array}$ \\
\hline 1912,1 & 621 & $\begin{array}{l}\text { im tiefen Schutt vor der Südfront des } \\
\text { Zuschauerraums }\end{array}$ & Fragment eines Architravfrieses \\
\hline 1912,3 & 241 & Süd-Parodos & Fragment eines Quaders \\
\hline 1922,2 & 498 & vor der Westfront & Oberteil einer Statuenbasis \\
\hline 1927,2 & 276 & Süd-Parodos & Fragment einer Statuenbasis \\
\hline 1938 & 3488 & unbekannt & $\begin{array}{l}\text { Fragment einer Basis oder einer großen } \\
\text { Platte }\end{array}$ \\
\hline $1941 \mathrm{~A}$ & 191 & Süd-Parodos & Fragment \\
\hline $1943 \mathrm{~A}$ & 246 & im Schutt & Fragment eines Quaders \\
\hline 1947A & 295 & Süd-Parodos & Fragment einer Namensliste \\
\hline 1948A & 373 & im Schutt der Orchestra & Lateinisches Fragment \\
\hline 1949A & 408 & im Schutt der Orchestra & Fragment einer lateinischen Inschrift \\
\hline $1950 \mathrm{~A}$ & 626 & vor dem Stiegenaufgang im Pflaster & Namen \\
\hline $1952 \mathrm{~A}$ & 667 & Süd-Parodos & Fragment eines Quaders \\
\hline 1962 & 1938 & Hellenistisches Brunnenhaus & Fragment \\
\hline $1975 \mathrm{~A}$ & 207 & Süd-Parodos & Fragment (Synkletos) \\
\hline
\end{tabular}




\begin{tabular}{|c|c|c|c|}
\hline IvE & Inv. & Fundort & Stichwort \\
\hline 2001 & 491,1 & in später Mauer auf Theaterplatz & $\begin{array}{l}\text { Volksbeschluss über den Verkauf des Bürger- } \\
\text { rechts (die Leute aus Priene in Charax) }\end{array}$ \\
\hline 2002 & 491,2 & vor der Westfront & Schluss eines Bürgerrechtsdekrets \\
\hline 2003 & 491,21 & vor der Westfront & Bürgerrechtsdekret \\
\hline 2004 & 491,3 & vor der Westfront & Bürgerrechtsdekret \\
\hline 2005 & 491,31 & vor der Westfront & $\begin{array}{l}\text { Volksbeschluss über den Verkauf des } \\
\text { Bürgerrechts }\end{array}$ \\
\hline 2006 & 492 & vor der Westfront & Bürgerrechtsdekret \\
\hline 2007 & 492,01 & vor der Westfront & Bürgerrechtsdekret \\
\hline 2008 & 492,02 & vor der Westfront & Bürgerrechtsdekret \\
\hline 2009 & 379 & Orchestra & Bürgerrechtsdekret \\
\hline 2010 & 218 & Aushub aus den Grabungen von J. T. Wood & Bürgerrechtsdekret \\
\hline 2011 & 566 & Theaterstraße & $\begin{array}{l}\text { Bürgerrechtsdekret für Nikanor, den } \\
\text { Adoptivsohn des Aristoteles }\end{array}$ \\
\hline 2012 & 566,1 & Theaterstraße & Bürgerrechtsdekret \\
\hline 2013 & 198 & Nord-Parodos & Fragment eines Bürgerrechtsdekrets \\
\hline 2013 & 274 & außerhalb der Nord-Parodos & Fragment eines Bürgerrechtsdekrets \\
\hline 2014 & 198,1 & Nord-Parodos & Fragment eines Bürgerrechtsdekrets \\
\hline 2014 & 274,1 & außerhalb der Nord-Parodos & Fragment eines Bürgerrechtsdekrets \\
\hline 2015 & 609 & Nord-Parodos & Bürgerrechtsdekret \\
\hline 2016 & 609,1 & Nord-Parodos & Bürgerrechtsdekret \\
\hline 2018 & 348 & vor der Mitte der Skene & $\begin{array}{l}\text { Volksbeschluss über die Zuteilung von } \\
\text { Wasser (?) }\end{array}$ \\
\hline 2018 & 371 & Theater, Orchestra & $\begin{array}{l}\text { Volksbeschluss über die Zuteilung von } \\
\text { Wasser (?); Antrag unter dem Prytanen } \\
\text { Alexandros Passalas, wasserrechtliche } \\
\text { Angelegenheiten betreffend; Wasserzuteilung }\end{array}$ \\
\hline $2020 \mathrm{~A}$ & & »über [IvE] 26« & $\begin{array}{l}\text { Beglaubigung eines Volksbeschlusses durch } \\
\text { die Grammateis }\end{array}$ \\
\hline 2025 & 560 & Theaterterrasse & $\begin{array}{l}\text { Präskript zu einem Erlass des Septimius } \\
\text { Severus und Caracalla }\end{array}$ \\
\hline 2026 & 486 & vor der Westfront & Brief des Caracalla \\
\hline 2031 & $\begin{array}{l}380,434,456,463 \\
802,1\end{array}$ & Logeionschutt & $\begin{array}{l}\text { Weihinschrift vom Fries des Oberstocks der } \\
\text { hellenistischen Bühne im Theater }\end{array}$ \\
\hline 2032 & 477 & Theater, Süd-Parodos & $\begin{array}{l}\text { drei Fragmente von einem Architrav, als } \\
\text { Türpfosten verwendet }\end{array}$ \\
\hline 2032 & 799 & $\begin{array}{l}\text { in der Außenwand der südl. Rampe beim } \\
\text { Bühnenraum vermauert }\end{array}$ & $\begin{array}{l}\text { drei Fragmente von einem Architrav, als } \\
\text { Türpfosten verwendet }\end{array}$ \\
\hline 2032 & 1896 I 33 & Süd-Parodos & $\begin{array}{l}\text { drei Fragmente von einem Architrav, als } \\
\text { Türpfosten verwendet }\end{array}$ \\
\hline 2033 & 669 & Südteil, oberster Eingang bei Ringmauer & $\begin{array}{l}\text { der Prytanis Hieron Aristogiton erbaut einen } \\
\text { der Zugänge zum Theater (Nr. 1) }\end{array}$ \\
\hline
\end{tabular}




\begin{tabular}{|c|c|c|c|}
\hline IvE & Inv. & Fundort & Stichwort \\
\hline 2034 & $\begin{array}{l}311,316,466-472 \\
478,590\end{array}$ & im Schutt der Orchestra & $\begin{array}{l}\text { Architrav vom ersten Geschoss der } \\
\text { römischen Bühnenwand unter Domitian } \\
\text { (Nr. 2) }\end{array}$ \\
\hline 2035 & 552 & obere Terrasse & $\begin{array}{l}\text { Weihinschrift am Nordflügel des } \\
\text { Zuschauerraums an Domitian; 20 Fragmente } \\
\text { (Nr. 3) }\end{array}$ \\
\hline 2036 & 629 & Südfront & Fragment einer Bauinschrift \\
\hline 2037 & 668,1288 & Mitteltor und Marmorstraße & Bauinschrift des T. Flavius Montanus (Nr. 5) \\
\hline 2038 & 215,462 & Süd-Parodos und Orchestra & $\begin{array}{l}\text { Bauinschrift von einem Architrav; P. Rutilius } \\
\text { Bassus }\end{array}$ \\
\hline 2039 & 1896 I 18,31 & am Nord- und Süd-Analemma & $\begin{array}{l}\text { Renovierung des Theaters unter Vedius } \\
\text { Antoninus (Nr. 9) }\end{array}$ \\
\hline 2040 & $\begin{array}{l}\text { 195-197, 220, 252, } \\
272,1895 \text { II } 8,1896 \\
\text { III } 38\end{array}$ & $\begin{array}{l}\text { Nord- und Süd-Parodos, Schutt aus den } \\
\text { Grabungen von J. T. Wood }\end{array}$ & $\begin{array}{l}\text { Reparatur der Vorrichtungen für das Dach } \\
\text { unter dem proconsul Tineius Sacerdos } \\
\text { (Nr. 10) }\end{array}$ \\
\hline 2041 & 627 & in der südlichen Frontmauer & $\begin{array}{l}\text { Reparatur der Vorrichtungen für das Dach im } \\
\text { Theater; Iulia Potentilla (Nr. 11) }\end{array}$ \\
\hline 2042 & 251 & Nord-Parodos & $\begin{array}{l}\text { Bauinschrift der Vorhalle des } \\
\text { Nemesisheiligtums im Theater }\end{array}$ \\
\hline 2043 & & in später Mauer unter 2. Diazoma & $\begin{array}{l}\text { Epigramm auf Messalinus, proconsul Asiae, } \\
\text { den Wiederhersteller des Theaters (Nr. 12) }\end{array}$ \\
\hline 2044 & & in später Mauer unter 2. Diazoma & $\begin{array}{l}\text { Epigramm auf Messalinus, proconsul Asiae, } \\
\text { den Wiederhersteller des Theaters (Nr. 13) }\end{array}$ \\
\hline 2045 & 562 & nördliche Stiege & $\begin{array}{l}\text { gute Wünsche für den proconsul } \\
\text { Ambrosi(o)s }\end{array}$ \\
\hline 2046 & 553 & obere Terrasse & Fragment \\
\hline 2047 & 558 & Nord-Parodos & Statue des Domitian im Theater \\
\hline 2048 & 415 & Orchestra Nordecke & $\begin{array}{l}\text { Statue des Domitian (eradiert) im Theater, } \\
\text { Synaeitai }\end{array}$ \\
\hline 2049 & 567,570 & $\begin{array}{l}\text { im Schutt der Orchestra und vor Nord- } \\
\text { Parodos }\end{array}$ & $\begin{array}{l}\text { Statuen der kaiserlichen Familie des } \\
\text { Antoninus Pius und Marc Aurel }\end{array}$ \\
\hline 2050 & $\begin{array}{l}289,302,303,313, \\
319,321,323,324, \\
331,346,374,376, \\
384,416,568,1896 \\
\text { I } 16\end{array}$ & $\begin{array}{l}\text { im Schutt der Nord- und Süd-Parodos und } \\
\text { Orchestra }\end{array}$ & $\begin{array}{l}\text { sechs Statuen des Antoninus Pius, aufgestellt } \\
\text { von den Phylen der Stadt }\end{array}$ \\
\hline 2051 & 353 & Logeion & $\begin{array}{l}\text { Verkleidungsplatte eines Postaments für eine } \\
\text { Statuengruppe des Septimius Severus, der } \\
\text { Iulia Domna und ihrer Söhne }\end{array}$ \\
\hline 2052 & 257,344 & Orchestra & $\begin{array}{l}\text { Statue des Demos der Ephesier, geweiht von } \\
\text { der Bule }\end{array}$ \\
\hline 2053 & 546 & vor der Westfront & Statue der Stadt Karthago \\
\hline 2054 & 559 & Nord-Analemma & Ehrenstatue des Demos von Knidos \\
\hline 2055 & 542 & Theaterstraße nahe dem Theater & Ehrenstatue des Demos von Kos \\
\hline 2056 & 549 & Orchestra & Ehrenstatue der Stadt Nicaea Cilbianorum \\
\hline
\end{tabular}




\begin{tabular}{|c|c|c|c|}
\hline IvE & Inv. & Fundort & Stichwort \\
\hline 2057 & 437 & Logeionschutt & Statue der Iomede \\
\hline 2058 & 465 & Logeion, Südhälfte & Statue des L. Agrius Publeianus \\
\hline 2059 & 476 & Logeion & Statue des Quaestors Cn. Domitius Corbulo \\
\hline 2061 & $620,632 \mathrm{a}, 5474$ & Süd-Parodos Mittelpfeiler & $\begin{array}{l}\text { Statuen des L. Vibius Lentulus und des T. } \\
\text { Flavius Montanus (Nr. 6) }\end{array}$ \\
\hline 2062 & 1384,1386 & $\begin{array}{l}\text { Marmorstraße, bei der Südecke des Theaters } \\
\text { im Schutt }\end{array}$ & Statue des Flavius Montanus (Nr. 7) \\
\hline 2063 & 200 & Süd-Parodos & Statue des Flavius Montanus \\
\hline 2064 & 393 & Orchestra & $\begin{array}{l}\text { Statuen des P. Vedius Antoninus Phaedrus } \\
\text { Sabinianus }\end{array}$ \\
\hline 2065 & 392 & Orchestra & $\begin{array}{l}\text { Die Professoren des Museions ehren Vedius } \\
\text { Antoninus Phaedrus Sabinianus }\end{array}$ \\
\hline 2066 & 385 & Orchestra & $\begin{array}{l}\text { Statue der Valeria Lepida, der Gattin des } \\
\text { Vedius Antoninus III. }\end{array}$ \\
\hline 2067 & $\begin{array}{l}230,238,425,430, \\
454\end{array}$ & $\begin{array}{l}\text { Süd-Parodos, vor der Westfront des Süd- } \\
\text { Analemma }\end{array}$ & Statue des M. Ulpius Damas [Catullinus] \\
\hline 2068 & 548 & vor der Westfront & $\begin{array}{l}\text { M. Gavius Cornelius Cethegus, legatus } \\
\text { Asiae }\end{array}$ \\
\hline 2069 & 390 & Orchestra & Statue des Gnaeus Pompeius Hermippos \\
\hline 2070 & 248 & $\begin{array}{l}\text { in einem späten Anbau an der Nordseite des } \\
\text { Bühnenhauses }\end{array}$ & $\begin{array}{l}\text { Statue des Pantomimen Tib. Iulius } \\
\text { Apolaustus }\end{array}$ \\
\hline 2071 & 275 & mittelalterliches Haus & $\begin{array}{l}\text { Statue des Pantomimen Tib. Iulius } \\
\text { Apolaustus }\end{array}$ \\
\hline 2072 & 547 & im Schutt vor der Westfront & $\begin{array}{l}\text { Totenehren und Statue für einen vielfachen } \\
\text { Sieger im Fünfkampf }\end{array}$ \\
\hline 2073 & & & Siegerinschrift \\
\hline 2074 & 659 & Skene & Architrav über einem Weinkeller (doliarium) \\
\hline 2075 & 632,3896 & vorderste Logeionmauer im Fundament & Weihinschrift für das Klision \\
\hline 2076 & 495,1 & vor der Westfront & Aufschrift auf Säule \\
\hline 2077 & 495,2 & vor der Westfront & Aufschrift auf Säule \\
\hline 2080 & 400 & zwischen 3. und 4. Stiege von Norden & Aufschrift auf Säule \\
\hline 2081 & 507 & Theater, Koilon bei Nord-Parodos & Aufschrift auf Säule \\
\hline 2082 & 387 & Theater, Logeion & Aufschrift auf Säule \\
\hline 2083 a & 394,3 & Orchestra & Toposinschrift \\
\hline $2083 \mathrm{~b}$ & & Theater, Rückseite der Salutaris-Postamente & Toposinschrift \\
\hline $2083 \mathrm{c}$ & 398,1 & Theater, Orchestra & Toposinschrift \\
\hline $2083 \mathrm{~d}$ & 457,1 & Theater, Rückseite der Salutaris-Postamente & Toposinschrift \\
\hline $2083 \mathrm{e}$ & 394,1 & Theater, Rückseite der Salutaris-Postamente & Toposinschrift \\
\hline $2083 \mathrm{f}$ & & Theater, Rückseite der Salutaris-Postamente & Toposinschrift \\
\hline $2083 \mathrm{~g}$ & & Theater, Rückseite der Salutaris-Postamente & Toposinschrift \\
\hline
\end{tabular}




\begin{tabular}{|c|c|c|c|}
\hline IvE & Inv. & Fundort & Stichwort \\
\hline 2084 & 399 & Süd-Parodos & Toposinschrift \\
\hline 2085 & 464 & vorderer Abschluss der Sitzreihen & Toposinschrift \\
\hline 2086 & 653 & 1. Diazoma & Toposinschrift \\
\hline $2087 \mathrm{a}$ & 655,1 & Theater, 2. Diazoma & Toposinschrift \\
\hline $2087 \mathrm{~b}$ & 655,2 & Theater, 2. Diazoma & Toposinschrift \\
\hline 2088 & 666 & Nord-Parodos & Versatzmarke? \\
\hline 2089 & 664 & späthellenistischer Oberstock & kleine Inschrift \\
\hline 2090 & & $\begin{array}{l}\text { in der byzantinischen Stadtmauer am } \\
\text { Südende der Bühnenhausterrasse }\end{array}$ & kleine Inschriften \\
\hline 2091 & 397 & Mitteleingang & Zeichnung eines Bühnenstücks (Mimus) \\
\hline 2092 & 436,474 & Skene & Zeichnungen von Schauspielern? \\
\hline 2093 & 506 & im Schutt der Orchestra & Darstellung einer Bühnenszene \\
\hline 2094 & 259 & Nord-Parodos & Zeichnung aus dem Theater \\
\hline 2327 & 208 & Süd-Parodos & Grab des oder der Xanthias \\
\hline $2236 \mathrm{E}$ & 496 & vor der Westfront & Grab des Claudius Polychronius \\
\hline 2435 & 671 & $\begin{array}{l}\text { Nordseite, in einer späten Mauer zwischen } \\
\text { dem untersten und dem mittleren Tor }\end{array}$ & Grabschrift \\
\hline 2437 & 673 & $\begin{array}{l}\text { Nordseite, in einer späten Mauer zwischen } \\
\text { dem untersten und dem mittleren Tor }\end{array}$ & fragmentarische Grabschrift \\
\hline 3515 & & & Grenzstein \\
\hline $\begin{array}{l}\text { SEG } \\
50,1161\end{array}$ & 5041 & Theater & Zeus Keraunios \\
\hline \multirow{15}{*}{$\begin{array}{l}\text { SEG } \\
50,1166\end{array}$} & 5102 & Theater & Grabschrift \\
\hline & 1896 I 15 & Gang im Skenengebäude & abgeschrägter Block \\
\hline & 192 & im Schutt der Süd-Parodos & Fragment \\
\hline & 193 & im Schutt der Süd-Parodos & Fragment \\
\hline & 194 & im Schutt der Süd-Parodos & Plattenfragment \\
\hline & 209 & Nord-Parodos & gestempelter Ziegel \\
\hline & 211 & Süd-Parodos & Quader \\
\hline & 229 & Süd-Parodos & Quader mit Inschrift, wiederverwendet \\
\hline & 231 & im Schutt des Hintergebäudes der Skene & Ziegel mit Stempel \\
\hline & 232 & Süd-Parodos & Fragment einer Basis \\
\hline & 233 & Süd-Parodos & Fragment \\
\hline & 234 & Süd-Parodos & Fragment eines größeren Stücks \\
\hline & 239 & Süd-Parodos & rechte obere Ecke eines Quaders \\
\hline & 240 & Süd-Parodos & Fragment einer Basis \\
\hline & 249 & Nord-Parodos & Basis \\
\hline
\end{tabular}




\begin{tabular}{|c|c|c|c|}
\hline IvE & Inv. & Fundort & Stichwort \\
\hline & 253 & Nord-Parodos & Fragment \\
\hline & 254 & Süd-Parodos & $\begin{array}{l}\text { Kassettenplatte, später zu Quader } \\
\text { umgearbeitet }\end{array}$ \\
\hline & 260 & im Schutt vor der Westfront & Fragment \\
\hline & 261 & im Schutt oben auf der Westfront & Fragment \\
\hline & 266 & Süd-Parodos & Fragment \\
\hline & 271 & Nord-Parodos & Fragment \\
\hline & 277 & Süd-Parodos & Fragment \\
\hline & 279 & Süd-Parodos & zwei Fragmente derselben Platte \\
\hline & 286 & Nord-Parodos & Fragment eines Quaders mit Baumarke \\
\hline & 288 & vor der Westfront im Schutt & Fragment eines Quaders \\
\hline & 290 & Nord-Parodos & Fragment \\
\hline & 292 & Nord-Parodos & Fragment eines Quaders \\
\hline & 301 & Süd-Parodos & Fragment \\
\hline & 304 & Süd-Parodos & Fragment einer lateinischen Inschrift \\
\hline & 308 & beim Tor an der Westfront & Fragment eines Architravs \\
\hline & 309 & Ecke der Westtreppe & rechter Rand eines Quaders \\
\hline & 315 & Orchestra & Fragment einer Basis (zu Inv. 249) \\
\hline & 317 & Orchestra & Plattenfragment \\
\hline & 322 & Orchestra & Fragment eines Quaders \\
\hline & 327 & Orchestra & rechte untere Ecke eines Quaders \\
\hline & 329 & Orchestra & Fragment einer Basis \\
\hline & 334 & Orchestra & Fragment mit Buchstabenresten \\
\hline & 335 & Orchestra & Fragment eines Quaders \\
\hline & 351 & gewölbter Gang, Südende & Fragment einer Säule (?) \\
\hline & 381 & Nord-Parodos & Fragment \\
\hline & 406 & im Schutt der Orchestra & Fragment \\
\hline & 407 & im Schutt der Orchestra & Fragment \\
\hline & 413 & im Schutt der Orchestra & Fragment \\
\hline & 420 & vor der Westfront & Fragment eines Quaders \\
\hline & 423 & vor der Westfront & Fragment einer Basis \\
\hline & 432 & vor der Westfront & Fragment von einem Architrav? \\
\hline & 433 & auf dem Logeion, im Schutt & $\begin{array}{l}\text { Block mit Inschrift, zu einem Architrav } \\
\text { zugerichtet }\end{array}$ \\
\hline & 440 & Süd-Parodos & Fragment \\
\hline & 441 & Süd-Parodos & Fragment \\
\hline & 442 & Süd-Parodos & Fragment \\
\hline
\end{tabular}




\begin{tabular}{|c|c|c|c|}
\hline IvE & Inv. & Fundort & Stichwort \\
\hline & 444 & im Schutt der Orchestra & Fragment \\
\hline & 445 & im Schutt der Orchestra & Fragment einer lateinischen Inschrift \\
\hline & 446 & $\begin{array}{l}\text { vor der Westfront, Aushub der Grabungen } \\
\text { von J. T. Wood }\end{array}$ & Fragment \\
\hline & 449 & im Schutt der Orchestra & $\begin{array}{l}\text { Fragment eines Quaders (vom Sockel der } \\
\text { scaenae frons?) }\end{array}$ \\
\hline & 452 & außen vor der Nord-Parodos & linke obere Quaderecke \\
\hline & 453 & außen an der Nord-Parodos & Fragment eines Quaders \\
\hline & 458 & Orchestra & Fragment \\
\hline & 459 & Orchestra & Fragment eines Altars \\
\hline & 475 & im Schutt in der Gangwölbung & $\begin{array}{l}\text { Fragment eines Gesimses oder einer } \\
\text { Sitzstufe }\end{array}$ \\
\hline & 483 & Logeion Nord-Parodos & \\
\hline & 487 & vor der Westfront & Plattenfragment \\
\hline & 488 & vor der Westfront & Fragment \\
\hline & 494 & beim hellenistischen Brunnenhaus & sechs Fragmente eines Bogens \\
\hline & 500,1 & auf Sockel der scaenae frons & Graffito \\
\hline & 500,2 & auf Sockel der scaenae frons & $\begin{array}{l}\text { Inschrift auf der Verkleidungsplatte vom } \\
\text { Sockels der scaenae frons }\end{array}$ \\
\hline & 500,3 & auf Sockel der scaenae frons & $\begin{array}{l}\text { Inschrift auf der Verkleidungsplatte vom } \\
\text { Sockels der scaenae frons }\end{array}$ \\
\hline & 501 & im Pflaster in der Mitteltür der Bühnenfront & Fußbodenplatte mit Graffiti \\
\hline & 502 & auf den Treppenstufen & Deckplatten der Sitzstufen \\
\hline & 504,1 & 2. Diazoma & Fragment \\
\hline & 504,2 & auf den Stufen & Fragment \\
\hline & 508 & vor der Westfront & Türschwelle \\
\hline & 510 & im Schutt auf dem gewölbten Gang & Fragment einer Säule oder einer Basis \\
\hline & 511 & Pfeiler der Logeionsstütze & Inschrift auf dem Pfeiler \\
\hline & 534 & vor der Nord-Parodos im Schutt & Fragment eines Quaders \\
\hline & 535 & vor der Nord-Parodos im Schutt & Fragment einer rottonigen Schüssel \\
\hline & 550 & Orchestra & Fragment einer Basis \\
\hline & 561 & im Schutt auf der Stiege & Fragment \\
\hline & 563 & Orchestra & Architrav \\
\hline & 564 & Orchestra & Fragment eines Türpfostens \\
\hline & 580 & Südende des Theaterplatzes & Verkleidungsplatte \\
\hline & 583 & in später Mauer auf Theaterplatz & Fragment einer Marmorschale \\
\hline & 584 & nahe der Nord-Parodos an der Straße & Architrav \\
\hline & 585 & nahe der Nord-Parodos an der Straße & Bogenquader \\
\hline
\end{tabular}




\begin{tabular}{|c|c|c|c|}
\hline IvE & Inv. & Fundort & Stichwort \\
\hline & 589 & Theaterplatz im Schutt & Fragment eines Quaders \\
\hline & 592 & Theaterplatz & Plattenfragment \\
\hline & 593 & Theaterplatz & Fragment \\
\hline & 603 & im Schutt der Nord-Parodos & Fragment einer lateinischen Inschrift \\
\hline & 605 & im Sockel der Bühnenarchitektur & wiederverwendeter Quader \\
\hline & 610 & im Schutt der Nord-Parodos & Fragment \\
\hline & 611 & im Schutt der Nord-Parodos & Platte mit Profil \\
\hline & 616 & im Schutt der Orchestra & Fragment einer Basis \\
\hline & 622 & $\begin{array}{l}\text { im Schutt vor der Südfront des } \\
\text { Zuschauerraums }\end{array}$ & Fragment \\
\hline & 628 & $\begin{array}{l}\text { im Schutt vor der Südfront des } \\
\text { Zuschauerraums }\end{array}$ & Fragment einer Basis \\
\hline & 629,4 & Südfront & Fragment \\
\hline & 630 & Südfront & Fragment \\
\hline & 640 & $\begin{array}{l}\text { in spätem Mauerklotz südlich der Torpfeiler } \\
\text { des hellenistischen Hafens }\end{array}$ & Fragment \\
\hline & 652 & unterhalb des 1. Diazomas & Fragment \\
\hline & 1258 & vor dem Südflügel & Fragment eines Wandquaders \\
\hline & 1636 & Orchestra & Architrav vom Theater, Schrift eradiert \\
\hline & 2479 & Theaterterrasse & Fragment einer Platte \\
\hline & 3489 & im Bereich des Theaters & Fragment \\
\hline
\end{tabular}

H. TAEUBER

Ch. SAMITZ 


\section{Der archäozoologische Befund aus der Verfüllung der Aristion-Leitung}

\subsection{EINLEITUNG, MATERIAL UND METHODE}

Aus den Grabungen im Süden des Theaters wurden in einem vielversprechenden Fundbereich der AristionLeitung ${ }^{1}$ zahlreiche tierische Überreste aus einer Verfüllung geborgen und archäozoologische Untersuchungen durchgeführt. Das tierische Material stammt aus jenem eingeschütteten Bereich, an dem die Leitung aus dem Theater austritt und sich nach leichter Richtungsänderung in dem Unterbau der Treppe fortsetzt. An der Austrittstelle überdeckten ehemals nur Stufensteine auf wenigen Metern die Leitung; dieser Abschnitt lag nach der Entfernung der Stufen offen (Taf. 162 Abb. 330. 331; 166 Abb. 338). Durch diese Öffnung drang Schutt in die Wasserleitung ein und verfüllte diese partiell bis zur Oberkante des Gewölbes. Der oberste Bereich der Verfüllung bestand aus deutlich feinerem Sediment als die tiefer liegenden (Taf. 161 Abb. 329). Alle Schichten haben sich im Zuge von Umbauarbeiten an der Treppe abgelagert; das darin enthaltene Fundmaterial datiert relativ einheitlich ins 6. Jh. n. Chr. ${ }^{2}$ und stammt vermutlich aus der an die Treppe angrenzenden Insula.

Der außerhalb der byzantinischen Stadtmauer gelegene Fundbereich erbrachte insgesamt 680 tierische Überreste, die aus insgesamt 34 verschiedenen stratigrafisch trennbaren sedimentären Einheiten stammen. Das tierische Material weist einen ausgezeichneten Erhaltungszustand auf und wurde entsprechend den archäozoologischen Erfordernissen nach Tierart, Element, Körperseite und Sterbealter ${ }^{3}$ aufgenommen. Neben der Beurteilung von Modifizierungen, wie Nagetier- und Karnivorenverbiss, sind die Knochen auch auf artifizielle Spuren, wie etwa Hack- und Schnittspuren, untersucht worden. Die metrische Erfassung des archäozoologischen Fundguts wurde nach den Richtlinien von A. von den Driesch ${ }^{4}$ durchgeführt. Zusätzlich wurde durch großflächiges Auflegen der Knochen erkannt, dass im Fundmaterial viele zusammenpassende Knochen vorliegen, die in verschiedenen stratigrafischen Einheiten ergraben wurden.

\subsection{ERGEBNISSE}

Die Faunenzusammensetzung aus der Wasserleitung erweist sich im Vergleich zu bereits bekannten Tierartenassoziationen archäologischer Fundstellen in Ephesos ${ }^{5}$ als ungewöhnlich. Reste von Haustieren, die üblicherweise die Hauptquelle für tierisches Protein darstellen, sind zwar am häufigsten vertreten, doch nur mit einem Anteil von rund $63 \%$ (Tab. 111. 112). Der Rest der Funde in numerischer Quantifikation repräsentiert Wildtiere, wobei Wildsäuger am häufigsten sind und Schildkröten, Mollusken und Wildgeflügel das Fundspektrum komplettieren.

Kleine Hauswiederkäuer und Rinder überwiegen unter den Haustieren, wogegen das Schwein nur durch eine sehr geringe Anzahl an Knochen auffällt (Grafik 48). Die Verteilung der Körperbereiche bei den kleinen Hauswiederkäuern entspricht einer Fleischnutzung. Die Rinderreste wurden in ein Teilskelett (Grafik 48; Bos taurus 1. Indiv.) und nicht zusammensetzbare Knochen differenziert (Grafik 48; Bos taurus). Während sich die einzelnen Rinderknochen, ähnlich wie die Reste der kleinen Hauswiederkäuer, verteilen, finden sich mehr Rumpf- und distale Extremitätenteile beim Teilskelett. Unter den Schweinen konnten dagegen kaum nutzbare Körperpartien gefunden werden. Die Anwesenheit von Katzenknochen in dieser Fundassoziation in derselben Fundfrequenz wie die Schweinereste ist sehr ungewöhnlich (Grafik 48). We-

\footnotetext{
${ }^{1}$ Kap. 3.6.1 u. 10.2.4.2.

${ }^{2}$ Kap. 4.

${ }^{3}$ Die Beurteilung der Sterbealter erfolgte nach Habermenl 1975.

${ }^{4}$ Die metrische Erfassung der Tierknochen erfolgte nach vON DEN DRIESCH 1976.

${ }^{5}$ Forstenpointner u. a. 1993; Forstenpointner u. a. 2002; Forstenpointner u. a. 2010; Forstenpointner u. a. 2008; Galik u. a. 2010a; GALIK u. a. 2010b.
} 
der die Katzenreste noch die so zahlreichen Hundeknochen können als regulärer Speiseabfall aus den Haushalten der nahen Insula interpretiert werden. Die restlichen Haustiere werden durch einen Milchzahn eines Esels und mehrere Pferdereste, die hauptsächlich Zähne und distale Extremitätenteile darstellen, repräsentiert. Auch diese Reste können kaum für eine Verwertung als Nahrung und für entsorgten Hausmüll sprechen (Grafik 48).

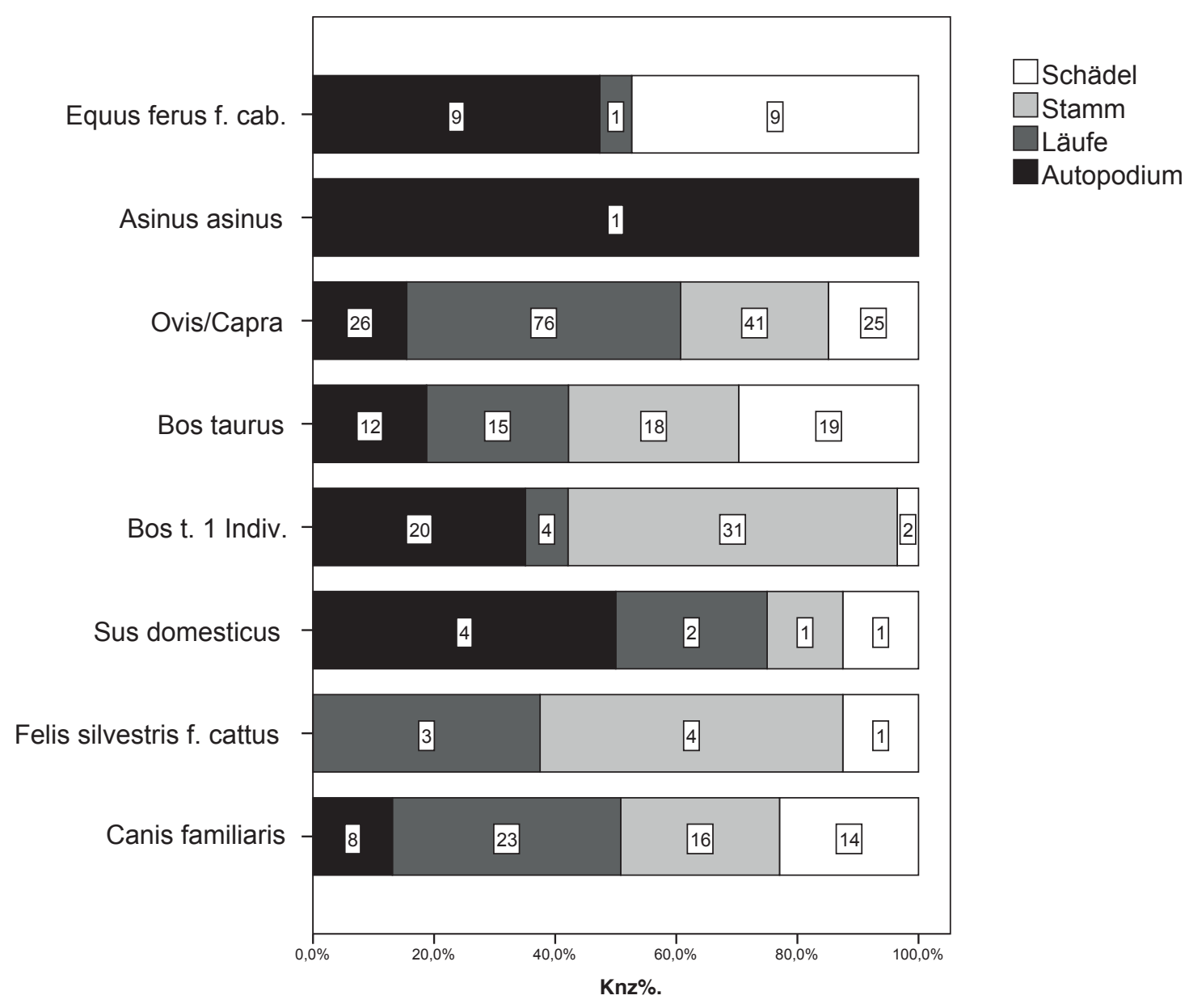

Grafik 48: Verteilung der Haustiere und der Körperpartien

An den Rinderknochen können keine artifiziellen Zerlegungsspuren nachgewiesen werden, doch zeigen sich zahlreiche Karnivorenverbissspuren an Unterkiefer, Oberarm- und Unterarmknochen, Mittelhand- und Mittelfußknochen sowie an Rippen und Fersenbein. Ähnlich verhält es sich mit Nagetierverbiss. Sie waren an Mittelhand- und Mittelfußknochen, Brustwirbel und Rippen nachweisbar. An einigen Knochen ließen sich krankhafte Veränderungen lokalisieren. Zwei Rippen zeigen ventral beziehungsweise mittig am Corpus versetzt verheilte Knochenbrüche. Zwei proximale Zehenknochen weisen leichtes, nach cranio-periphär gerichtetes lipping am oberen Gelenk auf und zwei distale Zehenknochen zeigen leichte Osteophytenbildung im kranialen Bereich des Gelenks.

Die anhand der Zahnabriebstadien rekonstruierbare Altersverteilung weist auf zwei Todeszeitpunkte bei den Rindern hin. Einerseits wurden zwei nicht- bzw. schwach abgekaute vierte Milchprämolaren gefunden, die eine Anwesenheit von Milchkälbern nahelegen (Grafik 49). Die sehr stark abgekauten Schneidezähne dagegen lassen eine Einschätzung von rund sieben- bis neunjährigen und vielleicht auch noch älteren Individuen zu (Grafik 49). Ähnlich sind auch die Abkauungsstadien der Prämolaren und Molaren zu bewerten, die auf mehrjährige bis hin zu alten Tieren hinweisen (Grafik 49). Am postkranialen Skelett sind bis auf einen Mittelhandknochen, dessen distale Epiphyse noch offen ist, sämtliche früh- und mittelschließenden 
Epiphysen bereits verwachsen. Soweit es sich beurteilen lässt, sind auch die spätschließenden Epiphysen der Langknochen und Rippen sowie die Extremitas der Wirbel verschlossen, woraus sich für die meisten der postkranialen Knochen ein höheres Sterbealter ableiten lässt.

Unter den Rinderknochen ergeben sich zwei Fundkategorien: einzelne Knochen ohne Anpassungen und Reste, die paarig sind oder entsprechende Anpassungen aufweisen. Zwei Einzelzähne, ein M1 und ein P4 aus einem Unterkiefer, stammen von einem Individuum. Andere Rinderknochen dürften, auch wenn oft keine direkten Anpassungen möglich waren, aufgrund ihrer Dimensionen und ihrer einheitlichen Erhaltung ein Individuum repräsentieren. Von dem Tier sind zwei Unterkieferfragmente, dreizehn Rippen, ein Halswirbel, acht Brustwirbel und sechs Lendenwirbel vorhanden. Dazu kommen zwei Kniescheiben und Schienbeine, ein Sprungbein, beide Fersenbeine, ein Mittelfußknochen und sechs proximale, vier mediale und zwei distale Zehenknochen, inklusive eines passenden Sesambeins. Die einzigen Verkohlungsspuren finden sich an Rinderknochen, wie z. B. an einer Speiche, rund $50 \mathrm{~mm}$ unter dem proximalen Gelenk. Auch die Elle ist kaudal ebenfalls schwarz, ein Wirbelfragment ist grau verkohlt (Tab. 113). Die beiden Unterkieferfragmente des Teilskeletts zeigen mittig am Corpus Verkohlungsspuren. Ein Halswirbel ist kleinräumig partiell kranial und kaudal über dem Wirbelkörper angekohlt, während eines der Fersenbeine proximal rötlich korrodiert oder leicht angekohlt erscheint.

Da die meisten der messbaren Knochen von diesem Individuum stammen, wird eine Größenbeurteilung der Rinder stark eingeschränkt. Das Rind war von schlankem Wuchs und lässt eine Widerristhöhe ${ }^{6}$ von rund $115 \mathrm{~cm}$ schätzen. Die beiden Messwerte anderer Individuen repräsentieren wohl geringfügig größere Rinder (Tab. 114-120).

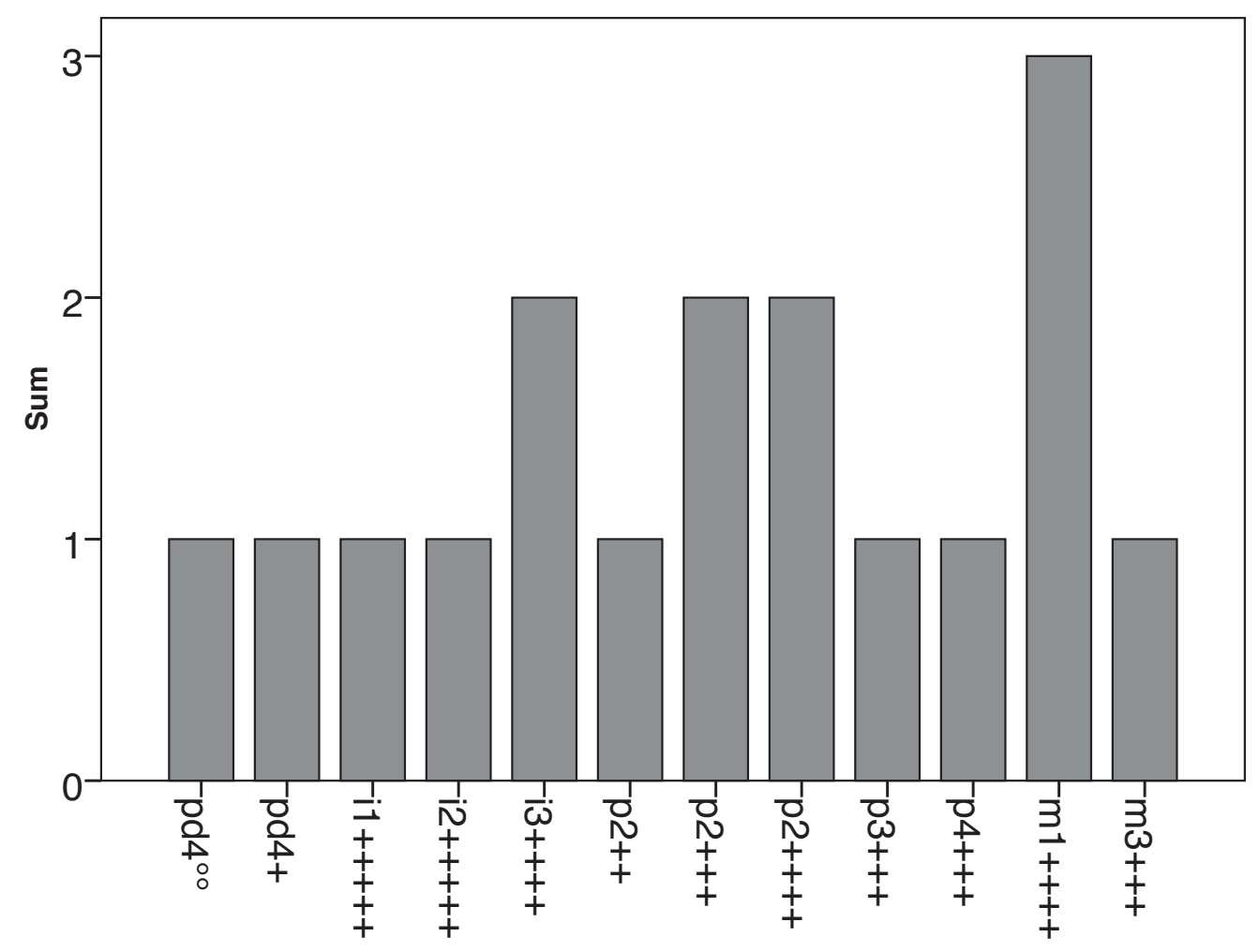

Grafik 49: Abkauungsstadien ${ }^{7}$ der Rinderzähne

${ }^{6}$ Die Berechnung anhand der Schienbeinlänge erfolgte anhand Angaben von MATOLCSI 1970, der Faktor beträgt 3,45.

${ }^{7} \mathrm{pd} 4^{\circ 0}$ - vierter Milchprämolar nicht in Reibung; pd4+ - vierter Milchprämolar schwach in Reibung; i1+++++ - erster Schneidezahn - sehr stark abgekaut; i2+++++ - zweiter Schneidezahn - sehr stark abgekaut; i3++++ - dritter Schneidezahn - stark abgekaut; p2++ - zweiter Prämolar deutlich in Reibung; p2+++ - zweiter Prämolar bis zur Hälfte abgekaut; p2++ - zweiter Prämolar stark abgekaut; p3+++ - dritter Prämolar bis zur Hälfte abgekaut; p4+++ - vierter Prämolar bis zur Hälfte abgekaut; m1++++ - erster Molar stark abgekaut; m3+++ - dritter Molar bis zur Hälfte abgekaut. 


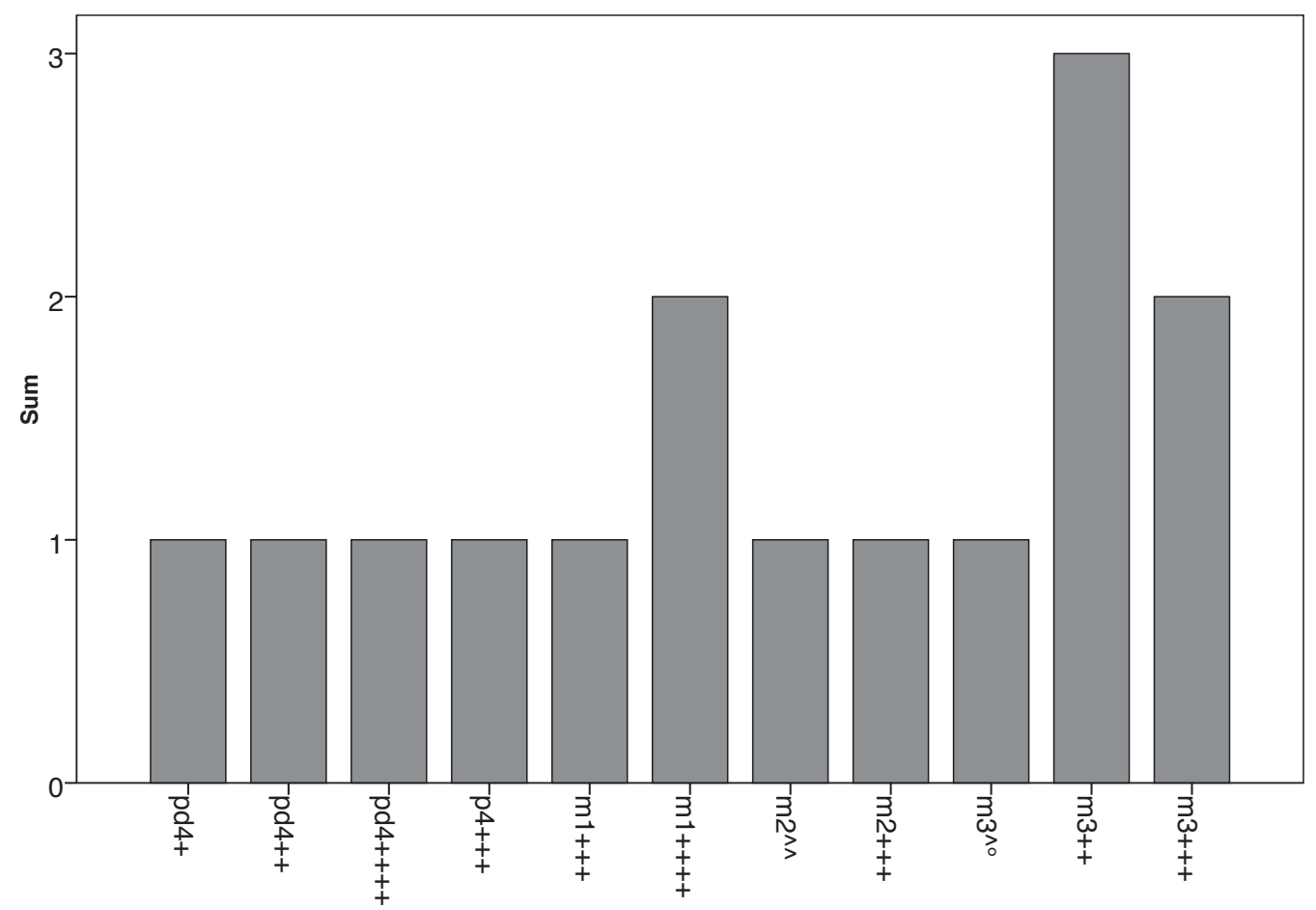

Grafik 50: Abkauungsstadien ${ }^{8}$ der Zähne kleiner Hauswiederkäuer

An einem Oberschenkelknochen eines kleinen Hauswiederkäuers findet sich eine artifizielle Modifikation in Form einer kurzen Schnittspur am Schaft, die wohl beim Entfernen des fleischigen Anteils angebracht wurde. Ein Schädelfragment ist schwarz verkohlt. Nagetierverbiss konnte dorsal an einem Halswirbel nachgewiesen werden. Die laterale Oberflächen eines Unterkiefers und eines Oberschenkelknochens distal sind massiv abgenagt worden. Im Gegensatz zu diesen wenigen Spuren konnte an insgesamt 42 Knochen kleiner Hauswiederkäuer, die aus dem ganzen Skelett stammen, Karnivorenverbiss festgestellt werden.

Die Sterbealtersverteilung der kleinen Hauswiederkäuer weist sowohl im Dental- als auch im Epiphyseschlussalter ähnliche Verteilungen auf (Grafik 49-51). Insgesamt wurden einige Milchlämmer und Milchzicklein sowie Tiere, die im Alter von bis zu einem Jahr geschlachtet worden waren, nachgewiesen. Die meisten wurden aber vor dem Erreichen des vierten Jahres getötet, obwohl in dieser Fundassoziation auch ein beträchtlicher Teil dieses Alter überlebt haben dürfte.

Unter den kleinen Hauswiederkäuern finden sich nur relativ wenige Zusammenpassungen. Zwei proximale Zehenknochen, deren proximale Epiphysen fehlten, dürften von einem Individuum stammen. Das Teilskelett stammt von einer Ziege und besteht aus beiden Oberschenkelknochen, beiden Schienbeinen, beiden Fersenbeinen und beiden Mittelfußknochen. An allen Knochen sind die Epiphysen noch nicht verwachsen.

Insgesamt würde das Verhältnis mit sieben zu vierzehn zugunsten der Ziegen ausfallen, bereinigt man aber das Teilskelett, so ergäbe sich ein Verhältnis von sieben Schafen zu fünf Ziegen. Anhand der vorhandenen Knochen kann nur relativ wenig über die Statur der Schafe und Ziegen ausgesagt werden. Anhand eines Mittelhandknochens lässt sich für ein Schaf eine Widerristhöhe ${ }^{9}$ von rund $59 \mathrm{~cm}$ schätzen. Jeweils ein Ziegen- und ein Schafsoberschenkelknochen, deren Längen vom Caput femoris aus gemessen werden konnten, dürften in einen ähnlichen Größenbereich fallen (Tab. 121-123).

Die wenigen Schweinereste lassen kaum Rückschlüsse auf deren Nutzung und Gestalt zu. Neben dem Fragment eines ersten Unterkieferschneidezahns liegen noch ein Oberarmknochen, eine Speiche, eine Rippe,

\footnotetext{
${ }^{8}$ pd4+ - vierter Milchprämolar schwach in Reibung; pd4++ - vierter Milchprämolar deutlich in Reibung; pd4++++ - vierter Milchprämolar stark in Reibung; p4+++ - vierter Prämolar bis zur Hälfte abgekaut; m1+++ - erster Molar bis zur Hälfte abgekaut; m1++++ - erster Molar stark abgekaut; $m 2^{\wedge \wedge}$ - zweiter Molar im Durchbruch; $m 2+++$ - zweiter Molar bis zur Hälfte abgekaut; $m 3^{\wedge \circ}$ - dritter Molar teilweise im Durchbruch; m3++ - dritter Molar deutlich in Reibung; m3+++ - dritter Molar bis zur Hälfte abgekaut.

${ }^{9}$ Nach Teichert 1975.
} 


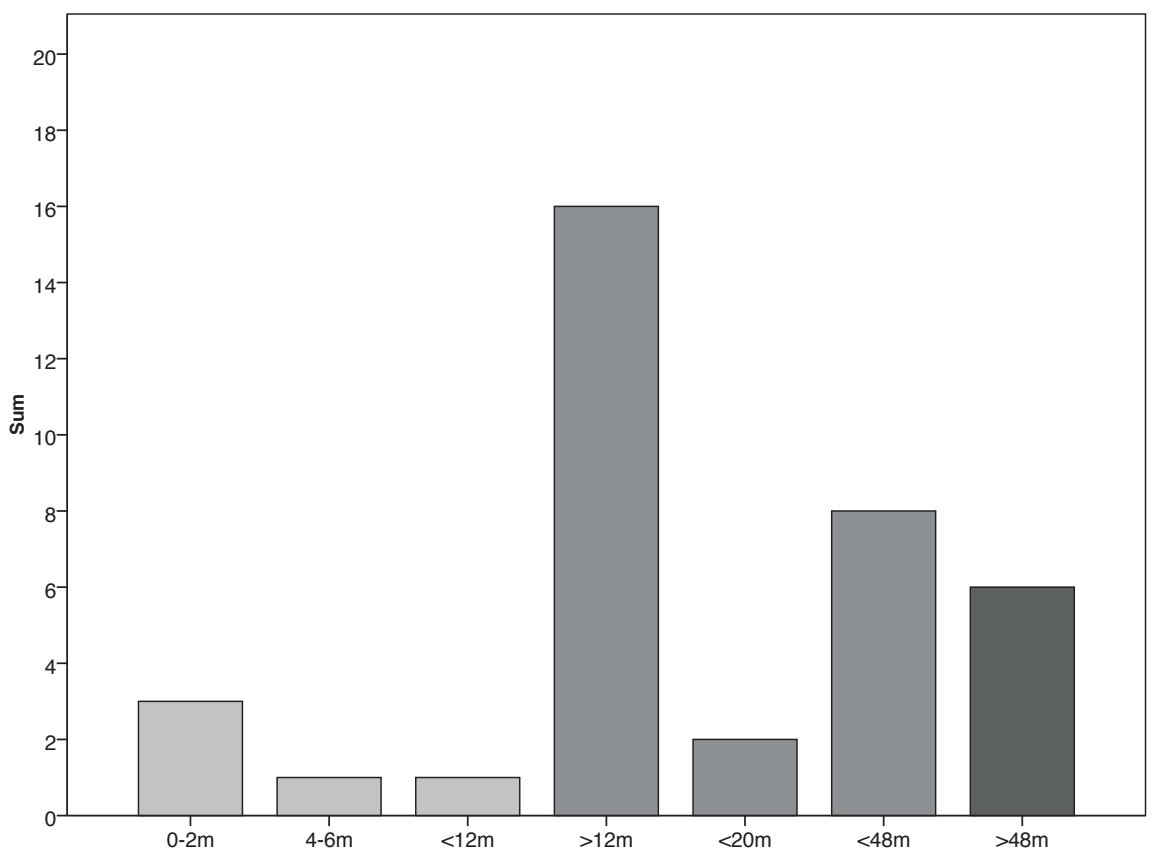

Grafik 51: Schlachtaltersverteilung kleiner Hauswiederkäuer anhand der Extremitätenknochen

ein Metapodium, eine obere und zwei mittlere Zehenknochen vor. Die proximale Epiphyse der Speiche, die Epiphysen der mittleren Zehenknochen, die des oberen Zehenknochens und des Metapodiums waren nicht verwachsen und weisen auf ein Sterbealter von unter einem bis maximal unter zwei Jahren hin. An den wenigen Schweineknochen konnten keinerlei oberflächliche Modifikationen nachgewiesen werden.

Auch an den Hundeknochen fehlen artifizielle Modifikationen, wogegen Verbissspuren an den Knochen nachweisbar waren. Ein Radius weist proximal und distal, ein Oberschenkelknochen weist distal Karnivorenverbiss auf. Ein Hundebecken hingegen ist rundum intensiv abgekaut. Ähnlich verteilt sich auch der Nagetierverbiss. Die Oberfläche eines Radius wurde komplett abgenagt. Weitere Nagerspuren finden sich am Corpus eines Brustwirbels und an einem Hundebecken.

Ein nicht geringer Anteil der Funde repräsentiert sehr junge Welpen, die auch durch erste Molaren, die sich noch im Durchbruch befanden, nachgewiesen werden können (Grafik 52. 53). Hunde, die unter einem Jahr zu Tode kamen, sind in geringer Menge vertreten. Das Verhältnis von offenen und bereits verschlossenen spätschließenden Epiphysen zeigt, dass offenbar mehr adulte als subadulte Hunde in die Wasserleitung gelangten (Grafik 52). Anhand der Abkauungsstadien wird allerdings deutlich, dass sich keine alten Individuen im Fundmaterial ansammelten (Grafik 51).

Unter den Hundeknochen wurden erstaunlicherweise keine >vertretbaren` Zusammenpassungen festgestellt, wenn auch vielleicht manche der Welpenknochen von einem Individuum stammen mögen. Insgesamt wurden nur wenige messbare Hundeknochen vorgefunden, die Aussagen über deren Morphologie zulassen. Ein komplett erhaltener Unterkiefer und ein Schädel (Taf. 422 Abb. 733-735) weisen auf eine massive Bauweise ${ }^{10}$ mit starker Dentition, dessen Breite im Verhältnis zur Länge stärker betont erscheint (Tab. 124. 125). Die wenigen Langknochen belegen zumindest zwei Hundetypen (Tab. 126). Ein Oberschenkelknochen, dessen Epiphysen verschlossen sind, ergibt eine Widerristhöhe ${ }^{11}$ von 30 Zentimeter und entspräche der Wüchsigkeit eines Schoßhündchens. Ein Oberschenkelknochen ohne Epiphysen deutet dagegen auf ein größeres Tier hin, da die Diaphyse auch ohne Epiphysen länger ist als die des Schoßhündchens. Eine wei-

\footnotetext{
${ }^{10}$ Der Schädel weist durchaus Ähnlichkeiten mit dem Fund aus dem Brunnen im Hamam III in Ayasuluk/Ephesos auf, s. GALIK u. a. 2010b, 85 .

${ }^{11}$ Berechnungen nach KoudeLKa 1885.
} 


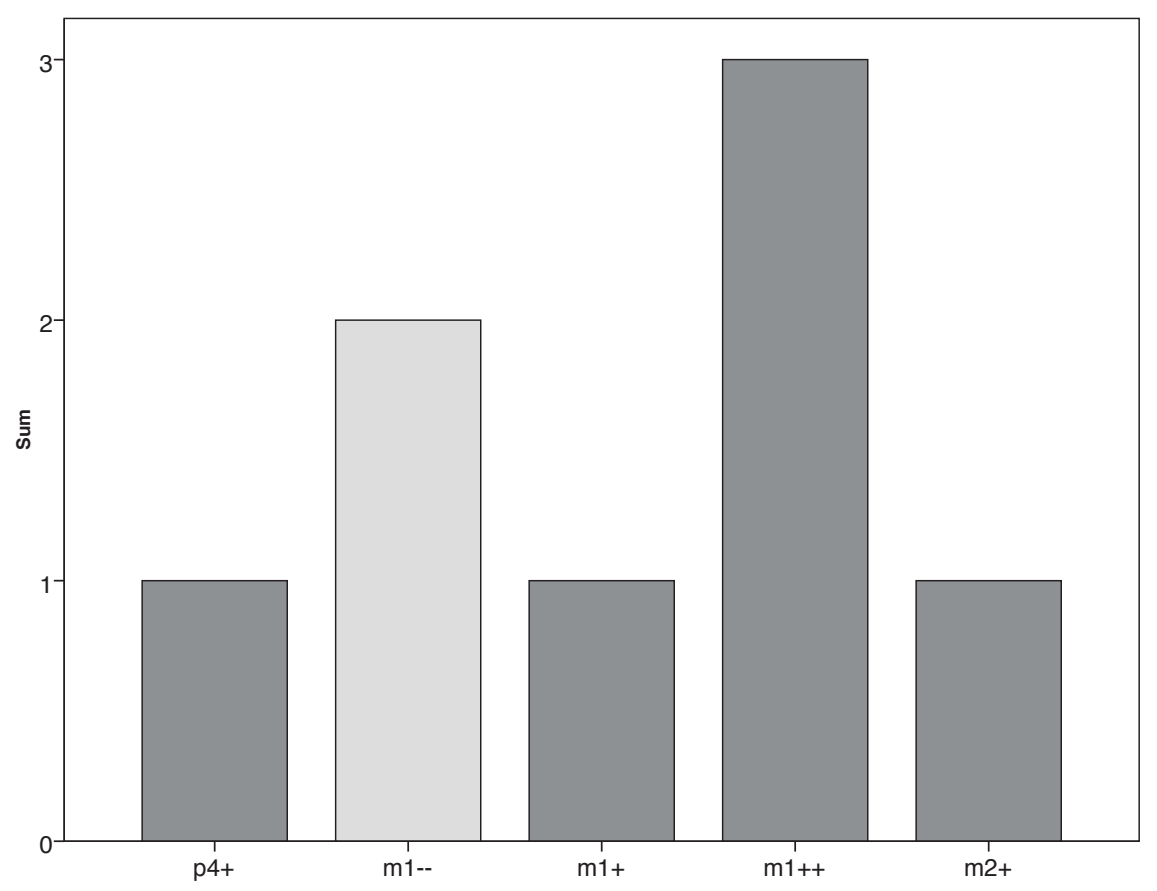

Grafik 52: Abkauungsstadien der Hundezähne

tere, an einem Radius berechnete Widerristhöhe ergibt $38 \mathrm{~cm}$ und damit einen etwas größeren, aber immer noch als relativ kleinwüchsig zu bezeichnenden Hund. Pathologische Veränderungen finden sich als Spuren von entzündetem Zahnfleisch am Unterkiefer auf Höhe des P4/M1 und der P2, der Eckzahn des Unterkiefers ist komplett verschliffen. Ein Oberschenkelknochen zeigt proximal am Schaft Spuren eines Osteosarcoms, wobei in diesem Bereich die Kompakta bereits komplett reduziert ist. Ein Metatarsus 4 ist kranial stark erweitert und zeigt eine beginnende Bildung einer Knochenbrücke zum Metatarsus 5. Ein weiterer Metatarsus weist eine leichte Verdickung des Schafts auf, ohne dass ein Knochenbruch offensichtlich ist.

Die Hauskatze ist anhand weniger Reste im Fundmaterial nachzuweisen. Es handelt sich um einen Unterkiefer, zwei Oberarmknochen, eine Speiche und mehrere Wirbel. Die distalen Epiphysen der Langknochen sind verwachsen und der Unterkiefer weist bereits das Dauergebiss auf. Die Extremitas des Brust- und des Halswirbels sind verwachsen, bei einem weiteren Halswirbel ist sie offen. Unter den wenigen Katzenresten konnten weder Pathologien noch Zusammenpassungen beobachtet werden, nur der Oberarmknochen trägt Karnivorenverbissspuren.

Typisches Jagdwild ${ }^{12}$ wird nur durch Hasen und einen einzelnen Wildschweinknochen belegt. Die Ansammlung in der Wasserleitung repräsentiert, neben einigen Fuchsresten und einem knorrigen Oberarmknochen eines Dachses, zahlreiche Reste von Goldschakal (Taf. 422 Abb. 736. 737) und Stachelschwein (Taf. 423 Abb. 738-743). Überraschenderweise konnte in der Wasserleitung für Ephesos erstmals die Hyäne nachgewiesen werden. Sämtliche Reste sind Milchzähne, ein Id3sup, ein Pd3sup (Taf. 423 Abb. 744) und beide Pd4inf, und dürften alle von einem Individuum stammen, welches aber noch vor dem Zahnwechsel zu Tode kam. Postkraniale Knochen sind offenbar nicht geborgen worden.

Die häufigeren Wildtierarten sind durch Knochen aus sämtlichen Körperbereichen vertreten; an vielen der Knochen konnte Karnivoren- und Nagetierverbiss nachgewiesen werden. Beim Goldschakal ist ein Unterkiefer und ein Schienbein verbissen, ebenso auch der einzige Wildschweinknochen (ein Beckenknochen). Während beim Fuchs mehr verbissene Reste auffallen, so finden sich unter den Stachelschweinknochen mehr Reste mit Nagetierverbiss. Andere Modifikationen sind an den Wildtierknochen nicht nachweisbar.

\footnotetext{
${ }^{12} \mathrm{Zu}$ jagdbarem Wild aus anderen Fundorten in Ephesos, s. ForstenPOINTNER u. a. 1993; ForstenPOINTNER u. a. 2002: ForSTENPOINTNER u. a. 2008; ForstenPoInTNER u. a. 2010; GALIK u. a. 2010a; GAliK u. a. 2010 b.
} 


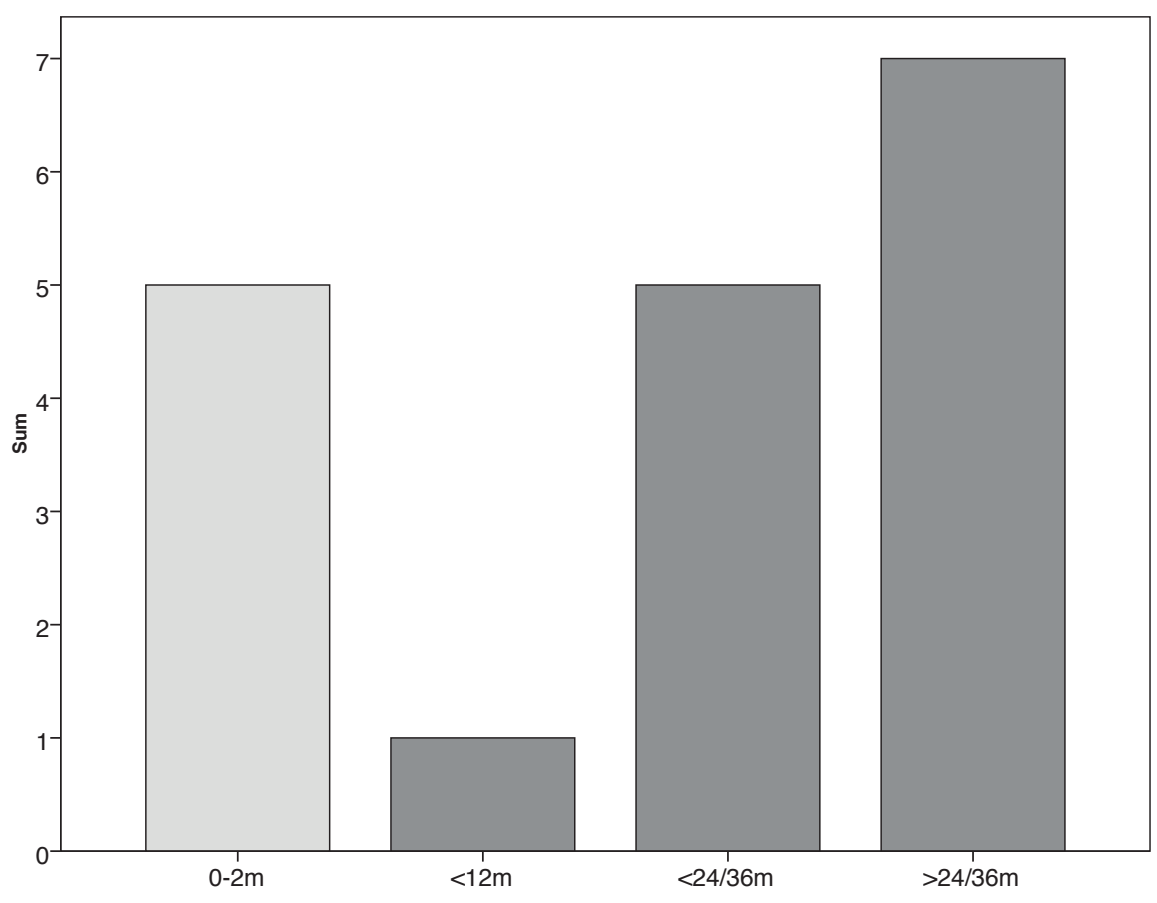

Grafik 53: Altersverteilung der Hundeknochen anhand des Epiphysenschlusses

Während die Knochen der Goldschakale von adulten Tieren stammen (Taf. 422 Abb. 736. 737), finden sich unter den Stachelschweinknochen einige sehr junge Individuen (Taf. 423 Abb. 740. 741), die wahrscheinlich maximal wenige Wochen alt waren. Daneben können auch Reste von juvenilen, aber auch adulten Stachelschwein-Individuen festgestellt werden (Taf. 423 Abb. 739. 742. 743). Die Reste vom Fuchs weisen hauptsächlich auf adulte Individuen hin. Ein Brustwirbel hat eine unverwachsene Extremitas, daneben finden sich ein Schienbein mit offener proximaler Epiphyse und ein Humerus mit sichtbarer Sutur an der proximalen Epiphyse.

Zusammenpassende Knochen beim Goldschakal sind ein Becken und ein Kreuzbein; ein Schädelfragment könnte mit den ersten fünf Halswirbeln korrespondieren. Unter den Stachelschweinresten passen ein Oberarmknochen gut mit einer Speiche und eine weitere Speiche mit einer Elle zusammen. Die Epiphysen dieser Knochen sind noch nicht verwachsen. Ein Schulterblatt, ein Oberarmknochen und eine Elle sind von ihren Dimensionen her sehr ähnlich und könnten vom gleichen, sehr jungen Individuum stammen. Daneben ließ sich ein Kreuzbein mit Lenden- und Schwanzwirbeln zusammenpassen (Taf. 423 Abb. 743). Vom Fuchs konnten zwei Lendenwirbel und zwei Brustwirbel zusammengepasst werden, außerdem wurde eine passende Speiche und Elle gefunden.

Die Wasserleitungsverfüllung enthielt auch einige anpassende Reste von griechischen Landschildkröten bzw. nicht genauer bestimmbare Schildkrötenknochen in verschiedenen Altersstadien. An den Knochen sind zwar keine Schnitt- oder Verbissspuren nachweisbar, doch konnten etliche kleinteilige Zusammenpassungen vornehmlich vom Rand des Panzers getätigt werden.

Hühner stellen die Hauptmasse der Vogelfunde dar. Die anderen Geflügelarten sind nur in geringem Ausmaß nachweisbar. Dies gilt für die Hausgans und die Taube sowie für Wildvögel, wie z. B. das Rotfußhuhn oder ein Raubvogel in Sperber- bzw. Habichtgröße.

Modifikationen wurden nur an Hühnerknochen festgestellt. Eine Schnittspur befand sich an einem Tarsometatarsus, eine Nagerspur an einem Tibiotarsus und ein Oberschenkelknochen ist von einem Raubtier angebissen worden.

Die in Ephesos sonst so häufig anzutreffenden Mollusken nehmen in diesem Befund eine untergeordnete Stellung ein. Nachweisbar sind wenige essbare Herzmuscheln, wenige Purpurschnecken und hauptsächlich Austern. 


\subsection{DISKUSSION}

Das ungewöhnliche Erhaltungsmuster und die ebenso ungewöhnliche Faunenzusammensetzung der archäozoologischen Funde aus der Wasserleitung verlangt nach differenzierten Interpretationen, um Erklärungen für diese Taphozönose zu finden. Artifizielle oberflächliche Modifikationen, die im Zusammenhang mit Schlachtung, Zerlegung oder Konsum entstanden sind, weisen nur sehr wenige Tierknochen auf (Tab. 113). Bemerkenswerterweise konnten an den Knochen keinerlei Hackspuren nachgewiesen werden, die beim Zerteilen der Kadaver mit schweren Messern oder Beilen entstehen ${ }^{13}$. In Fundkontexten mit besonderen Lagerungsumständen, wie in der Aristion-Leitung, finden sich häufig zusammenpassende und anpassende Tierknochen ${ }^{14}$. Dies ist mit Sicherheit auf die geschützte bauliche Situation zurückzuführen, wie dies auch aus den Knochenfunden aus den Kanalverfüllungen des Vediusgymnasiums ${ }^{15}$ mit ihren zahlreichen Raubtier- und Nagetierverbissspuren hervorgeht (Tab. 113). Nachweise dieser Aktivitäten sind jedenfalls häufiger als artifizielle Spuren menschlicher Einflussnahme an den Knochen, wodurch Aussagen zur Subsistenz eingeschränkt werden. Die Ernährung der Bewohner im Bereich der Wasserleitung dürfte im 6. Jh. n. Chr. hauptsächlich auf Wirtschaft mit kleinen Hauswiederkäuern, Rindern und Hausgeflügel basiert haben. Mollusken, wie Purpurschnecken und Austern, kamen sicherlich auch im 6. Jh. n. Chr. ergänzend auf den Speiseplan der Bewohner. Auffällig ist im Vergleich zu den spätantiken Funden aus dem Vediusgymnasi$u^{16}{ }^{16}$, dass in der Wasserleitungsverfüllung zwar kleine Hauswiederkäuer, Rinder und Hausgeflügel, aber kaum Hausschweine nachweisbar sind. Eventuell lässt sich hier ein anderer sozialer Hintergrund der konsumierenden Bewohner festmachen.

Erschwert wird die Interpretation auch durch die Zusammensetzung der nachgewiesenen Wildtiere. Für den Raum Ephesos sind erstmalig aus einem archäologischen Kontext Streifenhyäne ${ }^{17}$, Goldschakal und Stachelschwein nachzuweisen. Aus Ephesos sind bereits Löwen ${ }^{18}$ und Leoparden ${ }^{19}$ bekannt, Faunenelemente $^{20}$, die auch in Fundstellen in der weiteren Umgebung gefunden wurden ${ }^{21}$. Löwen und Leoparden, die zumeist gemeinsam mit Damwild in Wildtierassoziationen archäologischer Fundstellen auftreten, können durchaus als prestigeträchtige Jagdbeute gedeutet werden. Der Goldschakal ist, wie auch das Stachelschwein $^{22}$, eine Wildtierart, die offenbar in archäologischen Kontexten nur eine sehr unbedeutende Rolle spielt bzw. noch gar nicht nachgewiesen wurde.

Diese Tiere könnten Öffnungen in der Wasserleitung als Eingänge und die entsprechenden Hohlräume als Unterschlupf nutzen und damit auch für eine sekundäre Einbringung von Kadavern bzw. Knochenmaterial verantwortlich sein. Da vom Stachelschwein verschiedene Alterstadien, vom infantilen über juvenile bis hin zu geschlechtsreifen Tieren, in der Wasserleitung gefunden wurden, ist es gut vorstellbar, dass im aufgelassenen Kanal eine \Stachelschweinfamilieく lebte. Nagespuren weisen allerdings darauf hin, dass sie offenbar auch nicht vor den Knochen der Artgenossen halt machten, da sie diese ebenfalls abnagten. Am wahrscheinlichsten erscheint wohl eine abwechselnde Nutzung dieser Unterschlupfe von Goldschakal,

${ }^{13} \mathrm{Zu}$ Tierkörperzerlegungen aus hellenistischen und byzantinischen Befunden im Bereich des Lukasgrabs s. GALIK u. a. $2010 \mathrm{a}, 376 \mathrm{f}$.

${ }^{14}$ Auch in den Kanalverfüllungen im Vediusgymnasium konnten ähnliche, wenn auch nicht so große Teilbereiche von Individuen zusammengepasst werden, s. ForstenPOINTNER u. a. 2008, $232 \mathrm{f}$.

${ }^{15}$ FORSTENPOINTNER u. a. 2008, 233.

${ }^{16}$ ForstenPOINTNER u. a. 2008, 219 f.; $233 \mathrm{f}$.

${ }^{17}$ Nachweise für Streifenhyänen liegen aus Troia (Uerpmann 2006, 294) und Lidar Höyük (Kussinger 1988, 176 f.) vor.

${ }^{18} \mathrm{Im}$ Artemision von Ephesos gelangen Nachweise für Löwen, die im Zusammenhang mit dem Artemiskult standen, s. FoRSTENPOINTNER 1998.

${ }^{19}$ Aus frühbronzezeitlichen Schichten des Çukuriçi Höyük konnten Nachweise für Leopardenjagd gefunden werden, s. GALIK (in Vorbereitung).

${ }^{20} \mathrm{Zu}$ rezenten Untersuchungen zu Löwe, Leoparden und Hyänen in Anatolien, s. ÖZKURT 1998; ÇAN - LisE 2006; KASPAREK 1986; KaspareK u. a. 2004; Kumerloeve 1975.

${ }^{21}$ Löwenfunde liegen beispielsweise aus verschiedenen Orten vor: 1. Troia: Gündem 2010, 77. 149; UerpmanN 2006, $294 ; 2$. Kirklareli: Benecke 1998, 175; 3. Lidar Höyük: Kussinger 1988, 176 f.; 4. Arslantepe: Bartosiewitz 1998, 223 vor. Leoparden konnten ebenfalls in Troia (UerPMANN 2006, 194) und in Lidar Höyük (Kussinger 1988, 176 f.) nachgewiesen werden.

${ }^{22}$ Zwar wurden keine Stachelschweinfunde in den erwähnten Fundorten gemacht, doch fanden sich in den nördlich gelegene Orten Nachweise für ein anderes großes Nagetier, den Biber: 1. Lidar Höyük: Kussinger 1988, 181; 2. Troia: Uerpmann 2006, 293 ; 3. Kirklareli: BenECKe 1998, 175. Aus Hallan Çemi sind sowohl Leopard als auch Stachelschwein und Biber bekannt: STARKOVICH u. a. $2009,209$. 
Fuchs, Stachelschwein, Hyänen und auch Schildkröten. Das Teilskelett des Rinds könnte diese Theorie untermauern, wenn es als Kadaverteil, etwa von Hyänen, in die Wasserleitung gezerrt worden wäre. Jedoch finden sich an einigen Rinderknochen Verkohlungsspuren (Tab. 113), die menschliche Interaktionen mit dem Kadaver nahelegen, bevor dieser in die Wasserleitung gelangte. Somit erscheint ein Zusammenwirken von menschlichem und tierischem Verhalten gegeben, das wiederum auf eine Gleichzeitigkeit der Handlungen schließen lässt.

Der sedimentäre Aufbau des Verschlusses in der Wasserleitung lässt wahrscheinlich einen weiteren taphonomischen Faktor erkennen. Trotz des Verschlusses könnte auch weiterhin Wasser in der Wasserleitung geflossen sein. Bei höherem Wasserdurchfluss wird sich das Wasser jedoch dort aufgestaut haben, wodurch es zu einer erhöhten Feinsedimentablagerung im oberen Bereich des Sedimentkeils kam. Andererseits können durch die Wasserkraft auch Fundmaterial und Knochen transportiert werden, die sich als gröbere Anteile an der Basis des Sedimentkeils ablagern.

Insgesamt entsteht der Eindruck, dass mehrere Prozesse bei der Entstehung der Faunenassoziation beteiligt waren. Ein Teil des tierischen Fundmaterials steht sicherlich mit der Abfallentsorgung des 6. Jhs. n. Chr. in Zusammenhang und lässt offenbar auf einen anderen Ernährungsschwerpunkt als im Bereich des Vediusgymnasiums schließen. Die Tierreste, die im Zusammenhang mit >natürlicher`Akkumulation von Tieren in die Wasserleitung eingebracht wurden, sind dagegen nicht so einfach datierbar. Zwar wurden sie offenbar gleichzeitig mit menschlicher Tätigkeit eingebracht, doch waren weder die Wasserleitung noch das Theater in Betrieb. Nichtsdestotrotz sind die Nachweise der Streifenhyäne, des Stachelschweins und des Goldschakals nicht nur von zoologischem Interesse. Sie erweitern das zu erwartende Faunenspektrum im Bereich von Ephesos nicht nur für die Spätantike, sondern auch für die früheren Besiedlungsperioden in Ephesos.

Tabellen Fundverteilung:

\begin{tabular}{|c|c|c|c|c|c|c|c|c|c|c|c|c|c|c|c|c|c|c|c|c|c|}
\hline & 1-Bt & Bt & OC & Ch & Oa & Sd & Ec & Asas & $\mathrm{Fc}$ & $\mathbf{C f}$ & Canid & Caur & Ss & Lesp & Meme & Vuvu & Hyhy & Hycr & Nager & GKM & Total \\
\hline Calva & & & & & 1 & & & & & 2 & & & & & & & & & & 3 & 6 \\
\hline $\begin{array}{l}\text { cran. } \\
\text { Fragm. }\end{array}$ & & 1 & 5 & 1 & & & & & & 4 & & 2 & & 1 & & 2 & & 5 & 1 & & 22 \\
\hline $\begin{array}{l}\text { dens } \\
\text { sup. }\end{array}$ & & 9 & 6 & & & 1 & 1 & 1 & & 1 & & & & & & 2 & 3 & 1 & & & 24 \\
\hline Hyalia & & 1 & & & & & & & & & & & & & & & & & & & 1 \\
\hline $\begin{array}{l}\text { Mandi- } \\
\text { bula }\end{array}$ & 2 & 1 & 9 & & & & 2 & & 1 & 4 & & 2 & & 1 & & & & 1 & & & 23 \\
\hline dens inf. & & 7 & 3 & & & 1 & 5 & & & 3 & & & & & & 1 & 2 & & & & 22 \\
\hline Scapula & & & 2 & & & & & & & 1 & & 2 & & & & 2 & & 4 & & & 11 \\
\hline $\begin{array}{l}\text { Hume- } \\
\text { rus }\end{array}$ & & 6 & 12 & & 1 & 1 & 1 & & 2 & 2 & & & & 1 & 1 & 5 & & 6 & & & 38 \\
\hline $\begin{array}{l}\text { Antebra- } \\
\text { chium }\end{array}$ & & 2 & & & & & & & & & & & & & & & & & & & 2 \\
\hline Radius & & & 8 & & & 1 & & & 1 & 5 & 2 & & & 1 & & 3 & & 2 & & & 23 \\
\hline Ulna & & 1 & 4 & & & & & & & 2 & & & & & & 3 & & 3 & & & 13 \\
\hline Carpus & & & & & & & 2 & & & & & & & & & & & & & & 2 \\
\hline $\begin{array}{l}\text { Metacar- } \\
\text { pus }\end{array}$ & & 4 & 5 & & 1 & & & & & 1 & & & & & & & & & & & 11 \\
\hline Vertebra & & 1 & 1 & & & & & & & & & & & & & & & & & & 2 \\
\hline
\end{tabular}




\begin{tabular}{|c|c|c|c|c|c|c|c|c|c|c|c|c|c|c|c|c|c|c|c|c|c|}
\hline & 1-Bt & Bt & OC & Ch & Oa & Sd & Ec & Asas & $\mathbf{F c}$ & $\mathbf{C f}$ & Canid & Caur & Ss & Lesp & Meme & Vuvu & Hyhy & Hycr & Nager & GKM & Total \\
\hline $\begin{array}{l}\text { Vert. } \\
\text { cerv. }\end{array}$ & 4 & & 15 & & 2 & & & & 2 & 4 & & 5 & & & & 2 & & 9 & & & 43 \\
\hline $\begin{array}{l}\text { Vert. } \\
\text { thor. }\end{array}$ & 8 & 1 & 3 & & & & & & 2 & 3 & & 1 & & 2 & & 9 & & 10 & & & 39 \\
\hline $\begin{array}{l}\text { Vert. } \\
\text { lumb. }\end{array}$ & 6 & 1 & 1 & & & & & & & 2 & & & & 4 & & 2 & & 4 & & & 20 \\
\hline $\begin{array}{l}\text { Vert. } \\
\text { caud. }\end{array}$ & & 8 & & & & & & & & & & & & & & & & 6 & & & 14 \\
\hline Sternum & & & & & & & & & & 1 & & & & & & & & & & & 1 \\
\hline Costa & 13 & & 20 & & & 1 & & & & 4 & & 5 & & & & 10 & & 20 & & 1 & 74 \\
\hline $\begin{array}{l}\text { Costa } \\
\text { cartil. }\end{array}$ & & 7 & & & & & & & & & & & & & & & & & & & 7 \\
\hline Coxa & & & 7 & & & & & & & 3 & & 2 & 1 & & & & & 3 & 1 & & 16 \\
\hline $\begin{array}{l}\text { Os } \\
\text { sacrum }\end{array}$ & & & & & & & & & & 2 & & 1 & & & & & & 4 & & & 7 \\
\hline Femur & & 2 & 17 & 4 & 1 & & & & & 6 & & 1 & & 1 & & 3 & & 7 & & & 42 \\
\hline Patella & 2 & & & & & & & & & 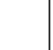 & & & & & & & & & & & 2 \\
\hline Tibia & 2 & 3 & 17 & 2 & & & & & & 4 & & 1 & & 2 & & 5 & & 8 & & & 44 \\
\hline Fibula & & 1 & & & & & & & & . & & & & & & 1 & & 2 & & & 4 \\
\hline Talus & 1 & & 1 & 2 & & & 1 & & & 1 & & & & & & & & & & & 6 \\
\hline $\begin{array}{l}\text { Calca- } \\
\text { neus }\end{array}$ & 2 & & 2 & 2 & 1 & & 1 & & & 2 & & & & & & & & & & & 10 \\
\hline Tarsus & 1 & & 1 & 1 & & & 1 & & & & & & & & & & & 1 & & & 5 \\
\hline $\begin{array}{l}\text { Meta- } \\
\text { tarsus }\end{array}$ & 2 & 3 & 6 & 2 & & & 4 & & & 4 & & & & & & 1 & & 1 & & & 23 \\
\hline $\begin{array}{l}\text { Meta- } \\
\text { podium }\end{array}$ & & 2 & 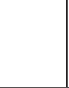 & & & 1 & 1 & & & & & & & & & & & & & & 4 \\
\hline $\begin{array}{l}\text { Phalanx } \\
\text { prox. }\end{array}$ & 6 & & 2 & & & 1 & & & & & & & & & & & & & & & 9 \\
\hline $\begin{array}{l}\text { Phalanx } \\
\text { med. }\end{array}$ & 4 & 2 & . & & & 2 & & & & & & & & & & & & & & & 8 \\
\hline $\begin{array}{l}\text { Phalanx } \\
\text { dist. }\end{array}$ & 2 & & & & & & & & & & & & & & & & & & & & 2 \\
\hline $\begin{array}{l}\text { Os } \\
\text { sesamo- } \\
\text { ideum }\end{array}$ & 2 & 1 & & & & & & & & & & & & & & & & & & & 3 \\
\hline Total & 57 & 64 & 147 & 14 & 7 & 8 & 19 & 1 & 8 & 61 & 2 & 22 & 1 & 13 & 1 & 51 & 5 & 97 & 1 & 4 & 583 \\
\hline
\end{tabular}

Tab. 111: Verteilung der Säugetiere ${ }^{23}$

${ }^{23}$ 1-Bt - Bos taurus, Hausrind ein Individuum, Bt - Bos taurus, Hausrind, OC - Ovis/Carpa, kleine Hauswiederkäuer, Ch - Capra hircus, Ziege, Oa - Ovis aries, Schaf, Sd - Sus domesticus, Hausschwein, Ec - Equus ferus $f$. cab., Pferd, Asas - Asinus asinus $f$. d., Esel, Fc - Felis silvestris f. cattus, Hauskatze, Cf - Canis familiaris, Hund, Caur - Canis aureus, Goldschakal, Ss - Sus scrofa, Wildschwein, Lesp - Lepus sp., Hase, Meme-Meles meles, Dachs, Vuvu - Vulpes vulpes, Fuchs, Hyhy - Hyaena hyaena, Hyäne, Hycr - Hystrix cristata, Nager - Nagetier, GKM - Größenklasse mittel. 


\begin{tabular}{|c|c|c|c|c|c|c|c|c|c|c|c|c|c|}
\hline & Tehe & testud & Accipit & AG & Alect & AM & Anan & Columb & Gado & Ceed & Hetr & Osed & Total \\
\hline cran. Fragm. & & & & & & & & & 1 & & & & 1 \\
\hline \multicolumn{14}{|l|}{ Mandibula } \\
\hline Scapula & & 1 & & & & & & & & & & & 0 \\
\hline Clavicula & & & & & & & & & 1 & & & & 1 \\
\hline Coracoid & & & & & & & & & 3 & & & & 3 \\
\hline Humerus & & 1 & & & 1 & & 1 & & 7 & & & & 9 \\
\hline Radius & & & & & & & & & 1 & & & & 1 \\
\hline Ulna & & & 1 & & 1 & & 1 & 1 & 1 & & & & 5 \\
\hline Carpometacarpus & & & & & & & & & 1 & & & & 1 \\
\hline Vert. cerv. & & & & & & & 1 & & 1 & & & & 2 \\
\hline Vert. thor. & & & & & & & & & 1 & & & & 1 \\
\hline Sternum & & & & & & & & & 2 & & & & 2 \\
\hline \multicolumn{14}{|l|}{ Costa } \\
\hline Coxa & & 2 & & & & & & & 1 & & & & 1 \\
\hline Femur & & 2 & & 1 & 1 & & 1 & & 12 & & & & 15 \\
\hline Tibiotarsus & & & 1 & & & 1 & & & 7 & & & & 9 \\
\hline Tarsometatarsus & & & 1 & 1 & 1 & & & & 3 & & & & 6 \\
\hline Gehäuse & & & & & & & & & & & 3 & & 3 \\
\hline Klappe & & & & & & & & & & 2 & & 10 & 12 \\
\hline Hypurale & 10 & & & & & & & & & & & & 0 \\
\hline Pleurale & 9 & & & & & & & & & & & & 0 \\
\hline Total & 19 & 6 & 3 & 2 & 4 & 1 & 4 & 1 & 42 & 2 & 3 & 10 & 97 \\
\hline
\end{tabular}

Tab. 112: Verteilung von Schildkröten, Geflügel und Mollusken ${ }^{24}$

\begin{tabular}{|c|c|c|c|c|c|c|}
\hline & Verbiss & Nager & Schnitte & Angekohl & Schwarz & Grau \\
\hline Bos primigenius f. taur. & 12 & 11 & & 5 & & 1 \\
\hline Ovis/Capra & 40 & 2 & 1 & & 1 & \\
\hline Ovis aries & 1 & 1 & & & & \\
\hline Capra hircus & 1 & & & & & \\
\hline Equus ferus f. cab. & 2 & & & & & \\
\hline Canis 1. f. fam. & 4 & 3 & & & & \\
\hline Felis silvestris f. cattus & 1 & & & & & \\
\hline Sus scrofa & 1 & & & & & \\
\hline Canis aureus & 2 & & & & & \\
\hline Vulpes vulpes & 9 & 4 & & & & \\
\hline Hystrix cristata & 3 & 5 & & & & \\
\hline Total & 76 & 26 & 1 & 5 & 1 & 1 \\
\hline
\end{tabular}

Tab. 113: Verteilung der oberflächlichen Modifikationen an den Tierknochen

${ }^{24}$ Tehe - Testudo hermanni, griechische Landschildkröte, testud - Testudinata, Schildkröten, Accipit - Accipiteridae, Sperber/ Habicht, AG - Aves Größenklasse groß, Alect - Alectoris sp., Rotfußhuhn, AM - Aves Größenklasse mittel, Anan - Anser anser f. dom., Hausgans, Columb - Columba sp., Taube, Gado-Gallus gallus f. d., Haushuhn, Ceed - Cerastoderma edulis, essbare Herzmuschel, Hetr - Hexaplex trunculus, Purpurschnecke, Osed - Ostrea edulis, Auster. 
Maßtabellen:

\begin{tabular}{|l|l|}
\hline & $\mathbf{m 3 + + +}$ \\
\hline GLM3 & 35,9 \\
\hline GBM3 & 15,9 \\
\hline
\end{tabular}

Tab. 114: Messwerte an M3inf vom rekonstruierten Rinderindividuum (1-Bt)

\begin{tabular}{|l|l|}
\hline Metacarpus & \\
\hline $\mathrm{Bp}$ & 44,8 \\
\hline $\mathrm{Tp}$ & 28,8 \\
\hline
\end{tabular}

Tab. 115: Messwerte am Metacarpus eines Rinds

\begin{tabular}{|l|l|l|}
\hline GL & 335 & 335 \\
\hline $\mathrm{Bp}$ & 89 & \\
\hline $\mathrm{Bd}$ & 58,4 & 58,2 \\
\hline $\mathrm{Td}$ & 43,9 & 44 \\
\hline
\end{tabular}

Tab. 116: Messwerte an einem Tibien-Paar des rekonstruierten Rinderindividuums (1-Bt)

\begin{tabular}{|l|l|}
\hline GL & 125,5 \\
\hline GB & 39,4 \\
\hline
\end{tabular}

Tab. 117: Messwerte am Calcaneus vom rekonstruierten Rinderindividuum (1-Bt)

\begin{tabular}{|l|l|l|l|l|l|}
\hline & P.prox.ant. & P.prox.ant. & P.prox.ant. & P.prox.ant. & P.prox.post. \\
\hline GLpe & 54,4 & 54,5 & 54,6 & 54,2 & 57,1 \\
\hline Bp & 27,9 & 28,4 & 28 & 27,8 & 25,9 \\
\hline Tp & 30,7 & 31,9 & 31,5 & 30,4 & 31,2 \\
\hline KD & 25,7 & 25,2 & 24,1 & 24 & 22,2 \\
\hline Bd & 25 & 25,1 & 26,5 & 24,7 & 24,5 \\
\hline
\end{tabular}

Tab. 118: Messwerte an proximalen Phalangen vom rekonstruierten Rinderindividuum (1-Bt)

\begin{tabular}{|l|l|l|l|l|l|}
\hline & P.med.ant. & P.med.ant. & P.med.ant. & P.med.post. & P.med.ant. \\
\hline GL & 36,4 & 36,9 & 37 & 35,7 & 44,3 \\
\hline Bp & 25,8 & 26,1 & 25,6 & 26,8 & 30,9 \\
\hline Tp & 31,3 & 30,4 & 30,8 & 31,4 & 34 \\
\hline KD & 20 & 21,6 & 20,5 & 22 & 26,7 \\
\hline Bd & 20,5 & 22,4 & 20 & 22,6 & 25,4 \\
\hline
\end{tabular}

Tab. 119: Messwerte an M3inf vom rekonstruierten Rinderindividuum (1-Bt), die Messwerte der letzten Reihe stammen von einem anderen Rind 


\begin{tabular}{|l|l|}
\hline & P.dist.post. \\
\hline DLS & 71,3 \\
\hline Ld & 52,5 \\
\hline MBS & 17,8 \\
\hline
\end{tabular}

Tab. 120: Messwerte an der distalen Phalanx vom rekonstruierten Rinderindividuum

\begin{tabular}{|l|l|l|}
\hline Länge der Backenzahnreihe (Alveolenmaß) & 71,8 & \\
\hline Länge der Prämolarenreihe (Alveolenmaß) & 34 & \\
\hline Länge der Molarenreihe (Alveolenmaß) & 47,6 & \\
\hline GLM3 & 23 & 23,7 \\
\hline GBM3 & 9,3 & 8,6 \\
\hline
\end{tabular}

Tab. 121: Messwerte an Unterkiefern von kleinen Hauswiederkäuern

\begin{tabular}{|l|l|}
\hline GL & 120,4 \\
\hline Bp & 24,3 \\
\hline $\mathrm{Tp}$ & 17,2 \\
\hline $\mathrm{KD}$ & 14,6 \\
\hline $\mathrm{Bd}$ & 27,2 \\
\hline $\mathrm{Td}$ & 17,4 \\
\hline
\end{tabular}

Tab. 122: Messwerte an einem kompletten Schaf-Mittelhandknochen

\begin{tabular}{|l|l|l|}
\hline & Ziege & Schaf \\
\hline GLC & 156 & 156 \\
\hline TC & 20,8 & 20,9 \\
\hline KD & 16,3 & 16,3 \\
\hline Bd & 35,3 & 34,6 \\
\hline
\end{tabular}

Tab. 123: Messwerte an Oberschenkelknochen von kleinen Hauswiederkäuern

\begin{tabular}{|l|l|l|l|l|}
\hline & $\mathbf{1}$ & $\mathbf{2}$ & $\mathbf{3}$ & $\mathbf{4}$ \\
\hline Totallänge: Akrokranion-Prosthion & 200 & 179 & & \\
\hline Condylobasallänge & 175 & 202 & & \\
\hline Basallänge & 167 & 172 & & \\
\hline Basicranialachse & 47 & 55 & & \\
\hline Basifacialachse & 108,6 & 137 & & \\
\hline Hirnschädellänge: Akrokranion-Stirnmitte & & 86 & & \\
\hline Gesichtsschädellänge: Nasion-Prosthion & 96,5 & 87 & & \\
\hline
\end{tabular}




\begin{tabular}{|c|c|c|c|c|}
\hline & 1 & 2 & 3 & 4 \\
\hline Gesichtsschädellänge: Stirnmitte-Prosthion & & 103 & & \\
\hline größte Länge der Nasenbeine & 70,7 & 73 & & \\
\hline Schnauzenlänge: Vorderrand der Orbitae-Prosthion & 82,1 & 82 & & \\
\hline mediane Gaumenlänge: Staphylion-Prosthion & 94,8 & 108 & & \\
\hline Gaumenlänge & 93,2 & 106 & & \\
\hline Länge der Backenzahnreihe (Alveolenmaß) & & 73 & & \\
\hline Länge der Prämolarenreihe (Alveolenmaß) & & 54 & & \\
\hline Länge der Molarenreihe (Alveolenmaß) & & 24 & & 17,8 \\
\hline GLP2 & 10,9 & 12,2 & & \\
\hline GBP2 & 5 & 5,4 & & \\
\hline GLP3 & 12,4 & 14,5 & & 12,1 \\
\hline GBP3 & 5,6 & 3,7 & & 4,9 \\
\hline GLP4 & 19,3 & 21,7 & & 18,6 \\
\hline GBP4 & 8,9 & 14 & & 10,1 \\
\hline GLM1 & 12,6 & 15,8 & & 12,4 \\
\hline GBM1 & 15,1 & 18,9 & & 16,1 \\
\hline GLM2 & 5,9 & 7,4 & 8 & 7 \\
\hline GBM2 & 9,3 & 10 & 11 & 8,6 \\
\hline größter Durchmesser der Bulla ossea & & 22,8 & & \\
\hline kleiner Durchmesser der Bulla ossea & & 20,7 & & \\
\hline größte Innenlänge einer Orbita & & 28,1 & & \\
\hline größte Innenhöhe einer Orbita & & 26,3 & & \\
\hline größte Mastoidbreite: Otion-Otion & & 76 & & \\
\hline Breite über den Ohröffnungen & & 73 & & \\
\hline Stirnbreite: Ectorbitale-Ectorbitale & & 62,7 & & \\
\hline größte Breite des Schädels & & 53 & & \\
\hline kleinste Breite zwischen den Orbitae: Entorbitale-Entorbitale & & 45 & & \\
\hline Jochbogenbreite: Zygion-Zygion & & 115 & & \\
\hline Schädelenge: kleinste Breite hinter den Processus surpaorbitales & & 44 & & \\
\hline kleinste Gaumenbreite & & 41 & & \\
\hline Breite über den Eckzahnalveolen & & 43 & & \\
\hline größte Gaumenbreite: zwischen den Außenrändern der Alveolen & & 74 & & \\
\hline Schädelhöhe & & 55,3 & & \\
\hline Schädelhöhe ohne Crista sagittalis & & 53,1 & & \\
\hline Höhe des Hinterhauptdreiecks: Akrokranoin-Basion & & 44,7 & & \\
\hline
\end{tabular}

Tab. 124: Messwerte an Hundeschädel und Zähnen 


\begin{tabular}{|c|c|c|c|}
\hline & 5 & 6 & 7 \\
\hline Totallänge: Länge vom Processus condyloideus-Infradentale & & 121,1 & \\
\hline Länge Processus angularis-Infradentale & & 123,6 & \\
\hline $\begin{array}{l}\text { Länge vom Einschnitt zwischen dem Processus condyloideus und dem Processus angularis- } \\
\text { Infradentale }\end{array}$ & & 116,9 & \\
\hline Länge Processus condyloideus-Hinterrand der Alveole des C & & 105,2 & \\
\hline $\begin{array}{l}\text { Länge vom Einschnitt zwischen dem Processus condyloideus und dem Processus angularis- } \\
\text { Hinterrand der Alveole des C }\end{array}$ & & 102,5 & \\
\hline Länge Processus angularis-Hinterrand der Alveole des C & & 109,3 & \\
\hline Größte Dicke des Corpus mandibuale & & 10,5 & \\
\hline Höhe des Unterkieferastes & & 46,3 & \\
\hline Höhe des Kiefers vor M1 & & 18 & \\
\hline Höhe des Kiefers zwischen P2 und P3 & & 16,9 & \\
\hline Länge der Backenzahnreihe (Alveolenmaß) & & 63,4 & \\
\hline Länge der Prämolarenreihe (Alveolenmaß) & & 32,8 & \\
\hline Länge der Molarenreihe (Alveolenmaß) & & 30,3 & \\
\hline GLP2 & & 7,8 & \\
\hline GBP2 & & 4,2 & \\
\hline GLP3 & & 9 & \\
\hline GBP3 & & 4,2 & \\
\hline GLP4 & 14,4 & 10,2 & \\
\hline GBP4 & 6,4 & & \\
\hline GLM1 & & 5,1 & 21,1 \\
\hline GBM1 & & 18,8 & 8,6 \\
\hline GLM2 & & 7,6 & \\
\hline GBM2 & & 6 & \\
\hline
\end{tabular}

Tab. 125: Messwerte an Hundeunterkiefer und Zähnen 


\begin{tabular}{|l|l|l|l|}
\hline & Radius & & Femur \\
\hline GL & 119,5 & GL & 102,2 \\
\hline Bp & 13 & Tp & 28,2 \\
\hline Tp & 9 & TC & 12,3 \\
\hline Bd & 17,2 & KD & 8,8 \\
\hline & & Bd & 21,9 \\
\hline Calcaneus & Tub.offen & Tub.verwachsen & \\
\hline GL & 35,8 & 36,1 & \\
\hline GB & & 14,4 & \\
\hline & Metatarsus4 & Metatarsus2 & Metatarsus2 \\
\hline GL & 66,3 & 56 & 52,5 \\
\hline Bp & & 6,1 & \\
\hline Tp & & 11 & 6,1 \\
\hline KD & & 6 & 6 \\
\hline Bd & & 7,3 & \\
\hline Td & 9,2 & 6,9 & 4,9 \\
\hline
\end{tabular}

Tab. 126: Postkraniale Messwerte beim Hund

A. GALIK

G. ForstenPoINTNER G. E. Weissengruber 


\section{Die bauliche Entwicklung des Theaters vom Hellenismus bis in die Spätzeit}

Die komplexe Forschungsgeschichte des Theaters von Ephesos ist im ersten Kapitel dargelegt. Dieser langen Periode von Untersuchungen vor Ort und Veränderungen am ursprünglichen Befund, die nicht immer mit nachvollziehbaren Zielen und Methoden vonstatten gingen, hatte auch das im Vorwort der Herausgeber erläuterte Publikationskonzept Rechnung zu tragen. Aus den in diesem Faszikel vorgelegten archäologischen Funden und Befunden allein lassen sich nicht alle baulichen Veränderungen des Theaters und deren chronologische Einordnung erschließen. Vor allem durch die Bauforschungen des letzten Jahrzehnts wurden neue Erkenntnisse erarbeitet, durch die aus heutiger Sicht weitgehend gesicherte Aussagen zu den Bauphasen des gesamten Koilon und zur Rekonstruktion des Bühnengebäudes möglich sind. Diese gehen freilich über das Thema des vorliegenden Archäologie-Bands weit hinaus. Es scheint gerade deshalb sinnvoll und notwendig, an dieser Stelle einen kompakten Überblick zur baulichen Entwicklung des Theaters zu bieten, der den Leser mit den wichtigsten Fragen und Erkenntnissen bekanntmacht, ohne der detaillierten Beschreibung der Befunde und der kritischen Auseinandersetzung mit der Problematik vorzugreifen, die in den bereits in Vorbereitung befindlichen und in geplanten weiteren Faszikeln vorgelegt werden sollen.

\subsection{DAS THEATER IN HELLENISTISCHER ZEIT}

\subsubsection{Hellenistisches Bühnengebäude}

Wie aus den Ausgrabungsbefunden der Kammern D $3^{1}$ und $D 8^{2}$ hervorgeht, können wir für die Errichtung der Theaterterrasse und des Skenengebäudes eine Entstehungszeit in der 1. Hälfte des 2. Jhs. v. Chr. angeben. Zum Beginn der Bauarbeiten am Koilon und auch der Orchestra lässt sich hingegen nichts Sicheres sagen. Es ist allerdings zu vermuten, dass in der Planung der neuen Stadt des Lysimachos das Theater an dieser Stelle vorgesehen war. Wie weit der aus den Ausgrabungen ermittelte Zeitraum für die Errichtung des Bühnengebäudes mit dem Bau des Koilon zusammenhängt, kann mangels präziser, chronologisch aussagekräftiger Befunde nicht beantwortet werden. Wir wissen, dass das erste große Bauwerk der hellenistischen Neustadt die etwa acht Kilometer lange Stadtmauer war. Demgegenüber zeigen die Ausgrabungen auf der Tetragonos-Agora, dass der unmittelbar am Hafen gelegene Marktplatz zwar recht bald nach der Stadtgründung angelegt worden war, seine monumentale Ausgestaltung aber deutlich später anzusetzen ist ${ }^{3}$. Ähnliches könnte man sich eventuell auch beim Bau des Theaters vorstellen. Von der Bauabfolge her erscheint es nicht ausgeschlossen, dass die Vorbereitung des Berghangs für das Koilon und die Errichtung der Orchestra dem monumentalen Bau des Skenengebäudes vorausgegangen war. Wie weit solche Herrichtungen aber zurückreichen könnten, und ob es hier eine provisorische Nutzung als Theaterplatz bereits vor der Errichtung der monumentalen Skene in der 1. Hälfte des 2. Jhs. v. Chr. gegeben haben mag, muss offen bleiben.

Für die Errichtung des Skenengebäudes musste eine $75 \mathrm{~m}$ lange und fast $20 \mathrm{~m}$ breite Terrasse westlich der Orchestra errichtet werden. Ihre erhaltenen Reste überragen an der Nordwestecke noch heute das byzantinische Straßenniveau um rund 4,50 m, während sie nach Süden hin mit der allmählich in diese Richtung ansteigenden Straße zusammenlaufen. Die Terrassenmauer ist aus großen, bossierten Kalksteinquadern ohne Mörtelbindung errichtet (Taf. 17 Abb. 27). Über der Theaterterrasse erhob sich das zweigeschossige Skenengebäude (Taf. 424 Abb. 745). Mit 41,65 m Länge und 10,77 m Breite gehörte es zu den größten hel-

\footnotetext{
${ }^{1}$ Kap. 3.1.1.1.

${ }^{2}$ Kap. 3.1.1.2.

${ }^{3}$ Die Ausstattung der Agora entsprach zunächst dem Notwendigsten: ein Areal mit Lehmboden und vorerst einfacher Bebauung aus Holz und Lehmziegeln. Erst nach und nach wurden im Laufe des 3. Jhs. v. Chr. die Bauten durch steinerne Hallen ersetzt. Vgl. SCHERRER - TRINKL 2006, 15-17.
} 
lenistischen Bühnengebäuden in Kleinasien. Seine Orientierung und Dimensionen sind im Norden klar auf die Terrassenmauer bezogen. Auch die Westfassade verläuft parallel zur Westmauer der Terrasse, ist aber von dieser um $6 \mathrm{~m}$ nach Osten eingerückt. Es liegt also ein einheitlicher Bauvorgang zugrunde. Die Mauern sind durchschnittlich $0,78 \mathrm{~m}$ stark und als zweischaliges pseudoisodomes Mauerwerk ausgeführt (Taf. 425 Abb. 746). Als Baumaterial dienten vorwiegend gelbbrauner Poros, rötliche Brekzie und Blöcke aus Muschelkalk. Als Türüberlager fand gelegentlich auch Marmor Verwendung. Wie bei der Terrassenmauer sind die Wände der Skene mörtellos gefügt. Verklammerungen kommen nur an den Gebäudeecken vor. Die Mauern des Skenengebäudes sind stellenweise bis zu einer Höhe von 7,78 m über die Fundamentoberkante erhalten. Insbesondere am Obergeschoss sind zahlreiche Ergänzungen und Umbauten späterer Zeit zu erkennen.

\section{UNTERGESCHOSS}

Das Untergeschoss ist mit Ausnahme der Nordwestecke noch heute vollständig erhalten. Wenngleich auch große Wandabschnitte durch kaiserzeitliches Mauerwerk verborgen sind (Taf 3 Abb. 3; 12 Abb. 20; 430 Abb. 758), ist der Grundriss gut fassbar. Im Inneren wird das Geschoss in der Längsrichtung zweigeteilt (Taf. 10). Die östliche Hälfte nimmt über die gesamte Länge des Skenengebäudes der langrechteckige Korridor A ein. Er weist mit 4,20 m Weite, die gleiche Innenbreite auf wie die Reihe von acht Kammern (D1D8), welche die westliche Hälfte einnehmen. Zwischen den Kammern D4 und D5 liegt in der Ost-WestAchse des Bauwerks ein 2,80 m breiter Mitteldurchgang C, der die Raumflucht trennt. Die Kammern D2 bis D7 haben mit durchschnittlich 4,2 × 4,12 bis 4,15 m die annähernd gleiche Größe. Sie sind vom Korridor A aus durch ca. $1 \mathrm{~m}$ breite und 2,46 m hohe Türen zugänglich, die jeweils in der Mitte der KammerOstmauern liegen. Die Überlager aller Kammertüren bestehen aus demselben Material wie die Mauern selbst. Die beiden äußeren Kammern D1 und D8 sind mit 3,15 m Breite deutlich schmäler und konnten nur durch Eingänge in der Westmauer - über die Theaterterrasse - betreten werden. Wie die Fundamente an den Südmauern und die Spuren der Zwischendecke in Kammer D8 zeigen, konnte man durch diese Kammern über Treppen ins Obergeschoss gelangen ${ }^{4}$. Die Kammern und der Durchgang C besaßen eine Holzbalkendecke (Taf. 425 Abb. 746). Dies kann auch für den Korridor A vorausgesetzt werden, wenngleich durch die kaiserzeitlichen Mauern, die als Gewölbeauflager vor die hellenistischen Längswände gesetzt wurden, keines der Balkenlöcher sichtbar blieb ist. Fenster gibt es an keiner Stelle, doch besitzen die sechs inneren Kammern D2 bis D7 immerhin an der Westwand (Taf. 425 Abb. 746), unmittelbar unter der Holzdecke, jeweils winzige Öffnungen.

Der Korridor A war durch Türen an der Nord und Südseite zugänglich. Die südliche Tür mit 1,27 m Breite ist erhalten, wurde in späterer Zeit aber vermauert. Die nördliche Tür ist nicht mehr vorhanden, kann aber aufgrund von zwei rund 2,40 m langen in situ befindlichen Steinblöcken, die über dem Türsturz gelegen haben dürften, erschlossen werden. Nach Osten sind in der Mitte und in der Nordhälfte zwei Türen nachgewiesen, die zum Proskenion und zur Orchestra geführt haben, in der Südhälfte kann ein der nördlichen Tür entsprechender dritter Durchgang ergänzt werden. Die mittlere Tür, mit einer lichten Weite von $1,92 \mathrm{~m}$, besaß einen Marmortürsturz, der heute gebrochen ist, sowie eine Schwelle aus Poros ${ }^{5}$, die durch den späteren Einbau eines Kanals ${ }^{6}$ teilweise zerstört wurde, sodass sich nur mehr der Südteil mit den Angellöchern für die Türflügel erhalten hat. Die nördliche Tür weist neben dem Türsturz auch eine Schwelle aus Marmor auf. Der mittlere Durchgang C wird zum Korridor A hin - in der Flucht der Nord-Süd verlaufenden Mittelwand - von einem flachen Gurtbogen aus Kalkstein überspannt (Taf. 426 Abb. 747). An der Unterseite sind Löcher sichtbar, die nach W. Wilberg der Anbringung eines Gitters gedient haben?. Dem Bogen gegenüber sind an der Westmauer die Reste eines 0,40 m hohen marmornen Überlagers erhalten (Taf. 426 Abb. 748).

\footnotetext{
${ }^{4}$ Kap. 3.1.1.2.

${ }^{5}$ Heberdey u. a. 1912, Abb. 11.

${ }^{6}$ Kap. 3.2.2.1.

${ }^{7}$ Heberdey u. a. 1912, 6.
} 


\section{OBergeschoss}

Von der originalen Bausubstanz des Obergeschosses ist deutlich weniger erhalten geblieben. Die zahlreichen späteren Baumaßnahmen in diesem Bereich führten hinsichtlich der ersten Gestaltung zu offenen Fragen. Wie der von W. Wilberg publizierte Plan zeigt (Taf. $11 \mathrm{Abb}$. 18), folgt der Grundriss im Obergeschoss weitgehend dem des Untergeschosses ${ }^{8}$ : An den langrechteckigen Korridor A' schließen im Westen ebenso acht Kammern und ein Durchgang C' an. Allein die Türen weichen deutlich vom Grundrissschema des unteren Geschosses ab. Keine der Türen liegt in der Mitte der Kammer-Ostwände, sie finden sich vielmehr alle in einer Ecke der Kammern. Diese Besonderheit fand in der Forschung unterschiedliche Interpretationen', sie konnte durch unsere Untersuchungen vom Sommer 2006 geklärt werden. Es hat sich gezeigt, dass es vier der aus dem hellenistischen Untergeschoss bekannten Zwischenwände im oberen Stock nicht gab (Taf. 11 Abb. 19). Es handelt sich um die Mauern zwischen den späteren Kammern D'2 und D'3 (heute nicht mehr erhalten), zwischen D'6 und D'7, sowie die den mittleren Durchgang C' begrenzenden Wände zwischen D'4 und D'5. Diese Mauern wurden vielmehr erst später eingefügt. Daraus ergeben sich für die erste Bauphase zwischen den beiden Treppenanlagen D1 und D8 im Obergeschoss drei große Räume. Für diese lassen sich aus den wenigen Hinweisen große Türöffnungen zum Korridor A' rekonstruieren, die - wie im Untergeschoss - jeweils in der Mitte der Ostwände lagen (Taf. 11 Abb. 19). Sowohl die Treppen in den beiden äußeren Kammern, die Unter- und Obergeschoss miteinander verbanden, als auch der Grundriss des Obergeschosses in Form eines durchlaufenden Korridors mit dahinterliegender Raumflucht dürften im hellenistischen Theaterbau singuläre Lösungen sein ${ }^{10}$.

Fenster konnten auch für das Obergeschoss nicht nachgewiesen werden. Aufgrund der erhaltenen Mauerhöhen sind größere Fenster vielmehr auszuschließen. Denkbar sind dagegen kleine Öffnungen, wie sie für die Kammern des Untergeschosses bekannt sind. Eine Ausnahme bildet eine große Öffnung in der Westwand des mittleren Saals mit einem oberen Bogenabschluss ${ }^{11}$ (Taf. 426 Abb. 748; 427 Abb. 749) direkt über der breiten Durchgangsöffnung von C'. Davon ist an beiden Seiten je ein Stück des Bogens erhalten. Die Porosblöcke sind keilförmig zugerichtet und reichen an der Südseite noch bis auf eine Höhe von $\mathrm{T}^{\mathrm{a}}$ 15,857 m, was dem Niveau von 5,35 m über der Fundament-Oberkante entspricht. Die ergänzte Höhe des Bogenscheitels liegt auf 6,04 m über den Fundamenten ( $T^{a}$ 16,55), woraus sich eine Raumhöhe von 2,94 m ergibt. Jeweils aus der nördlichen und südlichen Fensterlaibung herausragende Quaderstücke, die unmittelbar auf dem Marmorbalken über $\mathrm{C}$ liegen, machen deutlich, dass zumindest im Fußbodenbereich die Westwand über die Fensterbreite durchgelaufen ist. Auch die Stirnseiten der Quaderreihen darüber geben teilweise den Blick auf die Zweischaligkeit des Mauerwerks frei und zeigen die spätere Beseitigung einer einst vorhandenen Brüstung an. Ausnehmungen zur Anbringung von etwaigen Fensterläden oder eines Gitters sind nicht vorhanden.

\section{Die Ostfassade}

Für die Ostseite des Obergeschosses ist, wie bereits W. Wilberg gezeigt hat ${ }^{12}$, ein Umbau anzunehmen. Darauf deutet neben den unterschiedlichen Materialien - Poros für den ursprünglichen Bau, Marmor für den Umbau - die zugemauerte nördliche Tür >eく zwischen dem Korridor A und dem Proskenion hin (Taf. 10

\footnotetext{
${ }^{8}$ Diese Ansicht wurde in bisher allen auf W. Wilberg folgenden Publikationen wiedergegeben, was auch für den Artikel des Verfassers (HOFBaUER 2002, 180) gilt.

${ }^{9}$ De Bernardi Ferrero 1970, 50 versucht diese eigenartige Anordnung der Türen dadurch zu erklären, dass sie auf diese Weise von den >Thyromata<-Pfeilern verdeckt würden und nicht durch die Toröffnungen der Skenen-Front zu sehen gewesen wären. Doch ist diese Erklärung m. E. unbefriedigend. Denn das >Verstecken` dieser Türen kann bestenfalls für eine bestimmte Anzahl von Sitzreihen im mittleren Bereich des Koilon zutreffen, für die allermeisten jedoch nicht. Zudem geht diese Überlegung von den >Thyromata`-Pfeilern der zweiten Bauphase aus, und trifft somit für die erste Phase nicht zu.

${ }^{10}$ Hier kann in aller Kürze nur das Ergebnis der Forschungen vorgestellt werden. Eine detaillierte Argumentation und die architekturhistorische Bewertung des Befunds wird dem Baugeschichtsband zum Bühnengebäude zu entnehmen sein, s. dazu M. Hofbauer in: ÖZTÜRK (in Vorbereitung). Vorgestellt wurden diese Ergebnisse bereits in HofBAUER 2007, 46-58; HofBAUER 2012.

${ }^{11}$ Heberdey u. a. 1912, Abb. 9.

${ }^{12}$ Heberdey u. a. $1912,13.18 \mathrm{f}$.
} 
Abb. 17; 427 Abb. 750; 428 Abb. 751). Der Grund dafür liegt in einem über dieser Tür errichteten Marmorpfeiler der zweiten Phase $^{13}$ des Proskenion. Da man auf den Durchgang nicht verzichten wollte, wurde eine neue Öffnung herausgebrochen, die kaum $1 \mathrm{~m}$ südlich der ursprünglichen Tür liegt und sich damit zwischen den Pfeilern von Phase 2 befindet.

Wie die Ostseite der älteren Skenenfront ausgesehen hat, wissen wir nicht. Eine durchgehende Wand mit Türöffnungen wurde nur von A. von Gerkan vorgeschlagen ${ }^{14}$. Vage Andeutungen hinsichtlich älterer $>$ Thyromata sind schon bei W. Wilberg ${ }^{15}$ vorhanden und finden in den Werken von E. R. Fiechter ${ }^{16}$ und A. Frickenhaus ${ }^{17}$ Befürworter.

\section{Exkurs zur Frage der Thyromata}

Im Zusammenhang mit einem Theater findet sich der Begriff \Thyromata einmalig in einer Inschrift am Obergeschoss des Theaters von Oropos ${ }^{18}$. W. Dörpfeld bezieht den Begriff auf die Parodos-Tore, die aber nach E. R. Fiechter ${ }^{19}$ auch erst der römischen Phase angehören könnten. Fiechter verwendet den Begriff >Thyromata nicht, sondern spricht von Öffnungen im Skenengebäude. Dagegen hält R. C. Flickinger ${ }^{20}$ das Argument von Dörpfeld für eine Fehlinterpretation und bezieht die Bezeichnung >Thyromata explizit auf die Wandöffnungen der Skene. Letzthin entwickelte sich diese Bezeichnung zu einem oft verwendeten Terminus für diese torartigen Öffnungen im Bühnengebäude und im Zusammenhang damit zur Benennung eines bestimmten Bühnentyps, der >Thyromata-Bühne oder der >Thyromata-Front . Einige Autoren sprechen etwas bedachter von sogenannten Thyromata oder setzen den Begriff in Anführungszeichen ${ }^{21}$. Grundsätzliches zur Problematik des Begriffs und eine ausführlichere Diskussion findet sich zuletzt bei J.-Ch. Moretti ${ }^{22}$, der es konsequenterweise für wünschenswert hält, auf Begriffe wie `Thyromata-Fassade` oder >Thyromatabühne〈 gänzlich zu verzichten.

Soweit nicht in zitierender Weise gebraucht, hält es der Verf. daher im Folgenden so, dass er den forschungsgeschichtlich belasteten Begriff `Thyromata in Anführungszeichen setzt, sofern nicht ohnehin einem neutralen Wort, wie etwa Wandöffnungen oder Pfeilerwand der Vorzug gegeben wurde.

Immerhin sei bedacht, dass sich mit dem Begriff `Thyromata ‘ mittlerweile ein spezielles Verständnis für ein bauliches Element der hellenistischen Bühne etabliert hat.

In Bezug auf die ephesischen Skenenfront hatte A. von Gerkan ${ }^{23}>$ Thyromata< erst für die späthellenistische Phase angenommen. Dagegen halten H. Lauter ${ }^{24}$ und H. Froning ${ }^{25}$ und zuletzt auch S. Gogos ${ }^{26}>$ Thyromata für das Theater von Epidauros bereits im späten 4. Jh. v. Chr. für nicht unwahrscheinlich. Umso naheliegender dürfte es daher sein, eine solche Lösung in Ephesos für das erst in der 1. Hälfte des 2. Jhs. v. Chr. errichtete Bühnengebäude zu erschließen ${ }^{27}$.

\footnotetext{
${ }^{13}$ Vgl. unten in diesem Kap. den Abschnitt Periodisierung.

${ }^{14}$ VON GERKAN 1921, 90.

${ }^{15}$ Heberdey u. a. 1912, $12 \mathrm{f}$.

${ }^{16}$ FieChTER 1914, 35.

${ }^{17}$ Frickenhaus 1917, 38.

${ }^{18}$ Dörpfeld - Reisch 1896, 109; Petrakos 1997, Nr. 435.

${ }^{19}$ FieChTER 1930, 27. Dazu auch Fiechter 1914, 35.

${ }^{20}$ Flickinger 1918, 109.

${ }^{21}$ So beispielsweise Lauter 1986, 169 bei der ersten Nennung oder Gogos 2009, 86.114 (Glossar).

22 MoretTi 1997, 35-37.

${ }^{23}$ VON GERKAN - MÜLLER-WIENER 1961, $72 \mathrm{f}$.

${ }^{24}$ LAUTER 1986, $169 \mathrm{f}$.

${ }^{25}$ Froning 2002, 58

${ }^{26}$ Dieser Ansicht schließt sich auch Gogos 2011, 64 an: »Demnach wäre davon auszugehen, daß in Epidauros die >Thyromata bereits seit dem frühen Hellenismus, und nicht erst später, dem zeitgenössischen Theaterspiel entsprechen, den architektonischen und szenisch notwendigen Hintergrund der erhöhten Bühne (Logeion) bildeten«.

${ }^{27}$ Auch De Bernardi Ferrero 1970, 50 dürfte bei dem Versuch, die ungewöhnliche Türanordnung im Obergeschoss nach W. Wilberg zu begründen, an große Toröffnungen denken, da die Türanordnung bei einer geschlossenen Wand mit 3 (?) Türen wohl kaum eine solche Maßnahme bedingt hätte.
} 
Die Marmorpfeiler der Umbauphase wurden im Mauerwerk der kaiserzeitlichen scaenae frons bewahrt, woraus sich eine Pfeilerwand mit sieben Öffnungen folgern lässt (Taf. 428 Abb. 752; 429 Abb. 754-757). Die an den beiden äußeren Marmorpfeilern angebrachte Liste der Agonotheten ${ }^{28}$ gibt zumindest einen terminus ante quem von 51/50 v. Chr. für den Umbau. Die Liste endet im Jahr 18/17 v. Chr. und belegt die Existenz der hellenistischen Skene bis in die augusteische Epoche hinein.

\section{Die Theaterterrasse westlich des Skenengebäudes}

Die Westseite des Bühnenhauses bereitet die größten Probleme. W. Wilberg wollte auf dem $6 \mathrm{~m}$ breiten Streifen zwischen Skenen-Westwand und Terrassenmauer eine Säulenhalle (Taf. 10 Abb. 17) rekonstruie$\operatorname{ren}^{29}$. Dafür gibt es jedoch weder bauliche noch archäologische Hinweise. Bislang sind auch keine Architekturteile aufgetaucht, die eindeutig einer solchen Stoa zugewiesen werden könnten, sieht man von einem ionischen Kapitell ab, das von W. Wilberg mit dieser Halle in Verbindung gebracht wurde ${ }^{30}$. Auch am erhaltenen Mauerwerk des Skenengebäudes fehlen entsprechende Spuren. Für die Wände an den Stirnseiten der Halle, die W. Wilberg angibt, fehlen die zu erwartenden Anschlüsse zur Skene. Die obere Steinlage der Terrassenmauer ist wohl schon vor der Errichtung der byzantinischen Stadtmauer abhanden gekommen ${ }^{31}$, sodass auch hier jeder Hinweis auf eine Säulenstellung fehlt. Als einzige Spur ist an der Südwestecke der hellenistischen Skene eine rund $5 \mathrm{~cm}$ breite, aber sehr seichte Nut in die Südwand eingelassen. Sie mag zu einer Abschrankung gehört haben, ist mit einer eventuellen Säulenvorhalle aber kaum in Verbindung zu bringen.

\section{Proskenion}

Wie aus allen bisherigen Grabungen zu ersehen $w^{32}{ }^{32}$, sind keine Reste des hellenistischen Proskenion erhalten geblieben. Diese dürften durch den Bau der scaenae frons vollständig beseitigt worden sein. W. Wilberg weist die römische Bühnenfront dem Proskenion der zweiten hellenistischen Phase zu (Taf. 428 Abb. 753) $)^{33}$. Damit erklärt er auch die zweimalige Aufstellung, die aufgrund der nicht intakten Verdübelung beim Abtragen der Logeionpfeiler um 1900 festgestellt worden $w^{34}{ }^{34}$. Für die ältere Phase schlägt er eine Holzkonstruktion vor. Bereits von Gerkan widerspricht hier vehement ${ }^{35}$. Das >späthellenistische〈 Proskenion erkennt er als bereits kaiserzeitlich, das Holzproskenion lehnt er ab und spricht sich in weiterer Folge auch gegen die von Wilberg argumentierte Zweiphasigkeit aus. A. von Gerkan tritt für einen von Anfang an errichteten Steinbau ein. Er entwirft seine Version des hellenistischen Proskenion ${ }^{36}$ aufgrund zweier Balkenlöcher mit einem Achsabstand von 1,56 m über dem Sturz der nördlichen Tür vom Korridor A nach Osten, und einem der Außenkante des Ringkanals entsprechenden Kreis, dem er nach Vitruv ein Quadrat einschreibt.

Wie bereits festgestellt, ist das von W. Wilberg für die zweite hellenistische Phase ergänzte Proskenion das der ersten kaiserzeitlichen Anlage. Durch die Verwendung der beiden Seitenteile, die beim flavischen Bau notwendig waren, um die Bühnenfront über die ehemaligen Analemmata P und Q nach Osten vorragen zu lassen, erhält Wilbergs Rekonstruktion der hellenistischen Bühne die beiden seltsamen Rücksprünge an beiden Seiten der Proskenionfront und den Parodos-Toren ${ }^{37}$. Die Erkenntnis, dass die erhaltene Architektur

\footnotetext{
${ }^{28}$ IvE 9.

${ }^{29}$ W. Wilberg, in: HeberdeY u. a. 1912, 15 f. dazu: »Denkbar wäre, dass an dieser Stelle eine Halle sich erhob, die für das Wort ảvtí́кnvos der Inschrift Nr. 41 (= IvE 2041) eine Erklärung geben würde«. Dazu s. auch Kap. 8.6.1, Nr. 11 u. Kap. 8.6.2.

${ }^{30}$ Heberdey u. a. 1912, Abb. 22; Alzinger 1961, 110 datiert dieses Kapitell deutlich früher und führt ein identisches Exemplar an, welches beim Lukasgrab gefunden wurde.

${ }^{31}$ Kap. 3.1.2.3.

${ }^{32}$ Kap. 3.2.1.

${ }^{33}$ Heberdey u. a. 1912, 21-29.

${ }^{34}$ Heberdey u. a. 1912, 33.

35 VON GERKAN 1921, 92.

${ }^{36}$ VON GERKAN 1921, 91.

${ }^{37}$ Heberdey u. a. 1912, Abb. 56. Diese Rekonstruktion wird auch von Frickenhaus 1917, Taf. 1 wiedergegeben.
} 
bereits der Kaiserzeit angehört, befreit die Rekonstruktion von diesen eigenartigen Rücksprüngen an den Ecken. Für den Grundriss hellenistischer Zeit wird man die für Theaterbauten Kleinasiens charakteristische Trapezform (Taf. 11 Abb. 19) zugrunde legen können ${ }^{38}$.

\section{Periodisierung}

\section{Erste hellenistische Phase:}

Für die Errichtung von Theaterterrasse und Skenengebäude verweisen die Funde aus den Ausgrabungen in Kammern D3 und D8 des hellenistischen Bühnenhauses auf das frühe 2. Jh. v. Chr. Dieser Porosbau kann als typisches Theater des Hellenismus kleinasiatischer Prägung bezeichnet werden: ein langer, rechteckiger Bau mit zwei Geschossen, dessen Ostwand vermutlich schon von Anfang an mit großen Wandöffnungen ( Thyromata $)$ ausgestattet war. Obwohl nichts vom Proskenion erhalten geblieben ist, wird man guten Gewissens die in Kleinasien weit verbreitete Trapezform voraussetzen dürfen. Auf dem verbleibenden Areal im Westen des Bühnenhauses, über der Theaterterrasse, wurde zunächst eine Säulenhalle vorgeschlagen. Aufgrund mangelnder Hinweise kann sie nur hypothetisch rekonstruiert werden.

\section{Zweite hellenistische Phase:}

Große Veränderungen in ihrer Art dürfte die Skene bis zum Ende der hellenistischen Epoche nicht erfahren haben. Es kam lediglich zur Umgestaltung der Ostwand. Die einstigen Porospfeiler wurden dabei durch Pfeiler aus Marmor ersetzt, die ab dem Jahr 54/53 v. Chr. auch die Liste der Agonotheten trugen. Spätestens zu diesem Zeitpunkt muss der Umbau abgeschlossen gewesen sein. Ob das Proskenion davon betroffen war, scheint eine müßige Frage zu sein, besitzen wir doch vor dem flavischen Umbau überhaupt keine Reste davon. Bis ins vorletzte Jahrzehnt des 1 . Jhs. v. Chr. hat das Bühnengebäude des Theaters in dieser Form des hellenistischen >Thyromata-Typus« bestanden.

M. HofBaUer

\subsubsection{Hellenistische Orchestra}

Kern der hellenistischen Anlage ist die kreisrunde Orchestra (Taf. 12 Abb. 20; 13 Abb. 21; 77 Abb. 151; 78 Abb. 152), wie sie allgemein seit der 2. Hälfte des 4. Jhs. v. Chr. üblich geworden war ${ }^{39}$. Ihr Durchmesser beträgt bis zur Innenseite des sie umgebenden ringförmigen Kanals 12,35 m. Im Westen wird dieser Kreis im Schwellenbereich der Mitteltür vom Skenengebäude einigermaßen exakt tangiert (Taf. 430 Abb. 759). Um 0,34 m überragt die Schwelle der Mitteltür den Kreis nach Osten, was andererseits knapp der halben Wandstärke der Skenen-Ostmauer entspricht. Das zu ergänzende Proskenion hätte den Orchestrakreis um etwa $3 \mathrm{~m}$ überragt. Die Breite des Ringkanals nimmt von $0,45 \mathrm{~m}$ am Südende bis auf 0,59 $\mathrm{m}$ im Norden kontinuierlich zu und weist ein deutliches Süd-Nord-Gefälle auf. Im Nordwesten biegt der Kanal in leichtem Schwung um das Ende der Analemma-Mauer P und knickt daraufhin etwa im rechten Winkel nach Norden $\mathrm{ab}$, um die Flucht der nördlichen Parodos für den weiteren Verlauf - vermutlich bis zu einem Straßenkanal - zu benutzen. Das Material ist der gleiche gelblich braune Poros, wie er auch am Skenengebäude Verwendung fand. Der hellenistische Kanal verlief im gesamten Orchestrabereich offen. Nur in den Achsen der zwölf Treppen des Koilon bildeten Steinplatten kleine Brücken über den Kanal. Ab dem Nord-Analemma wurde er durch den Steinplattenboden der Parodos gedeckt.

In weniger als $1 \mathrm{~m}$ Abstand von der Innenkante des Ringkanals deutet eine im östlichen Halbkreis weitgehend erhaltene ringförmige Fundamentschar U mit gut zugerichteter Oberfläche (Taf. 82 Abb. 162; 90 Abb. 180) auf eine Abgrenzung des eigentlichen >Tanzplatzes` hin, die nach W. Wilberg beispielsweise in

${ }^{38}$ IsLER 1994, 105; MoRetti 1992, 13.

${ }^{39}$ ISLER 1994, 97. 
den Theatern von Epidauros und Oiniadai ${ }^{40}$ ihre Parallele hat. Sechs Steinplatten unter den Logeionpfeilern der kaiserzeitlichen Bühne werden von Wilberg aufgrund ihrer leicht gekrümmten Langseiten als einstige Decksteine über der Steinsetzung vermutet ${ }^{41}$. Bei den jüngsten Grabungen konnten Reste dieser Fundamentierung in S 3/2004 (Taf. 84 Abb. 166) und in S 1/2005 (Taf. 89 Abb. 177. 178; 90 Abb. 179. 180) erneut freigelegt werden.

Infolge der massiven kaiserzeitlichen Überformung der Orchestra und der großflächigen Grabungstätigkeit ließen sich bei den Ausgrabungen keine datierenden Funde für die hellenistische Anlage machen. Der erhaltene Ringkanal scheint mit dem Skenengebäude und Elementen des Koilon aber eine Einheit zu bilden und wird demnach der gleichen Zeitstellung zuzurechnen sein.

M. HofBAUER

\subsubsection{Hellenistisches Koilon}

Wie im Bühnengebäude, so haben sich auch im Bereich des Auditorium Abschnitte aus hellenistischer Zeit erhalten ${ }^{42}$. Wenngleich auch die genaue Zeitstellung und die ursprüngliche Form des hellenistischen Koilon nicht mehr vollständig nachvollziehbar ist, so können doch anhand der aktuellen Baubefunde einige Aussagen zu dessen Größe und Erscheinungsbild getroffen werden. Schon die beachtlichen Ausmaße der Skene, die mit annähernd $42 \mathrm{~m}$ Länge zu den größten hellenistischen Bühnengebäuden in Kleinasien zählt, lassen auch ein entsprechend dimensioniertes Koilon erwarten ${ }^{43}$. Zur ursprünglichen Gestalt des Auditorium und dessen baulicher Entwicklung werden in der Forschungsliteratur unterschiedliche Sichtweisen beschrieben: R. Heberdey und W. Wilberg nahmen bereits für das hellenistische Theater ein dreirangiges Koilon mit einer Kapazität für etwa 23.000 Zuschauer an ${ }^{44}$. Hingegen formulierten zunächst D. De Bernardi Ferrero und später St. Karwiese und I. Ataç die Vorstellung eines rangweise erweiterten Auditorium ${ }^{45}$.

Im Folgenden werden die Ergebnisse aus dem aktuellen Baubefund hinsichtlich Gestalt und Ausdehnung des hellenistischen Koilon zusammenfassend dargelegt.

Direkte Hinweise auf das hellenistische Koilon finden sich zunächst am unteren Beginn der Sitzreihen im Bereich der Orchestra. Während der dritten Grabungskampagne 1899 wurde unter dem kaiserzeitlichen Orchestrakanal sein hellenistischer Vorgänger freigelegt ${ }^{46}$. Dieser erste 0,55 bis $0,60 \mathrm{~m}$ breite Kanal verlief mit einem inneren Durchmesser von 24,66 m (entspricht 84 attischen Fuß zu 0,294 m) als offenes Gerinne um die Orchestra ${ }^{47}$. Davon ausgehend konnten bereits R. Heberdey und W. Wilberg sowohl das Niveau des dazugehörigen hellenistischen Orchestrabodens bestimmen als auch Rückschlüsse auf den ursprünglichen Beginn der unteren, später entfernten Sitzreihen im Koilon ziehen ${ }^{48}$. In ihrer Rekonstruktion von 1912 reich-

\footnotetext{
${ }^{40}$ Heberdey u. a. 1912, 14; Powell 1904, 188-190 Abb. 19 Taf. 8. Detaillierter ist die Planaufnahme bei Fiechter 1931, Taf. 1; s. auch Gogos 2009; Gogos 2011.

${ }^{41}$ Heberdey u. a. 1912, 14 mit Abb. 16.

${ }^{42} \mathrm{Im}$ vorliegenden Text werden die Ergebnisse der Bauforschung zu den wesentlichen Bauphasen im Auditorium beschrieben. Die Darstellung versteht sich als Überblick und beschränkt sich daher auf die zum Verständnis der Sachverhalte notwendigen Details. Eine vollständige Darlegung und ausführliche Diskussion aller Befunde erfolgt in STYHLER-AYDIN (in Vorbereitung).

${ }^{43}$ Zum Vergleich sei das Theater von Milet angeführt. Hier rekonstruierte F. Krauss ausgehend von dem ersten hellenistischen Bühnengebäude (Skene I) von 15,175 m Länge (KRAuss 1973, 8) sowie der dazugehörigen Orchestra mit D = 21,46 m (KRAUSs 1973, 46) auf Basis der Befunde bereits einen Zuschauerraum von ca. 73 m Durchmesser (Krauss 1973, 60 Textabb. e). Die Anzahl der von ihm ermittelten Sitzplätze war damit etwa der im Theater von Priene vergleichbar (Krauss 1973, 46). Die späthellenistische Großbühne (Skene IV) mit 39,89 m Länge (KRAuss 1973, 33) und einer Orchestra von D = 26,24 m hatte einen zumindest umgestalteten Zuschauerraum. Krauss schließt auch einen vollständigen Neubau in dieser Phase nicht aus (Krauss 1973, 51).

${ }^{44}$ Heberdey u. a.1912, 16.

${ }^{45}$ De Bernardi Ferrero 1970, 49-66; auch Scherrer 1995, 160; AtaÇ 1999b, 3.

${ }^{46}$ Heberdey 1900; Heberdey u. a. 1912, 14 Abb. 20; 15 Abb. 21.

${ }^{47}$ Heberdey u. a. 1912, 8 Abb. 6. Zum Fußmaß am Bühnenhaus vgl. Bammer 1961, 152. Der Orchestrakanal folgt der Kreisform nicht ganz gleichmäßig, sondern zeigt im Radius leichte Differenzen. Dies mag auch der Grund für die in der Literatur geringfügig abweichenden Radienangaben sein. Bei R. Heberdey und W. Wilberg beträgt der Radius 12,33 m. M. Hofbauer gibt ein Maß von $12,35 \mathrm{~m}$ an (Kap. 10.1.2).

${ }^{48}$ Heberdey u. a. 1912, 13-15; Hofbauer 2007, 13 f.
} 
ten demnach die Sitze mit der in der unteren Reihe angeordneten Prohedrie und einer entsprechenden Erschließungsfläche bis an den Rand des hellenistischen Kanals (Taf. 431 Abb. 760) ${ }^{49}$.

Mangels weiterer baulicher Evidenzen blieben diese Überlegungen hypothetisch und wären z. B. hinsichtlich der Aufstellung des einzigen erhaltenen, dreiseitig auf Ansicht gearbeiteten Prohedrie-Sessels vermutlich zu konkretisieren (Taf. 431 Abb. 761) ${ }^{50}$. Ein weiteres Argument für die genannte Rekonstruktion ergab sich jedoch bei Grabungen am Fußpunkt der heute sichtbaren Orchestrawand X. Es zeigte sich, dass die während der kaiserzeitlichen Bauphasen errichtete Stützwand bereits auf Fels gegründet wurde, den man in dem Bereich, der durch die Wegnahme der Sitzstufen entstand, horizontal auf ein neues Niveau abgearbeitet hatte ${ }^{51}$. Ein anderes Indiz für die Situation am Fuß des Koilon geben die in die Wandung des hellenistischen Kanals eingelassenen Aufnahmeflächen der ehemaligen Trittsteine. Diese $0,15 \mathrm{~m}$ dicken Platten überbrückten jeweils in direkter Verlängerung der zwölf Klimakes des unteren Rangs den offenen Kanal (Taf. 432 Abb. 762. 763) ${ }^{52}$. Die daraus abzuleitende Unterteilung des unteren Rangs in elf Kerkides hat sich bis heute erhalten. Lediglich die jeweils äußeren Kerkides wurden durch den späteren Einbau der scaenae frons mit der kaiserzeitlichen Bühne verändert (Plan 1). Hier zeigen jedoch wiederum der erhaltene nordwestlichste Trittstein am hellenistischen Orchestrakanal sowie die Kontaktflächen für die Stufenquader der äußeren Klimakes an den wenigen in situ-Bauteilen der hellenistischen Analemmata die ursprüngliche Situation.

Das hellenistische Koilon umfasste somit im unteren Rang einen Winkel von ca. $217^{\circ}$. Die kreisförmige Orchestra war durch etwa 3,50 m breite Parodoi von Süden und Norden erschlossen (Taf. 442 Abb. 783. $784)^{53}$. Aufgrund der umgebenden Topografie am Fuß des Panayırdağ, die ein Gefälle von Süd nach Nord aufweist, lag die nördliche Parodos höher als die Straße und müsste über eine Rampe oder zusätzliche Stufen vor dem Theater verfügt haben (Plan 3. 7) ${ }^{54}$. Im Süden war nach heutiger Einschätzung ein annähernd niveaugleicher Zugang über die Parodos zur Orchestra möglich (Plan 3. 8).

Bezüglich der Bauphasen in den oberen Rängen ergeben sich erste Anhaltspunkte aus der Analyse des Sitzstufenunterbaus. Bei der Betrachtung des erhaltenen Stufenkörpers fallen besonders die verschiedenen Materialien auf, aus denen die Sitzstufen und Radialtreppen im Rohbau hergestellt wurden. Im Bereich des Berghangs verwendete man - wie im unteren Rang - größerformatige Quader aus grauem Marmor oder der rötlichen Brekzie. Teilweise konnte der anstehende Felsen auch direkt als Unterbau für die Marmorverkleidung der Sitzstufen terrassiert werden. Für die in der Kaiserzeit angefügten, auf Substruktionen lagernden Sitzbereiche kam hingegen opus caementitium mit einem Aufbau aus vermauerten Bruchsteinen zur Herstellung der Stufenform zum Einsatz. Auch an den Diazomawänden sind die beiden unterschiedlichen Konstruktionstechniken im Unterbau der Stützwände, teilweise mit Abweichungen bis in die Fundamentzone, erkennbar ${ }^{55}$. Allerdings ist die während der Freilegung des Theaters vorgefundene Situation nur noch auf historischen Aufnahmen nachzuvollziehen ${ }^{56}$. Das heutige Erscheinungsbild zeigt das Ergebnis der Restaurierungen seit den 1960er Jahren. Opus caementitium-Bereiche wurden dabei als Imitation in Bruchstein neu aufgemauert.

Die beschriebenen unterschiedlichen Konstruktionstechniken im Unterbau der Sitzstufen geben einen ersten Hinweis auf die Ausdehnung des Koilon. Es wies demnach im Anschluss an den aus elf Kerkides bestehenden unteren Rang mindestens im Bereich des Berghangs bereits einen mittleren und oberen Rang auf. Darauf deuten auch die Befunde zum unteren Diazoma sowie der sichtbar nachträgliche Einbau der Aristion-Leitung in den hangseitigen Stufenkörper hin ${ }^{57}$.

${ }^{49}$ Heberdey u. a. 1912, 44 Abb. 86.

${ }^{50}$ Heberdey u. a. 1912, 16 f. mit Abb. 27; heute im Ephesos-Museum in Wien, vgl. Oberleitner u. a. 1978, 64 KatNr. 50. Auch im Theater von Metropolis haben sich Prohedrie-Sessel erhalten. Ihre Position vor der unteren Sitzreihe wurde in Einzelaufstellung jeweils mittig vor einer Kerkis rekonstruiert. Das Theater von Priene zeigt ebenfalls noch in Abständen angeordnete allseitig auf Ansicht gearbeitete Prohedrie-Sessel am Rand der Orchestra. Hier wurden die Zwischenräume jedoch durch eine nachträglich eingefügte Bankreihe geschlossen.

${ }^{51}$ Kap. 3.3.2.1 u. 10.2.4.2.

${ }^{52}$ Heberdey u. a. 1912, 13 Abb. 17; 14 Abb. 19.

${ }^{53}$ Heberdey u. a. 1912, 7 Abb. 5; Hofbauer 2007, 59.

${ }^{54}$ Einen Hinweis auf das Niveau der Straße in hellenistischer Zeit gibt das kleine hellenistische Brunnenhaus an der Nordwestecke der Theaterterrasse. Es liegt mehr als 5,00 m niedriger als die hellenistische Orchestra.

${ }^{55}$ Kap. 3.4.2.5.

${ }^{56} \mathrm{Vgl}$. De Bernardi-Ferrero 1970, 58 Abb. 55; 59 Abb. 61; 60 Abb. 62.64.

${ }^{57}$ Kap. 10.2.4.2. 
Eine weitere Auffälligkeit in Bezug auf die Bauphasen des Auditorium zeigt die Analyse der Theateraußenwände. Hier lässt sich sowohl im Norden als auch im Süden jeweils bei einem Winkel von $82^{\circ}$ bzw. $83^{\circ}$ zur Mittelachse des Gebäudes ein markanter Wechsel in der Fassadengestaltung feststellen (Taf. 433 Abb. 765; Plan 4. 5). Hangaufwärts besteht die Außenwand aus horizontalen Quaderlagen aus grauem Marmor, deren Ansichtsflächen leicht polsterförmig gewölbt sind. In Abständen ordnete man horizontale Versätze an. Die Fassadenquader weisen in den Vertikalen sowohl orthogonale als auch trapez- und parallelogrammförmige Zuschnitte auf. Der Wandaufbau im Norden zeigt zwei trocken hintereinander verlegte Quaderreihen, die durch Binderschichten verzahnt wurden. Das Erscheinungsbild der Fassadenabschnitte der nördlichen und südlichen Außenwand ähnelt hinsichtlich Baumaterial und Gestaltung der Terrassenmauer am Bühnengebäude (Taf. 434 Abb. 766. 767; 435 Abb. 768; Plan 3). Bereits R. Heberdey hatte den oberen Teil der Polsterquaderfassade im Norden noch dem hellenistischen Koilon zugeordnet ${ }^{58}$. Im Süden weist der in augusteische bis frühtiberische Zeit datierte obere Zugang ES3 durch seinen nachträglichen Einbau in die Polsterquaderfassade darauf hin, dass auch hier die Außenwand bereits bestanden haben muss, wenn sich der Wandabschnitt auch nicht enger zeitlich eingrenzen lässt ${ }^{59}$.

Da die Unterkonstruktion der Sitzstufen hinter den Abschnitten der Polsterquaderfassade sowohl im Norden als auch im Süden aus opus caementitium - bzw. dessen Zitat in Form der modernen Bruchsteinrestaurierung - besteht, liegt hier offenbar eine räumliche Überlagerung der Bauphasen vor. Besonders im Nordflügel wird durch die einheitliche Ausrichtung des nachträglich in die Polsterquaderfassade eingebauten vomitorium EN2 und der benachbarten Substruktionskammern deutlich, dass sie zusammenhängend im Rahmen der spätflavischen Erweiterung des Auditorium hinter der bestehenden Fassade errichtet wurden ${ }^{60}$. Wie der Unterbau hinter den Abschnitten der Polsterquaderfassade ursprünglich gestaltet war, lässt sich nicht mehr nachvollziehen. An anderen hellenistischen Theatern aus dem 2. Jh. v. Chr., wie z. B. in Termessos, Oinoanda oder Arycanda ${ }^{61}$, kann beobachtet werden, dass man die aus dem Berghang heraustretenden Gebäudeflügel durch massive Aufschichtungen in Verbindung mit Bruchsteinpackungen herstellte. Im Theater von Ephesos ist in Bezug auf die Baumasse des hellenistischen Koilon lediglich am nordwestlichen Gebäudeflügel des unteren Rangs ein Einblick in die Unterkonstruktion außerhalb des Berghangs möglich. Wie sich zeigt, besteht sie aus mehreren Lagen massiver, grob zugerichteter Quader (Taf. 435 Abb. 769).

Wenn auch die ursprüngliche westliche Begrenzung der Polsterquaderfassade im oberen Rang nicht mehr exakt nachvollzogen werden kann, zeigen die Befunde doch, dass auch außerhalb des Berghangs seit hellenistischer oder spätestens augusteischer Zeit Gebäudeflügel aufgebaut waren, die jedoch nicht die Ausdehnung des unteren Rangs erreichten. Eine gestalterische Lösung für diese Situation stellen sogenannte zurückgesetzte Analemmata dar, die sich z. B. in den Theatern von Epidauros (Anfang 3. Jh. v. Chr. mit Erweiterungen in der 1 . Hälfte des 2. Jhs. v. Chr. ${ }^{62}$ ) oder auch Alinda (2. Jh. v. $\mathrm{Chr}^{63}$ ) beobachten lassen. Eine derartige Gestaltung begrenzte die Höhe der außerhalb des Hangs aufzubauenden Volumen und kann auch als eine Reaktion auf die technischen Möglichkeiten der Zeit gelesen werden.

$\mathrm{Ob}$ es sich bei den Abschnitten der Polsterquaderfassade und den ursprünglich dahinterliegenden Sitzbereichen möglicherweise bereits um eine erste Erweiterung des hellenistischen Koilon handelt, kann nach aktuellem Wissensstand nicht bestimmt werden. Ebenso lässt die Befundlage im stark restaurierten Bestand eine genauere zeitliche Eingrenzung der Fassaden nicht zu. Entsprechende Fragestellungen liegen natürlich gerade durch die Kenntnis der zweiten hellenistischen Bauphase am Bühnengebäude nahe, wie sie mit dem Einbau der marmornen >Thyromata nachgewiesen ist. Sie müssen jedoch vorläufig unbeantwortet bleiben ${ }^{64}$.

Mögliche weitere - eventuell topografisch günstige - Zugänge zum Koilon, neben den Parodoi, sind nicht nachvollziehbar, aber auch keineswegs auszuschließen ${ }^{65}$.

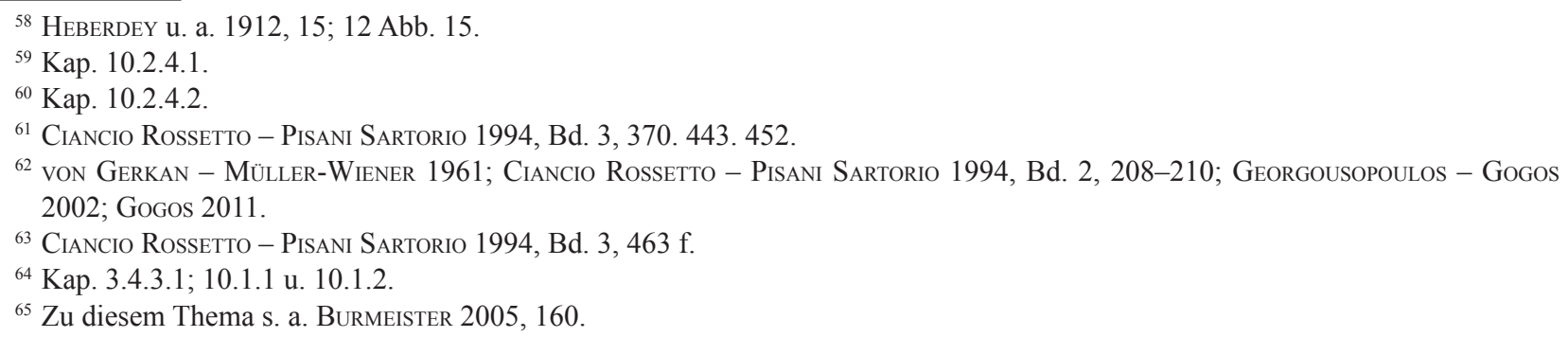


Offen bleibt zudem, wie der obere Abschluss des Koilon gestaltet war. R. Heberdey und W. Wilberg rekonstruierten im Bereich des Berghangs eine Halle und bringen sie mit Informationen aus einer Inschrift am Süd-Analemma in Zusammenhang ${ }^{66}$. Die im Verlauf der aktuellen Bauforschung im Bereich der Portikus aufgefundenen Architekturbauteile datieren jedoch viel später. Am oberen Diazoma fanden nach Aussage der Funde aus den archäologischen Sondagen zumindest in Teilbereichen Bauaktivitäten statt, die in den Späthellenismus bzw. die frühe Kaiserzeit weisen ${ }^{67}$. Hinsichtlich der Errichtung der Stützwand konnten jedoch keine Aussagen getroffen werden.

Die Sitzbereiche im Theater waren mit weißen Marmorplatten verkleidet, von denen sich lediglich ein geringer Prozentsatz erhalten hat. Zudem haben die verbliebenen Bauteile inzwischen oftmals ihren Platz gewechselt, sodass eine eindeutige räumliche Zuordnung nicht mehr möglich ist. Auch geben Technik und Stil der Marmorverkleidung bislang für eine zeitliche Einordnung keine ausreichend präzisen Hinweise. Der Fund einer Inschrift, die von R. Heberdey noch für das 3. Jh. v. Chr. angenommen wurde und sich an der Front einer marmornen Deckplatte der Diazomawand befindet, könnte für eine frühe Ausstattung mit Marmorplatten sprechen ${ }^{68}$. Eine Parallele fände die Verkleidungstechnik zudem im hellenistischen Theater von Metropolis, das um 150 v. Chr. datiert wird ${ }^{69}$. Auch das große Theater am Burgberg in Pergamon mit einer Verkleidung aus Andesit-Tuff-Platten sowie das Theater in Herakleia am Latmos, bei dem die Merkmale im erhaltenen Unterbau auf eine dem Theater in Ephesos verwandte Lösung der Verkleidungstechnik hindeuten, stammen aus der hellenistischen $\mathrm{Zeit}^{70}$.

G. STYHLER-AYDIN

\subsection{DAS THEATER IN DER RÖMISCHEN KAISERZEIT}

\subsubsection{Kaiserzeitliche Theaterfassaden}

Aus dem baulichen Bestand geht hervor, dass das Bühnengebäude in hellenistischer Zeit errichtet und in römischer Zeit grundlegend umgebaut wurde ${ }^{71}$. An die Stelle der hellenistischen >Thyromata< trat eine reich geschmückte kaiserzeitliche Theaterfassade ${ }^{72}$. Diese Fassade bestand aus einem Bühnenpodium (Proskenion) und einer scaenae frons, die sich über dem Proskenion erhob und eine dreigeschossige Tabernakelfassade besa $\beta^{73}$.

\section{ÄLtere ForschungSMeinungen}

Proskenion: Nach Abschluss der ersten Ausgrabungen wurde der Bereich des Proskenion im Rahmen der hellenistischen Anlage von W. Wilberg publiziert. Demnach gehörten die in situ befindlichen Stützen und das Triglyphengebälk der kaiserzeitlichen Bühne ursprünglich zum Proskenion der hellenistischen Bühne ${ }^{74}$. Im Zuge des Aufbaus der römischen scaenae frons wurden sie abgetragen und weiter vorne als Bühnenvorderwand teilweise wieder aufgebaut. Laut Wilberg ergibt sich die charakteristische Form der griechischen Proskenionstützen durch die Ergänzung der Vorderseite der in situ erhaltenen Stützen mit Halbsäulen ${ }^{75}$.

\footnotetext{
${ }^{66}$ IvE 2041. Vgl. Heberdey u. a. 1912, 15. 163 f. Die Inschrift datiert jedoch frühestens an das Ende des 2./Anfang des 3. Jhs. n. Chr. R. Heberdey selbst schlägt die späteren Jahrzehnte des 3. Jhs. n. Chr. vor. Dazu auch Kap. 8.6.1, Nr. 11 u. Kap. 8.6.2.

${ }^{67}$ Kap. 3.4.3.1.

${ }^{68}$ IvE 2087. Vgl. Heberdey u. a. 1912, 18. 186. Dazu auch Kap. 8.6.2.

${ }^{69}$ MERIÇ 2004, 85.

${ }^{70}$ Radt 1988, 287-292; Ciancio Rossetto - Pisani Sartorio 1994, 396-398; 459.

${ }^{71}$ Heberdey u. a. 1912, 5-52; s. auch Kap. 3.1.

${ }^{72}$ Die Forschungen vor Ort wurden im Jahr 2005 abgeschlossen, erste Ergebnisse wurden in folgenden Beiträgen vorgestellt: ÖzTÜRK 2005a; ÖZTÜRK 2005b; ÖZTÜRK 2006a; ÖZTÜRK 2006b; ÖZTÜRK 2010.

${ }^{73}$ Zur Terminologie s. ÖzTÜRK 2006b, 205 f.; s. auch ÖzTÜRK 2009, 11 f.

${ }^{74}$ Heberdey u. a. 1912, 17 Abb. 5.

${ }^{75}$ Heberdey u. a. 1912, 21 Abb. 38-40.
} 
A. von Gerkan interpretierte sowohl diese Stützen als auch das Triglyphengebälk nicht als Teile des hellenistischen Proskenion, sondern als frühkaiserzeitliche Bühne ${ }^{76}$. Darüber hinaus wies H. von Hesberg darauf hin, dass die Formen des Gebälks eine Erbauung im 1. Jh. n. Chr. nahelegen, weil der Fries schon weitgehend $\mathrm{zu}$ einem durchlaufenden Band stilisiert ist ${ }^{77}$.

scaenae frons: Für die kaiserzeitliche Bühne wurde von G. Niemann folgende Rekonstruktion vorgeschlagen: Die scaenae frons wurde vor die hellenistische Skene gesetzt ${ }^{78}$. Ihre ursprünglich zweigeschossige Ausführung wurde in einer späteren Periode um ein drittes Geschoss über der Attikamauer erhöht. Diese beiden Varianten, die Niemann erarbeitete, unterscheiden sich vor allem in Bezug auf das zweite Geschoss. In Variante 1 ist die Wand zwischen den Tabernakeln in fünf Rundbogennischen aufgelöst ${ }^{79}$. Während über der mittleren Nische ein gerades Gebälk lag, waren die seitlichen Nischen neben der Symmetrieachse mit konkaven Säulenstellungen ausgestattet. In Variante 2 sind die mittleren Tabernakel mit einem gesprengten Giebel verbunden ${ }^{80}$. Eine konkave Säulenstellung ist nicht vorgesehen.

Aufgrund der Architravinschrift des ersten Geschosses wurden die ersten zwei Geschosse der scaenae frons in das Jahr $66 \mathrm{n}$. Chr. datiert ${ }^{81}$, der Aufbau des dritten Geschosses wird demnach an den Anfang des 3. Jhs. n. Chr. gesetzt.

Ein weiter Rekonstruktionsversuch der ephesischen scaenae frons wurde von H. Hörmann vorgelegt ${ }^{82}$. Dieser basiert auf der von G. Niemann vorgeschlagenen Variante 2, unterscheidet sich aber von dieser in folgenden Punkten: Im ersten Geschoss stehen die kleineren Seitentüren in konkaven Säulenstellungen. Für das zweite Geschoss ist ein Sockelfries mit Erotenjagd vorgesehen. Die konkaven Säulenstellungen des dritten Geschosses wurden über den Achsen der Mitteltür und der größeren Seitentüren angeordnet. Hörmann ging davon aus, dass die scaenae frons nicht zu Beginn des 3. Jh. n. Chr., sondern bereits in der Mitte des 2. Jhs. n Chr. um ein Geschoss erhöht wurde.

\section{Bau der Kaiserzeitlichen Theaterfassade (Spätflavisch)}

Proskenion: Das erste kaiserzeitliche Proskenion wird anhand seiner in situ erhaltenen Reste bzw. dessen Stylobat, auf dem die Standspuren der einstigen Pfeiler vorhanden sind, rekonstruiert.

Das Proskenion war an seiner Front durch drei Türen gegliedert, wobei die Mitteltür in der Gebäudeachse besonders groß gestaltet war. Diese wurde von je 11 Stützen flankiert, die aus einem Eckpfeiler und 10 Halbsäulenpfeilern bestanden. Über den Stützen lag ein Triglyphengebälk.

Durch die aktuellen archäologischen Untersuchungen konnte für das Achsensystem der Stützen der ersten kaiserzeitlichen Bühne eine Entstehung in flavischer Zeit nachgewiesen werden ${ }^{83}$. Es galt daher zu prüfen, ob dieser Datierungsansatz auch für den weiteren Aufbau des Proskenion zutrifft. Das Gebälk ist auf den Mauern der seitlichen Eingänge der Parodoi, die mit geringer Veränderung auf dem hellenistischen Fundament aufgebaut wurden, zum Teil in situ erhalten. Es besteht aus einem dorischen Architrav, einem Triglyphen-Metopen-Fries und einem Konsolengesims (Taf. 436 Abb. 770). Architrav und Triglyphon entsprechen in ihrem Aufbau weitgehend der kanonischen dorischen Ordnung, wobei der Architrav jedoch anstelle einer Regula ein unprofiliertes Band aufweist. Im dorischen Gebälk des Proskenion wurde ein Konsolengeison verwendet. Aufgrund der stilistischen Ausführung dieser Architekturen vertrat H. von Hesberg eine Datierung ins 1. Jh. n. Chr. ${ }^{84}$.

\footnotetext{
${ }^{76}$ VON GERKAN 1921, 91.

77 vON Hesberg 1980, 56.

${ }^{78}$ HeBerdey u. a. 1912, 53-94.

79 Heberdey u. a. 1912, Taf. VII.

${ }^{80}$ Heberdey u. a. 1912, Taf. VIII.

${ }^{81}$ Heberdey u. a. 1912, 52.

${ }^{82}$ HöRMAnN 1923/1924, 275-345.

${ }^{83}$ Kap. 3.1.2.

${ }^{84}$ von Hesberg 1980, 50.
} 


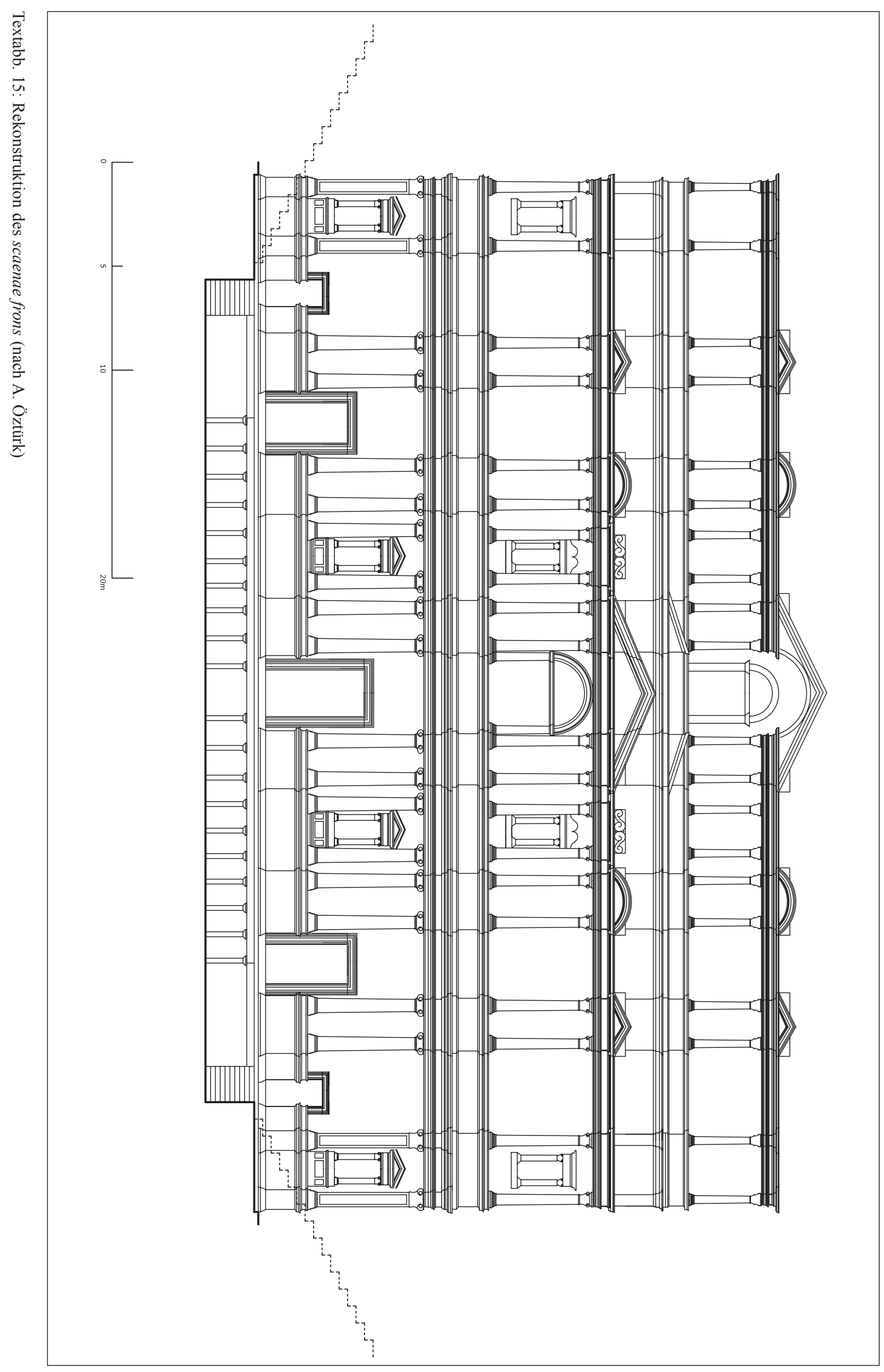


Die dorische Ordnung wurde in Ephesos sowohl bei hellenistischen als auch bei kaiserzeitlichen Bauten verwendet. Die Proportionen der hellenistischen Beispiele und die des augusteischen Prytaneion sind zunächst recht einheitlich ${ }^{85}$. Diese werden jedoch an kaiserzeitlichen Bauten, wie z. B. der Neronischen Halle, variiert, wobei das Verhältnis der Höhe von Architrav und Fries jedoch immer 1:1 beträgt.

Das Konsolengesims des Proskenion hat seine engste Parallele im Attikaabschluss der scaenae frons (Taf. 436 Abb. 771; 437 Abb. 772), der sich in spätflavische Zeit datieren lässt. Zeitstil und Machart der Proskenion- und Attikagesimse sind nahe verwandt. Dies gilt insbesondere für die Profilabfolge, die Motive für die Füllung der Kassetten sowie die sehr flach ausgearbeiteten Ornamente. Ein Unterschied lässt sich nur am Profil der Konsolen des Attikagesimses feststellen und kann in erster Linie durch die unterschiedliche Größe der Werkstücke sowie den Ort ihrer Anbringung erklärt werden.

Einen weiteren Hinweis auf die kaiserzeitliche Datierung der erhalten Reste des Proskenion liefert die Form der Stützen. Entgegen der Meinung W. Wilbergs unterscheiden sich die Halbsäulenpfeiler des ephesischen Proskenion aufgrund ihrer größeren Tiefe und geringeren Breite von der charakteristischen Form der griechischen Proskenionstützen ${ }^{86}$. Die erste Phase des kaiserzeitlichen Proskenion kann daher in flavische Zeit datiert werden.

scaenae frons: Aus der Untersuchung der Bauglieder und des in situ erhaltenen Baubefunds lässt sich die scaenae frons weitgehend rekonstruieren (Textabb. 15) ${ }^{87}$, wobei insbesondere die Architrave eingehend bearbeitet und zum größten Teil zugeordnet wurden. Durch diese konnte die Anordnung der Tabernakel erschlossen werden. Die ephesische scaenae frons bestand aus einer dreigeschossigen Tabernakelfassade ${ }^{88}$. Die Rückwand des ersten Geschosses wurde durch fünf Türen und vier Nischen gegliedert, zwei größere standen auf beiden Seiten der Mitteltür. Außerdem sind vier Ädikulen an der Rückwand nachweisbar. Die acht verkröpften Tabernakel des ersten Geschosses standen auf einer frieslosen Sockelzone. Die diagonal gearbeiteten ionischen Kapitelle tragen ein Gebälk, das über den großen Nischen konkav geformt war. Im zweiten Geschoss wurde die Rückwand durch vier Nischen mit Ädikularahmen und einer zentralen Rundbogennische aufgelöst, die mit einer Halbkuppel bekrönt war. Generell setzt das zweite Geschoss die Achsengliederung des ersten Geschosses fort. Die Säulenstellung des zweiten Geschosses stand ebenfalls auf einer Sockelzone, die jedoch mit einem Erotenjagdfries dekoriert war. Die Säulen ruhten auf attischen Basen. Die Kapitelle waren entweder in korinthischer oder kompositer Ordnung gefertigt ${ }^{89}$. Das Gebälk des zweiten Geschosses war geradlinig und über den Sockeln verkröpft. Abgesehen davon besaß das Gebälk je eine Verkröpfung neben der Symmetrieachse über den großen Nischen des ersten Geschosses. Der Mittelteil des zweiten Geschosses war von einem gesprengten Giebel abgeschlossen. In den mittleren Tabernakeln waren abwechselnd dreieckige und segmentförmige Giebel verbaut. Ein Block mit S-förmigen Voluten lag auf dem verkröpften Gebälk neben der Symmetrieachse. Das dritte Geschoss war zurückgesetzt und stand auf der Attikamauer des zweiten Geschosses. Eine kleine Nische mit Halbkuppel befand sich wahrscheinlich im mittleren Tabernakel. Die dritte Säulenordnung erhob sich über einer Sockelzone mit einem Girlandenfries. Die Säulen korinthischer Ordnung trugen ein konkaves Gebälk. Die drei mittleren Interkolumnien wurden höchst wahrscheinlich mit einem >syrischen Giebel überspannt. Die seitlichen Tabernakel waren von Rundund Dreiecksgiebeln überdeckt.

\footnotetext{
${ }^{85}$ Zur dorischen Ordnung in Ephesos s. ÖZTüRK 2010, 337 Abb. 8.

${ }^{86}$ Zum Vergleich der ephesischen Halbsäulenpfeiler mit den griechischen Proskenionstützen s. ÖzTüRK 2010, 337 Abb. 7.

${ }^{87}$ An dieser Stelle soll die neue Rekonstruktion nur kurz dargestellt werden, da eine steingerechte Rekonstruktion mit der Zuordnung aller erhaltenen Bauglieder und ein umfassender Vergleich aller Rekonstruktionen zur ephesischen Bühnenfront der Endpublikation vorbehalten bleiben. Zu den Hauptargumentationen der Rekonstruktion zur ephesischen scaenae frons s. ÖzTÜRK 2010, $338 \mathrm{f}$.

${ }^{88}$ Die Bühnenfassade stand im Osten des Bühnengebäudes. Aus den baulichen Befunden von G. Niemann (HeBERDEY u. a. 1912, 84 Abb. 171) und M. Hofbauer (Kap. 3.1.4) geht hervor, dass die scaenae frons nach Norden und Süden fortgesetzt war. In der Endpublikation wird auch die Rekonstruktion der Seiten des Bühnengebäudes näher untersucht werden. Vgl. ÖzTÜRK (in Vorbereitung) mit Beiträgen von $\mathrm{M}$. Hofbauer.

${ }^{89}$ Von beiden Typen wurde je ein Kapitell aufgefunden, deren Dimension und Dekoration gut mit den Säulenschäften des zweiten Geschosses kombiniert werden kann. Dieses Problem konnte noch nicht gelöst werden.
} 
Datierung: Den Ergebnissen der Ausgräber zufolge wurde die scaenae frons zunächst als zweigeschossige Fassade errichtet und später um ein weiteres Geschoss ergänzt ${ }^{90}$. Wie bereits erwähnt, wurde die erste Bauphase anhand einer Weihinschrift auf dem Architrav des ersten Geschosses in das Jahr 66 n. Chr. datiert ${ }^{91}$. Die zweite Bauphase, die die Errichtung des dritten Geschosses beinhaltete, wurde in der älteren Forschung aufgrund eines Epigramms aus der Zeit des Commodus an das Ende des 2. und den Beginn des 3. Jhs. n. Chr. gesetz ${ }^{92}$. Es erwies sich aber, dass dieser Inschriftenblock erst nachträglich im Zuge einer Reparatur verbaut wurde, wodurch er keinen direkten Hinweis für die Datierung der Errichtung des dritten Geschosses liefert. Daher soll die durch die Weihinschrift auf dem Architrav in das Jahr 66 n. Chr. vorgegebene Datierung durch eine stilistische Untersuchung der Bauornamentik im Folgenden zusätzlich überprüft werden.

In der Architravinschrift ist der Kaisername eradiert, erhalten ist aber der Titel Neokoros. Ausgehend von der Überlegung, dass der Name Neros eradiert wurde, schlussfolgerte R. Heberdey, dass die beiden unteren Geschosse 66 n. Chr. fertiggestellt wurden. Aber bereits 1919 konnte J. Keil beweisen, dass Ephesos seine erste Kaiserneokorie erst unter Domitian erhielt. Der eradierte Kaisername der Architravinschrift ist daher auf Domitian zu ergänzen. Da die Inschrift den Titel des Kaisers als »11. consul« nennt, lässt sich die Einweihung der scaenae frons in das Jahr $85 \mathrm{n}$. Chr. datieren ${ }^{93}$.

Für die stilistische Untersuchung der beiden ersten Geschosse werden im Folgenden Eierstäbe und Akanthusblätter herangezogen (Taf. 437 Abb. 773; 438 Abb. 774). Im ersten Geschoss ist die Gestaltung der Eier recht einheitlich, hingegen unterscheiden sich nach der Art der Verbindung von Schale und Zwischenblatt drei Typen. Bei einem steht die tief ausgearbeitete Trennung von Ei und Schale in auffälligem Gegensatz zum flachen Relief im Bereich zwischen Schalenaußenseite und Zwischenblatt. Dieser Typ findet sich auch im Gesims des zweiten Geschosses. Ein Eierstab dieses Typs ist auch am Laecanius Bassus Nymphäum erhalten, das mit einer Inschrift in das Jahr 79 oder $80 \mathrm{n}$. Chr. datiert wird ${ }^{94}$.

Die Konsolen des Gesimses des zweiten Geschosses werden von je einem Akanthusblatt unterfangen (Taf. 438 Abb. 774). Die einzelnen Blattfinger des Akanthusblatts liegen nicht in einer Ebene, sondern sind gegeneinander zickzackartig abgestuft. Die Bohrkanäle an beiden Seiten der Mittelrippe laufen nicht bis zum Ansatz der Mittelrippe durch, sondern werden an ihrem unteren Abschluss mit flacheren, gemuldeten Rillen fortgesetzt. Dieselbe Akanthusform kommt an zwei anderen Bauten flavischer Zeit in Ephesos vor: dem Laecanius Bassus Nymphäum und dem Domitiansbrunnen (Taf. 438 Abb. 775. 776) ${ }^{95}$.

Für das dritte Geschoss sollen an dieser Stelle die Pilasterkapitelle und der Lotos-Palmetten-Fries behandelt werden (Taf. 439 Abb. 777. 778; 440 Abb. 779. 780). Vorweg muss jedoch ein singulär stehendes Kompositkapitell behandelt werden, welches von G. Niemann auch dem dritten Geschoss zugeordnet wur$\mathrm{de}^{96}$. Die Zuweisung Niemanns erwies sich aber als nicht zutreffend. Aufgrund seiner Dimensionen kann das Kompositkapitell nicht den Säulen des dritten Geschosses zugeordnet werden, zudem ist es anhand von Vergleichen mit den Kapitellen des Vediusgymnasiums in antoninische Zeit zu datieren ${ }^{97}$. Maßgeblich für die Rekonstruktion und Datierung des dritten Geschosses ist jedoch eine Reihe von korinthischen Pilasterkapitellen, die aufgrund ihrer Ausmaße und Form ausschließlich vom dritten Geschoss stammen können. Die spätflavischen Kapitelle aus Ephesos weisen bestimmte Charakteristika auf, z. B. reichen die Akanthusblätter in ihrer ganzen Höhe nicht über die untere Kapitellhälfte hinaus ${ }^{98}$. Das Hochblatt setzt erst oberhalb der halben Kranzblatthöhe an und aus einem unverzierten Caulis wächst ein großer und breiter, zweiteiliger Hüllkelch heraus. Da sämtliche Pilasterkapitelle des dritten Geschosses diese Charakteristika aufweisen, lassen sie sich einheitlich in domitianische Zeit datieren ${ }^{99}$.

\footnotetext{
${ }^{90}$ Heberdey u. a. $1912,47-52$.

${ }^{91}$ Heberdey u. a. 1912, 157-160.

92 Heberdey u. a. $1912,109-112$.

${ }^{93}$ Ich danke F. Dönmez-Öztürk für ihre Hinweise zu dieser Inschrift.

${ }^{94}$ RathmaYr 2011, 131 Anm. 4.

${ }^{95}$ Der Domitiansbrunnen ist durch eine Inschrift in das Jahr 92 oder 93 n. Chr. datiert, s. BAMmER 1978/1980, 67.

${ }^{96}$ Heberdey u. a. 1912, 86. 88 Abb. 188.

${ }^{97}$ Strocka 1981, 128.

${ }^{98}$ PlattNer 2003, 51-54.

${ }^{99}$ PlattNer 2003, 51-54.
} 
An dem Lotos-Palmetten-Fries wechseln fünfteilige Lotosblüten stereotyp mit geschlossenen siebenteiligen Palmetten ab, sie sind durch Bodenranken miteinander verbunden. Die Spitzen der Blütenblätter berühren die geschlossenen Palmetten, die Blüte hat gezackte Seitenblätter. Die Blattkehlen sind mit dem Bohrer vertieft. Die engste Parallele des Lotos-Palmetten-Frieses ist am Kopfprofil des Architravs des ersten Geschosses erhalten. Zeitstil und Machart der beiden Friese sind nahe verwandt.

Mit Hilfe dieser kurzen stilistischen Analyse konnte gezeigt werden, dass sowohl das zweite als auch das dritte Geschoss der domitianischen Zeit angehören. Es lässt sich somit abschließend feststellen, dass alle drei Geschosse der scaenae frons sowie die erhöhte Bühne mit der dorischen Ordnung (Proskenion) in spätflavischer Zeit entstanden sind.

Die scaenae frons des Theaters zählt, wie auch die Prachtfassade des Laecanius Bassus Nymphäums, nicht nur zu den ersten Tabernakelfassaden in Ephesos, sondern stellt darüber hinaus auch eine der ersten dreigeschossigen Fassaden in der Stadt dar.

\section{Umbau des Kaiserzeitlichen Proskenion (Antoninisch?)}

Zur Zeit der ersten österreichischen Ausgrabungen war das Proskenion zum Teil noch in situ erhalten ${ }^{100}$. Die reckeckigen Pfeiler der Fassade standen zum größten Teil aufrecht, zwischen ihnen befanden sich Mauerreste. Zur Orchestra hin war die Fassade - wie Reste zeigen - mit Marmor verkleidet. Dieser Erhaltungszustand entspricht nicht der originalen Fassade, sondern steht im Zusammenhang mit einer späteren Umbauphase: Ursprünglich (in flavischer Zeit) trugen die Halbsäulenpfeiler ein Gebälk in dorischer Ordnung. Im Zuge der Anbringung der Marmorverkleidung dürften die Halbsäulen der Stützen abgearbeitet und das dorische Gebälk entfernt worden sein. Nach diesen Umbaumaßnahmen blieb das dorische Gebälk nur an den seitlichen Eingängen der Paradoi erhalten, da die Marmorverkleidung an den Seiten der Fassade nicht ausgeführt wurde.

Aus den archäologischen Untersuchungen geht hervor, dass die zwei Reihen der Pfeilerstellung, die im Logeion erhalten sind und direkt östlich des massiven Unterbaus der scaenae frons stehen, in antoninische Zeit datieren ${ }^{101}$. Es ist naheliegend, diese umfangreichen Umgestaltungen im Logeionbereich mit den Veränderungen an der Proskenionfassade in antoninischer Zeit in Verbindung zu bringen.

A. ÖZTÜRK

\subsubsection{Kaiserzeitliches Bühnengebäude}

Durch die großangelegte Umgestaltung des Theaters in flavischer Zeit erhielt das Bühnengebäude nicht nur seine prachtvolle dreigeschossige Fassade im Osten (Textabb. 15), sondern es wurde durch eine weitere Raumflucht im Westen deutlich vergrößert (Tab. 127; Taf. 12 Abb. 20; 13 Abb. 21; 430 Abb. 758) ${ }^{102}$. Dabei wurde die angrenzende Abfolge des hellenistischen Baus von acht Kammern und einem Durchgangskorridor in der Mitte aufgenommen. Jedoch gibt es mit Ausnahme der äußeren Kammern D1/E1 und D8/E8 und dem Durchgang $\mathrm{C}$ keine Verbindung zwischen den hellenistischen und den neu errichteten Kammern flavischer Zeit (Taf. 3 Abb. 3). Das betrifft sowohl das Untergeschoss als auch das hellenistische Obergeschoss. Weder die Raumhöhe der angebauten Kammern lässt sich bestimmen noch eine Ausführung entweder als flache Decke oder als Gewölbe. Klar ersichtlich ist nur, dass die Höhe der Kammern die Höhe des hellenistischen Untergeschosses deutlich überragt.

M. Hofbauer

\footnotetext{
${ }^{100}$ Heberdey u. a. 1912, 30-34.

${ }^{101}$ Kap. 3.2.2.

102 Zur kaiserzeitlichen Umgestaltung des Bühnengebäudes s. den Beitrag von M. Hofbauer in der abschließenden Publikation ÖzTÜRK (in Vorbereitung).
} 


\subsubsection{Kaiserzeitliche Orchestra}

Die scaenae frons nimmt den Platz des älteren hellenistischen Proskenion ein. Daraus ergibt sich für die über sechs Meter tiefe kaiserzeitliche Bühne eine Position, die weit in die ursprüngliche Orchestra hineinragt und diese dadurch nachhaltig verkleinerte (Taf. 78 Abb. 153). Beim Umbau wurden die alten Analemmata P und Q belassen (Taf. 12 Abb. 20; Plan 10. 18). Durch die nach Osten zurückgesetzten neuen Analemmata kam es auch zur Verlegung der Parodoi. Diese nun gedeckten Zugänge befinden sich seither entlang der Ostseite der Mauern P und Q. Vermutlich wurden auch die untersten Sitzreihen entfernt. Nicht genau zu erfassen ist jedoch der Umfang dieser baulichen Maßnahme und es bleibt unklar, ob diese Strukturen bereits in flavischer Zeit bis an die heute sichtbare Orchestrawand X (Taf. 444 Abb. 789; 445 Abb. 790) entfernt wurden. Zur flavischen Orchestra ist aber der Profilring $\mathrm{J}$ außerhalb des Orchestrakanals zu rechnen. Am Niveau der Orchestra änderte sich nichts. Auch der hellenistische Kanal blieb weiterhin erhalten. Er wurde innen mit opus signinum versiegelt und erhielt eine Abdeckung, von der die Abarbeitungen an den Oberkanten der Kanalwandungen zu erkennen sind. Vom Bodenbelag ist nichts erhalten geblieben. Praktisch der gesamte Bereich der Orchestra wurde später angehoben und ein neuer Unterbau für das Platzniveau eingezogen.

Eine Inschrift aus der Mitte des 2. Jhs. n. Chr. erwähnt einem Umbau am Proskenion und Logeion ${ }^{103}$. Damit dürfte eine größere Umgestaltung vonstatten gegangen sein, die nicht nur die Bühne in ihrer Gesamtheit betraf, sondern auch die Orchestra mit einbezog. Das dorische Proskenion mit Halbsäulen und MetopenTriglyphen-Fries (Taf. 81 Abb. 159-161; 436 Abb. 770) wurde beseitigt und eine durchlaufende Wand mit drei Durchgängen und zwei Nischen geschaffen. Die gesamte Front erhielt eine Marmorverkleidung, von der Reste noch in situ erhalten sind. Obzwar wir keinerlei epigrafische Evidenz für einen gleichzeitigen Umbau der Orchestra erhalten haben, scheint das Anheben des Orchestraniveaus um ca. 0,30 m doch derselben Phase wie die Neugestaltung der Bühne anzugehören und zu einer geringen Reduzierung der geschlossenen Bühnenfront geführt zu haben. Der alte Orchestrakanal wurde endgültig aufgegeben. Anstelle des hellenistischen Kanals wurde an gleicher Position, aber auf höherem Niveau, ein neuer, etwas flacherer Kanal errichtet, der wiederum offen verlief (Taf. 88 Abb. 174; 89 Abb. 177. 178; 90 Abb. 179 ). Wenn dies nicht bereits in flavischer Zeit realisiert worden ist, dann wurde spätestens jetzt die Orchestra bis an die Orchestrawand $\mathrm{X}$ erweitert.

M. HOFBAUER

\subsubsection{Kaiserzeitliche Cavea}

\subsubsection{FrühKaiserzeItLiche BaUAKTIVITÄTEN}

Der erste nachweisbare Eingriff in die Bausubstanz des Koilon betrifft die Anlage des Zugangs ES3 zur Erschließung des oberen Rangs (Tab. 127) ${ }^{104}$. Das Portal wurde in Fortführung der Akademiegasse nachträglich in die südliche Außenwand des Theaters eingebaut (Plan 5). Der Zugang ist 4,10 bis 4,20 m breit und wird mit einem Werksteingewölbe aus weißem Marmor überdeckt. In der Ansicht zeigen die Archivolten des Gewölbes eine Gliederung mit drei Faszien. Die Seitenwände sind mit Orthostatenplatten verkleidet. Über eine ursprünglich an der Innenarchivolte des Zugangs befindliche Inschrift, die als Stifter des Zugangs einen Hieron Aristogiton nennt, erfolgte die Einordnung der Baumaßnahme in augusteische bis frühtiberische Zeit ${ }^{105}$. An der südlichen Theateraußenwand ist zu erkennen, dass der Einbau des Eingangs eine Störung im pseudoisodomen Quadermauerwerk der Fassade verursachte (Taf. 441 Abb. 781). Zudem zeigte sich in der Sondage B1/C1 der ursprüngliche Verlauf der Außenwand, von der die Ausrichtung des Eingangs um ca.

\footnotetext{
${ }^{103}$ IvE 2039. Dazu auch Kap. 8.6.1, Nr. 9 u. Kap. 8.6.2.

104 Kap. 10.1.3.

${ }^{105}$ IvE 2033. Vgl. Heberdey u. a. 1912, 15. Die Bogenquader der Archivolte liegen mehrheitlich nicht mehr in situ. R. HeBerdeY und W. WILBERG fanden die mittleren drei Quader mit der Inschrift offenbar in Versturzlage nebeneinander im Schutt an der Innenseite des Portals. Heute sind die Bogenquader auf den restaurierten Sitzstufen neben dem Zugang aufgestellt. Zur Datierung s. auch MAYER 1995, 68.
} 
$12^{\circ}$ nach Norden abweicht ${ }^{106}$. Weitere bauliche Auffälligkeiten finden sich an der Innenseite im Bereich des Stufenbaus, denn der Zugang ist nicht wie üblich in Theatern an eine horizontale Verteilerebene angeschlossen. In Fortführung des Gassenniveaus konnte im Koilon sogar durch die Anordnung zusätzlicher aufwärts führender Treppenstufen lediglich ein Podest in Höhe der dritten Sitzstufe unterhalb des Diazoma erreicht werden (Taf. $441 \mathrm{Abb}$. 782). Insgesamt erscheint die Eintrittssituation in das Theater hier funktional und gestalterisch unbefriedigend gelöst, was sich jedoch durch die aus dem Bestand resultierenden Zwänge begründen ließe. Ob es einen vergleichbaren Zugang auch im Norden gegeben hat, ist aufgrund des Erhaltungszustands und der verstürzten Architektur vor der nördlichen Theateraußenmauer derzeit nicht zu beantworten ${ }^{107}$.

Für die frühe Kaiserzeit bzw. die 1. Hälfte des 1. Jhs. n. Chr. lassen sich auf Basis der archäologischen Fundkomplexe punktuell auch für das obere Diazoma sowie das Mittelpodest im südlichen Abschnitt des vomitorium EN1 Baumaßnahmen nachweisen, deren Umfang jedoch derzeit nicht abschließend geklärt werden $\mathrm{kann}^{108}$. So bleibt offen, ob die genannten Maßnahmen bereits Teil einer größeren Umbauplanung im Theater waren. Charakter und Einbausituation des zuvor beschriebenen oberen südlichen Zugangs ES3 sprächen allerdings eher für eine singuläre Maßnahme.

\subsubsection{Die Erweiterungen des Auditorium unter den Kaisern Domitian bis Trajan}

Entsprechend den inschriftlichen Zeugnissen können die umfangreichsten Veränderungen im Theater in die Regierungszeit des Kaisers Domitian eingeordnet werden ${ }^{109}$. Dazu zählen die Erweiterung des Bühnengebäudes mit der Errichtung der scaenae frons sowie dem weit in die hellenistische Orchestra hineinreichenden kaiserzeitlichen Logeion. Durch diese Eingriffe wurden außerdem bauliche Adaptionen im Bereich der Parodoi sowie an den unteren Sitzreihen um die Orchestra erforderlich. Im Auditorium ergänzte man den oberen Rang in Richtung Westen und integrierte dabei gleichzeitig ein neues Erschließungssystem. Auch eine der vier die Stadt Ephesos versorgenden Fernwasserleitungen, die Aristion-Leitung, wurde in dieser Bauperiode durch das Theater verlegt (Tab. 127; s. u.). Ihren Abschluss fanden die Arbeiten am Südflügel des Auditorium unter Kaiser Trajan. Im Folgenden wird auf die wesentlichen Maßnahmen im Zuschauerraum einzeln eingegangen.

\section{Orchestra, Parodoi und ima cavea}

Der großzügige Ausbau des hellenistischen Bühnengebäudes in flavischer Zeit hatte zwangsläufig auch bauliche Konsequenzen für die Orchestra, die hellenistischen Parodoi sowie die unteren Bereiche der Sitzreihen im Koilon. Die prinzipiellen Veränderungen im Bühne-Orchestra-Komplex wurden bereits von R. Heberdey und W. Wilberg beschrieben (Taf. 442 Abb. 783. 784). Die aktuelle Bauforschung erlaubt es nun, ihre Erkenntnisse zu ergänzen bzw. teilweise zu präzisieren. Dabei soll an dieser Stelle der Schwerpunkt auf den Adaptionen am Koilon liegen. Hinsichtlich der Umgestaltung des Bereichs von Skene und Proskenion sowie in der Orchestra sei auf die entsprechenden Kapitel zur Archäologie im Bühne-Orchestra-Komplex verwiesen ${ }^{110}$. Eine grundsätzliche Modifikation betraf die Parodoi als wichtige Erschließungsmöglichkeit des hellenistischen Theaters. Die Errichtung der scaenae frons mit der um ca. 6,0 m in die Orchestra hineinreichenden Spielfläche des neuen kaiserzeitlichen Logeion versperrte jedoch zunächst die nördliche und südliche Parodos ${ }^{111}$. Zur Aufrechterhaltung eines, wenn auch eingeschränkten, Zugangs zur Orchestra wurden östlich der bestehenden Parodoi neue überdeckte Zugänge von 2,00 bis 2,10 m Breite angelegt, indem man - wie es bereits in der Erstpublikation vereinfacht dargelegt wurde - »die unteren Enden der äußersten

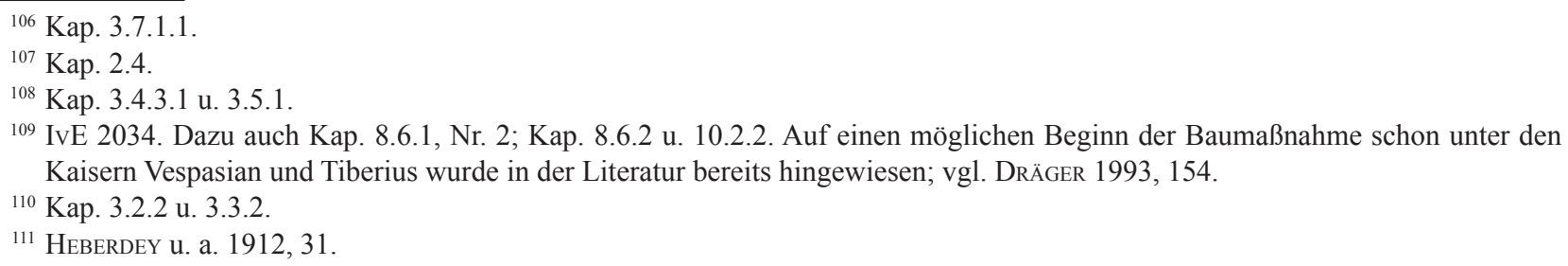


Sitzstufenkeile um etwa 1,50 m verschmälert « ${ }^{112}$. Dazu mussten mindestens die inneren Abschnitte der hellenistischen Analemmata mit dem angrenzenden Stufenbau abgetragen werden. Marmorbauteile dieser Fassaden fanden eine Wiederverwendung beim Aufbau der neuen Parodoswände, wie einige Spolien mit sichtbaren Kontaktflächen für den Stufenbelag der ehemaligen westlichsten Klimakes zeigen (Taf. 433 Abb. 764). Die ursprünglichen Analemmata bilden im Bereich des Logeion fortan die westliche Begrenzung der neuen Parodoi, wobei jedoch nur wenige Bauteile, wie z. B. am orchestraseitigen Beginn des hellenistischen Nord-Analemma, in situ blieben ${ }^{113}$. Ansonsten wurden die Analemma-Fundamente genutzt, um die orchestraseitigen Abschnitte der neuen Parodos-Westwände aus den abgetragenen Bauteilen neu aufzurichten. Schon nach wenigen Metern ändern die Parodoi jedoch ihre Ausrichtung leicht nach Westen und verlassen damit die Flucht der ursprünglichen Analemmata, um schließlich in einem stumpfen Winkel parallel zu den Stirnwänden des Bühnengebäudes nach Westen abzubiegen. In der Nord-Parodos wird dadurch der entlang des hellenistischen Analemma aus dem Theater herausführende Abschnitt des Entwässerungskanals um die Orchestra gekreuzt. Wie die Ableitung des Oberflächenwassers hier fortan gelöst war, kann derzeit nicht mehr nachvollzogen werden ${ }^{114}$.

Die Überdeckung der Parodoi erfolgte mit segmentbogenförmigen Gewölben aus Bruchstein, die auf einer Kämpferzone aus Marmor aufliegen. An den westlichen Eingängen sowie zur Orchestra ist die Überdeckung als Werksteingewölbe in weißem Marmor ausgeführt, wobei es sich bei diesen Bauteilen ebenfalls um Spolien handelte (Taf. 442 Abb. 785; 443 Abb. 786). Der starke Materialgegensatz zwischen dem Bruchsteingewölbe und den Marmoroberflächen der Wände oder dem partiellen Werksteingewölbe könnte dafür sprechen, dass im Bereich des Bruchsteingewölbes noch ein Putz geplant war. Oberhalb des Gewölbes entstand in Höhe des Laufniveaus des Logeion eine Plattform, die mit weißen Marmorplatten eingedeckt ist und von Norden bzw. Süden durch eine Rampe erschlossen wird (Rampe N und S) (Taf. 2 Abb. 2; 443 Abb. 787). Gegen Osten war auch hier eine neue Fassade zum Abschluss der ansteigenden Sitzstufen erforderlich. Diese jeweils innersten Wandbereiche der heute erhaltenen Analemmata zeigen jedoch im Grundriss eine andere Ausrichtung als die unterhalb verlaufenden östlichen Parodoi-Wände. Mit einem Teil sitzen die innersten Wandbereiche der Analemmata sogar auf dem Gewölbe der jeweiligen Parodos-Überdeckung auf, was bedeutet, dass sie erst nach Fertigstellung der Gewölbe bzw. der Plattform errichtet worden sein können (vgl. dazu unten die Darstellungen zum Nord- und Südflügel des Theaters). Der Anschluss der nördlichen und südlichen Rampe an die Plattform erfolgt erst außerhalb der Parodos-Grundrisse (Taf. 444 Abb. 788).

Eine weitere Adaption, die aufgrund der Veränderungen an den Parodoi ausgelöst wurde, betraf die unteren Sitzreihen des hellenistischen Koilon. Die ursprüngliche Eintrittssituation in die Orchestra war durch die Errichtung der neuen Bühne versperrt. Das bedeutete in Folge, dass die Radialtreppen des unteren Rangs von der Orchestra aus unzugänglich wurden. Um diese räumlichen Zwänge zu lösen, muss eine Veränderung an den unteren Sitzreihen stattgefunden haben. Schon R. Heberdey und W. Wilberg vermuteten, dass man bereits zu dieser Zeit die Prohedrie vollständig oder mindestens teilweise beseitigte, um so durch einen zusätzlichen Umgang außerhalb des hellenistischen Entwässerungskanals um die Orchestra eine neue Erschließungsmöglichkeit zu schaffen ${ }^{115}$. Die Wegnahme der unteren Sitzreihen bis in Höhe des Logeion und die Errichtung der Orchestrawand X wurden von ihnen jedoch erst der nachtrajanischen Zeit zugeordnet und mit den ungünstigen Sehverhältnissen in Bezug auf den erhöhten Spielplatz des Logeion begründet ${ }^{116}$. Am Bestand ließ sich eine etappenweise Veränderung der unteren Sitzreihen nicht nachvollziehen. Jedoch fällt auf, dass die orchestraseitigen Eingänge in die überdeckten Parodoi, die wie oben beschrieben mit einem Werksteingewölbe aus weißen Marmorspolien gearbeitet waren, nahe den westlichen Abschlüssen der heute sichtbaren Orchestrawand X liegen. Dass die Eingänge in die Parodoi ursprünglich eine Ansichtsfläche darstellten, zeigt auch das in Rohform angelegte Profil der zur Orchestra gelegenen Archivolten (Taf. 442 Abb. 785). Diese Situation wurde nachfolgend mehrmals umgebaut, wie die stumpf aneinanderstoßenden Wandabschnitte der orchestraseitigen Parodoi-Wände zeigen. An der Orchestrawand X ist selbst im heutigen restaurierten Bestand abzulesen, dass sich die Radialtreppen zunächst zur Orchestra öffneten. Dabei war der

\footnotetext{
${ }^{112}$ Heberdey u. a. 1912, 39.

${ }^{113}$ Kap. 3.2.2 u. 3.3.2.

${ }^{114}$ Kap. 3.2.2.4.

${ }^{115}$ HeBerdey u. a. 1912, 31 f. Abb. 57; s. auch Kap. 3.3.

${ }_{116}$ Heberdey u. a. 1912, 44 f. Abb. 86.
} 
untere Antritt der Treppen, ähnlich wie auf den Diazomata, durch seitliche Orthostatenplatten eingefasst, deren Stirnseiten ein Gestaltungsmotiv der Wand darstellten (Taf. 444 Abb. 789). Die Oberseite der Wand bekrönte ein Profil (Taf. 445 Abb. 790a. b) ${ }^{117}$. Es wäre also aufgrund der genannten Befunde zumindest zu hinterfragen, ob die Wegnahme der unteren Sitzstufen in mehreren Phasen erfolgte oder nicht vielmehr die bis heute erhaltene Ausdehnung der Orchestra bereits infolge der domitianischen Veränderungen an der Bühne und den Parodoi hergestellt wurde. Auch die Erwähnung von Gladiatorenkämpfen und Tierhetzen in der am Süd-Analemma angebrachten Ehreninschrift für Titus Flavius Montanus ${ }^{118}$, die zwischen 102 und $112 \mathrm{n}$. Chr. datiert wird, setzt eine dem Zweck entsprechende arenaartige Gestaltung der Orchestra voraus. In späteren Perioden erfolgten dann weitere Umbauten und Adaptionen ${ }^{119}$.

\section{Nordflügel des Theaters}

Soweit es sich nachvollziehen lässt, wurde mit der Erweiterung des Auditorium am Nordflügel des Theaters begonnen (Tab. 127). Hier sind gleich mehrere Baumaßnahmen ablesbar. Zum einen öffnete man einen Teil des bestehenden oberen Rangs von der nördlichen Außenwand bis zum mittleren Diazoma, um ein hohes, tonnenüberwölbtes vomitorium EN2 einzubauen (Taf. 2 Abb. 2; 146 Abb. 294). Der Unterschied zwischen dem Laufniveau außerhalb des Theaters und dem Eintrittspodest auf das mittlere Diazoma von ca. $6,40 \mathrm{~m}$ wurde durch eine Treppe im vomitorium überwunden (Textabb. 16) ${ }^{120}$ Unterhalb der Treppe tritt die Wasserleitung des Claudius Aristion in das Gebäude ein und verläuft direkt an der östlichen Wand des vomitorium nach Süden. Daraus sowie aus den Schnittstudien von vomitorium und Wasserleitung wird deutlich, dass es sich um eine gemeinsame Baumaßnahme handeln muss (Textabb. 17). Vorstellbar ist außerdem, dass das von Norden ankommende Niveau der Trasse sowie ein möglichst effizienter Leitungsverlauf im Theater für die Anordnung und Ausrichtung des vomitorium ausschlaggebend waren. Das könnte auch erklären, weshalb sich der Zugang nicht wie die übrigen vomitoria im Theater in Richtung Orchestra orientiert.

Die Sitzbereiche im nördlichen Flügel des hellenistischen Koilon lagen bereits außerhalb des nutzbaren Berghangs. Wie die Rangneigung hier ursprünglich hergestellt war, lässt sich nicht mehr nachvollziehen. Wie aus anderen hellenistischen Theatern bekannt, waren massive Schichtungen oder Aufschüttungen üblich $^{121}$. Heute sichtbar sind die Substruktionskammern aus opus caementitium, die man in Zusammenhang mit dem Einbau des vomitorium EN2 anstelle der vorherigen Konstruktion errichtete. Die übereinander angeordneten Hohlkammern wurden mit geringem Abstand zur Innenseite der bestehenden Theateraußenwand aufgebaut. Der Zwischenraum war eventuell mit einer losen Schüttung verfüllt. Sichtbar ist diese Situation etwas westlich oberhalb des vomitorium EN2. Hier liegen die Quader der älteren Umfassungswand an ihrer Innenseite auf eine längere Strecke frei und zeigen keinerlei Kontakt zu anderen Bauteilen bzw. Anhaftungen anderer Materialien (Taf. 445 Abb. 791) ) $^{122}$.

Eine weitere Baumaßnahme ist westlich des Zugangs EN2 abzulesen. Hier beginnt die bauliche Erweiterung des Auditorium. An der nördlichen Umfassungswand des Theaters ist dies zunächst durch den Materialwechsel der Wandquader erkennbar (Plan 4). Verzahnt mit den bestehenden Polsterquadern aus grauem Marmor der älteren Theateraußenwand wurde die Fassade nun in glatten, weißen Kalksteinquadern Richtung Westen weitergeführt. Da der überwiegende Teil dieses Wandabschnitts sich lediglich noch hinter einer im 4. Jh. n. Chr. vorgelagerten Verstärkungswand erhalten hat, ist heute vor allem die Nahtstelle der ehemaligen Verzahnung beider Fassaden auffällig (Textabb. 19; Taf. 472 Abb. 844).

Im Abstand von annähernd $20 \mathrm{~m}$ zum vomitorium EN2 wurde in das neue Bauvolumen ein Zugang EN1 zum unteren Diazoma integriert. Dieser war als ca. $40 \mathrm{~m}$ lange, hoch überwölbte Passage ausgelegt, die westlich

\footnotetext{
${ }^{117}$ Heberdey u. a. 1912, 45 Abb. 93.

${ }^{118}$ IvE 2061. Dazu auch Kap. 8.6.1, Nr. 6 u. Kap. 8.6.2.; SCHERRER 1997, 114.

${ }^{119}$ Kap. 10.2.4.3.

${ }^{120}$ Die Treppe im vomitorium EN2 ist heute bis zum Austritt auf das Diazoma verfüllt. St. Karwiese legte die oberen Stufen der Treppe in einer Sondage frei, s. Kap. 3.5.2.1.

${ }^{121}$ Kap. 10.1.3.

${ }^{122}$ Die im restaurierten Bestand angelegte Trittstufenfolge ist eine moderne Maßnahme aus der Zeit der Konsolidierungsarbeiten 1994 bis 1998. Nach Auskunft des damaligen Grabungsleiters St. Karwiese befindet sich darunter loses Schüttmaterial. Eine Dokumentation der originalen Situation ist nicht bekannt.
} 

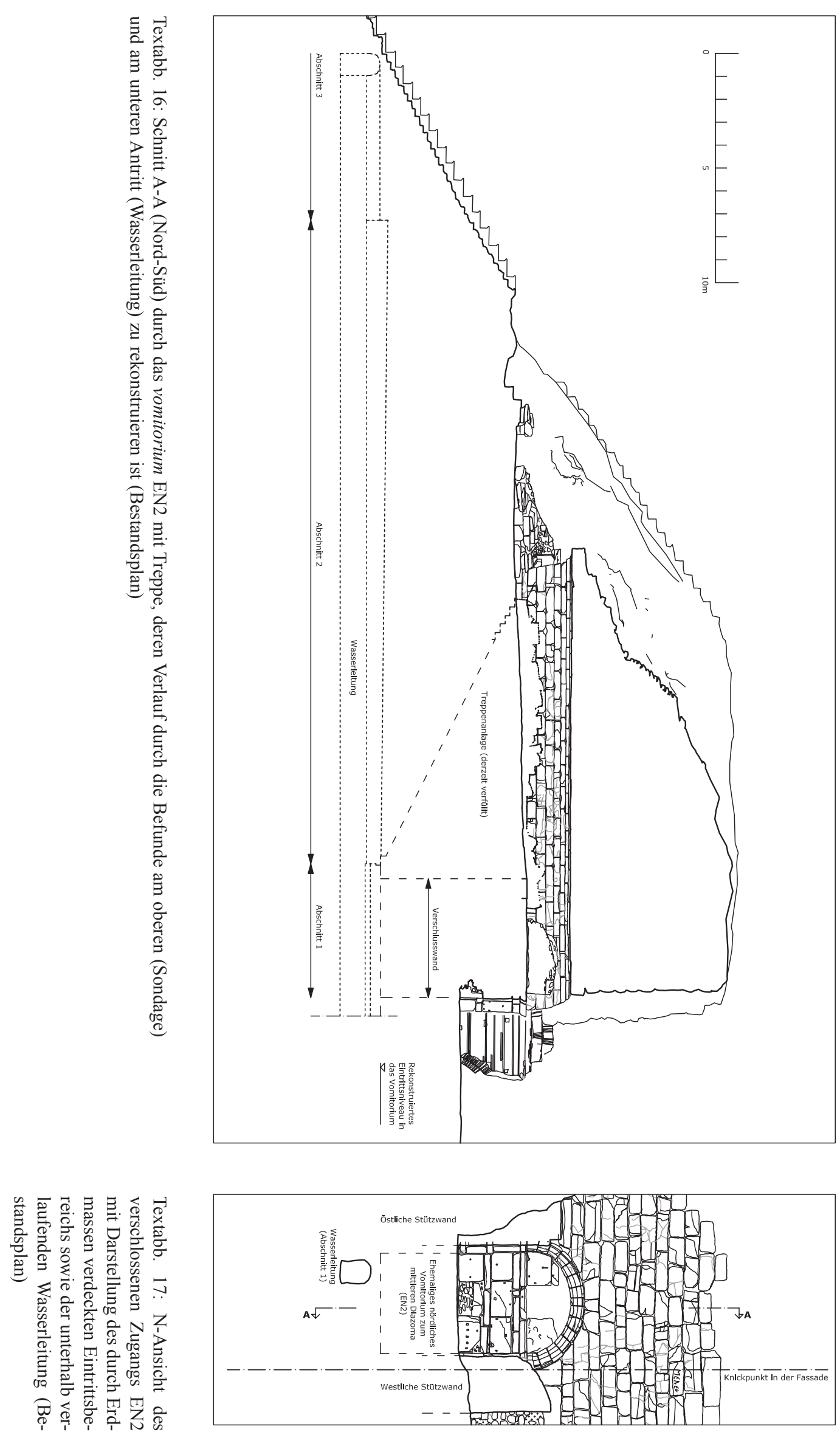
mehrere nutzbare Kammern flankierten (Plan 1; Textabb. 19). Die Kammern konnten von der Passage aus betreten werden. Einen weiteren Zugang zum vomitorium ermöglichte ein Treppenaufgang von Westen (EN1 West) ${ }^{123}$.

Alle das vomitorium begrenzenden Bauteile der Wände und des Gewölbes bestanden, wie schon im oberen Zugang EN2, aus weißem Marmor. Die Trennwände zwischen den angelagerten Kammern KN1 bis KN3 hingegen waren wie die nördliche Außenwand in weißen Kalksteinquadern ausgeführt. In seinem Verlauf gliederte sich das vomitorium in drei Abschnitte, die sich sowohl in ihrer linearen Ausrichtung als auch in Durchgangsbreite und Raumhöhe voneinander unterschieden. Zusätzlich waren der südliche und der mittlere Abschnitt durch einen vergleichsweise niedrigen Durchgang getrennt, dessen Bauelemente viele Auffälligkeiten zeigen und in der Ausführung nicht den Baugliedern in den übrigen Abschnitten des vomitorium entsprechen (Textabb. 18). Insgesamt ergibt sich der Eindruck, dass beim Bau des groß angelegten Erschließungskorridors, besonders im Bereich unterhalb des ehemaligen mittleren Rangs, auf bereits bestehende bauliche Strukturen Rücksicht genommen werden musste. Einen weiteren möglichen Hinweis diesbezüglich zeigte die Grabung auf dem mittleren Treppenpodest im Südabschnitt des vomitorium (Sondage S 2/98). Hier wurden im Unterbau zwei Niveaus nachgewiesen, wobei die Fundamentierung der ersten Phase noch in die 1. Hälfte des 1. Jhs. n. Chr. eingeordnet wird. Das Fundmaterial der jüngeren Fundamentierung ist hingegen nicht ausreichend signifikant zur Ermittlung einer eindeutigen Zeitstellung. Es ließ sich lediglich insgesamt als kaiserzeitlich eingrenzen ${ }^{124}$.

Der Abschnitt der nördlichen Theateraußenwand zwischen dem unteren Zugang EN1 sowie der Gebäudeecke zum begrenzenden Analemma im Westen ist derzeit fast vollständig verschüttet. Lediglich an der Gebäudeecke liegen in den oberen erhaltenen Mauerschichten einige Wandquader frei. Während nördlich der äußeren Kammer KN1 das glatte Quadermauerwerk aus weißem Kalkstein sichtbar ist, kamen nahe der Gebäudeecke zum Analemma graue Marmorquader mit polsterförmig gewölbter Oberfläche zum Einsatz. Aufgrund der nur geringfügig freiliegenden Außenwandfläche in diesem Bereich kann derzeit nicht eingeschätzt werden, ob es sich bei den Polsterquadern um den regulären Wandverband - eventuell unter Verwendung von Spolien - oder um eine Reparaturmaßnahme handelt (Taf. 446 Abb. 792. 793).

Die Erweiterung des Auditorium-Nordflügels hatte als westlichen Abschluss auch eine Ergänzung am nördlichen Analemma zur Folge. Dieser Fassade wurde in nördlicher Richtung ein Wandabschnitt von annähernd $17 \mathrm{~m}$ Länge angefügt, der sich in den unteren Quaderlagen stufenförmig um 0,50 m nach Westen verbreitert. Die glatten Fassadenquader bestehen wie die übrigen Ansichtsflächen der Analemmata aus weißem Marmor. Um die Veränderungen, die am nördlichen Analemma im Rahmen der Erweiterung des Auditorium vorgenommen wurden, verständlich zu erklären, sei im Folgenden etwas detaillierter auf die baulichen Befunde dieser Fassade eingegangen (Plan 7). Die dem Nord-Analemma vorgelagerte Terrassenanlage mit Freitreppe und verschiedenen Brunnenbecken wird an dieser Stelle nicht behandelt ${ }^{125}$.

Das Nord-Analemma gliedert sich auf einer Länge von ca. $57 \mathrm{~m}$, gemessen vom orchestraseitigen Beginn der ersten Sitzstufe oberhalb der Orchestrawand X bis zum Fußpunkt der nördlichen Gebäudeecke, in drei Hauptabschnitte. Sie lassen sich durch Unterschiede in der Wandgestaltung sowie leichte Abweichungen im Grundriss beschreiben. So verläuft die Flucht beider Analemmata im Grundriss nicht ganz linear, sondern ist durch unterschiedliche Abschnitte mit jeweils eigener linearer Ausrichtung geprägt.

Der innere südliche Wandabschnitt des Nord-Analemma reicht bis zum Treppenaufgang EN1 West. Die Fassade ist hier aus übereinander folgenden Reihen von Orthostaten und schmalen Binderlagen aufgebaut. Etwa in einem Abstand von 9,50 m vom orchestraseitigen Beginn springt die Wand um 0,50 m nach Westen vor (Taf. 447 Abb. 794). Bis zu diesem Vorsprung steht der innere Wandbereich auf der Parodos-Überdeckung auf und hängt dementsprechend mit den baulichen Veränderungen an den Parodoi in Folge der Umgestaltung des Bühne-Orchestra-Komplexes zusammen (s. o.). Die Hinterfüllung der Orthostaten und Binder sowie der Unterbau der östlich angrenzenden Radialtreppe T1 bestehen aus opus caementitium.

Im Gegensatz dazu wurde der nördliche Wandbereich ab dem Vorsprung hinter der äußeren Schale aus Orthostaten und Binderlagen massiv aus grauen Marmorquadern aufgeschichtet. Die Binder der Fassade

\footnotetext{
${ }^{123}$ Weitere Aufgänge von Westen, wie sie zuvor von St. Karwiese und I. Ataç rekonstruiert wurden, ließen sich nicht bestätigen (Karwiese 1997, 44-48; KARWIese 1998, 24-26; auch Heberdey u. a. 1912, 36).

${ }^{124}$ Kap. 3.5.1.4.2.

${ }^{125}$ Vgl. hierzu den geplanten Bauforschungs-Band STYHLER-Aydin (in Vorbereitung).
} 


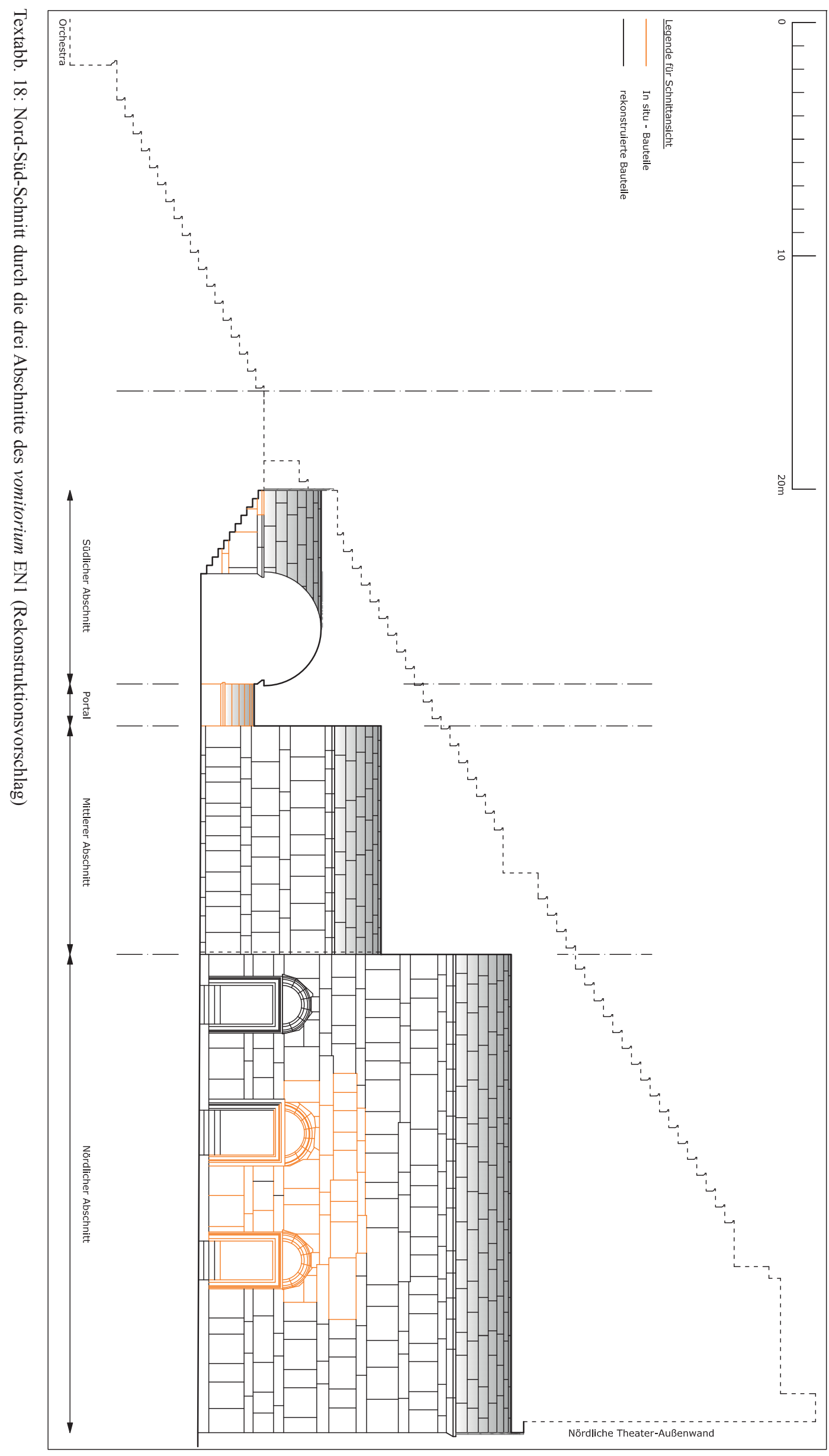


greifen jeweils mit mehr als der Hälfte ihrer Bauteiltiefe in diese rückwärtige Quaderlage ein. Der Fußpunkt des Wandbereichs wird durch die restaurierte Laufoberfläche der nördlichen Rampe verdeckt. Womöglich zeigt der leichte Unterschnitt an den jeweils unteren Bauteilen als Kontaktfläche für die Bodenplatten das ursprüngliche Laufniveau der Rampe an (Taf. 447 Abb. 795). Die Ansichtsflächen der Orthostaten und Binder wurden unter Verwendung von Hacke und Spitzeisen lediglich grob geglättet. Eine feine Oberflächenbearbeitung kam nicht zur Ausführung.

Der zweite Fassadenabschnitt beginnt nördlich des Treppenaufgangs EN1 West und wird durch das Motiv zweier geschlossener Bögen gegliedert. Die Fassadenquader waren hier mit dem Spitzeisen geglättet, teilweise hat sich noch der Saumschlag an den stark verwitterten Marmoroberflächen erhalten. Besonders an den Kontaktstellen der Fassadenquader ist sichtbar, dass Bogenpfeiler und Bogenfüllung aus einem gemeinsamen Herstellungsprozess resultieren. An einigen Fehlstellen der Wand zeigen sich die Quader des Kernmauerwerks, die teilweise hinter der fassadenseitigen Bogenlaibung weiterlaufen (Taf. 448 Abb. 796). Dies spricht ebenfalls dafür, dass es sich bei den geschlossenen Bögen nicht um echte Öffnungen, sondern um ein Gestaltungsmotiv der Fassade handelt ${ }^{126}$. Besonders auffällig ist jedoch der Fußpunkt des zweiten Fassadenabschnitts im Kontaktbereich mit der oberen Terrasse. Es ist deutlich sichtbar, dass der opus caementitium-Kern der Terrasse erst später dem Fassadenabschnitt vorgelagert wurde und sich demzufolge sein ursprünglicher Fußpunkt tiefer liegend hinter dem Gussmauerwerk verbirgt (Taf. 448 Abb. 797; Plan 7). Auch die auffällig gedrungene Proportion der beiden Scheinbögen lässt sich so erklären. Der Übergang vom mittleren zum nördlichen Fassadenabschnitt fällt im Grundriss zusammen mit der südlichsten Trennwand aus weißem Kalkstein zwischen den Kammern KN2 und KN3. Die beiden anderen, hinter dem mittleren Fassadenabschnitt liegenden Kammertrennwände (zwischen KN3 und KN4 sowie zwischen KN4 und dem Treppenaufgang EN1 West) wurden aus grob zugerichteten, grauen Marmorquadern aufgebaut (Textabb. 19). In der Summe deuten die Befunde an, dass es sich bei dem Fassadenabschnitt mit den beiden Scheinbögen um einen älteren Teil des Nord-Analemma handelt. Dies findet auch Bestätigung durch eine Inschrift, die im Bogenfeld des südlichen Scheinbogens angebracht ist. Es handelt sich dabei um einen Erlass des Statthalters Paullus Fabius Persicus an die Behörden von Ephesos, der in das Jahr 44 n. Chr. datiert wird (Taf. 449 Abb. 798a. b; 799) ${ }^{127}$. Für eine genauere Einordnung des Fassadenabschnitts in die Bauabläufe am Theater wären weitere umfangreiche Freilegungen im mittleren Bereich des verstürzten unteren vomitorium EN1, einschließlich der angrenzenden Kammern KN3 und KN4, sowie archäologische Grabungen erforderlich.

Nördlich an die beiden Scheinbögen angrenzend folgt der dritte Fassadenabschnitt, der - wie bereits beschrieben - die westliche Begrenzung des erweiterten oberen Rangs darstellt. In den unteren zehn Quaderlagen ist die Fassade hier weitgehend erhalten. Sie war demnach als glattes pseudoisodomes Quadermauerwerk aufgebaut. In den oberen Wandbereichen fehlen die Frontquader oder verblieben lediglich fragmentarisch im Wandverband (Taf. 450 Abb. 800). Es ist hier auch sichtbar, dass der Wandkern aus grobem Quadermauerwerk besteht, in den etwa jede zweite Lage der Frontquader einbindet. Horizontale Unebenheiten und vertikale Hohlräume zwischen den Quadern des Wandkerns wurden mit Steinsplittern und Mörtel ausgeglichen bzw. verfüllt.

Der dritte Fassadenabschnitt erhebt sich oberhalb der vorgelagerten Terrasse. Mit einem kleinen Unterschnitt ist der Laufbelag auf der Terrasse unter die Marmorquader der Fassade verlegt, was für eine gemeinsame Errichtungszeit spricht (Taf. 448 Abb. 797). Sowohl dem Bau der Terrasse als auch der treppenartigen Verbreiterung im unteren Bereich der Fassade lagen womöglich statische Überlegungen zugrunde. Der nördliche Flügel des Theaters stellte, bedingt durch die nach Norden abfallende Topografie, mit etwa $35 \mathrm{~m}$ Höhe, gemessen vom Fußpunkt der Terrasse bis zum Laufniveau in der Portikus, die größte Fassade des

\footnotetext{
${ }^{126}$ Schon R. Heberdey und W. Wilberg erkannten die beiden Bögen als Scheinbögen (HeBerdey u. a. 1912, 36). St. Karwiese und I. Ataç interpretierten die Bögen als »Zwillingsaufgänge« zum unteren nördlichen vomitorium EN1. Demzufolge sollte durch den südlichen der beiden Bögen das untere Diazoma erreichbar gewesen sein. Benutzer des benachbarten nördlichen Aufgangs hätten sich im vomitorium nach Norden gewandt und über die vermutete nördliche Außentreppe das mittlere Diazoma erschlossen (vgl. Karwiese 1997, 44-48; Karwiese 1998a, 24-26; Karwiese 1998b; Ataç 1999a, 6; Hofbauer 2007, 12). Unter Berücksichtigung der oben beschriebenen Befunde lässt sich diese Interpretation nicht mehr nachvollziehen, s. auch Kap. 3.5.1.2.

${ }^{127}$ IvE 2021. Vgl. HeberdeY u. a. 1912, 36. 112-116. Reste der lateinischen Entsprechung des Texts fanden sich in zwei Exemplaren (IvE 2022). R. Heberdey vermutete aufgrund der Fundumstände, dass ein Exemplar ebenfalls am Theater angebracht war; evtl. südlich des Aufgangs EN1 West (HeberdeY u. a. 1912, 116-119). Dazu auch Kap. 8.6.2.
} 


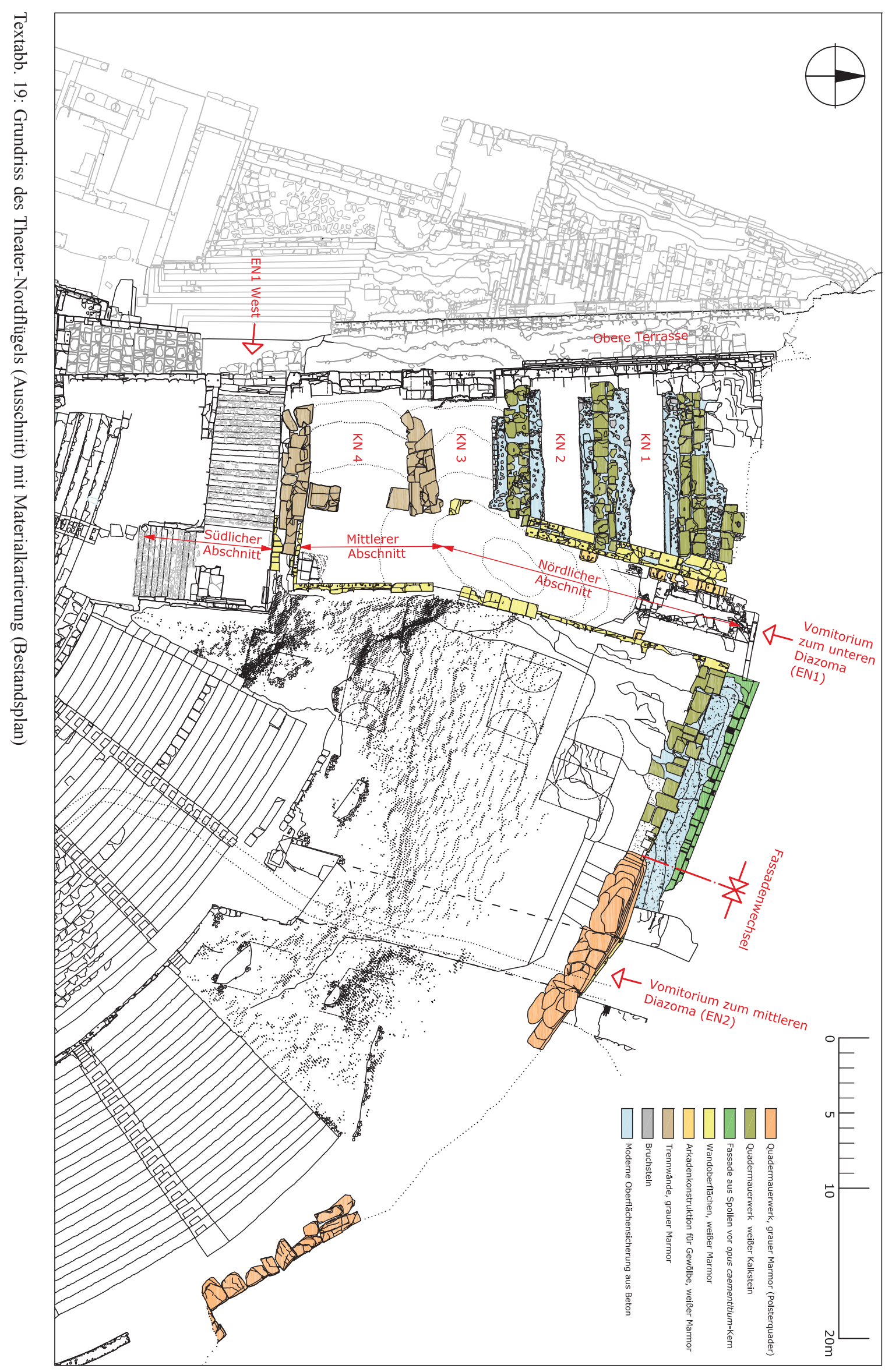


Gebäudes dar. Durch die treppenartige Verbreiterung um 0,50 m auf eine Länge von $17 \mathrm{~m}$ sowie die vorgelagerte 2,90 bis 3,30 m breite obere Terrasse war es möglich, die Aufstands- und Lastabtragsfläche dieses höchsten nördlichen Fassadenabschnitts zu vergrößern und mehr Standsicherheit zu erlangen.

Einen anderen baulichen Zusammenhang mit der oberen Terrasse zeigt der westliche Treppenaufgang EN1 West zum unteren vomitorium. Sein ehemals tonnenüberwölbtes Westportal mit einer Scheitelhöhe von ca. $11 \mathrm{~m}$ war seitlich von massiven Marmorquadern eingefasst ${ }^{128}$. Am Treppenfuß liegt die untere Marmorstufe auf dem Laufbelag der Terrasse auf. Das obere Ende des Treppenlaufs auf dem Mittelpodest ist u. a. durch Reste der erhaltenen Bodenplatten bestimmbar und resultierte vermutlich aus dem Laufniveau im vomitorium EN1 (Taf. 450 Abb. 801; 451 Abb. 802). Zusätzlich lässt sich die Position der ehemaligen Marmorstufen anhand der noch immer sichtbaren Kontaktflächen an den Seitenwänden des Treppenaufgangs rekonstruieren (Taf. 14 Abb. 23). Da der Treppenlauf nicht orthogonal zum Nord-Analemma angeordnet wurde, ergaben sich unterschiedlich lange Seitenwände. Diese Differenz von ca. 0,40 m glich man durch eine leicht konische Anordnung der unteren Marmorstufen aus.

Der untere Treppenlauf EN1 West und der südliche Abschnitt des vomitorium EN1 mit dem Treppenlauf auf das untere Diazoma stellen eine einheitliche Baumaßnahme dar und wurden in Zusammenhang mit der Anlage des vomitorium EN1 errichtet. Das Erfordernis westseitiger Aufgänge könnte gerade auch durch die Erweiterung an den Westfassaden des Theaters begründet sein. Durch die nun sehr langen Analemmata waren die wichtigen Publikumseingänge zu den Rängen an der Nord- und Südseite des Theaters von Westen aus nur über längere Wegstrecken zu erreichen. Im Süden wurde die Zugänglichkeit aufgrund der Geländesituation zusätzlich erschwert. Mit der Anordnung der westseitigen Aufgänge (EN1 West; ES1 West) konnte die direkte Anbindung an das Straßennetz sowie die Platzanlagen westlich des Theaters aufrechterhalten werden.

Die Fertigstellung des Nordflügels unter Kaiser Domitian 92 n. Chr. ist durch Fragmente der ca. 12 m langen Bauinschrift überliefert, die vor dem Nord-Analemma auf der oberen Terrasse sowie westlich davor gefunden wurden ${ }^{129}$. Bereits R. Heberdey gruppierte die dislozierten Quader mit der Inschrift sowohl in Läufer als auch Binder und erkannte den Zusammenhang mit dem Quaderverband am Nordflügel der Cavea, wenngleich auch eine genaue Position der Inschrift an der Fassade nicht mehr zu ermitteln war (Taf. 451 Abb. 803).

Für die folgende Nutzungszeit des Theaters lassen sich verschiedene bauliche Maßnahmen und Umgestaltungen am Nordflügel feststellen, die durch Beeinträchtigungen der Standsicherheit im Bereich der beiden vomitoria sowie der nördlichen Außenwand veranlasst waren ${ }^{130}$.

\section{Südflügel des Theaters}

Analog zur Nordfassade des Theaters sind auch im Süden bauliche Evidenzen zur Erweiterung des oberen Rangs nachweisbar (Tab. 127). Der Ansatzpunkt des jüngeren Abschnitts der Außenwand liegt hier direkt östlich des vomitorium ES2 (Taf. 2) und ist wie im Norden durch einen Wechsel hinsichtlich Material und Erscheinungsbild der Fassade charakterisiert (Taf. 433 Abb. 765; 452 Abb. 804). Im Anschluss an den hangaufwärts gelegenen älteren Wandabschnitt aus grauen Marmorquadern mit polsterförmig gewölbter Oberfläche wurde die Fassade hangabwärts in Richtung Westen aus weißen Kalksteinquadern mit glatter Front aufgebaut (Plan 5). Beide Fassadenabschnitte sind miteinander verzahnt. Westlich des Zugangs ES2 zum mittleren Diazoma hat sich am erweiterten Fassadenabschnitt ein Detail der Wandgliederung erhalten: Das Gesims der Kämpferzone des Tonnengewölbes wurde an der Südfassade des Theaters offenbar als horizontales Profil fortgeführt (Taf. $452 \mathrm{Abb} .805$ ).

\footnotetext{
${ }^{128}$ Auf der Südseite waren auf zwei der Eckquader des Portals ein Volksbeschluss, der nach der Thronbesteigung des Antoninus Pius 138 n. Chr. datiert, sowie der den Beschluss genehmigende Brief des Prokonsuls angebracht (IvE 21; vgl. HeberdeY u. a. 1912, 36. 107 f.). Der untere der beiden Quader befindet sich in situ; der ehemals darüber aufgestellte Quader lagert derzeit im Steingarten gegenüber dem Nord-Analemma. Für die mündliche Übersetzung der Inschrift und die Erläuterung des Inhalts danke ich H. Taeuber. Dazu auch Kap. 8.6.2.

${ }^{129}$ IvE 2035. Vgl. Heberdey u. a. 1912, 36 f. 160 f. Dazu auch Kap. 8.6.1, Nr. 3 u. Kap. 8.6.2.

${ }^{130}$ Kap. 10.3.4.
} 
Obwohl der Berghang des Panayırdağ in der Südhälfte des Theaters höher ansteht und demzufolge räumlich umfangreicher für die Anlage der Sitzreihen genutzt werden konnte, war im hellenistischen Koilon auch hier für den westlichen Flügel im oberen Rang ein Unterbau nötig, zu dessen Konstruktion jedoch keine Informationen mehr gewonnen werden können. Im Zuge der Rangerweiterung ersetzte man den Unterbau wie im Norden des Theaters ebenfalls durch Hohlkammern aus opus caementitium. Der Vergleich mit dem Nordflügel zeigt jedoch, dass im Süden zusätzlich zur bestehenden Außenwand aus Polsterquadern eine innere Wandschale aus opus caementitium angesetzt wurde (Taf. 453 Abb. 806).

Mit der Anlage des vomitorium ES2 zur Erschließung des mittleren Diazoma beginnt westwärts der durch Anordnung übereinanderliegender Substruktionskammern aufgebaute Südflügel des Theaters. Für die tragenden Wände der unteren Kammern, die gleichzeitig die größte Höhe aufweisen, wurden großformatige und lediglich grob zugerichtete Quader verwendet, von denen R. Heberdey und W. Wilberg vermuteten, dass sie aus dem hellenistischen Gebäude wiederverwendet sein könnten ${ }^{131}$. Erst für die Tonnengewölbe, die Trennwände sowie die Kammern in den höheren Ebenen kam opus caementitium zum Einsatz (Taf. 453 Abb. 807).

Wie schon für den Nordflügel beschrieben, wurden auch im Süden zwei tonnenüberwölbte Zugangskorridore (ES1. ES2) in das neue Bauvolumen integriert. Außerhalb des Theaters sind sie durch eine bis zu 8,90 $m$ breite Außentreppe untereinander sowie mit dem oberen Zugangskorridor ES3 verbunden (Plan 1). Über die Treppenpodeste war ein ebenengleicher Zugang in die vomitoria möglich. Das untere vomitorium ES1 wurde als hohe, tonnengewölbte Passage von ca. $42 \mathrm{~m}$ Länge und 4,70 bis 4,90 m Breite angelegt. Im Unterschied zum Gegenüber im Norden (EN1) verlief der Korridor jedoch linear hinter dem südlichen Analemma und war lediglich durch zwei Abschnitte mit unterschiedlicher Gewölbehöhe geprägt. Im $20 \mathrm{~m}$ langen südlichen Abschnitt lag der Bogenansatz des Werksteingewölbes 5,70 bis 5,80 m über dem Laufniveau im vomitorium. Westseitig flankierten drei Kammern den Zugang. Die Kammern waren über Türen vom Korridor aus betretbar. In situ erhalten sind jedoch lediglich die unteren Quaderlagen der Wände sowie Fragmente der profilierten Türgewände aus Marmor ${ }^{132}$. Im nördlichen Abschnitt des vomitorium, der eine Treppenanlage überwölbt und in den auch der westseitige Treppenanschluss zur sogenannten Marmorstraße mündet (ES1 West), verspringt der Ansatzpunkt des Werksteingewölbes um ca. 5,70 m nach unten. Um zwischen den unterschiedlichen Scheitelhöhen des hohen und niedrigen Gewölbes im vomitorium vermitteln zu können, war eine Schildwand erforderlich, von der sich die orthogonal zur Korridorwand ausgerichteten >Wartesteine aufgrund des Mauerverbands noch immer in situ befinden (Taf. 454 Abb. 808). Eine ähnliche bauliche Lösung der Vermittlung zwischen Gewölben unterschiedlicher Scheitelhöhe ist z. B. auch aus dem Theater in Milet bekannt (Taf. 454 Abb. 809).

Wie bereits erwähnt, waren die drei südlichen Zugänge zum Theater untereinander durch eine monumentale Treppenanlage entlang der Außenwand verbunden. R. Heberdey und W. Wilberg gingen davon aus, dass der Zugang ES1 - und damit das untere Podest der Außentreppe - über eine Straße aus dem südlich angrenzenden Stadtgebiet, deren westliche Stützwand mit der südlichen Gebäudeecke des Theaters im Verband hergestellt ist, erschlossen werden konnte ${ }^{133}$. Befunde im Rahmen der jüngsten archäologischen Freilegungen der Außentreppe stärken diese Annahme, wenn auch eine eindeutige bauliche Bestätigung bislang fehlt ${ }^{134}$. Der obere Abschluss der Treppenanlage mit dem Podest vor dem Zugangskorridor ES3 war über die von Süden ankommende Akademiegasse mit dem weiterführenden Gassensystem verbunden. Der Zugang ES2 zum mittleren Diazoma hingegen verfügte nach heutigem Wissensstand über keine direkte Anbindung an das Straßennetz südlich des Theaters, sondern konnte nur indirekt von den Gassen über die Treppenanlage erreicht werden. Auf der Außenarchivolte des vomitorium wird T. Flavius Montanus als Stifter der Baumaßnahme genannt ${ }^{135}$.

Eine weitere Besonderheit an der Außentreppe betrifft den Materialwechsel im Stufenbelag, der mit den beiden zuvor beschriebenen Abschnitten der südlichen Außenwand korrespondiert. So sind die Trittstufen des oberen Treppenlaufs zwischen den Zugängen ES3 und ES2 wie die Polsterquader der Fassade aus grauem

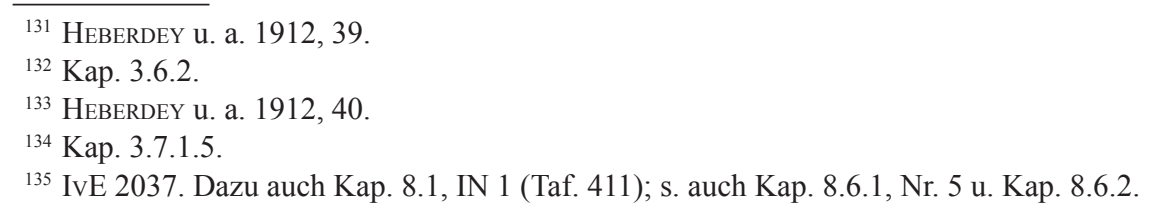


Marmor gefertigt (Taf. 434 Abb. 766). Für den unteren Treppenabschnitt zwischen den Zugängen ES2 und ES1, der sich durch ein schmales Podest nochmals in zwei Treppenläufe teilt, kam hingegen weißer Marmor als Stufenbelag zum Einsatz (Taf. 455 Abb. 810). Im Abstand von ca. 4,40 m östlich des Zugangs ES1 tritt die Aristion-Wasserleitung aus dem Gebäude aus und verläuft unterhalb der Außentreppe durch das südlich angrenzende Stadtgebiet zum Nymphaeum Traiani. Direkt am Austrittspunkt der Fassade war die Trasse lediglich durch die Stufensteine der Treppenanlage überdeckt (Taf. 163 Abb. 333; 276 Abb. 562; Plan 5).

Die Ergänzung des Theater-Südflügels im Bereich des oberen Rangs lässt sich wie im Norden auch am Analemma nachvollziehen. Allerdings gliedert sich das ca. 58,20 m lange südliche Analemma lediglich in zwei Hauptabschnitte mit unterschiedlicher Fassadengestaltung und leichten Abweichungen in der linearen Ausrichtung der Wandabschnitte, wobei sich der innere Abschnitt wie im Norden nochmals unterteilt (Plan 8).

Der innere nördliche Wandabschnitt des Süd-Analemma beginnt ebenfalls am orchestraseitigen Beginn der ersten Sitzstufe oberhalb der Orchestrawand X und reicht bis zur südlichen Begrenzung des Treppenaufgangs ES1 West, was im Grundriss einer Ausdehnung bis annähernd zur Stützwand des mittleren Diazoma entspricht. Die Fassade ist hier ähnlich dem inneren südlichen Wandabschnitt des Nord-Analemma gestaltet: In übereinander folgenden Reihen wechseln Orthostatenplatten und schmale Binderlagen einander ab. Auch wenn sich die Bauteilgrößen an den beiden Fassadenabschnitten nicht ganz entsprechen, ist das einheitliche Gestaltungsmotiv der Wände doch offenkundig ${ }^{136}$. Ebenfalls vergleichbar dem nördlichen Analemma verspringt die Fassade in einem Abstand von ca. 9,90 m vom orchestraseitigen Beginn um 0,50 m nach Westen. Am inneren Wandbereich, der bereits auf der Parodos-Überdeckung aufsteht und demzufolge nach Verlegung der Süd-Parodos neu errichtet wurde, war seit $104 \mathrm{n}$. Chr. die umfangreiche Inschrift zur Stiftung des C. Vibius Salutaris in sechs Kolumnen angebracht ${ }^{137}$. Nach der Demontage der Inschriftenquader durch J. T. Wood zwischen 1866 und 1868 befinden sich nur noch die untere Orthostatenreihe sowie die darauf folgende Binderschicht in situ (Taf. 455 Abb. 811; 456 Abb. 812). Die fehlenden Quader wurden während einer Restaurierungsphase in Bruchsteinmauerwerk ergänzt. Der ursprüngliche Wandkern sowie der Unterbau der östlich anschließenden Radialtreppe T11 sind derzeit kaum einsehbar. Auch ist eine Dokumentation des Wandbereichs vor der Restaurierung nicht bekannt. An wenigen Stellen deutet sich jedoch an, dass auch hier, vergleichbar der Situation im Norden, opus caementitium verwendet wurde. Auffallend ist, dass an beiden oberhalb der Parodoi gelegenen Wandbereichen die horizontale Fugenteilung vom benachbarten Wandbereich im Norden bzw. Süden abweicht, wenn auch der Wandaufbau aus Orthostaten und Binderquadern gleich ist. Im südlich folgenden Wandbereich des Süd-Analemma greift die äußere Schale aus Orthostaten und Binderlagen in ein aus grauen Marmorquadern errichtetes Kernmauerwerk ein, das wiederum mit opus caementitium hinterfüllt ist (Taf. $456 \mathrm{Abb} .813)^{138}$.

Im Bereich des westlichen Treppenaufgangs zum unteren vomitorium ist anhand einer Schicht Binderquader mit den auf der Setzfläche angeordneten Dübellöchern für die nächstfolgende Orthostatenreihe erkennbar, dass sich die Fassade des Analemma hier ursprünglich fortsetzte (Taf. 457 Abb. 814). Die Anlage des Treppenaufgangs ES1 West steht erst in Zusammenhang mit der Erweiterung des südlichen Gebäudeflügels und der Errichtung des vomitorium ES1. Für den nachträglichen Einbau des mächtigen, vertikalen Quaders, der die Fassadenöffnung des Treppenaufgangs auf der Nordseite begrenzt, war es erforderlich, Bauteile in einer Binderschicht der Fassade abzuarbeiten (Taf. 457 Abb. 815). Ob es sich bei dem südlichsten erhaltenen Quader der Binderschicht bereits um den Bereich der ehemaligen Gebäudeecke handelt oder sich der Fassadenabschnitt noch etwas weiter nach Süden erstreckte, kann nicht mehr festgestellt werden. Nach der Errichtung des Treppenaufgangs dienten die verbliebenen Quader der Binderschicht als Unterbau für die nicht mehr erhaltenen Trittstufen aus Marmor. Wie im Norden ist auch hier die ursprüngliche Tritthöhe der Treppe anhand der Kontaktflächen des Stufenbelags an den Seitenwänden des Aufgangs noch immer ablesbar (Taf. 458 Abb. 816).

\footnotetext{
${ }^{136}$ Auf die Ähnlichkeit der orchestraseitigen Analemma-Abschnitte im Norden und Süden wies bereits De Bernardi Ferrero 1970 , 59 f. hin.

${ }^{137}$ IvE 27, 167-222. Zur Anordnung der Inschrift und Gliederung der Wand vgl. Heberdey u. a. 1912, 128. Dazu auch Kap. 8.6.1, Nr. 4 u. Kap. 8.6.2.

${ }^{138}$ Während der Konsolidierungsarbeiten 1995 und 1996 wurden auskragende Quader dieses Kernmauerwerks mit sogenannten Mauerplomben aus Bruchstein unterstützt (KARWIESE 1996, 29-31, bes. Abb. 17; KARWIESE 1997, 47 Abb. 32).
} 
Der südlich folgende zweite Fassadenabschnitt besteht aus einem annähernd regelmäßigen Quadermauerwerk, das über einer polsterförmig gewölbten Sockellage errichtet ist. Der Fassadenabschnitt ist durch drei Pilaster gegliedert, die im Mittel 0,60 m vor die Fassade vorspringen. Während die beiden nördlichen Pilaster mit Abmaßen von 3,28 m und 3,32 m in etwa gleich breit sind, wurde der südliche Pilaster mit 3,75 m massiver ausgeführt und bildet gleichzeitig die Gebäudeecke des Theaters. Die Pilaster reichten jedoch nicht bis an den oberen Wandabschluss des Analemma. Verschiedene Architekturfragmente, die von R. Heberdey und W. Wilberg vor der Fassade gefunden wurden, zeigen einen oberen Pilasterabschluss vor rückwärtig aufsteigender Wand (Taf. 458 Abb. 817) ${ }^{139}$. Aus einer Ehreninschrift, die vermutlich am mittleren Pilaster angeordnet war, lässt sich zudem schließen, dass oberhalb des Pilasterabschlusses die Statuen des L. Vibius Lentulus und des T. Flavius Montanus aufgestellt waren ${ }^{140}$.

Mit dem Beginn des zweiten Fassadenabschnitts an der südlichen Seitenwand des Treppenaufgangs ES1 West ist - vergleichbar dem Nordflügel - auch ein Wechsel der Baumaterialien zu beobachten. Alle Bauteile, die an stark öffentlich frequentierte Bereiche angrenzten wie das Analemma oder die Oberflächen in den vomitoria, waren aus weißem Marmor hergestellt. Im Konstruktionsinneren zeigen sich jedoch Unterschiede. Während das Kernmauerwerk im südlichen Wandbereich des ersten Fassadenabschnitts, wie bereits beschrieben, zunächst aus großformatigen grauen Marmorquadern gefügt wurde, kam im zweiten Fassadenabschnitt für die Trennwände der den Korridor flankierenden Kammern KS1 bis KS3 sowie für die innere Wandschale des Analemma überwiegend der weiße Kalkstein zum Einsatz (Taf. 459 Abb. 818).

Die Fundamentquader des südlichen Fassadenabschnitts wurden in einer späteren Phase teilweise abgearbeitet und damit in Ergänzung des Laufbelags vor dem Süd-Analemma dem heute sichtbaren Niveau der sogenannten Marmorstraße angeglichen (Taf. 459 Abb. 819).

Der Abschluss der Baumaßnahmen am Südflügel des Theaters im Zeitraum zwischen 102 und $112 \mathrm{n}$. Chr. ist gleich durch mehrere Inschriften überliefert und fällt bereits in die Regierungszeit des Kaisers Trajan. Eine Bauinschrift befindet sich auf der Außenarchivolte des vomitorium ES2 zum mittleren Diazoma noch teilweise in $_{s i t u^{141}}$. Ein weiterer Block, der diese Bauinschrift offenbar wiederholt, kam während der jüngsten Forschungen im Theater zum Vorschein ${ }^{142}$. Auch vor dem Süd-Analemma am Fuß des Mittelpilasters sowie vor der südlichen Gebäudeecke des Theaters wurden Fragmente von zwei die Fertigstellung des Theaters betreffenden Inschriften gefunden (Taf. $460 \mathrm{Abb}$. 820. 821) ${ }^{143}$. In allen Inschriften wird Titus Flavius Montanus als Stifter der Baumaßnahmen am Südflügel und > Vollender Text, der u. a. vermutlich am Mittelpilaster des südlichen Analemma angebracht war, geht außerdem hervor, dass dieser das Theater zur Zeit seiner Erzpriesterschaft einweihte sowie Gladiatorenkämpfe und Tierhetzen veranstaltete ${ }^{144}$. Auch die Anbringung der Inschrift zur Stiftung des C. Vibius Salutaris am Süd-Analemma 104 n. Chr., in der u. a. die aufwendige Prozession vom Artemision zum Theater zur Aufstellung der gestifteten Weihegeschenke beschrieben wird, fällt in diesen Zeitraum. Sie könnte außerdem ein Hinweis darauf sein, dass die Wiedereinweihung des Theaters nach Abschluss der umfangreichen Erweiterungen eher für das 1. Jahrzehnt des 2. Jhs. n. Chr. anzunehmen ist ${ }^{145}$.

\section{Weitere Veränderungen im Auditorium - unteres Diazoma und Aristion-Leitung}

Neben der Erweiterung des Koilon nach Westen durch die oben beschriebene Ergänzung des Nord- und Südflügels konnten noch andere bauliche Veränderungen festgestellt werden, die sich in die große Umbauphase unter den Kaisern Domitian bis Trajan einordnen lassen (Tab. 127). Dazu zählen eine Verbreiterung des unteren Diazoma sowie die Verlegung des Trassenabschnitts der Aristion-Wasserleitung durch den Stufenbau.

\footnotetext{
${ }^{139}$ Heberdey u. a. 1912, 38.

${ }^{140}$ IvE 2061. Dazu auch Kap. 8.6.1, Nr. 6 u. Kap. 8.6.2.

${ }^{141}$ IvE 2037. Vgl. HeberdeY u. a. 1912, 40 f. 161. Dazu auch Kap. 8.6.1, Nr. 5 u. Kap. 8.6.2.

142 Kap. 8.1.

${ }^{143}$ IvE 2061. 2062. Vgl. Heberdey u. a. 1912, 41. 174-176. Dazu auch Kap. 8.6.1, Nr. 6. 7 u. Kap. 8.6.2.

${ }^{144}$ P. Scherrer folgert daraus, dass Montanus die 5. oder 6. Balbilleia 105 bzw. 109 n. Chr. geleitet haben könnte. Vgl. SchERRER 1997, 114. Für die mündliche Übersetzung der Inschrift und die Erläuterung des Inhalts bin ich H. Taeuber zu Dank verpflichtet.

${ }^{145} \mathrm{Im}$ Rahmen der trajanischen Bautätigkeit in Ephesos geht Scherrer 2008, 53 von einer Fertigstellung der Baumaßnahmen am Theater 104/105 n. Chr. aus.
} 
Bei der Betrachtung der Diazomata fällt zunächst auf, dass das Erscheinungsbild der drei Umgänge untereinander differiert. In Bezug auf die Wandgestaltung sowie die horizontale Zonierung besitzt das untere Diazoma einen eigenen Charakter. Aus der Analyse der Einzelbefunde ergeben sich für den Umgang zwei Bauphasen ${ }^{146}$.

In der ersten Phase hatte das Diazoma eine lichte Weite von im Mittel 1,80 m. Zieht man am Rand zum unteren Rang noch eine Bankreihe in Betracht, würde sich die Durchgangsweite auf ca. 1,00 m begrenzen. Diese Situation wurde sekundär dahingehend verändert, dass man die Diazomawand unter Wiederverwendung der Sockelquader um ca. 0,50 m gegen den oberen Rang versetzte. Gleichzeitig wurde das Gehniveau auf dem Umgang erhöht (Taf. 97 Abb. 192; 460 Abb. 822). Insgesamt konnte durch die Verbreiterungsmaßnahme eine lichte Weite von im Mittel 2,30 m bis zum Anschluss der ima cavea erreicht werden ${ }^{147}$.

Hinsichtlich der Gestaltung des Diazoma am Übergang zum unteren Rang existieren für die zweite Bauphase verschiedene Überlegungen. Zu nennen ist hier, neben der Anordnung von Sitzbänken ${ }^{148}$, vor allem die Aufstellung von Statuettenbasen in Zusammenhang mit der Stiftung des C. Vibius Salutaris, wie sie aus der bereits genannten Inschrift geschlossen werden kann ${ }^{149}$. Der hohe Grad an moderner Überformung mit nur wenigen in situ verbliebenen Bereichen am inneren Rand des Diazoma lässt eine Verifizierung der genannten Überlegungen derzeit jedoch nicht zu. Eine weitere Gestaltungsmöglichkeit wird durch die moderne Rekonstruktion des Diazoma in unmittelbarem Anschluss an den Eintritt des nördlichen und südlichen vomitorium (EN1. ES1) angedeutet. Hier lässt die Verlegung von Sitzstufenplatten mit einer vertieften rückwärtigen Aufnahmezone die Aufstellung von Balustradenplatten vermuten. Die Situation lässt sich, wie bereits beschrieben, in situ nicht mehr nachvollziehen. Die verwendeten Sitzplatten zumindest zeigen lediglich die Anschlussmerkmale des regulären Verbands der Plattenverkleidung mit der Aufnahmezone für die vertikale Verblendung der jeweils oberhalb folgenden Sitzstufe und nicht die für eine Balustrade erforderliche Bettung ${ }^{150}$.

Hinsichtlich der Fragen zur Ausdehnung des Auditorium und seiner Transformation sind zwei Aspekte an den Befunden auf dem unteren Diazoma aufschlussreich. Zum ersten zeigen die durchlaufenden Sockelquader der Diazomawand, die im Bereich der Klimakes die Funktion als untere Antrittsstufe übernehmen, durch die Abnutzungsspuren an den Stufenkanten, dass es bereits in der ersten Bauphase ein mindestens zweirangiges Auditorium gab.

Der zweite Aspekt betrifft den Umfang der Verbreiterungsmaßnahme. Im südwestlichsten Abschnitt des Diazoma, genauer im Bereich nach Eintritt des vomitorium ES1 bis zum Kontaktpunkt mit dem ehemaligen Analemma, deutet der erhaltene Bestand darauf hin, dass eine Versetzung der Diazomawand, wie oben beschrieben, hier nicht stattgefunden haben kann (Taf. 461 Abb. 823) ${ }^{151}$. Damit nimmt die Verbreiterung des Diazoma anscheinend auf den Eintrittsbereich des unteren südlichen vomitorium ES1 räumlich Bezug. Vergegenwärtigt man sich, dass die über jeweils zwei große Korridore (EN1. ES1) bzw. Treppenanlagen (EN1 West; ES1 West) aus dem Norden und Süden kommenden Besucher zunächst über den Umgang die Radialtreppen erreichen mussten, um zu ihren Sitzen zu gelangen, so zeigt sich die gesteigerte funktionale Bedeutung des unteren Diazoma für die Publikumserschließung. Mit der Verbreiterung schöpfte man die geringen räumlichen Möglichkeiten aus, die der Bestand an dieser Stelle bot.

\footnotetext{
${ }^{146}$ Zur ausführlichen Beschreibung und Auswertung der Befunde s. LIEBICH - STYHLER 2009, 469-481. Ein Zusammenhang der Bauphasen mit dem Ergebnis der archäologischen Sondage, die 1998 von St. Karwiese am Eintrittspodest des vomitorium EN1 auf das untere Diazoma angelegt wurde, konnte nicht hergestellt werden. Der gesamte Bereich ist durch moderne Restaurierungen und Rekonstruktionen stark überformt; s. Kap. 3.5.1.4.

${ }^{147}$ Kap. 3.4.1.2 u. 3.4.1.3.

${ }^{148}$ Von St. Karwiese wird eine Bankreihe auf dem unteren Diazoma genannt, jedoch nicht näher beschrieben (SCHERRER 1995, 162). Im Rahmen der aktuellen Bauforschung zum Auditorium wurden weitere Sitzbankfragmente aufgefunden und dem Theater zugeordnet. Variierende Anarbeitungen an den Bauteilen deuten auf unterschiedliche Aufstellpositionen, deren eindeutige Bestimmung derzeit nicht möglich ist.

${ }^{149}$ IvE 27. 28-35. Vgl. Heberdey u. a. 1912, 203; auch Kolb 1999, 101-103. Dazu auch Kap. 8.6.1, Nr. 4 u. Kap. 8.6.2.

${ }^{150}$ Zur Verkleidungstechnik im Stufenbau s. auch STYHLER 2010.

${ }^{151}$ Für die räumlich vergleichbare Situation im Norden wurde zur weiteren Klärung eine archäologische Sondage angelegt. Aufgrund des Erhaltungszustands sowie moderner Restaurierungen konnte die ursprüngliche Konstruktion jedoch kaum mehr nachvollzogen werden, s. Kap. 3.4.1.7.
} 
Eine weitere umfangreiche Baumaßnahme betraf die Verlegung einer Wasserleitung durch das Auditorium (Taf. 152 Abb. 309; 154 Abb. 314. 315; 155 Abb. 316. 317; 158 Abb. 322-325; 159 Abb. 326; 160 Abb. 327. 328; 161 Abb. 329; 162 Abb. 330). Der Trassenabschnitt im Theater ist Teil der $40 \mathrm{~km}$ langen Aristion-Leitung, die u. a. das vor $114 \mathrm{n}$. Chr. errichtete Nymphaeum Traiani versorgte ${ }^{152}$.

Der nachträgliche Einbau der Trasse ist im Auditorium durch den Materialwechsel im Bereich des Unterbaus der achten Sitzstufe der media cavea zu erkennen (Taf. 461 Abb. 824) ${ }^{153}$. Hier befinden sich annähernd symmetrisch zur Mittelachse des Theaters in der jeweils nördlichen und südlichen der mittleren vier Kerkides auch zwei Einstiegsöffnungen in die Leitung. Der vollständige Leitungsquerschnitt ist jedoch nur im südlichen Gebäudeteil am Treffpunkt mit dem verstürzten Gewölbe des unteren vomitorium ES1 sichtbar (Taf. 462 Abb. 825). Als ein Ergebnis der aktuellen Forschungen zum Theater ist heute der gesamte Streckenverlauf im Gebäude bekannt sowie auch der Eintrittspunkt der Wasserleitung im Norden und ihr Austrittspunkt durch die südliche Theateraußenwand lokalisiert. Während nach der Freilegung der südlich an das Gebäude anschließenden Außentreppe im Jahr 2009 auch der Austritt der Wasserleitung sichtbar wurde, bleibt dieser Punkt im Norden unter den Geländemassen außerhalb des Bauwerks verborgen ${ }^{154}$. Im Bereich der mittels Substruktionskammern aufgebauten Gebäudeflügel steht die Führung der Trasse räumlich und konstruktiv in Zusammenhang mit der Anlage der vomitoria EN2 im Norden und ES1 im Süden.

Die Wasserleitung durchläuft das Gebäude mit einer annähernd konstanten inneren Tunnelweite von ca. $1,00 \mathrm{~m}$. Veränderungen gibt es jedoch bezüglich der Tunnelhöhe, die zwischen 1,25 m und ca. 2,13 m variiert, sowie der Ausführung des Leitungsgewölbes. Insgesamt lassen sich innerhalb der $178 \mathrm{~m}$ langen Strecke unter dem Stufenbau des Theaters vier Teilstrecken mit drei unterschiedlichen Leitungsquerschnitten abgrenzen ${ }^{155}$. Die Wände der Trasse sind in unterschiedlicher Höhe mit opus signinum verputzt (Taf. 462 Abb. 826).

In der Achse der beiden mittleren Radialtreppen des mittleren Rangs (T11; T13 Taf. 2) zweigt nahe der oben genannten Einstiegsöffnungen dicht über dem Boden der Wasserleitung je eine Tonrohrleitung mit einem Innendurchmesser von 0,225 m in Richtung Orchestra ab (Taf. 463 Abb. 827). Der Abstand zwischen Einstiegsöffnung und Abzweigung der Tonrohrleitung beträgt 2,25 m bzw. 2,65 m. Der Verlauf der Tonrohrleitungen konnte auch an den Kreuzungspunkten mit dem unteren Diazoma nachvollzogen werden, wo in einem Fall sogar die Wandung eines Rohrstücks unter den Stufen der Klimax offen zu Tage trat. Archäologische Sondagen auf dem unteren Diazoma bestätigten die Fortsetzung der Tonrohrleitungen in Richtung Orchestra $^{156}$. Diese stellen jedoch nicht zwingend ein bauliches Indiz für die in der älteren Forschungsliteratur vermutete Veranstaltung von Wasserspielen im Theater dar ${ }^{157}$. Offen bleibt derzeit, wo sich die unteren Austrittspunkte der Tonrohre befinden und wie die Regulierung des Wasserzuflusses aus der Aristion-Leitung in die Tonrohre erfolgte. Eventuell könnte jedoch die Nähe der Einstiegsöffnungen in die Wasserleitung zu den Abzweigungen der beiden Tonrohrleitungen mit einer notwendigen Öffnung und Schließung derselben in Verbindung stehen.

Wie bei der archäologischen Freilegung der Stiegengasse vor der südlichen Theateraußenwand sichtbar wurde, war die nur geringfügig unterhalb der Treppenstufen aus dem Gebäude austretende Wasserleitung hier lokal zerstört. Die Ergebnisse der archäozoologischen Analysen des Fundmaterials vom südlichen Austrittspunkt der Trasse zeigten, dass mindestens der Leitungsverlauf ab der Südfassade des Theaters in Richtung Nymphaeum Traiani im 5./6. Jh. n. Chr. aufgegeben wurde ${ }^{158}$.

\footnotetext{
${ }^{152} \mathrm{Zu}$ den Wasserleitungen von Ephesos s. ForchHeImer 1923; AlZINGER 1987; ÖZIS - Atalay 1999; Wiplinger 2006a; WiPLINGER 2006b. Eine aktuelle Zusammenfassung der Forschungsgeschichte in: WIPLINGER 2006a, 15-17. Hinsichtlich der Identifizierung des Leitungsabschnitts als Teil der Leitung des Tiberius Claudius Aristion vgl. WIPLINGER 2006a, 19-35. Zum Nymphaeum Traiani vgl. QUATEMBER 2011.

${ }^{153}$ Vgl. dazu auch WiPLINGER 2006a, 34 f.; WiPLINGER 2006b, 29 f.

${ }^{154}$ Kap. 3.6.1.

${ }^{155}$ Zur Beschreibung der einzelnen Streckenabschnitte in der Wasserleitung, s. STYHLER-Aydin 2010, 79-81.

${ }^{156}$ Kap. 3.4.1.1 u. 3.4.1.5.

157 Vgl. De Bernardi Ferrero 1970, 63; De Bernardi Ferrero 1974, 150; vgl. Kap. 3.4.1.1 u. 3.4.1.5.

${ }^{158}$ Kap. 3.6.1 u. 10.3.4.
} 


\section{porticus in summa cavea}

Den oberen Abschluss des Theaters bildete eine Säulenhalle, die Portikus. Räumlich lässt sie sich noch im hangseitigen Bereich des Theaters oberhalb von 12 der ehemals 22 Kerkides der summa cavea fassen (Plan 1). Ihr westseitiger Abschluss in Richtung der Analemmata kann aufgrund des Erhaltungszustands nicht mehr nachvollzogen werden. Zum Auditorium war die Halle mit einer Kolonnade gestaltet, deren Architekturglieder sich jedoch nur fragmentarisch erhalten haben (Textabb. 20). Zu den identifizierten Bauteilen der Portikus-Architektur zählen zunächst Säulen mit attischen Basen und glatten monolithischen Säulenschäften, die mindestens teilweise aus Buntmarmoren gefertigt waren, und Blattkelchkapitellen. Des Weiteren konnten Fragmente von Architraven und Zahnschnittprofilen der Gebälkzone sowie Gesimsbauteile aus der Traufzone der Kolonnade zugeordnet werden. In Anbetracht der Vielzahl von Bauelementen, aus denen die Portikus-Architektur entsprechend ihrer räumlichen Dimension ursprünglich hätte aufgebaut sein müssen, ist die Fundlage verbliebener aussagekräftiger Bauteile für eine theoretische Rekonstruktion der Hallenarchitektur jedoch sehr gering. Insgesamt ergaben die aktuellen bauforscherischen Untersuchungen vor allem neue Erkenntnisse zur räumlichen Dimension der Portikus-Architektur sowie zur Ausstattung der Halle. Es konnte festgestellt werden, dass die Aufstellung der Kolonnade nicht auf dem oberen Diazoma erfolgte, wie bereits in der Erstpublikation dargestellt ${ }^{159}$, sondern ca. 2,50 m höher oberhalb der Diazomawand, was durch eine durchgehende Fundamentierung angezeigt wird (Taf. 463 Abb. 828; 464 Abb. 829). Zudem ergibt sich aus der Analyse der vorgefundenen Architekturfragmente allein für die Säulenstellung eine Höhe von ca. 5,30 m. Dieses Maß deckt sich auch mit Befunden, die an den hangseitig, hinter dem unteren Bereich der Portikus-Rückwand gelegenen >blinden` Kammern in Bezug auf deren ursprüngliche Höhe abzulesen sind (Taf. 464 Abb. 830). Fundstücke einer weiteren Säulenordnung geringerer Höhe sowie Pfeilerpostamente mit seitlichen Nuten und dazu passende Fragmente von durchbrochenen Schrankenplatten könnten zu einem Obergeschoss der Halle gehören ${ }^{160}$. Dafür sprächen auch die oberhalb der >blinden< Kammern hangseitig entlang der Portikus-Rückwand angeordneten Räume, die von einem östlich verlaufenden Gang erschlossen wurden (Tab. 127) ${ }^{161}$. Im Unterschied zur Rekonstruktion, wie sie von R. Heberdey und W. Wilberg vorgeschlagen wurde, ist die Halle in jedem Fall sehr viel höher anzunehmen und verändert mit dieser neuen Proportion nicht zuletzt unsere Vorstellungen von der Gesamterscheinung des Theaters.

Der Grundriss der Portikus vermittelt den Eindruck, dass sowohl im Norden als auch im Süden hinter der östlichen Begrenzungswand gelegene Raumstrukturen beim Bau berücksichtigt wurden. Lediglich im Verlauf der mittleren zwei Viertel hatte die Halle eine konstante Breite von 5,35 bis 5,40 m (Plan 1). In den äußeren hangseitigen Vierteln verringert sich dieses Maß oder wird durch vorspringende Mauern verändert. Von der Verbindung zwischen Halle und Cavea haben sich zwei schmale Treppen erhalten, die parallel zur Wand des oberen Diazoma angeordnet sind. Weitere Erschließungsmöglichkeiten aus dem Auditorium scheint es nicht gegeben zu haben.

Hangseitig allerdings waren mehrere Zugangsöffnungen in der Rückwand der Portikus angelegt ${ }^{162}$. Bei dem annähernd in der Mittelachse des Theaters befindlichen Eingang könnte es sich aufgrund der Öffnungsbreite und zentralen Position um einen Hauptzugang der Halle gehandelt haben. Die an dieser Stelle heute sichtbare, aus Spolien aufgebaute Treppenanlage ist jedoch sekundär (Taf. 465 Abb. 831. 832). Die Zugänge südlich und nördlich davon stehen in Zusammenhang mit einer hinter der Rückwand der Portikus beginnenden Raumstruktur, die zunächst nicht näher untersucht werden konnte. Jedoch erbrachte die Grabung 2009 Hinweise auf deren mögliche Funktion. Der hinter der Portikus-Rückwand freigelegte Raum wurde als Thermopolion identifiziert ${ }^{163}$. Eine Nutzung zu Versorgungszwecken in Verbindung mit der Portikus ist auch für die genannte Raumstruktur im nördlichen und südlichen Hangbereich denkbar.

\footnotetext{
${ }^{159}$ Heberdey u. a. 1912, 48 Abb. 96.

${ }^{160}$ Kap. 7.1.6

${ }^{161}$ Kap. 3.8.

${ }^{162}$ Sämtliche Zugangsöffnungen durch die Hallenrückwand waren sekundär verschlossen. Der Vergleich von historischen Fotos aus der Freilegungszeit der Portikus (De Bernardi-Ferrero, 1970, 58 Abb. 55. 56; 63 Abb. 73) mit dem heutigen Erscheinungsbild lässt vermuten, dass einige der ehemaligen Zugänge im Rahmen der Restaurierung der Portikus Ende der 1960er/Anfang der 1970er Jahre wieder geöffnet bzw. dass lediglich fragmentarisch erhaltene Verschlussmauern in dieser Phase rückgebaut wurden.

${ }^{163}$ Kap. 3.8.
} 


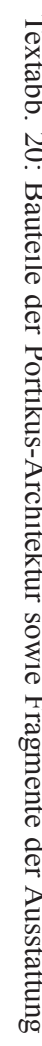

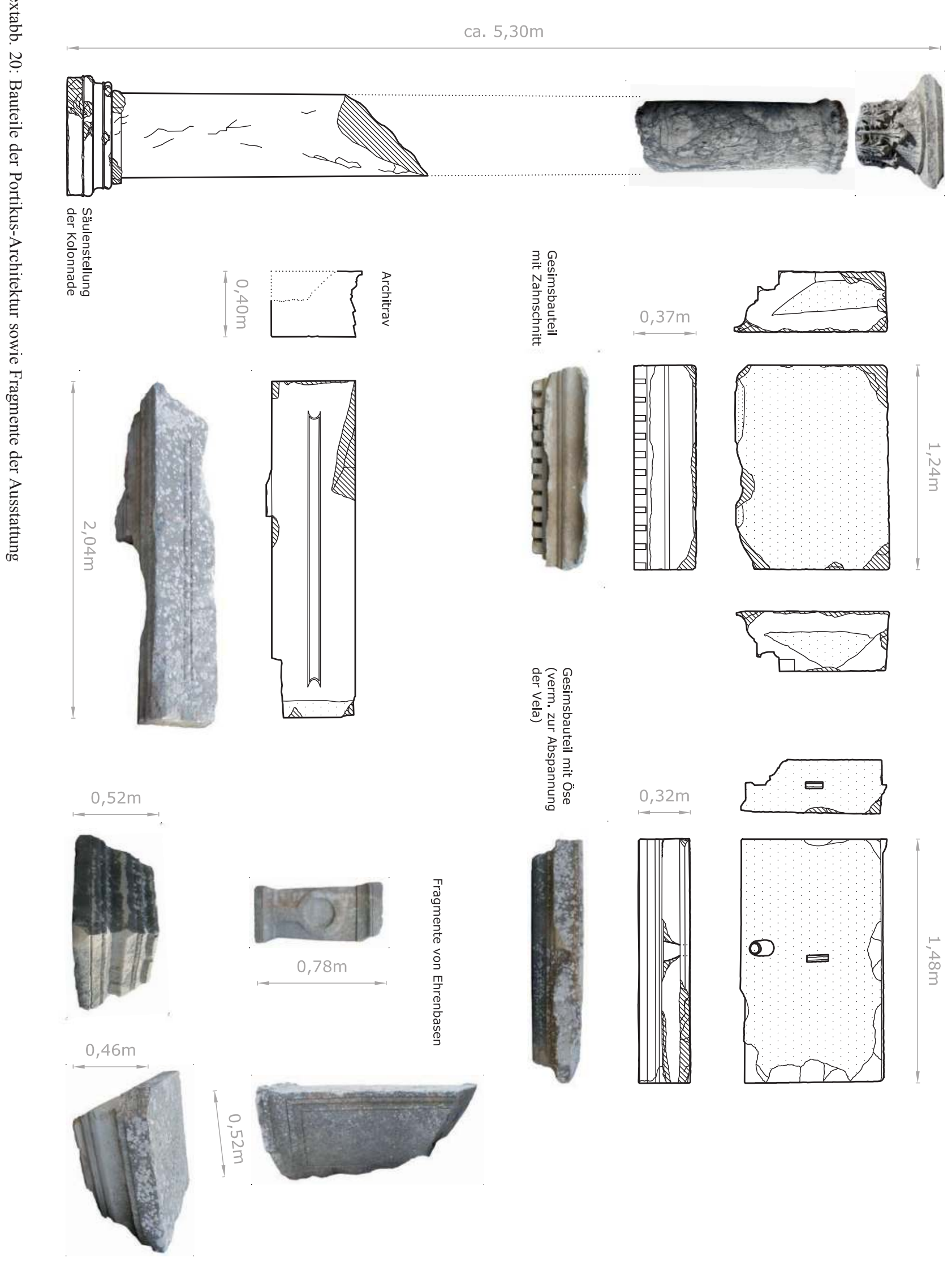


Das Laufniveau in der Halle lag ca. 0,50 m über der Oberkante der (restaurierten) Stützwand des oberen Diazoma, wie geringe Reste von erhaltenem Bodenbelag aus Marmor- bzw. Tuffsteinplatten zeigen. Ein weiteres Indiz dafür ist der in größeren Bereichen als Unterbau für den Fußboden terrassierte Fels des Berghangs, dessen Niveau mit der Unterkante des aufgefundenen Bodenbelags korrespondiert (Taf. 466 Abb. 833. 834).

Die im Wesentlichen aus Hausteinen im Mörtelverband hergestellte Rückwand der Halle war mit einer Marmorinkrustation gestaltet, von der sich neben wenigen Fragmenten vor allem die Metallverankerungen zur Befestigung der Marmortafeln in der Wand erhalten haben. Unter den Bruchstücken der Verkleidung befinden sich Platten von 1,0 bis 3,5 cm Dicke sowie verschiedene horizontale Profile und Leisten. Einige Plattenfragmente zeigen auch Buchstabenreste ${ }^{164}$. Insgesamt konnten mehr als zehn verschiedene Marmorarten, besonders Buntmarmore, festgestellt werden (Taf. 467 Abb. 835). Zusätzlich waren an der Wand offenbar auch tragische Masken angebracht, von denen einige bereits bei den Arbeiten des Museums in Selçuk zwischen 1966 und 1972 zu Tage kamen ${ }^{165}$. In einer späteren Phase wurden die Befestigungsanker der Marmorinkrustation an der Wandoberfläche abgeschlagen und die Wand verputzt. Aus dieser Phase haben sich Schichtfragmente des Putzes, teilweise mit Farbauftrag, erhalten.

Während der Untersuchung der Portikus wurden unter den Architekturgliedern in auffällig hoher Anzahl Bekrönungen dreiteiliger Basen bzw. einteilige Postamente, u. a. mit Siegerkranz, gefunden ${ }^{166}$. Teilweise sind die Bauteile erst in Rohform ausgearbeitet. Einige andere Fragmente tragen Ehreninschriften. Eine räumliche Zuordnung der Stücke ist nicht mehr möglich, ihr zahlreiches Vorhandensein lässt jedoch vermuten, dass sie zur Ausstattung der Portikus gehörten. In diesem Zusammenhang sind auch die Brüstungspfeiler mit Gladiatorenreliefs zu erwähnen, die während der Freilegungen im Norden des Theaters ${ }^{167}$ sowie entlang der Südfassade ${ }^{168}$ ergraben wurden. Bereits St. Karwiese ging von einer Aufstellung am oberen Abschluss des Theaters aus ${ }^{169}$.

Über die Ausdehnung der Portikus in Richtung Westen lassen sich lediglich Überlegungen anstellen. J. T. Wood rekonstruierte eine Säulenstellung entlang des gesamten Theaterrunds (Textabb. 9), was von R. Heberdey und W. Wilberg aufgrund der Raumverhältnisse abgelehnt wurde ${ }^{170}$. Stattdessen schlagen beide eine Kolonnade vor, die sich auf den verbreiterten Grundrissabschnitt im Bereich des Berghangs bezieht ${ }^{171}$. Aber auch diese Rekonstruktion baut auf idealisierten Annahmen auf. So ist der im Grundriss von 1912 dargestellte hangseitige südliche Rücksprung der Halle am Bau nicht nachzuvollziehen (Textabb. 11). Die Betrachtung des tatsächlichen Portikus-Grundrisses vermittelt eher den Eindruck, dass sich durch die einheitliche Front zur Cavea in Form der Säulenstellung die Unregelmäßigkeiten im Verlauf der PortikusRückwand relativierten. Unter diesem Blickwinkel wäre eine Fortsetzung der Kolonnade bis zu den westseitigen Analemmata wieder vorstellbar, wenn sich auch die tatsächlich nutzbare Halle lediglich auf den Hangbereich bezog. Mangels weiterer Befunde lassen sich diese Überlegungen jedoch nicht verifizieren.

Die Frage der Errichtungszeit der Portikus ist nicht ganz eindeutig zu beantworten. Anhaltspunkte geben zunächst bauliche Aktivitäten auf dem oberen Diazoma in der frühen Kaiserzeit bzw. dem 1. Jh. n. Chr. sowie die Datierung eines der beiden ergrabenen Räume östlich der Portikus-Rückwand, dessen erste Bauphase in die 1. Hälfte des 1 . Jhs. n. Chr. eingeordnet wird ${ }^{172}$. Wie der Bereich der Portikus in dieser Zeit gestaltet war, bleibt offen.

Aus den Bauinschriften zur großen Ausbauphase des Theaters unter Domitian bis Trajan geht nicht hervor, dass auch die Säulenhalle fertiggestellt war. Als Teil eines umfangreichen Bauprogramms zur Ro-

\footnotetext{
164 Kap. 8.

${ }^{165}$ Atalay 1972, 47. 51 f.; Kayan 1972, 56-64; s. auch Kap. 7.1.6 und den Beitrag von M. Aurenhammer in: StyHLER-Aydin (in Vorbereitung); vgl. allgemein auch Moretri 1993a, 207-217.

${ }^{166}$ Sämtliche Fragmente der Architektur und Ausstattung der Portikus sind disloziert. Sie wurden offenbar während der Freilegung und Restaurierung durch das Museum in Selçuk am inneren Rand der Portikus sowie auf dem oberen Diazoma gelagert. Eine entsprechende Dokumentation der Arbeiten ist nicht bekannt.

167 Kap. 3.5

${ }^{168}$ Kap. 3

${ }^{169}$ Karwiese Schlussbericht; s. auch Kap. 3.5.1; 7.1.6 u. Kap. 8, IN 7 (Taf. 413).

170 Wood 1877, Rekonstruktion des Grundrisses gegenüber S. 68; HeBERDEY u. a. 1912, 16.

${ }^{171}$ Heberdey u. a. 1912, 15 f. 50 Abb. 98.

${ }^{172}$ Kap. 3.4.3 u. 3.8.6.
} 
manisierung des Theaters könnte man allerdings auch die entsprechend übliche Gestaltung des oberen Gebäudeabschlusses mit einer Portikus erwarten. Auch die Tatsache, dass der zuvor genannte hangseitig an die Portikus-Rückwand anschließende Raum mindestens seit seiner zweiten Bauphase im späten 1. bzw. frühen 2. Jh. n. Chr. als Thermopolion in Verwendung war, deutet auf eine architektonische Fassung und räumliche Nutzung im oberen Bereich des Theaters hin ${ }^{173}$. Unter den Fragmenten der Portikus-Architektur aufgefundene Exemplare tragischer Masken, von denen angenommen werden kann, dass sie an der Hallenrückwand angebracht waren, datieren einige zwischen dem späten 1 . Jh. n. Chr. und dem 1. Drittel des 2. Jhs. n. Chr. ${ }^{174}$. Verschiedene Inschriften, die in den Zeitraum von 140 bis $144 \mathrm{n}$. Chr. sowie in das 3. Jh. n. Chr. datiert werden, berichten über die Reparatur des Petasos - des breitrandigen Hutes - im Theater, womit ein leichtes Sonnendach gemeint sein könnte ${ }^{175}$. Befestigungsösen, wie sie zur Abspannung von Seilen genutzt werden, lassen sich tatsächlich an Gesimsbauteilen der Portikus-Architektur sowie am mittleren Diazoma feststellen. Die stilistischen Merkmale sowie die Bearbeitungsqualität der wenigen erhaltenen aussagekräftigen Architekturglieder wie Kapitelle und Zahnschnittgesimse deuten hingegen auf eine Herstellung erst gegen Mitte des 2. Jhs. n. Chr. ${ }^{176}$, wobei die genannten Bauteile natürlich auch einer Reparaturphase entstammen können. Die aufgefundenen Inschriften reichen vom 2. Jh. n. Chr. bis in die 1. Hälfte des 3. Jhs. n. Chr. ${ }^{177}$.

Nur an wenigen erhaltenen kleinasiatischen Theatern lässt sich am Bestand auch noch der Bereich einer porticus in summa cavea nachvollziehen. Dazu zählen das Theater in Perge (datiert $120 \mathrm{n}$. Chr.; Portikus vermutlich um $200 \mathrm{n}$. Chr. ${ }^{178}$ ), das Theater in Aspendos (datiert 161-168 n. Chr.; Portikus sekundär ohne Datierung) und das Theater in Termessos (frühes 2. Jh. v. Chr., Umbau in der römischen Kaiserzeit) ${ }^{179}$. Die im Theater von Ephesos aktuell ermittelten baulichen Hinweise zur Grundrissbreite sowie zur rekonstruierten Höhe der Portikus-Architektur finden Parallelen in den Portiken der Theater in Perge und Aspendos. Dort hatten die Hallen jeweils eine Breite zwischen ca. 5,20 und 5,70 m und waren ca. 8,00 m bzw. ca. 7,50 $\mathrm{m}$ hoch $^{180}$.

Die jüngsten Grabungen direkt östlich des Theaters in Ephesos legten, wie bereits beschrieben, den kleinen Ausschnitt einer Raumstruktur frei, der als Thermopolion anzusprechen ist und in funktionalem Zusammenhang mit der Nutzung der porticus in summa cavea bzw. dem Theaterbetrieb stand ${ }^{181}$. Derartige Fundsituationen im nahen baulichen Kontext antiker Theater sind selten. Das gilt erst recht für die Nachbarschaft zur porticus in summa cavea. Es zeichnet sich hier eine aussichtsreiche Möglichkeit für zukünftige archäologische und bauhistorische Forschungen ab, neues Wissen zur Funktion und Versorgung dieser Hallen im Rahmen des antiken Theaterbetriebs zu ergründen.

\footnotetext{
${ }^{173}$ Kap. 3.8.6.

${ }^{174}$ Ich danke M. Aurenhammer für diesen Hinweis. Eine ausführliche Darstellung des Befunds durch M. Aurenhammer erfolgt in STYHLER-AYDIN (in Vorbereitung).

${ }^{175}$ IvE 2039-2041. Dazu auch Kap. 8.6.1, Nr. 9-11 u. Kap. 8.6.2. R. Heberdey interpretierte den Begriff Petasos als Sonnensegel, das sich aus einzelnen Bahnen zusammensetzte und auf Seilen aufgezogen werden konnte (HeBERDEY u. a. 1912, 162). Dieser Auslegung folgte auch R. Graefe in seiner Untersuchung zu den Zeltdächern der römischen Theater und machte außerdem Vorschläge wie die Sonnensegel in den kleinasiatischen Theatern möglicherweise aufgestellt waren (Graefe 1979, 15. 174 Abb. 196; 175 Abb. 197). J.-Ch. Moretti hingegen sieht es nicht als erwiesen an, dass der Begriff Petasos tatsächlich ein Sonnensegel bezeichnet und verneint die Existenz eines velum im Theater von Ephesos, da auch am Bau keine entsprechenden Indizien nachweisbar seien (Moretti 1993b, 137-140; vgl. auch Green 1995, 32). Die von R. Heberdey und W. Wilberg beschriebenen Pfostenquader am Rand der Orchestra und im Mittelfeld des unteren Rangs wurden bereits von ihnen mit der Aufstellung eines Baldachins über einem Ehrenplatz und nicht mit dem Sonnensegel in Zusammenhang gebracht (HeBERDEY u. a. 1912, 45 mit Abb. gegenüber S. 17). Vgl. Kap. 10.2.4.3. Aktuell konnten weitere Hinweise zur Aufstellung von Pfosten am unteren Diazoma festgestellt werden. Die Darlegung der Befunde wird in STYHLER-AYDIN (in Vorbereitung) erfolgen.

${ }^{176}$ Für die diesbezüglichen Hinweise von G. Plattner und H. Thür möchte ich an dieser Stelle herzlich danken.

${ }^{177}$ Kap. 8.2.

${ }^{178}$ Sear 2006, 372 f.; Ciancio Rossetto - Pisani Sartorio 1994-1996, Bd. 3, 357 f.; De Bernardi Ferrero 1974, 241; De Bernardi FERRERO 1970, 146-157 Taf. 28-30.

179 Zu Aspendos: Sear 2006, 366 f.; Ciancio Rossetto - Pisani Sartorio 1994-1996, Bd. 3 , 393 f.; De Bernardi Ferrero 1974, 241 ; De Bernardi Ferrero 1970, 173; zu Termessos: Sear 2006, 378 f.; Ciancio Rossetto - Pisani Sartorio 1994-1996, Bd. 3, 443; De Bernardi Ferrero 1974, 241; De Bernardi Ferrero 1969, $32 \mathrm{f}$.

${ }^{180}$ De Bernardi Ferrero 1970, Taf. 28. 31; 32A.

${ }^{181}$ Kap. 3.8.
} 


\section{Zusammenfassung}

Nach Abschluss der umfangreichen Umbau- und Erweiterungsmaßnahmen bietet das Theater am Anfang des 2. Jhs. n. Chr. folgendes Bild: Am Fuß des Panayırdağ erhebt sich der im Grundriss den Halbkreis überschreitende Zuschauerraum in drei Rängen, ca. $30 \mathrm{~m}$ über die Orchestra. Sein maximaler Durchmesser beträgt annähernd $150 \mathrm{~m}$. Der mächtige Stufenbau wird im Westen durch Analemmata von jeweils annähernd $60 \mathrm{~m}$ Länge begrenzt. Zwischen ihnen liegt das dreigeschossige, fast $42 \mathrm{~m}$ lange Bühnengebäude.

Die Einteilung des Auditorium in elf keilförmige Sektoren im unteren Rang sowie jeweils 22 im mittleren und oberen Rang lässt sich bis heute nachvollziehen. Die Anzahl der Sitzstufen variiert in den einzelnen Rängen und beträgt nach den kaiserzeitlichen Umbauten inklusive der Diazomata-Niveaus 18 für den unteren, 22 für den mittleren sowie 21 für den oberen Rang. Eine am vorgefundenen Bestand orientierte theoretische Ermittlung der Sitzplätze ergibt eine Kapazität von 20.000 Zuschauern ${ }^{182}$.

Funktional betrachtet ist das Auditorium in dieser Phase durch ein klar organisiertes Erschließungssystem geprägt: Die beiden unteren Ränge waren im Norden und Süden durch je einen überwölbten Korridor zugänglich. Zusätzlich dazu konnte der untere Rang über Treppenanlagen von Westen aus erschlossen werden. In den oberen Rang führt von Süden her ein älteres Portal. An der Südseite verbindet eine breite Außentreppe die drei genannten Zugänge miteinander. Eine ähnliche Lösung wird auch für die Zugänge im Norden vermutet.

Den oberen Abschluss des Theaters bildet eine Portikus, die sich mindestens auf den Hangbereich erstreckte.

\subsubsection{UmbaUten UND REPARATUREN IN ANTONINISChER ZeIT}

Auf Basis einer Inschrift ${ }^{183}$, die im Zeitrahmen zwischen 140-144 n. Chr. angesetzt wird und in zwei Exemplaren am jeweils nördlichen und südlichen Analemma im Bereich des oberen Ansatzes der Rampen (Rampe N; Rampe S) eingelassen ist (Taf. 2), ordneten bereits die ersten österreichischen Forscher eine Reihe baulich nachvollziehbarer Umgestaltungen im Bereich der Orchestra der antoninischen Zeit zu, die auch als Modernisierung verstanden werden können ${ }^{184}$. Dazu zählen u. a. eine Abschrankung in der Orchestra, die Überbauung des hellenistischen Orchestrakanals durch die Anlage eines neuen Abflusskanals auf etwas höherem Niveau, verbunden mit einer Erhöhung des Orchestrabodens sowie eine Neuauskleidung mit Marmorplatten $^{185}$. In der Orchestrawand X wurden fast alle Antritte der Radialtreppen verschlossen. Lediglich die mittleren Treppen konnten noch benutzt werden, was von R. Heberdey und W. Wilberg mit der Erschließung eines Ehrenplatzes in der mittleren Kerkis des unteren Rangs begründet wurde. Zur Zeit ihrer Forschungen hatten sich hier im Bereich der fünften Stufenreihe noch die Reste eines Marmorbodens sowie Quader mit Pfostenlöchern erhalten, die möglicherweise zur Aufstellung eines Baldachins dienten ${ }^{186}$. Im heutigen restaurierten Bestand kann diese Situation nicht mehr nachvollzogen werden.

Weitere Veränderungen erfolgten am Eintrittsbereich der Parodoi in die Orchestra sowie an der Front des Proskenion $^{187}$. Die beschriebenen baulichen Eingriffe wurden in der Literatur u. a. als Hinweis für die Aufführung von Gladiatorenspielen und Wasserspielen im Theater interpretiert ${ }^{188}$. Wie die jüngste Forschung zeigte, zweigen auch tatsächlich zwei Tonrohre aus der Aristion-Leitung in Richtung Orchestra ab (s. o., Taf. 93 Abb. 184. 185; 94 Abb. 186). Da jedoch deren Eintrittsöffnungen in die Orchestra im erhaltenen

\footnotetext{
${ }^{182}$ Für die Berechnung wurde eine Breite von 0,44 m pro Zuschauer zugrunde gelegt; vgl. CianCo Rossetto - Pisani Sartorio 1994, Bd. 1, 65 .

${ }^{183}$ IvE 2039. Vgl. HeberdeY u. a. 1912, 162 f. Dazu auch Kap. 8.6.1, Nr. 9 u. Kap. 8.6.2.

${ }^{184}$ HeBerdey u. a. 1912, 44-47.

${ }^{185}$ Auch die Wegnahme der Sitzreihen bis in Höhe des Logeion, verbunden mit der Errichtung der Orchestrawand, wurde in der Erstpublikation dieser Phase zugesprochen (Heberdey u. a. 1912, 44 f. 52). Angesichts des aktuellen Baubefunds rückt diese Maßnahme jedoch eher in die umfangreiche Ausbauzeit des Theaters unter den Kaisern Domitian bis Trajan; s. o. zu Orchestra, Parodoi und ima cavea; Kap. 3.3.

${ }^{186}$ Heberdey u. a. 1912, 45. 47 Abb. 95.

${ }^{187}$ Kap. 3.2.3 u. 10.2.1.3.

${ }^{188}$ De Bernardi Ferrero 1970, 63.
} 
Bestand nicht mehr nachvollzogen werden können, lassen sich hier keine weiteren, diese These stützenden Hinweise gewinnen. Generell wäre eine Wassernutzung in der Orchestra natürlich auch zu Reinigungszwecken vorstellbar. Die Nutzung der Orchestra als Becken erfordert in jedem Fall bauliche Maßnahmen zum Verschluss bestehender Öffnungen, welche sich am Bau selbst nicht nachweisen lassen ${ }^{189}$.

Inschriftlich überliefert sind zudem Baumaßnahmen zur Herstellung oder Erneuerung des Petasos (Tab. $127)^{190}$.

G. STYHLER-AydiN

\title{
10.3 DAS THEATER IN DER SPÄTZEIT
}

\subsubsection{Die Theaterfassade in der Spätzeit}

\author{
Spätere Nutzung (5. und 6. Jh. N. Chr.)
}

Am Sockel des ersten Geschosses sind zahlreiche Graffiti erhalten, in denen teilweise Aufführungen dargestellt sind ${ }^{191}$. Anhand der Kleidung der Schauspieler können diese Darstellungen in das 5. und 6. Jh. n. Chr. datiert werden. Das beweist, dass die Bühne auch noch bei spätantiken Veranstaltungen in Verwendung war.

\section{Reparaturen AN DER SCAENAe Frons (IN DER ANTIKe)}

An den Baugliedern der scaenae frons sind antike Reparaturen erhalten. Die Gesimsplatten der Attikamauer sind zum Teil aus Kassettenblöcken umgearbeitet, deren Spuren auf der oberen Seite des Gesimses vorhanden sind (Taf. 468 Abb. 836. 837). Ein konkaver Architrav des dritten Geschosses ist in drei Teile zerbrochen (Taf. 469 Abb. 838). Drei anpassende Architravfragmente tragen nahe beim Bruch Klammerlöcher, sie waren also bereits in der Antike mit Klammern repariert worden. Daraus ergibt sich, dass zumindest im dritten Geschoss eine Reparaturphase stattgefunden hat. Diese Reparaturphase konnte noch nicht datiert werden.

A. ÖZTÜRK

\subsubsection{Bühnengebäude in der Spätzeit}

Bei praktisch allen Kammern lassen sich Balkenlöcher feststellen. Sie sind in uneinheitlicher Höhe angebracht und weisen unterschiedliche Größen auf. Die Löcher befinden sich durchwegs an der Ost- bzw. Westwand. Zumeist ist je ein Balkenloch zur rechten und linken Seite der Eingangstür in der Westmauer erhalten, dem jeweils ein Gegenstück an der Ostmauer entspricht. Die Abstände unterliegen keinem regelmäßigen Schema. Man wird diese Balkenlöcher in Zusammenhang mit regalartigen, für Lagerungszwecke dienenden Einrichtungen zu beiden Seiten des Eingangs in Verbindung bringen dürfen.

In zwei der zwischen den Kammern E1 und E8 gelegenen Räume (E3 und E5) konnten bei der Reinigung Spuren einer Nutzung vorgefunden werden (Taf. 3 Abb. 3). In Kammer E3 wurden zwei in den Boden gesetzte Pithoi freigelegt (Taf. 24 Abb. 40. 41; 25 Abb. 42. 43; 26 Abb. 44. 45). Sie waren mit großformatigen Keramikfragmenten verfüllt. Es handelte sich dabei um Tafelgeschirr neronischer Zeit ${ }^{192}$. Die Pithoi waren von einer Schuttschicht SE 30 unterhalb des Mörtelbetts für den Ziegelplattenboden versiegelt. Keramik und auch eine Münze aus der Zeit Marc Aurels geben einen terminus ante quem für die Verfüllung der Pithoi und einen terminus post quem für die Errichtung des Ziegelplattenbodens im späten 2. Jh. n. Chr. ${ }^{193}$.

\footnotetext{
${ }^{189}$ Kap. 3.3.1 u. 3.3.2.

${ }^{190}$ IvE 2039 (zur Diskussion s. o.).

${ }^{191}$ ROUECHÉ 2002b, 257.

192 Kap. 4.1.2.2.

${ }^{193}$ Zur Datierung s. Kap. 4.1.2.2.
} 
Eventuell aus dem 4. Jh. n. Chr. stammt eine dreiteilige Beckenanlage in Kammer E5 (Taf. 28 Abb. 47; 29 Abb. 48. 49; 30 Abb. 50. 51; 31 Abb. 52). Diese wurde aus halbformatigen Ziegeln gebildet, die außen und innen mit einem feinen, weißen Putz versehen waren. Der Boden der Becken bestand aus einer Lage Ziegelplatten. Die Anlage wurde spätestens im 5./6. Jh. n. Chr. aufgegeben und über den Resten der Becken ein neues Bodenniveau aus Ziegelplatten errichtet. Reparaturen sind an den Mauern der Westerweiterung nicht zu erkennen. Doch sind Spuren einer in der Spätzeit anders gearteten Nutzung bzw. vielleicht sogar Funktion ersichtlich. Unmittelbar südlich des Eingangs in Kammer E5 setzt ein Tor der vermutlich im 6. Jh. n. Chr. errichteten byzantinischen Stadtmauer an, womit das Theater zwischen diesem Tor und dem Eingang ES3 einen Teil dieser Befestigung darstellte. Sehr wahrscheinlich wurden die Zugänge zu den Kammern E6, E7 und E8 in diesem Zusammenhang verschlossen, was zumindest für E6 und E7 mit einer generellen Aufgabe verbunden gewesen sein dürfte. Kammer E7 und E8 besitzen entlang der Westmauer eine Verstärkungsmauer (Taf. 32 Abb. 54. 55; 33 Abb 56). Dieser Umstand scheint gleichfalls mit dieser Baumaßnahme in Verbindung zu stehen. Allein aufgrund des Fundmaterials aus den Schichten der Hinterfüllung der Verstärkungsmauer von Kammer E7 kann ein chronologischer Zusammenhang von Mauerverstärkung und Stadtmauer nicht hergestellt werden. Das teilweise bis in das 3. Jh. n. Chr. reichende Fundmaterial aus der Hinterfüllung der Verstärkungsmauer könnte auch für eine bauliche Maßnahme sprechen, die nicht mit dem Bau der byzantinischen Stadtmauer und dem Tor in Verbindung steht (Taf. 51 Abb. 97), sondern die bereits eine Reparatur in Folge des Erdbebens von 262 n. Chr. darstellt (Tab. 127). Jedenfalls wurden durch das Einziehen der Verstärkungsmauer die Eingänge verschlossen. Eine aus Ziegeln gemauerte Stufe vor dem Eingang zu E5 setzt an der Stadtmauer an und gibt Zeugnis von der Nutzung der Eingänge, die nun innerhalb des ummauerten Stadtgebiets gelegen waren. Dies zumindest temporär, denn auch die Eingänge der Kammern E1 bis E5 wurden schließlich durch ein Spolienmauerwerk verschlossen. Der Durchgang C wurde im Bereich zwischen den Kammern E4 und E5 (nicht zwischen den hellenistischen Kammern D4 und D5) mit Spolien auf einen $0,75 \mathrm{~m}$ schmalen Korridor verengt. Im oberen Bereich ist der Rest einer massiven opus caemaentitium-Verfüllung erhalten. Aufgrund seiner Lage in unmittelbarer Nähe zur byzantinischen Stadtmauer und des Tors könnte es sich bei dieser Verfüllung um die Reste von Mauerwerk eines sekundären Einbaus in Form eines Turms handeln, der über dem westlichen Abschnitt des Durchgangs C errichtet worden war.

M. HOFBAUER

\subsection{3 Änderungen an Orchestra und Bühnenfront}

Im Großen und Ganzen blieb die Orchestra in ihrer Form bestehen, die auf das 2. Jh. n. Chr. zurückging. Die Durchgänge in der antoninischen Proskenionfront wurden abgemauert. Die beiden bereits oben genannten Rohrleitungen, die aus der Aristion-Leitung gespeist wurden, ließen sich 2006 bis auf das untere Diazoma verfolgen (Taf. 93 Abb. 184. 185; 94 Abb. 186). Ein Zusammenhang mit der Befüllung der Orchestra mit Wasser lässt sich derzeit am baulichen Befund nicht verifizieren ${ }^{194}$. Die Rohrleitungen könnten im Zusammenhang mit Brunneneinbauten gestanden haben, wie sie vom mittleren Diazoma bekannt sind, oder für Reinigungszecke im Rahmen der Gladiatorenkämpfe gedient haben.

M. Hofbauer

\subsubsection{Veränderungen im Auditorium}

\section{NORDFLÜGEL DES THEATERS}

Ein erster erkennbarer Eingriff im Nordflügel des Theaters erfolgte im Zugangskorridor EN1 ${ }^{195}$. In dessen nördlichen Abschnitt, der mit 11,00 m hohen Seitenwänden und ca. 13,35 m Scheitelhöhe des Tonnengewölbes sicherlich zu den höchsten überwölbten Räumen im Theater zählte, zog man eventuell zur Aussteifung

\footnotetext{
${ }^{194}$ Kap. 10.2.2.2.

${ }^{195}$ Kap. 10.1.3.
} 


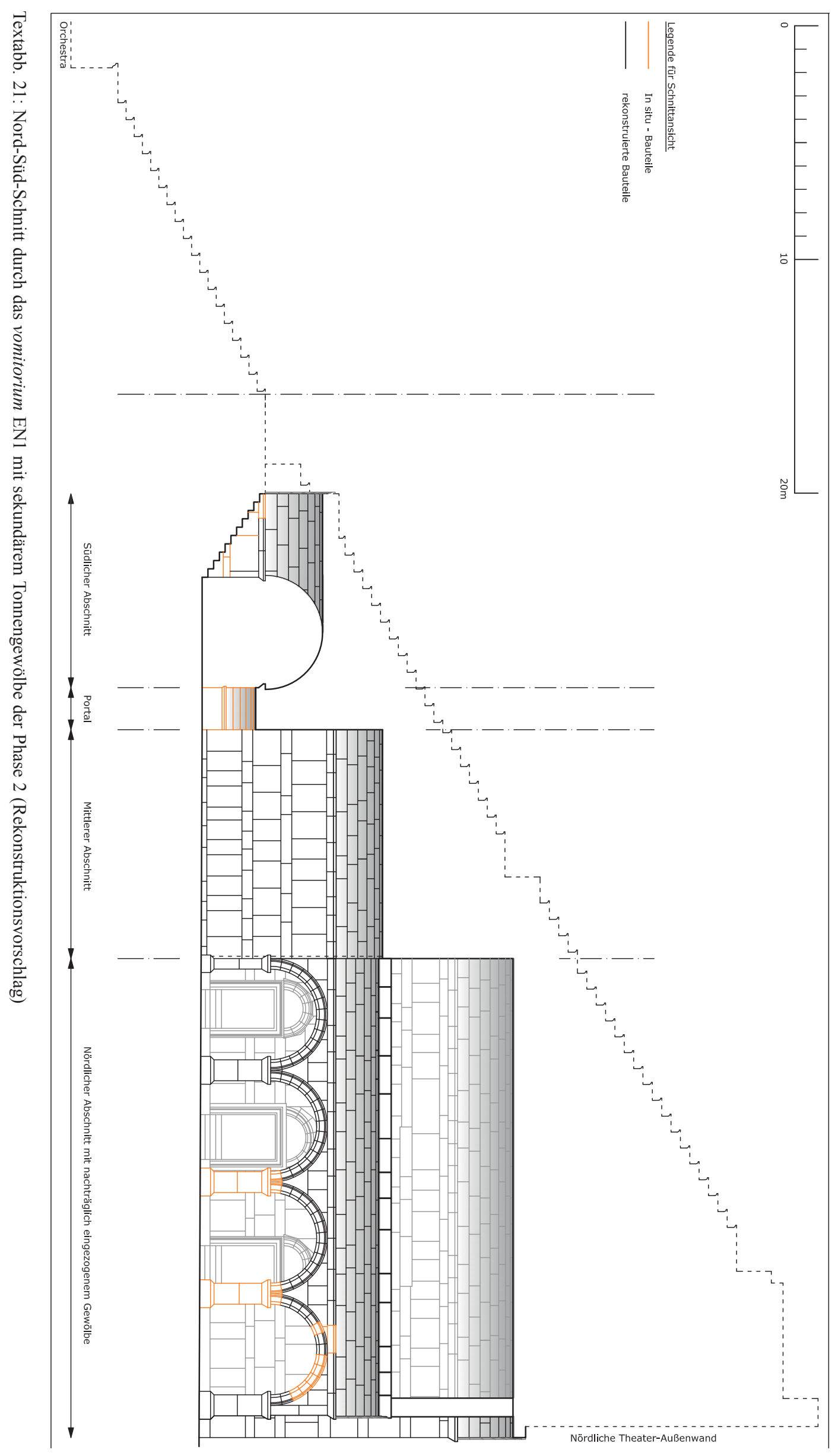


ein zweites, niedrigeres Gewölbe oder eine Decke ein ${ }^{196}$. Anscheinend etwas von der Nordfassade eingerückt, ruhte die Konstruktion auf vermutlich vier Arkadenbögen, die direkt vor den Seitenwänden des vomitorium aufgestellt wurden (Taf. 470 Abb. 840). An der Westseite waren die profilierten Tür- und Oberlichtgewände der Kammereingänge durch die Bogenstellungen zwar teilweise verdeckt bzw. mussten abgearbeitet werden, dennoch blieb die Zugänglichkeit und damit die Nutzung der Kammern weiterhin erhalten (Taf. 470 Abb. 841). Aus den noch in situ befindlichen Bauteilen der Arkadenkonstruktion lässt sich rekonstruieren, dass die Scheitelhöhe im nördlichen Abschnitt des vomitorium im Falle eines zusätzlichen Tonnengewölbes um etwa ein Drittel verringert worden wäre und annähernd der Gewölbehöhe im mittleren Korridorabschnitt entsprochen haben müsste (Textabb. 21). Aufgrund der hohen Versturzmassen im vomitorium ist die Arkadenkonstruktion heute nur ausschnitthaft zu erkennen ${ }^{197}$. Die erhaltenen sichtbaren Bauteile der Pfeilerbasen, Pfeilerkapitelle sowie der Kämpferzone blieben im Rohzuschnitt ohne angelegtes Profil. An der höher erhaltenen Westwand des vomitorium sind zwar Abarbeitungen, jedoch kaum Verankerungspunkte für die vorgelagerten Bauteile der Arkaden nachzuweisen. Insgesamt kann aufgrund der genannten Befunde derzeit nicht abschließend geklärt werden, ob die Baumaßnahme vollständig zur Ausführung kam ${ }^{198}$. Für eine Datierung des Eingriffs gibt es zunächst keine direkten Anhaltspunkte. St. Karwiese und I. Ataç zogen das 3. Jh. n. Chr. in Erwägung und sahen die beschriebene Baumaßnahme sowie weitere spätere Veränderungen im unteren Korridor im Zusammenhang mit historisch überlieferten Erdbeben in den Jahren $262 \mathrm{n}$. Chr. sowie 359 bis 366 n. Chr. (Tab. 127) ${ }^{199}$. Aktuell zeigt auch die Auswertung der Keramikfunde aus dem Theater Fundmaterial, das als Schutt des Erdbebens im 3. Viertel des 3. Jhs. n. Chr. angesprochen werden kann ${ }^{200}$. Die Befunde am Bau lassen gegenwärtig jedoch offen, inwiefern es sich bei der Errichtung der sekundären Arkadenkonstruktion um eine Baumaßnahme in Folge von tatsächlichen Schäden oder eher um eine präventive Intervention gegen drohende Instabilität im höchsten Abschnitt des vomitorium handelte.

Die spätere Nutzung des nördlichen und mittleren Korridorabschnitts als Zisterne spricht dafür, dass ein oberer Raumabschluss im 5./6. Jh. n. Chr. noch existierte (s. u.), wenn über dessen Gestaltung derzeit auch keine näheren Aussagen zu treffen sind.

Im 4. Jh. n. Chr. wurden umfangreiche Stabilisierungsmaßnahmen an der nördlichen Theateraußenwand vorgenommen (Tab. 127). In der älteren Forschungsliteratur ging man davon aus, dass eine Reihe historisch bezeugter schwerer Erdbeben, die sich im 3. Viertel des 4. Jhs. n. Chr. im östlichen Mittelmeergebiet ereigneten, Ephesos erschütterten und auch das Theater in Mitleidenschaft zogen ${ }^{201}$. Mangels diesbezüglich zweifelsfreier archäologischer Befunde auch an anderen Monumenten in Ephesos suchen jüngere Forschungen nach konkreten Evidenzen und äußern sich kritisch über die allgemeine Zuweisung von Befunden zu den genannten Beben ${ }^{202}$. An den erhaltenen Abschnitten der Nordfassade des Theaters zeugen die Rissbilder im Quadermauerwerk allerdings von starken Krafteinwirkungen, wie sie durch Erdbeben verursacht werden. Mit Hilfe der massiven Konsolidierungen wurde offensichtlich versucht, Teile der Theateraußenwand vor dem Einsturz zu bewahren.

Zunächst sicherte man anscheinend die ıSchwachstellen der Außenwand im Bereich der hohen Fassadenöffnungen der vomitoria EN1 und EN2. Der Zugang auf das mittlere Diazoma (EN2) wurde mit einer $5 \mathrm{~m}$ starken Wand massiv verschlossen (Taf. 146 Abb. 294; Textabb. 16). Zusätzlich stützten orthogonal zur Nordfassade angelagerte Strebemauern die Außenwand auf beiden Seiten des ehemaligen Zugangs ab (Taf. 148 Abb. 299. 300; Textabb. 17) ${ }^{203}$. Im unteren vomitorium EN1 deutet sich an, dass mindestens die

\footnotetext{
${ }^{196}$ St. Karwiese ging davon aus, dass mit der sekundären Konstruktion eine weitere Nutzungsebene im Korridor verbunden war, s. Karwiese Archiv ÖAI, 5; KarWIESE 1999, 26.

${ }^{197}$ Kap. 3.5.1.

${ }^{198}$ Eine Analyse der bereits zwischen 1993 und 1998 geborgenen Bauteile aus dem Versturz im vomitorium (derzeit nördlich des Theaters lagernd) verbunden mit weiteren Freilegungsarbeiten könnte hier in Zukunft genaueren Aufschluss geben.

${ }^{199}$ Karwiese Archiv ÖAI, 5; Karwiese 1998, 25; Scherrer 1995, 162; Ataç 1999b, 431; Ataç 1997. Die aktuellen Forschungen in Ephesos gehen auf Basis des Fundmaterials davon aus, dass die Stadt im 3. Viertel des 3. Jhs. n. Chr. durch ein schweres Erdbeben erschüttert wurde. Es ist jedoch noch unklar, welche Gebäude tatsächlich direkt von Beschädigung oder Zerstörung betroffen waren (LADSTÄTtER - PÜLZ 2007, 397; LADSTÄTter 2002, 26-29).

${ }^{200}$ Kap. 4.5.1.3; 4.6.2 u. 4.7.

${ }^{201}$ Zusammenfassend LADSTÄTter 2002, 29-31; SCHERRER 1995, 162.

${ }^{202}$ LADSTÄTter 2002, 29-31.

${ }^{203}$ Kap. 3.5.1.3.
} 
östliche Öffnungslaibung auf einer Länge von ca. 7,00 m verstärkt wurde. Möglicherweise sollte hier noch ein schmaler Zugang erhalten bleiben (Plan 4).

Schließlich lagerte man dem Fassadenabschnitt zwischen den beiden vomitoria eine zusätzliche 2,00 bis 2,60 m starke Wandschale vor. Dass diese Maßnahme bereits zu Beginn der Konsolidierungen geplant war, zeigt der Kontaktpunkt mit der westlichen Strebemauer. Die Ecke ist bereits im Verband hergestellt (Taf. 471 Abb. 842. 843). Allerdings hatte man anfangs offenbar ein anderes Baumaterial für die Ansicht der vorgelagerten Fassade geplant, denn die Eckverbindung zeigt ein Bruchsteinmauerwerk. Ausgeführt wurde die Wand jedoch mit einer Außenschale aus Marmorspolien ${ }^{204}$. An der Schnittstelle mit dem unteren vomitorium EN1 stieß die neue, vorgelagerte Fassade bereits an die Verstärkungswand um die östliche Öffnungslaibung an, wie am erhaltenen Negativabdruck des Füllmauerwerks aus opus caementitium zu erkennen ist (Taf. 472 Abb. 844). Datiert werden können die Konsolidierungen über zwei Bauinschriften, die sich in der Verschlusswand des vomitorium EN2 sowie in der östlichen Strebemauer befanden ${ }^{205}$. Darin wird der Statthalter Messalinos gepriesen, das Halbrund des Theaters wiederhergestellt zu haben (Tab. 127). Sämtliche neu entstandenen Fassadenflächen im Norden wurden in weißen Marmorspolien errichtet und verstärkten damit den repräsentativen Charakter. Insgesamt sind die Maßnahmen auch ein Indikator für die Bemühungen um den Erhalt des Gebäudes.

Noch eine weitere Sicherungsmaßnahme könnte mit den umfangreichen Konsolidierungen an der Nordfassade in Zusammenhang stehen. So wurden in die Kammern KN1-KN3, die das untere vomitorium EN1 auf der Westseite flankieren (Taf. 2 Abb. 2; 127 Abb. 254. 255), nachträglich niedrigere Ziegelgewölbe eingezogen. Sie ruhten auf 0,90 bis $1,00 \mathrm{~m}$ starken Wandschalen, die man den ursprünglichen Trennwänden der Kammern direkt vorlagerte (Textabb. 19). Die Türöffnungen vom Korridor in die Kammern waren dennoch weiterhin nutzbar und damit die Zugänglichkeit gewährleistet ${ }^{206}$. Um die Mitte des 5. Jhs. n. Chr. wandelte man den nördlichen und den mittleren Abschnitt des vomitorium EN1 in eine Zisterne mit einem Fassungsvermögen von mehr als $350 \mathrm{~m}^{3}$ um (Taf. $128 \mathrm{Abb}$. 256. 257) ${ }^{207}$. Sie wurde mit hoher Wahrscheinlichkeit aus der AristionLeitung über Tonrohre gespeist, die direkt vor der nördlichen Außenwand des Theaters verliefen.

Diese Umnutzung eines Teils des Korridors in einen Wasserspeicher machte verschiedene Umbauten erforderlich. So mussten die Türen zu den flankierenden Kammern, das Portal zum südlichen Korridorabschnitt sowie die Nordseite des vomitorium massiv verschlossen werden (Taf. 129 Abb. 260). Sämtliche dieser in Mörtelmauerwerk unter Nutzung von Spolien und Ziegeln ausgeführten Wände erhielten zisternenseitig einen wasserdichten Verputz. Die in Orthostaten-Binder-Technik errichteten ursprünglichen Korridorwände aus weißem Marmor blieben dagegen unverputzt. Der ehemalige Marmorboden des vomitorium wurde abgetieft teilweise bis in den Fundamentbereich der Korridorwände - und ein neuer Fußboden aus großformatigen Ziegelplatten mit einem Gefälle von Süd nach Nord eingebaut. Sowohl der oben beschriebene von Osten herangeführte Zufluss als auch der Ablauf und die Reinigungsöffnung der Zisterne liegen in der nördlichen Verschlusswand (Taf. 472 Abb. 845) ${ }^{208}$. Sondagen in den flankierenden Kammern KN1 bis KN3 ergaben, dass die Räume nach ihrer Aufgabe intentionell mit Erdmaterial verfüllt wurden (Taf. 134 Abb. 270. 271). Ob dies zeitgleich mit dem Verschluss der Türen oder später erfolgte, lässt sich nicht mit Sicherheit bestimmen ${ }^{209}$.

Basierend auf den archäologischen Funden wird von einer Nutzungszeit der Zisterne mindestens bis in das letzte Viertel des 6. Jhs. n. Chr. ausgegangen. Ab dem frühen 7. Jh. n. Chr. war das Becken durch den Einsturz des vomitorium bzw. der oberhalb liegenden Ränge verfüllt ${ }^{210}$.

Mit den Umbauten im vomitorium EN1 verzichtete man sowohl auf die direkte Erreichbarkeit des unteren Rangs von Norden als auch auf die Nutzung der Kammern westlich des Korridors. Die Zugänglichkeit der Cavea im Nordflügel beschränkte sich fortan auf die L-förmige Treppenanlage, die von Westen auf das untere Diazoma führt (über EN1 West).

\footnotetext{
${ }^{204}$ Unter den Spolien befinden sich drei Bauteile mit sichtbaren Inschriften, vgl. Kap. 8.3, IN 12. 13 (Taf. 415 ); IN 14 (Taf. 416 ).

${ }^{205}$ IvE 2043. 2044. Vgl. Wood 1877, 69; HeberdeY u. a. 1912, 52. 164 f. Dazu auch Kap. 8.6.1, Nr. 12. 13 u. Kap. 8.6.2. Beide Inschriften befinden sich nicht mehr in situ.

${ }^{206}$ Kap. 3.5.1.3

${ }^{207}$ Kap. 3.5.

${ }^{208}$ Mögliche weitere Abläufe sind aufgrund des massiven Versturzes in der Zisterne derzeit nicht nachvollziehbar.

${ }^{209}$ Kap. 3.5.1.2 u. 3.5.1.3.

${ }^{210}$ Kap. 3.5.1.
} 


\section{SÜDFLÜGEL DES ThEATERS}

Auch an der Südfassade sind die ursprünglichen Zugänge ins Auditorium nachträglich verschlossen worden (Tab. 127), wobei sich jedoch die Baumaßnahmen an den unteren beiden vomitoria (ES1. ES2) im Charakter vom Verschluss des oberen Zugangskorridors ES3 unterscheiden (Plan 5).

Erstere wurden unter Verwendung der Stufenbeläge der südlichen Freitreppe als äußere Wandschale vermauert. Die Stärke der Verschlussmauern entspricht dabei der Außenwandstärke in den benachbarten Substruktionskammern. Soweit aus den erhaltenen Resten der Abmauerungen gefolgert werden kann, kamen für das untere vomitorium ES1 die weißen Marmorquader des unteren Treppenabschnitts zum Einsatz (Taf. 286 Abb. 582; 473 Abb. 846). Für den Verschluss des vomitorium auf das mittlere Diazoma (ES2) wurden die grauen Quader des oberen Treppenabschnitts verwendet (Taf. 473 Abb. 847). Die Auswertung der Grabung auf der Stiegengasse weist die Vermauerung der beiden Zugänge in das fortgeschrittene 5. bzw. frühe 6. Jh. n. Chr. ${ }^{211}$. Auch der Schutt in den Kammern KS1 bis KS3, die den unteren südlichen Korridor westseitig flankierten (Taf. 172 Abb. 352), datiert anhand der Keramikfunde, neben Material aus dem 3. Jh. n. Chr., überwiegend in das 5. und 6. Jh. n. Chr. Die Aufgabe der Kammern wird im späten 6. Jh. n. Chr. angesetzt. Durch den Verschluss des vomitorium dürfte ihre Nutzung an Bedeutung verloren haben.

Des Weiteren wurde der obere Zugangskorridor ES3 vermauert (Taf. 219 Abb. 451; 441 Abb. 781). Die ca. 3,75 m starke Wand besteht aus Mörtelmauerwerk, für das Bruchsteine, Marmorspolien - u. a. viele Säulenfragmente, die womöglich von der Architektur der Portikus stammen - und Ziegel zum Einsatz kamen. Unter Aussparung der Spolien und größeren Bruchsteine verstrich man außerdem den Fugenmörtel dünn an der Wandoberfläche und zog ihn horizontal mit einer leichten Hohlkehle ab. Mörtelabdrücke, Sinterschichten und Tonrohrfragmente an der Außenfassade im Bereich des Portals zeigen eine Weiternutzung des Podests vor dem ehemaligen Zugang an ${ }^{212}$.

Bisher wird die Vermauerung der hangseitigen Zugänge des Theaters in Zusammenhang mit der fortifikatorischen Nutzung des Gebäudes in byzantinischer Zeit gesehen (Taf. 1) ${ }^{213}$. Die jüngsten Untersuchungen haben jedoch gezeigt, dass die Maßnahmen differenzierter zu bewerten sind. So sind auch im Süden zumindest für das untere vomitorium ES1 statische Sicherungsmaßnahmen nicht auszuschließen. Besonders im Bereich um die südliche Fassadenöffnung sind sämtliche erhaltene Außenwandquader stark beschädigt. Die vertikal verlaufenden Risse und Bruchstellen, die z. T. bis zum Verlust der Quaderoberflächen führten, deuten auf starke Erschütterungen hin (Taf. 455 Abb. 810). Zu diesen Befunden passt auch umfangreiches keramisches Fundmaterial aus den Theatergrabungen sowie der Freilegung der südlichen Außentreppe, das als Schutt des Erdbebens im 3. Viertel des 3. Jhs. n. Chr. interpretiert wird (Tab. 127; Plan 15. 16) ${ }^{214}$. Dagegen zeigt der erhaltene Teil der Verschlusswand kein Schadensbild.

Die Vermauerung der südlichen Zugänge zum Theater reduzierte die Erschließungsmöglichkeiten der Cavea im Südflügel (Plan 17) im Wesentlichen auf den Zugang von Westen (ES1 West). Zudem wurde die südliche Außentreppe durch die Verwendung der Stufenquader wenigstens in Teilbereichen unbrauchbar ${ }^{215}$.

\section{Ostabschluss des Theaters}

Bauliche Veränderungen können für die Spätzeit auch im Bereich der Portikus festgestellt werden und lassen sich vor allem an den Zugangsöffnungen nachvollziehen. Wenn auch vermutlich während der Restaurierungen weitgehend rückgebaut, zeigen doch einige in situ-Situationen sowie historische Fotos, dass auch hier die Eingänge mit Mörtelmauerwerk unter Verwendung von Bruchstein, Fragmenten von Marmorbauteilen sowie Ziegeln verschlossen waren ${ }^{216}$.

G. STYHLER-Aydin

\footnotetext{
${ }^{211}$ Kap. 3.7.2.1 $; 3.7 .2 .3$ u. 3.7.3.

${ }^{212}$ Kap. 3.7.1.1 u. 3.7.2.1.

${ }^{213}$ Hofbauer 2007, 74.

${ }^{214}$ Kap. 4.5.1.3; 4.6.2 u. 4.7.

${ }^{215}$ Kap. 3.7.2.

${ }^{216}$ De Bernardi-Ferrero 1970, 58 Abb. 55. 56; 63 Abb. 73.
} 


\section{The Architectural Development of the Theatre from the Hellenistic to the Byzantine Period}

The first chapter above outlines the complex research history of the theatre at Ephesus. The editor's foreword addresses the lengthy investigation period, as well as the methods and modifications on the original architectural structure, which were sometimes not comprehensible, during former restoration-works. The finds and results described in this fascicle cannot provide a complete picture of the theatre's structural changes, or its chronological development. Building research of the last decades has, however, brought new information to light and from today's perspective has made it possible to confirm construction phases of the entire koilon and to reconstruct the stage building. This goes beyond the subject of the current volume and for this reason it was considered practical and important to present a brief overview of the theatre's architectural development. The reader is made aware of the key issues, discoveries, and interpretations without the lengthy detailing of the finds and their critical analysis, which are being prepared for the future fascicles.

\subsection{THE HELLENISTIC PERIOD THEATRE}

\subsubsection{The Hellenistic Stage Building}

Based on the excavation results of rooms $\mathrm{D} 3^{1}$ and $\mathrm{D} 8^{2}$, the theatre terrace and the skene structure were erected in the $1^{\text {st }}$ half of the $2^{\text {nd }}$ century BC. Despite this, no firm date can be determined for the construction of the koilon or the orchestra. One can expect, however, that the building site and a preliminary design of the theatre were already established at the time of planning Lysimachus' new city. Because the excavations did not yield precise chronological evidence, the temporal connection between the construction of the stage building and koilon cannot be determined. We know that the first major structure in the Hellenistic town was the approximately $8 \mathrm{~km}$ long city wall. On the other hand the excavations at the Tetragonos Agora, the market situated near the harbour, indicate that it was erected soon after the city was founded, although its monumental design is obvious part of a later construction phase ${ }^{3}$. Similarly, one could possibly imagine this for the construction of the theatre. Taking the building sequence into consideration, it seems probable that the preparation of the slope for the koilon and the construction of the orchestra preceded the construction of the monumental stage building. It cannot be confirmed how far back such reconstructions can be dated. As well, the question as to whether this was used as a provisional theatre before the construction of the monumental stage building in the $1^{\text {st }}$ half of the $2^{\text {nd }}$ century $\mathrm{BC}$ remains open.

A terrace measuring $75 \mathrm{~m}$ long and nearly $20 \mathrm{~m}$ wide was constructed west of the orchestra in order to accommodate the stage building. The preserved remains protrude approximately $4.50 \mathrm{~m}$ on the northwest corner of today's Byzantine street level, while towards the south they converge with the gradually ascending road. The terrace wall consists of large ashlar limestone blocks without a mortar bond (Pl. 17 Fig. 27). The two-storey stage building rose above the theatre terrace (Pl. 424 Fig. 745). Measuring $41.65 \mathrm{~m}$ long and $10.77 \mathrm{~m}$ wide, it was one of the largest Hellenistic stage buildings in Asia Minor. Its orientation and dimensions are clearly linked with the terrace wall to the north. The west facade also runs parallel to the western wall of the terrace, but is set back by $6 \mathrm{~m}$ toward the east. It is therefore based on a uniform construction process. The walls are on average $0.78 \mathrm{~m}$ thick and constructed in double-walled pseudoisodomes masonry

\footnotetext{
${ }^{1}$ Cap. 3.1.1.1

${ }^{2}$ Cap. 3.1.1.2

${ }^{3}$ The fittings of the Agora correspond to the bare necessities: an area with a dirt floor and initially a simple structure made of wood and mud brick. Gradually during the course of the $3^{\text {rd }}$ century BC these were replaced by stone buildings. See SCHERRER - TRINKL 2006, 15-17.
} 
(P1. 425 Fig. 746). Building materials were predominantly yellow-brown limestone (»Poros«), reddish breccia and blocks of shelly limestone. Marble was occasionally used for door lintels. As with the terrace wall, the skene walls were constructed without mortar. The use of clamps occurs only at the corners of structure. In some areas, the preserved height of the stage building walls measures $7.78 \mathrm{~m}$ above the foundation. On the upper floor, in particular, numerous additions and modifications, dating to later periods, can be recognized.

\section{LOWER FLOOR}

The lower floor remains, with the exception of the northwest corner, completely intact today. Although large sections of wall are concealed by Roman age masonry (Pl. 3 Fig. 3; 12 Fig. 20; 430 Fig. 758), the layout is clear. The interior is divided in two, lengthwise (Pl. 10 Fig. 17). The rectangular Corridor A of the stage building spans the entire length of the eastern half. Its width of $4.20 \mathrm{~m}$ is the same as the interior width of the row of eight chambers (D1-D8), which comprise the western half. The $2.80 \mathrm{~m}$ wide central passage C lies between chambers D4 and D5; its orientation is east-west and it separates the space. Chambers D2 to D7 are similar in size, measuring on average $4.20 \times 4.12$ to $4.15 \mathrm{~m}$. They are accessible from corridor A by doors situated in the middle of their east walls and measure ca. $1 \mathrm{~m}$ wide and $2.46 \mathrm{~m}$ high. The lintels of all chamber doors are made of the same material as the walls. The outer chambers, D1 and D8, were considerably smaller at only $3.15 \mathrm{~m}$ wide; they were accessed through openings in the west wall, by way of the theatre terrace. The foundations of the south wall and traces of the false ceiling in chamber D8 indicate that the upper floor was attainable through these chambers by way of stairs ${ }^{4}$. The chambers and the passage $\mathrm{C}$ had timbered ceilings (P1. 425 Fig. 746). This can also be presumed for the corridor A, although no beam holes remained visible in the Imperial Era walls that served as arch supports in front of the Hellenistic longitudinal walls. There are no windows at any point, but the six inner chambers (D2 to D7) each have tiny openings on the west wall (P1. 425 Fig. 746), directly under the wooden ceiling.

Corridor A was accessible through doors located on its north and south sides. The southern door was $1.27 \mathrm{~m}$ wide is preserved, although it was walled in at a later date. The north door no longer exists, but can be identified by way of two ca. $2.40 \mathrm{~m}$ long stone blocks located in situ that were likely situated above the lintel. To the east, two doors are detected in the middle and in the northern half, which led to the proscenium and orchestra. In the southern half, one of the northern doors is interpreted as a third passage. The middle door had a clearance of $1.92 \mathrm{~m}$. It had a marble lintel, which is now broken, and a limestone threshold ${ }^{5}$, which was partially destroyed by the subsequent installation of a channel ${ }^{6}$, so that only the southern part of the hinge holes for the doors are preserved. The northern door has both a marble lintel, and threshold. The middle passage $\mathrm{C}$ extends in a north-south alignment to Corridor $\mathrm{A}$ and is spanned by flat transverse arches of limestone (Pl. 426 Fig. 747). Holes are visible on the underside; according to W. Wilberg, these were probably used to accommodate a grille? Across from the west wall, the remnants of a $0.40 \mathrm{~m}$ high wall are still in existence. Opposite the arches, the remains of a $0.40 \mathrm{~m}$ high marble lintel are still visible on the west wall (Pl. 426 Fig. 748).

\section{UPPER FLOOR}

Considerably less remains of the original structure on the upper floor. Numerous changes carried out later on have led to questions regarding the original structure. The plan published by W. Wilberg (Pl. 11 Fig. 18) indicates that the layout of the upper level largely followed that of the lower level ${ }^{8}$. Eight chambers and a central passage C' also comprise the western half of corridor A'. The doors are the only features that are not

\footnotetext{
${ }^{4}$ Cap. 3.1.1.2.

${ }^{5}$ Heberdey u. a. 1912, Fig. 11.

${ }^{6}$ Cap. 3.2.2.1.

${ }^{7}$ Heberdey u. a. $1912,6$.

${ }^{8}$ This view was reflected so far in all publications following W. Wilberg and also applies to the article of the author (HOFBAUER 2002, 180).
} 
consistent with the layout of that level. None of the doors are situated in the middle of the chambers' east walls, rather, they are mainly placed towards one of the corners. This unusual feature resulted in several interpretations ${ }^{9}$, and was clarified during our investigations in the summer of 2006. It was then revealed that four of the Hellenistic walls identified in the lower level did not exist in the upper level (P1. 11 Fig. 19). The walls in question are between chambers D'2 and D'3 (no longer extant), chambers D'6 and D'7, as well as the walls between passage C' and chambers D'4 and D'5. These walls were added much later. Thus, three rooms existed between stairways D1 and D8 in the original construction phase. Based on the little evidence available, large doorways to corridor A' have been reconstructed in the middle of the east wall, as they appear in the lower level (P1. 11 Fig. 19). Both the stairs located in the two outer chambers, which connected the lower and upper levels, as well as the layout of the upper level floor in the form of a continuous corridor with a suite of chambers lying behind it seem to be unique solutions in Hellenistic theatre ${ }^{10}$.

As well, no evidence of windows on the upper level exists. Due to the conserved height of the walls, larger windows are ruled out. On the other hand, small openings are conceivable as these are known to have existed on the lower level. One exception is a large opening in the west wall of the middle chamber; a vault ${ }^{11}$ is preserved in parts directly above the opening to passage C' and a portion of the arch was found on either side of this opening (P1. 426 Fig. 748; 427 Fig. 749). On the south side, the wedge-shaped limestone blocks reach a height of $\mathrm{T}^{\mathrm{a}} 15.857 \mathrm{~m}$, which corresponds to $5.35 \mathrm{~m}$ above the upper level of the foundation. The height of the completed arch apex lies at $6.04 \mathrm{~m}$ above the foundation $\left(\mathrm{T}^{\mathrm{a}} 16.55 \mathrm{~m}\right)$, which results in a room height of $2.94 \mathrm{~m}$. Blocks protruding from the northern and southern window soffits, respectively, lie directly on top of the marble joist above passage $C$, which makes it clear that at least at a lower level, the west wall has passed over the width of the window. The finishing of the stone blocks points to a double-faced masonry wall, as well as to the subsequent removal of a once-existing parapet or balustrade. Recesses for the attachment of shutters or a grating are unknown.

\section{The East Facade}

As indicated by W. Wilberg ${ }^{12}$, the east side of the upper level underwent modifications. Limestone was used for the original construction, and marble for the remodelling. In addition to the use of different materials, the north door »e« which originally connected corridor A with the proscenium, was sealed shut (P1. 10 Fig. 17; 427 Fig. 750; 428 Fig. 751). This is based on the fact that a marble pillar, dating to the second phase ${ }^{13}$ of the proscenium, was placed above the doorway. Because the passageway was still required, a new opening, situated between the phase 2 columns was created just $1 \mathrm{~m}$ south of the original opening.

The appearance of the east side of the older skene facade is unknown. The possibility of a continuous wall with door openings was only suggested by A. von Gerkan ${ }^{14}$. Broad suggestions regarding older $>$ thyromata are already presented in W. Wilberg ${ }^{15}$ and also found support in the works of E. R. Fiechter ${ }^{16}$ and A. Fricken$\operatorname{haus}^{17}$.

\footnotetext{
${ }^{9}$ De Bernardi Ferrero 1970, 50 tries to explain this peculiar arrangement of doors in that they were obscured by the thyromata and would not have been seen through the doorways of the skene. In my opinion, however, this explanation is unsatisfactory. The sinvisibility< of these doors can only be assumed for a certain number of seats in the central area of the koilon and not for the vast majority of seats. Moreover, this argument is based on the sthyromata pillars of the second phase and therefore does not apply to the first phase.

${ }^{10}$ Here the results of the research can only be briefly presented. A detailed discussion and the architectural-historical evaluation of the findings will be given in the volume outlining the construction history of the stage building, see also M. Hofbauer in: ÖZTÜRK (in preparation). These results were already presented in HOFBAUER 2007, 46-58; HOFBAUER 2012.

${ }^{11}$ Heberdey u. a. 1912, Fig. 9.

${ }^{12}$ Heberdey u. a. $1912,13.18-19$.

${ }^{13}$ Compare below: periodization.

${ }^{14}$ vON Gerkan 1921, 90.

${ }^{15}$ Heberdey u. a. $1912,12-13$.

${ }^{16}$ Fiechter 1914, 35.

${ }^{17}$ Frickenhaus 1917, 38.
} 


\section{Excursus Regarding THE THYROMATA}

In connection with a theatre we find the term $>$ thyromata appearing once in an inscription on the upper floor of the theatre at Oropos ${ }^{18}$. W. Dörpfeld applies the term to the parodos gates, but, according to E. R. Fiech$\operatorname{ter}^{19}$, that could also belong to the Roman period. Fiechter does not employ the term $>$ thyromata<, but refers to openings in stage building. On the other hand R. C. Flickinger ${ }^{20}$ considers Dörpfeld's argument as a misinterpretation and applies the term >thyromata< explicitly to describe the wall openings of skene. Recently sthyromata $<$ has developed into a frequently-used term for gate-like openings in the stage building and have led to identifying them as certain stage types, namely, >thyromata stage $<$, or thyromata-facadeく. Some authors are somewhat more mindful of the so-called thyromata and put the term in quotes ${ }^{21}$. Fundamental to the issue of the term, including a more elaborate discussion, can be found most recently in J.-Ch. Moretti ${ }^{22}$; he considers it desirable to dispense entirely with terms like $>$ thyromata-facade $<$ or $>$ thyromata-stage

If not being integrated citation the author considers it beneficial to employ quotation marks with the traditional research term >thyromata $<$ in those cases where more neutral terms such as $>$ wall openings $<$ or $>$ pillar wall are not used.

Nevertheless, the term $>$ thyromata $<$ is now considered to provide a special understanding of a structural element of the Hellenistic stage. In reference to the Ephesian skene facade, A. von Gerkan ${ }^{23}$ only accepted $t$ thyromata $<$ for the late Hellenistic period. On the other hand, H. Lauter ${ }^{24}$ and H. Froning ${ }^{25}$, and most recently S. $\operatorname{Gogos}^{26}$, consider it not unlikely that the $>$ thyromata $<$ for the theatre at Epidauros dates to the late $4^{\text {th }}$ century BC. Therefore it seems all the more logical to make a connection in Ephesus with the stage building which dates to the $1^{\text {st }}$ half of the $2^{\text {nd }}$ century BC. ${ }^{27}$

The marble pillars from the rebuilding phase have been preserved in the masonry of the imperial-era scaenae frons and based on which a pillar wall with seven openings has been concluded (Pl. 428 Fig. 752; 429 Fig. 754-757). Mounted on the two outer marble pillars was a list of agonothetes ${ }^{28}$; these provide, at least, a terminus ante quem of 51/50 BC for the rebuilding. The list ends in 18/17 BC and confirms the existence of the Hellenistic skene into the Augustan era.

\section{The Theatre Terrace west of the Stage Building}

The west side of the stage structure presents the most problems. W. Wilberg intended to reconstruct a portico on the $6 \mathrm{~m}$ wide strip of land between the west wall of the skene and the terrace wall (Pl. 17) ${ }^{29}$. There is, however, neither architectural nor archaeological evidence to support this. So far, no architectural elements have emerged that could be clearly assigned to such a stoa, if one disregards one Ionic capital, which was the basis for W. Wil-

\footnotetext{
${ }^{18}$ Dörpfeld - Reisch 1896, 109; Petrakos 1997, No. 435.

${ }^{19}$ Fiechter 1930, 27. Also Fiechter 1914, 35.

${ }^{20}$ FLICKINGER 1918, 109.

${ }^{21}$ For example, LAUTER 1986, 169 (for the first naming) or Gogos 2009, 86. 114 (glossary).

${ }^{22}$ Moretti 1997, 35-37.

${ }^{23}$ VON GERKAN - MÜLLER-WIENER 1961, 72-73.

${ }^{24}$ LAUTER 1986, 169-170.

${ }^{25}$ FRONING 2002, 58 .

${ }^{26}$ Gogos 2011, 64 is of the same opinion: »Demnach wäre davon auszugehen, daß in Epidauros die >Thyromata bereits seit dem frühen Hellenismus, und nicht erst später, dem zeitgenössischen Theaterspiel entsprechen, den architektonischen und szenisch notwendigen Hintergrund der erhöhten Bühne (Logeion) bildeten«.

${ }^{27}$ Also De Bernardi Ferrero 1970, 50 likely in an attempt to justify the unusual door arrangement on the upper level suggested by W. Wilberg, thought of large door openings because the door arrangement in a closed wall with three (?) doors seemed hardly necessary.

${ }^{28}$ IvE 9.

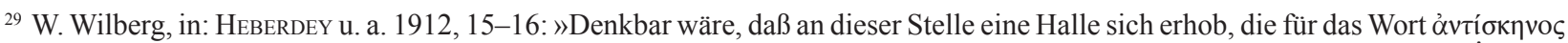
der Inschrift Nr. 41 (= IvE 2041) eine Erklärung geben würde«. Also see Cap. 8.6.1, No. 11 and Cap. 8.6.2.
} 
berg's portico reconstruction theory ${ }^{30}$. The preserved masonry of the stage building also bears no traces to support this. The walls on the front faces of the hall, indicated by W. Wilberg, lack the anticipated connection traces to the skene. The terrace wall's upper layer of stones was probably removed even before the establishment of the Byzantine city wall ${ }^{31}$, so here, too, there is no indication of columns. The only possible evidence is an approximately $5 \mathrm{~cm}$ wide, but very shallow notch embedded in the south wall at the southwest corner of the Hellenistic skene. It may be connected with an enclosure, but seems unlikely to be connected with a possible portico.

\section{Proscenium}

As could be seen from all previous excavations ${ }^{32}$, nothing of the Hellenistic proscenium remains intact. This seems to have been completely removed by the construction of the scaenae frons. W. Wilberg dates the Roman stage front of the proscenium to the second Hellenistic phase (Pl. 428 Fig. 753$)^{33}$. With this he also explains the two-time installation which had been established by the lack of intact doweling found when the logeion pillars were removed in $1900^{34}$. He suggests a wooden structure for the older phase, but von Gerkan ${ }^{35}$ vehemently disagrees with this. He recognizes the $>$ Late Hellenistic $<$ proscenium as imperial era, and refutes the idea of a wooden proscenium; subsequently he also argues against the two-phase theory suggested by Wilberg. A. von Gerkan advocates an original stone construction. He interpreted his version of the Hellenistic proscenium $^{36}$ based on two bar holes with a center distance of $1.56 \mathrm{~m}$ located above the lintel of the northern door from the corridor A to the East, as well as on a circuit which corresponds to the outer edge of the ring-channel corresponding circle, which he inscribes as a square, according Vitruvius.

As noted above, the first imperial era proscenium was identified as that of the second Hellenistic phase by W. Wilberg. Wilberg's reconstruction of the Hellenistic stage has two peculiar recesses on both sides of the proscenium facade and the parodos gates by using the two side sections that were necessary in the Flavian era construction to allow the stage front over the former analemmata $\mathrm{P}$ and $\mathrm{Q}$ to project eastwards ${ }^{37}$. Realizing that the preserved architecture dates to the imperial era frees his reconstruction of these peculiar recesses at the corners. The layout of Hellenistic theatre is based on the characteristically trapezoidal shape of theatres in Asia Minor (Pl. 11 Fig. 19)

\section{Periodization}

\section{The first Hellenistic phase:}

The construction of the theatre terrace and stage building date to the early $2^{\text {nd }}$ century $\mathrm{BC}$, based on the excavation results of chambers D3 and D8 in the Hellenistic stage building. This limestone structure can be described as typical for Hellenistic theatres in Asia Minor: a long, rectangular building comprised of two levels, and whose east wall was likely equipped with large wall openings ( thyromata $<$ ) from the very beginning. Although none of the proscenium has been preserved, one can assume, in good conscience that it took on the ubitquitous trapezoidal shape of theatres in Asia Minor. A portico is suggested for the area west of the stage area based on the theatre terrace. Yet, due to a lack of evidence, its reconstruction is hypothetical.

\footnotetext{
${ }^{30}$ Heberdey u. a. 1912, Fig. 22; Alzinger 1961, 110 assigns a much earlier date to this capital and indicates an identical example which was found at the >Lukasgrab $<$ grave.

${ }^{31}$ Cap. 3.1.2.3.

${ }^{32}$ Cap. 3.2.1.

${ }^{33}$ Heberdey u. a. 1912, 21-29.

${ }^{34}$ Heberdey u. a. 1912, 33.

${ }^{35}$ VON GERKAN 1921, 92.

${ }^{36}$ VON GERKAN 1921, 91.

${ }^{37}$ Heberdey u. a. 1912, Fig. 56. This reconstruction was also repeated by Frickenhaus 1917, Pl. 1.

${ }^{38}$ IsLer 1994, 105; MORETtI 1992, 13.
} 


\section{Second Hellenistic Phase:}

It seems that the skene was not affected by substantial changes until the end of the Hellenistic period, rather the transformation seems only to have affected the east wall. The erstwhile limestone pillars were replaced by marble ones, which also contained the list of the agonothetes as of 54/53 BC. The conversion must have been completed by this time at the latest. Whether or not the proscenium was affected is somewhat of a pointless question, as no evidence prior to the Flavian reconstruction exists. The stage building of the theatre retained its Hellenistic $>$ thyromata-type characteristics until the last decade of the $1^{\text {st }}$ century BC.

\section{HOFBAUER}

\subsubsection{The Hellenistic Orchestra}

Central to the Hellenistic building is a circular orchestra (Pl. 12 Fig. 20; 13 Fig. 21; 77 Fig. 151; 78 Fig. 152), which was customary since the $2^{\text {nd }}$ half of the $4^{\text {th }}$ century BC. ${ }^{39}$ The diameter is $12.35 \mathrm{~m}$, taking the inside of the circular channel into consideration. This channel is affected towards the west in the stage building, near the area of the central door's threshold (Pl. 430 Fig. 759). The threshold of the stage building's central door overlaps the circular channel $0.34 \mathrm{~m}$ to the east; this corresponds to almost half the wall thickness of the east skene wall. The proscenium would have overlapped the orchestra circuit by ca. $3 \mathrm{~m}$. The width of the ring channel gradually increases from $0.45 \mathrm{~m}$ at the south end to $0.59 \mathrm{~m}$ at the north end and has a distinct northsouth orientation. In the northwest, the channel curves gently around the end of the analemma wall $\mathrm{P}$ and then turns, at a right angle, towards the north in order to follow the northern part of the parodos, presumable to a street sewer. The same yellowish brown limestone was used here, as in the stage building. The course of the Hellenistic channel was uncovered throughout the orchestra area. Stone slabs were used in the axes of the twelve steps of the koilon; these formed little >bridges< over the channel. The stone slab pavement of the parodos covered the channel completely from the north part of the analemma onward.

Less than $1 \mathrm{~m}$ from the inner edge of the annular channel there is a circular foundation U. It is largely preserved in its eastern half with well prepared surface (Pl. 82 Fig. 162; 90 Fig. 180) on the edge of the actual >dancing ground`, which, according to W. Wilberg, has parallels in the theatres of Epidaurus and Oiniadai ${ }^{40}$. Wilberg presumed, on the basis of their slightly bent long sides, that six stone slabs located under the logeion pillars of the imperial stage are erstwhile slates of the stone setting ${ }^{41}$. At the most recent excavations remains of these foundations in S 3/2004 (Pl. 84 Fig. 166) and in S 1/2005 (Pl. 89 Fig. 177. 178; 90 Fig. 179. 180) could be uncovered again.

No datable finds linked to the Hellenistic building could be found due to the massive imperial-era configuration of the orchestra and large-scale excavations. The preserved annular channel seems to form a single unit with the stage building and elements of the koilon and for this reason is thought to date to the same time.

M. HOFBAUER

\subsubsection{Hellenistic Koilon}

As seen with the stage building, sections of the Hellenistic auditorium have been preserved ${ }^{42}$. Although the exact date and shape of the Hellenistic koilon cannot be determined, some conclusions can be drawn as to its

${ }^{39}$ ISLER 1994, 97.

${ }^{40}$ Heberdey u. a. 1912, 14; Powell 1904, 188-190 Fig. 19 Pl. 8. The plan recorded in Fiechter 1931, Pl. 1 is more detailed; see also Gogos 2009; Gogos 2011 .

${ }^{41}$ Heberdey u. a. 1912, 14 with Fig. 16.

${ }^{42}$ The results of construction research in the present text describe the essential phases in the auditorium. Its presentation is to be understood as an overview and is therefore limited to providing only those details necessary for understanding the issues. A full and detailed discussion of the whole evidence appears in STYHLER-AYDIN (in preparation). 
size and appearance based on the architectural remains. The considerable size of the $42 \mathrm{~m}$ long skene make it one of the largest Hellenistic stage buildings in Asia Minor, and one can therefore expect a similarly sized $k_{o i l o n}{ }^{43}$. Differing perspectives regarding the original shape of the auditorium and its structural development exist in the research literature. For example, R. Heberdey and W. Wilberg hypothesized a three-tier Hellenistic theatre with a capacity of 23,000 spectators $^{44}$, whereas D. De Bernardi Ferrero and later St. Karwiese and I. Ataç considered an extended auditorium ${ }^{45}$.

What follows is a synthesis of results based on the actual architectural evidence regarding the shape and extent of the Hellenistic koilon.

Direct evidence of the Hellenistic koilon is found at the bottom of the rows of seat in the orchestra. In 1899 , during the third excavation season, Hellenistic precursors were found beneath the imperial era orchestra channe ${ }^{46}$. This first channel measured between 0.55 and $0.60 \mathrm{~m}$ wide with an internal diameter of $24.66 \mathrm{~m}$, equivalent to 84 Attic feet, and ran around the orchestra as an open channel ${ }^{47}$. On this basis R. Heberdey and W. Wilberg already determined the level of the corresponding Hellenistic orchestra floor and were also able to draw conclusions regarding the location of the lower rows of koilon seats that had been removed ${ }^{48}$. In their reconstruction in 1912 the seats bordered on the opening beside the edge of the Hellenistic channel, with the lower seats arranged at the prohedrie (Pl. 431 Fig. 760$)^{49}$.

These considerations remained hypothetical, due to the absence of further structural evidence yet, for example, might be presumed with regard to the formation of the only preserved, three-sided prohedrie chair (P1. 431 Fig. 761 $)^{50}$. However, a further argument for the said reconstruction was found during excavations at the base of the currently visible orchestra wall X. It shows that the imperial era retaining wall was built directly upon the rock which was possible due to the removal of the tiered seating ${ }^{51}$. Another indication for the situation at the foot of the koilon are traces in the wall of the Hellenistic channel which are recesses that accommodated stepping stones These $0.15 \mathrm{~m}$ thick slabs acted to bridge the canal as a direct extension of the twelve klimakes in the lower row (Pl. 432 Fig. 763. 763) ${ }^{52}$. The lower row's resulting division into eleven kerkides has survived until today. Only the outer kerkides were modified as a result of the later installation of the scaenae frons and the imperial era logeion (Plan 1). However, here again the most northwesterly stepping stone on the Hellenistic orchestra channel as well as the contact surfaces of the outer klimakes' stone steps are the only in situ components of the Hellenistic analemmata.

The lowest tier of the Hellenistic koilon had an angle of ca. $217^{\circ}$. The circular orchestra was accessible by $3.5 \mathrm{~m}$ wide parodoi located to the south and north (P1. 442 Fig. 783. 784) ${ }^{53}$. Because the surrounding topography at the foot of the Panayırdağ sloped from south to north, the northern parodos was higher than the road

\footnotetext{
${ }^{43}$ For comparison, the theatre of Miletus was cited. Here, F. Krauss reconstructed the first Hellenistic stage building (skene I) as $15.175 \mathrm{~m}$ long (KRAUSS 1973, 8) and the associated orchestra with a diameter of $21.46 \mathrm{~m}$ (KRAUSS 1973, 46) on the basis of an audience space of ca. $73 \mathrm{~m}$ in diameter (Krauss 1973, 60 text fig. e). The quantity of seats determined by him was comparable with that of the theatre in Priene (Krauss 1973, 46). The late Hellenistic great stage (skene IV) measuring $39.89 \mathrm{~m}$ long and the 26.24 m diameter orchestra likely had at least a remodeled auditorium (KRAUss 1973, 51). Kraus also does not deny the possibility of a completely new construction during this phase.

${ }^{44}$ Heberdey u. a. 1912, 16.

${ }^{45}$ De Bernardi Ferrero 1970, 49-66; also Scherrer 1995, 160; AtaÇ 1999b, 3.

${ }^{46}$ Heberdey 1900; Heberdey u. a. 1912, 14 Fig. 20; 15 Fig. 21.

${ }^{47}$ Heberdey u. a. 1912, 8 Fig. 6. For the foot unit at the stage building compare BAmmer 1961, 152. The orchestra channel does not always follow the circular shape uniformly, but shows some variation in the radius. This may account for why the radius measurements differ in the literature. R. Heberdey and W. Wilberg note a radius of $12.33 \mathrm{~m}$; M. Hofbauer notes a measurement of $12.35 \mathrm{~m}$ (Cap. 10.1.2).

${ }^{48}$ Heberdey u. a. 1912, 13-15; HofBauer 2007, $13 \mathrm{f}$.

${ }^{49}$ Heberdey u. a. 1912, 44 Fig. 86.

${ }^{50}$ Heberdey u. a. 1912, 16-17 with Fig. 27; today in the Ephesos Museum in Vienna, compare Oberleitner u. a. 1978, 64 Cat. No. 50. Seats from the prohedrie have also been preserved at the theatre in Metropolis. Their position is reconstructed in front of the lower row of seats in a single formation, each centered in front of a kerkis. The theatre of Priene also shows prohedrie seats at the edge of the orchestra spaced at even intervals. Here the gaps between them were later filled with benches.

${ }^{51}$ Cap. 3.3.2.1 and 10.2.4.2.

${ }^{52}$ Heberdey u. a. 1912, 13 Fig. 17; 14 Fig. 19.

${ }^{53}$ Heberdey u. a. 1912, 7 Fig. 5; Hofbauer 2007, 59.
} 
and would have been accessible by a ramp or additional steps (Plan 3. 7) . $^{54}$. Based on current assessments, the access from the parodos to the orchestra was almost level (Plan 3. 8).

Initial indications regarding the construction of the upper rows were gleaned from the analysis of the tiered seating substructure. In considering the preserved rows, a selection of materials were used for the framework of the rows of seats and the radial stairs. Ashlar blocks of grey marble and reddish breccia were used on the slope as well as on the lower rows. In some cases the solid rock was used as the substructure for the marble clad tiered seating. However, the seating areas added during the imperial era consisted of opus caementitium and were built on a stepped substructure of rubble masonry. The two different construction techniques are also evident in the diazoma walls, particularly in the substructure of the supporting walls with some variations in the foundations ${ }^{55}$. This state, however, is based solely on the historical pictures of the original theatre excavation ${ }^{56}$. The current appearance is the result of restoration work done since the 1960s, in which areas of opus caementitium were imitated using quarry stones.

The different construction techniques employed in the substructure of the seating tiers provide a first indication of the koilon's expansion. In addition to the lower tier of eleven kerkides, it also indicates a middle and upper tier, at least in the area of the hillside. This is also suggested by the finds of the lower diazoma as well as the visible retrofitting of the Aristion aqueduct on the slope side of the terrace ${ }^{57}$.

Another distinctive feature in regard to the auditorium's construction phases comes to light in the analysis of the theatre's outer walls. Here, in both the north and south, respectively, there is a noticeable change in the facade construction caused by a $82^{\circ}$ to $83^{\circ}$ angle in relation to the central axis of the building (P1. 433 Fig. 765 ; Plan 4. 5). Further up the slope the outer wall consists of horizontal grey marble ashlar block, whose surface are slightly rounded and cushion-shaped. Horizontal offsets are arranged at intervals. The facing blocks display vertical, orthogonal, as well as trapezoidal and parallelogram-shaped cuts. The wall construction to the north displays two ashlar rows erected mortarless behind one another and that were interlocked with tie-rows. Sections of the facade of the north and south walls are similar in design and building materials to the terrace wall of the stage building (Pl. 434 Fig. 766. 767; 435 Fig. 768; Plan 3). R. Heberdey had already associated the top portion of the cushion-ashlar-facade with the Hellenistic koilon ${ }^{58}$. The upper access ES3 in the south, which dates to the Augustan or early Tiberian era, was a subsequent installation in this cushion-ashlar-facade and proves that the outer wall was already in existence, even if the section of wall cannot be more securely dated ${ }^{59}$.

The substructure of the tiered seating behind both north and south sections of the cushion-ashlar-facade consists of opus caementitium (or its modern quarry stone restoration) and indicates the spatial superimposition of construction phases. Particularly in the north wing it is apparent, from their uniform orientation that the subsequently added vomitorium EN2 and the adjacent substructure chambers were built as part of the late-Flavian era expansion of the auditorium behind the existing wall ${ }^{60}$. The original substructure behind the cushion-ashlar-facade sections cannot be reconstructed. At other Hellenistic theatres dating to the $2^{\text {nd }}$ century $\mathrm{BC}$, such as at Termessos, Oinoanda and Arycanda ${ }^{61}$, the wings of the structure protruding from the mountainside were associated with massive deposits of quarry stones. In regard to the structural dimensions of the Hellenistic koilon of the theatre at Ephesus, a glimpse of the substructure of the northwest wing is visible on the outer side of the slope, and it consists of several layers of massive, roughly-cut ashlars (Pl. 435 Fig. 769).

Although the original western boundary of the upper rows of the cushion-ashlar-facade cannot be accurately traced, the results indicate that by Hellenistic or Augustan times, at the latest, the wings of the building existed beyond the slope of the mountain but did not reach the full extent of the lower tiers. Creative solutions to this situation are the so-called recessed analemmata. Examples are found at the theatre at Epidaurus (early

\footnotetext{
${ }^{54}$ The small Hellenistic fountain house on the northwest corner of the theatre terrace gives an indication of the Hellenistic period street level. It is more than $5.00 \mathrm{~m}$ lower than the Hellenistic orchestra.

${ }_{55}^{55}$ Cap. 3.4.2.5.

${ }^{56}$ Compare De Bernardi Ferrero 1970, 58 Fig. 55; 59 Fig. 61; 60 Fig. 62. 64.

${ }^{57}$ hap. 10.2.4.2.

${ }^{58}$ HeberdeY u. a. 1912, 15; 12 Fig. 15.

${ }^{59}$ Cap. 10.2.4.1.

${ }^{60}$ Cap. 10.2.4.2.

${ }^{61}$ Ciancio Rossetto - Pisani Sartorio 1994, Vol. 3, 370. 443. 452.
} 
$3^{\text {rd }}$ century, with extensions in the $1^{\text {st }}$ half of the $2^{\text {nd }}$ century BC $)^{62}$ and at Alinda $\left(2^{\text {nd }} \text { century BC }\right)^{63}$. Such a design limited the height of the structure built on the other side of the slope and may be interpreted as a response to the technical possibilities available at that time.

According to current knowledge it cannot be determined whether the portions of cushion-ashlar-facade and the seating which lay behind it were the first expansion of the Hellenistic koilon. The results of its greatly restored state also do not allow for a more precise temporal limit of the facades to be determined. Corresponding questions also exist in connection with the second Hellenistic construction of the stage building as established by the incorporation of the marble sthyromata . These must, however, remain unanswered for the time being ${ }^{64}$.

Apart from the parodoi, other possible and perhaps topographically favourable, entrances to the koilon are not known, but cannot be ruled out ${ }^{65}$.

The design of the koilon's upper part also remains unknown. R. Heberdey and W. Wilberg reconstructed a hall in the area of the slope and associated it with information from an inscription located in the south analemma ${ }^{66}$. Architectural components found during the current building research in the area of the portico are of a much later date. Discoveries made as a result of the archaeological excavations in the upper diazoma indicate building activity in some areas during the late Hellenistic or early imperial periods ${ }^{67}$. No conclusions, however, could be made in regard to the erection of the supporting wall.

The seating areas in the theatre were clad with white marble slabs, of which a very small number have been preserved. In addition, any remaining components have changed place often enough that no clear spatial allocation is possible. The style and manufacture of the marble cladding does not provide any clear chronology. An inscription, which R. Heberdey dates to the $3^{\text {rd }}$ century BC and which is located on the face of a marble slab on the diazoma wall, could indicate an early date for the installation of the marble cladding ${ }^{68}$. A parallel for this cladding technique occurs at the Hellenistic theatre at Metropolis and which dates to ca. 150 BC. ${ }^{69}$ Both the large theatre on the acropolis at Pergamon, with its andesite tuff cladding, and the theatre at Herakleia on the Latmos date to the Hellenistic period and evidence found in the substructure of the latter may allude to similarities in the cladding techniques at the Ephesian theatre ${ }^{70}$.

G. STYHLER-Aydin

\subsection{THE THEATRE IN THE ROMAN IMPERIAL PERIOD}

\subsubsection{Imperial era theatre facades}

According to the architectural evidence the stage building was erected in the Hellenistic period and underwent major rebuilding in Roman times ${ }^{71}$. A richly decorated imperial era theatre facade replaced the Hellenistic $>$ thyromata $\wedge^{72}$. This facade was comprised of a stage podium (proscenium) and a scaenae frons, which rose over the proscenium and formed a three storey so-called tabernacle-facade ${ }^{73}$.

\footnotetext{
${ }^{62}$ von Gerkan - Müller-Wiener 1961; Ciancio Rossetto - Pisani Sartorio 1994, Vol. 2, 208-210; Georgousopoulos - Gogos 2002; GoGOS 2011.

${ }^{63}$ Ciancio Rossetto - Pisani Sartorio 1994, Vol. 3, 463-464.

${ }^{64}$ Cap. 3.4.3.1; 11.1.1 and 11.1.2.

${ }^{65}$ On this topic see also: BurmeIster 2005, 160.

${ }^{66}$ IvE 2041. Compare Heberdey u. a. 1912, 15. 163-164. The inscription, however, is dated no earlier than the end of the $2^{\text {nd }}$ century/ beginning of the $3^{\text {rd }}$ century AD. R. Heberdey himself suggests the later decades of the $3^{\text {rd }}$ century AD. See also Cap. 8.6.1, No. 11 and Cap. 8.6.2.

${ }^{67}$ Cap. 3.4.3.1.

${ }^{68}$ IvE 2087. Compare Heberdey u. a. 1912, 18. 186. See also Cap. 8.6.2.

${ }^{69}$ Meriç 2004, 85

${ }^{70}$ Radt 1988, 287-292; Ciancio Rossetto - Pisani Sartorio 1994, 396-398. 459.

${ }^{71}$ Heberdey u. a. 1912, 5-52. Also Cap. 3.1.

${ }^{72}$ Research at the site was concluded in 2005. The first results were presented in the following: ÖzTÜRK 2005a; ÖzTÜRK 2005b; ÖZTÜRK 2006a; ÖZTÜRK 2006b; ÖZTÜRK 2010.

${ }^{73}$ For terminology see ÖztÜRK 2006b, 205-206; see also ÖzTÜRK 2009, 11-12.
} 

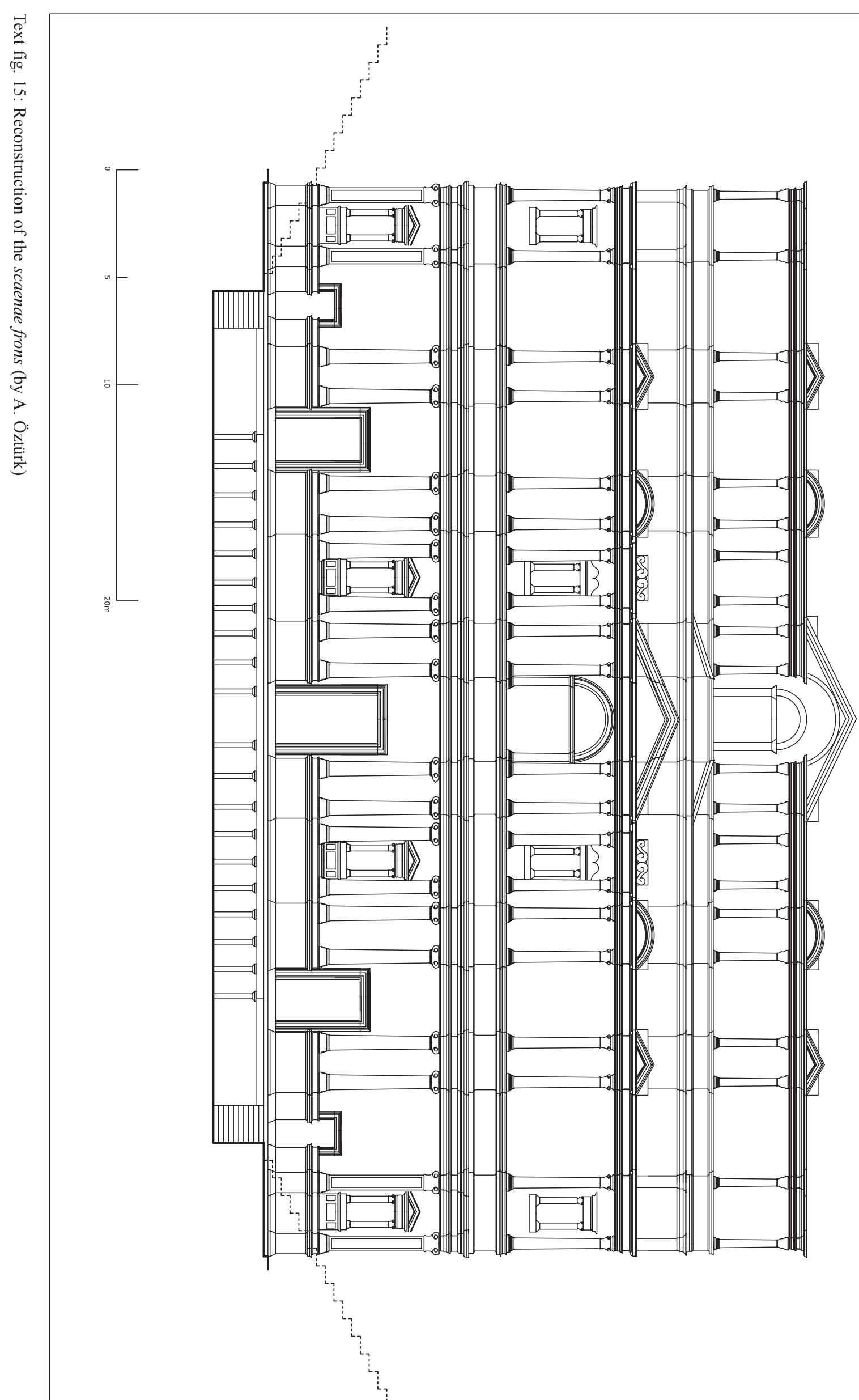


\section{Previous Interpretations}

Proscenium: After the first excavations the proscenium area was published by W. Wilberg in connection with the Hellenistic facility. Accordingly, the in situ supports and the triglyph entablature of the Roman era stage originally belonged to the stage of the Hellenistic proscenium ${ }^{74}$. During the construction of the Roman scaenae frons, they were dismantled and partially reinstalled further forward in the front wall of the stage. According to Wilberg, the characteristic shape of Greek proscenium supports was achieved by adding engaged columns to the front of the in situ supports ${ }^{75}$. A. von Gerkan did not interpret the supports and the triglyph entablature as parts of the Hellenistic proscenium, but as part of the early imperial stage ${ }^{76}$. Moreover, $\mathrm{H}$. von Hesberg suggested that the shape of the entablature was dated to the $1^{\text {st }}$ century AD because the frieze was for the most part styled as a continuous band ${ }^{77}$.

Scaenae frons: G. Niemann suggested the following reconstruction for the Roman era stage: the scaenae frons was placed in front of the Hellenistic skene ${ }^{78}$. A third storey, rising above the attica-parapet wall, was later added to its original two-storey design. These two versions, which were both drawn up by Niemann, differ mainly in relation to the second floor. Version 1 sees the tabernacles replaced with five arched niches ${ }^{79}$. A straight entablature was placed over the central niche, whereas the side niches had concave colonnades. In the second version, the center tabernacles are connected with a discontinuous pediment ${ }^{80}$. There is no provision for a concave column.

Because of the architrave inscription on the first floor, the lower two floors of the scaenae frons were dated to $66 \mathrm{AD}^{81}$, and the construction of the third floor is therefore set at the beginning of the $3^{\text {rd }}$ century AD.

Another attempt at reconstructing the Ephesian scaenae frons was presented by $\mathrm{H}$. Hörmann ${ }^{82}$. He based his reconstruction partially on G. Niemann's second version, but differed in the following ways: the smaller side doors located on the first floor were integrated in concave colonnades, and on the second floor a plinth frieze of erotes hunting was suggested. The concave colonnades of the third floor were arranged over the axes of the central door and the larger side doors. Hörmann assumed that the scaenae frons was raised by one level in the middle of the $2^{\text {nd }}$ century $\mathrm{AD}$, and not at the beginning of the $3^{\text {rd }}$ century $\mathrm{AD}$.

\section{Construction of the Imperial Era Theatre Facade (Late Flavian period)}

Proscenium: The first imperial period proscenium can be reconstructed based on in situ remnants such as its stylobate, upon which traces of former pillars still exist.

An arrangement of three doors made up the front of the proscenium; the middle door, centred on the building's axis was particularly large. It was flanked on each side by eleven pillars, namely one corner pillar and ten engaged pillars, which were followed by an entablature with triglyphs.

Based on current archaeological investigations the axial arrangement of the supports for the first imperial period stage could be dated to the Flavian $\mathrm{era}^{83}$. It was therefore necessary to determine whether this date could also apply to the construction of the proscenium. The entablature is partially preserved, in situ, on the walls of the side entrances to the parodoi; these were built on the Hellenistic foundations with very little alteration. The entablature consists of a Doric architrave, a frieze of triglyphs and metopes, and a console geison (P1. 436 Fig. 770). The architrave and triglyphs largely correspond to the Doric order, although unusually, the

\footnotetext{
${ }^{74}$ Heberdey u. a. 1912,17 Fig. 5.

${ }^{75}$ Heberdey u. a. 1912, 21 Fig. 38-40.

${ }^{76}$ VON GERKAN 1921, 91.

77 VON HeSBERg 1980, 56.

${ }^{78}$ Heberdey u. a. 1912, 53-94.

${ }^{79}$ Heberdey u. a. 1912, Pl. VII.

${ }^{80}$ Heberdey u. a. 1912, Pl. VIII.

${ }^{81}$ Heberdey u. a. 1912, 52.

${ }^{82}$ HÖRMAnN 1923/1924, 275-345.

${ }^{83}$ Cap. 3.1.2.
} 
architrave consists of an unprofiled band insteaed of a regula. A console geison was used in the Doric entablature of the proscenium. H. von Hesberg assigned the date of $1^{\text {st }}$ century AD based on the stylistic execution ${ }^{84}$.

In Ephesus the Doric order was employed both in Hellenistic and imperial period buildings. The proportions of the Hellenistic examples and that of the Augustan era Prytaneion are initially quite similar ${ }^{85}$.In other imperial period buildings, such as the Hall of Nero, the style varies, yet the height proportion of architrave and frieze remains $1: 1$.

The console geison of the proscenium has its closest parallel in the attica of the scaenae frons, which dates to the late Flavian era (Pl. 436 Fig. 771; 437 Fig. 772). The period and style of the proscenium and the attica cornice are closely related. This applies particularly to the profile design, the motifs used in the coffers, as well as the very flatly rendered ornamentation. One difference is in the profile of the console in the attica cornice and can be explained by the size variation and placement of the elements.

The shape of the supports also provides further justification for an imperial period date the proscenium remnants. Contrary to the opinion of W. Wilberg, the engaged pillars of the Ephesian proscenium differ from the characteristic form of Greek proscenium supports in that they are narrower and greater in depth ${ }^{86}$. The first phase of the imperial proscenium can therefore be dated to the Flavian era.

Scaenae frons: The scaenae frons can be largely reconstructed due to the investigation of the building elements

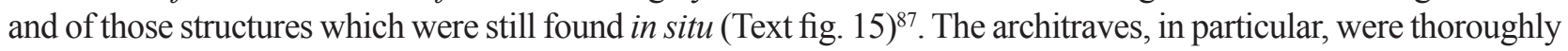
researched and largely identified in their original position. Due to this, the arrangement of the tabernacles could be determined. The Ephesian scaenae frons consisted of a three-storey tabernacle-facade ${ }^{88}$. The back wall of the first floor was divided by five doors and four niches; two larger ones flanked the sides of the central door. As well, four aedicules are also known in the back wall. The eight cranked tabernacles on the first storey stood on an undecorated plinth. The diagonally wrought Ionic capitals carry an entablature, that was concave shaped over the big niches. On the second level the rear wall was interspersed by four niches with aedicula framing, and a central arched niche that was crowned with a half cupola. In general, the second floor shows the same axial arrangement as the first floor. The second-floor columns stood on a plinth that was decorated with a frieze of erotes hunting. The pillars rested on Attic bases. The capitals were either Corinthian or of a composite order ${ }^{89}$. The entablature of the second storey proceeds straight and was cranked over the pedestals. Apart from this the entablature had projections which lined up in symmetrical axis over the major niches on the first floor. The middle part of the second floor was completed with a discontinuous pediment. The middle tabernacles were fitted with alternating triangular and segmented pediments. A block decorated with S-shaped volutes lay on the protruding entablature beside the axis. The third storey was set back and rested on the attica-wall of the second storey. A small, half-domed niche was probably situated in the middle tabernacle. The third storey columns rose above a basement decorated with a garland frieze. The Corinthian order columns bore a concave entablature. The three center intercolumniation were likely spanned by a `Syrian pediment . The lateral tabernacles were topped with round and triangular gables.

Dating: According to the results of the excavators, the scaenae frons was originally constructed as a two-storey facade, to which a third storey was later added ${ }^{90}$. As previously indicated, a dedication inscription on the architrave of the first floor provides a date of $66 \mathrm{AD}$ for the first building phase ${ }^{91}$. The second phase,

\footnotetext{
${ }^{84}$ VON HESBERG 1980, 50.

${ }^{85}$ See ÖzTÜrK 2010, 337 Fig. 8 for the Doric order in Ephesus.

${ }^{86}$ See ÖZTÜRK 2010, 337 Fig. 7 for a comparison of Ephesian engaged columns and Greek proskenion supports.

${ }^{87}$ Here, the new reconstruction will be only briefly addressed. A stone-by-stone reconstruction using all preserved architectural elements, and a comprehensive comparison of all reconstructions of the Ephesian stage front are planned for the final publication. The main arguments for the reconstruction of the Ephesian scanae frons can be found in ÖzTürK 2010, 338-339.

${ }^{88}$ The stage facade was situated on the east side of the stage building. The structural findings of G. Niemann (HeBERDEY u. a. 1912 , 84 Illus. 171) and M. Hofbauer (Cap. 3.1.4) show that the scaenae frons was continued toward the north and south. The final publication will also include a closer examination of the reconstruction of the stage building's sides. Compare ÖZTÜRK (in preparation) with contributions by M. Hofbauer.

${ }^{89}$ A capital of both types was found whose dimensions and decoration fit well with the column shafts of the second storey. This problem could not yet be solved.

${ }^{90}$ Heberdey u. a. $1912,47-52$.

${ }^{91}$ HeBerdey u. a. 1912, 157-160.
} 
during which the third storey was added, was dated to the end of the $2^{\text {nd }}$ century to the early $3^{\text {rd }}$ century AD because of the connection made by former research with an epigram from the time of Commodus ${ }^{92}$. It turned out, however, that this inscribed block was added during later repairs and can therefore not provide any concrete evidence for the construction date of the third storey. For this reason, the dedication inscription on the architrave which was dated to $66 \mathrm{AD}$ will undergo further verification by the examination of architectural ornamentation styles, below.

The name of the emperor was removed from the architrave inscription; the title »Neokoros«, however was preserved. Based on the consideration that the name removed was that of Nero, R. Heberdey concluded that the two lower stories were completed by 66 AD. As early as 1919, however, J. Keil proved that Ephesus received its first imperial neocorate under Domitian. Thus, it stands to reason that the name removed from the inscription must be that of Domitian. The inauguration of the scaenae frons is now therefore dated to $85 \mathrm{AD}$, since the inscription indicates that the emperor was in his eleventh consulship ${ }^{93}$.

Egg and dart, as well as acanthus leaf ornamentation will be consulted for the stylistic analysis of the first two floors (Pl. 437 Fig. 773; 438 Fig. 774). On the first floor the design of the egg is fairly consistent, yet there are three recognizable types in regard to the design of the cup surrounding the egg, and the alternating dart. One type features a distinct separation, in high relief, between the egg and the cup and is in striking contrast the low relief between the edge of the cup and the leaf. The cornice on the second floor also displays this type. An egg and dart decoration of this type is also found on the Laecanius Bassus Nymphaeum, whose inscription dates it to 79 or $80 \mathrm{AD}$ (P1. 438 Fig. 775. 776 $)^{94}$.

The consoles in the second floor cornice are each underpinned by an acanthus leaf (Pl. 438 Fig. 774). The lobes of the acanthus leaf are not in one even plane, rather, they are staggered in a zig-zag fashion. The drill holes on both sides of the midrib do not continue to the base, but are replaced with shallower grooves. Two other Flavian period buildings in Ephesus (Laecanius Bassus Nymphaeum and the Fountain of Domitian) display this type of leaf ${ }^{95}$.

The pilaster capitals and lotus-palmette frieze on the third floor must also be examined (Pl. 439 Fig. 777. 778; 440 Fig. 779. 780). Before this, however, the one composite-capital that G. Niemann attributed to the third floor needs to be considered ${ }^{96}$. Niemann's assignment to the third floor, however, proved to be incorrect. Due to its size this capital cannot be assigned to the columns of the third floor. Furthermore, it can be dated to the Antonine period, based on its favourable comparison with capitals of the Vedius Gymnasium ${ }^{97}$. Crucial for the reconstruction and dating of the third floor are a number of Corinthian capitals which, because of their size and shape, very likely come from the third floor. The late Flavian capitals from Ephesus display certain characteristics; for example, the acanthus leaves do not extend past the lower half of the capital $\left.\right|^{98}$. The bract only starts above midheight of the leaves of the crown and a large and broad involucre grows from an undecorated stem. Because all the capitals on the third floor display these characteristics, they can be dated to the time of Domitian ${ }^{99}$.

The lotus-palmette frieze consists of five-petalled lotus flowers alternating with seven-leaved palmettes, which are joined together by tendrils. The tips of the flower petals touch the closed palmettes and the flower itself has serrated side leaves. The hollows of the leaves are further recessed by drilling. The closest parallel to this frieze can be seen on top profile of the architrave on the first floor; both are closely related in terms of the style of the period and workmanship.

This brief stylistic analysis has shown that both the second and third floors date to the time of Domitian. It can therefore be concluded that all three floors of the scaenae frons, as well as the elevated stage with its Doric order (proscenium) originated during the late Flavian period.

The scaenae frons, as well as the magnificent facade of the Laecanius Bassus Nymphaeum, is the first examples of tabernacle facades in Ephesus; furthermore, they are also some of the first three-storey facades in the city.

\footnotetext{
${ }^{92}$ Heberdey u. a. 1912, 109-112.

${ }^{93}$ I thank F. Dönmez-Öztürk for her information to that inscription.

${ }^{94}$ RathmaYr 2011, 131 Note 4.

${ }^{95}$ Based on an inscription, the Fountain of Domitian is dated to either 92 or 93 AD, BAMMER 1978/1980, 67.

${ }^{96}$ Heberdey u. a. 1912, 86. 88 Fig. 188.

${ }^{97}$ Strocka 1981, 128.

${ }^{98}$ PlattNer 2003, 51-54.

${ }^{99}$ PlattNer 2003, 51-54.
} 


\section{Modification of the Imperial Period Proscenium (Antonine Period?)}

At the time of the first Austrian excavations the proscenium was partially preserved in situ ${ }^{100}$. The square pillars of the facade were largely standing upright and remains of a wall were found between them. Relicts indicate that the facade, towards the orchestra, was clad in marble. This preserved feature does not show the original facade, rather, it is associated with a later modification: Originally, during the Flavian period) the engaged-column pillars carried a Doric entablature. At the time of installing the marble cladding it seems that the engaged-column-facing of the pillars, and the Doric entablature were removed. After these alterations, the Doric entablature remained only at the side entrances of the parodoi as the sides of the facade were not clad in marble.

The archaeological investigations show that the two rows of pillars, which were preserved in the logeion and which are just east of the massive substructure of the scaenae frons, date to the Antonine period ${ }^{101}$. It is obvious to connect the extensive rebuilding in the logeion area with the Antonine period alterations of the proscenium facade.

A. ÖZTÜRK

\subsubsection{Imperial period stage building}

As a result of the large-scale transformation of the theatre in the Flavian period not only the splendid three-storey facade was added to the stage building in the east (Text fig. 15), but it was enlarged by the addition of a suite of rooms (Tab. 127; Pl. 12 Fig. 20; 13 Fig. 21; 430 Fig. 758) (102 $^{2}$

In the process, the eight-room Hellenistic structure with its corrdior was included in the centre. With the exception of the outer chambers D1/E1 and D8/E8 there is, however, no connection between the Hellenistic structure and the newly constructed chambers of the Flavian period (Pl. 3 Fig. 3). This applies to both the lower floor and the upper Hellenistic floor. Neither the room height of the attached chambers nor the shape of their ceilings as flate or vaulted construction could be determined. Clearly evident is only that the height of the chambers considerably dominated the height of the Hellenistic lower level.

M. Hofbauer

\subsubsection{Imperial Era Orchestra}

The scaenae frons incorporated the older Hellenistic proscenium. The result was that the $6 \mathrm{~m}$ deep imperial era stage extended far into the original orchestra, causing it to be diminished in size (Pl. 78 Fig. 153). During the reconstruction the old analemmata P and Q were abandoned (Pl. 12 Fig. 20; Plan 10. 18). The parodoi was relocated due to the new analemmata which was set back further to the east. Since then, the now covered entrances are located on the east side of walls P and Q. Presumably the lowest rows of seating were also removed. Less easy to understand is the extent of the remodelling and it remains unclear whether, in Flavian times, these structures were removed up to the still-visible orchestra wall X (Pl. 444 Fig. 789; 445 Fig. 790). Regarding the Flavian orchestra, however, it is expected that the profile ring J was located outside the orchestra channel. Nothing was changed at the level of the orchestra, and even the Hellenistic channel remained. The interior was sealed with opus signinum and was covered, as indicated by the processing marks of the upper edges of the channel walls. Nothing remains of the channel floor coating. Virtually the entire area of the orchestra was subsequently raised and the new foundation for the floor established.

An inscription of the $2^{\text {nd }}$ century AD mentions a reconstruction of the proscenium and logeion ${ }^{103}$. It is therefore likely that a major remodelling was carried out that affected not only the entire stage, but the orchestra as

\footnotetext{
${ }^{100}$ Heberdey u. a. 1912, 30-34.

${ }^{101}$ Cap. 3.2.2.

${ }^{102}$ See for the imperial era modification of the stage building the contribution by M. Hofbauer in the final publication ÖzTÜRK (in preparation).

${ }^{103}$ IvE 2039. Also Cap. 8.6.1, No. 9 and Cap. 8.6.2.
} 
well. The Doric proscenium with its engaged columns and metope-triglyph frieze (Pl. 81 Fig. 159-161; 436 Fig. 770) was removed, creating a continuous wall with three entrances and two niches. The entire face was clad in marble, some of which still remains in situ. There is no epigraphic evidence to confirm the simultaneous remodelling of the stage and orchestra. It seems likely, however, that raising the orchestra level by ca. $0.30 \mathrm{~m}$ belongs to the same phase as the reorganization of the stage, leading to the small reduction in size of the stage front. The old orchestra channel was finally abandoned and a new, shallower, uncovered channel was constructed in its place, albeit at a higher level (Pl. 88 Fig. 174; 89 Fig. 177. 178; 90 Fig. 179). The orchestra was, by this time at the latest, extended up to the orchestra wall X, had this not already taken place in the Flavian period.

M. Hofbauer

\subsubsection{Imperial Era Cavea}

\subsubsection{Construction Measures in the Early Imperial Period}

The first traceable modification to the koilon concerns the structure of access ES3 for the development of the upper tiers (Pl. 66 Fig. 127) ${ }^{104}$. It was subsequently incorporated into the southern outer wall of the theatre as the continuation of the >Akademiegasse ( (Plan 5). The entrance measures 4.10 to $4.20 \mathrm{~m}$ wide and is covered with a vault of white marble blocks. The front view the archivolts show an outline containing three fascia. The side walls are clad with orthostat panels. An inscription, originally located on the inner archivolt of the entrance, names Hieron Aristogiton as the donor; this led to the building project being dated to the Augustan to early Tiberian periods ${ }^{105}$. A disturbance in the pseudo isodome ashlar masonry facade of the theatre's southern exterior wall indicates the incorporation of this entrance (Pl. 441 Fig. 781). Moreover, the excavation trench in $\mathrm{B} 1 / \mathrm{C} 1$ uncovered the original course of the outer wall, and that the alignment of the entrance deviates by ca. $12^{\circ}$ to the north ${ }^{106}$. Further structural anomalies occur in the interior of the stepped seating structure because the accessibility was not guaranteed by a horizontal orientated infrastructure as it usually would be. By the continuation of the street level at the koilon, a podium, three rows below the diazoma was accessible by an arrangement of additional ascending steps ( $\mathrm{Pl} .441$ Fig. 782). Overall, it seems that the entrance to the theatre was neither functionally nor aesthetically pleasing, judging by the evidence of constraints. Based on the state of conservation of the north wall and the collapsed architecture in front of it, it is currently not possible to determine whether a comparable access existed on the north side ${ }^{107}$.

On the basis of archaeological find complexes, construction of the upper diazoma as well as the central platform in the area south of the vomitorium EN1 can be dated to the early Imperial period or into the $1^{\text {st }}$ half of the $1^{\text {st }}$ century $\mathrm{AD}$, although the scope of which cannot be understood at present ${ }^{108}$. It therefore remains unclear whether these measures were part of a major reconstruction plan in the theatre. The nature and circumstances of the aforementioned installation of the southern access ES3 more likely indicates a unique measure.

\subsubsection{The Extension of the Auditorium during the Reigns of Domitian and Trajan}

According to epigraphic evidence, the most extensive modification to the theatre occurred during the reign of Domitian ${ }^{109}$. These include the expansion of the stage building with the construction of the scaenae frons, as well as the imperial era logeion which extended far into the Hellenistic orchestra. In addition, these changes necessitated structural adaptations in the area of the parodoi, and the lower rows of seating around the

\footnotetext{
${ }^{104}$ Cap. 11.1.3.

${ }^{105}$ IvE 2033. Compare Heberdey u. a. 1912, 15. The ashlars of the archivolt are mostly no longer in situ. R. Heberdey and W. Wilberg found the inscribed three middle ashlars in the rubble on the inside of the portal. Today, the ashlars rest on the restored seats beside the entrance. For dating also see MAYER 1995, 68.

${ }^{106}$ Cap. 3.7.1.1.

${ }^{107}$ Cap. 2.4.

${ }^{108}$ Cap. 3.4.3.1 and 3.5.1.

${ }^{109}$ IvE 2034. See also Cap. 8.6.1, No. 2; Cap. 8.6.2 and 10.2.2. The possibility of the construction already having started under the emperors Vespasian and Tiberius has been suggested in the literature; compare DRÄGER 1993, 154.
} 
orchestra. In the auditorium the upper area to the west was added to, and a new circulation system for the visitors was integrated at the same time. As a result of this building phase, the Aristion aqueduct, one of the four aqueducts supplying Ephesus, was preceded through the theatre (Tab. 127; see below). Work was completed in the south wing of the auditorium during Trajan's rule. The following section describes each of the key measures undertaken in the auditorium.

\section{Orchestra, parodoi, and ima cavea}

The large-scale expansion of the Hellenistic stage building during the Flavian period inevitably had structural consequences for the orchestra, the Hellenistic parodoi, as well as the lower area of seating in the koilon. The principle modifications of the stage and orchestra areas have already been described by R. Heberdey and W. Wilberg (Pl. 442 Fig. 783. 784). Current research has allowed their information to be supplemented and, in some cases, clarified. The focus, here, is on the adaption to the koilon. With regard to the modification of the skene, proscenium, and orchestra areas, please refer to the chapter on the archaeology of the stage and orchestra complex ${ }^{110}$. One fundamental modification affecting the parodoi was important regarding the possibility of access to the Hellenistic theatre.

The construction of the scaenae frons and the stage of new imperial period logeion, which encroached the orchestra by ca. $6 \mathrm{~m}$, blocked the north and south parodoi ${ }^{111}$. In order to maintain even limited access to the orchestra, new, covered entrances measuring $2.00-2.10 \mathrm{~m}$ in width were established east of the existing parodoi by which (as indicated in the original publication) »die unteren Enden der äußersten Sitzstufenkeile um etwa $1,50 \mathrm{~m}$ verschmälert (wurden) « ${ }^{112}$. For this purpose the inner portions of the Hellenistic analemmata with the adjoining stepped benching had to be removed. Marble components from these facades were re-used in the construction of the new parodos walls, as is indicated by some spolia with visible contact surfaces used in the stairs covering the former western klimakes (P1. 433 Fig. 764). In the logeion area the original analemmata constitute the western boundary of the new parodoi. However, only a few components remained in situ, for example at the start of the orchestra side of the Hellenistic north analemma ${ }^{113}$. Apart from that, the removed parts of the analemma foundations were used to re-erect the orchestra side parts of the new west walls of the parodos. After a few meters, however, the orientation of the parodoi veers slightly to the west. In so doing they veer off the course of the original analemma, eventually heading west after an obtuse angle set them parallel with the end-walls of the stage building. As a result, the north parodos is crossed by a part of the drainage channel which leads out of the theatre along the Hellenistic analemma and around the orchestra. How the surface water was henceforth drained is not understood at this time ${ }^{114}$.

The parodoi were covered with segment-arched vaults, made of quarry stone, which lie on a marble abutment. At the western entrances as well as to the orchestra, the covering is a vault constructed of white marble ashlars consisting of spolia (Pl. 442 Fig. 785; 443 Fig. 786). The great difference in materials used - from quarry stone arches to marble wall surfaces, to a partial cut-stone vault - might suggest that a plaster coating had been planned for the areas with quarry stone arches. A platform was located above the vault and the level with the surface of the logeion; it was covered in white marble slabs and could be accessed by ramps located at the north and south ends (Ramps N and S) (Pl. 2 Fig. 2; 443 Fig. 787). Towards the east a new facade was required to complete the ascending rows of seats. However, the ground-plan of the innermost wall areas of the currently preserved analemmata differ in orientation from the eastern parodoi walls below. Parts of the innermost analemmata walls rest on the vault of the parodos covering, which indicates that they could only have been built after the completion of the vault, or the platform (see below the illustrations for the north and south wings of the theatre). The joints between the platform and the north and south ramps occurred outside

\footnotetext{
${ }^{110}$ Cap. 3.2.2 and 3.3.2.

${ }^{111}$ Heberdey u. a. $1912,31$.

112 Heberdey u. a. 1912, 39.

${ }^{113}$ Cap. 3.2.2 and 3.3.2.

${ }^{114}$ Cap. 3.2.2.4.
} 
the parodos floor plan (Pl. 444 Fig. 788). Another adaptation, which was triggered by the changes in the parodoi concerned the lower rows of seats of the Hellenistic koilon. The original position of the entrance to the orchestra was closed off, due to the construction of the new stage. As a consequence thereof, the radial stairs of the lowest rows were inaccessible from the orchestra. Some modification to the lower rows of seats must have taken place in order to remedy these spatial constraints. Already R. Heberdey and W. Wilberg presumed that the prohedria was completely, or at least partially, removed at this time. In so doing an additional approach beyond the Hellenistic drainage channel skirting the orchestra could be created that would make the area accessible ${ }^{115}$. They associated the removal of the lower rows of seats to the level of the logeion and the construction of orchestra wall $\mathrm{X}$ with post-Trajanic times, and justified this due to the unfavourable viewing conditions that would have been created with the increased level of the logeion ${ }^{116}$. A gradual alteration of the lower rows of seats cannot be reconstructed. It is noticeable, however, that the orchestra-side entrances to the covered parodoi - which had, as described above, stone vaults of white marble spolia - are close to the western terminations of the currently visible orchestra wall X. That the entrances to the parodoi originally presented a visible surface is also shown in the profile of the archivolts' structure at the orchestra (Pl. 442 Fig. 785). This spot was subsequently rebuilt several times, as the abutting portions of walls of the orchestra side of the parodoi indicate. Even in today's restored state, orchestra wall X shows that the radial stairs initially opened to the orchestra. Here, the start of the stairs at the bottom is similar to that of the diazomata, in that it was bordered by lateral orthostat slabs whose front sides were a design element of the wall (Pl. 444 Fig. 789). The top of the wall was crowned with a profile (P1. 445 Fig. 790a. b) ${ }^{117}$. On the basis of the aforementioned evidence one would question whether the removal of the lower seating levels occurred in several phases, or if the currently visible orchestra extension was already produced as a result of modifications to the stage and parodoi during the rule of Domitian. Gladiatorial contests and animal hunts are indicated in the honorary inscription for Titus Flavius Montanus ${ }^{118}$, that was attached on the south analemma, and which dates to 102-112 $\mathrm{AD}$; this presupposes an intention which corresponds to the arena-like configuration of the orchestra. In subsequent periods further conversions and adaptations occurred ${ }^{119}$.

\section{North Wing of the Theatre}

As can be determined, the north wing of the auditorium was started with the extension of the auditorium (P1. 66 Fig. 127). Several construction projects are evident here. Firstly, a portion of the existing upper level of the northern outer wall was opened to the middle diazoma in order to incorporate a high, barrel-vaulted vomitorium EN2 (Pl. 2 Fig. 2; 146 Fig. 294). A staircase in the vomitorium bridged the ca. $6.4 \mathrm{~m}$ difference between the floor level outside the theatre and the entrance to the middle diazoma (Text fig. 16) ${ }^{120}$. The aqueduct of Claudius Aristion enters the building below the stairs and runs directly along the eastern wall of the vomitorium toward the south. It is clear from this and from profile studies of the aqueduct and the vomitori$u m$ that these projects were carried out as a joint project (Text fig. 17). It is conceivable that the level of the route coming from the north, as well as an effective course of the aqueduct in the theatre were crucial for the arrangement and orientation of vomitorium. This could also explain why the access - which was dissimilar to the other vomitoria in the theatre - was oriented toward the orchestra.

The seating areas in the north wing of the Hellenistic koilon were situated beyond the usable portion of the hillside. It is no long possible to reconstruct the original slope of the seating tiers. As is known from other Hellenistic theatres, massive layering or landfills were common ${ }^{121}$. Still visible today are the vaulted chambers of the substructure built in opus caementitium which were erected in connection with the installation of

\footnotetext{
${ }^{115}$ Heberdey u. a. 1912, 31-32 Fig. 57; See also Cap. 3.3.

${ }^{116}$ Heberdey u. a. 1912, 44-45 Fig. 86.

${ }^{117}$ Heberdey u. a. 1912, 45 Fig. 93.

${ }^{118}$ IvE 2061. See also Cap. 8.6.1, No. 6 and Cap. 8.6.2.; SCHERRER 1997, 114.

${ }^{119}$ Cap.11.2.4.3.

${ }^{120}$ Today, the stairway in the vomitorium EN2 is filled up to the diazoma's exit. St. Karwiese exposed the upper steps of the stairway in an excavation see Cap. 3.5.2.1.

${ }^{121}$ Cap. 11.1.3.
} 

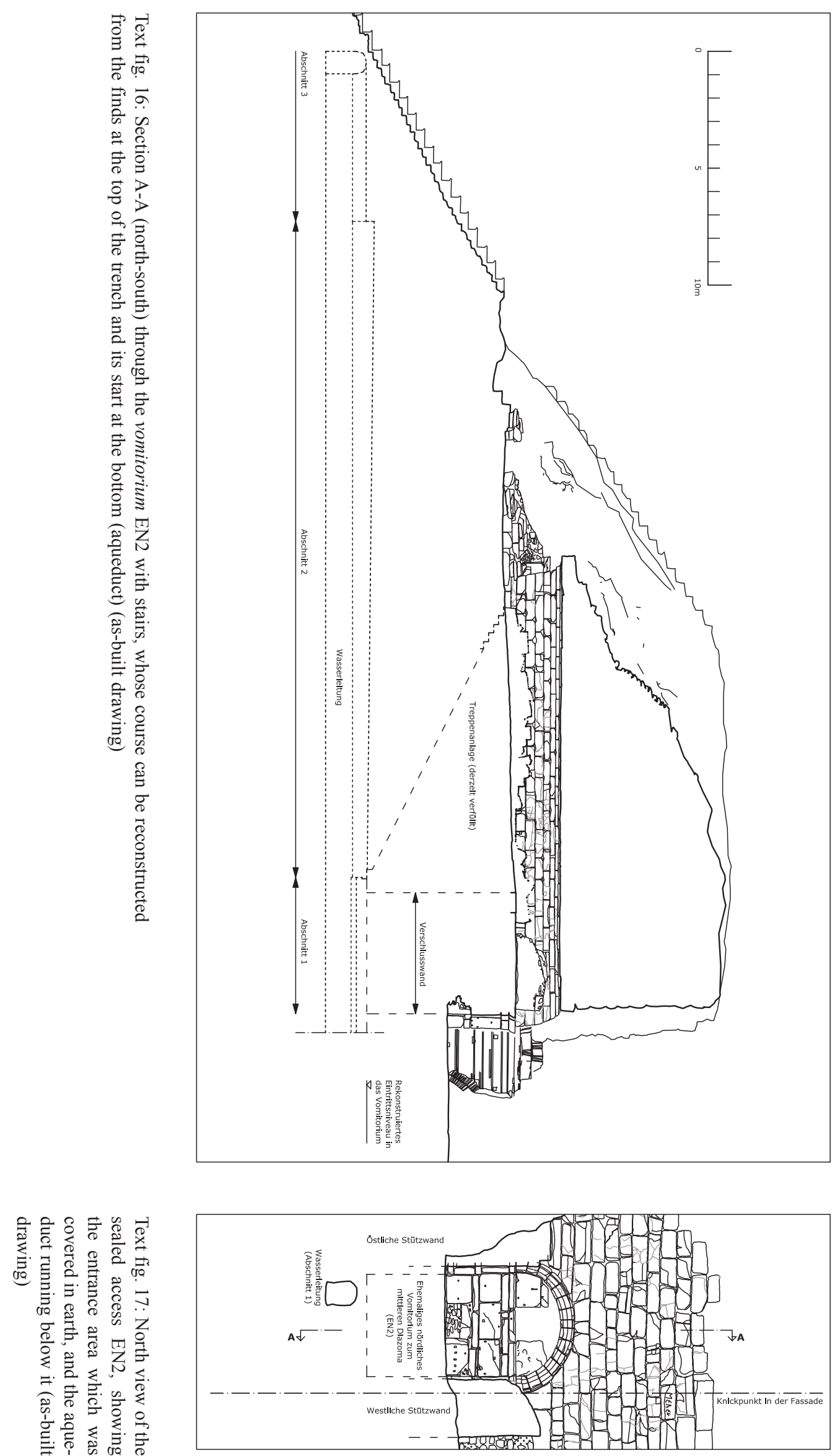
the vomitorium EN2, in place of the previous structure. The superimposed cavities were built a short distance from the inside of the theatre's exterior wall. The interstices were eventually filled with a loose packing. An example of this can be seen somewhat to the west and above vomitorium EN2. Here, the stone blocks of the older surrounding wall are visible on the inside for a long stretch and show no signs of contact with other building components or attachments made of other materials (Pl. 445 Fig. 791) $)^{122}$.

Another construction work can be detected west of entrance EN2. This is where the structural extension of the auditorium begins. This is recognizable through a change in material used on the northern perimeter wall of the theatre (Plan 4). The existing cushion-shaped ashlars of grey marble of the older exterior wall of the theatre were interlocked with smooth white limestone blocks which continued westward. Since a large part of this wall was preserved behind a reinforcement wall, dating to the $4^{\text {th }}$ century $\mathrm{AD}$, the interlocking of their facades is still noticeable (Text fig. 19; P1. 472 Fig. 844).

A doorway (EN2) to the lower diazoma was incorporated in the new structure at a distance of almost $20 \mathrm{~m}$ from the vomitorium. It was almost $40 \mathrm{~m}$ long and was constructed as a high vaulted passageway with several utilizable chambers (Plan 1) on its west side, which were also accessible from the passageway. Another entry (EN1 West) to the vomitorium provided access from the west by way of stairs ${ }^{123}$.

As with the upper entrance EN2, all walls and vaults that bounded the vomitorium were white marble. In contrast, the partition walls between the adjacent chambers KN1 to KN3 were constructed of white limestone, as was the northern outer wall. In its course the vomitorium was divided into three parts, which are distinguished from one each other by both their linear arrangement, as well as their width and height. In addition, the southern and central parts were divided by a comparatively low rising passage, whose structural elements display many anomalies which do not correspond to the other parts of the vomitorium (Text fig. 18). The overall impression is that the construction of this large-scale access corridor, particularly the area below the former middle tier, must have taken existing building structures into consideration. Another possible indicator in this regard was the excavation of the middle staircase platform in the southern sector of the vomitorium (Trench S 2/98). Two levels were detected here whereby the foundation work of the first phase can be dated to the $1^{\text {st }}$ half of the $1^{\text {st }}$ century AD. The finds of the more recent foundation, however, is not significant enough to determine a specific date other than it belonging to the imperial period ${ }^{124}$.

Part of the northern outer wall of the theatre - between the lower access EN1 and the corner between it and the neighbouring analemma in the west - is just about completely buried. Some ashlars in the upper courses of the wall are visible. While the smooth, white limestone ashlar masonry is visible north of the outer chamber KN1, grey, cushion-shaped marble ashlars with a curved surface, were used closer toward the adjoining corner with the analemma. Because of the marginally exposed wall surface in this area it cannot currently be determined if the cushion shaped ashlars were the commonly used building component, or if they were employed solely for reparations (Pl. 446 Fig. 792. 793).

The western end of the auditorium's north wing expansion resulted in an addition to the northern analem$m a$. The facade was extended towards the north by a portion of wall measuring almost $17 \mathrm{~m}$ long; towards the west, the lower courses of ashlar blocks were stepped, thereby widening the wall by $0.50 \mathrm{~m}$. As with other exposed surfaces of the analemmata, the flat ashlars of the facade were made of white marble. A detailed outline of the structural findings of this facade follow, in order to clearly explain the changes that were made to the northern analemma for the enlargement of the auditorium (Plan 7). The terrace in front of the north analemma with its staircase and various fountain basins is not dealt with here ${ }^{125}$.

The north analemma is approximately $57 \mathrm{~m}$ long, when measured from the first row of orchestra-side seating above the orchestra wall X to the base of the building's northern corner; it was divided into three main parts. They can be identified by differences in wall design and slight variations in the floor plan. Thus, the plan indicates that the course of both analemmata are not quite linear, but characterized by different sections, each with its own alignment.

\footnotetext{
${ }^{122}$ The restored step treads are a modern measure undertaken during consolidation work from 1994-1998. According to the former excavation director, St. Karwiese, loose rubble was found below. A documentation of the original state is unknown.

${ }^{123}$ Further stairs from the west, as reconstructed by St. Karwiese and I. Ataç could not be confirmed (KARWIESE 1997, 44-48; KARWIESE 1998, 24-26; also HeBERDEY u. a. 1912, 36).

${ }^{124}$ Cap. 3.5.1.4.2.

${ }^{125}$ Compare with the planned volume on building research by STYHLER-Aydin (in preparation).
} 


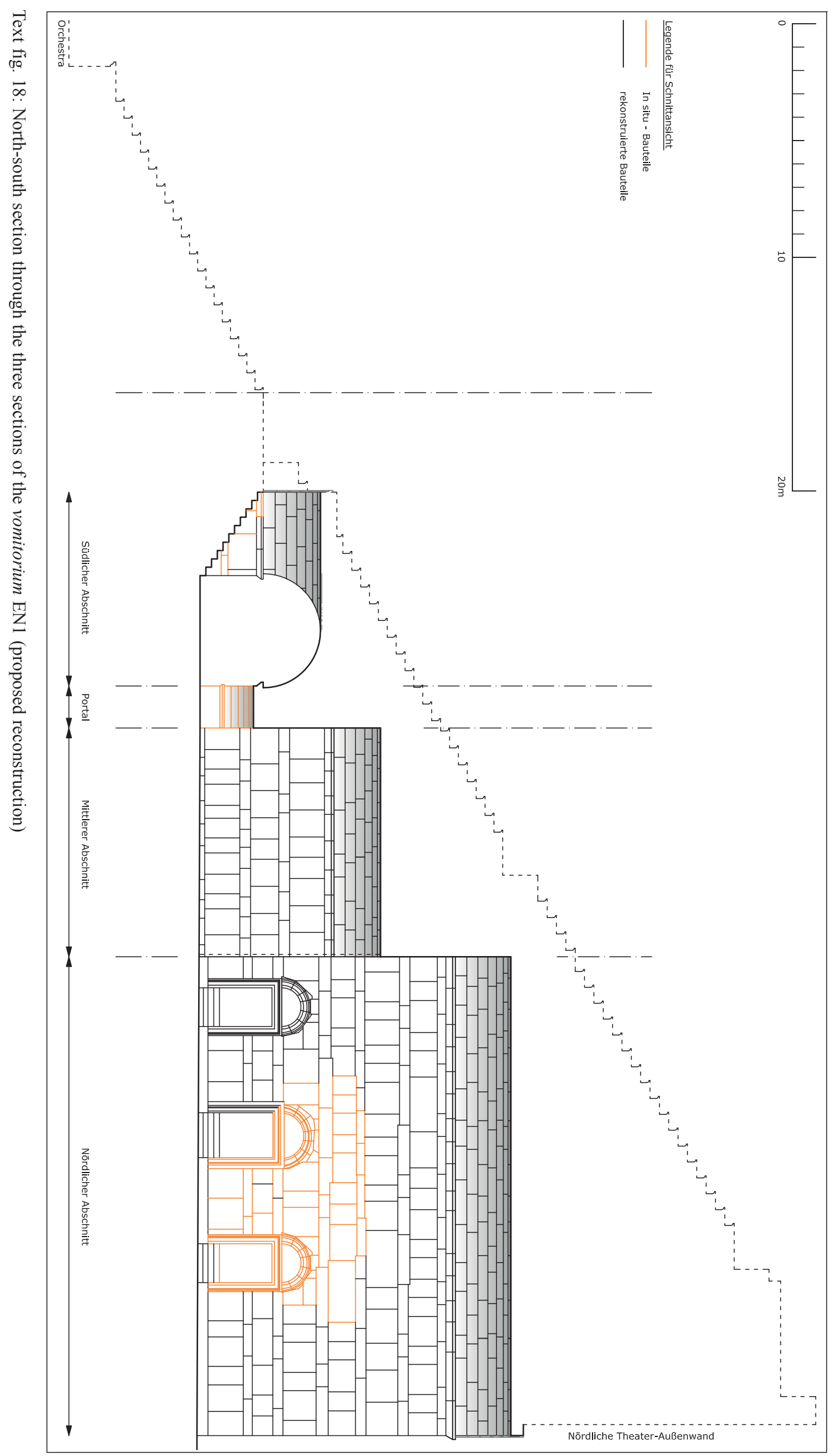


The southern inner portion of wall of the north analemma extends to the staircase EN1. Here the facade is constructed of successive rows of orthostats and small header courses. The wall veers to west by $0.50 \mathrm{~m}$, approximately $9.50 \mathrm{~m}$ from its start at the orchestra (Pl. 447 Fig. 794). Until this projection the inner wall rises to the parodos covering and is connected with the structural changes of the parodoi as a result of the modification of the stage and orchestra complex (see above). The backfill of the orthostats and headers, as well as the substructure of the adjacent radial staircase $\mathrm{T} 1$ to the east consist of opus caementitium.

In contrast, grey marble ashlars were used behind the outer shell of orthostats and headers. More than half of the depth of the facade headers extend into the ashlars behind. The base of the wall area is covered by the surface of the restored ramp to the north. Perhaps the slight undercut of the respective lower construction components indicate the surface of the floor slabs belonging to the original surface of the ramp (P1. 447 Fig. 795). The visible surfaces of the orthostats and headers were apparently roughly smoothed with picks and chisels. A finer surface treatment was not carried out.

The second part of the facade begins north of the stairway EN1 West and is articulated by the design of two closed arches. Here the facade ashlars were smoothed with a chisel; in some areas traces of chisel-draft are still visible on the heavily worn marble surfaces. It is particularly visible at the contact areas of the facade ashlars that the buttresses and their fill resulted from the same building process. The ashlars of the core masonry are visible at some damaged parts of the wall; it can be seen that they partly continue behind the facade side of the arch reveals (Pl. 448 Fig. 796). This suggests that the closed arches were a design element rather than being real openings ${ }^{126}$. Particularly striking is the base of the second facade section where it connects with the upper terrace. It is clearly visible that the opus caementitium core of the terrace was only later added in front of the facade section and consequently its original lower-lying base point is hidden behind the opus caementitium (Pl. 448 Fig. 797; Plan 7). The noticeably compact proportions of the two arches can also be explained in this way. The transition from the middle to the northern parts of the facade coincides with the ground plan of the most southerly wall of white limestone which divides chambers KN2 and KN3. The two other partition walls located behind the middle facade section (between $\mathrm{KN} 3$ and $\mathrm{KN}$ 4, and between KN4 and staircase EN1 West) were constructed of roughly finished grey marble ashlars (Text fig. 19). In sum, the results indicate that the part of the facade containing the two apparent arches was an older part of the northern analemma. This is also confirmed by an inscription mounted in the tympanum of the southern arch. It describes a decree of the governor Paullus Fabius Persicus to the authorities of Ephesus and is dated to $44 \mathrm{BC}$ (Pl. 449 Fig. 798a. b; 799) $)^{127}$. Further clearing and archaeological excavations would be necessary for a more detailed classification of the facade section and the building processes at the theatre, particularly in the areas of the central area of the collapsed vomitorium EN1 and the adjacent chambers KN3 and KN4.

The third part of the facade was adjacent and to the north of the arches; it represents the western boundary of the extended upper tiers. The lower ten courses of the facade are largely preserved. It was constructed of smooth pseudoisodome ashlar masonry. In the upper wall area some of the front ashlars are missing, or fragmentary in the wall bonding (Pl. 450 Fig. 800). It is also visible here that the core of the wall consisted of rough hewn ashlars and that the front ashlars were integrated about every two bloc course. Stone chips and mortar were used to correct and horizontal unevenness and to fill any gaps between the ashlars of the wall core.

The third portion of the facade rises above the terrace in front of it. The surfacing on the terrace is slightly undercut beneath the facade ashlars, which points to simultaneous construction (Pl. 448 Fig. 797). Both the construction of the terrace, as well as the stepped widening in the lower part of the facade were likely based on structural considerations. The northern wing of the theatre presented the largest facade of this building.

\footnotetext{
${ }^{126}$ Even R. Heberdey and W. Wilberg recognized the two arches as virtual arches (HeberdeY u. a. 1912, 36) St. Karwiese and I. Ataç interpreted the arches as >twin staircases〈 to the lower northern vomitorium EN1. Consequently, the lower diazoma should have been reached through the southern arch. Those using the neighbouring northern staircase would have had to turn north in the vomitorium use the presumed northern external staircase that accessed the middle diazoma (compare KARWIESE 1997, 44-48; Karwiese 1998a, 24-26; KARWIESE 1998b; AtaÇ 1999a, 6; HofBAUER 2007, 12). In consideration of the results described above, this interpretation can no longer be sustainable, see also Cap. 3.5.1.2.

${ }^{127}$ IvE 2021. Compare Heberdey u. a. 1912, 36. 112-116. Remnants of the Latin equivalent of the text were found in two copies (IvE 2022). R. Heberdey suspected that, based on the find circumstance, one copy was linked to the theatre, possibly south of staircase EN1 West (HeberdeY u. a. 1912, 116-119). See also Cap. 8.6.2.
} 


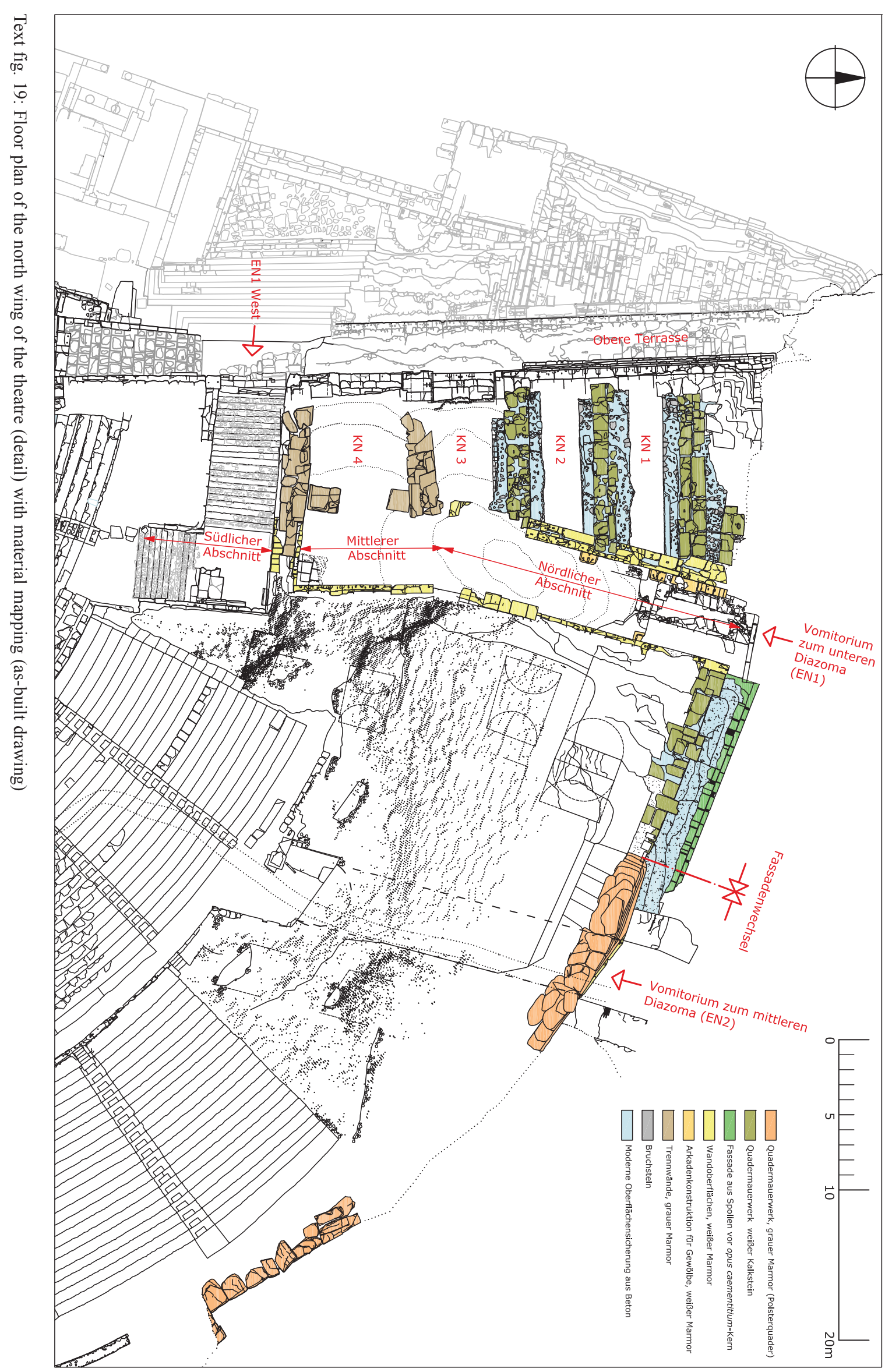


Due to the sloping topography to the north, it was approximately $35 \mathrm{~m}$ high when measuring from the base of the terrace to the surface of the portico. The step-like widening of $0.50 \mathrm{~m}$ over a $17 \mathrm{~m}$ distance and the enlargement of the terrace in front from 2.90 to $3.30 \mathrm{~m}$ made it possible to increase the footprint and the load transfer capacity of this highest portion of the facade in order to gain more stability.

The stairway EN1 West which leads to the lower vomitorium shows another structural connection with the upper terrace. Its former $11 \mathrm{~m}$ high, barrel-vaulted west portal was laterally framed by massive marble ashlars $^{128}$. The lowest step at the foot of the stairs lies on the surface of the terrace. The upper end of the flight of stairs on the central platform is, among other things, identified by remnants of preserved floor slabs and presumably were part of the surface of vomitorium EN1 (Pl. 450 Fig. 801; 451 Fig. 802). Additionally, the position of the former marble steps can be reconstructed due to the still visible contact surfaces on the sides walls (Pl. 14 Fig. 23). Since the flight of stairs was not arranged orthogonally to the north analemma, the side walls differ in length. This difference of approximately $0.40 \mathrm{~m}$ compensated for by a slightly conical arrangement of the lower marble stairs.

The lower staircase EN1 and the southern portion of vomitorium EN1 along with the flight of stairs leading to the lower diazoma present a uniform construction measure and were built in connection with the structure of vomitorium EN1. The need for stairs on the west side might be partly due to the expansion of the west facade of the theatre. Because of the now very long analemmata, the main public entrances to the north and south stands could only be reached from the west over longer distances. In the south, accessibility was even more difficult due to the terrain. With the placement of steps on the west side (EN1 West, ES1 West) direct access to the streets and to the facilities west of the theatre was established.

Completion of the north wing by Emperor Domitian in $92 \mathrm{AD}$ is known through fragments of a ca. $12 \mathrm{~m}$ long building inscription which were found on the upper terrace in front of the north analemma, as well as west of $\mathrm{it}^{129}$. R. Heberdey was already able to group the dislocated and inscribed ashlars from running as well as tie courses and realized their connection with the course of ashlars on the north wing of the cavea, although the exact position of the inscription on the facade could no longer be determined (Pl. 451 Fig. 803).

For subsequent periods of use of the theatre, various structural measures and alterations, which are detectable on the north wing, were the result of reduced stability in the region of both vomitoria and the external northern wall ${ }^{130}$.

\section{South wing of the theatre}

As with the north facade of the theatre, similar structural evidence indicating an expansion of the upper tiers in the south wing are evident (Tab. 127). The more recent portion of the outer wall starts here, just east of the vomitorium $\mathrm{ES} 2(\mathrm{Pl} .2)$; as in the northern wing the facade is characterized by a modification in material and appearance (Pl. 433 Fig. 765; 452 Fig. 804). Following the slope upwards the older facade consisted of grey marble ashlars with the cushion shaped surface; the facade heading west and downwards consisted of white limestone ashlars with a smoothed surface (Plan 5). Both facade segments are interlocked. West of the access ES2 to the middle diazoma a detail has been preserved on an extended portion of the facade: the combat area cornice of the barrel vault was apparently continued as a horizontal profile on the south facade of the theatre (P1. 452 Fig. 805).

The slope of the Panayirdag is higher in the south half of the theatre; consequently the area was more extensive and could be used for seating. However, for the Hellenistic koilon a substructure was necessary for the upper tiers of the west wing, for which no information has been recovered. As part of the expansion of the tiers hollow chambers made of opus caementitium replaced the substructure. In comparison with the north

\footnotetext{
${ }^{128}$ Two corner ashlars of the portal on the south side was a decree dating to the time after the accession of Antoninus Pius in 138 AD and also indicates the approval decision of the proconsul (IvE 21; compare HeBERDEY u. a. 1912, 36. 107-108). The lower of the two ashlars is still located in situ; the other, originally upper ashlar can now be found in the rock garden opposite the northern analemma. I thank H. Taeuber for the oral translation of the inscription and for the clarification of its content. See also Cap. 8.6.2.

${ }^{129}$ IvE 2035. Compare Heberdey u. a. 1912, 36-37. 160- 161. See also Cap. 8.6.1, No. 3 and Cap. 8.6.2.

${ }^{130}$ Cap. 11.3.4.
} 
wing, however, the south wing shows that an inner wall of opus caementitium was added to the existing outer wall of cushion shaped ashlars (P1. 453 Fig. 806).

With the installation of the vomitorium ES2 to provide access to the middle diazoma the south wing of the theatre starts to the west and was constructed by an arrangement of a series of superimposed substructure chambers. Large and only coarsely dressed ashlars were used for the supporting walls under the chambers, which at the same time exhibit the greatest height. R. Heberdey and W. Wilberg suggested that these ashlars could have been reused from the Hellenistic structure ${ }^{131}$. Opus caementitium was first used for the barrel vault, the partition walls, as well as the higher chambers (Pl. 453 Fig. 807).

As described for the north wing, above, two barrel-vaulted entrance corridors (ES 1, ES 2) were integrated into the new construction to the south. Outside the theatre, they are connected by an external staircase measuring up to $8.90 \mathrm{~m}$ wide, and are also connected to the upper access corridor ES3 (Plan 1). More equal access to the vomitoria was possible by way of the stair landings. The lower vomitorium ES1 was created as a high, barrel-vaulted passage measuring ca. $42 \mathrm{~m}$ in length and $4.70-4.90 \mathrm{~m}$ in width. In contrast to that in the north (EN1), however, the corridor ran in a linear fashion behind the southern analemma and was characterized by only two segments with differing vault heights. In the $20 \mathrm{~m}$ long southern section the spring of the stone vault's arch lay 5.70 to $5.80 \mathrm{~m}$ above the surface in the vomitorium. The access was flanked by three chambers on the west side. The chambers were accessed by doorways leading from the corridor. However, all that remains in situ are the lower courses of the ashlar walls as well as fragments of the profiled marble door frames ${ }^{132}$. The northern section of the vomitorium arched over a staircase whose western access opened onto the so-called Marmorstraße (ES 1); the starting point of the stone vault is offset downwards by ca. $5.70 \mathrm{~m}$. In order to reconcile the differing crown heights of the higher and lower vaults in the vomitorium, a shield wall was necessary. The stones supporting the shield wall which were orthogonally oriented to the corridor wall are still found in situ (Pl. 454 Fig. 808). A similar structural solution to reconcile different crown heights of vaults is also known at the theatre in Miletus (Pl. 454 Fig. 809).

As mentioned above, the three southern entrances to the theatre were interconnected by a monumental staircase along the outer wall. R. Heberdey and W. Wilberg assumed that the access ES1 (and therefore the lower landing of the outside stairs) was connected to a road proceeding through the southern urban area, whose supporting western wall is constructed in combination with the southern corner of the theatre building ${ }^{133}$. Findings in connection with the most recent archaeological excavations of the external staircase reinforce this assumption, although structural confirmation is still lacking ${ }^{134}$. The upper end of the stairs and the platform in front of the access corridor ES 3 was connected to the remaining street system by the $>$ Akademiegasse $<$ which joined the theatre from the south. In contrast and according to current knowledge, the entrance (ES 2) to the central diazoma had no direct connection to the road network south of the theatre; rather, it could only be reached indirectly by the staircase. On the exterior archivolt of the vomitorium T. Flavius Montanus is named as the sponsor of the construction work ${ }^{135}$.

Another feature of the exterior stairs concerns the change in material in the stair covering, which corresponds with the two previously mentioned portions of the southern exterior wall. Thus, treads of the upper flight of stairs between entrances ES3 and ES2 consist of the same grey marble as the cushion-shaped ashlars of the facade (Pl. 434 Fig. 766). White marble was used for the lower stairway between entrances ES2 and ES1 which is divided into two flights of stairs by a narrow landing (Pl. 455 Fig. 810). The Aristion aqueduct exits the building at a distance of approximately $4.40 \mathrm{~m}$ east of the entrance ES1 running underneath the exterior staircase and through the urban area to the south until it reached the Nymphaeum Traiani. Directly at its exit from the facade, the aqueduct was apparently covered with the stone treads of the staircase (Pl. 163 Fig. 333; 276 Fig. 562; Plan 5).

As was the case in the north, the addition of the theatre's south wing in the upper levels can be traced to the analemma. However, the ca. $58.20 \mathrm{~m}$ long southern analemma is divided into two main sections which display different facade construction and slight variations in the linear alignment of the wall sections, whereby the inner portion is subdivided again, as seen in the north (Plan 8).

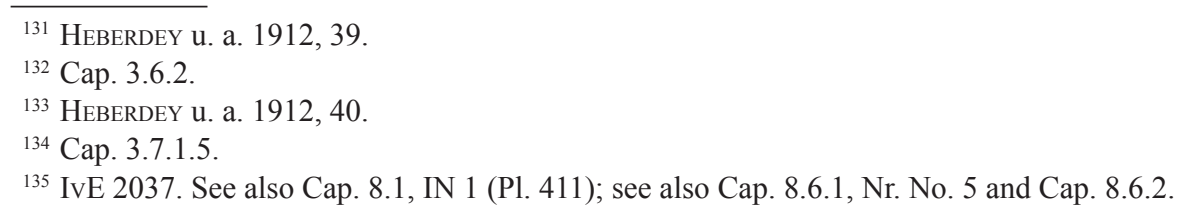


The inner northern wall segment of the south analemma also commences at the first row of orchestra-side seating above orchestra wall X and extends to the southern limit of stairway ES1 West, which represents an extension close to the support wall of the central diazoma. Here the facade is similar in design to the inner southern wall portion of the north analemma, namely, successive rows of alternating orthostats and small header courses. Although the size of the blocks do not quite match, the uniformity of the walls' design is obvious ${ }^{136}$. Also similar to the northern analemma is how the facade veers to west by $0.50 \mathrm{~m}$, approximately $9.90 \mathrm{~m}$ from its start at the orchestra. The large inscription which dates to $104 \mathrm{AD}$ and describes - in six columns - the donation of C. Vibius Salutaris was located on this inner wall area which rests on the parodos covering and which was consequently rebuilt after the relocation of the south parodos ${ }^{137}$. Only the lower orthostat and header courses remained in situ after the inscribed blocks were removed by J. T. Wood sometime between 1866 and 1868 (Pl. 455 Fig. 811; 456 Fig. 812). The missing blocks were replaced with quarry stone masonry during a restoration phase. The original wall core, and substructure of the radial staircase T11 to the east are currently not visible. As well, documentation of the wall area before its restoration does not exist. In a few areas, however, it is apparent that opus caementitium was used, as was seen in the north wing. It is striking that the horizontal joints dividing the adjacent wall area to the north and south are different in the areas situated above the parodoi, although the wall construction of orthostats and header blocks is the same. In the wall area just south of the south analemma the outer shell of orthostat and header courses meshes with a masonry core of grey marble ashlars, which in turn is backfilled with opus caementitium (Pl. 456 Fig. 813) $)^{138}$.

In the area of the western staircase leading to the lower vomitorium a row of header blocks can be seen with dowel holes arranged on its top surface for attaching the next course of orthostats; this indicates that the facade of the analemma originally continued here (Pl. 457 Fig. 814). The installation of the stairway ES1 West is first know in connection with the extension of the southern wing of the building and the establishment of the vomitorium ES1. For the later installation of the massive, vertical ashlars bordering the opening in the facade of the staircase on the north side, it was necessary to incorporate them into a course of header blocks (Pl. 457 Fig. 815). It can no longer be confirmed whether the southernmost preserved ashlar was part of the former building's corner, or if this section of the facade extended further to the south. After the construction of the stairway, the remaining ashlars of the header course served as the foundation for the no longer preserved marble treads. As in the north, the original height of the steps is still visible by way of the contact surfaces seen on the side walls (Pl. 458 Fig. 816).

The second facade section to the south consists of nearly consistent ashlar masonry erected on a vaulted cushion-shaped base. This part of the facade is divided by three pilasters which protrude a maximum of $0.60 \mathrm{~m}$ from the facade surface. While the two northern pilasters are almost equally broad (3.28 and $3.32 \mathrm{~m})$, the southernmost one was more solidly built $(3.75 \mathrm{~m})$ and served as the corner of the theatre structure. The pilasters, however, did not extend all the way to the top of the analemma's wall. Various architectural fragments were found in front of the facade by R. Heberdey and W. Wilberg, and indicate an upper pilaster crown ahead the rearward ascending wall (Pl. 458 Fig. 817) $)^{139}$. An honorary inscription which was probably located on the central pilaster suggests that statues of L. Vibius Lentulus and T. Flavius Montanus were situated above the pilaster terminal ${ }^{140}$.

As was evident in the north wing, a change of construction material is evident from the beginning of the second facade section on the south side-wall of the staircase ES1 West. All architectural components which were visible in very public areas, such as the analemma, or the upper levels of the vomitoria, were made of white marble. There are, however, differences in the internal construction. As described above, the core masonry of the south part of the first facade section consisted of grey, large-scale ashlars. Mainly white lime-

\footnotetext{
${ }^{136}$ On the similarity of the orchestra-side north and south portions of the analemma already indicated in De Bernardi FerRERo 1970 , 59-60.

${ }^{137}$ IvE 27, 167-222. For the arrangement of the inscription and wall articulation compare Heberdey u. a. 1912, 128. See also Cap. 8.6.1, No 4 and Cap. 8.6.2.

${ }^{138}$ During the consolidation work carried out in 1995 and 1996 ashlars protruding from this core masonry were supported by quarry stones (>Mauerplomben $<$ ) (KARwiese 1996, 29-31 Fig. 17; KARWIESE 1997, 47 Fig. 32).

${ }^{139}$ Heberdey u. a. 1912, 38.

${ }^{140}$ IvE 2061. Also Cap. 8.6.1, No. 6 and Cap. 8.6.2.
} 
stone, however, was used for in the second facade section, for the partition walls of chambers KS1 to KS3, which flanked the corridor, as well as the inner wall face of the analemma (Pl. 459 Fig. 818).

In a later phase, foundation ashlars of the southern portion of the facade were partially removed, and in addition to the tread in front of the south analemma it matched the currently still visible level of the so-called Marmorstraße (Pl. 459 Fig. 819).

That construction of the south wing of the theatre was completed in the period between 102 and $112 \mathrm{AD}$ is known through several inscriptions and falls within the reign of the emperor, Trajan. A building inscription is located on the outer archivolt of the central diazoma's vomitorium ES2 and remains partially in situ ${ }^{141}$. Another block which evidently repeats the building inscription came to light during the most recent investigations in the theatre ${ }^{142}$. Fragments from two inscriptions linked to the completion of the theatre were also found in front of the south analemma, at the foot of the middle pilaster as well as in front of the southern corner of the theatre (Pl. 460 Fig. 820. 821) ${ }^{143}$. In all these inscriptions Titus Flavius Montanus is named as the sponsor of the south wing construction and as the scompleter/ of the theatre. The text of the inscription presumably attached to the middle pilaster of the southern analemma indicates that the building was inaugurated during his priesthood and that gladiatorial contests, as well as animal hunts were organized ${ }^{144}$. Also from this time period is the inscription, dated to $104 \mathrm{AD}$, on the south analemma naming C. Vibius Salutaris as sponsor and describes, among other things, an elaborate procession from the Artemision to the theatre for the purpose of donating votive offerings. This could also be an indication that the re-dedication of the theatre after the completion of the extensive expansion more likely dates to the first decade of the $2^{\text {nd }}$ century $\mathrm{AD}^{145}$.

\section{Further Changes in the auditorium - lower diazoma and the Aristion aqueduct}

In addition to the enlargement of the koilon towards the west by the above-mentioned extension of the north and south wings, other structural alterations can also be confirmed; these also can be dated to the major reconstruction phase that took place from the time of Domitian to Trajan (Tab. 127). These include the widening of the lower diazoma, as well as the relocation of part of the Aristion aqueduct through the stepped benches.

In considering the diazomata, it is noticeable that the appearance of the three circuits differs from one another. The lower diazoma has its own character, in terms of the wall decoration and the horizontal >zoning In analyzing the individual finds, two building phases for the circuit can be identified ${ }^{146}$.

In its first phase the diazoma had an average clear breadth of $1.80 \mathrm{~m}$. The passage width would have been reduced to ca. $1.00 \mathrm{~m}$, if the lower row contained seating. This situation was modified by reusing base ashlars to offset the diazoma wall by ca. $0.50 \mathrm{~m}$ against the upper tier. At the same time the surface of the approach was raised (Pl. 97 Fig. 192; 460 Fig. 822). Overall, a clear width of ca. $2.30 \mathrm{~m}$ (average) up to the ima cavea could be achieved by this enlargement ${ }^{147}$.

Various considerations exist for the second phase in regard to the presentation of the diazoma at its transition to the lower tiers. In addition to the arrangement of the seats ${ }^{148}$, particular mention should be made regarding the erection of statue bases in connection with C. Vibius Salutaris' donation, as outlined in the

\footnotetext{
${ }^{141}$ IvE 2037. Compare Heberdey u. a. 1912, 40-41. 161. Also Cap. 8.6.1, No. 5 and Cap. 8.6.2.

${ }^{142}$ Cap. 8.1.

${ }^{143}$ IvE 2061. 2062. Compare Heberdey u. a. 1912, 41. 174-176. Also Cap. 8.6.1, No. 6. 7 and Cap. 8.6.2.

${ }^{144}$ P. Scherrer concludes that Montanus may have directed the fifth (105 AD) or sixth (109 AD) Balbilleia, Compare with SCHERRER 1997, 114. I extend my thanks to H. Taeuber for the oral translation of the inscription and clarification of its content.

${ }^{145}$ As part of the Trajanic construction activities in Ephesus, SCHERRER 2008, 53 dates the completion of building work at the theatre from 104-105 AD.

${ }^{146}$ For a detailed description and evaluation of the results see LIEBICH - STYHLER 2009, 469-481. The results of the archaeological test trench undertaken by St. Karwiese in 1998 at the entrance platform of the vomitorium EN1 at the lower diazoma yielded no connection with the construction phases. The whole area is strongly reshaped by modern restorations and reconstructions see Cap. 3.5.1.4.

${ }^{147}$ Cap. 3.4.1.2 and 3.4.1.3

${ }^{148}$ A row of benches on the lower diazoma is indicated by St. Karwiese, but not described in detail (SCHERRER 1995, 162). As part of the current building research of the auditorium, more bench fragments were found and attributed to the theatre. Varying prefabrication of building components indicates differing placements that cannot be clearly determined at this time.
} 
above-mentioned inscription ${ }^{149}$. Verifications of the above considerations are currently not possible due to the high level of modern remodelling and the existence of only a few in situ areas at the inner edge of the diazo$m a$. Another design option is indicated by the modern reconstruction of the diazoma by the direct connection to the entrances of the north and south vomitorium (EN1, ES1). Here, it is presumed that the relocation of the tiered seating slabs is connected with a recessed, rearward receiving area by the erection of balustrade panels. As discussed, a lack of $i n$ situ elements prevents the situation from being fully understood. At least the seating slabs used indicate the features of a regular connection to the panel cladding with the vertical facing to the seats above, and not for the bedding of a balustrade ${ }^{150}$.

Two aspects of the lower diazoma finds are revealing in regard to the issues regarding the extension and transformation of the auditorium. First, the continuous base ashlars of the diazoma wall functioned as the lowest step in the klimakes area; the signs of wear at the step edges indicate that a two-level auditorium (at least) existed in the first building stage.

The second aspect concerns the extent of the broadening measures that were undertaken. In the most southwesterly part of the diazoma - more specifically, in the area immediately following the entrance of the vomitorium ES1 to the former analemma - the preserved state suggests that the above mentioned relocation of the diazoma wall could not have occurred (Pl. 461 Fig. 823) ${ }^{151}$. This provides a spatial reference for the broadening of the diazoma in the entry area of the lower southern vomitorium ES1. If one considers that the visitors coming from the north and south from the two large corridors (EN1, ES1), and the stairways (EN1 West, ES1 West) first had to reach the radial staircase via the approach, it shows the increased functional relevance of the lower diazoma in terms of public access. The widening of the space drew on the limited spatial possibilities of this space.

Another major construction project involved the relocation of the aqueduct through the auditorium (Pl. 152 Fig. 309; 154 Fig. 314. 315; 155 Fig. 316. 317; 158 Fig. 322-325; 159 Fig. 326; 160 Fig. 327. 328; 161 Fig. 329 ; 162 Fig. 330). The section in the theatre is part of the $40 \mathrm{~km}$ long Aristion aqueduct which, among others, supplied the Nymphaeum Traiani, dating to before $114 \mathrm{AD}^{152}$.

The subsequent installation of the trench is visible through a change in materials in the substructure area around the eighth row of seats (P1. 461 Fig. 824) ${ }^{153}$. Here, two entrance openings into the aqueduct are almost symmetrical to the central axis of the theatre: in the north and south of the four kerkides, respectively. A full cross-section of the aqueduct is only visible in the southern part of the building, at the collapsed vault of the vomitorium ES1 (Pl. 462 Fig. 825). As a result of the current investigations of the theatre the entire course of the aqueduct is known, including its entrance in the north and its exit through the southern exterior wall of the theatre. While the exit of the aqueduct became visible after the 2009 excavation of the adjacent exterior stairs just south of the building, it entrance in the north remains buried just outside the building ${ }^{154}$. In the area of the wing built on top of the substructure chambers the route is spatially and structurally connected with the vomitoria EN2 in the north, and ES1 in the south.

The aqueduct runs through the building with a fairly constant interior width of ca. $1.00 \mathrm{~m}$. There are differences with regard to the tunnel height (which varies between 1.25 and $2.13 \mathrm{~m}$ ), and the construction of the channel vault. Four sections with three differing cross-sections can be defined over the aqueduct's $178 \mathrm{~m}$ length beneath the stepped benches of the theatre ${ }^{155}$. The walls of the trench are clad in opus signinum in varying heights (Pl. 462 Fig. 826).

At the axis of the two central radial stairs of the middle tier (T11, T13 Pl. 2) two clay pipes branch-off close to the above mentioned entrance openings in the ground just above the water line toward the orchestra; their interior diameter measures $0.225 \mathrm{~m}$ (Pl. 463 Fig. 827). The distance between the entrance openings and

\footnotetext{
${ }^{149}$ IvE 27. 28-35. Compare Heberdey u. a. 1912, 203; also Kolb 1999, 101-103. See also Cap. 8.6.1, No. 4 and Cap. 8.6.2.

${ }^{150}$ For cladding techniques in the bench structure see also STYHLER 2010.

${ }^{151}$ An archaeological test trench was dug for clarification of the spatially comparable situation in the north. However, due to the state of preservation and modern restorations, the original construction could hardly be traced, see Cap. 3.4.1.7.

${ }^{152}$ For aqueducts in Ephesus see ForchHeimer 1923; Alzinger 1987; ÖZIS - Atalay 1999; Wiplinger 2006a; Wiplinger 2006b. An up-to-date summary of the research history is in WIPLINGER 2006a, 15-17. With regard to the identification of the section of water line as part of the aqueduct of Tiberius Claudius Aristion compare WIPLINGER 2006a, 19-35. Regarding the Nymphaeum Traiani compare QUATEMBER 2011.

${ }^{153}$ Compare also WiPLinger 2006a, 34-35; WiPLINGER 2006b, 29-30.

${ }^{154}$ Cap. 3.6.1.

${ }^{155}$ For descriptions of the individual segments of the water line see STYHLER-Aydin 2010, 79-81.
} 


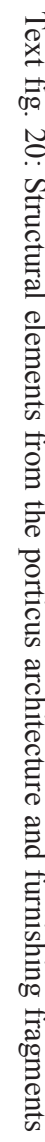

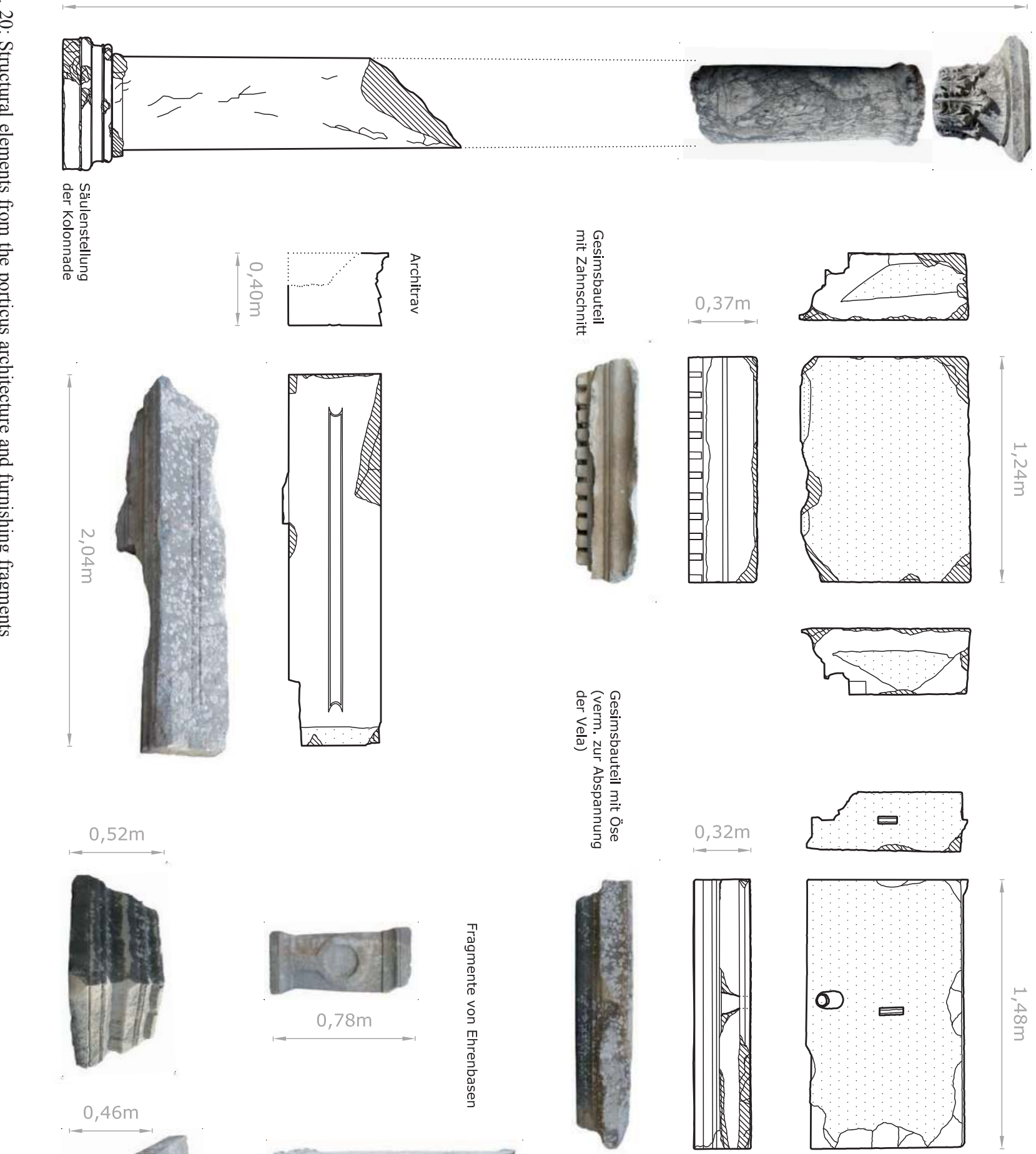


the branching-off of the clay pipes $2.25 \mathrm{~m}$ and $2.65 \mathrm{~m}$. The course of the clay pipes could also be detected at the intersections with the lower diazoma, where, in one case, a wall fragment of the pipe came to light under the steps of the klimax. Archaeological excavations of the lower diazoma confirmed the continuation of these clay pipes in the direction of the orchestra ${ }^{156}$. These, however, are not necessarily architectural evidence of the nautical games suggested in former research ${ }^{157}$. What currently remains unknown is where the lower exit points of the clay pipes are located, and how the water flowed from the Aristion aqueduct into these pipes. It is possible that a connection exists between the aqueducts entrance openings and the branching-off of the clay pipes for the necessary closing and unclosing of access.

As was visible through the archaeological excavation of the stepped alley in front of the southern exterior wall of the theatre, the water line exiting the building was only minimally disturbed beneath the stairs. The results of the archaeozoological analysis of the finds from this southern exit of the trench showed that at least the aqueduct course was abandoned from the south facade of theatre toward the Nymphaeum Traiani in the $5^{\text {th }} / 6^{\text {th }}$ century $\mathrm{AD}^{158}$.

\section{Porticus in summa cavea}

The upper part of the theatre formed a portico. Spatially, it can still be recognized on the slope side of the theatre, above twelve of the original twenty-two kerkides of the summa cavea (Plan 1). Because of its state of preservation, its western end toward the analemma can no longer be traced. The hall at the auditorium was designed with a colonnade, but whose architectural elements have only been preserved in fragments (Text fig. 20). Among the identified architectural components of the portico were columns with Attic bases, smooth, monolithic shafts at least partially composed of coloured marbles, and crowned by leaf capitals. Furthermore, fragments of architraves and dentils from the entablature as well as cornice fragments from the colonnade's entablature could be identified. Considering the large amount of architectural components that must have been used in the construction of the portico, the amount of components found on location is so low that a theoretical reconstruction is not possible. Overall, the current architectural investigations have brought new insights about the portico's spatial arrangement, and how it was decorated. It was confirmed that the colonnade was not erected on the upper diazo$m a$ (as originally indicated in the first publication ${ }^{159}$ ), rather that it was erected ca $2.50 \mathrm{~m}$ above the diazoma wall, as indicated by the foundation (P1. 463 Fig. 828; 464 Fig. 829). In addition, analyzing the architectural fragments that were found has resulted in determining that the columns rose to a height of about $5.30 \mathrm{~m}$. This measurement is also consistent with the results of the original height of the >blind « chambers located on the slope, behind the lower area of the porticus wall (Pl. 464 Fig. 830). Finds of another order of columns that were lower in height, bases with lateral grooves, and matching fragments of broken barrier plates could indicate an upper level of the hall ${ }^{160}$. This is confirmed by the rooms which were located above the >blind « chambers and along the slope side of the rear portico wall; they would also have opened onto an eastbound passage (Tab. 127) ${ }^{161}$. In any case, the hall was likely much higher in contrast to the proposed reconstruction of R. Heberdey and W. Wilberg; these new proportions changed our understanding of the overall appearance of the theatre.

The plan of the porticus gives the impression that to the north and south the structures on the bordering east wall were taken into consideration. Only the two middle quarters of the hall had a uniform width of 5.35 to $5.40 \mathrm{~m}$ (Plan 1). The size of the outer slope-side quarters were smaller, or affected by the projecting walls. Two small staircases connecting the hall and the cavea have been preserved; they were arranged parallel to the upper diazoma wall. Further possibilities of access to the auditorium do not seem to have existed.

However, on the slope side, multiple openings were created in the rear wall of the portico ${ }^{162}$. The entrance located close to the central axis of the theatre may have been the main entrance based on the size of its

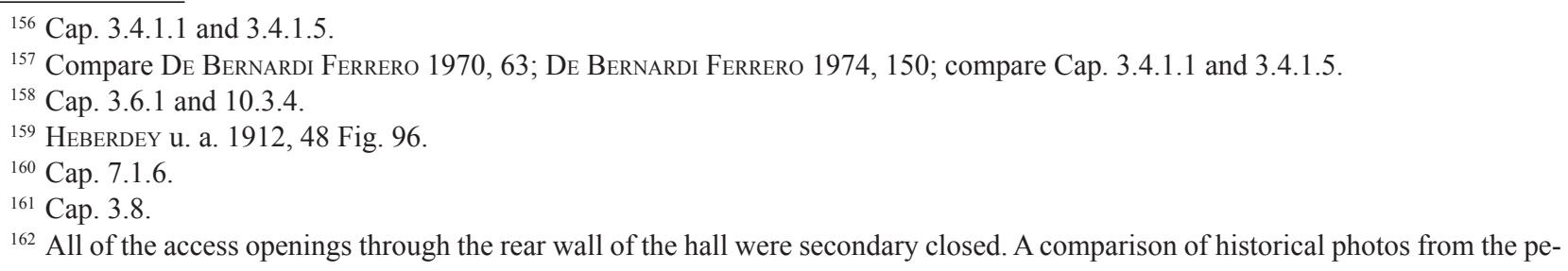


opening and its central location. The staircase constructed of spolia that one currently sees here is secondary (P1. 465 Fig. 831. 832). The entrances to the south and north of it are associated with a structure behind the rear wall of the portico that has, as yet, not been investigated further. Evidence gleaned from the 2009 excavations, however, may have provided some clues as to their possible function. The space exposed behind the rear wall of the portico has been identified as a thermopolion ${ }^{163}$. A use for supply purposes in connection with the portico is also conceivable for the chamber structure in the north and south slope areas.

As indicated by small remnants of preserved marble or tufa slab pavements, the walking surface in the hall lay approximately $0.50 \mathrm{~m}$ above the top edge of the (restored) supporting wall of the upper diazoma. Another indication is the terraced cliff of the slope which acted, in large areas, as the floor's substructure; its level corresponds to the bottom edge of the floor paving (Pl. 466 Fig. 833. 834).

The rear wall was essentially made of dressed stone in a mortar bond and was decorated with a marble incrustation; some marble fragments have survived, as well as metal anchors used for attaching the slabs to the wall. Cladding slabs measuring from 1.0 to $3.5 \mathrm{~cm}$ thick, and assorted horizontal profiles and rails were found among the fragments. Some slab fragments also show remnants of lettering ${ }^{164}$. In total, more than ten different types of marble - and especially coloured marble - were identified (Pl. 467 Fig. 835). As well, tragic masks were apparently attached to the wall; some of these came to light during work done at the museum in Selçuk between 1966 and $1972^{165}$. In a later phase the anchors used for fastening the marble slabs to the wall were struck off and the wall was plastered. Plaster fragments, some of which with traces of colour, come from this phase.

During the investigation of the portico, a high number of certain architectural fragments, such as the crowns of tripartite bases, pedestals, including some with victory wreaths, were found ${ }^{166}$. Some of the components are only worked in raw form. Other fragments bear honorific inscriptions. A spatial allocation of the remnants is no longer possible, yet, their great number suggests that they were part of the portico's decor. In this context the balustrade pillars, decorated with gladiatorial reliefs, should also be mentioned; they were discovered during the excavations in the north part of the theatre ${ }^{167}$, as well as along the south facade ${ }^{168}$. St. Karwiese already interpreted the pillars as decoration of the upper section of the theatre ${ }^{169}$.

Some considerations exist regarding the possible extension of the portico to the west. J. T. Wood reconstructed a row of columns around the entire sector (Text fig. 9), which was rejected by R. Heberdey and W. Wilberg because of space constraints ${ }^{170}$. Instead, they suggest a colonnade which would have occupied the section of widened floor plan in the area of the slope ${ }^{171}$. This reconstruction, however, is also founded on idealized assumptions. Thus, the 1912 floor plan with a recess on the south side of the slope is incomprehensive (Text fig. 11). In considering the actual floor plan of the portico gives more the impression that the unified front of the cavea relativized in irregularities in the course of the portico's back wall. From this perspective, one could imagine the continuation of the colonnade to the western analemmata, if the actually useable area of the hall was only on slope. These considerations, however, cannot be verified due to a lack of further evidence.

The question regarding the establishment of the portico cannot be answered clearly. Clues indicate that the first building activity on the upper diazoma occurred during the early imperial period or the $1^{\text {st }}$ century AD; as well, the first building phase of one of the two excavated areas east of the portico's rear wall can also be

riod during which the portico excavation took place (De Bernardi Ferrero, 1970, 58 Fig. 55. 56; 63 Fig. 73) with how it appears today suggests that some of the former access openings were re-opened in the 1960s/early 1970s, or that only fragmentary closing walls were reinstated at that time.

${ }^{163}$ Cap. 3.8.

${ }^{164}$ Cap. 8

${ }^{165}$ Atalay 1972, 47. 51 f.; Kayan 1972, 56-64; see also Cap. 7.1.6 and the contribution of M. Aurenhammer in: STYHLER-Aydin (in preparation); compare in general with MORETTI 1993a, 207-217.

${ }_{166}$ All architectural and decoration/furnishing fragments from the portico are dispersed. While the excavation and restoration of the inner edge of the portico and on the upper diazoma was carried out by the museum in Selçuk they were apparently stored. Proper documentation of this work in not known.

${ }^{167}$ Cap. 3.5.

${ }_{168}^{169}$ Cap. 3.

${ }^{169}$ KARWIESE SChlussbericht; see also Cap. 3.5.1; 7.1 .6 and Cap. 8, IN 7 (Pl. 413).

${ }^{170}$ Wood 1877, reconstruction of the floorplan opposite p. 68; HeBERDEY u. a. 1912, 16.

${ }^{171}$ Heberdey u. a. 1912, 15-16. 50 Fig. 98. 
dated to the $1^{\text {st }}$ half of the $1^{\text {st }}$ century $\mathrm{AD}^{172}$. How the area of the portico was configured at this time remains an open question.

The inscriptions referring to the major expansion of the theatre from the time of Domitian to Trajan do not indicate that the portico was completed. As part of an extensive construction program for the Romanization of the theatre, one could however expect the corresponding usual design of a portico completing the upper part of this structure. The fact that the previously mentioned space adjacent to the rear wall of the portico was used as a thermopolion since its second building phase (late $1^{\text {st }}$ or early $2^{\text {nd }}$ century AD) points to the likelihood of an architectural setting and usage of space in the upper part of the theatre ${ }^{173}$. The tragic masks found among the architectural fragments of the portico and which are presumed to have been attached to the rear wall date from the late $1^{\text {st }}$ century to the $1^{\text {st }}$ third of the $2^{\text {nd }}$ century $\mathrm{AD}^{174}$. Various inscriptions, which can be dated to 140 to $144 \mathrm{AD}$ as well as to the $3^{\text {rd }}$ century $\mathrm{AD}$, refer to the reparation of the petasos - a broad-rimed hat - in the theatre, which is thought to have referred to a lightweight canopy ${ }^{175}$. Mounting lugs, as used for guying ropes, can actually be detected on cornice fragments from the portico and the middle diazoma. The stylistic characteristics and quality of workmanship of the few preserved architectural elements, such as capitals and dentilled cornices, however, suggest a production date towards the middle of the $2^{\text {nd }}$ century $\mathrm{AD}^{176}$; these elements could also have come from a reparation phase. The inscriptions found range in date from the $2^{\text {nd }}$ century to the $1^{\text {st }}$ half of the $3^{\text {rd }}$ century $\mathrm{AD}^{177}$.

Only a few preserved theatres in Asia Minor show evidence of a porticus in summa cavea. These include the theatres in: Perge (dated to $120 \mathrm{AD}$, and the portico presumably around $200 \mathrm{AD}^{178}$ ); Aspendos (dated to 161-168 AD, secondary portico is undated); and Termessos (dated to the early $2^{\text {nd }}$ century $\mathrm{BC}$ and converted in the imperial era) $)^{179}$. Parallels for the currently determined information on the width and reconstructed height of the portico can be found in the theatres at Perge and Aspendos. Their halls were between ca. 5.20 and $5.70 \mathrm{~m}$ wide and ca. 8.00 and $7.50 \mathrm{~m}$ high, respectively ${ }^{180}$.

As described above, the most recent excavations just east of the Ephesian theatre uncovered a small section of a structure that is regarded as the thermopolion and whose function is thought to be connected with that of the porticus in summa cavea and the theatre ${ }^{181}$. Such examples in the context of antique theatres are rare. This is especially true for the area near the porticus in summa cavea. It is apparent here, that a promising possibility exists for future archaeological and structural-historical research that will uncover new insights about the function and utility of these spaces in the context of ancient theatres.

${ }^{172}$ Cap. 3.4.3 and 3.8.6

${ }^{173}$ Cap. 3.8.6.

${ }^{174}$ I thank M. Aurenhammer for this information. A detailed presentation of the results by M. Aurenhammer in STYHLER-AYDIN (in preparation).

${ }^{175}$ IvE 2039-2041. See also Cap. 8.6.1, No. 9-11 and Cap. 8.6.2. R. Heberdey interpreted the term petasos as >canopy< that was made up of individual webs and that could be mounted on ropes (HEBERDEY u. a. 1912, 162). R. Graefe also followed this interpretation in his investigation of canopies of Roman theatres and also made suggestions as to how the canopies were erected in the theatres of Asia Minor (Graefe 1979, 15. 174 Fig. 196; 175 Fig. 197). Conversely, J.-Ch. Moretti denies that the term actually denotes a canopy, and also denies the existence of a velum in the theatre of Ephesus, as no relevant evidence is detectable (MоRETTI 1993b, 137-140; compare also GREEN 1995, 32). The upright ashlars on the edge of the orchestra and in the center of the lower tiers described by R. Heberdey and W. Wilberg who connected them with the erection of a canopy (১baldachins $\varsigma$ ) over the place of honour and not with a canopy (HeBerdey u. a. 1912, 45 with Fig. opposite p. 17). Compare Cap. 10.2.4.3. Recently further evidence regarding the setting up of posts in the lower diazoma have been confirmed. The results will be presented in STYHLER-AYDIN (in preparation).

${ }^{176}$ I would like to thank G. Plattner and H. Thür for their information.

177 Cap. 8.2.

${ }^{178}$ Sear 2006, 372-373; Ciancio Rossetto - Pisani Sartorio 1994-1996, Vol. 3, 357-357; De Bernardi Ferrero 1974, 241; De Bernardi Ferrero 1970, 146-157 Pl. 28-30.

179 Aspendos: Sear 2006, 366-367; Ciancio Rossetto - Pisani Sartorio 1994-1996, Vol. 3, 393-394; De Bernardi Ferrero 1974, 241; De Bernardi Ferrero 1970, 173; Termessos: Sear 2006, 378 f.; Ciancio Rossetto - Pisani Sartorio 1994-1996, Bd. 3, 443; De Bernardi Ferrero 1974, 241; De Bernardi Ferrero 1969, 32 f.

${ }^{180}$ De Bernardi Ferrero 1970, Pl. 28. 31; 32A.

${ }^{181}$ Cap. 3.8. 


\section{Summary}

After the completion of the extensive renovation and expansion, the theatre presented itself as follows: at the foot of the Panayırdağ, the semi-circular, three-tiered auditorium rose $30 \mathrm{~m}$ over the orchestra. It maximum diameter was approximately $150 \mathrm{~m}$. The massive stepped structure is bounded on the west by the analemma$t a$, which each measured approximately $60 \mathrm{~m}$ in length. Between them lay the three storey, almost $42 \mathrm{~m}$ long stage building.

The still traceable layout of the auditorium consisted of eleven wedge-shaped sectors in the lower tier, and in twenty-two for both the middle and upper tiers. The number of seating steps varies in each tier; after the imperial era conversions including the diazoma, there were eighteen in the lower, and twenty-two for the middle and twenty-one for the upper tiers. Based on the existing seating, a theoretical determination of the theatre's capacity numbers 20,000 spectators ${ }^{182}$.

In consideration of its functionality, the auditorium in this phase is characterized by a clearly organized access system: the two lower tiers were accessible both to the north and south by vaulted corridors. Additionally, the lower tier could also be accessed from the staircases to the west. An older portal in the south is located on the top tier. On the south side a wide external staircase connects the three entrances with one another. A similar solution is presumed for the northern entrances. The upper end of the theatre is defined by a portico, that extended at least to the slope area.

\subsubsection{Modifications and Repairs during the Antonine Period}

Two copies of an inscription ${ }^{183}$, dating to $140-144 \mathrm{AD}$, were embedded in the upper area of the ramps (Ramp N, Ramp S). Based on this inscription, the first Austrian researchers were able to attribute a number of architecturally traceable alterations in the orchestra area to the Antonine period, which may also be understood as modernization ${ }^{184}$. These alterations include a (safety) barrier in the orchestra, the building-over of the Hellenistic orchestra to accommodate a new drainage channel at a slightly higher level, combined with increasing the level of the orchestra floor, and a new marble cladding ${ }^{185}$. In the orchestra wall X, almost all access points to the radial staircase were sealed. Only the middle stairs could still be used, with access to the place of honour in the central kerkis of the lower tier, as was established by R. Heberdey and W. Wilberg. At the time of their research the remnants of a marble pavement and ashlars bearing post holes - possibly for the erection of a canopy ( $>$ baldachins $\measuredangle$ ) - were still preserved ${ }^{186}$. These can no longer be traced in today's restored condition.

Further modifications occurred at the parodoi entrance areas in the orchestra, and at the front of the proscenium $^{187}$. The structural changes described above have been interpreted as proof for the performance of gladiatorial, as well as nautical games in the theatre ${ }^{188}$. As the most recent research indicates, two clay pipes branch off toward the orchestra from the Aristion water line (see above; Pl. 93 Fig. 184. 185; 94 Fig. 186). Since the outlets into the orchestra are no longer preserved, no further hypotheses can be made. In general, the use of water in the orchestra would also be conceivable for cleaning. Using the orchestra as a basin would have justified the closure of some existing openings, but this cannot be traced in the structure itself ${ }^{189}$. The inscriptions indicate building activities for the creation or renewal of the petasos (Tab. 127) ${ }^{190}$.

G. STYHLER-AYdin

\footnotetext{
182 A width of $0.44 \mathrm{~m}$ per spectator was used for the calculation; compare Cianco Rossetto - Pisani Sartorio 1994, Vol. 1, 65.

${ }^{183}$ IvE 2039. Compare Heberdey u. a. 1912, 162-163. See also Cap. 8.6.1, No. 9 and Cap. 8.6.2.

${ }^{184}$ HEBERDEY u. a. 1912, 44-47.

185 The removal of the seats up to the level of the logeion, and associated with the erection of the orchestra wall, was also attributed to this phase in the first publication (HEBERDEY u. a. 1912, 44-45. 52). However, given the current state of the architectural findings, it seems this measure was more likely to have occurred during the extensive expansion phase from the time of Domitian to Trajan; see above: orchestra, parodoi and ima cavea; Cap. 3.3.

${ }^{186}$ Heberdey u. a. 1912, 45. 47 Fig. 95.

${ }^{187}$ Cap. 3.2.3 and 10.2.1.3.

188 De Bernardi Ferrero 1970, 63.

${ }^{189}$ Cap. 3.3.1 and 3.3.2.

${ }^{190}$ IvE 2039 (see above for discussion).
} 


\subsection{THE THEATRE IN THE LATE PERIOD}

\subsubsection{The Theatre Facade in the Late Period}

\section{SubSEQUENT USE (5 ${ }^{\text {TH }}$ AND $6^{\mathrm{TH}}$ CENTURIES AD)}

Numerous graffiti are preserved on the base of the first floor, and in which performances are partially referenced ${ }^{191}$. These can be dated to the $5^{\text {th }}$ and $6^{\text {th }}$ centuries AD, based on the actors' clothing. This proves that the stage was still being used for events in late antiquity.

\section{REPAIRS TO THE SCAENAE FRONS (IN ANTIQUITY)}

Repairs, dating to antiquity, are preserved in the scaenae frons structure. Parts of the cornice of the attica have been fashioned out of coffers, traces of which can be seen on the upper side of the cornice (P1. 468 Fig. 836. 837). A concave architrave of the third storey is broken into three parts (P1. 469 Fig. 838). Three architrave fragments which fit together bear clamp holes near the breaks, indicating that they were already repaired with clamps in antiquity. Thus, a repair phase - at least for the third floor - took place, but cannot yet be dated.

A. ÖZTÜRK

\subsubsection{The Stage Building in the Late Period}

Beam holes can be observed in practically all of the chambers. They occur at different heights and are not the same size. The holes are located throughout the east and west walls. Preserved beam holes to the right and left of the entrance door correspond to their counterparts on the east wall. The distances do not follow a regular pattern. It seems these holes may be associated with shelf-like structures, for storage purposes, placed on either side of the door.

Traces of usage were detected during the clearing of two chambers (E3 and E5) located between Chambers E1 and E8 (P1. 3 Fig. 3). In chamber E3 two pithoi that had been set in the ground, were excavated (P1. 24-26). They were filled with large ceramic fragments of tableware dating to the Neronian period ${ }^{192}$. The pithoi were covered by a layer of debris (SE 30) below the mortar bed for the brick tile pavement. Pottery and a coin from the time of Marcus Aurelius provide both a terminus ante quem for the filling of the pithoi, and a terminus post quem for the installation of the brick tile floor, in the late $2^{\text {nd }}$ century $\mathrm{AD}^{193}$.

A three-part basin in chamber E5 possibly dates to the $4^{\text {th }}$ century AD (P1. 28-30; 31 Fig. 52). It was formed of half-format bricks, covered both inside and out with a fine white plaster coating. The bottom of the basin consisted of a layer of clay tiles. This was abandoned in the $5^{\text {th }} / 6^{\text {th }}$ century AD, at the latest, and a new floor level of brick slabs was constructed over the remains of the pool. Repairs cannot be identified on the walls of the western extension. But traces of a different type of usage, or perhaps even function, in the late period are evident. Immediately south of the entrance to chamber E5 is a gateway of the Byzantine city wall, which was presumably constructed in the $6^{\text {th }}$ century AD. The theatre structure between this gateway and the entrance E3 acted as part of this fortification. It is very likely that the entrances to chambers E6, E7, and E8 were sealed in context with this change, and for Chambers E6 and E7 what might also have been associated with a general abandonment. There is a reinforcing wall along the west wall of chambers E7 and E8 (P1. 32 Fig. 54. 55; 33 Fig. 56). This factor also seems to be associated with the construction project. A chronological connection for the reinforcing walls and the city fortification wall cannot be established based on the finds from the backfill layers of the reinforcing wall in Chamber E7 alone. The finds (some of which dating into the $3^{\text {rd }}$ century AD) from the backfill of the reinforcing wall may be linked to a building project that had nothing to do with the construction of the Byzantine city wall and gate (P1. 51 Fig. 97); rather, it could represent reparation work

\footnotetext{
191 Roueché 2002b, 257.

192 Cap. 4.1.2.2.

${ }^{193}$ For dating see Cap. 4.1.2.2.
} 
following the earthquake of $262 \mathrm{AD}$ (Tab. 127). In any case, the entrances were closed off by the retraction of the reinforcement wall. A step constructed of bricks in front of the entrance to E5 is attached to the city wall and bears witness to the use of entrances now located within the walled area of city. This was temporary as the entrances to chambers E1 to E5 were also eventually closed with spolia. In the area between the chambers E4 and E5 (not between the Hellenistic chambers D4 and D5), spolia were used to convert passage C into a narrow corridor, measuring $0.75 \mathrm{~m}$. Remains of a massive opus caementitium fill were preserved in the upper area. Given its location, in close proximity to the Byzantine city wall and the gate, this fill could be linked to the remains of walls of a secondary structure - such as a tower - which was erected over the western part of passage $\mathrm{C}$.

M. Hofbauer

\subsubsection{Changes to the Orchestra and Stage Front}

By and large the orchestra remained as it had existed since the $2^{\text {nd }}$ century AD. The passages in the Antonine-era stage front were walled. The course of the two aforementioned pipelines, supplied by the Aristion aqueduct, could be traced in 2006 to the lower diazoma (Pl. 93 Fig. 184. 185; 94 Fig. 186). Based on structural findings, a connection with a filling of the orchestra with water cannot, at present, be verified ${ }^{194}$. The pipelines may have been associated with fountain fixtures, as is known in the middle diazoma; they could also have served for cleaning in connection with gladiatorial games.

M. HofBAuer

\subsubsection{Alterations in the Auditorium}

\section{North Wing Of The Theatre}

The first identifiable intervention in the north wing of the theatre took place in the entrance corridor EN $1{ }^{195}$. In its northern part, the barrel vault with the $11.0 \mathrm{~m}$ high sidewalls and an apex of ca. $13.35 \mathrm{~m}$ - and surely one of the highest vaulted areas in the theatre - there was a second lower vault or ceiling for reinforcement purposes ${ }^{196}$. Indented apparently somewhat from the north facade, the structure rested on presumably four arcades which were placed immediately in front of the side walls of the vomitorium (Pl. $470 \mathrm{Fig}$. 840). On the west side, the profiled doors and fanlights of the chamber entrances were partially obscured by this addition and may have been partially dismantled; yet, the chambers continued to be accessible and useable (Pl. 470 Fig. 841). One can reconstruct, from the still in situ parts of the arcade structure, that the peak height in the northern portion of the vomitorium would have been reduced by about one-third due to the additional barrel vault; it would also have corresponded, approximately, with the vault height of the central corridor section (Text fig. 21). Due to the high quantity of rubble, the arcade structure is only fragmentarily identifiable in the vomitorium ${ }^{197}$. The preserved visible parts of pillar bases and capitals and the impost area are worked in rough shape, their profiles had not been rendered. Although some signs of processing exist in the better preserved west wall of the vomitorium, these are not proof of anchoring points for the arcade in front of it. Based on the findings, it cannot currently be concluded whether the construction project was fully completed ${ }^{198}$. There is currently no direct evidence for dating this modification. St. Karwiese and I. Ataç took the $3^{\text {rd }}$ century AD into consideration and associated the described construction measures and later subsequent changes in the lower

\footnotetext{
${ }^{194}$ Cap. 11.2.2.2.

195 Cap. 11.1.3.

196 St. Karwiese assumed that the secondary construction was connected with a further level, see KARWIESE ARCHIV ÖAI, 5; KARWIESE $1999,26$.

${ }^{197}$ Cap. 3.5.1.

${ }^{198}$ An analysis of structural elements that were excavated (1993-1998) from the debris in the vomitorium (currently stored north of the theatre) in conjunction with further excavations could provide more detailed insight in the future.
} 
corridor with the historically attested earthquakes of $262 \mathrm{AD}$ and 359-366 AD (Tab. 127) ${ }^{199}$. Also relevant is that the analysis of pottery finds from the theatre can be addressed as rubble from the earthquake in the $3^{\text {rd }}$ quarter of the $3^{\text {rd }}$ century $\mathrm{AD}^{200}$. The structural evidence, however, cannot confirm at present whether the subsidiary arcade construction was the result of actual damage, or a preventive measure against the threat of instability in the highest part of the vomitorium.

The subsequent use of the northern and central corridor sections as a cistern may be considered, as evidence of the covered space still existed in the $5^{\text {th }}-6^{\text {th }}$ centuries AD (see below), although at the moment no further explanations are possible.

In the $4^{\text {th }}$ century $\mathrm{AD}$ extensive stabilization measures were undertaken on the northern exterior wall of the theatre (Tab. 127). Former research literature assumed that a number of historically attested, severe earthquakes occurred in the $3^{\text {rd }}$ quarter of the $4^{\text {th }}$ century AD in the eastern Mediterranean, that also shook Ephesus and affected the theatre ${ }^{201}$. Due to a lack of unequivocal archaeological evidence here, and for other Ephesian monuments, recent research seeks more concrete evidence and is critical of the overall findings regarding the earthquakes ${ }^{202}$. Crack patterns in the ashlar masonry of the northern facade, however, indicate forceful impact such as those caused by earthquakes. The massive consolidations were obviously trying to prevent parts of the outer theatre wall from collapsing.

Initially, the sensitive areas of the high facade openings of the vomitoria EN1 and EN2 in the exterior wall were secured. The entrance to the central diazoma (EN2) was sealed with a massive wall measuring $5 \mathrm{~m}$ thick (Pl. 146 Fig. 294; Text fig. 16). In addition, the outer wall was supported, on both sides, by buttresses orthogonally arranged on the north facade (P1. 148 Fig. 299. 300; Text fig. 17) ${ }^{203}$. There are indications in the lower vomitorium $\mathrm{EN} 1$ that at least the eastern opening soffit was reinforced for approximately $7 \mathrm{~m}$. It is possible that a narrow entrance is still preserved here (Plan 4).

Finally, a $2.00-2.60 \mathrm{~m}$ thick wall is thought to have been superimposed on facade between the two vomitoria. That this measure was planned at the beginning of the consolidation efforts indicates a connection with the western counterfort wall. The corner is already linked in the formation (Pl. 471 Fig. 842. 843). However, it seems that different materials were foreseen for the construction of this front facade, because the joints to the corner are comprised of rubble stone. The wall was, however, constructed with an outer masonry of marble spoli $^{204}$. At the interface with the lower vomitorium EN1, the new anterior facade already connected with the reinforcing wall at the eastern opening soffit, as is evident in the negative imprint visible in the core masonry composed of opus caementititum (Pl. 472 Fig. 845). The consolidation work can be dated by two building inscriptions; one was found in the closure wall of the vomitorium EN2, the other in the eastern counterfort wall ${ }^{205}$. The governor, Messalinos, is accredited with having restored the theatre's semi-circle (P1. 66 Fig. 127). All newly created facades in the north were built with white marble spolia and thereby reinforcing its representative character. Overall, these measures can also be seen as an indication for the efforts made to preserve the building.

Another security measure could be related to the extensive consolidation measures on the northern facade. Low, brick vaults were incorporated in the chambers KN1-KN3 which flanked the lower vomitorium EN1 on its west side (Pl. 2 Fig. 2; 127 Fig. 254. 255). They rested on the $0.90-1.00 \mathrm{~m}$ thick wall-facings that were constructed directly in front of the original chamber partition walls (Text fig. 19). The doorways between the corridor and the chambers were still in use, thus confirming the accessibility of these chambers ${ }^{206}$. Around

\footnotetext{
${ }^{199}$ Karwiese Archiv ÖAI, 5; Karwiese 1998, 25; Scherrer 1995, 162; AtaÇ 1999b, 431; AtaÇ 1997. Based on the finds, current research in Ephesus assumes that the city was devastated by a severe earthquake in the $3^{\text {rd }}$ quarter of the $3^{\text {rd }}$ century AD. It is still unclear as to which buildings were directly affected from damage or destruction (LADSTÄTTER - PÜlz 2007, 397; LADSTÄTTER 2002, 26-29).

${ }^{200}$ Cap. 4.5.1.3; 4.6.2 and 4.7.

${ }^{201}$ In summary LADSTÄTTER 2002, 29-31; SCHERRER 1995, 162.

${ }^{202}$ LADSTÄTtER 2002, 29-31.

${ }^{203}$ Cap. 3.5.1.3.

${ }^{204}$ Three structural elements with visible inscriptions were found amongst the spolia; compare Cap. 8.3, IN 12. 13 (Pl. 415 ); IN 14 (PL. 416).

${ }^{205}$ IvE 2043. 2044. Compare Wood 1877, 69; Heberdey u. a. 1912, 52. 164-165. See also Cap. 8.6.1, No.12. 13 and Cap. 8.6.2. Both inscriptions are no longer in situ.

${ }^{206}$ Cap. 3.5.1.3.
} 


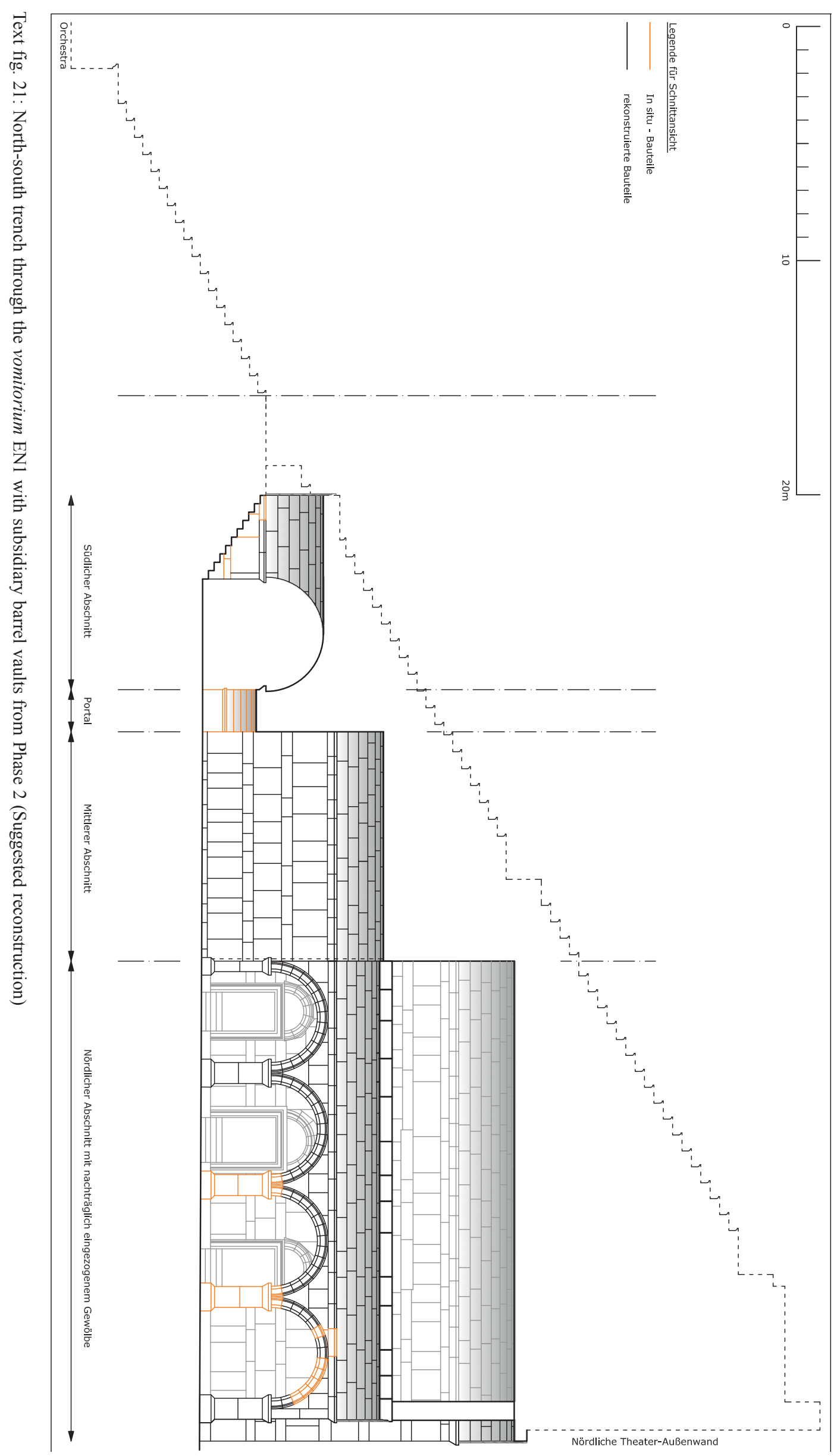


the middle of the $5^{\text {th }}$ century $\mathrm{AD}$, northern and central parts of the vomitorium $\mathrm{EN} 1$ were transformed into a cistern with a capacity of more than $350 \mathrm{~m}^{3}$ (Pl. 128 Fig. 256. 257) ${ }^{207}$. It was very likely fed by clay pipes leading from the Aristion aqueduct, that ran in front of the northern outer theatre wall.

Various modifications were required for converting a portion of this corridor into a cistern. The doors to the adjacent chambers, the portal to the southern part of the corridor and the north side of the vomitorium had to be massively blocked (Pl. 129 Fig. 260). All of these changes were done in mortar bonded masonry walls consisting of spolia and bricks; all walls orientated to the cistern were coated in a waterproof plaster. However, the original white marble corridor walls constructed in the orthostat/header style technique remained unplastered. The former marble floor of the vomitorium was deepened - in part to the level of the foundation of the corridor walls. A new floor of large format brick slabs with a gradient from south to north was installed. Both the aforementioned supply pipe from the east, as well as the cistern's drainage and the cleaning access are situated in the northern wall (Pl. 472 Fig. 845) 208 . Trenches in KN1 and KN3 showed that these adjacent chambers were intentionally filled with earth after their abandonment (Pl. 134 Fig. 270. 271). It cannot be confirmed whether this coincided with the sealing of the doors, or whether it was carried out at a later date $\mathrm{e}^{209}$.

The cistern was likely in use until the last quarter of the $6^{\text {th }}$ century $\mathrm{AD}$, based on the archaeological finds. From the early $7^{\text {th }}$ century $\mathrm{AD}$ the basin was filled by debris from the collapse of the vomitorium, or the tiers situated above $\mathrm{it}^{210}$.

With the modifications to the vomitorium EN1, direct access to the lower tiers from the north, as well as the usage of the chambers west of the corridor, was abandoned. The accessibility of the cavea in the north wing was henceforth limited to the L-shaped staircase which led from the west to the lower diazoma (via EN1 West).

\section{South Wing OF THE Theatre}

On the south facade, as well, the original entrances into the auditorium were later sealed (Tab. 127), although the character of the two lower vomitoria (ES1, ES2) differs from that of the upper corridor ES3 in terms of their closure (Plan 5).

The coverings of the southern staircase were dismantled and incorporated into the masonry of the outer wall of ES1 and ES2. The thickness of these closure walls corresponds to those of the neighbouring substructure chambers. In so far as can be determined from the preserved remains, the white marble ashlar blocks from the lower stairway were re-used for the lower vomitorium ES1 (Pl. 286 Fig. 582; 473 Abb. 846). The grey ashlars from the upper part of the staircase were used for the closure of the central diazoma (ES2) (Pl. 473 Fig. 847). The evaluation of the excavation on the >Stiegengasse indicates the walling-up of both entrances in the late $5^{\text {th }}$ to early $6^{\text {th }}$ centuries $\mathrm{AD}^{211}$. The pottery finds from the debris of chambers KS1 to KS3, which flanked the west side of the southern corridor (P1. 172 Fig. 352), date to the $3^{\text {rd }}$ century AD, but mainly to the $5^{\text {th }}$ and $6^{\text {th }}$ centuries $\mathrm{AD}$. The abandonment of these chambers is thought to date to the late $6^{\text {th }}$ century $\mathrm{AD}$. The importance of the vomitorium is thought to have diminished through its closure.

Moreover, the upper access corridor ES3 was sealed (P1. 219 Fig. 451; 441 Fig. 781). The wall was approximately $3.75 \mathrm{~m}$ thick and constructed of mortar bonded masonry made of quarry stones, bricks, and marble spolia - amongst which were many column fragments, possibly from the portico architecture. In addition to the recesses between the spolia and larger quarry stones, a thin layer of mortar was spread on the wall surface, with a slight horizontal concave moulding. Imprints in the mortar, sintered layers, and fragments of clay pipes on the facade near the portal indicate continued use of the platform in front of the former entrance ${ }^{212}$.

\footnotetext{
${ }^{207}$ Cap. 3.5.

${ }^{208}$ Further possible drains cannot currently be identified because of the massive debris in the cistern.

${ }^{209}$ Cap. 3.5.1.2 and 3.5.1.3.

${ }^{210}$ Cap. 3.5.1.

${ }^{211}$ Cap. 3.7.2.1; 3.7.2.3 and 3.7.3.

${ }^{212}$ Cap. 3.7.1.1 and 3.7.2.1.
} 
So far, the walling-up of the theatre's slope-side entrances is thought to be associated with its fortifying function in the Byzantine period ( $\mathrm{Pl} .1)^{213}$. The most recent investigations have shown that these measures should be evaluated differently. Protective measures in the south, or at least for the lower vomitorium ES1, cannot be ruled out. Particularly in the area around the southern facade opening, all of the preserved ashlars in the outer wall are badly damaged. Strong shocks are indicated by the vertical cracks and fractures, which in part led to the loss of some ashlars (Pl. 455 Fig. 810). These findings also fit well with the broad range of pottery from the theatre excavation, as well as the uncovering of the exterior staircase, which has been interpreted as rubble due to the earthquake in the $3^{\text {rd }}$ quarter of the $3^{\text {rd }}$ century AD (Tab. 127; Plan 15. 16) $)^{214}$. In contrast, the preserved part of the closure wall shows no damage.

The walling-in of the southern entrances to the theatre reduced the possibility of access to the cavea in the south wing (Plan 17), essentially to the western entrance (ES1 West). In addition, the southern exterior staircase became unusable in some parts through the removing of the covering blocs of the steps ${ }^{215}$.

\section{EAST End of The Theatre}

Structural changes can also be determined in the area of the portico during the late period, and can be traced particularly at the entrance openings. Although presumably dismantled to a large extent during the restoration work, some in situ settings, as well as historical photographs indicate that here, too, the entrances were walled-in with a mortar bonded masonry consisting of quarry stone, brick, and fragments of marble ${ }^{216}$.

G. STYHLER-AYDIN

\footnotetext{
${ }^{213}$ Hofbauer 2007, 74.

${ }^{214}$ Cap. 4.5.1.3; 4.6.2 and 4.7.

${ }^{215}$ Cap. 3.7.2.

${ }^{216}$ De Bernardi Ferrero 1970, 58 Fig. 55. 56; 63 Fig. 73.
} 


\section{Zusammenfassung und chronologischer Überblick}

Die aktuellen Forschungen zum Theater in Ephesos erlauben - ausgehend von Überlegungen zur Platzwahl sowie zu einem hypothetischen Vorgängerbau - eine chronologische Differenzierung von acht nachweisbaren Bau- bzw. Nutzungsphasen, die von der hellenistischen bis in die byzantinische Zeit reichen und einen Zeitraum von annähernd 800 Jahren beleuchten. Gegenüber der ersten Monografie zum Monument, die 1912 von R. Heberdey, G. Niemann und W. Wilberg verfasst und vom ÖAI publiziert wurde, liegen heute neue, detailreiche Erkenntnisse insbesondere zur Entstehung des Theaters, seiner Transformation unter römischer Herrschaft sowie zur späten Nutzung des Gebäudes in der byzantinischen Stadt vor. Aus der Gesamtbetrachtung der Ergebnisse aus Archäologie und Bauforschung sowie der Auswertung unterschiedlicher archäologischer Fundgattungen, wie Keramik- und Glasfunde, Terrakotten und Kleinfunde, Münzen, archäozoologische Funde, Skulpturen und Inschriften, resultiert ein anschaulicher Einblick in den Umgang mit dem Theater als stadtraumprägendes öffentliches Gebäude von Ephesos in antiker und spätantiker Zeit.

\section{PLATZWAHL UND HYPOTHETISCHER VORGÄNGERBAU}

Aus den aktuellen Grabungen erschließt sich der Baubeginn für das Bühnengebäude mit dem 2. Viertel des 2. Jhs. v. Chr. Wir können aber damit rechnen, dass zumindest der Bauplatz und eine vorläufige Gestaltung des Theaters schon mit der lysimachischen Neugründung festgelegt wurden. Auch von der Bauabfolge her erscheint es nicht unwahrscheinlich, dass die Vorbereitung des Berghangs für das Koilon und die Errichtung der Orchestra dem Bau des Bühnengebäudes vorausgegangen sind. Wie weit eine solche Herrichtung zurückreichen könnte und welche Intensität sie erreichte, muss offenbleiben, da wir für das Koilon keinerlei chronologische Hinweise auf die Errichtungszeit haben.

Dazu im Folgenden einige hypothetische Überlegungen: Das Theater liegt an der uralten Heiligen Straße, deren Verlauf die Planung des Gebäudes beeinflusst haben mag und welche im Stadtbild bis in byzantinische Zeit erhalten geblieben ist. Seine Lage am Westabhang des Panayırdağ macht sich eine natürliche Geländeformation zwischen den beiden Höckern des Hügels zunutze, die offensichtlich geodynamischen Ursprungs ist, und an der Sohle in einem nach Nordwesten auslaufenden engen Einschnitt und einem steil abfallenden Sedimentkegel endete, wobei die Geländekluft wasserführend war, wie aus der Position des Brunnenhauses hervorgeht. Mit der Errichtung einer über $70 \mathrm{~m}$ langen, Nord-Süd orientierten Terrassierung wurde der topografischen Situation am Hangfuß Rechnung getragen und dann jener Platz geschaffen, auf dem das monumentale hellenistische und später das kaiserzeitliche Bühnengebäude errichtet wurden. Auf die Gegebenheiten des Geländes ist wohl auch die festgestellte geringe Abweichung des Theaters von der Orientierung des hellenistischen Straßenrasters zurückzuführen, welche eine günstige Einbettung des gesamten Bauwerks erlaubt haben mag. Durch eine leichte Drehung der Ausrichtung der Terrassenmauer im Uhrzeigersinn wurde die Fundamentierung im abfallenden Gelände der Nordhälfte entscheidend erleichtert. Planimetrisch bezieht sich das Theater auf zwei insulae des hellenistischen Stadtplans, wobei es innerhalb des extrapolierten Verlaufs der Ost-West gerichteten Straßenzüge etwas nach Süden versetzt liegt. An den nach Westen gerichteten Analemmata deuten außerdem Baufugen darauf hin, dass hier das Raster der flankierenden Straßen auch noch in späteren Bauphasen Berücksichtigung gefunden hat. Dies trifft auch auf das Koilon und die Ostseite des Theaters zu, wo die verlängerte Achse der Nord-Süd führenden Badgasse mit der Lage der summa porticus korreliert. Erst die großangelegten Erweiterungen der römischen Kaiserzeit sprengten das alte Straßensystem.

Das kleine Brunnenhaus an der nordwestlichen Ecke des Bühnengebäudes wurde zuletzt von V. M. Strocka ${ }^{1}$ durch Vergleichsstudien mit der Sima des jüngeren Artemisions überzeugend in die Zeit um 280 v.

\footnotetext{
${ }^{1}$ Strocka 2005, 346 mit Anm.30; vgl. Kap. 3.1.4.1 mit Anm. 13.
} 
Chr. datiert. Es gehört somit in die Gründungszeit der Stadt, wofür auch seine Orientierung spricht. Leider wurde der ursprüngliche Befund zu diesem kleinen Bauwerk durch eine unsachgemäße Restaurierung zerstört, sodass wir seinen baulichen Zusammenhang mit der hellenistischen Terrassenmauer nicht mehr genau nachvollziehen können. Sein tiefliegendes Basisniveau ist wohl dem Quellhorizont ${ }^{2}$ geschuldet. Wir können daraus schließen, dass das von diesem Brunnenhaus nach Osten ansteigende Gelände schon in der Frühzeit eine gewisse Sicherung und Gestaltung erfahren hat, die als Vorläufer der monumentalen Terrassierung des frühen 2. Jhs. v. Chr. fungierte.

Die von W. Alzinger in den tiefen Sondagen der 1960er Jahre angetroffenen Steinsetzungen unter dem kaiserzeitlichen Bühnengebäude entziehen sich bis heute einer näheren Deutung. Sie liegen im nordöstlichen Sektor der hellenistischen Orchestra und scheinen in den natürlichen Schuttkegel verlegt worden zu sein. Wir können sie als Beleg dafür werten, dass die Niveauunterschiede zwischen der Ebene des Brunnenhauses und der späteren Orchestra durch Baumaßnahmen gestaltet wurden, der Hang jedenfalls gesichert war, schon bevor im 2. Viertel des 2. Jhs. v. Chr. die Terrassenmauer und das Fundament des Bühnengebäudes gesetzt wurden.

Auf der Ebene der Orchestra liegt - innerhalb des hellenistischen Orchestrakanals und deutlich unter seiner Oberkante - das Fundament U aus Kalkstein. Sein Kreissegment hat nicht nur den gleichen Mittelpunkt wie die Orchestra, sondern ist auch durch seine gleichmäßig gesetzte Innenkante auf diesen hin orientiert. Es endet im Norden und im Süden jeweils im gleichen Abstand von der kaiserzeitlichen Bühne, sodass es naheliegt, hier eine ursprünglich kreisrunde Steinsetzung anzunehmen, die im Zuge der kaiserzeitlichen Baumaßnahmen ausgerissen wurde. Die auffallend regelmäßig angeordneten rechteckigen Einarbeitungen mit den quer dazu verlaufenden länglichen Abarbeitungen lassen sich am ehesten als Hinweise auf eine Abschrankung aus Holz verstehen, die dem Verlauf der Orchestra folgte. Eine chronologische Einordnung oder die Zuweisung der Holzkonstruktion an eine bestimmte Phase der Orchestra-Gestaltung kann nicht belegt werden, weil durch die Altgrabungen der stratigrafische Verband völlig fehlt. Grundsätzlich wurde das Fundament U schon von W. Wilberg als Einfassung der ersten Orchestra, allerdings noch zeitgleich mit dem deutlich höher liegenden hellenistischen Ringkanal aus dem 2. Viertel des 2. Jhs. v. Chr. interpretiert $^{3}$. Es bietet sich an, in dem Steinkreis den Hinweis auf eine ältere Phase eines womöglich einfacheren Theaters und die planimetrische Grundlage aller nachfolgenden Phasen zu erkennen. Begrenzte die sorgsam gesetzte Innenseite den eigentlichen `Tanzplatz〈, wurde die Steinsetzung von dem Plattenbelag eines hangseitig anschließenden Umgangs bedeckt, wodurch auch die unterschiedlich vorspringende Außenkante des Fundaments U erklärt werden kann ${ }^{4}$.

Zusammenfassend sei daher die Hypothese formuliert, dass wir im Fundament $U$ die Begrenzung der ersten, provisorischen Orchestra, des Spielplatzes des Vorläuferbaus zum hellenistischen Theater erkennen können. Trifft diese Annahme zu, wäre damit auch der Beleg dafür gegeben, dass der Mittelpunkt der Orchestra seit der Gründung festgelegt und später nicht mehr verändert wurde. Dies wäre auch für die festgestellte Abweichung vom Straßennetz die einfachste Erklärung.

Es verbietet sich an dieser Stelle, weitergehende Überlegungen zur Gestalt dieser ersten Theater-Anlage anzustellen. Weder für die erste Skene noch für das Koilon haben wir annähernd verifizierbare Befunde.

\section{DIE ENTSTEHUNG DES HELLENISTISCHEN THEATERS}

Die hellenistische Skene wurde um 170 v. Ch. als monumentaler zweigeschossiger Bau konzipiert. Als Baumaterial für das Bühnengebäude wurde gelblich brauner Kalkstein, rote Brekzie und grauer Muschelkalk verwendet. Aus der weitgehenden Integration der hellenistischen Anlage in den großen kaiserzeitlichen Umbau hat sich der teilweise gute Erhaltungszustand des hellenistischen Bühnenhauses ergeben. Mit Aus-

\footnotetext{
${ }^{2}$ Wie auch an der unteren Kuretenstraße dürfte dieses Brunnenhaus ursprünglich von einem natürlichen Quellhorizont gespeist worden sein, der das Hangwasser der oben beschriebenen Rinne gesammelt hat. Durch die Veränderungen im Zuge des Theaterbaus könnte dieser versiegt sein, sodass die Wasserversorgung später über Tonrohrleitungen erfolgte, was durch die Reste in den Sondagen 5/05 und 6/05 (Taf. 37 Abb. 67; 38 Abb. 68) nahegelegt wird.

${ }^{3}$ Heberdey u. a. 1912, 14 Abb. 16.

${ }^{4}$ Vgl. die Überlegungen von M. Hofbauer zur Gestaltung dieses Umgangs in Kap. 3.3.3.
} 
nahme der Nordwestecke ist das Untergeschoss gänzlich erhalten, teilweise aber hinter dem Mauerwerk des römischen Bühnengebäudes verborgen. Die Zerstörungen am kaiserzeitlichen Gebäude hatten massive Auswirkungen auf die Bausubstanz des Obergeschosses, das wesentlich schlechter als das Untergeschoss erhalten ist. Doch sind auch hier wesentliche Details bis heute sichtbar, die eine Rekonstruktion der Skene hellenistischer Zeit erlauben. Mit über $41 \mathrm{~m}$ Länge ist das ephesische Bühnengebäude eines der größten in Kleinasien. Dementsprechend einzigartig ist auch die Raumaufteilung in einen langen, korridorartigen Raum in der Osthälfte und eine daran anschließende Kammernreihe im Westen. Es handelt sich dabei um zwei Gruppen von je vier Kammern, die durch einen Durchgang in der Ost-West-Achse mittig getrennt sind. Dieser Durchgang verband den Korridor mit einer circa $6 \mathrm{~m}$ breiten Fläche über der Theaterterrasse im Westen des Bühnengebäudes, für welche W. Wilberg die Gestaltung mittels einer ionischen Säulenhalle vorgeschlagen hatte. Bislang konnten jedoch keine baulichen Evidenzen für diese Halle gefunden werden. Während die inneren sechs Kammern Türen zum Korridor im Osten besitzen, sind die beiden äußeren Kammern des Bühnengebäudes nur von Westen her zugänglich. Sie fungierten, wie die Grabungen gezeigt haben, als Treppenhäuser, die das untere Geschoss mit dem oberen verbanden. Zwischen den beiden Treppenhäusern lagen im oberen Geschoss nur drei große, rechteckige Räume an Stelle der sechs Kammern und des mittleren Durchgangs, wie es dem Grundriss des Untergeschosses entspricht. Diese Räume waren durch weite Öffnungen vom Korridor aus zugänglich. Daneben war der mittlere Raum zusätzlich mit einem großen Fenster in der westlichen Außenwand ausgestattet. Es wurde nach oben hin durch einen Bogen abgeschlossen und ist die einzige bekannte Fensteröffnung des hellenistischen Baus. Äußerst dürftige Anhaltspunkte dagegen gibt es für die Ostfassade des Obergeschosses. Die im Mauerwerk der kaiserzeitlichen scaenae frons bewahrten Marmorpfeiler einer > Thyromatafront $<$ mit sieben Öffnungen gehören einer Umbauphase in späthellenistischer Zeit an. Eine für die ältere Phase vorgeschlagene Rekonstruktion, gleichfalls mit sieben Durchgängen, fügt sich gut in das Schema der Raumabfolge im Obergeschoss. In diesem Fall befinden sich die Türöffnungen der Räume zwischen den Treppenhäusern exakt in den Achsen des zweiten, vierten und sechsten $>$ Thyromak.

An die >Thyromatawand ist zur Orchestra hin wohl ein für Kleinasien charakteristisches Proskenion mit trapezförmigem Grundriss zu ergänzen. Davon lassen sich jedoch keine baulichen Spuren fassen; anstelle des Proskenion wurde in flavischer Zeit die Fassade der scaenae frons errichtet.

Die Orchestra wird durch einen umlaufenden Kanal begrenzt. Gemessen an der inneren Kanalwange hatte die hellenistische Orchestra einen Durchmesser von 12,35 m. Der dieser Konstruktion zugrundeliegende Kreis wird von der Ostmauer des Bühnengebäudes tangiert, jedoch durch das der Skene vorgesetzte Proskenion beschnitten. Der Orchestrakanal besteht, wie das Bühnengebäude, aus gelbbraunem Kalkstein. Vor der äußersten südlichen Klimax beginnend, verläuft er mit leichtem Gefälle um die Orchestra bis auf Höhe des hellenistischen Nord-Analemma. Hier knickt er nach Norden und führte unter dem Fußboden der Nord-Parodos aus dem Theater hinaus. Im Orchestrabereich verlief der Kanal ungedeckt, war aber in den Achsen der Klimakes mit Trittsteinen überbrückt. Wie der Boden dieser Orchestra gestaltet war, bleibt unbekannt.

Das Koilon verfügte bereits in hellenistischer Zeit über drei Ränge, wobei der in elf Kerkides unterteilte untere Rang mit der Prohedrie viel näher an den Orchestrakanal heranreichte als der heutige Bestand es zeigt. Im Anschluss an den unteren Rang wies das Koilon mindestens im Bereich des Berghangs bereits einen mittleren und oberen Rang auf. Auch abseits des Berghangs waren seit hellenistischer oder spätestens augusteischer Zeit Sitzbereiche aufgebaut, die jedoch nicht die Ausdehnung des unteren Rangs erreichten. Eine präzisere zeitliche Eingrenzung dieser Koilonflügel, und die damit verbundene genauere Einordnung in die Bauphasen, bleiben nach derzeitigem Wissenstand offen. Die Sitzbereiche waren mit weißen Marmorplatten verkleidet, von denen sich jedoch nur ein geringer Prozentsatz erhalten hat. Eine vergleichbare Verkleidungstechnik zeigt $u$. a. das nur zwanzig Kilometer entfernt liegende Theater von Metropolis, das um die Mitte des 2. Jhs. v. Chr. datiert wird.

Auch wenn die archäologischen Belege für das Theater somit aus jüngerer Zeit stammen, ist die Annahme berechtigt, dass die idealtypische Platzwahl für den Bau des Theaters auf den Entwurf der hellenistischen Stadtplanung des Lysimachos zurückgeht. Dafür spricht auch die allgemein akzeptierte Auffassung, dass bei der Anlage der großen hellenistischen Residenzstädte die lokale Disposition der raumgreifenden öffentlichen Anlagen in der Planung festgelegt und auch später in der Regel nicht verändert wurde, auch wenn sich dies, 
nicht zuletzt aufgrund des Forschungsstands, für Theaterbauten nicht immer in allen Einzelheiten nachvollziehen lässt.

So haben schon die ersten Ausgräber in Ephesos das älteste Theater an dieser Stelle angenommen, auch wenn die wenigen Mauerzüge unter der Skene kein aussagekräftiges bauliches Bild ergeben und uns daher jeder archäologische Nachweis für einen Vorgängerbau fehlt. Unter diesen Voraussetzungen könnte ein etwaiger früherer Theaterbau nur eine einfache Anlage gewesen sein, deren Orchestra wahrscheinlich auf höherem Niveau lag. Es ist naheliegend, dass eine solche Anlage im Zuge der tiefgreifenden Monumentalisierung des Theaters seit mittelhellenistischer Zeit vollständig abgetragen bzw. überbaut wurde.

Für das griechische Mutterland und die Ägäis lassen sich jedenfalls auf Delos, in Demetrias und im neugegründeten Sikyon Theaterbauten des 3. Jh. v. Chr. belegen. Weniger klar ist die Situation in Kleinasien, wo aus manchen Städten durchaus Theater frühhellenistischer Zeit bekannt sind (z. B. Aizanoi, Erythrai, Knidos, Milet, Phokeia und Priene), die Mehrzahl der monumentalen hellenistischen Anlagen wurde - soweit datierbar - aber offenbar erst ab dem 2. Jh. v. Chr. errichtet.

\section{DIE UMGESTALTUNG DER SKENE BIS 51/50 V. CHR.}

Eine erste Veränderung des hellenistischen Theaters lässt sich an der Ostfassade der Skene nachvollziehen, wo man die ursprüngliche Front durch eine marmorne Schauseite mit sieben Thyromata ersetzte. Die acht Marmorpfeiler dieses Umbaus wurden mit der Errichtung der flavischen scaenae frons nicht beseitigt, sondern ins Mauerwerk der Fassade integriert. Eine umfangreiche Liste der Agonotheten ${ }^{5}$ ist an den beiden äußeren Marmorpfeilern erhalten. Mit dem Beginn dieser Liste um 51/50 v. Chr. ist ein terminus ante quem für den Umbau gegeben. Das Ende der Liste im Jahr 17/16 v. Chr. belegt die Nutzung der hellenistischen Skene wenigstens bis in die augusteische Zeit hinein.

\section{FRÜHKAISERZEITLICHE BAUAKTIVITÄTEN}

Für die frühe Kaiserzeit können im Theater zumindest vereinzelt bauliche Aktivitäten nachgewiesen werden. So zeugen im Zuschauerraum archäologische Fundkomplexe auf dem oberen Diazoma sowie auf dem Mittelpodest des unteren vomitorium EN1 im Norden von Baumaßnahmen, deren vollständiger Umfang jedoch unbekannt bleibt. Sehr deutlich hingegen zeigt sich der sekundäre Einbau des oberen Zugangsportals ES3 im Süden, das in Fortführung der Akademiegasse in die Baumasse des südlichen Gebäudeflügels integriert wurde. Eine Inschrift ${ }^{6}$ an der Innenarchivolte des Eingangs weist die Maßnahme in augusteische bis frühtiberische Zeit.

\section{DIE UMGESTALTUNG DES THEATERS IN FLAVISCHER UND TRAJANISCHER ZEIT}

Eine tiefgreifende Umgestaltung erfuhr das ephesische Theater zur Zeit der Flavier. Während das hellenistische Bühnengebäude in den römisch-kaiserzeitlichen Bau integriert wurde, musste das Proskenion dem Unterbau für die prachtvolle Bühnenfassade weichen. Diese war als dreigeschossige Tabernakelfassade ausgeführt. Fünf Türen führten auf die Bühne. Die einzelnen Geschosse waren durch Nischen und Ädikulen gegliedert. Die ionische Säulenordnung des ersten Geschosses erhob sich über einer schmucklosen Sockelzone. Das zweite Geschoss folgt der Achsgliederung des unteren Geschosses. Die auf attischen Basen ruhenden Säulen erhoben sich über einer Sockelzone, die mit einem Erotenjagdfries gestaltet war. Unklar ist bislang noch die Säulenordnung des zweiten Geschosses. Das dritte Geschoss, welches in der älteren Forschung einer späteren Bauphase zugewiesen wurde, muss aktuell aufgrund stilistischer Untersuchungen zeitgleich mit den anderen beiden Geschossen datiert werden. Es war etwas zurückgesetzt und erhob sich mit seiner korinthischen Ordnung über der Attikamauer des zweiten Geschosses. Nach Westen wurde das

\footnotetext{
${ }^{5}$ IvE 9. Dazu auch Kap. 8.6.2.

${ }^{6}$ IvE 2033. Dazu auch Kap. 8.6.1, Nr. 1 u. Kap. 8.6.2.
} 
Bühnengebäude um eine zusätzliche Kammernreihe erweitert. Mit Ausnahme des mittleren Durchgangsbereichs und der beiden äußeren Kammern gab es zu den hellenistischen Räumen weder im Unter- noch im Obergeschoss Verbindungen. Der Abschluss der kaiserzeitlichen Kammern nach oben ist heute nicht mehr erhalten. Aus dem Baubefund geht allerdings hervor, dass diese Kammern deutlich höher anzunehmen sind als die Räume des hellenistischen Untergeschosses. Alle neu errichteten Kammern hatten ihre Zugangstüren im Westen und waren über einen schmalen Zugangsweg auf der rund $1,70 \mathrm{~m}$ breiten Terrassenmauer erreichbar. Aufgrund einer Bauinschrift ${ }^{7}$ am Architrav des unteren Geschosses kann die Einweihung der scaenae frons in das Jahr $85 \mathrm{n}$. Chr. datiert werden.

Die Front der kaiserzeitlichen Bühne besaß zunächst eine zierlich wirkende dorische Halbsäulenarchitektur mit einem Metopen-Triglyphen-Fries und einem darüber verlaufenden Konsolengesims. Die Front erinnert auffallend an hellenistische Vorbilder, ist funktional aber nicht mehr im Sinne eines hellenistischen Proskenion zu verstehen. Die Tiefe der kaiserzeitlichen Bühne von knapp über sechs Metern hatte weitreichende Folgen für das Koilon und die Orchestra. Letztere blieb auf dem Niveau der älteren Anlage, erfuhr aber wie das Bühnengebäude selbst eine Veränderung. Der Bau der neuen Bühne bewirkte eine deutlich verringerte Größe der Orchestra. Durch die Beseitigung der unteren Sitzreihen wurde dieser Umstand jedoch wieder ausgeglichen. Der hellenistische Kanal blieb erhalten und wurde auch weiterhin genutzt, allerdings durchgehend mit einer Abdeckung versehen.

Der großangelegte Umbau war damit aber nicht abgeschlossen. Im Koilon ergänzte man den oberen Rang in Richtung Westen und integrierte gleichzeitig ein neues Erschließungssystem für den unteren und mittleren Rang. Die überwiegend auf Substruktionskammern aus opus caementitium lagernden neuen Sitzbereiche überformten dabei auch Teile der bereits bestehenden Koilonflügel. Während der Baumaßnahmen wurde zudem ein Abschnitt der von Tiberius Claudius Aristion gestifteten Fernwasserleitung durch das Theater verlegt. Im Westen führte die Erweiterung des Koilon zu mächtigen Analemmata von annähernd $60 \mathrm{~m}$ Länge. Aus den Bauinschriften lässt sich ableiten, dass die Fertigstellung des Nordflügels noch unter Kaiser Domitian 92 n. Chr. erfolgte ${ }^{8}$. Die Arbeiten am Südflügel wurden hingegen erst unter Kaiser Trajan zwischen 102 und $112 \mathrm{n}$. Chr. abgeschlossen'. Soweit es sich theoretisch ermitteln lässt, bot die römische Cavea etwa 20.000 Personen Platz. Die Besucher konnten das Auditorium über eine Reihe großzügig angelegter, überwölbter Radialkorridore erreichen. Den oberen Abschluss des Gebäudes bildete eine mit Marmor prächtig ausgestattete Portikus, für deren Errichtungszeit allerdings eindeutige Evidenzen fehlen. Das Theater ragte mit nunmehr rund $150 \mathrm{~m}$ Ausdehnung deutlich über das in hellenistische Zeit zurückreichende Straßenraster hinaus. Nach Osten wird die Achse der Badgasse durch die porticus in summa cavea und die hangseitig anschließenden Räume erheblich überschritten, an der Südseite reicht das Analemma, bedingt durch die leichte Abweichung von den Fluchten des Stadtrasters, markant in die Marmorstraße hinein. Die Stiegengasse im Süden des Theaters, die in keinen der bislang von der Forschung erarbeiteten Stadtraster passt, stellt vermutlich eine Sonderlösung dar, die mit dem möglicherweise bereits in vorflavischer Zeit einsetzenden sukzessiven Ausbau des Koilon in Zusammenhang stehen dürfte. Bei der zwischen 2007 und 2009 freigelegten Stiegengasse ließen sich Unterschiede in Material und Ausführung zwischen dem oberen und dem unteren Treppenabschnitt feststellen, was auf eine unterschiedliche Zeitstellung schließen lässt und wohl die verschiedenen Bauabschnitte am Theater-Südflügel widerspiegelt. Die Funktion der Stiegengasse scheint sich nicht nur auf die Erschließung der südlichen Theatereingänge (ES1-ES3) beschränkt zu haben, sondern bestand vermutlich - durch den Anschluss eines weiteren Treppenabschnitts bei ES1 - auch in einer Verbindung zwischen Marmorstraße und Akademiegasse.

Hinsichtlich des antiken >Besucher-Leitsystems` im Theater von Ephesos lässt sich mit dem Abschluss der kaiserzeitlichen Umgestaltungen eine Unterscheidung zwischen dem Publikumsverkehr im Inneren des Theaters und der Regelung der äußeren Zugänge auf die unterschiedlichen Ränge des deutlich vergrößerten Koilon treffen: Die innere Aufschließung durch radiale Treppenstufen und horizontale Diazomata folgt der hellenistischen Anlage und damit der alten kanonischen Struktur des griechischen Theaters. In der differenzierten und leicht kontrollierbaren Zugänglichkeit zu den einzelnen Kerkides spiegelte sich wohl auch die

\footnotetext{
${ }^{7}$ IvE 2034. Dazu auch Kap. 8.6.1, Nr. 2 u. Kap. 8.6.2.

${ }^{8}$ IvE 2035. Dazu auch Kap. 8.6.1, Nr. 3 u. Kap. 8.6.2.

${ }^{9}$ IvE 2061. 2062. Dazu auch Kap. 8.6.1, Nr. 6. 7 u. Kap. 8.6.2.
} 
soziale Struktur des Publikums wider, deren gewährleisteter Sicherung bei öffentlichen Ereignissen keine geringe Rolle zukam. Während also diese vergleichbare innere Struktur im Prinzip bei allen Theatern anzutreffen ist, gibt es bei der Gestaltung der äußeren Zugänge jeweils ganz wesentliche Unterschiede, die eng mit den von Ort zu Ort unterschiedlichen topografischen Gegebenheiten und mit der Einbindung des Theaters in die Umgebung und in das städtische Gefüge zusammenhängen. Die interessantesten Lösungen sind dort anzutreffen, wo an den natürlichen Hang angelehnte hellenistische Theateranlagen für eine beabsichtigte Vergrößerung des Fassungsvermögens mit erheblich erweiterten Zuschauerrängen ausgestattet wurden, welche die früheren Dimensionen sowohl seitlich als auch in der Höhe monumental überbauten. Dafür entstanden mächtige Substruktionen und Gewölbebauten, in welchen zum Teil auch die nötigen Zugänge untergebracht wurden. So kamen ganz unterschiedliche komplexe Lösungen zustande, wie sie seit der Entwicklung der späthellenistischen Gewölbebauten bekannt und technisch beherrschbar waren.

Die in Ephesos gewählte Lösung ist im südlichen Analemma besonders eindrucksvoll nachzuvollziehen. In Entsprechung zu den drei Diazomata des Koilon ermöglichten drei überwölbte Korridore (ES1-ES3) den Zugang von außen. Eine imposante Treppenanlage vor der südlichen Außenfront, die jeweils vor den Zugängen mit großzügigen Podesten gestaltet war, stellte eine vertikale Außenverbindung zwischen den Diazomata her. Das oberste Podest vor ES3 liegt auf der Achse der nach Süden zur Kuretenstraße führenden Akademiegasse und damit exakt im hellenistischen Straßensystem. Zum mittleren Diazoma führte der Korridor ES2, auf ihn läuft vom Süden zwar keine Straße zu, doch war dieser Zugang über die Treppenanlage sowohl von oben als auch von unten zu erreichen. Über das hohe Substruktions- und Gewölbesystem von ES1, dessen gewaltige Dimensionen aus der heutigen Ruine kaum ablesbar sind, war nicht nur die Verbindung zu den repräsentativen Zugängen des unteren Diazoma gegeben, vieles spricht dafür, dass es auch einen etwas südlich gelegenen Treppenlauf zur darunterliegenden Marmorstraße gegeben hat. Damit waren die drei südlichen Eingänge zum Koilon mit einer unmittelbaren Anbindung des Theaters an die städtischen Siedlungsräume ausgestattet. Dies dürfte von der frühen Kaiserzeit bis zur großen Erdbebenkatastrophe des 3. Jhs. n. Chr. funktioniert haben. Es ist jedenfalls evident, dass durch den Einbau der Aristion-Leitung die südliche Treppenverbindung zwischen den vomitoria ES1 und ES2 nicht unterbrochen wurde.

Die Gestalt und Anbindung der nördlichen Koilon-Flanke des Theaters ist unter archäologischen Aspekten insgesamt weniger detailliert untersucht. Die Zugänge im Nordflügel dürften in ihrer Lage und Funktion den an der Südflanke getroffenen Lösungen entsprochen haben. Allein für die Erschließung des oberen Diazoma bleibt eine Lösung, wie sie mit dem Eingang ES3 an der Südfassade geschaffen wurde, aufgrund des Erhaltungszustands im Norden, des Versturzes vor der Nordfassade sowie neuer Erkenntnisse zum Straßenraster fraglich. In baulicher Hinsicht und in den Konstruktionsdetails unterscheidet sich die Situation im Nordflügel aber ganz deutlich. Insgesamt ist hier eine massivere und mächtigere Kubatur festzustellen, was sich aus den ursprünglichen Geländeformen erklärt. Hinsichtlich der Anbindung der Zugänge an das StraBennetz wissen wir zu wenig über die kaiserzeitliche Geländeform und die urbanistische Organisation des Gebietes zwischen dem Theater und dem Stadion, um sichere Aussagen zu machen. Zum vermauerten $\mathrm{Zu}-$ gang EN2, der in der verlängerten Achse der Akademiegasse angelegt wurde und über einen steilen, überwölbten Treppenlauf auf das mittlere Diazoma führte, muss festgestellt werden, dass das rekonstruierte Niveau der äußeren Schwelle wesentlich höher liegt als das Eintrittsniveau in den unteren Korridor EN1. Es ist daher in Analogie zur Südseite naheliegend, hier eine außen laufende Treppenanlage anzunehmen. Da bei den Grabungen vor dem Zugang EN2 das ursprüngliche Niveau des Zugangpodests erreicht wurde, ohne jedoch auf eine Pflasterung zu stoßen, könnte die Treppenanlage bei einem späteren Steinraub zumindest teilweise ausgeräumt worden sein. Der untere Zugang EN1, der sowohl von Norden als auch von Westen erschlossen war, erfuhr durch den späteren Einbau der großen Zisterne in einen Teilabschnitt des ursprünglichen Korridors tiefgreifende Veränderungen. Der mittlere Abschnitt des Nord-Analemma ist mit zwei geschlossenen Rundbögen gestaltet, die in der Literatur u. a. als sekundär verschlossene, ehemalige Aufgänge zum vomitorium EN1 gedeutet werden. Die aktuellen Befunde an der Fassade und im Korridor setzen dieser Sichtweise jedoch verschiedene Argumente entgegen ${ }^{10}$.

Die Haupteingänge zum Theater lagen immer im Westen. Seit der flavischen Erweiterung führte an den beiden Schmalseiten des Bühnengebäudes der Weg im Süden über eine Rampe, im Norden über eine mehr-

\footnotetext{
${ }^{10}$ Es darf auf die Publikation zur Baugeschichte des Theaters verwiesen werden, s. STYHLER-Aydin (in Vorbereitung).
} 
teilige Treppenanlage zunächst auf das Eintrittsniveau der unteren Treppenaufgänge (EN1 West; ES1 West) zum unteren Diazoma und dann weiter auf die Podeste der Parodoi-Überdeckungen am Ansatz der unteren Sitzreihen. Daneben war die Orchestra mit der Prohedrie auch durch die überwölbten Parodoi zu erreichen. Die Zugänge auf der Ebene der Orchestra sind durch die späteren Um- und Einbauten völlig verunklärt, trotz allem konnte die Forschung die ursprüngliche Situation, inklusive der Umgestaltungen, rekonstruieren. So wissen wir heute, wie die Zugänglichkeit zu verschiedenen Zeiten gelöst war.

Die hangseitige Ausdehnung des Theaters im Osten ist durch die beschriebene summa porticus bzw. deren Rückwand klar definiert. Mit der Errichtung der Portikus wurde der Verlauf der südlich des Theaters als Badgasse bekannten Straße 46 nach Osten überschritten, das kaiserzeitliche Theater nimmt also auf das hellenistische Straßensystem keine Rücksicht mehr. In älteren Forschungen hatte man an dieser Stelle ein Nemeseion vermutet, was sich durch die jüngste punktuelle Untersuchung vor Ort als nicht zutreffend erwies ${ }^{11}$. Die beiden östlich an die Rückwand der Portikus angesetzten Räumlichkeiten stehen funktional im Zusammenhang mit dem Theaterbetrieb (Thermopolion), architektonisch sind sie aber vom eigentlichen Theaterbau zu trennen und können am ehesten als Annex zu diesem aufgefasst werden. Die sichtbare Treppenanlage, und somit auch der obere Zugang (EO1), liegt deutlich außerhalb der Mittelachse des Theaters. Ihr Einbau zeigt die letzte Bauphase einer mehrfach veränderten Situation im Bereich der Portikus-Rückwand und ist daher später anzusetzen, auch wenn dazu keine exakten archäologischen Daten zur Verfügung stehen.

\section{UMBAUTEN UND REPARATUREN AB ANTONINISCHER ZEIT BIS IN DIE 1. HÄLFTE DES 3. JHS. N. CHR.}

Bereits wenige Jahrzehnte nach der Fertigstellung des flavisch-trajanischen Umbaus kam es um die Mitte des 2. Jhs. n. Chr. zu einer neuerlichen Veränderung. Diese betraf die Bühne und die Orchestra. Am Proskenion wurden die Interkolumnien verschlossen und die gesamte Front mit einer Marmortäfelung versehen. Zusammen mit dem Anheben des Orchestraniveaus um rund 0,30 m wurde der Bühnenbereich scheinbar optisch stärker den Bedürfnissen der römischen Kaiserzeit angepasst. Der alte hellenistische Orchestrakanal wurde aufgegeben und ein neuer Abflusskanal auf einem geringfügig höheren Niveau errichtet. Frühestens in dieser Zeit erfolgte auch der Einbau eines Ost-West verlaufenden Kanals, der unter der Orchestra, durch das Bühnengebäude hindurch, verlegt wurde. Vermutlich standen alle diese Maßnahmen in Zusammenhang mit der Einleitung von Trink- bzw. Nutzwasser (für Reinigungszecke) in den Orchestrabereich. Zwei aus der Aristion-Leitung gespeiste Tonrohrleitungen konnten von diesem ausgehend zumindest bis zum unteren Diazoma nachgewiesen werden. Sie dürften unterhalb der Radialtreppen T11 und T13 weiter in Richtung Orchestra verlaufen sein. Zur Ausstattung des Theaters gehörte auch ein Petasos. Das erste epigrafische Zeugnis, das die Existenz einer solchen Einrichtung belegt, entstammt der Zeit um die Mitte des 2. Jhs. n. $\mathrm{Chr}^{12}$. Ob es zu dieser Zeit erstmals installiert oder nur erneuert wurde, geht aus der Inschrift nicht hervor. Möglicherweise war hier ein leichtes Schutzdach gemeint. Zwei andere Inschriften sprechen dann von Reparaturen am Schutzdach. Das geschah einmal am Beginn des 3. Jhs. n. Chr. ${ }^{13}$ und ein weiteres Mal in der Regierungszeit des Kaisers Gordianus III. ${ }^{14}$. Eine weitere Inschrift aus der Zeit des Gordianus III. spricht von der Errichtung eines Pronaos am Nemeseion ${ }^{15}$, welches bislang noch nicht lokalisiert werden konnte. Auch der Zeitpunkt der Errichtung des Nemeseions selbst ist unbekannt. Gladiatorenkämpfe hingegen lassen sich bereits mit der Einweihung des kaiserzeitlichen Theaters im frühen 2. Jh. n. Chr. nachweisen ${ }^{16}$. Aus der Zeit ab der Mitte des 2. Jhs. n. Chr. datieren eine Reihe von Brüstungspfeilern mit Gladiatorenreliefs, die teilweise im Zerstörungsschutt des Theaters, teilweise in unmittelbarer Umgebung gefunden wurden. Zusammen mit späteren Ritzzeichnungen am Bühnengebäude verweisen sie auf das Theater als einen der Veranstaltungsorte von Gladiatorenkämpfen.

\footnotetext{
${ }^{11}$ AtaÇ 1997; Ataç 1999a, 432; AtaÇ 1999b, 3.

${ }^{12}$ IvE 2039. Dazu auch Kap. 8.6.1, Nr. 9 u. Kap. 8.6.2.

${ }^{13}$ IvE 2040. Dazu auch Kap. 8.6.1, Nr. 10 u. Kap. 8.6.2.

${ }^{14}$ IvE 2041. Dazu auch Kap. 8.6.1, Nr. 11 u. Kap. 8.6.2.

${ }^{15}$ IvE 2042. Dazu auch Kap. 8.6.2.

${ }^{16}$ IvE 2061. Dazu auch Kap. 8.6.1, Nr. 6 u. Kap. 8.6.2.
} 


\section{DIE BAULICHEN FOLGEN DER ERDBEBEN DES 3. UND 4. JHS. N. CHR.}

Inwieweit das Theater in der Regierungszeit des Kaisers Gallienus durch die Stadt heimsuchende Erdbeben in Mitleidenschaft gezogen wurde, ist unklar. An der Wohninsula unmittelbar südlich des Theaters ließen sich ähnlich schwere Schäden feststellen wie an den beiden Hanghäusern an der Kuretenstraße. Dabei gelangte der von der Insula stammende Zerstörungsschutt auch auf die südlich des Theaters verlaufende Stiegengasse. Der östliche Abschnitt der Treppe - zwischen den beiden oberen Theatereingängen ES2 und ES3 - wurde nach dem Beben allem Anschein nach nicht wieder komplett vom Schutt befreit. Entlang der Insula-Nordmauer blieben Teile des Erdbebenschutts liegen.

Am Nordflügel des Theaters konnten Stabilisierungsmaßnahmen festgestellt werden. So zog man in einen Teilbereich des unteren nördlichen vomitorum EN1 ein zusätzliches Gewölbe oder eine Decke ein. Ein Zusammenhang mit dem gallienischen Erdbeben kann zwar nicht zweifelsfrei bestimmt werden, ist aber auch nicht auszuschließen. Eventuell stellen auch Reparaturen an einigen Architekturbauteilen der scaenae frons eine Reaktion auf Folgen dieses Bebens dar.

In zwei aus dem späten 4. Jh. n. Chr. stammenden Inschriften ${ }^{17}$, die sich ursprünglich in der Verschlussmauer des nördlichen Zugangs EN2 und einer benachbarten Stützwand befanden, wird der Prokonsul Messalinus für die Wiederherstellung des Theaters gepriesen. Tatsächlich lassen sich umfangreiche Baumaßnahmen am Nordflügel mit diesen Inschriften in Zusammenhang bringen. Die Konsolidierungen waren vermutlich in Folge einer Erdbebenserie nach der Mitte des 4. Jhs. n. Chr. erforderlich und führten u. a. zur stark eingeschränkten Nutzung bzw. Aufgabe der nördlichen Zugänge. Auch bei der sekundären Einwölbung der Kammern im Nord-Analemma (KN1-KN3) könnte es sich um einen Teil dieser Sicherungsmaßnahmen handeln.

\section{DAS THEATER IM 5. UND 6. JH. N. CHR. BIS ZU SEINER INTEGRATION IN DIE BYZANTINISCHE STADTMAUER}

Um die Mitte des 5. Jh. n. Chr. wandelte man schließlich im Norden einen Abschnitt des unteren vomitorium EN1 in eine Zisterne mit einem Fassungsvermögen von mehr als $350 \mathrm{~m}^{3} \mathrm{um}$. Der vermutlich aus der Aristion-Leitung gespeiste Wasserspeicher blieb mindestens bis in das letzte Viertel des 6. Jhs. n. Chr. in Gebrauch. Weitere Baumaßnahmen im 5. bis Mitte des 6. Jhs. n. Chr. konnten am mittleren Treppenabsatz des Zugangs EN1 festgestellt werden. Darüber hinaus belegen Graffiti von Schauspielern an der Bühnenfassade, deren Kostüme dem 5./6. Jh. n. Chr. zugewiesen werden können, die Funktion des Theaters als Aufführungsort auch noch in der Spätzeit.

Auch am Südflügel kam es zum Verschluss der Eingänge ES1, ES2 und ES3. Die damit verbundene Aufgabe der Erschließung des Gebäudes von Süden dürfte vorrangig mit der Errichtung des byzantinischen Stadtmauerrings in Zusammenhang stehen, in den die Südseite des Theaters integriert worden ist. Eine bereits in hellenistischer Zeit bestehende Hangmauer östlich des Eingangs ES3 wurde aus Spolien - darunter viele Stufensteine der Treppe im Süden des Theaters - wiederhergestellt und als Stadtmauer adaptiert. Soweit es aus dem Fundmaterial über der Stiegengasse erschlossen werden kann, erfolgten diese Maßnahmen im späten 5. bis 6. Jh. n. Chr. Dabei wurde auch die Aristion-Leitung im Abschnitt zwischen dem Theater und dem Nymphaeum Traiani aufgegeben. Auch der südliche Bereich des Bühnengebäudes wurde durch das Vorblenden von Mauern verstärkt. Zudem erfuhren die Eingänge der Kammern einen massiven Verschluss. Zwischen den Kammern E5 und E6 setzt die Stadtmauer mit einem Tor wieder an und verlief von hier bis zum Hafenbecken im Westen. Das Areal südlich und südöstlich des Theaters wurde - extra muros gelegen - als Wohngegend langsam unattraktiv und zunehmend verlassen. Die Straßenzüge bis hinauf zur Oberstadt wurden zwar von Gewerbebetrieben und Werkstätten gesäumt, die Hänge um das Theater aber dürften weitgehend brach gelegen sein, was der große Anteil von Wildtierknochen in der Verfüllung der Aristion-Leitung belegt.

Wie lange das durch den Verschluss eines Teils seiner Eingänge für ein großes Publikum immer schwieriger zugängliche Theater für Versammlungen oder verschiedenartige Schaudarbietungen genutzt wurde, lässt sich nicht mehr eindeutig bestimmen. Inschriften von Kaiserakklamationen bis in die Zeit des He-

\footnotetext{
${ }^{17}$ IvE 2043. 2044. Dazu auch Kapitel 8.6.1, Nr. 12. 13 u. Kap. 8.6.2.
} 
rakleios finden sich auf mehreren Straßen um das Theater, das in diesem Zusammenhang wahrscheinlich auch im frühen 7. Jh. n. Chr. noch eine Rolle gespielt hat.

\section{FESTUNGSARTIGER AUSBAU DES BÜHNENGEBÄUDES IM 6. ODER FRÜHEN 7. JH. N. CHR.}

Der Verschluss von Eingängen am Bühnengebäude innerhalb der byzantinischen Stadtmauer, die im Bereich der Kammer E5 ansetzt, sowie massive Mauerverstärkungen an der Nordseite des Bühnengebäudes und der Nordrampe vermitteln schließlich einen festungsartigen Charakter. Dazu gesellt sich der mit Spolien auf eine schmale Öffnung reduzierte Durchgang zwischen den Kammern E4 und E5. Darüber war tonnenschwerer opus caementitium-Verguss aufgebracht worden. Die unmittelbare Nähe zum Stadttor macht die Umfunktionierung dieses Gebäudeteils zu einem Turm naheliegend. Ein Verschluss der Zugänge lässt sich auch im Bereich der Portikus feststellen. Allerdings mangelt es hier an Befunden für eine genaue zeitliche Einordnung.

Nachdem das Theater seine Bedeutung als Veranstaltungsort verloren hatte, diente es als Rohstoffquelle. Marmorne Verkleidungsplatten, wie sie von den Sitzstufen im Theater bekannt sind, finden sich in verschiedenen Gebäuden im Stadtgebiet wiederverwendet. Zudem wurden alle gut zugänglichen Bereiche der Fassaden und Marmorgewölbe ihrer Metallverklammerungen beraubt.

Mit dem 7. Jh. n. Chr. endet das aus den Ausgrabungen gewonnene Fundmaterial, zu dem auch Münzen aus der Zeit des Herakleios gehören. Dadurch kann ein terminus post quem für die Zerstörung des Theaters gewonnen werden, für welche Erdbeben verantwortlich gewesen sein dürften.

\begin{tabular}{|c|c|}
\hline \multicolumn{2}{|c|}{ I. Platzwahl und hypothetischer Vorgängerbau } \\
\hline $\begin{array}{l}\text { 3. Jh. v. Chr. bis } \\
\text { 1.Viertel 2. Jh. v. Chr. }\end{array}$ & $\begin{array}{l}\text { Der Platz für den Bau eines Theaters wird vermutlich mit der Planung des hellenistischen } \\
\text { Stadtrasters bestimmt. Es sind jedoch keine stratigrafisch gesicherten Belege für die } \\
\text { Existenz eines Theaters bekannt. }\end{array}$ \\
\hline \multicolumn{2}{|c|}{ II. Die Entstehung der hellenistischen Skene ab dem 2. Viertel des 2. Jhs. v. Chr. } \\
\hline ab dem 2. Viertel 2. Jh. v. Chr. & $\begin{array}{l}\text { Bau der Skene; keine datierenden Anhaltspunkte für das Koilon, das möglicherweise dem } \\
\text { Bau der Skene vorausgegangen war [A] }\end{array}$ \\
\hline \multicolumn{2}{|c|}{ III. Die Umgestaltung der hellenistischen Skene bis $51 / 50$ v. Chr. } \\
\hline bis $51 / 50$ v. Chr. & Umgestaltung der $>$ Thyromatafront $<$ in Marmor $[\mathrm{B}]$ \\
\hline \multicolumn{2}{|c|}{ IV. Frühkaiserzeitliche Bauaktivitäten } \\
\hline 1. Viertel 1. Jh. n. Chr. & Errichtung des Portals ES3 [E] \\
\hline \multicolumn{2}{|c|}{ V. Die Umgestaltung des Theaters ab spätflavischer bis in trajanische Zeit } \\
\hline 85 n. Chr. & $\begin{array}{l}\text { Fertigstellung und Einweihung des kaiserzeitlichen Bühnengebäudes mit der scaenae } \\
\text { frons }[\mathrm{E}]\end{array}$ \\
\hline bis $92 \mathrm{n}$. Chr. & Erweiterung des Theater-Nordflügels mit Errichtung des Nord-Analemma [E] \\
\hline bis $102-112 \mathrm{n}$. Chr. & $\begin{array}{l}\text { Erweiterung des Theater-Südflügels mit Errichtung des Süd-Analemma [E] } \\
\text { Bau der Aristion-Leitung durch das Auditorium [E] }\end{array}$ \\
\hline 1./2. Jh. n. Chr. & Errichtung von Räumen östlich der summa porticus [A] \\
\hline \multicolumn{2}{|c|}{ VI. Umbauten und Reparaturen ab antoninischer Zeit bis in die 1. H. des 3. Jhs. n. Chr. } \\
\hline um die Mitte 2. Jh. n. Chr. & $\begin{array}{l}\text { Umgestaltung von Bühne und Orchestra }[\mathrm{A}, \mathrm{B}, \mathrm{E}] \\
\text { Einbau oder Erneuerung eines Sonnensegels }[\mathrm{E}]\end{array}$ \\
\hline 205 n. Chr. & Reparatur des Sonnensegels [E] \\
\hline 238-244 n. Chr. & $\begin{array}{l}\text { Reparatur des Sonnensegels [E] } \\
\text { Errichtung eines Pronaos am (noch nicht lokalisierten) Nemeseion [E] }\end{array}$ \\
\hline
\end{tabular}




\begin{tabular}{|c|c|}
\hline Mitte 2. Jh./3. Jh. n. Chr. & Aufstellung von Brüstungspfeilern mit Gladiatorenreliefs im Theater $[\mathrm{A}, \mathrm{E}]$ \\
\hline \multicolumn{2}{|c|}{ VII. Die baulichen Folgen der Erdbeben des 3. und 4. Jhs. n. Chr. } \\
\hline 60er Jahre des 3. Jhs. n. Chr. & $\begin{array}{l}\text { mögliche Beschädigung des vomitorium EN1 durch ein für Ephesos verheerendes } \\
\text { Erdbeben. Einbau eines neuen Gewölbes oder einer Zwischendecke über einer } \\
\text { Pfeilerarkade in EN1 [B] } \\
\text { Massive Zerstörungen an der Insula südlich des Theaters. Die Treppe der Stiegengasse } \\
\text { wird dabei verschüttet und nur mehr teilweise vom Schutt befreit. [A] }\end{array}$ \\
\hline 359-366 n. Chr. & $\begin{array}{l}\text { mögliche Beschädigungen am Nord- und Südflügel des Theaters nach einer Erdbebenserie } \\
\text { [B] }\end{array}$ \\
\hline spätes 4. Jh. n. Chr. & $\begin{array}{l}\text { umfangreiche Sanierungsmaßnahmen am Nordflügel unter dem Prokonsul Messalinus [E] } \\
\text { verstärkende Wandschale an der Nordfassade [B] } \\
\text { teilweiser Verschluss des Eintrittportals in das vomitorium EN1 [B] } \\
\text { Stabilisierung der Kammern KN1-KN3 durch zusätzliche Mauerschalen und } \\
\text { Ziegelgewölbe ev. in dieser Periode [B] } \\
\text { Verschluss des Eingangs EN2 [B, E] } \\
\text { Strebemauern zu beiden Seiten des Eingangs EN2 [B, E] }\end{array}$ \\
\hline 4./5. Jh. n. Chr. & Aufgabe zumindest eines Teils der Räume hinter der summa porticus [A] \\
\hline \multicolumn{2}{|c|}{ VIII. Das Theater im 5. und 6. Jh. n. Chr. bis zu seiner Integration in die byzantinische Stadtmauer } \\
\hline 400-Mitte 5. Jh. n. Chr. & $\begin{array}{l}\text { Verfüllung der Kammern KN1-KN3 im Nordflügel [A] } \\
\text { Bau eines Wasserspeichers in einem Teilbereich des vomitorium EN1 (Die } \\
\text { Schwemmschicht bezeugt eine Nutzung zumindest bis in das späte 6. Jh. n. Chr.) [A, B] }\end{array}$ \\
\hline 5.-Mitte 6. Jh. n. Chr. & Baumaßnahmen am mittleren Treppenpodest von Zugang EN1 West [A] \\
\hline 5./6. Jh. n. Chr. & Graffiti am Bühnengebäude mit der Darstellung von Schaudarbietungen [A, E] \\
\hline spätes 5./frühes 6. Jh. n. Chr. & $\begin{array}{l}\text { Integration des Theaters in die byzantinische Stadtmauer: } \\
\text { Aufgabe der Aristion-Leitung im Bereich südlich des Theaters [A] } \\
\text { Verschluss der Zugänge ES1 und ES2 (ev. zeitlich abweichend ES3) [B] } \\
\text { Aufgabe der Stiegengasse [A] } \\
\text { Verschluss der Eingänge der Kammern E6-E8 am Bühnengebäude [B] } \\
\text { Verstärkung der Westmauern von den Kammern E7 und E8 [B] } \\
\text { Verstärkung der Südmauer des hellenistischen Bühnengebäudes [B] }\end{array}$ \\
\hline \multicolumn{2}{|c|}{ IX. Festungsartiger Ausbau des Bühnengebäudes } \\
\hline spätes 6./frühes 7. Jh. n. Chr. (?) & $\begin{array}{l}\text { festungsartiger Ausbau des Bühnengebäudes: } \\
\text { Verschluss der Kammern E1-E5 am Bühnengebäude [B] } \\
\text { Errichtung von Mauerverstärkungen im Norden des Bühnengebäudes [B] } \\
\text { turmartiger Ausbau des mittleren Durchgangs zwischen den Kammern E4 und E5 [B] }\end{array}$ \\
\hline 7. Jh. n. Chr. & terminus post quem für die Zerstörung des Theaters [A] \\
\hline
\end{tabular}

Tab. 127: Chronologischer Überblick

M. HofBAUer A. ÖZTÜRK

G. STYHLER-AYDIN 


\section{Summary and Chronological Overview}

Current research on the theatre in Ephesus, in consideration of site selection, as well as a hypothetical earlier structure, has identified eight different phases of construction and use, ranging from Hellenistic to Byzantine times, thereby illuminating a period lasting approximately 800 years. The first monograph on the monument was edited by R. Heberdey, G. Niemann and W. Wilberg and published by the OEAI in 1912. Today, new and more detailed and precise evidence has emerged regarding the development of the theatre, its transformation during the Roman period, and the later use of the building in the Byzantine-era city. A more vivid insight into the handling of the theatre as one of the characteristic urban public buildings of antique as well as late-antique Ephesus has been gained from the overall analysis of archaeological and architectural research results; the evaluation of assorted archaeological artefacts - such as ceramics, glass, terracotta and small finds, coins, sculptures and inscriptions as well as archaeozoological findings - has also contributed to gaining a better understanding.

\section{SITE SELECTION AND A HYPOTHETICAL EARLIER STRUCTURE}

Based on the excavation results construction of the theatre started as of the $2^{\text {nd }}$ quarter of the $2^{\text {nd }}$ century BC. One can expect, however, that the building site and a preliminary design of the theatre were already established by the time of Lysimachus. It is not improbable, in consideration of the building process, that preparation of the slope for the koilon and the establishment of the orchestra preceded the construction of the stage building. As no chronological evidence exists for the construction date of the koilon, we cannot determine how far back and to what intensity such preparations took place. As a result, the following are some hypothetical considerations: The theatre is located on the ancient sacred road, whose course may have influenced the planning of the building and which remained part of the cityscape until the Byzantine period. The position of the theatre on the western slope of the Panayırdağ takes advantage of a natural landform between the two humps of the hill. It has apparent geodynamic origins and the bottom peters out in a northwesterly direction into a narrow rift which ended in a steeply sloping sediment deposit; based on the location of the well structure, it appears the trough was water bearing. This situation was taken into consideration by the construction of a north-south oriented terrace, measuring more than $70 \mathrm{~m}$ in length, remedied this topographical situation, upon which the Hellenistic and later the imperial Roman period theatre buildings stood. The small deviation of the theatre from the north-south orientation of the road is likely due to these topographical conditions and the orientation of the Hellenistic street grid allowing for a favorable embedding of the structure. A slight clockwise rotation of the terrace wall's orientation significantly facilitated construction of the northern part of the structure. The theatre was located in two insulae according to the Hellenistic city plan and was offset somewhat to the south of the anticipated course of the eastwest streets. Building joints at the analemmata to the west also suggest that the street grid flanking the structure were adhered to in the later stages of construction. This also applies to koilon and the east side of the theatre, where the extended axis of the north-south oriented Badgasse corresponds with the position of the summa porticus. Only the large-scale expansion during the Roman imperial times skewed the original insula street grid. A comparative study by V. M. Strocka ${ }^{1}$ examined the small well house situated at the northwest corner of the stage building and the Sima of the more recent Artemision; as a result the well house could be dated to ca. $280 \mathrm{BC}$. It therefore belongs to the foundation period of the city, and its orientation confirms this. The structural connection between it and the Hellenistic terrace wall can no longer be verified due to improper earlier restoration. Its deep foundation is likely due to the level of the spring source ${ }^{2}$. We therefore conclude that

\footnotetext{
${ }^{1}$ Strocka 2005, 346 with note 30; compare Cap. 3.1.4.1.

${ }^{2}$ Similar to the situation at the lower Kuretenstraße that well house got supply from a natural spring source gathering slope water from the rift mentioned above. As result of the construction work the spring source seemed to run dry and the water supply was guaranteed by clayware pipes according to equivalent findings in SO 5/05 and SO 6/05 (Pl. 37 Fig. 67; 38 Fig. 68).
} 
already in the early period of its existence the rising slope of the terrain east of the well house was secured, a precursor to the monumental terracing project of the early $2^{\text {nd }}$ century $\mathrm{BC}$.

The stone settings discovered as a result of deep test trenches of W. Alzinger's excavations in the 1960s still elude accurate dating. These stones are located in the northeastern part of the Hellenistic orchestra and seem to have been laid in the natural alluvial level. The difference in level between the well structure and the later orchestra are the result of construction. The slope was certainly secured and the terrace walls and foundation of the stage building were erected before the $2^{\text {nd }}$ quarter of the $2^{\text {nd }}$ century $\mathrm{BC}$.

The limestone foundation, $\mathrm{U}$, was located at the level of the orchestra - within the Hellenistic Orchestra channel and significantly below its upper level. The circular segments of both structures shared the same midpoint, also the exactly shaped inner demarcation lines of foundation $U$ is orientated toward the orchestra. It ends in the north and in the south at the same distance from the Imperial-era stage; it is therefore possible to interpret that initially a circular stone setting existed, which was then removed as a consequence of Imperial-era construction. The conspicuous, regularly arranged right-angled fabrications running transverse to traces of removal can best be interpreted as evidence of safety enclosure, made of wood, which followed the course of the orchestra. A chronology or temporal assignment of the wooden structure to a certain phase of the orchestra design cannot be confirmed; earlier excavations destroyed any stratigraphic associations that may still have existed. In principle foundation $\mathrm{U}$ was already interpreted by $\mathrm{W}$. Wilberg as the enclosure of the first orchestra, yet contemporary to, but significantly higher-lying Hellenistic ring channel from the $2^{\text {nd }}$ quarter of the $2^{\text {nd }}$ century $\mathrm{BC}^{3}$. One can recognize an earlier phase of a possibly simpler theatre and the planimetric foundation of all subsequent stages in this stone circle. Restricted by the carefully laid inner side of the "dance floor", the stone setting was covered by the paving an adjoining circuit on the slope side; the different projecting outer edges of the foundation $U$ could thereby be explained ${ }^{4}$.

In sum, a hypothesis was formulated that the boundary of the first, provisional orchestra, preceding the construction of the Hellenistic theatre could be recognized in foundation U. If this assumption were true, it stands to reason that the hypothesis that the centre of the orchestra was established at its founding and remained unaltered later may also be true. This would also be the simplest explanation for recognized deviation of the road network.

At this point, it is impossible to further interpret the shape of this first theatre structure. Verifiable finds do not exist for the skene or the koilon.

\section{THE DEVELOPMENT OF THE HELLENISTIC THEATRE}

The Hellenistic skene was designed as a monumental two-storey building around $170 \mathrm{BC}$. Yellowish-brown limestone, red breccia and gray shell-limestone were used as materials for the theatre structure. The high degree of integration of the Hellenistic facility in the large Imperial conversion contributed to the good state of preservation of part of the Hellenistic skene. With the exception of the northwest corner, the lower level has been entirely preserved albeit partly concealed behind the walls of the Roman stage building. The upper level is in much worse condition due to its destruction during the construction of the Imperial era building. But even here, some essential details are still visible and have enabled the reconstruction of Hellenistic skene. Measuring more than $41 \mathrm{~m}$ in length, the Ephesian theatre building is one of the largest in Asia Minor. The interior arrangement is also unique: a long corridor-like room occupies the eastern half of the structure while the western half is comprised of a series of adjoining rooms. It is comprised of two groups of four chambers each, which are separated by a passageway oriented in an east-west axis. This passageway connected the corridor-like room with an area, approximately six-meters-wide, on the theatre terrace to the west of the stage building; it was here that W. Wilberg suggested an ionic portico once existed. So far, however, no structural evidence for this hall can be found. While the six interior chambers have doors leading to the corridor in the east, the two outer chambers of the stage building are only accessible from the west. Excavation evidence has shown that they served as stairways that connected the lower level with the upper level. Between these two staircases on the upper floor there

\footnotetext{
${ }^{3}$ HeBerdey u. a. 1912, 14 Abb. 16.

${ }^{4}$ Compare M. Hofbauer to the construction of this circuit in Cap. 3.3.3.
} 
were only three large, rectangular rooms, in comparison to the six chambers and the central passage which are evident in the floorplan of the lower floor. These rooms were accessible from the corridor by wide openings. In addition, the middle room had a large window in its western outer wall. The window terminated in an arch at the top and is the only known window opening in this Hellenistic construction. In contrast, there is extremely weak evidence for the east facade of the upper floor. Seven preserved marble pillars found in the masonry wall of the imperial period scaenae frons belong to the thyromata front containing seven openings and date to a reconstruction phase in the late Hellenistic period. A proposed reconstruction of the earlier phase, similarly consisting of seven openings, corresponds with the spatial sequence of the upper floor. In this case, the door openings of the spaces between the stairwells are exactly in line with the second, fourth and sixth thyroma.

The thyromata front was probably supplemented, in a way characteristic of Asia Minor, with a trapezoidal-shaped proskenion. No architectural traces of this can be identified, however, as in its place during the Flavian period, the facade of the scaenae frons was built.

The orchestra is bounded by a circumferential channel. Measured from the inner wall of the channel, the Hellenistic orchestra had a diameter of $12.35 \mathrm{~m}$. The underlying structure of this circuit is tangent to east wall of the stage building, but cut by the superior proskenion skene. The orchestra channel is made of the same yellow-brown limestone as the stage building. From the extreme southern end of the klimax, it extends, with a slight slope, around the orchestra to the level of the Hellenistic north analemma. At this point it bends to the north, and continues beneath the floor of the north parodos where it then exits the theatre. In the orchestra area the channel was uncovered; it was, however, covered with paving stones in the axes of the klimakes. The design of the orchestra floor remains unknown.

In Hellenistic times, the koilon possessed three tiers, whereas the lowest tier of the kerkides, subdivided into eleven tiers, reached much closer to the orchestra-channel than is indicated in its current state. In continuation of the lower tier, there is evidence that the koilon had a middle and upper level - at least in the mountain slope area. Since Hellenistic or at the latest during the time of Augustus seating areas were also constructed away from the slope but which did not reach the lower tiers. A more precise time-range for the dating of the koilon areas as well as a more accurate assignment of building phases remains uncertain. The seating areas were faced with white marble of which, however, only a small amount has survived. A similar facing technique was employed at the theatre in Metropolis, located just $20 \mathrm{~km}$ away and which is dates to the mid-second century BC.

Even if archaeological evidence for the theatre were to stem from more recent times, the assumption is justified that the ideal choice of location for the construction can be traced back to the Hellenistic urban design of Lysimachus. This is also supported by the generally accepted view that with the conception of the great Hellenistic royal-residence-cities, large-scale public facilities were specified in the local plans and, as a rule, were not changed later - even if this cannot always be verified in every detail, as is the case with theatre constructions.

Thus, even the very first excavators believed that oldest theatre in Ephesus was located at this point, although the very few traces of walls under the skene do not provide a convincing overall architectural design and any kind of archaeological evidence for such an older structure is missing. Under these circumstances, a possible former theatre could have only been a simple structure, whose orchestra was probably located at a higher level. It is obvious that such a structure would have been completely demolished and built over during the profound monumental restructuring of the theatre which started in mid-Hellenistic times.

In any case, in regard to the Greek mainland and the Aegean evidence proves $3^{\text {rd }}$ century BC theatre constructions on Delos, Demetrias and in the newly founded Sicyon. The situation is less clear in Asia Minor, where early Hellenistic-period theatres are well known in some cities (such as Priene, Erythrai, Miletus or Aizanoi); as far as can be dated, the majority of the monumental Hellenistic installations, however, were only erected as of the $2^{\text {nd }}$ century BC.

\section{THE TRANSFORMATION OF THE SKENE UP TO 51/50 AD}

One of the first changes to the Hellenistic theatre can be seen on the east facade of the skene where the original facade was replaced with a marble display side and seven thyromata. The eight marble pillars from this conversion were not removed when the Flavian era construction of the scaenae frons, rather, they were integrated 
into the masonry of the facade. An extensive list of agonothetes ${ }^{5}$ is preserved in the two outer pillars. A terminus ante quem of 51/50 $\mathrm{BC}$ has been established for the conversion based on the start date of this list. The end of the list in 17/16 BC indicates that the Hellenistic skene was used up to the Augustan period at the least.

\section{CONSTRUCTION ACTIVITIES DURING EARLY IMPERIAL TIMES}

Sporadic building activity dating to the early imperial period can be detected in the theatre. Thus, in the auditorium archaeological find-complexes found in the upper diazoma as well as the middle platform of the lower vomitorium in the north section (EN1) testify to building activity; however, the full extent of this activity remains unknown. In contrast, it is clearly visible that the secondary installation of the upper portal (ES3) in the south, was integrated into the structure of the southern wing of the building with the continuation of Akademiegasse. An inscription ${ }^{6}$ on the inner archivolt of the portal dates this action to the Augustan or early Tiberian era.

\section{THE TRANSFORMATION OF THEATRE FROM THE LATE FLAVIAN ERA TO THE TIME OF TRAIANUS}

The Ephesian theatre went through a profound transformation during the Flavian era. While the Hellenistic theatre building was incorporated into the Roman imperial era building, the proskenion had to give way to the substructure for the magnificent three-storey stage facade. This was designed as a three-storey tabernacle facade. Five doors led to the stage. The individual floors were structured with niches and aediculae. The Ionic order columns of the first floor rose above an unadorned plinth. The second floor followed the axial arrangement of the lower floor. The columns which rested on Attic bases rose above a plinth that was decorated with an Erotenjagdfries. Which architectural order was used for the columns on the second floor remains unclear. Earlier research had identified the third floor as being part of a later building phase; based on stylistic considerations, however, it is currently thought to coincide with the other two floors. It was slightly set back and rose, with its Corinthian order, over the attica wall of the second floor. The stage building was extended to the west by an additional series of rooms. With the exception of the middle passage and the two outer chambers there were no connections in the Hellenistic rooms neither in the lower nor in the upper floors. The upward closure of the imperial period chambers is no longer maintained. It is evident from the building remains, however, that these chambers are significantly higher than the chambers of the Hellenistic lower floor. All newly built chambers had their entrance doors on the west side and were accessible via a narrow path on the approximately $1.70 \mathrm{~m}$-wide terrace wall. The inauguration of the scaenae frons can be dated to the year 85 $\mathrm{AD}$ due to an inscription ${ }^{7}$ found on the architrave of the lower floor.

The front of the imperial period stage initially had a dainty-looking arrangement of Doric engaged columns surmounted by a Metopen-Triglyphen-Fries and a cornice with consoles. The front is functional and strikingly reminiscent of Hellenistic examples. It can, however, no longer be interpreted as a Hellenistic proskenion. The imperial period stage had a depth of just over six meters and had far-reaching consequences for the koilon and orchestra. The latter remained at the level of the older facility, but underwent a change such as the stage building itself. The construction of the new stage resulted in a significant reduction in size of the orchestra. This was offset by removing the lowest rows of seats. The Hellenistic channel remained and was still used, but was now covered in its entirety.

The large-scale remodeling was not yet completed. In the koilon the top tier was extended towards the west and at the same time integrated a new access system for the lower and middle tiers. The new seating areas, made of opus caementitium, were mainly placed over chambers in the substructure and covered parts of the existing koilon wings. During construction, a part of the aqueduct sponsored by Tiberius Claudius Aristion was laid through the theatre. In the west, the expansion of the koilon led to a massive, almost $60 \mathrm{~m}$ long an-

\footnotetext{
${ }^{5}$ IvE 9. See Cap. 8.6.2.

${ }^{6}$ IvE 2033. See Cap. 8.6.1, Nr. 1 and Cap. 8.6.2.

${ }^{7}$ IvE 2034. See Cap. 8.6.1, Nr. 2 and Cap. 8.6.2.
} 
alemmata. Due to building inscriptions ${ }^{8}$ it can be concluded that the completion of the north wing took place under Emperor Domitian, in $92 \mathrm{AD}$. Work on the south wing was, on the other hand, only completed under Emperor Traianus between 102 and 112 AD $^{9}$. As far as can be determined, theoretically, the Roman cavea offered seating for approximately about 20,000 people. Visitors were able to reach the auditorium through a number of generously-proportioned, vaulted radial corridors. The upper termination of the building was formed by a richly decorated marble portico; clear evidence for its construction date is lacking. The now roughly $150 \mathrm{~m}$ long theatre projected far beyond the street grid which dates back to Hellenistic times. To the east, the axis of Badgasse is considerably cut-across by the back wall of the summa porticus and adjoining rooms on the slope side; on the south side the analemma cuts noticeably into the Marmorstraße due to a slight deviation from the alignment of the city grid. The Stiegengasse to the south of the theatre does not fit into any city plans previously developed by researchers and probably represents a special arrangement which could be consistent with the gradual expansion of the koilon possibly in pre-Flavian times. Differences in materials and workmanship of the upper and lower sections of the terraced- stairway could be detected when the Stiegengasse was excavated (2007-2009); this suggests that it was constructed at different times which reflects the different stages of construction for the south wing of the theatre. The function of the Stiegengasse seems not to have been limited by providing access to entrances in the south part of the theatre (ES1-ES3), but presumably provided access to between Marmorstraße and Akademiegasse by way of another flight of stairs at ES1. With the conclusion of the imperial period transformations, a distinction can be made in regard to the ancient system of crowd control at the theatre of Ephesus: there was a distinction between the movement of people in the interior of the theatre and the regulation of the outer entrances as a result of the differing tiers of the much larger koilon; access to the interior by radial steps and the horizontal diazomata follows the Hellenistic construction and thus the old canonical structure of the Greek theatre. The differentiated and easily-controlled accessibility to each of the individual kerkides likely reflects the social structure of the audience, for whom the guarantee of safety played a great part. Thus while this similar internal structure is, in principle, found in all theatres, quite significant differences exist in the design of the outer entrances of each; these differences are closely related to the differing topography from one site to the other and with the inclusion of the theatre in its environment and in the urban texture. The most interesting solutions are found in Hellenistic theatres which abutted a natural hillside; a planned increase in capacity meant greatly expanded areas of spectator seats which exceeded the earlier monumental dimensions both laterally as well as vertically. As a result massive substructures as well as vaulted structures were created into which the necessary entrances were incorporated. Quite different and complex solutions were found since the design of their vaults was technically manageable after the development of arch technology in later Hellenistic times.

At Ephesus, the resulting solution in the southern analemma is particularly revealing. Corresponding to the three diazomata of the koilon, three vaulted corridors (ES 1 to ES 3) allowed access from the outside. A grand stairway in front of the southern exterior facade was designed with generous platforms in front of the entrances and established an outer vertical link between the diazomata. The topmost platform in front of ES3 lies on the axis of Akademiegasse which leads south to Kuretenstraße; it is thus exactly placed in the Hellenistic road system. Corridor ES2 led to the middle diazoma; no road led to it from the south, however, the entrance could be accessed, via the stairwell, from above (east) as well as from below (west). The high substructure and vault systems of ES1, whose vast dimensions are barely visible in today's ruins were not just the link to the representative entrances of the lower diazoma, rather, there is much to suggest that a staircase located slightly to the south provided access to Marmorstraße below. Thus, the three southern entrances to the koilon provided a direct connection of the theatre to the urban settlement areas. These were likely in use from the early Imperial period until the great earthquake in the $3^{\text {rd }}$ century AD. It is evident in any case that the installation of Aristion aqueduct did not cut the staircase between ES1 and ES2.

The archaeological aspects regarding the form and accessibility of the northern flank of the koilon has been examined in less detail. The entrances in the north wing should have corresponded in their position and function with the solutions adopted for the southern flank. A solution regarding the access to the third diazoma and how it was created with the upper gate (ES3) on the south side is currently open to question based on the

\footnotetext{
${ }^{8}$ IvE 2035. See Cap. 8.6.1, Nr. 3 and Cap. 8.6.2.

${ }^{9}$ IvE 2061. 2062. See Cap. 8.6.1, Nr. 6. 7 and Cap. 8.6.2.
} 
state of preservation on the north side, the rubble in front of the north facade as well as new insights into the street grid. In structural terms, and in the details of construction, the situation of the north wing differs quite significantly. Overall, a more massive and more powerful cubature can be determined and is explained by the original formation of the terrain. We know too little about the imperial period topography and the urban organization of the area between the theatre and the stadium to make definite conclusions regarding the connection of the entrances to the road network. In regard to the walled-in entrance EN2 in the axis of Akademiegasse (which was reached by a steep flight of stairs in the radial vaulted corridor of the middle diazoma) it must be noted that the reconstructed level of the outer threshold is much higher than the entry level in the lower corridor EN1. It is therefore possible, when compared to the south side, to accept the existence of an exterior staircase. Since the excavations in front of entry EN2 reached the original level of the access-landing without encountering a pavement, it may have been that the stairs were at least partially cleared by a later stone robbery. The lower entry EN1, which was accessible from both the north and the west experienced profound changes during the later construction of a large cistern in a section of the original corridor. The central portion of north analemma is designed with two closed arches and is interpreted (also in literature) as secondary sealed former entrances to vomitorium EN1. The current findings at the facade and in the corridor set this view in opposition with several other arguments. ${ }^{10}$

The main entrances to the theatre were always located on the west side. Since the Flavian expansion the two narrow sides of the stage building were connected by way of a ramp in the south and a segmented staircase in the north, both leading first to the entrance level of the lower stairways (EN1 west; ES1 west) to the lower diazoma and forward up to the pedestals being part of the recovery of the paradoi on the level of the lower seats. In addition, the orchestra and prohedria were connected by the covered parodoi. The entrances on the orchestra level are completely obscured by the subsequent alterations and constructions; nevertheless research has enabled the reconstruction of the original situation, including the alterations. Thus we know today how problems of accessibility were solved at different times.

The extent of the theatre towards the slope in the east is clearly determined by the described summa cavea and its external wall respectively. The construction of the porticus exceeded the course of street 46 known as Badgasse in the south of the theatre so that the theatre of Roman imperial times is not incorporated into the Hellenistic street grid. The older research postulates there a Nemeseion which could not be verified by the actual investigations ${ }^{11}$. The rooms attached in the east of the external wall of the porticus are functionally linked with the operating of the theatre (thermopolion); in architectural aspects they are not part of the original structure but more an annex of the building. The traceable stairway, and therefore the upper entrance (EO1) too, differ from the central axis of the theatre. Both are part of the latest state of a multiple modified situation in the sector of the external wall, although archaeological data for the exact fixing of their date are missing.

\section{ALTERATIONS AND REPAIRS FROM THE ANTONINE ERA UNTIL THE $1^{\text {ST }}$ HALF OF THE $3^{\text {RD }}$ CENTURY AD}

A renewed modification of the theatre occured in the middle of the $2^{\text {nd }}$ century AD, just a few decades after the completion of the Flavian-Trajanic conversion. This concerned the stage and the orchestra areas. The intercolumnia of the proskenion were closed and the entire facade fitted with a marble panelling. Together with the raising of the orchestra level by about $0.30 \mathrm{~m}$, the stage area was apparently visually adapted to better suit Roman taste. The old Hellenistic orchestra-channel was abandoned and a new drainage channel was constructed on a slightly higher level. During this time at the earliest an east-west running channel that processed under the orchestra and through the stage building was incorporated. Presumably, all these measures were related to the installation of a water supply in the orchestra section. Two supply lines fed from the Aristion aqueduct could be detected from the water conduit until at least the lower diazoma. They are likely to have continued further, underneath the radial staircases T11 and T13 in the direction of the orchestra. Another feature of the theatre was that it was equipped with an awning. The first epigraphic evidence attesting to its

\footnotetext{
${ }^{10}$ One may refer to the publication on the architectural history of the theatre; see STYHLER-AYDIN (in preparation).

${ }^{11}$ ATAÇ 1997; ATAÇ 1999a, 432; AtAÇ 1999b, 3.
} 
existence dates to the period around the middle of the $2^{\text {nd }}$ century $\mathrm{AD}^{12}$. The inscription is unclear whether it was installed first at this time or if it was replaced. Two other inscriptions refer to the awning being repaired. One repair occured at the beginning of the $3^{\text {rd }}$ century $\mathrm{AD}^{13}$ and the other during the reign of Emperor Gordian III. ${ }^{14}$. Another inscription from the time of Gordian III. refers to the construction of a pronaos at the Nemeseion $^{15}$, which as yet could not be located. The construction date of the Nemeseion itself is also unknown, but gladiatorial tournaments can be connected with the dedication of the imperial-era theatre in the early $2^{\text {nd }}$ century $\mathrm{AD}^{16}$. A number of balustrade pillars decorated with gladiator reliefs were found in the destruction rubble of the theatre and in its immediate vicinity; these date to the middle of the $2^{\text {nd }}$ century AD. Together with scratched drawings on stage building wall these reliefs point to the theatre being used as one of the venues for gladiator tournaments.

\section{THE STRUCTURAL IMPACT OF THE EARTHQUAKES IN THE $3^{\text {RD }}$ AND $4^{\text {TH }}$ CENTURIES AD}

It is unclear as to what extent the theatre was affected by the devastating earthquake that occured during the rule of Emperor Gallienus. In the insula immediately to the south of the theatre similar severe damage was detected, such as the two hillside houses located on Kuretenstraße. As a result the destruction debris which originated in the insula reached the staircase to the south of the theatre. The eastern part of the stairs - between the two upper theatre entrances (ES2, ES3) - was apparently never completely cleared of rubble after the earthquake. Along the northern wall of insula, portions of the earthquake rubble remained.

On the northern wing of the theatre stabilization measures could be determined. Thus an additional barrel vault was added to the lower level of the northern vomitorium (EN1). A connection with the earthquake during the reign of Gallienus cannot be determined with certainty, yet it can also not be dismissed. It is possible that repairs made to some the architectural components of the scaenae frons represent a response to the effects of this earthquake

Two inscriptions ${ }^{17}$ dating from the late $4^{\text {th }}$ century $\mathrm{AD}$ - which were originally located on the northern exterior wall - praise Proconsul Messalinus for restoring the theatre. One can connect extensive construction activities on the northern wing with these inscriptions. These consolidations were probably required as a result of a series of earthquakes which took place after the middle of the $4^{\text {th }}$ century $\mathrm{AD}$ and resulted in very limited use or total abandonment of the northern entrances. Even the employment of secondary arches in the chambers in the northern analemma $(\mathrm{KN} 1-\mathrm{KN} 3)$ could have been a part of these security measures.

\section{THE THEATRE IN THE $5^{\mathrm{TH}}$ AND 6 $^{\mathrm{TH}}$ CENTURIES AD UNTIL ITS INTEGRATION INTO THE BYZANTINE FORTIFICATION}

Around the middle of the $5^{\text {th }}$ century $\mathrm{AD}$ a section of the lower vomitorium (EN1) was converted into a cistern which had a capacity of more than $350 \mathrm{~m}^{3}$. The cistern which was presumably fed by the Aristion aqueduct remained in use until at least the last quarter of the $6^{\text {th }}$ century AD. Further construction activity, from the $5^{\text {th }}$ to mid- $6^{\text {th }}$ centuries $\mathrm{AD}$, could be determined on the middle landing of entrance EN1. Moreover there is graffiti on the stage facade from the actors whose costumes, dating to the $5^{\text {th }} / 6^{\text {th }}$ centuries $\mathrm{AD}$, attest to the theatre still being used as a performance venue even in late antiquity.

On south side, entrances (ES1, ES2 and ES3) were closed. The associated abandonment of access to the building from the south is mainly connected to the construction of the Byzantine fortification, into which the south side of the theatre was incorporated. A Hellenistic period retaining wall east of the entrance (ES3) was

\footnotetext{
${ }^{12}$ IvE 2039. See Cap. 8.6.1, Nr. 9 and Cap. 8.6.2.

${ }^{13}$ IvE 2040. See Cap. 8.6.1, Nr. 10 and Cap. 8.6.2.

${ }^{14}$ IvE 2041. See Cap. 8.6.1, Nr. 11 and Cap. 8.6.2.

${ }^{15}$ IvE 2042. See Cap. 8.6.2.

${ }^{16}$ IvE 2061. See Cap. 8.6.1, Nr. 6 and Cap. 8.6.2.

${ }^{17}$ IvE 2043. 2044. See Cap. 8.6.1, Nr. 12. 13 and Cap. 8.6.2.
} 
restored and adapted as part of the city wall by using spoils (including many stone steps) from the staircase south of the theatre. Based on the finds from the Stiegengasse, these measures were effected in the late $5^{\text {th }}$ to $6^{\text {th }}$ centuries AD. The section of the Aristion aqueduct between the theatre and the Nymphaeum Traiani was also abandoned. The southern area of the stage building was also reinforced by the superimposition of walls and the entrances of the chambers heavily sealed. A gate in the city wall was located between chambers E5 and E6; from here the fortification continued to the harbour basin in the west. The area south and southeast of the theatre - situated extra muros - was, as a residential area that became gradually and increasingly unappealing, abandoned. The streets leading to the upper town were lined with commercial buildings and workshops; the slopes around the theatre were likely laid to fallow, judging by the large proportion of wild animal bones found in the backfill of Aristion aqueduct.

With the closure of some of its entrances the theatre was increasingly more difficult for a large audience to access; for how long it remained in use for meetings and various performances can no longer be determined. Inscriptions of imperial acclamations dating up to the time of Heraclius were found on several streets around the theatre, which probably still played a role in this context in the early $7^{\text {th }}$ century AD.

\section{FORTRESS-LIKE MODIFICATIONS OF THE STAGE BUILDING IN THE ${ }^{\mathrm{TH}}$ OR EARLY $7^{\mathrm{TH}}$ CENTURIES AD}

The closure of the stage building entrances within the Byzantine fortification, which starts in the area of chamber E5, as well as massive wall reinforcements on the north side of the stage building and the north ramp ultimately convey a fortress-like character. In addition to this, the entrance between chamber E4 and E5 was reduced, using spolia, to a narrow opening. Very heavy opus caementitium-grouting was applied over this. Its close proximity to the city gate makes it evident that this part of the building was converted into a tower. The closure of entrances in the area of the portico can also be determined. However, a lack of findings prevents a more precise chronological ordering.

After the theatre had lost its significance as an entertainments venue, it was used as source of raw materials. Marble panels, known from the seating area in the theatre, find themselves reused in various buildings within the city. In addition, all easily accessible areas of the facade and marble vaults were robbed of their metal fittings (such as clamps or dowels).

Excavation finds from the theatre end with the $7^{\text {th }}$ century AD; these include coins from the time of Heraclius ${ }^{18}$. The resulting terminus post quem of the destruction, which may have been the result of one or more earthquakes, can only be understood as a temporal minimum.

\begin{tabular}{|l|l|}
\hline I. site selection and a hypothetical earlier structure \\
\hline $\begin{array}{l}3^{\text {rd }} \text { century BC to } 1^{\text {rst }} \text { quarter of the } \\
2^{\text {nd }} \text { century BC }\end{array}$ & $\begin{array}{l}\text { the space for the construction of a theatre was probably determined by the design of the } \\
\text { Hellenistic city grid. There is, however, no known firm evidence for the existence of a } \\
\text { theatre. }\end{array}$ \\
\hline II. Construction of the Hellenistic skene since the $\mathbf{2}^{\text {nd }}$ quarter of the $\mathbf{2}^{\text {nd }}$ century BC \\
\hline $\begin{array}{l}\text { since the } 2^{\text {nd }} \text { quarter of the } 2^{\text {nd }} \\
\text { century BC }\end{array}$ & $\begin{array}{l}\text { construction of skene (no datable evidence for the koilon that was possibly preceded by the } \\
\text { construction of skene) }[\mathrm{A}]\end{array}$ \\
\hline III. The transformation of the skene up to $\mathbf{5 1 / 5 0}$ AD \\
\hline up to $51 / 50$ AD & transformation of the thyromata front in marble [B] \\
\hline IV. Construction activities during early Imperial times \\
\hline $1^{\text {st }}$ quarter of the $1^{\text {st }}$ century AD & construction of portal ES3 [E] \\
\hline V. The transformation of the theatre from the late Flavian era up to the time of Traianus \\
\hline 85 AD & completion and inauguration of the imperial-era stage building with scaenae frons [E] \\
\hline
\end{tabular}

\footnotetext{
${ }^{18}$ Cap. 3.7.2.
} 


\begin{tabular}{|c|c|}
\hline up to $92 \mathrm{AD}$ & extension of the theatre's north wing with the construction of the north analemma $[\mathrm{E}]$ \\
\hline up to $102-112 \mathrm{AD}$ & $\begin{array}{l}\text { extension of the theatre's south wing with construction of the south analemma }[\mathrm{E}] \\
\text { construction of the Aristion aqueduct through the auditorium }[\mathrm{E}]\end{array}$ \\
\hline $1^{\text {st }} 2^{\text {nd }}$ century $\mathrm{AD}$ & construction of rooms east of the summa porticus [A] \\
\hline \multicolumn{2}{|c|}{ VI. Alterations and repairs from the Antonine era until the $1^{\text {st }}$ half of the $3^{\text {rd }}$ century AD } \\
\hline mid- $2^{\text {nd }}$ century AD & $\begin{array}{l}\text { modifications of the stage and orchestra }[\mathrm{A}, \mathrm{B}, \mathrm{E}] \\
\text { construction or renewal of a awning }[\mathrm{E}]\end{array}$ \\
\hline $205 \mathrm{AD}$ & repair of the awning $[\mathrm{E}]$ \\
\hline 238-244 AD & $\begin{array}{l}\text { repair of the awning }[\mathrm{E}] \\
\text { construction of a pronaos at the (not-yet-located) Nemeseion }[\mathrm{E}]\end{array}$ \\
\hline mid- $2^{\text {nd }} / 3^{\text {rd }}$ century AD & installation of balustrade pillars, decorated with reliefs of gladiators, in the theatre [A, E] \\
\hline \multicolumn{2}{|c|}{ VII. The structural impact of the earthquakes in the $3^{\text {rd }}$ and the $4^{\text {th }}$ century AD } \\
\hline $260 \mathrm{~s} A D$ & $\begin{array}{l}\text { possible damage to the vomitorium EN1 by a devastating earthquake in Ephesus. } \\
\text { Installation of a new vault or incerted ceiling over an arcade with pillars in EN1 [B] } \\
\text { massive destruction of the insula south of the theatre. The staircase of Stiegengasse was } \\
\text { submerged and only occasionally partially freed from the rubble. [A] }\end{array}$ \\
\hline 359-366 AD & $\begin{array}{l}\text { possible damage to the north and south wings of the theatre after a series of earthquakes } \\
\text { [B] }\end{array}$ \\
\hline late $4^{\text {th }}$ century $\mathrm{AD}$ & $\begin{array}{l}\text { considerable improvement of the northern wing under the proconsul Messalinus [E]: } \\
\text { reinforced facing added on the north facade [B] } \\
\text { partial closure of the entrance portal in the vomitorium EN1 [B] } \\
\text { stabilization of the chambers KN1-KN3 by means of adding reinforced wall facings and } \\
\text { brick vaults possibly during this period [B] } \\
\text { closure of the entrance EN2 [B, E] } \\
\text { buttresses added on either side of the entrance EN2 [B, E] }\end{array}$ \\
\hline $4^{\text {th }} / 5^{\text {th }}$ century $\mathrm{AD}$ & abandonment of at least some of the rooms behind the summa porticus [A] \\
\hline \multicolumn{2}{|c|}{ VIII. The theatre in the $5^{\text {th }}$ and the $6^{\text {th }}$ century AD until its integration into the Byzantine fortification } \\
\hline $400 \mathrm{AD}$ to mid- $5^{\text {th }}$ century $\mathrm{AD}$ & $\begin{array}{l}\text { backfilling of the chambers } \mathrm{KN} 1-\mathrm{KN} 3 \text { in the north wing }[\mathrm{A}] \\
\text { construction of a cistern in part of the vomitorium EN1 (The alluvial deposit indicates use } \\
\text { until at least the late } 6^{\text {th }} \text { century } \mathrm{AD} \text { ) }[\mathrm{A}, \mathrm{B}]\end{array}$ \\
\hline $5^{\text {th }}$ to mid- $6^{\text {th }}$ century $\mathrm{AD}$ & construction on the middle staircase landing of Entrance EN1-west [A] \\
\hline $5^{\text {th }} / 6^{\text {th }}$ century $\mathrm{AD}$ & graffiti on the stage building displaying performances $[\mathrm{A}, \mathrm{E}]$ \\
\hline late $5^{\text {th }} /$ early $6^{\text {th }}$ century $\mathrm{AD}$ & $\begin{array}{l}\text { integration of the theatre in the Byzantine fortification: } \\
\text { abandonment of the Aristion aqueduct in the region south of the theatre [A] } \\
\text { closure of entrances ES1 and ES2 (possibly temporally divergent from ES3) [B] } \\
\text { abandonment of the Stiegengasse [A] } \\
\text { closure of the entrances of chambers E6-E8 of the stage building [B] } \\
\text { reinforcing of the west walls of the chambers, E7 and E8 [B] } \\
\text { reinforcement of the southern wall of the Hellenistic the stage building [B] }\end{array}$ \\
\hline \multicolumn{2}{|c|}{ IX. Fortress-like modifications of the stage building in the $6^{\text {th }}$ or early $7^{\text {th }}$ century AD } \\
\hline late $6^{\text {th }} /$ early $7^{\text {th }}$ century AD? & $\begin{array}{l}\text { fortress-like expansion of the stage building: } \\
\text { closure of chambers E1-E5 at the stage building [B] } \\
\text { construction of wall reinforcements on the north side of the stage building [B] } \\
\text { tower-like construction of the central passage between the chambers and E4, E5 [B] }\end{array}$ \\
\hline $7^{\text {th }}$ century $A D$ & terminus post quem for the destruction of the theatre [A] \\
\hline
\end{tabular}

Tab. 127: Chronological overview 


\section{2. Özet ve kronolojiye genel bir bakış}

Ephesos tiyatrosunda sürdürülen - yer seçimine ve öncül bir yapı varsayımına dair düşüncelerden yola çıkan - güncel araştırmalar, sekiz yapım ve işlev evresinin zamansal olarak ayrıştırılmasını mümkün kılmıştır. Bu evreler Hellenistik Dönem'den Bizans Dönemi’ne uzanmakta ve yaklaşık 800 yıllık bir zaman dilimini aydınlatmaktadır. Yapıya ilişkin, 1912 yılında R. Heberdey, G. Niemann ve W. Wilberg tarafından yayımlanan ilk monografiye kıyasla, bugün özellikle tiyatronun oluşumuna, Roma hakimiyeti altındaki dönüşümüne ve yapının Bizans Dönemi kentindeki geç dönem işlevine dair yeni ve çok detaylı bilgiler mevcuttur. Arkeoloji ve yapı araştırması sonuçlarının yanı sıra, keramik ve cam buluntular, terrakottalar, küçük buluntular, sikkeler, arkeozoolojik buluntular, heykeller ve yaztllar gibi farklı arkeolojik buluntu türlerinin bütüncül bir değerlendirmesi sonucu, Ephesos'un kentsel mekanını şekillendiren kamusal bir yapı olan tiyatro hakkında somut bilgiler ortaya çıkmıştır.

\section{YER SEÇIMİ VE ÖNCÜL YAPI VARSAYIMI}

Güncel kazılardan elde edilen sonuca göre, sahne binasının yapımına MÖ 2. yüzyılın ikinci çeyreğinde başlanmıştır. Ancak, en azından yapının yeri ve geçici bir tiyatro tasarımı Lysimakhos Dönemi’ndeki [yeniden] kuruluş evresinde karara bağlanmıştır. Yapım sırasından anlaşıldığına göre, yamacın koilon için hazırlanması ve orkestranın inşası, sahne binasının yapımından önce gerçekleşmiştir. Böyle bir kurulumun ne kadar geriye görütülebileceği ve hangi yoğunluğa ulaştı̆̆ net değildir, çünkü elimizde koilon'un yapım tarihine ilişkin herhangi bir kronolojik ipucu yoktur. Buna ilişkin bazı varsayımsal yaklaşımlar: Tiyatro, güzergahı yapının planlamasını etkilemiş olabilecek ve kent dokusunda Bizans Dönemi’ne dek korunmuş olan çok eski kutsal yolun kenarında yer almaktadır. Panayırdağ’ın batı yamacındaki konumu, tepenin iki çıkıntısının arasındaki doğal arazi yapısından yararlanmaktadır. Bu yapı belli ki jeodinamik kökenlidir, ve kuzeybatıya doğru uzanan dar bir çanağın ve dik bir eğimle aşağı inen bir birikinti konisinin tabanında son bulmuştur. Ayrıca arazideki bu yarık suyun akışını sağlamıştır. Bu, çeşme binasının konumundan da belli olmaktadır. 70 m'den uzun, kuzey-güney doğrultulu bir terasın inşasıyla yamacın eteğindeki topografik durum dikkate alınmış ve üzerinde Hellenistik Dönem'de ve daha sonra İmparatorluk Dönemi'nde anıtsal sahne binasının inşa edileceği alan elde edilmiştir. Tiyatronun, Hellenistik Dönem sokak ağının doğrultusundan biraz sapması da herhalde topografik verilere bağlanmalıdır. Bu şekilde yapının araziye daha iyi yerleşmesi mümkün olmuştur. Teras duvarının doğrultusunun saat yönünde hafifçe döndürülmesi sayesinde, kuzey yarıdaki iftida kaybeden arazide gerçekleştirilen temel çalışmaları önemli ölçüde kolaylaşmış olmalıdır. Planimetrik olarak tiyatro, Hellenistik Dönem kent planındaki iki insulayı kaplar, ancak doğu-batı doğrultulu caddelerin tahmini hatlarında biraz güneye doğru kayar. Ayrıca batıya bakan analemmata'daki yapı derzleri, burada devam eden caddelerin ızgara sisteminin daha sonraki yapım evrelerinde de dikkate alındığına işaret eder. Bu, koilon'u ve tiyatronun doğu tarafını da etkilemiştir, burada kuzey-güney doğrultulu Hamam Sokağı'nın aksı [devam ettirildiğinde] summa porticus'un konumuna uyar. İlk olarak Roma İmparatorluk Dönemi’ndeki kapsamlı genişletme çalışmaları eski sokak ağını bozmuştur.

Sahne binasının kuzeybatı köşesinde yer alan ufak çeşme, son olarak V. M. Strocka ${ }^{1}$ tarafindan, geç dönem Artemision'unun simasıyla yapılan karşılaştırmalar sonucu ikna edici biçimde MÖ 280 civarına tarihlenmiştir. Böylece yapının kentin kuruluş devrine ait olduğu ortaya çıkar, yönlenişi de bu kanıyı desteklemektedir. Ne yazık ki bu küçük yapıya ilişkin orijinal kalıntı, uygunsuz bir restorasyon sonucu hasar görmüştür, öyle ki bugün yapının Hellenistik Dönem istinat duvarıyla olan yapısal bağlantısı artık net

\footnotetext{
${ }^{1}$ STROCKa 2005, 346 dipnot. 30; bknz. Kap. 3.1.4.1 dipnot 13.
} 
bir biçimde anlaşılamamaktadır. Yapının derin temel seviyesi herhalde su kaynağının kotu ${ }^{2}$ ile ilişkiliydi. $\mathrm{Bu}$ çeşme yapısından doğuya doğru yükselerek devam eden arazinin daha erken dönemde belirli bir güvenlik uygulamasına maruz kaldığı ve tasarlandığ 1 ve bunun MÖ 2. yüzyılın başındaki anıtsal teraslamanın öncülü olduğu anlaşılmaktadır.

1960'lı yıllarda açılan derin sondajlarda, W. Alzinger Roma İmparatorluk Dönemi sahne binasının altında taş sıraları tespit etmiştir, ancak bunlar bugüne dek daha detaylı olarak yorumlanmamıştır. Bu taş sıraları Helenistik orkestranın kuzeydoğu bölümünde yer almakta ve doğal birikinti konisine yerleştirilmiş gibi görünmektedir. Bunları, MÖ 2. yüzyılın 2. çeyreğinde istinat duvarı ve sahne binasının temeli inşa edilmeden önce, çeşme binası ile daha sonraki bir orkestra arasındaki kot farkının yapım aktiviteleriyle düzenlendiğine ve yamacın sağlamlaştırıldığına yönelik bir kanıt olarak değerlendirebiliriz.

Orkestra kotunda - Helenistik orkestra kanalı içinde ve bunun üst kenarının belirgin biçimde altında kireçtaşından inşa edilmiş Temel $\mathrm{U}$ yer almaktadır. Bu temelin yayı orkestranınkiyle aynı merkeze sahiptir ve düzenli bir biçimde oluşturulmuş iç kenarıyla da bu noktayı temel alır. Kuzeyde ve güneyde İmparatorluk Dönemi sahne binasından eşit uzaklıkta son bulur. Öyle ki burada baslangıçta tam daire bir taş dizisinin yer aldığı ve bunun İmparatorluk Dönemi yapım aktiviteleri esnasında bozulduğu akla yakın gelmektedir. Taş üzerlerinde dikkat çekecek kadar düzenli ayarlanmış dikdörtgen delikler ve bunlara dik uzanan kanallar, orkestranın seyrini izleyen ahşap bir bariyere işaret etmektedir. Ahşap konstrüksiyonun, orkestranın tasarımındaki belirli bir döneme tarihlendirilmesi mümkün değildir, çünkü eski kazılar nedeniyle stratigrafik bütünlük tümüyle kaybedilmiştir. Temel $\mathrm{U}$, daha $\mathrm{W}$. Wilberg tarafindan ilk orkestranın çerçevesi olarak yorumlanmış ancak belirgin biçimde daha üst kotta yer alan, MÖ 2. yüzyılın 2. çeyreğine ait Hellenistik kanal ile eşzamanlı oldugu düsünülmüstür ${ }^{3}$. Taş çemberde belki de daha basit bir tiyatronun daha önceki bir evresine ve bunu takip eden diğer tüm evrelerde temel alınmış bir plana ait izler okumak mümkündür. Dikkatlice yerleştirilmiş iç sıra asıl ,dans alanını' sınırlamış, [dış sıradaki] taş dizisi ise yamaç tarafında yer alan bir geçiş yolunun döşemesiyle kaplanmıştır ve bu, Temel U'nun dış kenarındaki taşların neden farklı çıkıntılara sahip olduklarını da açıklamaktadır".

Toparlamak gerekirse, burada Temel U'nun, Hellenistik tiyatronun öncül yapısının ilk, geçici orkestrasının, yani oyun alanının sınırını oluşturduğuna dair bir öneri ortaya konulmuştur. Bu yaklaşım isabetliyse, bununla birlikte orkestranın merkezinin kuruluş esnasında belirlendiğine ve daha sonra değiştirilmediğine yönelik bir kanıt da mevcuttur. Bu, doğrultunun cadde ağından hafif biçimde sapmasının da en basit açıklaması olur. Burada, bu ilk tiyatro yapısının tasarımına ilişkin daha fazla fikir yürütmek mümkün değildir. Ne ilk sahne ne de koilon için yaklaşık da olsa kabul edilebilecek buluntular mevcut değildir.

\section{HELENISTIK TIYYTRONUN OLUŞUMU}

Helenistik Dönem’e ait sahne, MÖ 170 yılı civarında iki katlı anıtsal bir yapı olarak tasarlanmıştır. Yapı malzemesi olarak sahne binası için sarımsı-kahverengi kireçtaşı, kırmızı breş ve gri traverten kullanılmıştır. Helenistik yapı Roma İmparatorluk Dönemi’ndeki dönüşüme adapte edildiği için Helenistik sahne binası kısmen iyi korunmuştur. Kuzeybatı köşesi hariç alt kat tümüyle günümüze ulaşmış, ancak kısmen Roma Dönemi sahne binasının duvarının arkasında kalmıştır. İmparatorluk Dönemi binasındaki hasarlar yapının üst katını ciddi biçimde etkilemiştir, öyle ki üst kat alt kata nazaran oldukça kötü durumdadır. Ancak yine de önemli detaylar günümüze ulaşmıştır ve bu, Helenistik Dönem sahnesinin restitüsyonuna imkan vermektedir. 41 m’yi aşan uzunluğuyla Ephesos sahne binası Anadolu'daki en büyük örneklerden biridir. Bununla birlikte, doğu yarıdaki uzun koridorumsu mekandaki bölümlenme ve buna bitişik olarak batıda devam eden oda sırası benzersizdir. Burada söz konusu olan, her biri dört odadan oluşan ve doğu-batı ekseninde bir

\footnotetext{
${ }^{2}$ Kuretler Caddesi'nin aşağısında da olduğu gibi, bu çeşme binası başlangıçta herhalde, yamacın suyunu yukarıda anlatılan yarıkta toplayan doğal bir kaynaktan besleniyordu. Tiyatro kapsamındaki değişiklikler sebebiyle bu kaynak kapatılmış olabilir, öyle ki su temini sonradan, 5/05 ve 6/05 sondajlarında (Taf. 37 Abb. 67; 38 Abb. 68) tespit edilen kalıntıların da gösterdiği gibi kil boru hatlarıyla sağlanmıştır.

${ }^{3}$ Heberdey v.d. 1912, 14 Abb. 16.

${ }^{4}$ Bknz. M. Hofbauer'in bu geçişin tasarımına dair düşünceleri. burada: Kap. 3.3.3.
} 
geçitle ortadan ayrılmış olan iki oda grubuydu. Bu geçit, koridoru sahne binasının batısında bulunan tiyatro terasının üzerindeki yaklaşık $6 \mathrm{~m}$ genişliğindeki bir alanla birleştiriyordu. Bunun tasarımı için W. Wilberg iyon sütunlu bir avlu önermişti, ancak bu avluya dair yapısal herhangi bir kanıt şimdiye dek bulunamamıştır. İçteki altı oda doğudaki koridora açılan kapılara sahipken, sahne binasının dıştaki iki odasına sadece batıdan girilebiliyordu. Bu odalar, kazılara göre, alt katı üst kat ile bağlayan merdiven kovaları olarak işlev görmekteydiler. Bu iki merdiven kovasının arasında, alt kattaki altı oda ve orta koridor düzeninden farklı olarak üst katta yalnızca üç büyük dikdörtgen oda bulunmaktaydı. Bu odalara koridordan geniş açıklıklarla giriliyordu. Bunun yanı sıra ortadaki oda dış batı duvarda büyük bir pencere ile donatılmıştı. Bu pencere yukarı doğru bir kemer ile tamamlanmaktadır ve Helenistik yapıdan bilinen tek pencere açıklığıdır. Buna karşılık, üst katın doğu cephesine ilişkin elimizde son derece az ipucu bulunmaktadır. Roma İmparatorluk Dönemi'ne ait scaenae frons'un duvarında korunmuş olan yedi açıklıklı bir thyromata cephesinde yer alan mermer payeler geç Hellenistik Dönem'deki bir dönüştürme evresine aittir. Daha eski bir evre için önerilen restitüsyon yine yedi geçişle planlanmıştır ve üst katın oda dizilimi şemasına uymaktadır. Bu durumda merdiven kovaları arasındaki odaların kapı açıklıkları tam olarak ikinci, dördüncü ve altıncı thyroma eksenlerinde yer alır.

Tyromata duvarının orkestraya bakan tarafinda muhtemelen Anadolu'ya özgü, çokgen - poligonal [trapez] planlı bir proskenion yer almıştır. Ancak buna ilişkin herhangi bir yapı kalıntısına rastlanmamıştır. İmparator Flavius Dönemi'nde proskenion yerine scaenae frons cephesi inşa edilmiştir.

Orkestra, çevresini saran bir kanal ile sınırlandırılmıştır. Kanalın iç duvarından başlayarak alınan ölçülere göre Helenistik orkestranın çapı 12,35 m'dir. Bu yapının temelini oluşturan daire, sahne binasının doğu duvarına değmekte ancak sahnenin önüne yerleştirilmiş proskenion tarafından kesilmektedir. Orkestra kanalı sahne binası gibi, sarı-kahverengi kireçtaşıyla inşa edilmişti. Güneyde en dışta yer alan klimax'tan [koilon'da yer alan basamaklar] başlayıp hafif bir eğimle orkestra çevresini dolanarak Helenistik kuzey analemma kotuna ilerliyordu. Burada kuzeye doğru kıvrılıyor ve kuzey paradosun döşeme seviyesinin altından geçerek tiyatrodan çıkıyordu. Orkestra bölümünde kanalın üstü kapalı değildi, ancak klimax ekseninde taşlarla örtülüydü. Orkestra tabanının nasıl tasarlandığı bilinmemektedir.

Koilon'un daha Helenistik Dönem'de üç halkası bulunuyordu. On bir kerkides'e bölünmüş olan prohedrie'li alt halka orkestra kanalına bugünkü bulgunun gösterdiğinden daha yakındı. Alt halkanın devamında, koilon'un en azından yamaç tarafındaki kısmında orta ve üst halka da bulunmaktaydı. Yamacın dışında da Helenistik Dönem'den ya da en geç Augustus Dönemi'nden beri oturma bölümleri yer alıyordu. Ancak bunlar alt halkanın genişliğine ulaşmamıştı. Bu koilon kanadının daha net bir tarihlendirmesi ve bununla bağlantılı olarak hangi yapım evresine ait olduğunun belirlenmesi, şu anki bilgilerle mümkün değildir. Oturma yerleri beyaz mermer levhalarla kaplıydı, ancak bunlardan günümüze ulaşanların oranı çok azdır. Bununla karş̧laştırılabilecek bir kaplama tekniği ile, sadece $20 \mathrm{~km}$ uzaklıkta yer alan ve MÖ 2. yüzyılın ortasına tarihlenen Metropolis tiyatrosunda karşılaşı1ır.

Tiyatroya dair arkeolojik belgeler daha geç dönemlere ait olsa da, tiyatro binası için tipik ideal yer seçiminin Lysimachos Dönemi’ndeki Helenistik kent planlamasına dayandığı yolundaki kabul haklılığını korumaktadır. Genel olarak kabul edilen anlayış da bu varsayımı destekliyor: Helenistik kent yerleşimlerinde, geniş kamusal yerleşkelerin kentteki konumuna planlama esnasında karar veriliyor ve bu daha sonra genellikle değiştirilmiyordu. Gerçi bu, tiyatro yapıları için her zaman bütün detaylarıyla anlaşılamamakta, ama bu biraz da araştırmaların bugünkü durumundan kaynaklanmaktadır.

Skene altındaki az sayıda duvar hattı yapıya yönelik anlamlı bir resim ortaya koymasa da ve bu nedenle bir öncül yapı için elimizde herhangi bir arkeolojik kanıt bulunmasa da, daha Ephesos'ta ilk kazı yapanlar bile en eski tiyatronun bu konumda bulunduğunu tahmin etmişlerdir. Bu varsayımlardan yola çıkıldığında, daha eski bir tiyatro yapısı, orkestrası muhtemelen daha yüksek kotta yer alan basit bir yerleşke olmuş olabilirdi. Böyle bir yerleşkenin, Orta Helenistik Dönem'den sonra başlayan kapsamlı anıtsallaştırma akımı esnasında ya tümüyle yıkıldığ 1 ya da dönüştürüldüğü anlaşılmaktadır.

Yunanistan ana karası ve Ege Denizi bölgesi için Delos, Demetrias ve yeni kurulan Sikyon'da MÖ 3. yüzyıla ait tiyatro binaları bulunmuştur. Anadolu için durum daha az nettir. Pek çok kentte şüpheye yer bırakmayacak şekilde Erken Helenistik Dönem'e ait tiyatro yapıları bilinmektedir (örneğin Aizanoi, Erythrai, Knidos, Milet, Phokeia ve Priene), ancak bu anıtsal Helenistik yerleşkelerin büyük kısmı - tarihlenebildiği kadarıyla - ilk olarak MÖ 2. yüzyıldan sonra inşa edilmiştir. 


\section{SAHNENIN MÖ 50/51 YILINA KADARKİ MIMMARİ GELİŞIMİ}

Hellenistik tiyatrodaki ilk değişim sahnenin doğu cephesinde görülmektedir. Burada orijinal cephe yedi thyromata 'lı mermer bir ön yüz ile değiştirilmiştir. Bu dönüşüme ait sekiz mermer paye Flavian Dönemi'ne ait scaenae frons'un inşasıyla yok edilmemiş, cephenin duvarına dahil edilmiştir. Agonothet'lerin ${ }^{5}$ kapsamlı bir listesi dışta yer alan iki mermer payede korunmuştur. Bu listenin başladığı MÖ 51/50 tarihi yapıdaki dönüşüm için bir terminus ante quem oluşturur. Listenin bittiği MÖ 17/16 tarihi ise Helenistik sahnenin en azından Augustus Dönemi'ne kadar kullanıldığını kanıtlar.

\section{ERKEN İMPARATORLUK DÖNEMINDEKİ İNŞAAT FAALIYYETLERİ}

Tiyatroda Erken İmparatorluk Dönemi için bir takım noktasal inşaat faaliyetleri kanıtlanabilmektedir. Seyirci bölümünde, üst diazoma'da ve EN1 [Eingang Nord 1: Kuzey giriş 1] olarak adlandırılan kuzeydeki alt vomitorium'un orta podestinde ele geçen arkeolojik buluntu grupları, genel çerçevesi henüz bilinmeyen yapım aktivitelerine işaret etmektedir. Buna karşılık, güneyde ikincil olarak inşa edilen ES3 [Eingang Süd 3: Güney giriş 3] olarak adlandırılan üst geçiş koridoru net biçimde görülmektedir. Bu, Akademi Sokağı'nın devamında güney bina kanadı kütlesine entegre edilmiştir. Girişteki kemerin iç kavisinde yer alan bir yazıt ${ }^{6}$ bu faaliyeti Augustus Dönemi ile Tiberius Dönemi’nin ilk yılları arasındaki bir zamana tarihlemektedir.

\section{TIYYTRONUN FLAVIUUS VE TRAJAN DÖNEMINDE GEÇIRDIĞİ MIMMARİ DEĞİŞIMLER}

Ephesos tiyatrosu en kapsamlı mimari dönüşümü Flavius Hanedanı Dönemi'nde yaşamıştır. Hellenistik sahne binası Roma İmparatorluk yapısına dahil edilmiş, proskenion görkemli sahne cephesinin temeli altında gözden kaybolmuştur. Bu cephe üç katlı bir tabernakel cephesi olarak tasarlanmıştı. Sahneye geçiş beş kapıdan sağlanıyordu. Her kat nişler ve aedikullar ile bölümlendirilmişti. İlk katın iyon düzenindeki sütunları bezemesiz bir temel bandı üzerinde yükseliyordu. İkinci katta alt katın aks düzeni devam ediyordu. Attika tipi kaideler üzerinde yükselen sütunlar Eros'lu av sahneleri ile bezenmiş bir temel bandı üzerinde yer alıyordu. Bu katın sütun düzenine dair net bir bilgi halen bulunmamaktadır. Daha önceki araştırmalarda daha geç bir yapım evresine tarihlenen üçüncü kat, güncel stilistik araştırmalara dayanarak diğer iki kat ile aynı yapım evresine tarihlenmelidir. Bu kat biraz geriye çekilmişti ve korint düzenindeki sütunları ikinci katın Attika stilindeki parapeti üzerinde yükseliyordu. Sahne binası batıya doğru ek bir oda sırası ile genişletilmişti. Ortadaki geçiş alanı ve kenardaki iki oda haricinde Hellenistik Dönem mekanlarıyla ne alt katta ne de üst katta bağlantılar bulunuyordu. İmparatorluk Dönemi'ne ait odaların üst bölümleri günümüze ulaşmamıştır ancak yapıdaki kalıntılardan bu odaların Hellenistik Dönem'e ait alt katın odalarından belirgin biçimde daha yüksek oldukları anlaşılmaktaydı. Yeni inşa edilen bütün odaların giriş kapıları batıda yer almaktaydı ve bu odalara yaklaşı1k 1,70 $m$ genişliğindeki teras duvarı üzerinde yer alan dar bir geçitten geçilerek ulaşılmaktaydı. Alt katın arşitravında yer alan bir inşa kitabesi ${ }^{7}$ sayesinde scaenae frons'un açilış töreni MS 85 yllına tarihlenebilmiştir.

İmparatorluk Dönemi'ne ait sahne cephesi öncelikle zarif görünümlü, metop-triglif frizli dorik yarım sütun düzenine ve bunun üzerinde uzanan konsol kiriş sistemine sahipti. Cephe belirgin biçimde Hellenistik örnekleri hatırlatmakta, ancak işlevsel olarak artık bir Hellenistik proskenion olarak anlaşılmamaktadır. İmparatorluk Dönemi sahnesinin 6 m'yi biraz aşan derinliği koilon ve orkestra bölümleri için önemli sonuçlar doğurmuştu. Orkestra eski yerleşkenin kotunda kalmış, ancak sahne binası gibi o da değişikliğe uğramıştır. Yeni sahnenin inşası orkestranın belirgin biçimde küçülmesine yol açmış ancak alt oturma sıralarının kaldırılmasıyla bu durum düzeltilmiştir. Hellenistik Dönem'e ait kanal korunmuş ve kullanılmaya devam etmiş, ancak üstü tümüyle kapatılmıştır.

Kapsamlı planlanmış bu mimari dönüşüm bununla bitmiyordu. Koilon'da üst halka batıya doğru genişletilmişti ve aynı zamanda alt ve orta halka için yeni bir dolaşım sistemi oluşturulmuştu. Büyük ölçüde opus

\footnotetext{
${ }^{5}$ IvE 9. Buna dair ayrıca bknz. Kap. 8.6.2.

${ }^{6}$ IvE 2033. Buna dair ayrıca bknz. Kap. 8.6.1, Nr. 2 ve Kap. 8.6.2.

${ }^{7}$ IvE 2034. Buna dair ayrica bknz. Kap. 8.6.1, Nr. 2 ve Kap. 8.6.2.
} 
caementitium'dan oluşan alt yapı mekanlarının üzerinde yer alan yeni oturma bölümleri önceden varolan koilon kanatlarınının bazı bölümlerini de değiştirmişti. Yapım çalışmaları sırasında ayrıca Tiberius Claudius Aristion tarafından yaptırılan su tesisatının bir bölümü tiyatronun içinden geçecek şekilde döşenmiştir. Koilon'un genişletilmesi batıda yaklaşık 60 m'ye varan devasa analemmata oluşumuna yol açmıştır. Yapı yazıtlarına göre, kuzey kanat daha İmparator Domitian zamanında, MS 92 yılında tamamlanmıştır karşın güney kanattaki çalışmalar ancak İmparator Trajan devrinde MS 102-112 bitirilmiştir'. Teorik olarak hesaplanana göre, Roma Devri cavea'sı yaklaşık 20.000 kişi alıyordu. Ziyaretçiler oditoryuma geniş, üstü kapalı, radyal koridorlardan ulaşabiliyordu. Binanın üst kısmı görkemli bir mermer dekorasyona sahip bir portikle tamamlanıyordu. Ancak bunun yapım tarihine ilişkin belirgin kanıtlar mevcut değildir. Tiyatro artık yaklaşık 150 m'lik genişliğiyle belirgin biçimde Hellenistik Dönem'e ait sokak sisteminin dışına taşıyordu. Doğuda, Hamam Sokağı'nın aksı porticus in summa cavea ve yamaç tarafinda devam eden odalar tarafindan epeyce aşılmışt, güney tarafta analemma, ızgara sokak hattından hafifçe saptı̆̆ için, belirgin biçimde Mermer Cadde'ye taşıyordu. Tiyatronun güneyindeki merdivenli sokak şimdiye kadar araştırmalara konu edilen hiç bir kent planına uymaz. Bu, muhtemelen İmparator Flavius döneminden önce koilon'da başlayan ve sonrasında devam eden mimari dönüşüm ile bağlantılı özel bir çözümdü. 2007-2009 yılları arasında açı̆̆a çıkarılan merdivenli sokakta, merdivenin üst ve alt bölümleri arasında malzeme ve uygulama farklılıkları tespit edilmiştir. Bu durum farklı uygulama dönemleri olduğu çıkarımına yol açmakta ve herhalde tiyatronun güney kanadındaki farklı yapı bölümlerini yansıtmaktadır. Bu merdivenli sokağın işlevi yalnızca tiyatronun güney girişlerine (ES1-ES3) ulaşımı sağlamakla sınırlı değildi ve muhtemelen ES1'e [alttaki güney girişe] başka bir merdivenin eklenmesiyle Mermer Cadde ve Akademi Caddesi arasında bir bağlantı oluşturmuştu. İmparatorluk Dönemi'ndeki mimari dönüşümün tamamlanmasının ardından, Ephesos Tiyatrosu'ndaki antik seyirci yönlendirme sisteminde, tiyatronun içindeki seyirci trafiği ile belirgin biçimde genişletilmiş koilon 'un farklı bölümlerine dışarıdan girişlerin düzenlenmesi arasında bir ayrım göze çarpar: Radyal merdiven basamaklarıyla ve yatay diazoma 'larla ulaşılan iç kısım Helenistik yerleşkeyi ve böylece Yunan tiyatrosunun eski alışıldık yapısını tekrar eder. Her bir kerkides 'te farklılaştırılmış ve kolayca kontrol edilebilen giriş-çıkış, seyircilerin sosyal yapısını da yansıtmaktaydı. Kamusal olaylarda seyirci güvenliğin garanti altına alınmasına önem veriliyordu. $\mathrm{Bu}$ iç yapıyla prensipte tüm tiyatrolarda karşılaşılsa da, dış girişlerin tasarımında temel farklılıklar bulunmaktadır. Bunlar, bölgeden bölgeye farklılaşan topografik durumlara ve tiyatronun çevresiyle ve kentsel dokuyla olan bağlantısına göre değişiyordu. En ilginç çözümlerle, doğal yamaca yaslanan Helenistik Dönem tiyatro yapılarının eski boyutlarının, seyirci kapasitesinin bilinçli bir şekilde yükseltilmesi amacıyla, hem yanlara hem de yukarı doğru anıtsal biçimde artırıldığı durumlarda karşıllaşılmaktaydı. Bu amaçla devasa altyapılar ve tonozlu yapılar inşa ediliyor, ve bu kısımlara kısmen gerekli giriş bölümleri de yerleştiriliyordu. Böylece, Geç Helenistik Dönem tonozlu yapıların gelişiminden bu yana bilinen ve tekniğine hakim olunan çok çeşitli, karmaşık çözümler ortaya çıkıyordu.

Ephesos'ta seçilen çözüm, güney analemma'da özellikle etkili biçimde anlaşılmaktadır. Koilon'daki üç diazoma'ya karşılık gelecek şekilde, üstü kapalı üç koridor (ES1-ES3) dışarıdan giriş imkanını sağlamıştır. Güney dış cephenin önünde bulunan ve her bir girişin önünde geniş sahanlıklarla tasarlanmış heybetli bir merdiven, diazoma 'lar arasında dikey bir dış bağlantı oluşturuyordu. ES3 önünde bulunan en üst sahanlık, güneye doğru Kuretler Caddesi'ne bağlanan Akademi Sokağı'nın ekseninde ve böylece tam olarak Hellenistik sokak sisteminde yer almaktaydı. Orta diazoma ya ES2 numaralı koridor üzerinden ulaş1lyordu, bu koridora güneyden bir sokak bağlanmasa da, bu girişe hem yukarıdan hem de aşağıdan merdivenlerle ulaşmak mümkündü. Muazzam boyutları bugünkü kalıntılardan anlaşılamasa da, ES1'in yüksek altyapısı ve tonoz sistemi üzerinden sadece alt diazoma'nın görkemli girişlerine değil, pek çok kanıtın gösterdiği gibi, alt kotta bulunan Mermer Cadde'ye inen biraz daha güneydeki merdivene de bir bağlantı bulunuyordu. Böylece koilon'a varan üç güney giriş sayesinde tiyatronun kentsel yerleşim alanlarıyla dolaysız bağlantısı sağlanmış oluyordu. Bu sistem İmparatorluk Dönemi'nin başından MS 3. yüzyıldaki büyük depreme dek işlemiş olmalıydı. Aristion hattının inşasıyla ES1 ve ES2 vomitorium 'ları arasındaki güney merdiven bağlantısının kesilmediği bilinmektedir.

Tiyatronun kuzey koilon kanadının tasarımı ve bağlantısı, arkeolojik bakış açısıyla genel olarak daha az detaylı araştırılmıştır. Kuzey kanattaki girişler mekansal ve işlevsel olarak güney kanatta uygulanan çözümlerle uyum

\footnotetext{
${ }^{8}$ IvE 2035. Buna dair ayrıca bknz. Kap. 8.6.1, Nr. 3 ve Kap. 8.6.2.

${ }^{9} \mathrm{IvE}$ 2061. 2062. Buna dair ayrıca bknz. Kap. 8.6.1, Nr. 6. 7 ve Kap. 8.6.2.
} 
içindeydiler. Yalnız üst diazoma' ya erişim için güney cephedeki ES3 girişinde uygulanana benzer bir çözüm, hem kuzeydeki korunmuşluk durumu ve kuzey cephe önündeki yıkıntı hem de cadde dokusuna yönelik yeni bilgiler nedeniyle şüphelidir. Ancak kuzey kanattaki durum, yapısal bakımdan ve konstrüksiyon detaylarında net bir biçimde farklılaşmaktadır. Burada genel olarak, orijinal arazi formasyonundan kaynaklanan daha masif ve heybetli bir kubatur tespit edilmiştir. Girişlerin sokak ağıyla olan ilişkisi bağlamında, Roma İmparatorluk Dönemi arazi yapısı ve tiyatro ile stadyum arasındaki bölgenin kentsel organizasyonu hakkındaki bilgimiz kesin çıkarımlar yapmak için çok yetersiz. Akademi Sokağı'nın ekseninin devamında yer alan ve dik, tonozla örtülü bir merdiven üzerinden orta diazoma' ya varan [sonradan] duvarla kapatılmış EN2 geçişine dair belirtmek gerekir ki, bu geçişin dış eşiğinin kotu, altta yer alan EN1 koridorunun giriş kotundan belirgin biçimde daha yüksektedir. Güney taraf ile yapılacak bir karşılaştırmaya dayanarak, burada dışarıdan işleyen bir merdivenin varlığı kabul edilebilir. EN2 geçişi önünde yapılan kazılarda giriş sahanlığının orijinal kotuna ulaşıldığından, ancak bu esnada herhangi bir döşemeye rastlanmadığından, bu merdiven tertibi daha sonraki bir taş yağması esnasında en azından kısmen ortadan kaldırılmış olabilir. Hem kuzeyden hem de batıdan ulaşılan EN1 numaralı alt geçiş, daha sonra inşa edilen büyük bir sarnıç nedeniyle orijinal koridorun bir bölümünde kapsamlı değişiklikler geçirmiştir. Kuzey analemma 'nın orta bölümü iki kör daire kemer ile düzenlenmiştir. Bunlar literatürde EN1 numaralı vomitorium'a varan ikincil, eski ve sonradan kapanmış geçişler olarak yorumlanmıştır. Cephedeki ve koridordaki güncel bulgular bu görüşe karşı farklı argümanlar sunmaktadır ${ }^{10}$.

Tiyatronun ana girişleri her zaman batıda yer almıştır. İmparator Flavius dönemindeki genişletme çalışmalarından beri, sahne binasının her iki dar kenarının yanından giden yol, güneyde bir rampa üzerinden, kuzeyde ise çok parçalı bir merdiven üzerinden önce alt diazoma'ya giden alt merdivenlerin (EN1 Batı; ES1 Batı) giriş kotuna, daha sonra alt oturma sıralarının başlangıcındaki parodos üst örtülerinin sahanlığına ulaşıyordu. Bunun yanı sıra prohedrie'li orkestraya üstü kapalı geçitlerden da erişilmekteydi. Orkestra seviyesine girişler daha sonraki mimari dönüşümler ve ekler nedeniyle anlaşılmaz bir durumdadır, ancak buna rağmen araştırma sonrasında orijinal durum, dönüşümleri de içerecek şekilde, restitüe edilebilmiştir. Böylece bugün giriş-çıkışların farklı dönemlerde nasıl çözüldüğünü bilmekteyiz. Tiyatronun doğuda yamaç tarafındaki sınırı, yukarıda tarif edilen summa porticus ve onun arka duvarı sayesinde net bir biçimde belirlenmiştir. Portiğin inşasıyla beraber, tiyatronun güneyindeki Hamam Sokağı olarak bilinen Cadde 46'nın güzergahı doğuya doğru aşılmıştır: İmparatorluk Dönemi tiyatrosu Hellenistik cadde sistemine artık önem vermiyordu. Eski araştırmalarda bu noktada bir nemeseion olduğu tahmin ediliyordu, ancak alanda o noktada yapılan en yeni incelemeler sonrasında bu tahminin çok isabetli olmadığ 1 anlaşılmıştır ${ }^{11}$. Ön avlunun [portik] arka duvarının doğusunda yer alan iki mekan işlevsel olarak tiyatro işleyişiyle (Thermopolion) bağlantılı görünmektedir, ancak mimari olarak asıl tiyatro yapısından ayrılmakta ve daha ziyade buna bir ek olarak inşa edildikleri düşünülmektedir. Görünür durumdaki merdiven ve bununla birlikte EO1 numaralı geçiş de tiyatronun orta aksının dışında yer almaktadır. Bunların yapıya eklenmesi, ön avlunun arka duvarı civarında pek çok kez değiştirilmiş bir durumun son evresini göstermekte ve bu nedenle, elimizde kesin arkeolojik veriler olmasa da, daha geç bir döneme tarihlenmektedir.

\section{IMPARATOR ANTONINUS DÖNEMINDEN MS 3. YÜZYILIN İLK YARISINA KADAR SÜREN DÖNÜŞTÜRME VE ONARIM ÇALIŞMALARI}

Flavius ve Trajan dönemlerindeki mimari dönüşümlerin tamamlanmasından birkaç onyıl sonra, MS 2. yüzyılın ortalarında yeni bir değişim gündeme geldi. Bu değişim sahne ve orkestra kısmını ilgilendiriyordu. Proskenion'da sütun araları kapatıldı ve tüm cephe mermer plakalarla donatıldı. Orkestra seviyesinin de yaklaşık 0,30 m yükseltilmesiyle, görünüşe göre sahne alanı Roma İmparatorluk Dönemi ihtiyaçlarına optik olarak daha uygun bir halde getirildi. Eski Hellenistik orkestra kanalından vazgeçildi ve biraz daha yüksek bir kotta yeni bir atık su kanalı oluşturuldu. Orkestra altında, sahne binasının içinden geçecek şekilde yerleştirilen doğu-batı doğrultulu bir kanalın inşası da en erken bu dönemde gerçekleşmiş olmalıdır. Tüm bu uygulamalar muhtemelen içme ve temizlik amacıyla kullanılan suyun orkestra bölgesine iletilmesiyle

\footnotetext{
${ }^{10}$ Burada tiyatronun yapı tarihine ilişkin yayına bakılabilir. STYHLER-AYDIN (hazırlanıyor).
}

11 ATAÇ 1997; AтAÇ 1999a, 432; AтAÇ 1999b, 3. 
bağlantılıydı. Aristion su hattından beslenen iki künk hattı, buradan en azından alt diazoma'ya kadar tespit edilebilmiştir. Bunlar T11 ve T13 numaralı radyal merdivenlerin altından geçerek orkestra yönüne doğru devam etmiş olabilirler. Tiyatronun donatıları arasında bir gölgelik de bulunuyordu. Böyle bir donatının varlı̆̆ını kanıtlayan ilk epigrafik belge MS 2. yüzyılın ortalarına aittir ${ }^{12}$. Bu ilk kez bu dönemde mi kuruldu yoksa sadece yenilendi mi? Yazıttan bu konuda bir çıkarım yapılamamaktadır. Muhtemelen burada hafif bir koruma çatısı kastedilmiştir. Başka iki yazıt koruma çatısındaki onarımlardan bahseder. Bu, bir defasında MS 3. yüzyılın başında ${ }^{13}$, başka bir defa ise İmparator Gordianus III $^{14}$ döneminde gerçekleşmiştir. Gordianus III döneminden başka bir yazıt Nemeseion' da $^{15}$ bir pronaos inşasından bahseder, ancak bu şimdiye kadar konumlandırılamamıştır. Nemeseion'un kendi inşa tarihi de bilinmemektedir. Buna karşın İmparatorluk Dönemi tiyatrosunun MS 2. yüzyıldaki açılışıyla birlikte gladyatör oyunları[nın da başladığı] kanıtlanmıştır ${ }^{16}$. MS 2. yüzyılın ortasından sonraki döneme tarihlenen gladyatör rölyefli payeler tiyatronun yıkıntıları arasında ya da bunların hemen yakın çevresinde bulunmuştur. Bunlar sahne binasına kazınmış daha geç tarihli çizimler ile birlikte, tiyatronun gladyatör oyunlarının sahnelendiği alanlardan biri olduğuna işaret eder.

\section{MS 3. VE 4. YÜZYILLARDAKİ DEPREMLERİN MIMMARİ SONUÇLARI}

İmparator Gallienus döneminde şehirde yaşanan deprem esnasında tiyatronun ne kadar zarar gördüğü halen bilinmiyor. Tiyatronun hemen güneyinde bulunan konut insulasında Kuretler Caddesi’ndeki iki yamaç evde görülenlere benzeyen ağır hasarlar tespit edilmiştir. Bu esnada insuladan gelen yıkıntı molozu tiyatronun güneyinde seyreden merdivenli sokağa da dökülmüştür. Merdivenin doğu bölümünde - ES2 ve ES3 numaralı tiyatro girişlerinin arasındaki kısım - bulunan yıkıntı molozu görünüşe göre deprem sonrasında tamamen temizlenmiş, insulanın kuzey duvarı boyunca deprem yıkıntısının parçaları durmaya devam etmiştir.

Tiyatronun kuzey kanadında sağlamlaştırma uygulamaları tespit edilmiştir. Buna göre, EN1 olarak adlandırılan alt kuzey vomitorium 'un bir kısmında ek bir tonoz ya da bir tavan inşa edilmiştir. Bu durumla Gallienus dönemindeki deprem arasında kuşkuya yer bırakmayan bir bağlantı belirlenemese de, ihtimal gözardı edilmemelidir. Scaenae frons 'un bazı mimari parçalarındaki onarımlar da muhtemelen bu depremin etkilerine karşı yapılanlardır.

Aslen EN2 numaralı kuzey geçişi kapatan duvarda ve buna komşu bir destek duvarında bulunan ve MS 4. yüzyılın sonlarına tarihlenen iki yazıtta ${ }^{17}$ Prokonsul Messalinus tiyatronun yeniden inşasından dolayı onurlandırılmaktadır. Gerçekten de, kuzey kanattaki kapsamlı yapım aktiviteleri bu yazıt ile bağlantılandırılabilmektedir. Konsolidasyonlar muhtemelen MS 4. yüzyılın ortasından sonra yaşanan bir dizi depremin ardından gerekli görülmüş ve başka etkilerinin yanı sıra kullanımın epey sınırlandırılmasına ya da kuzey girişlerden vazgeçilmesine sebep olmuştur. Kuzey analemma'daki odaların (KN1-KN3) üstlerinin ikinci bir kez tonozla kapatılması da belki bu sağlamlaştırma çalışmalarının bir parçasıydı.

\section{TIYYATRONUN MS 5. VE 6. YÜZYILDAKİ DURUMU VE BİZANS ŞEHİR SURUNA ENTEGRE EDİLIŞi}

MS 5. yüzyılın ortalarına doğru, kuzeydeki alt vomitorium'un (EN1) bir bölümü $350 \mathrm{~m}^{3}$ 'den fazla su kapasiteli bir sarnıca çevrilmişti. Büyük bir ihtimalle Aristion su hattından beslenen bu su deposu en az MÖ 6. yüzyılın son çeyreğine kadar işlevini sürdürmüştü. MS 5. yüzyıldan 6. yüzyılın ortasına kadar gerçekleşen başka yapım aktiviteleri EN1 girişinin merdiveninin ortalarında tespit edilebilmiştir. Bunun ötesinde, sahne cephesindeki aktör grafitileri MS 5./6. yüzyıla tarihlenebilen kıyafetlerinden ötürü, tiyatronun bir performans yeri olarak işlevinin geç dönemlerde de devam ettiğini kanıtlar.

\footnotetext{
${ }^{12}$ IvE 2039. Buna dair ayrıca bknz. Kap. 8.6.1, Nr. 9 ve Kap. 8.6.2.

${ }^{13} \mathrm{IvE} 2040$. Buna dair ayrica bknz. Kap. 8.6.1, Nr. 10 ve Kap. 8.6.2.

${ }^{14} \mathrm{IvE} 2041$. Buna dair ayrica bknz. Kap. 8.6.1, Nr. 11 ve Kap. 8.6.2.

${ }^{15}$ IvE 2042. Buna dair ayrica bknz. Kap. 8.6.2.

${ }^{16}$ IvE 2061. Buna dair ayrica bknz. Kap. 8.6.1, Nr. 6 ve Kap. 8.6.2.

${ }^{17} \mathrm{IvE}$ 2043. 2044. Buna dair ayrica bknz. Kap. 8.6.1, Nr. 12. 13 ve Kap. 8.6.2.
} 
Güney kanatta da ES1, ES2 ve ES3 girişleri kapatılmıştı. Yapıya güneyden erişimin sona ermesiyle Bizans Dönemi sur çemberinin inşası bağlantılı olmalıdır. Tiyatronun güneyi de bu sura entegre edilmişti. ES3 girişinin güneyinde yer alan ve daha Helenistik Dönem'de orada bulunan istinat duvarı, devşirme malzemelerle aralarında tiyatronun güneyindeki merdivenin bir çok basamağı da bulunmaktadır - yeniden inşa edilmiş ve sur sistemine uydurulmuştur. Merdivenli sokakta ele geçen buluntulara bakılacak olursa, bu çalışmalar MS 5. yüzyıl sonu ile 6. yüzyıl arasında gerçekleşmiş olmalıdır. Bu esnada Aristion su hattının tiyatro ile Trajan Nymphaeum'u arasındaki bölümünden de vazgeçilmiştir. Sahne binasının güney bölümü de duvarların önüne yeni bir duvar hattının çekilmesiyle güçlendirilmiştir. Bununla birlikte odaların girişleri de masif bir biçimde kapatılmıştır. E5 ve E6 odaları arasında bir kapı yer almakta ve sur buradan başlayarak batıdaki limana kadar devam etmektedir. Tiyatronun güneyi ve güneydoğusundaki bölge - extra muros [sur dış1] - konut bölgesi olarak çekiciliğini zamanla kaybetmiş ve gittikçe artan biçimde terkedilmiştir. Yukarı kente giden yol hatları ticari mekanlar ve atölyelerle çevrili olsa da tiyatro çevresindeki yamaçlar neredeyse tamamen boş bırakılmıştı. Aristion su hattındaki dolguda ele geçen yabani hayvan kemiklerinin yüksek oranı bunu kanıtlamaktadır.

Girişlerin bir bölümünün de kapatılmasıyla büyük bir seyirci kesimi tarafindan ulaşılması gitgide zorlaşan tiyatronun toplantılar ve çeşitli performanslar için ne kadar süreyle kullanıldığı net bir biçimde belirlenememektedir. Tiyatro çevresindeki çok sayıda sokakta Herakleios devrine kadarki imparatorluk ilanlarına dair yazıtlar bulunmuştur. Tiyatro muhtemelen MS 7. yüzyılın başlarında da bu bağlamda bir rol oynamıştır.

\section{SAHNE BİNASININ MS 6. YÜZYILDA VEYA MS 7. YÜZYILIN BAŞINDA KALEYE DÖNÜŞMESI}

E5 numaralı oda civarında başlayan sur kapsamında sahne binasındaki girişlerin kapatılması, sahne binasının kuzey tarafında masif duvar güçlendirmeleri ve kuzey rampa yapıya bir kale izlenimi vermiştir. Bunun yanı sıra E4 ve E5 numaralı odaların arasındaki geçişin devşirme malzemeler kullanılarak dar bir açıklığa dönüştürülmüş olması da bu izlenimi kuvvetlendirir. Bunun üzerine tonlarca ağırlıkta opus caementitium dökülmüştür. Kent kapısına olan yakınlığına bakılırsa, bu işlev değişikliği yapının bu kısmının kuleye dönüştüğüne işaret eder. Girişlerin kapatılmasına ön avlu çevresinde de rastlanmıştır. Ancak burada daha net bir tarihlendirmeye yarayacak buluntu mevcut değildir.

Gösteri mekanı olarak önemini yitirmesinin ardından tiyatro bir hammadde kaynağı olarak işlev görmeye başlamıştır. Mermer kaplama levhaları, tiyatronun oturma basamaklarında da görüldüğü gibi, kentteki çeşitli binalarda yeniden kullanılmıştır. Bunun yanı sıra cephelerin ve mermer tonozların rahat ulaşılan bölümlerindeki metal kenetler yağmalanmıştır.

Kazılardan ele geçen buluntular MS 7. yüzyılda son bulmaktadır. Bunlara Herakleios Dönemi'ne ait sikkeler de dahildir. Buradan hareketle tiyatrodaki, muhtemelen depremlerin sebep olduğu yıkım için bir terminus post quem elde edilmiş olur.

\begin{tabular}{|l|l|}
\hline I. yer seçimine ve öncül bir yapı varsayımına \\
\hline MÖ 3 yy'dan MÖ 2 yy'ın ilk çeyreği & $\begin{array}{l}\text { Hellenistik dönemin şehir planlama ölçeği düzenlemesinde tiyatronun inşaat alanı belirlen- } \\
\text { miş olabilir. Fakat tiyatronun varlığı unsurunda emin kanıtlar bulunmamaktadır. }\end{array}$ \\
\hline II. Hellenistik Skene'nin MÖ 2 yy'ın ikinci çeğreğinden sonra kuruluşu \\
\hline MÖ 2 yy'ın ikinci çeğreğinden sonra & Skene'nin inşaatı (Skene'den önce inşa edilen Koilon için emin noktalar bulunmamaktadır) [A] \\
\hline III. Hellenistik Skene'de MÖ 50/51 yılına kadar süren mimari değişimler \\
\hline MÖ 51/50 yüzyıl & Thyromata cephesinin mermere dönüştürülmesi [B] \\
\hline IV. İmparator döneminin başlangıcında yapılan inşaat çalışmaları \\
\hline MS 1 yy'ın ilk çeğreği & ES3 nolu ana kapının inşaat edilmesi[E] \\
\hline V. Geç Flavius döneminden İmparator Traian dönemine kadar tiyatroda yapılan değişimler \\
\hline MS 85 yılında & scaenae frons ve İmparator dönemine ait sahne binası inşaatının sonu ve açılış1 [E] \\
\hline MS 92 yılına kadar & Tiyatro kuzey kanadın genişletilmesi ve kuzey analemmanın inşaatı [E] \\
\hline
\end{tabular}




\begin{tabular}{|c|c|}
\hline MS 102-112 y1linda & $\begin{array}{l}\text { Tiyatro güney kanadın genişletilmesi ve güney analemmanın inşaatı [E] } \\
\text { Auditorium'dan geçen Aristion su tesisatının yapımı [E] }\end{array}$ \\
\hline MS 1. yada 2. yy'da & summa porticus'un doğusunda odaların yapımı [A] \\
\hline \multicolumn{2}{|c|}{ VI. İmparator Antonius döneminden MS 3 yy’ın ilk yarısına kadar süren mimari değişim ve onarımlar } \\
\hline MS 2 yy'ın ortalarında & $\begin{array}{l}\text { Sahne ve Orkestra'nın mimari değişimi }[\mathrm{A}, \mathrm{B}, \mathrm{E}] \\
\text { Güneş yelkeninin yapımı ve yenilenmesi [E] }\end{array}$ \\
\hline MS 205 yilında & Güneş yelkeninin tamiratı [E] \\
\hline MS 238-244 yy'ları arasinda & $\begin{array}{l}\text { Güneş yelkeninin tamiratı [E] } \\
\text { (halen lokalize edilemeyen) Nemeseion'da bir Pronaos'un inşaatı [E] }\end{array}$ \\
\hline MS 2. yada 3. yy`da & Gladyatör rölyefli siper desteklerinin tiyatro alanında kuruluşu [A, E] \\
\hline \multicolumn{2}{|c|}{ VII. MS 3 ve 4 yy'da yaşanan deprem faciasından sonraki mimari değişimler } \\
\hline MS 3 yy'ın 6011 yıllarında & $\begin{array}{l}\text { Efes'de yaşanan büyük bir deprem faciasından sonra EN1 nolu vomitorium'da görünen } \\
\text { zararlar. EN1' de yeni bir destek kemer veya tavan içerisinde üst kemerin inşaat edilmesi [B] } \\
\text { Tiyatro'nun güneyindeki İnsula 'da ağır zararlar. Stiegengasse'deki merdiven tamamen } \\
\text { toprak altında kalıyor ve sadece bir kısmı toprak altından kurtarılabiliyor. [A] }\end{array}$ \\
\hline MS 359-366 y1lina kadar & Kuzey ve güney kanat alanında yaşanan sayısal deprem sonrası görünen mümkün zararlar [B] \\
\hline En geç MS 4 yy'a kadar & $\begin{array}{l}\text { Proconsul Messalinus'un altındaki kuzey kanat bölümünde yapılan sayısal onarım } \\
\text { çalışmaları[E]: } \\
\text { Kuzey cephedeki sağlamlaştırıcı duvar kesimi [B] } \\
\text { EN1 nolu vomitorium'a giden giriş kapısının bir bölümünün kapatılması [B] } \\
\text { Muhtemelen bu zaman aşamasında KN1-KN3 odalarının ekstra bir duvar kısmıyla ve } \\
\text { tuğla kemeriyle sağlamlaştırılmas1 [B] } \\
\text { EN2 nolu girişin kapatılması [B, E] } \\
\text { EN2 nolu girişin iki tarafinda da duvar kurulmas1 [B, E] }\end{array}$ \\
\hline MS 4./5. yy'da & Summa porticus'un arka kısmındaki odaların bir bölümünün kapatılması [A] \\
\hline \multicolumn{2}{|c|}{ VIII. Tiyatronun MS 5 ve 6 yy’dan Bizans döneminde şehir surlarına entegre oluşuna kadar süren zaman } \\
\hline $\begin{array}{l}\text { MS } 400 \text { yılından MS } 5 \text { yy'in ortasina } \\
\text { kadar }\end{array}$ & $\begin{array}{l}\text { Kuzey kanadındaki KN1-KN3 odalarının doldurulması [A] } \\
\text { EN1 nolu vomitorium'un bir kısmında su deposunun inşaatı (Su taşkını düzeyi kullanımın } \\
\text { MS } 6 \text { yy'a kadar sürdüğünü göstermektedir) }[\mathrm{A}, \mathrm{B}]\end{array}$ \\
\hline $\begin{array}{l}\text { MS } 5 \text { yy'dan MS } 6 \text { yy'ın ortasina } \\
\text { kadar }\end{array}$ & EN1 nolu girişten batıya kadar orta merdiven podestindeki inşaat çalışmaları [A] \\
\hline MS 5. yada 6. yy'a kadar & Sahne binasındaki gösterimden kalan görüntülerle süslü graffitiler [A, E] \\
\hline $\begin{array}{l}\text { En geç MS } 5 \text { yy ve } \\
\text { En erken MS } 6 \text { yy'a kadar }\end{array}$ & $\begin{array}{l}\text { Tiyatronun Bizans dönemi şehir sınırına entegre edilişi: } \\
\text { Tiyatronun güneyinde bulunan Aristion su tesisatının kapatılmas1 [A] } \\
\text { ES1 ve ES2 nolu girişlerin kapatılması (ES3 nolu giriş büyük bir ihtimalle sonradan } \\
\text { kapatıldı) [B] } \\
\text { Stiegengasse'nin kapatılmas1 [A] } \\
\text { Sahne binasındaki E6-E8 nolu odaların girişinin kapatılması[B] } \\
\text { E7 ve E8 nolu odaların batı duvarının sağlamlaştırılması [B] } \\
\text { Hellenistik sahne binasının güney duvarının sağlamlaştırılmas1 [B] }\end{array}$ \\
\hline \multicolumn{2}{|c|}{ IX. Sahne binasının kaleye benzer değişimi } \\
\hline $\begin{array}{l}\text { En geç MS } 6 \text { yy ve } \\
\text { En erken MS } 7 \text { yy'a kadar (?) }\end{array}$ & $\begin{array}{l}\text { Sahne binasının kaleye benzer değişımi : } \\
\text { Sahne binasındaki E1-E5 nolu odaların kapatılması [B] } \\
\text { Sahne binasının kuzeyinde duvar sağlamlaştırmaları [B] } \\
\text { E4 ve E5 nolu odaların arasındaki orta geçitin kuleye benzer değişimi [B] }\end{array}$ \\
\hline MS 7 yy'da & Tiyatronun yıkımı için kullanılan terminus post quem [A] \\
\hline
\end{tabular}

Tab. 127: Kronolojiye genel bakiş 
Mit dem vorliegenden Band der „Forschungen in Ephesos" werden die Befunde und die Auswertung der jüngsten archäologischen Untersuchungen am Theater von Ephesos publiziert. Neben der Präsentation der Grabungsergebnisse erfolgt die detaillierte Vorlage der unterschiedlichen Fundgattungen, wie der Keramik- und Glasfunde, der Terrakotten, Skulpturen, Kleinfunde und Münzen sowie der archäozoologischen Evidenz und der neuen epigraphischen Zeugnisse. Somit kann der Kenntnisstand zur Chronologie und zur baulichen Entwicklung des ephesischen Theaters in geschlossener Form nachvollzogen und überprüft werden.
In this volume of the Forschungen in Ephesos the recent archaeological examinations at the Theater of Ephesus are published. Beside the results of the excavations the volume incorporates the analysis of the various find categories, such as pottery and glass, terracotta, sculptures, small finds and coins as well as archaeozoological and epigraphical finds. With this, the reader can comprehensively follow and review the architectural development and chronology of the Ephesian theater in the course of the eight building or usage phases.

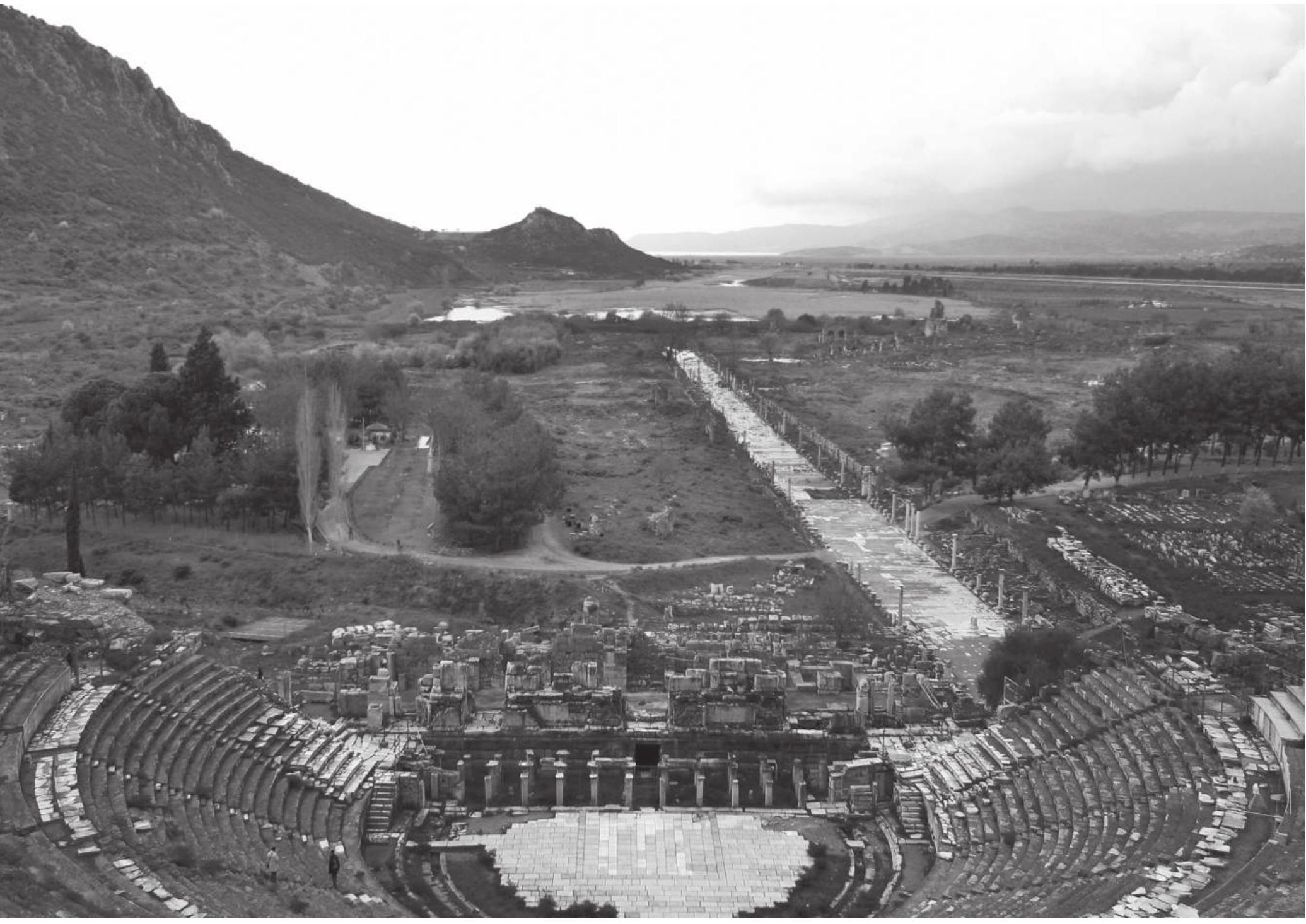

ISBN 978-3-7001-7590-2

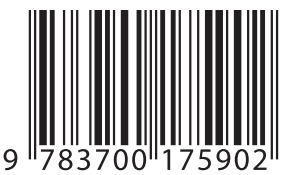

